DOC.20041115.0008

QA: QA

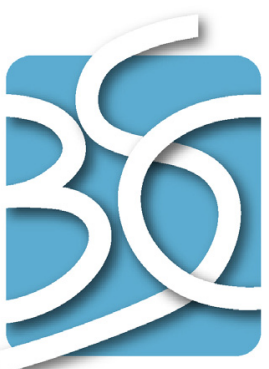

BECHTEL

SAIC $\underline{\text { COMPANYLC }}$

\title{
Saturated Zone In-Situ Testing
}

NOTICE OF OPEN CHANGE DOCUMENTS - THIS DOCUMENT IS IMPACTED BY THE LISTED CHANGE DOCUMENTS AND CANNOT BE USED WITHOUT THEM.

1) ACN-001, DATED 01/17/2006

November 2004

ANL-NBS-HS-000039 REV 01 


\section{DISCLAIMER}

This report was prepared as an account of work sponsored by an agency of the United States Government. Neither the United States Government nor any agency thereof, nor any of their employees, nor any of their contractors, subcontractors or their employees, makes any warranty, express or implied, or assumes any legal liability or responsibility for the accuracy, completeness, or any third party's use or the results of such use of any information, apparatus, product, or process disclosed, or represents that its use would not infringe privately owned rights. Reference herein to any specific commercial product, process, or service by trade name, trademark, manufacturer, or otherwise, does not necessarily constitute or imply its endorsement, recommendation, or favoring by the United States Government or any agency thereof or its contractors or subcontractors. The views and opinions of authors expressed herein do not necessarily state or reflect those of the United States Government or any agency thereof. 
QA: QA

Saturated Zone In-Situ Testing ANL-NBS-HS-000039 REV 01

November 2004 


\begin{tabular}{|c|c|c|}
\hline \multirow[t]{2}{*}{ OCRWM } & \multirow{2}{*}{$\begin{array}{l}\text { SCIENTIFIC ANALYSIS SIGNATURE PAGE } \\
\text { CHANGE HISTORY }\end{array}$} & Page ai: \\
\hline & & 1. Togl Pagan: 528 \\
\hline
\end{tabular}

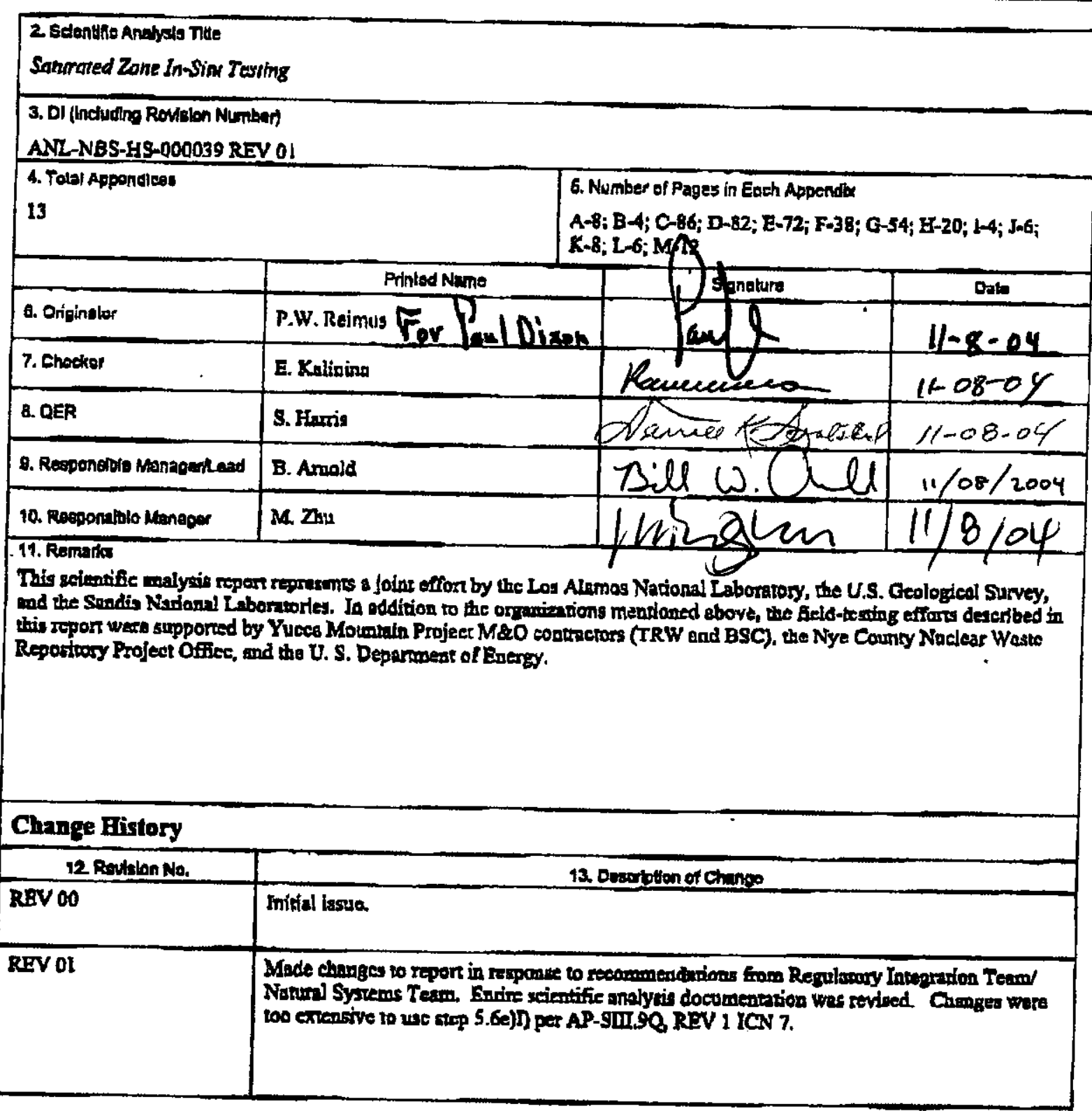


INTENTIONALLY LEFT BLANK 


\section{CONTENTS}

Page

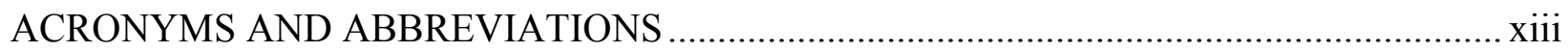

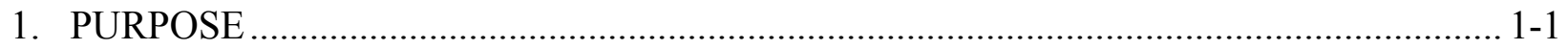

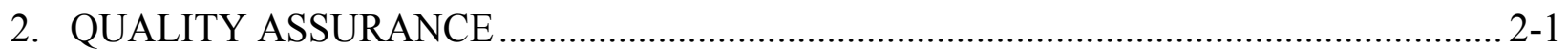

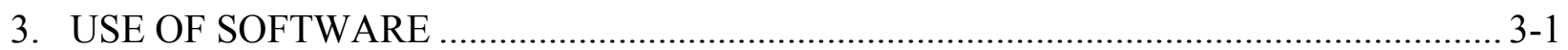

3.1 SOFTWARE TRACKED BY CONFIGURATION MANAGEMENT ........................ 3-1

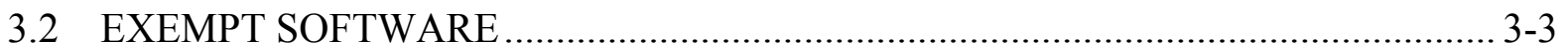

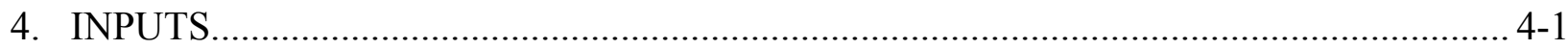

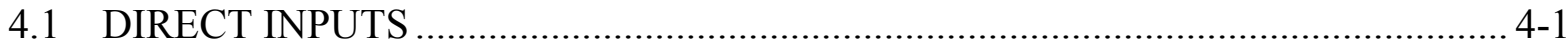

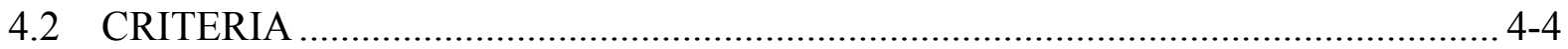

4.2.1 Acceptance Criteria from Section 2.2.1.3.8.3, Flow Paths in the

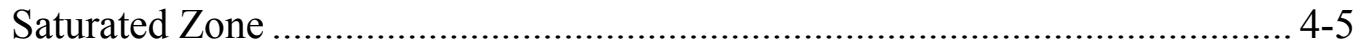

4.2.2 Acceptance Criteria from Section 2.2.1.3.9.3, Radionuclide Transport in the Saturated Zone …………………….................................................. 4-7

4.3 CODES, STANDARDS, AND REGULATIONS ............................................... 4-10

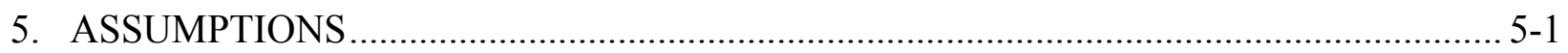

6. SCIENTIFIC ANALYSIS DISCUSSION...................................................................... 6-1

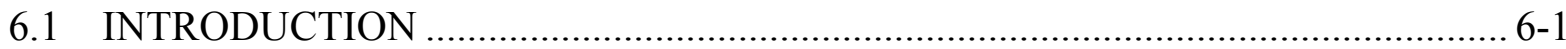

6.1.1 Hydrogeologic Settings...................................................................... 6-2

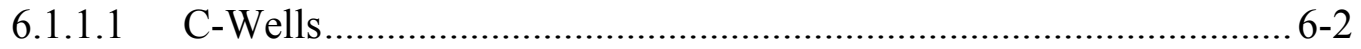

6.1.1.2 Alluvial Testing Complex ........................................................... 6-11

6.1.2 Features, Events, and Processes Supported by This Scientific Analysis........ 6-16

6.2 HYDROLOGIC PROPERTIES OF FRACTURED TUFFS (C-WELLS

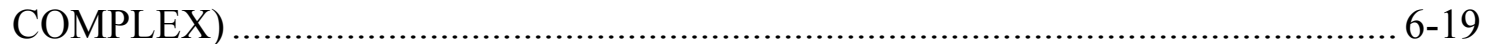

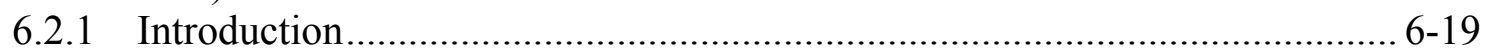

6.2.2 Summary of C-Wells Hydraulic Testing to Determine Hydrologic

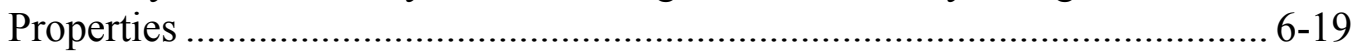

6.2.3 Hydraulic Test Interpretation Methods …………...................................... 6-20

6.2.4 Hydraulic Test Interpretations: Conceptual Flow Model Implications ......... 6-22

6.2.5 Hydraulic Test Interpretations: Hydrologic Parameter Estimates at the C-Wells .......................................................................................... 6-23

6.2.6 Hydraulic Test Interpretations: Horizontal Anisotropy in Hydraulic

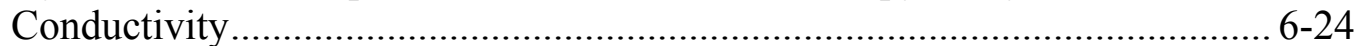

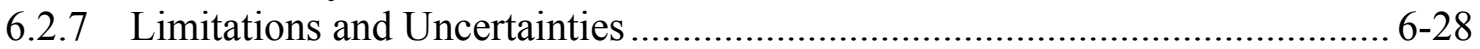

6.3 TRANSPORT PROPERTIES OF FRACTURED TUFFS (C-WELLS

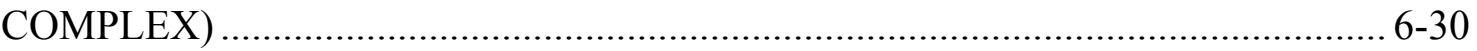

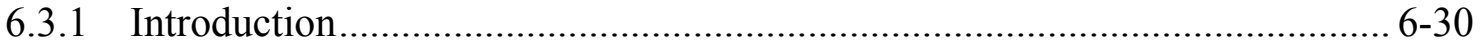

6.3.2 Summary of C-wells Tracer Testing, Including Objectives and Strategies.... 6-30 
6.3.3 Tracer Test Interpretation Methods ………................................................. 6-33

6.3.4 Tracer Test Interpretations: Conceptual Transport Model Implications........ 6-34

6.3.5 Tracer Test Interpretations: Transport Parameter Estimates at the C-

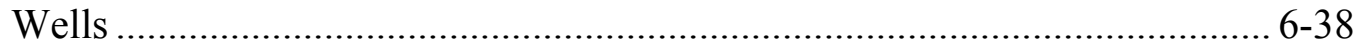

6.3.6 Laboratory Testing to Support C-wells Field Tracer Tests ............................ 6-39

6.3.7 Limitations and Uncertainties .................................................................... 6-41

6.4 HYDROLOGIC PROPERTIES OF ALLUVIUM (ALLUVIAL TESTING

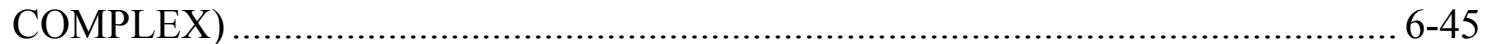

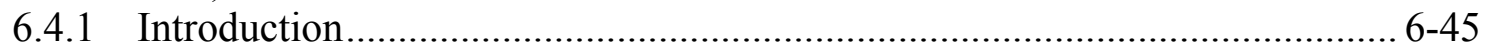

6.4.2 Summary of ATC Hydraulic Testing to Determine Hydrologic

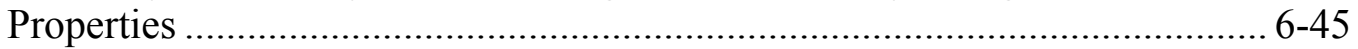

6.4.3 Hydraulic Test Interpretation Methods .................................................... 6-46

6.4.4 Hydraulic Test Interpretations: Conceptual Flow Model Implications ......... 6-48

6.4.5 Hydraulic Test Interpretations: Hydrologic Parameter Estimates at the

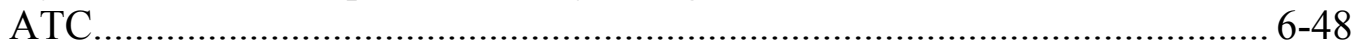

6.4.6 Limitations and Uncertainties .................................................................. 6-49

6.5 TRANSPORT PROPERTIES OF ALLUVIUM (ATC)...................................... 6-50

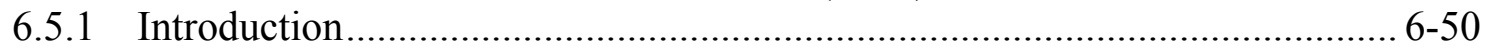

6.5.2 Summary of ATC Tracer Testing, Including Objectives and Strategies ........ 6-50

6.5.3 Single-Well Tracer Test Results .................................................................. 6-51

6.5.4 Tracer Test Interpretations: Conceptual Transport Model Implications........ 6-52

6.5.5 Tracer Test Interpretations: Estimates of Ambient Flow Velocity in

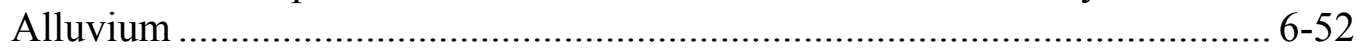

6.5.6 Laboratory Testing to Support ATC Field Tracer Tests................................. 6-56

6.5.7 Limitations and Uncertainties ………………….................................... 6-57

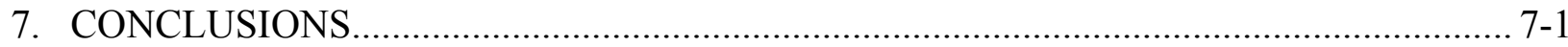

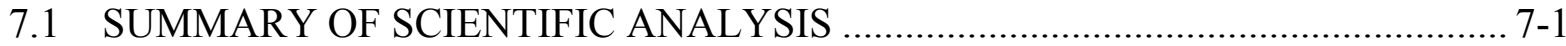

7.2 APPLICABLE ACCEPTANCE CRITERIA....................................................... 7-2

7.2.1 Acceptance Criteria from Section 2.2.1.3.8.3, Flow Paths in the Saturated Zone ................................................................................. 7-3

7.2.2 Acceptance Criteria from Section 2.2.1.3.9.3, Radionuclide Transport in the Saturated Zone …………………................................................... 7-6

7.3 OUTPUTS

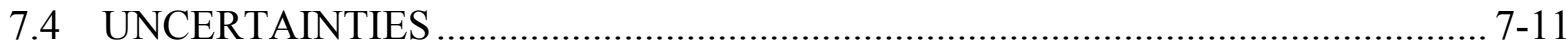

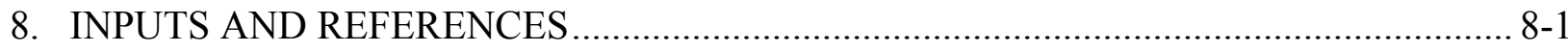

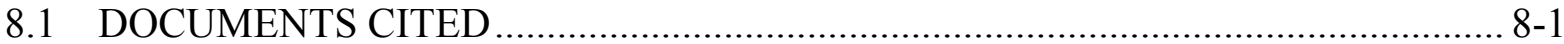

8.2 CODES, STANDARDS, REGULATIONS, AND PROCEDURES .......................... 8-13

8.3 SOURCE DATA, LISTED BY DATA TRACKING NUMBER …......................... 8-13

8.4 OUTPUT DATA, LISTED BY DATA TRACKING NUMBER …........................... 8-17

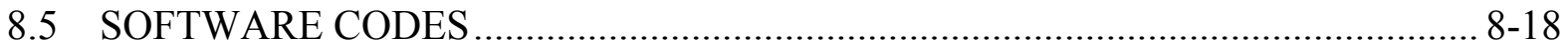




\section{CONTENTS (Continued)}

Page

APPENDIX A - QUALIFICATION OF EXTERNAL SOURCES …………………........... A-1

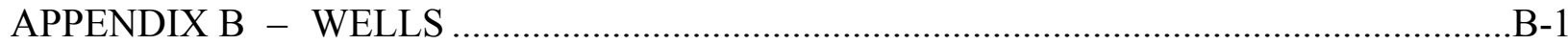

APPENDIX C - DETAILS OF HYDRAULIC TESTING AND TEST

INTERPRETATIONS AT THE C-WELLS COMPLEX................................. -1

APPENDIX D - DETAILS OF TRACER TESTING AND TRACER TEST INTERPRETATIONS AT THE C-WELLS COMPLEX............................. D-1

APPENDIX E - LABORATORY TESTING CONDUCTED TO SUPPORT INTERPRETATIONS OF TRACER TESTS AT THE C-WELLS COMPLEX E-1

APPENDIX F - DETAILS OF HYDRAULIC TESTING AND TEST INTERPRETATIONS AT THE ALLUVIAL TESTING COMPLEX (ATC). F-1

APPENDIX G - DETAILS OF TRACER TESTING AND TRACER TEST INTERPRETATIONS AT THE ALLUVIAL TESTING COMPLEX (ATC). G-1

APPENDIX H - LABORATORY TESTING CONDUCTED TO SUPPORT PLANNED TRACER TESTING AT THE ALLUVIAL TESTING COMPLEX (ATC)

APPENDIX I - TWO EXAMPLES OF STEPS INVOLVED IN PROCESSING INPUT DATA TO ARRIVE AT OUTPUT DATA

APPENDIX J - QUALIFICATION OF MINERALOGY DATA FOR SAMPLE FROM UE25C\#2, 2406 FT BELOW LAND SURFACE

(DTN: LA9909PR831231.004)

APPENDIX K - QUALIFICATION OF NC-EWDP-19IM2 WELL COMPLETION DATA (DTN: MO0306NYE05260.166). K-1

APPENDIX L - QUALIFCATION OF C-WELLS FLOW DISTRIBUTION DATA (DTN: GS031008312313.016)

APPENDIX M - QUALIFICATION OF UE25 ONC-1 DRAWDOWN DATA FROM APRIL 24, 1996 TO NOVEMBER 12, 1997

(DTN: MO0212SPANYESJ.149) AND CORRESPONDING QUALIFICATION OF PAGES 4 TO 51 "RESULTS OF HYDRAULIC TESTS IN MIOCENE TUFFACEOUS ROCKS AT THE C-HOLE COMPLEX, 1995 TO 1997, YUCCA MOUNTAIN, NEVADA" (DTN: GS030508312314.003) 


\section{INTENTIONALLY LEFT BLANK}




\section{FIGURES}

Page

1-1. Relationships and Flow of Key Information among Reports Pertaining to Flow and Transport in the SZ Source.

6.1-1. Location and Surface Layout of the C-Wells Complex

6.1-2. Stratigraphy, Lithology, Matrix Porosity, Fracture Density, and Inflow from Open-Hole Flow Surveys at the C-Wells

6.1-3. Generalized Geologic Map Showing the Location of the C-Wells Complex and Nearby Boreholes.

6.1-4. Potentiometric Surface of the Miocene Tuffaceous Rocks in the Vicinity of the CWells Complex, May 1995.

6.1-5. Hydrogeologic Intervals in the C-Wells Identified During Hydraulic and Tracer Testing from 1995 to 1997

6.1-6. Map Showing Location of Alluvial Testing Complex (ATC) in Relation to the Repository Footprint and the Nevada Test Site

6.1-7. Surface Layout of the Alluvial Testing Complex .................................................... 6-14

6.1-8. Schematic Diagram of NC-EWDP-19D, -19P, -19IM1, and -19IM2 Completions ..... 6-15

6.2-1. Example of a Match of an Analytical Flow Model to Drawdown Data in an Aquifer Pump Test. This Plot Shows the Match of the Streltsova-Adams FissureBlock Aquifer Solution to the Drawdown in UE-25 c\#1, Lower Bullfrog Interval, May 8, 1996, to March 26, 1997

6.2-2. Anisotropy Ratio of 3.3 at $15^{\circ}$ East of North Projected onto a North-South Anisotropy Ratio $\left(0^{\circ}\right)$ Resulting in a Projected Anisotropy Ratio of 2.5

6.2-3. Probability Density Function (a) and Corresponding Cumulative Distribution Function (b) for the North-South/East-West Anisotropy Ratio Used in FEHM Input Files.....

6.3-1. Hypothetical Cross-Hole Responses of Tracers with Different Physical and Chemical Characteristics in Single- and Dual-Porosity Media.

6.3-2. Solute Tracer Breakthrough Curves in the Multiple-Tracer Test in the Lower Bullfrog Tuff and RELAP/MULTRAN Fits to the Breakthrough Curves

6.3-3. Solute Tracer Breakthrough Curves in the Multiple-Tracer Test in the Prow Pass Tuff and RELAP/MULTRAN Fits to the Breakthrough Curves

6.3-4. RELAP Fits to Iodide Data from Prow Pass Tracer Test in which 2,4,5-TFBA Was Also Injected

6.3-5. RELAP Fits to the Iodide and 2,4,5-TFBA Data from the Prow Pass Tracer Test....... 6-45

6.4-1. Fit to the Theis (1935) Confined-Aquifer Solution of the Drawdown in NCEWDP-19IM2 Resulting from Pumping NC-EWDP-19D at $109 \mathrm{gpm}$. 6-47

6.5-1. Normalized Concentrations of Tracers in Production Water from NC-EWDP-19D as a Function of Gallons Pumped after a Rest Period of Approximately 2 Days 6-52

6.5-2. Normalized Concentrations of Fluorinated Benzoates as a Function of Gallons Pumped in Each of the Three Single-Well Tracer Tests in NC-EWDP-19D 6-54 


\section{INTENTIONALLY LEFT BLANK}




\section{TABLES}

Page

3-1. Software Used in Support of This Scientific Analysis ................................................... 3-1

3-2. Exempt Software Used in Support of This Scientific Analysis ..................................... 3-4

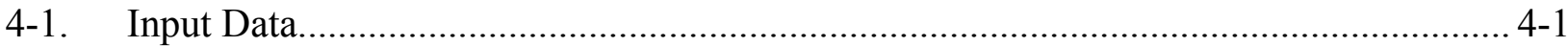

4-2. Project Requirements and YMRP Acceptance Criteria Applicable to This Scientific Analysis Report ................................................................................... 4-5

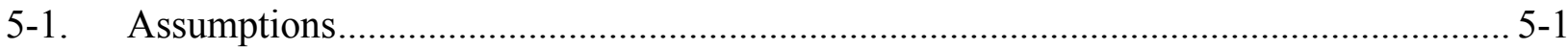

6.1-1. Approximate Interborehole Distances at the Midpoints of Hydrogeologic Intervals as Monitored During Hydraulic Tests at the C-Wells Complex, August 1995 to April 1996

6.1-2. Stratigraphy of Miocene Tuffaceous Rocks in the C-wells Area ................................... 6-5

6.1-3. Features, Events, and Processes Included in TSPA-LA and Relevant to This Model Report.

6.2-1. Highlights of Testing at the C-Wells Complex to Determine Hydrologic Properties (See Appendix C for Complete Description of Tests)

6.2-2. Ranges of Hydrologic Parameters Derived from C-Wells Cross-Hole Hydraulic Testing

6.2-3. Transmissivities and Storativities of Distant Wells for the Long-Term Pumping Test.

6.2-4. Calculated and Reported Anisotropies and Principal Directions.

6.3-1. Tracer Testing at the C-Wells Complex to Determine Transport Properties.

6.3-2. Ratios of Observed Tracer Arrival Times and Distances Squared, as well as Apparent Flow Anisotropy Ratios, for C-Wells Nonsorbing Tracer Tests

6.3-3. Transport Parameter Estimates Deduced from the Lower Bullfrog and Prow Pass Multiple-Tracer Tests.

6.3-4. Lithium Partition Coefficients Derived from Field Tracer Tests and Laboratory Measurements

6.3-5. Transport Parameters Obtained from RELAP Fits to Iodide Data Shown in Figure 6.3-4

6.3-6. Transport Parameter Ranges from Multiple-Tracer Tests at the C-Wells ...................... 6-44

6.4-1. Highlights of Testing at the ATC to Determine Hydrologic Properties (See Appendix F for Complete Description of Tests)

6.5-1. Summary of Tracers and Test Conditions in the Three Single-Well Tracer Tests in NC-EWDP-19D

6.5-2. Times and Pumped Volumes Associated with Each of the Arrival Times Used in the Different Methods of Estimating Groundwater Velocities

6.5-3. Specific Discharges and Groundwater Velocities Estimated from the Different Ambient Flow Velocity Analysis Methods as a Function of Assumed Flow Porosity 


\section{INTENTIONALLY LEFT BLANK}




\section{ACRONYMS AND ABBREVIATIONS}

ATC

Alluvial Testing Complex

CDF

cumulative distribution function

DFBA

difluorobenzoic acid or difluorobenzoate

DTN

data tracking number

EPM

equivalent porous medium

FBA

fluorinated benzoic acid or fluorinated benzoate

FEHM

finite-element heat and mass

FEP

feature, event, and process

LA license application

MTC

mass transfer coefficient (for matrix diffusion)

NTS

Nevada Test Site

PDF

probability distribution function

PFBA

pentafluorobenzoic acid or pentafluorobenzoate

SMR software management report

SZ

saturated zone

TDMS

Technical Data Management System

TFBA

trifluorobenzoic acid

TSPA

total system performance assessment

USGS U.S. Geological Survey

YMP Yucca Mountain Project

YMRP Yucca Mountain Review Plan, Final Report 


\section{INTENTIONALLY LEFT BLANK}




\section{PURPOSE}

The purpose of this scientific analysis is to document the results and interpretations of field experiments that test and validate conceptual flow and radionuclide transport models in the saturated zone (SZ) near Yucca Mountain, Nevada. The test interpretations provide estimates of flow and transport parameters used in the development of parameter distributions for total system performance assessment (TSPA) calculations. These parameter distributions are documented in Site-Scale Saturated Zone Flow Model (BSC 2004 [DIRS 170037]), Site-Scale Saturated Zone Transport (BSC 2004 [DIRS 170036]), Saturated Zone Colloid Transport (BSC 2004 [DIRS 170006]), and Saturated Zone Flow and Transport Model Abstraction (BSC 2004 [DIRS 170042]).

Specifically, this scientific analysis contributes the following to the assessment of the capability of the SZ to serve as part of a natural barrier for waste isolation for the Yucca Mountain repository system:

- The bases for selection of conceptual flow and transport models in the saturated volcanics and the saturated alluvium located near Yucca Mountain.

- Results and interpretations of hydraulic and tracer tests conducted in saturated fractured volcanics at the C-wells complex near Yucca Mountain. The test interpretations include estimates of hydraulic conductivities, anisotropy in hydraulic conductivity, storativities, total porosities, effective porosities, longitudinal dispersivities, matrix diffusion mass transfer coefficients, matrix diffusion coefficients, fracture apertures, and colloid transport parameters.

- Results and interpretations of hydraulic and tracer tests conducted in saturated alluvium at the Alluvial Testing Complex (ATC) located at the southwestern corner of the Nevada Test Site (NTS). The test interpretations include estimates of hydraulic conductivities, storativities, total porosities, effective porosities, longitudinal dispersivities, matrix diffusion mass transfer coefficients, and colloid transport parameters.

- Comparisons of sorption parameter estimates for a reactive solute tracer (lithium ion) derived from the $\mathrm{C}$-wells field tracer tests and laboratory tests using $\mathrm{C}$-wells core samples.

- Sorption parameter estimates for lithium ion derived from laboratory tests using alluvium samples from ATC well NC-EWDP-19D. These estimates will allow a comparison of laboratory- and field-derived sorption parameters to be made in saturated alluvium if cross-hole tracer tests are conducted at the ATC.

The comparisons between laboratory- and field-derived sorption parameter estimates for lithium ion are used to assess whether sorption parameters determined in the laboratory can be used reliably to predict field-scale transport. Favorable comparisons of lithium-ion sorption will lend credibility to the Yucca Mountain Project's (YMP's) use of laboratory-derived radionuclide sorption parameters when modeling field-scale radionuclide transport. The use of laboratory data for radionuclides is necessary because radionuclides cannot be tested in the field. 
Saturated-zone geochemistry measurements, including $\mathrm{Eh}$ and $\mathrm{pH}$, and water-level measurements are not addressed in this scientific analysis, because they can be used directly as inputs (without intermediate analyses) in downstream reports. Geochemistry measurements are used extensively in Appendix A of Saturated Zone Site-Scale Flow Model (BSC 2004 [DIRS 170037]) to delineate flow pathways. Eh and $\mathrm{pH}$ measurements are factored into the development of radionuclide $K_{\mathrm{d}}$ distributions in Appendix A of the model report Site-Scale Saturated Zone Transport (BSC 2004 [DIRS 170036]) and in the model report Radionuclide Transport Models Under Ambient Conditions (BSC 2004 [DIRS 164500]); and water-level measurements are used as calibration targets in the model report Saturated Zone Site-Scale Flow Model (BSC 2004 [DIRS 170037]).

The work activities in this scientific report are governed by the work direction and planning document Technical Work Plan for Natural System - Saturated Zone Analysis and Model Report Integration (BSC 2004 [DIRS 171421], Section 2.1). This report deviates from the Technical Work Plan (TWP) in the following ways:

- The report is Rev. 01 instead of Rev. 02, as Table 1-1 (p. 1) of the TWP indicates.

- Requirement PRD-002/T-014 is not addressed in this report as indicated in the TWP (see Section 4.2 for further discussion).

- Three features, events, and processes (FEPs) that are not identified in the TWP as being addressed by this report are, in fact, addressed in the report. The three addressed FEPs that constitute a deviation from the TWP are 2.2.03.01.0A, Stratigraphy, 2.2.07.12.0A, SZ Groundwater Flow in the Geosphere, and 2.2.08.09.0A, Sorption in the SZ. Table 6.1-3 identifies the locations where these FEPs are addressed in this report.

These are the only deviations from the TWP in this scientific report.

The data and analyses documented in this report are used as scientific supporting information in other Project reports recently revised or currently under revision, including:

- Saturated Zone Site-Scale Flow Model

- Site-Scale Saturated Zone Transport

- Saturated Zne Colloid Transport

- Saturated Zone Flow and Transport Model Abstraction.

Figure 1-1 shows the relationship of this report to other analysis and model reports that pertain to flow and transport in the SZ. Figure 1-1 also shows the flow of key information among the SZ reports. It should be noted that Figure 1-1 does not contain a complete representation of the data and parameter inputs and outputs of all SZ reports, nor does it show inputs external to this suite of SZ reports. In addition to the SZ analysis and model reports in Figure 1-1, this analysis report provides input (longitudinal dispersivity estimates from C-wells tracer tests) to the model reports, Radionuclide Transport Models Under Ambient Conditions and Particle Tracking Model And Abstraction Of Transport Processes. The inputs are indirect in the case of the former model report and direct in the case of the latter report. 
The bases for the conceptual models and the estimates of flow and transport parameters presented in this scientific analysis are derived from tests conducted at only one location in the saturated fractured volcanics (C-wells complex) and one location in the saturated alluvium (ATC). Consequently, several other sources of information are used to develop broader uncertainty distributions for flow and transport parameters in the TSPA for license application (LA) analyses. The development and bases of these distributions are documented in the SZ transport model abstractions report (BSC 2004 [DIRS 170042]), where it is shown that the overall parameter distributions used in the TSPA-LA analyses include considerations of literature data, expert elicitation input, and peer review input. The only uncertainty distribution presented in this report is one for the north-south/east-west anisotropy ratio of horizontal hydraulic conductivity in the fractured volcanics (Section 6.2.6).

The SZ FEPs included in the TSPA-LA and supported by the results of this report are listed in Table 6.1-3. The rationale for excluding an FEP from the TSPA-LA model will be given in Features, Events, and Processes in SZ Flow and Transport (BSC 2004 [DIRS 170013]). 


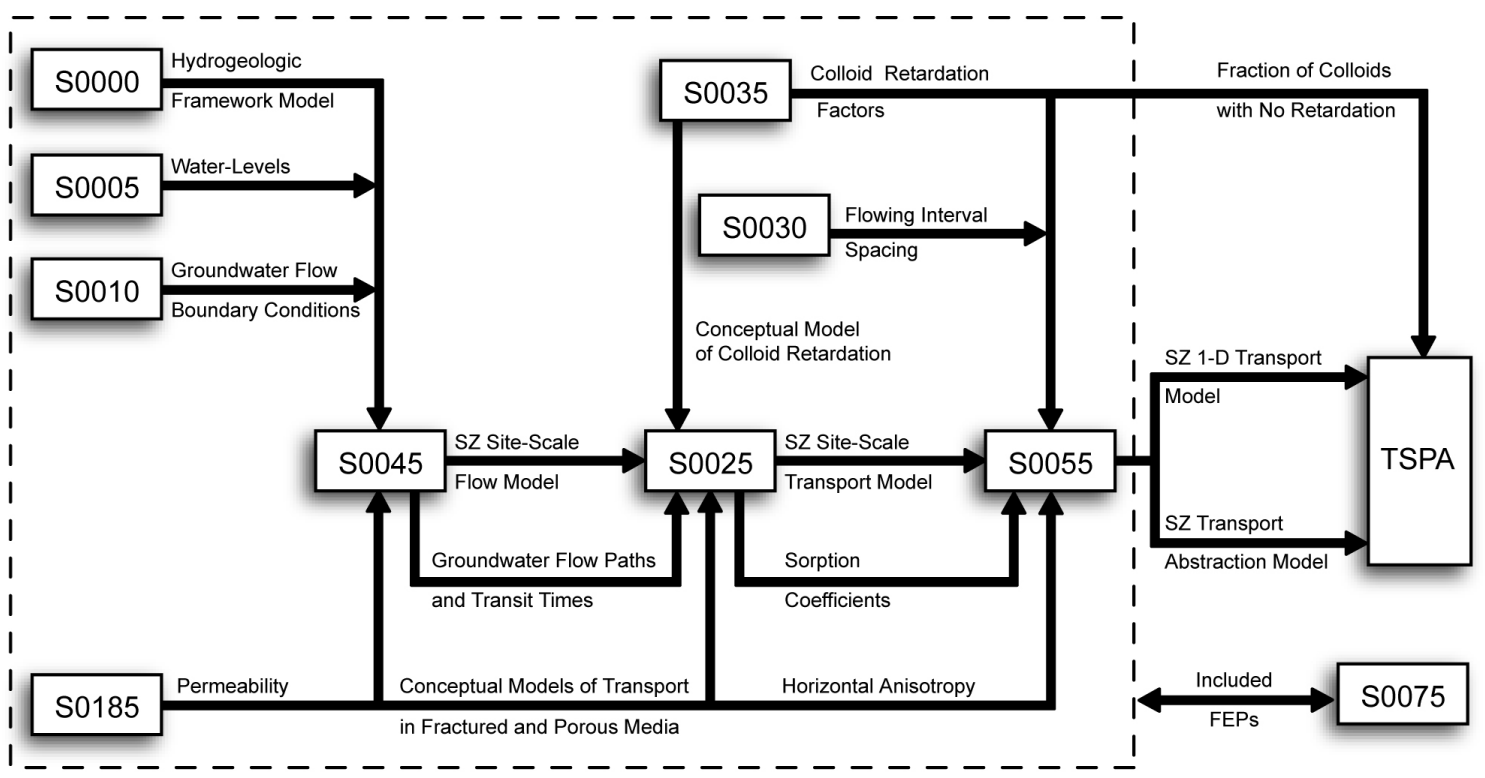

\begin{tabular}{|ll|}
\hline \multicolumn{1}{|c|}{ Legend } & \\
S0000 - Hydrogeologic Framework Model & MDL-NBS-HS-000024 \\
S0005 - Water-Level Data Analysis & ANL-NBS-HS-000034 \\
S0010 - Recharge and Lateral Groundwater Flow Boundary Conditions & ANL-NBS-MD-000010 \\
S0025 - Site-Scale Saturated Zone Transport & MDL-NBS-HS-000010 \\
S0030 - Probability Distribution for Flowing Interval Spacing & ANL-NBS-MD-00003 \\
S0035 - Saturated Zone Colloid Transport & ANL-NBS-HS-000031 \\
S0045 - Site-Scale Saturated Zone Flow Model & MDL-NBS-HS-000011 \\
S0055 - Saturated Zone Flow and Transport Model Abstraction & MDL-NBS-HS-000021 \\
S0075 - Features, Events, and Processes in SZ Flow and Transport & ANL-NBS-MD-000002 \\
S0185 - Saturated Zone In-Situ Testing & ANL-NBS-HS-000039 \\
\hline
\end{tabular}

NOTE: For illustrative purposes only. This figure is a simplified representation of the flow of information among SZ reports. See the DIRS of each report for a complete listing of data and parameter inputs. This figure does not show inputs external to this suite of $S Z$ reports.

Figure 1-1. Relationships and Flow of Key Information among Reports Pertaining to Flow and Transport in the SZ Source 


\section{QUALITY ASSURANCE}

Development of this report and supporting analyses are subject to the Office of Civilian Waste Management Quality Assurance Program (BSC 2004 [DIRS 171421], Section 8). Approved quality assurance procedures as indicated in Technical Work Plan For: Natural System Saturated Zone Analysis And Model Report Integration (BSC 2004 [DIRS 171421], Section 4) have been used to conduct and document the activities described in this report. The procedure governing the preparation of this report was AP-SIII.9Q, Scientific Analyses. Also, AP-SIII.2Q, Qualification of Unqualified Data, was implemented to qualify unqualified data for specific use in this report. The technical work plan also identifies the methods used to control the electronic management of data (BSC 2004 [DIRS 171421], Section 8). These methods were used to document the activities described in the technical work plan.

This scientific analysis provides information on the saturated zone (SZ), which is part of a natural barrier classified in Q-List (BSC 2004 [DIRS 168361]) as Safety Category because it is important to waste isolation, as defined in AP-2.22Q, Classification Analyses and Maintenance of the Q-List. The results of this report are important to the demonstration of compliance with the postclosure performance objectives (10 CFR 63.113 [DIRS 156605]). The report contributes to the analysis and modeling data used to support performance assessment; the conclusions do not directly impact engineered features important to safety, as defined in AP-2.22Q. 


\section{INTENTIONALLY LEFT BLANK}




\section{USE OF SOFTWARE}

\subsection{SOFTWARE TRACKED BY CONFIGURATION MANAGEMENT}

The computer codes used directly in this scientific analysis are summarized in Table 3-1. The qualification status of the software is indicated in the electronic Document Input Reference System database and in the Software Configuration Management System Baseline Report. All software was obtained from Software Configuration Management and is appropriate for the application. Qualified codes were used only within the range of validation as required by AP-SI.1Q, Software Management, the procedure governing software use when the outputs of this report were generated.

Table 3-1. Software Used in Support of This Scientific Analysis

\begin{tabular}{|c|c|c|c|}
\hline $\begin{array}{l}\text { Software } \\
\text { Name and } \\
\text { Version (V) }\end{array}$ & $\begin{array}{l}\text { Software } \\
\text { Tracking Number } \\
\text { (STN)/DIRS } \\
\text { Number }\end{array}$ & Description & $\begin{array}{l}\text { Computer and } \\
\text { Platform } \\
\text { Identification }\end{array}$ \\
\hline $\begin{array}{l}\text { 2WELLS_2D } \\
\text { V } 1.0\end{array}$ & $\begin{array}{l}\text { 10665-1.0-00 } \\
\text { [DIRS 159067] }\end{array}$ & $\begin{array}{l}\text { This software is used in the analysis of } \\
\text { longitudinal dispersivity in the Prow Pass Tuff C- } \\
\text { wells field tracer test. It is used to obtain } \\
\text { predicted tracer responses in homogeneous, } \\
\text { isotropic, confined (two-dimensional) aquifers } \\
\text { under partial recirculation conditions. It has been } \\
\text { used both to correct dispersion-coefficient } \\
\text { estimates for dispersion caused by a dipole-flow } \\
\text { pattern and for pretest predictions of ATC cross- } \\
\text { hole tracer tests. }\end{array}$ & $\begin{array}{l}\text { LANL, PC, Windows } \\
\text { 2000/NT } 4.0^{*}\end{array}$ \\
\hline $\begin{array}{l}\text { 2WELLS_3D } \\
\text { V } 1.0\end{array}$ & $\begin{array}{l}\text { 10667-1.0-00 } \\
\text { [DIRS 159036] }\end{array}$ & $\begin{array}{l}\text { This software is used to obtain predicted tracer } \\
\text { responses in homogeneous, isotropic, confined } \\
\text { three-dimensional aquifers under partial } \\
\text { recirculation conditions. It has been used both to } \\
\text { correct dispersion-coefficient estimates for } \\
\text { dispersion caused by a dipole-flow pattern and for } \\
\text { pretest predictions of ATC cross-hole tracer tests. }\end{array}$ & $\begin{array}{l}\text { LANL, PC, Windows } \\
2000 / N T 4.0^{*}\end{array}$ \\
\hline $\begin{array}{l}\text { DIFFCELL } \\
\text { V } 2.0\end{array}$ & $\begin{array}{l}\text { 10557-2.0-00 } \\
\text { [DIRS 159063] }\end{array}$ & $\begin{array}{l}\text { This software is used in the analysis of laboratory } \\
\text { diffusion cell experiments. It provides a numerical } \\
\text { solution to an equation describing one- } \\
\text { dimensional diffusive transport through a rock } \\
\text { wafer with time-dependent concentration } \\
\text { boundary conditions. }\end{array}$ & $\begin{array}{l}\text { LANL, PC, Windows } \\
\text { 2000/NT } 4.0^{*}\end{array}$ \\
\hline $\begin{array}{l}\text { EQUIL_FIT } \\
\text { V1.0 }\end{array}$ & $\begin{array}{l}\text { 10668-1.0-00 } \\
\text { [DIRS 159064] }\end{array}$ & $\begin{array}{l}\text { This software is used to obtain cation-exchange } \\
\text { coefficients, given experimental data on cation } \\
\text { sorption (both for sorbing and displaced cations) } \\
\text { and given independent cation-exchange-capacity } \\
\text { measurements. }\end{array}$ & $\begin{array}{l}\text { LANL, PC, Windows } \\
\text { 2000/NT } 4.0^{*}\end{array}$ \\
\hline $\begin{array}{l}\text { Filter.vi } \\
\text { V } 1.0\end{array}$ & $\begin{array}{l}\text { 10970-1.0-00 } \\
\text { [DIRS 162668] }\end{array}$ & $\begin{array}{l}\text { This software uses the standard Butterworth filter } \\
\text { with standard coefficients. It is for filtering higher- } \\
\text { frequency diurnal pressure changes due to } \\
\text { barometric pressure changes and tidal effects. }\end{array}$ & $\begin{array}{l}\text { USGS, PC, Windows } \\
2000 / \text { NT } 4.0 * / 98\end{array}$ \\
\hline $\begin{array}{l}\text { Injection_- } \\
\text { Pump- } \\
\text { back.vi } \\
\text { V } 1.0\end{array}$ & $\begin{array}{l}\text { 10675-1.0-00 } \\
\text { [DIRS 162749] }\end{array}$ & $\begin{array}{l}\text { This software is used for tracer test analysis for } \\
\text { single-well testing. Analysis considers tracer } \\
\text { injection, drift, and pumpback. }\end{array}$ & $\begin{array}{l}\text { USGS, PC, Windows } \\
\text { 2000/NT } 4.0^{*}\end{array}$ \\
\hline
\end{tabular}


Table 3-1. Software Used in Support of This Scientific Analysis (Continued)

\begin{tabular}{|c|c|c|c|}
\hline $\begin{array}{l}\text { Software } \\
\text { Name and } \\
\text { Version (V) }\end{array}$ & $\begin{array}{c}\text { Software } \\
\text { Tracking Number } \\
\text { (STN)/DIRS } \\
\text { Number }\end{array}$ & Description & $\begin{array}{l}\text { Computer and } \\
\text { Platform } \\
\text { Identification }\end{array}$ \\
\hline $\begin{array}{l}\text { rcv2amos.exe } \\
\text { and } \\
\text { MOENCH.vi, } \\
\text { Function(1), } \\
\text { V } 1.0\end{array}$ & $\begin{array}{l}\text { 10583-1.0-00 } \\
\text { [DIRS 162750] }\end{array}$ & $\begin{array}{l}\text { The software routine rcv2amos.exe is used to } \\
\text { analyze cross-hole tracer tests. In conjunction } \\
\text { with the use of rcv2amos.exe, the routine } \\
\text { MOENCH.vi was developed to serve as a user } \\
\text { interface and to display the results. }\end{array}$ & $\begin{array}{l}\text { USGS, PC, Windows } \\
2000 * \text { NT } 4.0 / 98\end{array}$ \\
\hline $\begin{array}{l}\text { MOENCH.vi } \\
\text { Function(2) } \\
\text { V } 1.0\end{array}$ & $\begin{array}{l}\text { 10582-1.0-00 } \\
\text { [DIRS 162752] }\end{array}$ & $\begin{array}{l}\text { This software is used for the analysis of cross- } \\
\text { hole tracer tests. }\end{array}$ & $\begin{array}{l}\text { USGS, PC, Windows } \\
2000 * \text { NT } 4.0 / 98\end{array}$ \\
\hline $\begin{array}{l}\text { MULTRAN } \\
\text { V } 1.0\end{array}$ & $\begin{array}{l}\text { 10666-1.0-00 } \\
\text { [DIRS 159068] }\end{array}$ & $\begin{array}{l}\text { This is a two-dimensional numerical model that } \\
\text { uses an implicit-in-time, alternating-direction, } \\
\text { finite-difference method to solve the equations } \\
\text { describing multicomponent transport of sorbing } \\
\text { and nonsorbing solutes in a dual-porosity } \\
\text { medium. This software is used for analysis of } \\
\text { laboratory crushed-rock and alluvium column } \\
\text { experiments. It is also used for the analysis of } \\
\text { the first peak in the Bullfrog Tuff C-wells field } \\
\text { tracer test and for prediction and analysis of } \\
\text { ATC tracer experiments. }\end{array}$ & $\begin{array}{l}\text { LANL, PC, Windows } \\
\text { 2000/NT } 4.0^{*}\end{array}$ \\
\hline $\begin{array}{l}\text { Neuman.vi } \\
\text { V } 1.0\end{array}$ & $\begin{array}{l}\text { 10972-1.0-00 } \\
\text { [DIRS 162754] }\end{array}$ & $\begin{array}{l}\text { This software displays the standard and } \\
\text { accepted type curve for unconfined aquifers } \\
\text { and allows the fitting of the input data curves } \\
\text { over the type curve. The .vi extension displays } \\
\text { the appropriate resulting hydrologic parameters } \\
\text { associated with the data curve matching } \\
\text { (transmissivity and storativity). }\end{array}$ & $\begin{array}{l}\text { USGS, PC, Windows } \\
\text { 2000/NT } 4.0^{*} / 98\end{array}$ \\
\hline $\begin{array}{l}\text { PEST } \\
\text { V } 5.5\end{array}$ & $\begin{array}{l}\text { 10289-5.5-00 } \\
\text { [DIRS 161564] }\end{array}$ & $\begin{array}{l}\text { This software assists in data interpretation, } \\
\text { model calibration, and predictive analysis. } \\
\text { PEST adjusts model parameters and/or } \\
\text { excitations until the fit between model output } \\
\text { and field or laboratory observations is } \\
\text { optimized in the weighted least-squares sense. }\end{array}$ & $\begin{array}{l}\text { USGS, PC, Windows } \\
2000^{*}\end{array}$ \\
\hline $\begin{array}{l}\text { RECIRC.vi } \\
\text { V } 1.0\end{array}$ & $\begin{array}{l}\text { 10673-1.0-00 } \\
\text { [DIRS 164432] }\end{array}$ & $\begin{array}{l}\text { This program is used for recirculating and } \\
\text { partial-recirculation cross-hole tracer test } \\
\text { analysis. }\end{array}$ & $\begin{array}{l}\text { USGS, PC, Windows } \\
\text { 98/NT } 4.0^{*} / 2000\end{array}$ \\
\hline $\begin{array}{l}\text { RELAP } \\
\text { V. } 2.0\end{array}$ & $\begin{array}{l}\text { 10551-2.0-00 } \\
\text { [DIRS 159065] }\end{array}$ & $\begin{array}{l}\text { This software models tracer transport by } \\
\text { convoluting a Laplace-domain transfer function } \\
\text { for transport through dual-porosity media with } \\
\text { transfer functions that describe tracer injection, } \\
\text { mixing in the injection and production wellbores } \\
\text { (or flow manifolds in laboratory experiments), } \\
\text { and recirculation of the product fluid (in field } \\
\text { experiments only). It also performs curve fits to } \\
\text { field or laboratory tracer test data to obtain the } \\
\text { best-fitting transport parameter values. }\end{array}$ & $\begin{array}{l}\text { LANL, PC, Windows } \\
\text { 2000/NT } 4.0^{*}\end{array}$ \\
\hline $\begin{array}{l}\text { RETRAN } \\
\text { V } 2.0\end{array}$ & $\begin{array}{l}\text { 10552-2.0-00 } \\
\text { [DIRS 159066] }\end{array}$ & $\begin{array}{l}\text { This software models reactive transport in dual- } \\
\text { porosity media with a general, nonlinear } \\
\text { sorption isotherm and with time-varying flow } \\
\text { rates. }\end{array}$ & $\begin{array}{l}\text { LANL, PC, Windows } \\
2000 / N T 4.0^{*}\end{array}$ \\
\hline
\end{tabular}


Table 3-1. Software Used in Support of This Scientific Analysis (Continued)

\begin{tabular}{|c|c|c|c|}
\hline $\begin{array}{c}\text { Software } \\
\text { Name and } \\
\text { Version (V) }\end{array}$ & $\begin{array}{c}\text { Software } \\
\text { Tracking Number } \\
\text { (STN)/DIRS } \\
\text { Number }\end{array}$ & Description & $\begin{array}{l}\text { Computer and } \\
\text { Platform } \\
\text { Identification }\end{array}$ \\
\hline $\begin{array}{l}\text { Streltsova- } \\
\text { Adams.vi } \\
\text { V } 1.0\end{array}$ & $\begin{array}{l}\text { 10971-1.0-00 } \\
\text { [DIRS 162756] }\end{array}$ & $\begin{array}{l}\text { This software displays the standard and } \\
\text { accepted Streltsova-Adams type curve for } \\
\text { fractured aquifers and allows the fitting of the } \\
\text { input data curves over this type curve. The .vi } \\
\text { extension displays the appropriate resulting } \\
\text { hydrologic parameters associated with the data } \\
\text { curve matching (transmissivity and storativity). }\end{array}$ & $\begin{array}{l}\text { USGS, PC, Windows } \\
\text { 2000/NT } 4.0 * / 98\end{array}$ \\
\hline $\begin{array}{l}\text { Theis.vi } \\
\text { V } 1.0\end{array}$ & $\begin{array}{l}\text { 10974-1.0-00 } \\
\text { [DIRS 162758] }\end{array}$ & $\begin{array}{l}\text { This software displays the standard and } \\
\text { accepted Theis type curve and allows the fitting } \\
\text { of the input data curves over this type curve. } \\
\text { The .vi extension displays the appropriate } \\
\text { resulting hydrologic parameters associated } \\
\text { with the data curve matching (transmissivity } \\
\text { and storativity). }\end{array}$ & $\begin{array}{l}\text { USGS, PC, Windows } \\
\text { 2000/NT } 4.0 * / 98\end{array}$ \\
\hline
\end{tabular}

* Asterisks indicate the operating system platform used for software applications described in this analysis report.

ATC=Alluvial Testing Complex; DIRS=Document Input Reference System; LANL=Los Alamos National Laboratory; USGS= U.S. Geological Survey.

All computer codes listed in Table 3-1 were selected for use in this scientific analysis because they were developed expressly for the purpose of conducting the various analyses to which they were applied. The range of use and the limitations on output of each code are specified in the Software Management Report (SMR) for each code (under AP-SI.1Q, the SMR is where the range and limitations were documented). The codes were always used within their specified range of use, and their limitations on output, in addition to being identified in the SMRs, are discussed in appropriate places in this report (especially in sections that address "limitations and uncertainties").

The software, finite element heat and mass transfer code (FEHM) (V. 2.20, STN: 10086-2.20-00 [DIRS 161725]), was used to conduct a sensitivity study to illustrate that the potentiometric head distributions calculated by the site-scale SZ flow model are quite insensitive to the horizontal hydraulic conductivity anisotropy ratio in the fractured volcanics. This sensitivity study (Appendix C, Section C6.4) was not used to generate any inputs or outputs for this report, so FEHM is not listed in Table 3-1 above.

\subsection{EXEMPT SOFTWARE}

Commercial, off-the-shelf software used in support of this scientific analysis is listed in Table 3-2. This software was exempt from the requirements of AP-SI.1Q, Software Management, the procedure governing software use when the outputs of this report were generated. 
Table 3-2. Exempt Software Used in Support of This Scientific Analysis

\begin{tabular}{|l|l|l|}
\hline $\begin{array}{c}\text { Software Name } \\
\text { and Version (V) }\end{array}$ & \multicolumn{1}{c|}{ Description } & $\begin{array}{c}\text { Computer and } \\
\text { Platform Identification }\end{array}$ \\
\hline $\begin{array}{l}\text { Microsoft Excel, 97 } \\
\text { SR-1 }\end{array}$ & $\begin{array}{l}\text { The commercial software, Microsoft Excel, 97 SR-1, was used for } \\
\text { statistical analysis of data and plotting graphs. Only built-in } \\
\text { standard functions in this software were used. No software } \\
\text { routines or macros were used with the software to prepare this } \\
\text { report. The output was visually checked for correctness, and the } \\
\text { results of all calculations were hand-checked. }\end{array}$ & PC, Windows 2000/NT \\
\hline
\end{tabular}

Calculations and spreadsheets used in this analysis can be found in the Technical Data Management System (TDMS) within data packages that have been assigned data tracking numbers (DTNs). Alternatively, some calculations and spreadsheets can be found in scientific notebooks. The DTN numbers or notebooks (including page numbers), or both, are identified in appropriate places throughout Section 6 and various appendices of this report to allow the independent reviewer to reproduce or verify results by visual inspection or hand calculation. Calculations and spreadsheets are not included as appendices to this report because of their voluminous nature. 


\section{INPUTS}

\subsection{DIRECT INPUTS}

The data used in interpretation of the hydraulic tests discussed in Section 6.2 and Appendix C have been submitted as data packages (Table 4-1) to the TDMS. Data packages submitted to the U.S. Department of Energy are available for inspection at the Office of Repository Development, Records Processing Center in Las Vegas, Nevada. The data and other technical information providing input for the development of parameters documented in this scientific analysis are identified in Table 4-1. The listed data and the technical information are appropriate sources for the analyses documented in this report. A brief description of the data, the DTN used as input, or the source of the data are listed in Table 4-1. The table is divided according to the sections in this analysis in which the data are used. The qualification status of data input is indicated in the TDMS and in the Document Input Reference System database.

Table 4-1. Input Data

\begin{tabular}{|c|c|}
\hline Data Description & Data Tracking Number (DTN) or Source \\
\hline \multicolumn{2}{|c|}{ Direct Inputs Section 6.1} \\
\hline $\begin{array}{l}\text { Results of hydraulic tests in Miocene tuffaceous rocks } \\
\text { at the C-hole complex, } 1995 \text { to 1997, Yucca Mountain, } \\
\text { Nevada }\end{array}$ & $\begin{array}{l}\text { GS030508312314.003 [DIRS 164425] } \\
\text { (Qualified for intended use in Appendix M) }\end{array}$ \\
\hline Well completion information for NC-EWDP-19D & MO0112DQRWLNYE.018 [DIRS 157187] \\
\hline Well completion information for NC-EWDP-19IM2 & $\begin{array}{l}\text { MO0306NYE05260.166 [DIRS 165877] } \\
\text { (Qualified for intended use in Appendix K) }\end{array}$ \\
\hline Results of C-wells flow surveys & $\begin{array}{l}\text { GS931008312313.016 [DIRS 148173] } \\
\text { (Qualified for intended use in Appendix L) }\end{array}$ \\
\hline \multicolumn{2}{|c|}{ Direct Inputs Section 6.2} \\
\hline $\begin{array}{l}\text { Results of hydraulic tests in Miocene tuffaceous rocks } \\
\text { at the C-hole complex, } 1995 \text { to 1997, Yucca Mountain, } \\
\text { Nevada }\end{array}$ & $\begin{array}{l}\text { GS030508312314.003 [DIRS 164425] } \\
\text { (Qualified for intended use in Appendix M) }\end{array}$ \\
\hline $\begin{array}{l}\text { Water-level altitude data from four wells in the } \\
\text { continuous network, May through December } 1996\end{array}$ & GS970308312314.002 [DIRS 161273] \\
\hline $\begin{array}{l}\text { Transducer, barometric pressure, and discharge data } \\
\text { collected from } 4 / 18 / 98 \text { through } 11 / 24 / 98 \text { in support of } \\
\text { the ongoing hydraulic tracer tests being conducted at } \\
\text { the UE-25 C-wells complex, Nevada }\end{array}$ & GS990408312315.002 [DIRS 140115] \\
\hline $\begin{array}{l}\text { UE-25 ONC-1 transducer pressures, March } 1996 \text { to } \\
\text { December, } 1997\end{array}$ & $\begin{array}{l}\text { MO0212SPANYESJ.149 [DIRS 161274] } \\
\text { (Qualified for intended use in Appendix M) }\end{array}$ \\
\hline \multicolumn{2}{|c|}{ Direct Inputs Section 6.3} \\
\hline $\begin{array}{l}\text { Results of hydraulic tests in Miocene tuffaceous rocks } \\
\text { at the C-hole complex, } 1995 \text { to 1997, Yucca Mountain, } \\
\text { Nevada }\end{array}$ & $\begin{array}{l}\text { GS030508312314.003 [DIRS 164425] } \\
\text { (Qualified for intended use in Appendix M) }\end{array}$ \\
\hline $\begin{array}{l}\text { Concentrations of } 2,6 \text {-DFBA and pyridone from tracer } \\
\text { test conducted at the C-wells complex, } 1 / 8 / 97- \\
7 / 11 / 97\end{array}$ & GS010508312315.001 [DIRS 155860] \\
\hline $\begin{array}{l}\text { Tracer recovery data from testing in the Prow Pass } \\
\text { interval }\end{array}$ & GS990208312315.001 [DIRS 159238] \\
\hline Prow Pass reactive-tracer-test field data & LAPR831231AQ99.001 [DIRS 140134] \\
\hline Bullfrog reactive tracer test data & LA0007PR831231.001 [DIRS 156043] \\
\hline Bromide and PFBA sorption data onto C-wells tuffs & LA0302PR831231.001 [DIRS 162605] \\
\hline
\end{tabular}


Table 4-1. Input Data (Continued)

\begin{tabular}{|c|c|}
\hline Data Description & Data Tracking Number (DTN) or Source \\
\hline \multicolumn{2}{|c|}{ Direct Inputs Section 6.3 (Continued) } \\
\hline $\begin{array}{l}\text { 2,3,4,5 TeFBA Response in Prow Pass from } \\
\text { UE-25 c\#1 to UE-25 c\#2, } 1998\end{array}$ & MO0308SPATRCRC.000 [DIRS 164821] \\
\hline Results of C-wells flow surveys & $\begin{array}{l}\text { GS931008312313.016 [DIRS 148173] } \\
\text { (Qualified for intended use in Appendix L) }\end{array}$ \\
\hline $\begin{array}{l}\text { Normalized Tracer Concentrations and Recoveries in } \\
\text { C-Wells Tracer Tests }\end{array}$ & LA0410PR831231.001 [DIRS 171899] \\
\hline \multicolumn{2}{|c|}{ Direct Inputs Section 6.4} \\
\hline $\begin{array}{l}\text { Flow rates, pressures, and temperatures for hydraulic } \\
\text { and tracer testing at the NC-EWDP-19D, NC-EWDP- } \\
\text { 19IM1, and NC-EWDP-19IM2 Alluvial Testing } \\
\text { Complex from December 18, } 2001 \text { to March 22, } 2002 .\end{array}$ & GS020908312316.002 [DIRS 162679] \\
\hline \multicolumn{2}{|c|}{ Direct Inputs Section 6.5} \\
\hline $\begin{array}{l}\text { 2,6 DFBA and I concentrations in single-well tracer } \\
\text { test with 2-day rest period in NC-EWDP-19D }\end{array}$ & UN0102SPA008KS.003 [DIRS 162614] \\
\hline $\begin{array}{l}2,4 \text { DFBA and } \mathrm{Cl} \text { concentrations in single-well tracer } \\
\text { test with } 0.5 \text {-hr rest period in NC-EWDP-19D }\end{array}$ & UN0109SPA008IF.006 [DIRS 162442] \\
\hline $\begin{array}{l}\text { PFBA concentrations in single-well tracer test with } 30- \\
\text { day rest period in NC-EWDP-19D }\end{array}$ & UN0109SPA008KS.007 [DIRS 162615] \\
\hline $\begin{array}{l}\text { Bromide concentrations in single-well tracer test with } \\
\text { 30-day rest period in NC-EWDP-19D }\end{array}$ & UN0109SPA008KS.008 [DIRS 162616] \\
\hline $\begin{array}{l}\text { NC-EWDP-19D, ATC single-hole hydraulic testing } \\
\text { associated with the July } 7,2000 \text { to April } 26,2001 \\
\text { tracer study }\end{array}$ & GS020708312316.001 [DIRS 162678] \\
\hline \multicolumn{2}{|c|}{ Direct Inputs Appendix C } \\
\hline $\begin{array}{l}\text { Results of hydraulic tests in Miocene tuffaceous rocks } \\
\text { at the C-hole complex, } 1995 \text { to 1997, Yucca Mountain, } \\
\text { Nevada }\end{array}$ & $\begin{array}{l}\text { GS030508312314.003 [DIRS 164425] } \\
\text { (Qualified for intended use in Appendix M) }\end{array}$ \\
\hline $\begin{array}{l}\text { Water-level altitude data from four wells in the } \\
\text { continuous network, May through December } 1996\end{array}$ & GS970308312314.002 [DIRS 161273] \\
\hline $\begin{array}{l}\text { Pump test data collected at the C-wells complex } \\
5 / 7 / 96-12 / 31 / 96\end{array}$ & GS981008312314.003 [DIRS 144464] \\
\hline $\begin{array}{l}\text { Transducer, barometric pressure, and discharge data } \\
\text { collected from } 4 / 18 / 98 \text { through } 11 / 24 / 98 \text { in support of } \\
\text { the ongoing hydraulic tracer tests being conducted at } \\
\text { the UE-25 C-wells complex, Nevada }\end{array}$ & GS990408312315.002 [DIRS 140115] \\
\hline $\begin{array}{l}\text { UE-25 ONC-1 transducer pressures, March } 1996 \text { to } \\
\text { December, } 1997\end{array}$ & $\begin{array}{l}\text { MO0212SPANYESJ.149 [DIRS 161274] } \\
\text { (Qualified for intended use in Appendix M) }\end{array}$ \\
\hline \multicolumn{2}{|c|}{ Direct Inputs Appendix D } \\
\hline $\begin{array}{l}\text { Results of hydraulic tests in Miocene tuffaceous rocks } \\
\text { at the C-hole complex, } 1995 \text { to 1997, Yucca Mountain, } \\
\text { Nevada }\end{array}$ & GS030508312314.003 [DIRS 164425] \\
\hline $\begin{array}{l}\text { Concentrations of } 2,6-\text { DFBA and pyridone from tracer } \\
\text { test conducted at the C-wells complex, } \\
1 / 8 / 97-7 / 11 / 97\end{array}$ & GS010508312315.001 [DIRS 155860] \\
\hline $\begin{array}{l}\text { 2,3,4,5 TeFBA Response in Prow Pass from } \\
\text { UE-25 c\#1 to UE-25 c\#2, } 1998\end{array}$ & MO0308SPATRCRC.000 [DIRS 164821] \\
\hline $\begin{array}{l}\text { Data obtained from the analysis of the iodide tracer } \\
\text { test water samples collected during the } 2 / 13 / 96 \\
\text { convergent tracer test conducted at the C-wells } \\
\text { complex }\end{array}$ & GS960808312315.001 [DIRS 159235] \\
\hline
\end{tabular}


Table 4-1. Input Data (Continued)

\begin{tabular}{|c|c|}
\hline Data Description & Data Tracking Number (DTN) or Source \\
\hline \multicolumn{2}{|c|}{ Direct Inputs Appendix D (Continued) } \\
\hline $\begin{array}{l}\text { Tracer recovery data from testing in the Prow Pass } \\
\text { interval }\end{array}$ & GS990208312315.001 [DIRS 159238] \\
\hline $\begin{array}{l}\text { Transducer, barometric pressure, and discharge data } \\
\text { collected from } 4 / 18 / 98 \text { through } 11 / 24 / 98 \text { in support of } \\
\text { the ongoing hydraulic tracer tests being conducted at } \\
\text { the UE-25 C-wells complex, Nevada }\end{array}$ & GS990408312315.002 [DIRS 140115] \\
\hline Prow Pass reactive-tracer-test field data & LAPR831231AQ99.001 [DIRS 140134] \\
\hline Bullfrog reactive tracer test data & LA0007PR831231.001 [DIRS 156043] \\
\hline Injection and production flow rates for Prow Pass test & GS010799992315.001 [DIRS 157067] \\
\hline Bromide and lithium matrix diffusion coefficients & $\begin{array}{l}\text { Newman } 1973 \text { [DIRS 148719] } \\
\text { (Qualified as external source in Appendix A) }\end{array}$ \\
\hline Fluorinated benzoic acid diffusion coefficients & $\begin{array}{l}\text { Bowman } 1984 \text { [DIRS 156645] } \\
\text { (Qualified as external source in Appendix A) }\end{array}$ \\
\hline $\begin{array}{l}\text { Pump test data collected at the C-wells complex } \\
1 / 8 / 97-3 / 31 / 97\end{array}$ & GS981008312314.002 [DIRS 147068] \\
\hline $\begin{array}{l}\text { Pumping test data collected at the C-wells complex, } \\
5 / 7 / 96-12 / 31 / 96\end{array}$ & GS981008312314.003 [DIRS 144464] \\
\hline Tabulations of Data used in Tracer Test Interpretations & LA0401PR831231.001 [DIRS 171859] \\
\hline $\begin{array}{l}\text { Normalized Tracer Concentrations and Recoveries in } \\
\text { C-Wells Tracer Tests }\end{array}$ & LA0410PR831231.001 [DIRS 171899] \\
\hline lodide diffusion coefficients & $\begin{array}{l}\text { Skagius and Neretnieks } 1986 \text { [DIRS 156862] } \\
\text { (Qualified as external source in Appendix A) }\end{array}$ \\
\hline \multicolumn{2}{|c|}{ Direct Inputs Appendix E } \\
\hline $\begin{array}{l}\text { Mineral abundance data of C-well tuffs from UE-25 } \\
\text { C\#1 and c\#2 }\end{array}$ & MO0012MINLCHOL.000 [DIRS 153370] \\
\hline $\begin{array}{l}\text { Sorbing element concentration data of } \mathrm{J}-13 \text { and } \mathrm{C}-3 \\
\text { well water from UE- } 25 \mathrm{c} \# 1 \text { and } \mathrm{c} \# 2\end{array}$ & MO0012SORBCHOL.000 [DIRS 153375] \\
\hline $\begin{array}{l}\text { PFBA and bromide tracer diffusion in tuff from UE-25 } \\
\text { C\#1 }\end{array}$ & MO0012DIFFCHOL.000 [DIRS 159243] \\
\hline Porosity data for UE-25 c\#1, c\#2, and c\#3 & MO0012POROCHOL.000 [DIRS 153376] \\
\hline Permeability data for UE-25 c\#1, c\#2, and c\#3 & MO0012PERMCHOL.000 [DIRS 153368] \\
\hline Bromide and PFBA sorption data onto C-wells tuffs & LA0302PR831231.001 [DIRS 162605] \\
\hline 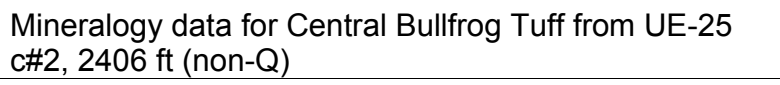 & $\begin{array}{l}\text { LA9909PR831231.004 [DIRS 129623] } \\
\text { (Qualified for intended use in Appendix J) }\end{array}$ \\
\hline $\begin{array}{l}\text { Bromide and lithium tracer movement in crushed tuff } \\
\text { columns for UE-25 c\#2 tuff }\end{array}$ & LA0301PR831231.001 [DIRS 162603] \\
\hline $\begin{array}{l}\text { lodide concentrations in C-wells fractured core } \\
\text { experiments }\end{array}$ & LA0212PR831231.001 [DIRS 162607] \\
\hline $\begin{array}{l}\text { Lithium, bromide, and PFBA concentrations in C-wells } \\
\text { fractured core experiments }\end{array}$ & LA0212PR831231.003 [DIRS 162609] \\
\hline $\begin{array}{l}\text { Sodium and calcium concentrations in fractured core } \\
\text { experiments in all C-wells cores except for core UE- } 25 \\
\text { c\#2, } 1,745 \mathrm{ft}\end{array}$ & LA0212PR831231.002 [DIRS 162608] \\
\hline $\begin{array}{l}\text { Sodium and calcium concentrations in fractured core } \\
\text { experiments in core UE- } 25 \mathrm{c} \# 2,1,745 \mathrm{ft} \text {. }\end{array}$ & LA0212PR831231.005 [DIRS 166215] \\
\hline Results of C-wells flow surveys & $\begin{array}{l}\text { GS931008312313.016 [DIRS 148173] } \\
\text { (Qualified for intended use in Appendix L) }\end{array}$ \\
\hline $\begin{array}{l}\text { Water viscosity, water density, gravitational } \\
\text { acceleration }\end{array}$ & Weast and Astle 1981 [DIRS 100833]) \\
\hline
\end{tabular}


Table 4-1. Input Data (Continued)

\begin{tabular}{|c|c|}
\hline Data Description & Data Tracking Number (DTN) or Source \\
\hline \multicolumn{2}{|c|}{ Direct Inputs Appendix F } \\
\hline $\begin{array}{l}\text { NC-EWDP-19D, ATC single-hole hydraulic testing } \\
\text { associated with the July } 7,2000 \text { to April } 26,2001 \\
\text { tracer study }\end{array}$ & GS020708312316.001 [DIRS 162678] \\
\hline $\begin{array}{l}\text { Flow rates, pressures, and temperatures for hydraulic } \\
\text { and tracer testing at the NC-EWDP-19D, NC-EWDP- } \\
\text { 19IM1, and NC-EWDP-19IM2 Alluvial Testing } \\
\text { Complex from December 18, } 2001 \text { to March 22, } 2002\end{array}$ & GS020908312316.002 [DIRS 162679] \\
\hline $\begin{array}{l}\text { Background pressures and temperatures during } \\
\text { barometric monitoring at the NC-EWDP-19D, NC- } \\
\text { EWDP-19IM1, and NC-EWDP-19IM2 Alluvial Testing } \\
\text { Complex from May 1, 2002 through July 3, } 2002\end{array}$ & GS020908312316.003 [DIRS 162680] \\
\hline $\begin{array}{l}\text { Grain size analysis of alluvium samples from wells } \\
19 D \text { and 19P of the Alluvial Test Complex }\end{array}$ & LA0201JS831421.001 [DIRS 162613] \\
\hline Geophysical log data from Borehole NC-EWDP-19D & MO0105GPLOG19D.000 [DIRS 163480] \\
\hline \multicolumn{2}{|c|}{ Direct Inputs Appendix G } \\
\hline $\begin{array}{l}2,6 \text { DFBA and I concentrations in single-well tracer } \\
\text { test with 2-day rest period in NC-EWDP-19D }\end{array}$ & UN0102SPA008KS.003 [DIRS 162614] \\
\hline $\begin{array}{l}2,4 \text { DFBA and } \mathrm{Cl} \text { concentrations in single-well tracer } \\
\text { test with 0.5-hr rest period in NC-EWDP-19D }\end{array}$ & UN0109SPA008IF.006 [DIRS 162442] \\
\hline $\begin{array}{l}\text { PFBA concentrations in single-well tracer test with } 30- \\
\text { day rest period in NC-EWDP-19D }\end{array}$ & UN0109SPA008KS.007 [DIRS 162615] \\
\hline $\begin{array}{l}\text { Bromide concentrations in single-well tracer test with } \\
\text { 30-day rest period in NC-EWDP-19D }\end{array}$ & UN0109SPA008KS.008 [DIRS 162616] \\
\hline $\begin{array}{l}\text { 2,4 DFBA concentrations in single-well tracer test in } \\
\text { interval \#4 of NC-EWDP-19D }\end{array}$ & MO0205UCC008IF.001 [DIRS 162617] \\
\hline $\begin{array}{l}\text { Microsphere concentrations in single-well tracer tests } \\
\text { in NC-EWDP-19D }\end{array}$ & LA0207PR831352.001 [DIRS 162431] \\
\hline $\begin{array}{l}\text { NC-EWDP-19D, ATC single-hole hydraulic testing } \\
\text { associated with the July } 7,2000 \text { to April } 26,2001 \\
\text { tracer study }\end{array}$ & GS020708312316.001 [DIRS 162678] \\
\hline Drawdown data for NC-EWDP boreholes & GS020908312316.002 [DIRS 162679] \\
\hline
\end{tabular}

ATC= Alluvial Testing Complex; BET=Brunauer-Emmet-Teller; DFBA=difluorobenzoic acid;

PFBA=pentafluorobenzoic acid; $Q=$ qualified

\subsection{CRITERIA}

The general requirements to be satisfied by the TSPA-LA are stated in 10 CFR 63.114 [DIRS 156605]. Technical requirements to be satisfied by the TSPA-LA are identified in Project Requirements Document (Canori and Leitner 2003 [DIRS 166275]). The acceptance criteria that will be used by the U.S. Nuclear Regulatory Commission to determine whether the technical requirements have been met are identified in Yucca Mountain Review Plan, Final Report (YMRP) (NRC 2003 [DIRS 163274]). The pertinent requirements and criteria for this report from Section 3.5 of Technical Work Plan for: Natural System - Saturated Zone Analysis and Model Report Integration (BSC 2004 [DIRS 171421])) are summarized in Table 4-2. Note that the technical work plan also lists PRD-002/T-014, Performance Objectives for the Geologic Repository after Permanent Closure (YMRP Acceptance Criterion 2.2.1.1.3, Criteria 2 and 3), as 
a requirement; but a Project regulatory expert determined that this requirement was not applicable to this scientific report.

In accordance with Section 3.3 of the technical work plan (BSC 2004 [DIRS 171421]), the level of accuracy, precision, and representativeness of results are discussed in appropriate places in Section 6 and in Appendices $\mathrm{C}$ through $\mathrm{H}$ of this report. There are no Condition Reports associated with this scientific report, so the completion criteria of Section 3.4 of the technical work plan (BSC 2004 [DIRS 171421]) are satisfied for this report.

Table 4-2. Project Requirements and YMRP Acceptance Criteria Applicable to This Scientific Analysis Report

\begin{tabular}{|c|c|c|c|}
\hline $\begin{array}{c}\text { Requirement } \\
\text { Number }^{a}\end{array}$ & Requirement Title $^{a}$ & 10 CFR 63 Link & $\begin{array}{c}\text { YMRP Acceptance } \\
\text { Criteria }\end{array}$ \\
\hline PRD -002/T-015 & Requirements for Performance Assessment & $\begin{array}{l}10 \text { CFR } 63.114 \\
(\mathrm{a})-(\mathrm{c}) \text { and }(\mathrm{e}) \\
\text { and }(\mathrm{g})\end{array}$ & $\begin{array}{l}\text { 2.2.1.3.8.3, criteria } 1 \text { to } 5 \\
2.2 .1 .3 .9 .3 \text {, criteria } 1 \text { to } 4\end{array}$ \\
\hline
\end{tabular}

a from Canori and Leitner (2003 [DIRS 166275]).

${ }^{b}$ from NRC (2003 [DIRS 163274]).

YMRP $=$ Yucca Mountain Review Plan, Final Report.

The applicable acceptance criteria identified in Sections 2.2.1.3.8.3 and 2.2.1.3.9.3 of the YMRP (NRC 2003 [DIRS 163274]) are listed below. In cases where subsidiary criteria are listed in the YMRP for a given criterion, only the subsidiary criteria addressed by this scientific analysis are listed below.

\subsubsection{Acceptance Criteria from Section 2.2.1.3.8.3, Flow Paths in the Saturated Zone}

\section{Acceptance Criterion 1: System Description and Model Integration Are Adequate.}

- Subcriterion (2)-The description of the aspects of hydrology, geology, geochemistry, design features, physical phenomena, and couplings, which may affect flow paths in the saturated zone, is adequate. Conditions and assumptions in the abstraction of flow paths in the saturated zone are readily identified, and consistent with the body of data presented in the description.

- Subcriterion (3)-The abstraction of flow paths in the saturated zone uses assumptions, technical bases, data, and models that are appropriate and consistent with other related DOE abstractions. For example, the assumptions used for flow paths in the saturated zone are consistent with the total system performance assessment abstraction of representative volume (Section 2.2.1.3.12 of the YMRP). The descriptions and technical bases provide transparent and traceable support for the abstraction of flow paths in the saturated zone.

- Subcriterion (10)-Guidance in NUREG-1297 and NUREG-1298 (Altman et al. 1988 [DIRS 103597; DIRS 103750]), or other acceptable approaches for peer review and data qualification is followed. 


\section{Acceptance Criterion 2: Data Are Sufficient for Model Justification.}

- Subcriterion (1)-Geological, hydrological, and geochemical values used in the license application to evaluate flow paths in the saturated zone are adequately justified. Adequate descriptions of how the data were used, interpreted, and appropriately synthesized into the parameters are provided.

- Subcriterion (2)-Sufficient data have been collected on the natural system to establish initial and boundary conditions for the abstraction of flow paths in the saturated zone.

- Subcriterion (3)-Data on the geology, hydrology, and geochemistry of the saturated zone used in the total system performance assessment abstraction are based on appropriate techniques. These techniques may include laboratory experiments, site-specific field measurements, natural analog research, and process-level modeling studies. As appropriate, sensitivity or uncertainty analyses, used to support the DOE total system performance assessment abstraction, are adequate to determine the possible need for additional data.

- Subcriterion (4)-Sufficient information is provided to substantiate that the proposed mathematical groundwater modeling approach and proposed model(s) are calibrated and applicable to site conditions.

\section{Acceptance Criterion 3: $\quad$ Data Uncertainty Is Characterized and Propagated} Through the Model Abstraction.

- Subcriterion (1)-Models use parameter values, assumed ranges, probability distributions, and bounding assumptions that are technically defensible, reasonably account for uncertainties and variabilities, and do not result in an under-representation of the risk estimate.

- Subcriterion (3)-Uncertainty is adequately represented in parameter development for conceptual models, process-level models, and alternative conceptual models, considered in developing the abstraction of flow paths in the saturated zone. This may be done through either sensitivity analyses or use of conservative limits. For example, sensitivity analyses and/or similar analyses are sufficient to identify saturated zone flow parameters that are expected to significantly affect the abstraction model outcome.

\section{Acceptance Criterion 4: Model Uncertainty Is Characterized and Propagated Through the Model Abstraction.}

- Subcriterion (1)-Alternative modeling approaches of features, events, and processes are considered and are consistent with available data and current scientific understanding, and the results and limitations are appropriately considered in the abstraction. 
- Subcriterion (2)-Conceptual model uncertainties are adequately defined and documented, and effects on conclusions regarding performance are properly assessed. For example, uncertainty in data interpretations is considered by either analyzing reasonable conceptual flow models that are supported by site data or demonstrating through sensitivity studies that the uncertainties have little impact on repository performance.

- Subcriterion (3)-Consideration of conceptual model uncertainty is consistent with available site characterization data, laboratory experiments, field measurements, natural analog information and process-level modeling studies; the treatment of conceptual model uncertainty does not result in an under-representation of the risk estimate.

- Subcriterion (4)-Appropriate alternative modeling approaches are consistent with available data and current scientific knowledge, and appropriately consider their results and limitations, using tests and analyses that are sensitive to the processes modeled.

\section{Acceptance Criterion 5: $\quad$ Model Abstraction Output Is Supported by Objective Comparisons.}

- Subcriterion (4)-Sensitivity analyses or bounding analyses are provided to support the abstraction of flow paths in the saturated zone, that cover ranges consistent with site data, field or laboratory experiments and tests, and natural analog research.

\subsubsection{Acceptance Criteria from Section 2.2.1.3.9.3, Radionuclide Transport in the Saturated Zone}

\section{Acceptance Criterion 1: System Description and Model Integration Are Adequate.}

- Subcriterion (1)-Total system performance assessment adequately incorporates important design features, physical phenomena, and couplings, and uses consistent and appropriate assumptions throughout the radionuclide transport in the saturated zone abstraction process.

- Subcriterion (2)-The description of the aspects of hydrology, geology, geochemistry, design features, physical phenomena, and couplings, that may affect radionuclide transport in the saturated zone, is adequate. For example, the description includes changes in transport properties in the saturated zone, from water-rock interaction. Conditions and assumptions in the abstraction of radionuclide transport in the saturated zone are readily identified, and consistent with the body of data presented in the description.

- Subcriterion (3)-The abstraction of radionuclide transport in the saturated zone uses assumptions, technical bases, data, and models that are appropriate 
and consistent with other related DOE abstractions. For example, assumptions used for radionuclide transport in the saturated zone are consistent with the total system performance assessment abstractions of radionuclide release rates and solubility limits, and flow paths in the saturated zone (Sections 2.2.1.3.4 and 2.2.1.3.8 of the YMRP, respectively). The descriptions and technical bases provide transparent and traceable support for the abstraction of radionuclide transport in the saturated zone.

- Subcriterion (5)-Sufficient data and technical bases for the inclusion of features, events, and processes related to radionuclide transport in the saturated zone in the total system performance assessment abstraction are provided.

- Subcriterion (6)-Guidance in NUREG-1297 and NUREG-1298 (Altman et al. 1988 [DIRS 103597; DIRS 103750]), or other acceptable approaches for peer review and data qualification is followed.

\section{Acceptance Criterion 2: Data Are Sufficient for Model Justification.}

- Subcriterion (1)-Geological, hydrological, and geochemical values used in the license application are adequately justified (e.g., flow path lengths, sorption coefficients, retardation factors, colloid concentrations, etc.). Adequate descriptions of how the data were used, interpreted, and appropriately synthesized into the parameters are provided.

- Subcriterion (2)-Sufficient data have been collected on the characteristics of the natural system to establish initial and boundary conditions for the total system performance assessment abstraction of radionuclide transport in the saturated zone.

- Subcriterion (3)-Data on the geology, hydrology, and geochemistry of the saturated zone, including the influence of structural features, fracture distributions, fracture properties, and stratigraphy, used in the total system performance assessment abstraction, are based on appropriate techniques. These techniques may include laboratory experiments, site-specific field measurements, natural analog research, and process-level modeling studies. As appropriate, sensitivity or uncertainty analyses used to support the DOE total system performance assessment abstraction are adequate to determine the possible need for additional data.

\section{Acceptance Criterion 3: $\quad$ Data Uncertainty Is Characterized and Propagated Through the Model Abstraction.}

- Subcriterion (1)-Models use parameter values, assumed ranges, probability distributions, and bounding assumptions that are technically defensible, reasonably account for uncertainties and variabilities, and do not result in an under-representation of the risk estimate. 
- Subcriterion (2)-For those radionuclides where the total system performance assessment abstraction indicates that transport in fractures and matrix in the saturated zone is important to waste isolation: (i) estimated flow and transport parameters are appropriate and valid, based on techniques that may include laboratory experiments, field measurements, natural analog research, and process-level modeling studies conducted under conditions relevant to the saturated zone at Yucca Mountain; and (ii) models are demonstrated to adequately predict field transport test results. For example, if a sorption coefficient approach is used, the assumptions implicit in that approach are validated.

- Subcriterion (4)-Parameter values for processes, such as matrix diffusion, dispersion, and ground-water mixing, are based on reasonable assumptions about climate, aquifer properties, and ground-water volumetric fluxes (Section 2.2.1.3.8 of the Yucca Mountain Review Plan).

- Subcriterion (5)-Uncertainty is adequately represented in parameter development for conceptual models, process-level models, and alternative conceptual models considered in developing the abstraction of radionuclide transport in the saturated zone. This may be done either through sensitivity analyses or use of conservative limits.

\section{Acceptance Criterion 4: Model Uncertainty Is Characterized and Propagated Through the Model Abstraction.}

- Subcriterion (1)-Alternative modeling approaches of features, events, and processes are considered and are consistent with available data and current scientific understanding, and the results and limitations are appropriately considered in the abstraction.

- Subcriterion (2)-Conceptual model uncertainties are adequately defined and documented, and effects on conclusions regarding performance are properly assessed.

- Subcriterion (3)-Consideration of conceptual model uncertainty is consistent with available site characterization data, laboratory experiments, field measurements, natural analog information and process-level modeling studies; and the treatment of conceptual model uncertainty does not result in an underrepresentation of the risk estimate.

- Subcriterion (4)-Appropriate alternative modeling approaches are consistent with available data and current scientific knowledge, and appropriately consider their results and limitations using tests and analyses that are sensitive to the processes modeled. For example, for radionuclide transport through fractures, the DOE adequately considers alternative modeling approaches to develop its understanding of fracture distributions and ranges of fracture flow and transport properties in the SZ. 


\subsection{CODES, STANDARDS, AND REGULATIONS}

No codes, standards, or regulations other than those identified in Project Requirements Document (Canori and Leitner 2003 [DIRS 166275], Table 2-3) and determined to be applicable (Table 4-2) were used in this analysis. 


\section{ASSUMPTIONS}

A list of the assumptions used in this scientific analysis is provided in Table 5-1. Subsections are identified where assumptions are used. The rationale for each assumption is also provided.

\section{Table 5-1. Assumptions}

\begin{tabular}{|c|c|c|c|}
\hline Number & Assumption & Rationale & $\begin{array}{l}\text { Location in } \\
\text { Report }\end{array}$ \\
\hline 1 & $\begin{array}{l}\text { For the purposes of inferring } \\
\text { radionuclide matrix diffusion } \\
\text { coefficients from field and } \\
\text { laboratory tracer tests, bromide and } \\
\text { PFBA effectively bound the sizes } \\
\text { (and hence diffusion coefficients) of } \\
\text { radionuclide solute species } \\
\text { expected in the SZ beneath Yucca } \\
\text { Mountain. }\end{array}$ & $\begin{array}{l}\text { Bromide is a simple halide, while PFBA } \\
\text { is a large aromatic organic molecule. } \\
\text { The latter should be similar in size or } \\
\text { larger than radionuclide complexes with } \\
\text { carbonate or other potential inorganic } \\
\text { complexants. This assumption does not } \\
\text { apply to colloidal radionuclides (including } \\
\text { complexes to large natural organic } \\
\text { matter). }\end{array}$ & $\begin{array}{l}\text { Sections } 6.3 .5 \\
\text { (Table 6.3-3) } \\
\text { and D4 }\end{array}$ \\
\hline 2 & $\begin{array}{l}\text { For the purposes of calculating } \mathrm{K}_{\mathrm{d}} \\
\text { values from retardation factors and } \\
\text { for estimating total porosity from } \\
\text { alluvium bulk density } \\
\text { measurements made by borehole } \\
\text { gravimetry, the density of crushed } \\
\text { tuff and alluvium grains is } \\
2.65 \mathrm{~g} / \mathrm{cm}^{3} \text {. }\end{array}$ & $\begin{array}{l}2.65 \mathrm{~g} / \mathrm{cm}^{3} \text { is the density of most silicate } \\
\text { phases, which dominate the mineralogy } \\
\text { of the tuffs and alluvium. }\end{array}$ & $\begin{array}{l}\text { Sections } 6.3 .6 \text {, } \\
\text { F4, E3, G3, and } \\
\mathrm{H} 1\end{array}$ \\
\hline
\end{tabular}

PFBA=pentafluorobenzoic acid or pentafluorobenzoate; $S Z=$ saturated zone. 


\section{INTENTIONALLY LEFT BLANK}




\section{SCIENTIFIC ANALYSIS DISCUSSION}

\subsection{INTRODUCTION}

The SZ near Yucca Mountain, along potential flow paths from the repository to the accessible environment, can be divided into two types of flow systems: (1) fractured tuffs that underlie the repository and that extend for several kilometers to the south of Yucca Mountain (in the general direction of flow), and (2) valley-fill or alluvium deposits that the water table transitions into before the current approximately 18-km performance compliance boundary (10 CFR 63 [DIRS 156605], Subpart 63.302). Radionuclides released from the repository would first have to travel through the saturated fractured tuffs and then through the saturated alluvium to reach the compliance boundary.

To support the characterization of the saturated fractured tuffs, several hydraulic and tracer tests were conducted at a three-well complex (UE-25 c\#1, UE-25 c\#2, and UE-25 c\#3, hereafter referred to as $\mathrm{c} \# 1, \mathrm{c} \# 2$, and $\mathrm{c} \# 3$, respectively) known as the $\mathrm{C}$-wells. This complex is located approximately $2 \mathrm{~km}$ southeast of the repository footprint. Hydraulic tests conducted at the $\mathrm{C}$-wells are summarized in Section 6.2, and tracer tests conducted at the C-wells are summarized in Section 6.3. These sections present both the conceptual understanding and the hydrologic and transport parameter estimates derived from hydraulic and tracer testing, respectively. Details of the results and interpretations of the hydraulic and tracer tests are provided in Appendices $\mathrm{C}$ and $\mathrm{D}$, respectively. Laboratory testing conducted to support the interpretations of the C-wells tracer tests is discussed in detail in Appendix E.

To support the characterization of the saturated alluvium, both hydraulic and tracer testing were conducted at the ATC, centered around well NC-EWDP-19D (hereafter referred to as 19D), which is located just outside the southwest corner of the NTS, essentially right at the compliance boundary. Hydraulic tests conducted at the ATC are summarized in Section 6.4, and tracer tests conducted at the ATC are summarized in Section 6.5. Appendices F and G provide detailed discussions of the results and interpretations of hydraulic and tracer testing, respectively, conducted at the ATC. Appendix $\mathrm{H}$ provides a detailed discussion of laboratory testing conducted to support the planning and interpretation of cross-hole tracer tests that were going to be conducted at the ATC, but were not because of a revocation of environmental permits by the State of Nevada. The NRC has indicated that the alluvium may provide a significant natural barrier to the transport of radionuclides (NRC 2004 [DIRS 170243], Sections 4.3.8 and 4.3.9). These tracer tests would help to further understand the degree of radiation protection provided by the alluvium to the residents of Amargosa Valley.

The interpretive methods and corresponding software used to discriminate between conceptual models and to estimate flow and transport parameters in this report are primarily analytical or semi-analytical in nature. Numerical methods embodied in sophisticated three-dimensional computer codes were not used because detailed information on the spatial distribution of flow and transport properties in the subsurface, including boundary conditions, was not available for the in-situ tests. Such information is considered necessary to justify the use of sophisticated numerical models for conceptual model discrimination and parameter estimation. On the other hand, the analytical or semi-analytical methods and software employed for model discrimination and parameter estimation implicitly honor the lack of detailed subsurface information in the insitu tests. 


\subsubsection{Hydrogeologic Settings}

\subsubsection{C-Wells}

Figure 6.1-1 shows the location and surface layout of the C-wells. This location was chosen for drilling and testing because it was believed to be immediately down-gradient of the repository horizon and was thus thought to be highly representative of fractured volcanic tuffs that radionuclides would encounter should they reach the saturated zone. The wells were drilled on a two-tiered drill pad in a channel of an ephemeral stream that cuts through Bow Ridge, a spur of Yucca Mountain. The lower tier of the pad, in which Borehole c\#1 was drilled, is at an altitude of 1,130.5 m above mean sea level. The upper tier, in which Boreholes c\#2 and c\#3 were drilled, is at an altitude of $1,132.3 \mathrm{~m}$. The C-wells are 30.4 to $76.6 \mathrm{~m}$ apart at the land surface, but they deviate substantially at depth (Geldon 1993 [DIRS 101045], p. 6, Figure 2; p. 8, Figure 4) (Figure 6.1-1 and Table 6.1-1).

The C-wells were drilled to a depth of $914 \mathrm{~m}$ below land surface in Miocene tuffaceous rocks, mainly of the Paintbrush Group, the Calico Hills Formation, and the Crater Flat Group (Table 6.1-2), which are overlain by 0 to $24 \mathrm{~m}$ of Quaternary alluvium. The geology below the water table at the C-wells is depicted in Figure 6.1-2, along with fracture densities and estimated average matrix porosities in each unit. The tuffaceous rocks are estimated to be 1,000 to $1,600 \mathrm{~m}$ thick in the vicinity of the C-wells complex, where they consist of nonwelded to densely welded ash-flow tuff with intervals of ash-fall tuff and volcaniclastic rocks (Geldon 1993 [DIRS 101045]; Geldon et al. 1998 [DIRS 129721]). The tuffaceous rocks have pervasive tectonic and cooling fractures that strike predominantly north-northeast to north-northwest and dip westward at angles of $50^{\circ}$ to $87^{\circ}$ (Geldon 1996 [DIRS 100396], pp. 7 to 9). Several thousand meters of Paleozoic limestone and dolomite likely underlie the tuffaceous rocks about $460 \mathrm{~m}$ below the bottom of the C-wells or approximately $1,370 \mathrm{~m}$ below land surface [based on extrapolations from relations in Borehole UE-25 p\#1, presented in Geology of Drill Hole UE25p\#1: A Test Hole Into Pre-Tertiary Rocks Near Yucca Mountain, Southern Nevada (Carr et al. 1986 [DIRS 102046]). (Hereafter, in this report, UE-25 p\#1 is referred to as p\#1; see Table B-1 for a list of abbreviations.) 


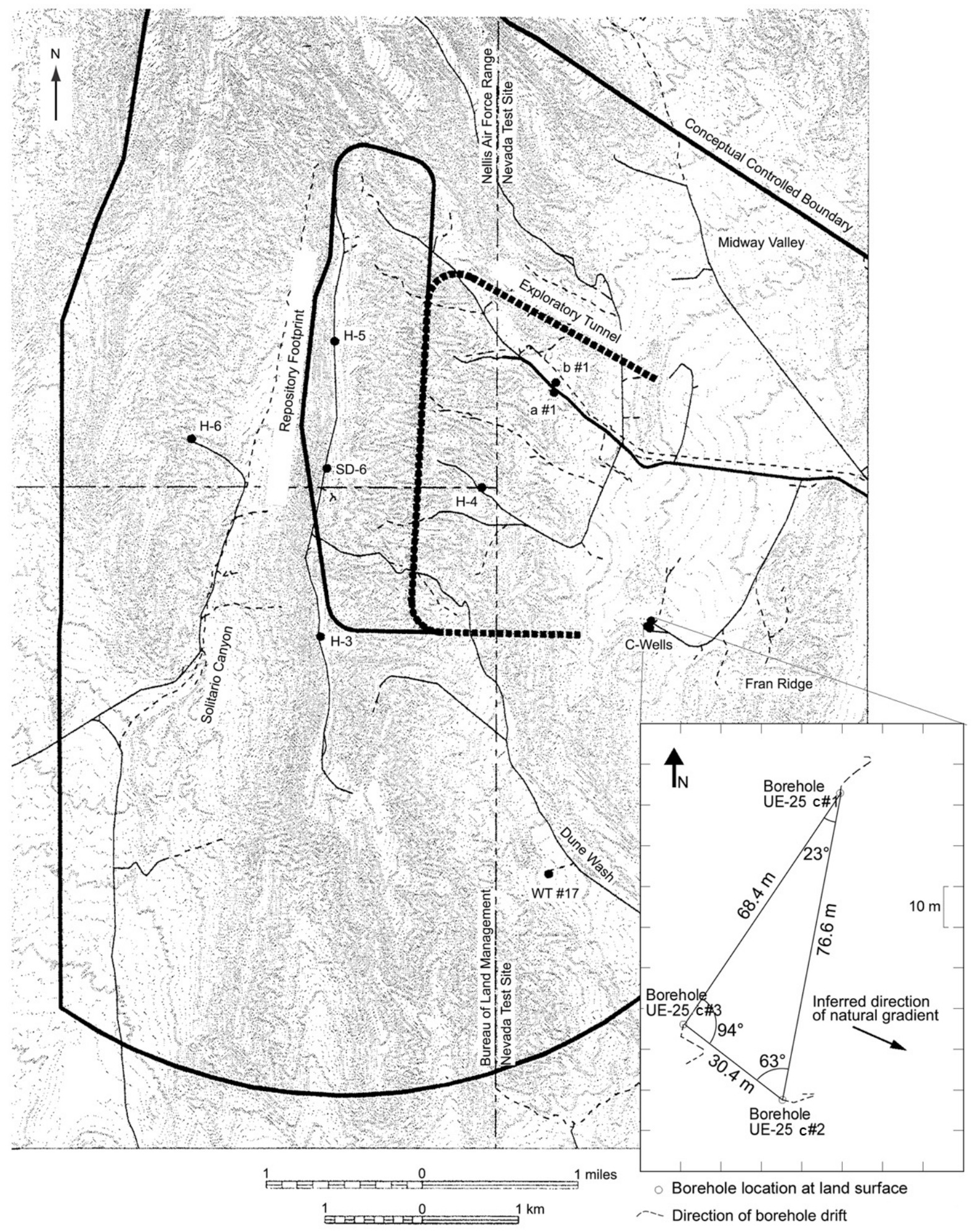

Source: Based on Geldon et al. 1998 [DIRS 129721], p 3, Figure 1.

Figure 6.1-1. Location and Surface Layout of the C-Wells Complex 
Table 6.1-1. Approximate Interborehole Distances at the Midpoints of Hydrogeologic Intervals as Monitored During Hydraulic Tests at the C-wells Complex, August 1995 to April 1996

\begin{tabular}{|c|c|c|c|c|c|}
\hline & \multicolumn{3}{|c|}{ Borehole Data } & \multicolumn{2}{|c|}{ Interborehole Distances } \\
\hline & c\#1 & c\#2 & c\#3 & c\#1 to c\#3 & c\#2 to c\#3 \\
\hline \multicolumn{6}{|c|}{ Calico Hills } \\
\hline Top depth (m) & 418 & 416 & 417 & 78.6 & 29.0 \\
\hline Bottom depth (m) & 547 & 531 & 540 & & \\
\hline Midpoint depth (m) & 483 & 474 & 478 & & \\
\hline North coordinate (m) & 230,771 & 230,691 & 230,703 & & \\
\hline East coordinate (m) & 173,646 & 173,633 & 173,607 & & \\
\hline Distance north/south from c\#3 (m) & 68.3 & 12.2 & - & & \\
\hline Distance east/west from c\#3 (m) & 39.3 & 26.2 & - & & \\
\hline \multicolumn{6}{|c|}{ Prow Pass } \\
\hline Top depth (m) & 549 & 533 & 542 & 81.1 & 28.6 \\
\hline Bottom depth (m) & 605 & 606 & 610 & & \\
\hline Midpoint depth (m) & 577 & 569 & 576 & & \\
\hline North coordinate (m) & 230,772 & 230,691 & 230,702 & & \\
\hline East coordinate (m) & 173,648 & 173,634 & 173,607 & & \\
\hline Distance north/south from c\#3 (m) & 70.4 & 11.0 & 一 & & \\
\hline Distance east/west from c\#3 (m) & 40.2 & 26.5 & - & & \\
\hline \multicolumn{6}{|c|}{ Upper Bullfrog } \\
\hline Top depth (m) & 607 & 607 & 612 & 83.2 & 28.6 \\
\hline Bottom depth (m) & 698 & 696 & 695 & & \\
\hline Midpoint depth (m) & 653 & 652 & 653 & & \\
\hline North coordinate $(\mathrm{m})$ & 230,773 & 230,691 & 230,701 & & \\
\hline East coordinate $(\mathrm{m})$ & 173,648 & 173,634 & 173,607 & & \\
\hline Distance north/south from c\#3 (m) & 72.2 & 9.75 & 一 & & \\
\hline Distance east/west from c\#3 (m) & 41.4 & 26.8 & - & & \\
\hline \multicolumn{6}{|c|}{ Lower Bullfrog } \\
\hline Top depth (m) & 700 & 698 & 697 & 85.6 & 29.3 \\
\hline Bottom depth (m) & 797 & 792 & 813 & & \\
\hline Midpoint depth (m) & 749 & 745 & 755 & & \\
\hline North coordinate $(\mathrm{m})$ & 230,774 & 230,692 & 230,700 & & \\
\hline East coordinate (m) & 173,649 & 173,633 & 173,606 & & \\
\hline Distance north/south from c\#3 (m) & 73.8 & 8.84 & 一 & & \\
\hline Distance east/west from c\#3 (m) & 43.3 & 27.7 & - & & \\
\hline
\end{tabular}


Table 6.1-1. Approximate Interborehole Distances at the Midpoints of Hydrogeologic Intervals as Monitored During Hydraulic Tests at the C-wells Complex, August 1995 to April 1996 (Continued)

\begin{tabular}{|c|c|c|c|c|c|}
\hline & \multicolumn{3}{|c|}{ Borehole Data } & \multicolumn{2}{|c|}{ Interborehole Distances } \\
\hline & c\#1 & c\#2 & c\#3 & c\#1 - c\#3 & c\#2 - c\#3 \\
\hline \multicolumn{6}{|c|}{ Upper Tram } \\
\hline Top depth $(m)$ & 799 & 794 & 814 & 86.9 & 29.6 \\
\hline Bottom depth (m) & 870 & 870 & 878 & & \\
\hline Midpoint depth (m) & 834 & 832 & 846 & & \\
\hline North coordinate (m) & 230,774 & 230,691 & 230,700 & & \\
\hline East coordinate $(\mathrm{m})$ & 173,648 & 173,632 & 173,604 & & \\
\hline Distance north/south from c\#3 (m) & 74.7 & 8.53 & - & & \\
\hline Distance east/west from c\#3 (m) & 44.2 & 28.3 & - & & \\
\hline \multicolumn{6}{|c|}{ Lower Tram } \\
\hline Top depth (m) & 872 & 871 & 879 & 87.2 & 29.9 \\
\hline Bottom depth $(\mathrm{m})$ & 898 & 903 & 900 & & \\
\hline Midpoint depth (m) & 885 & 887 & 890 & & \\
\hline North coordinate $(\mathrm{m})$ & 230,774 & 230,691 & 230,700 & & \\
\hline East coordinate $(\mathrm{m})$ & 173,648 & 173,632 & 173,603 & & \\
\hline Distance north/south from c\#3 (m) & 74.7 & 8.23 & - & & \\
\hline Distance east/west from c\#3 (m) & 44.8 & 28.6 & - & & \\
\hline
\end{tabular}

Source: DTN: GS030508312314.003 ([DIRS 164425], p. 6, Table 1).

NOTE: North and south are referenced to Nevada State Zone 2 coordinates. Depths in c\#3 and interborehole distances changed slightly in April 1996 when instrumentation in c\#3 was reconfigured.

Table 6.1-2. Stratigraphy of Miocene Tuffaceous Rocks in the C-wells Area

\begin{tabular}{|l|c|c|c|c|c|}
\hline \multirow{2}{*}{\multicolumn{1}{|c|}{ Geologic Unit }} & \multicolumn{5}{c|}{ Depth Below Land Surface (m) } \\
\cline { 2 - 6 } & USW H-4 & c\#1 & c\#2 & c\#3 & UE-25 p\#1 \\
\hline Timber Mountain Group & & & & & \\
\hline Rainier Mesa Tuff & not present & not present & not present & not present & $39-55$ \\
\hline Paintbrush Group & & & & & \\
\hline Tiva Canyon Tuff & $0-65$ & $0-96$ & $21-88$ & $24-88$ & $55-81$ \\
\hline Topopah Spring Tuff & $65-400$ & $96-406$ & $88-401$ & $88-396$ & $81-381$ \\
\hline Calico Hills Formation & $400-496$ & $406-516$ & $401-510$ & $396-496$ & $381-436$ \\
\hline Crater Flat Group & & & & & \\
\hline Prow Pass Tuff & $496-693$ & $516-656$ & $510-652$ & $496-644$ & $436-558$ \\
\hline Bullfrog Tuff & $693-812$ & $656-828$ & $652-829$ & $644-814$ & $558-691$ \\
\hline Tram Tuff & $812-1,164$ & $828-914+$ & $829-914+$ & $814-914+$ & $691-873$ \\
\hline Lithic Ridge Tuff & $1,164-1,219+$ & not reached & not reached & not reached & $873-1,068$ \\
\hline
\end{tabular}

Source: DTN: GS030508312314.003 ([DIRS 164425] p. 7, Table 2). 
In the vicinity of the C-wells complex, northerly and northwesterly trending high-angle faults, such as the Paintbrush Canyon, Midway Valley, and Bow Ridge faults, have brecciated, offset, and tilted the tuffaceous rocks (Day et al. 1998 [DIRS 101557]; Dickerson and Drake 1998 [DIRS 102781]). Figure 6.1-3 shows major faults and structural features in the vicinity of Yucca Mountain. The dip of the tuffaceous rocks increases from $5^{\circ}$ to $10^{\circ}$ eastward at the crest of Yucca Mountain to about $20^{\circ}$ eastward at the C-wells complex (Frizzell and Shulters 1990 [DIRS 105454], Map I-2046). At the C-wells complex, the north-striking Midway Valley fault or Paintbrush Canyon fault dropped Miocene tuffaceous rocks down to the west. Those rocks later were dropped to the northeast by a northwest-striking fault that cuts through Bow Ridge (Figure 6.1-3).

Hydrogeologic data and numerical modeling indicate that groundwater recharge in the Yucca Mountain area discharges mostly to Carson Slough, Ash Meadows, Alkali Flat, the lower Amargosa River Valley, and Death Valley (D’Agnese et al. 1997 [DIRS 100131]). Locally, groundwater flows mainly through Tertiary volcanic rocks and Quaternary and Tertiary alluvium and lacustrine deposits. Controlled largely by faults and related fractures, groundwater flows from basin to basin, mainly through deeper Paleozoic carbonate rocks (Faunt 1997 [DIRS 100146]). Cohen et al. (1996 [DIRS 156651]) demonstrated by two-dimensional numerical modeling that water in Miocene rocks at the $\mathrm{C}$-wells complex could be derived from the Paleozoic carbonate rocks by upward flow along the Paintbrush Canyon, Midway Valley, or Bow Ridge faults. Geldon et al. (1998 [DIRS 129721], pp. 23 to 25, Figure 2; p. 31) concluded that a northwest-trending zone of discontinuous faults between Bow Ridge and Antler Wash also transmits groundwater. 


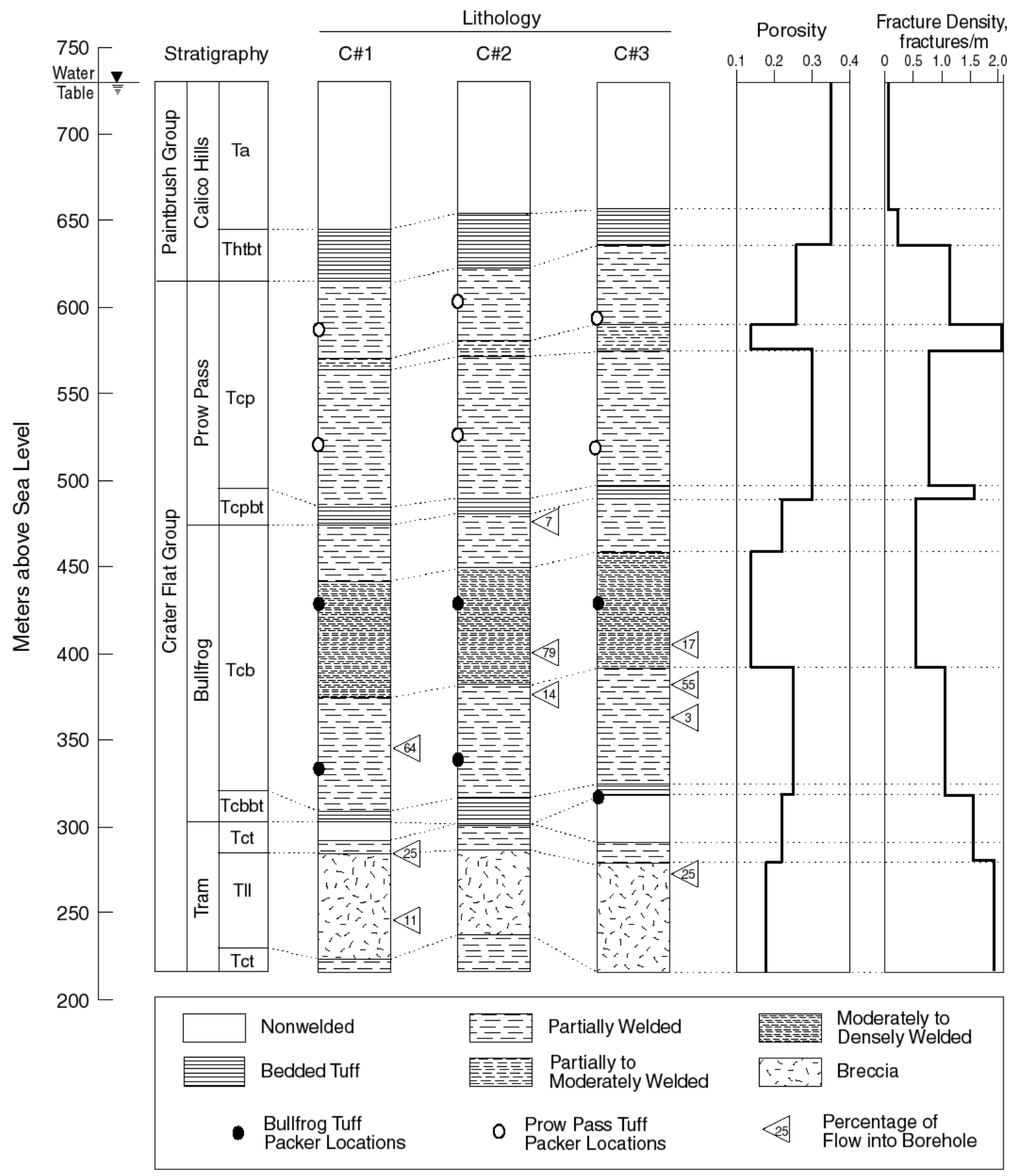

Source: Geologic information derived from Geldon (1993 [DIRS 101045], pp. 35 to 37, 68 to 70). Packer locations for Bullfrog Tuff and for Prow Pass Tuff in c\#1 from DTN: GS030508312314.003 ([DIRS 164425], p. 12, Table 3); packer locations for Prow Pass Tuff in c\#2 and c\#3 from Umari (2002 [DIRS 162858], Binder 10, Section L-11, pp. 70 to 71, Section L-9, pp. 57 to 58). Flow survey information from DTN: GS931008312313.016 [DIRS 148173] (qualified for use in this report in Appendix L).

NOTE: Packer locations indicate intervals in which tracer tests described in this report were conducted. Fracture densities shown are from Borehole UE-25 c\#1.

Figure 6.1-2. Stratigraphy, Lithology, Matrix Porosity, Fracture Density, and Inflow from Open-Hole Flow Surveys at the C-Wells 


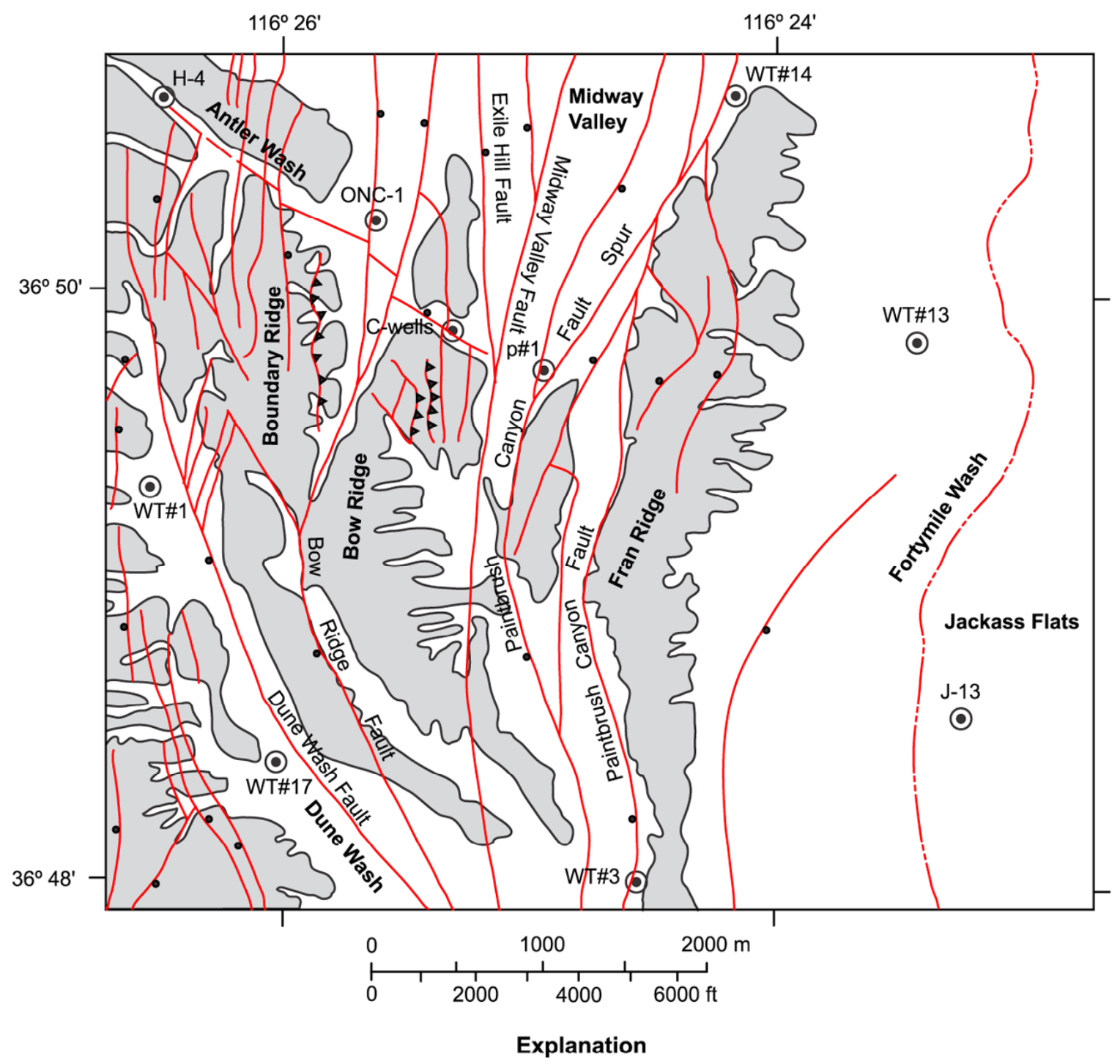

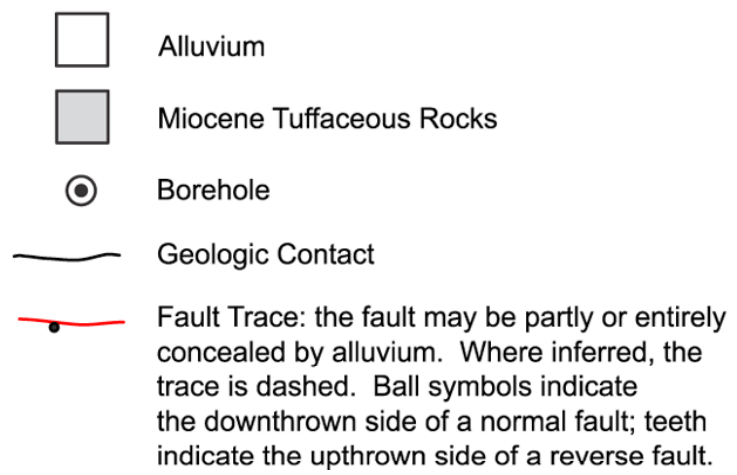

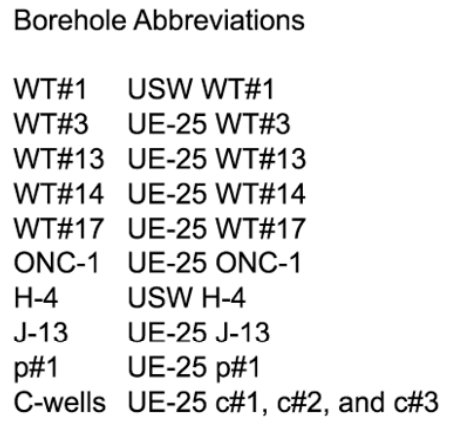

NOTE: The geology is based on Day et al. 1998 [DIRS 100027]. Faults concealed beneath Quaternary cover are inferred and approximately located.

Figure 6.1-3. Generalized Geologic Map Showing the Location of the C-Wells Complex and Nearby Boreholes 
The water table in the Miocene tuffaceous rocks at Yucca Mountain in the vicinity of the C-wells complex ranges from about 335 to $520 \mathrm{~m}$ below land surface (O'Brien et al. 1995 [DIRS 101279], p. 3, Table 1; pp. 35 to 69) and from 400 to $402 \mathrm{~m}$ in the C-wells. These depths all correspond to a water-table elevation of approximately $730 \mathrm{~m}$ above mean sea level in the vicinity of the $\mathrm{C}$-wells. Water in the tuffaceous rocks generally flows southeasterly (Ervin et al. 1994 [DIRS 100633]; Tucci and Burkhardt 1995 [DIRS 101060]), but flow patterns are disrupted by faults acting as conduits or barriers to flow. Water-level data are sparse in the vicinity of the C-wells complex, but the Paintbrush Canyon, Bow Ridge, and other faults apparently created a groundwater divide centered on Bow Ridge and Boundary Ridge that directs flow southward to Dune Wash, northward to Midway Valley, and eastward to Fortymile Wash (Figure 6.1-4). Flow from the west into the area of the C-wells is inhibited by the north-striking Solitario Canyon fault (Figure 6.1-3; Tucci and Burkhardt 1995 [DIRS 101060]).

The Miocene tuffs near the C-wells complex behave as a single fissure-block aquifer, in which the volume and direction of groundwater flow are controlled mainly by proximity to faults, fracture zones, and partings (Geldon et al. 1998 [DIRS 129721], p. 4). In a fissure-block aquifer, the permeability of the matrix is essentially negligible compared to the permeability of the fractures; and, hence, the aquifer behaves as a "dual-porosity" system in which the matrix acts as a reservoir for stagnant groundwater and flow occurs almost exclusively in fractures. Fractures in transmissive intervals have no preferred orientation, and fracture density appears unrelated to the extent of welding and permeability. Matrix permeability of the Calico Hills Formation and the Crater Flat Group within $5 \mathrm{~km}$ of the C-wells complex reaches $20 \mathrm{~m}$ Darcy (Geldon 1996 [DIRS 100396], Figure 5). On the basis of barometric efficiency and specific storage, the average effective porosity of the Calico Hills Formation near the water table in the C-wells was determined to be 36 percent (Geldon et al. 1997 [DIRS 156827], p. 11). The Crater Flat Group is less porous than the Calico Hills Formation. The average porosity of those geologic units in the C-wells is 21 percent [computed from porosity values reported by Geldon (1993 [DIRS 101045], pp. 60 to 62)]. Despite the influence of fractures, rock within about $3 \mathrm{~km}$ of the $\mathrm{C}$-wells complex responds to hydraulic tests in a manner that is consistent with the response of a porous medium. In this report, such a rock mass is referred to as an "equivalent porous medium," where the word "equivalent" indicates that the medium is not a true porous medium, but that, at the scale of observation, volume-averaged properties normally assigned to porous media can describe the hydraulic behavior of the rock mass.

Borehole flow surveys in combination with geophysical logs and aquifer tests show that flow within the tuffs at the C-wells complex comes primarily from discrete intervals (Figure 6.1-2). The total thickness of transmissive intervals identified in individual boreholes ranges from 165 to 274 m (Geldon 1996 [DIRS 100396], pp. 13 to 20). Hydraulic tests conducted in 1984 indicated that those intervals have layered heterogeneity (Geldon 1996 [DIRS 100396], pp. 9 to 69). Figure 6.1-5 is a depiction of the hydrogeologic intervals identified in the C-wells during hydraulic and tracer testing from 1995 to 1997 (Geldon 1996 [DIRS 100396], pp. 9 to 69). 


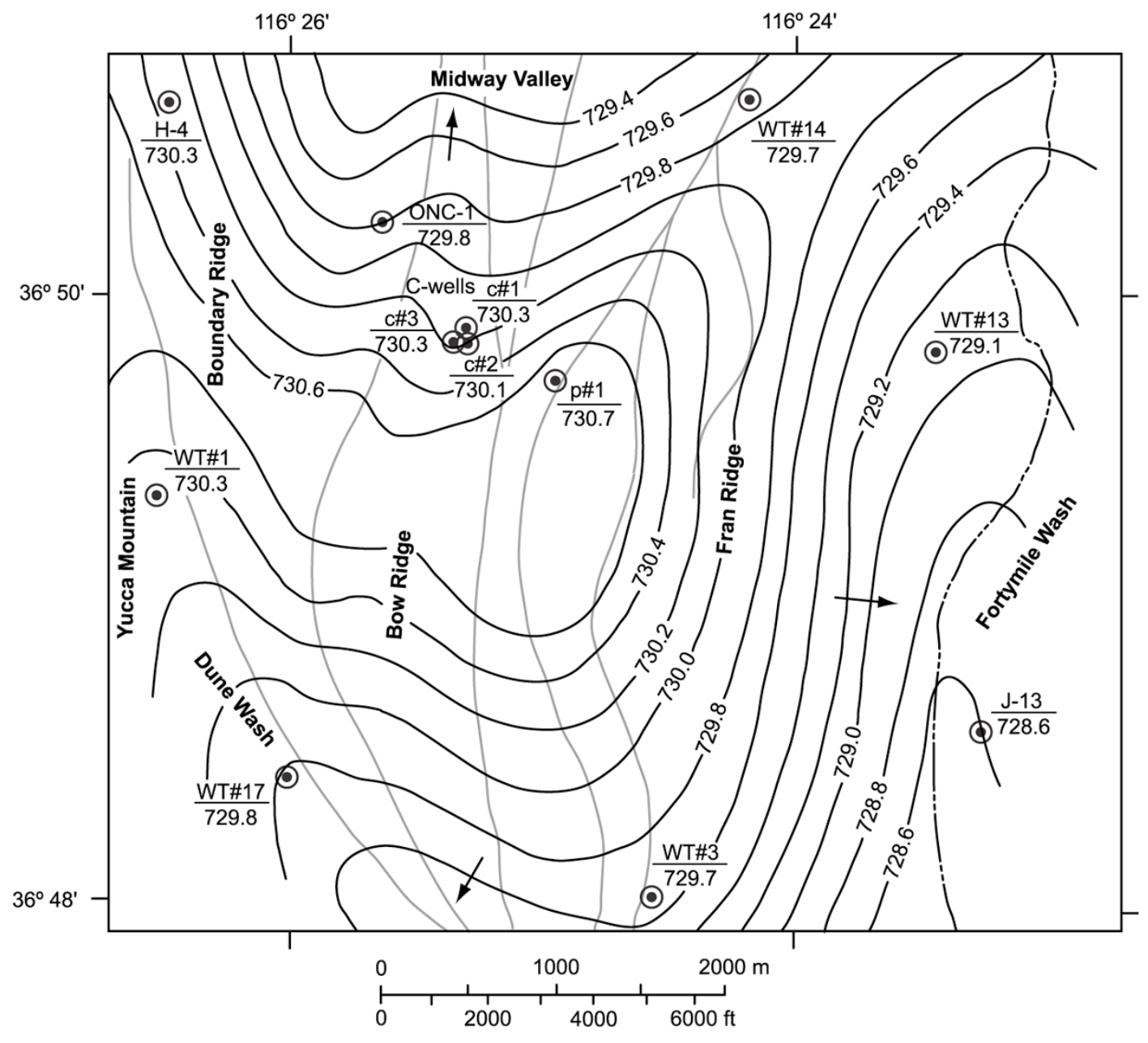

Explanation

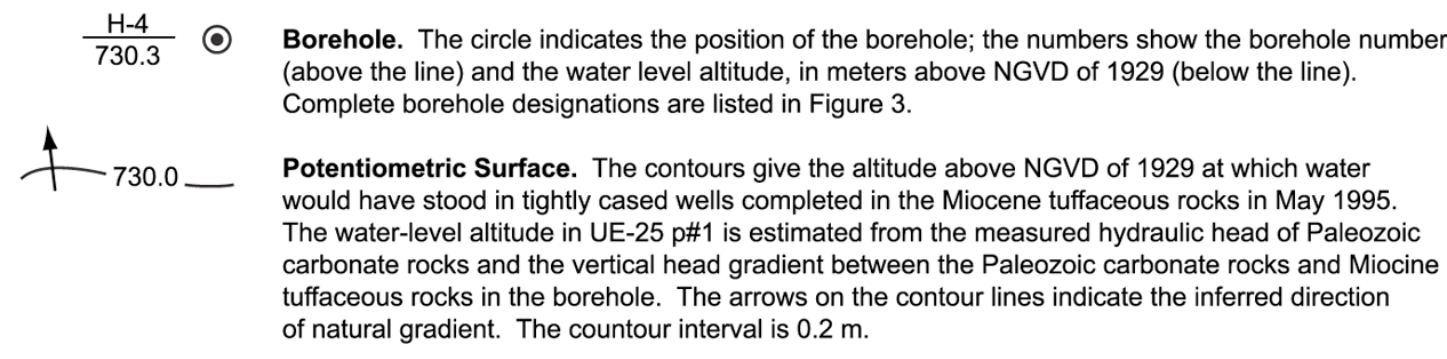

natural gradient. The countour in

Fault Trace.

Source: $\quad$ Results of Hydraulic Tests in Miocene Tuffaceous Rocks at the C-Hole Complex, 1995-1997, Yucca Mountain, Nye County, Nevada (Geldon et al. 2002, [DIRS 161163], p. 8, Figure 3); Nye County Nuclear Waste Repository Project Office (1995 [DIRS 156859], ONC-1 Drilling log).

NOTE: See Figure 6.1-3 for names of faults.

Figure 6.1-4. Potentiometric Surface of the Miocene Tuffaceous Rocks in the Vicinity of the C-Wells Complex, May 1995 


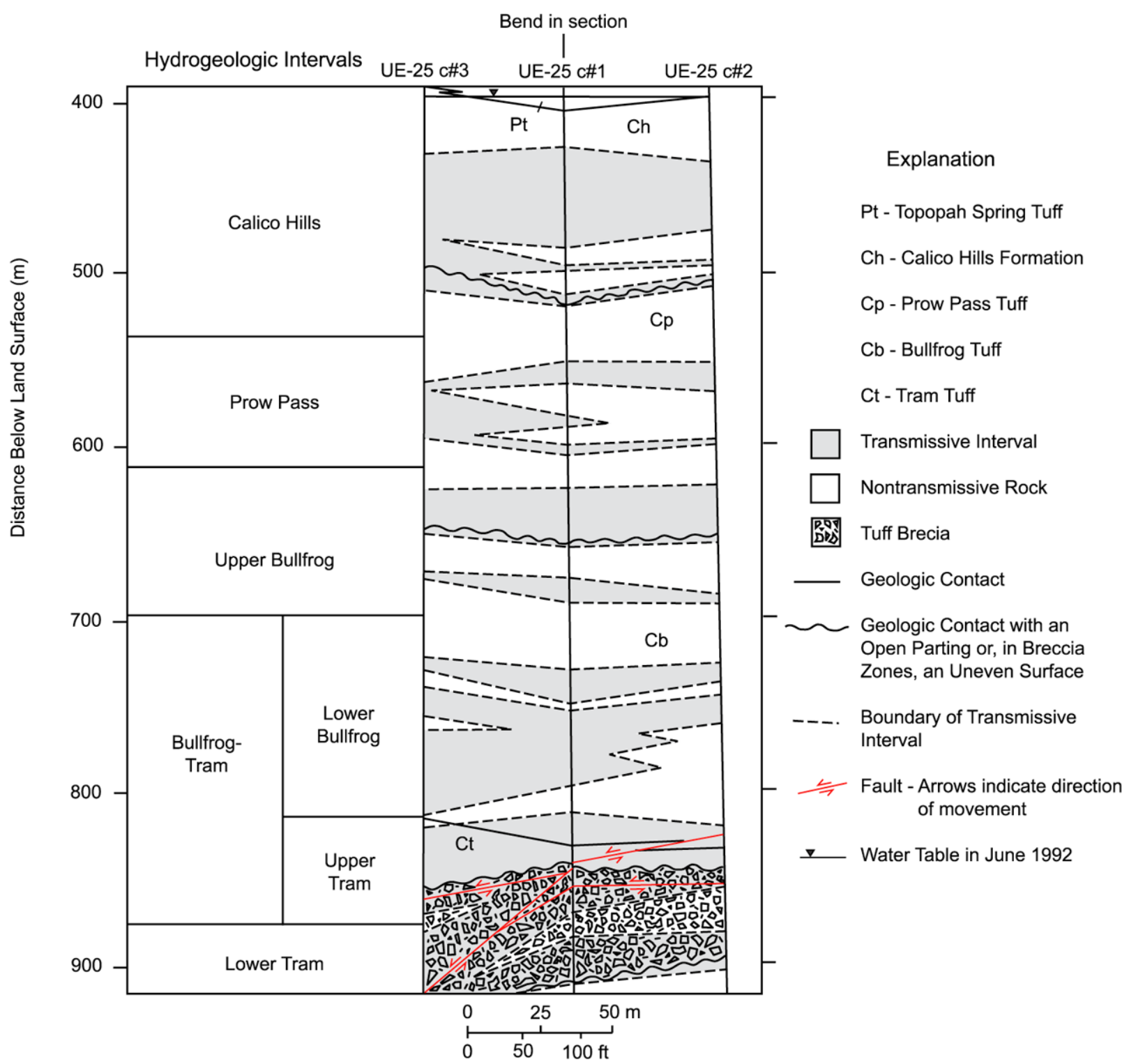

Source: DTN: GS030508312314.003 ([DIRS 164425], p. 9, Figure 4).

Figure 6.1-5. Hydrogeologic Intervals in the C-Wells Identified During Hydraulic and Tracer Testing from 1995 to 1997

\subsubsection{Alluvial Testing Complex}

The SZ flow system to the south of Yucca Mountain transitions from a fractured tuff aquifer to a valley-fill (alluvium) aquifer before reaching the approximately 18-km performance compliance boundary at the southern boundary of the NTS. The exact location of this transition is uncertain and depends to a large extent on the direction of the flow pathways from the repository footprint to the compliance boundary, but available information suggests that radionuclides will transport through 2 to $10 \mathrm{~km}$ of saturated alluvium before reaching the boundary (BSC 2004 [DIRS 170037], Sections 6.3 and 6.4). Characterization of the valley-fill system was conducted just outside the southwest corner of the NTS at the ATC, which is the site of 
the Nye County Early Warning Drilling Program (NC-EWDP) wells NC-EWDP-19D, -19P, -19IM1, and -19IM2 (these wells will be referred to as 19D, 19P, 19IM1, and 19IM2; Table B-1). The location of the ATC is shown in Figure 6.1-6. The surface layout of the wells at the ATC is shown in Figure 6.1-7.

Well 19D was drilled using a mud/rotary technique in March and April 2000 to a total depth of $443.8 \mathrm{~m}(1,456 \mathrm{ft})$ below land surface, with the water table being encountered at approximately $106 \mathrm{~m}(348 \mathrm{ft})$ below land surface (DTN: MO0101NYE03734.073 [DIRS 155267]). The well was completed using 18-cm (7.0-in.) outer dimension and 15.8-cm (6.24-in.) inner dimension steel pipe to allow pumps, packers, pressure transducers, and tracer injection equipment to be lowered into the hole (DTN: MO0112DQRWLNYE.018 [DIRS 157187]). This completion also allows for installation of the Westbay monitoring/sampling system that Nye County uses for long-term monitoring.

A piezometer well, 19P, was drilled just prior to drilling 19D at a location that ultimately ended up being approximately $25 \mathrm{~m}$ northeast of 19D at land surface. 19P was drilled using an air/hammer technique in March 2000 to a total depth of $142 \mathrm{~m}$ below land surface, with the water table being encountered at $112 \mathrm{~m}$ (368 ft) below land surface (DTN: MO0101NYE03734.073 [DIRS 155267]). This well was completed with a 7.3-cm (2-7/8-in.) outer diameter pipe casing and was screened from 109 to $139.5 \mathrm{~m}$ (358 to $458 \mathrm{ft})$ below land surface. The screened interval was developed by air injection. The well was intended to serve as a piezometer or monitoring well during pumping of 19D.

Wells 19IM1 and 19IM2 were drilled and completed in August and September, respectively, of 2001. 19IM1 was completed to a depth of $308.6 \mathrm{~m}(1,012.5 \mathrm{ft})$ below land surface, and 19IM2 was competed to $294.3 \mathrm{~m}(965.6 \mathrm{ft})$ below land surface. Figure 6.1-8 shows the completions of 19D, 19P, 19IM1, and 19IM2 along with the site lithology, as determined from onsite geological logging during drilling.

As Figure 6.1-8 shows, 19D was screened over seven different depth intervals, with the bottom three intervals completed below the valley-fill deposits (DTN: MO0112DQRWLNYE.018 [DIRS 157187]). A volcanic tuff was encountered at about $250 \mathrm{~m}(820 \mathrm{ft})$ below land surface, and a claystone/siltstone was encountered at approximately $378 \mathrm{~m}$ (approximately 1,260 $\mathrm{ft}$ ) below land surface (DTN: GS011008314211.001 [DIRS 158690]). Although these intervals are potentially significant, they were not the primary focus of the ATC investigations. Thus, 19IM1 and 19IM2 were drilled and completed only to the depth of the highest screened interval in the volcanic tuff in 19D. It was desirable to have one interval completed below the valley-fill deposits in each well so that hydraulic communication between the valley fill and the underlying tuff could be investigated. The wells were developed by air injection just below each of the screened intervals and also by pumping for 48 hours (hr) under open-hole conditions. In the case of 19D, the well was pumped in an open-hole configuration (no packers or plugs) at approximately 610 liters per minute (L/min) (approximately 160 gallons per minute) (gpm) with a total drawdown of 4.6 to $6.1 \mathrm{~m}(15$ to $20 \mathrm{ft})$. The hydrogeologic setting in the vicinity of the ATC, and especially to the north of the ATC along Fortymile Wash, is in the process of being established. Understanding of the hydrogeologic setting near the 18-km compliance boundary is a major goal of the NC-EWDP. 


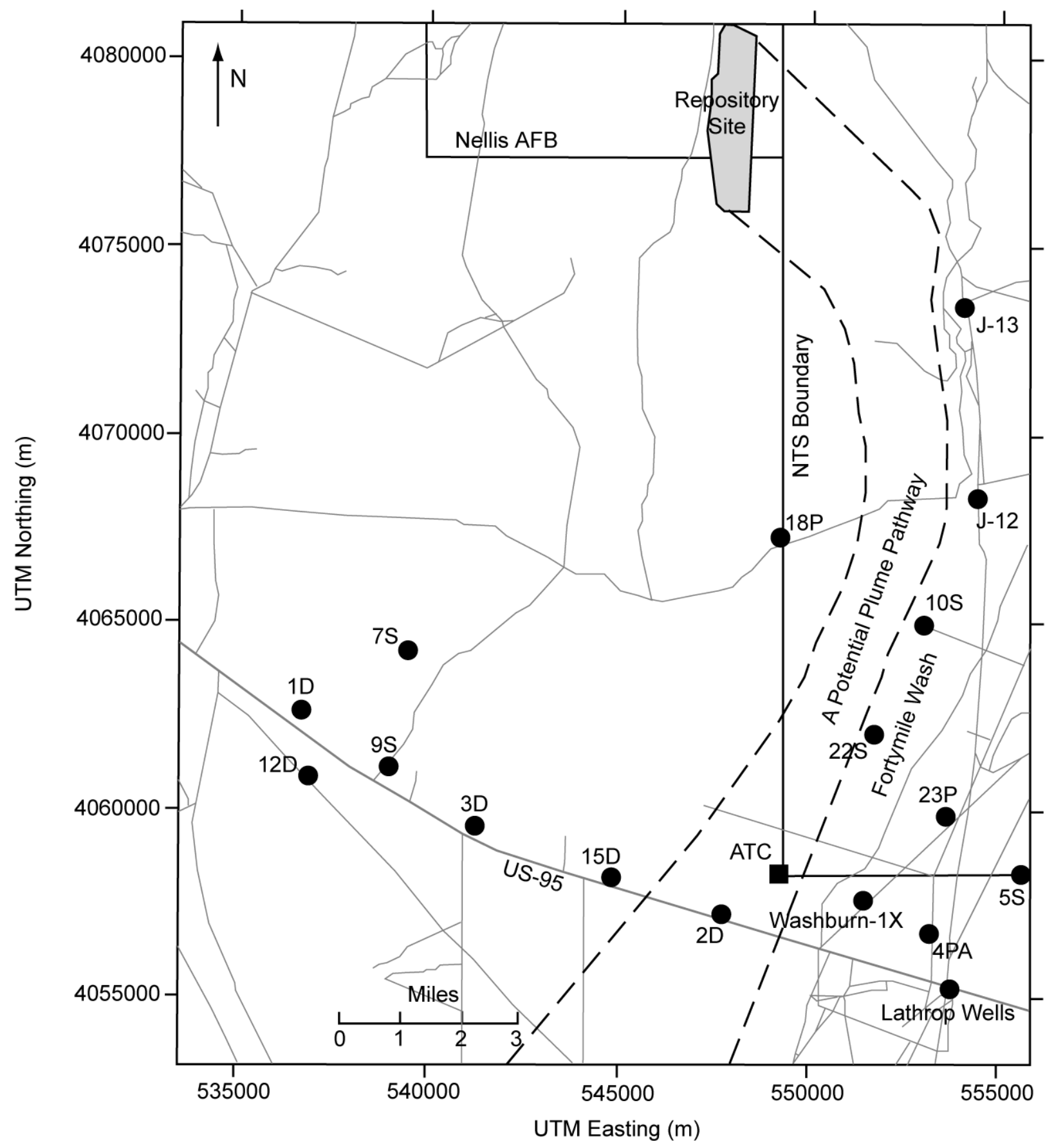

Source: DTN: MO0401COV03168.000 [DIRS 168534] is used as reference only.

NOTE: Figure is for illustration purposes only. The black circles indicate locations of other wells.

Figure 6.1-6. Map Showing Location of Alluvial Testing Complex (ATC) in Relation to the Repository Footprint and the Nevada Test Site 


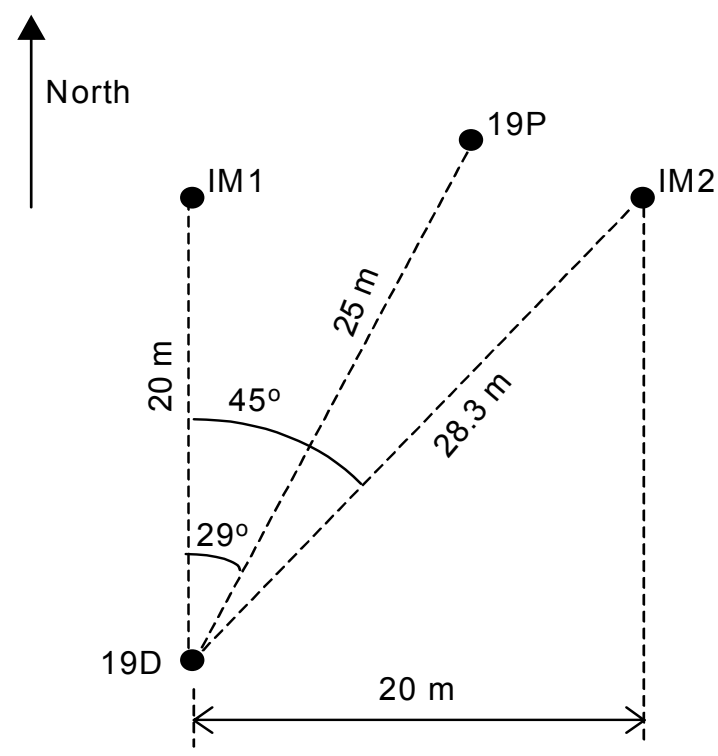

Not to Scale

Source: Based on BSC 2002 [DIRS 171585], p. 34, Figure 2.

NOTE: For illustration purposes only. Full well names are preceded by "NC-EWDP-."

Figure 6.1-7. Surface Layout of the Alluvial Testing Complex 


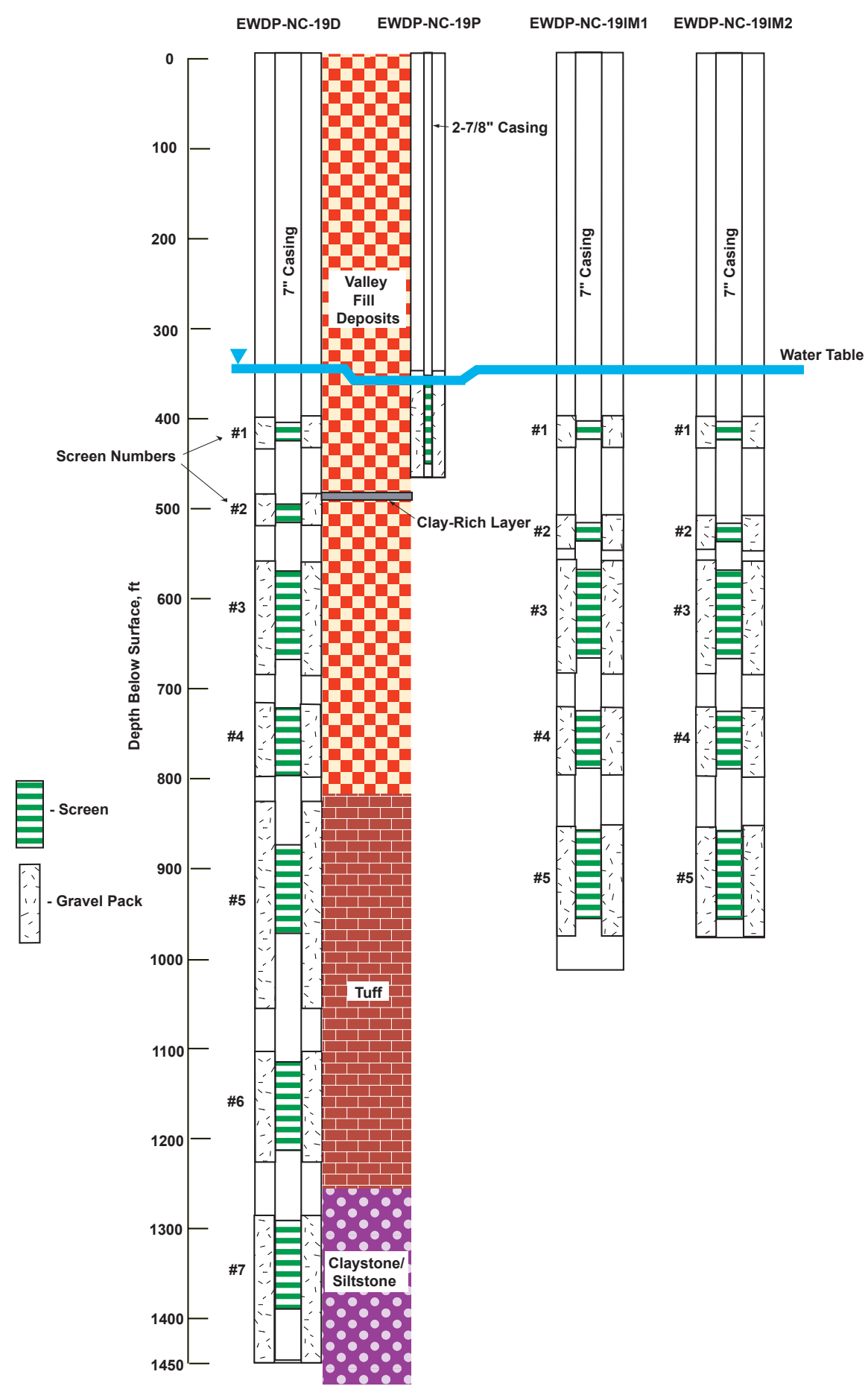

Source: DTNs: MO0112DQRWLNYE.018 [DIRS 157187] (19D completion); MO0112DQRWLNYE.014 [DIRS 157184] (19P completion); GS011008314211.001 [DIRS 158690] (19D lithologic log); MO0306NYE05259.165 [DIRS 165876] (19IM1 well completion); MO0306NYE05260.166 qualified for use in this report in Appendix K [DIRS 165877] (19IM2 well completion).

NOTE: The water table is higher in NC-EWDP-19D than in -19P because hydraulic head increases with depth. The white spaces between gravel packs below the water table are "grout and bentonite seals." The Nye County Nuclear Waste Repository Project Office reports all depths in feet.

Figure 6.1-8. Schematic Diagram of NC-EWDP-19D, -19P, -19IM1, and -19IM2 Completions 


\subsubsection{Features, Events, and Processes Supported by This Scientific Analysis}

As stipulated in Technical Work Plan For: Natural System - Saturated Zone Analysis Model Report Integration (BSC 2004 [DIRS 171421]), this model report addresses the SZ FEPs pertaining to saturated zone in-situ testing included in TSPA-LA (Table 6.1-3). Table 6.1-3 provides a list of FEPs relevant to this model analysis in accordance with their assignment in the LA FEP list (DTN: MO0407SEPFEPLA.000 [DIRS 170760]). Specific reference to the various sections within this document where issues related to each FEP are addressed is provided in the table. The detailed discussion of these FEPs and their implementation in the TSPA-LA are documented in Features, Events, and Processes in SZ Flow and Transport (BSC 2004 [DIRS 170013]). Saturated Zone FEPs that were excluded in TSPA-LA are described in Features, Events, and Processes in SZ Flow and Transport (BSC 2004 [DIRS 170013]).

Table 6.1-3.Features, Events, and Processes Included in TSPA-LA and Relevant to This Model Report

\begin{tabular}{|c|c|c|c|}
\hline FEP No. & FEP Name & $\begin{array}{c}\text { Sections Where Disposition } \\
\text { Is Supported }\end{array}$ & $\begin{array}{l}\text { FEP Topic Addressed in Other } \\
\text { SZ Analysis or Model Reports }\end{array}$ \\
\hline 1.2.02.01.0A & Fractures & $\begin{array}{l}\text { Flow in fractures is addressed } \\
\text { throughout Section } 6.2 \text { and } \\
\text { Appendix C. Transport in } \\
\text { fractures is addressed } \\
\text { throughout Section } 6.3 \text { and } \\
\text { Appendix D. Also, discussion } \\
\text { of lab transport studies in } \\
\text { fractures is provided in } \\
\text { Appendix E (Section E3.2). }\end{array}$ & $\begin{array}{l}\text { Upstream Feeds }{ }^{\mathrm{a}-N / A} \text {. } \\
\text { Expanded Discussion }{ }^{\mathrm{b}}- \\
\text { BSC } 2004 \text { [DIRS 170014]. } \\
\text { Corroborating }{ }^{\mathrm{c}}- \\
\text { BSC } 2004 \text { [DIRS 170008]; } \\
\text { BSC } 2004 \text { [DIRS 170036]; } \\
\text { BSC } 2004 \text { [DIRS 170037]; } \\
\text { BSC } 2004 \text { [DIRS 170042] }\end{array}$ \\
\hline $1.2 .02 .02 .0 \mathrm{~A}$ & Faults & $\begin{array}{l}\text { The influence of faults (or the } \\
\text { potential influence of faults) } \\
\text { on flow in the saturated } \\
\text { volcanics is discussed in } \\
\text { Sections } 6.1 .1 .1,6.2 .3,6.2 .4 \text {, } \\
6.2 .7 \text {, C5, and C6.2. }\end{array}$ & $\begin{array}{l}\text { Upstream Feeds }{ }^{\mathrm{a}-N / A} \\
\text { Expanded Discussion }^{\mathrm{b}}- \\
\text { BSC } 2004 \text { [DIRS 170008] } \\
\text { Corroborating }{ }^{\mathrm{c}}- \\
\text { BSC } 2004 \text { [DIRS 170036]; } \\
\text { BSC } 2004 \text { [DIRS 170042] }\end{array}$ \\
\hline 2.2.03.01.0A & Stratigraphy & $\begin{array}{l}\text { Hydrologic settings (including } \\
\text { stratigraphy) for the hydraulic } \\
\text { and tracer tests in the } \\
\text { fractured volcanics and in the } \\
\text { alluvium are discussed in } \\
\text { Sections } 6.1 .1 .1 \text { and } 6.1 .1 .2 \text {, } \\
\text { respectively. }\end{array}$ & $\begin{array}{l}\text { Upstream Feeds }{ }^{\mathrm{a}}-\mathrm{N} / \mathrm{A} \\
\text { Expanded Discussion }^{\mathrm{b}}- \\
\text { BSC } 2004 \text { [DIRS 170008]; } \\
\text { BSC } 2004 \text { [DIRS 170037]. } \\
\text { Corroborating }{ }^{\mathrm{c}}- \\
\text { BSC } 2004 \text { [DIRS 170042]; } \\
\text { BSC } 2004 \text { [DIRS 170014] }\end{array}$ \\
\hline 2.2.03.02.0A & $\begin{array}{l}\text { Rock properties of host rock } \\
\text { and other units }\end{array}$ & $\begin{array}{l}\text { Rock properties as they relate } \\
\text { to flow and transport are } \\
\text { addressed in many places } \\
\text { throughout Sections } 6.1 .1 \text {, } \\
6.2 \text { through } 6.5 \text {, and in } \\
\text { Appendices } \mathrm{C} \text { through } \mathrm{H} \text {. }\end{array}$ & 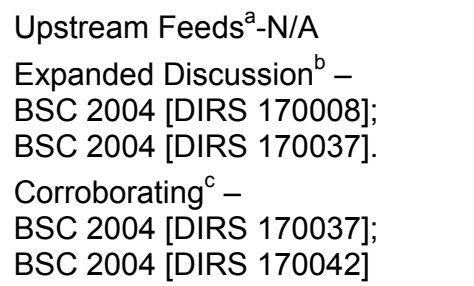 \\
\hline
\end{tabular}


Table 6.1-3. Features, Events, and Processes Included in TSPA-LA and Relevant to This Model Report (Continued)

\begin{tabular}{|c|c|c|c|}
\hline FEP No. & FEP Name & $\begin{array}{c}\text { Sections Where Disposition } \\
\text { Is Supported }\end{array}$ & $\begin{array}{l}\text { FEP Topic Addressed in Other } \\
\text { SZ Analysis or Model Reports }\end{array}$ \\
\hline 2.2.07.12.0A & $\begin{array}{l}\text { Saturated groundwater flow } \\
\text { in the geosphere }\end{array}$ & $\begin{array}{l}\text { Saturated groundwater flow in } \\
\text { the fractured volcanics is } \\
\text { addressed in Section } 6.2 \text { and } \\
\text { Appendix C. Saturated } \\
\text { groundwater flow in the } \\
\text { alluvium is addressed in } \\
\text { Section } 6.4 \text { and Appendix F. }\end{array}$ & $\begin{array}{l}\text { Upstream Feeds }{ }^{\mathrm{a}-N / A} \text {. } \\
\text { Expanded Discussion }^{\mathrm{b}}- \\
\text { BSC } 2004 \text { [DIRS 170037]. } \\
\text { Corroborating }^{\mathrm{c}}- \\
\text { BSC } 2004 \text { [DIRS 170037], } \\
\text { Appendix I; BSC 2004 } \\
\text { [DIRS 170015]; BSC } 2004 \\
\text { [DIRS 170014]; BSC } 2004 \\
\text { [DIRS 170042] }\end{array}$ \\
\hline 2.2.07.13.0A & $\begin{array}{l}\text { Water-conducting features } \\
\text { in the SZ }\end{array}$ & $\begin{array}{l}\text { Geologic features affecting } \\
\text { flow in the fractured volcanics } \\
\text { are addressed in Section } \\
6.1 .1 .1 \text {, Section } 6.2 \text {, and } \\
\text { Appendix C. Geologic } \\
\text { features affecting flow in the } \\
\text { alluvium are addressed in } \\
\text { Section } 6.1 .1 .2 \text {, Section } 6.4 \\
\text { and Appendix F. }\end{array}$ & $\begin{array}{l}\text { Upstream Feeds }{ }^{\mathrm{a}-N / A} \text {. } \\
\text { Expanded Discussion }^{\mathrm{b}}- \\
\text { BSC } 2004 \text { [DIRS 170037]; } \\
\text { BSC } 2004 \text { [DIRS 170042]. } \\
\text { Corroborating }{ }^{\mathrm{c}}- \\
\text { BSC } 2004 \text { [DIRS 170014] }\end{array}$ \\
\hline 2.2.07.15.0A & $\begin{array}{l}\text { Advection and dispersion in } \\
\text { the SZ }\end{array}$ & $\begin{array}{l}\text { Advection and dispersion } \\
\text { effects on transport in the } \\
\text { fractured volcanics are } \\
\text { discussed throughout Section } \\
6.3 \text { and Appendix } \mathrm{D} \text {, and they } \\
\text { are discussed for the alluvium } \\
\text { throughout Section } 6.5 \text { and } \\
\text { Appendix G. Scale } \\
\text { dependence of dispersion in } \\
\text { the fractured volcanics is } \\
\text { addressed in Section E4.1. }\end{array}$ & $\begin{array}{l}\text { Upstream Feeds }{ }^{\mathrm{a}-N / A} \\
\text { Expanded Discussion }^{\mathrm{b}}- \\
\text { BSC } 2004 \text { [DIRS 170036]; } \\
\text { BSC } 2004 \text { [DIRS 170042]. } \\
\text { Corroborating }^{\mathrm{C}}- \\
\text { BSC } 2004 \text { [DIRS 170037]; } \\
\text { BSC } 2004 \text { [DIRS 170015] }\end{array}$ \\
\hline 2.2.07.17.0A & Diffusion in the SZ & $\begin{array}{l}\text { Molecular diffusion processes } \\
\text { in the volcanics are } \\
\text { addressed in Section } 6.3 \text { and } \\
\text { in several places in } \\
\text { Appendices } D \text { and } E \text {. In } \\
\text { Section } 6.5 \text { and Appendix } G \text {, } \\
\text { molecular diffusion is } \\
\text { discussed for the alluvium, } \\
\text { but it was concluded that it } \\
\text { did not have a major effect on } \\
\text { transport in the alluvium. }\end{array}$ & 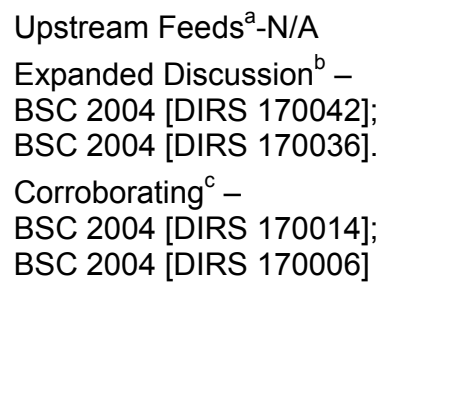 \\
\hline
\end{tabular}


Table 6.1-3. Features, Events, and Processes Included in TSPA-LA and Relevant to This Model Report (Continued)

\begin{tabular}{|c|c|c|c|}
\hline FEP No. & FEP Name & $\begin{array}{c}\text { Sections Where Disposition } \\
\text { Is Supported }\end{array}$ & $\begin{array}{l}\text { FEP Topic Addressed in Other } \\
\text { SZ Analysis or Model Reports }\end{array}$ \\
\hline 2.2.08.08.0A & Matrix diffusion in the SZ & $\begin{array}{l}\text { The effects of matrix diffusion } \\
\text { on transport in the volcanics } \\
\text { are discussed in Section } \\
6.3 .2 \text { and in Sections } D 4 \text {. and } \\
\text { E4.2. Observations and } \\
\text { parameterizations of matrix } \\
\text { diffusion in the volcanics are } \\
\text { addressed in several places } \\
\text { in Section } 6.3 \text { and } \\
\text { Appendices } D \text { and E. Matrix } \\
\text { diffusion in the alluvium is } \\
\text { discussed in Sections } 6.5 .2 \text {, } \\
6.5 .4 \text { and in Appendix G, but } \\
\text { it was concluded that matrix } \\
\text { diffusion did not have a } \\
\text { significant effect on transport } \\
\text { in the alluvium. }\end{array}$ & $\begin{array}{l}\text { Upstream Feeds }{ }^{\mathrm{a}-N / A} \\
\text { Expanded Discussion }^{\mathrm{b}}- \\
\text { BSC } 2004 \text { [DIRS 170042]; } \\
\text { BSC } 2004 \text { [DIRS 170036]. } \\
\text { Corroborating }{ }^{\mathrm{c}-} \\
\text { BSC } 2004 \text { [DIRS 170014]; } \\
\text { BSC } 2004 \text { [DIRS 170006] }\end{array}$ \\
\hline 2.2.08.09.0A & Sorption in the SZ & $\begin{array}{l}\text { Sorption in the } \mathrm{SZ} \text { is } \\
\text { addressed in Sections } 6.3 .4 \text {, } \\
6.3 .5,6.3 .6 \text {, and } 6.5 .6 \text {. It is } \\
\text { also addressed in detail in the } \\
\text { following appendix sections: } \\
\mathrm{D} 4, \mathrm{E} 1, \mathrm{E} 3, \mathrm{H} 1 \text {, and } \mathrm{H} 2 \text {. The } \\
\text { material in Sections } 6.3 \text { and } \\
\text { D4 address field-scale } \\
\text { observations of sorption, and } \\
\text { the material in the other } \\
\text { sections addresses laboratory } \\
\text { observations of sorption of } \\
\text { sorbing tracer used in the } \\
\text { field tracer tests. }\end{array}$ & $\begin{array}{l}\text { Upstream Feeds }{ }^{\mathrm{a}}-\mathrm{N} / \mathrm{A} \\
\text { Expanded Discussion }^{\mathrm{b}}- \\
\text { BSC } 2004 \text { [DIRS 170036]; } \\
\text { BSC } 2004 \text { [DIRS 170042]. } \\
\text { Corroborating }{ }^{\mathrm{c}-} \\
\text { None (This analysis is } \\
\text { corroborating to the two reports } \\
\text { above that contain expanded } \\
\text { discussions). }\end{array}$ \\
\hline 2.2.08.10.0A & Colloidal transport in the SZ & $\begin{array}{l}\text { Colloid transport in the } \\
\text { volcanics is addressed in } \\
\text { Section D4. Colloid } \\
\text { detachment rates in the } \\
\text { alluvium are addressed in } \\
\text { Section G4.6. Colloid- } \\
\text { facilitated transport of } \\
\text { radionuclides is not directly } \\
\text { addressed in this report. }\end{array}$ & $\begin{array}{l}\text { Upstream Feeds }{ }^{\mathrm{a}-N / A} \\
\text { Expanded Discussion }^{\mathrm{b}}- \\
\text { BSC } 2004 \text { [DIRS 170006]; } \\
\text { BSC } 2004 \text { [DIRS 170042]. } \\
\text { Corroborating }{ }^{\mathrm{c}}- \\
\text { BSC } 2004 \text { [DIRS 170036] }\end{array}$ \\
\hline 2.2.12.00.0B & $\begin{array}{l}\text { Undetected features in the } \\
\text { SZ }\end{array}$ & $\begin{array}{l}\text { Undetected features are } \\
\text { indirectly addressed in the } \\
\text { discussion of anisotropy in } \\
\text { horizontal hydraulic } \\
\text { conductivity in the fractured } \\
\text { volcanics in Sections } 6.2 .6, \\
\text { C6.2, and C6.3. Flow } \\
\text { anisotropy may be the result } \\
\text { of undetected features such } \\
\text { as fracture sets or faults. }\end{array}$ & $\begin{array}{l}\text { Upstream Feeds }{ }^{\mathrm{a}-N / A} \\
\text { Expanded Discussion }^{\mathrm{b}}- \\
\text { BSC } 2004 \text { [DIRS 170037]. } \\
\text { Corroborating } \\
\text { BSC } 2004 \text { [DIRS 170014]; } \\
\text { BSC } 2004 \text { [DIRS 170042] }\end{array}$ \\
\hline
\end{tabular}


Table 6.1-3. Features, Events, and Processes Included in TSPA-LA and Relevant to This Model Report (Continued)

\begin{tabular}{|c|c|c|c|}
\hline FEP No. & FEP Name & $\begin{array}{c}\text { Sections Where Disposition } \\
\text { Is Supported }\end{array}$ & $\begin{array}{l}\text { FEP Topic Addressed in Other } \\
\text { SZ Analysis or Model Reports }\end{array}$ \\
\hline $\begin{array}{l}{ }^{a} \text { Upstream } \\
\text { performed } \\
\text { b } \text { Expanded } \\
{ }^{c} \text { Corrobora }\end{array}$ & $\begin{array}{l}- \text { The FEP to } \\
\text { borative aspe }\end{array}$ & $\begin{array}{l}\text { reening position adopted in this } \\
\text { analyses. } \\
\text { ressed in more detail in an SZ } \\
\text { e FEP topic is (are) discussed in }\end{array}$ & $\begin{array}{l}\text { report are a result of } \mathrm{SZ} \text { analyses } \\
\text { halysis or model report. } \\
\text { an } \mathrm{SZ} \text { analysis or model report. }\end{array}$ \\
\hline
\end{tabular}

\subsection{HYDROLOGIC PROPERTIES OF FRACTURED TUFFS (C-WELLS COMPLEX)}

\subsubsection{Introduction}

This section of the report (1) summarizes the hydraulic tests conducted at the C-wells complex and the interpretive analyses performed on the test data; (2) discusses the implications of the test interpretations, including implications for conceptual understanding of groundwater flow in the fractured volcanics, hydrologic parameter estimates, and horizontal flow anisotropy in the fractured volcanics; and (3) discusses the uncertainties and limitations associated with the hydrologic properties determined from the test analyses.

\subsubsection{Summary of C-Wells Hydraulic Testing to Determine Hydrologic Properties}

Table 6.2-1 summarizes the hydraulic testing conducted at the C-wells complex over a fifteen-year period. Aquifer storativities and transmissivities were estimated primarily from water-level drawdowns measured in observation wells as a function of pumping time of a production well (i.e., drawdown curves) in the last five tests listed Table 6.2-1. The other tests listed in Table 6.2-1 provided valuable information on flowing intervals within each well; some of this information was used to convert aquifer transmissivity estimates to hydraulic conductivity estimates for flowing intervals. Details of hydraulic testing at the $\mathrm{C}$-wells, especially the tests listed in the last four rows of Table 6.2-1, are provided in Appendix C.

In the last four tests of Table 6.2-1, the C-wells were equipped with packers that could be inflated to isolate selected intervals and allow observations of drawdown above, below, and in the pumped interval (or in isolated intervals in the observation well when the production well was pumped as an open hole). The test intervals were given names corresponding to the major lithologies located between each pair of packers, above the top packer, and below the bottom packer (although malfunctioning pressure/temperature transducers prevented data collection in some of the intervals during some time periods). In order of increasing depth, these intervals are referred to as the Calico Hills, Prow Pass, Upper Bullfrog, Lower Bullfrog, Upper Tram, and Lower Tram intervals (Table 6.1-1). Water-level drawdowns in the isolated intervals provided valuable insights into aquifer characteristics at the scale of the $\mathrm{C}$-wells complex. Distant observation wells, which provided information on large-scale aquifer properties, were typically open holes. Drawdowns in production wells were not analyzed to estimate hydrologic parameters, as they proved to be unreliable indicators of aquifer transmissivity because of well losses. 


\subsubsection{Hydraulic Test Interpretation Methods}

Storativity and transmissivity estimates were obtained from observation well drawdown data by adjusting these two hydrologic parameters in various analytical solutions of the groundwater flow equation until a match to the data was achieved. An example of a curve match is shown in Figure 6.2-1. The data were corrected for barometric pressure fluctuations and earth tide fluctuations prior to being analyzed. The analytical solutions employed included the unconfined aquifer solution from "Analysis of Pumping Test Data from Anisotropic Unconfined Aquifers Considering Delayed Gravity Response" (Neuman 1975 [DIRS 150321]); the confined-aquifer, single-porosity solution from "The Relation Between the Lowering of the Piezometric Surface and the Rate and Duration of Discharge of a Well Using Ground-Water Storage" (Theis 1935 [DIRS 150327]); the confined-aquifer, dual-porosity solution from "Well Hydraulics in Heterogeneous Aquifer Formations" (Streltsova-Adams 1978 [DIRS 150754]); and the leaky-confined aquifer solution from "Analysis of Data from Pumping Tests in Leaking Aquifers" (Hantush 1956 [DIRS 165169]). With the exception of the Neuman (1975 [DIRS 150321]) unconfined-aquifer solution, which assumes both vertical and horizontal flow, these analytical solutions all assume radial flow to the pumping well in a homogenous, isotropic aquifer of constant thickness.

Table 6.2-1. Highlights of Testing at the C-Wells Complex to Determine Hydrologic Properties (See Appendix C for Complete Description of Tests)

\begin{tabular}{|c|c|c|}
\hline Dates & Testing Summary & References \\
\hline 1983-1984 & $\begin{array}{l}\text { Geophysical logs; open-hole flow and temperature surveys } \\
\text { during pumping (with pump well drawdown monitored); } \\
\text { tracejector surveys using radioactive iodide; falling-head } \\
\text { and pressure-injection tests in c\#1 (1983); constant-flux } \\
\text { injection test in c\#2 and } 3 \text { pump tests in c\#2 and c\#3 (1984) }\end{array}$ & $\begin{array}{l}\text { Geldon } 1993 \text { [DIRS 101045] } \\
\text { Geldon } 1996 \text { [DIRS 100396] }\end{array}$ \\
\hline 1991 & Heat-pulse flowmeter surveys (nonpumping) & Geldon 1996 [DIRS 100396] \\
\hline 1992 & Television logs & Geldon 1993 [DIRS 101045] \\
\hline 1993 & Seismic tomogram between $\mathrm{c} \# 2$ and $\mathrm{c \# 3}$ & $\begin{array}{l}\text { Communication from E. } \\
\text { Majer, LBNL (Geldon et al. } \\
2002 \text { [DIRS 161163], p. 2) }\end{array}$ \\
\hline 1993 & $\begin{array}{l}\text { Barometric efficiency from simultaneous monitoring of water } \\
\text { levels and atmospheric pressure }\end{array}$ & $\begin{array}{l}\text { Geldon et al. } 1997 \\
\text { [DIRS 156827], p. } 11\end{array}$ \\
\hline June 1995 & Spinner and oxygen-activation surveys in c\#3 & $\begin{array}{l}\text { Geldon et al. } 1998 \\
\text { [DIRS 129721] }\end{array}$ \\
\hline $\begin{array}{l}\text { May 22-June 12, } \\
1995\end{array}$ & $\begin{array}{l}\text { Open hole pumping of } \mathrm{c \# 3} \text { while monitoring } \mathrm{c \# 1}, \mathrm{c \# 2} \text {, } \\
\text { ONC-1, and USW } \mathrm{H}-4 \text { (all open holes) }\end{array}$ & $\begin{array}{l}\text { Geldon et al. } 1998 \\
\text { [DIRS 129721] }\end{array}$ \\
\hline June 12-22, 1995 & $\begin{array}{l}\text { Open hole pumping of } \mathrm{c} \# 3 \text { while monitoring } 6 \text { intervals (with } \\
5 \text { inflated packers) in } \mathrm{c} \# 1 \text { and } \mathrm{c} \# 2\end{array}$ & $\begin{array}{l}\text { Geldon et al. } 2002 \\
\text { [DIRS 161163] }\end{array}$ \\
\hline Feb. 8-13, 1996 & $\begin{array}{l}\text { Pumping of combined lower Bullfrog-Tram interval in c\#3 } \\
\text { while monitoring combined lower Bullfrog-upper Tram } \\
\text { interval (and above and below this interval) in c\#1 and c\#2 }\end{array}$ & $\begin{array}{l}\text { Geldon et al. } 2002 \\
\text { [DIRS 161163] }\end{array}$ \\
\hline $\begin{array}{l}\text { May } 81996 \text { to Nov. } \\
12,1997\end{array}$ & $\begin{array}{l}\text { Pumping of lower Bullfrog interval in c\#3 while monitoring } 6 \\
\text { intervals (with } 5 \text { inflated packers) in c\#1 and c\#2. Also, } \\
\text { monitoring of ONC-1, USW H-4, UE25 WT\#14, UE25 } \\
\text { WT\#3, and UE25 p\#1 }\end{array}$ & $\begin{array}{l}\text { Geldon et al. } 2002 \\
\text { [DIRS 161163] }\end{array}$ \\
\hline $\begin{array}{l}\text { June 2-Sept. 22, } \\
1998\end{array}$ & $\begin{array}{l}\text { Pumping of Prow Pass interval in c\#2 while monitoring the } \\
\text { Prow Pass interval (and above and below this interval) in } \\
\text { c\#1 and c\#3 }\end{array}$ & Appendix C, Section C3.2 \\
\hline
\end{tabular}




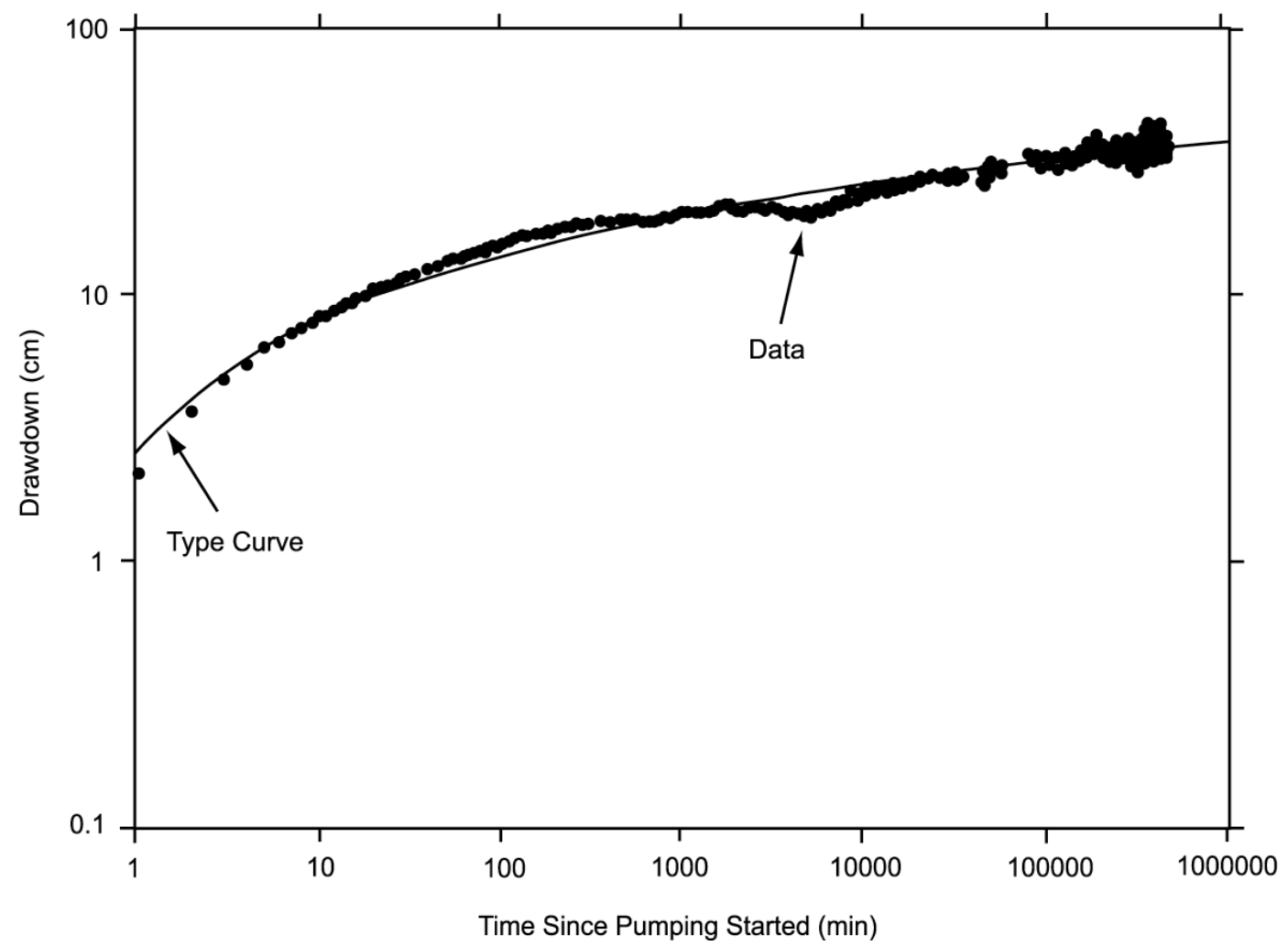

Source: Results of Hydraulic Tests in Miocene Tuffaceous Rocks at the C-Hole Complex, 1995-1997, Yucca Mountain, Nye County, Nevada (Geldon et al. 2002 DIRS 161163], p. 39, Figure 29).

NOTE: This figure also appears as Figure C-30 in Appendix C, where the details of the analysis are discussed.

Figure 6.2-1. Example of a Match of an Analytical Flow Model to Drawdown Data in an Aquifer Pump Test. This Plot Shows the Match of the Streltsova-Adams Fissure-Block Aquifer Solution to the Drawdown in UE-25 c\#1, Lower Bullfrog Interval, May 8, 1996, to March 26, 1997

The analytical solutions used for each of the test intervals at the C-wells were selected based on both the knowledge of interval flow characteristics gained from previous logging and testing and on the characteristic shapes of the interval drawdown curves. The Neuman (1975 [DIRS 150321]) unconfined-aquifer solution was applied to the Calico Hills interval because the upper boundary for this interval is the water table (therefore, it is unconfined by definition). This solution was also applied to the hydraulic test conducted in May-June 1995, in which all three C-wells were open holes. This test provided a composite estimate of vertical hydraulic conductivity at the C-wells location. The Theis (1935 [DIRS 150327]) and Streltsova-Adams (1978 [DIRS 150754]) confined aquifer solutions were applied to the Prow Pass, Upper Bullfrog, and Lower Bullfrog intervals because these intervals responded as though they were confined by overlying aquitards. The Streltsova-Adams (1978 [DIRS 150754]) solution was used when there was a slight but noticeable increase in the slope of the drawdown curve at late times, indicative of water release from secondary porosity in the aquifer (assumed to be the matrix in fractured media). Finally, the Hantush (1956 [DIRS 165169]) leaky-confined aquifer solution was used for the Tram intervals, which are intersected by known faults present at the bottom of the C-wells that appear to provide a source of recharge or "leakage." In each case, the analytical 
solutions yielded satisfactory matches to the observation well drawdown curves. Details of the test interpretations are provided in Appendix C.

Methods used to estimate anisotropy in horizontal hydraulic conductivity over large scales in the fractured volcanics are discussed in more detail in Section 6.2.6. These methods rely on an initial well-by-well analysis of drawdown data in distant observation wells during the May 1996 to November 1997 test of the lower Bullfrog interval using simple analytical methods to estimate storativity and transmissivity in the general direction of each observation well that responded to pumping. Then, either the method of Hantush (1966 [DIRS 161160]) or the method of Papadopulos (1967 [DIRS 150265]) was used to determine anisotropy in horizontal hydraulic conductivity from the individual well analyses.

\subsubsection{Hydraulic Test Interpretations: Conceptual Flow Model Implications}

The fact that the analytical solutions yielded satisfactory matches to the hydraulic test drawdown data suggests that, at least at scales of approximately $30 \mathrm{~m}$ or more, the fractured volcanic rocks in the vicinity of the C-wells behave as an "equivalent porous medium" (implicitly assumed in the analytical solutions), as noted in Section 6.1.1.1. The term "equivalent porous medium" is used to indicate that the flow intervals respond to pumping as if they were porous media, even though flow actually occurs within discrete fracture networks. Based on this consistent observation, flow and transport through the saturated fractured volcanic rocks was modeled using a continuum modeling approach (i.e., as an equivalent porous medium) in the SZ site-scale flow model (BSC 2004 [DIRS 170037]).

Another important aspect of conceptual flow modeling supported by $\mathrm{C}$-wells hydraulic testing is that flow in the fractured volcanics is not confined to stratigraphic or lithologic boundaries. Although drawdown responses were often consistent with that of a confined aquifer (and analyzed as such), intervals in observation wells above and below the pumped intervals typically had significant responses to pumping (in some cases exhibiting even greater drawdown than in the interval that was pumped). These observations suggest that fracture networks conducting flow extend beyond stratigraphic and lithologic contacts. Also, the interpretation of the open-hole aquifer test conducted in May-June 1995 indicated that there is a significant composite vertical hydraulic conductivity at the C-wells, although it is anywhere from 2.5 to 12 times less than the composite horizontal hydraulic conductivity. Collectively, these results support the approach taken in the SZ site-scale flow model (BSC 2004 [DIRS 170037]) of allowing flow to occur across stratigraphic contacts, and assuming an overall vertical hydraulic conductivity (or permeability) smaller than the horizontal hydraulic conductivity.

Finally, the $\mathrm{C}$-wells hydraulic testing results suggest that structures such as faults may play an important role in determining hydrologic characteristics both locally and over large distance scales. The most transmissive interval at the C-wells is the Lower Bullfrog Tuff, which is located adjacent to the fault zone that intersects the $\mathrm{C}$-wells. The second most transmissive interval is the Upper Tram, in which the fault zone occurs. Transmissivities become progressively smaller in intervals further away from the fault zone (Table 6.2-2). Also, the responses of distant wells, especially ONC-1 and USW H-4, to pumping the C-wells suggest a correlation between hydraulic responses and structures inferred from surface topography. These structural influences are not explicitly accounted for in the SZ site-scale flow model (BSC 2004 [DIRS 170037]), but they are indirectly accounted for by specifying a horizontal anisotropy in 
hydraulic conductivity in the fractured volcanics consistent with the responses in distant wells to pumping of the $\mathrm{C}$-wells.

\subsubsection{Hydraulic Test Interpretations: Hydrologic Parameter Estimates at the C-Wells}

The storativity, transmissivity, and hydraulic conductivity estimates obtained from analyzing the C-wells responses in the hydraulic tests listed in the last five rows of Table 6.2-1 are provided in Table 6.2-2. Details of the test interpretations are provided in Appendix C. Ranges are provided for the parameters because the values represent the results from either multiple observation wells and/or multiple tests. When only one value is presented, it means that the parameters estimated from all wells and tests were identical. Table 6.2-2 does not include any hydrologic parameter estimates obtained from analyzing responses in distant observation wells (i.e., outside the C-wells complex). These responses are discussed in more detail in the next section on large-scale horizontal anisotropy of hydraulic conductivity.

The parameter values in Table 6.2-2 are not used directly in the SZ site-scale flow model (BSC 2004 [DIRS 170037]). Instead, the hydraulic conductivities (or permeabilities) of different stratigraphic or lithologic "layers" in the SZ site-scale flow model are adjusted to "calibrate" the model to water level measurements throughout the model domain and to flux targets at the boundaries of the domain. The results of this calibration (as well as some alternative calibrations), are discussed in the SZ site-scale flow model report (BSC 2004 [DIRS 170037], Sections 6.6, 6.7, 6.8, and 7). Interestingly, they suggest that the Bullfrog unit is one of the more permeable "layers" in the model (BSC 2004 [DIRS 170037], Table 6-19), a result that is qualitatively consistent with the hydraulic testing result that the Lower Bullfrog interval has the largest transmissivity and hydraulic conductivity at the $\mathrm{C}$-wells complex.

Table 6.2-2. Ranges of Hydrologic Parameters Derived from C-Wells Cross-Hole Hydraulic Testing

\begin{tabular}{|c|c|c|c|}
\hline Flow Interval & Storativity & Transmissivity ( $\mathrm{m}^{2} /$ day) & Hydraulic Conductivity (m/day) \\
\hline Calico Hills $^{(b)}$ & $0.0002-0.0006$ & $4-10$ & $0.08-0.2$ \\
\hline Prow Pass & $0.0002-0.003$ & $30-60$ & $0.8-3$ \\
\hline Upper Bullfrog $^{(b)}$ & $0.00002-0.0009$ & $40-100$ & $0.8-4$ \\
\hline Lower Bullfrog & $0.0002-0.003$ & $1300-1900$ & $30-60$ \\
\hline $\begin{array}{l}\text { Lower Bullfrog - } \\
\text { Upper Tram }\end{array}$ & $0.0003-0.002$ & 2500 & $20-50$ \\
\hline Upper Tram ${ }^{(\mathrm{b})}$ & $0.0001-0.001$ & $800-900$ & $20-40$ \\
\hline Composite ${ }^{(\mathrm{c})}$ & $0.001-0.003$ & $1800-2100$ & $\begin{array}{l}\text { Horizontal: } 3.6-4.2 \\
\text { Vertical: } 0.3-1.7\end{array}$ \\
\hline
\end{tabular}

Output DTN: GS031008312314.004 (from Input DTNs: GS030508312314.003 [DIRS 164425], pp. 34 to 35, Table 8, and GS990408312315.002 [DIRS 140115]).

${ }^{\text {a }}$ Values obtained by estimating a transmissive thickness within each interval from various lines of evidence [Conductivity $=$ Transmissivity/(Transmissive Thickness)].

b Values obtained by estimating an "equivalent radial volumetric flow rate" for these intervals, which were never isolated for pumping - See Appendix $C$ for details.

${ }^{c}$ Composite values obtained from open-hole aquifer test conducted May 22-June 12, 1995 (hence, the transmissivities for each interval do not add up to the composite). This test was interpreted using an unconfined aquifer solution to provide estimates of composite vertical hydraulic conductivity. The horizontal hydraulic conductivities were calculated assuming that the entire thickness of the saturated zone tested (approximately $500 \mathrm{~m}$ ) was the transmissive thickness. 


\subsubsection{Hydraulic Test Interpretations: Horizontal Anisotropy in Hydraulic Conductivity}

The hydraulic responses at the $\mathrm{C}$-wells indicated very little flow anisotropy at the local scale (Table C-7). This apparent lack of anisotropy was qualitatively confirmed by C-wells tracer responses in both the lower Bullfrog and the Prow Pass intervals (Section 6.3.4, Table 6.3-2). However, hydraulic responses in more distant wells (to pumping the C-wells) indicated significant flow anisotropy at larger scales in the fractured volcanic tuffs. The long-term pumping test from May 8, 1996, through November 12, 1997 (in which the Lower Bullfrog interval in $\mathrm{c} \# 3$ was pumped at about $570 \mathrm{~L} / \mathrm{min}$ ) was the only hydraulic test conducted at the C-wells that yielded data suitable for estimating the hydrologic properties of the fractured volcanics on a scale beyond the immediate vicinity of the $\mathrm{C}$-wells. Changes in local groundwater elevations due to pumping at the C-wells complex were monitored at four distant wells (H-4, ONC-1, WT\#3, and WT\#14 exhibited sufficient drawdown for hydrologic parameter estimation), allowing a horizontal anisotropy ratio and principal direction to be estimated over an approximately $21-\mathrm{km}^{2}$ area in the fractured volcanics. The C-wells responses were not considered in analyses of anisotropy.

Four different sets of storativity and transmissivity estimates were obtained for each of the four wells that responded to pumping the Lower Bullfrog interval of the C-wells (Table 6.2-3). The first set was taken from the analysis of Winterle and LeFemina (1999 [DIRS 129796], Section 4.5), who processed the long-term pumping data using AQTESOLV, with the Theis (1935 [DIRS 150327]) confined-aquifer solution being used to obtain transmissivity and storativity estimates. The second set of estimates was obtained by applying the Cooper-Jacob (1946 [DIRS 150245]) method to filtered and derivative-analyzed drawdown data. The third and fourth sets of estimates was obtained by applying the methods discussed in Section 6.2.3, with the Streltsova-Adams (1978 [DIRS 150754]) confined fissure-block solution being used for the ONC-1 analysis and the Theis (1935 [DIRS 150327]) confined aquifer solution being used for the other three wells. The differences between these two sets of estimates are attributable to different methods of filtering the drawdown data prior to the analyses. Details of these methods of estimating storativities and transmissivities are provided in Appendix C.

After storativity and transmissivity were estimated for each well, the horizontal anisotropy was estimated from these parameters using either the Hantush (1966 [DIRS 161160]) method, the Papadopulos (1967 [DIRS 150265]) method, or three different applications of the Papadopulos (1967 [DIRS 150265]) method combined with the PEST parameter-estimation program, Version 5.5 (STN: 10289-5.5-00 [DIRS 161564]). The method of Hantush (1966 [DIRS 161160]) was applied to the storativities and transmissivities obtained by the CooperJacob (1946 [DIRS 150245]) method, although the H-4 results were excluded from this analysis because their inclusion yielded a negative anisotropy ratio. Winterle and LeFemina (1999 [DIRS 129796], Section 4.5) used the Papadopulos (1967 [DIRS 150265]) method to estimate anisotropy, and they also excluded the H-4 results to obtain a meaningful anisotropy ratio. Ferrill et al. (1999 [DIRS 118941]) conducted a separate analysis using the individual well parameter estimates of Winterle and LeFemina (1999 [DIRS 129796]) and the Papadopulos (1967 [DIRS 150265]) method, but with a slight modification of the WT\#14 transmissivity (from 1,330 to $1,370 \mathrm{~m}^{2} /$ day) due to a difference in technique for correcting barometric pressures. H-4 results were also excluded from their analyses. The Papadopulos (1967 [DIRS 150265])-PEST method was applied to two sets of transmissivity/storativity values 
obtained from the same analysis methods (Theis 1935 [DIRS 150327] for WT\#3, WT\#14, and H-4, Streltsova-Adams 1978 [DIRS 150754] for ONC-1) but with different methods of filtering the raw drawdown data (see pp. 15 to 16 of Geldon et al. (2002 [DIRS 161163]), and Appendix C, Section C6.2.1 for the two filtering methods). Finally, a third Papadopulos-PEST analysis was conducted assuming a transmissivity of $1,000 \mathrm{~m}^{2} /$ day for each well. H-4 results were included in all the Papadopulos-PEST analyses. Details of the anisotropy analyses are presented in Appendix C. The results are summarized in Table 6.2-4.

Table 6.2-3. Transmissivities and Storativities of Distant Wells for the Long-Term Pumping Test

\begin{tabular}{|c|c|c|c|c|c|c|}
\hline & \multicolumn{2}{|c|}{$\begin{array}{c}\text { Winterle and La Femina } \\
(\mathbf{1 9 9 9})^{\mathbf{a}}\end{array}$} & \multicolumn{2}{c|}{$\begin{array}{c}\text { Cooper-Jacob } \\
\text { Analysis }^{\mathbf{b}}\end{array}$} & \multicolumn{2}{c|}{$\begin{array}{c}\text { Using Methods of } \\
\text { Section 6.2.3 }\end{array}$} \\
\hline Well & $T\left(\mathrm{~m}^{2} / \mathrm{day}\right)$ & $S(-)$ & $T\left(\mathrm{~m}^{2} / \mathrm{day}\right)$ & $S(-)$ & $T\left(\mathrm{~m}^{2} /\right.$ day $)$ & $S(-)$ \\
\hline UE-25 ONC1 & 1,340 & 0.008 & 1,465 & 0.009 & $1,000 / 1,230$ & $0.001 / 0.0012$ \\
\hline UE-25 WT\#3 & 1,230 & 0.005 & 1,566 & 0.003 & $2,600 / 861$ & $0.002 / 0.0045$ \\
\hline UE-25 WT\#14 & $1,330 / 1,370^{(\mathrm{d})}$ & 0.002 & 1,043 & 0.002 & $1,300 / 743$ & $0.002 / 0.0029$ \\
\hline USW H-4 & 670 & 0.002 & 598 & 0.002 & $700 / 700$ & $0.002 / 0.0024$ \\
\hline
\end{tabular}

Source: DTNs: GS030508312314.003 [DIRS 164425], p. 41, Table 9; GS970308312314.002 [DIRS 161273]; MO0212SPANYESJ.149 [DIRS 161274] (qualified for use in this report in Appendix M).

Output DTNs: GS031008312314.004, SN0409T0502203.002.

a The Theis (1935 [DIRS 150327]) method was used by Winterle and La Femina (1999 [DIRS 129796], pp. 4 to 25$)$ to obtain these estimates.

b The Cooper-Jacob (1946 [DIRS 150245]) method was used to obtain these estimates (see Appendix C for details).

${ }^{c}$ Two sets of transmissivity and storativity estimates were obtained as a result of using different methods to filter the raw drawdown data (see text).

${ }^{d}$ Ferrill et al. (1999 [DIRS 118941]) used the second transmissivity value (see text).

Because the SZ site-scale flow model (BSC 2004 [DIRS 170037]) can only implement anisotropy oriented in a north-south or east-west direction, the principal anisotropy directions listed in Table 6.2-4 must be projected onto the north-south, east-west orientation of the model grid. For example, the analytical result for anisotropy using the Cooper-Jacob (1946 [DIRS 150245]), a ratio of 3.3 at $15^{\circ}$ east of north, is converted to an anisotropy ratio of 2.5 with a north-south $\left(0^{\circ}\right)$ orientation (Figure 6.2-2). This anisotropy ratio was calculated by dividing the maximum $y$ value on the anisotropy ellipse oriented $15^{\circ}$ east of north (horizontal blue line at top in Figure 6.2-2) by its maximum $x$ value (vertical green line at right). Similarly, the projected north-south anisotropy ratio for an anisotropy ratio of 5 oriented $33^{\circ}$ east of north is 1.5 . 
Table 6.2-4.Calculated and Reported Anisotropies and Principal Directions

\begin{tabular}{|c|c|c|c|c|}
\hline Data Set Used / Method & $\begin{array}{c}T_{\max } \\
\left(\mathrm{m}^{2} / \text { day }\right)\end{array}$ & $\begin{array}{c}T_{\min } \\
\left.\text { ( } \mathrm{m}^{2} / \text { day }\right)\end{array}$ & $\begin{array}{l}\text { Anisotropy } \\
\text { Ratio }^{b}\end{array}$ & Azimuth $^{\text {b }}$ \\
\hline Cooper-Jacob Data / Hantush ${ }^{\mathrm{a}}$ & 2,457 & 752 & 3.3 & $15^{\circ} \mathrm{E}$ \\
\hline Winterle and La Femina $(1999)^{a} /$ Papadopulos $^{\mathrm{a}}$ & 2,900 & 580 & 5 & $33^{\circ} \mathrm{E}$ \\
\hline Ferrill et al. $(1999)^{a} /$ Papadopulos ${ }^{a}$ & 5,400 & 315 & 17 & $30^{\circ} \mathrm{E}$ \\
\hline$T=700-2,600 \mathrm{~m}^{2} /$ day $/$ Papadopulos-PEST ${ }^{\mathrm{a}}$ & 3,272 & 599 & 5.5 & $1^{\circ} \mathrm{E}$ \\
\hline$T=700-1,230 \mathrm{~m}^{2} /$ day $/$ Papadopulos-PEST ${ }^{a}$ & 3,047 & 271 & 11.3 & $35^{\circ} \mathrm{W}$ \\
\hline$T=1,000 \mathrm{~m}^{2} /$ day $/$ Papadopulos-PEST ${ }^{\mathrm{a}}$ & 1,863 & 537 & 3.5 & $79^{\circ} \mathrm{W}$ \\
\hline
\end{tabular}

Source: DTNs: GS970308312314.002 [DIRS 161273]; MO0212SPANYESJ.149 [DIRS 161274] (qualified for use in this report in Appendix M).

Output DTNs: GS031008312314.004, SN0409T0502203.002.

${ }^{\text {a }}$ For a description of the methods used, refer to Hantush (1966 [DIRS 161160]), Papadopulos (1967 [DIRS 150265]), Ferrill et al. (1999 [DIRS 118941]), and Winterle and La Femina (1999 [DIRS 129796]).

$\mathrm{b}$ The last two columns list reported values.

Based on consultations between Sandia National Laboratories staff, Los Alamos National Laboratory staff, U.S. Geological Survey staff, and the YMP Parameters Team, as well as results from the analytical anisotropy analyses, curve (a) of Figure 6.2-3 is considered to be the best estimate of the probability density function (PDF) for the anisotropy ratio in the SZ near the C-wells complex (Eddebbarh 2004 [DIRS 171918]). Curve (b) of Figure 6.2-3 is the corresponding cumulative distribution function (CDF).

There are three noteworthy points based on three distinct regions of the anisotropy ratio distribution (Output DTN: SN0302T0502203.001).

- Anisotropy ratio between 5 and 20. The maximum anisotropy ratio of 20:1 is physically based. Although features such as high transmissivity zones and fractures may yield very large anisotropy ratios locally, globally, their effects are attenuated. That is, over the area of the saturated-zone model, $45 \times 30 \mathrm{~km}^{2}$, an anisotropy ratio of 20 is the expected upper bound. Additionally, the highest calculated anisotropy ratio reported is 17:1 (Ferrill et al. 1999 [DIRS 118941], p. 7). The 5.5 anisotropy ratio calculated by the second approach of the modified Papadopulos-PEST method lies in this range near its highest probability point. Therefore, between 5 and 20, a triangularly distributed anisotropy ratio is constructed that decreases to zero probability at 20 . Given that 3 of the 6 estimates of anisotropy ratio in Table 6.2-4 fall between 5 and 20, and one of these three estimates is just barely greater than 5 (5.5), a 40 percent probability is assigned to this portion of the PDF.

- Anisotropy ratio between 0.05 and 1. Discussions among Sandia National Laboratories and U.S. Geological Survey staff established that, although it is likely the saturated zone is anisotropic with principal direction approximately northeast, it is possible the media could be isotropic, as well as a small probability that the principal direction could be significantly different from northeast. Correspondingly, anisotropies less than one are possible, and the minimum anisotropy ratio is set equal to the inverse of the maximum, 1:20, with a triangularly distributed 10 percent probability decreasing to zero at a ratio of 
0.05. The 3.5 anisotropy ratio calculated by the first approach of the modified Papadopulos-PEST method, when adjusted according to Figure 6.2-2, falls in this range.

- Anisotropy ratio between 1 and 5. A uniformly distributed 50 percent probability is assigned to the range of anisotropy ratios between 1 and 5. This interval comprises the most likely values of anisotropy ratios with no specific value more likely than another.

Figure 6.2-3, curves (a) and (b), are the best estimates for the PDF and the CDF, respectively, of north-south anisotropy ratios in the saturated zone modeled with FEHM in Saturated Zone SiteScale Flow Model (BSC 2004 [DIRS 170037], Section 6.4.3).

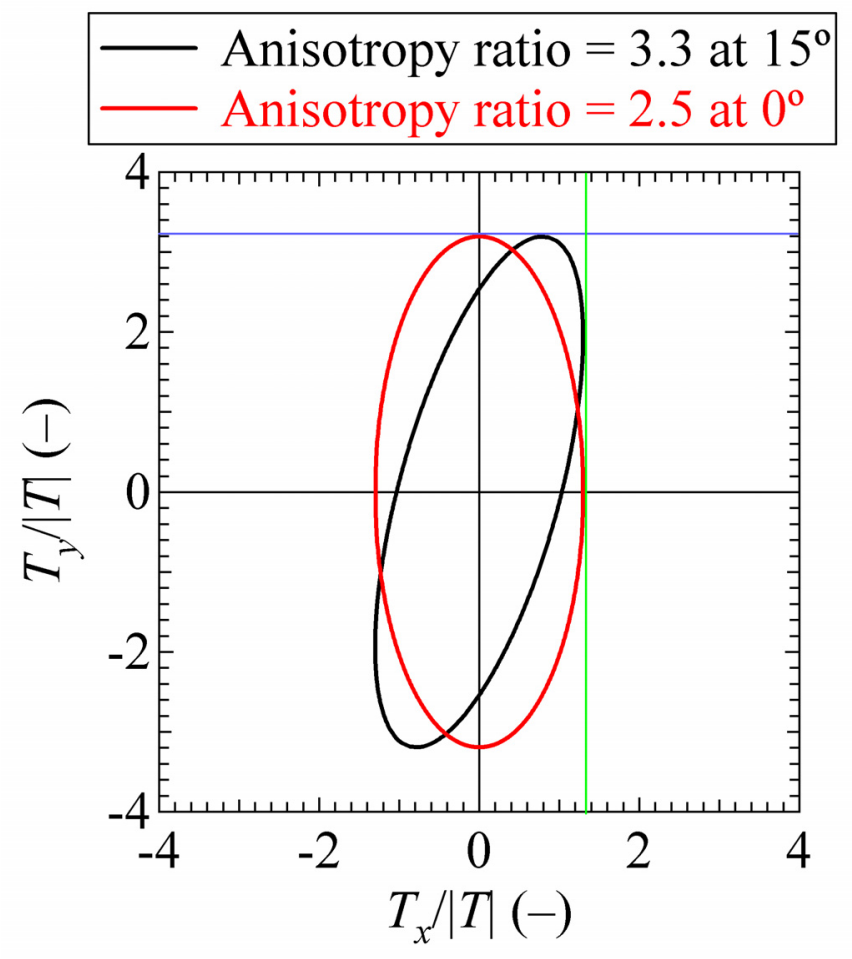

Output DTN: GS031008312314.004.

Figure 6.2-2. Anisotropy Ratio of 3.3 at $15^{\circ}$ East of North Projected onto a North-South Anisotropy Ratio $\left(0^{\circ}\right)$ Resulting in a Projected Anisotropy Ratio of 2.5 


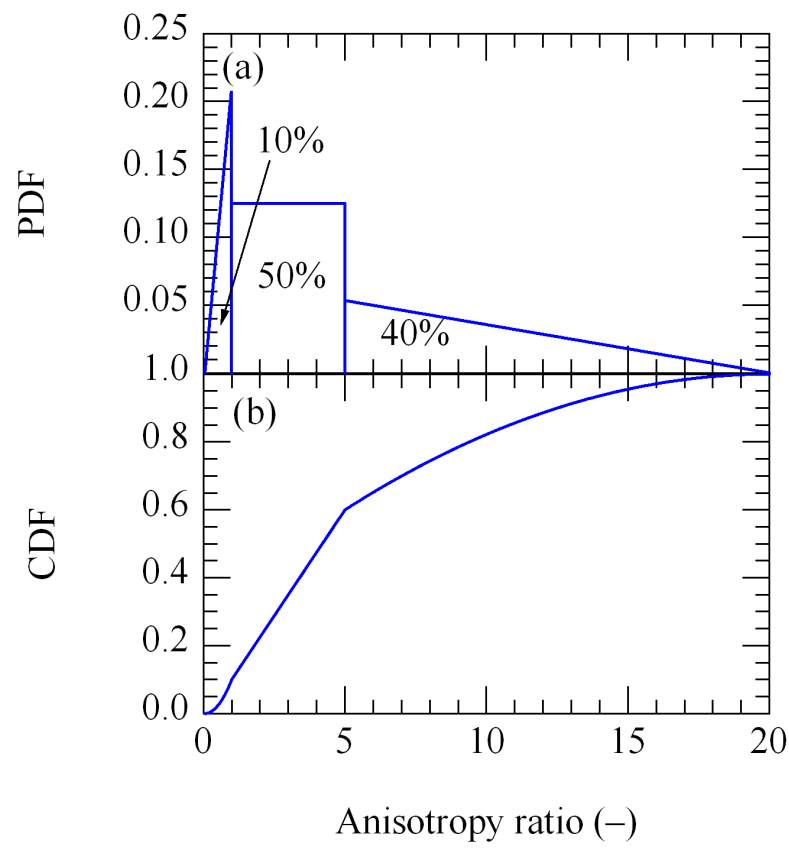

Output DTN: SN0302T0502203.001.

Figure 6.2-3. Probability Density Function (a) and Corresponding Cumulative Distribution Function (b) for the North-South/East-West Anisotropy Ratio Used in FEHM Input Files

\subsubsection{Limitations and Uncertainties}

Analytic solutions provide first-order estimates of hydrologic parameters consistent with both the current knowledge of the nature and extent of subsurface heterogeneities in the fractured volcanics at the scale of the C-wells complex and the manner in which hydrologic parameter estimates are used in the SZ site-scale flow model. The analytical methods assume simplified flow geometries in an equivalent porous medium, and they also assume that the test interval has one average transmissivity and storativity value between the pumping well and the observation well. Similarly, the SZ flow model assumes that single average intrinsic hydrologic property values (e.g., permeability, porosity) apply to individual stratigraphic intervals over large spatial areas in the SZ flow system, so the use of simple analytical methods to estimate parameters is consistent with simplifications that are, by necessity, made in the SZ site-scale flow model. Furthermore, with the exception of anisotropy of horizontal transmissivity, the hydrologic parameters derived from $\mathrm{C}$-wells testing are not used as direct inputs in the SZ site-scale flow model, but rather they are used primarily for qualitative/corroborative consistency checks with the hydrologic parameters derived from calibrations of the SZ site-scale flow model.

All the analytical methods used in this study, except for the Neuman (1975 [DIRS 150321]) method, assume radial flow to the pumping well, and, therefore, ignore vertical flow (application of the Neuman fully penetrating-well solution, as was done in this analysis, to cases where pumping was in one interval and the analyzed drawdown response was in another also ignores vertical flow). The drawdown in intervals other than the one being pumped that was detected during hydraulic tests in February 1996 and May 1996 to November 1997 indicates that flow during those tests was actually three-dimensional. To obtain hydrologic parameter estimates in nonpumped intervals, it was necessary to assume an equivalent radial volumetric flow rate in 
these intervals. These estimates of equivalent radial flow were quite uncertain, and they could have resulted in significant errors in hydrologic parameter estimates in nonpumped intervals. However, parameter estimates based on an assumed radial flow in nonpumped intervals were generally in good agreement with estimates obtained from open-hole pumping of $\mathrm{c \# 3}$ in May-June 1995, and also from later pumping of the intervals when they were isolated (e.g., estimates for the Prow Pass interval when the Lower Bullfrog was pumped in 1996-1997 were in good agreement with estimates obtained when the Prow Pass interval was pumped directly in 1998). Thus, the approach taken seems to have yielded reasonable hydrologic parameter estimates in the cases in which it could be verified with a more direct measurement.

Uncertainties in estimates of storativity, transmissivity, and hydraulic conductivity were not quantitatively analyzed because these parameter estimates were not used directly in the SZ site-scale flow model (BSC 2004 [DIRS 170037], Sections 6.6, 6.7 and 7); they were used only qualitatively/corroboratively in the flow model. Based on the ranges of storativity and transmissivity estimates obtained by different analysts or different methods using the same drawdown data from the distant wells that responded to pumping c\#3 in 1996-97 (Table 6.2-3), the transmissivity estimates determined in this analysis can be considered accurate to perhaps a factor of 3 (that is, the true transmissivity may be 3 times higher or 3 times lower than the estimate), and storativity estimates can be considered accurate to within an order of magnitude or so. However, relative values of transmissivity estimates (that is, the ratios of transmissivites of different flow intervals) are considered more accurate because errors and biases should be reasonably consistent for estimates obtained by the same analyst using similar assumptions and methods (as is the case here). Estimates of hydraulic conductivity are more uncertain than transmissivity estimates because hydraulic conductivity is calculated by dividing the transmissivity by either the known thickness of transmissive intervals within a test interval, the entire thickness of the test interval, or an assumed thickness of transmissive rock between the observation and pumping wells. In many cases, the transmissive thickness was unknown, so it was only possible to obtain bounding estimates of the hydraulic conductivity. Even when hydraulic conductivity could be estimated, it was done with limited confidence. For example, it is impossible to know whether the hydraulic conductivity of the Lower Bullfrog interval in c\#1 really is about half that in $\mathrm{c} \# 2$ or whether these calculated hydraulic conductivity values result from dividing approximately the same transmissivity in each borehole by an assumed transmissive thickness twice as large in $\mathrm{c} \# 1$ as in $\mathrm{c} \# 2$.

Given the intended use of the hydrologic parameters derived from this scientific analysis in the SZ site-scale flow model (BSC 2004 [DIRS 170037]) (for qualitative/corroborative consistency checks), the uncertainties associated with the parameter estimates and the resulting assessment of their accuracy (discussed above) are considered acceptable. Because anisotropy in horizontal transmissivity in the fractured volcanics is a direct input in the SZ site-scale flow model, additional effort was expended to estimate its uncertainty and to present this uncertainty as probability distributions for both the direction and the magnitude of the anisotropy (Section 6.2.6). The implications of C-wells hydraulic test results for conceptual flow models are based primarily on qualitative observations (e.g., large-scale equivalent porous medium behavior, vertical flow communication between intervals with some vertical anisotropy, and the influence of structures, particularly faults), so these important implications are not significantly influenced by uncertainties in parameter estimates. 


\subsection{TRANSPORT PROPERTIES OF FRACTURED TUFFS (C-WELLS COMPLEX)}

\subsubsection{Introduction}

This section (1) summarizes the tracer tests conducted at the C-wells complex and the interpretive analyses performed on the test data; (2) discusses the implications of the test interpretations, including transport parameter estimates and implications for conceptual transport modeling in the fractured volcanics; and (3) discusses the limitations and uncertainties associated with the transport properties determined from the test analyses.

\subsubsection{Summary of C-wells Tracer Testing, Including Objectives and Strategies}

Table 6.3-1 summarizes the tracer testing conducted at the C-wells complex over a four-year period from 1996 to 1999. Details of each test are provided in Appendix D. Estimates of transport parameters were obtained from the tests by fitting the tracer breakthrough curves (normalized tracer concentrations vs. time) using semi-analytical dual-porosity transport models (Section 6.3.3). The term "dual-porosity" refers to a system in which flow occurs predominantly within a "primary" porosity (e.g., fractures in the volcanic tuffs) but there is a significant "secondary" porosity that contains stagnant or near-stagnant water into which solutes can diffuse from the primary porosity (e.g., the matrix in the volcanic tuffs). In contrast, a "single-porosity" system is a system that contains only primary porosity; that is, flow occurs through all of the system porosity, and there is little or no stagnant water.

A key objective of tracer testing was to determine if a dual-porosity conceptualization is valid in the saturated volcanic tuffs or if the tuffs behave as a single-porosity system (with no secondary porosity into which solutes can diffuse). Distinguishing between these two types of conceptual models has important radionuclide transport implications because solutes moving through fractures in a dual-porosity system will spend a significant amount of time in the stagnant matrix water, thus resulting in a significant increase in their transport time through the system relative to the transport time they would experience in only the primary fracture porosity. Furthermore, sorbing radionuclides will come in contact with much more surface area for sorption in the matrix pores of a dual-porosity system than they would in a fracture-only system. Tracer tests were conducted in both a high transmissivity interval (the lower Bullfrog) and a low transmissivity interval (the Prow Pass) at the C-wells to determine if transport behavior and transport parameter estimates differ in intervals of significantly different hydrologic characteristics.

All tracer tests were conducted by injecting one or more tracers (dissolved or suspended in groundwater) into an isolated interval in one of the $\mathrm{C}$-wells while the corresponding interval in another of the $\mathrm{C}$-wells was pumped. These types of tests are called cross-hole tracer tests. The water produced from the pumped well was sampled at regular intervals and analyzed for the tracers to develop a tracer breakthrough curve. The test intervals in both the injection and production wells were isolated using inflatable packers in the same way that intervals were isolated for hydraulic testing (Section 6.2). In each tracer test, a steady flow field was established prior to tracer injection, and this flow field was maintained for an extended period of time after injection. Tracer tests were typically conducted immediately after hydraulic tests were completed in a given test interval, although hydraulic data continued to be collected throughout each tracer test. 
Table 6.3-1. Tracer Testing at the C-Wells Complex to Determine Transport Properties.

\begin{tabular}{|c|c|c|c|}
\hline Dates & Testing Summary & $\begin{array}{c}\text { Interpretative } \\
\text { Method }\end{array}$ & References \\
\hline Feb-April 1996 & $\begin{array}{l}\text { Injection of iodide into combined lower Bullfrog-upper } \\
\text { Tram interval in c\#2 while pumping the same interval } \\
\text { in c\#3 at approximately } 450 \mathrm{~L} / \mathrm{min} \text {. No recirculation } \\
\text { was employed. }\end{array}$ & Moench & $\begin{array}{l}\text { Fahy } 1997 \\
\text { [DIRS 137456]; } \\
\text { Appendix D1 }\end{array}$ \\
\hline $\begin{array}{l}\text { May-October } \\
1996\end{array}$ & $\begin{array}{l}\text { Injection of pentafluorobenzoate (PFBA) into lower } \\
\text { Bullfrog interval in c\#2 while pumping the same } \\
\text { interval in c\#3 at approximately } 575 \mathrm{~L} / \mathrm{min} \text {. } \\
\text { Approximately } 3.5 \text { percent of the production water } \\
\text { was recirculated into the injection well for } 23 \text { days } \\
\text { after injection. }\end{array}$ & Qualitative only & Appendix D1 \\
\hline $\begin{array}{l}\text { June-October } \\
1996\end{array}$ & $\begin{array}{l}\text { Injection of iodide into lower Bullfrog interval in c\#1 } \\
\text { while pumping the same interval in c\#3 at } \\
\text { approximately } 575 \mathrm{~L} / \mathrm{min} \text {. Approximately } 2.6 \text { percent } \\
\text { of the production water was recirculated into the } \\
\text { injection well for } 16 \text { days after injection. }\end{array}$ & Qualitative only & Appendix D1 \\
\hline $\begin{array}{l}\text { October } 1996 \text { - } \\
\text { Sept. } 1997\end{array}$ & $\begin{array}{l}\text { Simultaneous injection of PFBA, bromide, lithium, } \\
\text { and polystyrene microspheres into lower Bullfrog } \\
\text { interval in c\#2 while pumping the same interval in c\#3 } \\
\text { at approximately } 575 \mathrm{~L} / \mathrm{min} \text {. Approximately } 3.3 \\
\text { percent of the production water was recirculated into } \\
\text { the injection well for } 40 \text { days after injection }\end{array}$ & $\begin{array}{l}\text { RELAP/ } \\
\text { MULTRAN }\end{array}$ & Appendix D4 \\
\hline $\begin{array}{l}\text { January-Nov. } \\
1997\end{array}$ & $\begin{array}{l}\text { Injection of pyridone into lower Bullfrog interval in c\#1 } \\
\text { while pumping the same interval in c\#3 at } \\
\text { approximately } 575 \mathrm{~L} / \mathrm{min} \text {. No recirculation was } \\
\text { employed. }\end{array}$ & Moench & Appendix D1 \\
\hline $\begin{array}{l}\text { January-Nov. } \\
1997\end{array}$ & $\begin{array}{l}\text { Injection of } 2,6 \text { difluorobenzoate (DFBA) into lower } \\
\text { Bullfrog interval in c\#2 while pumping the same } \\
\text { interval in c\#3 at approximately } 575 \mathrm{~L} / \mathrm{min} \text {. No } \\
\text { recirculation was employed. }\end{array}$ & Moench & Appendix D1 \\
\hline $\begin{array}{l}\text { June } 1998 \text { - } \\
\text { January } 1999\end{array}$ & $\begin{array}{l}\text { Injection of } 2,4,5 \text { trifluorobenzoate (TFBA) and iodide } \\
\text { into Prow Pass interval in c\#3 while pumping the } \\
\text { same interval in c\#2 at approximately } 19 \mathrm{~L} / \mathrm{min} \text {. } \\
\text { Approximately } 30 \text { percent of the production water } \\
\text { was recirculated into the injection well for the duration } \\
\text { of the test. }\end{array}$ & $\begin{array}{l}\text { Moench with } \\
\text { adjustments to } \\
\text { account for } \\
\text { recirculation. } \\
\text { Also, RELAP }\end{array}$ & Appendix D2 \\
\hline $\begin{array}{l}\text { July } 1998 \text { - } \\
\text { January } 1999\end{array}$ & $\begin{array}{l}\text { Injection of } 2,3,4,5 \text { tetrafluorobenzoate (TeFBA) into } \\
\text { Prow Pass interval in c\#1 while pumping the same } \\
\text { interval in c\#2 at approximately } 19 \mathrm{~L} / \mathrm{min} \text {. No } \\
\text { recirculation was employed (although recirculation } \\
\text { into c\#3 continued). }\end{array}$ & Qualitative only & Appendix D2 \\
\hline $\begin{array}{l}\text { Sept. } 1998 \text { - } \\
\text { January } 1999\end{array}$ & $\begin{array}{l}\text { Injection of PFBA, bromide, lithium, and polystyrene } \\
\text { microspheres into Prow Pass interval in c\#3 while } \\
\text { pumping the same interval in c\#2 at approximately } 19 \\
\text { L/min. Approximately } 30 \text { percent of the production } \\
\text { water was recirculated into the injection well for the } \\
\text { duration of the test. }\end{array}$ & $\begin{array}{l}\text { RELAP/ } \\
\text { MULTRAN }\end{array}$ & Appendix D4 \\
\hline
\end{tabular}

The tracer tests were conducted either in a radial-convergent flow configuration or in a partial recirculation flow configuration. In the latter case, a fraction of the water pumped from the production well was reinjected into the injection well for an extended period of time after tracer injection. For radial-convergent flow tests, there was no injection of water after tracer injection other than a small amount used to evacuate the injection tubing. 
The best insights into conceptual transport characteristics of the fractured tuffs and the best-constrained transport parameter estimates were obtained from tracer tests in which two or three different solute tracers having different physical and/or chemical properties were simultaneously injected. By dissolving the tracers in the same solution and simultaneously introducing them, it was ensured that they all experienced the same flow field and, hence, initially followed identical flow pathways through the system.

The rationale for using multiple solute tracers in cross-hole tracer tests is illustrated in Figure 6.3-1 (Section 6.3.3). The left plot of this figure shows hypothetical solute tracer responses (log normalized concentration versus log time) for a cross-hole tracer test with a short injection pulse in a single-porosity system. Note that there is no distinction between nonsorbing tracers with different diffusion coefficients in this plot because there is no secondary porosity for the tracers to diffuse into and, hence, no separation of their responses. The sorbing tracer response is delayed in time and lower in concentration than the nonsorbing tracers. In contrast, the right plot of Figure 6.3-1 shows hypothetical solute tracer responses for a test in a dualporosity system. In this case, there is a separation between nonsorbing tracers with different diffusion coefficients, with the higher diffusivity tracer exhibiting a lower peak concentration and a longer tail than the lower diffusivity tracer. This separation occurs because the higher-diffusivity tracer diffuses more readily into the matrix than the lower-diffusivity tracer, resulting in a lower recovery at early times but a longer tail due to subsequent diffusion back out of the matrix after the tracer pulse has passed.

Figure 6.3-1 also shows two possible responses for a sorbing tracer: (1) one with sorption occurring in the matrix, and (2) one with sorption occurring in the fractures and the matrix (if the fractures have sorptive mineral coatings or are filled with sorptive granular material). Note that in the matrix-only case, the sorbing tracer response is attenuated in peak concentration but not significantly in time relative to the nonsorbing tracers, whereas in the latter case both a concentration and a time attenuation are apparent. The minimal time attenuation of the sorbing tracer relative to the nonsorbing tracers in the matrix-only sorption case is primarily a result of the relatively short duration of a typical cross-hole tracer test relative to characteristic times of diffusion into the matrix; as transport times increase, the time and concentration attenuation of a sorbing tracer relative to nonsorbing tracers should increase. 


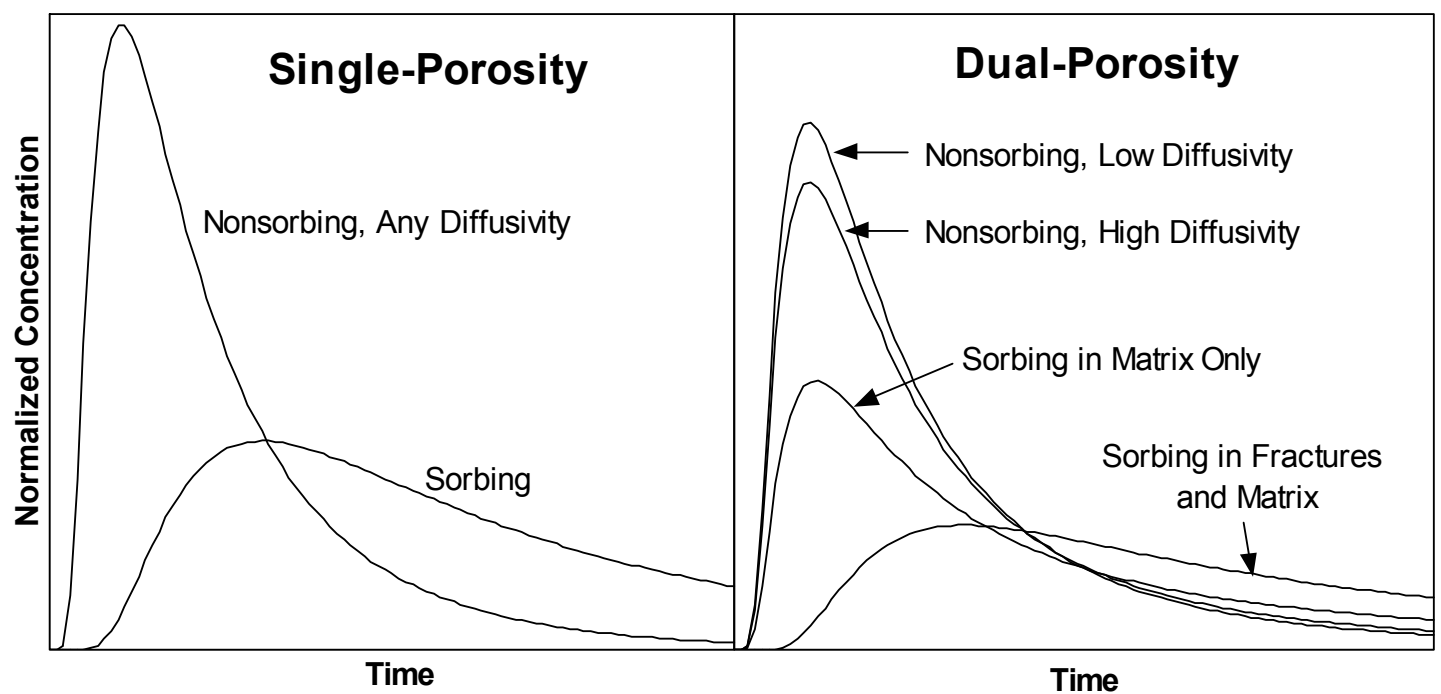

NOTE: For illustration purposes only. The figure illustrates how multiple tracers can be used to distinguish between single- and dual-porosity systems (Reimus 2003 [DIRS 165129], Attachment A, pp. A-198 to A-208). As cross-hole travel times increase, the "nonsorbing, high diffusivity" and "sorbing, matrix only" peaks on the right-hand plot will begin to arrive later than the "nonsorbing, low diffusivity" peak. The curves were generated using the RELAP V 2.0 code (STN: 10551-2.0-00 [DIRS 159065]) with arbitrary input parameters intended to qualitatively illustrate the differences between tracer responses in single- and dual-porosity media. The inputs and outputs of the simulations were not submitted to the TDMS and do not have a DTN.

Figure 6.3-1. Hypothetical Cross-Hole Responses of Tracers with Different Physical and Chemical Characteristics in Single- and Dual-Porosity Media

\subsubsection{Tracer Test Interpretation Methods}

To obtain estimates of solute transport parameters in the tracer tests, semi-analytical dual-porosity transport models with appropriate initial and boundary conditions were used to fit the normalized solute tracer responses (tracer concentrations in the production water divided by tracer injection masses as a function of time since injection. Two different interpretive approaches were used for the test interpretations. The first was based on the work of Moench (1989 [DIRS 101146]; 1995 [DIRS 148784]), implemented using the MOENCH.vi Function(1) code in conjunction with the rcv2amos.exe routine (STN: 10582-1.0-00 [DIRS 162750]) and the MOENCH.vi, Function(2), V 1.0 code (STN: 10583-1.0 [DIRS 162752]). These combined codes solve the dual-porosity advection-dispersion equation(s) in a steady-state radialconvergent flow field with initial and boundary conditions that correspond to a finite-pulse injection and well-mixed injection and production intervals. The second modeling approach employed the RELAP (Reactive transport LAPlace transform inversion computer code) V 2.0 (STN: 10551-2.0-00 [DIRS 159065]) and MULTRAN V 1.0 (STN: 10666-1.0-00 [DIRS 159068]) codes. RELAP essentially combines a dual-porosity transport solution derived by Maloszewski and Zuber (1984 [DIRS 156840], Appendix; 1985 [DIRS 148312]) (modified to account for linear solute sorption) with functions that describe a finite-pulse injection, ideally mixed injection and production intervals, and recirculation. MULTRAN is a code that embodies a numerical model that duplicates what RELAP does analytically, but it also accounts for multicomponent transport processes and local charge balance to more accurately describe reactive tracer transport. The third column of Table 6.3-1 indicates which modeling approach was used for each tracer test. 
For both modeling approaches, it was assumed that tracer transport in fractures can be described by the one-dimensional advection-dispersion equation with one-dimensional diffusion occurring into the surrounding matrix perpendicular to the flow direction in fractures. The geometry of the matrix is assumed to be planar in the RELAP/MULTRAN codes, and it is spherical in MOENCH.vi and its sister codes. Both assumptions are reasonable given the unknown and probably highly-variable geometry of the matrix blocks. Each model can be used to simulate single-porosity transport behavior by simply specifying a matrix with zero porosity. Details of the two modeling approaches are provided in Appendix D.

The Moench model was typically applied to tracer tests in which only a single nonsorbing (also called "nonreactive" or "conservative") tracer was injected. The only exception was a test in the Prow Pass interval in which two nonsorbing tracers with different diffusion coefficients were injected. The interpretation of single-tracer tests was inherently less well-constrained than the interpretation of tests involving multiple tracers. Multiple-tracer tests involving both nonsorbing and reactive tracers were interpreted using the RELAP/MULTRAN codes. The test involving two nonsorbing tracers in the Prow Pass interval was interpreted using both modeling approaches to highlight some of the differences between the approaches and to assess the uncertainty in transport parameter estimates resulting from these differences. This topic is discussed in greater detail in Appendix D5.2.

The process of obtaining transport parameter estimates from the tracer breakthrough curves in multiple-tracer tests was as follows:

- First, the breakthrough curves of the two nonsorbing solute tracers with different diffusion coefficients (pentafluorobenzoic acid or pentafluorobenzoate [PFBA] and bromide) were simultaneously fitted to obtain estimates of physical transport parameters for the flow system (e.g., mean residence time, longitudinal dispersivity, and matrix diffusion parameters).

- The transport parameters determined for the nonsorbing tracers were assumed to apply to the reactive tracer, lithium (with adjustments to account for differences in diffusion coefficient), and the lithium response was fitted by adjusting only the matrix and fracture retardation factors to obtain estimates of these parameters.

- Colloid transport parameters were estimated by assuming that the transport parameters obtained for the nonsorbing tracers also applied to the polystyrene microsphere tracers, except that the microspheres did not diffuse into the matrix. Attachment and detachment rate constants were then estimated by adjusting filtration rate constants and retardation factors to fit to the microsphere breakthrough curves (the filtration rate constant was then divided by the retardation factor minus one to obtain an estimate of the product of the detachment rate constant and the fracture aperture).

\subsubsection{Tracer Test Interpretations: Conceptual Transport Model Implications}

The solute tracer breakthrough curves and model fits for the multiple tracer tests involving the reactive tracer lithium in the lower Bullfrog interval and the Prow Pass interval at the C-wells are shown in Figures 6.3-2 and 6.3-3, respectively. The double-peaked tracer responses in the lower 
Bullfrog test (Figure 6.3-2) are attributed to a small fraction of the injected tracer mass entering relatively fast flow pathways in the upper portion of the injection interval, resulting in the early peaks, while the majority of the mass traveled through slower pathways in the lower portion of the injection interval, resulting in the later peaks. A detailed discussion of this explanation and of the interpretation of this test are provided in Appendix D.

Even without quantitative parameter estimation, it is clear that the tracer responses in both the lower Bullfrog and the Prow Pass tests are consistent with a dual-porosity conceptual transport model for the fractured volcanic tuffs illustrated in Figure 6.3-1. It is not possible to account for the differences in the bromide and PFBA responses or the relatively small time attenuation but significant concentration attenuation of the lithium responses relative to the nonsorbing tracers (in the Prow Pass test and the first peak of the Bullfrog test) without invoking diffusion between flowing fractures and stagnant matrix water. Some diffusion into stagnant water within fractures (e.g., dead-end fractures or along rough fracture walls) cannot be ruled out. However, if the stagnant water were primarily in fractures, the surface area for sorption would be limited, and it is unlikely that there would be as much concentration attenuation of lithium relative to the nonsorbing solutes as observed in the tracer tests. The large surface-area-to-volume ratio necessary to result in the large observed concentration attenuation of lithium is plausible only if a significant fraction of the stagnant water is in matrix pores. Thus, the tracer tests indicate that a dual-porosity conceptual transport model is applicable in the fractured volcanic tuffs in both high-transmissivity (lower Bullfrog) and low-transmissivity (Prow Pass) intervals. 

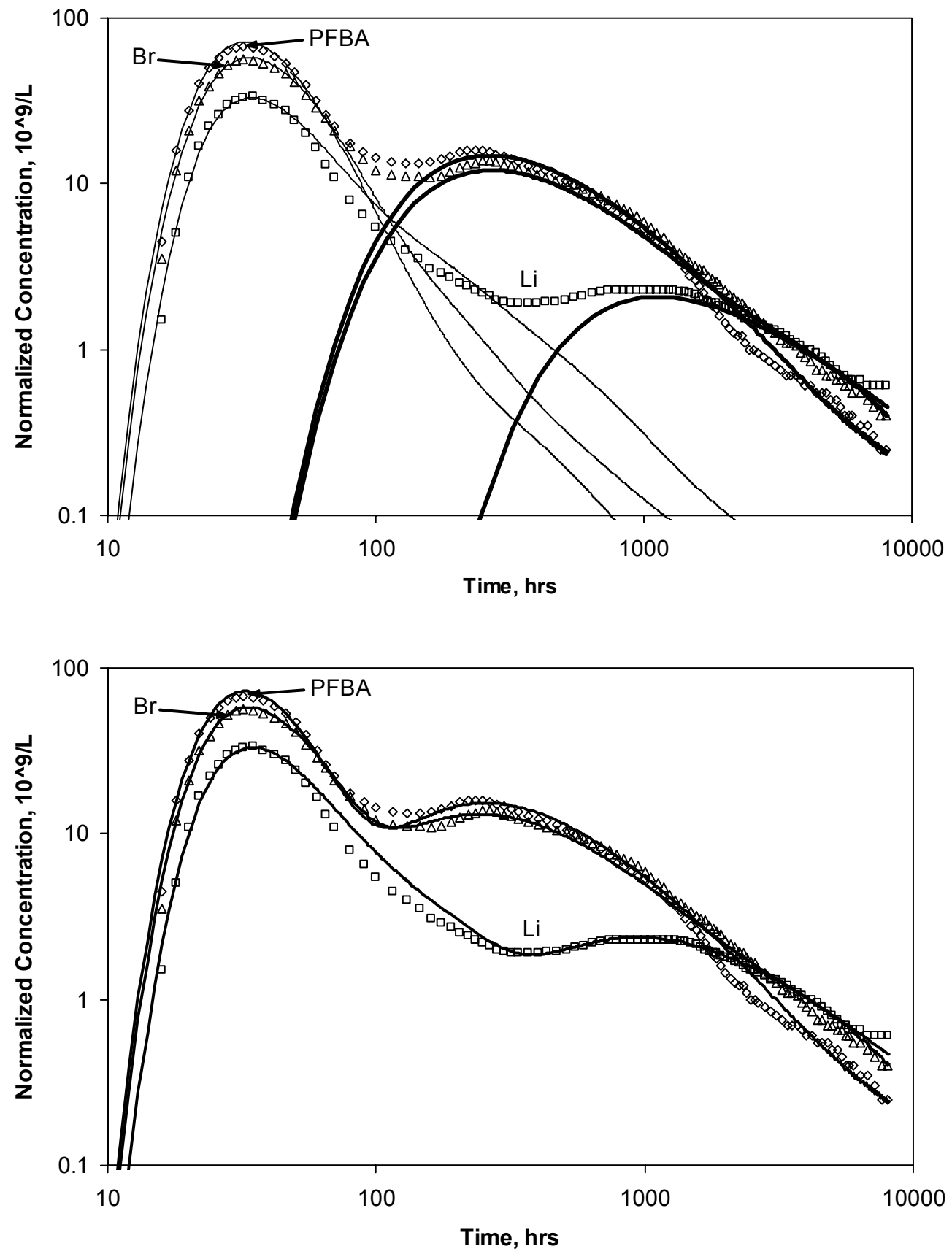

Source: DTNs: LA0007PR831231.001 [DIRS 156043] (raw data), LA0410PR831231.001 [DIRS 171899] (normalized concentrations).

Output DTN: LA0303PR831231.003 (model).

NOTE: $\quad$ The upper plot shows individual fits to first and second tracer peaks (MULTRAN V 1.0

(STN: 10666-1.0-00 [DIRS 159068]) and RELAP V 2.0 (STN: 10551-2.0-00 [DIRS 159065], respectively), and the lower plot shows composite fits. For clarity, the data points shown are a subset of the actual data.

Figure 6.3-2. Solute Tracer Breakthrough Curves in the Multiple-Tracer Test in the Lower Bullfrog Tuff and RELAP/MULTRAN Fits to the Breakthrough Curves 


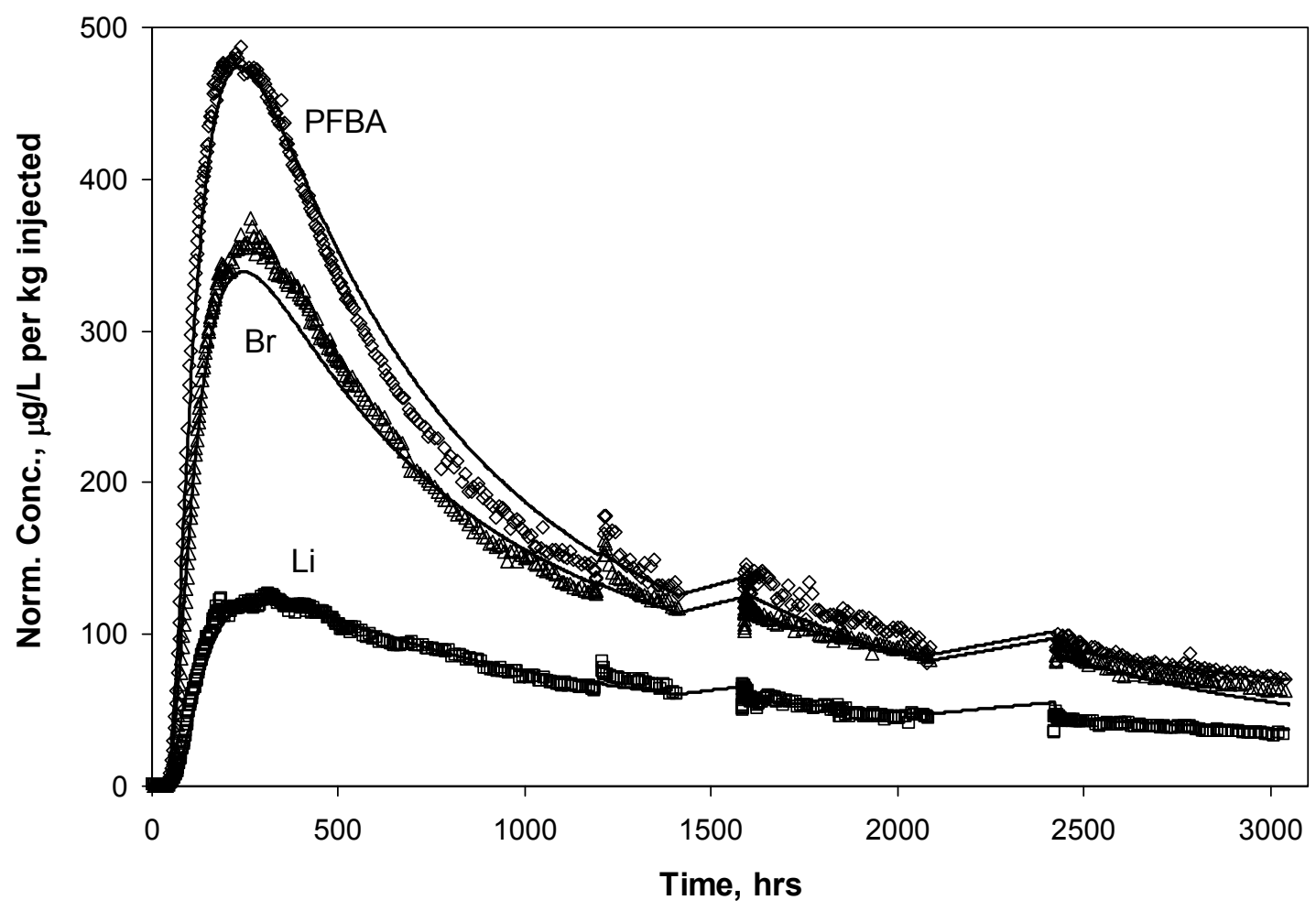

Source: DTNs: LAPR831231AQ99.001 [DIRS 140134] (raw data), LA0410PR831231.001 [DIRS 171899] (normalized concentrations).

Output DTN: LA0303PR831231.003 (model).

Figure 6.3-3. Solute Tracer Breakthrough Curves in the Multiple-Tracer Test in the Prow Pass Tuff and RELAP/MULTRAN Fits to the Breakthrough Curves

Flow anisotropy at the scale of the C-wells was examined by comparing tracer responses resulting from injections into well $\mathrm{c} \# 1$ and into either well $\mathrm{c} \# 2$ or $\mathrm{c} \# 3$ (while pumping the other well). Table 6.3-2 lists the ratios of peak arrival times or first arrival times for nonsorbing tracers between $\mathrm{c} \# 1$ and the production well (either $\mathrm{c} \# 2$ or $\mathrm{c} \# 3$ ) and between $\mathrm{c} \# 2$ and $\mathrm{c} \# 3$ for all tests in which a comparison was possible. For a homogeneous, isotropic medium, the arrival times under radial flow conditions are expected to vary as $r_{\mathrm{L}}^{2}$, the distance squared between injection and production well (Guimerà and Carrera 2000 [DIRS 156830], Equation 6). The ratios of $r_{\mathrm{L}}^{2}$ values corresponding to each case are also listed in Table 6.3-2. If the ratio of arrival times is less than the ratio of distances squared, then the direction from c\#1 to the production well is a preferred flow orientation; on the other hand, if the ratio of arrival times is greater than the ratio of distances squared, then the direction from $\mathrm{c} \# 2$ to $\mathrm{c} \# 3$ is a preferred flow orientation. Furthermore, the ratio of arrival times divided by the ratio of distances squared can be taken as a measure of the flow anisotropy ratio for the two different directions relative to the production well (note that these two directions are not strictly orthogonal). 
Table 6.3-2. Ratios of Observed Tracer Arrival Times and Distances Squared, as well as Apparent Flow Anisotropy Ratios, for C-Wells Nonsorbing Tracer Tests

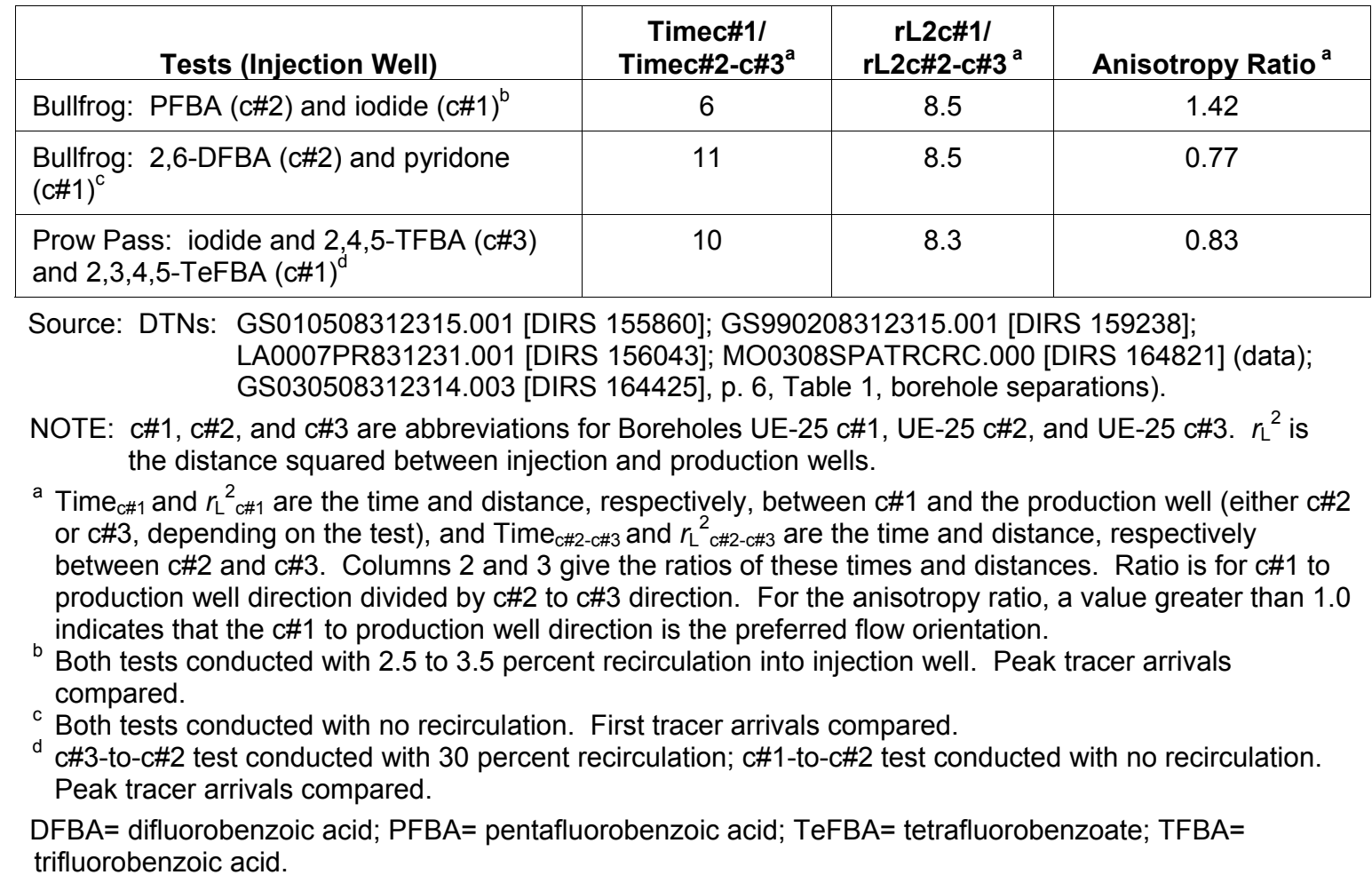

The ratios of tracer arrival times and $r_{\mathrm{L}}{ }^{2}$ values are in reasonably good agreement in all three cases, with apparent flow anisotropy ratios (c\#1 to production well direction divided by c\#2-c\#3 direction) varying from 0.77 to 1.42 . These relatively small ratios suggest that flow anisotropy at the scale of the $\mathrm{C}$-wells may be relatively small despite the apparent orientation of the fracture network in the general direction of $\mathrm{c} \# 1$ to $\mathrm{c} \# 2$ (Geldon 1993 [DIRS 101045], pp. 43 to 51). The apparent flow anisotropy ratios deduced from the tracer arrival times should be carefully distinguished from the flow anisotropy ratios discussed in Section 6.2.6, which were based on drawdown observations over much larger scales.

\subsubsection{Tracer Test Interpretations: Transport Parameter Estimates at the C-Wells}

Estimates of transport parameters that can be used directly in solute transport models were derived from the best-fitting model parameters associated with the model fits shown in Figures 6.3-2 and 6.3-3, as well as from other model fits discussed in Appendix D. The parameter estimates associated with the fits of Figures 6.3-2 and 6.3-3 are presented in Table 6.3-3 as ranges of values consistent with the tracer test interpretation(s). Additional discussion of these ranges and how they were derived is provided in Appendix D. Transport parameter estimates obtained from other tracer tests were generally consistent with the ranges presented in Table 6.3-3 when differences in assumptions regarding tracer residence times in injection intervals were accounted for (Appendix D5.2). 
Table 6.3-3. Transport Parameter Estimates Deduced from the Lower Bullfrog and Prow Pass Multiple-Tracer Tests

\begin{tabular}{|l|l|l|l|l|}
\hline \multirow{2}{*}{ Parameter } & \multicolumn{2}{c|}{ Prow Pass } & \multicolumn{2}{c|}{ Bullfrog } \\
\cline { 2 - 5 } & Lower Bound & Upper Bound & Lower Bound & Upper Bound \\
\hline $\begin{array}{l}\text { Effective flow porosity (Eq. 10, Appendix } \\
\text { D, Section D4.8.5) }\end{array}$ & 0.003 & 0.006 & $0.003^{\mathrm{a}}$ & $0.031^{\mathrm{a}}$ \\
\hline Longitudinal dispersivity, $\mathrm{m}^{\mathrm{b}}$ & 13.0 & 61.5 & 3.2 & 62.5 \\
\hline MTC, $\frac{\phi}{b} \sqrt{D_{\mathrm{m}}}$, for radionuclides $\left(\mathrm{sec}^{-1 / 2}\right)^{\mathrm{c}}$ & 0.00054 & 0.00095 & 0.00027 & 0.0015 \\
\hline Fracture aperture $(\mathrm{cm})$ & 0.18 & 1.05 & 0.081 & 1.31 \\
\hline Fracture spacing $(\mathrm{cm})$ & 6.4 & $\infty$ & 4.4 & $\infty$ \\
\hline Ratio of stagnant to flowing water volumes & 3.1 & $\infty$ & 2.1 & $\infty$ \\
\hline Colloid filtration rate constant, $1 / \mathrm{hr}^{\mathrm{d}}$ & 0.043 & 0.2 & 0.04 & 0.175 \\
\hline Colloid detachment rate const., $1 / \mathrm{cm}^{\mathrm{h}} \mathrm{hr}^{\mathrm{d}}$ & 0.00015 & 0.00025 & 0.0002 & 1.08 \\
\hline
\end{tabular}

Output DTNs: LA0303PR831231.003, LA0303PR831231.005.

NOTE: These values above are provided as ranges of values; see Appendix $D$ for explanations.

${ }^{a}$ These estimates assume that 75 percent of the production flow was associated with flow pathways that resulted in the first tracer peak and 25 percent was associated with the second tracer peak (based on flow survey information (DTN: GS931008312313.016 - qualified for use in this report in Appendix L [DIRS 148173]).

b Lower bounds assume Peclet numbers for radial flow and 30-m travel distance; upper bounds assume Peclet numbers for linear flow and interval thicknesses as travel distances (see Table 6.1-1 for actual borehole separations and interval thicknesses; also DTN: GS030508312314.003 [DIRS 164425]), p. 6, Table 1).

${ }^{c}$ MTC is the matrix diffusion mass transfer coefficient. It is assumed that bromide and pentafluorobenzoate effectively bound molecular sizes and diffusion coefficients of radionuclide solution species.

${ }^{d}$ Based on interpretations of polystyrene microsphere breakthrough curves; see Appendix D for details.

\subsubsection{Laboratory Testing to Support C-wells Field Tracer Tests}

An additional objective of tracer testing at the $\mathrm{C}$-wells complex was to assess the applicability of laboratory-derived tracer transport parameters to field-scale transport predictions. This objective is important because radionuclides cannot be tested in the field, so favorable comparisons of laboratory- and field-scale transport of nonradioactive tracers can lend credibility to the practice of using laboratory-derived radionuclide transport parameters in field-scale predictive simulations. Much of this laboratory testing focused on the sorption characteristics and reactive transport behavior of lithium ion. Comparison of lithium sorption behavior at laboratory and field scales was considered especially important because the Yucca Mountain TSPA-LA relies heavily on radionuclide sorption parameters determined from laboratory experiments to predict field-scale reactive transport behavior in the saturated zone.

The laboratory experiments also provided information useful in constraining the interpretations of the field tracer tests (e.g., direct estimates of matrix diffusion coefficients), and they provided valuable insights into the scaling behavior of transport processes and parameters in the saturated volcanic tuffs. Laboratory testing conducted in support of $\mathrm{C}$-wells tracer testing included:

- Batch sorption tests to determine lithium sorption parameters associated with various C-wells lithologies (Appendix E, Section E1)

- Batch sorption tests to verify that bromide and PFBA do not sorb to C-wells tuffs - DTN: LA0302PR831231.001 [DIRS 162605] 
- Diffusion cell experiments to determine matrix diffusion coefficients of PFBA and bromide in various C-wells lithologies (Appendix E, Section E2)

- Matrix porosity and permeability measurements for various C-wells lithologies (Appendix E, Section E2)

- Lithium bromide tracer tests in columns packed with crushed Bullfrog tuff to determine lithium transport characteristics under flowing conditions (Appendix E, Section E3.1)

- Multiple-tracer experiments at different flow rates in fractured C-wells cores to determine tracer transport characteristics/parameters in fractured tuffs at much smaller time and length scales than in the field (also to determine if lithium transport behavior in laboratory scale fractures is consistent with batch sorption measurements onto same rock types) (Section Appendix E, E3.2).

Details of the conduct and results of all laboratory tests are provided in Appendix E. Because of its importance for TSPA, a comparison of laboratory- and field-derived partition coefficients ( $K_{d}$ values) for lithium is provided in Table 6.3-4. It is apparent that the lithium $K_{\mathrm{d}}$ values deduced from the field tracer tests (assuming any given lithologic unit) are consistently larger than the corresponding $K_{\mathrm{d}}$ values measured at the lowest lithium concentrations in the laboratory. A likely explanation for this result is that the lithium in the field tests came into contact mineral surfaces that were not present or were under-represented in the small-scale laboratory tests. These results suggest that the use of laboratory-derived $K_{\mathrm{d}}$ values to predict sorbing species transport in the saturated fractured tuffs near the C-wells location would tend to underpredict the amount of sorption experienced by the species in the field. 
Table 6.3-4. Lithium Partition Coefficients Derived from Field Tracer Tests and Laboratory Measurements

\begin{tabular}{|c|c|c|}
\hline Parameter & Field $K_{\mathrm{d}}(\mathrm{mL} / \mathrm{g})$ & Laboratory $K_{d}{ }^{a}(\mathrm{~mL} / \mathrm{g})$ \\
\hline Prow Pass matrix $K_{\mathrm{d}}$ assuming Central Prow Pass Tuff & 0.66 & $\begin{array}{l}0.13 \\
(0.26 \text { at infinite dilution })\end{array}$ \\
\hline Prow Pass matrix $K_{\mathrm{d}}$ assuming Lower Prow Pass Tuff & 1.68 & $\begin{array}{l}0.084 \\
(0.44 \text { at infinite dilution) }\end{array}$ \\
\hline $\begin{array}{l}\text { Bullfrog matrix } K_{d} \text { in Pathway } 1 \text { assuming Central Bullfrog } \\
\text { Tuff }{ }^{b}\end{array}$ & $0.58-4.1$ (nonlinear) $^{\mathrm{C}}$ & $\begin{array}{l}0.19 \\
(0.44 \text { at infinite dilution })\end{array}$ \\
\hline $\begin{array}{l}\text { Bullfrog matrix } K_{d} \text { in Pathway } 1 \text { assuming Lower Bullfrog } \\
\text { Tuff }{ }^{\text {b }}\end{array}$ & $0.58-4.1$ (nonlinear) $^{\mathrm{c}}$ & $\begin{array}{l}0.32 \\
(1.64 \text { at infinite dilution) }\end{array}$ \\
\hline $\begin{array}{l}\text { Bullfrog matrix } K_{d} \text { in Pathway } 2 \text { assuming Central Bullfrog } \\
\text { Tuff }{ }^{\mathrm{b}}\end{array}$ & 0.74 & $\begin{array}{l}0.19 \\
(0.44 \text { at infinite dilution })\end{array}$ \\
\hline $\begin{array}{l}\text { Bullfrog matrix } K_{d} \text { in Pathway } 2 \text { assuming Lower Bullfrog } \\
\text { Tuff }{ }^{\mathrm{b}}\end{array}$ & 3.04 & $\begin{array}{l}0.32 \\
\text { (1.64 at infinite dilution) }\end{array}$ \\
\hline
\end{tabular}

Output DTN: LA0303PR831231.005.

NOTE: These lithium partition coefficients $\left(K_{d}\right.$ values) were derived from field tracer tests assuming transport in different lithologies within the test intervals.

a Values at "infinite dilution" obtained from Langmuir isotherm fits to the data (asymptotic slope at very low concentrations (i.e., $K_{\mathrm{L}} S_{\max }-$ see Section 6.3.7.2 for definitions). Other values obtained from a simple linear fit to the entire range of data.

b "Pathway 1" refers to pathways that resulted in the first tracer peak in the Bullfrog reactive tracer test, and "Pathway 2" refers to pathways that resulted in the second peak in this test. $K_{\mathrm{d}}$ values were calculated from the smallest matrix retardation factors obtained from alternative interpretations of the test.

${ }^{c}$ The first number corresponds to a $K_{\mathrm{d}}$ value calculated at approximately $600 \mathrm{mg} / \mathrm{L} \mathrm{Li}{ }^{+}$using the threecomponent cation exchange model parameters yielding the best fit to the first lithium peak (see Section E3.1.3 for description of three-component model); the second number corresponds to a $K_{\mathrm{d}}$ value calculated at 0.5 $\mathrm{mg} / \mathrm{L} \mathrm{Li}{ }^{+}$concentration using the same model parameters. In obtaining the field parameters, a matrix porosity of 0.10 was assumed in the MULTRAN V 1.0 (STN: 10666-1.0-00 [DIRS 159068]) simulations (approximately equal to that of the Central Bullfrog Tuff). The $K_{d}$ values for pathway 1 would increase if a greater matrix porosity was assumed, and they would decrease if a smaller matrix porosity was assumed.

The scaling of longitudinal dispersivities and matrix diffusion mass transfer coefficients (MTC) values is also important for TSPA, as abstractions of these parameters for use in field-scale predictive modeling should account for apparent trends observed in laboratory and field tracer tests. The apparent scaling of these two parameters is discussed in detail at the end of Appendix E.

\subsubsection{Limitations and Uncertainties}

A detailed treatment of the limitations and uncertainties associated with the transport parameter estimates derived from $\mathrm{C}$-wells tracer test interpretations is provided at the end of Appendix D. Limitations and sources of uncertainty included the following:

- Accuracy and precision of tracer chemical analyses, which are considered to have relatively minor influence on the test interpretations.

- Uncertainties associated with assumptions in the interpretive methods that were not strictly met or could not be verified:

- The assumption of radial or linear (constant velocity) flow in a homogeneous, isotropic system, which results in highly uncertain effective flow porosity estimates. 
- The assumption of steady flow conditions - there were degradations in pump performance and power outages that resulted in flow rate changes and interruptions.

- The assumption of complete evacuation of tracers from the injection intervals in each test - this was quite unlikely, especially when recirculation was not employed.

- The assumption that mean tracer residence times in the injection intervals were long enough that the apparent tracer travel times were dominated by the slow release of tracers from the injection well rather than by their travel time(s) in the aquifer.

- The assumption that the natural gradient had no influence on the tracer breakthrough curves.

- The assumption that there was no flow at all in the matrix.

- The assumption that fractures are parallel-plate flow channels and that the matrix is either composed of rectangular blocks or spheres.

- Uncertainties associated with the nonuniqueness of test interpretations.

Most of these uncertainties cannot be quantitatively addressed. However, the uncertainty associated with the assumption of a very slow evacuation rate of tracers from the injection interval is addressed at length in Appendix D. The nonuniqueness of test interpretations is also quantitatively addressed in Appendix D, and it is summarized here because of its importance.

A prime example of nonuniqueness of test interpretations is that long tails in tracer responses can be interpreted as either being the result of large longitudinal dispersion or significant matrix diffusion. When only a single conservative tracer is used in a test, this distinction is essentially impossible to make. Figure 6.3-4 shows three RELAP V 2.0 (STN: 10551-2.0-00 [DIRS 159065]) fits to the iodide response in the Prow Pass tracer test in which 2,4,5-TFBA was also injected. 


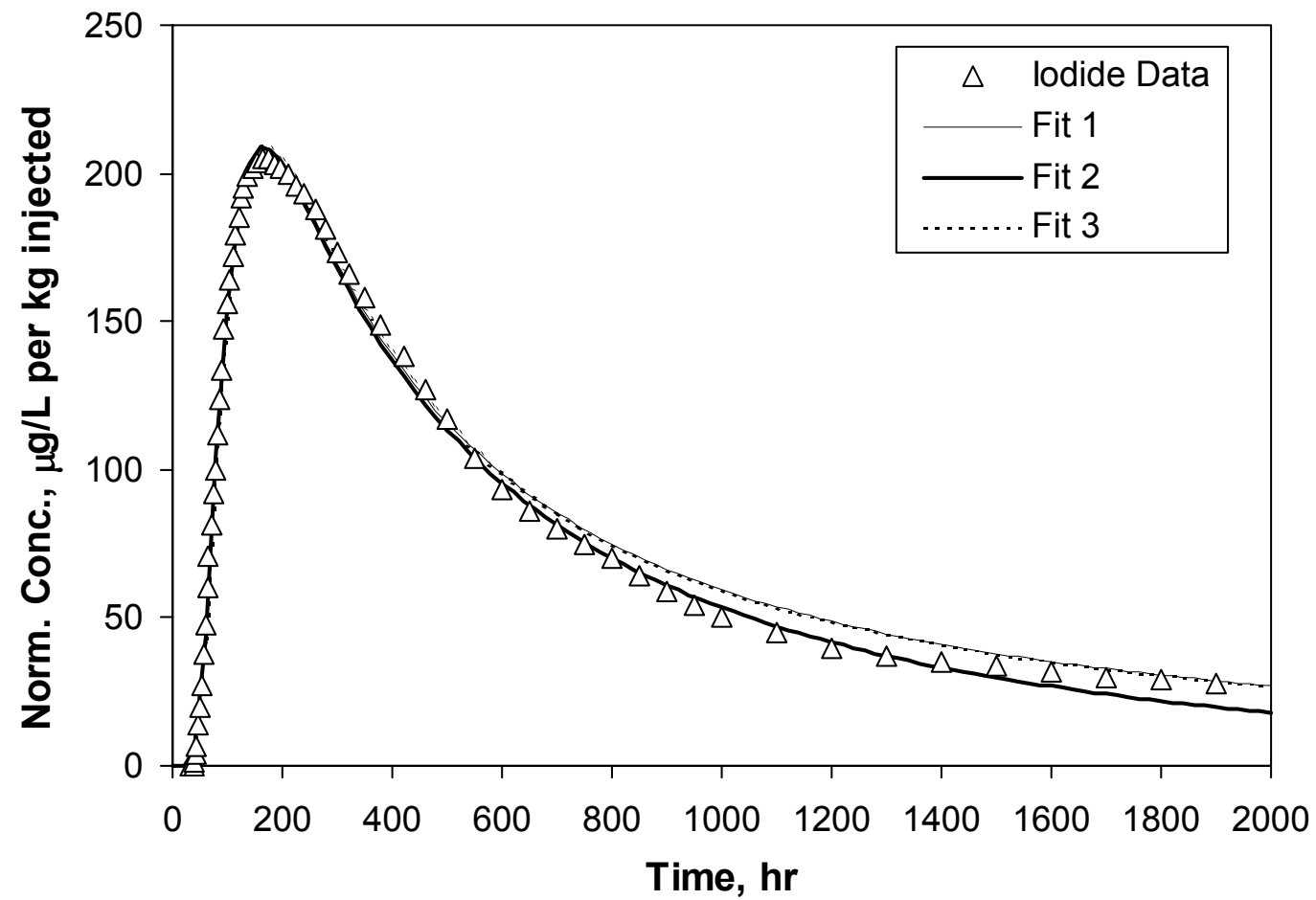

Output DTN: LA0304PR831231.001.

NOTE: Data points represent a subset of the actual data. Model parameters associated with the fits are listed in Table 6.3-5. Note that Fits 1 and 3 essentially fall on top of each other.

Figure 6.3-4. RELAP Fits to lodide Data from Prow Pass Tracer Test in which 2,4,5-TFBA Was Also Injected

These fits, which were obtained by arbitrarily fixing the Peclet number and then allowing the mean residence time, mass fraction, and matrix diffusion MTC to be adjusted to achieve a fit, are arguably equally good. However, the best-fitting parameters, listed in Table 6.3-5, vary by 2 to 4 orders of magnitude, and it is not even possible to distinguish between a singleporosity and a dual-porosity system (MTC can be zero).

In multiple-tracer tests, nonuniqueness of interpretations was minimized by simultaneously fitting the tracer responses using known ratios of diffusion coefficients as constraints on the relative matrix diffusion of different tracers. However, even after taking these measures, there is considerable nonuniqueness associated with tracer test interpretations.

A similar exercise in determining nonuniqueness of test interpretations was conducted for each of the multiple-tracer responses (i.e., two in the Prow Pass Tuff and two in the Bullfrog Tuff (two peaks in this case)). If an arbitrary criterion is established that any sum of squares of differences between model and data less than 1.5 times the minimum sum of squares difference is an equally good fit to the data, then the ranges of parameter values that provide equally good fits to the data sets are listed in Table 6.3-6. Fits having sum-of-squares differences of less than a factor of 1.5 times the minimum are essentially equally good in appearance; and when one considers that the best fits are dependent on data scatter and on variability in data point density in the breakthrough curves (e.g., more data in tails as opposed to peaks), then a good case can be 
made that the fits are equally plausible. Figure 6.3-5 shows the fits to the iodide and 2,4,5-TFBA data from the Prow Pass tracer test that had the lowest and highest optimized sum-of-squares differences (with the highest still being within a factor of 1.5 of the lowest).

Although there are significant uncertainties in the parameter estimates of Table 6.3-6, the uncertainties are far smaller than when there is only a single tracer breakthrough curve to interpret (i.e., Table 6.3-5). For this reason, transport parameter estimates from multiple-tracer tests should be given more weight in the development of transport parameter distributions than parameter estimates from single-tracer tests. Additional discussion of this examination of nonuniqueness of test interpretations is provided in Appendix D5.3.

The transport parameter ranges of Tables 6.3-3 and 6.3-6, while not necessarily rigorously quantified, are considered to be very effectively captured in the parameter uncertainty distributions specified in Saturated Zone Flow and Transport Model Abstraction (BSC 2004 [DIRS 170042]). These transport parameter uncertainty distributions, which are ultimately propagated forward in TSPA, consistently encompass the ranges of estimates in Tables 6.3-3 and 6.3-6. The distributions even tend to be skewed such that the ranges obtained from saturated zone tracer testing often fall in the non-conservative ends of the distributions. For example, the flow porosity estimates of Table 6.3-3 are significantly higher than the lower limit obtained from the distributions of flowing interval spacing and fracture aperture, two parameters that combine to define the effective flow porosity in fractured tuffs in Saturated Zone Flow and Transport Model Abstraction (BSC 2004 [DIRS 170042]). Thus, the uncertainties inherent in transport parameter estimates obtained from tracer testing are typically propagated forward in TSPA in a conservative manner.

Table 6.3-5.Transport Parameters Obtained from RELAP Fits to lodide Data Shown in Figure 6.3-4

\begin{tabular}{|l|c|c|c|}
\hline \multicolumn{1}{|c|}{ Parameter } & Fit 1 & Fit 2 & Fit 3 \\
\hline Mass Fraction & 0.23 & 0.11 & 0.24 \\
\hline Mean Res. Time, $\tau$, hr (linear flow) & 50 & 700 & 9,000 \\
\hline Peclet number, Pe (linear flow) & 17 & 1.3 & 0.1 \\
\hline lodide MTC, $\frac{\phi}{b} \sqrt{D_{\mathrm{m}}}, \mathrm{sec}^{-1 / 2}$ & 0.01 & 0.0 & 0.0001 \\
\hline
\end{tabular}

Output DTN: LA0304PR831231.001.

Table 6.3-6. Transport Parameter Ranges from Multiple-Tracer Tests at the C-Wells

\begin{tabular}{|l|c|c|c|c|}
\hline \multicolumn{1}{|c|}{ Parameter } & BF, Peak 1 & BF, Peak 2 & PP, I-TFBA & PP, Br-PFBA \\
\hline Mass Fraction & $0.11-0.13$ & $0.56-0.7$ & $0.17-0.3$ & $0.56-0.82$ \\
\hline Mean Res. Time, $\tau$, hr (linear flow) & $320-420$ & $700-1,800$ & $340-1,340$ & $600-1,900$ \\
\hline Peclet number, Pe (linear flow) & $5-8$ & $0.9-2.4$ & $0.6-2.6$ & $0.6-1.9$ \\
\hline Halide MTC, $\frac{\phi}{b} \sqrt{D_{\mathrm{m}}}, \mathrm{sec}^{-1 / 2}$ & $0.000837-$ & $0.000245-$ & $0.000775-$ & $0.000632-$ \\
& 0.00224 & 0.000775 & 0.00122 & 0.00122 \\
\hline
\end{tabular}

Output DTN: LA0304PR831231.001.

$\mathrm{BF}=\mathrm{Bullfrog}$; PFBA=pentafluorobenzoic acid; PP=Prow Pass; TFBA= trifluorobenzoic acid. 


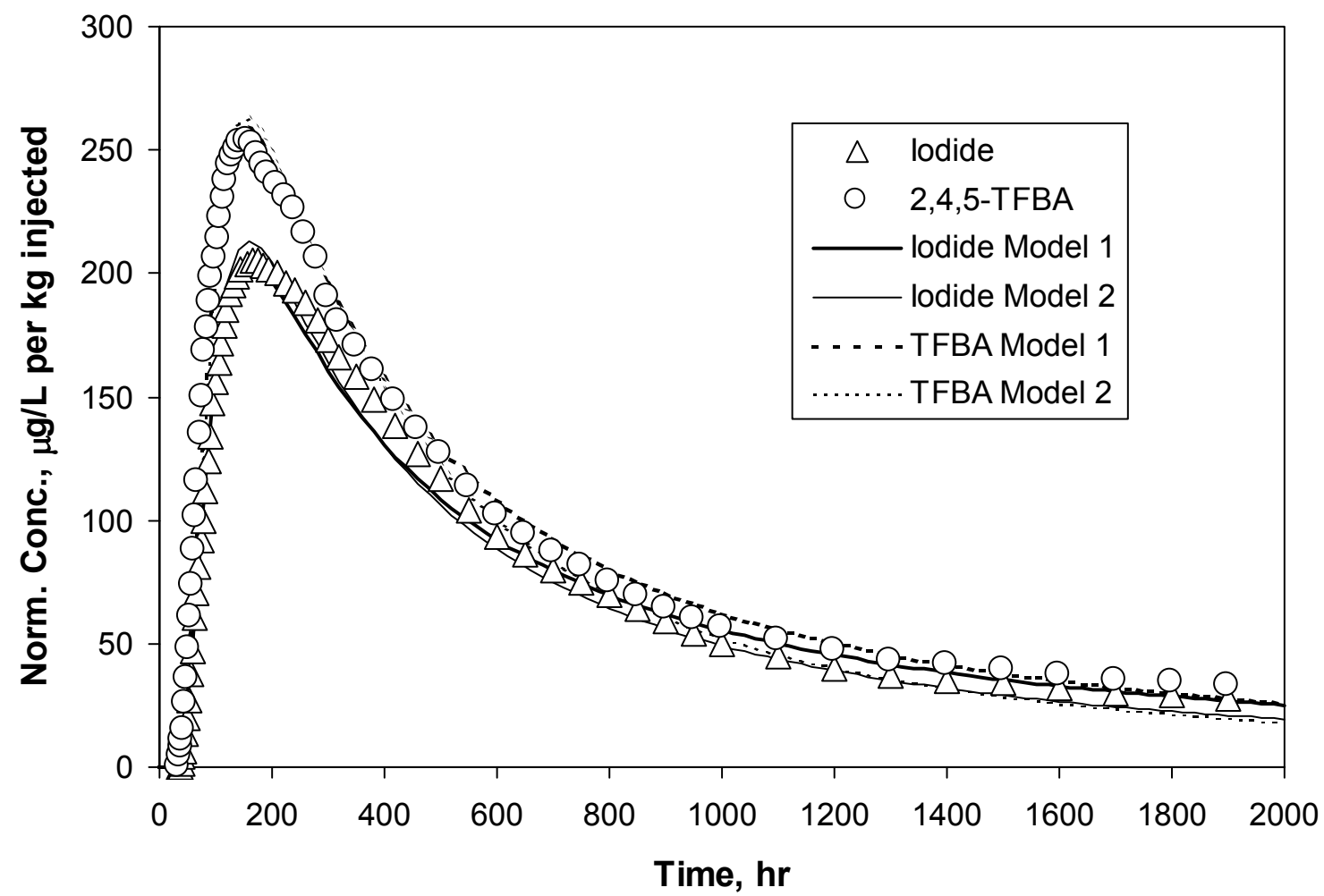

Output DTN: LA0304PR831231.001.

NOTE: Data points represent a subset of the actual data. Bold curves represent the best fits to data. The sum of squares differences between data and models are within a factor of 1.5 of each other.

Figure 6.3-5. RELAP Fits to the lodide and 2,4,5-TFBA Data from the Prow Pass Tracer Test

\subsection{HYDROLOGIC PROPERTIES OF ALLUVIUM (ALLUVIAL TESTING COMPLEX)}

\subsubsection{Introduction}

This section of the report (1) summarizes the hydraulic tests conducted at the ATC (NC-EWDP-19D, 19IM1, and 19IM2) and the interpretive analyses performed on the test data; (2) discusses the implications of the test interpretations, including implications for conceptual flow modeling in the alluvium and hydrologic parameter estimates; and (3) discusses the uncertainties and limitations associated with the hydrologic properties determined from the test analyses. Details of hydraulic testing at the ATC are provided in Appendix F.

\subsubsection{Summary of ATC Hydraulic Testing to Determine Hydrologic Properties}

Table 6.4-1 summarizes the hydraulic testing conducted at the ATC over a two-year period from July 2000 to July 2002. Most of the testing was conducted in a single-well configuration in NC-EWDP-19D before NC-EWDP-19IM1 and 19IM2 were completed.

The single-well tests included separate tests in which each of the four intervals completed in the alluvium in NC-EWDP-19D were isolated (by inflatable packers) and pumped, as well as a test 
in which the four intervals completed in the alluvium were simultaneously pumped as a single interval. These tests provided valuable insights into the relative transmissivities of the four screened intervals completed in the alluvium at this location as well as insights into the general characteristics of the alluvium flow system. However, later cross-hole hydraulic testing conducted after 19IM1 and 19IM2 were completed indicated that well losses in 19D resulted in poor quantitative estimates of storativity and transmissivity in the single-well tests. Therefore, storativity and transmissivity in the alluvium were estimated exclusively from water-level drawdowns measured in 19IM2 during pumping of 19D (19IM1 was also monitored, but the data were nonqualified (non-Q). The storativity and transmissivity estimates were based on a single test in which 19D was pumped from all four combined intervals completed in the alluvium while 19IM2 was monitored in a configuration in which all four alluvium intervals were combined.

Although not considered a hydraulic test, a borehole gravimeter survey of NC-EWDP-19D in September 2000 provided direct estimates of in situ bulk density and hence indirect estimates of total porosity as a function of depth at the ATC location. Total porosity of the alluvium was also estimated from storativity and barometric efficiency estimates derived from hydraulic tests. These total porosity estimates serve as useful upper bounds for alluvium effective flow porosity in transport models. Details are provided in Appendix F.

\subsubsection{Hydraulic Test Interpretation Methods}

All single-well tests conducted in NC-EWDP-19D had drawdown curves that conformed to the Neuman (1975 [DIRS 150321]) unconfined-aquifer solution for a single-porosity system, and they were, therefore, interpreted using this solution. However, quantitative storativity and transmissivity estimates from cross-hole drawdown responses in 19IM2 when 19D was pumped were obtained using the Theis (1935 [DIRS 150327]) confined-aquifer solution for a single-porosity system (Section 6.4.4). The match of the Theis (1935 [DIRS 150327]) solution to the drawdown in this cross-hole hydraulic test is shown in Figure 6.4-1.

Table 6.4-1. Highlights of Testing at the ATC to Determine Hydrologic Properties (See Appendix F for Complete Description of Tests)

\begin{tabular}{|l|l|}
\hline \multicolumn{1}{|c|}{ Dates } & \multicolumn{1}{c|}{ Testing Summary } \\
\hline July 2000 & $\begin{array}{l}\text { Single-well hydraulic test in all four combined intervals completed in the alluvium in } \\
\text { NC-EWDP-19D }\end{array}$ \\
\hline August 2000 & $\begin{array}{l}\text { Single-well hydraulic test in fourth screened interval from the top of NC-EWDP-19D } \\
\text { (isolated) }\end{array}$ \\
\hline September 2000 & $\begin{array}{l}\text { Single-well hydraulic test in third screened interval from the top of NC-EWDP-19D } \\
\text { (isolated) }\end{array}$ \\
\hline September 2000 & $\begin{array}{l}\text { Borehole gravimeter survey to obtain direct estimates of in situ bulk density and indirect } \\
\text { estimates of in situ total porosity as a function of depth }\end{array}$ \\
\hline October 2000 & Single-well hydraulic test in uppermost screened interval (isolated) of NC-EWDP-19D \\
\hline $\begin{array}{l}\text { October to November } \\
2000\end{array}$ & $\begin{array}{l}\text { Single-well hydraulic test in second screened interval from the top of NC-EWDP-19D } \\
\text { (isolated) }\end{array}$ \\
\hline December 2001 & $\begin{array}{l}\text { Single-well hydraulic test in which screens 5-7 of NC-EWDP-19D (completed in rocks } \\
\text { underlying the alluvium) were pumped while screen 4 and combined screens 1-3 were } \\
\text { monitored for drawdown }\end{array}$ \\
\hline
\end{tabular}


Table 6.4-1. Highlights of Testing at the ATC to Determine Hydrologic Properties (See Appendix F for Complete Description of Tests) (Continued)

\begin{tabular}{|l|l|}
\hline \multicolumn{1}{|c|}{ Dates } & \multicolumn{1}{c|}{ Testing Summary } \\
\hline January 2002 & $\begin{array}{l}\text { Single-well hydraulic test in which screen 5 of NC-EWDP-19D was pumped while screen } \\
\text { 4, combined screens 6-7, and combined screens 1-3 were monitored for drawdown }\end{array}$ \\
\hline January 2002 & $\begin{array}{l}\text { Single-well hydraulic test in which screen 4 of NC-EWDP-19D was pumped while screen } \\
\text { 3, combined screens 5-7, and combined screens 1-2 were monitored for drawdown }\end{array}$ \\
\hline January 2002 & $\begin{array}{l}\text { Cross-hole hydraulic test in which combined screens 1-4 (all screens completed in the } \\
\text { alluvium) of NC-EWDP-19D were pumped while all four alluvium intervals in 19IM1 and } \\
\text { 19IM2 were isolated and monitored for drawdown }\end{array}$ \\
\hline $\begin{array}{l}\text { January to February } \\
2002\end{array}$ & $\begin{array}{l}\text { Cross-hole hydraulic test in which combined screens 1-4 (all screens completed in the } \\
\text { alluvium) of NC-EWDP-19D were pumped while all four alluvium intervals in 19IM1 were } \\
\text { isolated and monitored and all four alluvium intervals in 19IM2 were combined and } \\
\text { monitored as a single interval (for drawdown) }\end{array}$ \\
\hline May to July 2002 & $\begin{array}{l}\text { Monitoring of barometric pressure and water levels in NC-EWDP-19D to determine } \\
\text { barometric efficiency }\end{array}$ \\
\hline
\end{tabular}

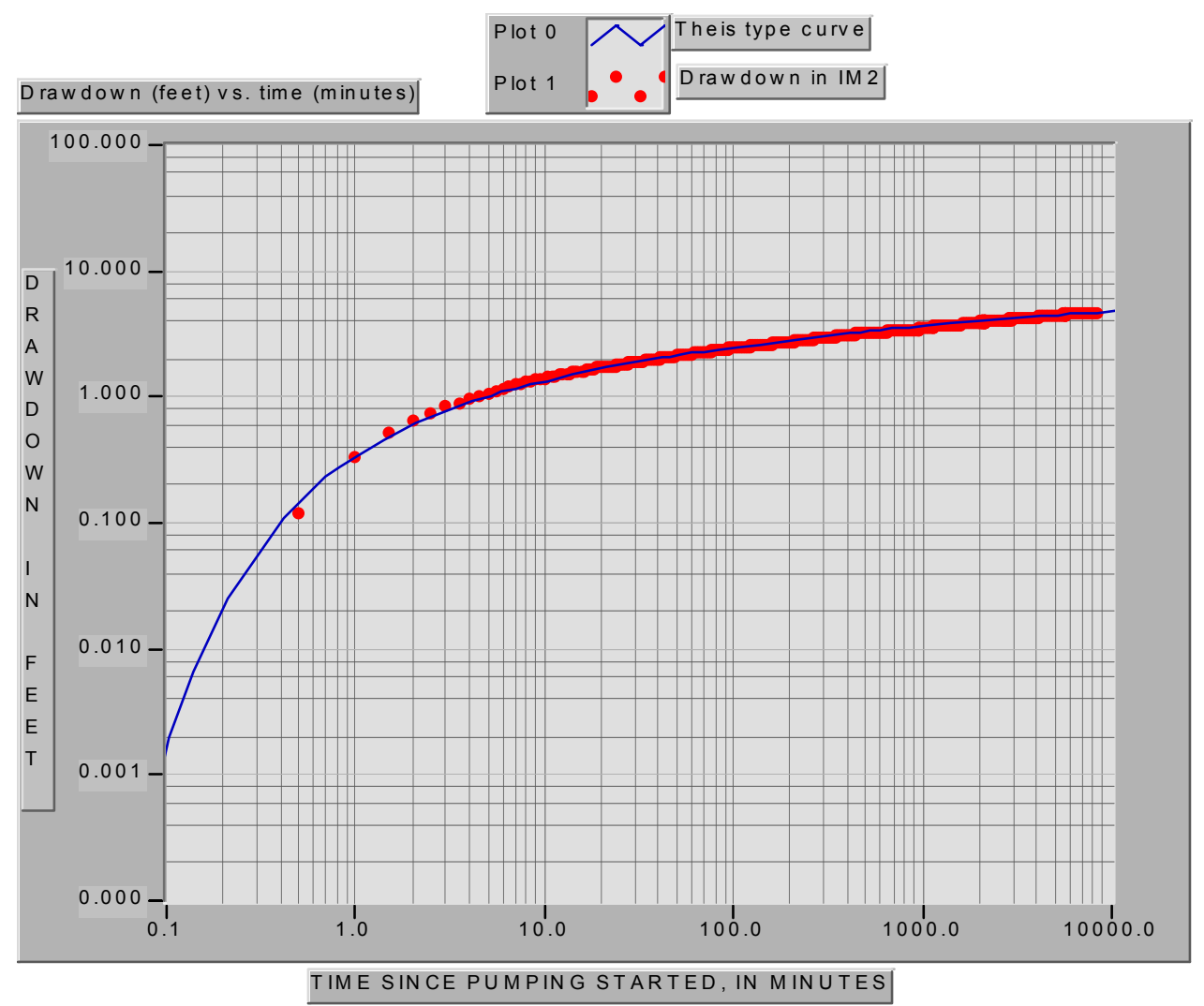

Source: DTN: GS020908312316.002 [DIRS 162679] (data).

Output DTN: GS031008312316.002 (analysis).

NOTE: English units are shown in the figure because the analysis was conducted in English units. However, parameter estimates are reported in metric units to downstream users.

Figure 6.4-1. Fit to the Theis (1935 [DIRS 150327]) Confined-Aquifer Solution of the Drawdown in NCEWDP-19IM2 Resulting from Pumping NC-EWDP-19D at $109 \mathrm{gpm}$ 


\subsubsection{Hydraulic Test Interpretations: Conceptual Flow Model Implications}

The single-well hydraulic tests in NC-EWDP-19D all indicated that the alluvium in the immediate vicinity of this well behaves as an unconfined porous medium. Although the transmissivity estimates from these tests were considered to be biased low because of large well losses (discussion in Appendix F), there was good agreement between the hydraulic conductivity estimates (transmissivity divided by interval length) in three of the four isolated screened intervals and in the test involving all four combined alluvium intervals after making corrections to account for the fact that a fully penetrating solution (Neuman 1975 [DIRS 150321]) was used to analyze a partially penetrating geometry. These results suggest that the alluvium at the NC-EWDP-19D location not only behaves as an unconfined aquifer, but that the hydraulic conductivity of the alluvium at this location does not vary significantly with depth. The second screened interval below the water table in 19D was the only interval that had a transmissivity inconsistent with the other intervals. However, this interval was known to be completed in or very close to a clay-rich layer (Figure 6.1-8). The apparent hydraulic conductivity in this interval was nearly an order of magnitude less than in the other intervals, possibly because the finer material present in this interval partially clogged the gravel pack and/or well screen during aquifer testing.

The fact that the Theis (1935 [DIRS 150327]) confined-aquifer solution provided a good match to the water-level drawdowns observed in NC-EWDP-19IM2 when 19D was pumped suggests that the alluvium at the ATC location behaved as a confined porous medium flow system when a larger volume was interrogated than in the single-well tests. It is possible that the well losses in the single-well tests precluded observations that would have indicated a confined system. The possibility was also considered that the drawdown in 19IM2 was so small relative to the saturated thickness at this observation well (approximately 2 percent) that the response followed that of a confined aquifer even though the aquifer was unconfined. However, attempts to fit the Neuman (1975 [DIRS 150321]) (Neuman.vi V 1.0, STN: 10972-1.0-00 [DIRS 162754]) unconfined aquifer solution to the drawdown response indicated that the test had been conducted long enough to exhibit the flattening in drawdown at late times that would be expected if the aquifer were unconfined. Because this flattening did not occur, it appears likely that a confining layer influenced the response near 19IM2.

The relative drawdown responses of 19IM1 and 19IM2 during cross-hole hydraulic testing qualitatively suggest that the preferred orientation of horizontal anisotropy of hydraulic conductivity in the alluvium at the ATC is in the northeast-southwest direction (i.e., the direction from 19IM2 to 19D). Quantitative estimates of horizontal anisotropy orientation and ratio were not possible because there were only two observation wells and because the 19IM1 data are non-Q.

\subsubsection{Hydraulic Test Interpretations: Hydrologic Parameter Estimates at the ATC}

The storativity, transmissivity, and hydraulic conductivity estimates obtained from analyzing the drawdown response in NC-EWDP-19IM2 as a result of pumping all four combined alluvium intervals in NC-EWDP-19D using the Theis (1935 [DIRS 150327]) confined-aquifer solution are $0.00045,306 \mathrm{~m}^{2} /$ day, and $2.3 \mathrm{~m} /$ day, respectively (Appendix F, Section F2). The estimate of hydraulic conductivity assumes an interval thickness of $133 \mathrm{~m}$, which is the total thickness of the 
saturated alluvium from the water table to the bottom of the deepest screen completed in the alluvium in NC-EWDP-19D. Vertical transmissivity and hydraulic conductivity were not estimated from the test results because the cross-hole hydraulic response conformed to that of a confined aquifer (i.e., no vertical flow) rather than an unconfined aquifer.

The estimate of total porosity in the alluvium obtained from storativity and barometric efficiency estimates at the ATC was approximately 0.41 (Appendix F, Section F3). Total porosity estimates from borehole gravimetry ranged from approximately 0.18 to approximately 0.29 , depending on depth in the alluvium NC-EWDP-19D (Appendix F, Section F4). The estimates from borehole gravimetry are considered more accurate and reliable than those from storativity and barometric efficiency.

\subsubsection{Limitations and Uncertainties}

Analytic solutions provide first-order estimates of hydrologic parameters consistent with both the limited knowledge of the nature and extent of subsurface heterogeneities in the alluvium at the scale of the ATC and the manner in which hydrologic parameter estimates are used in the SZ site-scale flow model (BSC 2004 [DIRS 170037]). The analytical methods assume that the test interval has one average transmissivity and storativity value. Similarly, the SZ site-scale flow model (BSC 2004 [DIRS 170037]) assumes that single, average, intrinsic, hydrologic property (i.e., permeability, porosity) values apply to the alluvium over large spatial areas in the SZ flow system. Furthermore, the hydrologic parameters derived from ATC testing are not used as direct inputs in the SZ site-scale flow model, but rather they are used primarily for qualitative/corroborative consistency checks with the hydrologic parameters derived from calibrations of the SZ site-scale flow model.

Uncertainties in estimates of storativity, transmissivity, and hydraulic conductivity were not quantitatively analyzed because these parameter estimates were not used directly in the SZ site-scale flow model (BSC 2004 [DIRS 170037], Sections 6.6, 6.7 and 7); they were used only qualitatively/corroboratively in the flow model. Estimates of transmissivity and storativity should be considered no more accurate than for the fractured volcanics (Section 6.2.7) (i.e., within at best a factor of 3 for transmissivity and an order of magnitude for storativity). Horizontal hydraulic conductivity was calculated by dividing the transmissivity determined in the cross-hole test between NC-EWDP-19IM2 and NC-EWDP-19D by essentially the entire thickness of the saturated alluvium at this location. In reality, the thickness of the alluvium actually conducting flow may have been less than this total thickness (as suggested by the fact that the drawdown response in 19IM2 conformed to that of a confined aquifer, indicating that some layers in the alluvium may not have conducted flow). Only a qualitative estimate of the preferred orientation of horizontal anisotropy of hydraulic conductivity in the alluvium (northeast to southwest) was possible from the cross-hole hydraulic test results at the ATC, and no estimate of the anisotropy ratio was possible.

Given the intended use of the hydrologic parameters derived from this scientific analysis in the SZ site-scale flow model (for qualitative/corroborative consistency checks), the large uncertainties associated with the parameter estimates are considered acceptable. The implications of ATC hydraulic test results for conceptual flow models are based primarily on qualitative observations (e.g., porous medium behavior, either confined or unconfined flow 
system), so these important implications are not significantly influenced by uncertainties in parameter estimates.

\subsection{TRANSPORT PROPERTIES OF ALLUVIUM (ATC)}

\subsubsection{Introduction}

This section (1) summarizes the tracer tests conducted at the ATC and the interpretive analyses performed on the test data; (2) discusses the implications of the test interpretations, including transport parameter estimates and implications for conceptual transport modeling in the alluvium; and (3) discusses the limitations and uncertainties associated with the transport properties determined from the test analyses.

\subsubsection{Summary of ATC Tracer Testing, Including Objectives and Strategies}

Three single-well injection-withdrawal tracer tests were conducted in the saturated alluvium in the uppermost screened interval of NC-EWDP-19D between December 2000 and April 2001 (Appendix G, Section G4). This interval ranges from approximately 14 to $23 \mathrm{~m}$ (45 to $75 \mathrm{ft}$ ) below the water table at the ATC location (Figure 6.1-8). In each of the three tests, two nonsorbing solute tracers with different diffusion coefficients were simultaneously injected (a halide and a fluorinated benzoate [FBA] dissolved in about 11,000 L of groundwater), followed immediately by the injection of a much larger volume $(83,000 \mathrm{~L})$ of tracer-free groundwater called "chase" water. The chase water was intended to push the tracers into the aquifer so as to minimize the influence of the wellbore and gravel pack on the test results. The three tests were conducted in essentially the same manner except for the time allowed to elapse between the cessation of chase water injection and the initiation of pumping, the so-called "rest" or "shut-in" period. The rest period was systematically varied from approximately $0.5 \mathrm{hr}$, to approximately 2 days, to approximately 30 days, after which the well was pumped back and water samples were collected to analyze for tracers. The different rest periods were employed to allow estimates of ambient groundwater velocity (Section 6.5.5 for details). Pumping was continued until the majority of the tracer mass had been recovered. Flow interruptions were intentionally introduced during the pumping phase of two of the three tests to determine if they had any effect on the responses of the tracers. The tracers and test conditions in the three single-well tests are summarized in Table 6.5-1. A fourth single-well test was conducted in the deepest interval in NC-EWDP-19D using a single FBA in early 2002, but this test was not used for transport parameter estimation because the FBA was not paired with a halide to allow diffusion into stagnant water to be evaluated and because additional tests with different rest periods were not conducted to allow estimates of ambient groundwater velocity.

The objectives of the single-well tracer tests were:

- To determine whether the alluvium behaves as a single- or a dual-porosity transport system based on the differences in the responses of the halide and FBA tracers in the same test (discussion in Section 6.3.2) 
- To obtain estimates of diffusive mass transfer parameters (if a dual-porosity system is indicated) based on the magnitude of the differences between the halide and FBA tracer responses in tests of different rest periods)

- To obtain estimates of the ambient flow velocity in the alluvium based on the responses of the tracers in the tests of different rest periods.

Details of the single-well tracer testing strategy, including a discussion of pretest model predictions that illustrates how the results from the different tests could be used to achieve the above objectives, are provided in Appendix G. Cross-hole tracer tests were planned at the ATC, but these tests were not conducted because environmental permits were rescinded by the State of Nevada before they could be started.

Table 6.5-1. Summary of Tracers and Test Conditions in the Three Single-Well Tracer Tests in NC-EWDP-19D

\begin{tabular}{|c|c|c|c|}
\hline Rest Period (Test) & $0.5 \mathrm{hr}$ & 2 days & 30 days \\
\hline Dates & $1 / 5 / 01-1 / 12 / 01$ & $12 / 1 / 00-12 / 18 / 00$ & $1 / 27 / 01-4 / 25 / 01$ \\
\hline Tracers (concentration) & $\begin{array}{l}\text { 2,4-DFBA }(0.46 \mathrm{~g} / \mathrm{L}) \\
\mathrm{Cl}^{-}(0.62 \mathrm{~g} / \mathrm{L} \mathrm{NaCl}) \\
640-\mathrm{nm} \text { microspheres }\end{array}$ & $\begin{array}{l}2,6-D F B A(0.46 \mathrm{~g} / \mathrm{L}) \\
\mathrm{I}^{-}(0.64 \mathrm{~g} / \mathrm{L} \mathrm{KI})\end{array}$ & $\begin{array}{l}\text { PFBA }(0.46 \mathrm{~g} / \mathrm{L}) \\
\mathrm{Br}^{-}(0.64 \mathrm{~g} / \mathrm{L} \mathrm{NaBr})\end{array}$ \\
\hline Injection rate (L/min [gpm]) & $56.8[15.0]$ & $56.8[15.0]$ & 56.8 [15.0] \\
\hline $\begin{array}{l}\text { Average pumping rate (L/min } \\
\text { [gpm]) }\end{array}$ & $50.3[13.3]$ & $41.3[10.9]$ & $51.67[13.65]$ \\
\hline Pumping duration (days) & 7 & 14 & 54 \\
\hline Total liters [gallons] pumped & $510,600[134,900]$ & $833,000[220,000]$ & $4,024,000[1,063,000]$ \\
\hline Tracer recovery (FBA) & 0.864 & 0.928 & 0.913 \\
\hline
\end{tabular}

Source: DTNs: GS020708312316.001 [DIRS 162678] (data); UN0109SPA008IF.006 [DIRS 162442] (data); UN0109SPA008KS.007 [DIRS 162615] (data); UN0109SPA008KS.008 [DIRS 162616] (data).

DFBA = difluorobenzoate; FBA=fluorinated benzoate; gpm=gallons per minute; PFBA = pentafluorobenzoate.

\subsubsection{Single-Well Tracer Test Results}

Figure 6.5-1 shows the normalized solute tracer responses in the single-well tracer test with a rest period of approximately 2 days. It is apparent that the two solute tracers had essentially identical responses (within experimental error) in this test. The tracer responses were also identical in the other two single-well tests (Appendix G). However, Figure 6.5-2 shows that the tracer responses were highly dependent on the rest period of each test. These differences cannot be attributed to diffusion processes because the responses of the tracers with different diffusion coefficients were identical in each individual test. The differences must, therefore, be attributed to the different times that the tracers were allowed to drift in the ambient flow field in each test.

The response of the polystyrene microspheres injected in the single-well test with a 0.5 -hr rest period, and the estimates of colloid detachment rate constants obtained from this response are discussed in Appendix G. 


\subsubsection{Tracer Test Interpretations: Conceptual Transport Model Implications}

The absence of solute tracer diffusion into stagnant or nearly stagnant water in the alluvium over the time scales of the single-well tests is consistent with a single-porosity conceptualization of the alluvium (i.e., flow occurs in nearly all the accessible porosity in the flow system). The flow interruptions during the tailing portions of the two longer tests provided additional evidence for very little diffusive mass transfer in the aquifer. If diffusive mass transfer were an important process, the tracer concentrations would have increased significantly immediately after the flow interruptions due to tracers diffusing out of stagnant water and into flowing water during the interruptions.

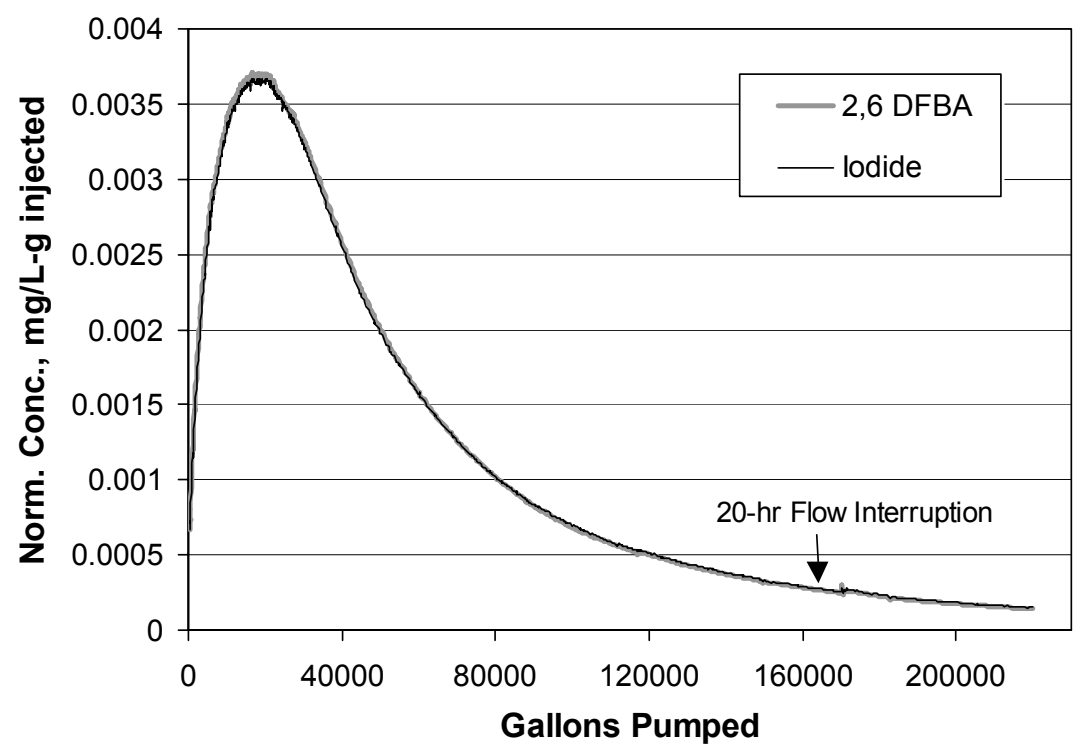

Source: DTN: UN0102SPA008KS.003 [DIRS 162614].

Output DTN: LA0303PR831231.002 (volumes).

NOTE: The tracer responses are almost identical, so it is difficult to distinguish between the two responses. The figure is plotted in English units because the data were obtained in those units. However, parameter estimates are reported in metric units to downstream users.

Figure 6.5-1. Normalized Concentrations of Tracers in Production Water from NC-EWDP-19D as a Function of Gallons Pumped after a Rest Period of Approximately 2 Days

\subsubsection{Tracer Test Interpretations: Estimates of Ambient Flow Velocity in Alluvium}

Four methods were used to obtain groundwater velocity estimates from the single-well tracer tests. The first three methods involved relatively simple spreadsheet calculations that, given various simplifying assumptions, solve for groundwater velocities consistent with the observed differences in the following:

(1) Peak tracer concentration arrival times

(2) "Late" tracer arrival times, defined as the times in each test when the fractional tracer mass recovery was equal to the final recovery in the test having the lowest overall mass recovery. Given that the total mass recoveries in the three tests were 0.864 , 
0.928 , and 0.913 (Table 6.5-1), then the late arrival time in each test was the time at which the mass recovery was 0.864 .

(3) "Mean" arrival times of tracer mass recovered at the same arbitrarily selected high fractional recovery in each test. Two different fractional recoveries were selected to calculate mean arrival times: 0.864 , the lowest fractional recovery in any of the tests, and 0.913 , the fractional recovery in the 30-day rest-period test. In the latter case, the tracer responses in the test with a mass recovery of 0.864 were extrapolated to 0.913 (Appendix G4.2.3) to allow a calculation of the mean arrival time. This alternative method of calculating the mean arrival time was employed because the 30-day test had the largest calculated mean arrival time, and it was therefore considered to have the greatest amount of information pertinent to groundwater velocity estimates. 

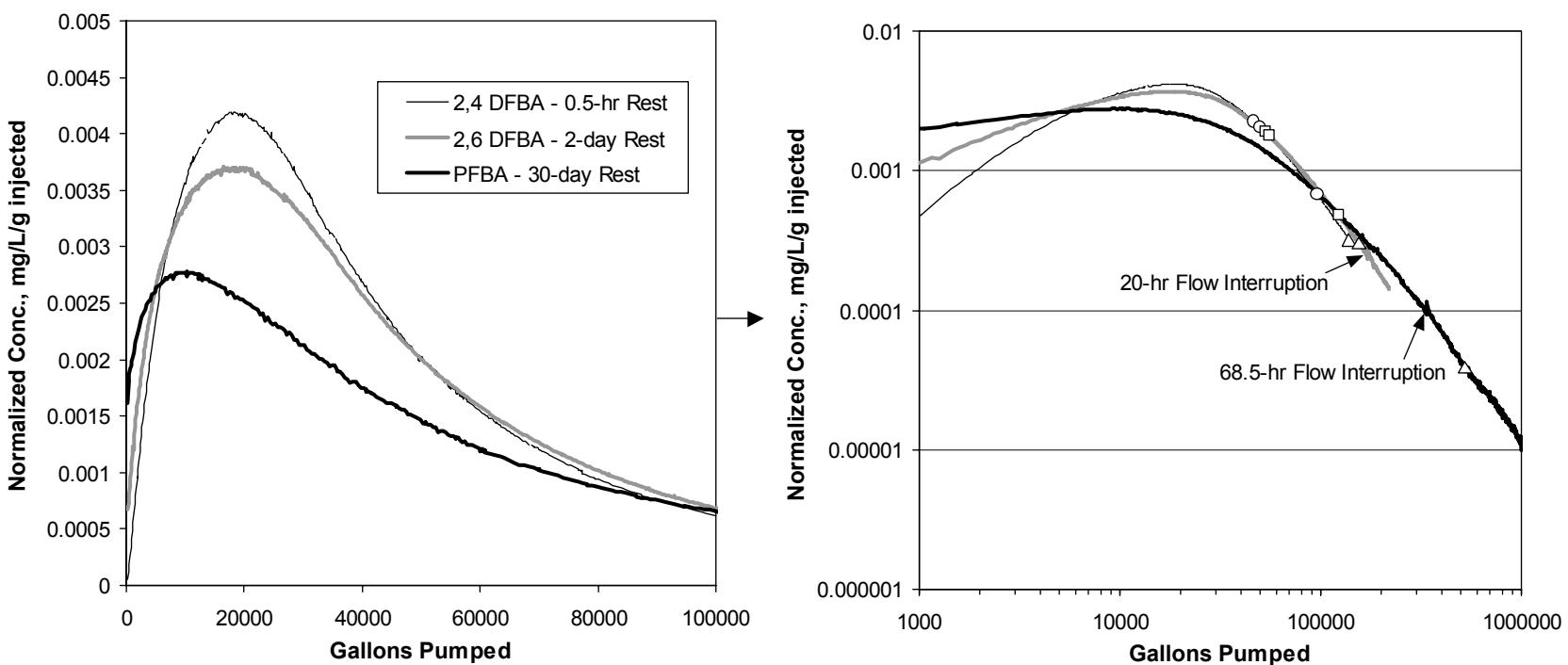

Source: DTNs: UN0109SPA008IF.006 [DIRS 162442] (2,4-DFBA), UN0102SPA008KS.003 [DIRS 162614] (2,6-DFBA), UN0109SPA008KS.007 [DIRS 162615] (PFBA).

Output DTN: LA0303PR831231.002. (volumes).

NOTE: On the right-hand plot, circles indicate volumes associated with mean arrival times (for each tracer response), squares indicate volumes associated with alternate mean arrival times, and triangles indicate volumes associated with "late" arrival times. The left-most symbol is always associated with the 0.5 -hr rest-period test, and the right-most symbol is associated with the 30-day rest-period test. The bases for these different arrival times/volumes are discussed in detail in Appendix G. The figure is plotted in English units because the data were obtained in those units. However, parameter estimates are reported in metric units to downstream users.

Figure 6.5-2. Normalized Concentrations of Fluorinated Benzoates as a Function of Gallons Pumped in Each of the Three Single-Well Tracer Tests in NC-EWDP-19D 
Note that these three times also correspond to volumes pumped, and because the pumping rates varied in the different tests, the relationship between times and volumes is different for each test. The peak, late, and mean arrival times (and corresponding volumes) for each test are listed in Table 6.5-2. The points on the tracer breakthrough curves corresponding to the mean and late arrival times in each test are identified in the right-hand plot of Figure 6.5-2.

The fourth method of estimating ambient groundwater velocity involved detailed analytical calculations of tracer migration during the tests by linking together solute transport solutions for the injection, rest, and pumping phases that assume a two-dimensional homogeneous and isotropic aquifer. This method also provided estimates of effective flow porosity and longitudinal dispersivity in the alluvium, although these estimates are not well constrained.

The details of the calculations associated with four estimation methods are provided in Appendix G. Table 6.5-3 lists the results obtained for both the groundwater velocity, $\mathrm{v}_{\mathrm{GW}}$, and the specific discharge, $\mathrm{v}_{\mathrm{S}}\left(=\eta \mathrm{v}_{\mathrm{GW}}\right)$, as a function of assumed flow porosity $(\eta)$ by all four methods of estimation. Of the first three methods, the peak analysis method offers the smallest estimates, and the analysis of late-arriving mass (high recovery) offers the largest. The range of the estimates from the four methods spans about a factor of three for a given assumed value of flow porosity. The velocity estimate from the linked analytical solutions is in good agreement with the peak analysis method. The peak-analysis method yields a velocity estimate of $17.5 \mathrm{~m} /$ year (specific discharge of $1.75 \mathrm{~m} /$ year), as compared to $15 \mathrm{~m} /$ year $(1.5 \mathrm{~m} /$ year specific discharge) from the linked analytical solutions, when a flow porosity of 0.10 is assumed (the flow porosity obtained from the linked analytical solutions).

The specific discharge estimates of Table 6.5-3 are in good agreement with the range of 1.9 to $3.2 \mathrm{~m} /$ year derived from SZ flow-model calibrations (to head and hydraulic conductivity data), which assume a wide range of potential anisotropy in horizontal hydraulic conductivity (BSC 2004 [DIRS 170042], Table 6-6). The range of values in Table 6.5-3 has been factored into the probability distribution used for specific discharge in the alluvium in Yucca Mountain performance assessment simulations (BSC 2004 [DIRS 170042], Figure 6-7). 
Table 6.5-2. Times and Pumped Volumes Associated with Each of the Arrival Times Used in the Different Methods of Estimating Groundwater Velocities

\begin{tabular}{|l|l|l|l|}
\hline & \multicolumn{3}{|c|}{ Arrival Time (hr)/Volume (L [gal]) } \\
\hline Rest Period (Test): & $0.5 \mathrm{hr}$ & 2 days & 30 days \\
\hline Peak arrival & $24 / 76,000[20,000]$ & $30.5 / 76,000[20,000]$ & $12.2 / 38,600[10,200]$ \\
\hline${\text { Late } \text { arrival }^{\mathrm{a}}}^{\mathrm{M}}$ & $168 / 511,000[135,000]$ & $225 / 556,000[147,000]$ & $639 / 1,780,000[471,000]$ \\
\hline Mean arrival $^{\mathrm{b}}$ & $52 / 161,000[42,500]$ & $71 / 178,000[46,500]$ & $109 / 344,000[91,000]$ \\
\hline Alternate mean arrival $^{\mathrm{c}}$ & $61.5 / 189,000[50,000]$ & $81 / 201,000[53,000]$ & $149 / 469,000[124,000]$ \\
\hline
\end{tabular}

Source: DTNs: UN0109SPA008IF.006 [DIRS 162442] (0.5 hr); UN0102SPA008KS.003 [DIRS 162614] (2 days); UN0109SPA008KS.007 [DIRS 162615] (30 days).

Output DTN: LA0303PR831231.002 (volumes).

${ }^{a}$ Time/volume associated with approximately 86.4 percent mass recovery in each test (the final recovery in the 0.5 -hr rest period test, which had the lowest final recovery of any test).

${ }^{\mathrm{b}}$ Mean arrival time calculated by truncating all tracer response curves at approximately 86.4 percent recovery in each test.

${ }^{c}$ Alternate mean arrival time calculated by extrapolating the tracer response curves in the 0.5 -hr rest-period test to 91.3 percent and truncating the response curves in the 2-day rest period test to 91.3 percent recovery (the final recovery in the 30-day rest period test).

Table 6.5-3. Specific Discharges and Groundwater Velocities Estimated from the Different Ambient Flow Velocity Analysis Methods as a Function of Assumed Flow Porosity

\begin{tabular}{|l|c|c|c|}
\hline & \multicolumn{3}{|c|}{ Specific Discharge (m/year) / Groundwater Velocity (m/year) } \\
\hline \multicolumn{1}{|c|}{ Assumed Flow Porosity } & $\mathbf{0}$ & $\mathbf{0 . 1 8}$ & $\mathbf{0 . 3}$ \\
\hline Peak Arrival Analysis & $1.2 / 24.5$ & $2.4 / 13.1$ & $3.0 / 9.9$ \\
\hline Late Arrival Analysis $^{\mathrm{b}}$ & $3.9 / 77.1$ & $7.3 / 40.4$ & $9.4 / 31.3$ \\
\hline Mean Arrival Analysis $^{\mathrm{c}}$ & $2.0 / 40.3$ & $3.8 / 20.9$ & $4.9 / 16.4$ \\
\hline Mean Arrival Analysis $^{\mathrm{d}}$ & $2.5 / 49.1$ & $4.6 / 25.8$ & $6.0 / 20.2$ \\
\hline Linked Analytical Solutions $^{\mid}$ & $1.5 / 15$ with a flow porosity of 0.10 and a longitudinal dispersivity of $5 \mathrm{~m}$. \\
\hline
\end{tabular}

Output DTN: LA0303PR831231.002.

${ }^{a}$ The three values are approximately the lowest, expected, and highest values of the alluvium flow porosity used in Yucca Mountain performance assessments (BSC 2004 [DIRS 170042]).

b Time/Volume associated with approximately 86.4 percent recovery in each test (the final recovery in the 0.5 -hr rest period test, which had the lowest final recovery of any test).

${ }^{c}$ Mean arrival time calculated by truncating all tracer response curves at approximately 86.4 percent recovery in each test.

${ }^{d}$ Alternative mean arrival time calculated by extrapolating the tracer response curves in the 0.5 -hr rest period test to 91.3 percent and truncating the response curves in the 2-day rest-period test to 91.3 percent recovery (the final recovery in the 30-day rest-period test).

\subsubsection{Laboratory Testing to Support ATC Field Tracer Tests}

A number of laboratory tests were conducted to support planned cross-hole tracer testing efforts at the ATC (Appendix H). These tests focused on the batch sorption characteristics and column transport behavior of lithium ion, which was to be used as a reactive tracer in cross-hole tracer testing. The motivation for comparing lithium sorption parameters obtained in laboratory and field tests was the same as that discussed in Section 6.3.6 for laboratory testing conducted in support of C-wells tracer testing: favorable comparisons of laboratory- and field-derived 
transport parameters of nonradioactive tracers lend credibility to the practice of using laboratoryderived radionuclide transport parameters in field-scale predictive simulations.

Laboratory testing conducted in support of ATC tracer testing included:

- Batch sorption tests to determine lithium sorption parameters associated with various depth intervals at the ATC and their dependence on mineralogical characteristics of the alluvium

- Lithium bromide and PFBA tracer tests in columns packed with alluvium from NC-EWDP-19D to determine lithium transport characteristics as a function of lithium injection concentration.

Details of the conduct and results of these laboratory tests are provided in Appendix H. These tests are not discussed further here because the field tracer test involving lithium ion was never conducted.

\subsubsection{Limitations and Uncertainties}

Single-well tracer tests do not provide well-constrained estimates of effective flow porosity or longitudinal dispersivity, so the estimates of these parameters obtained from the linked analytical solutions method ( 0.1 and $5 \mathrm{~m}$, respectively) are considered to be highly uncertain. The estimates of groundwater velocity and specific discharge in the alluvium at the ATC in Table 6.5-3 vary over a range of about a factor of 3 for a given flow porosity assumption, and over a range of about a factor of 9 for any reasonable flow porosity assumption. These estimates are in reasonably good agreement with estimates obtained using potentiometric head and hydraulic conductivity data, so the one-order-of-magnitude range in the values is considered to be a reasonable reflection of the uncertainty associated with the estimates.

All the groundwater velocity estimation methods rely either implicitly or explicitly on the assumption of a homogeneous, isotropic, two-dimensional aquifer. Although these assumptions are clearly oversimplifications, it is doubtful that the estimates could be improved significantly by more sophisticated modeling without more detailed information on the distribution of tracer mass after the injection and rest phases of the tests and more information on the spatial distribution of hydraulic conductivity in the aquifer. 


\section{INTENTIONALLY LEFT BLANK}




\section{CONCLUSIONS}

\subsection{SUMMARY OF SCIENTIFIC ANALYSIS}

This scientific report documents the results of numerous in situ field hydraulic and tracer tests conducted in the SZ near Yucca Mountain over the past 10 years. These tests were conducted to verify or validate conceptual models of flow and transport in the SZ and to obtain field-scale estimates of flow and transport parameters to support the development of parameter distributions used in process and TSPA models. This report also documents the results of several laboratory experiments conducted to help constrain field tracer test interpretations and to provide comparisons between field- and laboratory-derived sorption parameters for the lithium ion, which is a weakly sorbing tracer.

The most significant conclusions from in situ field testing with regard to barrier capability of the $\mathrm{SZ}$ are the following:

- For flow modeling purposes, the saturated volcanic tuffs near Yucca Mountain can be treated as an equivalent porous medium. The fracture networks in the tuffaceous rocks are connected well enough that hydraulic responses are similar to those observed in porous media. However, the flow system exhibits layered heterogeneity with layers of high permeability often associated with relatively narrow fractured intervals. Also, larger-scale hydraulic characteristics of the saturated tuffs are strongly influenced by structural features such as faults. Hydraulic parameters derived from cross-hole testing in the fractured volcanics are summarized in Section 6.2, Tables 6.2-2 through 6.2-4.

- Horizontal anisotropy in hydraulic conductivity in the saturated fractured volcanic tuffs near Yucca Mountain, as determined from drawdown responses in distant wells during the 1996-1997 long-term pumping test in UE-25 c\#3, is oriented roughly north-south (direction of greatest conductivity) with an anisotropy ratio of about $4: 1$. A cumulative distribution function for anisotropy ratio assuming a north-south orientation of anisotropy is provided in Section 6.2.6, Figure 6.2-3.

- Solute tracer responses in cross-hole tracer tests at the $\mathrm{C}$-wells were consistent with a dual-porosity conceptual transport model. In this model, solute migration occurs primarily in flowing fractures. The solutes are effectively attenuated by diffusion into stagnant water in the porous rock matrix (matrix diffusion). Solute transport parameters derived from cross-hole tracer testing at the C-wells are summarized in Section 6.3, Table 6.3-3.

- Apparent sorption of an ion-exchanging tracer (lithium) was generally greater in field tracer tests in the volcanic tuffs than in laboratory tests using the same materials. These results lend credibility to the practice of using laboratory-derived radionuclide sorption parameters in performance assessment simulations, as they suggest that laboratory parameters will tend to result in overestimation of radionuclide transport rates in the tuffs. Comparisons of field and laboratory lithium sorption parameters are provided in Section 6.3, Table 6.3-4. 
- Polystyrene microsphere responses in cross-hole tracer tests at the C-wells suggest that filtration processes effectively attenuate a large percentage of the microspheres over relatively short distances. However, some of the filtered microspheres later detach from fracture surfaces and continue to migrate. Also, flow transients appear to be capable of initiating detachment. Estimates of microsphere transport parameters derived from the C-wells tracer tests are provided in Section 6.3, Table 6.3-3.

- Single-well hydraulic testing in the saturated alluvium at the NC-EWDP-19D location south of Yucca Mountain has indicated that the alluvium behaves as an unconfined aquifer. However, cross-hole hydraulic test responses are more consistent with a confined aquifer analytical solution than an unconfined analytical solution. These results suggest that the confining layer for the observation well of the cross-hole hydraulic test may not be persistent and is not present at the single-well hydraulic testing location only $28 \mathrm{~m}$ away. This would indicate substantial lateral heterogeneity in the alluvium. Horizontal hydraulic conductivity estimates from cross-hole hydraulic testing in the alluvium are on the order of $2 \mathrm{~m} /$ day (6.7 ft/day) (Section 6.4).

- Single-well injection-withdrawal tracer testing in the saturated alluvium in the uppermost screened interval of NC-EWDP-19D indicated that the saturated alluvium at this location behaves as a single-porosity medium. The tracer tests yielded estimates of specific discharge at the NC-EWDP-19D location that range from about $1 \mathrm{~m}$ to $10 \mathrm{~m} /$ year (Section 6.5.5). They also yielded preliminary detachment rate constants for polystyrene microspheres.

- All of these conclusions indicate that the SZ beneath and downgradient of the Yucca Mountain repository should serve as an effective barrier to radionuclide transport. In the context of the over-all predicted performance of the engineered and natural barrier systems, the results documented in this report and the uncertainties associated with these results support the adequacy of the SZ to meet its performance expectations. Section 7.4 lists specific locations in Section 6 and in the appendices where the reader can find discussions of uncertainties associated with hydrologic and transport parameters derived from SZ in situ testing. These uncertainties are incorporated into probability distributions for parameters documented primarily in the SZ transport model abstraction report (BSC 2004 [DIRS 170042]).

The SZ included FEPs supported by this scientific analysis are listed in Section 6.1.2 of this report, which also indicates where in the report the FEPs are addressed.

The specific acceptance criteria that relate to this report are discussed in Section 4.2.

\subsection{APPLICABLE ACCEPTANCE CRITERIA}

The following information describes how this analysis addresses the acceptance criteria in Yucca Mountain Review Plan, Final Report (NRC 2003 [DIRS 163274], Sections 2.2.1.3.8.3 and 2.2.1.3.9.3). Only those acceptance criteria applicable to this report (Section 4.2) are discussed. In most cases, the applicable acceptance criteria are not addressed solely by this report; rather, 
the acceptance criteria are fully addressed when this report is considered in conjunction with other analysis and model reports that describe flow and transport in the saturated zone.

\subsubsection{Acceptance Criteria from Section 2.2.1.3.8.3, Flow Paths in the Saturated Zone}

\section{Acceptance Criterion 1: System Description and Model Integration Are Adequate}

- Subcriterion (2)-Sections 6.2 and 6.4 (and Appendices C and F) adequately describe and identify aspects of hydrology, geology, physical phenomena, and couplings, that may affect flow paths in the saturated zone. Conditions and assumptions supporting the abstraction of flow paths in the saturated zone are readily identified and supported in these two sections. Section 6.2 and Appendix $\mathrm{C}$ describe the hydraulic tests conducted and analyses performed on the test data, and extrapolates test results to estimate hydrogeologic properties of the volcanic rocks. Section 6.4 and Appendix F present hydrogeologic properties of the alluvium through interpretation of test results. Volcanic and alluvium hydrogeologic properties affect flow paths in the saturated zone.

- Subcriterion (3)-The assumptions, technical bases, data, and models incorporated in this report are appropriate and consistent with those supporting other abstractions because they are derived from tests and experiments directly applicable to the saturated zone at Yucca Mountain as described in Sections 6.2 and 6.4 (and Appendices C and F). Descriptions and technical bases provided in Sections 6.2 and 6.4, and in Appendices C and F) are transparent and traceable (Section 4.1 for data references) for items that support the total system performance assessment and abstraction for flow paths in the saturated zone.

- Subcriterion (10)-This document has been developed under YMP Quality Assurance Requirements and Description (QARD) (DOE 2004 [DIRS 171539]).

\section{Acceptance Criterion 2: Data Are Sufficient for Model Justification}

- Subcriterion (1) -The description of how the geological and hydrological data were used to develop conceptual models and parameters that are used to support evaluation of flow paths in the saturated zone is adequately justified. The adequacy of the descriptions of how the data were used, interpreted, and appropriately synthesized into the parameters is summarized in Sections 6.2.2 through 6.2.6 and 6.4.2 through 6.4.5. Details are provided in Appendix C, Sections C1 through C4, C6, Appendix F, Sections F1 and F2. Section $\mathrm{C} 1$ discusses early studies that were conducted to define hydrostratigraphic units, flow patterns, effects of the different geologic features, geologic properties of the rocks, and the results of an open-hole test in the C-wells. Section C2 provides descriptions of equipment used and indicates that the equipment received extensive performance evaluation during prototype hydraulic tests. Section C3 provides detailed data, results, and interpretations of the hydraulic tests including the conceptual models considered and tested. Hydraulic properties of the volcanic rocks for the various hydrogeologic intervals at the C-wells are discussed in Section C4. Section C6 describes how reviews of a number of published studies are used in conjunction with reanalyzing the data to suggest a distribution of anisotropy ratios. The tests to determine hydraulic properties of the 
alluvium are described and their results adequately justified in detail in Section 6.4 and Appendix F, including single-well hydraulic testing (Section F1) and cross-hole hydraulic testing (Section F2).

- Subcriterion (2)-Sufficient data have been collected as discussed in Sections 6.2 and 6.4 on the natural system to establish boundary conditions for the abstraction of flow paths in the saturated zone. The discussions in Appendix C, Sections C1, C3, C6; and Appendix F, Section F4 show that the data employed from earlier studies and recent studies are sufficient to establish boundary conditions used in the abstraction of flow paths in the saturated zone.

- Subcriterion (3)-Data on the geology and hydrology of the saturated zone used in the total system performance assessment abstraction are based on appropriate techniques as discussed in detail in Sections 6.2 and 6.4, and in Appendices C and F. These techniques included site-specific field measurements and process-level modeling studies described in Sections 6.2 and 6.4, and in Appendices C and F. Sensitivity of parameters and uncertainty in the data were addressed in the analyses. A formal analysis of sensitivity to anisotropy in horizontal hydraulic conductivity is described in Appendix C, Section C6.4, FEHM Sensitivity Study. Other sensitivity considerations are discussed in Sections 6.2.7, 6.4; Appendix C, Section C5; and Appendix F.

- Subcriterion (4)-Sufficient information is provided in Sections 6.2.4, 6.2.6, and 6.4, as well as in Appendix C, Sections C4, C6; and Appendix F to substantiate the conclusions that the proposed conceptual groundwater modeling approach and model are applicable to site conditions. Confidence that the model is applicable to site conditions is provided by the extensive justifications of the methods and parameters used. Summaries of the conceptual models considered for fractured volcanics and the alluvium are presented in Sections 6.2.4 and 6.4.4, respectively.

\section{Acceptance Criterion 3: Data Uncertainty Is Characterized and Propagated Through the Model Abstraction}

- Subcriterion (1)-Technically defensible models that adequately account for uncertainties and risk are employed. Sections 6.2.6, 6.2.7, and 6.4, as well as Appendix C, Sections C5, C6; and Appendix F, discuss uncertainties and variabilities of the data and models. Sections 6.2.7 and C5 evaluate the uncertainties associated with the test data, analyses, methods, assumptions, and values of hydraulic properties of the volcanic rocks determined from test analyses and discusses why the simplifications used in the models are appropriate for estimating hydrogeologic parameters and uncertainty associated with them (which affect groundwater velocities and transport times). By addressing uncertainty in these parameters, assurance is provided that the groundwater velocities and transport times, and, consequently, the risk will not be underestimated. Section 6.4 and Appendix F discuss uncertainties related to alluvium zone deposits data, models, and assumptions. For example, this section describes why results from single-hole hydraulic testing results were replaced with cross-hole hydraulic and tracer tests for determination of hydraulic properties of the alluvium in the saturated zone to more accurately predict the flow. 
- Subcriterion (3)-Uncertainty in parameter development for conceptual models, processlevel models, and alternative conceptual models was considered in Sections 6.2.4, 6.2.6, and 6.4, as well as in Appendix C, Sections C5, C6; and Appendix F, for developing the abstraction of flow paths in the saturated zone. This was accomplished through considerations of data sensitivity and the use of conservative limits. Discussions in these sections identify uncertainties in saturated zone flow parameters that could affect the analyses.

\section{Acceptance Criterion 4: Model Uncertainty Is Characterized and Propagated Through the Model Abstraction}

- Subcriterion (1)-Alternative modeling consistent with available data and current scientific understanding is considered in Sections 6.2 and 6.4, and in Appendices C and F. The results and limitations are appropriately considered in the models that support the abstraction.

- Subcriterion (2)-Conceptual model uncertainties are adequately defined and documented in Sections 6.2.6, 6.2.7, and 6.4, as well as in Appendix C, Sections C5, C6 and Appendix F, and their effects on conclusions regarding performance are properly assessed. Model uncertainties and limitations are discussed in Sections 6.2.7 and C5. Particularly, the uncertainties associated with the assumption that the aquifer behaves as an equivalent porous medium even though the flow system consists of a fracture network are discussed. Uncertainty in anisotropy ratios is examined in Sections 6.2.6 and C6. Conceptual flow models are also supported by site data. The most appropriate conceptual model of flow in the volcanics (predominant flow through the fracture network) is derived in Section 6.2.4 (and C7) based on consideration of all the C-wells hydrologic test results. Section 6.4 and Appendix F address the hydrogeologic properties of the alluvium and describe the measures that were taken (cross-hole hydraulic testing) to improve estimates of alluvium transmissivity and horizontal hydraulic conductivity that were obtained from initial single-well hydraulic tests.

- Subcriterion (3)-Consideration of conceptual model uncertainty is consistent with available site characterization data, field measurements, and process-level modeling studies as discussed in Sections 6.2.2 through 6.2.6, 6.4, with details provided in Appendix C, Sections C1 through C4, C6; Appendix F, Sections F1 and F2; see the responses to Acceptance Criteria 1 (1) and (3). Uncertainties in the report are summarized in Section 7.3.

- Subcriterion (4)-Appropriate alternative modeling approaches discussed in Sections 6.2.4, 6.2.6, and 6.4 (also Appendix C, Sections C3, C6; and Appendix F) are consistent with available data and current scientific knowledge, and appropriately consider their results and limitations, using tests and analyses that are sensitive to the processes modeled. Sections 6.2.3 and C3 describe different conceptual models that were obtained for the different test intervals in the fractured tuffs at the $\mathrm{C}$-wells based on the analyses of the interval responses to pumping. Depending on these responses, either a confined Equivalent Porous Medium (EPM), confined fissure block, unconfined EPM, or a leaky confined EPM model was selected as being most appropriate for the various 
intervals. In Section 6.2.6, anisotropy ratio analyses performed employ two different methods with different approaches considered for each (also described in Section C6.2.5. Section 6.4 indicates that the analytical solutions used for individual test interpretations were selected primarily on the basis of the conformance of the test responses to idealized responses predicted by alternative solutions/conceptual models.

\section{Acceptance Criterion 5: Model Abstraction Output Is Supported by Objective Comparisons}

- Subcriterion (4)-Sensitivity analyses that cover ranges of hydrogeologic parameter estimates consistent with site data, field experiments, and tests are discussed in Sections 6.2 and 6.4 (also in Appendices $\mathrm{C}$ and F). Corresponding ranges are provided for the major hydrogeologic parameters in support of the abstraction of flow paths in the saturated zone.

\subsubsection{Acceptance Criteria from Section 2.2.1.3.9.3, Radionuclide Transport in the Saturated Zone}

\section{Acceptance Criterion 1: System Description and Model Integration Are Adequate}

- Subcriterion (1)-The analyses described in Sections 6.3 and 6.5 (and in Appendices D and G) adequately incorporate important physical phenomena and couplings, and use consistent and appropriate assumptions to support the saturated zone transport abstraction process. Section 6.3 (and Appendix D) provides a thorough discussion of transport properties of fractured tuffs including field tracer tests, lithium sorption tests, diffusion cell experiments, transport calculations, and model analysis. Section 6.5 (and Appendix G) analyzes transport properties of the alluvium. In Appendix G, it is shown that three conceptual alluvium transport models were considered for the alluvium, and transport parameters were estimated from results of tracer tests.

- Subcriterion (2)-Sections 6.3 and 6.5 (and Appendices D and G) provide adequate descriptions of the aspects of hydrology, geology, geochemistry, physical phenomena, and couplings that may affect radionuclide transport in the saturated zone. The descriptions include field tracer tests and laboratory experiments (Appendices $\mathrm{E}$ and $\mathrm{H}$ ) designed to provide additional confidence in the model and in the physical and geochemical processes affecting radionuclide transport. Conditions and assumptions supporting the abstraction of radionuclide transport in the saturated zone are readily identified in Sections 6.3.3, 6.5.4, D4, D5, G1, and G4, and they are consistent with the body of data presented.

- Subcriterion (3)-Assumptions used in Sections 6.3 and 6.5 (and in Appendices D and G) for transport in the saturated zone are consistent with the total system performance assessment abstractions of radionuclide transport in the saturated zone. The detailed descriptions of the transport models and site data to which they were fitted and the associated technical bases provide transparent and traceable support for the abstraction of radionuclide transport in the saturated zone. 
- Subcriterion (5)-Sections 6.3 and 6.5 (and Appendices D and G) provide sufficient data and technical bases for the inclusion of features and processes related to radionuclide transport in the saturated zone supporting the total system performance assessment abstraction. Section 6.3 (and Appendix D) analyzes the results of cross-hole tracer tests in the fractured volcanics and experiments and conceptual models employed to predict the results. Sections 6.5.3 through 6.5.5 present the results and interpretations of three single-well injection-withdrawal tests in the alluvium. Several laboratory experiments that have been conducted to support the ATC testing effort are discussed in Appendix H.

- Subcriterion (6)-This document has been developed under Quality Assurance Requirements and Description (QARD) (DOE 2004 [DIRS 171539]).

\section{Acceptance Criterion 2: Data Are Sufficient for Model Justification}

- Subcriterion (1)-Geological, hydrological, and geochemical values used in the license application are adequately justified in Sections 6.3 and 6.5 (described in detail in Appendices D and G). Adequate descriptions of how the data were used, interpreted, and appropriately synthesized into the parameters are provided in those two sections. Detailed descriptions of the methods for obtaining data, interpretations of the data, and limitations on use of the data are provided in Sections 6.3 and 6.5 (and in Appendices D and $\mathrm{G}$ ) and in the supporting documents listed in Section 4.1 from which the data were taken.

- Subcriterion (2)-Sufficient data have been collected on the characteristics of the natural system, as summarized in Sections 6.3 and 6.5 (described in detail in Appendices D and $\mathrm{G})$, to establish boundary conditions for transport analyses supporting the total system performance assessment abstraction of radionuclide transport in the saturated zone. Section 6.3, Appendices D, and E describe the different transport boundary conditions used for interpreting the field and laboratory experiments for fractured volcanics. Sections 6.5, Appendices $\mathrm{G}$, and $\mathrm{H}$ discuss the different transport boundary conditions applicable to the field and laboratory experiments conducted in alluvium deposits.

- Subcriterion (3)-Data presented in Sections 6.3 and 6.5 on the geology, hydrology, and geochemistry of the saturated zone, including the influence of structural features, fracture distributions, fracture properties, and stratigraphy are based on appropriate techniques. These techniques include laboratory studies of lithium sorption and transport (Appendices $\mathrm{E}$ and $\mathrm{H}$ ), borehole gravimetry logging measurements for porosity (Appendix F), diffusion cell experiments (Appendix D), site-specific field tracer tests (single well and cross-hole) and process-level modeling studies. Sensitivity and uncertainty analyses performed as discussed in Sections 6.3 and 6.5 to support the total system performance assessment abstraction are adequate to determine the need for additional data. 


\section{Acceptance Criterion 3: Data Uncertainty Is Characterized and Propagated Through the Model Abstraction}

- Subcriterion (1)-Models use parameter values, assumed ranges, probability distributions, and bounding assumptions that are technically defensible, and reasonably account for uncertainties and variabilities. Sections 6.3.7, 6.5.5, 6.5.7; Appendix D, Sections D1, D3, D4, D5; Appendix E, Section E10; Appendix G, Sections G3 and G4 provide sensitivity and uncertainty estimations and analyses for various aspects of transport parameters.

- Subcriterion (2)-Sections 6.3 and 6.5 (with details in Appendices D, Sections D1 and D6, E, Sections E1, E2, E3, E4; G, Sections G1, G2, G3, G4; H, Sections H1 and H2 provide evidence that estimated flow and transport parameters are appropriate and valid, based on techniques that include laboratory studies of transport, borehole gravimetry logging measurements for porosity, diffusion cell experiments, site-specific field tracer tests (single well and cross-hole), lithium sorption tests, and process-level modeling studies conducted under conditions relevant to the saturated zone at Yucca Mountain. Models are demonstrated in Sections 6.3, D3, D4, and G1 to adequately predict field transport test results.

- Subcriterion (4)-Appendix D, Section D4 and Appendix G discuss how parameter values for different transport processes, including matrix diffusion, dispersion, and ground-water mixing, are based on reasonable assumptions about aquifer properties and ground-water volumetric fluxes.

- Subcriterion (5)-Sections 6.3, 6.5, Appendices D, Sections D1, D3, D4; E, Section E2; G, Sections G1, G3, and G4 show how adequate representations of uncertainty were developed in parameters for conceptual models, process-level models, and alternative conceptual models considered in this report and supporting the abstraction of radionuclide transport in the saturated zone. Both sensitivity analyses and conservative limits were used as discussed in those sections.

\section{Acceptance Criterion 4: Model Uncertainty Is Characterized and Propagated Through the Model Abstraction}

- Subcriterion (1)-Alternative modeling approaches of features, events, and processes are considered in Sections 6.3 and 6.5 (and in Appendices D and G) and are consistent with available data and current scientific understanding, and the results and limitations are appropriately considered in the abstraction. Appendix D Sections D3, D5, and Appendix G, Section G1 particularly, discuss conceptual models considered and justify the selection of the appropriate models.

- Subcriterion (2)-Conceptual model uncertainties are adequately defined and documented, and effects on conclusions regarding performance are properly assessed in Sections 6.3.7, 6.5.7, Appendices D, Sections D1, D3, D4, D5; E, Sections E2 and E4; G, Sections G3 and G4. 
- Subcriterion (3)-Consideration of conceptual model uncertainty is consistent with available site characterization data, laboratory experiments, field measurements, and process-level modeling studies shown throughout Sections 6.3 and 6.5 (and Appendices $\mathrm{D}$ and $\mathrm{G})$.

- Subcriterion (4)-Appropriate alternative modeling approaches discussed in Sections 6.3 and 6.5 and, more specifically, in Appendix D, Sections D3, D5, and Appendix G, Section G1, are consistent with available data and current scientific knowledge, and appropriately consider their results and limitations using tests and analyses that are sensitive to the processes modeled. For example, for radionuclide transport through fractures in volcanic rocks and porous media in alluvium, the report adequately considers alternative modeling approaches to develop its understanding of distributions and ranges of transport properties in the saturated zone.

\subsection{OUTPUTS}

Table 7-1 lists the output data for this scientific report. The data will be used primarily to support the development of CDFs for various flow and transport parameters used in TSPA simulations. These CDFs are documented in the SZ flow and transport abstraction model report (BSC 2004 [DIRS 170042]). The horizontal hydraulic conductivity anisotropy ratio described in Section 6.2.6 will also be used to support flow model calibrations described in the revision to the SZ flow model report (BSC 2004 [DIRS 170037]). Also, transport parameters and tracer breakthrough curves from C-wells tracer testing (Sections 6.3 and Appendix D) will be used in the model validation section of the revision to the SZ transport model report (BSC 2004 [DIRS 170036]) and in the development of colloid transport parameter distributions in the revision to the SZ colloid transport scientific report (BSC 2004 [DIRS 170006]).

The steps involved in processing the input data listed in Table 4-1 to arrive at the output data listed in Table 7-1 is often quite involved and is unique to each output DTN. Appendix I lists all the steps associated with this process for Figure C-21 (an example for a hydraulic test interpretation) and for Figure 6.3-3 (an example for a tracer test interpretation). These examples are provided for the benefit of the reader who is interested in following this process for any given table or figure appearing in this report (including all appendices). However, the reader is cautioned that each case will be slightly different, and that all steps for any given figure or table are not necessarily represented in Appendix I.

Table 7-1. Output Data

\begin{tabular}{|l|c|l|}
\hline \multicolumn{1}{|c|}{ Data Description } & Data Tracking Number & \multicolumn{1}{c|}{$\begin{array}{c}\text { Location of Output DTNs } \\
\text { in This Report }\end{array}$} \\
\hline $\begin{array}{l}\text { Filtered UE-25 ONC-1 water levels, May 1996 to } \\
\text { November 1996 }\end{array}$ & GS030208312314.001 & Sections C6.1.2, C6.2.1 \\
\hline $\begin{array}{l}\text { Filtered UE-25 WT\#3, UE-25 WT\#14, and USW H-4 } \\
\text { water levels, May 1996 to December 1996 }\end{array}$ & GS030208312314.002 & Sections C6.1.2, C6.2.1 \\
\hline $\begin{array}{l}\text { Cooper-Jacob Transmissivity and Storativity Analysis } \\
\text { of Wells UE-25 ONC-1, UE-25 WT\#3, UE-25 WT\#14, } \\
\text { And USW H4 }\end{array}$ & SN0409T0502203.002 & $\begin{array}{l}\text { Tables 6.2-3, 6.2-4 } \\
\text { Figure C-41 } \\
\text { Tables C-10, C-12 }\end{array}$ \\
\hline
\end{tabular}


Table 7-1. Output Data (Continued)

\begin{tabular}{|c|c|c|}
\hline Data Description & Data Tracking Number & $\begin{array}{l}\text { Location of Output DTNs } \\
\text { in This Report }\end{array}$ \\
\hline $\begin{array}{l}\mathrm{PDF} \text { and CDF for in north-south/east-west anisotropy } \\
\text { ratio in fractured volcanics }\end{array}$ & SN0302T0502203.001 & $\begin{array}{l}\text { Section } 6.2 .6 \\
\text { Figure } 6.2-3 \\
\text { Figure C-46 } \\
\text { Section } 66.3\end{array}$ \\
\hline $\begin{array}{l}\text { Analysis of hydrologic properties of fractured tuffs } \\
\text { (C-wells complex) }\end{array}$ & GS031008312314.004 & $\begin{array}{l}\text { Tables } 6.2-1,6.6-2 \\
\text { Figures } 6.2-2 \text { to } 6.2-4 \\
\text { Figures C-1 to C-45 } \\
\text { Tables C-1 to C-10 } \\
\text { Table C-12 }\end{array}$ \\
\hline Analysis of hydraulic testing, ATC & GS031008312316.002 & $\begin{array}{l}\text { Figure } 6.4-1 \\
\text { Figure F-2 } \\
\text { Figures F-4 to F-8 } \\
\text { Figures F-10 to F-13 } \\
\text { Figures F-23 to F-24 } \\
\text { Sections F1.2 to F1.5 } \\
\text { Sections F2, F2.1 } \\
\text { Sections F3, F4 }\end{array}$ \\
\hline Analysis of tracer testing, C-wells, Bullfrog, and Tram & GS031008312315.002 & $\begin{array}{l}\text { Figure D-1 } \\
\text { Figures D-3 to D-9 } \\
\text { Figures D-12 to D-13 } \\
\text { Figures D-15 to D-16 } \\
\text { Tables D-2 to D-3 }\end{array}$ \\
\hline Analysis of tracer testing, ATC & GS031008312316.003 & $\begin{array}{l}\text { Figures G-24 to G-26 } \\
\text { Figure G-28 } \\
\text { Sections G4.2.4, G4.5 } \\
\text { Section G5 }\end{array}$ \\
\hline Simulations/modeling of field tracer tests & LA0303PR831231.003 & $\begin{array}{l}\text { Figures } 6.3-2,6.3-3 \\
\text { Table } 6.3-3 \\
\text { Figures D-26 to D-30 } \\
\text { Figures E-40 to E-41 } \\
\text { Tables D-6 to D-9 }\end{array}$ \\
\hline $\begin{array}{l}\text { Fitting or simulations of lithium sorption to C-wells } \\
\text { tuffs. }\end{array}$ & LA0303PR831341.003 & $\begin{array}{l}\text { Figures E-2 to E-9 } \\
\text { Figure E-37 } \\
\text { Table E-4 }\end{array}$ \\
\hline $\begin{array}{l}\text { Cation exchange capacity calculations for C-wells } \\
\text { tuffs }\end{array}$ & LA0303PR831341.001 & $\begin{array}{l}\text { Figure E-10 } \\
\text { Table E-5 }\end{array}$ \\
\hline $\begin{array}{l}\text { DIFFCELL V } 2.0 \text { (STN: } 10557-2.0-00 \\
\text { [DIRS 159063]) simulations of diffusion cell data }\end{array}$ & LA0303PR831362.001 & $\begin{array}{l}\text { Figures E-12 to E-19 } \\
\text { Tables E-6; E-18 }\end{array}$ \\
\hline $\begin{array}{l}\text { Simulations of crushed C-wells tuff column } \\
\text { experiments }\end{array}$ & LA0303PR831361.003 & $\begin{array}{l}\text { Figures E-20 to E-28 } \\
\text { Figure E-38 } \\
\text { Table E-7 }\end{array}$ \\
\hline Simulations of C-wells fractured core experiments & LA0303PR831361.004 & $\begin{array}{l}\text { Figures E-31 to E-36 } \\
\text { Figure E-41 } \\
\text { Tables E-14 to E-18 }\end{array}$ \\
\hline $\begin{array}{l}\text { Calculations to obtain values reported in tables and } \\
\text { figures (generally combinations of other values } \\
\text { reported or unit conversions) }\end{array}$ & LA0303PR831231.005 & $\begin{array}{l}\text { Tables } 6.3-3,6.3-4 \\
\text { Figure E-41 } \\
\text { Tables D-6 to D-8 } \\
\text { Tables D-10 to D-11 } \\
\text { Tables E-14 to E-17 } \\
\text { Table G-4 } \\
\text { Table H-5 }\end{array}$ \\
\hline
\end{tabular}


Table 7-1. Output Data (Continued)

\begin{tabular}{|c|c|c|}
\hline Data Description & Data Tracking Number & $\begin{array}{l}\text { Location of Output DTNs } \\
\text { in This Report }\end{array}$ \\
\hline $\begin{array}{l}\text { Predictions of transport behavior in single-well and } \\
\text { cross-hole tracer tests in the saturated alluvium at the } \\
\text { ATC }\end{array}$ & LA0303PR831231.001 & $\begin{array}{l}\text { Figures } \mathrm{G}-2 \text { to } \mathrm{G}-3 \text {, } \\
\text { G-5 to } \mathrm{G}-8, \mathrm{G}-16 \text { to } \mathrm{G}-17 \\
\text { Tables } \mathrm{G}-1 \text { to } \mathrm{G}-3 \\
\text { Section } \mathrm{G} 3\end{array}$ \\
\hline $\begin{array}{l}\text { Predictions of transport behavior in cross-hole tracer } \\
\text { tests in single-porosity media }\end{array}$ & LA0403PR831231.001 & $\begin{array}{l}\text { Figures } \mathrm{G}-9 \text { to } \mathrm{G}-10 \\
\text { G-12, G-14 to } \mathrm{G}-15 \\
\text { Table G-4 }\end{array}$ \\
\hline $\begin{array}{l}\text { Calculations to estimate ambient groundwater } \\
\text { velocity at NC-EWDP-19D from single-well tracer test } \\
\text { responses }\end{array}$ & LA0303PR831231.002 & $\begin{array}{l}\text { Figures } 6.5-1,6.5-2 \\
\text { Tables } 6.5-2,6.5-3 \\
\text { Figures G-19 to G-21 } \\
\text { Tables G-6 to G-7 } \\
\text { Section G4.2 }\end{array}$ \\
\hline $\begin{array}{l}\text { Calculations to determine microsphere detachment } \\
\text { rate constant in a single-well tracer test in saturated } \\
\text { alluvium at NC-EWDP-19D }\end{array}$ & LA0303PR831352.001 & Section G4.6 \\
\hline $\begin{array}{l}\text { Determination of cation exchange parameters from } \\
\text { EQUIL_FIT V } 1.0 \text { (STN: 10668-1.0-00 } \\
\text { [DIRS 159064]) fits to cation concentration data from } \\
\text { lithium batch sorption measurements onto alluvium } \\
\text { from different intervals in NC-EWDP-19P and -19D }\end{array}$ & LA0303PR831341.002 & $\begin{array}{l}\text { Figure } \mathrm{H}-32 \\
\text { Table } \mathrm{H}-10\end{array}$ \\
\hline $\begin{array}{l}\text { Simulations of column transport experiments in } \\
\text { alluvium from NC-EWDP-19D }\end{array}$ & LA0303PR831361.002 & $\begin{array}{l}\text { Figure } \mathrm{H}-31 \\
\text { Figures } \mathrm{H}-33 \text { to } \mathrm{H}-35 \\
\text { Table } \mathrm{H}-12\end{array}$ \\
\hline C-wells tracer test sensitivity calculations & LA0304PR831231.001 & $\begin{array}{l}\text { Figures } 6.3-4,6.3-5 \\
\text { Tables } 6.3-5,6.3-6 \\
\text { Figures D-31 to D-38 } \\
\text { Tables D-13 to D-14 }\end{array}$ \\
\hline
\end{tabular}

NOTE: $A T C=A l l u v i a l$ Testing Complex; DTN=data tracking number; STN=software tracking number.

\subsection{UNCERTAINTIES}

Discussions of uncertainties associated with the flow and transport parameters presented in this report can be found in the following sections:

- Hydraulic testing and test interpretations in saturated fractured volcanics at the C-wells are discussed in detail in Section 6.2.7 (also Appendix C, Section C5).

- Anisotropy of horizontal hydraulic conductivity in the fractured volcanics are discussed in Section 6.2.6.

- Tracer testing and test interpretations at the C-wells are discussed in detail in Section 6.3.7 (also Appendix D, Section D5).

- Hydraulic testing and test interpretations in the saturated alluvium at NC-EWDP-19D are discussed in Section 6.4.6 (also Appendix F, Section F4).

- Single-well tracer testing and test interpretations at the ATC are summarized in Section 6.5.6 and discussed in detail in Appendic G, Section G4.4. 
Uncertainty distributions for SZ flow and transport parameters are provided in the SZ transport model abstraction report (BSC 2004 [DIRS 170042]). The rationale for documenting the uncertainty distributions in the model abstraction report rather than in this scientific analysis is that the distributions are based only in part on the parameters (and their uncertainties) presented in this report. The only exception is that the uncertainty distribution for the north-south and east-west anisotropy ratio of horizontal hydraulic conductivity in the fractured volcanics is derived entirely from the information presented in this scientific analysis (Section 6.2.6 and Appendic C, Section C6).

Literature data, expert elicitation input, and peer review input were considered in the development of parameter distributions because of the limited spatial representation of the SZ offered by the C-wells and ATC hydraulic and tracer tests. Also, the time and distance scales of the C-wells and ATC tests were relatively small compared to time and distance scales of performance assessment calculations. One exception is the long-term $\mathrm{C}$-wells hydraulic test that led to the uncertainty distribution for hydraulic conductivity anisotropy ratio over an approximately $21 \mathrm{~km}^{2}$ area. Thus, the flow and transport parameters derived from the C-wells and ATC tests represent only discrete points in continuous distributions of parameter values spatially distributed throughout the SZ, and that potentially have scale dependencies that would not be revealed by $\mathrm{C}$-wells and ATC testing. The parameter uncertainty distributions in the SZ model abstraction report (BSC 2004 [DIRS 170042]) are consistent with and supported by the parameters presented in this report, but they generally consist of a much wider range of potential values because of representativeness and scale of the field tests. 


\section{INPUTS AND REFERENCES}

The following is a list of the references cited in this document. Column 2 represents the unique six digit numerical identifier (the Document Input Reference System number), which is placed in the text following the reference callout (e.g., BSC 2002 [DIRS 171585]). The purpose of these numbers is to assist in locating a specific reference. Within the reference list, multiple sources by the same author (e.g., BSC 2002) are sorted alphabetically by title.

\subsection{DOCUMENTS CITED}

Altman, W.D.; Donnelly, J.P.; and Kennedy, J.E. 1988. Qualification of Existing Data 103750 for High-Level Nuclear Waste Repositories: Generic Technical Position.

NUREG-1298. Washington, D.C.: U.S. Nuclear Regulatory Commission.

TIC: 200652.

Altman, W.D.; Donnelly, J.P.; and Kennedy, J.E. 1988. Peer Review for High-Level

103597

Nuclear Waste Repositories: Generic Technical Position. NUREG-1297.

Washington, D.C.: U.S. Nuclear Regulatory Commission. TIC: 200651.

Anghel, I.; Turin, H.J.; and Reimus, P.W. 2002. "Lithium Sorption to Yucca

164635

Mountain Tuffs." Applied Geochemistry, 17, (6), 819-824. New York, New York:

Pergamon. TIC: 254046.

Bachmat, Y.; Mandel, S.; and Bugayevski, M. 1988. "A Single-Well Tracer

Technique for Evaluating Aquifer Parameters, I. Theoretical Work." Journal of

Hydrology, 99, (1-2), 143-163. Amsterdam, The Netherlands: Elsevier. TIC: 254194.

Bear, J. 1979. Hydraulics of Groundwater. New York, New York: McGraw-Hill.

105038 TIC: 217574.

Becker, M.W. and Charbeneau, R.J. 2000. "First-Passage-Time Transfer Functions for

156633 Groundwater Tracer Tests Conducted in Radially Convergent Flow." Journal of Contaminant Hydrology, 40, (4), 299-310. New York, New York: Elsevier.

TIC: 251009.

Benson, C.F. and Bowman, R.S. 1994. "Tri- and Tetrafluorobenzoates as Nonreactive 122788 Tracers in Soil and Groundwater." Soil Science Society of America Journal, 58, (4), 1123-1129. Madison, Wisconsin: Soil Science Society of America. TIC: 246741.

Benson, C.F. and Bowman, R.S. 1996. "Erratum, Tri- and Tetrafluorobenzoates as 153427 Nonreactive Tracers in Soil and Groundwater." Soil Science Society of America Journal, 60, 1780. Madison, Wisconsin: Soil Science Society of America.

TIC: 246741.

Bolt, G.H. and Bruggenwert, M.G.M., eds. 1978. Soil Chemistry, A. Basic Elements. 113856 Developments in Soil Science 5A. 2nd Revised Edition. New York, New York: Elsevier. TIC: 243742. 
Borchardt, G. 1995. "Smectites." Chapter 14 of Minerals in Soil Environments. 2nd Edition. Dixon J.B. and Weed, S.B., eds. SSSA Book Series, No. 1. Madison, Wisconsin: Soil Science Society of America. TIC: 237222.

Bouwer, H. 1978. Groundwater Hydrology. McGraw-Hill Series in Water Resources and Environmental Engineering. New York, New York: McGraw-Hill. TIC: 244844.

Bowman, R.S. 1984. "Evaluation of Some New Tracers for Soil Water Studies." Soil 156645 Science Society of America Journal, 48, (5), 987-993. Madison, Wisconsin: Soil Science Society of America. TIC: 251011.

Brunauer, S.; Emmett, P.H.; and Teller, E. 1938. "Adsorption of Gases in 156646 Multimolecular Layers." Journal of American Chemical Society, 60, 309-319. Washington, D.C.: American Chemical Society. TIC: 224534.

Brusseau, M.L.; Hu, Q.; and Srivastava, R. 1997. "Using Flow Interruption to Identify Factors Causing Nonideal Contaminant Transport." Journal of Contaminant Hydrology, 24, (3/4), 205-219. New York, New York: Elsevier. TIC: 250759.

BSC (Bechtel SAIC Company) 2001. Data Qualification Report: Water Level Data 172175 from Nye County Wells for Use on the Yucca Mountain Project.

TDR-NBS-HS-000016 REV 00. Las Vegas, Nevada: Bechtel SAIC Company. ACC: MOL.20011218.0002.

BSC 2002. Test Plan for Alluvial Testing Complex-Single-Well, Multi-Well, and Laboratory Studies. SITP-02-SZ-003 REV 01 ICN 01. Las Vegas, Nevada: Bechtel SAIC Company. ACC: MOL.20020509.0351.

BSC 2004. Features, Events, and Processes in SZ Flow and Transport. ANL-NBS-MD-000002, Rev. 03. Las Vegas, Nevada: Bechtel SAIC Company.

BSC 2004. Hydrogeologic Framework Model for the Saturated Zone Site Scale Flow and Transport Model. MDL-NBS-HS-000024, Rev. 00. Las Vegas, Nevada: Bechtel 170008 SAIC Company.

BSC 2004. Probability Distribution for Flowing Interval Spacing.

ANL-NBS-MD-000003 REV 01. Las Vegas, Nevada: Bechtel SAIC Company. ACC: DOC.20040923.0003.

BSC 2004. Q-List. 000-30R-MGR0-00500-000-000 REV 00. Las Vegas, Nevada: Bechtel SAIC Company. ACC: ENG.20040721.0007.

BSC 2004. Radionuclide Transport Models Under Ambient Conditions. 164500 MDL-NBS-HS-000008 REV 02. Las Vegas, Nevada: Bechtel SAIC Company. ACC: DOC.20041101.0002. 
BSC 2004. Recharge and Lateral Groundwater Flow Boundary Conditions for the

170015 Saturated Zone Site-Scale Flow and Transport Model. ANL-NBS-MD-000010

REV 01. Las Vegas, Nevada: Bechtel SAIC Company. ACC: DOC.20041008.0004.

BSC 2004. Saturated Zone Colloid Transport. ANL-NBS-HS-000031 REV 02.

170006

Las Vegas, Nevada: Bechtel SAIC Company. ACC: DOC.20041008.0007.

BSC 2004. Saturated Zone Flow and Transport Model Abstraction.

170042

MDL-NBS-HS-000021 REV 02. Las Vegas, Nevada: Bechtel SAIC Company.

ACC: DOC.20041028.0003.

BSC 2004. Saturated Zone Site-Scale Flow Model. MDL-NBS-HS-000011, Rev. 02.

170037

Las Vegas, Nevada: Bechtel SAIC Company.

BSC 2004. Site-Scale Saturated Zone Transport. MDL-NBS-HS-000010 REV 02.

170036

Las Vegas, Nevada: Bechtel SAIC Company. ACC: DOC.20041103.0004.

BSC 2004. Technical Work Plan for: Natural System - Saturated Zone Analysis and

171421 Model Report Integration. TWP-NBS-MD-000002 REV 02 ICN 01. Las Vegas,

Nevada: Bechtel SAIC Company. ACC: DOC.20040818.0004.

Bussod, G. 2001. LA-EES-1-NBK-98-005, UZ Transport Test Notebook 2. Scientific Notebook SN-LANL-SCI-038-V1. ACC: MOL.20010830.0382.

Callahan, T. 2001. LA-CST-NMTECHA-NBK-96-001, Laboratory Investigation YMP C-Wells Reactive Tracers Test. Scientific Notebook SN-LANL-SCI-028-V1. ACC: MOL.20010830.0385.

Callahan, T.J. 2001. Laboratory Investigations and Analytical and Numerical 156649 Modeling of the Transport of Dissolved Solutes Through Saturated Fractured Rock. Ph.D. dissertation. Socorro, New Mexico: New Mexico Institute of Mining and Technology. TIC: 251010.

Callahan, T.J.; Reimus, P.W.; Bowman, R.S.; and Haga, M.J. 2000. "Using Multiple 156648 Experimental Methods to Determine Fracture/Matrix Interactions and Dispersion of Nonreactive Solutes in Saturated Volcanic Tuff." Water Resources Research, 36, (12), 3547-3558. Washington, D.C.: American Geophysical Union. TIC: 250760.

Canori, G.F. and Leitner, M.M. 2003. Project Requirements Document. 166275 TER-MGR-MD-000001 REV 02. Las Vegas, Nevada: Bechtel SAIC Company. ACC: DOC.20031222.0006.

Carr, M.D.; Waddell, S.J.; Vick, G.S.; Stock, J.M.; Monsen, S.A.; Harris, A.G.; Cork, 102046 B.W.; and Byers, F.M., Jr. 1986. Geology of Drill Hole UE25p\#1: A Test Hole Into Pre-Tertiary Rocks Near Yucca Mountain, Southern Nevada. Open-File Report 86-175. Menlo Park, California: U.S. Geological Survey.

ACC: HQS.19880517.2633. 
Chipera, S.J. and Bish, D.L. 1995. "Multireflection RIR and Intensity Normalizations

105075

for Quantitative Analyses: Applications to Feldspars and Zeolites." Powder

Diffraction, 10, (1), 47-55. Newtown Square, Pennsylvania: Joint Committee on

Powder Diffraction Standards. TIC: 222001.

Cohen, J.B.; Najita, J.; Karasaki, K.; and Simmons, A. 1996. Conceptual Model

156651

Development of Saturated Zone Flow in the Vicinity of C-Holes, Yucca Mountain,

Nevada. Berkeley, California: Lawrence Berkeley National Laboratory.

ACC: MOL.19961122.0314.

Cooper, H.H., Jr. and Jacob, C.E. 1946. "A Generalized Graphical Method for

150245

Evaluating Formation Constants and Summarizing Well-Field History." Transactions, American Geophysical Union, 27, (IV), 526-534. Washington, D.C.: American

Geophysical Union. TIC: 225279.

Craig, R.W. and Robison, J.H. 1984. Geohydrology of Rocks Penetrated by Test Well UE-25p\#1, Yucca Mountain Area, Nye County, Nevada. Water-Resources Investigations Report 84-4248. Denver, Colorado: U.S. Geological Survey. ACC: NNA.19890905.0209.

CRWMS M\&O 2000. Data Qualification Report: Flowing Interval Data for Use on the Yucca Mountain Project. TDR-NBS-GS-000017 REV 00. Las Vegas, Nevada: CRWMS M\&O. ACC: MOL.20000830.0191.

D’Agnese, F.A.; Faunt, C.C.; Turner, A.K.; and Hill, M.C. 1997. Hydrogeologic Evaluation and Numerical Simulation of the Death Valley Regional Ground-Water Flow System, Nevada and California. Water-Resources Investigations Report 96-4300. Denver, Colorado: U.S. Geological Survey. ACC: MOL.19980306.0253.

Dabros, T. and Van de Ven, T.G.M. 1982. "Kinetics of Coating by Colloidal 143278 Particles." Journal of Colloid and Interface Science, 89, (1), 232-244. Orlando, Florida: Academic Press. TIC: 224945.

Dabros, T. and van de Ven, T.G.M. 1983. "On the Effects of Blocking and Particle 156652 Detachment on Coating Kinetics." Journal of Colloid and Interface Science, 93, (2), 576-579. New York, New York: Academic Press. TIC: 224944.

Day, W.C.; Dickerson, R.P.; Potter, C.J.; Sweetkind, D.S.; San Juan, C.A.; Drake, 100027 R.M., II; and Fridrich, C.J. 1998. Bedrock Geologic Map of the Yucca Mountain Area, Nye County, Nevada. Geologic Investigations Series I-2627. Denver, Colorado: U.S. Geological Survey. ACC: MOL.19981014.0301.

Day, W.C.; Potter, C.J.; Sweetkind, D.S.; Dickerson, R.P.; and San Juan, C.A. 1998. 101557 Bedrock Geologic Map of the Central Block Area, Yucca Mountain, Nye County, Nevada. Miscellaneous Investigations Series Map I-2601. Washington, D.C.: U.S. Geological Survey. ACC: MOL.19980611.0339. 
De Wiest, R.J.M. 1965. Geohydrology. New York, New York: John Wiley \& Sons. TIC: 254221

Dean, J.A. 1992. Lange's Handbook of Chemistry. 14th Edition. New York, 100722 New York: McGraw-Hill. TIC: 240690.

Dickerson, R.P. and Drake, R.M., II 1998. "Structural Interpretation of Midway 102781 Valley, Yucca Mountain, Nevada.” High-Level Radioactive Waste Management, Proceedings of the Eighth International Conference, Las Vegas, Nevada, May 11-14, 1998. Pages 254-256. La Grange Park, Illinois: American Nuclear Society.

TIC: 237082.

DOE (U.S. Department of Energy) 2004. Quality Assurance Requirements and Description. DOE/RW-0333P, Rev. 16. Washington, D.C.: U.S. Department of Energy, Office of Civilian Radioactive Waste Management.

ACC: DOC.20040907.0002.

Eckstein, Y.; Yaalon, D.H.; and Yariv, S. 1970. "The Effect of Lithium on the Cation Exchange Behaviour of Crystalline and Amorphous Clays." Israel Journal of Chemistry, 8, 335-342. Jerusalem, Israel: Laser Pages Publishing. TIC: 251012.

Eddebbarh, A.A. 2004. “Anistropy Distribution.” Interoffice memorandum from A.A. 171918 Eddebbarh (BSC) to P. Reimus, October 5, 2004, 1004043437.

ACC: MOL.20041005.0224.

Ervin, E.M.; Luckey, R.R.; and Burkhardt, D.J. 1994. Revised Potentiometric-Surface Map, Yucca Mountain and Vicinity, Nevada. Water-Resources Investigations Report 93-4000. Denver, Colorado: U.S. Geological Survey. ACC: NNA.19930212.0018.

Fahy, M. 1997. "Masses Recovered from Tracer Testing at C-Wells." E-mail from M. 162811 Fahy to A. Randall, July 21, 1997. ACC: MOL.20030515.0196.

Fahy, M.F. 1997. "Dual-Porosity Analysis of Conservative Tracer Testing in 137456 Saturated Volcanic Rocks at Yucca Mountain in Nye County, Nevada." International Journal of Rock Mechanics and Mining Sciences. 34, (3-4). Amsterdam, The Netherlands: Elsevier. TIC: 237601.

Farrell, D.A.; Armstrong, A.; Winterle, J.R.; Turner, D.R.; Ferrill, D.A.; Stamatakos, J.A.; Coleman, N.M.; Gray, M.B.; and Sandberg, S.K. 1999. Structural Controls on Groundwater Flow in the Yucca Mountain Region. San Antonio, Texas: Center for Nuclear Waste Regulatory Analyses. TIC: 254265.

Faunt, C.C. 1997. Effect of Faulting on Ground-Water Movement in the Death Valley Region, Nevada and California. Water-Resources Investigations Report 95-4132.

Denver, Colorado: U.S. Geological Survey. ACC: MOL.19980429.0119. 
Ferrill, D.A.; Winterle, J.; Wittmeyer, G.; Sims, D.; Colton, S.; Armstrong, A.; and Morris, A.P. 1999. "Stressed Rock Strains Groundwater at Yucca Mountain, Nevada." GSA Today, 9, (5), 1-8. Boulder, Colorado: Geological Society of America.

TIC: 246229.

Fetter, C.W. 1993. Contaminant Hydrogeology. Upper Saddle River, New Jersey: Prentice Hall. TIC: 240691.

Freeze, R.A. and Cherry, J.A. 1979. Groundwater. Englewood Cliffs, New Jersey: 101173 Prentice-Hall. TIC: 217571.

Frizzell, V.A., Jr. and Shulters, J. 1990. Geologic Map of the Nevada Test Site, 105454 Southern Nevada. Miscellaneous Investigations Series Map I-2046.

Denver, Colorado: U.S. Geological Survey. TIC: 200459.

Galloway, D. and Rojstaczer, S. 1988. "Analysis of the Frequency Response of Water 156826 Levels in Wells to Earth Tides and Atmospheric Loading." Proceedings, Fourth Canadian/American Conference on Hydrogeology, Fluid Flow, Heat Transfer, and Mass Transport in Fractured Rocks, Banff, Alberta, Canada, June 21-24, 1988. Hitchon, B. and Bachu, S., eds. Pages 100-113. Dublin, Ohio: National Water Well Association. TIC: 222289.

Geldon, A.L. 1993. Preliminary Hydrogeologic Assessment of Boreholes UE-25c \#1, $U E-25 c$ \#2, and UE-25c \#3, Yucca Mountain, Nye County, Nevada. Water-Resources Investigations Report 92-4016. Denver, Colorado: U.S. Geological Survey. ACC: MOL.19960808.0136.

Geldon, A.L. 1996. Results and Interpretation of Preliminary Aquifer Tests in 100396 Boreholes UE-25c \#1, UE-25c \#2, and UE-25c \#3, Yucca Mountain, Nye County, Nevada. Water-Resources Investigations Report 94-4177. Denver, Colorado: U.S. Geological Survey. ACC: MOL.19980724.0389.

Geldon, A.L.; Earle, J.D.; and Umari, A.M.A. 1997. Determination of Barometric Efficiency and Effective Porosity, Boreholes UE-25, c\#1, UE-25 c\#2, and UE-25 c\#3, Yucca Mountain, Nye County, Nevada. Water-Resources Investigations Report 974098. Denver, Colorado: U.S. Geological Survey. ACC: MOL.19980226.0570.

Geldon, A.L.; Umari, A.M.A.; Earle, J.D.; Fahy, M.F.; Gemmell, J.M.; and Darnell, J. 129721 1998. Analysis of a Multiple-Well Interference Test in Miocene Tuffaceous Rocks at the C-Hole Complex, May-June 1995, Yucca Mountain, Nye County, Nevada. Water-Resources Investigations Report 97-4166. Denver, Colorado: U.S. Geological Survey. TIC: 236724.

Geldon, A.L.; Umari, A.M.A.; Fahy, M.F.; Earle, J.D.; Gemmell, J.M.; and Darnell, J. 161163 2002. Results of Hydraulic Tests in Miocene Tuffaceous Rocks at the C-Hole Complex, 1995 to 1997, Yucca Mountain, Nye County, Nevada. Water-Resources Investigations Report 02-4141. Denver, Colorado: U.S. Geological Survey. TIC: 253755. 
Graves, R.P.; Tucci, P.; and O’Brien, G.M. 1997. Analysis of Water-Level Data in the 101046 Yucca Mountain Area, Nevada, 1985-95. Water-Resources Investigations Report 96-4256. Denver, Colorado: U.S. Geological Survey. ACC: MOL.19980219.0851.

Grisak, G.E. and Pickens, J.F. 1980. "Solute Transport Through Fractured Media, 1. 101132 The Effect of Matrix Diffusion." Water Resources Research, 16, (4), 719-730. Washington, D.C.: American Geophysical Union. TIC: 222056.

Guimerà, J. and Carrera, J. 2000. "A Comparison of Hydraulic and Transport Parameters Measured in Low-Permeability Fractured Media." Journal of Contaminant Hydrology, 41, (3-4), 261-281. New York, New York: Elsevier. TIC: 251013.

Haggerty, R. and Gorelick, S.M. 1995. "Multiple-Rate Mass Transfer for Modeling 156831 Diffusion and Surface Reactions in Media with Pore-Scale Heterogeneity." Water Resource Research, 31, (10), 2383-2400. Washington, D.C.: American Geophysical Union. TIC: 244502.

Haggerty, R.; McKenna, S.A.; and Meigs, L.C. 2000. "On the Late-Time Behavior of 156832 Tracer Test Breakthrough Curves." Water Resources Research, 36, (12), 3467-3479. Washington, D.C.: American Geophysical Union. TIC: 250770.

Hantush, M.S. 1956. "Analysis of Data from Pumping Tests in Leaky Aquifers." Transactions, American Geophysical Union, 37, (6), 702-714. Washington, D.C.: American Geophysical Union. TIC: 255072.

Hantush, M.S. 1966. "Analysis of Data from Pumping Tests in Anisotropic Aquifers." Journal of Geophysical Research, 71, (2), 421-426. Washington, D.C.: American Geophysical Union. TIC: 225281.

Happel, J. and Brenner, H. 1965. Low Reynolds Number Hydrodynamics with Special Applications to Particulate Media. Englewood Cliffs, New Jersey: Prentice-Hall. TIC: 251939.

Harrar, J.E.; Carley, J.F.; Isherwood, W.F.; and Raber, E. 1990. Report of the 100814 Committee to Review the Use of J-13 Well Water in Nevada Nuclear Waste Storage Investigations. UCID-21867. Livermore, California: Lawrence Livermore National Laboratory. ACC: NNA.19910131.0274.

Hiemenz, P.C. 1986. Principles of Colloid and Surface Chemistry. 2nd Edition, Revised and Expanded. Undergraduate Chemistry Volume 9. Lagowski, J.J., ed. New York, New York: Marcel Dekker. TIC: 246392.

Israelachvili, J.N. 2000. Intermolecular and Surface Forces. 2nd Edition. San Diego, 156835 California: Academic Press. TIC: 251020.

Jenson, V.G. and Jeffreys, G.V. 1977. Mathematical Methods in Chemical 156836 Engineering. 2nd Edition. Orlando, Florida: Academic Press. TIC: 251165. 
Johnson, G.W. 1994. Labview Graphical Programming, Practical Applications in

Kasenow, M. 2002. Determination of Hydraulic Conductivity from Grain Size

164666 Analysis, with Errata and Grain-Size Analysis Supplement CDROM. Highlands Ranch, Colorado: Water Resources Publications. TIC: 254721.

Lahoud, R.G.; Lobmeyer, D.H.; and Whitfield, M.S., Jr. 1984. Geohydrology of Volcanic Tuff Penetrated by Test Well UE-25b \#1, Yucca Mountain, Nye County, Nevada. Water-Resources Investigations Report 84-4253. Denver, Colorado: U.S. Geological Survey. ACC: NNA.19890511.0117.

LeCain, G.D.; Anna, L.O.; and Fahy, M.F. 2000. Results from Geothermal Logging, Air and Core-Water Chemistry Sampling, Air-Injection Testing, and Tracer Testing in the Northern Ghost Dance Fault, Yucca Mountain, Nevada, November 1996 to August 1998. Water-Resources Investigations Report 99-4210. Denver, Colorado: U.S. Geological Survey. TIC: 247708.

Levenspiel, O. 1972. Chemical Reaction Engineering. 2nd Edition. New York, New York: John Wiley \& Sons. TIC: 224877.

Lohman, S.W. 1972. Ground-Water Hydraulics. Professional Paper 708. Washington, D.C.: U.S. Geological Survey. ACC: NNA.19891220.0169.

Luckey, R.R.; Tucci, P.; Faunt, C.C.; Ervin, E.M.; Steinkampf, W.C.; D’Agnese, F.A.; 100465 and Patterson, G.L. 1996. Status of Understanding of the Saturated-Zone GroundWater Flow System at Yucca Mountain, Nevada, as of 1995. Water-Resources Investigations Report 96-4077. Denver, Colorado: U.S. Geological Survey. ACC: MOL.19970513.0209.

Moench, A.F. 1989. "Convergent Radial Dispersion: A Laplace Transform Solution for Aquifer Tracer Testing." Water Resources Research, 25, (3), 439-447. Washington, D.C.: American Geophysical Union. TIC: 238283.

Moench, A.F. 1995. "Convergent Radial Dispersion in a Double-Porosity Aquifer with Fracture Skin: Analytical Solution and Application to a Field Experiment in Fractured Chalk." Water Resources Research, 31, (8), 1823-1835. Washington, D.C.: American Geophysical Union. TIC: 233132.

National Research Council. 1996. Rock Fractures and Fluid Flow, Contemporary Understanding and Applications. Washington, D.C.: National Academy Press. TIC: 235913.

Neretnieks, I. 1980. "Diffusion in the Rock Matrix: An Important Factor in 101148 Radionuclide Retardation." Journal of Geophysical Research, 85, (B8), 4379-4397. Washington, D.C.: American Geophysical Union. TIC: 221345. 
Neuman, S.P. 1975. "Analysis of Pumping Test Data from Anisotropic Unconfined 150321 Aquifers Considering Delayed Gravity Response." Water Resources Research, 11, (2), 329-342. Washington, D.C.: American Geophysical Union. TIC: 222414.

Neuman, S.P. 1990. "Universal Scaling of Hydraulic Conductivities and Dispersivities 101464 in Geologic Media." Water Resources Research, 26, (8), 1749-1758. Washington, D.C.: American Geophysical Union. TIC: 237977.

Newman, B.D.; Fuentes, H.R.; and Polzer, W.L. 1991. "An Evaluation of Lithium 156849 Sorption Isotherms and Their Application to Ground-Water Transport." Ground Water, 29, (6), 818-824. Worthington, Ohio: Water Well Journal Publishing. TIC: 203790.

Newman, J. 1973. Electrochemical Systems. Englewood Cliffs, New Jersey: Prentice-Hall. TIC: 210201.

NRC (U.S. Nuclear Regulatory Commission) 2003. Yucca Mountain Review Plan, Final Report. NUREG-1804, Rev. 2. Washington, D.C.: U.S. Nuclear Regulatory Commission, Office of Nuclear Material Safety and Safeguards. TIC: 254568.

NRC (U.S. Nuclear Regulatory Commission) 2004. Risk Insights Baseline Report. Washington, D.C.: U.S. Nuclear Regulatory Commission, Office of Nuclear Material Safety and Safeguards. ACC: MOL.20040629.0235.

NWRPO (Nye County Nuclear Waste Repository Project Office) 2003. "Program Management." Pahrump, Nevada: Nye County Nuclear Waste Repository Project Office. Accessed December 12, 2003. ACC: MOL.20031212.0014. http://www.nyecounty.com/Program_mgmnt.htm

Nye County Nuclear Waste Repository Project Office. 1995. Borehole UE-25 ONC \#1 156859 and USW NRG-4 Drilling and Instrumentation Report, Yucca Mountain, Nevada, September 1, 1995, Nye County Independent Scientific Investigation Program. Pahrump, Nevada: Nye County Nuclear Waste Repository Project Office. ACC: MOL.19960910.0231.

O’Brien, G.M.; Tucci, P.; and Burkhardt, D.J. 1995. Water Levels in the Yucca 101279 Mountain Area, Nevada, 1992. Open-File Report 94-311. Denver, Colorado: U.S. Geological Survey. ACC: NNA.19940627.0003.

Papadopulos, I.S. 1967. "Nonsteady Flow to a Well in an Infinite Anisotropic Aquifer." Hydrology of Fractured Rocks, Proceedings of the Dubrovnik Symposium, October 1965. 1, 21-31. Gentbrugge, Belgium: Association Internationale d'Hydrologie Scientifique. TIC: 223152.

Papadopulos, S.S. and Cooper, H.H., Jr. 1967. "Drawdown in a Well of Large 150323 Diameter." Water Resources Research, 3, (1), 241-244. Washington, D.C.: American Geophysical Union. TIC: 225288. 
Reimus, P. 2000. General C-Wells Notebook and Microsphere Analyses for C-Wells. 165125 Scientific Notebook SN-LANL-SCI-214-V1. ACC: MOL.20000413.0220;

MOL.20000824.0084.

Reimus, P. 2000. LA-CST-CW-NBK-98-001, YMP C-Wells Rocks. Scientific

165124

Notebook SN-LANL-SCI-146-V1. ACC: MOL.20010308.0191.

Reimus, P. 2000. LA-CST-CW-NBK-98-003, YMP C-Wells Sorption. Scientific Notebook SN-LANL-SCI-006-V1. ACC: MOL.20010308.0193.

Reimus, P. 2000. LA-CST-CW-NBK-98-004, YMP C-Wells Diffusion Cells.

Scientific Notebook SN-LANL-SCI-007-V1. ACC: MOL.20010308.0195.

Reimus, P. 2000. LANL C-Wells Prow Pass Field Notebook. Scientific Notebook SN-LANL-SCI-233-V1. ACC: MOL.20000824.0066.

Reimus, P. 2003. LA-CST-NBK-98-011, Modeling and Interpretation of Transport Tests. Scientific Notebook SN-LANL-SCI-255-V1. ACC：MOL.20020206.0093; MOL.20031027.0086; MOL.20031027.0087.

Reimus, P. 2003. Laboratory Testing in Support of Saturated Zone Investigations. 163760 Scientific Notebook SN-LANL-SCI-280-V1. ACC: MOL.20030227.0286.

Reimus, P.W. 1995. The Use of Synthetic Colloids in Tracer Transport Experiments in 101474 Saturated Rock Fractures. Ph.D. dissertation. LA-13004-T. Los Alamos, New Mexico: Los Alamos National Laboratory. TIC: 240694.

Reimus, P.W. 2000. C-Wells Bullfrog Multiple Tracer Test Notebook. Scientific 162855 Notebook SN-LANL-SCI-223-V1. ACC: MOL.20000818.0075.

Reimus, P.W. 2000. LA-EES-4-NBK-96-003(b), C-Wells Bullfrog Multiple Tracer 164624

Test. Scientific Notebook for SN-LANL-SCI-224-V1. ACC: MOL.20000824.0094.

Reimus, P.W. 2000. QA Notebook for C-Wells Tracer Testing (PFBA/C\#2 Test). Scientific Notebook SN-LANL-SCI-217-V1. ACC: MOL.20000818.0063.

Reimus, P.W. 2000. QA Notebook Iodide/C\#1 Tracer Test. Scientific Notebook 165127 SN-LANL-SCI-218-V1. ACC: MOL.20000818.0071.

Reimus, P.W. 2003. Single-Well and Cross-Hole Alluvial Tracer Testing. Scientific 165128 Notebook SN-LANL-SCI-251-V1. ACC: MOL.20030313.0331; MOL.20030313.0332; MOL.20030313.0333; MOL.20030313.0334.

Reimus, P.W. and Haga, M.J. 1999. Analysis of Tracer Responses in the BULLION Forced-Gradient Experiment at Pahute Mesa, Nevada. LA-13615-MS. Los Alamos, New Mexico: Los Alamos National Laboratory. TIC: 249826. 
Robinson, B.A. 1994. "A Strategy for Validating a Conceptual Model for 101154 Radionuclide Migration in the Saturated Zone Beneath Yucca Mountain." Radioactive Waste Management and Environmental Restoration, 19, (1-3), 73-96. Yverdon, Switzerland: Harwood Academic Publishers. TIC: 222513.

Robinson, R.A. and Stokes, R.H. 1965. Electrolyte Solutions, The Measurement and Interpretation of Conductance, Chemical Potential and Diffusion in Solutions of Simple Electrolytes. 2nd Edition (Revised). Washington, D.C.: Butterworth. TIC: 242575.

Skagius, K. and Neretnieks, I. 1986. "Porosities and Diffusivities of Some Nonsorbing Species in Crystalline Rocks." Water Resources Research, 22, (3), 389-398.

Washington, D.C.: American Geophysical Union. TIC: 225291.

Stetzenbach, K.J. and Thompson, G.M. 1983. "A New Method for Simultaneous Measurement of $\mathrm{Cl}^{-}, \mathrm{Br}^{-}, \mathrm{NO}_{3}{ }^{-}, \mathrm{SCN}^{-}$, and $\mathrm{I}^{-}$at $\mathrm{Sub}$-ppm Levels in Ground Water." Ground Water, 21, (1), 36-41. Worthington, Ohio: Water Well Journal Publishing. TIC: 252098.

Streltsova-Adams, T.D. 1978. "Well Hydraulics in Heterogeneous Aquifer 150754 Formations." Volume 11 of Advances in Hydroscience. Chow, V.T., ed.. Pages 357-423. New York, New York: Academic Press. TIC: 225957.

Sullivan, E.J. 2002. Laboratory Testing in Support of Alluvial Tracer Testing. 164623 Scientific Notebook SN-LANL-SCI-213-V1. ACC: MOL.20021015.0198.

Tang, D.H.; Frind, E.O.; and Sudicky, E.A. 1981. "Contaminant Transport in Fractured Porous Media: Analytical Solution for a Single Fracture." Water Resources Research, 17, (3), 555-564. Washington, D.C.: American Geophysical Union. TIC: 225358.

Theis, C.V. 1935. "The Relation Between the Lowering of the Piezometric Surface 150327 and the Rate and Duration of Discharge of a Well Using Ground-Water Storage." Transactions of the American Geophysical Union Sixteenth Annual Meeting, April 25 and 26, 1935, Washington, D.C. Pages 519-524. Washington, D.C.: National Academy of Science, National Research Council. TIC: 223158.

Thompson, J.L. 1989. "Actinide Behavior on Crushed Rock Columns." Journal of 100830 Radioanalytical and Nuclear Chemistry, Articles, 130, (2), 353-364. Lausanne, Switzerland: Elsevier. TIC: 222698.

Treher, E.N. and Raybold, N.A. 1982. The Elution of Radionuclides Through Columns of Crushed Rock from the Nevada Test Site. LA-9329-MS. Los Alamos, New Mexico: Los Alamos National Laboratory. ACC: NNA.19920922.0021. 
Triay, I.R.; Meijer, A.; Conca, J.L.; Kung, K.S.; Rundberg, R.S.; Strietelmeier, B.A.;

100422 and Tait, C.D. 1997. Summary and Synthesis Report on Radionuclide Retardation for the Yucca Mountain Site Characterization Project. Eckhardt, R.C., ed. LA-13262-MS. Los Alamos, New Mexico: Los Alamos National Laboratory.

ACC: MOL.19971210.0177.

Tsang, Y.W. 1992. "Usage of "Equivalent Apertures" for Rock Fractures as Derived 113901 from Hydraulic and Tracer Tests." Water Resources Research, 28, (5), 1451-1455. Washington, D.C.: American Geophysical Union. TIC: 245891.

Tucci, P. and Burkhardt, D.J. 1995. Potentiometric-Surface Map, 1993, Yucca 101060 Mountain and Vicinity, Nevada. Water-Resources Investigations Report 95-4149. Denver, Colorado: U.S. Geological Survey. ACC: MOL.19960924.0517.

Umari, A.M.J.; Geldon, A.; Patterson, G.; Gemmell, J.; Earle, J.; and Darnell, J. 1994. 164543 "Use of an Analog Site Near Raymond, California, to Develop Equipment and Methods for Characterizing a Potential High-Level, Nuclear Waste Repository Site at Yucca Mountain, Nevada." High Level Radioactive Waste Management, Proceedings of the Fifth Annual International Conference, Las Vegas, Nevada, May 22-26, 1994. 4, 2413-2422. La Grange Park, Illinois: American Nuclear Society. TIC: 210984.

USGS (U.S. Geological Survey) n.d. Bulk Density. Denver, Colorado: U.S. Geological Survey. ACC: NNA.19940406.0076.

Valocchi, A.J. 1985. "Validity of the Local Equilibrium Assumption for Modeling Sorbing Solute Transport Through Homogeneous Soils." Water Resources Research, 21, (6), 808-820. Washington, D.C.: American Geophysical Union. TIC: 223203.

van Genuchten, M.Th.; Wierenga, P.J.; and O’Connor, G.A. 1977. "Mass Transfer Studies in Sorbing Porous Media: III. Experimental Evaluation with 2,4,5-T." Soil Science Society of America Journal, 41, 278-285. Madison, Wisconsin: Soil Science Society of America. TIC: 251016.

Vaughn, D.E.W. 1978. "Properties of Natural Zeolites." Natural Zeolites, 156867 Occurrence, Properties, Use, A Selection of Papers Presented at Zeolite, 76, an International Conference on the Occurrence, Properties, and Utilization of Natural Zeolites, Tucson, Arizona, June 1976. Sand, L.B. and Mumpton, F.A., eds. Pages 353-371. New York, New York: Pergamon Press. TIC: 206755.

Weast, R.C. and Astle, M.J., eds. 1981. CRC Handbook of Chemistry and Physics. 62nd Edition. Boca Raton, Florida: CRC Press. TIC: 240722.

Whitfield, M.S., Jr.; Thordarson, W.; and Eshom, E.P. 1984. Geohydrologic and Drill-Hole Data for Test Well USW H-4, Yucca Mountain, Nye County, Nevada. Open-File Report 84-449. Denver, Colorado: U.S. Geological Survey. ACC: NNA.19870407.0317. 
Winterle, J.R. and La Femina, P.C. 1999. Review and Analysis of Hydraulic and

Tracer Testing at the C-Holes Complex Near Yucca Mountain, Nevada. San Antonio,

Texas: Center for Nuclear Waste Regulatory Analyses. TIC: 246623.

YMP (Yucca Mountain Site Characterization Project) 1998. Saturated Zone C-Hole

104211

Tracer Testing. Field Work Package FWP-SB-97-008, Rev. 1. Las Vegas, Nevada:

Yucca Mountain Site Characterization Office. ACC: MOL.19981029.0058.

Zyvoloski, G.A.; Robinson, B.A.; Dash, Z.V.; and Trease, L.L. 1997. Summary of the

Models and Methods for the FEHM Application-A Finite-Element Heat-and Mass-Transfer Code. LA-13307-MS. Los Alamos, New Mexico: Los Alamos

National Laboratory. TIC: 235587.

\subsection{CODES, STANDARDS, REGULATIONS, AND PROCEDURES}

10 CFR 50. 2002. Energy: Domestic Licensing of Production and Utilization

Facilities. Readily available.

10 CFR 63. Energy: Disposal of High-Level Radioactive Wastes in a Geologic

Repository at Yucca Mountain, Nevada. Readily available.

AP-2.22Q, Rev. 1, ICN 1. Classification Analyses and Maintenance of the Q-List. Washington, D.C.: U.S. Department of Energy, Office of Civilian Radioactive Waste Management. ACC: DOC.20040714.0002.

AP-SI.1Q REV 5, ICN 2, Software Management. Washington, D.C.: Department of Energy, Office of Civilian Radioactive Waste Management.

ACC: DOC.20030902.0003.

AP-SIII.2Q REV 1, ICN 2, Qualification of Unqualified Data. Washington, D.C.: Department of Energy, Office of Civilian Radioactive Waste Management. ACC: DOC.20040127.0008

AP-SIII.9Q, REV. 1 ICN 7. Scientific Analyses. Washington, D.C.: U.S. Department of Energy, Office of Civilian Radioactive Waste Management.

ACC: DOC.20040920.0001.

\subsection{SOURCE DATA, LISTED BY DATA TRACKING NUMBER}

GS010508312315.001. Concentrations of Difluorobenzoic Acid and Pyridone from

Tracer Tests Conducted at the C-Well Complex, 1/8/97 - 7/11/97.

Submittal date: 06/01/2001.

GS010799992315.001. Injection and Production Flow Rates for the LANL Prow Pass Test, 11/30/98 through 1/27/99. Submittal date: 07/25/2001. 
GS011008314211.001. Interpretation of the Lithostratigraphy in Deep Boreholes NC- 158690 EWDP-19D1 and NC-EWDP-2DB Nye County Early Warning Drilling Program.

Submittal date: 01/16/2001.

GS020708312316.001. NC-EWDP-19D, ATC Single-Hole Hydraulic Testing

162678

Associated with the July 7, 2000 to April 26, 2001 Tracer Study.

Submittal date: 09/10/2002.

GS020908312316.002. Flow Rates, Pressures, and Temperatures for Hydraulic and

162679

Tracer Testing at the NC-EWDP-19D, NC-EWDP-19IM1, and NC-EWDP-19IM2

Alluvial Testing Complex from December 18, 2001 to March 22, 2002.

Submittal date: 09/30/2002.

GS020908312316.003. Background Pressures and Temperatures During Barometric

Monitoring at the NC-EWDP-19D, NC-EWDP-19IM1, and NC-EWDP-19IM2

Alluvial Testing Complex from May 1, 2002 through July 3, 2002.

Submittal date: 10/15/2002.

GS030508312314.003. Results of Hydraulic Tests in Miocene Tuffaceous Rocks at the 164425 C-Hole Complex, 1995 to 1997, Yucca Mountain, Nevada.

Submittal date: 05/08/2003.

GS931008312313.016. Results and Interpretation of Preliminary Aquifer Tests in 148173 Boreholes UE-25C \#1, UE-25C \#2, and UE-25C \#3, Yucca Mountain, Nye County, Nevada. Submittal date: 09/29/1993.

GS960108312313.001. 280 Gallon per Minute Pump Test at the C-Hole Complex. Submittal date: 01/24/1996.

GS960108312313.002. 6/12/95 356 GPM Test in UE-25 C\#3 with C\#1 and C\#2 Packed Off. Submittal date: 01/23/1996.

GS960808312315.001. Data Obtained from the Analysis of the Iodide-Tracer-Test 159235 Water Samples Collected During the 2/13/96 Convergent-Tracer Test Conducted at the C-Well Complex. Submittal date: 08/12/1996.

GS970308312314.002. Water-Level Altitude Data from Four Wells in the Continuous Network, May through December, 1996. Submittal date: 03/13/1997.

GS981008312314.002. Pump Test Data Collected at the C-Wells Complex 1/8/97 - 3/31/97. Submittal date: 10/28/1998.

GS981008312314.003. Pumping Test Data Collected at the C-Well Complex, 164801 5/7/96 - 12/31/96. Submittal date: 10/28/1998.

GS990208312315.001. Tracer Recovery Data from Testing in the Prow Pass Interval. 159238 Submittal date: 02/11/1999. 
GS990408312315.002. Transducer, Barometric Pressure and Discharge Data Collected 140115 from 4/18/98 through 11/24/98 in Support of the Ongoing Hydraulic and Tracer Tests Being Conducted at the UE-25 C-Well Complex, Nevada. Submittal date: 04/06/1999.

LA0007PR831231.001. Bullfrog Reactive Tracer Test Data.

156043

Submittal date: 07/21/2000.

LA0201JS831321.001. Alluvial Test Complex X-Ray Diffraction Results.

Submittal date: $01 / 16 / 2002$.

LA0201JS831341.001. Alluvial Test Complex Cation Exchange Capacity Batch Study, 162627 Wells 19D and 19P Alluvium; 10/31/00, 06/12/01, 08/12/01.

Submittal date: 01/16/2002.

LA0201JS831361.001. Alluvial Test Complex Column Study, Well 19D Alluvium and 162629 Water, 12/13/00. Submittal date: 01/24/2002.

LA0201JS831361.005. Alluvial Test Complex Column Study, Well 19D Alluvium and 166205 Water, 02/22/01. Submittal date: 01/29/2002.

LA0201JS831361.007. Alluvial Test Complex Column Study, Well 19D Alluvium and 162630 Water, 04/02/01. Submittal date: 01/29/2002.

LA0201JS831421.001. Grain Size Analysis of Alluvium Samples from Wells 19D and 162613 19P of the Alluvial Test Complex. Submittal date: 01/30/2002.

LA0201JS831421.002. BET Surface Area Measurements for 19D and 19P Alluvium Samples. Submittal date: 01/30/2002.

LA0207PR831352.001. Microsphere Data from Single-Well Tracer Testing at 162431 NC-EWDP-19D1 (ATC). Submittal date: 07/30/2002.

LA0212PR831231.001. Breakthrough Curves of Iodide in Saturated Fractured Cores 162607 from the C Wells. Submittal date: 01/30/2003.

LA0212PR831231.002. Breakthrough Curves of Sodium, Calcium, Copper, Iodide, 162608 and Chloride in Saturated Fractured Cores from the C Wells.

Submittal date: 01/21/2003.

LA0212PR831231.003. Breakthrough Curves of Lithium, Bromide, and PFBA in 162609 Saturated Fractured Cores from the C Wells. Submittal date: 01/21/2003.

LA0212PR831231.005. Breakthrough Curves of Sodium, Iodide, Calcium, and 166215 Chloride in Saturated Fractured Cores from the C Wells. Submittal date: 01/21/2003. 
LA0301PR831231.001. Bromide and Lithium Abundance Data from Column Studies of Crushed Central Bullfrog Tuff, UE-25 C\#2 at $2406 \mathrm{ft}$. with Filtered J-13 Water. Submittal date: $02 / 25 / 2003$.

LA0302JS831341.001. Final Cation Concentrations in Libr Batch Sorption 162628 Experiments Involving Alluvium from Wells NC-EWDP-19D and NC-EWDP-19P. Submittal date: 03/06/2003.

LA0302PR831231.001. Batch Experiments to Measure Bromide and PFBA Sorption 162605 onto C-Wells Tuffs. Submittal date: 03/06/2003.

LA0302PR831341.001. Cation Exchange Capacity Measurements on C-Wells Tuffs Involving Displacement of Li and Other Cations by Cs. Submittal date: 03/06/2003.

LA0303PR831232.001. Major Ion Chemistry of NC-EWDP-19D1 Waters Used in Batch Sorption and Column Transport Experiments. Submittal date: 03/12/2003.

LA0401PR831231.001. Tabulations of Data Used in Tracer Test Interpretations. Submittal date: 01/29/2004.

LA0410PR831231.001. Normalized Tracer Concentrations and Recoveries in C-Wells 171899 Tracer Tests. Submittal date: 10/04/2004.

LA9909PR831231.004. Laboratory Data from C-Wells Core.

Submittal date: 09/02/1999.

LAPR831231AQ99.001. Prow Pass Reactive Tracer Test Field Data.

Submittal date: 02/10/1999.

TMUE25C3000095.001. Geophysical Logs for UE-25 C\#3.

172179

Submittal date: $11 / 14 / 1995$.

UN0102SPA008KS.003. Concentration Dataset for Tracers (2, 6-Difluorobenzoic 162614 Acid and Iodide) Used for 48 Hour Shut in Tracer Test at the Alluvial Tracer Complex in Nye County. Submittal date: 06/11/2001.

UN0109SPA008IF.006. Concentration Dataset for Tracers (2,4-Difluorobenzoic Acid 162442 and Chloride) Used for the 30-Day Shut in Tracer Test at the Alluvial Tracer Complex in Nye County Nevada. Submittal date: 09/28/2001.

UN0109SPA008KS.007. Concentration Dataset for Tracer (Pentafluorobenzoic Acid) 162615 Used for the 30Day-Shut in Tracer Test at the Alluvial Tracer Complex in Nye County Nevada. Submittal date: 09/21/2001.

UN0109SPA008KS.008. Concentration Dataset for Tracer (Bromide) Used for the 30 162616 Day-Shut in Tracer Test at the Alluvial Tracer Complex in Nye County Nevada. Submittal date: 09/21/2001. 


\subsection{OUTPUT DATA, LISTED BY DATA TRACKING NUMBER}

GS030208312314.001. Filtered Water Level Data for UE-25 ONC-1. Submittal date: $02 / 28 / 2003$.

GS030208312314.002. Filtered Water Level Data For USW-H4, UE-25 WT\#3 and UE-25 WT\#14. Submittal date: 02/28/2003.

GS031008312314.004. Hydraulic Parameters from Analysis of Hydraulic Tests Conducted in the Fractured Tuff at the C-hole Complex from 1995 to 1999.

Submittal date: 10/09/2003.

GS031008312315.002. Transport Parameters from Analysis of Conservative (Non-Sorbing) Tracer Tests Conducted in the Fractured Tuff at the C-hole Complex from 1996 to 1999. Submittal date: 10/09/2003.

GS031008312316.002. Hydraulic Parameters from Analysis of Hydraulic Tests Conducted in the Alluvium at the Alluvial Testing Complex (ATC), and Total Porosity from Grain-size Distribution and from Background Monitoring. Submittal Date: 10/09/2003.

GS031008312316.003. Transport Parameters and Specific Discharge from Analysis of Single-Hole Tracer Tests Conducted in the Alluvium at the Alluvial Testing Complex (ATC), and Total Porosity from the Borehole-Gravimetry Survey at NC-EWDP-19D1. Submittal Date: 10/09/2003.

LA0303PR831231.001. Simulations Conducted to Predict Tracer Responses from Single-Well and Cross-Hole Tracer Tests at the Alluvial Testing Complex. Submittal date: $03 / 20 / 2003$.

LA0303PR831231.002. Estimation of Groundwater Drift Velocity from Tracer Responses in Single-Well Tracer Tests at the Alluvial Testing Complex. Submittal date: $03 / 18 / 2003$.

LA0303PR831231.003. Solute Data From ER-20-6\#3 in the BULLION Forced-Gradient Field Tracer Test At The ER-20-6 Wells at NTS. Submittal date: 02/03/2003.

LA0403PR831231.001. Simulations Conducted to Generate a Spreadsheet that can be Used for Predictions of Mean, Peak, and First Tracer Arrival Times in Field Tracer Tests. Submittal date: 04/18/2004.

LA0303PR831231.005. Simple Calculations for SZ In-Situ Testing AMR. Submittal date: $03 / 19 / 2003$.

LA0303PR831352.001. Calculations to Determine Detachment Rate Constant of Microspheres in a Single-Well Tracer Test in Saturated Alluvium. Submittal date: $03 / 31 / 2003$. 
LA0303PR831341.001. Calculations and Plots Associated with C-wells Cation Exchange Capacity Measurements. Submittal date: 04/08/2003.

LA0303PR831341.002. Model Interpretations of Alluvium Testing Complex Lithium Sorption Experiments. Submittal date: 04/16/2003.

LA0303PR831341.003. Model Interpretations of C-wells Lithium Sorption Experiments. Submittal date: 04/16/2003.

LA0303PR831361.002. Model Interpretations of ATC Alluvium-Packed Column Transport Experiments. Submittal date: 04/16/2003.

LA0303PR831361.003. Model Interpretations of C-wells Crushed Rock Column Experiments. Submittal date: 04/16/2003.

LA0303PR831361.004. Model Interpretations of C-wells Fractured Core Transport Experiments. Submittal date: 04/02/2003.

LA0303PR831362.001. Model Interpretations of C-wells Diffusion Cell Experiments. Submittal date: 04/02/2003.

LA0304PR831231.001. C-wells Tracer Test Sensitivity Calculations. Submittal date: $04 / 17 / 2003$.

SN0302T0502203.001. Saturated Zone Anisotropy Distribution Near the C-wells. Submittal date: 02/26/2003.

SN0409T0502203.002. Cooper-Jacob Transmissivity and Storativity Analysis of Wells UE-25 ONC-1, UE-25 WT\#3, UE-25 WT\#14, And USW H4. Submittal date: $09 / 23 / 04$.

\subsection{SOFTWARE CODES}

LANL (Los Alamos National Laboratory) 2002. EQUIL_FIT. V1.0. PC, Windows 159064 2000/NT 4.0/98. 10668-1.0-00.

LANL 2002. Software Code: 2WELLS_2D. V1.0. PC, Windows 2000/NT 4.0/98. 10665-1.0-00.

LANL 2002. Software Code: 2WELLS 3D. V1.0. PC, Windows 2000/NT 4.0/98.

159036 10667-1.0-00.

LANL 2002. Software Code: DIFFCELL. V2.0. PC, Windows 2000/NT. 10557-2.0-00.

LANL 2002. Software Code: MULTRAN. V1.0. PC, Windows 2000/NT 4.0. 10666-1.0-00. 
LANL 2002. Software Code: RELAP. V2.0. PC, Windows 2000/NT. 10551-2.0-00. 159065

LANL 2002. Software Code: RETRAN. V2.0. PC, Windows 2000/NT. 10552-2.0-00. 159066

LANL 2002. Software Management Report (SMR) for Multran Version 1.0.

171587

SDN: 10666-SMR-1.0-00. Los Alamos, New Mexico: Los Alamos National Laboratory. ACC: MOL.20021021.0385.

LANL 2003. Software Code: FEHM. V2.20. SUN, PC. 10086-2.20-00.

161725

USGS (U.S. Geological Survey) 2002. Software Code: Filter.vi. V 1.0. PC, Windows 162668 2000/NT 4.0/98. 10970-1.0-00.

USGS 2002. Software Code: MOENCH.vi, Function(2). V 1.0. PC, Windows

162752 2000/NT 4.0/98. 10582-1.0-00.

USGS 2002. Software Code: Neuman.vi. V 1.0. PC, Windows 2000/NT 4.0/98.

162754 10972-1.0-00.

USGS 2002. Software Code: rcv2amos.exe and MOENCH.vi, Function(1). V 1.0. PC, 162750 Windows 2000/NT 4.0/98. 10583-1.0-00.

USGS 2002. Software Code: Theis.vi. V 1.0. PC, Windows 2000/NT 4.0/98.

162758 10974-1.0-00.

USGS 2003. Software Code: Injection Pumpback.vi. V 1.0. PC, Windows 2000/NT 162749 4.0/98. 10675-1.0-00.

USGS 2003. Software Code: RECIRC.vi. V1.0. PC, Windows 98/NT 4.0/2000. 10673-1.0-00.

USGS 2003. Software Code: Streltsova-Adams.vi. V 1.0. PC, Windows 2000/NT 4.0/98. 10971-1.0-00.

Watermark Computing. 2002. Software Code: PEST. V5.5. SUN, PC, Linux.

161564 10289-5.5-00. 
INTENTIONALLY LEFT BLANK 
APPENDIX A

\section{QUALIFICATION OF EXTERNAL SOURCES}




\section{A1. INTRODUCTION}

External sources have provided unqualified data that have been used as direct input to this document. The inputs from these sources are qualified for intended use within the document using the criteria found in AP-SIII.9Q, Scientific Analyses. These criteria represent a subset of the methods and attributes required for qualification of data per AP-SIII.2Q, Qualification of Unqualified Data. The following information is provided for each source: the full reference citation, a description of the data used from the source, and the extent to which the data demonstrate the properties of interest. In addition, one or more of the following criteria is also addressed:

- Reliability of data source

- Qualifications of personnel or organizations generating the data

- Prior uses of the data

- Availability of corroborating data.

The criteria described above meet the requirements of AP-SIII.9Q and are provided as justification that the data used from these sources are considered to be qualified for intended use.

\section{A2. EVALUATION OF SOME NEW TRACERS FOR SOIL WATER STUDIES}

\section{A2.1 REFERENCE}

[DIRS 156645] Bowman, R.S., 1984. "Evaluation of Some New Tracers for Soil Water Studies." Soil Science Society of America Journal, 48, (5), 987-993. Madison, Wisconsin: Soil Science Society of America. TIC: 251011.

\section{A2.2 DESCRIPTION OF USE}

Bowman (1984 [DIRS 156645]) is cited in Section D1.2.1.3 as the source for the free-water diffusion coefficient of 2,4,5 trifluorobenzoic acid (TFBA), which was used as a tracer in a cross-hole tracer test conducted in the Prow Pass interval at the C-wells. Specifically, data presented by Bowman (1984 [DIRS 156645], Table 2) were used in conjunction with data for the free-water diffusion coefficient of iodide ion taken from Skagius and Neretnieks (1986 [DIRS 156862]) to establish a ratio of 2,4,5 TFBA and iodide diffusion coefficients used in the interpretation of the tracer test described in Section D1.2.1.3. Note that the absolute values of tracer diffusion coefficients are not important-only their ratio is used in the calculations.

\section{A2.3 EXTENT TO WHICH THE DATA DEMONSTRATE THE PROPERTIES OF INTEREST}

The data from Bowman (1984 [DIRS 156645]) are based on correlations of free-water diffusion coefficients and molecular/ionic size, and also as on limited diffusion coefficient data for fluorinated benzoates structurally similar to 2,4,5 TFBA. A single value was selected from Table 2 of Bowman (1984 [DIRS 156645]) to represent the diffusion coefficient of 2,4,5 TFBA. The actual property of interest is the diffusion coefficient in the saturated rock matrix rather than the free-water diffusion coefficient, but it is assumed that the ratio of matrix diffusion coefficients is the same as the ratio of free-water diffusion coefficients (and only a ratio is used 
in the calculations). The results of the diffusion cell experiments described in Section E2 indicate that this is a very reasonable assumption.

\section{A2.4 RELIABILITY OF DATA SOURCE}

Bowman (1984 [DIRS 156645]) published his work in the Soil Science Society of America Journal (SSAJ), a professional scientific research journal dedicated to publications on soil science and geochemistry. It is sponsored and published by the Soil Science Society of America. Contributions to the journal are evaluated for scientific merit by thorough professional review. Peer review is an essential and integral aspect of SSSAJ. The SSSAJ uses a double blind review format. Authors are anonymous to reviewers and reviewers are anonymous to authors. The fundamental role of the reviewers is to advise the Associate Editor on the technical virtues, or lack thereof, of a manuscript submitted for publication, and the Associate Editor, in turn, provides recommendations to the Technical Editor regarding the suitability of the manuscript for publication in the journal. The author is notified of all reviewer comments in writing, and the manuscript is either accepted or rejected for publication. In most cases, acceptance is conditional on revising the manuscript (per reviewer and editor comments) as necessary to meet publication standards. Rejected manuscripts can typically be revised significantly to address reviewer and/or editor comments and then resubmitted for consideration for publication.

\section{A3. POROSITIES AND DIFFUSIVITIES OF SOME NONSORBING SPECIES IN CRYSTALLINE ROCKS}

\section{A3.1 REFERENCE}

[DIRS 156862] Skagius, K. and Neretnieks, I., 1986. "Porosities and Diffusivities of Some Nonsorbing Species in Crystalline Rocks." Water Resources Research, 22, (3), 389-398. Washington, D.C.: American Geophysical Union. TIC: 225291.

\section{A3.2 DESCRIPTION OF USE}

Skagius and Neretnieks (1986 [DIRS 156862]) are cited in Section D1.2.1.3 as the source for the free-water diffusion coefficient of iodide ion, which was used as a tracer in a cross-hole tracer test conducted in the Prow Pass interval at the C-wells. Specifically, data presented in Skagius and Neretnieks (1986) were used in conjunction with an estimate of the free-water diffusion coefficient of 2,4,5-TFBA taken from Bowman (1984 [DIRS 156645]) to establish a ratio of 2,4,5 TFBA and iodide diffusion coefficients used in the interpretation of the tracer test described in Appendix D, Section D1.2.1.3. Note that the absolute values of the tracer diffusion coefficients are not important - only their ratio is really used in the calculations.

\section{A3.3 EXTENT TO WHICH THE DATA DEMONSTRATE THE PROPERTIES OF INTEREST}

Skagius and Neretnieks (1986 [DIRS 156862]) report a single value (Tables 2 and 3) for the free-water diffusion coefficient of iodide ion. The actual property of interest is the diffusion coefficient in the saturated rock matrix rather than the free-water diffusion coefficient, but it is assumed that the ratio of matrix diffusion coefficients is the same as the ratio of free-water 
diffusion coefficients (and only a ratio is used in the calculations). The results of the diffusion cell experiments described in Section E2 suggest that this is a very reasonable assumption.

\section{A3.4 RELIABILITY OF DATA SOURCE}

Skagius and Neretnieks (1986 [DIRS 156862]) published their work in Water Resources Research, a professional scientific research journal dedicated to "the social and natural sciences of water." It has long been recognized as one of the premier technical journals in the world for hydrology and contaminant transport. It is sponsored and published by the American Geophysical Union. Contributions to the journal are evaluated for scientific merit by thorough professional review. Peer review is an essential and integral aspect of Water Resources Research. Each manuscript submission is assigned to an Associate Editor, who then assigns at least two independent technical reviewers with expertise on the subject matter to thoroughly review the manuscript. These reviews are done anonymously. The Associate Editor also, generally, conducts a less-detailed technical review of the manuscript. The reviewers advise the Associate Editor on the technical virtues, or lack thereof, of the manuscript, and the Associate Editor then makes a decision regarding the suitability of the manuscript for publication. The author is notified of manuscript acceptance or rejection, and is provided all reviewer comments in writing. In most cases, acceptance is conditional on revising the manuscript (per reviewer and editor comments) as necessary to meet publication and scientific standards. Rejected manuscripts can typically be revised significantly to address reviewer and/or editor comments and then resubmitted for consideration for publication.

\section{A4. ELECTROCHEMICAL SYSTEMS}

\section{A4.1 REFERENCE}

[DIRS 148719] Newman, J. 1973. Electrochemical Systems. Englewood Cliffs, New Jersey: Prentice-Hall. TIC: 210201.

[DIRS 108567] Robinson, R.A. and Stokes, R.H. 1965. Electrolyte Solutions, The Measurement and Interpretation of Conductance, Chemical Potential and Diffusion in Solutions of Simple Electrolytes. 2nd Edition (Revised). Washington, D.C.: Butterworth. TIC: 242575.

\section{A4.2 DESCRIPTION OF USE}

Newman (1973 [DIRS 148719], p. 230, Table 75-1) is cited in Appendix D of this report as a source for the free-water diffusion coefficients of bromide and lithium ions. The ratio of the free-water diffusion coefficients of these ions was assumed to be equal to the ratio of their matrix diffusion coefficients for the interpretation of the $\mathrm{C}$-wells cross-hole tracer tests in which both ions are used as tracers. Basing the ratio of matrix diffusion coefficients of lithium and bromide on free-water diffusion coefficient values is justified given that the free-water and matrix diffusion coefficient ratios for pentafluorobenzoate and bromide are almost identical based on the data in Table D-4 and the diffusion cell data of Section E.2. However, this ratio had to be modified to account for other factors. 
Newman (1973 [DIRS 148719], Table 75-1) reports the bromide-to-lithium diffusion coefficient ratio is approximately 2:1. The ratio used in the analyses of the C-wells tracer was modified to 3:2 (with bromide larger) because the values reported by Newman (1973 [DIRS 148719], Table 75-1) are based on ionic conductances at infinite dilution, not on data or correlations applicable at the high ionic concentrations present in the tracer test solutions. The justification for using an effective ratio of 3:2 instead of 2:1 is that when a cation and an anion dominate the ionic strength of a solution (as in the case of $\mathrm{Li}^{+}$and $\mathrm{Br}^{-}$in the tracer solutions), they cannot diffuse independently of each other because local charge balance must always be maintained. In the extreme case of having only one cation and one anion in solution (i.e., a binary electrolyte), the anion and cation would have exactly the same effective diffusion coefficient (a value that falls in between the diffusion coefficients of each ion at infinite dilution) because their charges cannot be separated. Given that there were other ions in solution besides $\mathrm{Li}^{+}$and $\mathrm{Br}^{-}$, and that $\mathrm{Li}^{+}$and $\mathrm{Br}^{-}$should have been diluted significantly in the flow system after tracer injection, a ratio of 3:2 was thought to be a reasonable interpolation between the 2:1 ratio at infinite dilution and the 1:1 ratio that would exist in a perfect binary solution of $\mathrm{LiBr}$. The absolute values of the ion diffusion coefficients are not important for the tracer test analysis - only their ratio is used in the calculations.

\section{A4.3 EXTENT TO WHICH THE DATA DEMONSTRATE THE PROPERTIES OF INTEREST}

Newman (1973 [DIRS 148719], Table 75-1) reports values for free-water diffusion coefficients of many ions (including $\mathrm{Li}^{+}$and $\mathrm{Br}^{-}$) based on ionic conductances at infinite dilution. Free-water diffusion coefficients of ions are always measured for cation-anion pairs rather than for individual ions because individual ions cannot be spatially separated in solution (local charge balance cannot be violated). If the effective free-water diffusion coefficient of an ion pair is measured and the conductance of the solution is also measured, it is possible to determine the conductance that each individual ion contributes to the overall solution conductance. This determination is made by simultaneously solving Newman's equations 75-2 and 75-7 (1973 [DIRS 148719]) using the Nernst-Einstein relation (Newman 1973 [DIRS 148719], Eq. 75-6) to express the ionic diffusion coefficients in terms of ionic conductances. Typically, the measurements are repeated at several different concentrations of the ion-pair, and the results are extrapolated to zero concentration to obtain the ionic conductances at infinite dilution (which is what is usually reported in the literature). Once the ionic conductances are known for a specific ion pair, the ionic conductances of other ions can be easily determined by measuring the conductances of solutions in which one of the known ions is paired with the ion to be determined (the overall solution conductance is the sum of the ionic conductances). Ionic diffusion coefficients are then calculated from the ionic conductances using the Nernst-Einstein relation. This indirect method of determining ionic diffusion coefficients is employed because it is much easier to measure solution conductances than it is to measure diffusion coefficients of ion pairs.

\section{A4.5 RELIABILITY OF DATA SOURCE}

Newman (1973 [DIRS 148719]) is a widely used and widely cited textbook recognized as an authoritative reference on electrochemical systems. Although Newman provides no specific citations, the ionic conductances and diffusion coefficients in his Table 75-1 are a compilation of values that can be found in many other reference books and peer-reviewed publications. Most of the ionic conductances in his table can be found in the classic reference book, Electrolyte 
Solutions (Robinson and Stokes 1965 [DIRS 108567]). In fact, it is quite likely that Newman compiled much of his Table 75-1 from the information in this source. In summary, the values of ionic conductance (and hence ionic diffusion coefficients) in Newman's Table 75-1 have been in widespread use for several decades, and they are generally accepted as established fact in the scientific literature on electrolyte solutions. 


\section{INTENTIONALLY LEFT BLANK}




\section{APPENDIX B}

WELLS 
Table B-1. Wells Discussed in This Scientific Analysis Report and Their Abbreviations

\begin{tabular}{|l|l|}
\hline \multicolumn{1}{|c|}{ Name } & \multicolumn{1}{c|}{ Abbreviation } \\
\hline NC-EWDP-4PA, NC-EWDP-4PB & N/A* \\
\hline NC-EWDP-15P & N/A \\
\hline NC-EWDP-19D & $19 D$ \\
\hline NC-EWDP-19IM1, NC-EWDP-19IM2 & $19 I M 1,19 I M 2$ \\
\hline NC-EWDP-19P & $19 P$ \\
\hline UE-25 b\#1 & b\#1 \\
\hline UE-25 c\#1 & c\#1 \\
\hline UE-25 c\#2 & c\#2 \\
\hline UE-25 c\#3 & c\#3 \\
\hline UE-25 ONC-1 & ONC-1 \\
\hline UE-25 p\#1 & p\#1 \\
\hline UE-25 J-13 & J-13 \\
\hline UE-25 WT\#3 & WT\#3 \\
\hline UE-25 WT\#13 & WT\#13 \\
\hline UE-25 WT\#14 & WT\#14 \\
\hline UE-25 WT\#17 & WT\#17 \\
\hline USW H-4 & H-4 \\
\hline USW WT\#1 & WT\#1 \\
\hline Washburn-1X & N/A \\
\hline
\end{tabular}

NOTE: $\quad$ N/A in this table means that an abbreviation is not used for that well in this report. 


\section{INTENTIONALLY LEFT BLANK}


APPENDIX C

DETAILS OF HYDRAULIC TESTING AND TEST INTERPRETATIONS AT THE C-WELLS COMPLEX 
The hydrologic properties of the fractured tuffs at Yucca Mountain were obtained as part of investigations of the hydrologic and geologic suitability of Yucca Mountain as a high-level nuclear waste repository by the U.S. Geological Survey (USGS) in cooperation with the U.S. Department of Energy. Five cross-hole hydraulic tests, some in conjunction with tracer tests, were conducted by the USGS at the C-wells complex in May and June 1995, February 1996, from May 1996 to November 1997, and between June and September 1998. The first test, conducted in May 1995, is documented by Geldon et al. (1998 [DIRS 129721]). The second through fourth tests (June 1995, February 1996, and May 1996 to November 1997) are documented by Geldon et al. (2002 [DIRS 161163]) and reproduced in this report. The fifth test, conducted between June and September 1998, is only described in this report.

This appendix describes the hydraulic tests conducted, the changes in water levels in monitoring wells as a result of pumping, and analyses performed on the C-wells hydraulic test data. Estimates of aquifer transmissivity, hydraulic conductivity, and storativity were obtained by analyzing the test data using various analytical (as opposed to numerical) solutions of the groundwater flow equation, which assume a radial flow regime to the pumping well, constant aquifer thickness, and a homogeneous and isotropic medium. In order to calculate anisotropy in the horizontal hydraulic conductivity, analytic solutions of the groundwater flow equation for homogeneous, anisotropic media were employed.

These analytic solutions provide first-order estimates of hydrologic parameters consistent with both the limited knowledge of the nature and extent of subsurface heterogeneities in the fractured volcanics at the scale of the C-wells complex and the manner in which hydrologic parameter estimates are used in the site-scale saturated zone (SZ) flow model. The analytical methods assume that the test interval has one average transmissivity and storativity value between the pumping well and the observation well. Similarly, the SZ flow model assumes that single average intrinsic hydrologic property (i.e., permeability, porosity) values apply to individual stratigraphic intervals over large spatial areas in the SZ flow system. Furthermore, the hydrologic parameters derived from $\mathrm{C}$-wells testing are not used as direct inputs in the site-scale SZ flow model, but, rather, they are used primarily for qualitative/corroborative consistency checks with the hydrologic parameters derived from calibrations of the SZ flow model. Because of this qualitative end use of the parameter estimates, detailed analyses of the uncertainty and nonuniqueness of the estimates were not conducted.

At the C-wells complex, several analytic solutions to the groundwater flow equation were used. Following are the dominant modes of analysis used for each geohydrologic interval or aquifer. Details of these solutions and exceptions to the dominant modes presented here are found in Section C4. To analyze responses in the Calico Hills aquifer, which is at the water table, the Neuman (1975 [DIRS 150321]) unconfined-aquifer solution was used to successfully analyze five out of six responses in this aquifer among the various tests. To analyze the Prow Pass aquifer and the Upper Bullfrog and Lower Bullfrog aquifers, which are confined below the largely unconfined Calico Hills aquifer, either confined single-porosity (Theis 1935 [DIRS 150327]) or confined dual-porosity (Streltsova-Adams 1978 [DIRS 150754]) solutions were mostly used, depending upon whether the test duration was long enough for the fracturedrock aquifers to exhibit their dual-porosity character. To analyze the Upper Tram aquifer, which is intersected by the known faults present at the bottom of the $\mathrm{C}$-wells that provide a source of 
recharge or "leakage," the leaky-confined Hantush (1956 [DIRS 165169]) solution was used successfully for all tests.

\section{C1. EARLIER STUDIES}

Before the in situ testing of the fractured tuffs at Yucca Mountain began in May 1995 (Geldon et al. 1998 [DIRS 129721]), studies were conducted to determine hydrogeologic intervals of the rocks, flow patterns, geologic influences, geologic properties of the rocks, and the hydraulic results of an open-hole test in one of the C-wells. Most of these studies have been published and are referred to in this section. Hydrogeologic intervals discussed in this report were identified by Geldon (1996 [DIRS 100396], pp. 9 to 69) on the basis of borehole geophysical logs, borehole flow surveys, cross-hole seismic tomography, and aquifer tests. Geophysical logs run in the $\mathrm{C}$-wells include caliper, borehole-deviation, temperature, resistivity, gamma-gamma, acoustic, epithermal neutron, acoustic televiewer, and television logs (Geldon 1993 [DIRS 101045], pp. 14 to 18). Flow surveys run in the C-wells include tracejector, heat-pulse flowmeter, spinner, and oxygen-activation surveys (Geldon 1993 [DIRS 101045], pp. 14 to 18; Geldon 1996 [DIRS 100396], pp. 12 to 69). Tracejector surveys using radioactive iodide were run in the $\mathrm{C}$-wells during hydraulic tests conducted in 1983 and 1984. Heat-pulse flowmeter surveys were run in 1991 without the boreholes being pumped. Spinner and oxygen-activation surveys were run in Borehole c\#3 during the hydraulic test in June 1995 (described in Section A3.1). In 1993, a seismic tomogram was conducted between Boreholes c\#2 and c\#3 by Lawrence Berkeley National Laboratory (LBNL) for the USGS and reported to the USGS by written communication from E. Majer, LBNL (Geldon et al. 2002 [DIRS 161163], p. 2). That tomogram showed many of the hydrogeologic details evident from borehole lithologic and geophysical logs and flow surveys.

Hydrologic properties of the intervals in the C-wells and the manner in which they transmit water were determined provisionally by Geldon (1996 [DIRS 100396], pp. 12 to 69) from geophysical logs, laboratory analyses, and aquifer tests. A matrix-porosity profile for the C-wells was developed from a gamma-gamma log and nine values of core porosity obtained from c\#1 in 1983 (Geldon 1993 [DIRS 101045], p. 62, Table 13). Geldon (1996 [DIRS 100396], pp. 9 to 69) developed a matrix-permeability profile for the C-wells from permeameter tests on 89 core samples obtained from the C-wells and four nearby boreholes between 1980 and 1984. Geldon (1996 [DIRS 100396], pp. 9 to 69) developed a hydraulic-conductivity profile for the C-wells by analyzing falling-head and pressure-injection tests done in c\#1 in 1983. Transmissivity, hydraulic conductivity, and storativity of discrete intervals within the Calico Hills Formation and the Crater Flat Group were determined (Geldon 1996 [DIRS 100396], pp. 9 to 69) from analyses of a constant-flux injection test in c\#2 and three hydraulic tests in c\#2 and c\#3 performed in 1984. Simultaneous monitoring of water-level and atmospheric-pressure fluctuations in 1993 established the barometric efficiency of the C-wells (Geldon et al. 1997 [DIRS 156827], p. 11). The open-hole hydraulic test determined the transmissivity, hydraulic conductivity, and storativity of the composite saturated thickness of Miocene tuffaceous rocks at the $\mathrm{C}$-wells complex; lateral variations in hydrologic properties within a 3.2-km radius of the C-wells complex; and possible hydraulic connection between the tuffaceous rocks and the underlying regional aquifer composed of Paleozoic carbonate rocks (Geldon et al. 1998 [DIRS 129721], pp. 30, 31). 
A hydraulic test conducted at the C-wells complex from May 22 to June 12, 1995 (data reside in DTN: GS960108312313.001 [DIRS 164801]), indicated that the composite section of tuffaceous rocks in the vicinity of the C-wells has a transmissivity of $2,300 \mathrm{~m}^{2} / \mathrm{d}$ (square meters per day) and a storativity of 0.003 (Geldon et al. 1998 [DIRS 129721], p. 41). That test also indicated transmissivity values of 1,600 to $3,200 \mathrm{~m}^{2} / \mathrm{d}$ and storativity values of 0.001 to 0.003 for the rocks in individual boreholes (c\#1, c\#2, ONC-1, and USW H-4). Hydraulic tests conducted in 1984 indicated that those intervals have layered heterogeneity (Geldon 1996 [DIRS 100396], pp. 9 to 69 ).

\section{C2. INSTRUMENTATION USED IN C-WELLS HYDRAULIC TESTING}

Principal components of the equipment installed at the $\mathrm{C}$-wells complex to conduct hydraulic tests from 1995 to 1997 are available commercially, but much of this hardware and software has not been used extensively because of its relatively recent development. Consequently, all of the equipment received extensive performance evaluation during prototype hydraulic tests conducted jointly with LBNL from 1992 to 1994 at a research site near Raymond, California. Modifications to system components and their assembly were made to address problems encountered during prototype testing and after the equipment was installed and initially used at the C-wells complex (Umari et al. 1994 [DIRS 164543], pp. 2413 to 2422). With few exceptions (discussed below), most system components performed to specifications, despite being operated almost continuously for more than two years.

\section{C2.1 PACKERS}

Dual-mandrel packers, manufactured by TAM International, Inc., were installed in c\#1 and c\#2 throughout the tests and in $\mathrm{c} \# 3$ after August 1995. The packers are about $1.83 \mathrm{~m}$ long and have a deflated diameter of about 21.6 centimeters (cm) (see Geldon et al. 2002 [DIRS 161163], Figure 5). When inflated, the packers seal off the borehole to prevent upward or downward flow within the borehole, which effectively isolates "intervals" between the packers. Suspended on 7.30-cm-diameter tubing, each packer contains 12 pass-through tubes to allow packer-inflation lines and electrical cable to be installed in the borehole. The packers are inflated individually by injection of argon gas through $0.64-\mathrm{cm}$, stainless-steel tubing. Inflation pressures, which are about $1,034 \mathrm{kPa}$ above hydrostatic pressure, range from about 2,758 to $5,861 \mathrm{kPa}$ at the depths at which packers were set in the C-wells from 1995 to 1997. Packer depths from 1995 to 1997, as measured from the land surface, are listed in Table C-1. 
Table C-1. Location of Packers Emplaced in the C-wells Complex for Hydraulic Tests, 1995 to 1997

\begin{tabular}{|c|c|c|c|c|}
\hline \multirow{3}{*}{$\begin{array}{l}\text { Packer } \\
\text { Number }\end{array}$} & \multicolumn{4}{|c|}{ Packer Depth ( $m$ below land surface) } \\
\hline & \multirow[b]{2}{*}{ UE-25 c\#1 } & \multirow[b]{2}{*}{ UE-25 c\#2 } & \multicolumn{2}{|c|}{ UE-25 c\#3 } \\
\hline & & & $8 / 95-4 / 96$ & $4 / 96-11 / 97$ \\
\hline 1 & $547.4-549.3$ & $531.3-533.1$ & $540.4-542.2$ & None \\
\hline 2 & $605.3-607.2$ & $605.6-607.5$ & $609.9-611.7$ & None \\
\hline 3 & $698.3-700.1$ & $696.5-698.3$ & $695.0-696.8$ & $694.6-696.5$ \\
\hline 4 & $797.1-798.9$ & 791.9-793.7 & $812.6-814.4$ & $812.9-814.7$ \\
\hline 5 & $869.9-871.7$ & $869.6-871.4$ & $877.5-879.4$ & $878.1-880.0$ \\
\hline
\end{tabular}

Output DTN: GS031008312314.004 (from Input DTN: GS030508312314.003 [DIRS 164425], p. 12, Table 3).

NOTE: There were no packers in UE-25 c\#3 before August 1995.

\section{C2.2 TRANSDUCERS}

Continuous records of pressures and temperatures in packed-off intervals during hydraulic tests were obtained using absolute pressure transducers (manufactured by Paroscientific, Inc), which record water pressure plus atmospheric pressure. The transducers used in the C-wells were strapped into brackets welded onto the $7.30-\mathrm{cm}$-diameter tubing on which the packers were suspended. Field determinations indicated a precision of $0.30 \mathrm{~cm}$ under pumping conditions and $0.061 \mathrm{~cm}$ under nonpumping conditions.

Although transducers were installed in all hydrogeologic intervals, several of the transducers failed after installation. Transducers operative during some or all of the hydraulic tests conducted from 1995 to 1997 and the locations of those transducers, as determined by subtracting recorded pressure heads from static water-level altitudes, are listed in Table C-2. Listed transducer altitudes have an accuracy of $\pm 0.3 \mathrm{~m}$.

\section{C2.3 BAROMETERS}

A nonsubmersible, temperature-compensated pressure transducer, manufactured by Paroscientific, Inc., was used as a barometer during the 1995 to 1997 hydraulic tests. The barometer operated in a temperature-controlled office trailer at the $\mathrm{C}$-wells complex. The factory-calibrated accuracy of this barometer is \pm 0.005 percent of its full operating range $(103 \mathrm{kPa})$. The barometer was checked periodically against another barometer of the same type in the same office trailer.

\section{C2.4 PUMPS}

A 37-stage, 1,512 liters per minute (L/min) capacity, Centrilift submersible pump was used during the hydraulic test in June 1995. The pump was suspended in Borehole c\#3 on 13.9-cm-diameter tubing. The pump intake depth was $450.1 \mathrm{~m}(48.0 \mathrm{~m}$ below the water-level altitude prior to pumping). The pump was powered by a $250-\mathrm{kW}$ generator, and its frequency was regulated by a variable-speed controller. Water discharged by the pump was transported by a 15-cm-diameter pipeline to a leachfield in Fortymile Wash, about $8 \mathrm{~km}$ from the C-wells complex. 
Table C-2. Operative Transducers in the C-wells, 1995 to 1997

\begin{tabular}{|c|c|c|c|c|}
\hline \multirow[b]{2}{*}{ Borehole } & \multirow[b]{2}{*}{ Interval } & \multicolumn{3}{|c|}{ Transducer } \\
\hline & & Number & Depth (meters) & Altitude (meters) \\
\hline \multirow[t]{3}{*}{ UE-25 c\#1 } & Prow Pass & 2 & 552.09 & 578.51 \\
\hline & Upper Bullfrog & 3 & 610.03 & 520.57 \\
\hline & Lower Bullfrog $^{a}$ & 4 & 703.04 & 427.56 \\
\hline \multirow[t]{4}{*}{ UE-25 c\#2 } & Calico Hills & 1 & 519.83 & 612.36 \\
\hline & Prow Pass & 2 & 536.28 & 595.91 \\
\hline & Upper Bullfrog & 3 & 610.70 & 521.49 \\
\hline & Lower Bullfrog $^{a}$ & 4 & 701.58 & 430.61 \\
\hline \multirow[t]{4}{*}{ UE-25 c\#3 } & Calico Hills $^{b}$ & 1 & 533.81 & 598.62 \\
\hline & Upper Bullfrog & 3 & 614.49 & 517.93 \\
\hline & Lower Bullfrog $^{\mathrm{C}}$ & 4 & 708.93 & 423.49 \\
\hline & Upper Tram $^{d}$ & 5 & 817.68 & 314.75 \\
\hline
\end{tabular}

Output DTN: GS031008312314.004 (from Input DTN: GS030508312314.003 [DIRS 164425], Table 4).

${ }^{a}$ Monitored Lower Bullfrog and Upper Tram together, February to March 1996.

${ }^{b}$ Listed transducer locations are for August 1995 to March 1996. Prior to August 1995, a single transducer was installed in the Calico Hills interval at a depth of $441.12 \mathrm{~m}$ (altitude $=691.30 \mathrm{~m}$ ) to monitor the composite geologic section in c\#3. After April 1996, a new transducer was installed at a depth of $691.31 \mathrm{~m}$ (altitude $=441.11 \mathrm{~m}$ ) to monitor the Calico Hills, Prow Pass, and Upper Bullfrog intervals combined.

c Operative after April 1996.

d Monitored Lower Bullfrog and Upper Tram together in February and March 1996; replaced in April 1996 by a transducer at a depth of $819.32 \mathrm{~m}$ (altitude $=313.11 \mathrm{~m}$ ).

The original pump was replaced in August 1995 by a 43-stage, 756 L/min-capacity, Centrilift submersible pump. That pump, enclosed in a protective shroud, was offset from the main part of the 7.30-cm-diameter tubing on which the packers were suspended by a 22.9-m-long "Y-block" assembly (see Geldon et al. 2002 [DIRS 161163], Figure 6 for detailed drawing). The Y-block assembly was designed to allow wireline tool access past the pump for opening and closing sliding sleeves (screens installed to allow water movement to or from test intervals) and for placing a plug in the tubing to prevent recirculation of water through the pump shroud.

Although the Y-block assembly facilitated operations, its placement in the instrument string created problems that eventually caused pump performance to degrade beyond an acceptable level during hydraulic and tracer tests conducted in February and March 1996. Because the combined diameter of the Y-block assembly and main section of the instrument tubing $(24.7 \mathrm{~cm})$ was about the same as the borehole diameter below a depth of $463.4 \mathrm{~m}$, the pump intake had to be set about $247 \mathrm{~m}$ above the top of the slotted section of pipe open in the test interval. Frictional head losses produced by water flowing through small openings (slots) in the intake tubing and through the tubing from the test interval to the pump intake caused the pump to operate at the limit of its designed performance range. Consequently, discharge decreased from $526.2 \mathrm{~L} / \mathrm{min}$ when pumping started on February 8, 1996, to $370.8 \mathrm{~L} / \mathrm{min}$ when pumping was terminated on March 29, 1996.

In April 1996, the pump-performance problem was addressed by (1) discarding the Y-block; (2) suspending a 72-stage, $756 \mathrm{~L} /$ min-capacity Centrilift pump enclosed in a narrower shroud directly on the 7.30-cm-diameter tubing; (3) lowering the pump to within about $47 \mathrm{~m}$ of the 
interval to be tested; and (4) adding $6.1 \mathrm{~m}$ of slotted pipe in the test interval. From May 1996 to March 1997, the reconfigured pump assembly performed without major problems and sustained a relatively constant discharge of 560.4 to $590.4 \mathrm{~L} / \mathrm{min}$. Problems with one of the generators providing power to the pump caused the pump to operate erratically between March 26 and May 8, 1997, but the pump performed adequately again after the generator problem was resolved. These generator/pump problems had essentially no impact on the hydraulic test interpretations, as the responses in the $\mathrm{C}$-wells were not quantitatively analyzed after March 26, 1997, and the responses in more distant wells were not significantly affected by the pumping perturbations.

\section{C2.5 FLOWMETERS}

A McCrometer turbine-type flowmeter was used during the hydraulic test in June 1995. Subsequently, the primary device used for monitoring discharge was a differential switched capacitor, vortex flowmeter manufactured by Endress and Hauser, measuring vortex frequency past a bluff body with signal output converted to voltage output across a temperature-controlled resistor.

The flowmeter signal was recorded at user-specified intervals by monitoring software installed on a personal computer (PC) in the office trailer at the C-wells complex (Section C2.6). The software program used a regression equation developed on the basis of the flowmeter calibration to convert the voltage signal from the flowmeter to a discharge rate.

\section{C2.6 DATA ACQUISITION AND INSTRUMENT CONTROL}

Data acquisition from and control of the transducers, barometer, flowmeter, and an automatic water sampler used for tracer tests was accomplished with a commercially available, graphic-language software program called LabView (Johnson 1994 [DIRS 156837]). Installed on the PC in the office trailer, LabView made the PC monitor screen look and act like an instrument panel.

Two separate "virtual instrument" routines (VIs) were written for data acquisition and instrument control. One VI communicated with the transducers, barometer, and flowmeter; the other VI communicated with the automated water sampler during tracer tests. The two VIs ran simultaneously. Both VIs employed standard LabView functions for data acquisition and control, and they performed no manipulations on the acquired data. Also, the acquired data in all cases constituted input data packages (DTNs) for this analysis report; they are not product outputs. The only case in which raw acquired data was manipulated before being submitted to the Technical Data Management System (TDMS) was for flow meter readings, which were converted from voltages to flow rates in Excel spreadsheets prior to being submitted to the TDMS. These conversion calculations can be readily verified using simple formulas documented in the Yucca Mountain Project (YMP) RISweb system in records associated with data packages (see records roadmaps). For example, in the case of data package DTN: GS990408312315.002 [DIRS 140115], which contains flow rate data obtained during testing of the Prow Pass interval at the C-wells between 4/18/98 and 11/24/98, the supporting RISweb record with accession number MOL.20010712.0251 contains the formulas supplied by the calibration vendor for converting measured voltages to the flow rates that appear in the 
TDMS. These formulas were used in Excel spreadsheets contained on a CD-ROM referred to in another supporting record with accession number MOL.20010712.0252. This approach was used consistently in going from raw data acquisition to data submittals for all hydraulic tests.

\section{C3. RESULTS AND INTERPRETATIONS OF HYDRAULIC TESTS}

The results and interpretations of the hydraulic tests discussed below include the conceptual models considered and tested.

\section{C3.1 HYDRAULIC TESTS CONDUCTED BETWEEN JUNE 1995 AND NOVEMBER 1997}

Three hydraulic tests were conducted at the C-wells complex from June 1995 to November 1997. During June 12 to June 22, 1995, well c\#3 was pumped, without packers installed, and drawdown and recovery were measured in six hydrogeologic intervals (Figure C-5) separated by packers in wells c\#1 and c\#2 (Table C-1). From February 8 to February 13, 1996, c\#3 was pumped, with packers inflated to isolate the Bullfrog-Tram interval, to establish a steady-state hydraulic gradient for a tracer test in the Bullfrog-Tram interval that continued until March 29, 1996. Drawdown was analyzed in the Bullfrog-Tram interval and in all other packedoff intervals of $\mathrm{c} \# 1$ and $\mathrm{c} \# 2$ that responded to pumping during the hydraulic test.

In the third hydraulic test, with packers inflated to isolate the Lower Bullfrog Tuff interval, c\#3 was pumped for 553 days, from May 8, 1996 to November 12, 1997, before and during a series of tracer tests in the Lower Bullfrog interval. Drawdown was analyzed in this interval and in all other intervals of $\mathrm{c} \# 1$ and $\mathrm{c} \# 2$ that responded to pumping before mechanical problems developed on March 26, 1997. Drawdown was analyzed in UE-25 ONC-1 (ONC-1), USW H-4 (H-4), UE-25 WT\#14 (WT\#14), and UE-25 WT\#3 (WT\#3) for periods from 7 to 18 months to evaluate heterogeneity and scale effects in the Miocene tuffaceous rocks. Water levels in UE-25 p\#1 (p\#1), completed in Paleozoic carbonate rocks, were measured to detect a hydraulic connection between the Miocene tuffaceous rocks and the Paleozoic carbonate rocks in the vicinity of the C-wells.

\section{C3.1.1 Analytical Methods}

Although rock at the C-wells complex is fractured pervasively, hydrogeologic intervals respond to pumping in a manner consistent with an equivalent porous medium (EPM) (Geldon 1996 [DIRS 100396], pp. 12 to 69; Geldon et al. 1998 [DIRS 129721], pp. 29 to 31). To obtain estimates of hydrologic parameters, "type curves" from analytical solutions of drawdown vs. time and distance corresponding to different conceptual aquifer flow models were matched to drawdown data in pumping tests. The following alternative aquifer models were considered for individual test intervals: EPM, confined fissure block, unconfined, and leaky confined. The analytical solution that provided the best match to a given data set with the least number of adjustable parameters was used for parameter estimation. Whenever it is stated in this section (Section C) that an interval responds as a given type of aquifer, the reader should take this to mean that the response is consistent with that type of aquifer and, therefore, that type of aquifer was assumed for parameter estimation purposes. 
The Calico Hills interval in the vicinity of the C-wells complex typically responds to pumping as an anisotropic, unconfined aquifer, consistent with the fact that the water table occurs in this interval. With pervasive fracturing that apparently extends to the water table (Geldon et al. 2002 [DIRS 161163], p. 15]), the Prow Pass and Upper Bullfrog intervals respond to pumping as either an unconfined, fissure-block, or confined aquifer. The Lower Bullfrog interval typically responds to pumping as a confined aquifer, consistent with the fact that it is isolated by layers of relatively unfractured, low-transmissivity rock. Apparently recharged by flow from fractures related to faults (identified on lithologic logs prepared by Richard W. Spengler and included in a report by Geldon (1993 [DIRS 101045], pp. 35 to 37, Table 4), the Upper Tram interval typically responds to pumping as a leaky, confined aquifer without confining bed storage.

Analytical methods used for hydraulic tests discussed in this section are those of Theis (1935 [DIRS 150327]) and Cooper and Jacob (1946 [DIRS 150245]) for infinite, homogeneous, isotropic, confined aquifers; Neuman (1975 [DIRS 150321]) for infinite, homogeneous, anisotropic, unconfined aquifers; and Streltsova-Adams (1978 [DIRS 150754]) for fissure-block aquifers. Geldon (1996 [DIRS 100396], pp. 21 to 69) discusses assumptions, equations, and application of these analytical methods in hydraulic tests at the $\mathrm{C}$-wells complex. Analysis of drawdown in this study was restricted to observation wells because drawdown in pumping wells at the C-wells complex typically is too large and rapid to be explained solely by hydrologic properties of the pumped interval (Geldon 1996 [DIRS 100396], pp. 21 to 69). This observation can be illustrated by looking at the drawdown in c\#3 at 464,000 minutes (322.22 days) after pumping began on May 8, 1996. That drawdown was $599 \mathrm{~cm}$. With hydrologic properties computed for the Lower Bullfrog interval in $\mathrm{c} \# 1$ and $\mathrm{c} \# 2$ inserted into an approximation of the Theis (1935 [DIRS 150327]) equation, as given by Equation 19 of Lohman (1972 [DIRS 150250]), the drawdown in c\#3 attributable to aquifer characteristics should have been no more than 69 to $72 \mathrm{~cm}$ after 322.22 days of pumping, or 12 percent of the actual recorded drawdown. Most of the drawdown in c\#3 probably can be attributed to frictional head loss. Therefore, calculation of hydrologic properties from that drawdown is not reliable.

All of the analytical methods used in this study, except for the Neuman (1975 [DIRS 150321]) method, assume radial flow to the pumping well, and, therefore, ignore vertical flow (application of the Neuman fully penetrating-well solution, as was done in this report, to cases where pumping was in one interval and the analyzed drawdown response was in another, also ignores vertical flow). However, in hydraulic tests of the Bullfrog-Tram interval (February 1996) and the Lower Bullfrog interval (May 1996 to March 1997), drawdown was observed in the Calico Hills, Prow Pass, and Upper Bullfrog intervals, even though the sliding sleeves allowing direct communication between those intervals and the flow intake piping were not open. For water to reach the pumping well from the intervals that did not have open sliding sleeves, a downward component of flow must have occurred. The downward flow was assumed by the investigators to be much less than radial flow to the pumping well in order to analyze the drawdown from the nonopen intervals by the methods outlined in this section. Clearly, improved estimates of hydrologic parameters could be obtained using a three-dimensional numerical model to analyze the drawdowns in the nonpumped intervals by accounting for both horizontal and vertical flow. However, hydrologic properties calculated assuming radial flow have a reasonable level of confidence because they generally are consistent with quantitative results of the hydraulic test conducted in June 1995, which was designed such that flow from hydrogeologic intervals in c\#1 and $\mathrm{c} \# 2$ to $\mathrm{c \# 3}$ would be largely radial. 


\section{C3.1.2 Earth Tides and Barometric Effects}

Previous monitoring of water levels in observation wells before, during, and after hydraulic tests conducted in the C-wells indicated that all of those boreholes respond to Earth tides and atmospheric pressure changes. With frequencies of 0.9 to 2.0 cycles per day (Galloway and Rojstaczer 1988 [DIRS 156826], p. 107, Table 2), Earth tides caused water levels in the C-wells to fluctuate as much as $12 \mathrm{~cm}$ during a 10-day hydraulic test conducted at the C-wells complex from May to June 1995 (Geldon et al. 1998 [DIRS 129721], Figure 21). Consequently, in the hydraulic testing described here, Earth-tide effects were removed from water levels, and cycles of the same frequency as Earth tides were removed from simultaneously recorded atmospheric pressures before computing the barometric efficiency of most borehole intervals. Earth-tide effects also were removed from the records of observation wells in which drawdown caused by pumping was expected to be obscured by Earth tides (Boreholes H-4, WT\#14, WT\#3, and p\#1). The boreholes requiring an Earth-tide correction to water-level records were completed in Miocene tuffaceous rocks more than $1,500 \mathrm{~m}$ from $\mathrm{c} \# 3$ or were completed in a different aquifer than that of the C-wells complex (i.e., in the Paleozoic carbonate rocks). Earth-tide effects were removed from records of water levels, and cycles of the same frequency as Earth tides were removed from simultaneously recorded atmospheric pressure by applying a low-pass filter with a cutoff frequency of 0.8 cycles/day to those records. As shown in Figure C-1, this filtering removes semi-diurnal changes in water levels while preserving longer-term trends.

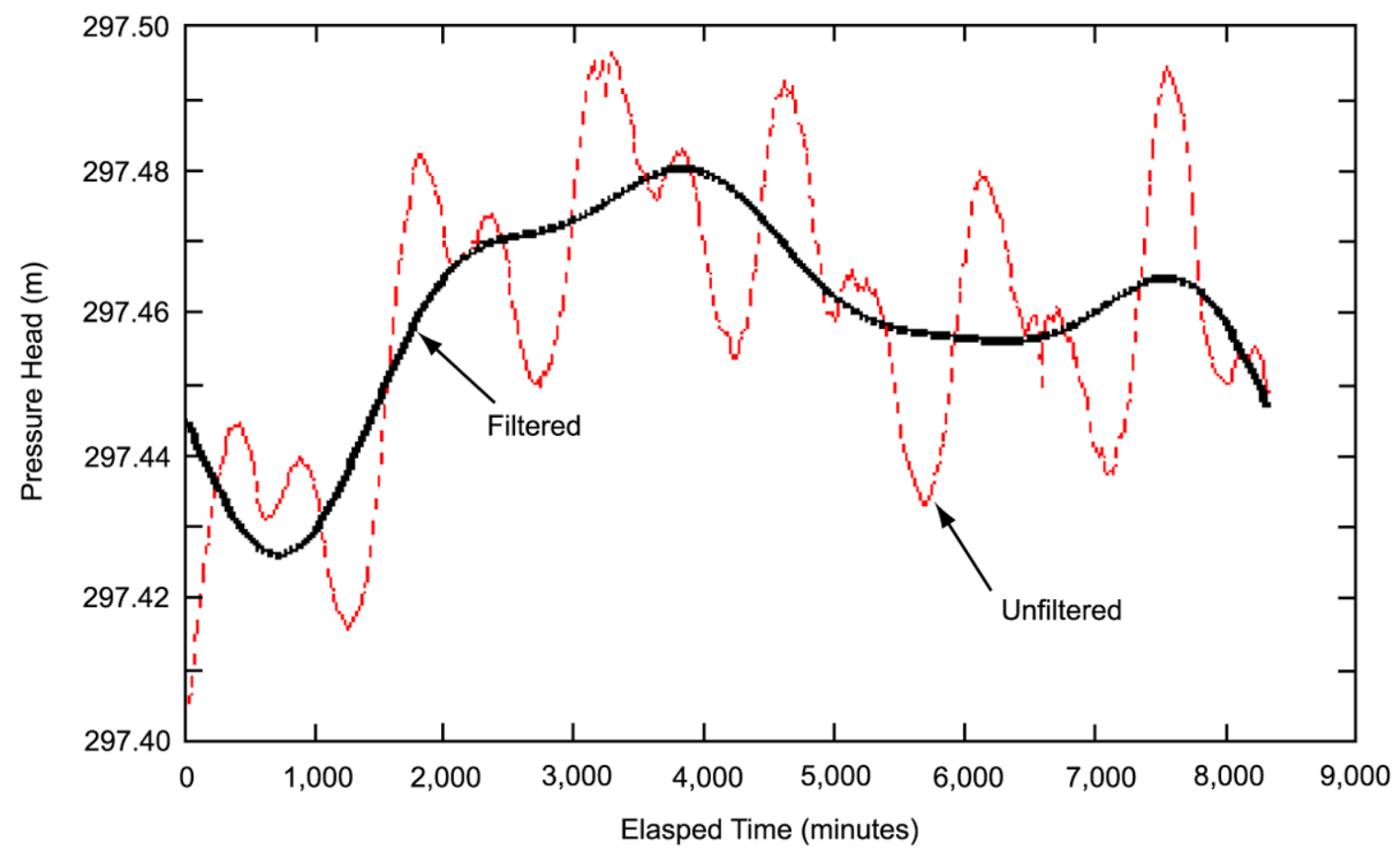

Output DTN: GS031008312314.004 (from Input DTN: GS030508312314.003 [DIRS 164425], p. 16, Figure 7).

Figure C-1. Result of Filtering Out Earth Tides on UE-25 c\#2 Lower Bullfrog Interval Pressure Heads, June 23 to 29,1995 
Changes in atmospheric pressure in the vicinity of the C-wells complex typically produce synchronous (but opposite) changes in water levels in boreholes (Figure C-2). The slope of a line fit to a plot of water-level change as a function of atmospheric-pressure change is called the barometric efficiency. Determination of the barometric efficiency of the Lower Bullfrog interval in $\mathrm{c \# 2}$ is shown in Figure C-3. Barometric efficiency values of borehole intervals for which drawdown was computed during this study ranged from 0.75 to 0.99 (Table C-3). To compute barometrically corrected drawdown, barometric effects were removed from borehole records by subtracting the product of atmospheric-pressure change and barometric efficiency from the change in water level.

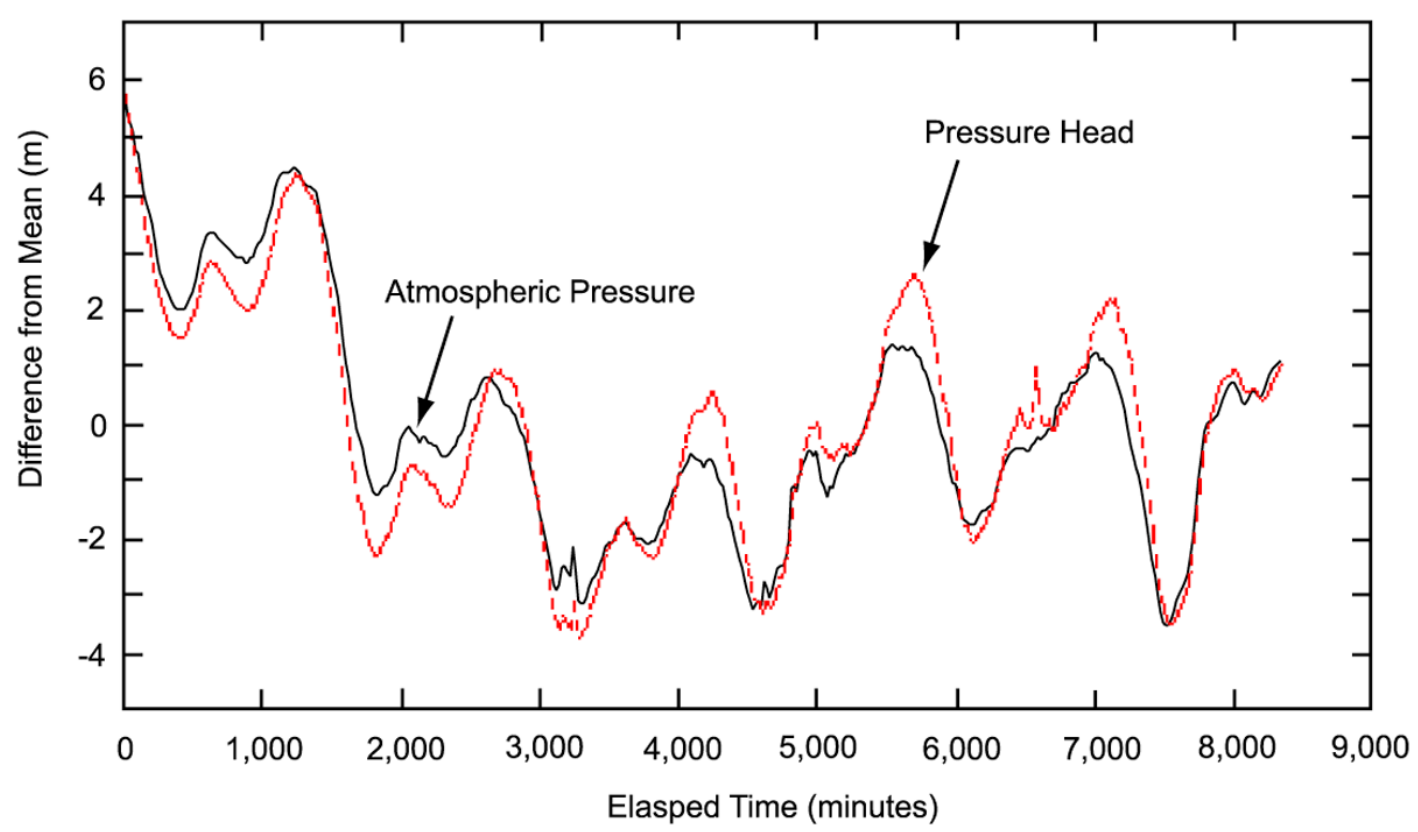

Output DTN： GS031008312314.004 (from Input DTN： GS030508312314.003 [DIRS 164425], Figure 8).

Figure C-2. Difference of the Atmospheric Pressure from Its Mean Plotted Against the Opposite of the Difference of Concurrent Pressure Head from Its Mean 


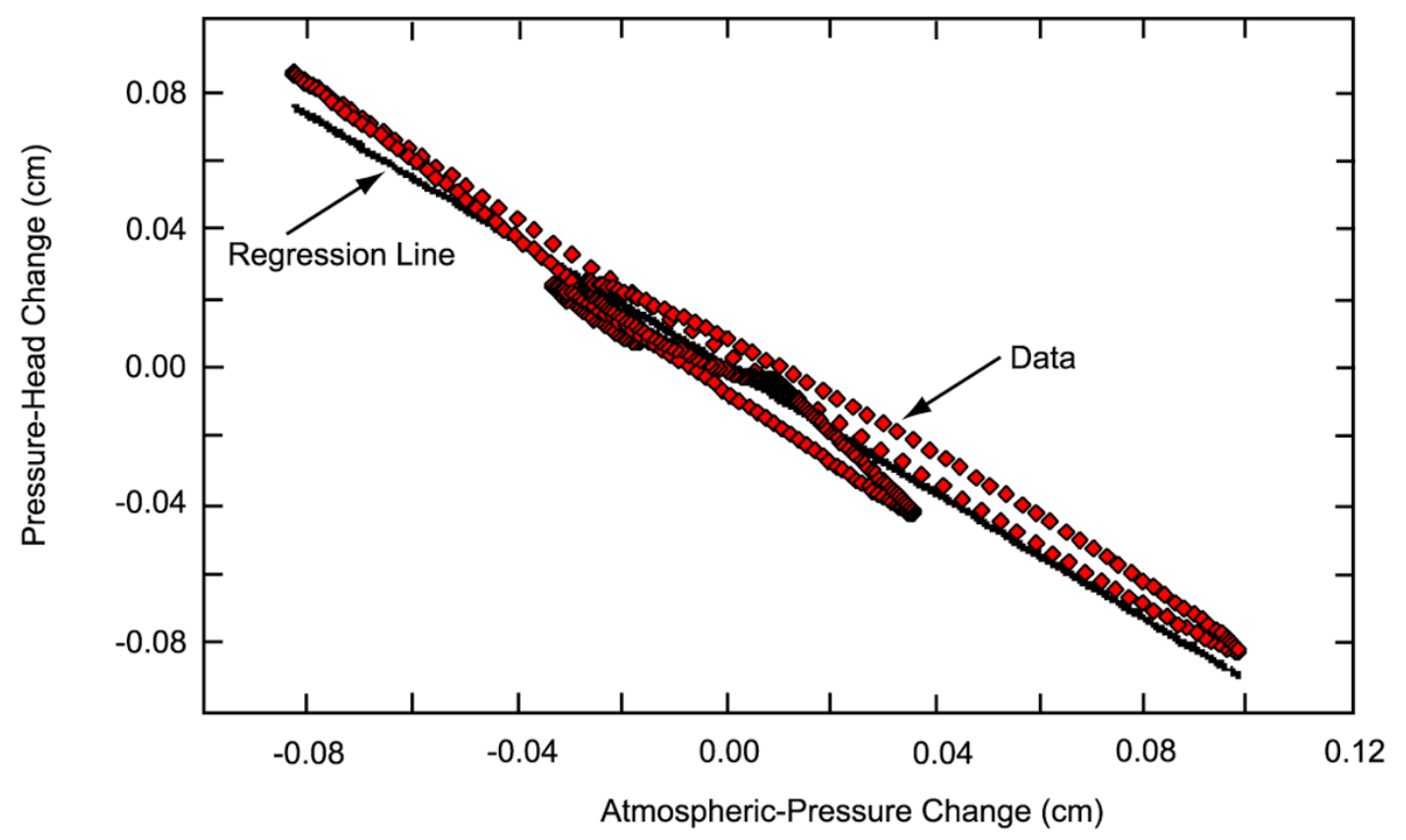

Output DTN： GS031008312314.004 (from Input DTN: GS030508312314.003 [DIRS 164425], Figure 9).

Figure C-3. Filtered Pressure-head Change in UE-25 c\#2 Lower Bullfrog Interval as a Function of Filtered Atmospheric-Pressure Change at the C-wells Complex, June 23 to 29, 1995 
Table C-3. Barometric Efficiency Values Determined for Borehole Intervals Monitored at the C-wells Complex Through May 13, 1996

\begin{tabular}{|c|c|c|c|c|c|}
\hline Borehole & Interval & $\begin{array}{c}\text { Barometer } \\
\text { Location }\end{array}$ & Period of Record & $\begin{array}{l}\text { Barometric } \\
\text { Efficiency }\end{array}$ & $\begin{array}{l}\text { Regression } \\
\text { Coefficient }\end{array}$ \\
\hline \multirow[t]{4}{*}{ UE-25 c\#1 } & Prow Pass & C-wells & June 23-29, 1995 & 0.96 & 0.98 \\
\hline & Upper Bullfrog & C-wells & June $24-29,1995$ & 0.99 & 0.97 \\
\hline & Lower Bullfrog $^{(a)}$ & C-wells & June 23-29, 1995 & 0.97 & 0.98 \\
\hline & Bullfrog-Tram & C-wells & June $23-29,1995$ & 0.97 & 0.98 \\
\hline \multirow[t]{5}{*}{ UE-25 c\#2 } & Calico Hills & C-wells & June 23-29, 1995 & 0.93 & 0.94 \\
\hline & Prow Pass & C-wells & June 23-29, 1995 & 0.93 & 0.97 \\
\hline & Upper Bullfrog & C-wells & June 23-29, 1995 & 0.93 & 0.97 \\
\hline & Lower Bullfrog ${ }^{(a)}$ & C-wells & June 23-29, 1995 & 0.91 & 0.96 \\
\hline & Bullfrog-Tram & C-wells & June $23-29,1995$ & 0.91 & 0.96 \\
\hline \multirow[t]{3}{*}{ UE-25 c\#3 } & Calico Hills ${ }^{(b)}$ & C-wells & February 7-8, 1996 & 0.83 & 0.89 \\
\hline & Lower Bullfrog & C-wells & May 9-13, 1996 & 0.87 & 0.92 \\
\hline & Bullfrog-Tram & C-wells & Not applicable & $0.94^{(\mathrm{c})}$ & Not applicable \\
\hline UE-25 ONC-1 & Prow Pass & ONC-1 & July 1-Sept. 13,1995 & 0.99 & 0.90 \\
\hline USW H-4 & $\begin{array}{l}\text { Prow Pass to Lithic } \\
\text { Ridge }\end{array}$ & ONC-1 & June 8-12, 1995 & 0.91 & 0.87 \\
\hline UE-25 WT\#14 & Calico Hills & C-wells & June 4-12, 1995 & 0.89 & 0.94 \\
\hline UE-25 WT\#3 & Lower Bullfrog & C-wells & June 4-12, 1995 & 0.91 & 0.82 \\
\hline UE-25 p\#1 & Paleozoic carbonates & C-wells & Jan. 1-June 20, 1986 & 0.75 & Not applicable \\
\hline
\end{tabular}

Output DTN: GS031008312314.004 (from Input DTN: GS030508312314.003 [DIRS 164425], p. 18, Table 5).

a Barometric efficiency of Lower Bullfrog used also for Bullfrog-Tram in hydraulic test February 8-13, 1996.

b Barometric efficiency of Calico Hills used also for Calico Hills-Upper Bullfrog in hydraulic test February 8-13, 1996.

${ }^{c}$ Barometric efficiency estimated from values for Bullfrog-Tram in c\#1 and c\#2.

d "Not applicable" means that no record was used to calculate the barometric efficiency for the Bullfrog-Tram in c\#3, per se. The barometric efficiency, in this case, was "estimated" by assuming that it was the average of the barometric efficiency for the Bullfrog-Tram in c\#1 and c\#2.

\section{C3.1.3 Flow Distribution in the C-Wells}

During hydraulic tests conducted in the C-wells in February 1996 and from May 1996 to November 1997, all hydrogeologic intervals in the $\mathrm{C}$-wells being monitored responded to pumping, regardless of the interval being pumped. Leakage around packers could have occurred, although the packers were seated in nonrugose, sparsely fractured zones, but it is extremely unlikely that all packers failed to seal properly. A more likely explanation is that fractures beyond borehole walls are so interconnected that packers emplaced in the C-wells do not isolate the interval being pumped from other transmissive intervals within the volume of aquifer stressed by the pumping.

Spinner and oxygen-activation flow surveys (Figure C-4) were run in $\mathrm{c} \# 3$ during the hydraulic test in June 1995 to determine the flow distribution in the $\mathrm{C}$-wells under pumping conditions. However, those flow surveys failed to detect flow from the Prow Pass interval indicated by heat-pulse flowmeter surveys conducted without pumping in the C-wells in 1991 (Geldon 1996 [DIRS 100396], pp. 12 to 20). Oxygen activation logs, employing high-energy "fast" neutrons, 
can dynamically detect water movement inside and outside of casing. The technique consists of a short neutron-activation period followed by a longer data-acquisition period; flow is detected when the measured count-rate profile does not match the expected profile for a static environment. Results of the 1991 and 1995 flow surveys were combined algebraically to estimate a flow distribution during the hydraulic test in June 1995 (Table C-4). That flow distribution was adjusted for the hydraulic tests conducted in February 1996 and May 1996 to November 1997 (Table C-4) by inserting discharge and drawdown values recorded at the same elapsed time in the three hydraulic tests into Equation 1c, which is an algebraic manipulation of Equations $1 \mathrm{a}$ and $1 \mathrm{~b}$ :

$$
\begin{aligned}
& s_{1}=\left(P_{1} Q_{1} /(4 \pi T)\right) W(u) \\
& s_{2}=\left(P_{2} Q_{2} /(4 \pi T)\right) W(u) \\
& P_{2}=Q_{1} P_{1} s_{2} / Q_{2} s_{1}
\end{aligned}
$$

where

$u=r^{2} S / 4 T \mathrm{t}$ is a dimensionless parameter in which:

$r[\mathrm{~L}]=$ radial distance from pumping well

$\mathrm{S}\left[\mathrm{L}^{0}\right]=$ storativity

$\mathrm{T}[\mathrm{L} / \mathrm{T}]=$ transmissivity of the tested interval in question, which is the same in Equations $1 \mathrm{a}$ and $1 \mathrm{~b}$

$\mathrm{t}[\mathrm{T}]=$ elapsed time from beginning of pumping.

$W(u)=\int_{\mathrm{u}}^{\infty}\left(\mathrm{e}^{-\mathrm{u}} / \mathrm{u}\right) \mathrm{du} ; W(u)$ is the well function, which can be a confined, unconfined, or leaky well function

$P_{1}\left[\mathrm{~L}^{0}\right]=$ the proportion of flow determined for a hydrogeologic interval during the hydraulic test in June 1995

$P_{2}\left[\mathrm{~L}^{0}\right]=$ the proportion of flow determined for a hydrogeologic interval during a hydraulic test in either February 1996 or May 1996 to November 1997, as appropriate

$Q_{1}\left[\mathrm{~L}^{3} / \mathrm{T}\right]=$ the average discharge during the hydraulic test in June 1995

$Q_{2}\left[\mathrm{~L}^{3} / \mathrm{T}\right]=$ the average discharge during a hydraulic test in February 1996 or May 1996 to November 1997, as appropriate

$s_{1}[\mathrm{~L}]=$ the drawdown in a hydrogeologic interval during the hydraulic test in June 1995

$s_{2}[\mathrm{~L}]=$ the drawdown in a hydrogeologic interval during a hydraulic test in either February 1996 or May 1996 to November 1997, as appropriate.

Equations $1 \mathrm{a}$ and $1 \mathrm{~b}$ are based on the Theis equation (1935 [DIRS 150327], p. 520, Equation 4) except that $s$ is used for drawdown instead of $v$, and $Q$ is used for the discharge rate instead of $F$. 
In the three hydraulic tests discussed in this report, the Lower Bullfrog interval consistently contributed about 70 percent of the flow from observation wells to the pumping well at the C-wells complex; the Upper Tram interval consistently contributed about 20 percent of that flow; and all other intervals combined contributed about 10 percent of the total flow. To analyze the drawdown in any hydrogeologic interval, the total discharge from c\#3 first was multiplied by the percentage of flow contributed by the interval being analyzed to avoid calculating erroneously large values of transmissivity and storativity (both of which are directly proportional to discharge).

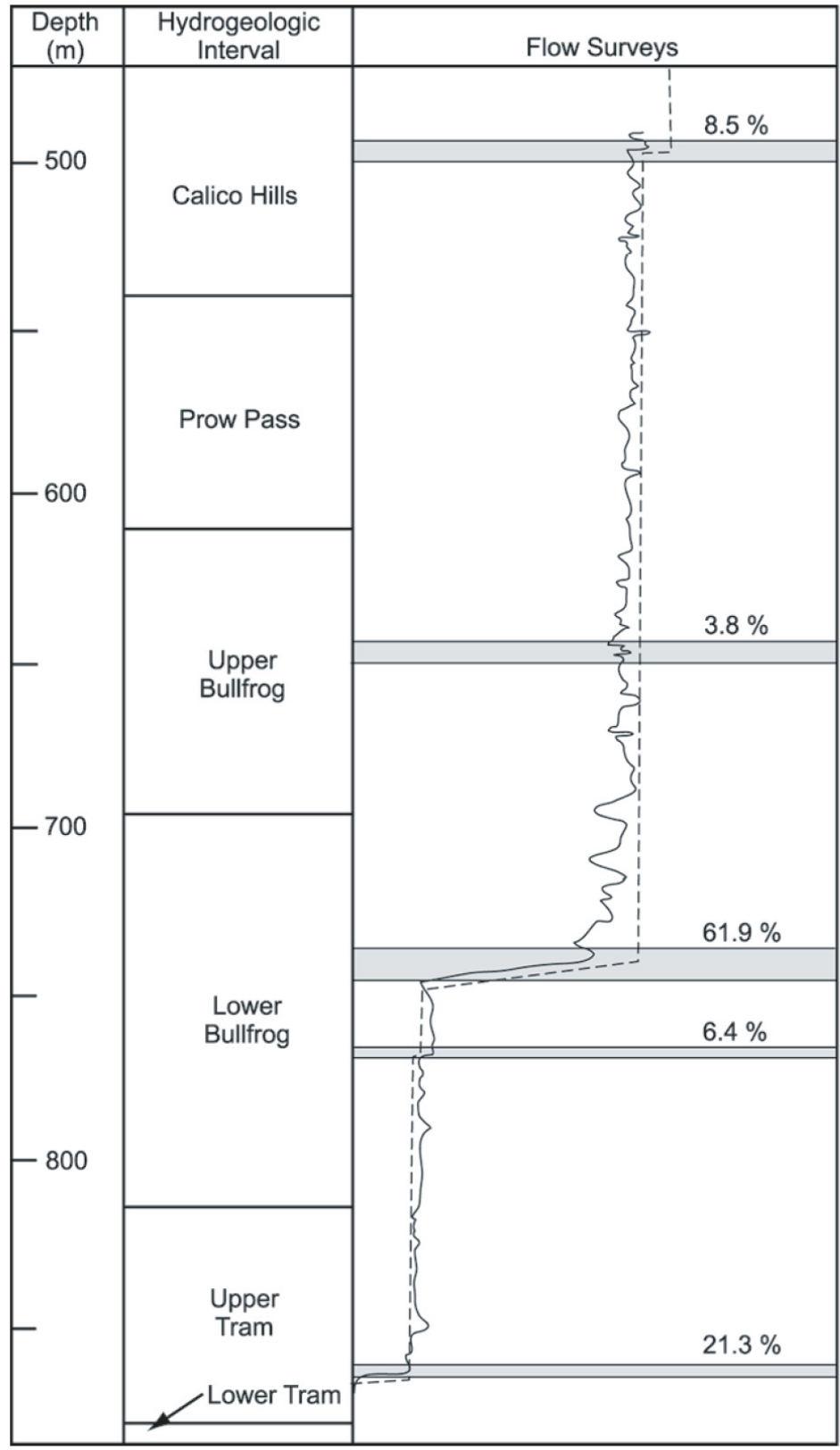

Explanation

Spinner Survey

$\sim$ Oxygen-Activation Survey

Flow Zone: Percent of total discharge rate from UE-25 c\#3 during flow surveys indicated above zone

Output DTN: GS031008312314.004 (from Input DTN: GS030508312314.003 [DIRS 164425], p. 19, Figure 10).

Figure C-4. Flow Surveys in UE-25 c\#3 During Hydraulic Testing in June 1995 
Table C-4. Interval Discharges 5,800 Minutes after Pumping Started in Hydraulic Tests in UE-25 c\#3, June 1995 to November 1997

\begin{tabular}{|c|c|c|c|c|c|c|c|c|c|}
\hline \multirow[b]{2}{*}{$\begin{array}{l}\text { Hydro- } \\
\text { geologic } \\
\text { Unit }\end{array}$} & \multicolumn{3}{|c|}{ June 1995} & \multicolumn{3}{|c|}{ February 1996} & \multicolumn{3}{|c|}{ May 1996 to November 1997} \\
\hline & $\begin{array}{l}\text { Dis- } \\
\text { charge } \\
\text { (L/min) }\end{array}$ & $\begin{array}{l}\text { Draw- } \\
\text { down } \\
\text { (cm) }\end{array}$ & $\begin{array}{c}\text { Flow } \\
\%\end{array}$ & $\begin{array}{l}\text { Dis- } \\
\text { charge } \\
\text { (L/min) }\end{array}$ & $\begin{array}{l}\text { Draw- } \\
\text { down } \\
\text { (cm) }\end{array}$ & $\begin{array}{c}\text { Flow } \\
\%\end{array}$ & $\begin{array}{l}\text { Dis- } \\
\text { charge } \\
\text { (L/min) }\end{array}$ & $\begin{array}{l}\text { Draw- } \\
\text { down } \\
(\mathbf{c m})\end{array}$ & $\begin{array}{c}\text { Flow } \\
\%\end{array}$ \\
\hline \multicolumn{10}{|l|}{ UE-25 c\#1 } \\
\hline Calico Hills & 1,350 & No data & 3.8 & 507 & No data & 0.5 (est) & 583.2 & No data & 1.1 (est) \\
\hline Prow Pass & 1,350 & 43.0 & 2.9 & 507 & 14.0 & 2.5 & 583.2 & 14.9 & 2.3 \\
\hline Upper Bullfrog & 1,350 & 52.1 & 3.9 & 507 & 21.6 & 4.3 & 583.2 & 19.2 & 3.3 \\
\hline Lower Bullfrog & 1,350 & 49.7 & 68.3 & 507 & No data & No data & 583.2 & 21.0 & 66.8 \\
\hline Bullfrog-Tram & 1,350 & No data & 89.4 & 507 & 19.5 & 92.7 & 583.2 & N/A & $\mathrm{N} / \mathrm{A}$ \\
\hline Upper Tram & 1,350 & No data & 21.1 & 507 & No data & No data & 583.2 & No data & 26.5 \\
\hline Lower Tram & 1,350 & No data & trace & 507 & No data & trace & 583.2 & No data & trace \\
\hline \multicolumn{10}{|l|}{ UE-25 c\#2 } \\
\hline Calico Hills & 1,350 & 351.7 & 3.8 & 507 & 16.4 & 0.5 & 583.2 & 43.0 & 1.1 \\
\hline Prow Pass & 1,350 & 75.6 & 2.9 & 507 & 14.6 & 1.5 & 583.2 & 22.2 & 2.0 \\
\hline Upper Bullfrog & 1,350 & 62.2 & 3.9 & 507 & 25.0 & 4.2 & 583.2 & 26.5 & 3.8 \\
\hline Lower Bullfrog & 1,350 & 49.4 & 68.3 & 507 & No data & No data & 583.2 & 21.9 & 70.2 \\
\hline Bullfrog-Tram & 1,350 & No data & 89.4 & 507 & 21.0 & 93.8 & 583.2 & $\mathrm{~N} / \mathrm{A}$ & $\mathrm{N} / \mathrm{A}$ \\
\hline Upper Tram & 1,350 & 283.2 & 21.1 & 507 & No data & No data & 583.2 & No data & 22.9 \\
\hline Lower Tram & 1,350 & 239.6 & trace & 507 & No data & trace & 583.2 & No data & trace \\
\hline
\end{tabular}

Output DTN: GS031008312314.004 (from Input DTN: GS030508312314.003 [DIRS 164425], p. 20, Table 6).

NOTE: The Bullfrog-Tram refers to the combined Lower Bullfrog and Upper Tram intervals tested together as one unit during the February 1996 test. Flow proportion for the Bullfrog-Tram interval shown in June 1995 is the sum of values for the Lower Bullfrog and Upper Tram intervals.

est $=$ estimated; N/A = not applicable.

\section{C3.1.4 Monitoring Network}

The monitoring network at the C-wells complex was selected after Borehole c\#3 was chosen as the pumping well for all hydraulic tests conducted from 1995 to 1997 on the basis of its successful performance during two hydraulic tests conducted in 1984 (Geldon 1996 [DIRS 100396], pp. 48 to 68). Boreholes c\#1 and c\#2 were used as observation wells for the hydraulic tests conducted in June 1995 and February 1996. Boreholes ONC-1, H-4, WT\#14, WT\#3, and p\#1 were also used as observation wells for the longer-term hydraulic test conducted from May 1996 to November 1997. Recording barometers were located at the C-wells complex during all hydraulic tests; a barometer located at borehole ONC-1 also was used during the third hydraulic test. (See Figure 6.1-3 for a map showing the location of the observation wells.)

Borehole c\#3 is $900.4 \mathrm{~m}$ deep (Geldon 1993 [DIRS 101045], p. 2). The borehole is cased and grouted to a depth of approximately $417 \mathrm{~m}$, just below the water table (Geldon 1993 [DIRS 101045], p. 7, Figure 3). During the hydraulic test in June 1995, c\#3 did not contain packers and was open from the Calico Hills Formation to the Lower Tram interval. After packers were emplaced in August 1995, manipulation of the packers, sliding sleeves, and slotted casing allowed selective hydraulic communication with only the Lower Bullfrog and Upper 
Tram intervals during hydraulic and tracer tests in February and March 1996, and with only the Lower Bullfrog interval from May 1996 to December 1997.

Borehole c\#2 is $30.4 \mathrm{~m}$ from c\#3 at the land surface (Geldon et al. 1998 [DIRS 129721], p. 3, Figure 1) and $910.1 \mathrm{~m}$ deep (Geldon 1993 [DIRS 101045], p. 2). It is cased and grouted to a depth of approximately $416.0 \mathrm{~m}$ (Geldon 1993 [DIRS 101045], p. 7, Figure 3). Five dual-mandrel packers, suspended on $7.30-\mathrm{cm}$-diameter tubing, were emplaced in the borehole to isolate hydrogeologic intervals throughout the period of testing discussed in this report. Manipulation of packers and sliding sleeves allowed hydraulic communication with six separate hydrogeologic intervals (Figure 6.1-5 and Table C-1) in June 1995, with the Lower Bullfrog and Upper Tram intervals in February and March 1996, and with the Lower Bullfrog interval from May 1996 to December 1997.

Borehole c\#1 is $68.4 \mathrm{~m}$ from $\mathrm{c} \# 3$ at the land surface (Geldon et al. 1998 [DIRS 129721], p. 3, Figure 1) and is $897.6 \mathrm{~m}$ deep (Geldon 1993 [DIRS 101045], p. 2). It is cased and grouted to a depth of approximately $417.9 \mathrm{~m}$ (Geldon 1993 [DIRS 101045], p. 7, Figure 3). Five dual-mandrel packers, suspended on 7.30-cm-diameter tubing, were emplaced in the borehole to isolate hydrogeologic intervals throughout the period of testing discussed in this report. Manipulation of packers and sliding sleeves allowed hydraulic communication with the Calico Hills, Prow Pass, Upper Bullfrog, and Lower Bullfrog intervals in June 1995, with the Lower Bullfrog and Upper Tram intervals in February and March 1996, and with the Lower Bullfrog interval from May 1996 to December 1997.

Borehole ONC-1 is $842.8 \mathrm{~m}$ from Borehole c\#3 at the land surface and is $469.4 \mathrm{~m}$ deep (extending about $36.3 \mathrm{~m}$ below the water level in the borehole) (Nye County Nuclear Waste Repository Project Office 1995 [DIRS 156859], ONC-1 Drilling log). The borehole is telescoped downward and has a diameter of about $13 \mathrm{~cm}$ in the SZ. Seven packers inflated between the bottom of the casing and a depth of $410 \mathrm{~m}$ separate the unsaturated and SZs; another packer emplaced at a depth of $452 \mathrm{~m}$ divides the SZ into two intervals. The upper of the saturated-zone intervals is open in the Calico Hills Formation and the Prow Pass Tuff; the lower of those intervals is open in the Prow Pass Tuff. Absolute transducers, installed in all packed-off intervals, transmitted total (atmospheric plus hydraulic) pressures to a data logger every 15 to 20 minutes during the tests reported here. Data from the lowermost transducer, positioned at a depth of $458 \mathrm{~m}$, were converted to pressure heads for analysis.

Borehole $\mathrm{H}-4$, which is 2,245 $\mathrm{m}$ from Borehole $\mathrm{c} \# 3$ at the land surface, is 1,219 $\mathrm{m}$ deep. The borehole diameter is $37.5 \mathrm{~cm}$ to a depth of $564 \mathrm{~m}$ and $22.2 \mathrm{~cm}$ below $564 \mathrm{~m}$. Casing extends to a depth of $561 \mathrm{~m}$; it is perforated below the water level, which was at an average depth of $518.3 \mathrm{~m}$ from 1985 to 1995. A packer emplaced at a depth of 1,181 m separates the Prow Pass, Bullfrog, and Tram Tuffs and the upper part of the Lithic Ridge Tuff from the lower part of the Lithic Ridge Tuff in the borehole. A 48-mm-diameter piezometer tube is installed in the upper part of the borehole, and a 62-mm-diameter piezometer tube is installed in the lower part of the borehole. (Graves et al. 1997 [DIRS 101046], pp. 4 to 5, Table 1; p. 100). Differential transducers emplaced in the two monitored intervals transmitted hydraulic pressures to a data logger every 15 minutes during this study. Only the data from the upper interval were used. 
Borehole WT\#14, which is 2,249 $\mathrm{m}$ from Borehole c\#3 at the land surface, is $399 \mathrm{~m}$ deep. The borehole has a diameter of $22.2 \mathrm{~cm}$ below the water table, which was at an average depth of $346.4 \mathrm{~m}$ from 1985 to 1995 . The borehole is cased to a depth of $37 \mathrm{~m}$ and is open in the Topopah Spring Tuff and Calico Hills Formation. A 62-mm-diameter piezometer tube is installed in the borehole. (Graves et al. 1997 [DIRS 101046], pp. 4 to 5, Table 1; p. 84). A differential transducer emplaced in the piezometer tube transmitted hydraulic pressures to a data logger every 15 minutes during this study.

Borehole WT\#3, which is 3,526 $\mathrm{m}$ from Borehole $\mathrm{c} \# 3$ at the land surface, is $348 \mathrm{~m}$ deep. The borehole has a diameter of $22.2 \mathrm{~cm}$ below the water table, which was at an average depth of $300.5 \mathrm{~m}$ from 1985 to 1995 . The borehole is cased to a depth of $12 \mathrm{~m}$ and is open in the Bullfrog Tuff. A 62-mm-diameter piezometer tube is installed in the borehole (Graves et al. 1997 [DIRS 101046], pp. 4 to 5, Table 1; p. 76). A differential transducer emplaced in the piezometer tube transmitted hydraulic pressures to a data logger every 15 minutes during this study.

Borehole $\mathrm{p} \# 1$, which is $630 \mathrm{~m}$ from Borehole $\mathrm{c} \# 3$ at the land surface, is $1,805 \mathrm{~m}$ deep. The borehole diameter decreases from 37.5 to $15.6 \mathrm{~cm}$ with depth. Casing and cement emplaced to a depth of 1,297 $\mathrm{m}$ isolate the Miocene tuffaceous rocks in the upper part of the borehole from Paleozoic carbonate rocks in the lower part of the borehole. The water level for the Paleozoic carbonate rocks in $\mathrm{p} \# 1$ was monitored through a $38-\mathrm{mm}$-diameter piezometer tube. The average depth to water in the piezometer tube was $361.8 \mathrm{~m}$ from 1985 to 1995 . (Graves et al. 1997 [DIRS 101046], pp. 4 to 5, Table 1; p. 90). A differential transducer emplaced in the piezometer tube transmitted hydraulic pressures to a data logger every 60 minutes during this study.

\section{C3.1.5 Description of Tests}

A hydraulic test (DTN: GS960108312313.002 [DIRS 159228]) was conducted in June 1995 to determine hydrologic properties of six hydrogeologic intervals (Figure C-5) at the C-wells complex (Table C-1) [a detailed description of the field tests is contained in the scientific notebook, Performing Various Hydraulic and Tracer Test Using Prototype Pressure Transducer and Packer Assemblies (Umari 2002 [DIRS 162858], Binder 3, Sections D-2 to D-6)]. The six intervals were isolated by packers in Boreholes $\mathrm{c} \# 1$ and $\mathrm{c} \# 2$. Sliding sleeves open in the packed-off intervals of the observation wells allowed hydraulic communication with the pumping well $\mathrm{c} \# 3$, which was uncased and contained no packers to isolate intervals. Because of malfunctioning transducers, analyzable data were obtained only from the Prow Pass, Upper Bullfrog, and Lower Bullfrog intervals of $\mathrm{c \# 1}$ and from the Calico Hills, Prow Pass, Upper Bullfrog, and Lower Bullfrog intervals of c\#2.

The hydraulic test began on June 12 and ended on June 16, after 4.03 days of pumping. (Note that data were collected over thousands of elapsed minutes, the measure of time used by data-acquisition software and needed for hydraulic calculations. For the summarizing discussions here, those time intervals are expressed in hours and days.) Recovery was monitored until June 29, by which date it appeared to be complete in all intervals. At an average discharge rate of $1350 \mathrm{~L} / \mathrm{min}$, drawdown in $\mathrm{c} \# 3$ rapidly increased to a maximum of $10.9 \mathrm{~m}$ (Figure C-5). The pumping in c\#3 produced drawdown ranging from 43.0 to $52.1 \mathrm{~cm}$ in intervals of c\#1 (Figure C-6) and from 49.4 to $352 \mathrm{~cm}$ in intervals of c\#2 (Figure C-7). 

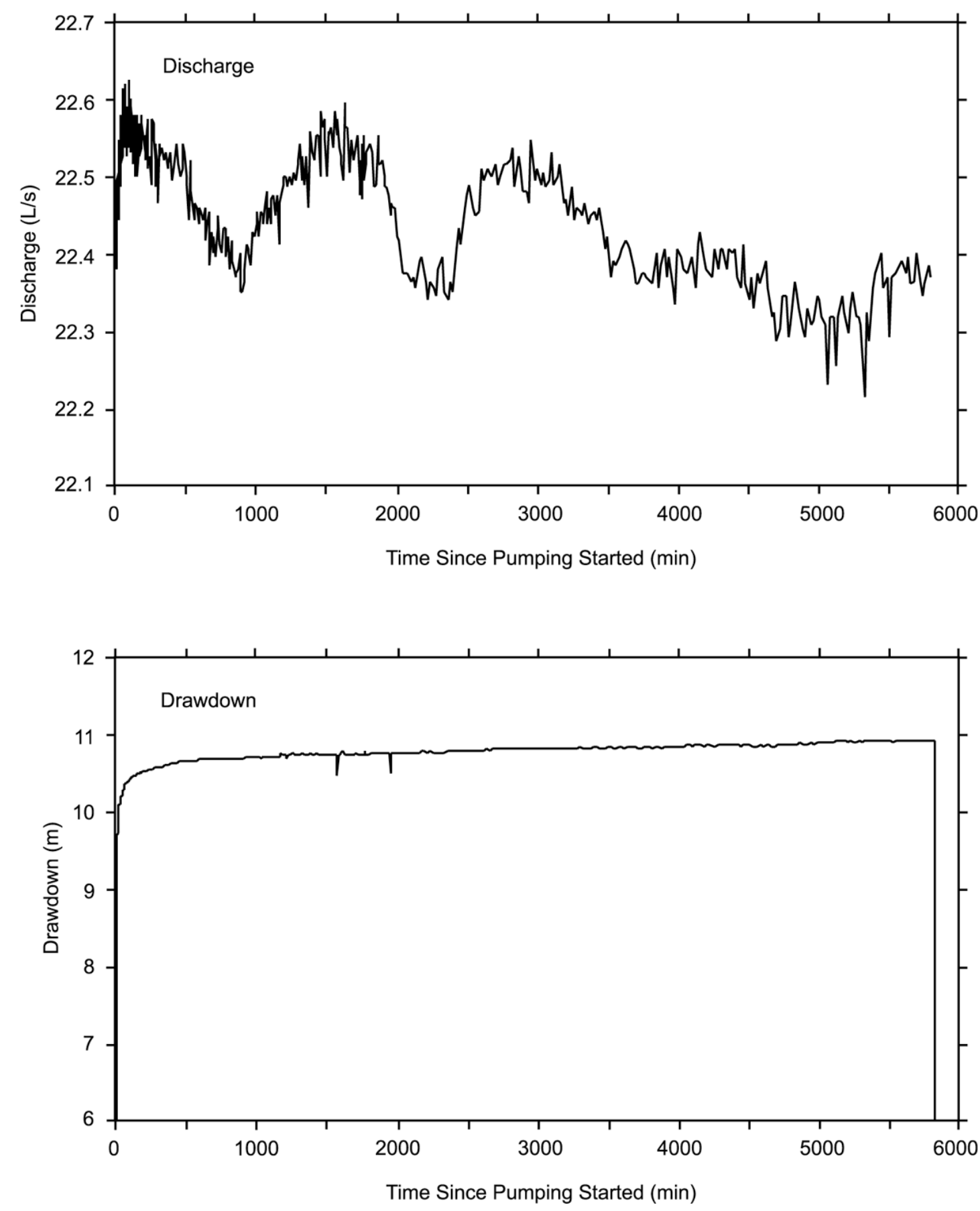

Output DTN: GS031008312314.004 (from Input DTN: GS030508312314.003 [DIRS 164425], p. 22, Figure 11). Note: Discharge units in text are L/min.

Figure C-5. UE-25 c\#3 Discharge and Drawdown, June 12, 1995 (Approximately 0 Minutes), to June 16, 1995 (Approximately 5,800 Minutes) 


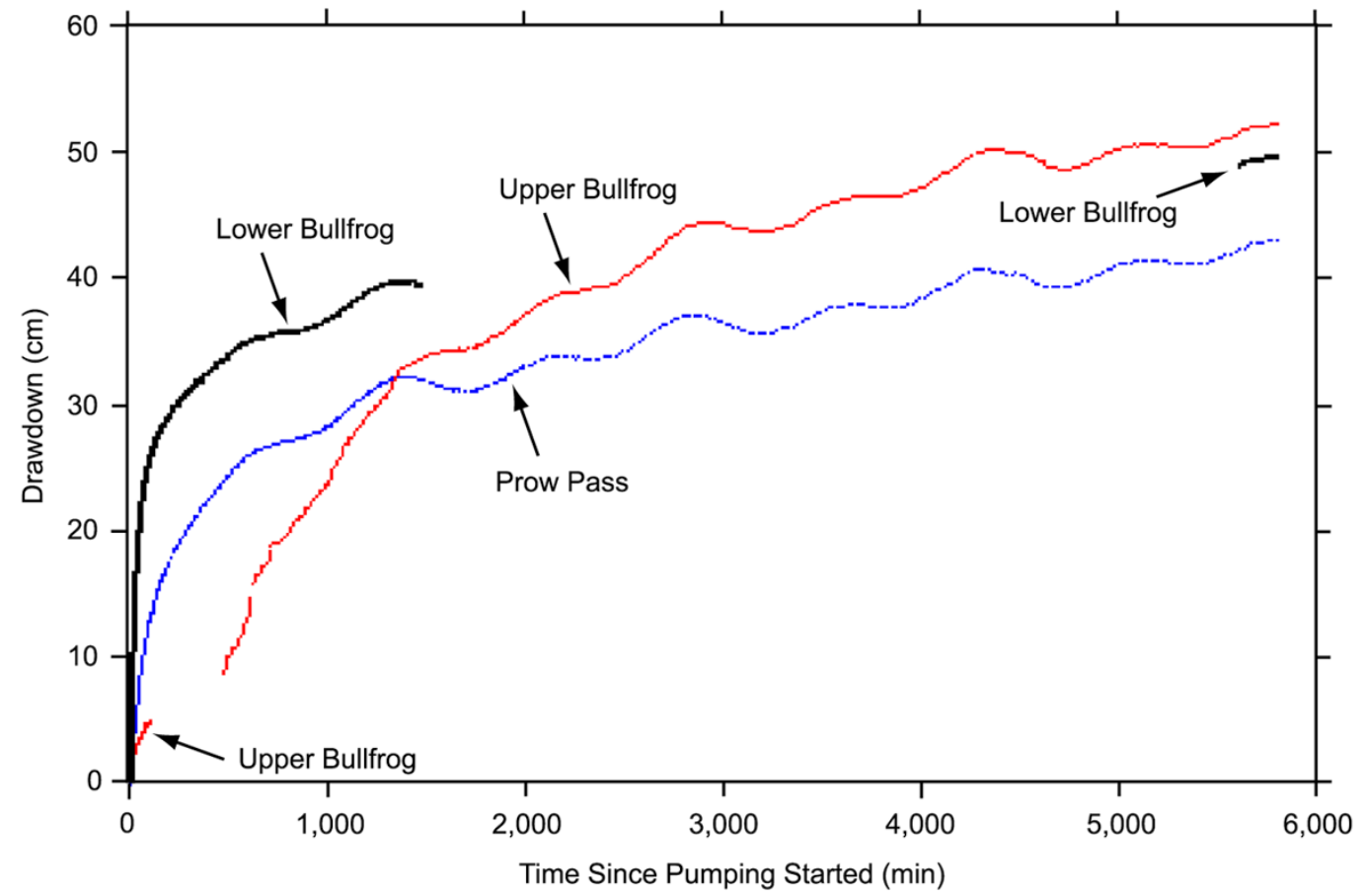

Output DTN: GS031008312314.004 (from Input DTN: GS030508312314.003 [DIRS 164425], p. 23, Figure 12).

Figure C-6. UE-25 c\#1 Drawdown

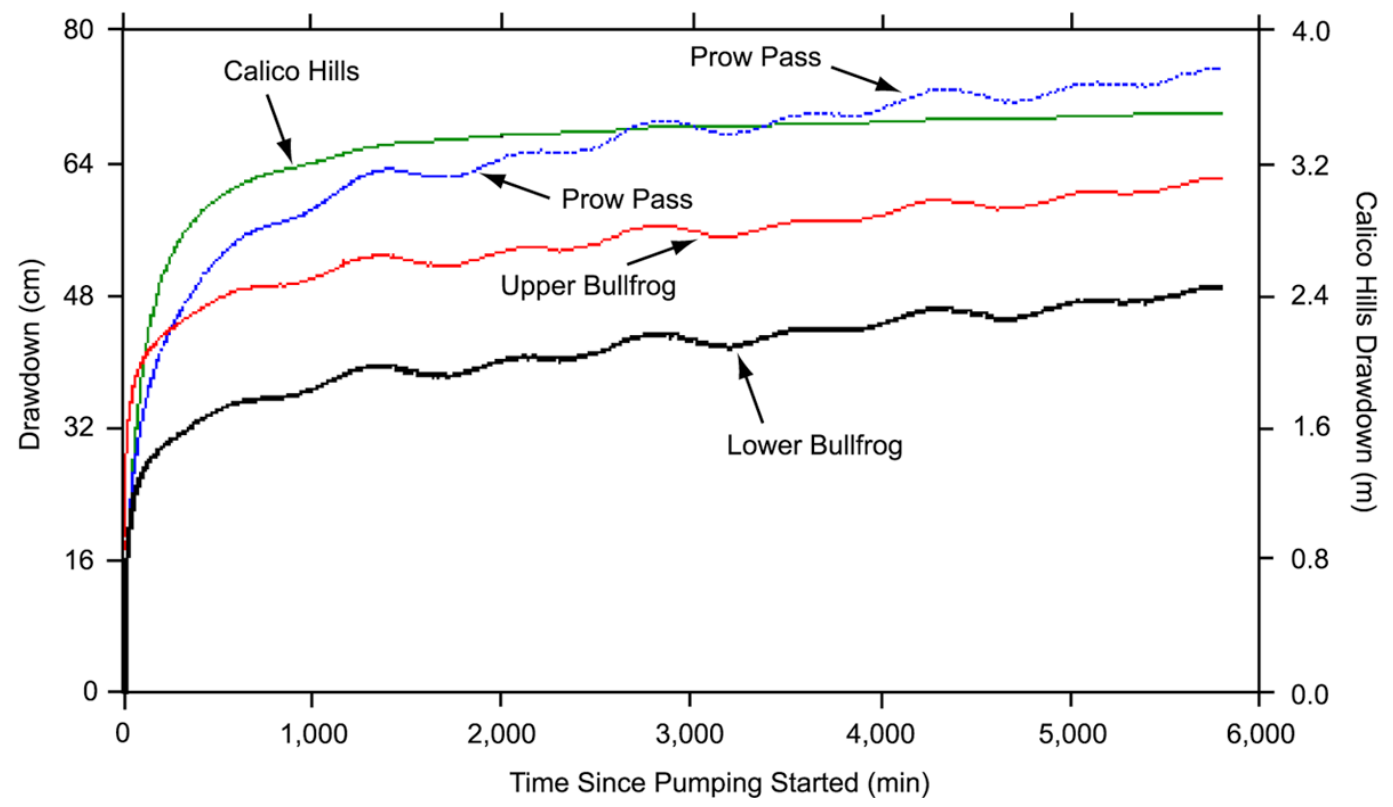

Output DTN: GS031008312314.004 (from Input DTN: GS030508312314.003 [DIRS 164425], p. 23, Figure 13).

Figure C-7. UE-25 c\#2 Drawdown 
The most permeable interval identified in the hydraulic test conducted in June 1995, the Lower Bullfrog interval, was chosen for subsequent tracer tests at the C-wells complex to increase the chance of successful transport of tracers between the injection and recovery wells. Because the transducer in the Lower Bullfrog interval of $\mathrm{c \# 3}$ was not working, the packers between the Lower Bullfrog and Upper Tram intervals in all three of the C-wells were deflated, and the combined Lower Bullfrog and Upper Tram intervals (shown in Figure 6.1-5 as the Bullfrog-Tram interval) became the test interval for the following series of tests.

After testing pump performance in January 1996 and allowing water levels in the C-wells to recover, pumping began on February 8, 1996, to establish a steep, quasi-steady-state hydraulic gradient between $\mathrm{c \# 2}$ (the injection well) and $\mathrm{c \# 3}$ (the recovery well) for a conservative tracer test. Tracer injection on February 13 disturbed the hydraulic pressure in the injection interval for 12.5 hours and effectively terminated the analyzable drawdown record. The 4.85 days of drawdown recorded between the start of pumping and the injection of tracer on February 13 (when the hydraulic pressure in the injection interval was disturbed) were analyzed as an hydraulic test.

During the hydraulic test in February 1996, operation of the pump outside its optimal performance range caused discharge to decrease steadily, despite an adjustment of the pump speed on February 12, about 5,640 minutes (3.917 days) after pumping started. Prior to that adjustment, discharge decreased from 526.8 to $492.6 \mathrm{~L} / \mathrm{min}$. Adjusting the pump speed restored the discharge to $525 \mathrm{~L} / \mathrm{min}$, but discharge immediately began to decrease and was at $514.2 \mathrm{~L} / \mathrm{min}$ when the tracer test started on February 13 (Figure C-8). Although average discharge after adjusting the pump speed was $6.0 \mathrm{~L} / \mathrm{min}$ larger than before that adjustment, deviation from the average discharge of $509.4 \mathrm{~L} / \mathrm{min}$ was just 3 percent for the entire period of pumping.

As shown in Figure C-8, the pumping produced as much as $2.86 \mathrm{~m}$ of drawdown in the Bullfrog-Tram interval of $\mathrm{c \# 3}$ (96 percent of which occurred in the first 10 minutes). Adjustment of the pump speed caused a step-like increase of $0.19 \mathrm{~m}$ in c\#3 drawdown, but it had no discernible effect on drawdown in the other C-wells. Although oscillatory, drawdown in c\#1 steadily increased and ranged from 14.3 to $22.1 \mathrm{~cm}$ in the Prow Pass, Upper Bullfrog, and Bullfrog-Tram intervals (Figure C-9). Likewise, oscillatory drawdown in c\#2 steadily increased and ranged from 14.9 to $25.3 \mathrm{~cm}$ in the Calico Hills, Prow Pass, Upper Bullfrog, and Bullfrog-Tram intervals (Figure C-10). Steady increases in observation-well drawdown together with small deviations from the average discharge enabled the observation-well drawdown for the entire period before tracer injection to be analyzable. 

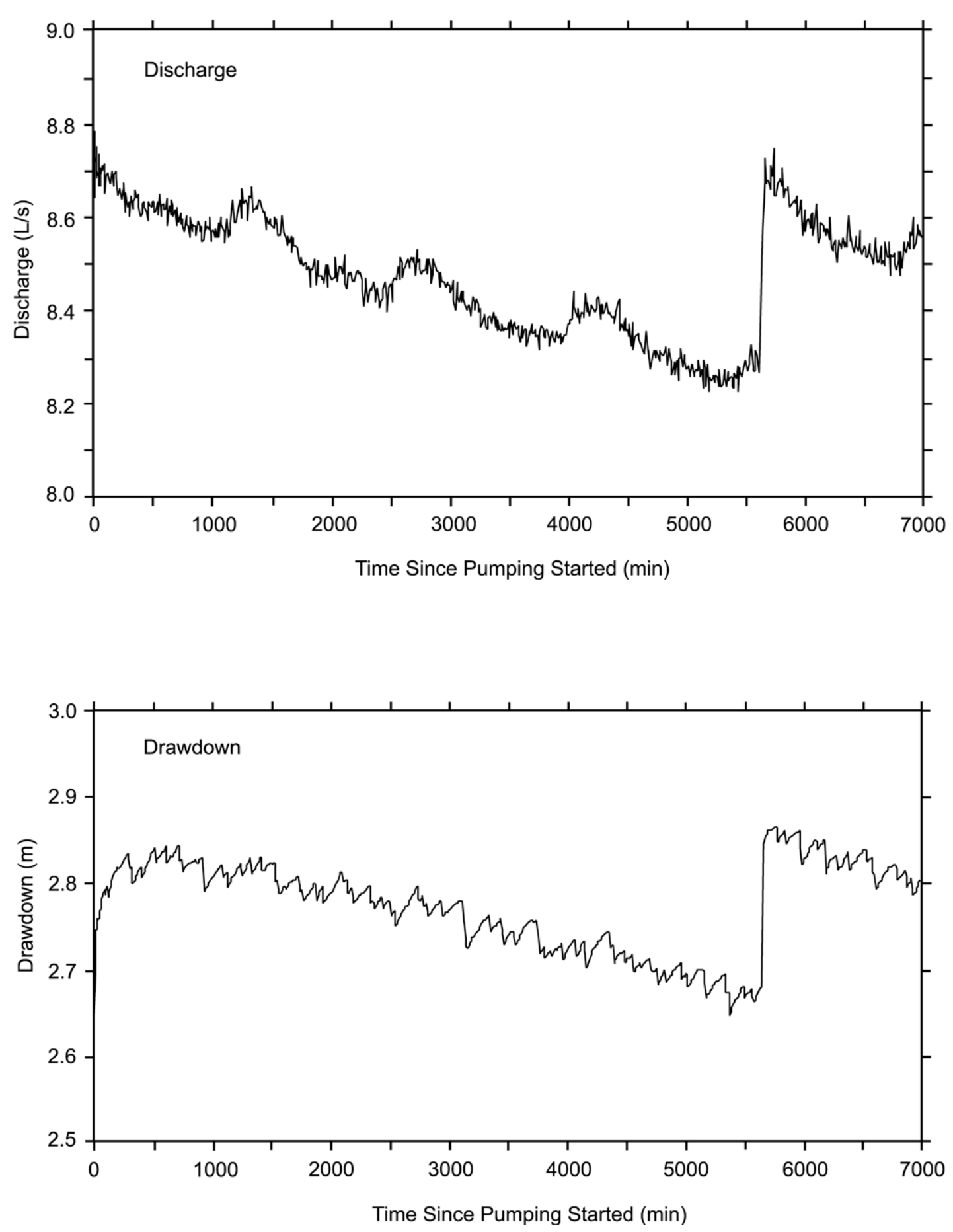

Output DTN: GS031008312314.004 (from Input DTN: GS030508312314.003 [DIRS 164425], p. 24, Figure 14). NOTE: Discharge units in text are L/min.

Figure C-8. UE-25 c\#3 Discharge and Drawdown, February 8, 1996 (Approximately 0 Minutes), to February 13, 1996 (Approximately 7,000 Minutes) 


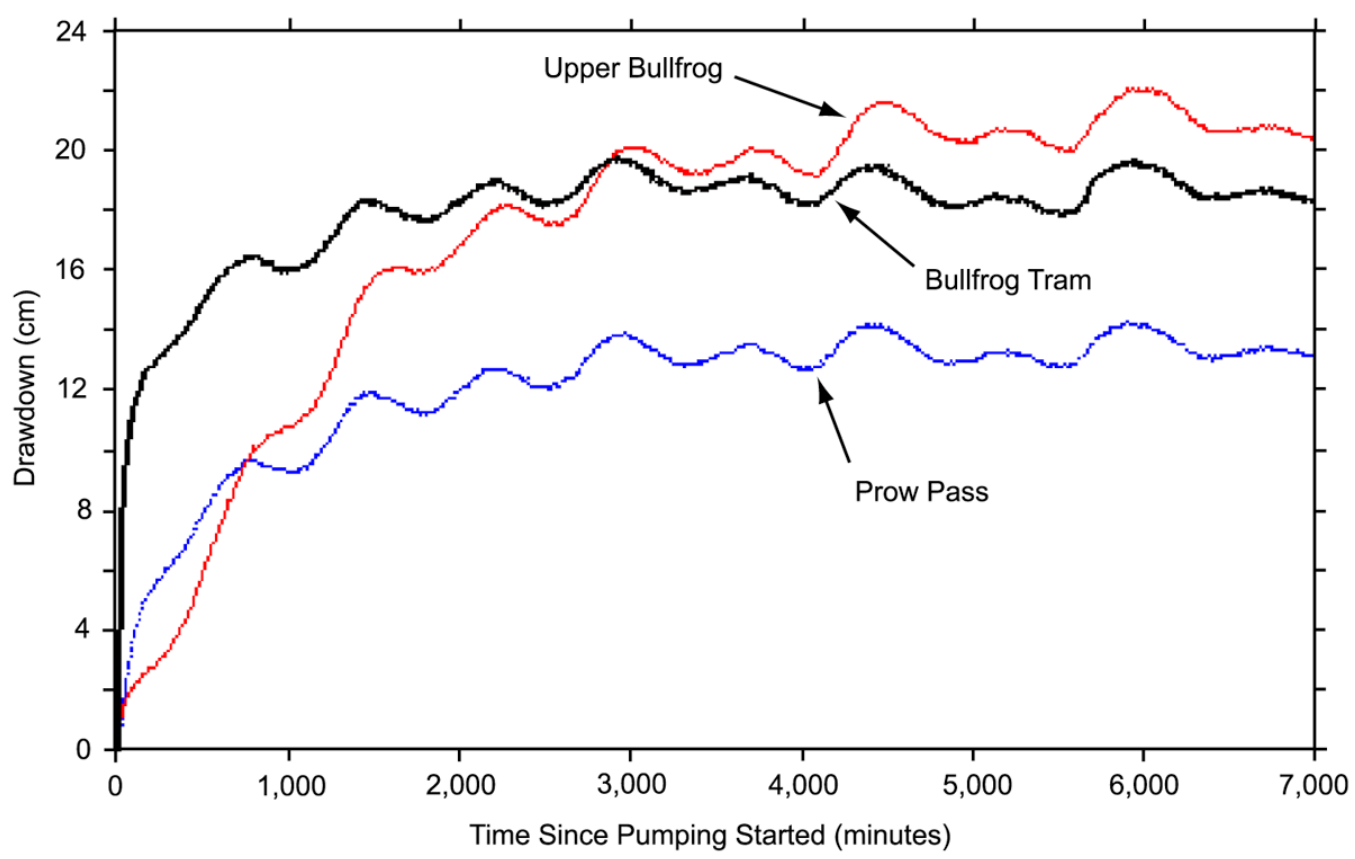

Output DTN: GS031008312314.004 (from Input DTN: GS030508312314.003 ([DIRS 164425], p. 25, Figure 15).

Figure C-9. UE-25 c\#1 Drawdown, February 8, 1996 (Approximately 0 Minutes), to February 13, 1996 (Approximately 7,000 Minutes)

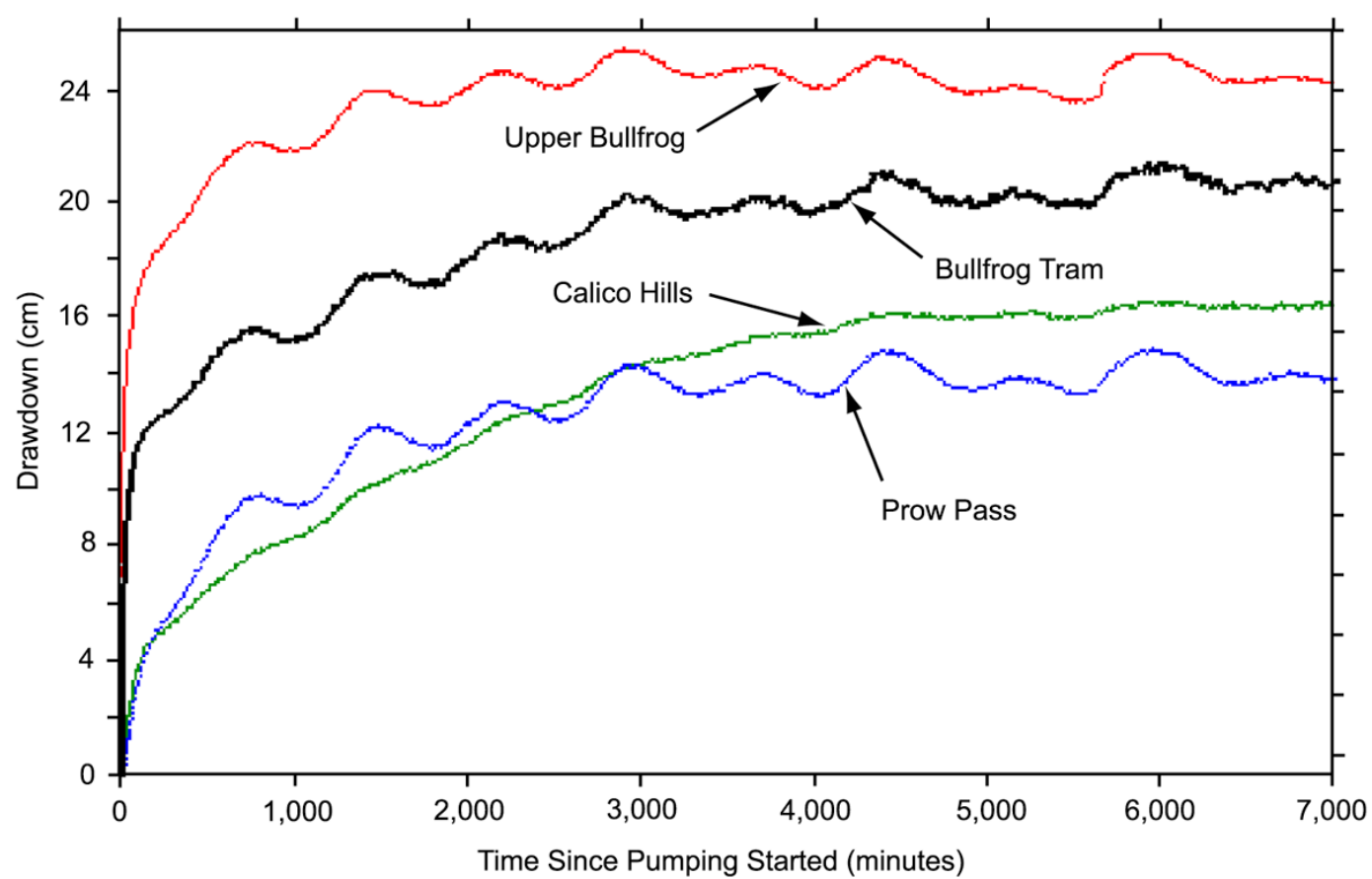

Output DTN: GS031008312314.004 (from Input DTN: GS030508312314.003 [DIRS 164425], p. 25, Figure 16).

Figure C-10. UE-25 c\#2 Drawdown, February 8, 1996 (Approximately 0 Minutes), to February 13, 1996 (Approximately 7,000 Minutes) 
After the tracer test in the Bullfrog-Tram interval ended in March 1996, a new transducer was installed in the Lower Bullfrog interval of $\mathrm{c} \# 3$, and packers in the borehole were reconfigured. Subsequently, it was possible to conduct hydraulic and tracer tests in the isolated Lower Bullfrog interval. With nearly continuous pumping, a series of tracer tests was conducted in that interval by the USGS and by Los Alamos National Laboratory from May 1996 to November 1997. Pumping in c\#3 to establish a steep, quasi-steady-state hydraulic gradient for tracer tests in the Lower Bullfrog interval began May 8, 1996. From May 24, 1996, to March 26, 1997, the pump shut off 11 times because of problems with the generators that provided power to the site. Between March 26 and May 8, 1997, the pump operated erratically because of continued problems with one of the generators. Problems with the power supply caused the pump to shut off intermittently between May 30 and September 29, 1997, and at least once a day between October 15 and November 12, 1997. Pumping was terminated on November 12, 1997, 553.24 days after pumping started, and recovery was monitored until December 31, 1997.

Discharge between May 8, 1996, and March 26, 1997, initially oscillated between 576 and 588 $\mathrm{L} / \mathrm{min}$, eventually stabilized at about $564 \mathrm{~L} / \mathrm{min}$, and averaged $571.8 \mathrm{~L} / \mathrm{min}$ (Figure C-11). After generator problems were resolved on May 8, 1997, discharge decreased steadily from 558 to $534 \mathrm{~L} / \mathrm{min}$ on November 12, 1997, and averaged $540.6 \mathrm{~L} / \mathrm{min}$. The volume of water withdrawn between May 8, 1996, and November 12, 1997, was 440.2 million L, equivalent to an average discharge of $552.6 \mathrm{~L} / \mathrm{min}$.

As in previous hydraulic tests, drawdown in the pumped well was large and reached steady-state conditions rapidly (Figure C-11). Drawdown in the Lower Bullfrog interval of c\#3 reached $4.8 \mathrm{~m}$ in 60 minutes and remained at 4.85 to $5.0 \mathrm{~m}$ until October 16, 1996, 161.11 days (232,000 minutes) after pumping started. After March 26, the frequent pump shutoffs kept drawdown less than $5.9 \mathrm{~m}$, except during the process of restarting the pump. Pump shutoffs typically caused rapid and complete or nearly complete recovery in c\#3, but those effects were reversed just as rapidly when the pump was restarted. Tracer-test operations affected drawdown in the pumped well minimally. Recovery from pumping on December 12, 1997, approximately 30 days (42,965 minutes) after pumping stopped, was 99 percent of antecedent drawdown. The prolonged period of unsteady pump discharge after March 26, 1997, effectively ended the drawdown record that could be analyzed as a hydraulic test for all observation wells except ONC-1. The analyzable drawdown record from May 8, 1996, to March 26, 1997, is 322.32 days in duration. With 11 down times ranging from 2 to 185 minutes, the pump was off for 10.82 hours (649 minutes), about 0.1 percent of the time, during that period. 

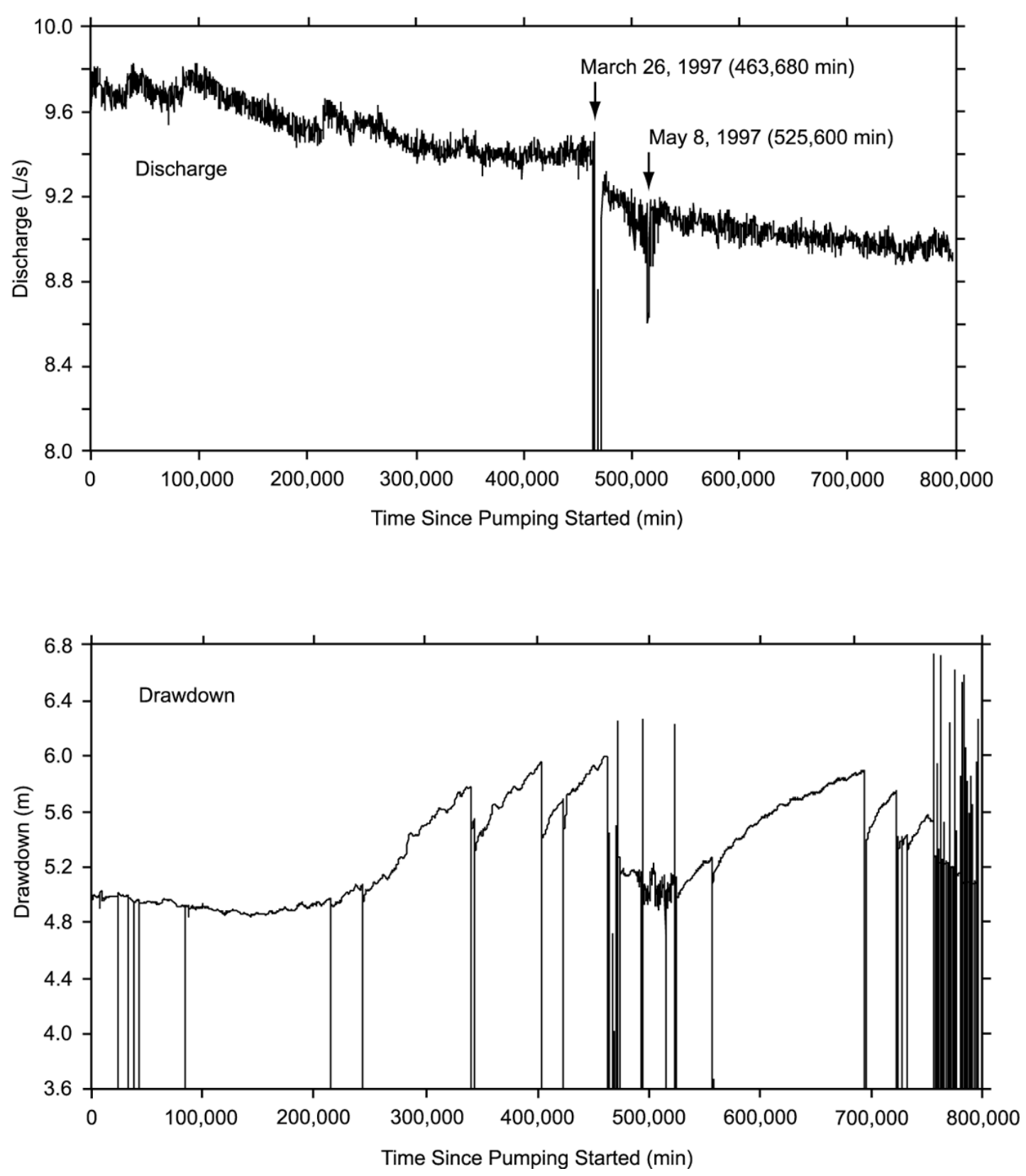

Output DTN: GS031008312314.004 (from Input DTN: GS030508312314.003 [DIRS 164425], p. 26, Figure 17). NOTE: Discharge units in text are L/min.

Figure C-11. UE-25 c\#3 Discharge and Drawdown, May 8, 1996 (Approximately 0 Minutes), to November 12, 1997 (Approximately 800,000 Minutes) 
Drawdown in response to pumping the Lower Bullfrog interval of c\#3 is known to have occurred in the Prow Pass, Upper Bullfrog, and Lower Bullfrog intervals of c\#1 and in the Calico Hills, Prow Pass, Upper Bullfrog, and Lower Bullfrog intervals of c\#2. Drawdown in all intervals of these boreholes generally increased steadily but was very oscillatory. Peak drawdown by March 26, 1997, ranged from about 36 to $42 \mathrm{~cm}$ in intervals of $\mathrm{c} \# 1$ (Figure C-12) and from about 35 to $51 \mathrm{~cm}$ in intervals of $\mathrm{c} \# 2$ (Figure C-13).

Disruptions of drawdown in the Lower Bullfrog and other intervals of c\#1 and c\#2 occurred from pump shutoffs 11 times between May 1996 and March 1997. Pump shutoffs (most of the unlabeled downward spikes in Figures C-12 and C-13) generally resulted in 20 to 50 percent recovery of water levels. However, these effects dissipated 50 to 500 minutes after the pump was restarted and did not affect analysis of the drawdown.

Recirculation of water during tracer tests conducted between May and November 1996 generally caused small decreases in drawdown in the Lower Bullfrog interval of $\mathrm{c} \# 1$ or decreases followed by increases in drawdown in the Lower Bullfrog interval of c\#2 at the start and end of recirculation, which generally lasted 70 to 560 minutes. However, recirculation of water in $\mathrm{c} \# 1$ from June 17 to July 3, 1996, to facilitate transport of iodide tracer between the injection and recovery wells caused drawdown in the Lower Bullfrog interval of c\#1 to decrease in steps for 23,350 minutes (Figures C-12 and C-14a). Pumping water into c\#1 faster than it could drain probably caused the drawdown to decrease. Periodic increases in the injection pump rate caused this decrease to occur in steps.

Tracer injection during four tests conducted between May 1996 and November 1997 caused increased drawdown in the Lower Bullfrog interval of $\mathrm{c} \# 1$ or $\mathrm{c} \# 2$ that generally lasted 180 to 750 minutes. However, following injection of 2,6 difluorobenzoic acid tracer into c\#2 on January 10, 1997, drawdown in the Lower Bullfrog interval of $\mathrm{c} \# 2$ remained high for 8,360 minutes (Figures C-13 and C-14b). Changes in hydraulic head associated with the dense tracer injection solution also could have produced the observed water-level changes in $\mathrm{c} \# 2$. 

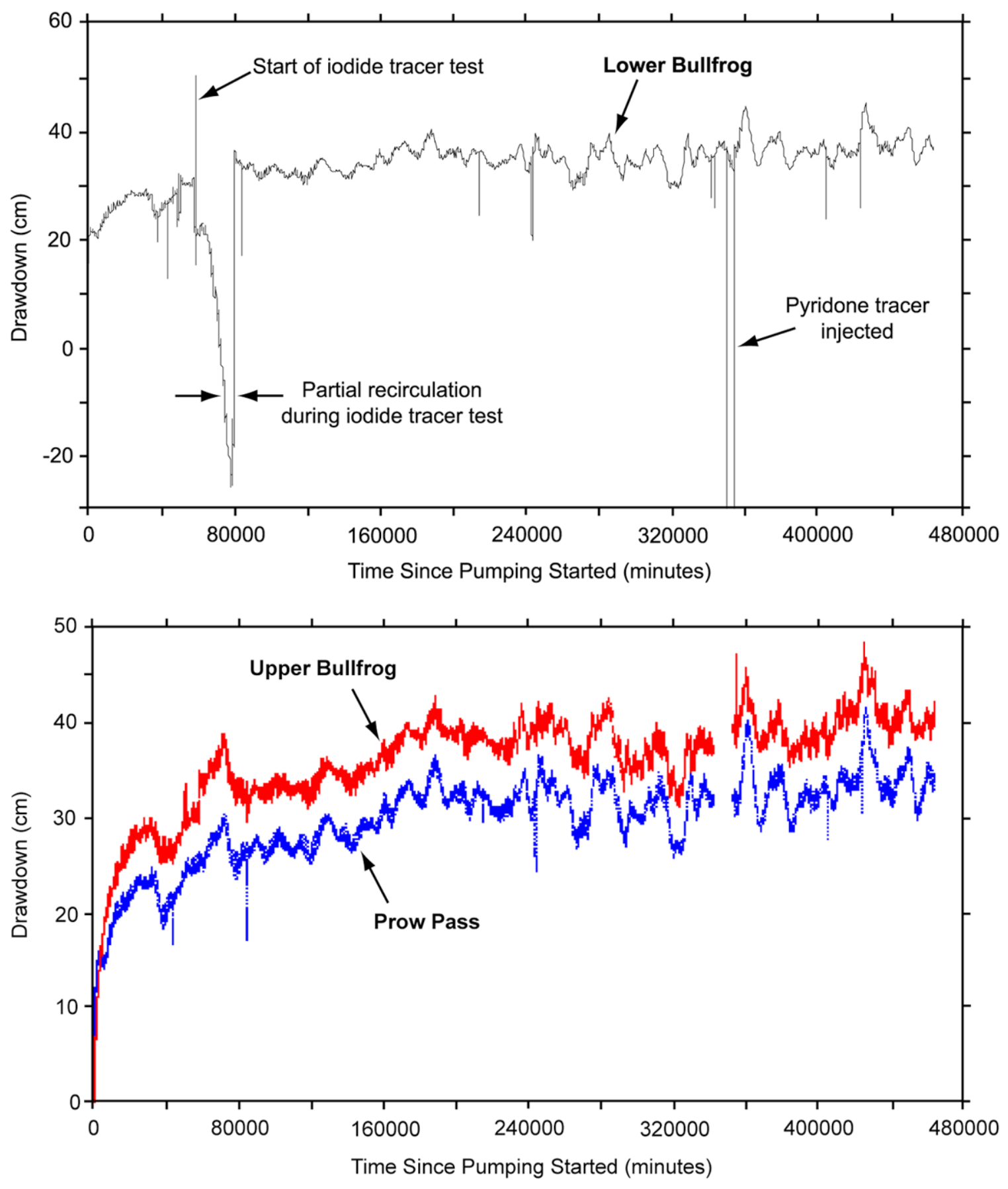

Output DTN: GS031008312314.004 (from Input DTN: GS030508312314.003 [DIRS 164425], p. 27, Figure 18).

Figure C-12. UE-25 c\#1 Drawdown, May 8, 1996 (Approximately 0 Minutes), to March 26, 1997 (Approximately 470,000 Minutes) 

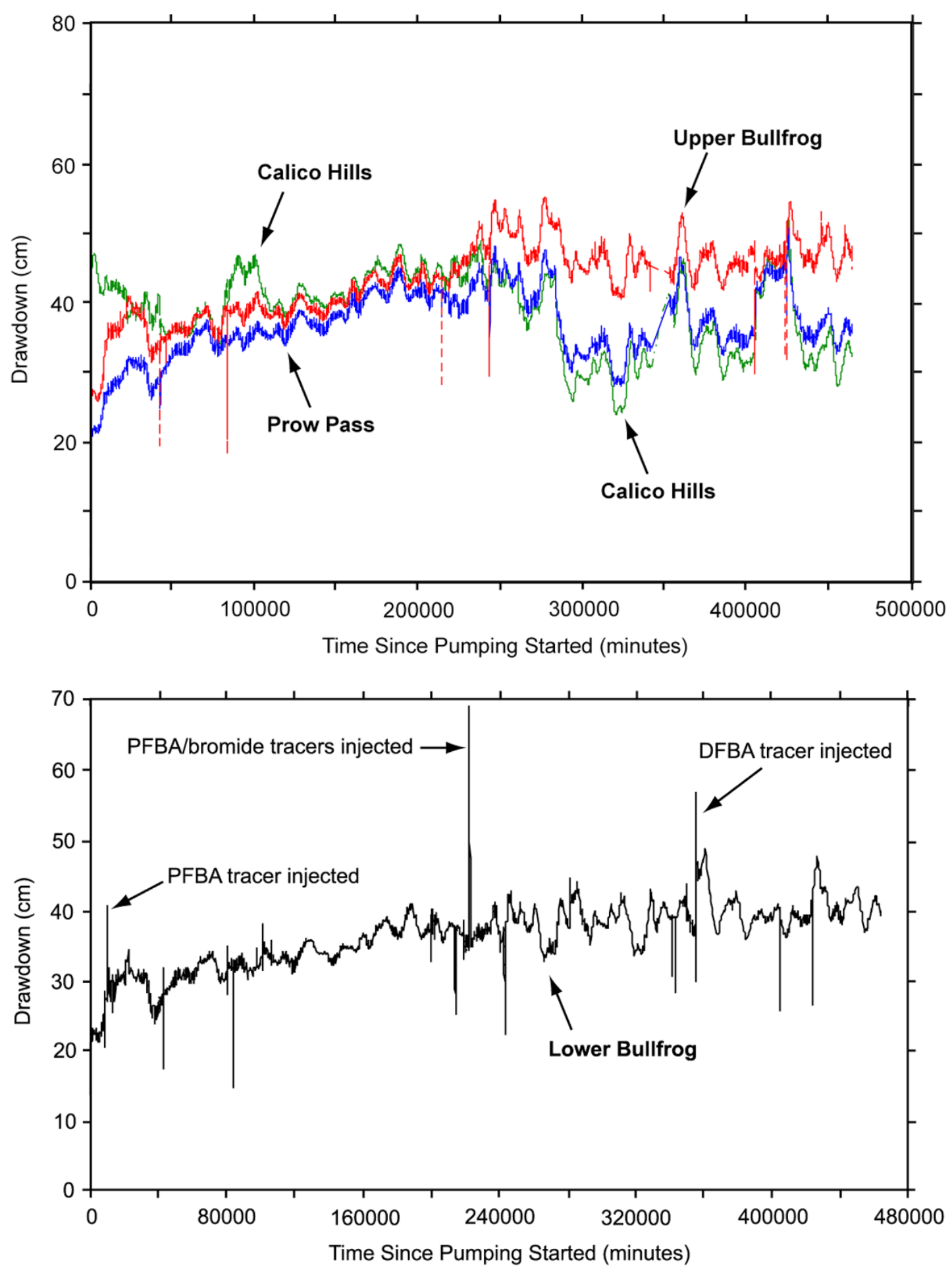

Output DTN: GS031008312314.004 (from Input DTN: GS030508312314.003 [DIRS 164425], p. 28, Figure 19). NOTE: PFBA=Pentafluorobenzoic acid; DFBA=2,6 difluorobenzoic acid.

Figure C-13. UE-25 c\#2 Drawdown, May 8, 1996 (Approximately 0 Minutes), to March 26, 1997 (Approximately 470,000 Minutes) 
a)

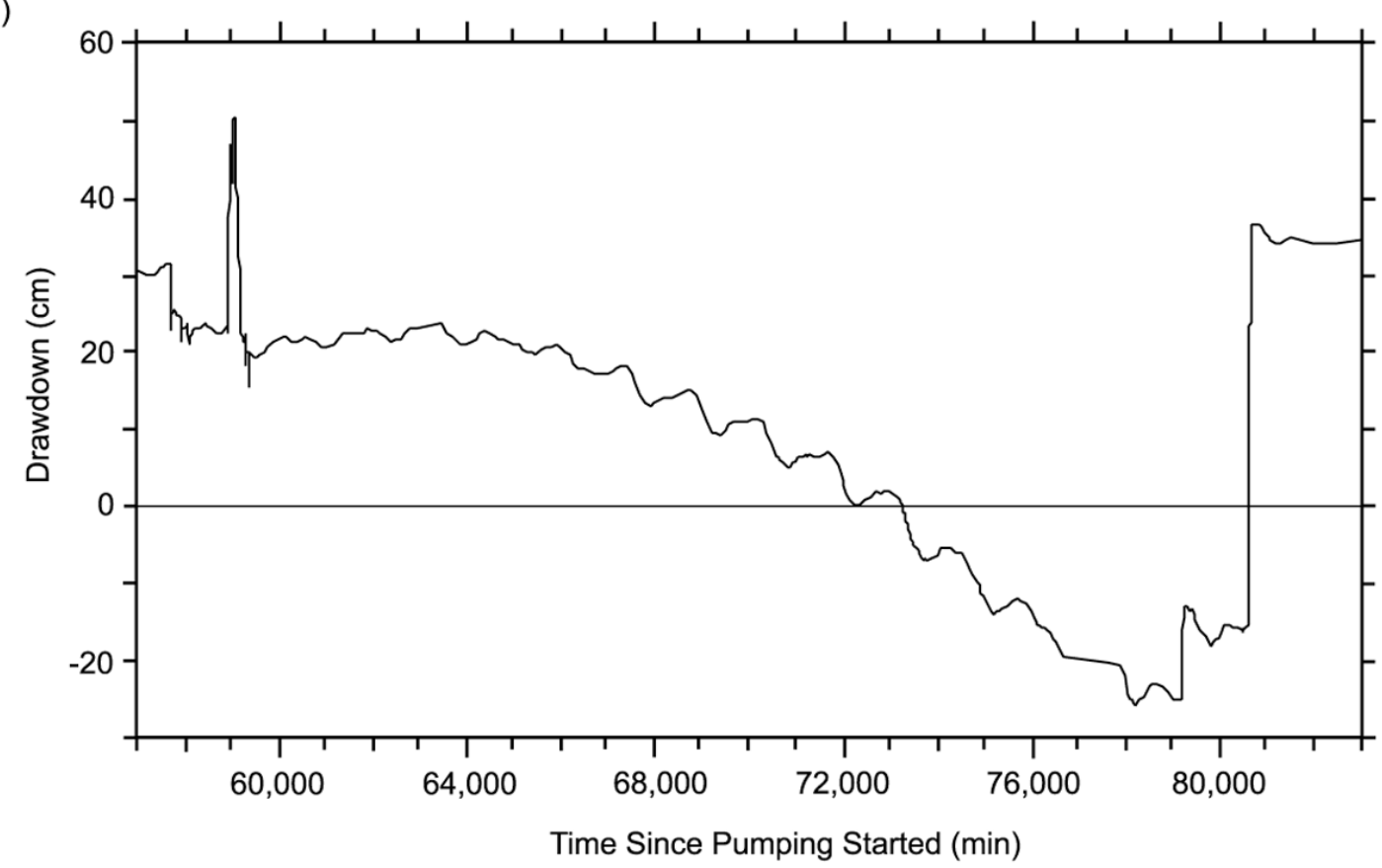

b)

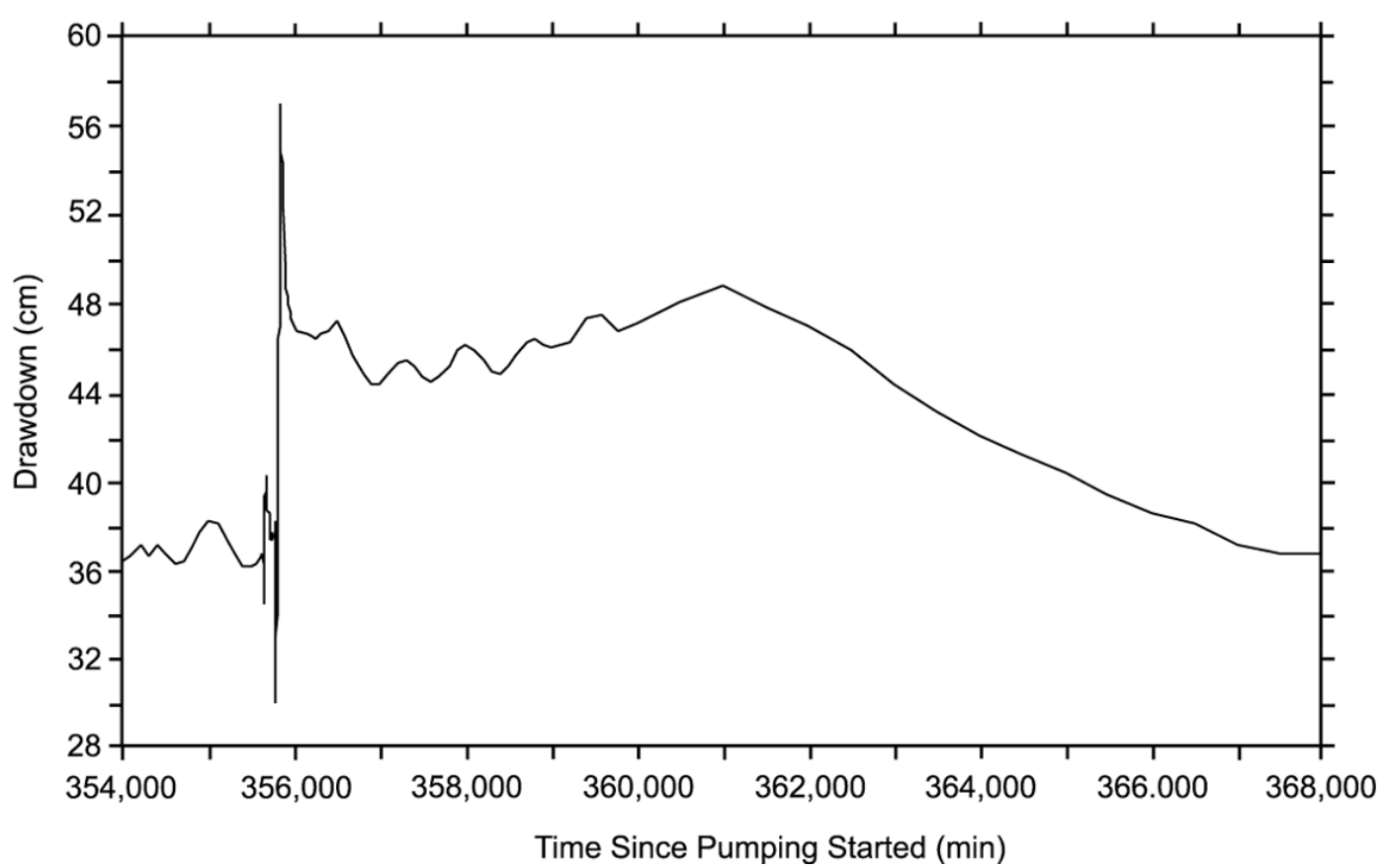

Output DTN: GS031008312314.004 (from Input DTN: GS030508312314.003 [DIRS 164425], p. 29, Figure 20).

NOTE: a) lodide tracer test in c\#1, June 17, 1996 (approximately 57,000 minutes), to July 5, 1996 (approximately 83,000 minutes). b) 2,6 Difluorobenzoic acid tracer test in c\#2, January 9, 1997 (approximately 354,000 minutes), to January 18, 1997 (approximately 368,000 minutes).

Figure C-14. Disturbance of Drawdown in Lower Bullfrog Interval of UE-25 c\#1 and UE-25 c\#2 by Tracer Tests in (a) 1996 and (b) 1997 
Hypotheses regarding disturbances from tracer-test operations cannot be tested and, therefore, are presented only for consideration. It is important to note that (1) tracer-test operations conducted in one borehole generally did not affect drawdown in other boreholes and (2) disturbances from tracer-test operations did not affect analyses of drawdown in $\mathrm{c} \# 1$ and $\mathrm{c} \# 2$.

Events of unknown origin caused hydraulic heads in the Lower Bullfrog interval of c\#1 and c\#2 to rise $5 \mathrm{~cm}$ to $8 \mathrm{~cm}$ from June 1 to June 11, 1996 (a period of 14,800 minutes), and from November 6, 1996 to November 14, 1996 (a period of 11,900 minutes). Because six observation wells within $3.5 \mathrm{~km}$ of $\mathrm{c \#} 3$ showed similar rises in hydraulic head, the events that produced these disturbances could not have been local in scale.

Shutting off the pump in c\#3 on November 12, 1997, caused erratic responses in the Lower Bullfrog intervals of $\mathrm{c} \# 2$ and $\mathrm{c \# 1}$ that are not analyzable. Recovery in the Lower Bullfrog interval of $\mathrm{c} \# 1$ reached a plateau from 8,000 to 38,500 minutes after pumping stopped, after which it began increasing cyclically. On December 29, 1997, 46.53 days (67,000 minutes) after pumping stopped, recovery in the Lower Bullfrog interval of c\#1 was about 95 percent of the antecedent drawdown (Figure C-15). The transducer in the Lower Bullfrog interval of $\mathrm{c} \# 2$ was removed on December 9, 1997, at a time when readings from the transducer were erratic, and recovery was only about 70 percent of the antecedent drawdown.

"Recovery" (as used in the previous paragraph and in Figure C-15) is a calculated value. First, the pattern of water-level decline prior to stopping the pump (antecedent water-level decline) is extrapolated beyond the time of stopping the pump. This extrapolated antecedent water-level decline is presented as the blue antecedent drawdown curve in Figure C-15. Then, for any point in time after pump stoppage, the "recovery" is calculated as the distance from the extrapolated antecedent water level to the recovered water level. So, "recovery" is larger than the distance that the water level has rebounded relative to where it was at the point of shutting off the pump.

Pumping in the Lower Bullfrog interval of c\#3 from May 1996 to March 1997 caused drawdown in all four of the observation wells beyond the C-wells complex that are completed in Miocene tuffaceous rocks. As in $\mathrm{c} \# 1$ and $\mathrm{c} \# 2$, drawdown in the four outlying observation wells was very oscillatory. Drawdown in these wells was not affected by pump shutoffs or tracer test operations.

Drawdown in ONC-1, the nearest observation well to the C-wells, was detected 200 minutes after pumping started and increased steadily thereafter (Figure C-16). Peak drawdown by March 26, 1997, was about 28 to $30 \mathrm{~cm}$. Peak drawdown when pumping ended on November 12, 1997, was about 36 to $37 \mathrm{~cm}$. Recovery in ONC-1 followed a pattern similar to the Lower Bullfrog interval in c\#1 (Figure C-15). On December 29, 1997, 46.875 days (67,500 minutes) after pumping stopped, recovery in ONC-1 was about 76 percent of the antecedent drawdown.

Borehole WT\#3, the farthest observation well from the $\mathrm{C}$-wells, responded like the $\mathrm{C}$-wells and ONC-1 to the pumping in $\mathrm{c} \# 3$ that began on May 8, 1996. Drawdown in WT\#3 was detected 6.34 days (9,130 minutes) after pumping started (Figure C-17). Peak drawdown by March 26, 1997, was about 14 to $16 \mathrm{~cm}$. Drawdown in WT\#3 was more oscillatory than in the other observation wells after 166.67 days (240,000 minutes) of pumping. This behavior was possibly because (1) WT\#3 was much farther from the pumping well than the other observation 
wells and affected by environmental stresses that did not extend to the other wells, and (2) pumping-related water-level changes in WT\#3 were much smaller than in the other observation wells and, therefore, harder to separate from barometric and Earth-tide effects.

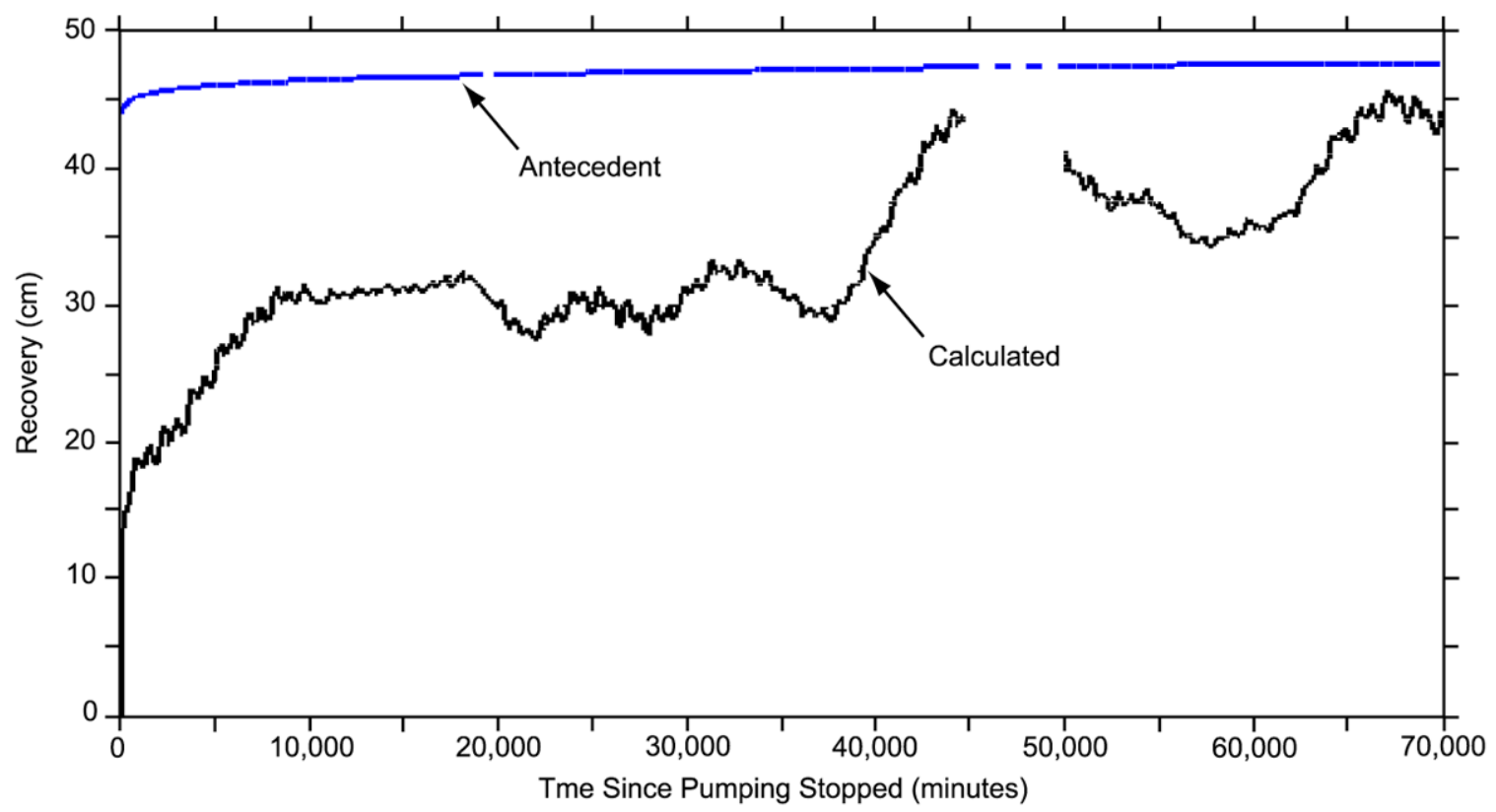

Output DTN: GS031008312314.004 (from Input DTN: GS030508312314.003 [DIRS 164425], p. 30, Figure 21). NOTE: Pump was turned off 11/12/97 at 15:59:50 PST.

Figure C-15. UE-25 c\#1 Lower Bullfrog Recovery, November 12, 1997 (Approximately 0 Minutes), to December 31, 1997 (Approximately 70,000 Minutes) 


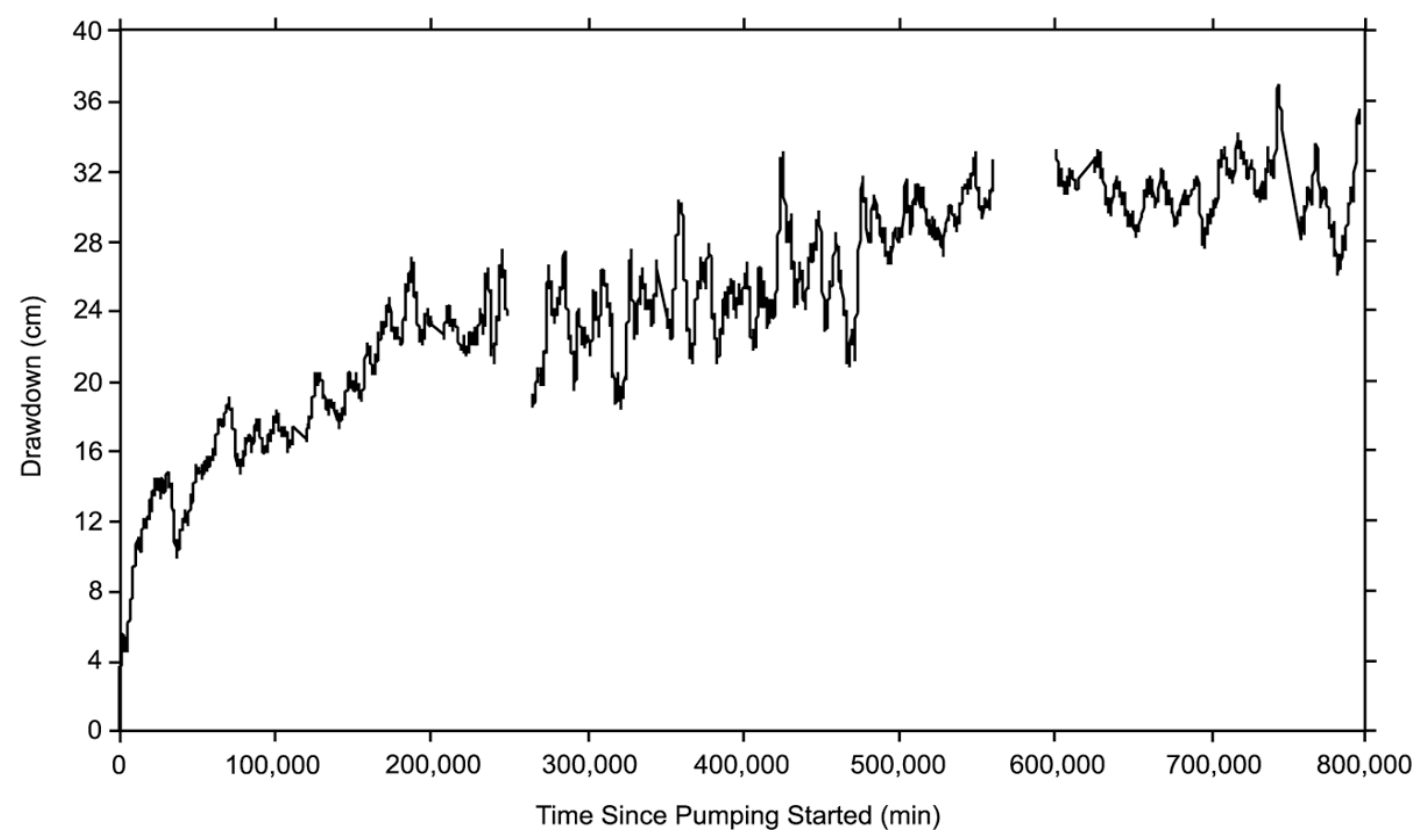

Output DTN: GS031008312314.004 (from Input DTN: GS030508312314.003 [DIRS 164425], p. 31, Figure 22).

Figure C-16. Drawdown in UE-25 ONC-1, May 8, 1996 (Approximately 0 Minutes), to November 12, 1997 (Approximately 800,000 Minutes)

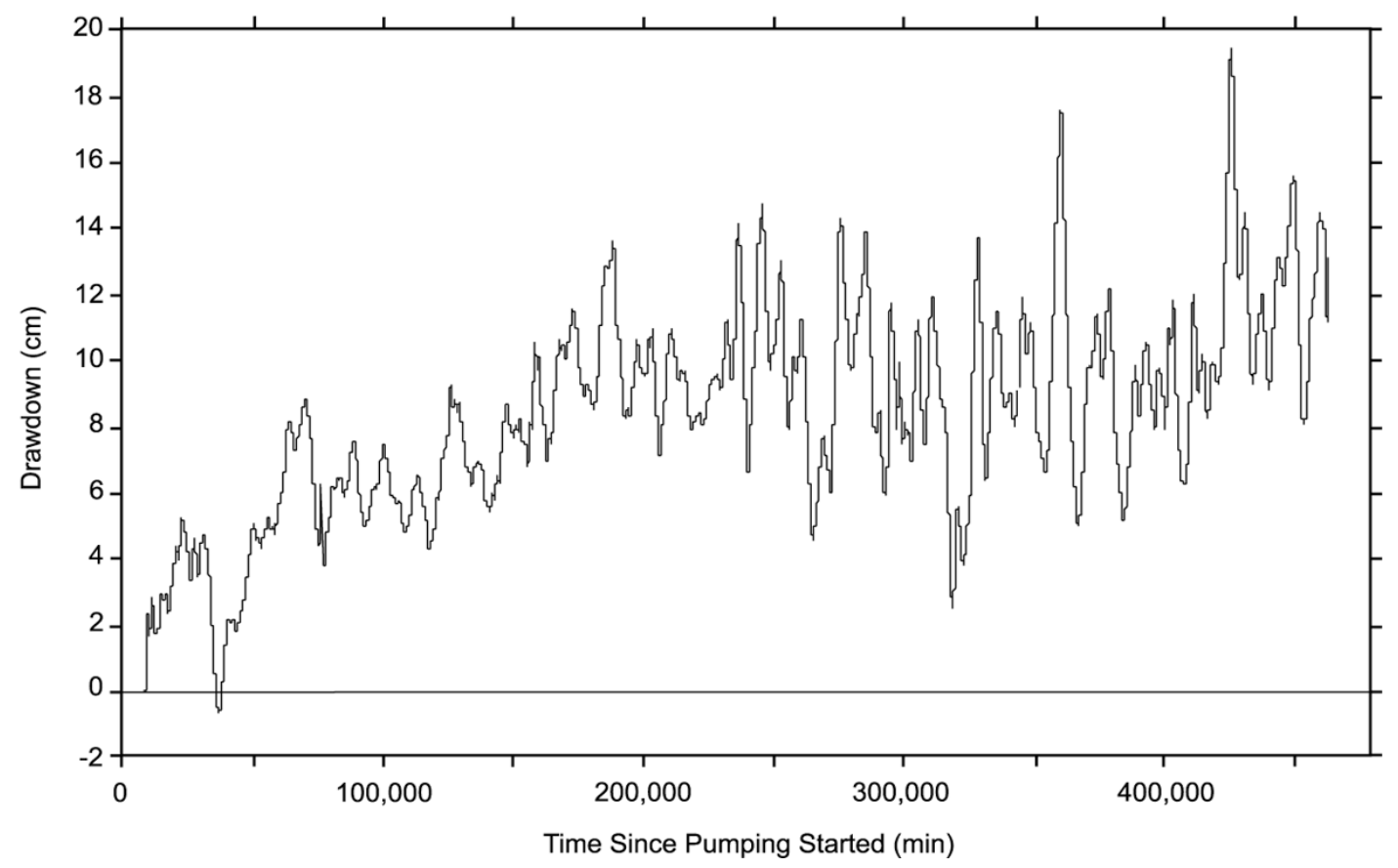

Output DTN: GS031008312314.004 (from Input DTN: GS030508312314.003 [DIRS 164425], p. 31, Figure 23).

Figure C-17. Drawdown in UE-25 WT\#3, May 8, 1996 (Approximately 0 Minutes), to March 26, 1997 (Approximately 480,000 Minutes) 
Unlike other observation wells monitored during the hydraulic test that began in May 1996, H-4 and WT\#14 exhibited steady-state drawdown as pumping progressed (Figure C-18). Drawdown in both boreholes was delayed for about 5,000 minutes after pumping started, although very small, oscillatory water-level changes, possibly caused by borehole-storage release, occurred during this time. Between 5,000 and 72,000 minutes after pumping started, drawdown increased steadily in response to pumping. Drawdown in $\mathrm{H}-4$ peaked at about $22 \mathrm{~cm}$; drawdown in WT\#14 peaked at about $15 \mathrm{~cm}$. After about 50 days $(72,000$ minutes) of pumping, fluxes from recharge boundaries, probably a transmissive fault, prevented further drawdown. As in a hydraulic test of the Tram interval in c\#1 conducted in 1984 (Geldon 1996 [DIRS 100396], pp. 67 to 68), recharge boundaries affecting H-4 and WT\#14 are inferred to be faults present near the observation wells. Numerous faults are located near H-4 (Day et al. 1998 [DIRS 101557]), and several segments of the Paintbrush Canyon fault are located near WT\#14 (Dickerson and Drake 1998 [DIRS 102781]). Conversely, there are no known changes in stratigraphy or lithology between the $\mathrm{C}$-wells and either H-4 or WT\#14 that might be interpreted to create a hydraulic boundary.

\section{C3.2 HYDRAULIC TESTS CONDUCTED IN 1998 AND 1999 (PROW PASS INTERVAL)}

Pumping in $\mathrm{c} \# 2$ to create a forced hydraulic gradient for tracer tests in the Prow Pass interval at the C-wells complex began June 2, 1998, and continued uninterrupted until September 22, 1998. [Detailed description of the field tests is reported by Umari (2002 [DIRS 162858], Binder 12, Sections M-20 to M-22.)] The pump in c\#2 shut off for 70 minutes on September 22 as one of two packers at the bottom of the Prow Pass interval (number 3) was being deflated. Injection of water into c\#3 to expedite tracer transport began June 11 and continued without interruption until September 2. The injection pump was off briefly on September 2 and 3 while injection tubing was removed from c\#3. Tracers were injected into c\#3 on June 17 and into c\#1 on July 31.

Responses of c\#1, c\#3, and ONC-1 to pumping June 2 to June 11, in advance of the tracer tests, were analyzed as a constant-rate withdrawal (CRW) test. After water injection into c\#3 began on June 11, the superimposed effects of pumping water from $\mathrm{c} \# 2$, injecting water into $\mathrm{c} \# 3$, injecting tracers into $\mathrm{c} \# 3$ and $\mathrm{c} \# 1$, operating a mixing pump in $\mathrm{c} \# 3$ intermittently, and mechanical problems that affected pumping and injection rates made it difficult to analyze data from the $\mathrm{C}$-wells quantitatively. However, ONC-1 was far enough away from the pumping and injection wells that a water-level rise in ONC-1 resulting from injecting water into c\#3 clearly could be separated from relatively minor drawdown in the well caused by pumping $\mathrm{c} \# 2$. The water-level rise in ONC-1 from June 11 to September 1 was analyzed as a constant-rate injection test. 

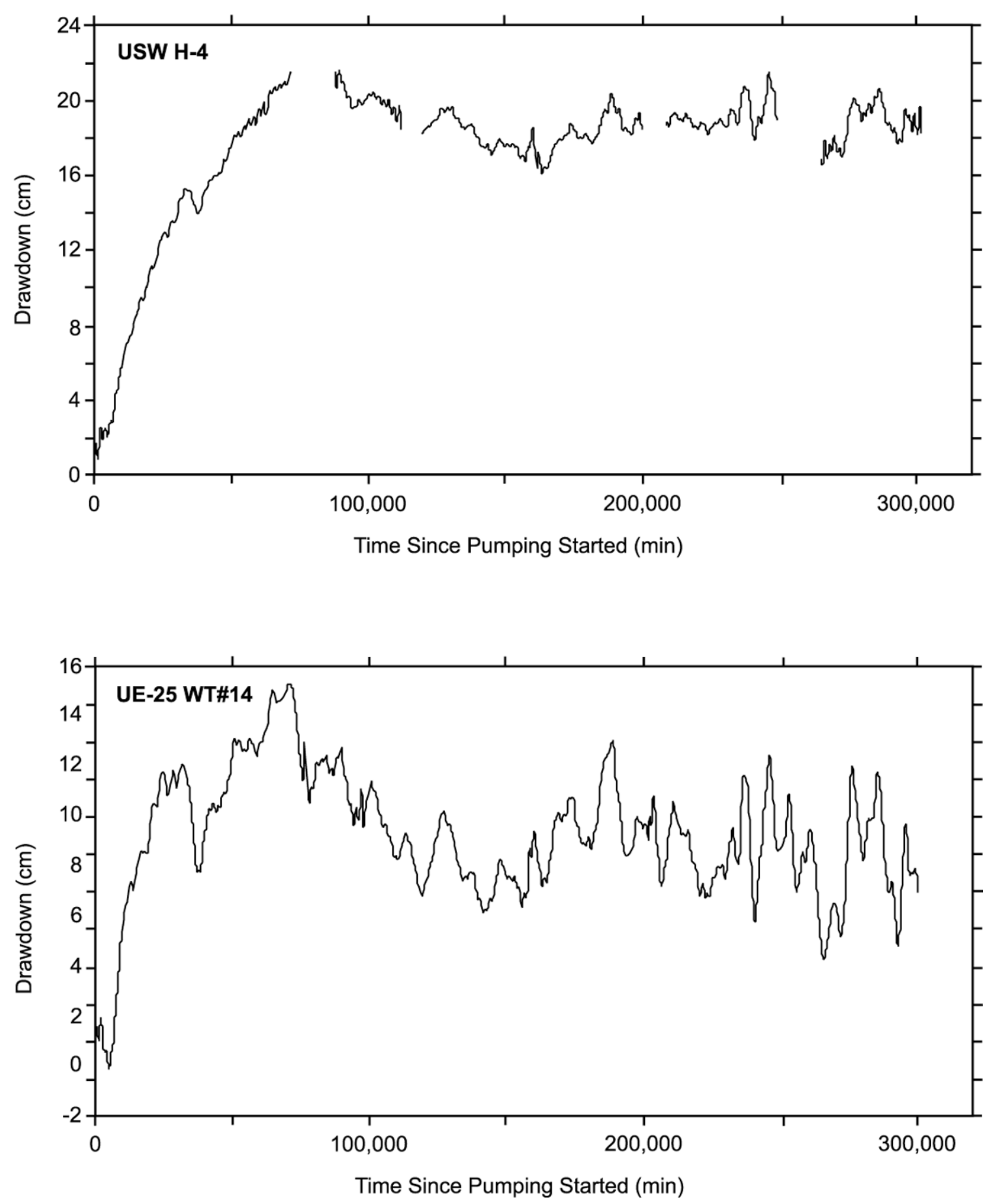

Output DTN: GS031008312314.004 (from Input DTN: GS030508312314.003 [DIRS 164425], p. 32, Figure 24).

Figure C-18. Drawdown in USW H-4 and UE-25 WT\#14, May 8, 1996 (Approximately 0 Minutes), to December 3, 1996 (Approximately 300,000 Minutes) 


\section{C3.2.1 Performance Tests}

Hydraulic and tracer tests in the Prow Pass interval were preceded by pump-performance, step-drawdown, and 1-day hydraulic tests conducted in $\mathrm{c} \# 2$ and $\mathrm{c} \# 3$ from April 21 to May 29, 1998. These tests were designed primarily to determine whether c\#2 could be used as a pumping well for tracer tests and what the optimum pumping rate should be. These tests also were analyzed to determine values of hydrologic properties that would be expected from a longer hydraulic test planned to precede tracer tests in the Prow Pass interval. Fluctuations in water and atmospheric pressures between performance tests indicated barometric efficiency values (Table C-5) for the C-wells and ONC-1 that were used to analyze hydraulic tests (DTNs: GS990408312315.002 [DIRS 140115]; MO0212SPANYESJ.149 [DIRS 161274]) in the Prow Pass interval.

Table C-5. Barometric Efficiency in the C-wells and UE-25 ONC-1

\begin{tabular}{|c|c|c|c|c|}
\hline Interval & c\#1 & c\#2 & c\#3 & UE-25 ONC-1 \\
\hline Calico Hills & $\mathrm{N} / \mathrm{A}$ & 0.93 & 0.94 & $\mathrm{~N} / \mathrm{A}$ \\
\hline Prow Pass & 0.96 & 0.93 & 1.0 & 0.99 \\
\hline Upper Bullfrog & 0.99 & 0.93 & $\cong 1.0$ & $\mathrm{~N} / \mathrm{A}$ \\
\hline Lower Bullfrog & 0.97 & $N / A$ & $\mathrm{~N} / \mathrm{A}$ & $N / A$ \\
\hline
\end{tabular}

\section{C3.2.2 Analytical Methods}

Analytical solutions were used to analyze data from hydraulic tests in the Prow Pass interval. Most of the data were analyzed using the method of Streltsova-Adams (1978 [DIRS 150754]) (Strelsova-Adams.vi V 1.0, STN: 10971-1.0-00 [DIRS 162756]) for a fissure-block aquifer. Analysis of data in this study was restricted to observation wells because most water-level changes in pumping wells at the C-wells complex are too large and rapid (Geldon 1996 [DIRS 100396], pp. 12 to 69) to be explained solely by hydrologic properties of the pumped interval.

\section{C3.2.3 Constant-Rate Withdrawal Test}

A CRW test in the Prow Pass interval started June 2, 1998. The pumping well for this test was $\mathrm{c} \# 2$, and the observation wells for the test were c\#1, c\#3, and ONC-1.

Prior to starting the test, the packer in c\#2 between the Prow Pass and Calico Hills intervals was deflated, and the two intervals, together, were pumped for 37 minutes at a rate of $34.2 \mathrm{~L} / \mathrm{min}$ to fill tubing in the pumping well to the level of the flowmeter. After pumping stopped, the packer in c\#2 between the Prow Pass and Calico Hills intervals was reinflated. With slight residual effects from the pretest pumping (which were removed to analyze the test), pumping for the CRW test in the Prow Pass began at 16:00 hours on June 2. Discharge averaged 19.8 L/min between June 2 and 11, a period of 12,500 minutes. Pumping water into c\#1 on June 5 to attempt a tracer test, injecting argon gas into c\#1 on June 9 to blow sediment out of the tracer injection valve, and testing the downhole mixing pump in $\mathrm{c} \# 3$ on June 10 briefly disturbed 
discharge from $\mathrm{c \# 2}$ as well as pressures in $\mathrm{c} \# 1$ and $\mathrm{c} \# 3$. The CRW test was terminated on June 11, 1998, at 08:19 when operations began for a tracer test between c\#3 and c\#2.

The pumping in $\mathrm{c} \# 2$ caused $135 \mathrm{~m}$ of drawdown in the Prow Pass interval of $\mathrm{c} \# 2$ three minutes after pumping started. However, the water level rebounded $22 \mathrm{~m}$ in the next nine minutes. Subsequently, drawdown increased steadily but slowly and was about $128 \mathrm{~m}$ after 12,500 minutes of pumping. On the basis of values of transmissivity and storativity determined in this and previous tests in which the drawdown in the Prow Pass in observation wells was analyzed, only 1.04 percent of the 128-m drawdown in the Prow Pass of the pumped well c\#2, namely 1.34 $\mathrm{m}$, is estimated to have resulted from stressing the aquifer. The remainder of the drawdown is attributed to head losses in the well bore.

The pumping in c\#2 caused oscillatory drawdown in the Prow Pass interval of the observation wells. After 12,500 minutes of pumping, this drawdown was $54 \mathrm{~cm}$ in $\mathrm{c} \# 3$ (Figure C-19), $12 \mathrm{~cm}$ in c\#1 (Figure C-20), and $0.9 \mathrm{~cm}$ in ONC-1. Plotted on log-log scales, drawdown in the Prow Pass interval of $\mathrm{c} \# 1$ and $\mathrm{c} \# 3$ indicated delayed yield characteristic of a fissure-block aquifer (Streltsova-Adams 1978 [DIRS 150754]), Figures C-21 and C-22).

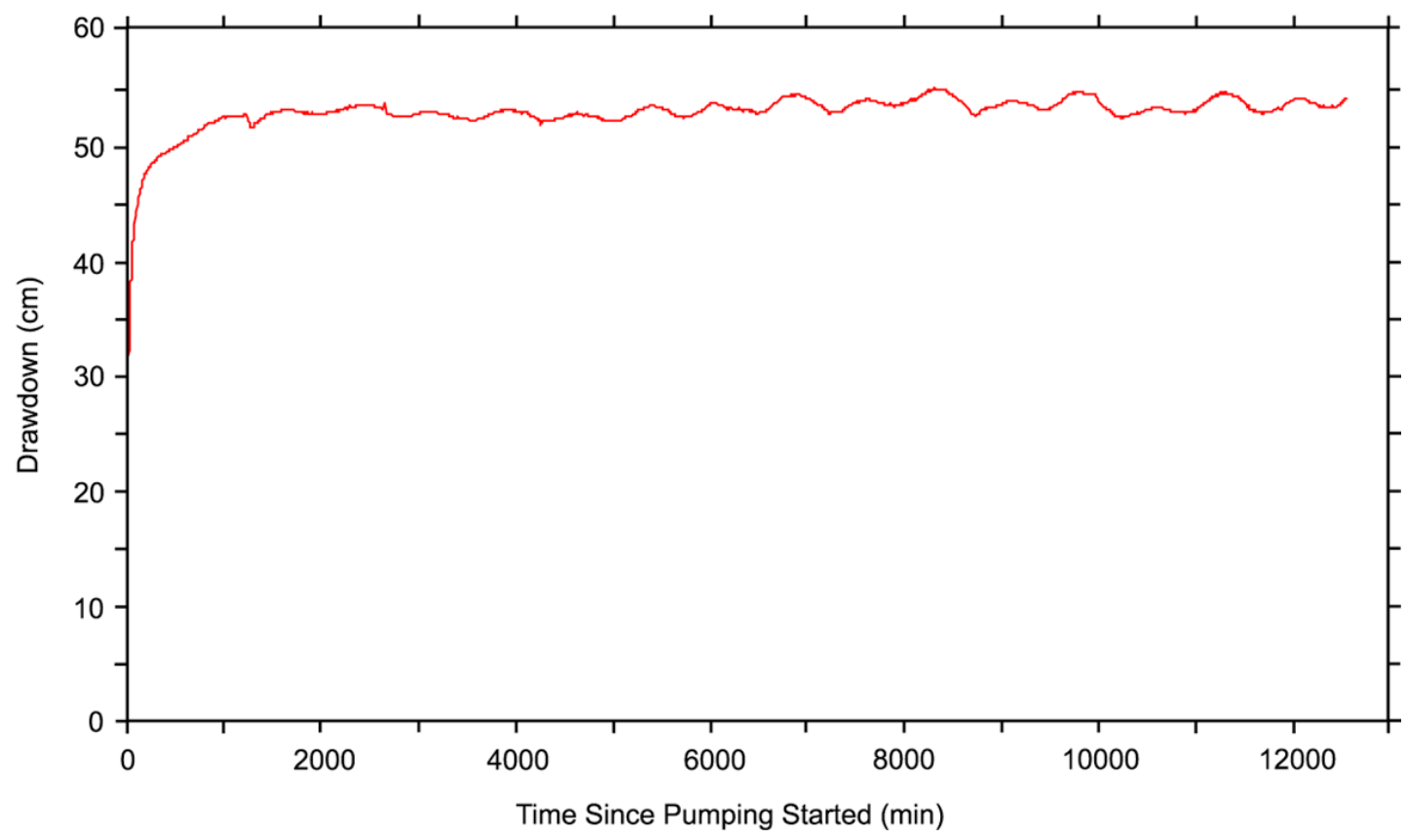

Output DTN: GS031008312314.004 (from Input DTN: GS990408312315.002 [DIRS 140115]).

Figure C-19. UE-25 c\#3 Prow Pass Drawdown, June 2, 1998 (Approximately 0 Minutes), to June 11, 1998 (Approximately 12,800 Minutes) 


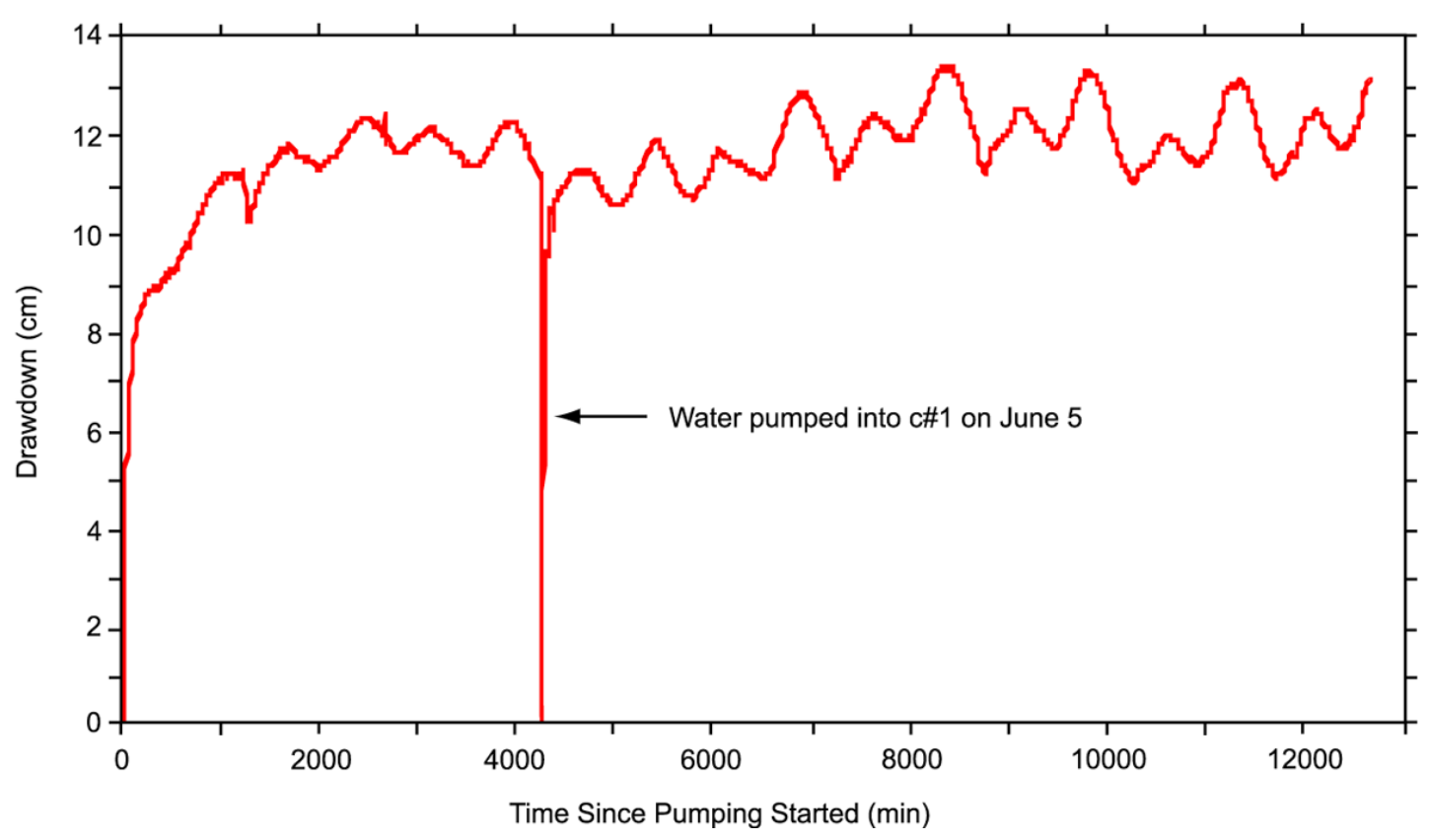

Output DTN: GS031008312314.004 (from Input DTN: GS990408312315.002 [DIRS 140115]).

Figure C-20. UE-25 c\#1 Prow Pass Drawdown, June 2, 1998 (Approximately 0 Minutes), to June 11, 1998 (Approximately 12,800 Minutes)

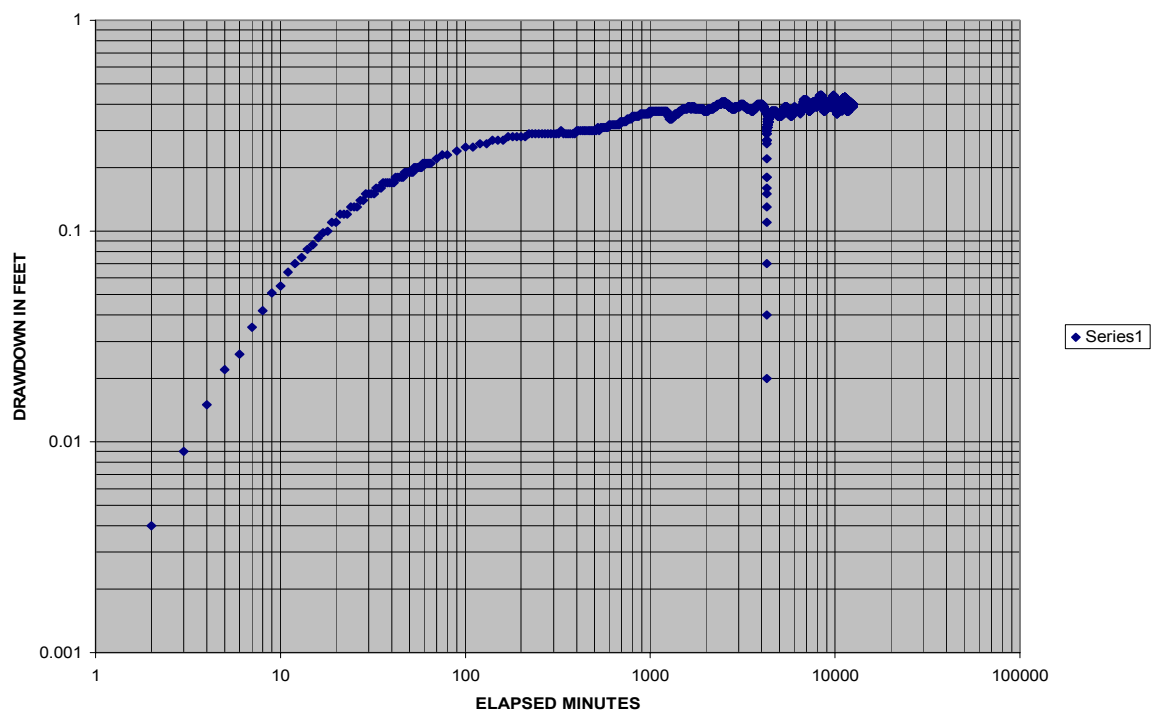

Output DTN: GS031008312314.004 (from Input DTN: GS990408312315.002 [DIRS 140115]).

NOTE: English units are shown in the figure because the analysis was conducted in English units. However, parameter estimates are reported in metric units to downstream users.

Figure C-21. Drawdown in the Prow Pass Interval of $\mathrm{c \# 1}$ in Response to Pumping c\#2, Starting June 2, 1998, Exhibiting Delayed Yield, Characteristic of a Fissure-Block Aquifer 


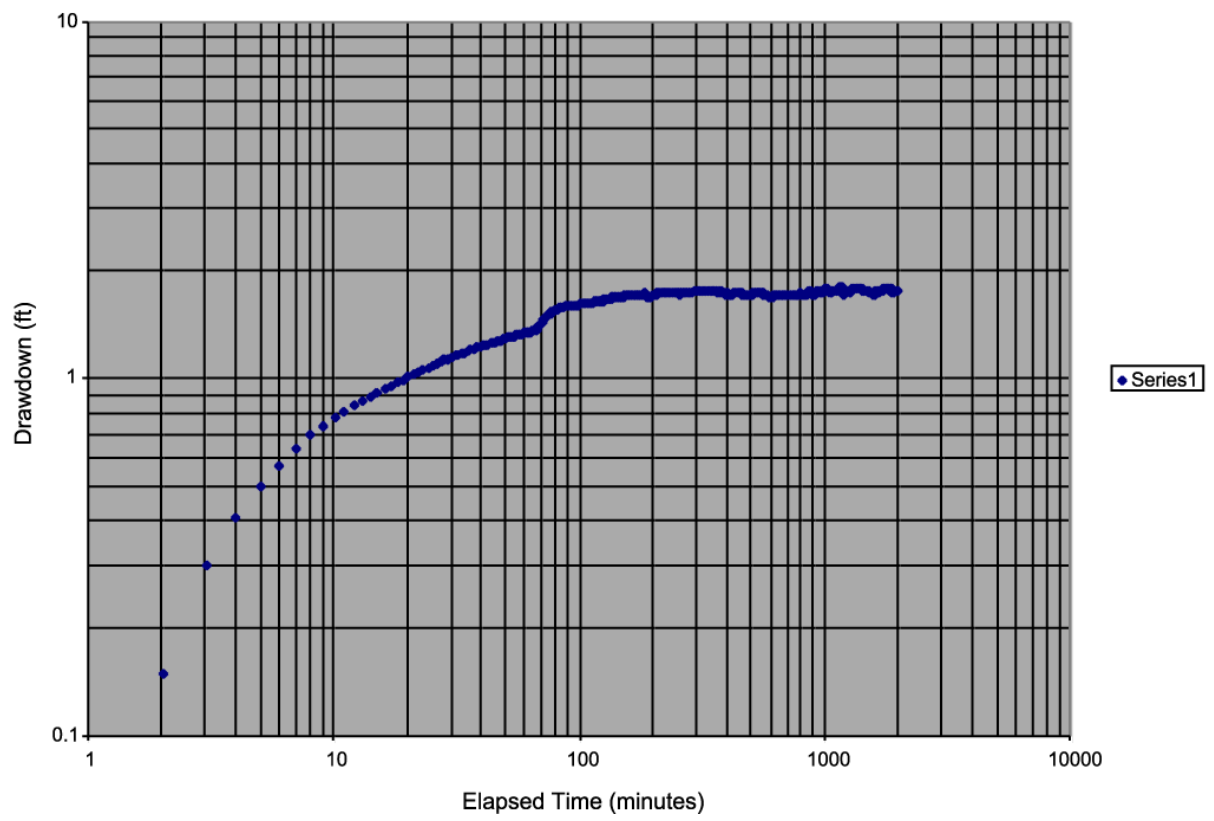

Output DTN: GS031008312314.004 (from Input DTN: GS990408312315.002 [DIRS 140115]).

NOTE: English units are shown in the figure because the analysis was conducted in English units. However, parameter estimates are reported in metric units to downstream users.

Figure C-22. Drawdown in the Prow Pass Interval of $\mathrm{c \# 3}$ in Response to Pumping c\#2, Starting June 2, 1998, Exhibiting Delayed Yield, Characteristic of a Fissure-Block Aquifer

The pumping in $\mathrm{c} \# 2$ indicated that the Calico Hills and Prow Pass intervals are connected by fractures beyond borehole walls because the Calico Hills responded to pumping in the Prow Pass wherever it was monitored. During the CRW test, the water level in the Calico Hills interval was drawn down as much as $19 \mathrm{~cm}$ in $\mathrm{c} \# 2$ and $12 \mathrm{~cm}$ in $\mathrm{c} \# 3$. In contrast, no drawdown was observed below the Prow Pass interval in c\#2 and c\#3 and below the Upper Bullfrog interval in c\#1 during this test. The Upper Bullfrog drawdown in c\#1 was $55 \mathrm{~cm}$. The general lack of a response to pumping below the Prow Pass probably indicates that the highly permeable Lower Bullfrog and Upper Tram intervals in the C-wells were isolated from the Prow Pass interval during the CRW test.

The responses of the Calico Hills in the C-wells and the Upper Bullfrog in c\#1 during pumping of the Prow Pass interval in c\#2 made it necessary to apportion flow among the responding intervals to determine hydrologic properties. Lacking a flow survey for the test conditions, interval flow was determined by solving analytical equations simultaneously for interval discharge and transmissivity. To make the number of equations equal to the number of unknowns, it was assumed that (1) transmissivity values for the Calico Hills and Prow Pass intervals in the C-wells are constant, (2) the transmissivity of the Calico Hills is $5.6 \mathrm{~m} 2 / \mathrm{d}$ (on the basis of previous hydraulic tests), and (3) flow laterally and vertically within the Calico Hills interval was the same in each of the C-wells during the test. These assumptions were based on analyses and interpretations of previous hydraulic tests, borehole flow surveys, borehole geophysical logs, and other information, which are discussed in Section C4.1 and in the report by Geldon (1996 [DIRS 100396], pp. 12 to 69). 
Calculations indicated that the Prow Pass interval contributed 94 percent of the total flow in c\#2 and c\#3 but only 24 percent of the flow in c\#1. The substantially different flow from the Prow Pass in c\#1 does not seem reasonable because lithologic changes that might account for variable flow do not occur in the Prow Pass interval at the C-wells complex. It is more likely that flow from the Calico Hills interval, the interconnectivity between the Calico Hills and Prow Pass, or the transmissivity of either or both the Prow Pass and Calico Hills intervals is not constant throughout the C-wells complex. Unquantifiable uncertainty results from failure to apportion flow satisfactorily.

Hydrologic properties of the Prow Pass interval determined from analyses of drawdown during the CRW test are summarized in Table C-6. Input parameters (aquifer thickness, fracture half-spacing, interborehole distance, and discharge rate) needed in the analyses are also presented in Table C-6.

\section{C3.2.4 Constant-Rate Injection Test}

From June 11 to September 1, 1998, a period of 118,159 minutes, 676,973 L of water was pumped into $\mathrm{c} \# 3$ to conduct tracer tests. The injection rate ranged from 1.92 to $9.6 \mathrm{~L} / \mathrm{min}$ before tracers were injected into c\#3 on June 17, but it subsequently was stabilized by periodic valve adjustments. From June 11 to September 1, the injection rate averaged 5.7 L/min.

As water was being injected into c\#3 from June 11 to September 1; 2,311,290 L of water were withdrawn from $\mathrm{c} \# 2$ at an average rate of $19.8 \mathrm{~L} / \mathrm{min}$. Injecting water into $\mathrm{c} \# 3$ caused the discharge from c\#2 to oscillate within a range of $3.0 \mathrm{~L} / \mathrm{min}$. The discharge from $\mathrm{c} \# 2$ ranged from 18 to $21 \mathrm{~L} / \mathrm{min}$ after water injection into c\#3 started. Lowering the frequency of the pump in c\#2 and increasing backpressure on it between August 3 and 31 decreased the discharge from c\#2 to a range of 16.8 to $19.8 \mathrm{~L} / \mathrm{min}$ after August 31 .

Table C-6. Hydrologic Properties of the Prow Pass Interval in the C-Wells and Input Parameters Used in Obtaining Them

\begin{tabular}{|c|c|c|c|}
\hline Borehole & c\#1 & c\#3 & ONC-1 \\
\hline Test dates & June 2-11, 1998 & June $2-11,1998$ & June 11-Sep. 1, 1998 \\
\hline Period of record (min) & 12,500 & 12,500 & $\cong 140,000$ \\
\hline Analyzed data & Drawdown & Drawdown & Water-level rise \\
\hline Transmissivity $\left(\mathrm{m}^{2} / \mathrm{d}\right)$ & 30 & 30 & 30 \\
\hline Hydraulic conductivity, fractures $(\mathrm{m} / \mathrm{d})$ & 1 & 0.8 & 2 \\
\hline Hydraulic conductivity, matrix $(\mathrm{m} / \mathrm{d})$ & 0.000003 & 0.0002 & 0.00002 \\
\hline Storativity, fractures & 0.00004 & 0.00004 & 0.0002 \\
\hline Storativity, matrix & 0.0003 & 0.0004 & 0.002 \\
\hline Storativity $^{a}$ & 0.0004 & 0.0004 & 0.002 \\
\hline Distance from pumping well, c\#2(m) & 82.6 & 28.7 & $\cong 843$ \\
\hline
\end{tabular}


Table C-6. Hydrologic Properties of the Prow Pass Interval in the C-wells and Input Parameters Used in Obtaining Them (Continued)

\begin{tabular}{|l|c|c|c|}
\hline \multicolumn{1}{|c|}{ Borehole } & c\#1 & c\#3 & ONC-1 \\
\hline Transmissive thickness $(\mathrm{m})$ & 18.9 & 31.7 & 18.9 \\
\hline Fracture half-spacing $(\mathrm{m})$ & 0.34 & 2.0 & 0.34 \\
\hline Discharge from c\#2 (L/min) & $4.68^{\mathrm{b}}$ & 18.54 & $-5.7^{\mathrm{c}}$ \\
\hline
\end{tabular}

Source: DTN: GS990408312315.002 [DIRS 140115] (c\#1 and c\#3 data). Source for ONC-1 Data: MO0408NYE05474.217 [DIRS 171464] (corroborative data).

Output DTN: GS031008312314.004 (c\#1 and c\#3 parameters only).

Note: The ONC-1 column of this table is used for corroborative purposes only. The hydraulic test analyses indicate that the transmissivity obtained from the ONC-1 response is in good agreement with the transmissivity obtained from the c\#1 and c\#3 responses, which correspond too much smaller scales. However, the storativity obtained from analyzing the ONC-1 response is about an order-of-magnitude larger than the storativity from $\mathrm{C \# 1}$ and $\mathrm{c \# 3}$ responses.

a Combined storativity: sum of fractures and matrix storativities.

b Assumed to be 24 percent of the total discharge from c\#2.

${ }^{c}$ Negative discharge indicates an injection rate into c\#3, leading to a water-level rise in ONC-1.

Water levels in the Prow Pass interval of $\mathrm{c} \# 2$ oscillated as much as $10 \mathrm{~m}$ between readings due to injection of water into $\mathrm{c} \# 3$. Although the water injection into $\mathrm{c} \# 3$ caused drawdown in the Prow Pass interval of $\mathrm{c} \# 2$ to decrease from 128 to $115 \mathrm{~m}$ in the first 11 days after it began, pumping in c\#2 eventually predominated over the superimposed effects of the water injection. From June 22 to September 1, the range in c\#2 drawdown increased from 115 to $125 \mathrm{~m}$ to 130 to $143 \mathrm{~m}$ (Figure C-23).

Drawdown in the Prow Pass interval of $\mathrm{c} \# 3$ decreased from $+0.58 \mathrm{~m}$ to a range typically between -25 and $-30 \mathrm{~m}$ between June 11 and September 1 (the period of continuous injection of water into c\#3 [Figure C-24]). This pronounced water-level rise was affected slightly by periodically adjusting the injection rate. Drawdown fluctuated markedly from +87 to $-32 \mathrm{~m}$ while tracers were injected into c\#3 on June 17 and 18.

Drawdown in the Prow Pass interval of c\#1 was disturbed significantly by tracer-test operations in c\#3 and c\#1 from June 11 to September 1. Injection of water into c\#3 decreased drawdown in c\#1 from 13 to $2.8 \mathrm{~cm}$ between June 11 and July 27, but drawdown subsequently increased and ranged from 4.0 to $7.9 \mathrm{~cm}$ by September 1 (Figure C-25). Injection of tracers into c\#3 on June 17 increased drawdown from $8.9 \mathrm{~cm}$ to as much as $13 \mathrm{~cm}$, whereas tracer injection in $\mathrm{c} \# 1$ on July 31 decreased drawdown from +5.9 to $-174 \mathrm{~cm}$ and then increased it to $+10 \mathrm{~cm}$. Removal of injection tubing from $\mathrm{c} \# 1$ on June 26 to replace a cracking valve increased drawdown from 10 to $217 \mathrm{~cm}$ and then decreased it to $-16 \mathrm{~cm}$. Reinstallation of the tubing on July 13 increased drawdown from 5.5 to $10 \mathrm{~cm}$ and then decreased it to $-1,150 \mathrm{~cm}$.

Drawdown in ONC-1 decreased irregularly from +1.1 to $-2.3 \mathrm{~cm}$ between June 11 and September 1 (Figure C-26). Sharply increased drawdown about 9,000 minutes after injection of water into c\#3 began may be related to tracer injection into c\#3 on June 17, although the timing of this spike does not correlate precisely with the timing of tracer injection in $\mathrm{c} \# 3$. 


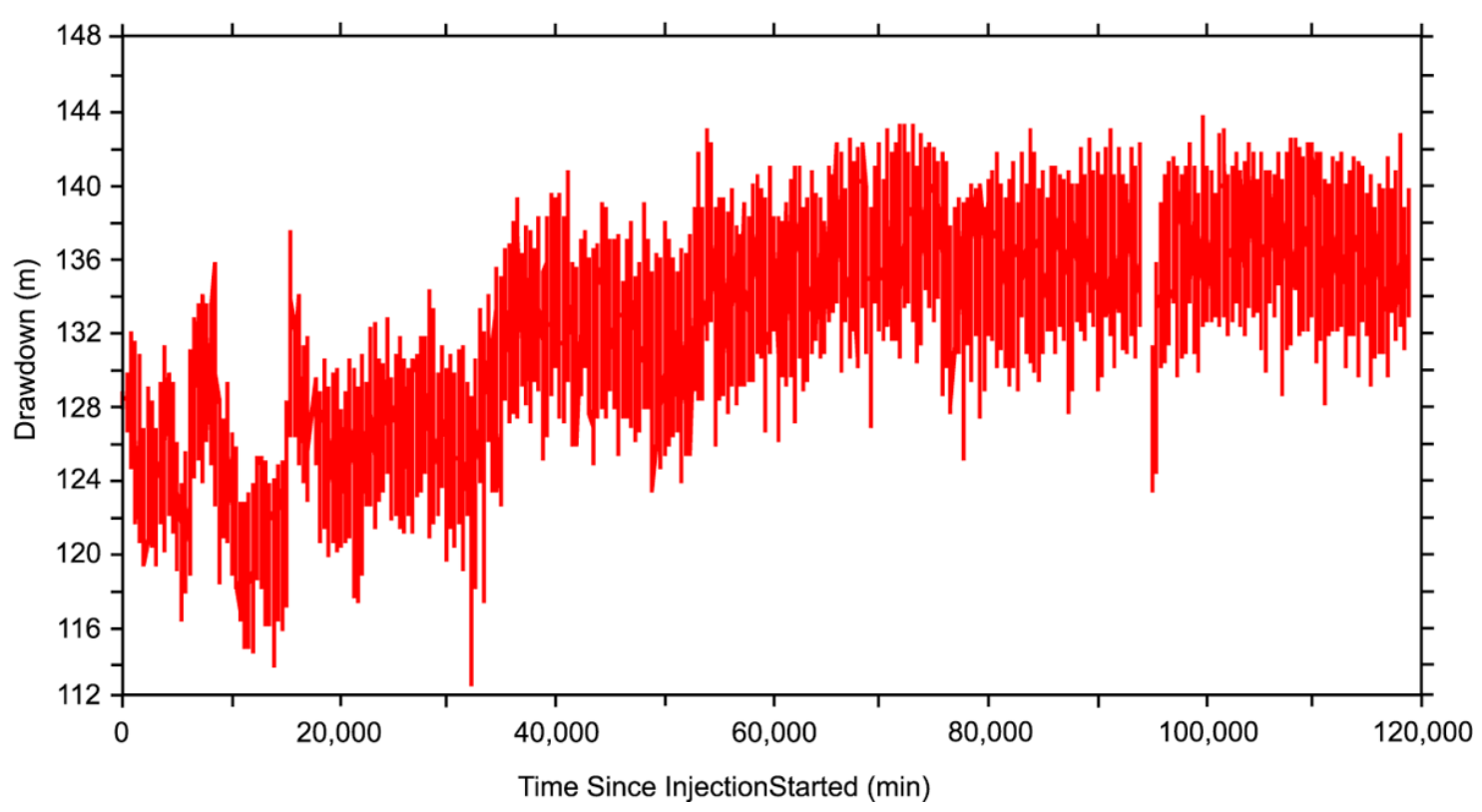

Source: DTN: GS990408312315.002 [DIRS 140115].

Output DTN: GS031008312314.004.

Figure C-23. UE-25 c\#2 Prow Pass Drawdown, June 11, 1998 (Approximately 0 Minutes), to September 1, 1998 (Approximately 120,000 Minutes)

Water-level rises in the C-wells from June 11 to September 1, 1998, were very irregular and too disturbed by tracer-test operations to be analyzed quantitatively. However, the water-level rise in ONC-1 during this period (with superimposed drawdown from pumping c\#2 removed) could be matched to the type curves of Streltsova-Adams (1978 [DIRS 150754]) (Streltsova-Adams.vi, V 1.0, STN: 10971-1.0-00 [DIRS 162756]) for a fissure-block aquifer. This analysis (presented in Table C-6) indicated a transmissivity of $30 \mathrm{~m}^{2} / \mathrm{d}$, a fracture hydraulic conductivity of $2 \mathrm{~m} / \mathrm{d}$, insignificant matrix hydraulic conductivity, and a storativity of 0.002 (90 percent of which is in the matrix). The Prow Pass interval in $\mathrm{ONC}-1$ and the $\mathrm{C}$-wells have equally low permeability, but storativity is an order of magnitude larger between $\mathrm{ONC}-1$ and the $\mathrm{C}$-wells than at the C-wells complex. 


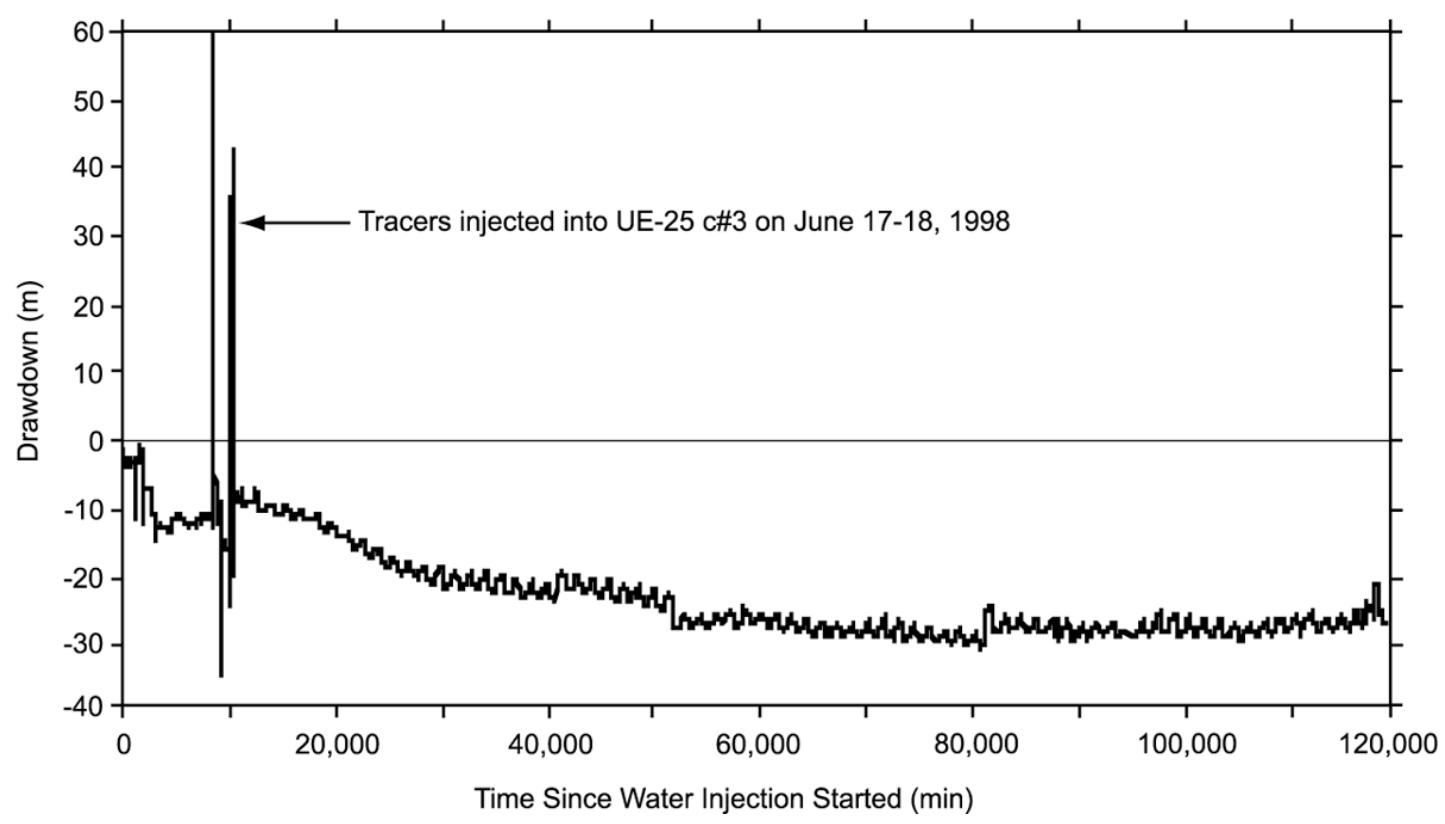

Source: DTN: GS990408312315.002 [DIRS 140115].

Output DTN: GS031008312314.004.

Figure C-24. UE-25 c\#3 Prow Pass Drawdown, June 11, 1998 (Approximately 0 Minutes), to September 1, 1998 (Approximately 120,000 Minutes)

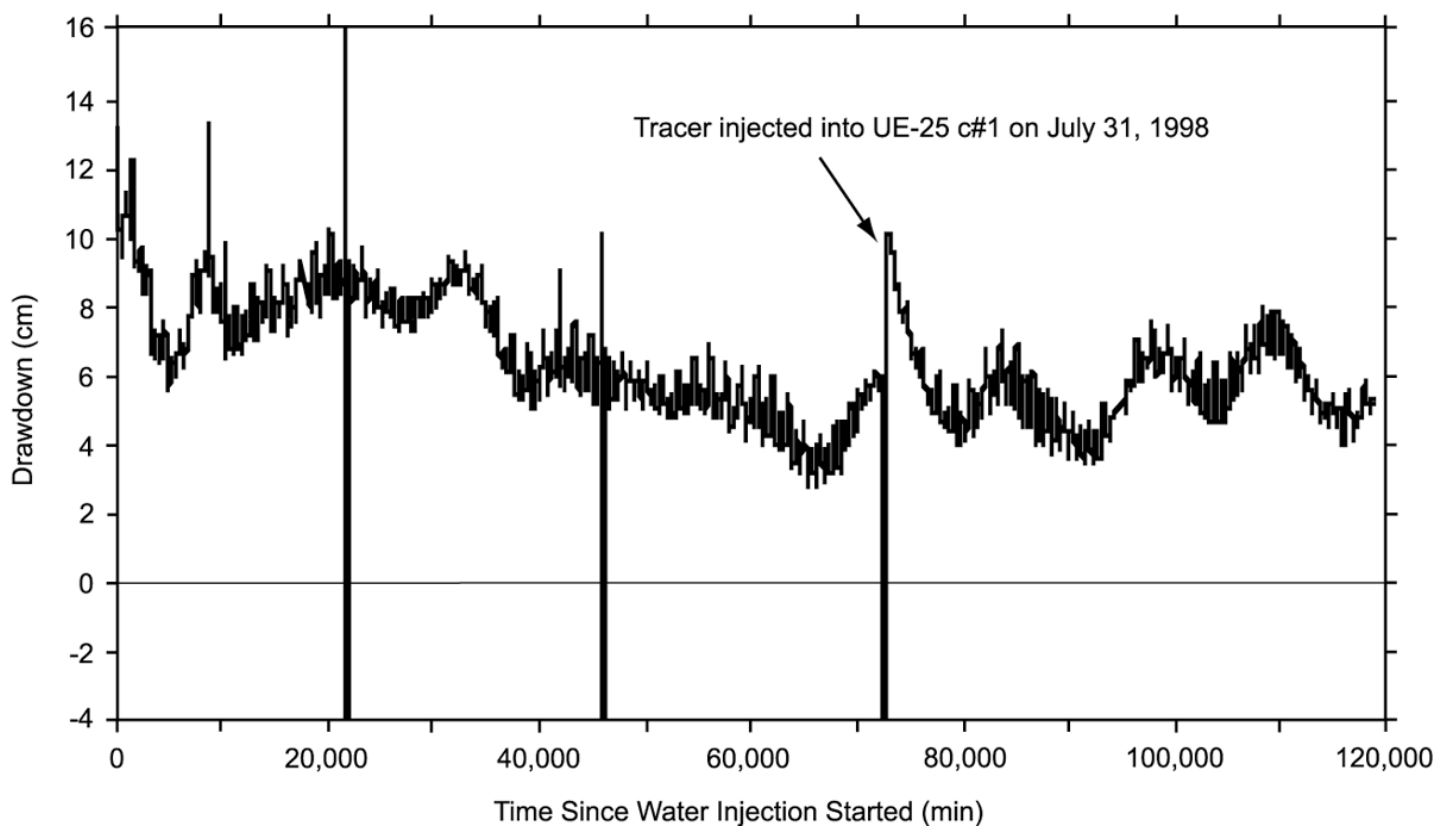

Source: DTN: GS990408312315.002 [DIRS 140115].

Output DTN: GS031008312314.004.

Figure C-25. UE-25 c\#1 Prow Pass Drawdown, June 11, 1998 (Approximately 0 Minutes), to September 1, 1998 (Approximately 120,000 Minutes) 


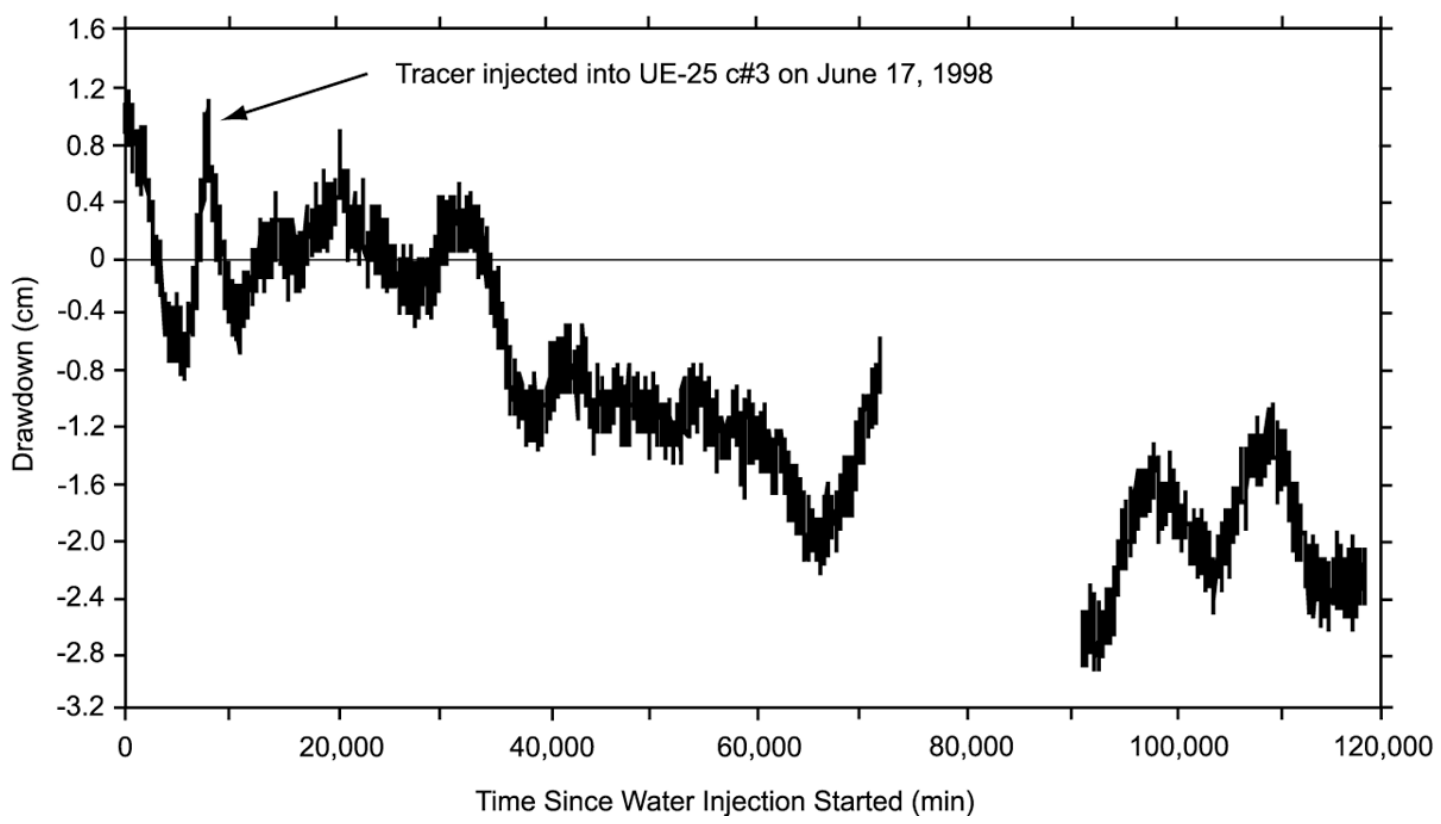

Source: DTN: MO0408NYE05474.217 [DIRS 171464] (corroborative data).

Figure C-26. UE-25 ONC-1 Prow Pass Drawdown, June 11, 1998 (Approximately 0 Minutes), to September 1, 1998 (Approximately 120,000 Minutes)

\section{C4. HYDROLOGIC PROPERTIES}

Hydraulic tests conducted at the C-wells complex from 1995 to 1997 revealed much about the ability of hydrogeologic intervals in the $\mathrm{C}$-wells and the Miocene tuffaceous rocks in the vicinity to store and transmit water. However, it must be emphasized that hydrologic properties computed from these tests pertain only to the structural setting in which the tests were conducted. The Lower Bullfrog interval is the most permeable interval in the C-wells because it is located in these boreholes where two intersecting faults have caused intense fracturing. The Calico Hills interval is the least permeable interval in the $\mathrm{C}$-wells, probably because it is the farthest interval vertically from faults that intersect these boreholes. The combination of its large distance from faults and its low degree of welding (and, thus, high ductility) result in the Calico Hills interval being the least fractured, and, hence, least transmissive interval at the C-wells. In a different structural setting, the Lower Bullfrog, Calico Hills, and other intervals of the Miocene tuffaceous rocks would be expected to have different hydrologic properties than indicated at the C-wells complex. For example, the Bullfrog Tuff yielded very little of the water produced from the Miocene tuffaceous rocks during a tracejector flow survey of p\#1 (Craig and Robison 1984 [DIRS 101040]), and the Calico Hills Formation yielded 32 percent of the water produced from the Miocene tuffaceous rocks during a tracejector flow survey of b\#1 (Lahoud et al. 1984 [DIRS 101049]).

Hydrologic properties for the various hydrogeologic intervals at the C-wells are discussed in the following subsections. With the exception of the Prow Pass interval, all of the hydrologic properties were derived from testing conducted prior to 1998. Properties of the Prow Pass interval were derived from testing conducted both prior to and during 1998. The 1998 testing involved pumping of only the Prow Pass interval. 
In the analyses described in the following subsections, the interborehole distances were as given in Tables 6.1-1, C-6, and C-7; borehole diameters for all C-wells were assumed to be $27.94 \mathrm{~cm}$ (11 in), and aquifer thicknesses were as given under "transmissive thickness" in Tables C-6 and C-7.

\section{C4.1 CALICO HILLS INTERVAL}

The Calico Hills interval responded in most hydraulic tests, including one conducted from May to June 1984 (Geldon 1996 [DIRS 100396], pp. 12 to 69), as an unconfined aquifer. In four tests conducted from 1984 to 1997, the Calico Hills interval consistently was determined to be the least permeable interval in the C-wells (Table C-7). The hydraulic test in May and June 1984 indicated that the Calico Hills interval in c\#1 has a transmissivity of $9 \mathrm{~m}^{2} / \mathrm{d}$, a horizontal hydraulic conductivity of $0.2 \mathrm{~m} / \mathrm{d}$, a vertical hydraulic conductivity of $0.3 \mathrm{~m} / \mathrm{d}$, and a specific yield of 0.003 (Geldon 1996 [DIRS 100396], pp. 12 to 69). The hydraulic test in June 1995 indicated that the Calico Hills interval in $\mathrm{c} \# 2$ has a transmissivity of $6 \mathrm{~m}^{2} / \mathrm{d}$, a horizontal hydraulic conductivity of $0.1 \mathrm{~m} / \mathrm{d}$, and a storativity of 0.0002 . Hydraulic tests conducted in February 1996 and from May 1996 to November 1997 generally supported the previous analyses. The specific yield of 0.4 obtained for the Calico Hills in c\#2 from analyzing the May 8, 1996, response is much higher than expected for fractured rock [it can go up to 30 percent for unconsolidated materials (Bouwer 1978 [DIRS 162675], p. 30)]. A representative plot indicating a match between the data and one of the type curves of Neuman (1975 [DIRS 150321]) for an unconfined, anisotropic aquifer is shown in Figure C-27.

\section{C4.2 PROW PASS INTERVAL}

The Prow Pass interval generally responded to hydraulic tests conducted from June 1995 to November 1997 as a confined aquifer (Table C-7). The hydraulic test in June 1995 indicated that the Prow Pass interval in $\mathrm{c} \# 1$ had a transmissivity of $60 \mathrm{~m} 2 / \mathrm{d}$, a hydraulic conductivity of $3 \mathrm{~m} / \mathrm{d}$, and a storativity of 0.0003 . The same hydraulic test indicated that the Prow Pass interval in $\mathrm{c} \# 2$ has a transmissivity of $40 \mathrm{~m} 2 / \mathrm{d}$, a hydraulic conductivity of $2 \mathrm{~m} / \mathrm{d}$, and a storativity of 0.0004. Analyses of hydraulic tests conducted in February 1996 and from May 1996 to March 1997 generally produced parameter values similar to those produced by the previous analyses, even when the February 1996 response was analyzed as an unconfinedaquifer response. A representative plot indicates a match between the data and the type curve byTheis (1935 [DIRS 150327]) for a confined aquifer (Figure C-28).

Hydraulic testing of the Prow Pass interval conducted in 1998 by pumping c\#2 indicated a fissure-block aquifer with transmissivity of $30 \mathrm{~m} 2 / \mathrm{d}$ in both $\mathrm{c} \# 1$ and c\#3. Fracture hydraulic conductivities derived from responses in c\#1 and c\#3 were $1 \mathrm{~m} / \mathrm{d}$ and $0.8 \mathrm{~m} / \mathrm{d}$, respectively. Matrix hydraulic conductivities were negligible, and overall storativity was 0.0004 , with most of that being attributed to the matrix. These parameter estimates are in good agreement with those derived from earlier testing in which the Prow Pass interval was not pumped directly (above). This result instills confidence in the ability to estimate hydrologic parameters for intervals that are not pumped directly but that respond to pumping other intervals. Even though comparable parameter values were obtained in $\mathrm{c} \# 1$ by analyzing some of the test responses in the Prow Pass as either unconfined or fissure-block aquifer responses, the later interpretation is more logical because the Prow Pass interval is not at the water table. 
Table C-7. Results of Hydraulic Tests in Borehole UE-25 c\#3, June 1995 to November 1997

\begin{tabular}{|c|c|c|c|c|c|c|c|c|c|}
\hline Starting Date & $06 / 12 / 95$ & $02 / 08 / 96$ & $\begin{array}{c}\text { 02/08/96 } \\
\text { c\#1 }\end{array}$ & $05 / 08 / 96$ & $05 / 08 / 96$ & $06 / 12 / 95$ & $\begin{array}{c}02 / 08 / 96 \\
\text { c\#2 }\end{array}$ & 05/08/96 & 05/08/96 \\
\hline \multicolumn{10}{|l|}{ Calico Hills } \\
\hline Analyzed data & None & None & N/A & None & $N / A$ & Drawdown & Drawdown & Drawdown & N/A \\
\hline Period of record (min) & N/A & $N / A$ & $N / A$ & $N / A$ & N/A & 5,800 & 7,000 & 464,100 & $\mathrm{~N} / \mathrm{A}$ \\
\hline Aquifer type & Unconfined & Unconfined & $\mathrm{N} / \mathrm{A}$ & Unconfined & N/A & Unconfined & Confined & Unconfined & $N / A$ \\
\hline Transmissive thickness $(\mathrm{m})$ & 60.4 & 60.4 & N/A & 60.4 & $\mathrm{~N} / \mathrm{A}$ & 45.4 & 45.4 & 45.4 & $\mathrm{~N} / \mathrm{A}$ \\
\hline Distance from pumping well $(\mathrm{m})$ & 78.3 & 78.3 & $\mathrm{~N} / \mathrm{A}$ & 78.3 & N/A & 29.0 & 29.0 & 29.0 & $\mathrm{~N} / \mathrm{A}$ \\
\hline Average discharge (L/min) & 51 & 2.52 & N/A & 6.0 & $\mathrm{~N} / \mathrm{A}$ & 51 & 2.52 & 6.0 & $\mathrm{~N} / \mathrm{A}$ \\
\hline Transmissivity (m²/day) & 9(est) & 9 (est) & N/A & 9 (est) & $\mathrm{N} / \mathrm{A}$ & 6 & 10 & 4 & $\mathrm{~N} / \mathrm{A}$ \\
\hline Horizontal hydraulic conductivity (m/day) & $0.2(\mathrm{est})$ & 0.2 (est) & $\mathrm{N} / \mathrm{A}$ & 0.2 (est) & $\mathrm{N} / \mathrm{A}$ & 0.1 & 0.2 & 0.08 & $\mathrm{~N} / \mathrm{A}$ \\
\hline Vertical hydraulic conductivity (m/day) & $0.3(\mathrm{est})$ & $0.3(\mathrm{est})$ & $\mathrm{N} / \mathrm{A}$ & $0.3(\mathrm{est})$ & $\mathrm{N} / \mathrm{A}$ & ND & ND & 0.01 & $\mathrm{~N} / \mathrm{A}$ \\
\hline Storativity (dimensionless) & ND & ND & $\mathrm{N} / \mathrm{A}$ & ND & $\mathrm{N} / \mathrm{A}$ & 0.0002 & 0.0006 & 0.0003 & $\mathrm{~N} / \mathrm{A}$ \\
\hline Specific yield (dimensionless) & 0.003 (est) & 0.003 (est) & N/A & 0.003 (est) & $\mathrm{N} / \mathrm{A}$ & ND & ND & 0.4 & $N / A$ \\
\hline \multicolumn{10}{|l|}{ Prow Pass } \\
\hline Analyzed data & Drawdown & Drawdown & Drawdown & Drawdown & N/A & Drawdown & Drawdown & Drawdown & $N / A$ \\
\hline Period of record (min) & 5,800 & 7,000 & 7,000 & 464,100 & $\mathrm{~N} / \mathrm{A}$ & 5,800 & 7,000 & 464,100 & N/A \\
\hline Aquifer type & Confined & Unconfined & Confined & Confined & $\mathrm{N} / \mathrm{A}$ & Confined & Confined & Confined & $N / A$ \\
\hline Transmissive thickness $(\mathrm{m})$ & 18.9 & 18.9 & 18.9 & 18.9 & $\mathrm{~N} / \mathrm{A}$ & 23.8 & 23.8 & 23.8 & $\mathrm{~N} / \mathrm{A}$ \\
\hline Distance from pumping well $(\mathrm{m})$ & 81.1 & 81.1 & 81.1 & 81.1 & $\mathrm{~N} / \mathrm{A}$ & 28.6 & 28.6 & 28.6 & $N / A$ \\
\hline Average discharge (L/min) & 39 & 12.6 & 12.6 & 13.2 & N/A & 39 & 7.8 & 11.4 & N/A \\
\hline Transmissivity (m²/day) & 60 & 50 & 60 & 50 & N/A & 40 & 30 & 30 & $\mathrm{~N} / \mathrm{A}$ \\
\hline Horizontal hydraulic conductivity (m/day) & 3 & 3 & 3 & 3 & $\mathrm{~N} / \mathrm{A}$ & 2 & 1 & 1 & $\mathrm{~N} / \mathrm{A}$ \\
\hline Vertical hydraulic conductivity (m/day) & ND & 0.0001 & ND & ND & $\mathrm{N} / \mathrm{A}$ & ND & ND & ND & N/A \\
\hline Storativity (dimensionless) & 0.0003 & 0.0003 & 0.0004 & 0.0002 & $\mathrm{~N} / \mathrm{A}$ & 0.0004 & 0.003 & 0.0008 & N/A \\
\hline Specific yield (dimensionless) & ND & ND & ND & ND & $\mathrm{N} / \mathrm{A}$ & ND & ND & ND & $\mathrm{N} / \mathrm{A}$ \\
\hline \multicolumn{10}{|l|}{ Upper Bullfrog } \\
\hline Analyzed data & Recovery & Drawdown & $\mathrm{N} / \mathrm{A}$ & Drawdown & $\mathrm{N} / \mathrm{A}$ & Drawdown & Drawdown & Drawdown & $\mathrm{N} / \mathrm{A}$ \\
\hline Period of record $(\mathrm{min})$ & 5,700 & 7,000 & $\mathrm{~N} / \mathrm{A}$ & 464,100 & N/A & 5,800 & 7,000 & 464,100 & N/A \\
\hline
\end{tabular}


Table C-7. Results of Hydraulic Tests in Borehole UE-25 c\#3, June 1995 to November 1997 (Continued)

\begin{tabular}{|c|c|c|c|c|c|c|c|c|c|}
\hline Starting Date & 06/12/95 & 02/08/96 & $\begin{array}{c}02 / 08 / 96 \\
\mathrm{C \# 1}\end{array}$ & $05 / 08 / 96$ & 05/08/96 & 06/12/95 & $\begin{array}{c}02 / 08 / 96 \\
\text { C\#2 }\end{array}$ & $05 / 08 / 96$ & 05/08/96 \\
\hline \multicolumn{10}{|l|}{ Upper Bullfrog (Continued) } \\
\hline Aquifer type & Confined & Unconfined & $N / A$ & $\begin{array}{l}\text { Fissure- } \\
\text { block }\end{array}$ & $N / A$ & Confined & Confined & Confined & N/A \\
\hline Transmissive thickness (m) & 46.0 & 46.0 & $\mathrm{~N} / \mathrm{A}$ & 46.0 & $\mathrm{~N} / \mathrm{A}$ & 24.1 & 24.1 & 24.1 & $\mathrm{~N} / \mathrm{A}$ \\
\hline Distance from pumping well (m) & 83.2 & 83.2 & $\mathrm{~N} / \mathrm{A}$ & 82.3 & $\mathrm{~N} / \mathrm{A}$ & 28.6 & 28.6 & 28.6 & $\mathrm{~N} / \mathrm{A}$ \\
\hline Average discharge (L/min) & 52.8 & 22.2 & $\mathrm{~N} / \mathrm{A}$ & 19.2 & $\mathrm{~N} / \mathrm{A}$ & 52.8 & 21.6 & 21.6 & $\mathrm{~N} / \mathrm{A}$ \\
\hline Transmissivity (m²/day) & 90 & 40 & $\mathrm{~N} / \mathrm{A}$ & 50 & $\mathrm{~N} / \mathrm{A}$ & 100 & 100 & 80 & $\mathrm{~N} / \mathrm{A}$ \\
\hline Horizontal hydraulic conductivity (m/day) & 2 & 0.8 & $\mathrm{~N} / \mathrm{A}$ & $1 / 0.00002^{*}$ & $\mathrm{~N} / \mathrm{A}$ & 4 & 4 & 3 & $\mathrm{~N} / \mathrm{A}$ \\
\hline Vertical hydraulic conductivity (m/day) & ND & 0.5 & $\mathrm{~N} / \mathrm{A}$ & ND & $\mathrm{N} / \mathrm{A}$ & ND & ND & ND & N/A \\
\hline Storativity (dimensionless) & 0.00006 & 0.0009 & $N / A$ & $\begin{array}{c}0.0001 / 0.00 \\
09^{*}\end{array}$ & $\mathrm{~N} / \mathrm{A}$ & 0.00003 & 0.00002 & 0.00002 & $\mathrm{~N} / \mathrm{A}$ \\
\hline Specific yield (dimensionless) & ND & 0.002 & $\mathrm{~N} / \mathrm{A}$ & ND & $\mathrm{N} / \mathrm{A}$ & ND & ND & ND & $\mathrm{N} / \mathrm{A}$ \\
\hline \multicolumn{10}{|l|}{ Bullfrog-Tram } \\
\hline Analyzed data & $\mathrm{N} / \mathrm{A}$ & Drawdown & $\mathrm{N} / \mathrm{A}$ & $\mathrm{N} / \mathrm{A}$ & $\mathrm{N} / \mathrm{A}$ & $\mathrm{N} / \mathrm{A}$ & Drawdown & $N / A$ & N/A \\
\hline Period of record (min) & $\mathrm{N} / \mathrm{A}$ & 7,000 & $\mathrm{~N} / \mathrm{A}$ & $\mathrm{N} / \mathrm{A}$ & $\mathrm{N} / \mathrm{A}$ & $\mathrm{N} / \mathrm{A}$ & 7,000 & $\mathrm{~N} / \mathrm{A}$ & $\mathrm{N} / \mathrm{A}$ \\
\hline Aquifer type & $\mathrm{N} / \mathrm{A}$ & Confined & $\mathrm{N} / \mathrm{A}$ & N/A & $\mathrm{N} / \mathrm{A}$ & $\mathrm{N} / \mathrm{A}$ & Confined & $\mathrm{N} / \mathrm{A}$ & $\mathrm{N} / \mathrm{A}$ \\
\hline Transmissive thickness $(\mathrm{m})$ & $\mathrm{N} / \mathrm{A}$ & 112 & $\mathrm{~N} / \mathrm{A}$ & $\mathrm{N} / \mathrm{A}$ & $\mathrm{N} / \mathrm{A}$ & $\mathrm{N} / \mathrm{A}$ & 51.2 & $\mathrm{~N} / \mathrm{A}$ & $\mathrm{N} / \mathrm{A}$ \\
\hline Distance from pumping well (m) & N/A & 86.3 & $\mathrm{~N} / \mathrm{A}$ & $\mathrm{N} / \mathrm{A}$ & $\mathrm{N} / \mathrm{A}$ & $\mathrm{N} / \mathrm{A}$ & 29 & $N / A$ & $\mathrm{~N} / \mathrm{A}$ \\
\hline Average discharge (L/min) & N/A & 470.4 & N/A & N/A & N/A & N/A & 475.8 & N/A & $\mathrm{N} / \mathrm{A}$ \\
\hline Transmissivity $\left(\mathrm{m}^{2} /\right.$ day $)$ & $\mathrm{N} / \mathrm{A}$ & 2,500 & $\mathrm{~N} / \mathrm{A}$ & $\mathrm{N} / \mathrm{A}$ & $\mathrm{N} / \mathrm{A}$ & $\mathrm{N} / \mathrm{A}$ & 2,500 & $\mathrm{~N} / \mathrm{A}$ & $\mathrm{N} / \mathrm{A}$ \\
\hline Horizontal hydraulic conductivity (m/day) & $\mathrm{N} / \mathrm{A}$ & 20 & $\mathrm{~N} / \mathrm{A}$ & $\mathrm{N} / \mathrm{A}$ & $\mathrm{N} / \mathrm{A}$ & $\mathrm{N} / \mathrm{A}$ & 50 & $\mathrm{~N} / \mathrm{A}$ & $\mathrm{N} / \mathrm{A}$ \\
\hline Vertical hydraulic conductivity (m/day) & $\mathrm{N} / \mathrm{A}$ & ND & $\mathrm{N} / \mathrm{A}$ & N/A & $\mathrm{N} / \mathrm{A}$ & $\mathrm{N} / \mathrm{A}$ & ND & $N / A$ & $\mathrm{~N} / \mathrm{A}$ \\
\hline Storativity (dimensionless) & N/A & 0.0003 & $\mathrm{~N} / \mathrm{A}$ & $\mathrm{N} / \mathrm{A}$ & $\mathrm{N} / \mathrm{A}$ & $\mathrm{N} / \mathrm{A}$ & 0.002 & $N / A$ & $\mathrm{~N} / \mathrm{A}$ \\
\hline Specific yield (dimensionless) & $\mathrm{N} / \mathrm{A}$ & ND & $\mathrm{N} / \mathrm{A}$ & $\mathrm{N} / \mathrm{A}$ & $\mathrm{N} / \mathrm{A}$ & $N / A$ & ND & $N / A$ & $\mathrm{~N} / \mathrm{A}$ \\
\hline \multicolumn{10}{|l|}{ Lower Bullfrog } \\
\hline Analyzed data & Recovery & None & $N / A$ & Drawdown & Drawdown & Drawdown & None & Drawdown & Drawdown \\
\hline Period of record $(\mathrm{min})$ & 6,300 & $\mathrm{~N} / \mathrm{A}$ & N/A & 464,100 & 464,100 & 5,800 & $\mathrm{~N} / \mathrm{A}$ & 464,100 & 464,100 \\
\hline
\end{tabular}


Table C-7. Results of Hydraulic Tests in Borehole UE-25 c\#3, June 1995 to November 1997 (Continued)

\begin{tabular}{|c|c|c|c|c|c|c|c|c|c|}
\hline Starting Date & $06 / 12 / 95$ & $02 / 08 / 96$ & $\begin{array}{c}02 / 08 / 96 \\
\text { c\#1 }\end{array}$ & $05 / 08 / 96$ & $05 / 08 / 96$ & $06 / 12 / 95$ & $\begin{array}{c}02 / 08 / 96 \\
\mathrm{C \# 2} \\
\end{array}$ & $05 / 08 / 96$ & $05 / 08 / 96$ \\
\hline \multicolumn{10}{|l|}{ Lower Bullfrog (Continued) } \\
\hline Aquifer type & Confined & Confined & $N / A$ & Confined & $\begin{array}{l}\text { Fissure- } \\
\text { block }\end{array}$ & Confined & Confined & Confined & $\begin{array}{l}\text { Fissure- } \\
\text { block }\end{array}$ \\
\hline Transmissive thickness (m) & 62.8 & 62.8 & $N / A$ & 62.8 & 62.8 & 29.9 & 29.9 & 29.9 & 29.9 \\
\hline Distance from pumping well (m) & 85.6 & 85.6 & $N / A$ & 85.6 & 85.6 & 29.3 & 29.3 & 29.3 & 29.3 \\
\hline Average discharge (L/min) & 918 & ND & $N / A$ & 382.2 & 382.2 & 918 & ND & 401.4 & 401.4 \\
\hline Transmissivity $\left(\mathrm{m}^{2} / \mathrm{day}\right)$ & 1,800 & ND & $\mathrm{N} / \mathrm{A}$ & 1,600 & 1,300 & 1,900 & ND & 1,600 & 1,300 \\
\hline Horizontal hydraulic conductivity (m/day) & 30 & ND & $N / A$ & 30 & $20 / 0.0004^{*}$ & 60 & ND & 50 & $40 / 0.001^{*}$ \\
\hline Vertical hydraulic conductivity (m/day) & ND & ND & N/A & ND & ND & ND & ND & ND & ND \\
\hline Storativity (dimensionless) & 0.0004 & ND & $N / A$ & 0.0002 & $\begin{array}{c}0.0002 / 0.00 \\
2^{*}\end{array}$ & 0.003 & ND & 0.001 & $0.002 / 0.02^{*}$ \\
\hline Specific yield (dimensionless) & ND & ND & $\mathrm{N} / \mathrm{A}$ & ND & ND & ND & ND & ND & ND \\
\hline \multicolumn{10}{|l|}{ Upper Tram } \\
\hline Analyzed data & None & None & $N / A$ & None & N/A & None & None & None & $N / A$ \\
\hline Period of record $(\mathrm{min})$ & $\mathrm{N} / \mathrm{A}$ & $\mathrm{N} / \mathrm{A}$ & $\mathrm{N} / \mathrm{A}$ & $\mathrm{N} / \mathrm{A}$ & $\mathrm{N} / \mathrm{A}$ & $\mathrm{N} / \mathrm{A}$ & $\mathrm{N} / \mathrm{A}$ & $\mathrm{N} / \mathrm{A}$ & $\mathrm{N} / \mathrm{A}$ \\
\hline Aquifer type & Leaky & Leaky & $\mathrm{N} / \mathrm{A}$ & Leaky & $\mathrm{N} / \mathrm{A}$ & Leaky & Leaky & Leaky & $\mathrm{N} / \mathrm{A}$ \\
\hline Transmissive thickness $(\mathrm{m})$ & 49.7 & 49.7 & $\mathrm{~N} / \mathrm{A}$ & 49.7 & N/A & 21.3 & 21.3 & 21.3 & $\mathrm{~N} / \mathrm{A}$ \\
\hline Distance from pumping well (m) & 86.9 & 86.9 & N/A & 86.9 & N/A & 29.6 & 29.6 & 29.6 & $\mathrm{~N} / \mathrm{A}$ \\
\hline Average discharge (L/min) & 284.4 & ND & $\mathrm{N} / \mathrm{A}$ & 151.2 & $\mathrm{~N} / \mathrm{A}$ & 284.4 & ND & 130.8 & $\mathrm{~N} / \mathrm{A}$ \\
\hline Transmissivity ( $\mathrm{m}^{2} /$ day) & ND & ND & $\mathrm{N} / \mathrm{A}$ & 800 & $\mathrm{~N} / \mathrm{A}$ & ND & ND & 900 & $\mathrm{~N} / \mathrm{A}$ \\
\hline Horizontal hydraulic conductivity (m/day) & ND & ND & N/A & 20 & $\mathrm{~N} / \mathrm{A}$ & ND & ND & 40 & $\mathrm{~N} / \mathrm{A}$ \\
\hline Vertical hydraulic conductivity (m/day) & ND & ND & $\mathrm{N} / \mathrm{A}$ & ND & $\mathrm{N} / \mathrm{A}$ & ND & ND & ND & $N / A$ \\
\hline Storativity (dimensionless) & ND & ND & $N / A$ & 0.0001 & $N / A$ & ND & ND & 0.001 & $N / A$ \\
\hline Specific yield (dimensionless) & ND & ND & $N / A$ & ND & $N / A$ & ND & ND & ND & $N / A$ \\
\hline
\end{tabular}

Output DTN: GS031008312314.004 (from Input DTN: GS030508312314.003 [DIRS 164425], pp. 34 to 35, Table 8).

NOTE: First number is for fractures; second is for matrix.

$\mathrm{ND}=$ no data; $N / A=$ not applicable; est=estimated to be the same as values obtained from a hydraulic test in May 1984. 


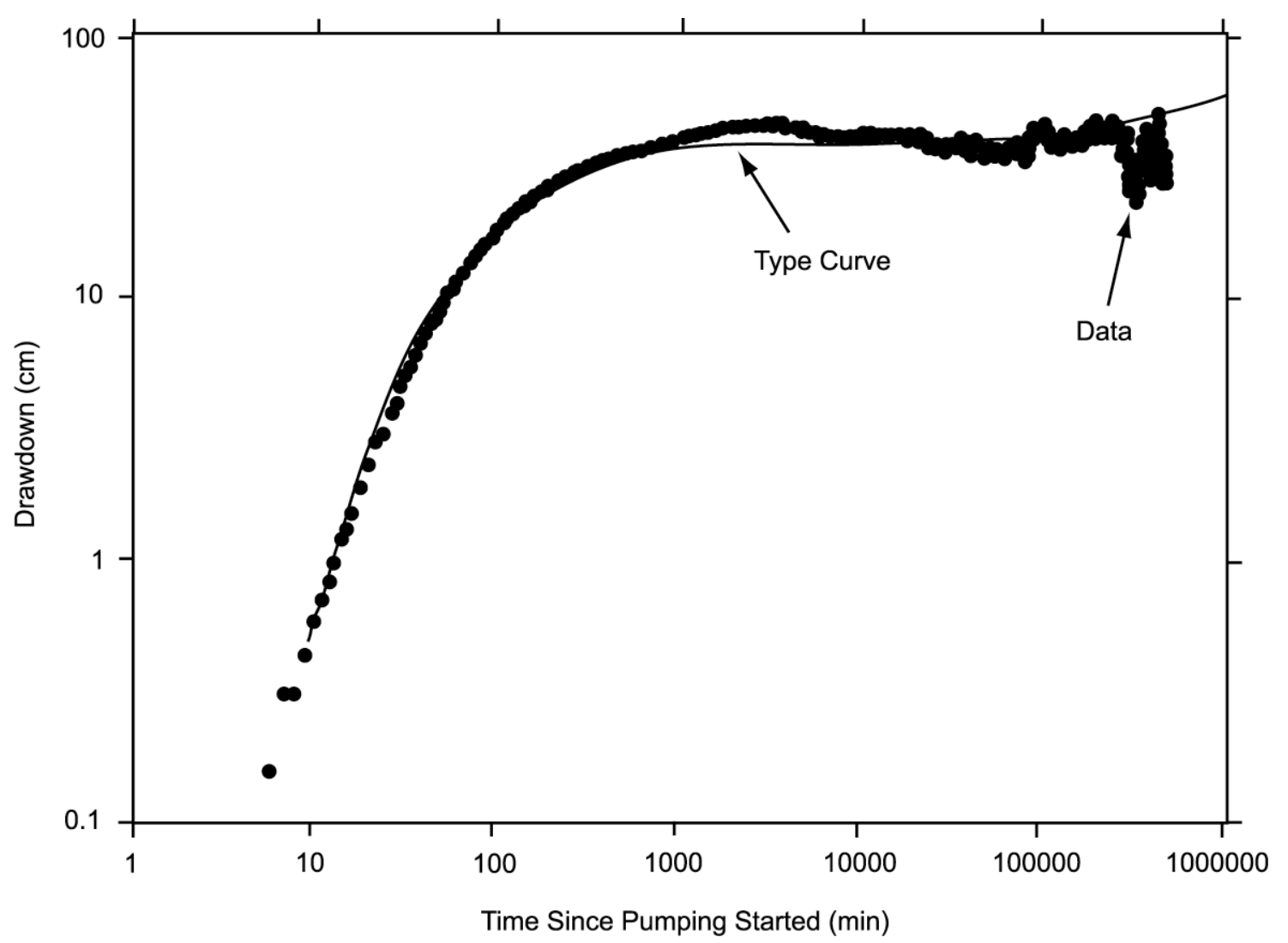

Output DTN: GS031008312314.004 (from Input DTN: GS030508312314.003 [DIRS 164425], p. 36, Figure 25).

Figure C-27. Analysis of Drawdown in the Calico Hills Interval of UE-25 c\#2, May 8, 1996 (Approximately 0 Minutes), to March 26, 1997 (Approximately 470,000 Minutes), by the Method of Neuman 


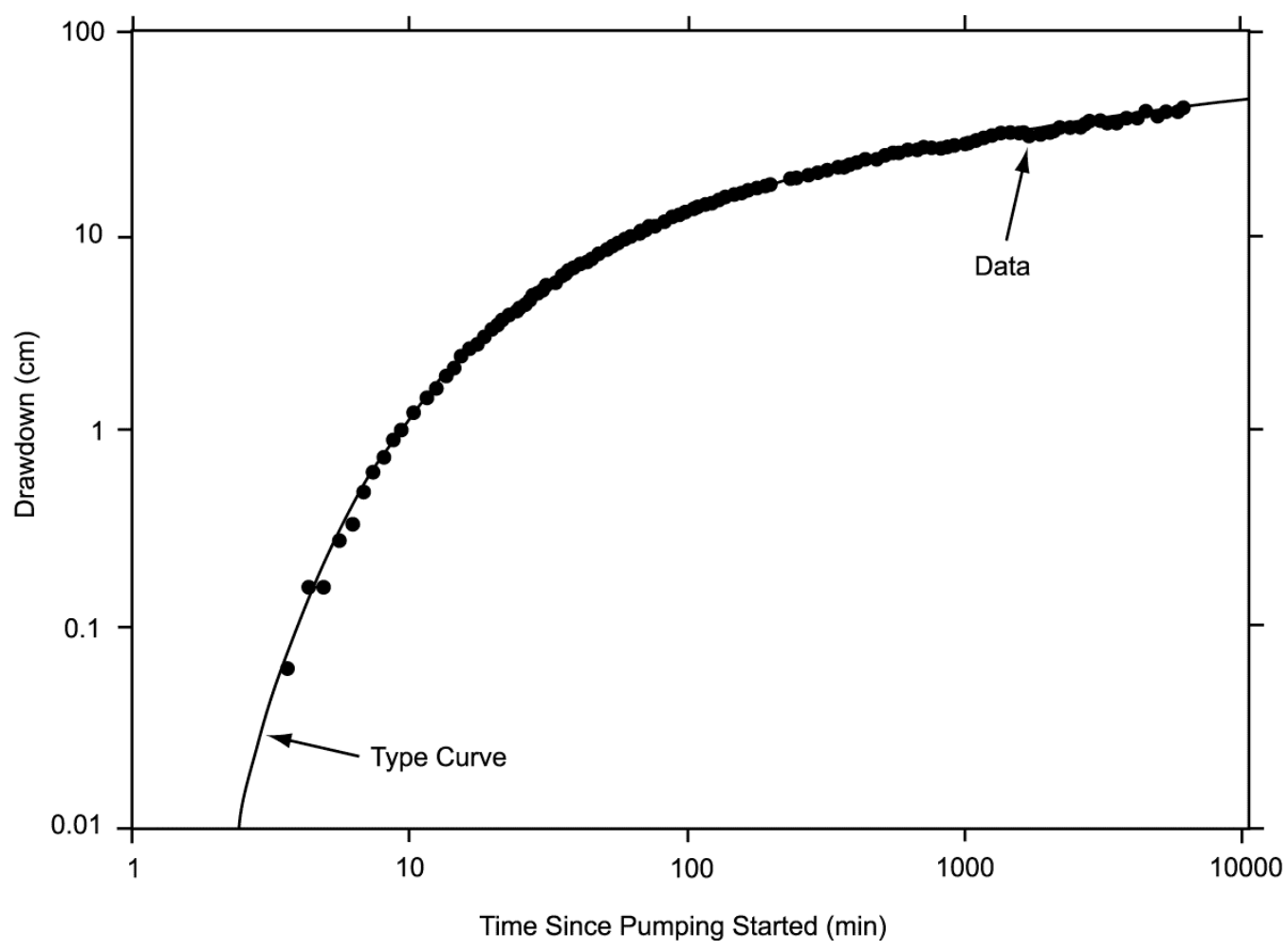

Output DTN: GS031008312314.004 (from Input DTN: GS030508312314.003 [DIRS 164425], p. 37, Figure 26).

Figure C-28. Analysis of Drawdown in the Prow Pass Interval of UE-25 c\#1, June 12-16, 1995, by the Method of Theis

\section{C4.3 UPPER BULLFROG INTERVAL}

The Upper Bullfrog interval in $\mathrm{c} \# 2$ responded to all hydraulic tests as a confined aquifer (Table C-7). Those tests consistently indicated a transmissivity of 80 to $100 \mathrm{~m}^{2} / \mathrm{d}$, a hydraulic conductivity of 3 to $4 \mathrm{~m} / \mathrm{d}$, and a storativity of 0.00002 to 0.00003 . A representative plot indicates a match between the data and the type curve of Theis (1935 [DIRS 150327]) for a confined aquifer (Figure C-29).

The hydraulic test in June 1995 produced results for the Upper Bullfrog interval in c\#1 consistent with results for that interval in c\#2 (Table C-7). During longer tests conducted in February 1996 and May 1996, sufficient time elapsed to reveal the effects of fractures on flow between the Upper Bullfrog interval in c\#1 and open intervals in the pumping well. Analyses of drawdown (complicated by downward flow through fractures) indicated smaller values of transmissivity and hydraulic conductivity and larger values of storativity than analyses of drawdown in which the effects of fractures were not evident (Table C-7). Hydrologic properties determined from hydraulic tests conducted in 1996 and 1997 using unconfined and fissure-block interpretations are less reliable than properties determined from the hydraulic test in June 1995 because of the sliding sleeve placement in the observation and pumping wells in the later tests. Unconfined and fissure-block responses are similar; however, a fissure-block interpretation is more logical for the Upper Bullfrog aquifer than an unconfined interpretation because this aquifer is not at the water table. Also, the specific yield calculated from the unconfined solution, 0.002, seems unrealistically low. 


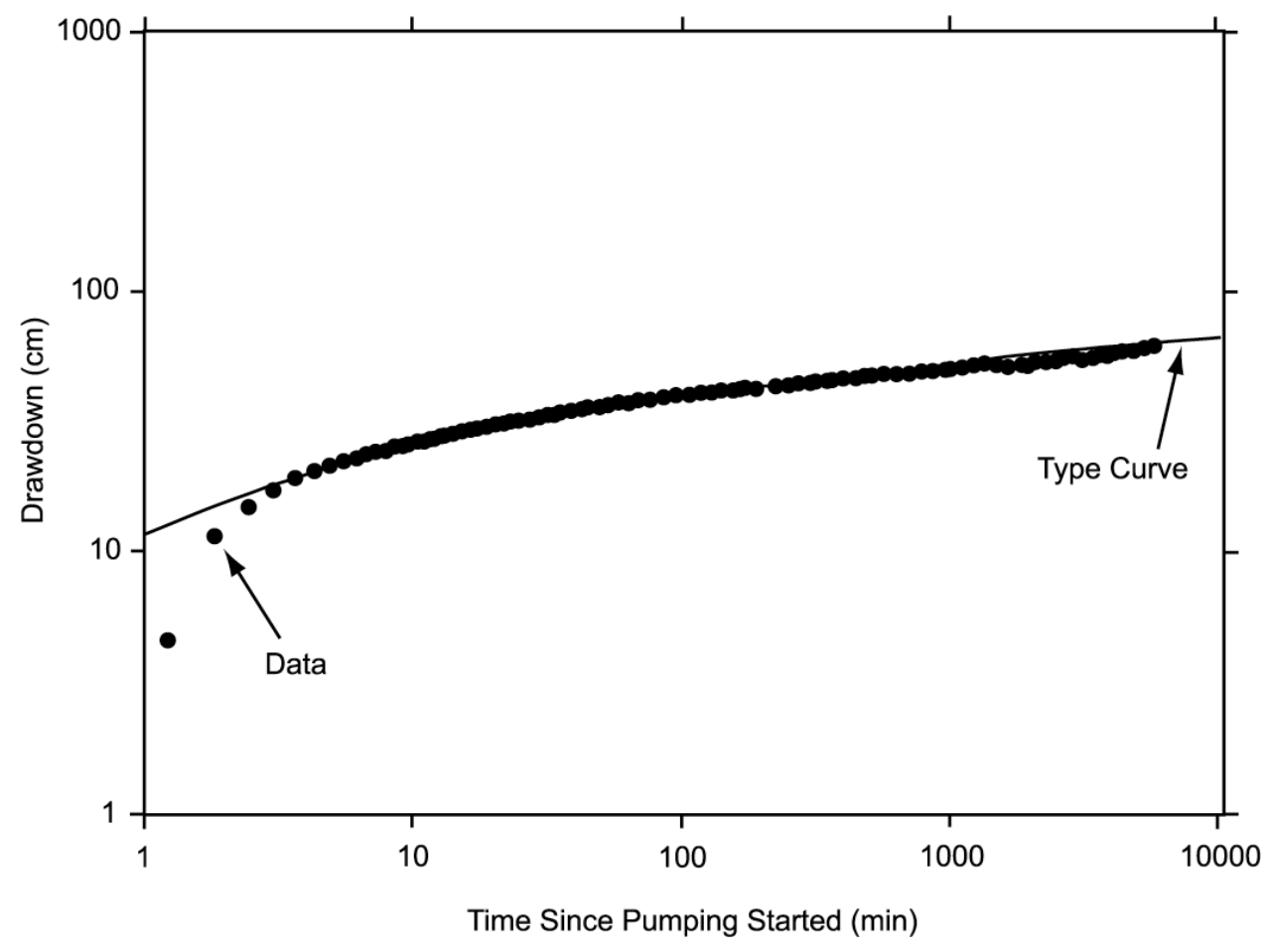

Output DTN: GS031008312314.004 (from Input DTN: GS030508312314.003 [DIRS 164425], p. 38, Figure 27).

Figure C-29. Analysis of Drawdown in UE-25 c\#2 Upper Bullfrog Interval, June 12 to 16, 1995, by the Method of Theis

\section{C4.4 LOWER BULLFROG INTERVAL}

Undisturbed drawdown in the Lower Bullfrog interval of c\#1 and c\#2 during the hydraulic test conducted from May 1996 to November 1997 can be interpreted in several ways not evident from previous hydraulic tests of much shorter duration. Although previous tests indicated a confined-aquifer response, the test beginning in May 1996 progressed long enough to develop a double-humped drawdown curve characteristic of a fissure-block aquifer. From 158,000 minutes (110 days) after pumping started in May 1996 to the end of the analyzed record (464,100 minutes [312 days] after pumping started), drawdown in c\#1 and c\#2 was greater than anticipated on the basis of extrapolating the earlier drawdown for long periods (using the equation of Theis (1935 [DIRS 150327]) to extrapolate drawdown). The oscillatory pattern of drawdown in the C-wells after 158,000 minutes (110 days) of pumping can be interpreted to indicate that the spreading cone of depression encompassed volumes of the Lower Bullfrog interval that were alternately less transmissive or as transmissive as the Lower Bullfrog in the C-wells.

Values of transmissivity computed for the Lower Bullfrog interval are significantly different depending on whether the interval is considered a confined aquifer or a fissure-block aquifer (Table C-7). In c\#1 and c\#2, transmissivity is $1,600 \mathrm{~m}^{2} / \mathrm{d}$ if the Lower Bullfrog is analyzed as a confined aquifer (Figure C-30), and $1,300 \mathrm{~m}^{2} / \mathrm{d}$ if analyzed as a fissure-block aquifer (Figure C-31). Although the two analytical solutions produced equally plausible results, the fissure-block aquifer solution is consistent with a tracer test conducted from February to 
March 1996 that indicated dual porosity in the Bullfrog-Tram interval (Fahy 1997 [DIRS 137456], third \{unnumbered\} page). Also, the longer pumping required for the fissureblock aquifer response to develop and the lower transmissivity value determined from that response can be interpreted to confirm that less-transmissive rocks were reached as the cone of depression spread to increasingly distant areas during the hydraulic test that began in May 1996.

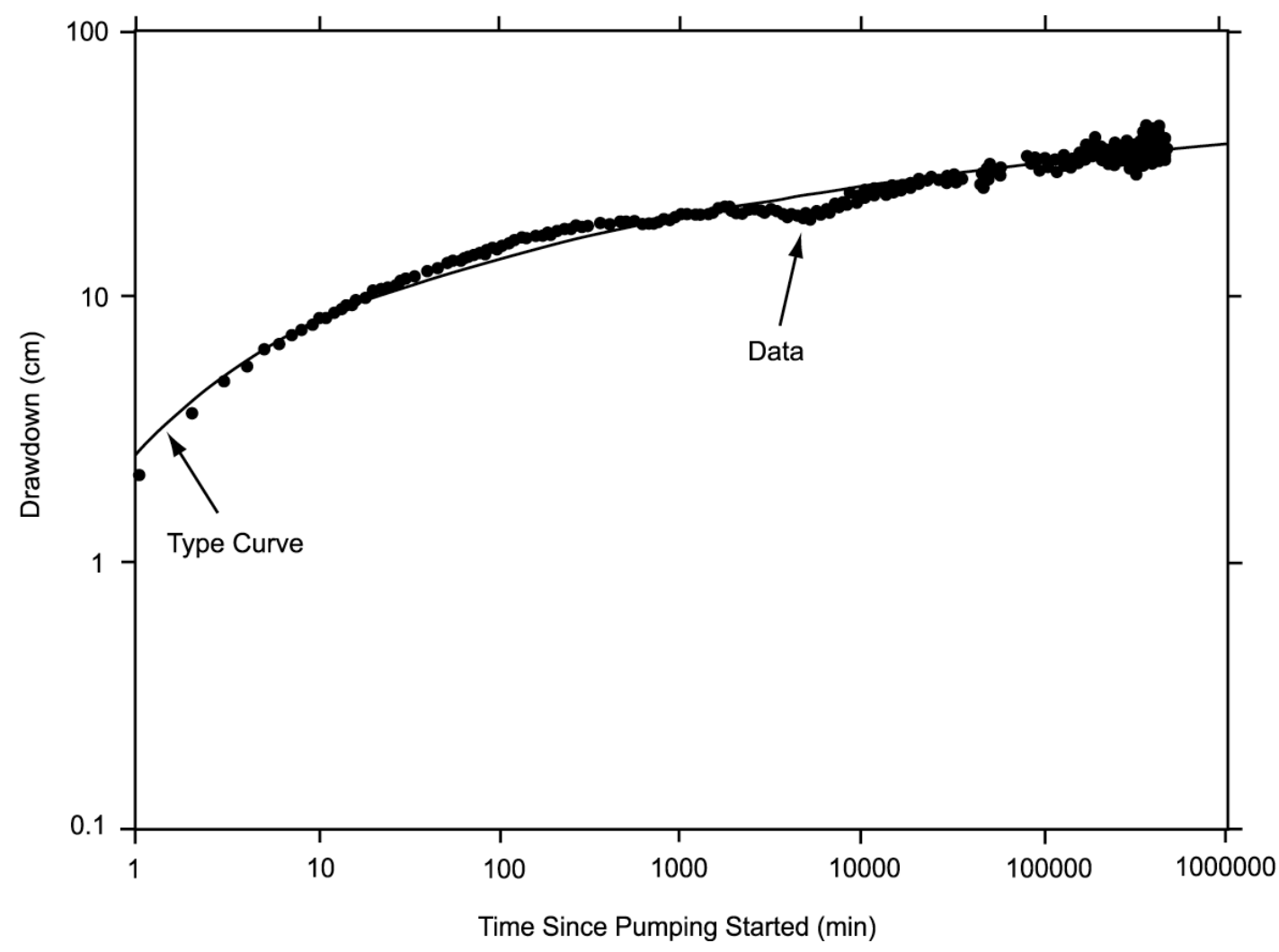

Output DTN: GS031008312314.004 (from Input DTN: GS030508312314.003 [DIRS 164425], p. 39, Figure 28).

Figure C-30. Analysis of Drawdown in UE-25 c\#1 Lower Bullfrog Interval, May 8, 1996, to March 26, 1997, by the Method of Theis

Values of hydraulic conductivity and storativity are considerably larger in the rock mass between $\mathrm{c \# 2}$ and c\#3 than in the rock mass between $\mathrm{c} \# 1$ and $\mathrm{c \# 3}$. When analyzed as a confined aquifer, the hydraulic conductivity of the Lower Bullfrog interval is $50 \mathrm{~m} / \mathrm{d}$ in $\mathrm{c} \# 2$ and $30 \mathrm{~m} / \mathrm{d}$ in c\#1, and its storativity is 0.001 in $\mathrm{c} \# 2$ and 0.0002 in $\mathrm{c} \# 1$. (These hydraulic conductivities and storativities of the interval in both boreholes are about the same as those of the fractures in the interval in both boreholes obtained when the Lower Bullfrog is analyzed as a fissure-block aquifer; Table C-7.) 


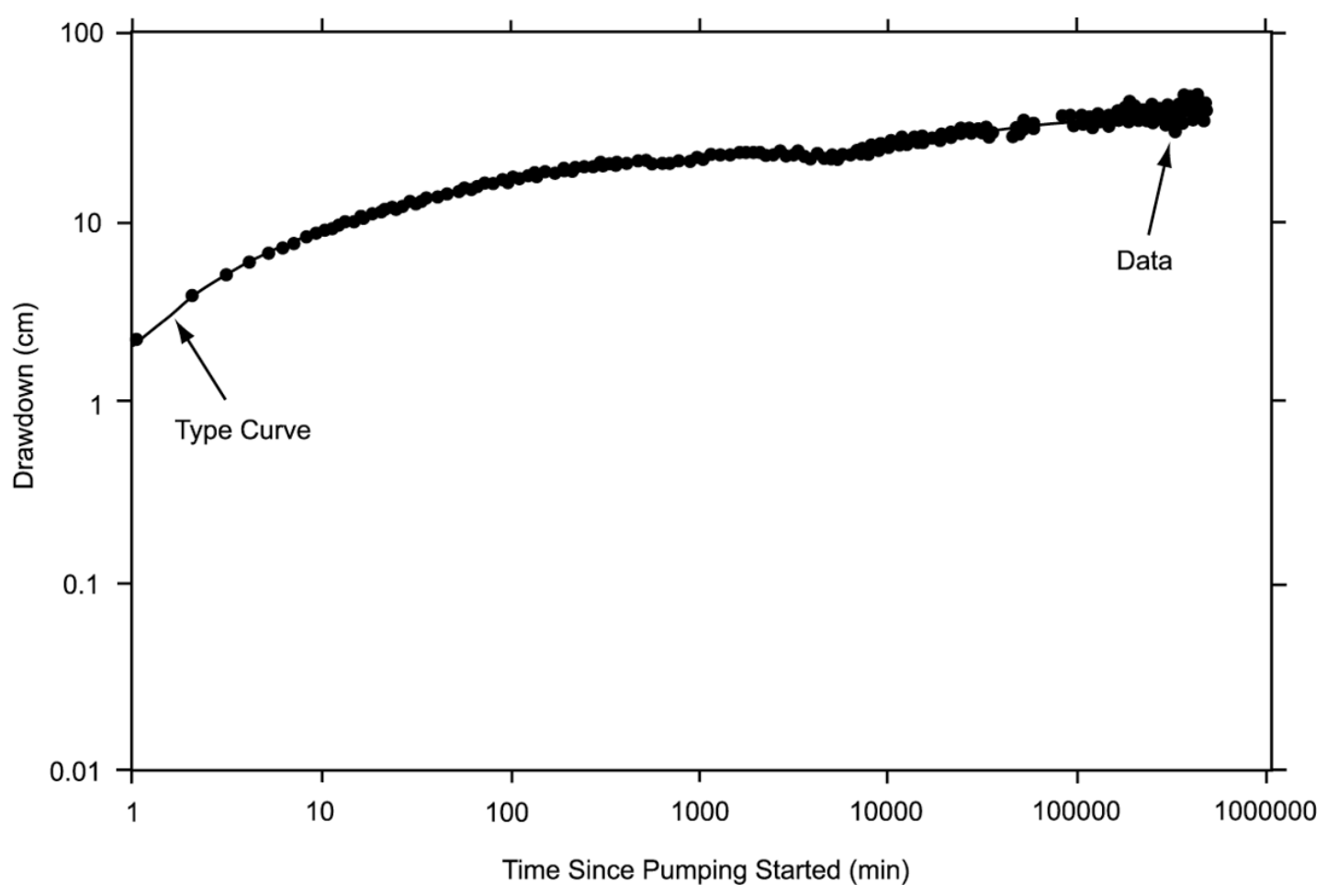

Output DTN: GS031008312314.004 (from Input DTN: GS030508312314.003 [DIRS 164425], p. 39, Figure 29). NOTE: For the analysis curve, the parameter $\tau / B=0.05$.

Figure C-31. Analysis of Drawdown in UE-25 c\#1 Lower Bullfrog Interval, May 8, 1996, to March 26, 1997, by the Method of Streltsova-Adams

\section{C4.5 UPPER TRAM INTERVAL}

The Upper Tram interval was known from earlier hydraulic tests (conducted in 1984) to respond to pumping as a leaky aquifer without confining bed storage because of recharge from faults that intersect the C-wells in that interval (Geldon 1996 [DIRS 100396], pp. 12 to 69). Although hydrologic properties of the Upper Tram (UT) interval could not be determined directly from hydraulic tests conducted during this study (because of transducer malfunction), they could be estimated by subtracting values of hydrologic properties determined for the Lower Bullfrog (LB) interval from those determined for the Bullfrog-Tram (вт) interval. This is deemed acceptable based on the assumption that flow during the Bullfrog-Tram test and the Lower Bullfrog test was radial in an equivalent porous medium that is homogeneous and isotropic, and composed of interconnected fractures. The following equations (2 to 4) were used (Geldon et al. 2002 [DIRS 161163], p. 38):

$$
\begin{gathered}
T_{\mathrm{UT}}=T_{\mathrm{BT}}-T_{\mathrm{LB}} \\
S_{\mathrm{UT}}=S_{\mathrm{BT}}-S_{\mathrm{LB}} \\
K_{\mathrm{UT}}=\left(K_{\mathrm{BT} \times} b_{\mathrm{BT}}-K_{\mathrm{LB} \times} b_{\mathrm{LB}}\right) / b_{\mathrm{UT}}
\end{gathered}
$$


where

$$
\begin{aligned}
& T=\operatorname{transmissivity}\left(\mathrm{L}^{2} / \mathrm{T}\right) \\
& S=\text { storativity }(\text { dimensionless }) \\
& K=\text { hydraulic conductivity }(\mathrm{L} / \mathrm{T}) \\
& b=\text { thickness }(\mathrm{L}) .
\end{aligned}
$$

Only hydrologic properties of the Lower Bullfrog interval determined by the Theis (1935 [DIRS 150327]) solution were used in these calculations because hydrologic properties of the Bullfrog-Tram interval (which includes the Lower Bullfrog) were determined by this method. These calculations indicated a transmissivity of $800 \mathrm{~m}^{2} /$ day, a hydraulic conductivity of $20 \mathrm{~m} /$ day, and a storativity of 0.0001 for the Upper Tram interval in c\#1; and a transmissivity of $900 \mathrm{~m}^{2} /$ day, a hydraulic conductivity of $40 \mathrm{~m} /$ day, and a storativity of 0.001 for the Upper Tram interval in $\mathrm{c} \# 2$ (Table C-7).

\section{C4.6 MIOCENE TUFFACEOUS ROCKS: HYDROLOGIC PROPERTIES AND LARGE-SCALE HORIZONTAL ANISOTROPY}

Indicative of hydraulic connection through a highly developed fracture network, diverse intervals of the Miocene tuffaceous rocks in six observation wells responded to the pumping in c\#3 from May 1995 to November 1997 (Table C-8). The C-wells, ONC-1, and H-4 appear to be connected hydraulically through a northwest-trending zone of discontinuous faults that extends from Bow Ridge to Antler Wash (Geldon et al. 1998 [DIRS 129721], pp. 23 to 25, Figure 2; p. 31). The Paintbrush Canyon and related faults that intersect WT\#14 and the C-wells probably enhance hydraulic communication between those boreholes. Hydraulic communication between the C-wells and WT\#3 is probably enabled both stratigraphically and structurally because those boreholes were open during hydraulic tests in the same geologic unit (the Bullfrog Tuff) and are cut by the same faults (the Paintbrush Canyon and related faults).

Analyses of the drawdown in individual observation wells (Figures C-32 to C-35) provide hydrologic properties of the rock mass at the scale of the distance between those boreholes and c\#3 (Table C-8). Analyses of drawdown in multiple observation wells, either as a function of time (normalized by dividing by the square of the distance between the observation and pumping wells) or as a function of distance at a specified time, allow computation of hydrologic properties of the tuffaceous rock mass in which all of the included observation wells are located. 
Table C-8. Hydrologic Properties Computed from Observation Well Responses to Pumping in UE-25-c\#3, May 1995 to November 1997

\begin{tabular}{|c|c|c|c|c|}
\hline Borehole & c\#2 & c\#2 & c\#1 & c\#1 \\
\hline Starting date of hydraulic test & 05/22/95 & 05/08/96 & 05/22/95 & 05/08/96 \\
\hline Period of record (min) & 14,400 & 464,100 & 11,400 & 464,100 \\
\hline Analyzed data & Drawdown & Drawdown & Recovery & Drawdown \\
\hline Geologic units in monitored interval & $\begin{array}{l}\text { Calico Hills } \\
\text { to Tram }\end{array}$ & $\begin{array}{l}\text { Calico Hills } \\
\text { to Tram }\end{array}$ & $\begin{array}{l}\text { Calico Hills } \\
\text { to Tram }\end{array}$ & $\begin{array}{l}\text { Calico Hills } \\
\text { to Tram }\end{array}$ \\
\hline Aquifer type & Unconfined & Variable & Unconfined & Variable \\
\hline 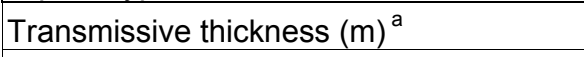 & 165 & 144 & 252 & 238 \\
\hline Distance from pumping well (m) & 29.0 & 29.0 & 82.6 & 82.9 \\
\hline Average discharge (L/min) & 1074 & 571.8 & 1074 & 571.8 \\
\hline Transmissivity ( $\mathrm{m}^{2} /$ day) & 2,100 & $2,400-2,600$ & 1,800 & $2,200-2,600$ \\
\hline Horizontal hydraulic conductivity (m/day) & 13 & $16-18$ & 7 & $9-11$ \\
\hline Vertical hydraulic conductivity (m/day) & 1.7 & Not estimated & 0.3 & Not estimated \\
\hline Storativity (dimensionless) & 0.003 & $0.003-0.004$ & 0.001 & 0.002 \\
\hline Specific yield (dimensionless) & 0.2 & Not estimated & 0.01 & Not estimated \\
\hline
\end{tabular}

\begin{tabular}{|c|c|c|c|c|}
\hline Borehole & UE-25 ONC-1 & USW H-4 & UE-25 WT\#14 & UE-25 WT\#3 \\
\hline Starting date of hydraulic test & 05/08/96 & 05/08/96 & 05/08/96 & 05/08/96 \\
\hline Period of record (min) & 796,663 & 72,000 & 72,000 & 463,500 \\
\hline Analyzed data & Drawdown & Drawdown & Drawdown & Drawdown \\
\hline Geologic units in monitored interval & Prow Pass & $\begin{array}{l}\text { Prow Pass to } \\
\text { Lithic Ridge }\end{array}$ & $\begin{array}{l}\text { Topopah } \\
\text { Spring and } \\
\text { Calico Hills }\end{array}$ & Bullfrog \\
\hline Aquifer type & Fissure-block & Confined & Confined & Confined \\
\hline Transmissive thickness $(\mathrm{m})$ & 193 (est) & 276 & Not estimated & 47.5 (estimated) \\
\hline Distance from pumping well $(\mathrm{m})$ & 843 & 2,245 & 2,249 & 3,526 \\
\hline Average discharge (L/min) & 552.6 & 583.2 & 583.2 & 575.4 \\
\hline Transmissivity ( $\mathrm{m}^{2} /$ day $)$ & 1,000 & 700 & 1,300 & 2,600 \\
\hline Horizontal hydraulic conductivity (m/day) & $5 / .002^{b}$ & 2 & Not estimated & 56 \\
\hline Storativity (dimensionless) & $0.001 / 0.01^{b}$ & 0.002 & 0.002 & 0.002 \\
\hline
\end{tabular}

Output DTN: GS031008312314.004 (from Input DTN: GS030508312314.003 [DIRS 164425], p. 41, Table 9).

a The sum of transmissive thicknesses of component geologic units is shown in Table C-7 for the corresponding test.

b The first number is for fractures; the second is for matrix (values of transmissivity and hydraulic conductivity listed for UE-25 ONC-1 and USW H-4 differ from those obtained from a hydraulic test conducted from May 22 to June 1, 1995, but the values determined from the longer test beginning in May 1996 are considered more reliable). 


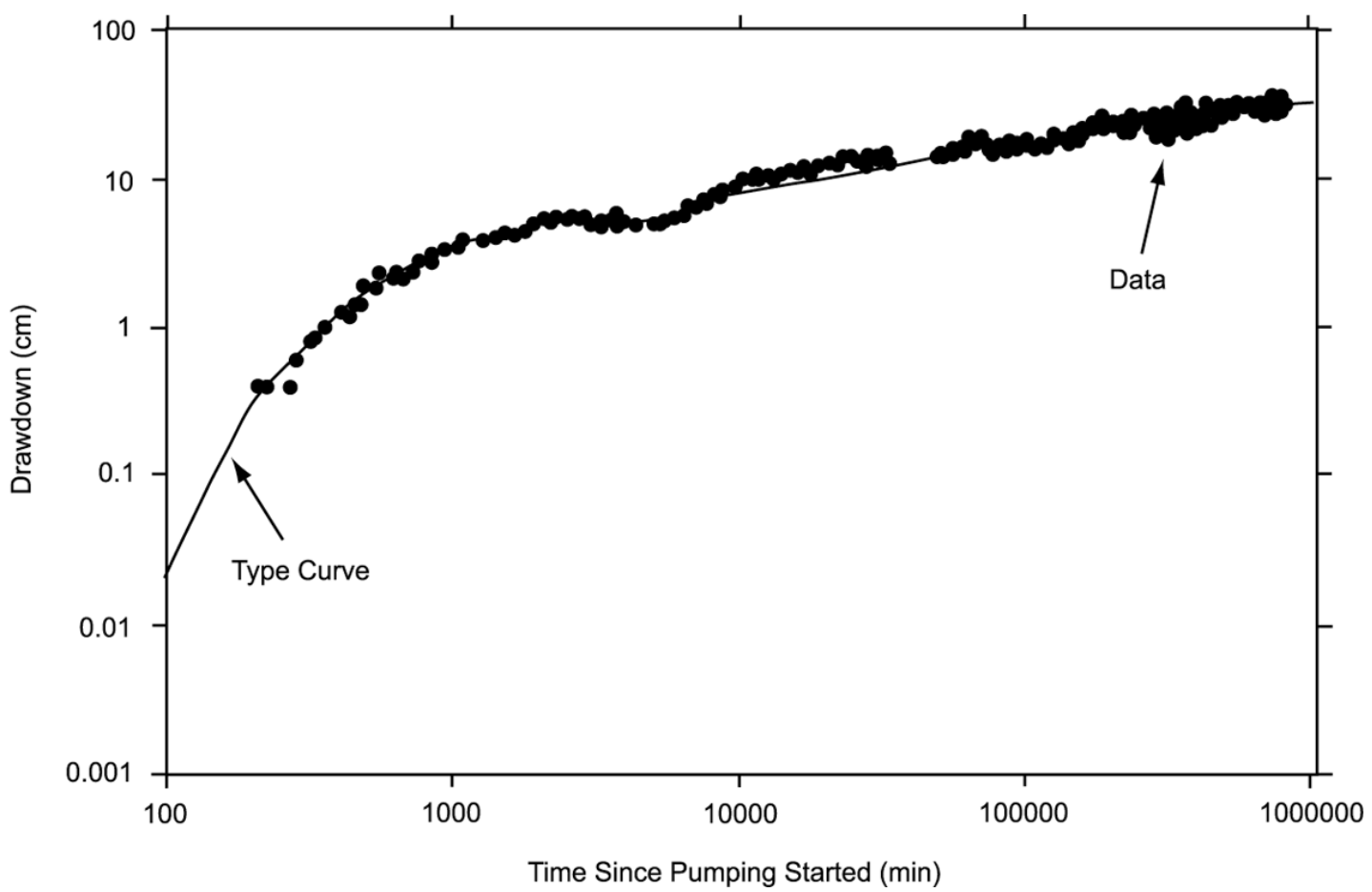

Output DTN: GS031008312314.004 (from Input DTN: GS030508312314.003 [DIRS 164425], p. 42, Figure 30). NOTE: For the analysis curve, the parameter $\tau / B=0.05$.

Figure C-32. Analysis of Drawdown in UE-25 ONC-1, May 8, 1996, to November 12, 1997, by the Method of Streltsova-Adams

Observation wells showed clear responses to the pumping, allowing computation of hydrologic parameters. Despite being $843 \mathrm{~m}$ from c\#3, ONC-1 responded to pumping after only 200 minutes because it is in the same structural block as the C-wells (between the Bow Ridge and Paintbrush Canyon faults), and is connected by fractures related to northwest-striking faults. That fracture connection is reflected in a characteristic fissure-block aquifer response. From 200 to 2,000 minutes (up to 1.4 days), flow from fractures caused drawdown to increase as a function of $\log$ time. From 2,000 to 6,000 minutes (1.4 days to 4 days), drawdown remained relatively constant as flow occurred from the rock matrix into fractures. After 6,000 minutes (4 days), drawdown increased again as a function of log time as flow from both the fractures and matrix occurred. Drawdown conformed to the type curve of Streltsova-Adams (1978 [DIRS 150754]; see Figure C-32). Transmissivity computed from the type-curve match equals $1,000 \mathrm{~m}^{2} / \mathrm{d}$. If the transmissive thickness between the C-wells complex and ONC-1 is assumed to vary linearly between known thicknesses in $\mathrm{c} \# 2$ and $\mathrm{H}-4$, then it can be estimated to be about $193 \mathrm{~m}$ in ONC-1. Dividing transmissivity by the estimated transmissive thickness indicates a fracture hydraulic conductivity of $5 \mathrm{~m} / \mathrm{d}$. In comparison, the hydraulic conductivity of the matrix (Table C-8) is insignificant. Computed storativity for the fractures in ONC-1 is 0.001 , which is a tenth of the computed storativity of the matrix. 


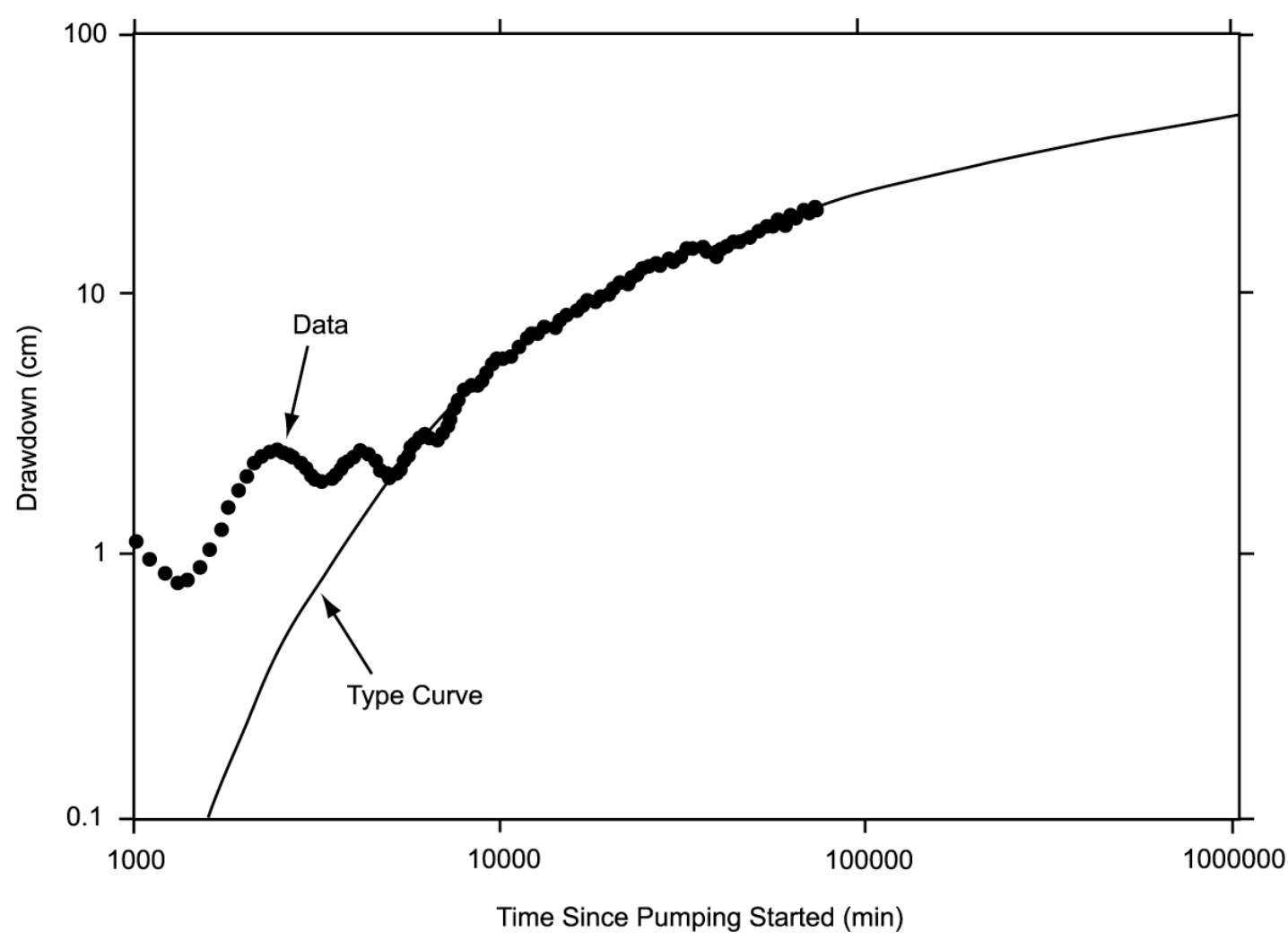

Output DTN: GS031008312314.004 (from Input DTN: GS030508312314.003 [DIRS 164425], p. 42, Figure 31).

Figure C-33. Analysis of Drawdown in USW H-4, May 8, 1996, to June 27, 1996, by the Method of Theis

Because of its location 2,245 $\mathrm{m}$ from $\mathrm{c \# 3}$, Borehole $\mathrm{H}-4$ took 5,000 minutes (3.5 days) to respond to pumping. Even though an extensive effort had been made to remove the effects of Earth tides and barometric changes on water-level fluctuations, the process is approximate and residual effects are still visible in the H-4 water-level record up to 5,000 minutes. After 5,000 minutes, the effect of pumping $\mathrm{c \# 3}$ at $\mathrm{H}-4$ became discernible above the residual water-level fluctuations, and the drawdown became analyzable (Figure C-33). From 5,000 to 72,000 minutes (3.5 to 50 days) after pumping started, drawdown in $\mathrm{H}-4$ conformed to the type curve of Theis (1935 [DIRS 150327]) for a confined aquifer (Figure C-33). After 72,000 minutes (50 days), drawdown became relatively constant, probably in response to flux from a nearby fault boundary. The preboundary drawdown indicated transmissivity of $700 \mathrm{~m}^{2} / \mathrm{d}$ and storativity of 0.002 (Table C-8). Dividing transmissivity by the transmissive thickness obtained from a flow survey (Whitfield et al. 1984 [DIRS 101366]) indicated a hydraulic conductivity of $2 \mathrm{~m} / \mathrm{d}$. The location of the recharge boundary could not be ascertained because only H-4 was affected by that boundary, and the analytical solution to determine the location of a boundary (Lohman 1972 [DIRS 150250], pp. 57 to 61) requires that at least two wells be affected by the same boundary. 


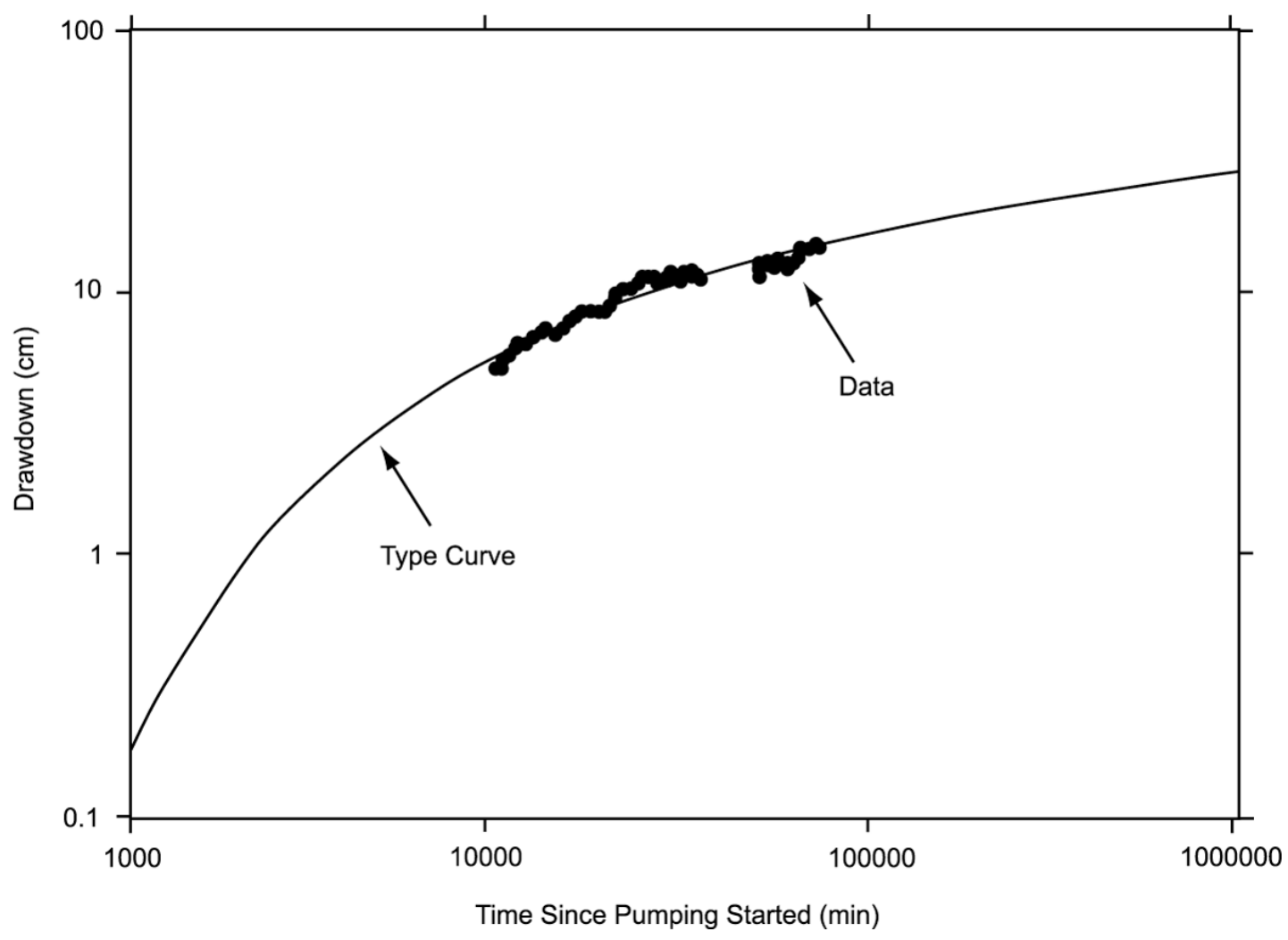

Output DTN: GS031008312314.004 (from Input DTN: GS030508312314.003 ([DIRS 164425], p. 43, Figure 32).

Figure C-34. Analysis of Drawdown in UE-25 WT\#14, May 8, 1996, to June 27, 1996, by the Method of Theis

Located a nearly identical distance $(2,249 \mathrm{~m})$ from $\mathrm{c} \# 3$, Borehole WT\#14 took slightly longer $(5,250$ minutes or 3.7 days $)$ to respond to pumping. From 3.7 days to just over 6 days $(5,250$ to 9,000 minutes), a transition from borehole-storage release to release of water from the aquifer occurred. From 6 to 50 days (9,000 to 72,000 minutes) after pumping started, drawdown in WT\#14 conformed to the type curve of Theis (1935 [DIRS 150327]) for a confined aquifer (Figure C-34). After that time, drawdown became strongly oscillatory, but those broad oscillations in the data deviated about a relatively constant value. Both the period of transition from borehole-storage release (5,250 to 9,000 minutes) and the strongly oscillatory drawdown period (after 72,000 minutes) are not shown in Figure C-34, which is intended to show only the portion of the record that conforms to the confined Theis (1935 [DIRS 150327]) solution. The late-time data are interpreted to represent less-than-ideal response to a recharge boundary. The preboundary drawdown indicates transmissivity of $1,300 \mathrm{~m}^{2} / \mathrm{d}$ and storativity of 0.002 (Table C-8). Hydraulic conductivity and the location of the boundary could not be determined because of insufficient data. 


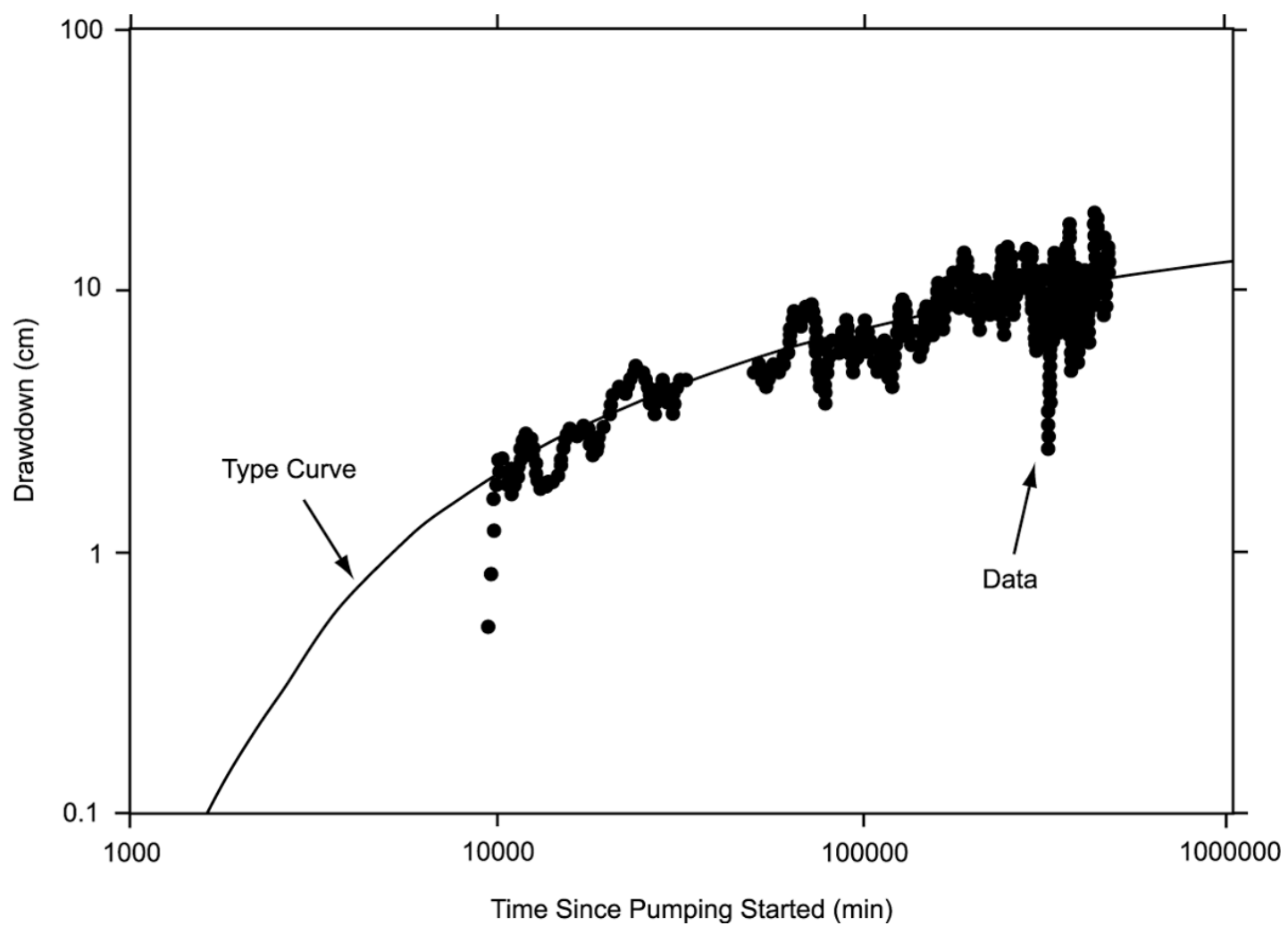

Output DTN: GS031008312314.004 (from Input DTN: GS030508312314.003 [DIRS 164425], p. 43, Figure 33).

Figure C-35. Analysis of Drawdown in UE-25 WT\#3, May 8, 1996, to March 26, 1997, by the Method of Theis

Borehole WT\#3 is located 3,526 $\mathrm{m}$ from c\#3 and took more than 6 days $(9,130$ minutes) to respond to pumping. Thereafter, drawdown in WT\#3 was oscillatory, but the data could be fit to the type curve of Theis (1935 [DIRS 150327]) for a confined aquifer (Figure C-35). The oscillations, which are substantially larger than those occurring at the other distant observation wells are likely caused by a combination of factors: (1) a possible low-quality transducer signal; (2) excessive distance from the pumping well (at 3,526 km, WT\#3 is the farthest of the distant observation wells from the C-hole complex); and (3) residual Earth-tide and barometric-pressure effects remaining, even after substantial, but approximate, efforts to remove them. The solution indicated a transmissivity of $2,600 \mathrm{~m}^{2} / \mathrm{d}$ and a storativity of 0.002 (Table C-8). Dividing transmissivity by the length of the open interval in WT\#3 $(47.5 \mathrm{~m})$ indicated a hydraulic conductivity of $56 \mathrm{~m} / \mathrm{d}$. Actual hydraulic conductivity probably is smaller than the calculated value because the thickness of transmissive rock between the C-wells complex and WT\#3 probably exceeds the length of the open interval.

The transmissivity of the Miocene tuffaceous rocks appears to decrease northwestward in the area containing the observation wells used in the hydraulic test that began in May 1996. Depending on the analytical solutions used, transmissivity could be interpreted to decrease from $2,600 \mathrm{~m}^{2} / \mathrm{d}$ in the vicinity of WT\#3 to about $2,000 \mathrm{~m}^{2} / \mathrm{d}$ in the vicinity of the C-wells. The transmissivity of the Miocene tuffs is $1,300 \mathrm{~m}^{2} / \mathrm{d}$ in the vicinity of WT\#14, $1,000 \mathrm{~m}^{2} / \mathrm{d}$ in the vicinity of ONC-1, and $700 \mathrm{~m}^{2} / \mathrm{d}$ in the vicinity of $\mathrm{H}-4$. 
The distribution of hydraulic conductivity in the tuffs in the vicinity of the C-wells complex appears to be structurally controlled. Hydraulic conductivity in $\mathrm{c} \# 2$ decreases sharply from a range of 20 to $60 \mathrm{~m} / \mathrm{d}$ in the Upper Tram and Lower Bullfrog intervals to a range of 0.08 to $0.2 \mathrm{~m} / \mathrm{d}$ in the Calico Hills interval as the vertical distance from faults that intersect the boreholes increases (Table C-7). Average hydraulic conductivity of the Miocene tuffaceous rocks in $\mathrm{c} \# 2$ is twice that of $\mathrm{c \# 1}$ (Table C-8), possibly because $\mathrm{c \# 2}$ is located nearer to the subsurface intersection of the north-striking Paintbrush Canyon or Midway Valley faults and a northwest-striking fault (shown in Figure C-36) that underlies the gap through the northern part of Bow Ridge. If spatial relations between faults and hydraulic conductivity at the C-wells complex are combined with values of hydraulic conductivity determined from analyses of drawdown in ONC-1, WT\#3, and H-4 (Table C-8), then a possible distribution of hydraulic conductivity for the Miocene tuffaceous rocks in the vicinity of the C-wells can be inferred (Figure C-36). Clearly, this distribution is not unique; just one possible scenario that attempts to extrapolate areally the correlation between vertical proximity of geohydrologic units at the C-hole complex to faults and the hydraulic conductivities of these units. When that correlation is applied areally, relative to known geologic structures in the area, while honoring the hydraulic conductivities obtained at the C-hole complex itself and the distant observation wells (ONC-1, H-4, WT\#14, and WT\#3), one obtains Figure C-36.

In the $21-\mathrm{km}^{2}$ area encompassed by observation wells used in hydraulic tests at the C-wells complex from 1995 to 1997, the storativity of Miocene tuffaceous rocks in those observation wells uniformly is 0.001 to 0.003 (Table C-8). Analysis of drawdown in observation wells not affected by boundaries as a function of the time divided by the square of the distance from the pumping well (Figure C-37) indicates that the average storativity of the tuffs in the observation area is 0.002 . This same analysis indicates that the average transmissivity of the Miocene tuffaceous rocks in the area is $2,200 \mathrm{~m}^{2} / \mathrm{d}$. Derivation of a single analytical solution for $\mathrm{c} \# 1, \mathrm{c} \# 2$, ONC-1, and WT\#3 confirms that the Miocene tuffaceous rocks, at least as far north as lower Midway Valley in the structural block delineated by the Paintbrush Canyon, Bow Ridge, and Dune Wash faults, are a single aquifer in which flow is influenced by the same structural and stratigraphic factors.

Plots of drawdown in observation wells as a function of distance 30,000, 100,000, 200,000, 305,000 , and 463,000 minutes $(21,69,139,212$, and 322 days) after pumping started in May 1996 (drawdown contours at 30,000 and 463,000 minutes shown in Figure C-38) confirm an ovoid pattern of drawdown aligned with faults extending from Bow Ridge to Antler Wash detected during the hydraulic test conducted from May 22 to June 1, 1995 (Geldon et al. 1998 [DIRS 129721], pp. 23 to 25, Figure 2; p. 31). Analyzed by the method of Cooper and Jacob (1946 [DIRS 150245]), plots of drawdown as a function of distance (Figure C-39) indicate values of transmissivity ranging from 2,100 to $2,600 \mathrm{~m}^{2} / \mathrm{d}$ and values of storativity ranging from 0.0005 to 0.002 (Table C-9). 


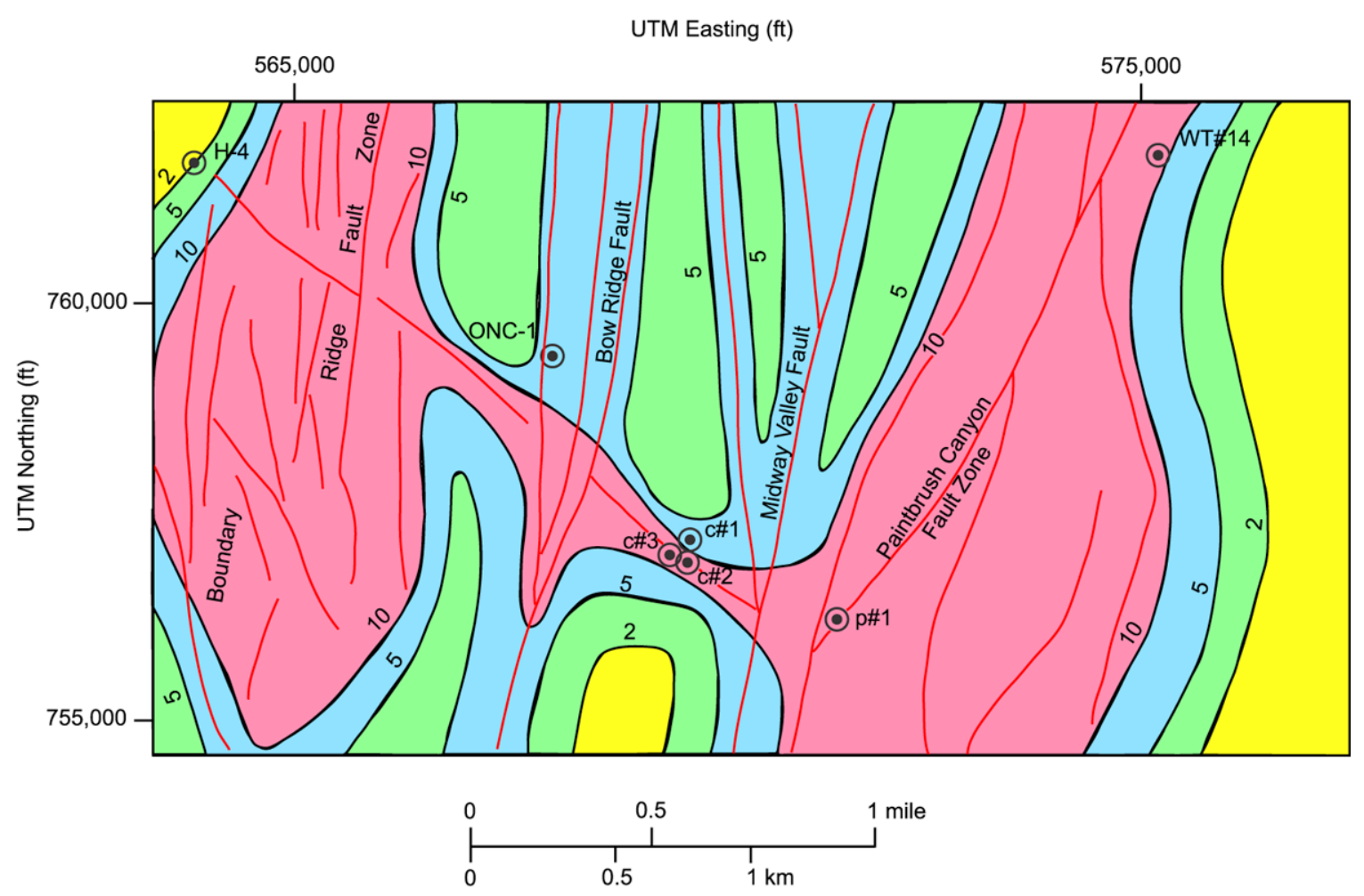

Explanation
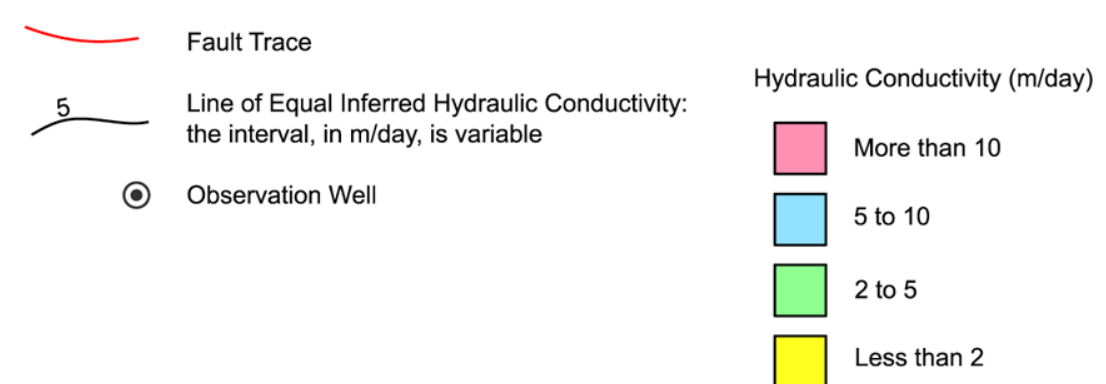

Output DTN: GS031008312314.004 (from Input DTN: GS030508312314.003 ([DIRS 164425], p. 45, Figure 34).

Figure C-36. Inferred Distribution of Hydraulic Conductivity of Miocene Tuffaceous Rocks in the Vicinity of the C-wells 


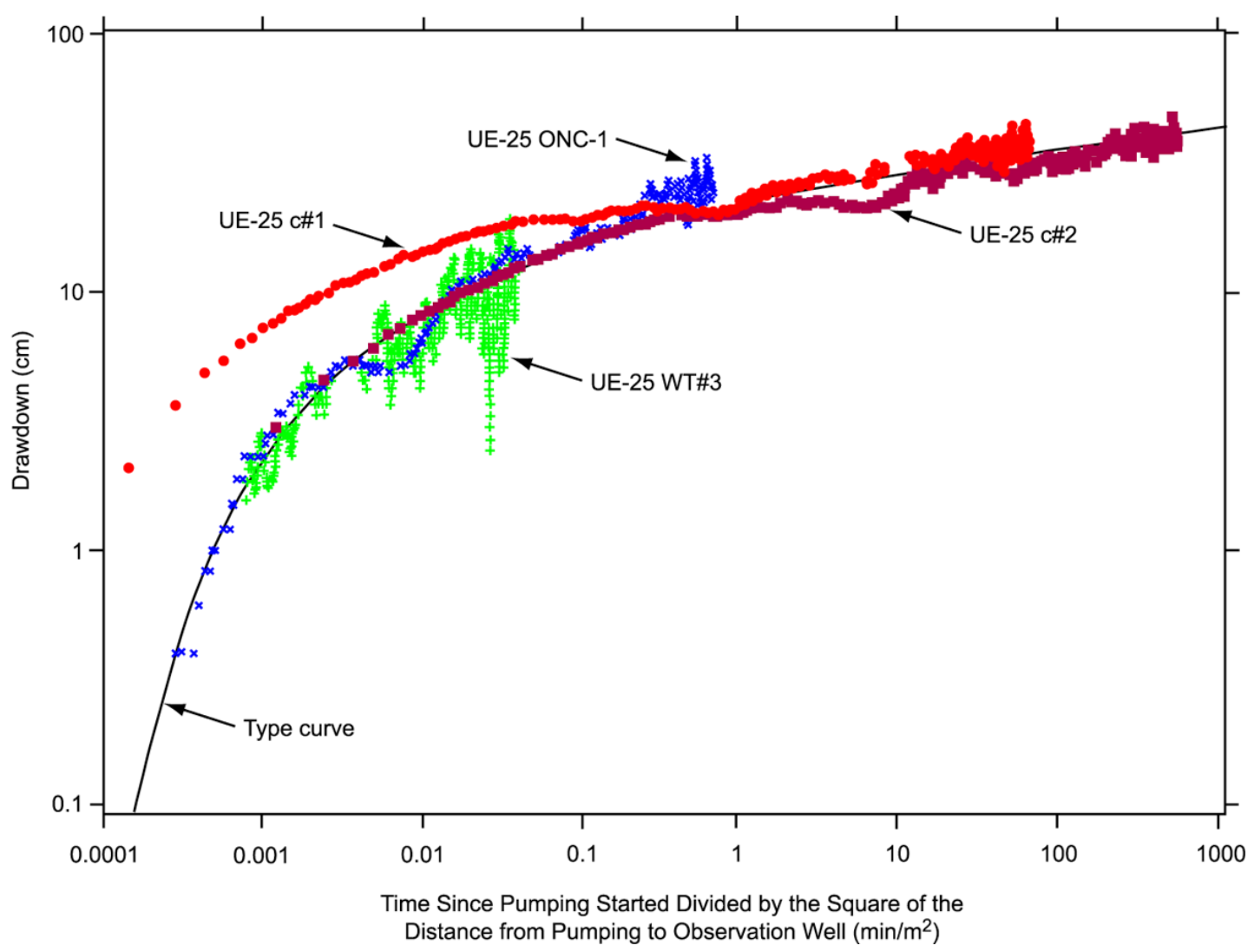

Output DTN: GS031008312314.004 (from Input DTN: GS030508312314.003 [DIRS 164425], p. 46, Figure 35).

Figure C-37. Analysis of Drawdown in Observation Wells as a Function of Time Divided by the Square of the Distance from the Pumping Well, UE-25 c\#3

Because the higher transmissivity and lower storativity values resulting from the 30,000- and 100,000-minute analyses in Table C-9 give way to more stable and consistent lower transmissivity and higher storativity values from later-time analyses, the later values appear to be more reliable. In comparison, the same type of analysis of drawdown in observation wells as a function of distance 10 days (14,000 minutes) after pumping started in May 1995 had indicated a transmissivity of 2,300 m²/d and storativity of 0.003 (Geldon et al. 1998 [DIRS 129721], p. 29). Distance-drawdown and time-drawdown analyses discussed in this section converge on similar solutions.

The ovoid pattern of drawdown aligned with faults extending from Bow Ridge to Antler Wash detected during the hydraulic test conducted from May 22 to June 1, 1995 (Geldon et al. 1998 [DIRS 129721], pp. 23 to 25, Figure 2; p. 31) and confirmed in this study (Figure C-38) indicates large-scale anisotropy caused by heterogeneity and structure. Large-scale transmissivity is higher in the direction of the long axis of the ovoid and lower in the direction perpendicular to it. 


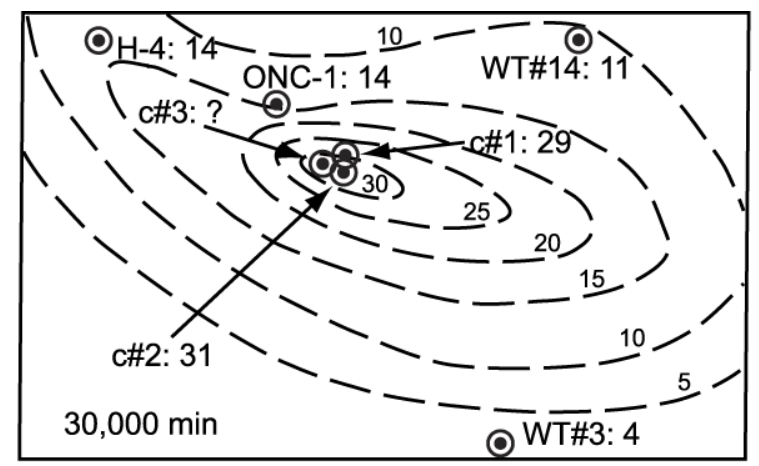

\section{Explanation}

WT\#3: 11 Observation Well Number: Drawdown $(\mathrm{cm})$ N/A: not applicable because drawdown is affected by a recharge boundary

25 - Line of Equal Drawdown (5-cm interval)
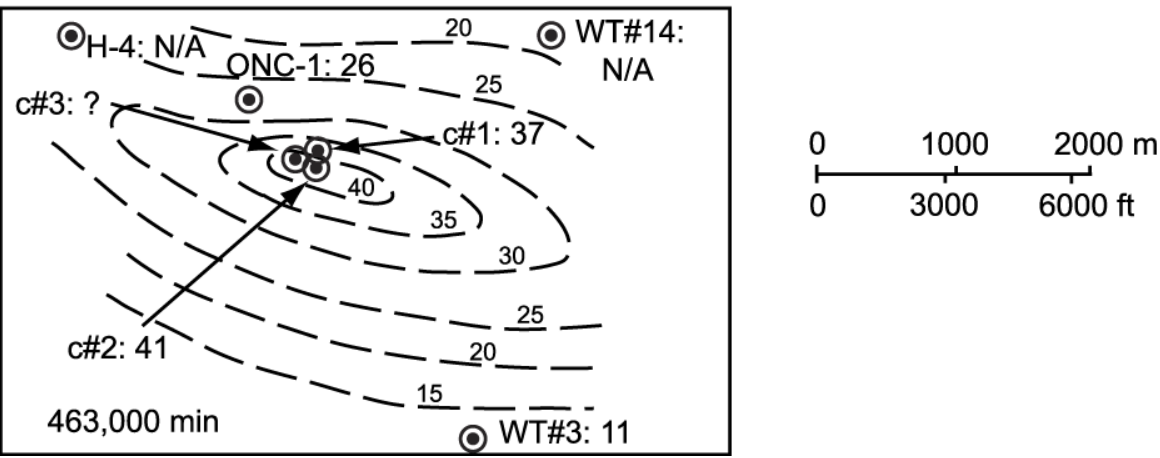

Output DTN: GS031008312314.004 (from Input DTN: GS030508312314.003 [DIRS 164425], p. 46, Figure 35).

NOTE: $\quad$ The upper panel shows the drawdown distribution 30,000 minutes (20.8 days) after pumping started; the lower panel shows the distribution 463,000 minutes (321.5 days) after pumping started.

The reason for the question mark in the figure is that the drawdown in the aquifer at the location of the pumped well, c\#3, is unknown; only the apparent drawdown in the well, which contains a lot of friction head, is known.

Figure C-38. Distribution of Drawdown in Observation Wells at Two Times after Pumping Started in UE-25 c\#3 on May 8, 1996

Table C-9. Hydrologic Properties Determined from Drawdown in Observation Wells as a Function of Distance From the Pumping Well UE-25 c\#3, May 1996 to November 1997

\begin{tabular}{|l|l|c|}
\hline Time Since Pumping Started & \multicolumn{1}{|c|}{ Transmissivity $\left(\mathbf{m}^{2} /\right.$ day $)$} & Storativity \\
\hline 30,000 & 2,600 & 0.0005 \\
\hline 100,000 & 2,500 & 0.0009 \\
\hline 200,000 & 2,100 & 0.002 \\
\hline 305,000 & 2,300 & 0.001 \\
\hline 402,000 & 2,200 & 0.001 \\
\hline 463,000 & 2,200 & 0.001 \\
\hline
\end{tabular}

Output DTN: GS031008312314.004 (from DTN: GS030508312314.003

[DIRS 164425], p. 50, Figure 10). 

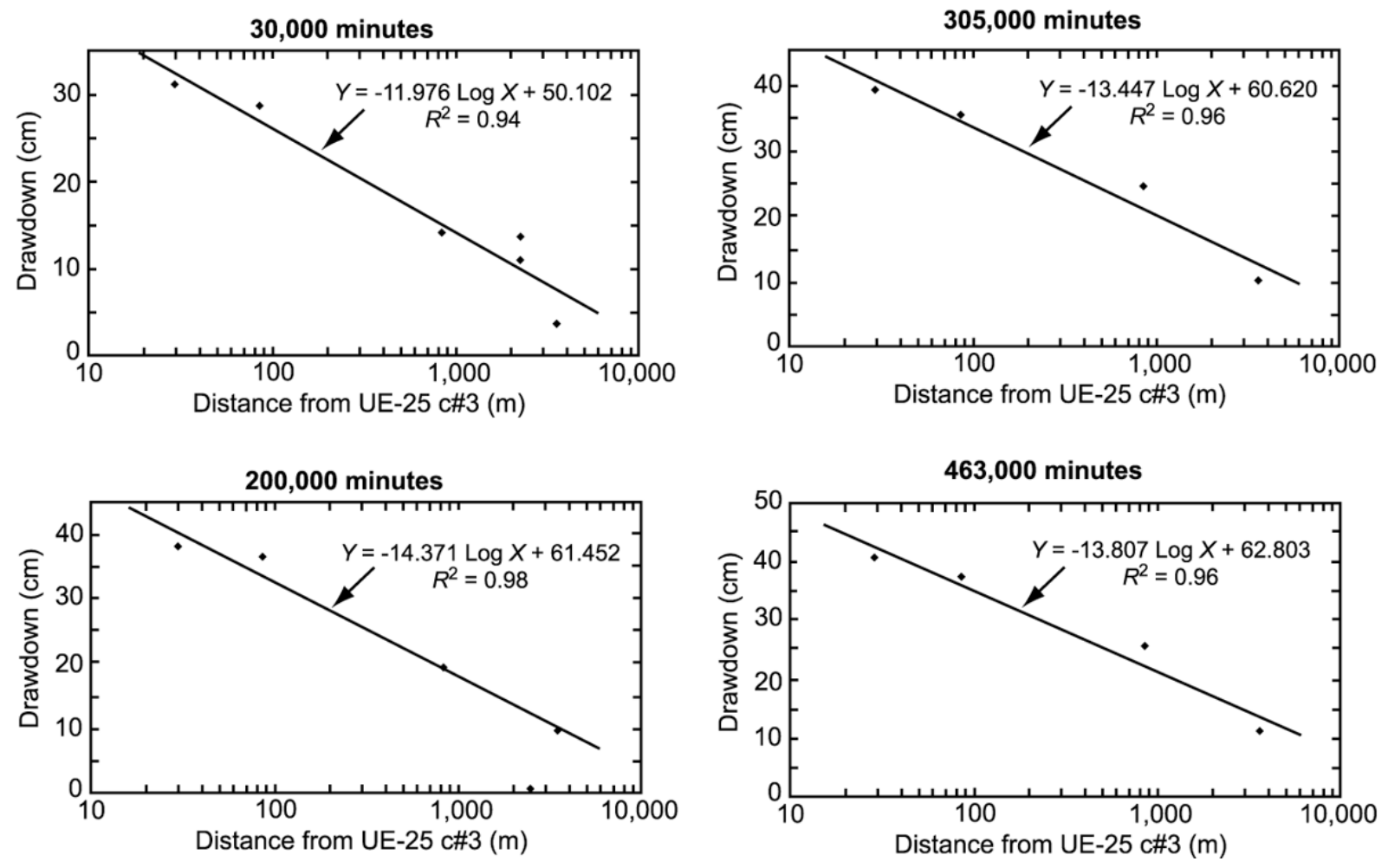

Output DTN: GS031008312314.004 (from Input DTN: GS030508312314.003 [DIRS 164425], pp. 48 and 49 , Figure 37).

NOTE: The panels show the drawdown analyses at 30,000 (upper left), 200,000 (lower left), 305,000 (upper right), and 463,000 (lower right) minutes after pumping started.

Figure C-39. Analyses of Drawdown in Observation Wells as a Function of Distance from the Pumping Well at Various Times after Pumping Started in UE-25 c\#3

\section{C4.7 PALEOZOIC CARBONATE ROCKS}

Borehole p\#1 was monitored during hydraulic tests in 1995 and 1996 to detect hydraulic connection between the Miocene tuffaceous rocks and Paleozoic carbonate rocks in the vicinity of the C-wells. Hydraulic connection previously had been indicated by hydraulic head measurements in $\mathrm{p} \# 1$ and by borehole flow surveys in the C-wells. Measurements made as $\mathrm{p} \# 1$ was being drilled in 1983 detected a 22-m difference in hydraulic heads for the Paleozoic carbonate rocks and Miocene tuffaceous rocks in p\#1 (Craig and Robison 1984 [DIRS 101040]), which indicated a potential for water to flow from the lower to the upper of those hydrogeologic units. Flow surveys conducted in the C-wells in 1991 detected upward flow in the lower parts of those boreholes (Geldon 1996 [DIRS 100396], pp. 12 to 69) that most likely originated in the Paleozoic carbonate rocks because the intervening tuffaceous rocks generally behave as a confining unit (Luckey et al. 1996 [DIRS 100465], p. 18, Figure 7). 
Although p\#1 was monitored for 10 days (14,400 minutes) after pumping started in May 1995 (Geldon et al. 1998 [DIRS 129721]), and for about 180 days (256,200 minutes) after pumping started in May 1996, drawdown in the Paleozoic carbonate rocks was not detected (Figure C-40). This lack of drawdown could indicate that the water being pumped was drawn laterally from the Miocene tuffaceous rocks. Alternatively, the water could have been drawn upward from Paleozoic carbonate rocks without causing drawdown in the underlying aquifer if the Paleozoic rocks have a large storage capacity. Hydraulic connection between the Miocene tuffaceous rocks and Paleozoic carbonate rocks could not be confirmed or refuted by monitoring water levels in p\#1 during the study reported here.

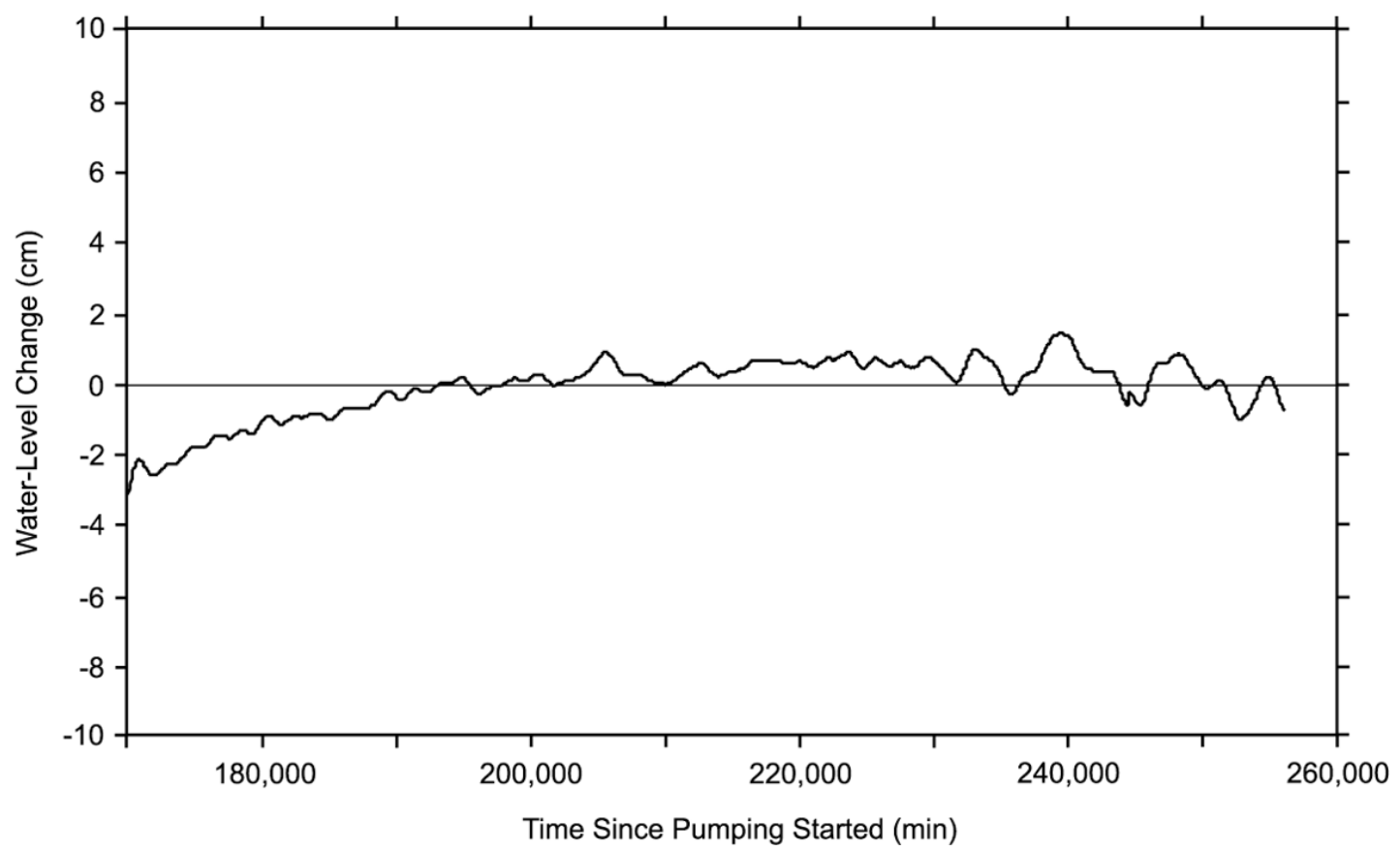

Output DTN: GS031008312314.004 (from Input DTN: GS030508312314.003 ([DIRS 164425], p. 50, Figure 38). NOTE: Water-level change is relative to the water level in p\#1 prior to start of pumping in c\#3 on May 8, 1996.

Figure C-40. Water-level Changes in UE-25 p\#1, September 3 to November 2, 1996

\section{C5. LIMITATIONS AND UNCERTAINTIES}

All analytical methods used in this study to determine hydrologic properties from drawdown or recovery responses assume that the aquifer is an equivalent porous medium. Although the flow system consists of a fracture network rather than a porous medium, the pressure responses conform quite well to type curves derived for either porous media or uniformly fractured media (Strelsova-Adams 1978 [DIRS 150754]). Thus, the fracture network at the C-wells is apparently interconnected in such a way that the fractured tuffs respond to pumping as "an equivalent porous medium." Another fundamental assumption is that flow to the pumping well is derived from an aquifer of infinite extent. The many faults near the C-wells complex that potentially function as either recharge or barrier boundaries make the concept of an infinite aquifer difficult to support. However, only observation wells that lay between faults bounding the structural block in which the C-wells are located were considered in the analyses, so boundary effects, 
while not completely eliminated, should have been minimized. Drawdown in H-4 and WT\#14 obviously was affected by recharge boundaries.

All the analytical methods used in this study assume a constant thickness for the interval for which drawdown is being analyzed, whereas, in reality, the intervals have variable thicknesses. This is a necessary simplification, and extreme care was taken to define transmissive intervals in each well and a meaningful resulting assumed-interval thickness between the pumped and observation well.

In addition, all the analytical methods used in this study, except for the Neuman (1975 [DIRS 150321]) method, assume radial flow to the pumping well, and, therefore, ignore vertical flow (application of the Neuman fully penetrating-well solution, as was done in this report, to cases where pumping was in one interval and the analyzed drawdown response was in another, also ignores vertical flow). The flow from intervals other than the one being pumped that was detected during hydraulic tests in February 1996 and May 1996 to November 1997 indicates that flow during those tests actually was three-dimensional. To obtain hydrologic parameter estimates in nonpumped intervals, it was necessary to assume an equivalent radial volumetric flow rate in these intervals. These estimates of equivalent radial flow were quite uncertain, and they could have resulted in significant errors in hydrologic parameter estimates in nonpumped intervals. However, parameter estimates based on an assumed radial flow in nonpumped intervals were generally in good agreement with estimates obtained from open-hole pumping of c\#3 in May through June 1995, and also from later pumping of the intervals when they were isolated (e.g., estimates for the Prow Pass interval when the Lower Bullfrog was pumped in 1996-1997 were in good agreement with estimates obtained when the Prow Pass interval was pumped directly in 1998). Thus, the approach taken seems to have yielded reasonable hydrologic parameter estimates in the cases in which it could be verified with a more direct measurement.

All the analytical techniques used in this study required input parameters that had to be determined or approximated for hydrogeologic intervals or boreholes in which drawdown was monitored. Included in those parameters are the distance of the interval or borehole from the pumping well, the transmissive thickness of the interval or borehole, the barometric efficiency of the interval or borehole, the proportion of flow from a given hydrogeologic interval, and the fracture spacing within a hydrogeologic interval. Errors in deriving any of those input parameters could have changed calculated hydrologic properties considerably.

Uncertainties and nonuniqueness in estimates of storativity, transmissivity, and hydraulic conductivity were not quantitatively analyzed because these parameter estimates were not used directly in the SZ site-scale flow model (BSC 2004 [DIRS 170037], Sections 6.6, 6.7 and 7); they were used only qualitatively/corroboratively in the flow model. Based on the ranges of storativity and transmissivity estimates obtained by different analysts or different methods using the same drawdown data from the distant wells that responded to pumping c\#3 in 1996-97 (see Section C6.2), the transmissivity estimates determined in this analysis can be considered accurate to perhaps only a factor of 3 (that is, the true transmissivity may be 3 times higher or 3 times lower than the estimate), and storativity estimates can be considered accurate to only within an order of magnitude or so. However, relative values of transmissivity estimates (that is, the ratios of transmissivites of different flow intervals) can be considered more accurate because errors and 
biases should be reasonably consistent for estimates obtained by the same analyst using similar assumptions and methods (as is the case here). Estimates of hydraulic conductivity are more uncertain than transmissivity estimates because hydraulic conductivity is calculated by dividing the transmissivity by either the known thickness of transmissive intervals within a test interval, the entire thickness of the test interval, or an assumed thickness of transmissive rock between the observation and pumping wells. In many cases, the transmissive thickness was unknown, so it was only possible to obtain bounding estimates of the hydraulic conductivity. Even when hydraulic conductivity could be estimated, it was done with limited confidence. For example, it is impossible to know whether the hydraulic conductivity of the Lower Bullfrog interval in c\#1 really is about half that in $\mathrm{c} \# 2$ or whether these calculated hydraulic conductivity values result from dividing approximately the same transmissivity in each borehole by an assumed transmissive thickness twice as large in $\mathrm{c} \# 1$ as in $\mathrm{c} \# 2$.

\section{C6. SATURATED ZONE ANISOTROPY NEAR THE C-WELLS COMPLEX}

\section{C6.1 INTRODUCTION}

Understanding SZ flow and transport near the high-level nuclear waste repository at Yucca Mountain is critical to a successful license application. Because radionuclides released from the repository at Yucca Mountain must travel through the saturated fractured tuff and the saturated alluvium before reaching the compliance boundary, it is important to characterize the hydrogeologic properties of the down-gradient media. Since the completion of the site-characterization wells in 1983, several single- and cross-hole tracer and pumping tests have been conducted to gain a better understanding of the hydrogeology of the region. A number of published studies have assigned transmissivities, storativities, and anisotropy ratios to the SZ in this area (Farrell et al. 1999 [DIRS 157319]); Ferrill et al. 1999 [DIRS 118941]; Winterle and La Femina 1999 [DIRS 129796]). In this scientific analysis report, reviews of the above mentioned studies are used in conjunction with independent re-analyses of the data to suggest a distribution of anisotropy ratios to be used in the finite-element, heat and mass transfer (FEHM) stochastic flow model of the SZ (Zyvoloski et al. 1997 [DIRS 110491]).

\section{C6.1.1 Background}

A geologic description of the C-wells complex and the surrounding area can be found in several publications (including Geldon et al. 1998 [DIRS 129721], Table 1, Figures 3 and 5; Farrell et al. 1999 [DIRS 157319]; Ferrill et al. 1999 [DIRS 118941]; Winterle and La Femina 1999 [DIRS 129796]). Nevertheless, one geologic characteristic bears mentioning. Based on in situ stress-field analyses, the maximum horizontal geologic stress runs north-northeast (azimuth between $25^{\circ}$ and $30^{\circ}$ east of north). Therefore, any fractures oriented in this direction tend to dilate and present potential preferential flow pathways (Farrell et al. 1999 [DIRS 157319], p. 4-1; Ferrill et al. 1999 [DIRS 118941], p. 1). This finding supports some of the calculated principal directions of anisotropy discussed below, but not all.

Although many hydraulic tests have been conducted at the C-wells complex, only the long-term pumping test from May 8, 1996, through November 12, 1997, yielded data suitable for estimating the hydrologic properties of the medium on a broad scale beyond the immediate vicinity of the $\mathrm{C}$-wells. These data may help to estimate an overall anisotropy ratio for the area. 
Specifically, changes in local groundwater elevations due to pumping at the C-wells complex were monitored at several distant wells, the locations of which are shown in Figure 6.1-4 (only H-4, ONC-1, WT\#3, and WT\#14 exhibited sufficient drawdown for an anisotropy analysis). Well c\#3 has traditionally served as the pumping well because of its record of consistent production rates.

Although several cross-hole hydraulic tests have been conducted by USGS investigators, only the long-term pumping test yielded data suitable for calculating a nonlocal anisotropy ratio. For this test, well c\#3 was packed around the Lower Bullfrog interval, and water levels were monitored at H-4, ONC-1, WT\#3, and WT\#14. Data collected during this test were used to calculate transmissivity and storativity at each well-parameters necessary to analytically estimate an anisotropy ratio for the area. Although water levels were monitored at other wells, none yielded data suitable for an analytic treatment of anisotropy.

\section{C6.1.2 Technical Approaches}

Water-level data for wells H-4, WT\#3, and WT\#14 were obtained from the DTN: GS970308312314.002 [DIRS 161273]. Data from well ONC-1 were collected by Nye County under the Nye County Nuclear Waste Repository Project Office (NWRPO) QA program (QAP) (NWRPO 2003 [DIRS 165947], Program Management, Quality Assurance Program). Nye County requires that the NWRPO establish and maintain a documented QAP that meets the requirements of American National Standards Institute/American Society of Mechanical Engineers NQA-1 and the criteria of 10 CFR 50 (2002 [DIRS 165855], Appendix B). These data are available under DTN: MO0212SPANYESJ.149 [DIRS 161274].

Winterle and La Femina (1999 [DIRS 129796]) reduced and filtered the drawdown data for the above wells to obtain estimates of hydrologic parameters over the affected area. In the analyses presented here, the filtering of data from wells H-4, WT\#3, WT\#14, and ONC-1 was accomplished with Filter.vi (STN: 10970-1-00 [DIRS 162668]). These filtered drawdown data are identified by Output DTNs: GS030208312314.001 and GS030208312314.002.

The first analytical anisotropy analysis in this report was calculated in Microsoft Excel ${ }^{\mathrm{TM}}$ using the standard formulation offered by Hantush (1966 [DIRS 161160]); the second uses a modification of the method of Papadopulos (1967 [DIRS 150265]) combined with the PEST parameter-estimation program, Version 5.5 (STN: 10289-5.5-00 [DIRS 161564]). Winterle and La Femina (1999 [DIRS 129796]) used AQTESOLV, Version 2.12, marketed by HydroSOLVE, Inc., to analyze pump tests. Based on Geldon et al. (2002 [DIRS 161163]), the authors of this report used analytical solutions of Theis (1935 [DIRS 150327]) or Streltsova-Adams (1978 [DIRS 150754]) for analyses of the responses at the four observation wells to pumping at c\#3. These analyses were performed using Theis.vi (STN: 10974-1-00 [DIRS 162758]) and Streltsova-Adams.vi (STN: 10971-1-00 [DIRS 162756]), respectively.

\section{C6.2 ESTIMATING ANISOTROPY}

Interpretation of well test data with analytical solutions consists of inferring the hydrologic properties of the system from its measured responses based on, among other things, an assumed flow geometry (i.e., radial). The problem becomes more complicated, however, when the system 
geometry cannot be specified with reasonable certainty. In a layered sedimentary system lacking extreme heterogeneity, flow might reasonably be expected to be radial during an hydraulic test. When hydraulic tests are conducted at some arbitrary point within a three-dimensional fractured rock mass, however, the flow geometry is convoluted. Radial flow would occur only if the test were performed in a single uniform fracture of effectively infinite extent or within a network of fractures confined to a planar body in which the fractures were so densely interconnected that the network behaves like an equivalent porous medium. More likely, flow would be nonradial and variable, as fracture terminations and additional fracture intersections were reached. The nonradial nature of the cone of depression near Yucca Mountain is illustrated in Figure C-38. Despite all of this, analytic solutions provide important requisite first-order answers commensurate with the spatial distribution of the available hydrogeologic and geophysical data, and that can only be improved by numerical modeling if that data distribution is enhanced by substantial new data-gathering efforts.

Through the fractured tuff near Yucca Mountain, there are significant heterogeneity and hydrologic properties that not only vary spatially but also differ depending upon the direction in which they are measured (both horizontally and vertically). In this analysis, transmissivity and storativity are the key parameters defining large-scale anisotropy, and their measured values reflect the heterogeneity of the media. The concept of anisotropy is typically associated with a homogeneous medium - a criterion not met here. Nevertheless, there are clearly spatial and directional variations in transmissivity, and the notion remains that, over a large enough representative elementary volume, there exists a preferential flow direction that can be termed "anisotropy."

Data from the long-term pumping test conducted from May 8, 1996, to November 12, 1997, can be used to evaluate the anisotropy of the $\mathrm{C}$-wells complex and vicinity because transmissivity and storativity can be calculated at four distant wells (H-4, ONC-1, WT\#3, and WT\#14). The hydrologic properties measured at these wells are used to develop an estimate for the anisotropy ratio. Data from the other $\mathrm{C}$-wells (c\#1 and $\mathrm{c \# 2)}$ were not used in the anisotropy analysis because, according to Farrell et al. (1999 [DIRS 157319], p. 4-9):

- Over the small scale of observation at the C-wells, pump-test results are likely dominated by discrete fractures (i.e., inhomogeneities)

- Three-dimensional flow effects are likely

- Recirculation from simultaneous tracer tests obscured results.

Furthermore, because anisotropy is conceptually difficult to define for heterogeneous media, it is more easily described as an average preferential flow over as large a representative elementary volume as possible. Thus, it makes little sense to attempt to define anisotropy over an heterogeneous area as small as that of the C-wells.

\section{C6.2.1 Data Filtering and Reduction}

Because drawdown was measured at great distances from the pumping well (up to $3,526 \mathrm{~m}$ between WT\#3 and c\#3), natural variations in groundwater levels obscured responses due to 
pumping and had to be filtered out before the drawdown data could be analyzed. Drawdowns were corrected for Earth-tide effects (head fluctuations of up to $0.12 \mathrm{~m}$ ) and atmospheric pressure change (head fluctuation of up to $0.25 \mathrm{~m}$ ). First, the water levels were processed with a low-pass filter (Filter.vi V 1.0, STN: 10970-1-00 [DIRS 162668]) to remove oscillations with a frequency greater than 0.8 cycles per day to eliminate Earth-tide effects and semi-diurnal barometric-pressure effects, leaving only the effects of long-term weather-related barometric-pressure changes. The barometric record from the $\mathrm{C}$-wells complex, which was assumed to apply to all the wells, was also filtered to remove frequencies greater than 0.8 cycles per day to eliminate semi-diurnal barometric-pressure fluctuations, leaving only long-term weather-related barometric pressure changes. Using barometric efficiency values of the wells, the effects of long-term, weather-related, barometric-pressure changes were removed from the filtered water levels, leaving only the effect of c\#3 pumping. The filtered and barometrically corrected water-level data for the four observation wells can be found in Output DTNs: GS030208312314.001 and GS030208312314.002. The water-level data for H-4, WT\#3, and WT\#14 were obtained from DTN: GS970308312314.002 [DIRS 161273], and the water levels for ONC-1 were obtained from DTN: MO0212SPANYESJ.149 [DIRS 161274]. The barometric record used for the above processing was from the C-wells complex (DTN: GS981008312314.003 [DIRS 144464]).

Winterle and La Femina (1999 [DIRS 129796], pp. 3-4 to 3-6) also applied a second stage of filtering to the long-term pumping test to remove barometric effects that reached the aquifer through the unsaturated zone by accounting for the time lag and attenuation that occurs in the unsaturated zone. Second-stage barometric pressure effects were filtered using a 2.6-day running average, multiplied by an attenuation factor of 0.6 , and lagged by a period of 0.42 days.

The derivative of the filtered drawdowns with respect to the log of time was calculated for $\mathrm{H}-4$, WT\#3, WT\#14, and ONC-1 to establish the optimum range of data to fit with the straight-line method of Cooper and Jacob (1946 [DIRS 150245]). The flattest (zero-slope) portion of the resulting curve is deemed the best location for a linear fit to the drawdown data.

\section{C6.2.2 Transmissivity and Storativity Calculations}

In the first analysis of this section, the Cooper-Jacob (1946 [DIRS 150245]) method applied to filtered and derivative-analyzed data is used to calculate transmissivities and storativities. The key to a reasonable estimate of anisotropy is an accurate assessment of transmissivity and storativity at each monitoring well. Figure C-41 is a plot of the filtered drawdowns fit with the Cooper-Jacob straight-line method to the appropriate portion of the derivative curve. Note the inconsistent slope of the fit to drawdown in well $\mathrm{H}-4$ resulting in a significantly lower transmissivity at this well. Transmissivity and storativity values are presented in Table C-10.

In the second analysis methodology of this report, which uses the modified Papadopulos-PEST method, the response of each of observation wells H-4, WT\#14, and WT\#3 is analyzed using the homogeneous, isotropic method of Theis (1935 [DIRS 150327]) (Theis.vi V 1.0, STN: 10974100 [DIRS 162758]) for confined aquifers, and the response of observation well ONC-1 is analyzed using the homogeneous, isotropic method of Streltsova-Adams (1978 [DIRS 150754]) (Streltsova-Adams.vi, V 1.0, STN 10971-1.0-00 [DIRS 162756]) for fissure-block aquifers-both type-curve-fitting techniques-to obtain transmissivity and 
storativity values. Three analyses were made: one with transmissivities constrained to 1,000 $\mathrm{m}^{2} /$ day, the other with the transmissivities and storativities as given in Geldon et al. (2002 [DIRS 161163], p. 50; DTN: GS030508312314.003 [DIRS 164425]), and the third with transmissivities and storativities obtained from analyzing the filtered and barometrically corrected water levels processed for this report and described in the first paragraph of Section C6.2.1. The three sets of values are used to produce three sets of anisotropy magnitudes and directions as discussed below.

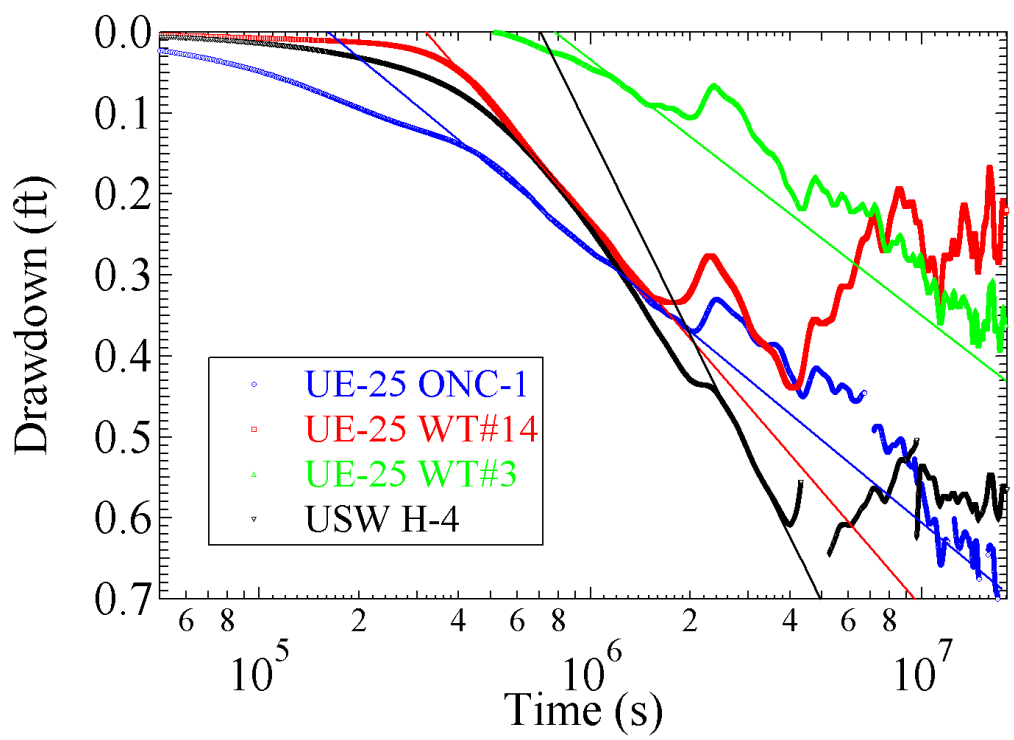

Source: DTNs: GS970308312314.002 [DIRS 161273]; MO0212SPANYESJ.149 [DIRS 161274].

Output DTN: SN0409T0502203.002.

NOTE: The straight lines were fit to relatively small portions of each drawdown curve selected because they had the most constant derivatives (i.e., the least noisy portions of the curves). Fitting a straight line to larger portions of the curves could result in slopes and, hence, estimated transmissivities that differ by nearly a factor of two.

Figure C-41. Straight Line Fits to the Filtered and Derivative-Analyzed Data at the Four Monitoring Wells 
Table C-10. Transmissivities and Storativities Calculated by the Cooper-Jacob Method Using the Filtered and Derivative-Analyzed Data

\begin{tabular}{|c|c|c|}
\hline \multirow[b]{2}{*}{ Well } & \multicolumn{2}{|c|}{ Cooper-Jacob ${ }^{a}$ Analysis } \\
\hline & $T$ (m²/day) & $S(-)$ \\
\hline UE-25 ONC-1 & 1465 & 0.009 \\
\hline UE-25 WT\#3 & 1566 & 0.003 \\
\hline UE-25 WT\#14 & 1043 & 0.002 \\
\hline USW H-4 & 598 & 0.002 \\
\hline \multicolumn{3}{|c|}{$\begin{aligned} \text { Source: DTNs: GS970308312314.002 [DIRS 161273]; } \\
\text { MO0212SPANYESJ.149 [DIRS 161274]. }\end{aligned}$} \\
\hline \multicolumn{3}{|c|}{ Output DTN: SN0409T0502203.002. } \\
\hline
\end{tabular}

\section{C6.2.3 Previously Reported Results}

Winterle and La Femina (1999 [DIRS 129796], Section 4.5) processed the long-term pumping data with AQTESOLV, and their transmissivity and storativity results (obtained with the Theis 1935 [DIRS 150327] method) are shown in Table C-11. Considering the differences in the Cooper-Jacob (1946 [DIRS 150245]) and Theis (1935 [DIRS 150327]) analysis methods, as well as differences in data reduction methods, the Winterle and La Femina (1999 [DIRS 129796], p. 4-25) transmissivities agree reasonably well with the results from the analyses shown in Table C-10. The drawdown data from the long-term pumping test in Section C4.6 and from Winterle and La Femina (1999 [DIRS 129796], p. 4-25) were also analyzed using the Theis method, and these results are reproduced in Table C-11. With the exception of WT\#3, the transmissivities are in good agreement with those of Winterle and La Femina (1999 [DIRS 129796], p. 4-25). The difference of more than a factor of 2 in the transmissivity of WT\#3 can probably be attributed to differences in data reduction methods, which lead to greater differences in parameter estimates when the overall drawdown is relatively small (as it is for WT\#3).

Table C-11. Transmissivities and Storativities of Distant Wells for the Long-Term Pumping Test

\begin{tabular}{|l|c|c|c|c|}
\hline & \multicolumn{2}{|c|}{ Winterle and La Femina (1999) $)^{\mathbf{a}}$} & \multicolumn{2}{c|}{ Based on Section C4.6 } \\
\hline \multicolumn{1}{|c|}{ Well } & $\boldsymbol{T} \mathbf{m}^{2} /$ day $)$ & $\boldsymbol{S}(-)$ & $\boldsymbol{T}\left(\mathbf{m}^{2} /\right.$ day $)$ & $\boldsymbol{S}(-)$ \\
\hline UE-25 ONC1 & 1,340 & 0.008 & 1,000 & 0.001 \\
\hline UE-25 WT\#3 & 1,230 & 0.005 & 2,600 & 0.002 \\
\hline UE-25 WT\#14 & 1,330 & 0.002 & 1,300 & 0.002 \\
\hline USW H-4 & 670 & 0.002 & 700 & 0.002 \\
\hline
\end{tabular}

a Source: Winterle and La Femina (1999 [DIRS 129796], p. 4-25).

\section{C6.2.4 ONC-1 Data}

The ONC-1 drawdown data were acquired by the Nye County Nuclear Waste Repository Project Office (NWRPO) under the NWRPO QAP, which was established to meet the requirements of American National Standards Institute/American Society of Mechanical Engineers NQA 1 and 
the criteria in 10 CFR 50 (2002 [DIRS 165855]). These data are qualified in Appendix M of this analysis report for their intended use in the determination of anisotropy in horizontal hydraulic conductivity (documented in this section of Appendix $\mathrm{C}$ and in Section 6.2.6).

\section{C6.2.5 Anisotropy Ratios}

Anisotropy ratio analyses performed for this report employ the analytical solution of Hantush (1966 [DIRS 161160]) or a modification of the analytic solution of Papadopulos (1967 [DIRS 150265]) combined with PEST (STN: 10289-5.5-00 [DIRS 161564]). The analyses of Winterle and La Femina (1999 [DIRS 129796], p. 4-24) and Ferrill et al. (1999 [DIRS 118941], p. 6) used the Papadopulos (1967 [DIRS 150265]) method. Although all techniques assume homogeneous confined aquifers with radial flow to the pumping well, some deviations from these assumptions may still yield reasonable estimates of anisotropy. In particular, these methods require as input transmissivity, storativity, and the locations of a minimum of three monitoring wells. With this information, anisotropy ratios and principal directions may be calculated. Results from all analyses are presented in Table C-12.

Using transmissivities and storativities from Table C-10 with the Hantush (1966 [DIRS 161160]) method yields an anisotropy ratio of 3.3 at principal direction $15^{\circ}$ east of north. The data from H-4 were excluded from this analysis (as they were in the Winterle and La Femina (1999 [DIRS 129796]) and Ferrill et al. (1999 [DIRS 118941]) analyses) because including the data resulted in an undefined (negative) anisotropy ratio.

In the modified Papadopulos-PEST method, three approaches were considered. In the first approach and in order to satisfy the homogeneous, anisotropic assumption of Papadopulos (1967 [DIRS 150265]), which requires that all the observation-well responses produce the same transmissivity (to honor the homogeneity assumption), Theis (1935 [DIRS 150327]) (Theis.vi V 1.0, STN: 10974-1-00 [DIRS 162758]) type-curve fits for H-4, WT\#3, WT\#14, and a Streltsova-Adams (1978 [DIRS 150754]) (Streltsova-Adams.vi V 1.0, STN: 10971-1.0-00 [DIRS 162756]) type-curve fit for ONC-1 were constrained to produce the intermediate transmissivity value of $1,000 \mathrm{~m}^{2} / \mathrm{d}$ (the nonconstrained values published in Geldon et al. (2002 [DIRS 161163], Table 9; DTN: GS030508312314.003 [DIRS 164425] ranged from $700 \mathrm{~m}^{2} / \mathrm{d}$ for $\mathrm{H}-4$ to $2,600 \mathrm{~m}^{2} / \mathrm{d}$ for WT\#3). These constrained fits produce storativities of $0.0023,0.0052$, 0.0026 , and 0.0013 for wells H-4, WT\#3, WT\#14, and ONC-1, respectively. From these constrained fits, ratios of the directional transmissivity over storativity, $T_{d} / S$, were obtained after Papadopulos (1967 [DIRS 150265]). The square roots of these ratios were plotted on a polar plot with the pumping well, c\#3, at the center.

It is important to note that while the Theis (1935 [DIRS 150327]) well function was used to develop the anisotropy ratios in this report, there is no reason why the well function cannot be replaced by another appropriate function. For example, if the medium responds as a fissure-block system, the fissure-block well function of Streltsova-Adams (1978 [DIRS 150754]) may be used. Because anisotropy analyses assume that drawdown is proportional to the well function $W(u)$ through the relation $s=(Q /(4 \pi T)) W(u)$, where $Q$ is the pumping rate, substitution of other well functions should not affect the anisotropy calculation methodology. 
The modified Papadopulos-PEST method then fits an ellipse, centered at the pumping well, through the $\left(T_{d} / S\right)^{1 / 2}$ data. This fitting was done with PEST V 5.5 (STN: 10289-5.5-00 [DIRS 161564]), in conjunction with a Microsoft Excel spreadsheet (PEST-callable Excel Spreadsheet for Anisotropy Calculations in ANL-NBS-HS-000039. ACC: MOL.20040901.0189), which calculates the shortest distance from each of the $\left(T_{d} / S\right)^{1 / 2}$ data points to the constructed ellipse (a notebook reference will be provided). PEST is instructed to vary the long and short axes of the ellipse and the principal direction to minimize the distances of all four $\left(T_{d} / S\right)^{1 / 2}$ data points from the ellipse. The ellipse in Figure C-42 is the optimal PEST ellipse. For this fit, PEST indicates that the direction of anisotropy is $79^{\circ}$ west of north (with a 95 percent confidence interval of $75^{\circ}$ to $82^{\circ}$ ), and that the magnitude of anisotropy is $3.5: 1$ (with a 95 percent confidence interval of $2.7: 1$ to $4.3: 1$ ). This direction of anisotropy is consistent with the geologic evidence of the Antler Wash series of fractures and faults running northwest from the C-wells to H-4. Two types of anisotropy are present within the study area: one is the NE-SW uniformly distributed anisotropy caused by regional stresses, and another is a NW-SE anisotropy related to the Antler Wash fault zone. The well H-4 is located along Antler Wash, northwest from the C-wells. When the well $\mathrm{H}-4$ is included in the analysis, the results are greatly affected by Antler Wash and represent the NW-SE anisotropy related to this system. When the well H-4 is not included in the analysis, the results represent the NE-SW uniformly distributed anisotropy caused by regional stresses. 


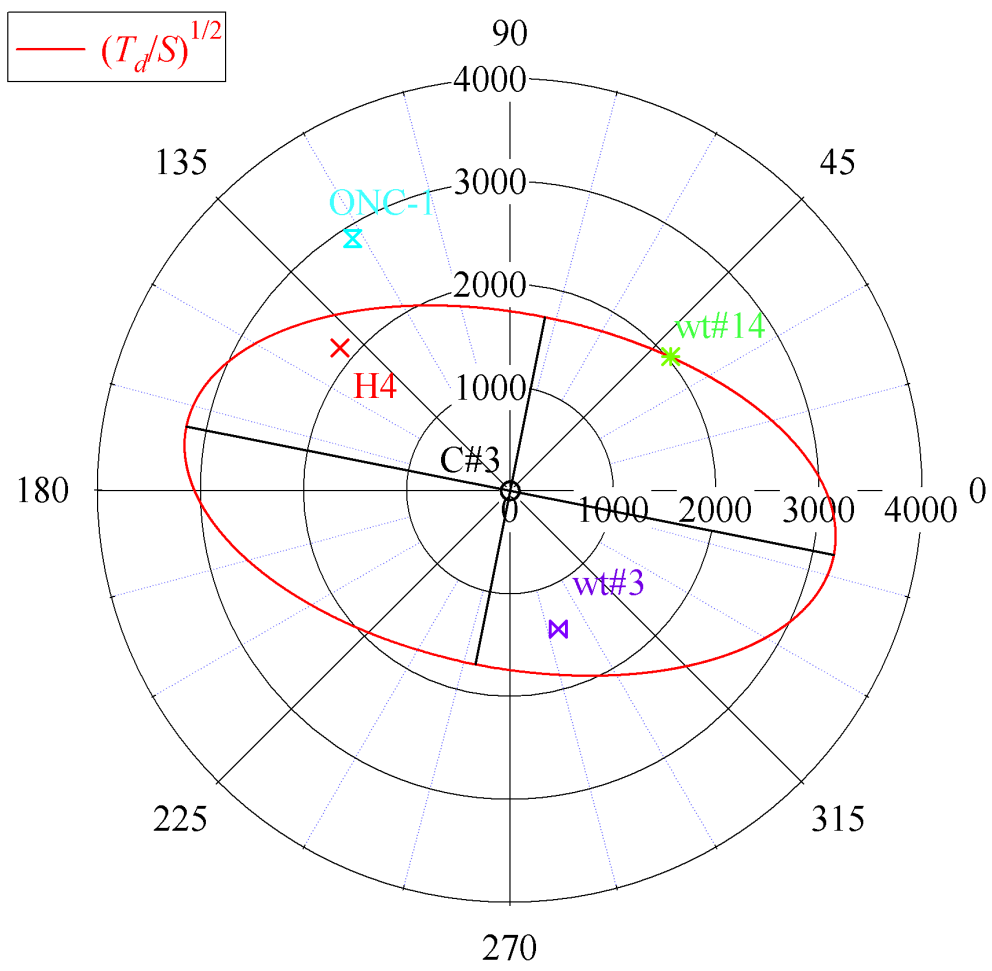

Source: DTNs: GS970308312314.002 [DIRS 161273]; MO0212SPANYESJ.149 [DIRS 161274].

Output DTN: $\quad$ GS031008312314.004.

Figure C-42. Optimal Papadopulos-PEST Ellipse Fit to the Square Root of the Ratio of Directional Transmissivity to Storativity for USW H-4, UE-25 WT\#3, UE-25 WT\#14, and UE-25 ONC-1 for the $1,000 \mathrm{~m}^{2} /$ day Transmissivity Fit for All Wells

In the second modified Papadopulos-PEST approach, an optimal PEST ellipse was obtained for the unconstrained transmissivity values from DTN: GS030508312314.003 [DIRS 164425], (published in Geldon et al. 2002 [DIRS 161163], p. 41, Table 9), although it violates the homogeneity requirement inherent in the Papadopulos (1967 [DIRS 150265]) method. The values for $T$ and $S$ are $700 \mathrm{~m}^{2} /$ day and 0.002 , respectively, for well $\mathrm{H}-4 ; 2,600 \mathrm{~m}^{2} /$ day and 0.002 for WT\#3; $1,300 \mathrm{~m}^{2} /$ day and 0.002 for WT\#14; and $1,000 \mathrm{~m}^{2} /$ day and 0.001 for ONC-1. From these nonconstrained fits, ratios of the directional transmissivity over storativity, $T_{d} / S$, were obtained following the Papadopulos (1967 [DIRS 150265]) technique. The square roots of these ratios were plotted on a polar plot with the pumping well, $\mathrm{c} \# 3$, at the center (Figure C-43). For this fit, PEST V 5.5 (STN: 10289-5.5-00 [DIRS 161564]) indicates that the direction of anisotropy is $1.1^{\circ}$ east of north (with a 95 percent confidence interval of $0.5^{\circ}$ to $1.7^{\circ}$ ) and that the magnitude of anisotropy is 5.5:1 (with a 95 percent confidence interval of 5.2:1 to 5.8:1). 


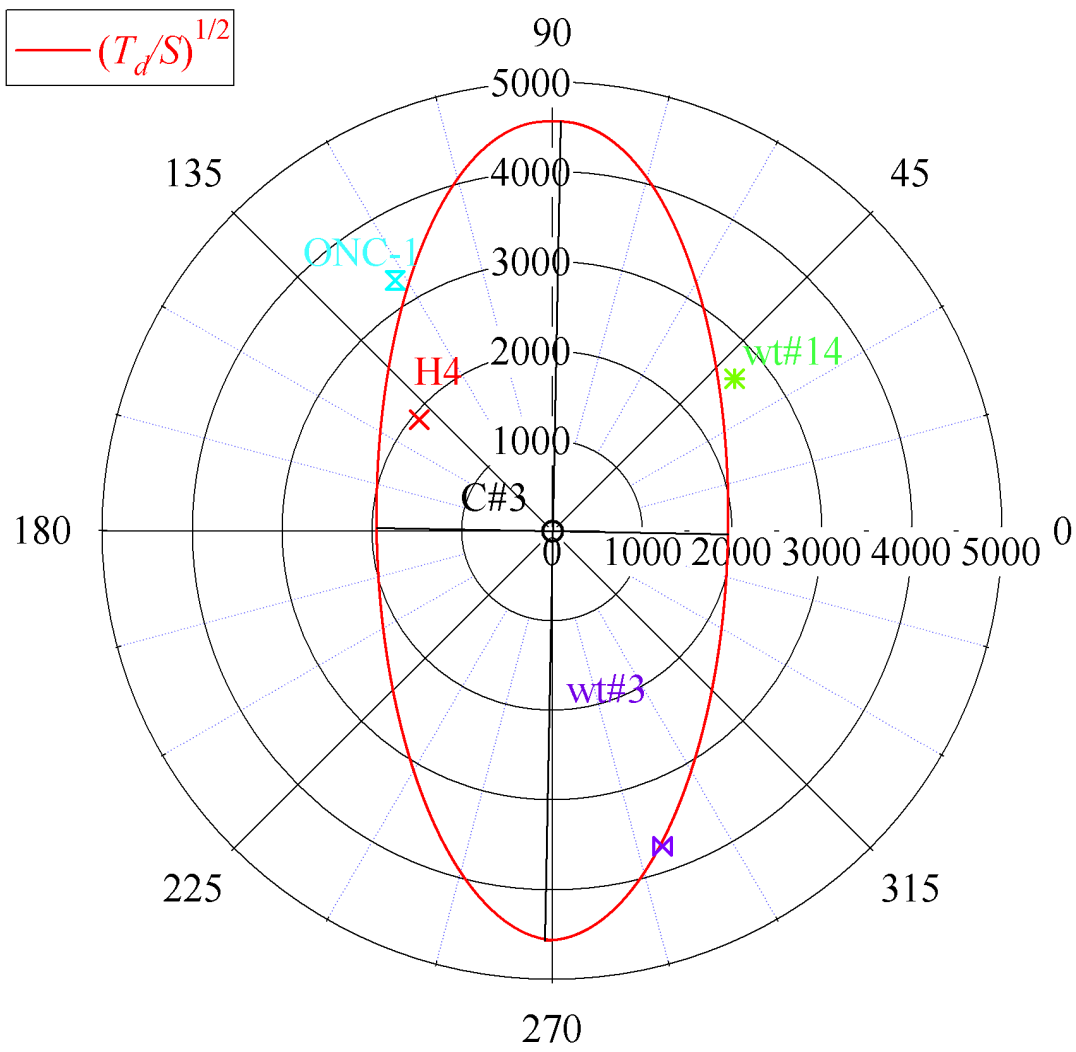

Source: DTNs: GS030508312314.003 [DIRS 164425]; MO0212SPANYESJ.149 [DIRS 161274].

Output DTN: GS031008312314.004.

Figure C-43. Optimal Modified-Papadopulos Ellipse Fit to the Square Root of the Ratio of Directional Transmissivity to Storativity for USW H-4, UE-25 WT\#3, UE-25 WT\#14, and UE-25 ONC-1 Using PEST for Variable (700 to $2,600 \mathrm{~m}^{2} /$ day, Not in Order of Listed Wells) Transmissivities for the Four Wells

In the third modified Papadopulos-PEST approach, an optimal PEST ellipse was obtained for unconstrained transmissivity values resulting from Theis (1935 [DIRS 150327]) (Theis.vi V 1.0, STN: 10974-1-00 [DIRS 162758]) type-curve fits for H-4, WT\#3, WT\#14, and Streltsova-Adams (1978 [DIRS 150754]) (Streltsova-Adams.vi V 1.0, STN: 10971-1.0-00 [DIRS 162756]) type-curve fits for ONC-1, using the filtered water-level data described in the first paragraph under Section C6.2.1. The unconstrained values for $T$ and $S$ resulting from analyzing the filtered data are $700 \mathrm{~m}^{2} /$ day and 0.0024 , respectively, for well $\mathrm{H}-4 ; 861 \mathrm{~m}^{2} /$ day and 0.0045 for WT\#3; $743 \mathrm{~m}^{2} /$ day and 0.0029 for WT\#14; and $1,230 \mathrm{~m}^{2} /$ day and 0.0012 for ONC-1. From these values, ratios of the directional transmissivity over storativity, $T_{d} / S$, were obtained after Papadopulos (1967 [DIRS 150265]). The square roots of these ratios were plotted on a polar plot with the pumping well, c\#3, at the center (Figure C-44). For this fit, PEST V 5.5 (STN: 10289-5.5-00 [DIRS 161564]) indicates that the direction of anisotropy is $34.7^{\circ}$ west of north (with a 95 percent confidence interval of $31.7^{\circ}$ to $37.7^{\circ}$ ) and that the magnitude of anisotropy is $11.3: 1$ (with a 95 percent confidence interval of 9.3:1 to 13.9:1). 


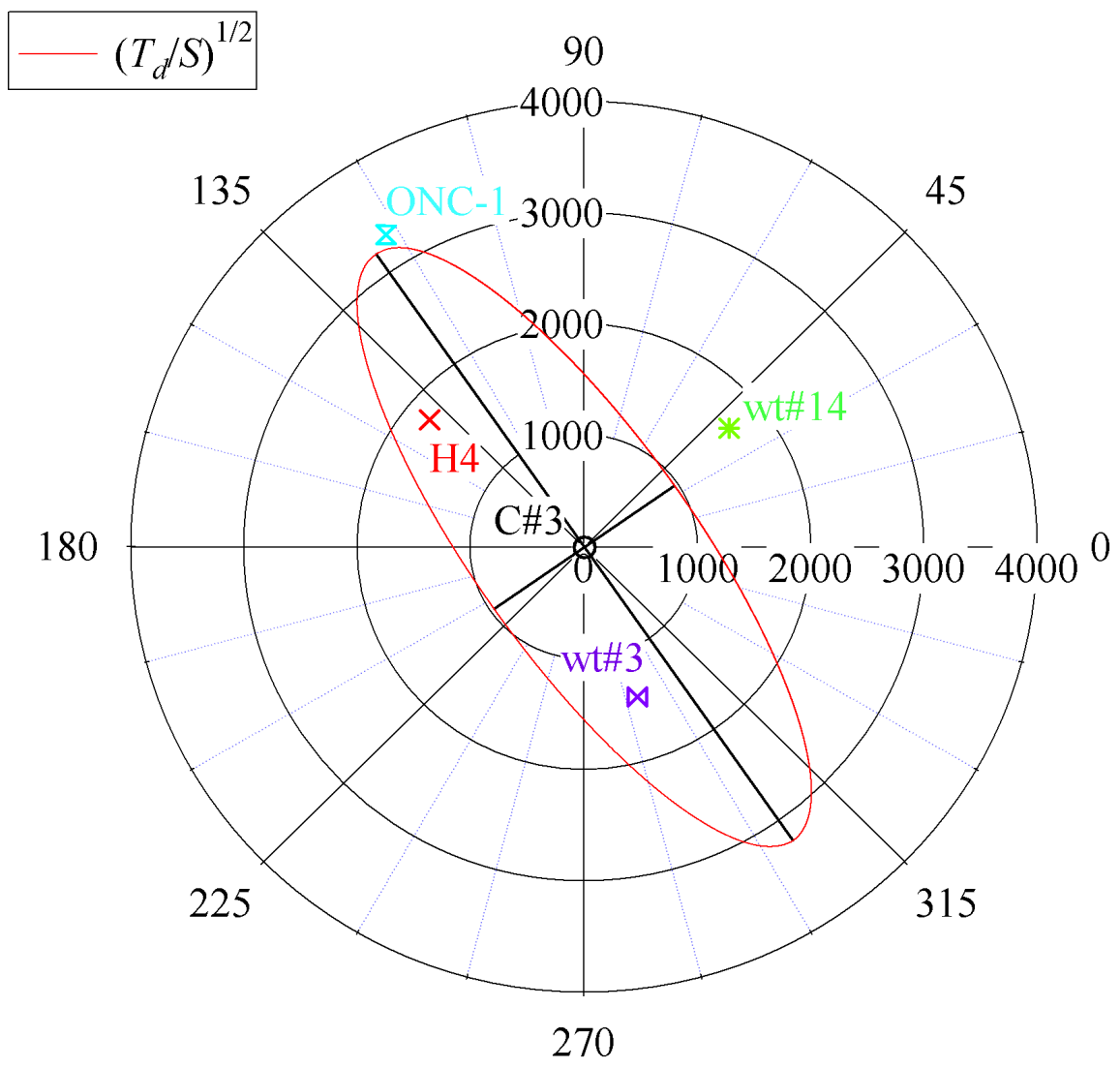

Source: DTNs: GS970308312314.002 [DIRS 161273]; MO0212SPANYESJ.149 [DIRS 161274]. Output DTN: GS031008312314.004.

Figure C-44. Optimal Modified-Papadopulos Ellipse Fit to the Square Root of the Ratio of Directional Transmissivity to Storativity for USW H-4, UE-25 WT\#3, UE-25 WT\#14, and UE-25 ONC-1, using PEST, for Variable $\left(700-1,230 \mathrm{~m}^{2} /\right.$ day) Transmissivities Obtained from Filtered Water Levels for the Four Wells

Using the analytical solution of Papadopulos (1967 [DIRS 150265]), which assumes an homogeneous, confined aquifer, Ferrill et al. (1999 [DIRS 118941], p. 7) report an anisotropy ratio of 17:1 with principal direction at azimuth $30^{\circ}$ (east of north).

The anisotropy ratio of Winterle and La Femina (1999 [DIRS 129796], p. 4-23) is listed in the last row of Table $\mathrm{C}-12$ as 5 at $33^{\circ}$ east of north. It should be noted that the difference in reported anisotropy between Ferrill et al. (1999 [DIRS 118941], p. 7) and Winterle and La Femina (1999 [DIRS 129796], p. 4-23) was solely due to a change in transmissivity for well WT\#14, which decreased from 1,370 to $1,330 \mathrm{~m}^{2} /$ day due to a difference in technique for correcting barometric pressures. The sensitivity of the analytical solution is demonstrated by the 3 percent change in transmissivity manifesting itself as a 70-percent decrease in the anisotropy ratio to 5:1.

Although not listed in Table C-12, the Hantush (1966 [DIRS 161160]) technique was applied to the transmissivities and storativities of Section C4.6 of this report, yielding an undefined anisotropy ratio (i.e., the transmissivities do not define an ellipse). However, when the modified 
Papadopulos-PEST analysis methodology was applied to these transmissivities and storativities, the anisotropy ratio was estimated as 5.5, as indicated in the third row of Table $\mathrm{C}-12$. With the varied results, it is clear that the anisotropy ratio is highly sensitive to the locations and transmissivities of the monitoring wells. Three of the principal directions of anisotropy presented in Table C-12 vary between $15^{\circ}$ and $33^{\circ}$. These values agree favorably with the geologically interpreted value of between $25^{\circ}$ and $30^{\circ}$, the principal directional trend of faults in the Yucca Mountain area. In the methods producing these values, H-4 was not included in the analysis, and, hence, the resulting anisotropy values appear to not be affected by the Antler Wash structure; rather, they may be showing the underlying uniformly distributed anisotropy.

Table C-12. Calculated and Reported Anisotropies and Principal Directions

\begin{tabular}{|c|c|c|c|c|}
\hline Data Set Used (Method) & $T_{\max }\left(\mathrm{m}^{2} /\right.$ day $)$ & $T_{\min }\left(\mathrm{m}^{2} /\right.$ day $)$ & Anisotropy $^{\mathrm{a}}$ & Azimuth $^{\mathrm{a}}$ \\
\hline Table C-10 (Hantush 1966 [DIRS 150265]) ${ }^{\text {b }}$ & 2,455 & 751 & 3.3 & $15^{\circ} \mathrm{E}$ \\
\hline$T=1,000 \mathrm{~m}^{2} /$ day $\left(\right.$ Papadopulos-PEST) ${ }^{\mathrm{b}}$ & 1,863 & 537 & 3.5 & $79^{\circ} \mathrm{W}$ \\
\hline$T=700-2,600 \mathrm{~m}^{2} /$ day $\left(\right.$ Papadopulos-PEST) ${ }^{\mathrm{b}}$ & 3,272 & 599 & 5.5 & $1^{\circ} \mathrm{E}$ \\
\hline $\mathrm{T}=700-1,230 \mathrm{~m}^{2} /$ day $\left(\right.$ Papadopulos-PEST) ${ }^{\mathrm{b}}$ & 3,047 & 271 & 11.3 & $35^{\circ} \mathrm{W}$ \\
\hline Ferrill et al. $\left(1999\right.$ [DIRS 118941\}) ${ }^{b}$ & 5,400 & 315 & 17 & $30^{\circ} \mathrm{E}$ \\
\hline 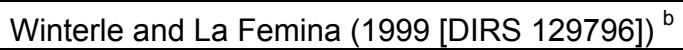 & 2,900 & 580 & 5 & $33^{\circ} \mathrm{E}$ \\
\hline
\end{tabular}

Source: DTNs: GS970308312314.002 [DIRS 161273]; MO0212SPANYESJ.149 [DIRS 161274].

Output DTNs: GS031008312314.004, SN0409T0502203.002.

${ }^{a}$ The last two columns list reported values.

${ }^{\mathrm{b}}$ For a description of the methods used, refer to Hantush (1966 [DIRS 161160]), Papadopulos (1967 [DIRS 150265]), Ferrill et al. (1999 [DIRS 118941]), and Winterle and La Femina (1999 [DIRS 129796]).

Winterle and La Femina (1999 [DIRS 129796], p. 4-25) claim a low degree of confidence in their anisotropy ratio because the problem is poorly constrained (e.g., data from only the minimum number of wells necessary for a solution is used; the medium is not homogeneous; the flow is not radial; and the aquifer may not be confined). Data from well H-4 were only used in the modified Papadopulos-PEST method. When data from H-4 were not used, it was because the transmissivity for this well was consistently about half of the other wells (note that both of the analytical solutions of Hantush (1966 [DIRS 161160]) and Papadopulos (1967 [DIRS 150265]) require that all wells have equal or nearly equal transmissivities). The rationale for excluding H-4 from the horizontal anisotropy analysis, in some cases, was also based on the Geldon et al. (1998 [DIRS 129721], p. 31) suggestion that a preferential flow path exists between well H-4 and the C-wells. However, inclusion of the H-4 data in the modified Papadopulos-PEST method and constraining the transmissivity to $1,000 \mathrm{~m}^{2} /$ day (as described above) produced a direction of anisotropy consistent with the alignment of this preferential pathway. It is also noted that after approximately 50 days of pumping, water levels in wells H-4 and WT\#14 stopped responding to pumping and actually began to increase, a phenomenon attributed to a recharge or high transmissivity boundary to the east or northeast of WT\#14, which could potentially be a transmissive fault. This water-level increase was never observed in well ONC-1, even after 237 days of monitoring. This result implies that not all of the assumptions used in the anisotropy analysis are justifiable. Overall, this conclusion should serve to underscore the level of uncertainty in reported anisotropy ratios. 
Considering the range of values demonstrated by the various anisotropy calculations, the results in Table C-12 help characterize a parameter that was not targeted explicitly for measurement when the data ultimately used to calculate it were obtained.

\section{$\begin{array}{llllll}\text { C6.3 INTERPRETATION AND ASSIGNMENT } & \text { OF THE ANISOTROPY }\end{array}$ DISTRIBUTION}

Well-test analysis is the process of estimating hydrologic parameters of interest (in this case, transmissivity and storativity) from measured drawdown data, and is known as an inverse (or parameter-estimation) problem. An inherent quality of inverse problems is that the parameters estimated via this process have some degree of uncertainty associated with their values. More importantly, when solving an inverse problem, a family of solutions should be matched to the data. Because there are typically infinitely many solutions that fit the data, reporting only a single value imparts no real information. It is much more important to examine the range of solutions and to evaluate the sensitivity of each parameter to the solution. In other words, uncertainty must be quantified. To date, there have been no attempts to assign confidence intervals to the estimated parameters. Comparing the well test results of previous researchers helps to emphasize the dependence of the estimated hydrologic parameters upon the solution technique and input data used. Analytical techniques alone cannot provide a measure of confidence in their reported solution. Therefore, it is left to scientific judgment to assign a distribution of anisotropy ratios based upon the available scientific evidence.

Practically speaking, an anisotropy ratio must be selected for each of the 200 stochastic model realizations used as input to the SZ site-scale flow model, which is implemented using the software code FEHM. Because the current version of FEHM (V. 2.20, STN: 10086-2.20-00 [DIRS 161725]) can only implement anisotropy oriented in a north-south direction, principal directions discussed above are not applicable in the model. The net result of being unable to specify a principal direction is that uncertainty in the anisotropy ratio can only increase. For example, the analytical result for anisotropy using the Cooper-Jacob (1946 [DIRS 150245]) method is 3.3 at $15^{\circ}$ east of north. A projection that orients the principal direction north-south $\left(0^{\circ}\right)$ results in a new anisotropy ratio of 2.5. As illustrated in Figure C-45, this value was calculated by dividing the maximum $y$ value on the anisotropy ellipse oriented $15^{\circ}$ east of north (horizontal blue line at top) by its maximum $x$ value (vertical green line at right). Similarly, the projected north-south anisotropy ratio for an anisotropy ratio of 5 oriented $33^{\circ}$ east of north is 1.5 . Uncertainty in the analytically calculated anisotropy ratio is propagated in the projected anisotropy ratio and magnified as a function of the uncertainty in the principal direction. In fact, this line of reasoning suggests that it is possible for the projected north-south anisotropy ratio to be significantly less than one. 


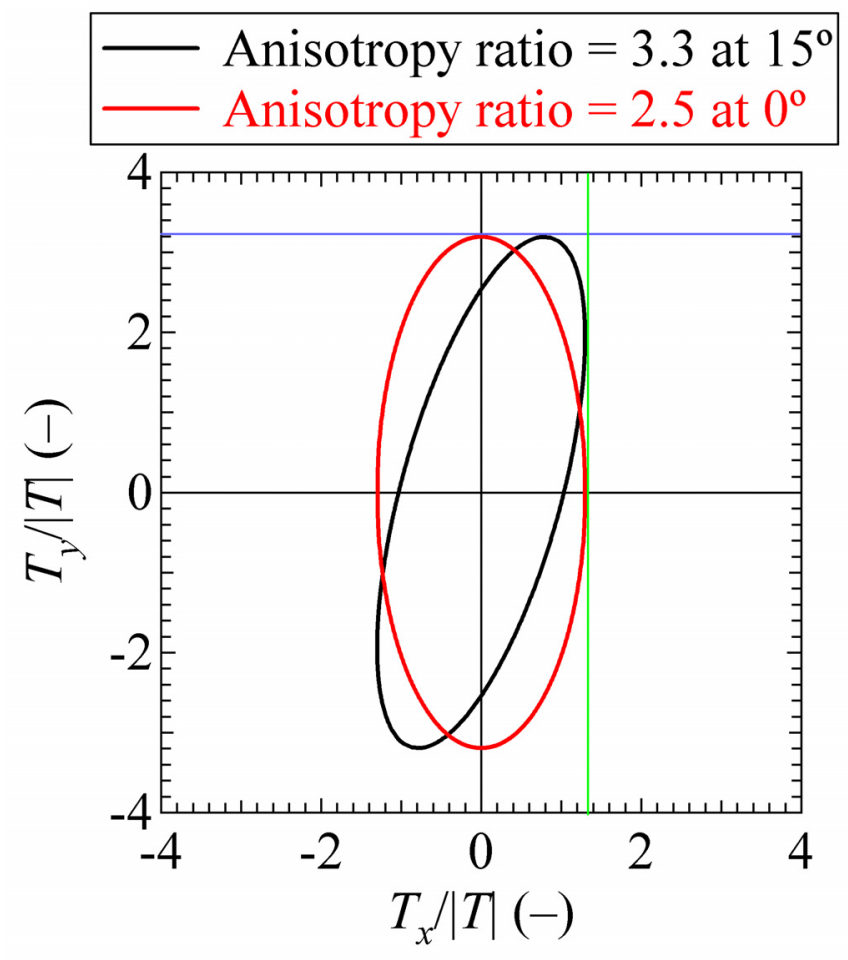

Output DTN: GS031008312314.004.

Figure C-45. Anisotropy Ratio of 3.3 at $15^{\circ}$ East of North Projected onto a North-South Anisotropy Ratio $\left(0^{\circ}\right)$ Resulting in a Projected Anisotropy Ratio of 2.5

Based on consultations between Sandia National Laboratories (SNL) staff, USGS staff, and the YMP Parameters Team, as well as results from the analytical anisotropy analyses, Figure C-46 (a) represents the best estimate of the probability density function (PDF) for the anisotropy ratio in the SZ near the C-wells complex (Eddebbarh 2004 [171918]). Figure C-46 (b) is the corresponding cumulative distribution function. 


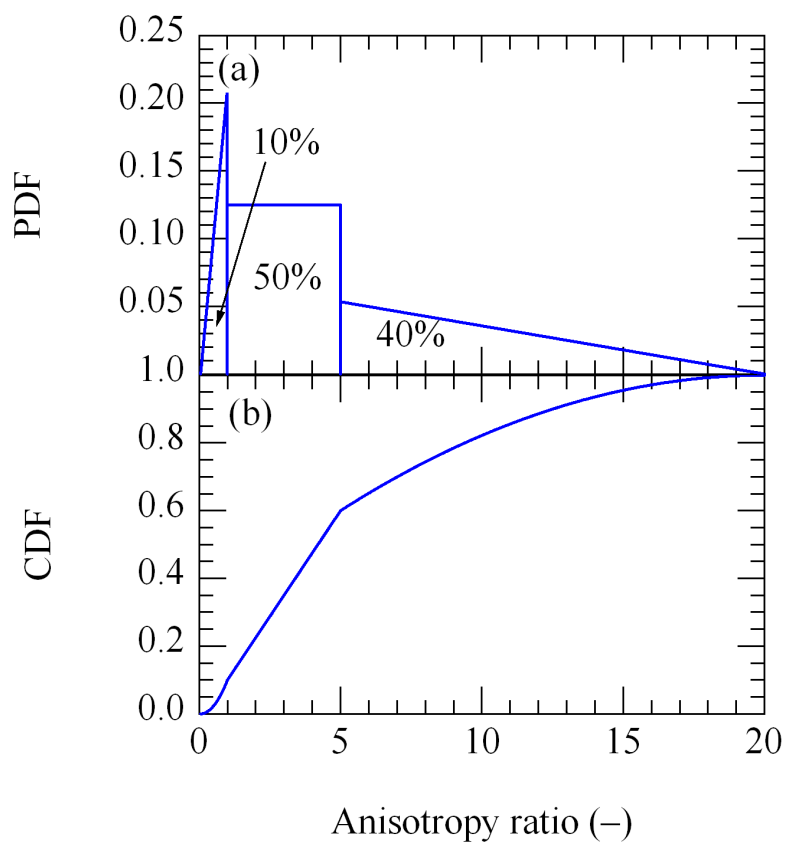

Output DTN: SN0302T0502203.001.

Figure C-46. Probability Density Function (a) and Corresponding Cumulative Distribution Function (b) for the North-South/East-West Anisotropy Ratio Used in FEHM Input Files

There are three noteworthy points based on three distinct regions of the anisotropy ratio distribution (Output DTN: SN0302T0502203.001):

- Anisotropy ratio between 5 and 20. The maximum anisotropy ratio of 20:1 is physically based. Although features such as high transmissivity zones and fractures may yield very large anisotropy ratios locally, globally, their effects are attenuated. That is, over the area of the saturated-zone model, $45 \times 30 \mathrm{~km}^{2}$, an anisotropy ratio of 20 is the expected upper bound. Additionally, the highest calculated anisotropy ratio reported is 17:1 (Ferrill et al. 1999 [DIRS 118941], p. 7). The 5.5 anisotropy ratio calculated by the second approach of the modified Papadopulos-PEST method lies in this range near its highest probability point. Therefore, between 5 and 20, a triangularly distributed anisotropy ratio is constructed that decreases to zero probability at 20 . Given that 3 of the 6 estimates of anisotropy ratio in Table 6.2-4 fall between 5 and 20, and one of these three estimates is just barely greater than 5 (5.5), a 40-percent probability is assigned to this portion of the PDF.

- Anisotropy ratio between 0.05 and 1. Discussions among Sandia National Laboratories and USGS staff established that, although it is likely the SZ is anisotropic with principal direction approximately northeast, it is possible the media could be isotropic, as well as a small probability that the principal direction could be significantly different from northeast. Correspondingly, anisotropies less than one are possible, and the minimum anisotropy ratio is set equal to the inverse of the maximum, 1:20, with a triangularly distributed 10 percent probability decreasing to zero at a ratio of 0.05 . The 
3.5 anisotropy ratio calculated by the first approach of the modified Papadopulos-PEST method, when adjusted according to Figure C-45, falls in this range.

- Anisotropy ratio between 1 and 5. A uniformly distributed 50 percent probability is assigned to the range of anisotropy ratios between 1 and 5. This interval comprises the most likely values of anisotropy ratios with no specific value more likely than another.

Figure $\mathrm{C}-46$ ( $\mathrm{a}$ and $\mathrm{b}$ ) is the best estimate for the PDF and the cumulative distribution function, respectively, of north-south anisotropy ratios in the SZ to be used as input to the SZ site-scale flow model.

\section{C6.4 FEHM SENSITIVITY STUDY}

One last point worthy of mention is that a sensitivity analysis of FEHM V 2.20 (STN: 10086-2.20-00 [DIRS 161725]) results to the anisotropy ratio demonstrated that the modeled heads are insensitive to the input anisotropy ratio. However, inferred groundwater transport times and flow pathways, which, ultimately, are more important for radionuclide transport predictions than heads, are more sensitive to the anisotropy ratio. Figure C-47 illustrates how varying the anisotropy ratio affects the weighted root-mean-square error (RMSE) between measured and FEHM modeled heads. Note that the RMSE ranges only between 6.9 and 7.6. Although this short range demonstrates relative insensitivity of the modeled heads to the anisotropy ratio, it is encouraging to note that the minimum RMSE corresponds to an anisotropy ratio of 20.

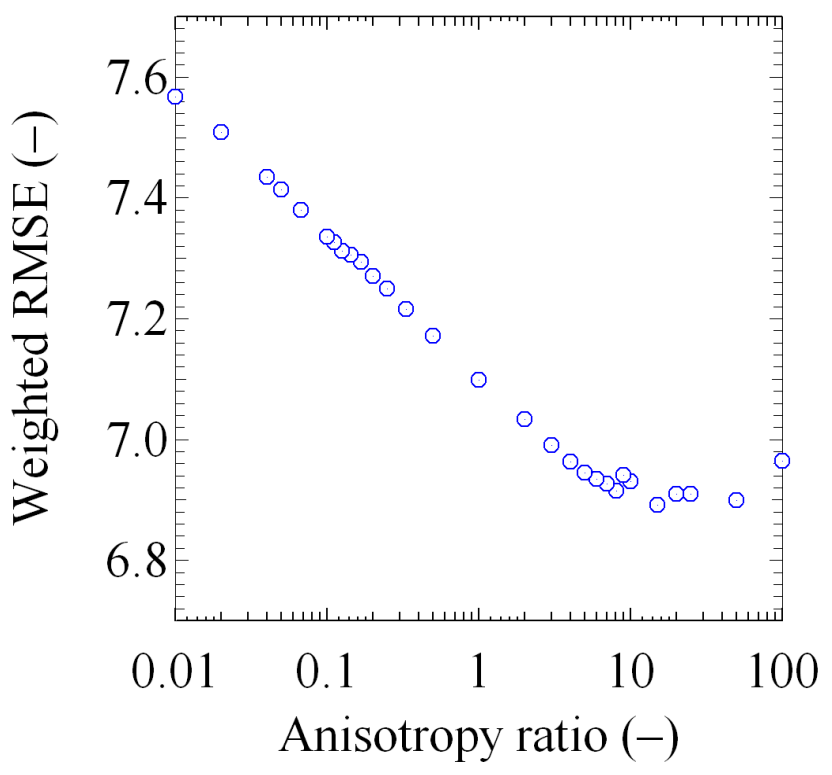

NOTE: For information purposes only.

Figure C-47. Weighted Root-Mean-Square Error (RMSE) between Measured Heads and FEHM Modeled Heads Subject to a Range of Anisotropy Ratios between 0.01 and 100 


\section{C6.5 CONCLUSIONS}

Although analytical and graphical techniques can produce a single, specific anisotropy ratio, this value is sensitive to both the solution technique and the analyst's interpretation of the data (e.g., what filtering parameters were used or how the slopes of drawdown were calculated). A wide distribution of anisotropy ratios is suggested to account for the significant uncertainty in this hydrologic property. Each run of FEHM V 2.20 (STN: 10086-2.20-00 [DIRS 161725]) must have a single value of anisotropy assigned to the anisotropy zone of the model area, and, though this is unrealistic (no single value of anisotropy truly applies to such a large heterogeneous area), drawing an anisotropy ratio from the specified distribution and running FEHM stochastically should effectively account for the uncertainty in this model parameter. Additionally, because the current version of FEHM cannot specify the principal direction of anisotropy, the range of possible north-south anisotropies is increased to consider this fact.

\section{C7. SUMMARY OF CONCEPTUAL MODELS AND PARAMETERS}

Hydraulic tests conducted by the USGS in Miocene tuffaceous rocks at the C-wells complex, Yucca Mountain, Nevada, between May 1995 and November 1997 determined flow characteristics in six saturated-zone hydrogeologic intervals. North- and northwest-striking faults intersect boreholes of the C-wells complex, defining hydrogeologic intervals by spatially related faults and fracture zones. Flow within those intervals comes from diversely oriented fractures and from the interstices of variably welded ash-flow, ash fall, and reworked tuff. The tuffs in the immediate vicinity of the $\mathrm{C}$-wells act as a single aquifer. About 70 percent of flow seen in hydraulic tests was contributed by the Lower Bullfrog interval, and another 20 percent came from the Upper Tram interval. Identified hydrogeologic units, and related hydrologic properties, cannot be extended far beyond the immediate vicinity of the $\mathrm{C}$-wells complex due to control of those intervals by fault and fracture zones.

In several hydraulic tests from 1995 to 1997, Borehole c\#3 of the C-wells complex was used as the pumping well. Boreholes c\#1 and c\#2 (tens of meters distant) were used as observation wells. Each of the wells of the complex is about $900 \mathrm{~m}$ deep, and all are open below surface casings to the penetrated formations. Additional boreholes were used as observation wells in some of the hydraulic tests, including ONC-1, H-4, WT\#14, WT\#3, and p\#1. The observation wells were completed in various intervals seen also in the holes of the C-wells complex; p\#1 was completed in Paleozoic carbonate rocks. Those observation wells were sited 630 to $3,526 \mathrm{~m}$ from $\mathrm{c} \# 3$, allowing some extrapolation of hydraulic characteristics from the $\mathrm{C}$-wells location. The hydraulic tests were conducted to determine: (1) properties of the composite saturated-zone section in the C-wells; (2) hydrologic properties of the six intervals in those holes; and (3) heterogeneity in the tuffs, including the influence of faults. Monitoring in Borehole p\#1 was intended to establish whether the tuffs are connected hydraulically to the Paleozoic carbonate rocks (a regional aquifer), estimated to lie some $455 \mathrm{~m}$ below the $\mathrm{C}$-wells.

The series of hydraulic tests began with short-term test episodes. The 10-day test of May 1995 pumped Borehole $\mathrm{c} \# 3$ at an average rate of 1,074 L/min and produced pumping-well drawdown of $7.76 \mathrm{~m}$. Drawdown in observation wells ranged from 0 to $42 \mathrm{~cm}$. The June 1995 test lasted four days and used packers to isolate the six saturated-zone hydrogeologic intervals of the C-wells complex. After pumping at a rate of 1,350 L/min, drawdown in the pumping well 
was $10.9 \mathrm{~m}$, and drawdown in monitored intervals of observation wells c\#1 and c\#2 ranged from 43 to $352 \mathrm{~cm}$. The five-day test of February 1996 used packers to isolate and pump the Lower Bullfrog and Upper Tram intervals at a rate of $510 \mathrm{~L} / \mathrm{min}$. All monitored intervals responded to that pumping. Drawdown in the pumping well was $2.86 \mathrm{~m}$, and drawdown in $\mathrm{c} \# 2$ and $\mathrm{c} \# 1$ ranged from 14 to $25 \mathrm{~cm}$.

A long-term test in which the Lower Bullfrog interval was isolated was conducted over more than 550 days starting in May 1996. All monitored intervals again responded to pumping (at a rate of $552 \mathrm{~L} / \mathrm{min}$ ). Drawdown reached nearly $6 \mathrm{~m}$ by late March 1997 when some disruption due to pump shutoffs occurred. Drawdown in all observation wells was strongly oscillatory, with peak drawdown in the C-wells complex observation holes of 35 to $51 \mathrm{~cm}$. Drawdown in distant observation wells began after hours to days of pumping and ranged from 15 to $37 \mathrm{~cm}$. No drawdown had been observed in p\#1 (completed in the carbonate aquifer) by December 1996.

In all of these tests, significant, rapid drawdown and recovery in the pumping well far exceeded amounts that could be predicted from hydrologic properties calculated from observation-well drawdown in the same tests. Much of that excess likely can be attributed to frictional head loss ("borehole skin") in the pumping well. Thus, analysis of pumping-well drawdown data may lead to misleading values for the transmissivity and hydraulic conductivity of the aquifer due to effects of turbulence in the well bore and attendant well losses.

Hydrogeologic intervals in the $\mathrm{C}$-wells exhibit layered heterogeneity. The response in the Calico Hills interval is consistent with an unconfined aquifer; responses in the Prow Pass and Upper Bullfrog intervals are consistent with either an EPM or a fissure-block confined aquifer; response in the Lower Bullfrog interval is consistent with a fissure-block confined aquifer; and the response in the Upper Tram interval is consistent with a leaky confined aquifer receiving flow from cross-cutting faults. Transmissivity increases downhole from a range of 4 to $10 \mathrm{~m}^{2} / \mathrm{d}$ in the Calico Hills interval to a range of 1,300 to $1,600 \mathrm{~m}^{2} / \mathrm{d}$ in the Lower Bullfrog interval. This trend is reversed near the bottom of the wells: i.e., in the Upper Tram Interval, transmissivity is 800 to $900 \mathrm{~m}^{2} / \mathrm{d}$. Likewise, hydraulic conductivity increases downhole from about $0.2 \mathrm{~m} / \mathrm{d}$ in the Calico Hills interval to a range of 20 to $50 \mathrm{~m} / \mathrm{d}$ in the Lower Bullfrog and Upper Tram intervals. Storativity generally increases downhole; for example, in c\#2 it increases from a range of about 0.0002 to 0.0004 in the Calico Hills and Prow Pass intervals to a range of 0.001 to 0.002 in the Lower Bullfrog and Upper Tram intervals. Order-of-magnitude differences, though, are evident between wells of the C-wells complex and nearby observation wells. These vertical distributions of hydrologic properties reflect the greater influence of faults and related fractures toward the bottom of the boreholes.

During hydraulic tests at the C-wells complex, drawdown occurred in all monitored intervals of those holes and in observation wells, regardless of the interval being pumped. The hydraulic connection across lithostratigraphic contacts likely results from interconnected faults, fractures, and intervals with large matrix permeability. The Miocene tuffaceous rocks thereby act as a single aquifer within a portion of the structural block bounded by the Paintbrush Canyon and Dune Wash faults as well as by faults cutting Boundary Ridge (extending at least as far north as lower Midway Valley). This aquifer encompasses a $21-\mathrm{km}^{2}$ area surrounding the C-wells complex. 
Drawdown data from monitored wells during the long-term hydraulic test matched the type curve for a confined aquifer and indicated a transmissivity of 2,200 $\mathrm{m}^{2} / \mathrm{d}$ and a storativity of 0.002 for the tuffs in the region around the C-wells complex. Plots of drawdown in observation wells as a function of distance during the same test showed a transmissivity of 2,100 to $2,600 \mathrm{~m}^{2} / \mathrm{d}$ and a storativity of 0.0005 to 0.002 . Analyses of drawdown in the C-wells and in outlying observation wells indicated a northwestward decrease in transmissivity from $2,600 \mathrm{~m}^{2} / \mathrm{d}$ in WT\#3 to about $2,000 \mathrm{~m}^{2} / \mathrm{d}$ at the C-wells and, eventually, to $700 \mathrm{~m}^{2} / \mathrm{d}$ in $\mathrm{H}-4$. (Hydraulic conductivity is smallest toward the crest of Yucca Mountain and toward Jackass Flats.) Distributions of drawdown likewise were influenced strongly by northwest- and north-striking faults, as was hydraulic conductivity. Drawdown in observation well ONC-1 showed a fissure-block aquifer response during the long-term test, possibly due to a northwesterly zone of discontinuous faults that extends beneath Bow Ridge and Antler Wash. Drawdown in other observation wells reached a steady state after some 50 days of pumping, again likely in response to faults and fracture zones. Hydraulic conductivity ranges areally from less than 2 to more than $10 \mathrm{~m} / \mathrm{d}$, and is largest where prominent north-striking faults are closely spaced or intersected by northwest-striking faults. Relatively large hydraulic conductivity occurs beneath Fran Ridge, Bow Ridge, and Boundary Ridge.

Collective consideration of all the $\mathrm{C}$-wells hydrologic test results suggests that the most appropriate conceptual model for flow in the saturated volcanic tuffs near Yucca Mountain is one in which flow occurs predominantly through fractures, with these fractures tending to form better-connected networks in the horizontal direction than in the vertical direction, resulting in some apparent stratification of flow (that is, greater horizontal hydraulic conductivity than vertical hydraulic conductivity). Besides hydraulic test results, other lines of evidence suggesting some degree of horizontal stratification are the significant upward vertical hydraulic gradient in the volcanic tuffs and the apparent lack of mixing of waters in the tuffs with water from the underlying carbonate aquifer at the C-wells. This upward gradient and the lack of vertical mixing, which are observed at other locations around Yucca Mountain as well, presumably could not be sustained if it were not for some confinement of flow in the vertical direction. However, hydraulic responses in intervals above and below pumped intervals at the $\mathrm{C}$-wells clearly indicate that there is some hydraulic communication vertically within the tuffs. This point is mentioned because the use of analytical solutions for confined aquifers to estimate hydrologic parameters for some intervals may give the impression that some intervals are completely confined. A more accurate conceptualization is that, over larger scales, the vertical hydraulic conductivity in the fractured tuffs is considerably smaller than the horizontal hydraulic conductivity, resulting in an effective anisotropy favoring horizontal flow over vertical flow.

Flow surveys at the C-wells and in other wells in the fractured tuffs indicate that not all fractures in the SZ contribute significantly to flow, and they also suggest that flowing intervals appear to be much less extensive in the vertical direction than the stratigraphic intervals in which they are contained. Thus, the concept of assigning bulk hydrologic properties to entire stratigraphic intervals may be somewhat misleading, and it may be more appropriate to consider the concept of flowing intervals that are spatially separated but nevertheless interconnected at larger scales. Faults undoubtedly play an important role in the larger-scale interconnectedness of flowing intervals. In addition, because faults tend to be steeply dipping near Yucca Mountain, they may have an important influence on effective hydrologic properties in the vertical direction over large scales in the SZ. 
Uncertainties in hydrologic parameter estimates, including uncertainties associated with the data-analysis methods, are discussed in detail in Section C5. When all of the contributing uncertainties are considered, storativity and transmissivity estimates are considered accurate to within one significant figure. Hydraulic conductivity estimates are considered to be somewhat less accurate because of the inherent uncertainty in the assumed transmissive thickness of a given test interval.

The responses of WT\#3, WT\#14, ONC-1, and in some cases H-4, to the long-term hydraulic test were analyzed for anisotropy of the hydraulic conductivity. When $\mathrm{H}-4$ was not included in the analysis, the principal directions of anisotropy vary between $15^{\circ} \mathrm{E}$ and $33^{\circ} \mathrm{E}$. These values agree favorably with the geologically interpreted value of between $25^{\circ} \mathrm{E}$ and $30^{\circ} \mathrm{E}$, the principal directional trend of faults in the Yucca Mountain area. Because the methods producing these values do not include $\mathrm{H}-4$ results, the resulting anisotropy values do not appear to be affected by the northwesterly trending Antler Wash structure; rather, they may be showing the underlying uniformly distributed anisotropy. When H-4 was included in the analysis of anisotropy, the influence of the northwesterly trending Antler Wash structure is seen, and the resulting principal directions of anisotropy range from $79^{\circ} \mathrm{W}$ to $1^{\circ} \mathrm{E}$.

Based on these analyses, a PDF was derived for north-south/east-west anisotropy in horizontal hydraulic conductivity in the fractured volcanics (Figure C-46). This PDF reflects the uncertainty in horizontal anisotropy associated with the analysis of the long-term hydraulic test data. The PDF assigns a probability of 0.9 to a north-south orientation of the anisotropy "ellipse," with a 0.5 probability of the anisotropy ratio ranging from 1 to 5 and a 0.4 probability of the ratio ranging from 5 to 20 . Although this is a relatively wide range of possible anisotropy ratios, flow simulations indicated little sensitivity of modeled heads to the full range of ratios. However, flow rates would be expected to be more sensitive to the assumed anisotropy ratio, and the range of specific discharges used in performance assessments reflect this uncertainty. 
APPENDIX D

DETAILS OF TRACER TESTING AND TRACER TEST INTERPRETATIONS AT THE C-WELLS COMPLEX 


\section{D1. NONSORBING TRACER TESTS AT THE C-WELLS}

Nonsorbing tracer tests conducted at the C-wells complex included: (1) iodide injection into the combined Bullfrog-Tram interval; (2) injection of pentafluorobenzoic acid (PFBA) into the Lower Bullfrog interval, (3) injection of iodide into the Lower Bullfrog interval; (4) injection of 2,6 Difluorobenzoic acid (DFBA) into the Lower Bullfrog interval; (5) injection of 3-carbamoyl-2-pyridone (Pyridone) into the Lower Bullfrog interval; (6) injection of iodide and 2,4,5 trifluorobenzoic acid (TFBA) into the Prow Pass formation; and (7) injection of 2,3,4,5 tetrafluorobenzoic acid (TeFBA) into the Prow Pass formation.

The purpose of testing with nonsorbing tracers was to obtain estimates of flow porosity and longitudinal dispersivity of the Bullfrog and the Prow Pass Tuffs. The approach to developing parameters was to conduct multiple tests in a cross-hole system and use different mathematical solutions to interpret the results. Consequently, uncertainties and the sensitivity of the system were better understood.

Iodide, benzoic acids (including DFBA, TFBA, TeFBA, and PFBA), and pyridone can be analyzed by high-performance liquid chromatography (HPLC) with either ultraviolet (UV) absorbance detection or fluorescence detection (pyridone). This method was selected not only because it is precise and sensitive but also because the groundwater samples can be injected directly into the instrument, allowing analyses to be conducted easily in the field for immediate test results.

All nonsorbing tracer tests were analyzed by the Moench (1989 [DIRS 101146]; 1995 [DIRS 148784]) single- and dual-porosity analytical solutions to the advection-dispersion equation or by superposition of these solutions. Both solutions are implemented using the MOENCH.vi Function(1) code in conjunction with the rcv2amos.exe routine (STN: 10583-1.0-00 [DIRS 162750]) and the MOENCH.vi, Function(2), V 1.0 code (STN: 10582-1.0 [DIRS 162752]). The first software package implements the published dimensionless solutions. The second allows for curve matching to actual, dimensional, tracer breakthrough curves. The input parameters required by the Moench single-porosity and dual-porosity solutions are:

- Production rate, $q_{\mathrm{o}}(\mathrm{L} / \mathrm{min})$

- Distance from the production to injection well, $r_{\mathrm{L}}(\mathrm{m})$

- Aquifer thickness, $h(\mathrm{~m})$

- Radius of production well, $r_{\mathrm{w}}$; and injection well, $r_{\mathrm{i}}(\mathrm{m})$

- Thickness where mixing occurs in the production well, $h_{\mathrm{w}}(\mathrm{m})$

- Thickness where mixing occurs in the injection well, $h_{\mathrm{i}}(\mathrm{m})$

- Mass of tracer injected, $M(\mathrm{~g})$ 
- Volume of water in which the mass of tracer is dissolved prior to entering the aquifer, $V(\mathrm{~L})$

- Time for the tracer slug to enter the aquifer, $t_{\text {inj }}(\mathrm{sec})$

- Flow porosity, $\phi_{\mathrm{f}}$, and matrix porosity, $\phi^{\prime}$ (matrix porosity is also referred to, interchangeably, as "storage porosity" in Appendix B)

- Longitudinal dispersivity, $\alpha_{\mathrm{L}}$, in the form of a Peclet number $\left(P e=r_{\mathrm{L}} / \alpha_{\mathrm{L}}\right)(\mathrm{m})$

- Retardation coefficients representing linear, reversible adsorption $R$ in the fractures and $R^{\prime}$ in the matrix (always assumed to be 1.0 for conservative tracers).

- Dimensionless diffusion coefficient, Gamma, which is a function of the effective coefficient of diffusion from the fractures into the matrix, $D^{\prime}$, and of $h, \phi_{\mathrm{f}}, R, q_{\mathrm{o}}$, and the radius, $b^{\prime}$, of theoretical sphere-shaped matrix blocks of the dual-porosity aquifer

- Dimensionless storage parameter, Sigma, which is a function of $\phi_{\mathrm{f}}, \phi^{\prime}, R$, and $R^{\prime}$

- Dimensionless skin parameter, $S K$, which is a function of the mass transfer coefficient, $k_{\mathrm{s}}$, representing the continuity of diffusive flux across the "skin" (such as mineral fracture-surface coatings separating fractures from matrix blocks), and of $D^{\prime}$ and $b^{\prime}$.

In a radially convergent flow field, the volume of interest is a cylinder centered at the production borehole and extending to the injection borehole. Moench (1989 [DIRS 101146]) assumes that the injection borehole is well mixed and that the tracer is distributed over a specified fraction of the borehole interval length (i.e., the "mixing length").

Radially convergent, flow-type curves were generated for a range of Peclet numbers. These single-porosity and dual-porosity type curves are in the form of log-log plots of dimensionless concentration, $C_{\mathrm{D}}=\mathrm{C} / \mathrm{Ci}$, where $\mathrm{Ci}=$ average concentration in injection borehole after tracer injection, versus dimensionless time, $t_{\mathrm{D}}=\mathrm{t} /\left(\pi h \phi\left(r_{\mathrm{L}}{ }^{2}-r_{\mathrm{W}}{ }^{2}\right) / q_{\mathrm{o}}\right)$, where the denominator is referred to as the advective transport time, $\mathrm{t}_{\mathrm{a}}$. The observed field tracer breakthrough data are presented in the form of log-log plots of normalized concentration, $C / C_{\max }$ (where the concentration is normalized by the maximum observed concentration), versus time since injection. By overlaying the type curve and dimensionless breakthrough curve and matching the rising portions of the two curves, an estimate of the advective transport time, $t_{\mathrm{a}}$, is obtained when the match point $\left(C_{\mathrm{D}}=1\right.$, $\left.t_{\mathrm{D}}=1\right)$ is projected onto the log-time axis of the dimensionless field breakthrough curve (e.g., Figure D-1, which shows this process for the tracer test described in Section D1.1.1). In addition, because dimensionless time is defined as the ratio of time since injection to the advective transport time, the value of ta is equal to the time since injection, indicated on the time axis of the breakthrough curve, corresponding to $t_{\mathrm{D}}=1$. The Peclet number is also estimated based on the type curve match. In the dual-porosity solution, diffusion is minimal on the rising limb of the breakthrough curve, but it was calculated on the falling limb. The tail of the observed data was matched to a theoretical dual-porosity breakthrough curve with diffusion processes in which the controlling parameters include the Gamma and Sigma terms. The physical parameters that are estimated are the matrix porosity, $\phi$, and the dimensionless diffusion coefficient, Gamma. 


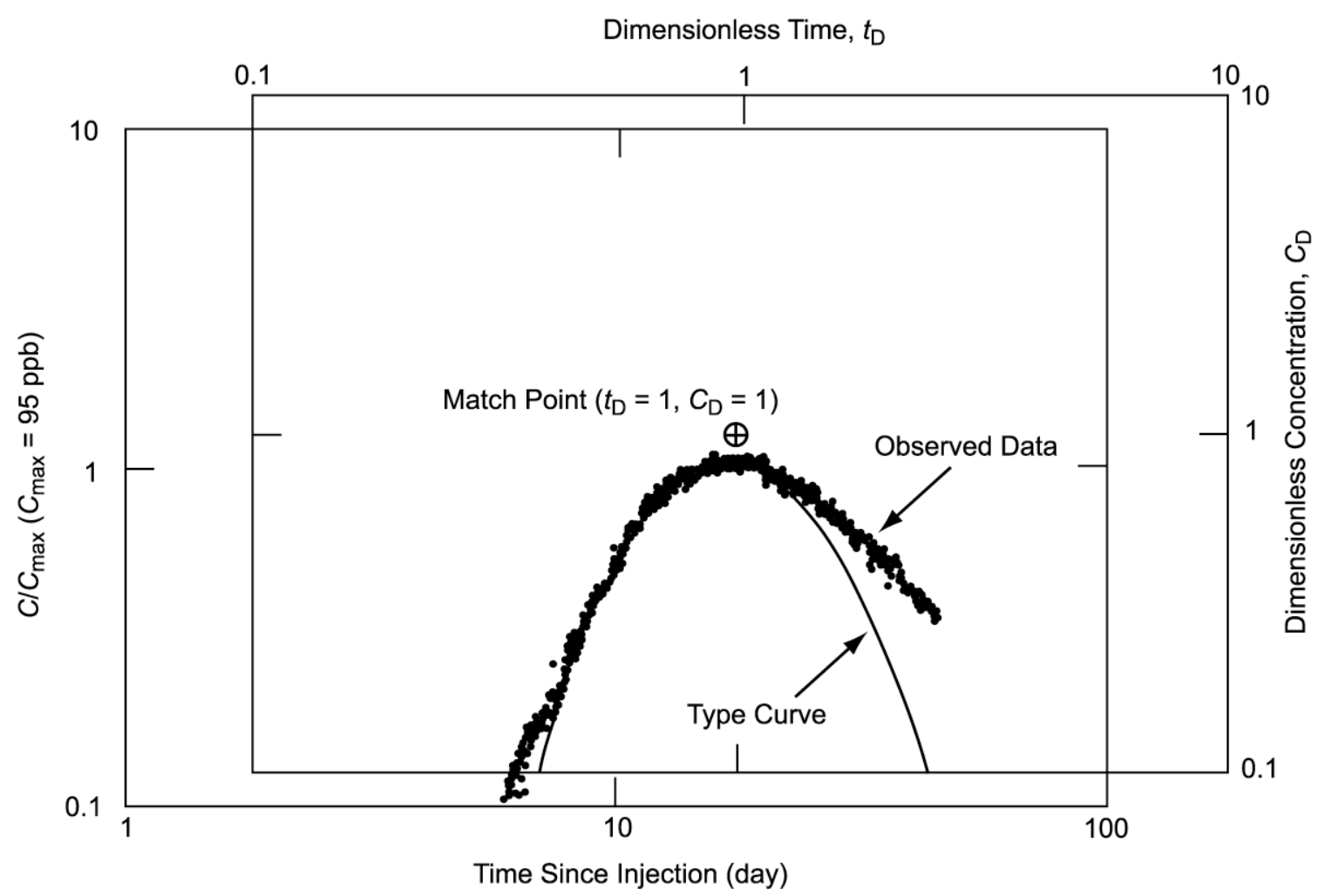

Source: DTN: GS960808312315.001 [DIRS 159235] (data).

Output DTN: GS031008312315.002 (analysis).

NOTE: The Peclet number $P e=11$.

Figure D-1. Type-Curve Match for lodide Injection into UE-25 c\#2

Some of the analyses of nonsorbing tracer tests in this report used the single-porosity Moench solution, some used the dual-porosity solution, and some used a combination of both, depending on the type of test. This was done to explore the effectiveness of a particular solution method in matching a particular set of data. When both the single- and dual-porosity solutions were used, the $t_{a}$ and Peclet number were first obtained from the match of the single-porosity type curves to the rising limb of the data curve; then Moench's dual-porosity solution was used to obtain estimates of Gamma and Sigma by fitting to the whole data curve.

To constrain the range of parameter values (such as of flow porosity) that can result from various possible interpretations of tracer tests, the fracture characteristics of the formations in which tracer testing was conducted should be considered. Fracture orientations in the Lower Bullfrog were based on televiewer data reported by Geldon (1996 [DIRS 100396], pp. 14 to 17, Table 6) and obtained in the 1980s when the boreholes were drilled. Two orientations are statistically significant. The dip and strike of the fracture planes are: 77/167 and 78/191 (first number is degrees from horizontal, and second number is degrees from due north in a clockwise direction; the two orientations are shown in Figure D-2, relative to the sides of the C-wells triangle). The fractures at the C-wells complex are moderately to steeply inclined, trend in a northerly direction, and have a probable nonuniform spacing. If transport is along fractures and faults, then the orientation data represent the possible directions of transport that may be occurring at the small scale in any interpretation. 


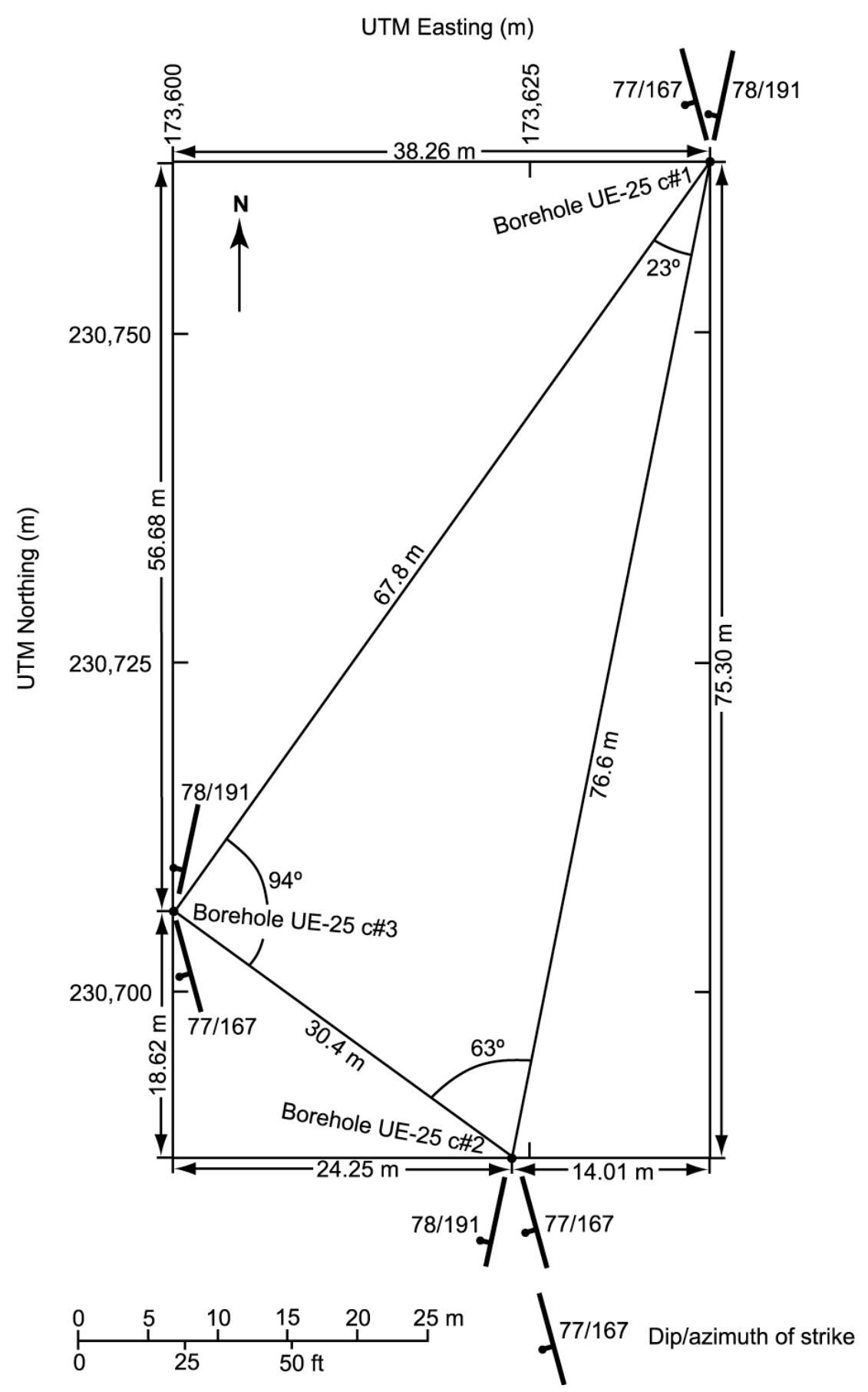

Source: Geldon (1993 [DIRS 101045], p. 6 for well locations); Geldon (1996 [DIRS 100396], pp. 74 to 119 for fracture information).

Figure D-2. Dominant Bullfrog Tuff Fracture Sets in Each of the C-wells 


\section{D1.1 RESULTS AND INTERPRETATIONS OF NONSORBING TRACER TESTS: BULLFROG AND TRAM FORMATIONS}

\section{D1.1.1 Iodide Tracer Test in the Lower Bullfrog/Upper Tram Interval}

Following establishment of a quasi-steady-state hydraulic gradient by pumping the recovery borehole (c\#3) for about 7,000 minutes, the first convergent tracer test at the C-wells complex was initiated in the Bullfrog-Tram Tuff interval on February 13, 1996, under convergent flow field conditions (Umari 2002 [DIRS 162858], Binder 4, Section F-12; Binder 5, Sections G-4 to G-12, H-1 to H-7; Binder 6, Sections H-1 to H-7, H-10 to H-11). Tracer solution was injected into the Bullfrog-Tram interval of Borehole $\mathrm{c \# 2}$ for 28 minutes at an average rate of 24.6 (liters per minute $[\mathrm{L} / \mathrm{min}])$ (6.5 gallons per minute $[\mathrm{gpm}])$. This test was conducted in the most transmissive interval in the C-wells (the Bullfrog-Tram interval), over the shortest interborehole distance (from Borehole $\mathrm{c} \# 2$ to Borehole $\mathrm{c} \# 3$ ), and using the simplest flow field (a convergent flow field) to enhance the possibility of successful tracer recovery.

The tracer solution consisted of 5.9 kilograms $(\mathrm{kg})$ of sodium iodide (of which $5 \mathrm{~kg}$ were iodide) dissolved in 500 liters (L) (132 gallons) of water from Borehole c\#3 (Umari 2002 [DIRS 162858]). The tracer solution was chased with $182 \mathrm{~L}$ (48 gallons) of water from c\#3, which was pumped into Borehole $\mathrm{c} \# 2$ to ensure evacuation of the injection string (Umari 2002 [DIRS 162858]).

The chemical constituent used as a tracer was iodide with an injection concentration of 10,200 parts per million (ppm). The iodide injection from $\mathrm{c} \# 2$ on February 13, 1996, has been discussed by Fahy (1997 [DIRS 137456], second and third unnumbered pages). Iodide concentrations in water sampled during the tracer test were obtained by a reverse-phase, HPLC in conjunction with a UV-absorption detector (Stetzenbach and Thompson 1983 [DIRS 156863], pp. 36 to 41). The field-determined detection limit for iodide was $3 \mu \mathrm{g} / \mathrm{L}$. The precision of the HPLC analytical technique, as determined by comparing replicate analyses, was 2.3 percent for the field-determined concentrations and 1.61 percent for laboratory-determined concentrations.

Iodide breakthrough occurred 5.07 days after injection. The peak concentration occurred 17.75 days after injection. The test was terminated 45.1 days after injection. The iodide mass recovered was estimated as $2.347 \mathrm{~kg}, 47$ percent of the injected mass (Fahy 1997 [DIRS 137456], second and third unnumbered pages).

The tracer test was complicated by progressively decreasing discharge from the recovery well, which was caused by a mechanically failing pump. The pump discharge decreased from $510 \mathrm{~L} / \mathrm{min}$ (134.7 gpm) on February 13, 1996, to $372 \mathrm{~L} / \mathrm{min}$ (98.3 gpm) on March 29, 1996. For analysis of the tracer test, the median value of $444 \mathrm{~L} / \mathrm{min}(117.3 \mathrm{gpm})$ was used as the discharge rate (the decline in discharge rate was approximately linear with time and the discharge measurements were obtained at equal time increments, so the median and mean of all measurements were essentially the same). Despite these problems, a breakthrough curve, with breakthrough and peak arrival times readily discernible, was clearly established by March 29, 1996. 


\section{Interpretation of Test}

Both the single- and dual-porosity Moench (1989 [DIRS 101146]; 1995 [DIRS 148784]) solutions were used to interpret the iodide test in the Bullfrog-Tram interval. The rising limb was first analyzed using the single-porosity solution, as presented in Figure D-1, to obtain the flow porosity and Peclet number. The dual porosity solution was then used with these parameter values to fit the whole curve and obtain the matrix porosity. Input parameters and results are the following:

- Discharge equal to the median value of $444 \mathrm{~L} / \mathrm{min}$ (117.3 gpm)

- Aquifer thickness equal to the transmissive thickness of the Bullfrog-Tram interval between Boreholes $\mathrm{c} \# 2$ and $\mathrm{c} \# 3$ (168 ft $(51.2 \mathrm{~m})$. Note that the transmissive thickness is less than the average packed-off interval thickness because significant water production occurred over only a fraction of the total interval thickness, as previously reported in Geldon (1996 [DIRS 100396], pp. 12 to 20). This test, the 2,6 DFBA test in the lower Bullfrog interval (Section D1.1.2), and the pyridone test in the lower Bullfrog interval (Section D1.1.3) were the only tracer tests in which the aquifer thickness was assumed to be less than the total interval thickness on the basis of flow logging information.

- Peclet number of 11 to 12 , which corresponds to a longitudinal dispersivity of approximately $2.5 \mathrm{~m}$

- Advection transport time of 17.75 days (calculated from peak concentration; Figure D-1)

- The flow porosity, $\phi_{\mathrm{f}}$, was estimated as 0.086 . This porosity estimate is high if only fractures are considered as the flow pathways. Typical fracture porosities are of the order of 0.01 maximum (Freeze and Cherry 1979 [DIRS 101173], p. 408)].

- The complete curve match (Figure D-3) results in an estimate of the matrix porosity of 0.19 .

The high flow porosity values above indicate that either (1) a composite flow pathway occurred for the iodide (a combination of both fractures and matrix), or (2) flow heterogeneity resulted in much longer transport times than would be expected under ideal radial convergent flow conditions in a homogeneous, isotropic medium. In the first case, the solute is hypothesized as traveling through a connected-fracture-network segment, then through a segment of matrix until it reaches the next connected-fracture-network segment. In the second case, flow to the production well is seen as being nonuniformly distributed in the flow domain, with a relatively small amount of flow coming from the direction of the injection well. The matrix porosity estimated is reasonable, based on geophysical logging conducted at the C-wells complex (Geldon 1996 [DIRS 100396], pp. 12 to 69).

The software program PEST V 5.5 (STN: 10289-5.5-00 [DIRS 161564]) was used to corroborate tracer solution results and to obtain optimal parameter values based on the iodide test results. The PEST optimization started with the visual graphical match to the breakthrough curve presented in Figure D-3 for which Pe $=11, \mathrm{Sigma}=2.0$, and Gamma $=0.04$. Three PEST 
runs were conducted with each of these parameters changed from the above values while the others were held constant. In the first run, PEST was given Pe $=11$, Sigma $=1.0$ (intentionally "perturbed" from its good-visual-fit value of 2.0), and Gamma $=0.04$; PEST was allowed to change only Sigma. At the end of this run, PEST converged on an optimal value of Sigma = 1.7175 and an associated confidence interval for Sigma. In the second run, PEST was given the values $P e=8$ (intentionally perturbed from its good-visual-match value of 11 ), Sigma $=1.7175$, and Gamma $=0.04$; PEST was allowed to change only Pe. At the end of this run, PEST converged on an optimal value of $\mathrm{Pe}=11.478$ and an associated confidence interval for Pe. In the third run, PEST was given the values $\mathrm{Pe}=11.478$, Sigma $=1.7175$, and Gamma $=1.0$ (intentionally perturbed from its good-visual-fit value of 0.04); PEST was allowed to change only Gamma. At the end of this run, PEST converged on an optimal value of Gamma $=0.03565$ and an associated confidence interval for Gamma. The above optimal values, their associated confidence intervals, and the fit to the actual breakthrough curve that they produce are presented in Figure D-4.

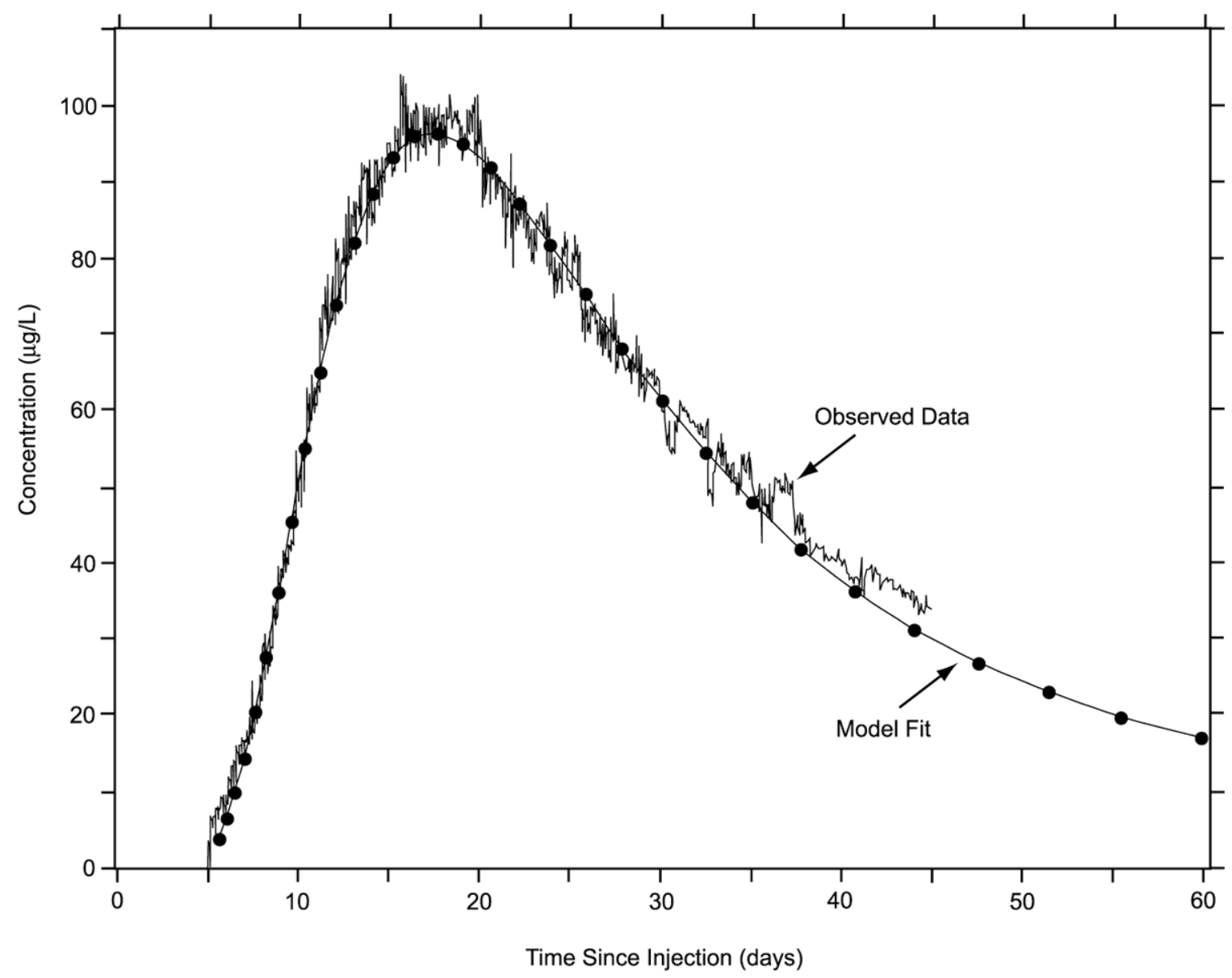

Source: DTN: GS960808312315.001 [DIRS 159235] (data).

Output DTN: GS031008312315.002 (analysis).

NOTE: Estimated parameters are Peclet number, $\mathrm{Pe}=11$; dispersivity, $\alpha \mathrm{L}=2.6 \mathrm{~m}(8.5 \mathrm{ft})$; flow porosity, $\phi_{\mathrm{f}}=0.086$; and matrix porosity, $\phi^{\prime}=0.19$. The dots on the model fit curve have no significance. ("Model fit" refers to the match of the analytical solution to the data.)

Figure D-3. Preliminary Moench Analytical Solution Fit for lodide Injection in UE-25 c\#2 


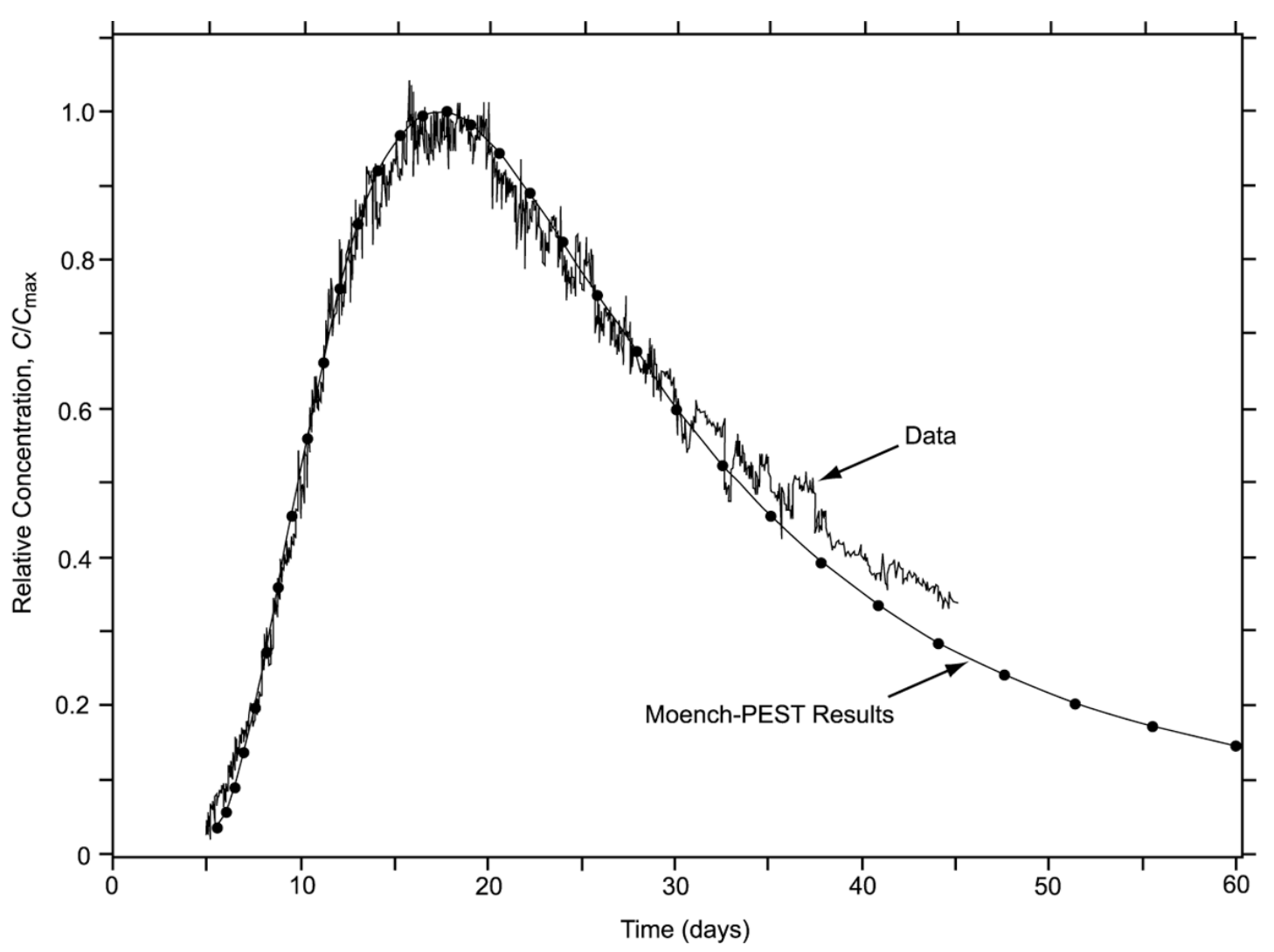

Source: DTN: GS960808312315.001 [DIRS 159235] (data).

Output DTN: GS031008312315.002 (analysis).

NOTE: The breakthrough curve was matched by the PEST V 5.5 (STN: 10289-5.5-00 [DIRS 161564]) program with initial estimates from a manual match. The optimal PEST results, with 95 percent confidence intervals in parentheses, are $\mathrm{Pe}=11.478(11.2276-11.7284), \mathrm{R}=1.0$, Sigma $=1.71746(1.4353-1.99962)$, and Gamma $=0.0356464(0-0.12744)$, and the other estimated parameters are dispersivity $\alpha \mathrm{L}=2.52 \mathrm{~m}(8.28 \mathrm{ft})$, flow porosity $\phi f=0.087$, and matrix porosity $\phi^{\prime}=0.163$. The dots on the model fit curve have no significance.

Figure D-4. Breakthrough Curve for February 13, 1996, lodide Tracer Test

The visual graphical match and the optimized PEST V 5.5 (STN: 10289-5.5-00 [DIRS 161564]) parameters are in good agreement. The Peclet number and dispersivity estimates vary by approximately 4 percent, as can be seen by comparing the values listed in the notes under Figures D-3 and D-4. The flow porosity estimates vary by less than 1 percent. The visual-graphical-match matrix-porosity estimate is 0.19 , and the PEST estimate is 0.163 .

The difference in values is attributed to the different weights assigned to fitting/matching portions of the breakthrough curve. The rising limb is used exclusively in the visual graphical match to estimate the Peclet number and the advective transport time, and then the advective transport time is used to estimate the flow porosity. The PEST V 5.5 (STN: 10289-5.5-00 [DIRS 161564]) approach uses all of the data, both rising- and falling-limb, and optimizes the fit to these data. This results in a slightly different fit than the visual graphical match. Tables D-2 and D-3 in Section D3 (summary section) list the parameter values obtained from all of the nonsorbing tracer testing described in Section D1. 


\section{D1.1.2 Difluorobenzoic Acid Tracer Test in the Lower Bullfrog Interval}

On January 10, 1997, a purely convergent conservative tracer test was initiated from c\#2 to c\#3 in the Lower Bullfrog interval at an average rate of $568 \mathrm{~L} / \mathrm{min}$ (Umari 2002 [DIRS 162858] Binder 7, Sections J-6 to J-12, K-1 to K-9; Binder 8, Sections J-6 to J-12, K-1 to K-9; Binder 9, Sections J-6 to J-12, K-1 to K-9, K-11 to K-12, L-3). Approximately $11.35 \mathrm{~kg}$ of 2,6 DFBA mixed with $795 \mathrm{~L}$ (210 gallons) of $\mathrm{c \# 3}$ water were injected into the Lower Bullfrog Tuff in Borehole c\#2, followed by 238 L (62.9 gallons) of chase water. A total of 1,798 L (475 gallons) of fluid was injected, the first portion of which was the fluid in the injection string preceding the injectate solution. The average injection rate was $31.2 \mathrm{~L} / \mathrm{min}(8.2 \mathrm{gpm})$, with a range of 28.8 to $33.0 \mathrm{~L} / \mathrm{min}$ (7.6 to $8.8 \mathrm{gpm}$ ). The average progressive-cavity pump (injection pump) pressure measured at the surface was 1.541 megapascals (MPa) (223.6 psi), with a range of 1.5 to 1.6 MPa (215 to $230 \mathrm{psi}$ ). The chemical constituent used as a tracer in this test was 2,6 DFBA. Chemical analysis indicated that the 2,6 DFBA injectate solution had a concentration of $15,560 \mathrm{mg} / \mathrm{L}$. The field-determined detection limit for DFBA was $40 \mu \mathrm{g} / \mathrm{L}$. The precision of the HPLC analytical technique, as determined by comparing replicate analyses, was \pm 10 percent.

Breakthrough occurred at c\#3 on January 15, 1997, 5.07 days after injection. The peak concentration occurred 13.5 days after injection. The mass recovered is estimated as $7.6 \mathrm{~kg}$, which is approximately 67 percent of the injected mass (Fahy 1997 [DIRS 162811]).

\section{Interpretation of Test}

Interpretation of the DFBA test using the Moench (1995 [DIRS 148784]) dual-porosity analytical solution for radially convergent flow produced the following results.

- Discharge rate and transmissive thickness used for the analysis were $568 \mathrm{~L} / \mathrm{min}$ and $51.2 \mathrm{~m}$, respectively. Note that the transmissive thickness is less than the average packed-off interval thickness because significant water production occurred over only a fraction of the total interval thickness, as previously reported by Geldon (1996 [DIRS 100396], pp. 12 to 20).

- Peclet number between 12 and 15 (Figures D-5, D-6, and D-7)

- Advection transport time between 12 and 16.5 days

- Flow porosity between 0.072 and 0.099 (Figures D-6 and D-7)

- Matrix porosity between 0.088 and 0.132 , and a longitudinal dispersivity value between $1.94 \mathrm{~m}$ (6.37 feet) and $2.43 \mathrm{~m}$ (7.96 feet): (Figures D-6 and D-7).

The range of values reflects two approaches for obtaining a curve match using a dual-porosity solution. In the first approach, the rising limb of the breakthrough curve plus the very early portion of the tail of the breakthrough curve were matched to obtain a Peclet number of 12, a flow porosity of 0.099 , a matrix porosity of 0.088 , and a dispersivity of $2.43 \mathrm{~m}$ (7.96 feet). Figures D-5 and D-6 show the resulting curve fits on plots with log-log and linear-linear axes scales, respectively. At longer times, the data and curve fits diverge, possibly indicating 
secondary arrivals from longer residence time flow pathways. In the second curve-matching approach, both the rising limb and the entire tail of the breakthrough curve were considered equally in the curve-fitting process, resulting in the curve fits of Figure D-7 with corresponding parameter values of $\mathrm{Pe}=15.0$ (longitudinal dispersivity $=1.94 \mathrm{ft}$ ), Sigma $=1.7$, and Gamma $=0.12$ (equivalent to a flow porosity of 0.072 and a matrix porosity of 0.132 ). In both curve-matching approaches, the parameter estimates were obtained from visual matches to the breakthrough data.

The program PEST V 5.5 (STN: 10289-5.5-00 [DIRS 161564]) was applied to the DFBA test results by starting with the visual graphical match to the breakthrough curve presented in Figure $\mathrm{D}-7$, for which $\mathrm{Pe}=15.0, \mathrm{Sigma}=1.7$, and Gamma $=0.12$.

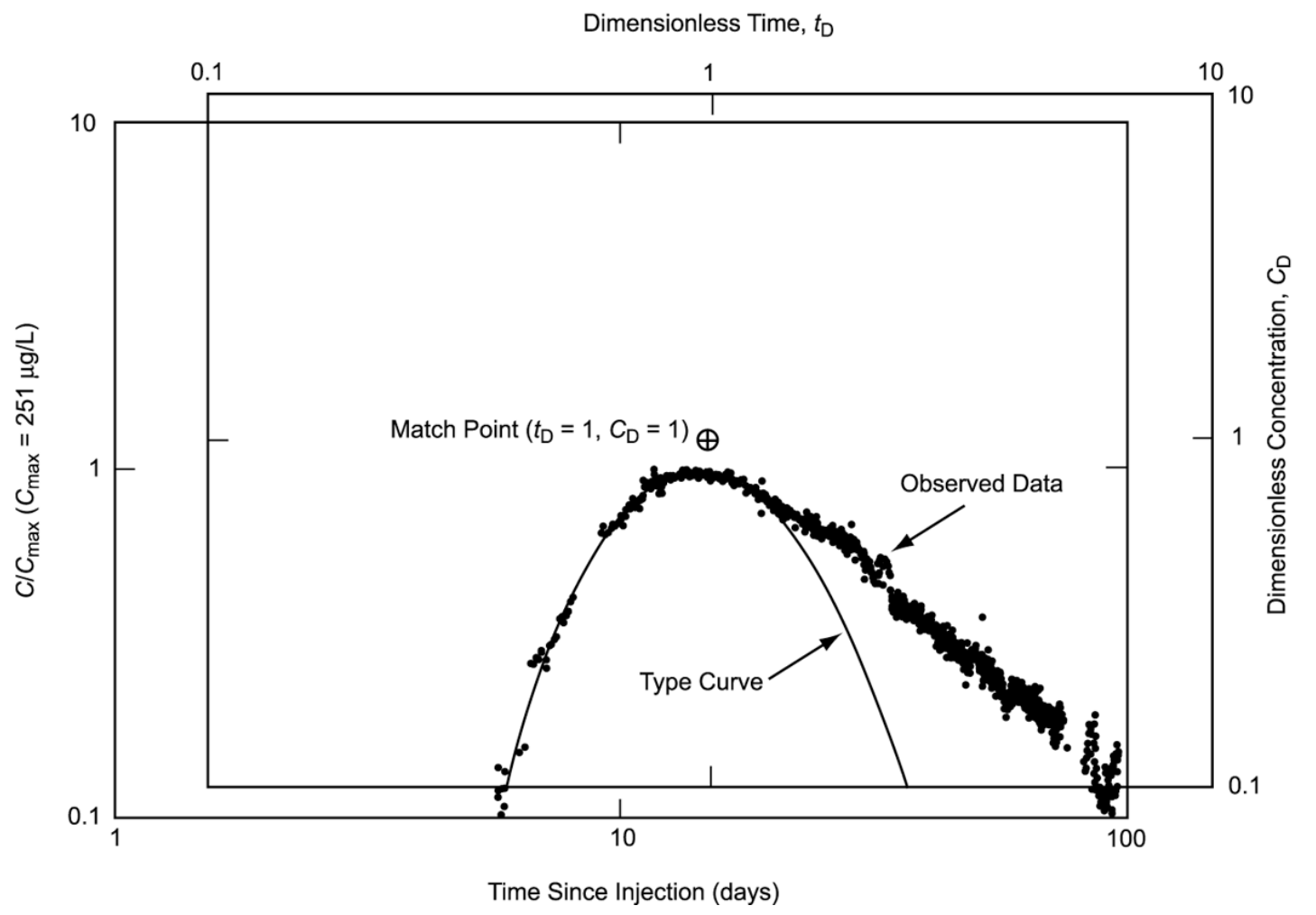

Source: DTN: GS010508312315.001 (data) [DIRS 155860].

Output DTN: GS031008312315.002 (analysis).

NOTE: The Peclet number $P e=12$. Only the rising limb of the observed data was fit because the falling limb could be the result of secondary arrivals.

Figure D-5. Type Curve Fit for 2,6 DFBA Injection in UE-25 c\#2

The latter set of parameter values were then used as initial guesses in three PEST V 5.5 (STN: 10289-5.5-00 [DIRS 161564]) runs, each conducted with one of the three parameters (Pe, Sigma, and Gamma) changed from the above values while the other parameters were held constant. In the first run, PEST was given $\mathrm{Pe}=15$, Sigma $=3.0$ (intentionally "perturbed" from its good-visual-fit value of 1.7), and Gamma $=0.12$; PEST was allowed to change only Sigma. At the end of this run, PEST converged on an optimal value of Sigma $=1.8776$ and an associated confidence interval for Sigma. In the second run, PEST was given the values $\mathrm{Pe}=8$ 
(intentionally "perturbed" from its good-visual-fit value of 15.0), Sigma $=1.8776$, and Gamma $=0.12$; PEST was allowed to change only Pe. At the end of this run, PEST converged on an optimal value of $\mathrm{Pe}=15.8$ and an associated confidence interval for Pe. In the third run, PEST was given the values $\mathrm{Pe}=15.8$, Sigma $=1.8776$, and Gamma $=1.0$ (intentionally perturbed from its good-visual-fit value of 0.12); PEST was allowed to change only Gamma. At the end of this run, PEST converged on an optimal value of Gamma $=0.11793$ and an associated confidence interval for Gamma. The above optimal values, their associated confidence intervals, and the fit to the actual breakthrough curve that they produce are presented in Figure D-8.

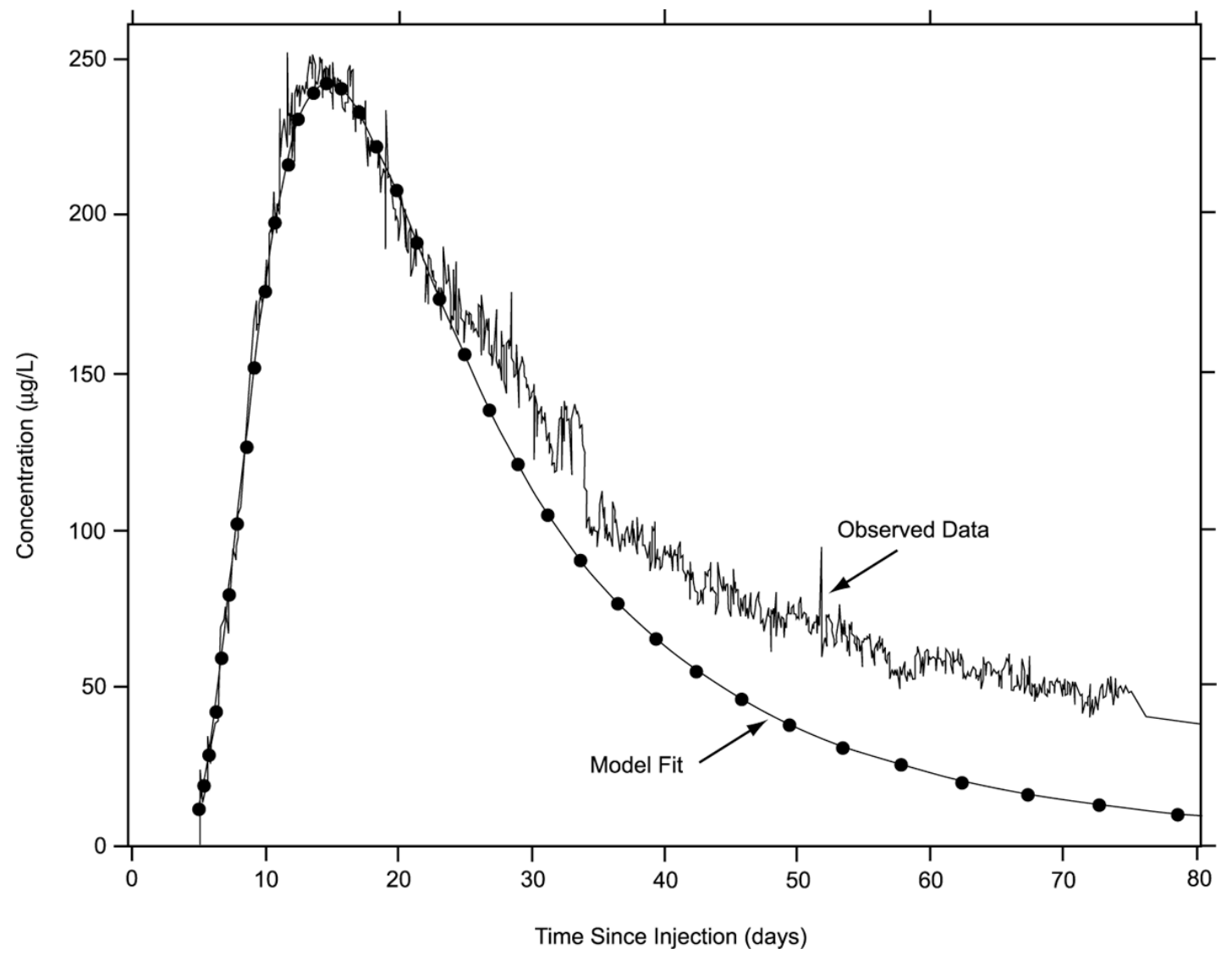

Source: DTN: GS010508312315.001 (data) [DIRS 155860].

Output DTN: GS031008312315.002 (analysis).

NOTE: The Fit 1 estimated parameters are Peclet number $P e=12$, dispersivity $\alpha_{\mathrm{L}}=2.4 \mathrm{~m}(7.96 \mathrm{ft}$ ), flow porosity $\phi_{\mathrm{f}}=0.099$, and matrix porosity $\phi^{\prime}=0.088$. Only the rising limb of the observed data was fit because the falling limb could be the result of secondary arrivals. The dots on the model fit curve have no significance. ("Model fit" refers to the match of the analytical solution to the data.)

Figure D-6. Fit 1 Preliminary Moench Analytical Solution for 2,6 DFBA Injection in UE-25 c\#2

The visual-graphical match and the optimized PEST V 5.5 (STN: 10289-5.5-00 [DIRS 161564]) parameters are in good agreement. The Peclet number and dispersivity estimates vary by approximately 5 percent, as can be seen by comparing the values listed in the notes under Figures D-7 and D-8. The flow porosity estimates are identical. The visual-graphical-match matrix porosity estimate is 0.132 , and the PEST estimate is 0.146 . 


\section{D1.1.3 Pyridone Tracer Test in the Lower Bullfrog Interval from $\mathrm{c \# 1}$ to $\mathrm{c \# 3}$}

On January 9, 1997, approximately $3.018 \mathrm{~kg}$ of 3-carbamoyl-2-pyridone (pyridone), mixed with $795 \mathrm{~L}$ (210 gallons) of Borehole c\#3 water, was injected into Borehole c\#1, followed by $252 \mathrm{~L}$ (66.6 gallons) of chase water to test the Lower Bullfrog interval (Umari 2002 [DIRS 162858], Binder 7, Sections J-6 to J-12, K-1 to K-9; Binder 8, Sections J-6 to J-12, K-1 to K-9; Binder 9, Sections J-6 to J-12, K-1 to K-9, K-11 to K-12, L-3). This injection was made while $\mathrm{c} \# 3$ was being pumped at an average rate of $572 \mathrm{~L} / \mathrm{min}(151.1 \mathrm{gpm})$.

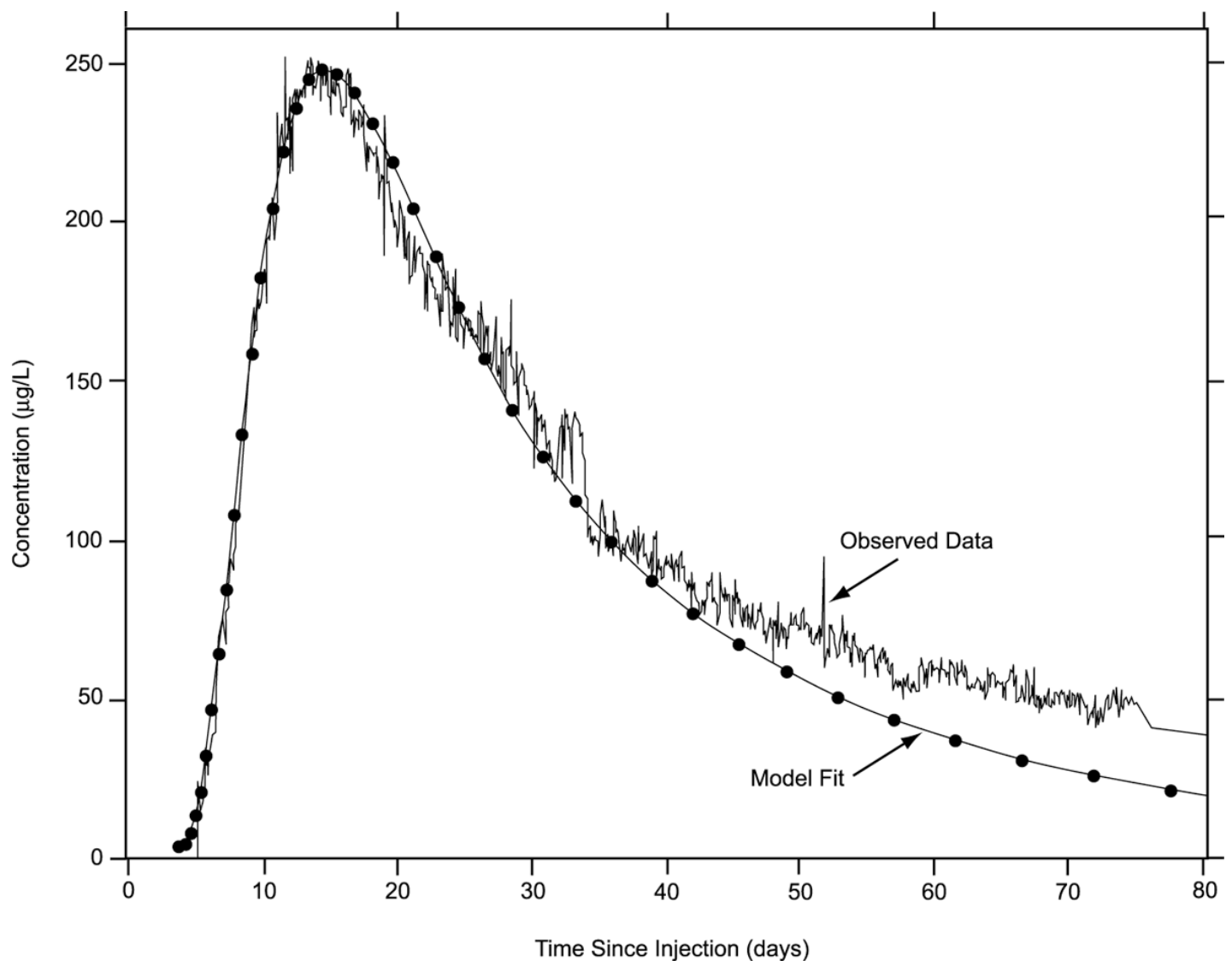

Source: DTN: GS010508312315.001 (data) [DIRS 155860].

Output DTN: GS031008312315.002 (analysis).

NOTE: The Fit 2 estimated parameters are Peclet number $P e=15$, dispersivity $\alpha_{\mathrm{L}}=1.9 \mathrm{~m}$ (6.37 ft), flow porosity $\phi_{\mathrm{f}}=0.072$, and matrix porosity $\phi^{\prime}=0.132$. The dots on the model fit curve have no significance. ("Model fit" refers to the match of the analytical solution to the data.)

Figure D-7. Fit 2 Preliminary Moench Analytical Solution for 2,6 DFBA Injection in UE-25 c\#2

A total of 2,082 L (550 gallons) of fluid were injected, the first portion of which was the fluid in the injection string preceding the injectate solution. The average injection rate was $22.8 \mathrm{~L} / \mathrm{min}$ (6.1 gpm), with a range of 16.8 to $37.2 \mathrm{~L} / \mathrm{min}$ (4.4 to $9.8 \mathrm{gpm}$ ). The average progressive-cavity pump (injection pump) pressure, measured at the surface, was $1.743 \mathrm{MPa}(252.8 \mathrm{psi})$, with a range of 0.3 to $2 \mathrm{MPa}$ (50 to $300 \mathrm{psi}$ ). Chemical analysis indicated that the pyridone injectate solution had an average concentration of $2,998 \mathrm{mg} / \mathrm{L}$ (or 2,998,000 $\mu \mathrm{g} / \mathrm{L}$ ). The field-determined 
detection limit for pyridone was $0.1 \mu \mathrm{g} / \mathrm{L}$. The precision of the HPLC/fluorometry analytical technique, as determined by comparing replicate analyses, was \pm 10 percent.

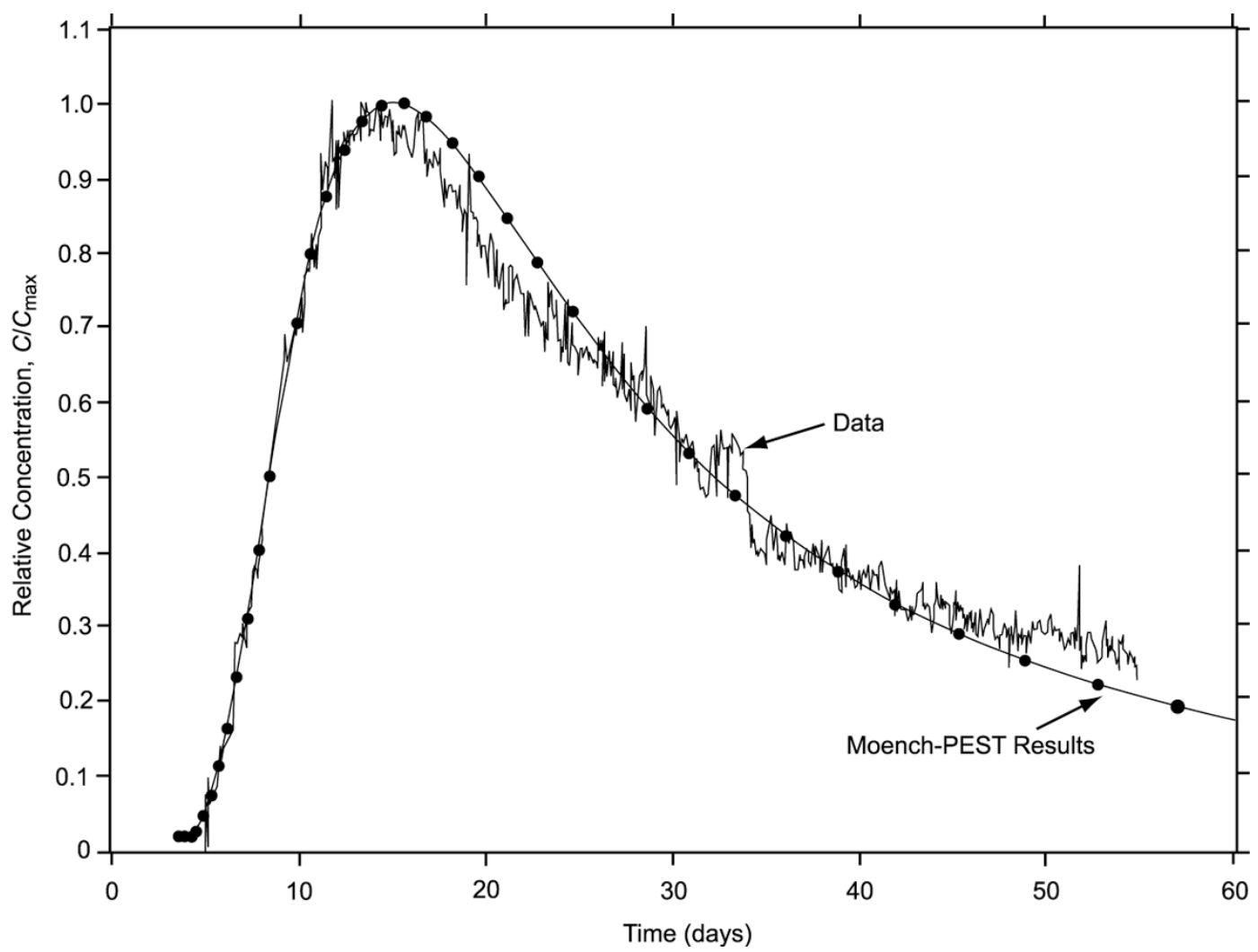

Source: DTN: GS010508312315.001 (data) [DIRS 155860].

Output DTN: GS031008312315.002 (analysis).

NOTE: The breakthrough curve was matched by the PEST V 5.5 (STN: 10289-5.5-00 [DIRS 161564]) program with initial estimates from a manual match. The optimal PEST results, with 95 percent confidence intervals in parentheses, are $P e=15.7954$ (15.4998-16.091), $R=1.0, \sigma=1.87763$ (1.65457-2.10068), and $\gamma=$ $0.117934(0.01741397-0.218454)$, and the other estimated parameters are dispersivity $\alpha_{\mathrm{L}}=1.83 \mathrm{~m}(6.01 \mathrm{ft})$, flow porosity $\phi_{\mathrm{f}}=0.072$, and matrix porosity $\phi^{\prime}=0.146$. The dots on the Moench-PEST results curve have no significance.

Figure D-8. Breakthrough Curve for January 10, 1997, DFBA Tracer Test

Breakthrough at c\#3 occurred on March 27, 1997, 56.3 days after injection. The concentration of pyridone continued to increase but at a gradually decreasing rate until the end of the test (the test was terminated before a clear peak was observed). The maximum concentration of Pyridone reached was $0.210 \mu \mathrm{g} / \mathrm{L}$ (parts per billion), or 210 parts per trillion (ppt), which was determined by analyses in the laboratory where detection limits were much lower than $0.1 \mu \mathrm{g} / \mathrm{L}$.

The precision of the pyridone concentration values varies. For concentrations less than $100 \mathrm{ppt}$, errors exceeded \pm 10 percent, based on replicate sample analyses. Concentrations of pyridone less than $100 \mathrm{ppt}$ are shown as open-circles on Figure D-9. The filled-circles indicate concentrations of pyridone greater than $100 \mathrm{ppt}$, and those samples with replicate errors less than or equal to \pm 10 percent. 


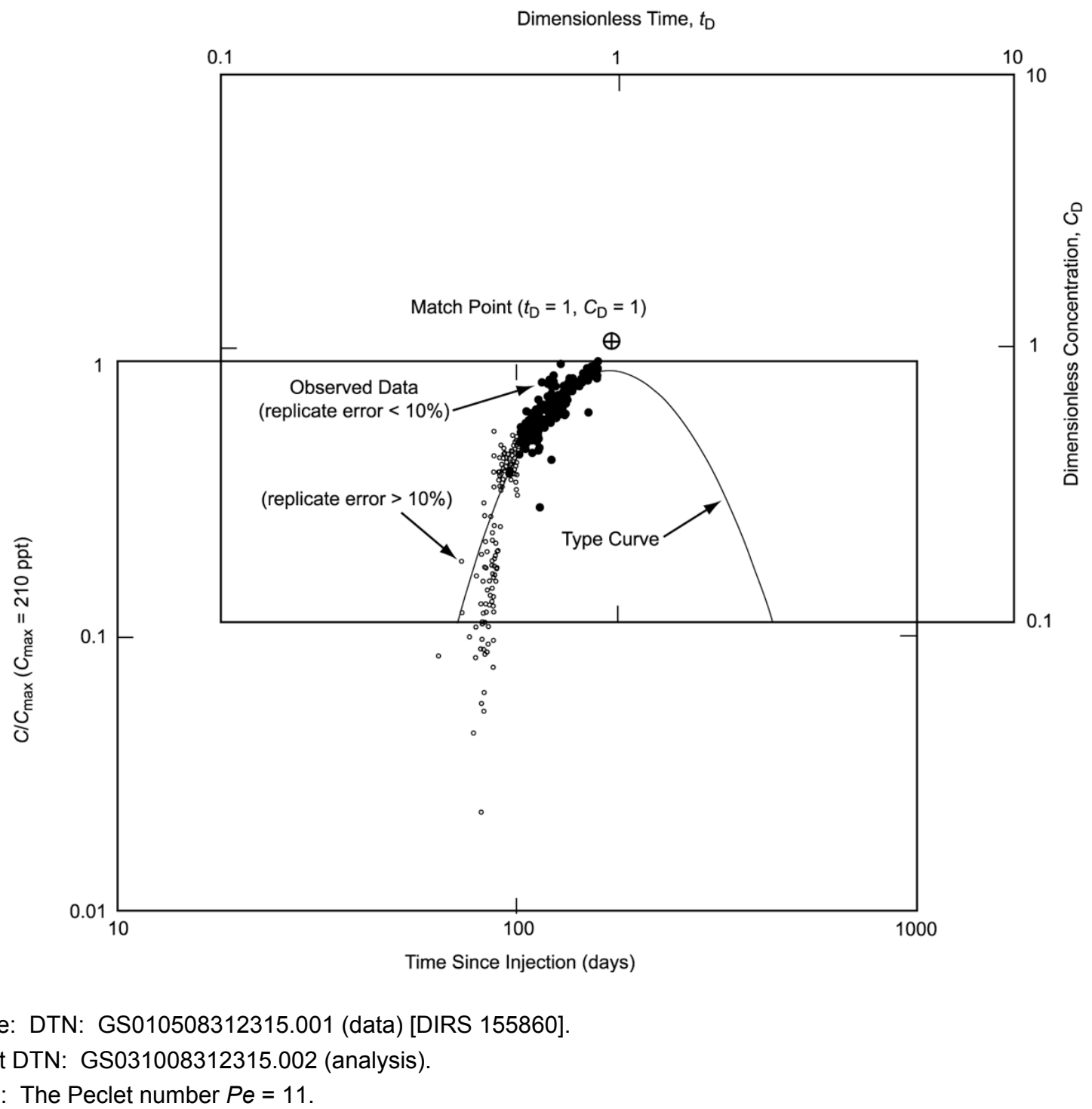

Figure D-9. Type Curve for Pyridone Injection in UE-25 c\#1

\section{Interpretation of Test}

Because the pyridone test was terminated before a peak concentration was reached, only the rising limb part of the test was analyzed. The type curve depicted in Figure D-9 fits the rising limb well. Assuming that the $0.210 \mu \mathrm{g} / \mathrm{L}$ concentration of pyridone is the maximum for the breakthrough curve, the dual-porosity (Moench 1995 [DIRS 148784]) analytical solution with a Peclet number of 11 matches the pyridone dimensionless concentration against the dimensionless time curve (Figure D-9). The single-porosity analytical solution (Moench 1989 [DIRS 101146]) would have produced a similar result if used to fit the rising limb because the matrix diffusion effects do not manifest themselves until the falling-limb phase of the test. 


\section{D1.1.4 PFBA and Iodide Tracer Tests in the Lower Bullfrog Interval}

In cooperation with the U.S. Geological Survey, Los Alamos National Laboratory conducted two "pilot" tracer tests, each involving the injection of a single nonsorbing tracer in the Lower Bullfrog interval during 1996. These tests were conducted primarily to determine which well, $\mathrm{c} \# 1$ or $\mathrm{c} \# 2$, would serve as a better injection well for the planned multiple-tracer test. The primary motivation was the concern that the responses of both sorbing and colloid tracers might be highly attenuated or excessively delayed relative to nonsorbing tracers, which could make test durations impractically long. Thus, it was desirable to determine which potential injection well yielded the quickest and highest-concentration responses at the production well, c\#3. It was not taken for granted that the best response would be from $\mathrm{c \# 2}$, the injection well closest to $\mathrm{c} \# 3$, because $\mathrm{c} \# 1$ and $\mathrm{c} \# 3$ are more closely aligned with the predominant fracture strike direction at the C-wells than $\mathrm{c} \# 2$ and $\mathrm{c} \# 3$.

The first pilot tracer test involved the injection of approximately $10 \mathrm{~kg}$ of PFBA into the lower Bullfrog interval in well c\#2 on May 15, 1996. This same interval in c\#3 was pumped continuously at about $575 \mathrm{~L} / \mathrm{min}$ throughout the test (starting on May 8, 1996, prior to tracer injection). The PFBA was dissolved in approximately $1,000 \mathrm{~L}$ of groundwater from c\#3. The test was conducted under partial recirculation conditions with about $20 \mathrm{~L} / \mathrm{min}$ of the water produced from $\mathrm{c} \# 3$ (approximately 3.5 percent of production rate) being continuously reinjected into $\mathrm{c} \# 2$. The recirculation was initiated approximately $24 \mathrm{hr}$ before tracer injection to establish a steady flow field, and it was continued for 23 days after injection. The tracer solution was plumbed into the recirculation loop such that there were no flow interruptions during injection. Information pertaining to the PFBA pilot test is documented by Reimus (2000 [DIRS 165126]).

The second pilot test involved the injection of about $12.7 \mathrm{~kg}$ of iodide (approximately $15 \mathrm{~kg}$ of sodium iodide dissolved in approximately $1,000 \mathrm{~L}$ of groundwater from $\mathrm{c} \# 3$ ) into the Lower Bullfrog interval in $\mathrm{c} \# 1$. It was conducted in a manner very similar to the PFBA pilot test and was initiated on June 18, 1996. The recirculation rate in this test was about $15 \mathrm{~L} / \mathrm{min}$ (approximately 2.6 percent of production rate), and recirculation continued for approximately 16 days after injection. Production from c\#3 was maintained at approximately $575 \mathrm{~L} / \mathrm{min}$ throughout the test, the same as that of the PFBA pilot test. Information pertaining to the iodide pilot test is documented by Reimus (2000 [DIRS 165127]).

It was clear a few days after the injection of iodide into $\mathrm{c} \# 1$ that the PFBA response from $\mathrm{c \# 2}$ was much more conducive to multiple-tracer testing than the iodide response from $\mathrm{c} \# 1$. The results of the PFBA test are relevant to the interpretation of the multiple-tracer test conducted in the Lower Bullfrog interval, so they are discussed in Section D4 of this report along with the results of the multiple-tracer test. The iodide response between $\mathrm{c} \# 1$ and $\mathrm{c} \# 3$ is shown in Figure D-10. This response is complicated by the initially high and gradually declining iodide background concentrations, which are attributed to the residual iodide in the aquifer from the February 13, 1996, injection of iodide into the Bullfrog-Tram interval in c\#2. However, there is clear evidence of a peak occurring about 2 months after injection. The estimated iodide recovery from the $\mathrm{c} \# 1$ injection by October 1, 1996, (after correcting for the declining background by assuming that it followed an exponential decay) was approximately 13 percent of the injected iodide mass (DTN: LA0410PR831231.001 [DIRS 171899]). In contrast, the PFBA recovery from c\#2 was about 72 percent on October 1, 1996 (DTN: LA0410PR831231.001 
[DIRS 171899]). Neither the PFBA nor the iodide pilot tracer tests were interpreted quantitatively.

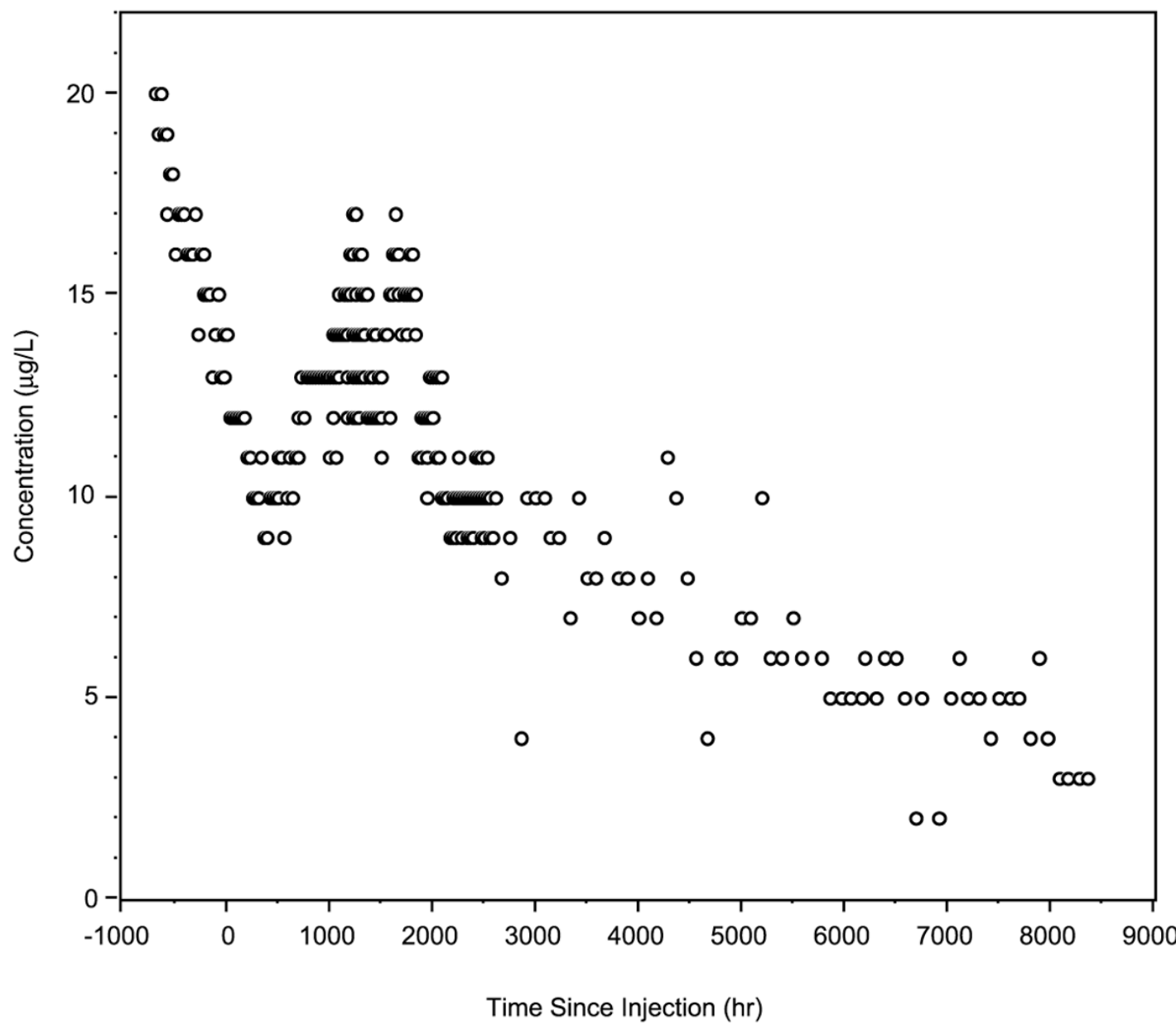

Source: DTN: LA0007PR831231.001 [DIRS 156043] (data).

NOTE: The breakthrough curve is a result of injection of approximately $12.7 \mathrm{~kg}$ of iodide into c\#1 on June 18, 1996; the declining background prior to and immediately after injection is due to recovery of iodide from a February 1996 iodide injection into c\#2; and the estimated recovery from c\#1 accounting c\#2 background was approximately 13 percent through June 1, 1997.

Figure D-10. Breakthrough Curve for lodide Injection in UE-25 c\#1

\section{D1.2 RESULTS AND INTERPRETATIONS OF NONSORBING TRACER TESTS: PROW PASS FORMATION}

\section{D1.2.1 2,4,5 Trifluorobenzoic Acid and Iodide Test from c\#3 to c\#2}

On June 17, 1998, a partial-recirculation nonsorbing tracer test was initiated from c\#3 to c\#2 by injecting approximately $14.83 \mathrm{~kg}$ of 2,4,5 trifluorobenzoic acid (TFBA) and $12.26 \mathrm{~kg}$ of iodide (in the form of sodium iodide) into the Prow Pass interval of c\#3 while c\#2 was pumped at the rate of approximately $5.2 \mathrm{gpm}(19.7 \mathrm{~L} / \mathrm{min})$. The concentration of 2,4,5 TFBA was 14,239 ppm in the injected slug, and that of iodide $14,307 \mathrm{ppm}$. Of the $5.2 \mathrm{gpm}(19.7 \mathrm{~L} / \mathrm{min})$ pumped from 
c\#2, $1.5 \mathrm{gpm}(5.7 \mathrm{~L} / \mathrm{min})$ was continuously reinjected into the Prow Pass interval of c\#3 (Umari 2002 [DIRS 162858], Binder 13, Sections M-29 to M-36; Binder 14, Sections M-29 to M-36, M-40, M-43 to M-44).

Approximately 40 hours after the injection, breakthrough of both tracers occurred in $\mathrm{c} \# 2$. The peak for the 2,4,5 TFBA occurred 6.74 days after injection, and the peak for iodide at 7 days after injection (Figure D-11).

The iodide and 2,4,5 TFBA breakthrough curves were analyzed using the single- and dual-porosity analytical solutions of the advection-dispersion equation as given in Moench (1989 [DIRS 101146]; 1995 [DIRS 148784]). These solutions were used, as is, for a hypothetical purely convergent flow field, and they were also lagged and superposed to obtain the solution for the actual partial-recirculation flow field (Section D1.2.1.2). The curves were first analyzed assuming Moench's single-porosity solution for both the convergent and the partially recirculating flow-field assumptions, using the entire curves for the matches to obtain the flow porosity and longitudinal dispersivity. In this case, the aquifer is considered to be an equivalent porous medium made up of a network of fractures, some of them continuous, and some potentially discontinuous with connecting segments of matrix (Fahy 1997 [DIRS 137456], fourth and fifth \{unnumbered\} pages). The porosity of this network of fractures and connecting segments of matrix, through which flow of solutes occurs, is referred to herein as "flow porosity" (Fahy 1997 [DIRS 137456], fourth and fifth \{unnumbered\} pages). The curves were then analyzed assuming a dual-porosity system, also using the entire curves for the match. In addition to the above network of fractures and connecting segments of matrix, the dual-porosity medium is conceptualized as having a storage component consisting of dead-end fractures and the part of the matrix not contributing to the flow network.

The flow porosity and longitudinal dispersivity are different for each of the solutions presented. The retardation coefficient used for all solutions was 1.0, assuming that iodide and 2,4,5 TFBA are considered nonsorbing with respect to the Prow Pass Tuff. All of the solutions used the following input parameters:

- Production rate of $19.7 \mathrm{~L} / \mathrm{min}$ (5.2 gpm; represents the average rate for the test)

- Aquifer thickness of $61 \mathrm{~m}$ (200 ft, packed-off interval, rounded to one significant figure) (Umari 2002 [DIRS 162858], Binder 10, Section L-11, pp. 70 to 71, Section L-9, pp. 57 to 58). In this case, the entire interval thickness was assumed to be transmissive despite the fact that earlier hydraulic tests (in 1995 and 1996 - Table C-7) had indicated that only a portion of the interval may be significantly transmissive. The earlier hydraulic tests were considered to have significant uncertainty because the Prow Pass interval was never isolated for hydraulic testing as it was for tracer testing in 1998 and 1999.

- Distance between injection and production wells of $29 \mathrm{~m}$ (95.15 ft) (Table A-6)

- Radii of injection and production wells of $13.97 \mathrm{~cm}$ (5.5 in.) (assumed for rugose, variable-diameter open-hole portion of C-wells where all testing was conducted, based on C-wells caliper logs (Geldon 1993 [DIRS 101045], p. 10) 
- Borehole mixing length of $30.5 \mathrm{~m}$ (100 ft; assumed, as discussed below)

- Recirculation rate of $5.7 \mathrm{~L} / \mathrm{min}$ (for the partially recirculation solution).

\section{D1.2.1.1 Single-Porosity, Purely Convergent Interpretation}

The single-porosity, purely convergent solution is obtained directly from the Moench (1989 [DIRS 101146]) solution to the advection-dispersion equation. A best visually matching single-porosity solution corresponding to flow porosity and longitudinal dispersivity values of 0.0007 and $1.45 \mathrm{~m}$, respectively, is presented in Figure D-12, along with the iodide and 2,4,5 TFBA breakthrough curves. All breakthrough curves, such as the ones in Figure D-12, were normalized by dividing the measured concentrations by the maximum concentration, $C_{\max }$, rather than by the concentration of the injected mass slug, $C_{0}$. Longitudinal dispersivity is a measure of the media's ability to disperse a solute along streamlines. Transverse dispersivity, which represents the media's ability to disperse a solute in a direction perpendicular to streamlines, is not obtainable from this analysis method and flow geometry. The longitudinal dispersivity of $1.45 \mathrm{~m}$ and the $29-\mathrm{m}$ flow length correspond to a Peclet number of 20 . Note that only one curve fit is shown in Figure D-12 because a single-porosity solution is capable of simulating only a single breakthrough curve for tracers with different diffusion coefficients.

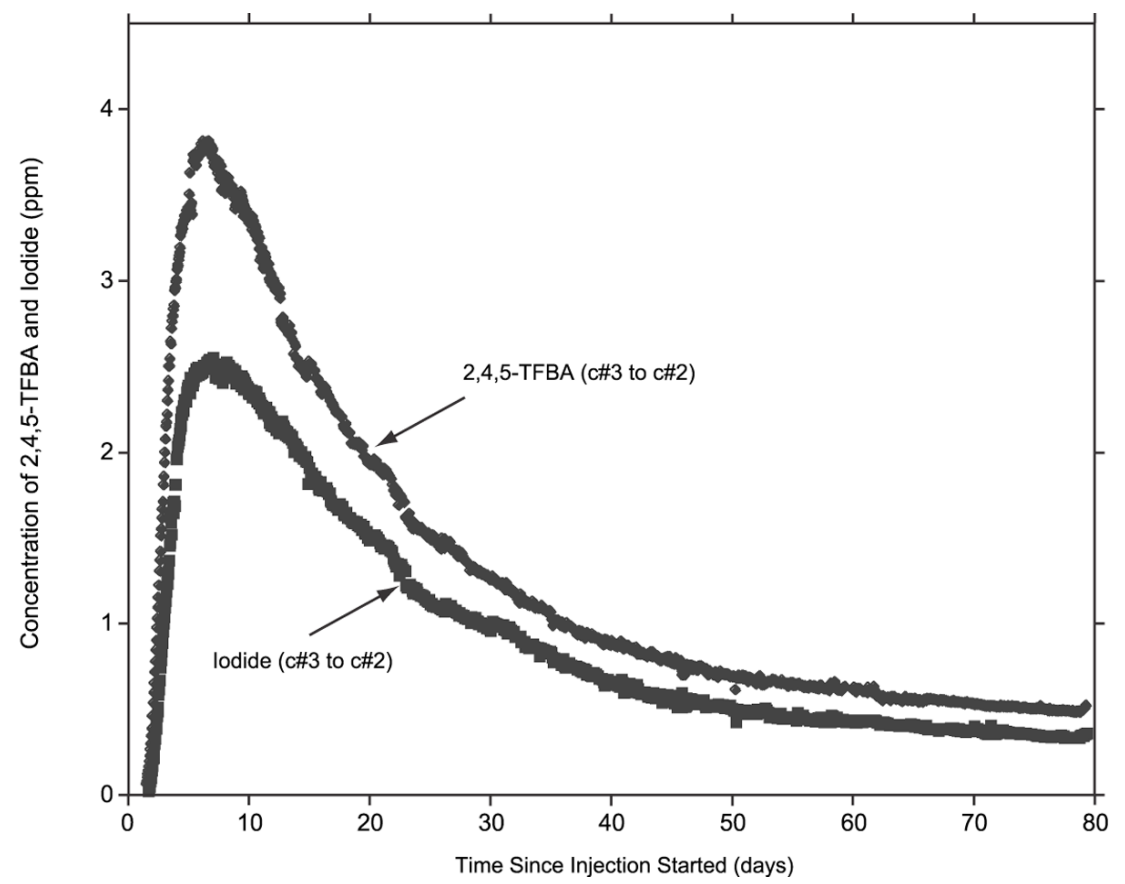

Source: DTN: GS990208312315.001 [DIRS 159238] (data).

NOTE: C\#2 and C\#3 refer to UE-25 c\#2 and UE-25 c\#3, respectively.

Figure D-11. Breakthrough Curves for 2,4,5 TFBA and lodide Tracer Test from UE-25 c\#3 to UE-25 c\#2 


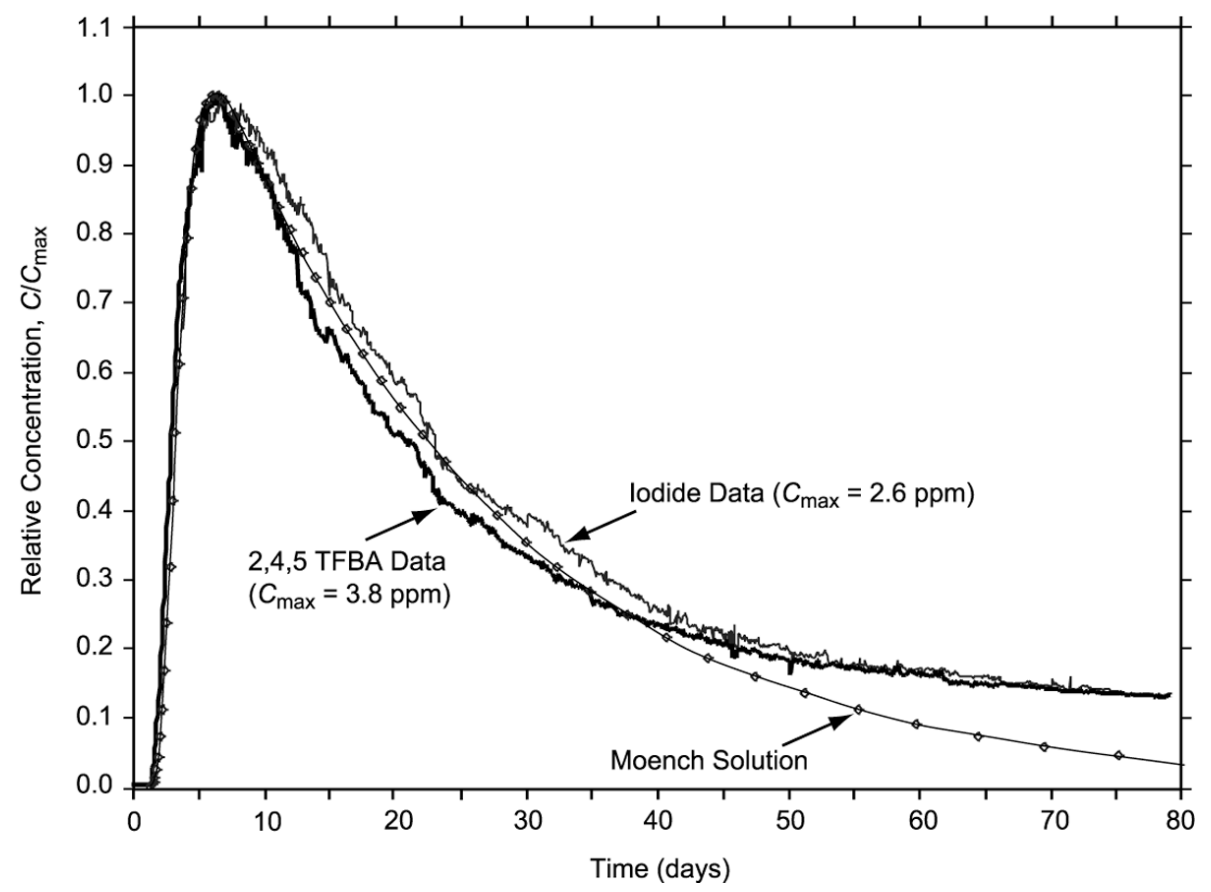

Source: DTN: GS990208312315.001 [DIRS 159238] (data).

Output DTN: GS031008312315.002 (analysis).

NOTE: Flow porosity $=0.0007$, storage porosity was not applicable because a single-porosity medium was assumed, and longitudinal dispersivity $=1.45 \mathrm{~m}$. The dots on the Moench solution curve have no significance.

Figure D-12. Breakthrough Curve for June 17, 1998, 2,4,5 TFBA and lodide Tracer Test Matched by the Single-Porosity, Purely Convergent Moench Solution

The matched values of longitudinal dispersivity and flow porosity may be sensitive to the mixing lengths assumed for the injection and pumped wells. The mixing lengths represent those lengths within the boreholes through which the tracer enters or exits the aquifer. The $30.5-\mathrm{m}$ mixing length assumed for all solutions is based on the thickness of the transmissive interval within the packed-off Prow Pass interval in c\#3 (Table C-6), and is consistent with the hydrogeology of the interval (Geldon 1996 [DIRS 100396], pp. 9 to 69).

The residence time of the tracer slug within the borehole is directly proportional to the mixing length. Data collected during the tracer injection indicate that the borehole was flushed in $8.5 \mathrm{hrs}$ (the concentration in the injected interval was measured in the field and found to rise from below detection limit to $2,721 \mathrm{ppm}$ and then back to below detection limit in 8.5 hrs, 8:00 A.M. to 4:30 P.M.) (Umari 2002 [DIRS 162858], Binder 13, p. 91). When the mixing length is reduced to $0.3 \mathrm{~m}$ and only the rising limb of the actual breakthrough curve is matched to the theoretical breakthrough curve from the single-porosity solution of Moench (1989 [DIRS 101146], assuming minimal diffusion during the rising limb), a longitudinal dispersivity value of $4.27 \mathrm{~m}$ and a flow porosity value of 0.0016 are obtained as fitting parameters. Changing the mixing length from $30.5 \mathrm{~m}$ to $0.3 \mathrm{~m}$ constitutes a two-orders-of-magnitude change in this parameter. Corresponding to this change in the assumed mixing length, the estimates of longitudinal dispersivity and flow porosity change from $1.45 \mathrm{~m}$ and 0.0007 (for a $30.5-\mathrm{m}$ mixing length) to $4.3 \mathrm{~m}$ and 0.0016 (for a $0.3-\mathrm{m}$ mixing length). This is a three-fold change of longitudinal 
dispersivity and a two-fold change of flow porosity, both less than one order of magnitude. The estimated parameters, therefore, are not very sensitive to the mixing length.

The above porosity value of 0.0007 is in the range of 0.00001 to 0.01 cited in the literature to represent fracture porosity [see, for example, Freeze and Cherry (1979 [DIRS 101173], p. 408)]. This implies that the flow network for this test in the Prow Pass Tuff is composed predominantly of fractures.

\section{D1.2.1.2 Single-Porosity, Partially Recirculating Interpretation}

When the purely convergent flow field of Figure D-12 is replaced by a partially recirculating flow field, the resulting solution to the advection-dispersion equation changes from the curve labeled "Moench solution" in Figure D-12 to the curve labeled "Modified Moench solution" shown in Figure D-13. The difference between the two solutions reflects the difference in flow field representation and in the fitted values of longitudinal dispersivity and flow porosity used (or implied) for each solution. Two elements of partial recirculation are represented in the partial-recirculation solution, which is obtained using the RECIRC.vi V 1.0 code (STN: 10673-1.0-00 [DIRS 164432]). Rather than straight converging rays into the production well, the partially recirculating flow field streamlines within the capture zone of the production well emanate from the injection well and curve towards the production well (Figure D-14a). The streamlines shown in Figure D-14a are lines of equal stream function values, in which the stream function of the partial-recirculation field is calculated as the sum of the stream functions of a $19.8 \mathrm{~L} / \mathrm{min}$ sink (production rate) and a $5.7 \mathrm{~L} / \mathrm{min}$ source (recirculation rate) in a confined aquifer of constant thickness (two-dimensional flow). The volume of rock between pairs of these curved streamlines emanating from the injection well and curving towards the production well constitute distinct pathways for the solute (tracer) to take from the injection to the production well. Three such inter-streamline pathways emanating from the injection well and curving towards the production well (Figure D-14a) are assumed for the partial-recirculation analysis in this section. These pathways, labeled Interstreamline pathway 1, 2, and 3 in Figure D-14a, and the three nonlabeled pathways, which are mirror images of them around the horizontal line of symmetry, carry all of the tracer mass from injection to production well. Symmetry allows that the analysis be restricted to only three of the six interstreamline pathways emanating from the injection well and curving towards the production well, namely Interstreamline pathway 1,2 , and 3, and that half of the mass of the tracer and half of the reinjection flow rate be carried by these three pathways. The Moench (1989 [DIRS 101146]) single-porosity, purely convergent solution is viewed as the solution of the advection-dispersion equation along a single straight pathway (Figure D-14b). This solution for a particular longitudinal dispersivity value and flow porosity is applied to each of the above three distinct pathways. Because the Moench solution is for a strictly convergent flow field, its application to the first-diverging-then-converging flow pattern within Interstreamline pathway 1, 2, and 3 in Figure D-14a is an approximation and will introduce some error. A proper delay factor (the advective transport time calculated from the volume of rock of each pathway, the flow rate within the pathway, and the assumed porosity) is used to account for the differences in lengths, or swept volumes, of these pathways relative to the straight purely convergent pathway, and the injected mass is distributed among the three pathways in proportion to the flow in each of them. 


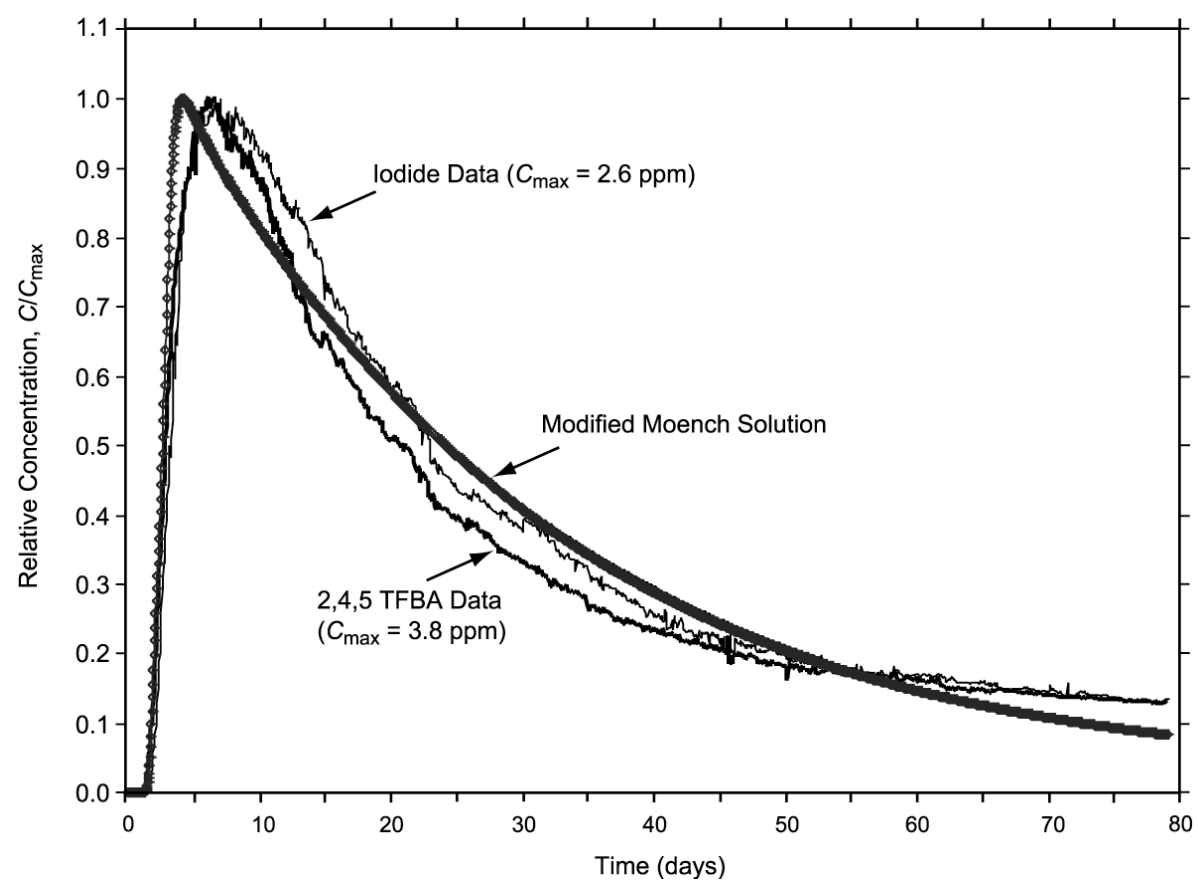

Source: DTN: GS990208312315.001 [DIRS 159238] (data).

Output DTN: GS031008312315.002 (analysis).

NOTE: Three inter-streamline pathways were assumed with delay factors of 2.01 days, 2.99 days, and 3.11 days. The flow porosity $=0.00045$, storage porosity was not applicable because a single-porosity solution was assumed, and longitudinal dispersivity $=0.27 \mathrm{~m}(\mathrm{Pe}=107)$. Borehole mixing length was $30.5 \mathrm{~m}$.

Figure D-13. Breakthrough Curve for June 17, 1998, 2,4,5 TFBA and lodide Tracer Test Matched by the Single-Porosity, Partial-Recirculation Solution Derived from Moench

The solutions from Moench (1989 [DIRS 101146]) for a particular longitudinal dispersivity value, flow porosity, and an instantaneous-slug injection are then superimposed with appropriate delay factors (defined above) to obtain what is considered to be the system's unit response function. The summed curve represents what is seen at the pumped well in response to an instantaneous input function at the injection well in a partial-recirculation flow field.

The second element of partial recirculation is that the reinjected water contains a small amount of tracer; therefore, the tracer is continuously reintroduced into the aquifer. For the calculations presented here, it was assumed that this lag duration is approximately $1 \mathrm{hr}$, which was the estimated time for travel of the recirculated fluid in the $2.5-\mathrm{cm}$ (1-in) coil-tubing return line (YMP 1998 [DIRS 104211], Attachment 5, p. 2) from the production well, c\#2, to the injection well, c\#3 (536 m [1,760 ft] at $5.7 \mathrm{~L} / \mathrm{min}$ [1.5 gpm]) (Umari 2002 [DIRS 162858], Binder 10, 57 th page of binder - pages are not numbered sequentially). The input concentration curve at the injection well is, therefore, constructed by starting with the breakthrough curve at the pumped (or extraction) well and then lagging it by the "lag duration." The input concentration curve at the injection well is then convolved (Levenspiel 1972 [DIRS 156839], Chapter 9) with the unit response function to produce the calculated partial-recirculation breakthrough curve at the production well. Different flow porosity and longitudinal dispersivity values are used in a trial and error process to iteratively repeat the process described above until the calculated partial-recirculation breakthrough curve is as visually close as possible to the measured breakthrough curve. 
a)

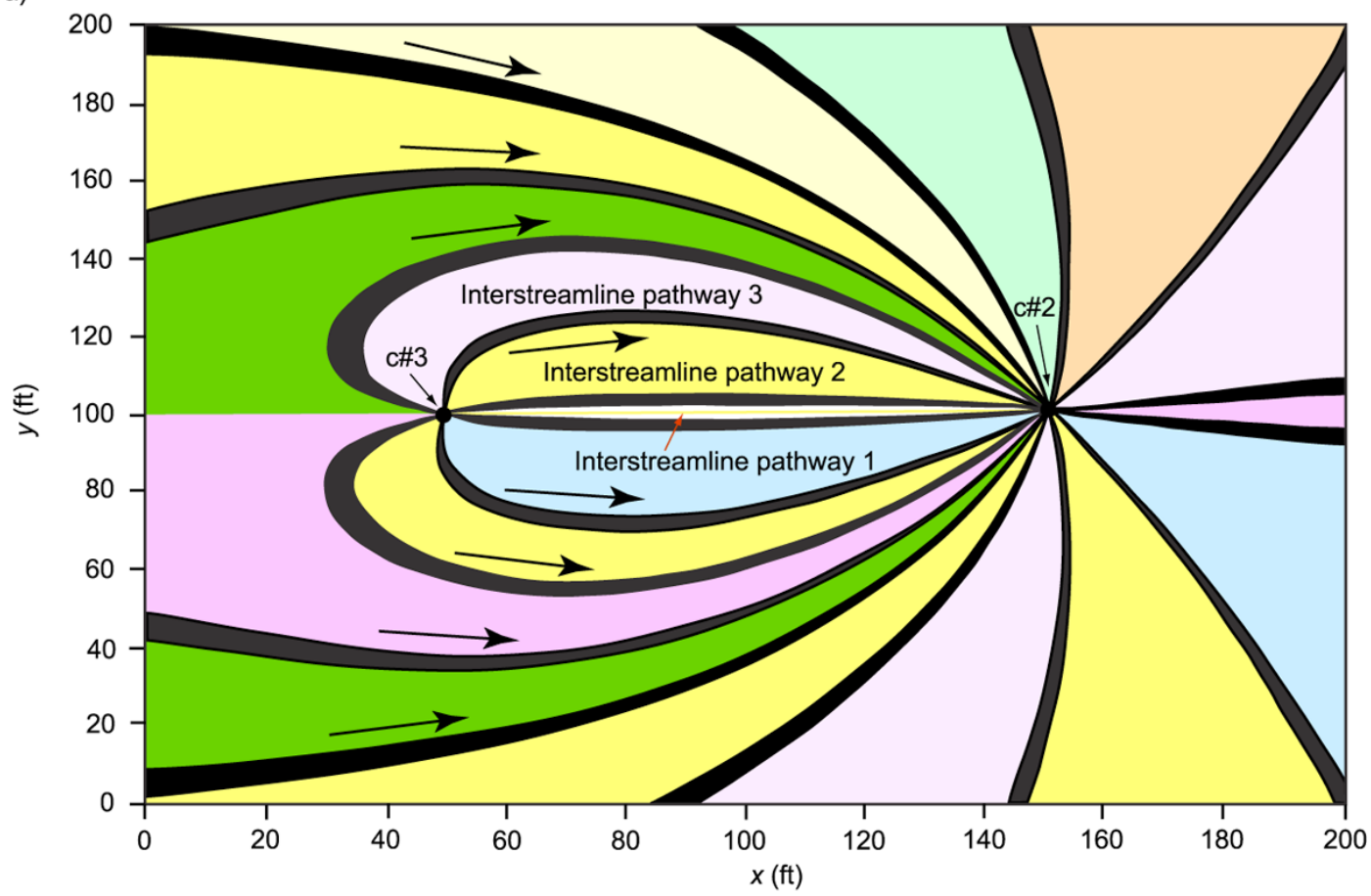

b)

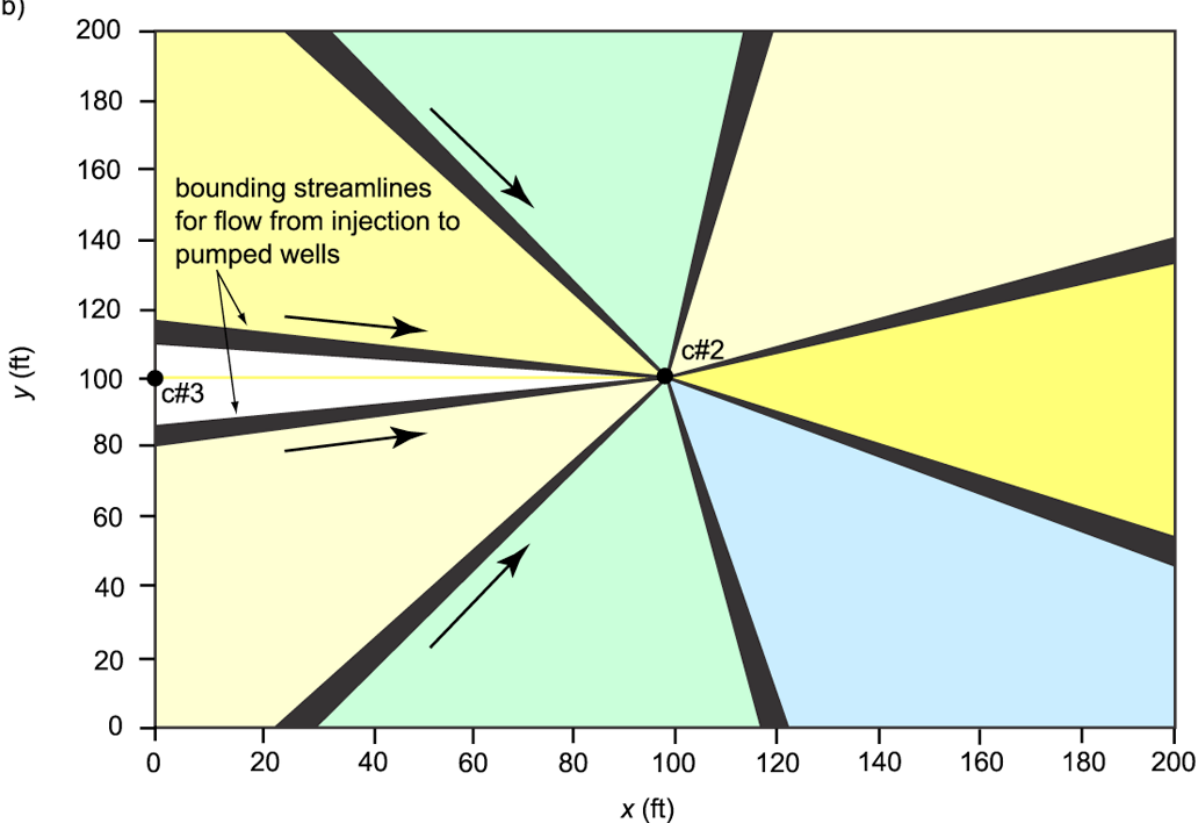

NOTE: Figures generated using RECIRC.vi (STN: 10673-1.0-00 [DIRS 164432]). English units are shown in the figure because the analysis was conducted in English units.

Figure D-14. Streamlines for a) Partial-Recirculation Flow Field and b) Purely Convergent Flow Field 
Using the iterative parameter-matching process described above, a longitudinal dispersivity of $0.27 \mathrm{~m}(\mathrm{Pe}=107.4)$ and a flow porosity of 0.00045 were selected as optimal for the single-porosity, partial-recirculation case (as opposed to the $1.45 \mathrm{~m}$ and 0.0007 optimal values found earlier for the single-porosity, purely convergent solution). These parameters result in the calculated partial-recirculation breakthrough curve presented in Figure D-13.

The delay factors for the three inter-streamline pathways inherent in the calculation of the breakthrough curve of Figure D-13 were initially assumed to be 1.83 days for the first pathway, 3.5 days for the second, and 7.5 days for the third (these are the advective transport times calculated from the volume of rock of each pathway, the assumed porosity, and the flow rate within the pathway).

However, use of these delay factors (as defined above) produced a calculated breakthrough curve that did not visually match the actual curve. The visual match was substantially improved by changing the delay factors to 2.01 days, 2.99 days, and 3.11 days, which resulted in the calculated breakthrough curve of Figure D-13. Because these three delay factors are not the ones indicated by the volumes of rock calculated for the three inter-streamline pathways, they are interpreted to represent the uncertainty in either the single-flow porosity value or in the assumed streamline pattern and resulting rock volumes. If the streamline pattern with associated rock volumes is assumed correct, then the delay factors of 2.01, 2.99, and 3.11 days correspond to storage porosities of $0.0005,0.0004$, and 0.0002 for the three inter-streamline pathways, respectively. However, because different porosities for the three pathways are not compatible with the underlying homogeneity assumption, the three porosities are taken to provide a range of uncertainty for the single-porosity estimate of 0.00045 used for all partial recirculation cases.

The results shown in Figures D-12 and D-13 indicate that if the breakthrough curves of 2,4,5 TFBA and iodide are analyzed as if they result from a purely convergent flow field, ignoring that the real flow field is partially recirculating, some error in the derived parameters results. A longitudinal dispersivity of $1.45 \mathrm{~m}$ is obtained when purely convergent conditions are assumed, five times the $0.27 \mathrm{~m}$ obtained when the partial-recirculation flow field is recognized. The flow porosity of 0.0007 obtained for purely convergent conditions is 56 percent higher than the flow porosity of 0.00045 obtained for partial recirculation.

The partial-recirculation solution shown in Figure D-13, and others in the remainder of Section D1.2 are not as good fits to the actual tracer breakthrough curves as the purely convergent solution of Figure D-12, even though the latter ignores the flow field created by partial recirculation. This could either mean that the explicit representation of the partial-recirculation flow field is not important and that the test can be analyzed successfully as a purely convergent tracer test, or that the homogeneous and isotropic representation of the partial-recirculation flow field presented here does not capture the real partial-recirculation flow field. Perhaps increasing the number of the inter-streamline pathways beyond three to, in effect, "discretize" the flow field more finely would improve the fits. This increased discretization was not attempted. 


\section{D1.2.1.3 Dual-Porosity, Partially Recirculating Interpretation}

In the dual-porosity case, the medium is comprised of flow and storage components. The flow component is conceptualized as a flow network of (1) continuous fractures and (2) discontinuous fractures with interconnecting segments of matrix. The porosity of the flow component of the medium is referred to as the "flow porosity." The storage component is assumed to consist of dead-end fractures and the part of the matrix not contributing to the flow network. The porosity of the storage component of the medium is referred to as the "storage porosity" (within Appendix B of this report, "matrix porosity" means the same thing as "storage porosity"). The flow network is represented by a longitudinal dispersivity and a flow porosity, and the storage component is represented by a storage porosity and a dimensionless matrix diffusion coefficient.

The calculated dual-porosity, partial recirculation solution is predicated upon the single-porosity, partial-recirculation solution presented earlier, i.e., a longitudinal dispersivity of $0.27 \mathrm{~m}$ and a flow porosity of 0.00045 . Two calculated breakthrough curves obtained for a storage porosity of 0.001 and two dimensionless matrix diffusion coefficients (Gamma), namely 0.000444 and 0.001, are presented in Figure D-15 along with the actual breakthrough curves of 2,4,5 TFBA and iodide.

The free-water molecular diffusion coefficients of 2,4,5 TFBA and iodide are $8.0 \times 10^{-6} \mathrm{~cm}^{2} / \mathrm{s}$ and $18.0 \times 10-6 \mathrm{~cm}^{2} / \mathrm{s}$, respectively (Bowman 1984 [DIRS 156645], Table 2; Skagius and Neretnieks 1986 [DIRS 156862], Tables 2 and 3), which corresponds to a ratio of 1:2.25 (TFBA: iodide). When a solution is placed in a porous medium and it diffuses into the matrix, the extent of matrix diffusion is represented by the dimensionless matrix diffusion parameter, Gamma, defined in Moench (1995 [DIRS 148784], p. 1826, Table 1). According to Moench (1995 [DIRS 148784], p. 1826, Table 1), the ratio of the dimensionless matrix diffusion parameter, Gamma, for the two tracers is the same as the ratio of their free-water molecular diffusion coefficients. The Gamma values of 0.000444 and 0.001 were chosen for Figure D-15 because they have the same ratio as the Gamma values of 2,4,5 TFBA and iodide, namely 1:2.25. Figure D-15 shows the effects on matrix diffusion, as represented by the two calculated breakthrough curves, of changing the free-water diffusion coefficient by a factor of 2.25 for a fixed storage porosity of 0.001 and the fixed flow rate of the test. The effect of increasing the free-water diffusion coefficient, which increases Gamma, is a delay of the calculated breakthrough curve for higher Gamma relative to the breakthrough curve for lower Gamma. This "differential matrix diffusion delay" is seen as a horizontal offset between the two calculated breakthrough curves in Figure D-15 and later figures. The larger the difference in Gamma between the two curves, the larger the differential matrix diffusion delay. 


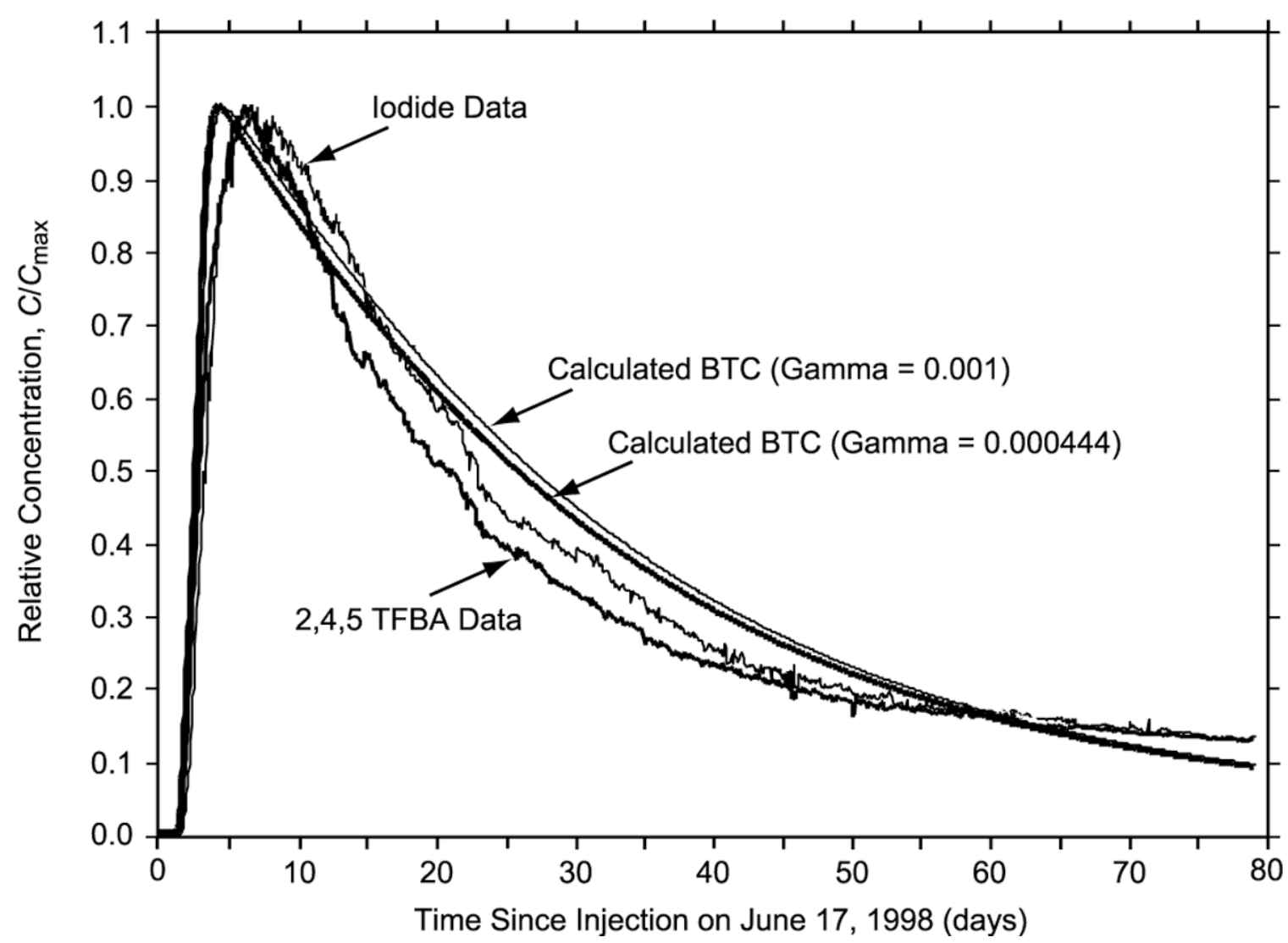

Source: DTN: GS990208312315.001 [DIRS 159238] (data).

Output DTN: GS031008312315.002 (analysis).

NOTE: The breakthrough curves were matched by the dual-porosity, partial-recirculation solution derived from Moench (1995 [DIRS 148784]) with storage porosity of 0.001 and dimensionless diffusion coefficients, Gamma, of 0.000444 and 0.001 . Three inter-streamline pathways were assumed to have delay factors of 2.01 days, 2.9 days, and 3.11 days. Longitudinal dispersivity $=0.27 \mathrm{~m} \mathrm{(0.9ft)}$.

Figure D-15. Breakthrough Curve for June 17, 1998, 2,4,5 TFBA and lodide Tracer Test Matched with a Lower Storage Porosity and a Higher Diffusion Coefficient

In addition, it is seen from a comparison of Figures D-15 and D-16 that this differential matrix diffusion delay for a particular pair of free-water diffusion coefficients (or Gamma values) increases with increasing storage porosity. Figure D-16, which uses the same pair of Gamma values used in Figure D-15, shows that when the storage porosity is increased from the 0.001 value of Figure D-15 to 0.01 , the differential matrix diffusion delay is markedly larger than what it is in Figure D-15. 


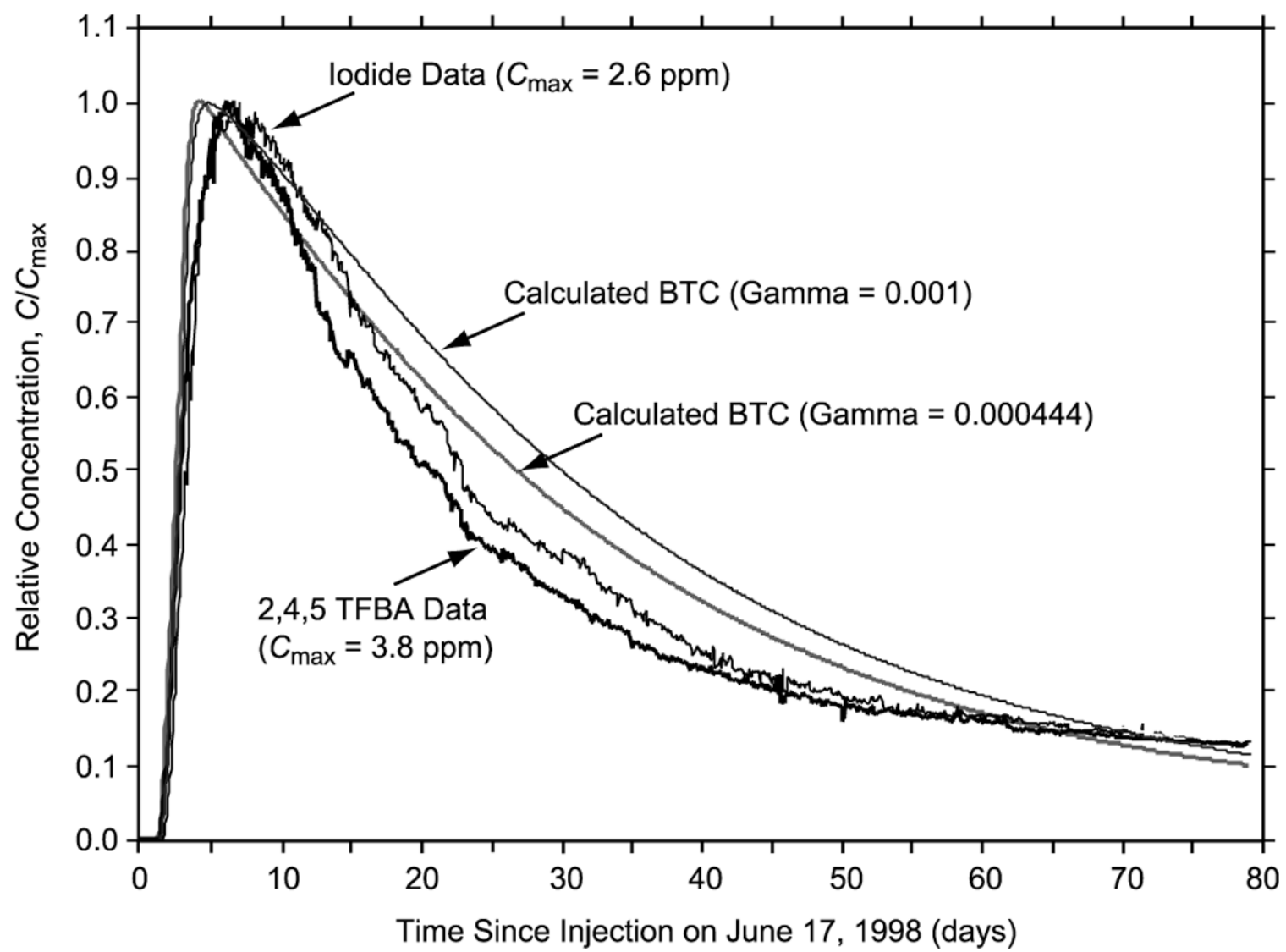

Source: DTN: GS990208312315.001 [DIRS 159238] (data).

Output DTN: GS031008312315.002 (analysis).

NOTE: The breakthrough curves were matched by the dual-porosity, partial-recirculation solution derived from Moench (1995 [DIRS 148784]) with storage porosity of 0.01 and dimensionless diffusion coefficients, Gamma, of 0.000444 and 0.001 . Three inter-streamline pathways were assumed with delay factors of 2.01 days, 2.9 days, and 3.11 days. The flow porosity was 0.00045 , and the longitudinal dispersivity was $0.27 \mathrm{~m}$.

Figure D-16. Breakthrough Curve for June 17, 1998, 2,4,5 TFBA and lodide Tracer Test Matched with a Higher Storage Porosity and a Higher Diffusion Coefficient

The differential matrix diffusion delay between calculated breakthrough curves in Figure D-16 is similar to that between the actual 2,4,5 TFBA and iodide, suggesting a storage porosity value of approximately 0.01 . This result is combined with earlier ones to indicate a dual-porosity medium with a flow porosity of 0.00045 (with an uncertainty range of 0.0002 to 0.0005 ), a storage porosity of 0.01 , and a longitudinal dispersivity of $0.27 \mathrm{~m}$. The flow porosity and longitudinal dispersivity characterize a flow network within this medium comprised of (1) continuous fractures and (2) discontinuous fractures with interconnecting segments of matrix. The storage porosity characterizes a storage component of the conceptualized dual-porosity medium consisting of dead-end fractures and the part of the matrix not contributing to the flow network. 


\section{D1.2.2 2,3,4,5 Tetrafluorobenzoic Acid Test from c\#1 to c\#2}

On July 31, 1998, the nonsorbing tracer 2,3,4,5 tetrafluorobenzoic acid (2,3,4,5 TeFBA) was injected in the Prow Pass interval of c\#1 while c\#2 continued to be pumped at the rate of approximately $19.3 \mathrm{~L} / \mathrm{min}$ (5.1 gpm) (Umari 2002 [DIRS 162858], Binder 13, Sections M-23 to M-25; Binder 14, Section M-40; Binder 15, Section M-34). Breakthrough of this tracer occurred on August 17, 1998, in the water pumped out of $\mathrm{c} \# 2$, and the concentration eventually rose to a maximum of around 90 parts per billion, approximately 65 days after tracer injection (Figure D-17). The results of this tracer test were used to qualitatively assess flow heterogeneity at the C-wells (Table D-1)

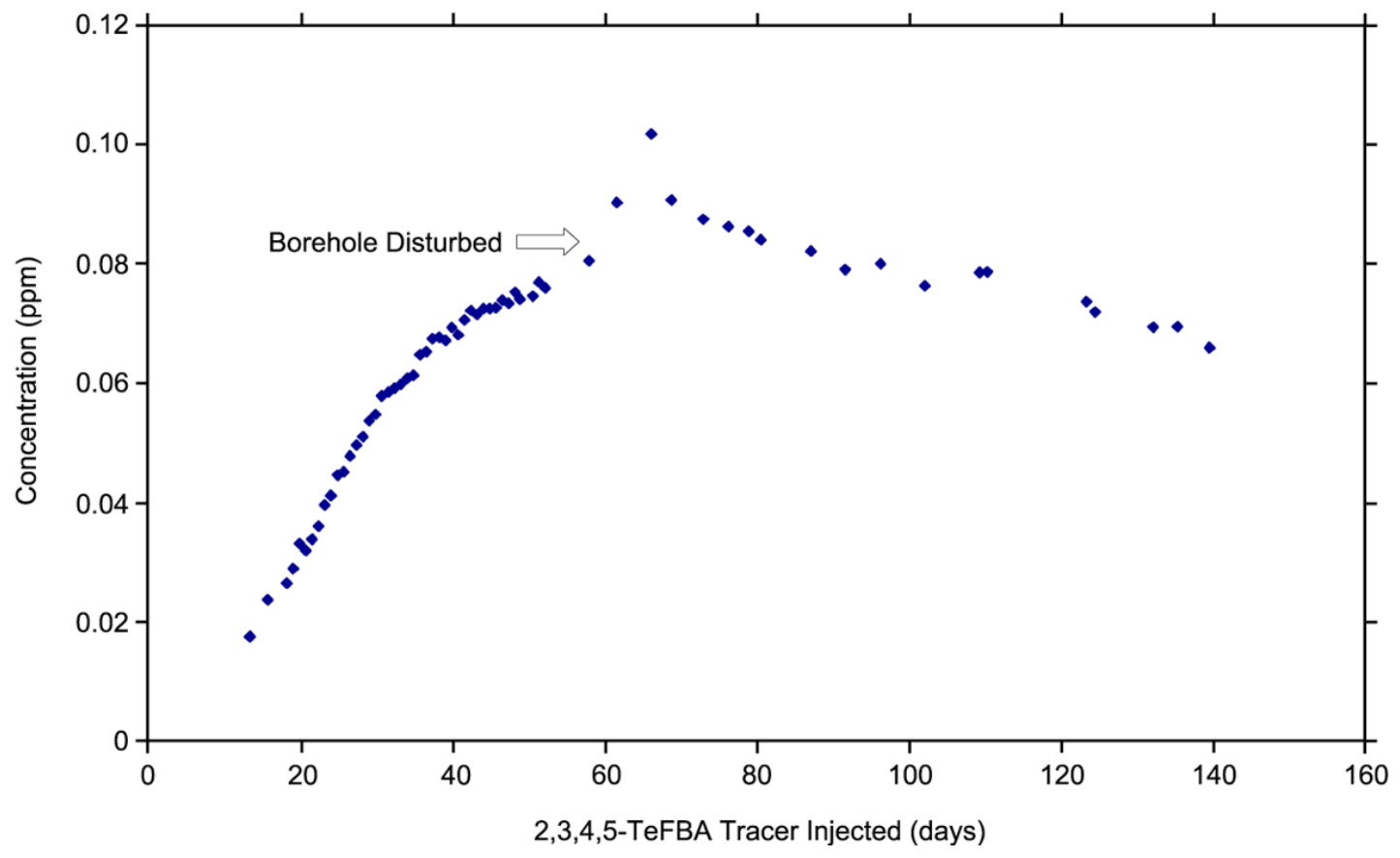

Source: DTN: MO0308SPATRCRC.000 [DIRS 164821].

Figure D-17. Breakthrough Curve for 2,3,4,5 TeFBA Tracer Test in Prow Passfrom UE-25 c\#1 to UE-25 c\#2

\section{D2. FLOW ANISOTROPY AT THE SCALE OF THE C-WELLS FROM NONSORBING TRACER ARRIVAL TIMES}

The comparisons of tracer responses resulting from injections into well c\#1 and into either well $\mathrm{c \# 2}$ or $\mathrm{c \# 3}$ (while pumping the other well) provided some insights into flow heterogeneity/ anisotropy at the scale of the C-wells. Table D-1 lists the ratios of peak arrival times or first arrival times for nonsorbing tracers between $\mathrm{c} \# 1$ and the production well (either $\mathrm{c \# 2}$ or $\mathrm{c \# 3}$ ) and between c\#2 and c\#3 for all tests in which a comparison was possible. For a homogeneous, isotropic medium, the arrival times under radial flow conditions are expected to vary as $r_{\mathrm{L}}^{2}$, the distance squared between injection and production well (Guimerà and Carrera 2000 [DIRS 156830], Equation 6). The ratios of $r_{\mathrm{L}}{ }^{2}$ values corresponding to each case are also listed in Table D-1. If the ratio of arrival times is less than the ratio of distances squared, then the direction from $\mathrm{c} \# 1$ to the production well is a preferred flow orientation; on the other 
hand, if the ratio of arrival times is greater than the ratio of distances squared, then the direction from $\mathrm{c} \# 2$ to $\mathrm{c} \# 3$ is a preferred flow orientation. Furthermore, the ratio of arrival times divided by the ratio of distances squared can be taken as a measure of the flow anisotropy ratio for the two different directions relative to the production well (note that these two directions are not strictly orthogonal). The ratios of tracer arrival times and $r_{\mathrm{L}}{ }^{2}$ values are in reasonably good agreement in all three cases, with apparent flow anisotropy ratios (c\#1 to production well direction divided by c\#2-c\#3 direction) varying from 0.77 to 1.42 . These relatively small ratios suggest that flow anisotropy at the scale of the C-wells may be relatively small despite the apparent orientation of the fracture network in the general direction of c\#1 to c\#2 (Geldon 1993 [DIRS 101045], pp. 43 to 51). The apparent flow anisotropy ratios deduced from the tracer arrival times should be carefully distinguished from the flow anisotropy ratios derived in Section A6, which were based on drawdown observations over much larger scales.

Table D-1. Ratios of Observed Tracer Arrival Times and Distances Squared, as Well as Apparent Flow Anisotropy Ratios, for C-Wells Nonsorbing Tracer Tests

\begin{tabular}{|c|c|c|c|}
\hline Tests (Injection Well) & $\begin{array}{c}\text { Timec\#1/ } \\
\text { Timec\#2-c\#3 }^{\text {a }}\end{array}$ & $\underset{r_{L}{ }^{2}{ }^{2}{ }^{2}{ }^{2 \# 1+c k \# 3} l}{a}$ & Anisotropy Ratio ${ }^{a}$ \\
\hline Bullfrog: PFBA (c\#2) and iodide $(\mathrm{c \# 1})^{\mathrm{b}}$ & 6 & 8.5 & 1.42 \\
\hline $\begin{array}{l}\text { Bullfrog: } 2,6-D F B A(c \# 2) \text { and pyridone } \\
(\mathrm{c} \# 1)^{\mathrm{c}}\end{array}$ & 11 & 8.5 & 0.77 \\
\hline $\begin{array}{l}\text { Prow Pass: iodide and 2,4,5-TFBA (c\#3) } \\
\text { and } 2,3,4,5-\text { TeFBA (c\#1) }\end{array}$ & 10 & 8.3 & 0.83 \\
\hline
\end{tabular}

DTNs: $\quad$ GS010508312315.001 [DIRS 155860]; GS990208312315.001 [DIRS 159238]; LA0007PR831231.001 [DIRS 156043] (data); GS030508312314.003 [DIRS 164425], p. 6, Table 1, borehole separations).

NOTE: $c \# 1, c \# 2$, and $c \# 3$ are abbreviations for Boreholes UE-25 c\#1, UE-25 c\#2, and UE-25 c\#3. $r_{\mathrm{L}}{ }^{2}$ is the distance squared between injection and production wells.

${ }^{a}$ Time $_{c \# 1}$ and $r_{L}{ }^{2}{ }^{\prime}$ are the time and distance, respectively, between $c \# 1$ and the production well (either $\mathrm{c \# 2}$ or $\mathrm{C \# 3}$, depending on the test), and Time ${ }_{c \# 2-\text { - } \# 3}$ and $r_{\mathrm{L}}{ }_{\mathrm{c} \# 2-\mathrm{c} \# 3}$ are the time and distance, respectively between $\mathrm{c \# 2}$ and $\mathrm{c \# 3}$. Columns 2 and 3 give the ratios of these times and distances. Ratio is for $\mathrm{c \# 1}$ to production well direction divided by $\mathrm{c} \# 2$ to $\mathrm{c \# 3}$ direction. For the anisotropy ratio, a value greater than 1.0 indicates that the $\mathrm{C \# 1}$ to production well direction is the preferred flow orientation.

${ }^{b}$ Both tests conducted with 2.5 to 3.5 percent recirculation into injection well. Peak tracer arrivals compared.

${ }^{c}$ Both tests conducted with no recirculation. First tracer arrivals compared.

d c\#3-to-c\#2 test conducted with 30 percent recirculation; c\#1-to-c\#2 test conducted with no recirculation. Peak tracer arrivals compared.

DFBA = difluorobenzoic acid or difluorobenzoate; PFBA= pentafluorobenzoic acid or pentafluorobenzoate; TFBA= trifluorobenzoic acid.

\section{D3. SUMMARY OF CONCEPTUAL MODELS AND PARAMETERS FROM NONSORBING TRACER TESTS AT THE C-WELLS}

Uncertainty in the values of longitudinal dispersivity, flow porosity, and matrix (or storage) porosity result from physical processes, such as the scale-dependence of dispersivity (when comparing tracer tests conducted from Borehole c\#1 to those conducted between Boreholes c\#2 and c\#3), as well as from variability in the transport characteristics of the tracer materials. However, there is good agreement in dispersivity values obtained from tracer tests conducted between Boreholes $\mathrm{c} \# 2$ and $\mathrm{c} \# 3$ in the Bullfrog and Tram intervals. Peclet numbers range from 11 to 15; therefore, the longitudinal dispersivities are similar (Table D-2). 
The breakthrough times are identical for the iodide and the DFBA tracer tests (Table D-2), and the advective transport times are within 10 percent. Therefore, the inferred flow porosities are similar, which implies that similar flow pathways are used by the tracers in those tests. These differences can be explained by the different thicknesses of the zones tested: the iodide tracer test was conducted in the combined Bullfrog-Tram zone, and the DFBA tracer test was conducted in the Lower Bullfrog zone.

The parameter estimates are robust because the visual-graphic match is close to the PEST fit (which is based on the dual-porosity analytical solution.) The differences are less than 5 percent for all parameters except matrix porosity, and these estimates vary by only 0.03 .

The estimated flow porosities suggest that the pathways between Boreholes c\#2 and c\#3 in the Bullfrog and Tram intervals are not well-connected. This possibility is supported by the interpretation of the higher-than-expected flow porosities for the Bullfrog and Tram Tuffs. The microsphere responses (Section D4) are consistent with this interpretation. The arrival of the microspheres at the recovery borehole indicates the existence of a connected pathway, somewhere, with an aperture at least $0.36 \mu \mathrm{m}$ (the diameter of the spheres).

Table D-2. Summary of Results and Transport Properties for the Bullfrog and Tram Tuffs from Nonsorbing Tracer Tests.

\begin{tabular}{|l|l|l|l|}
\hline & $\begin{array}{c}\text { lodide test from c\#2 to } \\
\text { c\#3 in Bullfrog-Tram }\end{array}$ & $\begin{array}{l}\text { DFBA test from c\#2 to } \\
\text { c\#3 in Lower Bullfrog }\end{array}$ & $\begin{array}{c}\text { Pyridone test from c\#1 } \\
\text { to c\#3 in Lower Bullfrog }\end{array}$ \\
\hline Breakthrough (days) & 5.07 & 5.07 & 56.3 \\
\hline Peak concentration $(\mu \mathrm{g} / \mathrm{L})$ & 99.5 & 251 & 0.210 (final value) \\
\hline Peclet number & 11 & $12-15$ & 11 \\
\hline Dispersivity $(\mathrm{m})$ & 2.6 & $2.4-1.9$ & 6.2 \\
\hline Flow porosity, $\phi \boldsymbol{\phi}(\%)$ & 8.6 & $9.9-7.2$ & \\
\hline $\begin{array}{l}\text { Matrix (or storage) porosity, } \\
\phi^{\prime}(\%)\end{array}$ & 19 & $8.8-13.2$ & \\
\hline
\end{tabular}

Source: DTNs: GS960808312315.001 [DIRS 159235] (lodide data) and GS010508312315.001 [DIRS 155860] (DFBA and Pyridone data).

Output DTN: GS031008312315.002 (analysis).

NOTES: $\quad c \# 1, c \# 2$, and $c \# 3$ are abbreviations for Boreholes UE-25 c\#1, UE-25 c\#2, and UE-25 c\#3, respectively. DFBA $=$ difluorobenzoic acid or difluorobenzoate.

This report presents the first unequivocal tracer testing from Borehole c\#1 to c\#3 in the Lower Bullfrog test and from $\mathrm{c} \# 1$ to $\mathrm{c} \# 2$ in the Prow Pass test. The preliminary results suggest that the arrival time from $\mathrm{c \# 1}$ to $\mathrm{c \# 3}, 56.3$ days, is consistent with the arrival time from $\mathrm{c} \# 2$ to $\mathrm{c} \# 3$, 5.07 days, because, as implemented in the Moench (1989 [DIRS 101146]) solution, the arrival time is directly proportional to the square of the distance between injection and production wells (Section D2).

Tracer testing in the Prow Pass interval (Table D-3) showed different transport characteristics than those obtained in the Bullfrog and Tram intervals. The flow porosity was found to be 0.00045 in the Prow Pass as opposed to 0.072 to 0.099 in the Bullfrog and Tram Tuffs (Table D-2). This result indicates that the flow network in the Prow Pass is dominated by interconnected fractures (fracture porosity is in the range from 0.00001 to 0.01 ), whereas in the 
Bullfrog and Tram, it was dominated by discontinuous fractures with interconnecting segments of matrix. Alternatively, the flow heterogeneity in the Bullfrog and Tram Tuffs may have been such that a vast majority of the water produced from $\mathrm{c} \# 3$ came from locations that were not in communication with the injection wells (i.e., only a small amount of the production flow rate came from the direction of the injection wells).

Longitudinal dispersivity in the Prow Pass Tuff testing at the scale of the distance between c\#2 and $\mathrm{c} \# 3$ was calculated as $0.27 \mathrm{~m}$, whereas it was 1.9 to $2.6 \mathrm{~m}$ in the Bullfrog and Tram intervals at the same scale. A relatively small dispersivity is consistent with a flow network dominated by interconnected fractures (Prow Pass), and a relatively large dispersivity is consistent with a flow network dominated by discontinuous fractures with interconnecting segments of matrix (Bullfrog and Tram) because the more the actual microscopic flow pathways are different from the macroscopic, averaged, flow pathway, the larger is the longitudinal dispersivity. Clearly, a flow network dominated by discontinuous fractures with interconnecting segments of matrix (Bullfrog and Tram) would have more microscopic flow pathways than a flow network dominated by interconnected fractures (Prow Pass).

The storage porosity (or matrix porosity) calculated for the Prow Pass Tuff was 0.01 (Table D-3), whereas it was 0.088 to 0.19 for the Bullfrog and Tram (Table D-2). A small storage porosity is consistent with a dual-porosity medium dominated by interconnected fractures (Prow Pass). In such a medium, the storage component, which is assumed to consist of dead-end fractures and the part of the matrix not contributing to the flow network, would be dominated by fractures, which have very small porosities. Similarly, a large storage porosity is consistent with a dual-porosity medium dominated by discontinuous fractures with interconnecting segments of matrix (Bullfrog and Tram). In such a medium, the porosity of the storage component (dead-end fractures and the part of the matrix not contributing to the flow network) would be dominated by the large porosity of the matrix component of storage.

Table D-3. Summary of Results and Transport Properties in a Partly Recirculating Tracer Test from Borehole c\#3 to c\#2 and from Borehole c\#1 to c\#2, Prow Pass Tuff

\begin{tabular}{|c|c|c|c|}
\hline Parameter & \multicolumn{2}{|c|}{$\begin{array}{c}2,4,5 \text { TFBA \& lodide: } \\
\text { c\#3 to c\#2 }\end{array}$} & $\begin{array}{c}2,3,4,5 \text { TeFBA: } \\
\text { c\#1 to c\#2 }\end{array}$ \\
\hline Breakthrough (days) & \multicolumn{2}{|c|}{1.67} & 17 \\
\hline Peak concentration (ppm) & \multicolumn{2}{|c|}{$\begin{array}{l}\text { TFBA : } 3.7 \\
\text { lodide : } 2.7\end{array}$} & 0.09 \\
\hline & $\begin{array}{l}\text { Single-Porosity, Partial } \\
\text { Recirc. Solution }\end{array}$ & $\begin{array}{l}\text { Dual -Porosity, Partial } \\
\text { Recirc. Solution }\end{array}$ & \\
\hline Longitudinal dispersivity (m) & 0.27 & 0.27 & \\
\hline Peclet number & 107.4 & 107.4 & \\
\hline Flow porosity, $\phi_{f}$ & 0.00045 & 0.00045 & \\
\hline $\begin{array}{l}\text { Gamma (dimensionless } \\
\text { matrix diffusion coefficient) }\end{array}$ & $\mathrm{N} / \mathrm{A}$ & $\begin{array}{c}0.000444,0.001 \text { (TFBA } \\
\text { and lodide, respectively) }\end{array}$ & \\
\hline Storage porosity, $\phi^{\prime}$ & $\mathrm{N} / \mathrm{A}$ & 0.01 & \\
\hline
\end{tabular}

Source: DTNs: GS990208312315.001 [DIRS 159238] and MO0308SPATRCRC.000 [DIRS 164821] (data).

Output DTN: GS031008312315.002 (analysis).

NOTE: c\#1, c\#2, and c\#3 are abbreviations for Boreholes UE-25 c\#1, UE-25 c\#2, and UE-25 c\#3, respectively. Borehole mixing length was assumed to be $30.5 \mathrm{~m}$. N/A stands for "Not Applicable."

TFBA $=$ trifluorobenzoic acid. 


\section{D4. MULTIPLE TRACER TESTS WITH SORBING SOLUTES AND COLLOID TRACERS AT THE C-WELLS}

\section{D4.1 INTRODUCTION AND OBJECTIVES}

This section describes the conduct and interpretation of two cross-hole tracer tests between c\#2 and c\#3 in which multiple solute tracers and colloid tracers (carboxylate-modified latex (CML) microspheres) were simultaneously injected. One test was conducted in the Lower Bullfrog Tuff and the other was conducted in the Prow Pass Tuff (referred to as the Bullfrog test and the Prow Pass test, respectively). The objectives of the multiple-tracer tests in the fractured tuffs at the C-wells included the following:

- Testing/validating the applicability of a dual-porosity conceptual transport model (Section D4.2) in the saturated, fractured volcanic tuffs that underlie Yucca Mountain

- Obtaining estimates of key transport parameters in the flow system, including parameters for colloid transport

- Assessing the applicability of laboratory-derived tracer transport parameters to field-scale transport predictions.

The latter objective is important because radionuclides cannot be tested in the field, so favorable comparisons of laboratory- and field-scale transport of nonradioactive tracers can lend credibility to the practice of using laboratory-derived radionuclide transport parameters in field-scale predictive simulations.

This section also summarizes laboratory experiments that were conducted to support the C-wells field test interpretations and to provide the comparisons between laboratory-derived transport parameters and field-scale transport parameters. Special emphasis is given to the sorption behavior of the lithium ion, which was used as a sorbing tracer in the field tracer tests.

\section{D4.2 DUAL-POROSITY CONCEPTUAL TRANSPORT MODEL}

A consistent observation in all hydrogeologic units below the water table at the C-wells is that bulk permeabilities (determined from aquifer tests) exceed matrix permeabilities (determined from laboratory core measurements) by 2 to 6 orders of magnitude (Geldon 1993 [DIRS 101045], pp. 58 to 64; Geldon 1996 [DIRS 100396], pp. 69 to 71). This ratio of bulk to matrix permeabilities suggests that flow in the Miocene tuffs at the $\mathrm{C}$-wells occurs predominantly in fractures. However, matrix porosities in the $\mathrm{C}$-wells range from about 0.10 to 0.35 (Geldon 1993 [DIRS 101045], pp. 58 to 64), so most of the water in these rocks is stored in the pores of the matrix. Radionuclide and tracer transport in fractures, therefore, could be attenuated by diffusive mass transfer between the fractures and the rock matrix, a process known as matrix diffusion. Matrix diffusion in fractured systems has been discussed and modeled at length by Neretnieks (1980 [DIRS 101148], pp. 4379 to 4397), Grisak and Pickens (1980 [DIRS 101132]), Tang et al. (1981 [DIRS 101160], pp. 555 to 564), Maloszewski and Zuber (1984 [DIRS 156840]; 1985 [DIRS 148312]), and Moench (1995 [DIRS 148784]). A system exhibiting fracture and matrix flow frequently is called a "dual-porosity, dual-permeability" 
system. When the matrix permeability is small compared to the fracture permeability (e.g., smaller by a factor of 100 or more), the matrix permeability can be assumed to be negligible in transport calculations, and the system is often referred to as simply a "dual-porosity" system. It has been suggested elsewhere that the saturated zone in the vicinity of Yucca Mountain should behave as a dual-porosity system (Robinson 1994 [DIRS 101154]). This concept has important transport implications, particularly for sorbing radionuclides, because it suggests that solutes moving through fractures will have access to a very large surface area for sorption once they diffuse out of fractures and into adjacent matrix pores.

\section{D4.3 TRACER TESTING STRATEGY}

To accomplish all of the test objectives mentioned in Section D4.1 in a reasonable time, cross-hole, forced-gradient tracer tests were conducted in which three different solute tracers having different physical and chemical properties were simultaneously injected into the lower Bullfrog and Prow Pass flow systems. By dissolving the tracers in the same solution and simultaneously introducing them, it was ensured that they all experienced the same flow field and, hence, initially followed identical flow pathways through the system. This assurance is especially important in field tests where it can be extremely difficult to reproduce exact flow conditions for different tracer injections because of equipment problems and possible irreversible changes in the system (e.g., well development, biofouling, unsteady drawdown, etc.). The test interpretations were then based on comparing the responses of the different tracers. The tracers used in each test included two nonsorbing solutes having different diffusion coefficients (bromide and penta-fluoro-benzoate) and a weakly sorbing, ion-exchanging solute (lithium ion). The bromide and pentafluorobenzoate were verified to be nonsorbing in a limited set of batch adsorption experiments involving the seven different $\mathrm{C}$-wells tuff lithologies listed in Tables D-16 and D-17 (DTN: LA0302PR831231.001 [DIRS 162605]). CML polystyrene microspheres were also injected in both tests to serve as colloid tracers. These microspheres have negatively charged hydrophilic surfaces at $\mathrm{pH}$ greater than 5 , which tends to minimize their attachment to rock surfaces (Reimus 1995 [DIRS 101474], p. 35, Table 3.6). The properties of all tracers are summarized in Table D-4, along with the injection masses and concentrations used in the tracer tests.

The rationale for using multiple solute tracers in cross-hole tests is illustrated in Figure D-18. The left plot of this figure shows hypothetical solute tracer responses (log normalized concentration versus log time) for a cross-hole tracer test with a short injection pulse in a singleporosity system. Note that there is no distinction between nonsorbing tracers with different diffusion coefficients in this plot because there is no secondary porosity for the tracers to diffuse into and, hence, no separation of their responses. The sorbing tracer response is delayed in time and lower in concentration than the nonsorbing tracers. In contrast, the right plot of Figure D-18 shows hypothetical solute tracer responses for a test in a dual-porosity system. In this case, there is a separation between nonsorbing tracers with different diffusion coefficients, with the higher diffusivity tracer exhibiting a lower peak concentration and a longer tail than the lower diffusivity tracer. This separation occurs because the higher-diffusivity tracer diffuses more readily into the matrix than the lower-diffusivity tracer, resulting in a lower recovery at early times but a longer tail due to subsequent diffusion back out of the matrix after the tracer pulse has passed. 
Figure D-18 also shows two possible responses for a sorbing tracer: (1) one with sorption occurring in the matrix and (2) one with sorption occurring in the fractures and the matrix (if the fractures have sorptive mineral coatings or are filled with sorptive granular material). Note that in the matrix-only case, the sorbing tracer response is attenuated in peak concentration but not significantly in time relative to the nonsorbing tracers, whereas in the latter case both a concentration and a time attenuation are apparent. The minimal time attenuation of the sorbing tracer relative to the nonsorbing tracers in the matrix-only sorption case is primarily a result of the relatively short duration of a typical cross-hole tracer test relative to characteristic times of diffusion into the matrix; as transport times increase, the time and concentration attenuation of a sorbing tracer relative to nonsorbing tracers should increase.

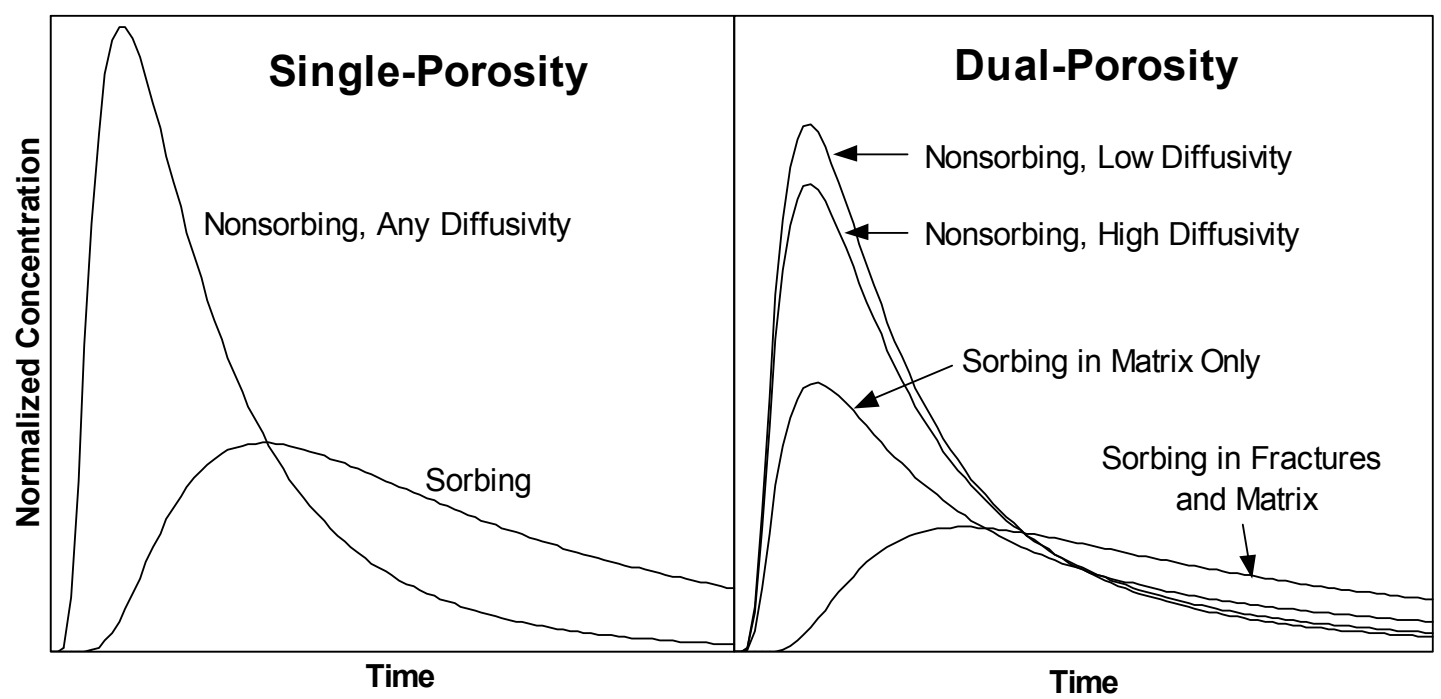

NOTE: For illustration purposes only. The figure illustrates how multiple tracers can be used to distinguish between single- and dual-porosity systems (Reimus 2003 [DIRS 165129], Attachment A, pp. A-198 to A-208). As cross-hole transport times increase, the "nonsorbing, high diffusivity" and "sorbing, matrix only" peaks on the right-hand plot will begin to arrive later than the "nonsorbing, low diffusivity" peak. The curves were generated using the RELAP V 2.0 code (STN: 10551-2.0-00 [DIRS 159065]) with arbitrary input parameters intended to qualitatively illustrate the differences between tracer responses in single- and dual-porosity media. The inputs and outputs of the simulations were not submitted to the TDMS and do not have a DTN.

Figure D-18. Hypothetical Cross-Hole Responses of Tracers with Different Physical and Chemical Characteristics in Single- and Dual-Porosity Media 
Table D-4. Tracer Characteristics, Injection Masses, and Injection Concentrations in the Two Multiple-Tracer Tests

\begin{tabular}{|c|c|c|c|}
\hline \multicolumn{4}{|c|}{ Solute Tracers } \\
\hline Parameters & PFBA & Bromide & Lithium \\
\hline Free water diffusion coefficient, $D_{\mathrm{f}}\left(\mathrm{cm}^{2} / \mathrm{sec}\right)^{a}$ & $7.2 \times 10^{-6 b}$ & $2.1 \times 10^{-5 c}$ & $1.0 \times 10^{-5 c}$ \\
\hline Sorption $^{\mathrm{d}}$ & \multirow{2}{*}{ None $^{\mathrm{d}}$} & None $e^{d}$ & Weak (ion exchange) \\
\hline Bullfrog test injection mass $(\mathrm{kg})$ & & 165.6 & 14.39 \\
\hline Bullfrog test injection concentration $(\mathrm{mg} / \mathrm{L})^{\mathrm{e}}$ & 1,000 & 13,800 & 1,200 \\
\hline Prow Pass test injection mass $(\mathrm{kg})$ & 12.0 & 30.6 & $16.0^{f}$ \\
\hline Prow Pass test injection concentration $(\mathrm{mg} / \mathrm{L})^{\mathrm{g}}$ & 2,000 & 5,100 & 2,670 \\
\hline \multicolumn{4}{|c|}{ CML Microsphere Tracers } \\
\hline Tracer (fluorescent dye color) & Test & Injection Amount ${ }^{(j)}$ & $\begin{array}{c}\text { Injection } \\
\text { Concentration }^{(\mathrm{k})}\end{array}$ \\
\hline $0.36-\mu \mathrm{m}$ CML microspheres (yellow) ${ }^{\mathrm{h}}$ & Bullfrog & $3.6 \times 10^{14}$ spheres & $4.6 \times 10^{10}$ spheres $/ \mathrm{L}$ \\
\hline 0.64- $\mu \mathrm{m}$ CML microspheres (blue) ${ }^{i}$ & Prow Pass & $3.0 \times 10^{14}$ spheres & $5.1 \times 10^{10}$ spheres $/ \mathrm{L}$ \\
\hline $0.28-\mu \mathrm{m}$ CML microspheres (orange) ${ }^{\mathrm{i}}$ & Prow Pass & $2.1 \times 10^{14}$ spheres & $3.5 \times 10^{10}$ spheres $/ \mathrm{L}$ \\
\hline 0.28-um CML microspheres (yellow) & Prow Pass & $2.1 \times 10^{14}$ spheres & $3.5 \times 10^{10}$ spheres $/ \mathrm{L}$ \\
\hline
\end{tabular}

Source: DTNs: LA0007PR831231.001 [DIRS 156043] (Bullfrog Test); LAPR831231AQ99.001 [DIRS 140134] (Prow Pass Test); LA0302PR831231.001[DIRS 162605]; LA0401PR831231.001 [DIRS 171859].

${ }^{a}$ Callahan et al. (2000 [DIRS 156648], Table 7) found that diffusion coefficients in rock matrices had the same ratio as free water diffusion coefficients for PFBA and bromide.

b Benson and Bowman (1994 [DIRS 122788], p. 1125; 1996 [DIRS 153427]).

c Newman (1973 [DIRS 148719], p. 230, Table 75-1); based on ionic conductances at infinite dilution.

${ }^{d}$ Based on results of laboratory batch sorption experiments (DTN: LA0302PR831231.001 [DIRS 162605]).

e Tracers were dissolved in approximately 12,000 L of groundwater from c\#3 (DTN: LA0401PR831231.001 [DIRS 171859]).

f Lithium was injected as $33.3 \mathrm{~kg} \mathrm{LiBr}$ and $80.8 \mathrm{~kg} \mathrm{LiCl}$ (Reimus 2000 [DIRS 162855]).

$\mathrm{g}$ Tracers were dissolved in approximately 6,000 L of groundwater from c\#2 (DTN: LA0401PR831231.001 [DIRS 171859]).

$\mathrm{h}$ The microsphere injection was initiated 3.5 hours after the start of injection of solute tracers in the Bullfrog test. The microsphere and solute injections ended at the same time. (Reimus 2000 [DIRS 162855]).

i These microspheres were injected 2 days prior to solute tracers in the Prow Pass test (dispersed in approximately $6,000 \mathrm{~L}$ of groundwater from $\mathrm{C \# 2}$ ) to avoid the possible destabilization of the microspheres in the high-ionic strength injection solution containing the solute tracers (Reimus 2000 [DIRS 162852]). Based on average concentration measured in a dilution of a known volume fraction of the microsphere stock solution injected. Sources: concentration measurements (Reimus 2000 [DIRS 165125]); preparation of dilutions for Bullfrog test (Reimus 2000 [DIRS 162855]); preparation of dilutions for Prow Pass test (Reimus 2000 [DIRS 162852]); and summary of calculations (DTN: LA0401PR831231.001 [DIRS 171859], also Reimus 2003 [DIRS 165129], pp. 115 to 116; Attachment A, pp. A-1 to A-6). Injection concentrations calculated by dividing number of spheres injected by injection volumes of $12,000 \mathrm{~L} \times(6.5 / 10)=7,800 \mathrm{~L}$ (Bullfrog test) and 6,000 L (Prow Pass test). The factor of $6.5 / 10$ for the Bullfrog test accounts for the fact that the microspheres were injected for only 6.5 hours of the total of $10 \mathrm{hrs}$ that the $12,000 \mathrm{~L}$ was injected.

NOTE: $C M L=$ carboxylate-modified latex; PFBA=pentafluorobenzoic acid or pentafluorobenzoate.

The hypothetical responses in Figure D-18 suggest that a multiple tracer test involving the simultaneous injection of nonsorbing solute tracers with different diffusion coefficients and a sorbing tracer should allow qualitative discrimination between a single-porosity system and a dual-porosity system. That is, if nonsorbing tracers of different diffusion coefficients have different responses and/or if a sorbing tracer has a peak concentration that occurs at about the same time as a nonsorbing tracer but with a lower concentration, then a dual-porosity system is suggested. This approach was taken by Maloszewski et al. (1999 [DIRS 156841]), although they used only multiple nonsorbing tracers in a fractured sandstone/quartzite/slate system. 
Furthermore, if a dual-porosity response is observed and one knows the relative diffusion coefficients of the two nonsorbing tracers, it should be possible to determine how much of the apparent dispersion in the responses is due to true hydrodynamic dispersion and how much is due to matrix diffusion. Both of these processes have the effect of broadening the response curves or increasing the tailing of the tracers, but only matrix diffusion can cause a separation of the responses of the two tracers. The magnitude of the separation can be used to distinguish quantitatively between the effects of matrix diffusion and hydrodynamic dispersion, resulting in unambiguous estimates of mean residence times, dispersion coefficients, and matrix diffusion parameters in a tracer test.

Effective sorption parameters associated with the response of a simultaneously injected sorbing tracer can then be estimated by assuming that the sorbing tracer experiences the same mean residence time, longitudinal dispersivity, and matrix diffusion (subject to its diffusion coefficient) as the nonsorbing tracers. In this case, only the sorption parameter(s) need be adjusted to obtain a fit/match to the sorbing tracer response. Likewise, colloid filtration/attachment and detachment parameters can be obtained by assuming that the CML microspheres experience the same mean residence times and longitudinal dispersivities as the nonsorbing solute tracers. For the microspheres, matrix diffusion is assumed to be negligible because of their large size and small diffusivity relative to the solutes.

\section{D4.4 CONDUCT OF TRACER TESTS}

The cross-hole tracer tests were conducted between wells c\#2 and c\#3, which are separated by about $30 \mathrm{~m}$ at the surface (Figure D-2). c\#2 was used as the tracer injection well and c\#3 as the production well in the lower Bullfrog Tuff (Reimus 2000 [DIRS 162855]; [DIRS 164624]). In the Prow Pass Tuff, c\#3 was the injection well, and c\#2 was the production well (Reimus 2000 [DIRS 162852]). The natural gradient at the $\mathrm{C}$-wells site, though quite flat, is believed to be oriented in the direction from c\#3 to c\#2 (Figure D-2), so tracer movement in the Bullfrog test was against the gradient, and in the Prow Pass test, it was with the gradient. Prior to injecting tracers, a weak-dipole flow field was established in each test by reinjecting a fraction of the water pumped from the production well into the injection well. The production and recirculation flow rates are summarized in Table D-5. The weak-dipole flow configuration was chosen over a convergent flow configuration (no recirculation) to ensure that tracers were "flushed" out of the injection wellbore instead of relying on the flow field induced by pumping the production well to draw tracers out of the wellbore. Pressure transducers continuously monitored pressures between the packers, above the upper packer, and below the lower packer in each well during the tests. Because of the drastic differences in transmissivity of the two test intervals, the water level drawdown in the Prow Pass interval $(62 \mathrm{~m})$ was over an order of magnitude greater than the drawdown in the Bullfrog interval $(5 \mathrm{~m})$ despite the fact that the production rate in the Bullfrog test was approximately 30 times greater than in the Prow Pass test.

After establishing a reasonably steady weak-dipole flow field, as indicated by stable water levels in the packed-off intervals, the recirculation of produced water into the injection well was replaced by the injection of a groundwater solution containing the three solute tracers. The tracer solution was injected at the same flow rate as the recirculation and without any interruption to the flow, and when the injection was complete, recirculation was immediately resumed without interruption. Thus, there were no pressure or flow transients introduced to the system as a result 
of tracer injection. Recirculation of produced water was discontinued after 40 days in the Bullfrog test, but it was maintained throughout the Prow Pass test. The Bullfrog test was conducted for 337 days, and the Prow Pass test was conducted for 127 days.

Table D-5. Average Production and Recirculation Rates During the Bullfrog and Prow Pass Tracer Tests and Summary of Flow Interruptions During the Prow Pass Test

\begin{tabular}{|c|c|c|c|}
\hline Test & Production Rate (L/min) & Recirculation Rate (L/min) & Recirculation Ratio \\
\hline Bullfrog ${ }^{a}$ & 568 & 19 (zero after 40 days) & 0.033 \\
\hline Prow Pass ${ }^{b}$ & 19 & 5.7 & 0.3 \\
\hline \multicolumn{4}{|c|}{ Prow Pass Test Flow Interruptions: $^{c}$} \\
\hline Interruption & Flow Shut Off & Flow Turned On & Duration (hr) \\
\hline 1 & 11/14/98, 9:00 am & $11 / 14 / 98, \sim 11: 00 \mathrm{pm}$ & $\sim 14$ \\
\hline 2 & 11/23/98, 9:00 am & 11/30/98, 4:00 pm & $\sim 175$ \\
\hline 3 & $12 / 21 / 98, \sim 9: 00 \mathrm{am}$ & $1 / 4 / 99, \sim 11: 00 \mathrm{pm}$ & $\sim 337$ \\
\hline \multicolumn{4}{|c|}{$\begin{array}{l}\text { Source: DTNs: GS981008312314.002 [DIRS 147068]; GS981008312314.003 [DIRS 144464] (Bullfrog rates); } \\
\text { GS010799992315.001 [DIRS 157067] (Prow Pass rates). }\end{array}$} \\
\hline
\end{tabular}

The Prow Pass test featured three different flow interruptions (two intentional) during the tailing portion of the test. The times and durations of these interruptions are summarized in Table D-5. The first interruption was unplanned and occurred as a result of a diesel generator failure. The latter two interruptions were intentional and coincided with the Thanksgiving and Christmas-New Year's holiday breaks, respectively. In addition to the practical consideration of not staffing the remote field site over the holidays, these flow interruptions offered the opportunity to obtain independent confirmation of matrix diffusion in the flow system. If a flow interruption is introduced during the tailing portion of a tracer test in a dual-porosity medium when tracers are diffusing back out of the matrix, then an increase in nonsorbing tracer concentrations should result when flow is resumed.

Water samples were collected at the production well throughout both tests using an automatic sampler. The sampling interval was gradually increased as the tests progressed. Sampling of the injection interval was not possible in the Bullfrog test, but a sampling loop that was designed to continuously mix the injection interval in c\#3 was implemented in the Prow Pass test. Unfortunately, the submersible pump used to bring water to the surface generated more heat than could be efficiently removed from the loop, so the use of the loop for mixing had to be abandoned to prevent overheating of the downhole instrumentation. However, the loop was used 40 days into the Prow Pass test to obtain samples over a 10-hr period to assess how well the injection wellbore had been purged of tracers by the reinjection of production water.

Groundwater samples were analyzed for bromide $\left(\mathrm{Br}^{-}\right)$by liquid chromatography (with a conductivity detector) and for lithium $\left(\mathrm{Li}^{+}\right)$by inductively coupled-plasma, atomic-emissionspectroscopy at Los Alamos National Laboratory. PFBA was analyzed by HPLC (with a UVabsorbance detector), also at Los Alamos. The fluorescent CML microspheres were analyzed by flow cytometry. 


\section{D4.5 TRACER TEST RESULTS}

Figure D-19 shows the normalized concentrations of the three solute tracers at the production well as a function of time during the Bullfrog test. All concentrations are normalized to the injection masses of tracers $\left(\mu \mathrm{g} / \mathrm{L}-\mathrm{kg}\right.$ injected or $\left.\mathrm{L}^{-1} \times 10^{9}\right)$. The axes in Figure D-19 have logarithmic scales so that the details of the breakthrough curves can be seen throughout the entire test. The fractional recoveries of the tracers over the duration of the test were 0.74 for PFBA, 0.69 for bromide, and 0.39 for lithium (DTN: LA0410PR831231.001 [DIRS 171899]). Figure D-20 shows the response of the $360-\mathrm{nm}$ diameter CML microspheres relative to the PFBA response in the Bullfrog tracer test. It is apparent that, while the microspheres arrived slightly earlier than the PFBA, they were significantly attenuated relative to the PFBA throughout the test. The fractional recovery of microspheres during the test was 0.145 (LA0410PR831231.001 [DIRS 171899]).

The most striking feature of the tracer breakthrough curves (Figures D-19 and D-20) is their bimodal shape. It is believed that the double-peak responses were the result of at least two distinct fracture-flow pathways between the injection and production wells located at different depths within the relatively long (approximately $100 \mathrm{~m}$ ) test interval. The flow survey information in Figure 6.1-2 suggests that there were probably two principal zones of outflow during tracer injection and recirculation in $\mathrm{c \# 2}$ (see the triangles indicating percentages of flow during open-hole pumping). Because of the lack of mixing in the injection interval, the tracer solutions, which were injected directly below the top packer and were approximately 2 percent more dense than the groundwater, probably sank rapidly to the bottom of the interval (approximately $200 \mathrm{~kg}$ of tracers dissolved in approximately 12,000 L (or $\mathrm{kg}$ ) of groundwater would have resulted in an approximately 2 percent increase in water density). Under these conditions, the majority of the tracer mass would be expected to exit c\#2 from the lower flow zone; and, indeed, the majority of the tracer mass (60 percent) was associated with the second tracer peak. The first peak was apparently the result of a small percentage (approximately 12 percent) of the tracer mass exiting c\#2 from the upper flow zone. This zone was apparently more conductive (as suggested by the greater percentage of flow during open-hole pumping) and much better connected hydraulically to $\mathrm{c} \# 3$ than the lower zone, as the transport time between the wells in this zone was much shorter. Additional evidence to support this hypothesis is obtained by comparing the PFBA response of Figure D-19 with the response of the same tracer injected into $\mathrm{c} \# 2$ six months prior to the start of the multiple tracer test. Figure D-21 shows that the PFBA breakthrough curve in the earlier test was a more conventional single-peak response with a peak arrival time that coincided with the arrival time of the second peak in the latter test. The earlier test was conducted in the same interval between c\#2 and c\#3 and under the same flow conditions as the multiple-tracer test. The only noteworthy difference between the two tests, besides the additional tracers in the second test, was that only approximately 1,000 L of tracer solution was injected in the first test, whereas approximately $12,000 \mathrm{~L}$ was injected in the second. The larger volume in the second test was due to the large mass of $\mathrm{LiBr}$ that was dissolved to ensure a quantifiable response of lithium ion. Given that the volume of the injection interval (volume between the two packers) was approximately 4,300 L, it seems logical that the approximately $1000 \mathrm{~L}$ of tracer solution injected in the first test would have sunk rapidly and exited the borehole via only the lower flow zone. In contrast, the approximately $12,000 \mathrm{~L}$ of 


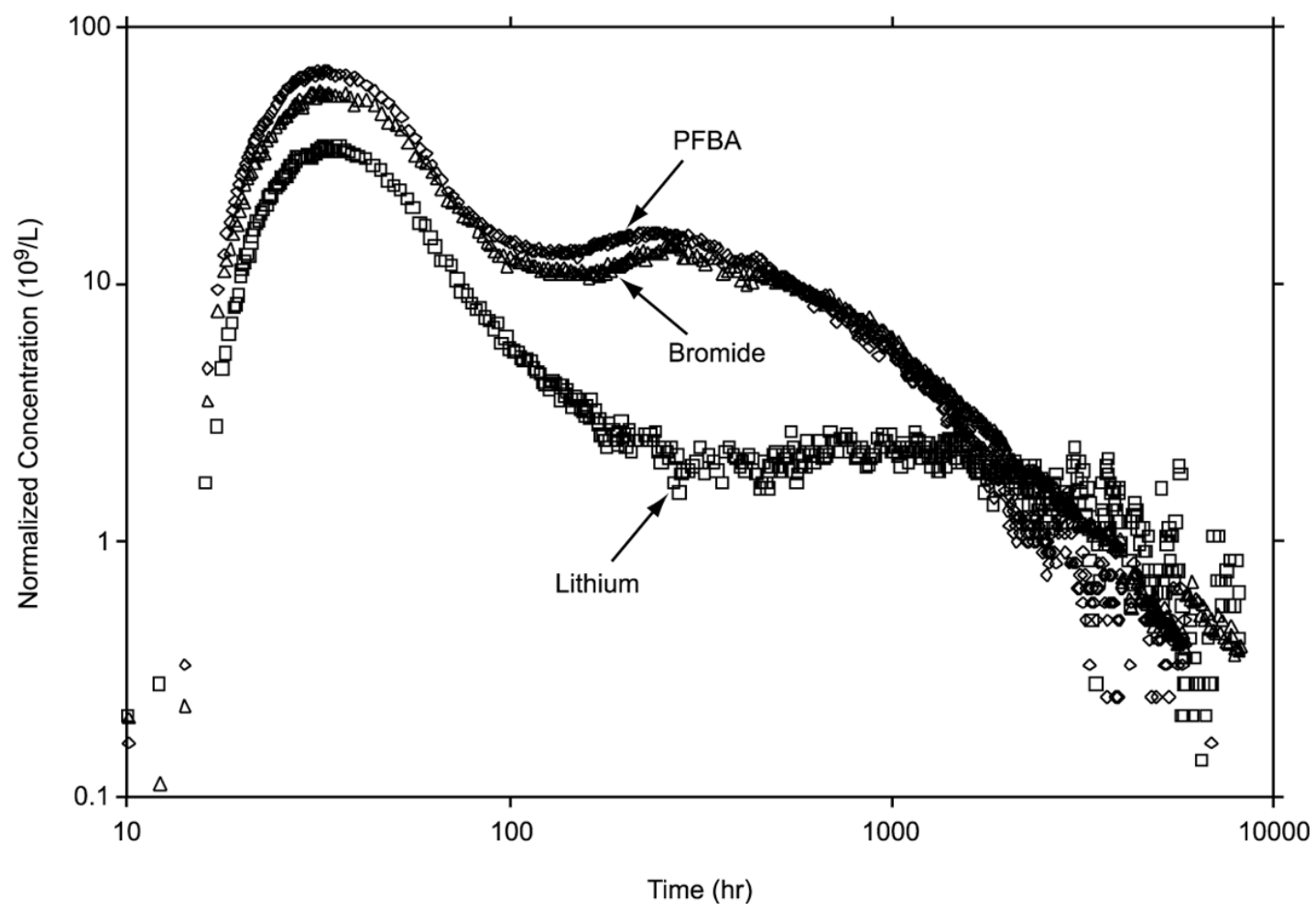

Source: DTNs: LA0007PR831231.001 [DIRS 156043] (raw data), LA0410PR831231.001 [DIRS 171899] (normalized concentrations).

NOTE: Log-log scales are used for the axes so that the bimodal nature of the tracer responses can be seen more clearly.

Figure D-19. Normalized Tracer Concentrations Versus Time in the Bullfrog Tuff Tracer Test Conducted from October 1996 to September 1997

tracer solution injected in the second test (approximately 3 interval volumes) would have eventually "filled up" the interval, and a small fraction of the tracer mass apparently accessed the upper flow zone.

PFBA concentrations in the earlier test were monitored for just over 3,000 hr with a total fractional recovery of 0.72 ; at $3,000 \mathrm{hr}$ into the second test, the total PFBA fractional recovery was 0.60 (DTN: LA0410PR831231.001 [DIRS 171899]). Thus, the tracer recovery in the former test was actually higher than in the latter test despite the early tracer arrival in the latter test. This observation, plus the fact that the shapes of the common peaks of the two tests are different, suggest that a considerable fraction of the mass injected in the latter test followed additional pathways not accessed in the first test. Although the possibility of additional recovery of PFBA from the first test in the second test cannot be ruled out, it is not plausible that the PFBA from the first test could have caused either the first or second PFBA peak in the second test because all of the other tracers used in the second test (which were not injected in the first test) exhibited a bimodal response. 


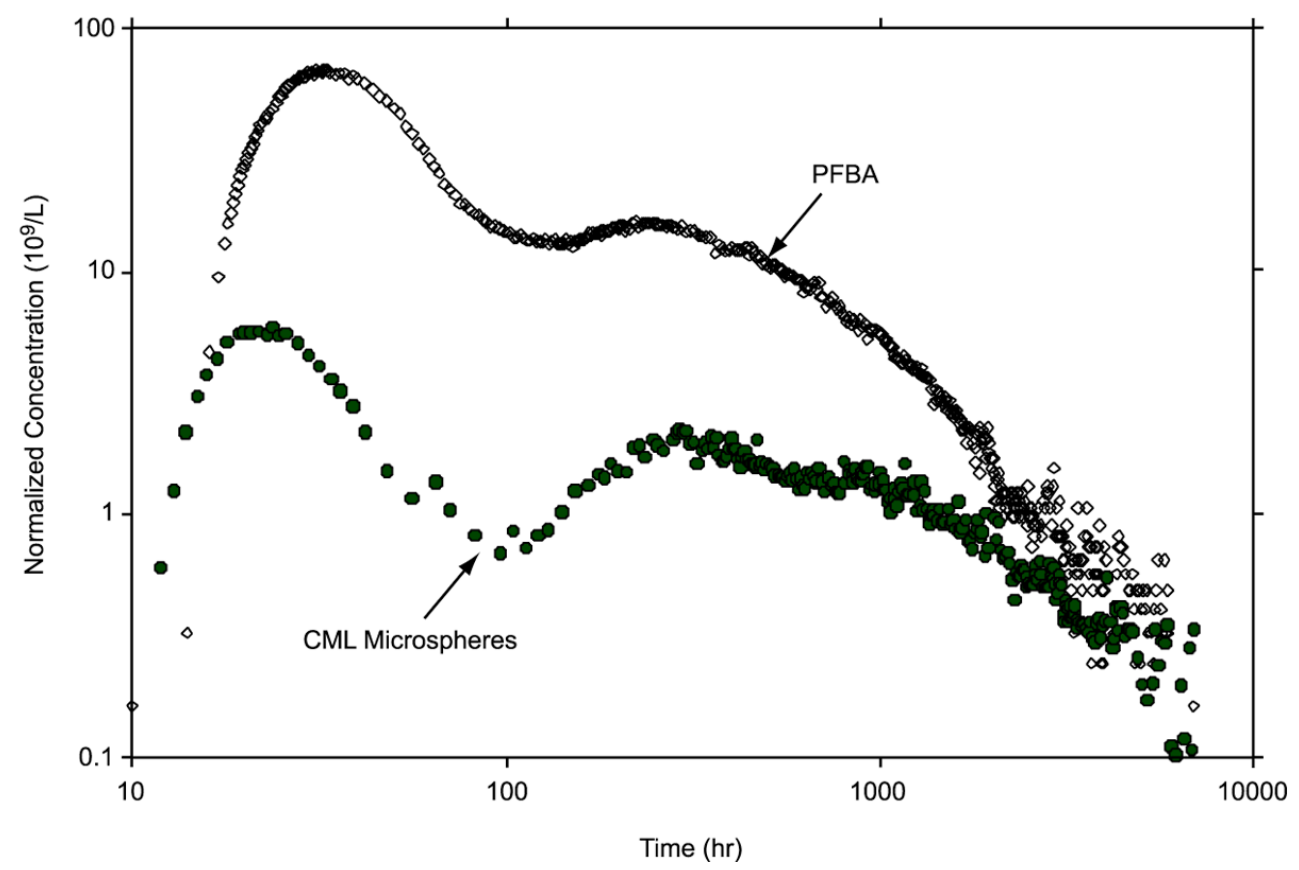

Source: DTNs: LA0007PR831231.001 [DIRS 156043] (raw data), LA0410PR831231.001 [DIRS 171899] (normalized concentrations).

NOTE: Log-log scales are used for the axes so that the bimodal nature of the tracer responses can be seen more clearly.

Figure D-20. Normalized Concentrations of PFBA and 360-nm-Diameter Carboxylate-Modified Polystyrene Latex Microspheres in the Bullfrog Tuff Tracer Test

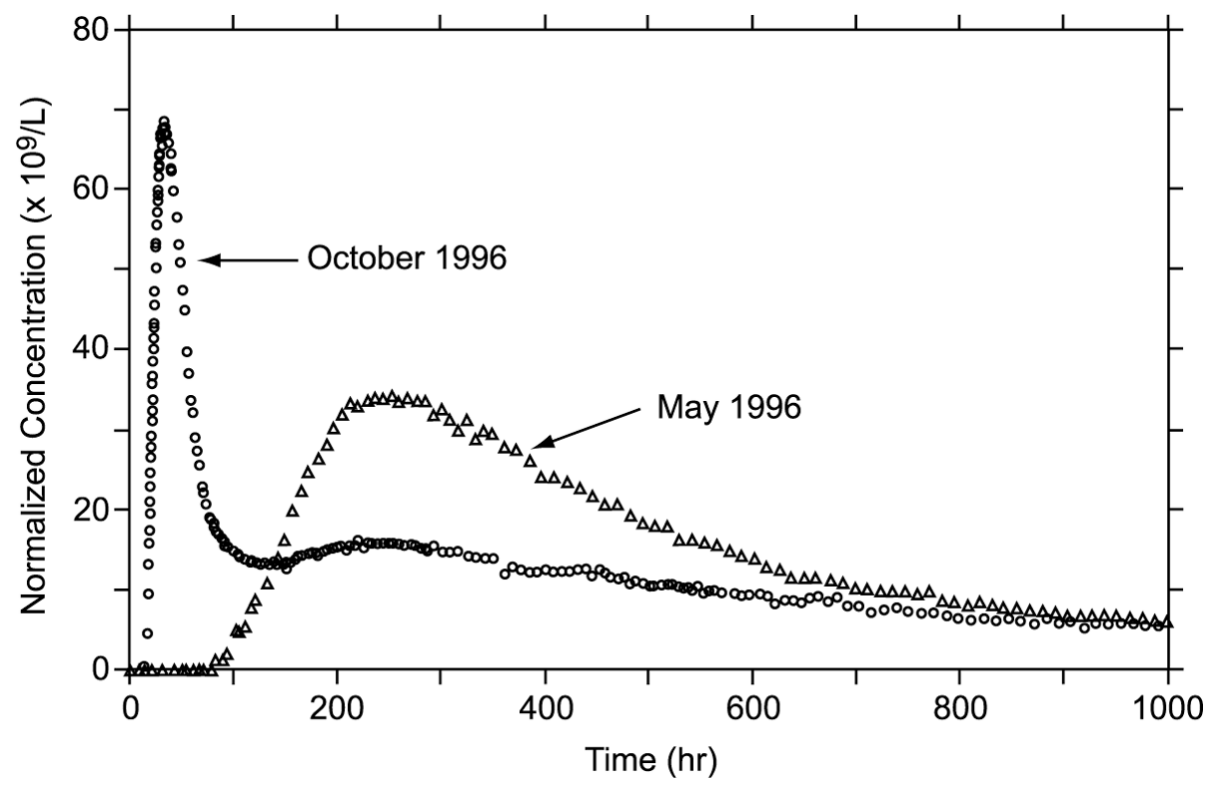

Source: DTNs: LA0007PR831231.001 [DIRS 156043] (raw data), LA0410PR831231.001 [DIRS 171899] (normalized concentrations).

NOTE: The test conditions were the same in both tests, but the injection solution volume was approximately $1000 \mathrm{~L}$ in the May test and approximately 12,000 L in the October test.

Figure D-21. Comparison of Normalized PFBA Responses in the Bullfrog Tuff Resulting from Tracer Injections in May 1996 and October 1996 
Figure D-22 shows the normalized concentrations of the three solute tracers at the production well as a function of time during the Prow Pass test. In contrast to the Bullfrog test, the responses in this test had a more conventional single-peak shape. Figure D-22 also shows that there was indeed an increase in the tracer concentrations upon resumption of flow after each of the three interruptions. The fractional recoveries of the solute tracers over the duration of the test were 0.52 for PFBA, 0.43 for bromide, and 0.19 for lithium ion (LA0410PR831231.001 [DIRS 171899]). Note that the axes in Figure D-22 have a linear scale as opposed to the logarithmic scale used in Figure D-19 for the Bullfrog test.

It is apparent in both Figures D-19 and D-22 that there is considerable separation between the peak normalized concentrations of bromide and PFBA in the two tracer tests, with PFBA always having a higher normalized concentration in each peak. It is also apparent that the tails of the responses of these two tracers converge, with a suggestion of a crossover at late times. However, the appearance of a second peak in the Bullfrog test precluded a crossover after the first peak, and the Prow Pass test was not conducted long enough to see a definitive crossover. Referring to Figure D-18, these breakthrough-curve features are qualitatively consistent with a dual-porosity transport system. The lithium responses in the first peak of the Bullfrog test and in the Prow Pass test are highly attenuated in normalized concentration compared to the nonsorbing tracers, although they are not significantly attenuated in time. Again referring to Figure D-18, these responses are qualitatively consistent with a dual-porosity transport system in which most of the sorption is occurring in the matrix (after diffusive mass transfer from the fractures), with possibly a small amount of sorption also occurring on fracture surfaces. In the case of the second peak in the Bullfrog test, the lithium response is attenuated both in concentration and in time, which is consistent with sorption occurring in both the matrix and on fracture surfaces.

The responses of the CML microspheres relative to PFBA in the Prow Pass test are shown in Figure D-23, which has a logarithmic normalized concentration axis because of the very low normalized concentrations of the microspheres. The fractional recoveries of microspheres in this test were 0.0033 for the 640 -nm-diameter blue microspheres, 0.0012 for the 280 -nm-diameter orange microspheres, and, effectively, zero for the 280 -nm-diameter yellow microspheres (DTN: LA0410PR831231.001 [DIRS 171899]). The response of the yellow microspheres is not shown in Figure D-23 because these microspheres, effectively, never arrived at the production well. The 280-nm-diameter orange and 640-nm-diameter blue microspheres were injected 2 days before the solutes, whereas the 280-nm-diameter yellow microspheres were injected simultaneously with the solutes. It is likely that the high ionic strength of the injection solution (approximately $0.4 \mathrm{M}$ ) caused the yellow microspheres to attach to rock surfaces much more readily than the other microspheres, which were injected in untraced groundwater (ionic strength equals approximately $0.003 \mathrm{M}$ ). It is also interesting to note that the peak concentrations of blue and orange microspheres occurred at about the same time that solutes began arriving at $\mathrm{c} \# 2$, and then the microspheres rapidly decreased in concentration as the solute concentrations increased. This behavior may be purely coincidental, or it may hint that the increased ionic strength associated with the solutes caused the remaining microspheres to attach more readily to rock surfaces. The microsphere "spikes" occurring at about 1,000 hr into the test (Figure D-23) actually correspond to a few days after the c\#3 mixing/sampling loop was run, which suggests that the pressure and flow transients caused by the mixing may have mobilized/detached some microspheres. The timing of this response was consistent with the arrival time of the microspheres after injection into c\#3 on September 23, 1998. A second spike 
in microsphere concentrations occurred the day after the unplanned flow interruption on November 14, 1998 (Figure D-23), which further supports the hypothesis that flow and pressure transients may have resulted in microsphere detachment.

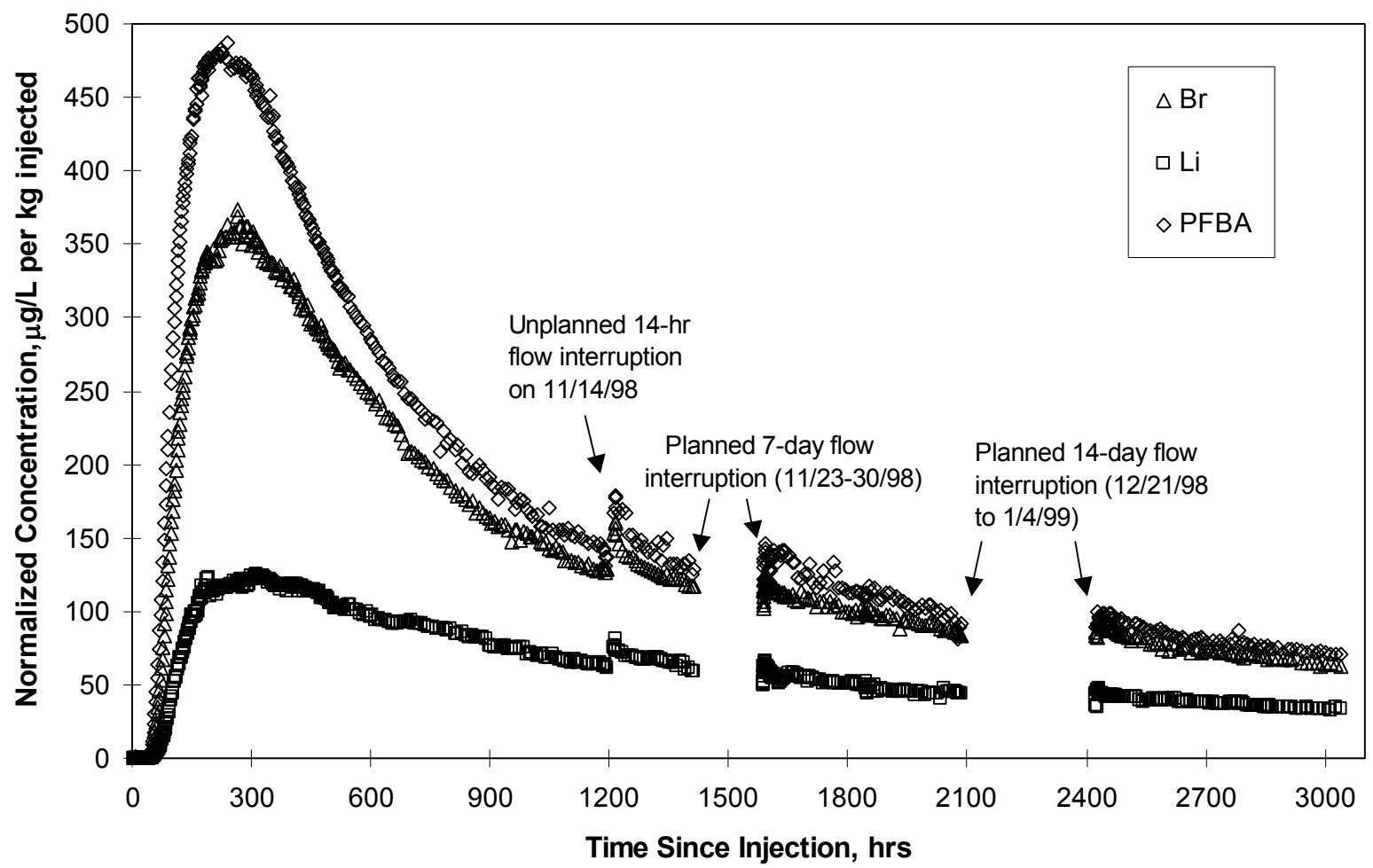

Source: DTNs: LAPR831231AQ99.001 [DIRS 140134] (raw data), LA0410PR831231.001 [DIRS 171899] (normalized concentrations).

NOTE: "Spheres" in the legend refers to CML microspheres.

Figure D-22. Normalized Tracer Concentrations Versus Time in the Prow Pass Tracer Test Conducted from September 1998 to January 1999 


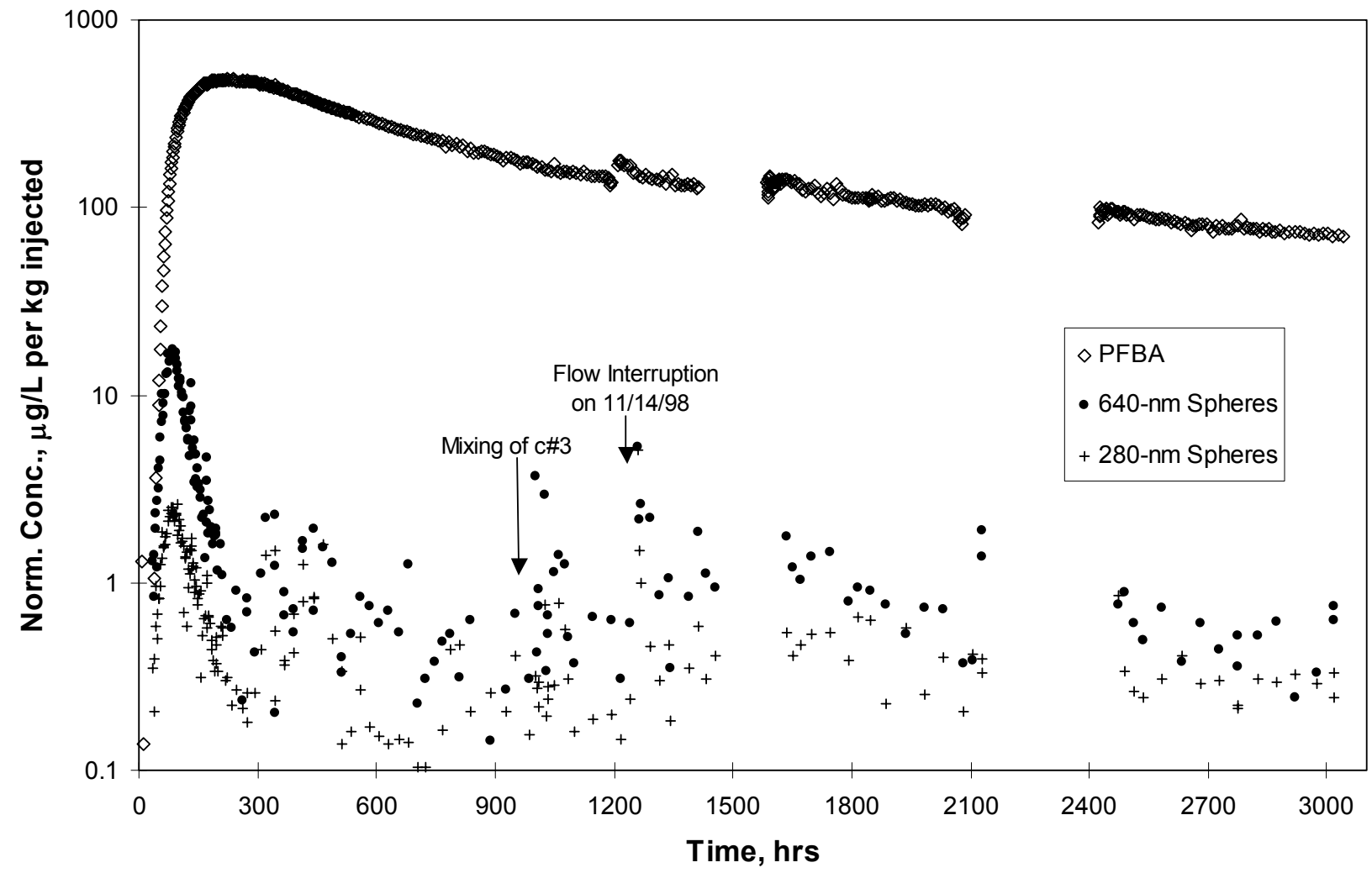

Source: DTNs: LAPR831231AQ99.001 [DIRS 140134] (raw data), LA0410PR831231.001 [DIRS 171899] (normalized concentrations).

NOTE: "Spheres" in the legend refers to CML microspheres. The 280-nm-diameter spheres are the orange-dyed microspheres injected two days prior to the solutes. The $280-\mathrm{nm}$-diameter yellow-dyed spheres that were injected with the solutes were not recovered.

Figure D-23. Normalized Concentrations of PFBA and Carboxylate-Modified Polystyrene Latex Microspheres in the Prow Pass Tracer Test

The sampling loop in c\#3 in the Prow Pass test afforded the opportunity to see how well tracers had been "flushed" from the injection borehole after the test had been running for approximately 40 days. The sampling loop was run for approximately $11 \mathrm{hr}$, and over 50 samples were collected at the surface during this time. The "responses" from the injection interval are shown in Figure D-24. These responses clearly indicate that there was a "slug" of concentrated tracer solution remaining in the interval and that this slug circulated around the sampling loop/borehole several times during the $11 \mathrm{hr}$ of loop operation, dispersing as it circulated (indicated by the lowering and broadening of tracer peaks). Interestingly, the microspheres appear to precede the solutes each time the tracers cycle through the loop, which suggests that there was some as yet unexplained spatial separation of microspheres and solutes in the borehole. The total mass of any given tracer associated with the slugs was less than 0.1 percent of the mass that was injected, so the injection interval had been reasonably well purged of all tracers. This result is important because it shows that the unaccounted-for tracer mass in the overall test is not the result of mass being left behind in the injection borehole, but rather it is mass that is being "lost" by other means (e.g., flow into the matrix that never makes it to the production borehole, stagnation points, losses due to density-driven flow). Given the flow rate through the sampling loop and the 
volumes of the injection interval and piping, the timing of the slug(s) suggested that they had been near the bottom of the interval where the pump intake was located. This result is consistent with the expectation that some of the dense tracer solution would have sunk to the bottom of the interval and remained there if there was no flow to push it out.

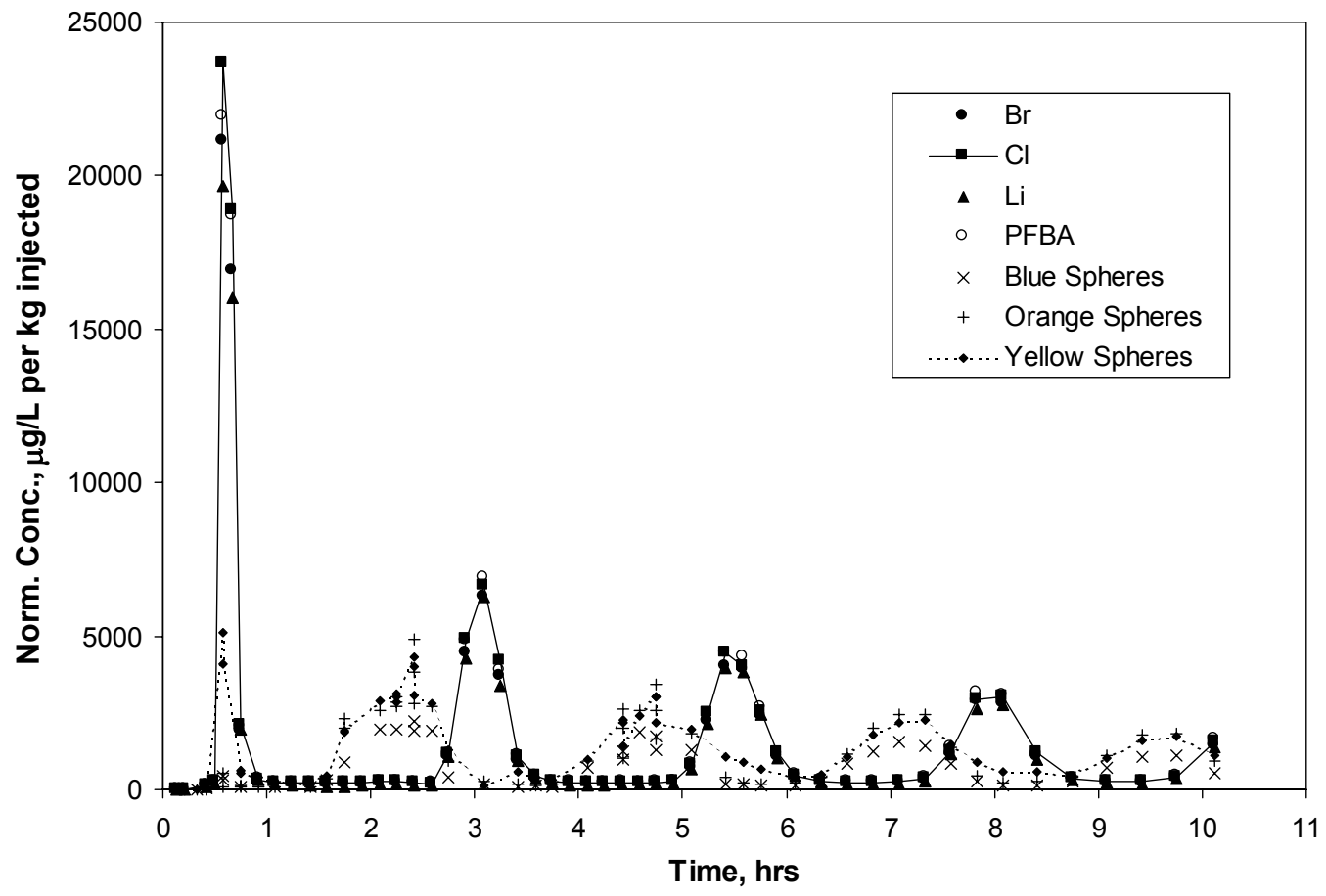

Source: DTNs: LAPR831231AQ99.001 [DIRS 140134] (raw data), LA0410PR831231.001 [DIRS 171899] (normalized concentrations).

NOTE: "Spheres" in the legend refers to CML microspheres. The tracers remaining in the injection interval were apparently highly stratified, probably at the bottom of the interval. Total masses remaining in the injection interval were less than 0.1 percent of the total injection mass of each tracer.

Figure D-24. Tracer Concentrations Mixing Loop 40 Days after Tracer Injection in UE-25 c\#3 in the Prow Pass Tracer Test

\section{D4.6 TRACER TEST INTERPRETIVE MODELING APPROACH}

\section{D4.6.1 Solute Tracers}

To obtain estimates of solute transport parameters in the flow system, the semi-analytical dual-porosity transport code RELAP (REactive transport LAPlace transform inversion computer code) V 2.0 (STN: 10551-2.0-00 [DIRS 159065]) was used to fit simultaneously the solute tracer responses. RELAP, which is described in detail by Reimus and Haga (1999 [DIRS 154705], Appendix B), essentially combines the Laplace-domain dual-porosity transport equations derived by Maloszewski and Zuber (1984 [DIRS 156840], Appendix; 1985 [DIRS 148312]) (modified to account for linear sorption) with Laplace-domain transfer functions that describe a finite-pulse injection, wellbore mixing, and recirculation. Similar approaches have been used by others (Moench 1989 [DIRS 101146], 1995 [DIRS 148784]; Becker and 
Charbeneau 2000 [DIRS 156633], pp. 299 to 310). Maloszewski and Zuber (1984 [DIRS 156840], Appendix; 1985 [DIRS 148312]) assumed that tracer transport in fractures was described by the one-dimensional advection-dispersion equation with one-dimensional diffusion occurring into the surrounding matrix perpendicular to the flow direction in fractures. This simplified flow-system geometry assumed by RELAP is shown in Figure D-25. The solution embodied in the code assumes parallel-plate fractures of constant aperture, $2 \mathrm{~b}$, and constant spacing, L, no concentration gradients across the fracture aperture, and a steady flow rate in fractures.
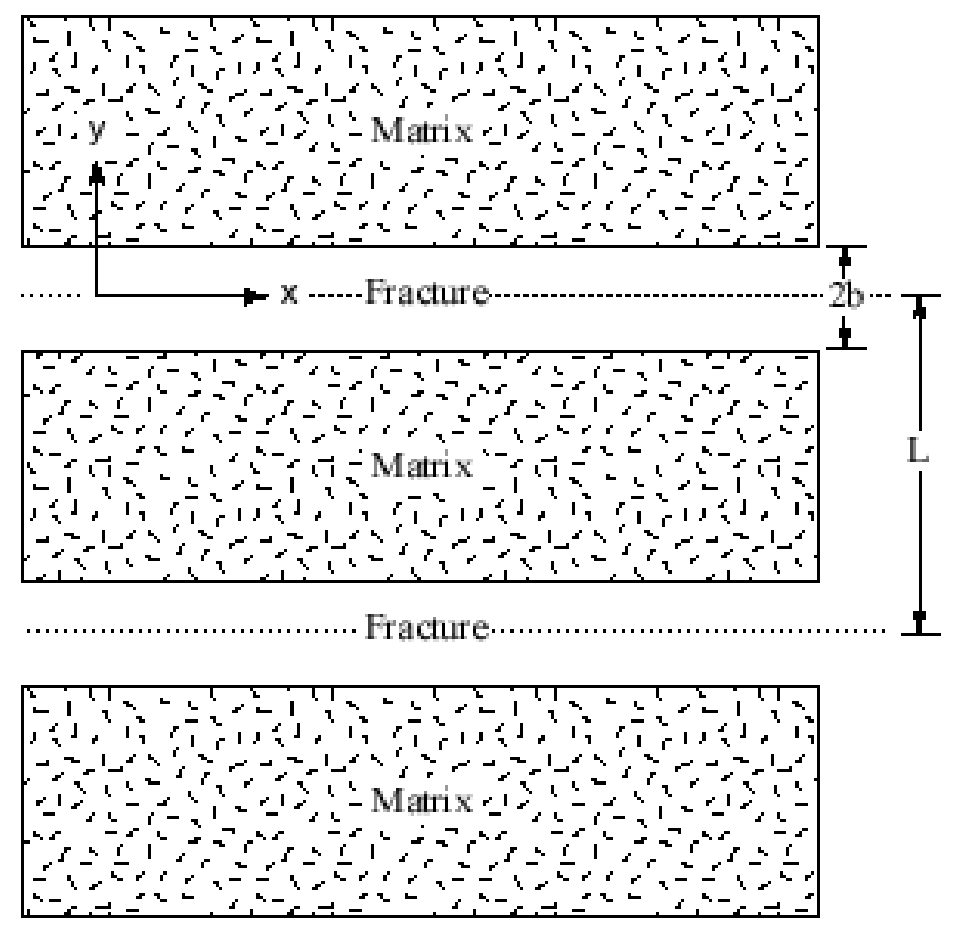

NOTE: For illustration purposes only. Matrix and fractures extend infinitely in $z$ direction.

Figure D-25. System Geometry Assumed in the RELAP and MULTRAN Codes 
The equations describing dual-porosity transport under these conditions are the following [based on work by Maloszewski and Zuber (1984 [DIRS 156840], Appendix)]

Fracture:

$$
R_{\mathrm{f}} \frac{\partial C_{\mathrm{f}}}{\partial t}+v_{\mathrm{f}} \frac{\partial C_{\mathrm{f}}}{\partial x}-D_{\mathrm{f}} \frac{\partial^{2} C_{\mathrm{f}}}{\partial x^{2}}-\left.\frac{\phi D_{\mathrm{m}}}{b \eta} \frac{\partial C_{\mathrm{m}}}{\partial y}\right|_{y=b}=0
$$

Matrix:

$$
R_{\mathrm{m}} \frac{\partial C_{\mathrm{m}}}{\partial t}-D_{\mathrm{m}} \frac{\partial^{2} C_{\mathrm{m}}}{\partial y^{2}}=0
$$

subject to the following initial and boundary conditions:

$$
\begin{gathered}
C_{\mathrm{f}}(x, 0)=0 \\
C_{\mathrm{f}}(x, 0)=C_{\mathrm{p}} \text { from } t=0 \text { to } t=t_{\text {pulse }} \text { (i.e., pulse input) } \\
C_{\mathrm{f}}(\infty, t)=0 \\
C_{\mathrm{m}}(y, x, 0)=0 \\
C_{\mathrm{m}}(b, x, t)=C_{\mathrm{f}}(x, t) \\
\left.\frac{\partial C_{\mathrm{m}}}{\partial y}\right|_{y=\frac{L}{2}}=0 \text { (finite matrix) or } C_{\mathrm{m}}(\infty, x, t)=0 \text { (semi - inifinte matrix) }
\end{gathered}
$$

where

$C_{\mathrm{f}}=$ tracer concentration in solution in fractures, $\mu \mathrm{g} / \mathrm{cm}^{3}$

$C_{\mathrm{m}}=$ tracer concentration in solution in matrix, $\mu \mathrm{g} / \mathrm{cm}^{3}$

$C_{\mathrm{p}}=$ pulse concentration, $\mu \mathrm{g} / \mathrm{cm}^{3}$

$v_{\mathrm{f}}=$ fluid velocity in fractures (in $\mathrm{x}$ direction), $\mathrm{cm} / \mathrm{sec}$

$D_{\mathrm{f}}=$ dispersion coefficient in fractures, $\mathrm{cm}^{2} / \mathrm{sec}$

$D_{\mathrm{m}}=$ molecular diffusion coefficient in matrix, $\mathrm{cm}^{2} / \mathrm{sec}$

$R_{\mathrm{f}}=$ retardation factor in fractures $=1+A_{\mathrm{sp}} k_{A}\left(\right.$ or $\left.1+\frac{2}{b} k_{A}\right)$ for open parallel-plate

fractures). Alternatively, for fractures that are filled with aquifer material, $R_{\mathrm{f}}=1+\frac{\rho_{\mathrm{f}}}{\eta} K_{\mathrm{d}}$ 
$R_{\mathrm{m}}=$ retardation factor in matrix $=1+\frac{\rho_{\mathrm{B}}}{\phi} K_{\mathrm{d}}$

$K_{\mathrm{d}}=$ sorption partition coefficient $=$ mass of tracer sorbed per unit mass of aquifer material divided by solution concentration of tracer at equilibrium, $\mathrm{cm}^{3} / \mathrm{g}$

$k_{A}=K_{\mathrm{d}} / A_{\mathrm{sp}}$ sorption partition coefficient on a unit surface area basis (i.e., mass of tracer sorbed per unit surface area of aquifer material divided by solution concentration of tracer at equilibrium $-K_{\mathrm{d}}$ is defined above, and $A_{\mathrm{sp}}$ is defined below), $\mathrm{cm}^{3} / \mathrm{cm}^{2}$

$A_{\text {sp }}=$ surface area per unit mass of material in fractures or on fracture walls, $\mathrm{cm}^{2} / \mathrm{g}$

$\rho_{\mathrm{f}}=$ bulk density in fractures, $\mathrm{g} / \mathrm{cm}^{3}$

$\rho_{\mathrm{B}}=$ bulk density in matrix, $\mathrm{g} / \mathrm{cm}^{3}$

$\eta=$ porosity within fractures

$\phi=$ matrix porosity

$b=$ fracture half aperture, $\mathrm{cm}$

$L=$ spacing between centerlines of adjacent fractures, $\mathrm{cm}$.

The transformation of Equations 5 and 6 to the Laplace domain and their subsequent solution in the Laplace domain and inversion of the solution back to the time domain are described by Reimus and Haga (1999 [DIRS 154705], Appendix B). Note that Equations 5 and 6 reduce to a single-porosity system if the matrix porosity, $\phi$, (or the matrix diffusion coefficient, $D_{\mathrm{m}}$ ) is set equal to zero. RELAP V 2.0 (STN: 10551-2.0-00 [DIRS 159065]) provides a simultaneous least-squares fit to up to four tracer data sets by automatically adjusting the following parameters (which arise from the dimensionless forms of the governing equations):

- the mean fluid residence time in fractures $(\tau)$

- the Peclet number $\left(P e=r_{\mathrm{L}} / \alpha\right.$, where $r_{\mathrm{L}}=$ distance between wells, $\mathrm{m}$, and $\alpha=$ dispersivity in fractures, $\mathrm{m}$ )

- the mass fraction of tracers participating in the test $(f)$

- a matrix diffusion mass-transfer coefficient, $\frac{\phi}{b} \sqrt{D_{\mathrm{m}}}$, which is obtained from the Laplace transformations of Equations 5 and 6.

- the characteristic fracture spacing, $L$

- the fracture retardation factor, $R_{\mathrm{f}}$

- the matrix retardation factor, $R_{\mathrm{m}}$.

The fractional mass participation $(f)$ is used as an adjustable parameter because low mass recoveries are frequently observed in field tracer tests in fractured rock (e.g., Reimus and Haga 1999 [DIRS 154705], Appendix B), presumably due to (1) dense tracer solutions "sinking" out of the zone of influence of pumping, (2) a significant volumetric flow of tracer solution into the matrix within the injection wellbore (this tracer mass will not make it to the production well during the tracer test because of the very low flow velocities in the matrix), or (3) the loss of tracer mass due to stagnation points induced either by recirculation or by the superposition of the 
induced flow field on the ambient flow field. Although these phenomena can affect absolute tracer responses, they should not, in principle, affect the relative responses of different tracers that are injected simultaneously.

The interpretation of the tracer responses in each test involved first fitting the two nonsorbing tracer responses by simultaneously adjusting all of the parameters listed above with the constraint that the matrix diffusion coefficient, $\mathrm{D}_{\mathrm{m}}$, for bromide was three times that of PFBA (and therefore the matrix diffusion mass transfer coefficient, $\phi \mathrm{D}_{\mathrm{m}}{ }^{1 / 2} / \mathrm{b}$, was approximately 1.7 times that of PFBA). This factor-of-three difference is based on the experimental diffusion cell results discussed in Section E2. $R_{f}$ and $R_{m}$ were held equal to 1 for the two nonsorbing tracers. This fitting procedure implicitly assumed that both tracers had exactly the same mean residence time, Peclet number, mass fraction participation, and characteristic fracture spacing during the tracer tests, which is justified because the tracers were injected simultaneously and, thus, should have experienced the same flow system and same flow conditions.

For the Bullfrog test, the two sets of tracer peaks were fitted sequentially with the second peak being fitted after accounting for the contribution of the tail from the first peak. The analytical solution parameters were allowed to vary independently for each peak, as the peaks were assumed to represent different flow pathways with different transport characteristics. Although the tracer injection duration in the Bullfrog test was about $10 \mathrm{hr}$, it was assumed that for the first peak there was a delay of $4 \mathrm{hr}$, followed by a 6-hr injection of tracer into the pathways that resulted in the first peak. The rationale for this assumption was that there was no early peak in the earlier PFBA test (Figure D-21), which involved an injection of less than one hour, so it seemed logical to assume that the earliest injected tracer solution did not follow the earliestarriving pathways. A 4-hr delay time was chosen because the injected-tracer-solution volume exceeded the injection-interval volume by this time, and it was felt that this was a reasonable criterion for when at least a portion of the tracer solution should have begun moving through the early arriving pathways.

In contrast to the Bullfrog test, the fitting procedure for the Prow Pass test was very straightforward, as only one set of tracer peaks was observed. However, because RELAP V 2.0 (STN: 10551-2.0-00 [DIRS 159065]) is based on a semi-analytical Laplace transform inversion method, it was not capable of simulating the flow transients associated with the flow interruptions during the latter part of the test. To simulate these transients, the computer code MULTRAN (multicomponent transport) V 1.0 (STN: 10666-1.0-00 [DIRS 159068]) was used. MULTRAN is an implicit alternating-direction, two-dimensional, finite-difference code that accounts for cation exchange (involving up to three exchanging cations), charge balance, and multicomponent diffusion in a dual-porosity transport system (Section C.3.2.2). The best-fitting transport parameters obtained from RELAP fits to the tracer data up until the time of the flow interruptions were used in MULTRAN to extend the simulations throughout the entire test.

Once best simultaneous fits to the nonsorbing tracer responses in both tests were obtained, the lithium responses associated with each distinct tracer peak were fitted with RELAP V 2.0 (STN: 10551-2.0-00 [DIRS 159065]) by adjusting $\mathrm{R}_{\mathrm{f}}$ and $\mathrm{R}_{\mathrm{m}}$ while holding all other parameters equal to the values that provided the best fits to the nonsorbing tracers. However, $D_{m}$ for lithium was assumed to be two-thirds that of bromide (and approximately 2 times that of PFBA), rather than about half that of bromide as indicated in Table D-4, because lithium and bromide would 
tend to diffuse together to maintain local charge balance (see Appendix A3 for further discussion). Rate-limited sorption was not considered in the field tests because the response times were all quite long relative to typical rates of ion exchange.

RELAP V 2.0 (STN: 10551-2.0-00 [DIRS 159065]) provided a good match to the lithium response associated with the second peak in the Bullfrog test and also to the lithium response in the Prow Pass test. However, in the case of the first peak in the Bullfrog test, RELAP consistently overestimated the normalized concentrations in the lithium tail when the leading edge of the lithium response was fitted well. The inability to fit the response of an ion-exchanging tracer using a linear equilibrium sorption model ( $K_{d}$ model) had been previously encountered when trying to fit cation responses from both laboratory-scale fracture-transport experiments (Section E3.2) and crushed-rock column experiments (Section E3.1). In these previous studies, it was observed that cation-exchanging tracers transport with less apparent sorption than $K_{d}$ models predict when the tracer injection concentration is high relative to the ionic strength of the groundwater (that is, when the total cation equivalents in the system are dominated by the cation tracer). Under these conditions, some of the cation tracer mass tends to elute with the anion tracers to maintain local charge balance in the system. When tracer concentrations are sufficiently dilute, local charge balance can be maintained by exchanging cations, and a $K_{d}$ model tends to approximate more closely the observed transport behavior. In the Bullfrog test, the injection concentration of lithium was approximately $0.1 \mathrm{M}$, whereas the ionic strength of the C-wells groundwater was approximately $0.003 \mathrm{M}$; therefore, the conditions of a very high cation injection concentration relative to the groundwater ionic strength were met. MULTRAN V1.0 (STN: 10666-1.0-00 [DIRS 159068]) provided much better predictions of cation transport data in laboratory-scale dual-porosity systems under these conditions than RELAP because it explicitly accounts for ion-exchange reactions, multicomponent diffusion, and local charge balance (Section E3.2.2). For this reason, MULTRAN was employed to match the lithium data in the first peak of the Bullfrog test using the mean residence time, Peclet number, and matrix-diffusion, mass-transfer coefficient obtained from the best RELAP fit to the nonsorbing tracer data and allowing the lithium ion-exchange parameters to be varied to fit the lithium data. Lithium was assumed to exchange with sodium and calcium ions based on the results of cation exchange capacity measurements conducted on $\mathrm{C}$-wells tuffs (Section E1.2).

It should be noted that the relatively low tracer concentrations observed at the production well in the Bullfrog test do not necessarily reflect the concentrations that existed in the fractures in which transport occurred; it is very likely that a significant amount of dilution occurred in the production borehole. Thus, concentrations could have remained quite high in the fractures that conducted tracers, satisfying conditions for weakly sorbing transport of the lithium ion. For the second lithium peak of the Bullfrog test and for the Prow Pass test, concentrations in the fractures apparently were dilute enough during the much longer residence times associated with these responses that the lithium transport behavior could be reasonably approximated by a $K_{d}$ model.

\section{D4.6.2 Colloid Tracers (Microspheres)}

As with the solutes, the microsphere responses in the tracer tests were interpreted using the RELAP V 2.0 (STN: 10551-2.0-00 [DIRS 159065]) code to fit the data. The differential equations used to describe microsphere transport were: 


$$
\begin{gathered}
\frac{\partial C}{\partial t}+v_{\mathrm{f}} \frac{\partial C}{\partial x}-D \frac{\partial^{2} C}{\partial x^{2}}+k_{\text {filt }} C-k_{\text {res }} S=0 \\
\frac{1}{b} \frac{\partial S}{\partial t}-k_{\text {filt }} C+k_{\text {res }} S=0
\end{gathered}
$$

where

$C=$ colloid concentration in solution, no. $/ \mathrm{L}$

$S=$ colloid concentration on surfaces, no. $/ \mathrm{cm}^{2}$

$v_{\mathrm{f}}=$ flow velocity in fractures, $\mathrm{cm} / \mathrm{sec}$

$D=$ dispersion coefficient, $\mathrm{cm}^{2} / \mathrm{sec}$

$k_{\text {filt }}=$ filtration rate constant $(1 / \mathrm{sec})=\lambda v_{\mathrm{f}}$, where $\lambda=$ filtration coefficient $(1 / \mathrm{cm})$

$k_{\text {res }}=$ resuspension rate constant, $1 / \mathrm{cm}$-sec

$x, t=$ independent variables for distance and time, respectively.

These equations assume that microspheres are confined to fractures because they are too large to diffuse significantly into the porous rock matrix. The RELAP V 2.0 (STN: 10551-2.0-00 [DIRS 159065]) semi-analytical solution is capable of representing Equations 7 and 8 by making use of its rate-limited sorption features and setting the matrix porosity equal to zero (to eliminate matrix diffusion). It was assumed that the mass fractions, mean residence times, and Peclet numbers that provided the best fits to the nonsorbing solute responses also applied to the microspheres. Any size exclusion chromatography effects (Hiemenz 1986 [DIRS 117358], pp. 42 to 45) that would have resulted in a shorter mean residence time for the microspheres compared to the solutes were assumed to be accounted for by not allowing the microspheres to diffuse into the matrix. Thus, the only adjustable parameters in the analysis were a forward first-order filtration-rate constant and a first-order reverse-filtration-rate constant (also called a resuspension or detachment-rate constant). The product of the latter and the fracture aperture was actually obtained by dividing the best-fitting filtration rate constant by a best-fitting retardation factor minus 1 (i.e., $\mathrm{b} k_{\mathrm{res}}=k_{\text {filt }}\left(\mathrm{R}_{\mathrm{f}}-1\right)$ ).

Initially, attempts to fit the microsphere response associated with the first peak in the Bullfrog test were made by assuming only irreversible filtration with no resuspension/detachment. Although this approach was capable of fitting the timing and normalized concentration of the first microsphere peak, it resulted in a much shorter tail than the data indicated. Therefore, to account for the tail, a small fraction of the filtered microspheres was assumed to detach. A fit to the tail was obtained by adjusting both the fraction of microspheres detaching and the detachment rate constant (only a single-forward filtration-rate constant was assumed for all the microspheres in the first peak). Mathematically, these adjustments are equivalent to making the following changes to equation (8):

$$
\frac{1}{b} \frac{\partial S}{\partial t}-\mathrm{f}_{1} k_{\text {filt }} C+k_{\text {res }} S=0
$$

where 
$\mathrm{f}_{1}=$ fraction of colloids that are reversibly attached or reversibly filtered (if $\mathrm{f}_{1}=1.0$, all colloids are reversibly filtered and equation 8a becomes identical to equation 8), and

$S=$ concentration of reversibly attached colloids on surfaces, no. $/ \mathrm{cm}^{2}$.

A fit to the second microsphere peak in the Bullfrog test was obtained in the same manner. However, in this case, the forward filtration rate constant had to be adjusted large enough so that, essentially, all of the microspheres were filtered as they moved through the system. This approach was necessary because any microspheres moving through the system without being filtered were predicted to arrive too early to match the observed response (note that the second microsphere peak occurred after the second nonsorbing solute peaks; Figure D-20). Unfiltered microspheres moving through the second set of pathways were predicted to arrive at about the same time as the low point in concentration between the two peaks. Thus, to account for the second microsphere peak, it was necessary to assume that a substantial fraction of the microspheres in the second set of pathways were reversibly filtered. The peak itself was fit by assuming a fraction of the microspheres experienced one detachment rate, and the tail was fit by assuming a separate fraction experienced another detachment rate. The remaining microspheres were assumed to not detach at all. This approach implies that there is a distribution of detachment rate constants, a possibility that has been discussed by Dabros and Ven de Ven (1982 [DIRS 143278], pp. 232 to 244); 1983 [DIRS 156652], pp. 576 to 579). The forward rate constant associated with each of these mass fractions was set equal to the minimum rate constant necessary to ensure that nearly all of the microspheres were filtered before making it through the system. Mathematically, these adjustments are equivalent to making the following changes to equations (7) and (8):

$$
\begin{gathered}
\frac{\partial C}{\partial t}+v_{\mathrm{f}} \frac{\partial C}{\partial x}-D \frac{\partial^{2} C}{\partial x^{2}}+k_{\text {filt }} C-k_{\text {res }, 1} S_{1}-k_{\text {res }, 2} S_{2}=0 \\
\frac{1}{b} \frac{\partial S_{1}}{\partial t}-\mathrm{f}_{1} k_{\text {filt }} C+k_{\text {res }, 1} S_{1}=0 \\
\frac{1}{b} \frac{\partial S_{2}}{\partial t}-\mathrm{f}_{2} k_{\text {filt }} C+k_{\text {res }, 2} S_{2}=0
\end{gathered}
$$

where, $\mathrm{f}_{1}=$ fraction of reversibly attached colloids detaching with detachment rate constant $k_{\mathrm{res}, 1}$,

$\mathrm{f}_{2}=$ fraction of reversibly attached colloids detaching with detachment rate constant $k_{\mathrm{res}, 2}$, (if $\mathrm{f}_{1}+\mathrm{f}_{2}=1.0$, all colloids are reversibly attached), and

$S_{1}$ and $S_{2}=$ concentrations of reversibly attached colloids on surfaces that detach according to detachment rate constants $k_{\mathrm{res}, 1}$ and $k_{\mathrm{res}, 2}$, respectively, no. $/ \mathrm{cm}^{2}$.

In the Prow Pass test, only a single filtration and detachment-rate constant were needed to fit the responses of each microsphere, provided the "spikes" associated with the flow transients could be ignored. No attempt was made to fit these spikes. 


\section{D4.7 TRACER TEST INTERPRETATIONS}

\section{D4.7.1 Solute Tracers}

The best RELAP/MULTRAN fits to the solute tracer breakthrough curves in the Bullfrog test are shown in Figure D-26. As discussed above, RELAP V 2.0 (STN: 10551-2.0-00 [DIRS 159065]) was used to fit the nonsorbing tracer responses and the lithium response in the second peak, and MULTRAN V 1.0 (STN: 10666-1.0-00 [DIRS 159068]) was used to fit the lithium response in the first peak (MULTRAN fits to the bromide and PFBA data are also shown for the first peak in Figure D-26). The RELAP fits were obtained assuming a constant production rate of $568 \mathrm{~L} / \mathrm{min}$ and a constant recirculation rate of $19 \mathrm{~L} / \mathrm{min}$ (3.3 percent of production), despite the fact that recirculation in the field test was stopped after 40 days. Both tracer peaks occurred well before recirculation was terminated, so the only portion of the test that was incorrectly interpreted was the latter tailing portion of the second peak. Separate simulations comparing the results of MULTRAN runs with and without recirculation after 40 days indicated that the assumption of continued recirculation after 40 days had negligible effect on the fits or the values of the fitted parameters.

The best-fitting parameters from RELAP V 2.0 (STN: 10551-2.0-00 [DIRS 159065]) for the Bullfrog test are listed in Table D-6. Note that separate estimates of $\tau$ and $P e$ are provided, depending on whether linear flow (constant flow velocity between injection and production well) or radial flow (flow velocity inversely proportional to distance from production well) is assumed to occur in the test interval. RELAP is capable of providing estimates for these parameters under either assumption (the quality of the fits and the other fitted parameters are not affected). In a heterogeneous, confined aquifer with fully penetrating wells (i.e., no flow in the vertical direction), the flow velocity to a single production well with no recirculation into an injection well is expected to vary between linear and radial (National Research Council 1996 [DIRS 139151], pp. 252 to 261). Thus, if it is assumed that the test interval was reasonably confined, presenting the two values of $\tau$ and $P e$ in Table D-6 is a rough way of bounding these parameter estimates as a result of flow-field uncertainty. Although the Bullfrog flow system was not perfectly confined, this approach should still yield reasonable bounds for $\tau$ and $P e$, as the flow velocities in pathways carrying tracers from $\mathrm{c} \# 2$ to $\mathrm{c} \# 3$ should have started out relatively high due to the recirculation into $\mathrm{c} \# 2$, gone through a minimum, and then increased again in the vicinity of $\mathrm{c} \# 3$. Thus, the weak dipole should have resulted in a flow pattern that was intermediate between linear and radial flow. 

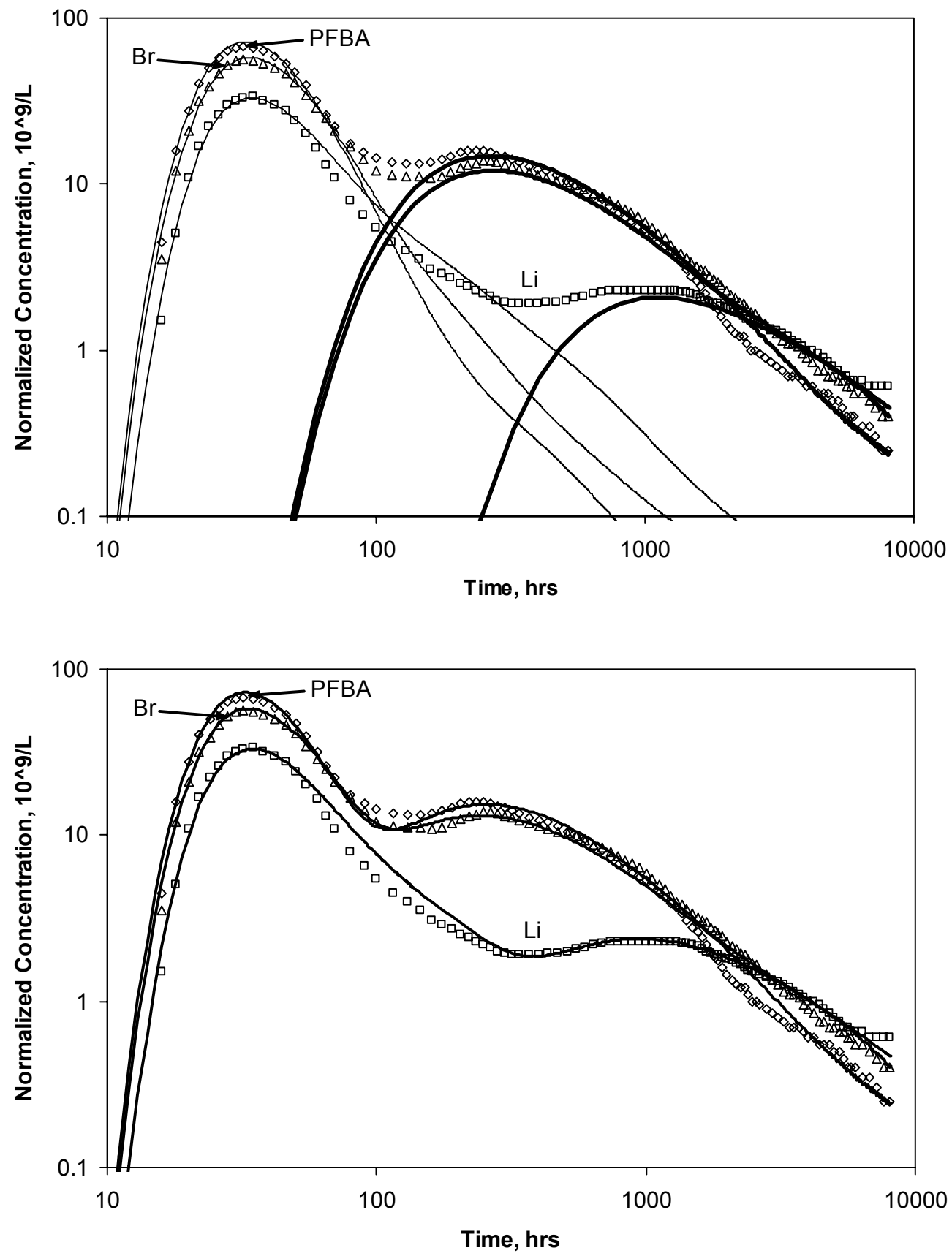

Source: DTNs: LA0007PR831231.001 [DIRS 156043] (data), LA0410PR831231.001 [DIRS 171899] (normalized concentrations).

Output DTN: LA0303PR831231.003 (interpretive fits).

NOTE: The upper plot shows individual fits to first and second tracer peaks (MULTRAN V 1.0 (STN: 10666-1.0-00 [DIRS 159068]) and RELAP V 2.0 (STN: 10551-2.0-00 [DIRS 159065], respectively), and the lower plot shows composite fits. For clarity, the data points shown are a subset of the actual data. The best-fitting model parameters are provided in Table D-6.

Figure D-26. RELAP and MULTRAN Fits to the Tracer Response Curves in the Bullfrog Tuff Tracer Test 
Table D-6. RELAP Model Parameters Providing the Best Fits to the Bullfrog Tracer Test Data

\begin{tabular}{|c|c|c|}
\hline Parameter & Pathway 1 & Pathway 2 \\
\hline Mass fraction, $f$ & 0.115 & 0.60 \\
\hline Mean residence time, $\tau$, for linear flow (hr) & 36 & 1020 \\
\hline Peclet number, $P e$, for linear flow & 6.5 & 1.6 \\
\hline Mean residence time, $\tau$, for radial flow (hr) & 30 & 630 \\
\hline Peclet number, $P e$, for radial flow & 9.3 & 2.8 \\
\hline$\frac{\phi}{b} \sqrt{D_{\mathrm{m}}}$ for bromide $\left(\sec ^{-1 / 2}\right)^{\mathrm{a}}$ & 0.0015 & 0.000469 \\
\hline Fracture spacing $(\mathrm{cm})$ & $\infty(2.4)^{b}$ & 4.4 \\
\hline Lithium fracture retardation factor, $R_{\mathrm{f}}$ & 1 & 4 \\
\hline Lithium matrix retardation factor, $R_{\mathrm{m}}$ & $7.5^{c}$ & 20 \\
\hline
\end{tabular}

Output DTNs: LA0303PR831231.003; LA0303PR831231.005

NOTE: Pathway 1 and Pathway 2 are associated with the first and second tracer peaks, respectively. The fits are shown in Figure D-26 (MULTRAN V 1.0 (STN: 10666-1.0-00 [DIRS 159068]) was used to fit first lithium peak in Figure D-26).

a The mass transfer coefficient, $M T C=\frac{\phi}{b} \sqrt{D_{\mathrm{m}}}$, for PFBA is 0.577 times that for bromide.

b The number in parentheses is the minimum fracture spacing that yields the same results as an infinite fracture spacing.

c Lithium response associated with first tracer peak was poorly fitted by RELAP V 2.0 (STN: 10551-2.0-00 [DIRS 159065]), so MULTRAN was used to obtain a better fit, which is shown in Figure D-26.

MTC=mass transfer coefficient.

Figure D-27 shows the best RELAP/MULTRAN fits to the Prow Pass solute tracer test data, and Table D-7 gives the best-fitting RELAP V 2.0 (STN: 10551-2.0-00 [DIRS 159065]) parameters (obtained by simulating the first $1,200 \mathrm{hr}$ of the test, prior to the first flow interruption). MULTRAN V 1.0 (STN: 10666-1.0-00 [DIRS 159068]) was used after the first flow interruption to interpret the remainder of the test using the best-fitting parameters from RELAP to extend the simulations. Because the tracer concentrations were significantly higher in this test than in the Bullfrog test, it was possible to determine the responses of the cations (sodium and calcium) that exchanged with lithium during the test. (The background concentrations of the exchanging cations were too high relative to their signals in the Bullfrog test to determine their responses.) Figure D-28 shows the responses of lithium, sodium, and calcium ions in the Prow Pass test, expressed as meq/L versus time. MULTRAN fits to the data are also included in Figure D-28. Although not shown here, it was confirmed that the total cation and anion charges balanced each other, as they must, throughout the test (DTN: LA0410PR831231.001 [DIRS 171899]). 


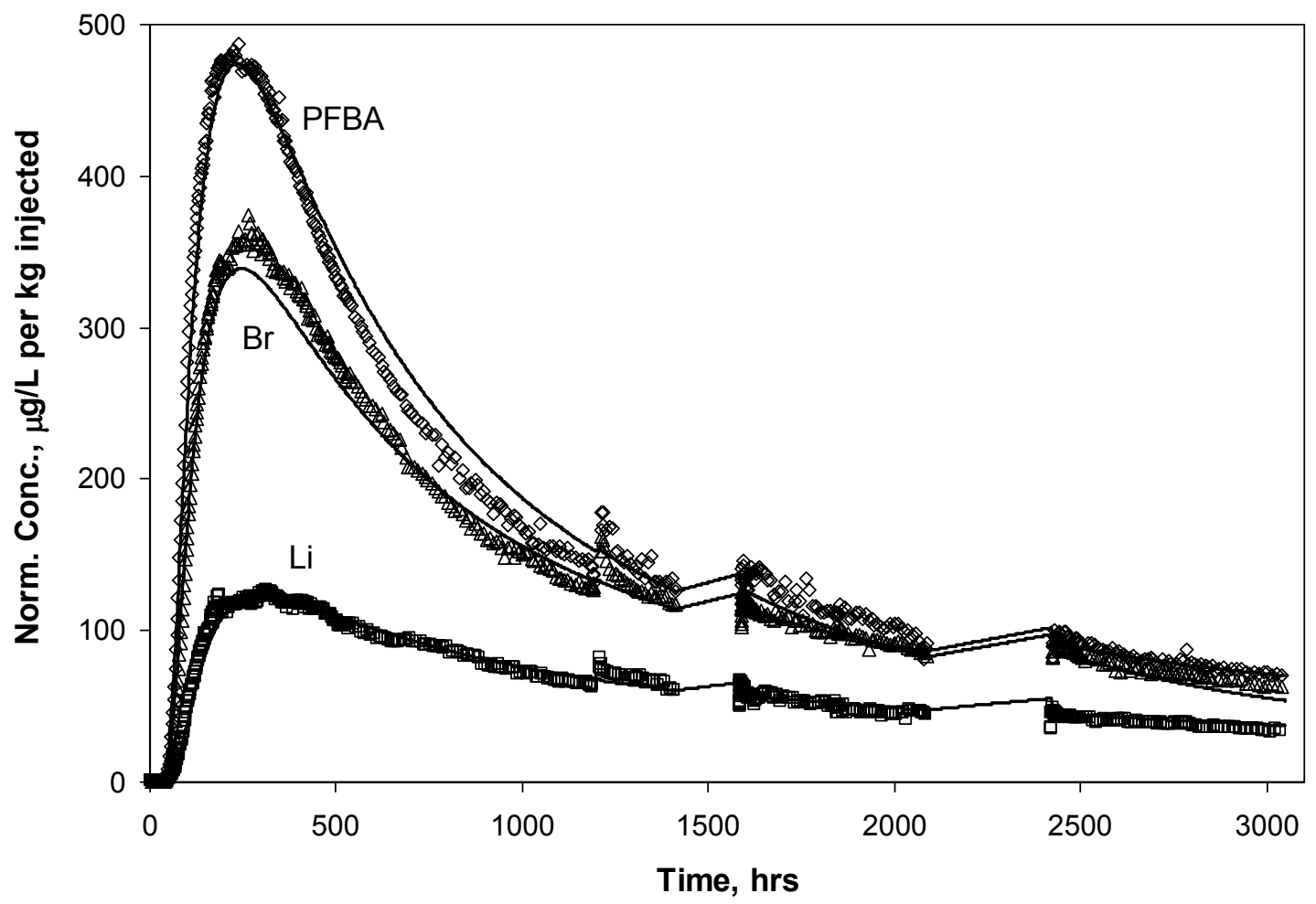

Source: DTNs: LAPR831231AQ99.001 [DIRS 140134] (raw data), LA0410PR831231.001 [DIRS 171899] (normalized concentrations).

Output DTN: LA0303PR831231.003 (interpretive fits).

NOTE: The best-fitting model parameters are provided in Table D-7.

Figure D-27. RELAP/MULTRAN Fits to the Tracer Response Curves in the Prow Pass Tuff Tracer Test 
Table D-7. RELAP Parameters Providing the Best Fits to the First 1200 Hours of Prow Pass Tracer Test Data

\begin{tabular}{|l|c|}
\hline \multicolumn{1}{|c|}{ Parameter } & Parameter Value \\
\hline Mass fraction, $f$ & 0.72 \\
\hline Mean residence time, $\tau$, for linear flow $(\mathrm{hr})$ & 1210 \\
\hline Peclet number, $P e$, for linear flow & $1.3^{\mathrm{a}}$ \\
\hline Mean residence time, $\tau$, for radial flow $(\mathrm{hr})$ & 610 \\
\hline Peclet number, $P e$, for radial flow & $2.3^{\mathrm{a}}$ \\
\hline$\frac{\phi}{b} \sqrt{D_{\mathrm{m}}}$ for bromide $\left(\mathrm{sec}^{-1 / 2}\right)^{\mathrm{b}}$ & 0.00095 \\
\hline Fracture spacing $(\mathrm{cm})$ & \\
\hline Lithium fracture retardation factor, $R_{\mathrm{f}}$ & $\infty(6.4)^{\mathrm{c}}$ \\
\hline Lithium matrix retardation factor, $R_{\mathrm{m}}$ & 1 \\
\hline
\end{tabular}

Output DTNs: LA0303PR831231.003; LA0303PR831231.005.

NOTE: The fits (extended by MULTRAN V 1.0 (STN: 10666-1.0-00 [DIRS 159068) simulations) are shown in Figure D-27.

${ }^{a}$ The Peclet numbers were adjusted to correct for the theoretical dispersion caused by the partial recirculation flow field (see text). Peclet numbers obtained directly from RELAP V 2.0 (STN: 10551-2.0-00 [DIRS 159065]) were 0.9 (linear flow) and 1.9 (radial flow).

${ }^{\mathrm{b}}$ The mass transfer coefficient, MTC $=\frac{\phi}{b} \sqrt{D_{\mathrm{m}}}$, for PFBA is 0.577 times that for bromide.

c The number in parentheses is the minimum fracture spacing that yields the same results as infinite fracture spacing.

MTC=mass transfer coefficient. 


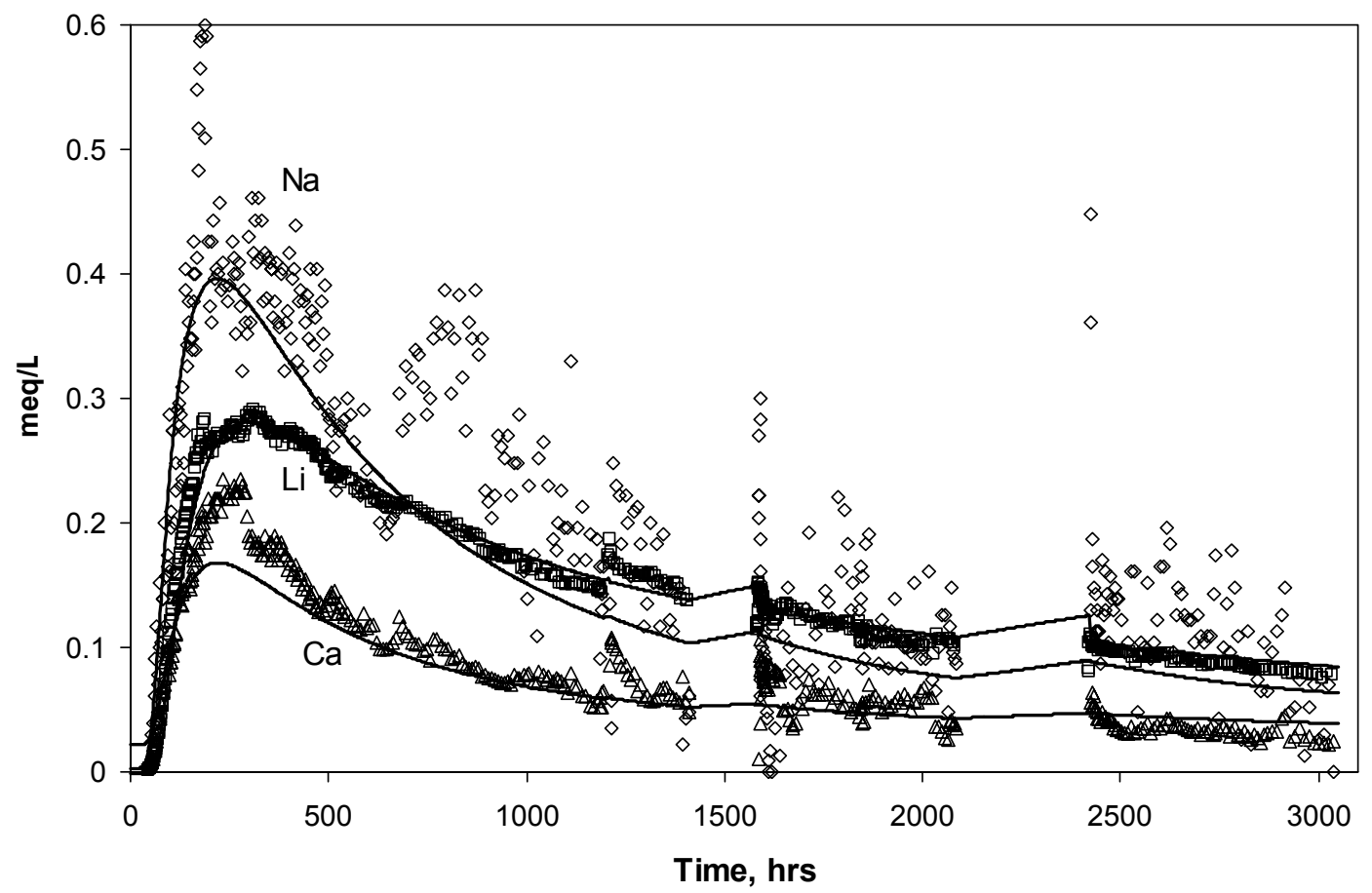

Source: DTNs: LAPR831231AQ99.001 [DIRS 140134] (raw data), LA0410PR831231.001 [DIRS 171899] (meq/L). Output DTN: LA0303PR831231.003 (interpretive fits).

NOTE: Scatter for sodium is due to the background, which has been subtracted, being large relative to the signal.

Figure D-28. MULTRAN Fits to Cation Responses in the Prow Pass Tracer Test

\section{D4.7.2 Colloid Tracers (Microspheres)}

The fit(s) to the Bullfrog test microsphere data are shown in Figure D-29. The "pathways" labeled $1 \mathrm{~A}$ and $1 \mathrm{~B}$ represent the nondetaching (or very slowly detaching) and detaching fractions, respectively, of the microspheres following the pathway(s) that resulted in the first solute peak. Pathways 2A, 2B, and 2C in Figure D-29 represent the nondetaching (or very slowly detaching) and the two detaching fractions, respectively, of the microspheres following the pathway(s) that resulted in the second solute peak. The fitted mass fractions and filtration parameters associated with the "subpathways" in Figure D-29 are given in Table D-8.

Note that the predicted first arrival of microspheres precedes their actual first arrival by 2 to $3 \mathrm{hr}$. This result can be attributed to the fact that a 4-hr delay was not assumed for the injection of microspheres into the pathways that resulted in the first tracer peaks (as it was for the solutes). No delay was assumed for the microspheres because the microsphere injection began about $3.5 \mathrm{hr}$ after the solutes were injected. If the solutes did not begin entering the pathways resulting in the first tracer peaks until after the microspheres were injected, then it would be reasonable to assume that the microspheres should have entered those pathways at the same time as the solutes. 


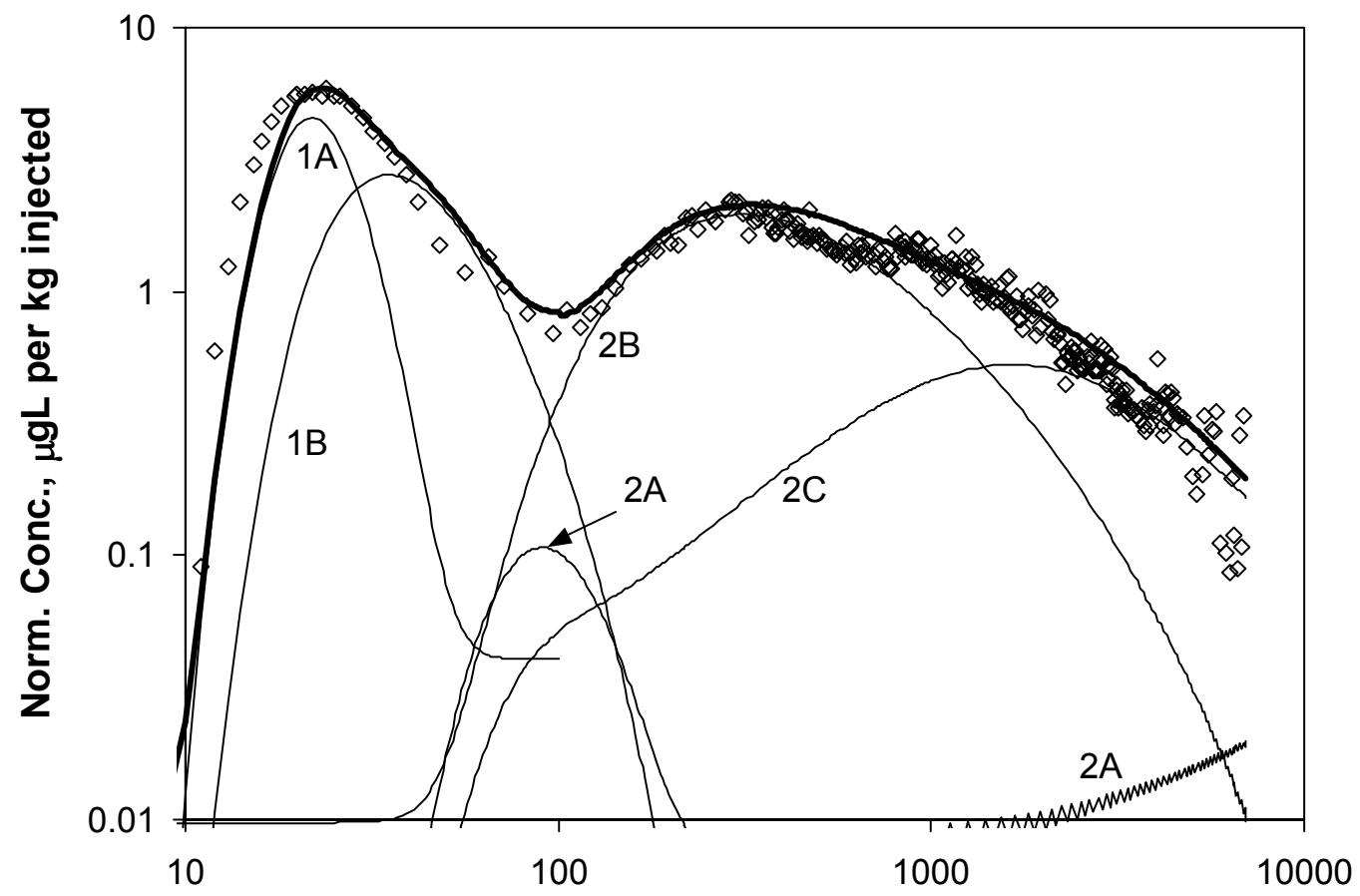

Time, hrs

Source: DTNs: LA0007PR831231.001 [DIRS 156043] (raw data), LA0410PR831231.001 [DIRS 171899] (normalized concentrations).

Output DTN: LA0303PR831231.003 (interpretive fits).

NOTE: Diamonds are microsphere data points. Numbers followed by letters indicate flow pathways discussed in text and listed in Table D-8. Bold line is the sum of all the pathways.

Figure D-29. RELAP Fits to CML Microsphere Response in Bullfrog Tuff Tracer Test

Table D-8. Microsphere Filtration and Detachment Parameters Associated with the Fits Shown in Figure D-29

\begin{tabular}{|l|l|l|l|l|l|}
\hline \multicolumn{1}{|c|}{ Parameter } & \multicolumn{1}{c|}{ Path 1A } & \multicolumn{1}{c|}{ Path 1B } & \multicolumn{1}{c|}{ Path 2A } & \multicolumn{1}{c|}{ Path 2B } & \multicolumn{1}{c|}{ Path 2C } \\
\hline Mass fraction, $f$ & 0.111 & 0.004 & 0.42 & 0.07 & 0.11 \\
\hline$k_{\text {filt }}(1 / \mathrm{hr})$ & 0.175 & 0.175 & 0.04 & 0.04 & 0.04 \\
\hline$\lambda^{\mathrm{a}}(1 / \mathrm{cm})$ & 0.0017 & 0.0017 & 0.0084 & 0.0084 & 0.0084 \\
\hline$b k_{\text {res }}{ }^{\mathrm{b}}(1 / \mathrm{hr})$ & $0.000219^{\mathrm{c}}$ & 1.08 & $0.000201^{\mathrm{c}}$ & 0.211 & 0.00755 \\
\hline
\end{tabular}

Output DTNs: LA0303PR831231.003; LA0303PR831231.005.

NOTE: Other transport parameters used to obtain the fits are given in Table $D-6$. Note that subpathways $1 \mathrm{~A}$ and $1 B$ represent a mass fraction split of Pathway 1 from Table $D-6$, and subpathways $2 A, 2 B$, and $2 C$ represent a mass fraction split of Pathway 2 from Table D-6. The parameter $f_{1}$ in equation (8a) is $0.004 / 0.115=0.035$ for pathway 1 and the parameters $f_{1}$ and $f_{2}$ in equations $(7 a),(8 b)$, and $(8 c)$ are $f_{1}$ $=0.07 / 0.6=0.117$ and $\mathrm{f}_{2}=0.11 / 0.6=0.183$ for pathway 2 .

a $\lambda$ calculated as $k_{\text {fit }} / v_{\mathrm{f}}$, where $v_{\mathrm{f}}=$ average linear velocity determined from mean fluid residence time.

${ }^{\mathrm{b}} b=$ fracture half aperture in $\mathrm{cm}$. The fitted detachment rate constant is this lumped parameter.

${ }^{c}$ Maximum detachment rate constant; cannot distinguish between this value and zero, so microspheres could be very slowly detaching or not detaching at all. 
However, if the microspheres experienced a delay similar to the solutes, then their predicted first arrival would actually be slightly later than the observed first arrival. In fact, in this case, the first arrival would coincide almost exactly with the first arrival of solutes. Thus, the uncertainty associated with when the microspheres actually began entering the flow system causes uncertainty in the predicted first arrival of the microspheres.

The fits to the Prow Pass test microsphere data are shown in Figure D-30, and the corresponding best-fitting filtration and detachment rate constants are listed in Table D-9. The fits suggest that the small peaks in this test were the result of a very small fraction of microspheres that moved through the flow system unfiltered, and the long tails were the result of small detachment rate constants. The filtration-rate constant listed in Table D-9 for the 280-nm-diameter yellow microspheres was not obtained from fitting, but rather it was the smallest filtration coefficient that resulted in a peak concentration of microspheres at or below detection limits. This number can be considered a lower-bound estimate of the yellow-microsphere filtration coefficient because any larger value will result in more filtration and an even lower recovery. Unlike the Bullfrog test, only a single filtration and detachment rate constant were needed to effectively fit the microsphere responses in the Prow Pass test. As mentioned in Section D4.6.2, no attempt was made to fit the "spikes" in microsphere concentration that occurred after flow transients.

It should be pointed out that the interpretations of the microsphere responses presented in the preceding paragraphs, particularly for the Bullfrog test, are by no means unique. First, it is quite likely that there exists a continuous distribution of filtration and detachment rate constants rather than a few discrete ones, as assumed in the above analyses. Such a distribution could arise from a distribution of colloid surface properties and/or physical and chemical heterogeneities in fracture surfaces (Dabros and Van de Ven 1982 [DIRS 143278], pp. 232 to 244; 1983 [DIRS 156652], pp. 576 to 579). It is also possible that colloid filtration and detachment are not linear first-order processes as assumed in Equations 7 and 8. Rather, they might be better described as nonlinear and/or stochastic processes. Finally, as mentioned above, the interpretation of the microsphere response relative to the solutes is complicated by the fact that, with the exception of the 280-nm-diameter yellow microspheres in the Prow Pass test, the microsphere injections were not started at exactly the same times as the solute injections (they were started about 3.5 hours later in the Bullfrog test and about 2 days earlier in the Prow Pass test). In addition to causing uncertainty as to when the microspheres actually began moving into flow pathways (relative to the solutes), the differences in injection times may have resulted in the microspheres not being distributed into flow pathways in exactly the same proportion as the solutes (i.e., a different source term). If different assumptions were made about the distribution of microspheres between the two major sets of pathways in the Bullfrog test, different filtration parameters would be obtained. 


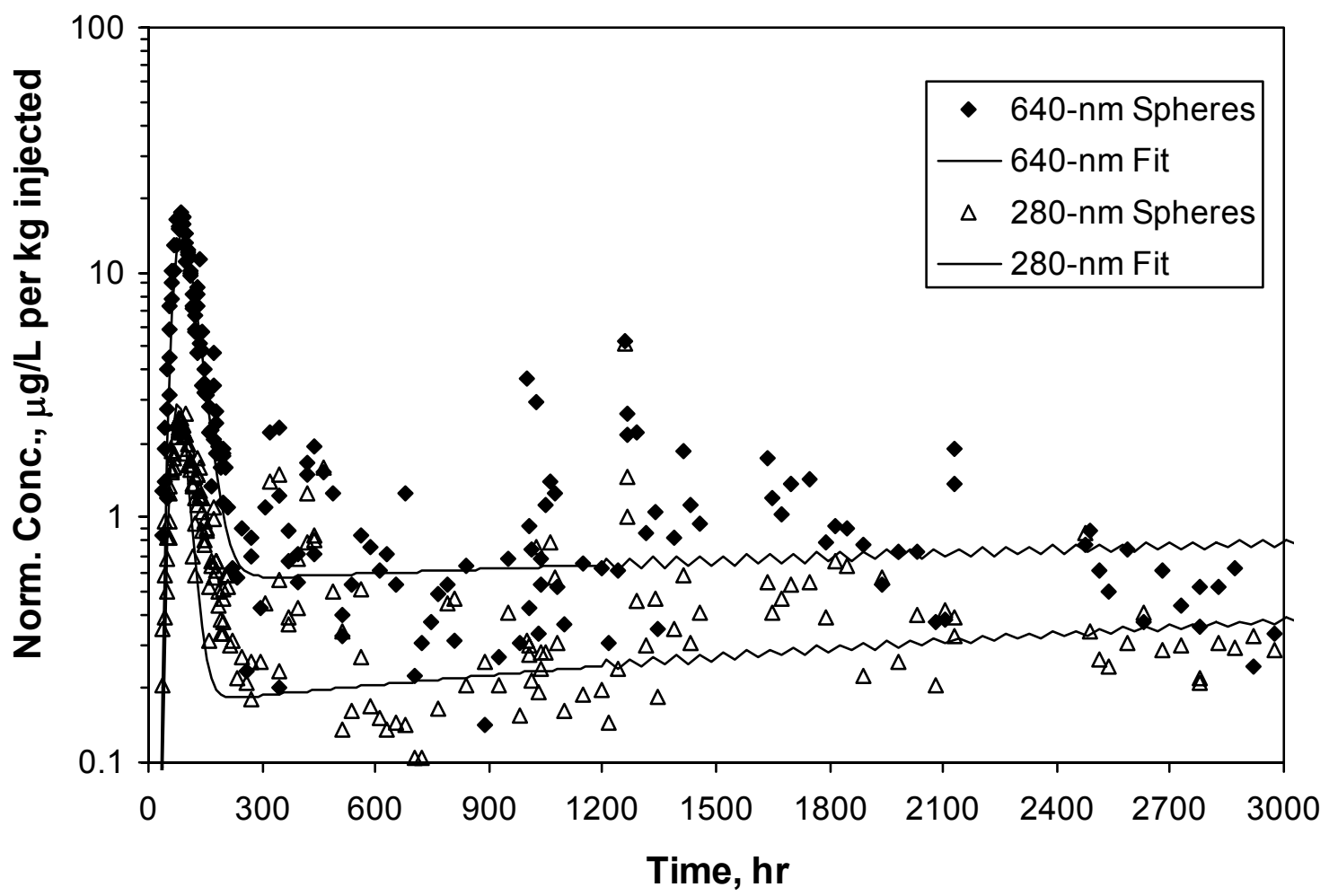

Source: DTNs: LAPR831231AQ99.001 [DIRS 140134] (raw data), LA0410PR831231.001 [DIRS 171899] (normalized concentrations).

Output DTN: LA0303PR831231.003 (interpretive fits).

NOTE: The jagged appearance of the fits starting at approximately $1000 \mathrm{hr}$ is the result of instabilities in the Laplace transform inversion algorithm of RELAP V 2.0 (STN: 10551-2.0-00 [DIRS 159065]). "Spheres" in the legend refers to CML-microspheres.

Figure D-30. RELAP Fits to the CML Microsphere Responses in the Prow Pass Tracer Test

Table D-9. Filtration and Detachment Rate Constants for the CML Microspheres in the Prow Pass Tuff Tracer Test

\begin{tabular}{|l|c|c|c|}
\hline & \multicolumn{3}{|c|}{ Microspheres } \\
\hline \multicolumn{1}{|c|}{ Parameter } & $\mathbf{6 4 0 - n m ~ B l u e ~}$ & $\mathbf{2 8 0 - n m ~ O r a n g e ~}$ & $\mathbf{2 8 0}^{-n m}$ Yellow \\
\hline$k_{\text {filt }}(1 / \mathrm{hr})$ & 0.043 & 0.07 & $0.2^{\text {a }}$ \\
\hline$\lambda(1 / \mathrm{cm})$ & 0.0087 & 0.014 & 0.041 \\
\hline$b k_{\text {res }}{ }^{b}(1 / h r)$ & 0.000154 & 0.000251 & 0.0002 \\
\hline
\end{tabular}

Output DTN: LA0303PR831231.003.

NOTE: Mass fractions are assumed to be the same as for solutes (Table D-7).

${ }^{a}$ Minimum value that is consistent with the lack of appearance of these spheres at the production well. The actual filtration rate constant could be much higher.

b Maximum values; cannot distinguish between these values and zero. See also footnote (b) of Table D-8. 


\section{D4.8 DISCUSSION OF FIELD TRACER TEST RESULTS}

Estimates of transport parameters that can be used directly in solute transport models were derived from the best-fitting parameters in Tables D-6 and D-7. These parameter estimates are presented in Table D-10 as ranges of values consistent with the tracer test interpretation(s). Additional discussion of these ranges and how they were derived is provided in the following sections. This parameter estimation exercise has several important implications for radionuclide transport in fractured volcanic tuffs near Yucca Mountain.

Table D-10. Transport Parameter Estimates Deduced from the Bullfrog and Prow Pass Multiple-Tracer Tests

\begin{tabular}{|c|c|c|c|c|}
\hline \multirow[b]{2}{*}{ Parameter } & \multicolumn{2}{|c|}{ Prow Pass } & \multicolumn{2}{|c|}{ Bullfrog } \\
\hline & Lower Bound & Upper Bound & Lower Bound & Upper Bound \\
\hline $\begin{array}{l}\text { Effective flow porosity (Eq. 10, Appendix } \\
\text { D, Section D4.8.5) }\end{array}$ & 0.003 & 0.006 & $0.003^{a}$ & $0.031^{a}$ \\
\hline Longitudinal dispersivity, $m^{\mathrm{b}}$ & 13.0 & 61.5 & 3.2 & 62.5 \\
\hline MTC, $\frac{\phi}{b} \sqrt{D_{\mathrm{m}}}$, for radionuclides $\left(\sec ^{-1 / 2}\right)^{\mathrm{c}}$ & 0.00054 & 0.00095 & 0.00027 & 0.0015 \\
\hline Fracture aperture $(\mathrm{cm})$ & 0.18 & 1.05 & 0.081 & 1.31 \\
\hline Fracture spacing $(\mathrm{cm})$ & 6.4 & $\infty$ & 4.4 & $\infty$ \\
\hline Ratio of stagnant to flowing water volumes & 3.1 & $\infty$ & 2.1 & $\infty$ \\
\hline
\end{tabular}

Output DTN: LA0303PR831231.005.

NOTE: These values above are provided as ranges of values; see text for explanations.

a These estimates assume that 75 percent of the production flow was associated with flow pathways that resulted in the first tracer peak and 25 percent was associated with the second tracer peak (based on flow survey information (DTN: GS931008312313.016 [DIRS 148173]); see Figure 6.1-2).

b Lower bounds assume Peclet numbers for radial flow and 30-m travel distance; upper bounds assume Peclet numbers for linear flow and interval thicknesses as travel distances (see Table 6.1-1 for actual borehole separations and interval thicknesses; also DTN: GS030508312314.003 [DIRS 164425]), p. 6, Table 1).

${ }^{c}$ Assumes that bromide and PFBA effectively bound molecular sizes and diffusion coefficients of radionuclide solution species.

MTC=mass transfer coefficient; PFBA= pentafluorobenzoic acid or pentafluorobenzoate.

\section{D4.8.1 Conceptual Transport Model}

Even without quantitative parameter estimation, it is clear that the tracer responses in both the Bullfrog and Prow Pass tests are consistent with a dual-porosity conceptual transport model for the fractured volcanic tuffs. It is simply not possible to account for the differences in the bromide and PFBA responses or the relatively small time attenuation but significant concentration attenuation of the lithium response relative to the nonsorbing tracers (in the Prow Pass test and the first peak of the Bullfrog test) without invoking diffusion between flowing fractures and stagnant matrix water. Some diffusion into stagnant water within fractures (e.g., dead-end fractures or along rough fracture walls) cannot be ruled out. However, if the stagnant water were primarily in fractures, the surface area for sorption would be limited, and it is unlikely that there would be as much concentration attenuation of lithium relative to the nonsorbing solutes as observed in the tracer tests. The large surface-area-to-volume ratio necessary to result in the large observed concentration attenuation of lithium seems plausible only if a significant fraction of the stagnant water is in matrix pores. 
The quantitative estimates of the lumped mass transfer parameter, $\frac{\phi}{b} \sqrt{D_{\mathrm{m}}}$ for bromide in Tables D-6 and D-7 are based on the assumption that bromide has a diffusion coefficient a factor of three greater than PFBA. This assumption is based on matrix diffusion coefficients measured in laboratory diffusion cell tests, which are discussed in Section E2. It is worth noting that RELAP V 2.0 (STN: 10551-2.0-00 [DIRS 159065]) simulations in which a finite matrix was assumed (i.e., a finite spacing between fractures) offered a slightly better fit to the tracer responses associated with the second peak of the Bullfrog test than simulations assuming an infinite matrix. This result suggests that tracer molecules may have diffused far enough into the matrix to begin encountering molecules from neighboring fractures, which implies a relatively small fracture spacing. Alternatively, the tracers may have encountered diffusion boundaries (no-flux boundaries) within the matrix, which implies a significant increase in tortuosity or a decrease in interconnected porosity at some distance into the matrix from fracture surfaces. For the first peak in the Bullfrog test and for the Prow Pass test, a finite matrix offered no better fits to the tracer data than an infinite matrix. In these cases, it can only be stated that the fracture spacing must have exceeded some threshold value below which the tracer responses would have been significantly different than observed. The applicable threshold values for the first Bullfrog test peak and for the Prow Pass test were estimated by adjusting the fracture spacing in RELAP until the simulated tracer responses began to differ significantly from the simulated responses assuming an infinite matrix. The results are presented in Table D-10 as lower bounds for fracture spacing.

The tracer responses and the qualitative and quantitative conclusions about matrix diffusion that can be drawn from them illustrate very clearly the advantages of using multiple nonsorbing tracers with different diffusion coefficients in tracer tests to distinguish between alternative conceptual transport models. The individual responses of either bromide or PFBA could have been fit reasonably well assuming no matrix diffusion at all. Only when the responses of these tracers are considered together is it obvious that diffusive mass transfer must be invoked to explain the test results. Even long tails that plot linearly on log-log plots of tracer responses (power-law behavior), which are often said to infer matrix diffusion when single tracer responses are analyzed (Haggerty et al. 2000 [DIRS 156832], pp. 3467 to 3469), do not unequivocally substantiate diffusive mass transfer. Such responses can also be attributed to hydrodynamic dispersion that scales with residence time (due to the recirculating flow field or effects of density-driven flow), stagnation points, and/or source-term effects (e.g., the slow release of tracers from the injection borehole). Furthermore, the fact that the lithium responses were significantly attenuated in concentration but not in time supports the concept that a significant amount of diffusion occurred into the matrix pores and not simply into stagnant water within the fracture network. This conclusion is very important for Yucca Mountain performance assessment because mass transfer between flowing fractures and the true matrix implies that a large amount of surface area will be available for sorption of radionuclides in the saturated, fractured tuffs.

\section{D4.8.2 Fracture Apertures}

An estimate of the average fracture aperture $(2 b)$ experienced by the tracers in the Bullfrog and Prow Pass tests can be obtained from the estimate of the lumped, diffusive, mass-transfer parameter, $\phi \mathrm{D}_{\mathrm{m}}{ }^{1 / 2} / \mathrm{b}$ provided independent estimates of matrix porosity, $\phi$, and matrix diffusion 
coefficients, $D_{\mathrm{m}}$, are available. Using estimates of $\phi$ determined from laboratory measurements and $D_{\mathrm{m}}$ for bromide and PFBA from diffusion cell tests (Section E2), estimates of $2 \mathrm{~b}$ range from 0.081 to $1.31 \mathrm{~cm}$ in the Bullfrog Tuff and from 0.18 to $1.05 \mathrm{~cm}$ in the Prow Pass Tuff, as listed in Table D-10. Because the long tracer test intervals in each test both included more than one major lithology (Figure 6.1-2), it was necessary to estimate $2 b$ for each major lithologic unit in each interval. The fact that there is a positive correlation between matrix porosity and matrix diffusion coefficient results in a relatively large range of aperture estimates. If it is assumed that the flow pathways associated with the first tracer peak in the Bullfrog test were in the central Bullfrog unit and the pathways associated with the second tracer peak were in the lower Bullfrog unit, then the aperture estimates in these two units correspond to the two extremes listed in Table D-10. These aperture estimates based on tracer responses should be distinguished from friction loss or cubic-law aperture estimates obtained from hydraulic responses (Tsang 1992 [DIRS 113901], pp. 1451 to 1455), although they should be the most appropriate aperture estimates to use for transport calculations.

\section{D4.8.3 Ratios of Stagnant Water to Flowing Water Volumes}

Estimates of the ratio of stagnant water volume to flowing water volume in the flow system(s) can be calculated from estimates of fracture spacings obtained from RELAP V 2.0 (STN: 10551-2.0-00 [DIRS 159065]) simulations and the matrix porosities and fracture apertures used in the RELAP simulations (ratio $=\phi(L / 2 b-1)$ ). Ranges of these estimates are listed in Table D-10. The upper-bound ratios for both tracer tests are listed as infinite because all tracer responses could be fitted reasonably well, assuming infinite fracture spacing. The lower bounds in Table D-10 were obtained using fracture spacings that yielded slightly better fits to the tracer responses than the fits obtained assuming an infinite fracture spacing. These ratios plus one can be considered physical retardation factors for nonsorbing species in the flow system when flow rates are low enough that there is ample time for solutes to diffuse throughout the stagnant water in the system (Robinson 1994 [DIRS 101154]).

\section{D4.8.4 Lithium Sorption Behavior}

Tables D-6 and D-7 list the best-fitting values of the lithium fracture and matrix retardation factors ( $R_{\mathrm{f}}$ and $R_{\mathrm{m}}$, respectively) for the Bullfrog and Prow Pass tests. Note that the $R_{\mathrm{f}}$ values are 1 for both the Prow Pass test and for the first peak in the Bullfrog test, implying negligible retardation within the fractures and sorption only in the matrix. Note that a fracture retardation factor of 1 does not necessarily imply that sorption did not occur on fracture surfaces; it merely suggests that the majority of the lithium sorption occurred after a diffusive mass-transfer step to sorptive surfaces in the matrix. For the second peak in the Bullfrog test, the lithium response was best fitted with $R_{\mathrm{f}}=4$ and $R_{\mathrm{m}}=20$, implying some sorption in fractures and a large amount of sorption in the matrix. 
Matrix $K_{\mathrm{d}}$ values were deduced from the fitted matrix retardation factors by simple rearrangement of the expression defining the retardation factor:

$$
K_{\mathrm{d}}=\frac{\phi}{\rho_{\mathrm{B}}}\left(R_{\mathrm{m}}-1\right)
$$

Because the $K_{\mathrm{d}}$ values depend on the matrix porosity, values are listed in Table D-11 for each lithologic unit that transport may have occurred in for each test (matrix porosities from Section E.2, Table E-6, were used in Equation 9). For a given retardation factor, the corresponding $K_{\mathrm{d}}$ value is always higher in a unit with higher matrix porosity. The $R_{\mathrm{m}}$ value associated with the first lithium peak in the Bullfrog test (Table D-6) was obtained by fitting the rising limb of the lithium response using RELAP V 2.0 (STN: 10551-2.0-00 [DIRS 159065]). However, because it was necessary to use MULTRAN V 1.0 (STN: 10666-1.0-00 [DIRS 159068]) to achieve a reasonable fit to the tail of the response (see above), the $K_{d}$ value for this peak was estimated from the ion-exchange parameters that yielded the best fit to the lithium data (see Section E.3.1.3 for a discussion of using ion-exchange parameters to fit lithium responses in laboratory experiments) rather than from the $R_{\mathrm{m}}$ value obtained from RELAP. The best-fitting, ion-exchange parameters suggested a nonlinear sorption isotherm for lithium in the matrix; hence, $K_{\mathrm{d}}$ values are reported in Table D-11 for lithium concentrations of both approximately $600 \mathrm{mg} / \mathrm{L}$ (low $K_{\mathrm{d}}$ value) and approximately $0.5 \mathrm{mg} / \mathrm{L}$ (high $K_{\mathrm{d}}$ value). This range of concentrations should reasonably bound the concentrations experienced in the field test.

Laboratory batch measurements of lithium sorption onto crushed tuff from $\mathrm{C}$-wells cores indicated a dependence of $K_{\mathrm{d}}$ values on both lithium concentrations and the mineralogy associated with the different lithologies (Section E1). The concentration dependence in each case could be represented by a classic nonlinear isotherm in which $K_{\mathrm{d}}$ values decreased as lithium solution concentrations increased. There was also a strong dependence of lithium $K_{\mathrm{d}}$ values on the smectite and zeolite content of the tuffs (Anghel et al. 2002 [DIRS 164635], pp. 822 to 824 , Section 3.2). The range of laboratory-derived $K_{\mathrm{d}}$ values associated with each unit that could have participated in the Bullfrog and Prow Pass tests is listed in Table D-11 next to each corresponding field-derived $K_{\mathrm{d}}$ value.

The lithium $\mathrm{Kd}$ values deduced from the field tracer tests (assuming any given lithologic unit) are consistently higher than the corresponding $\mathrm{Kd}$ values measured at the lowest lithium concentrations in the laboratory. These results suggest that the use of laboratory-derived Kd values to predict sorbing species transport in the saturated fractured tuffs near the C-wells location would tend to underpredict the amount of sorption experienced by the species in the field. The fact that the field $\mathrm{Kd}$ values tended to be greater than the laboratory $\mathrm{Kd}$ values suggests that lithium may have come into contact with alteration minerals in the field that were not present or were depleted in the lab rock samples. Any loosely adhering alteration minerals (e.g., clays) that may have been present in the core samples would very likely have been lost during crushing and wet sieving of the material when it was prepared for the batch sorption experiments. 
Table D-11. Lithium Partition Coefficients Derived from Field Tracer Tests and Laboratory Measurements

\begin{tabular}{|c|c|c|}
\hline Parameter & Field $K_{d}(\mathrm{~mL} / \mathrm{g})$ & Laboratory $K_{d}{ }^{a}(m L / g)$ \\
\hline Prow Pass matrix $K_{d}$ assuming Central Prow Pass Tuff & 0.66 & $\begin{array}{c}0.13 \\
\text { (0.26 at infinite dilution) }\end{array}$ \\
\hline Prow Pass matrix $K_{d}$ assuming Lower Prow Pass Tuff & 1.68 & $\begin{array}{c}0.084 \\
\text { (0.44 at infinite dilution) }\end{array}$ \\
\hline $\begin{array}{l}\text { Bullfrog matrix } K_{d} \text { in Pathway } 1 \text { assuming Central Bullfrog } \\
\text { Tuff }{ }^{\text {b }}\end{array}$ & $0.58-4.1$ (nonlinear) $^{c}$ & $\begin{array}{c}0.19 \\
\text { (0.44 at infinite dilution) }\end{array}$ \\
\hline $\begin{array}{l}\text { Bullfrog matrix } K_{d} \text { in Pathway } 1 \text { assuming Lower Bullfrog } \\
\text { Tuff }{ }^{b}\end{array}$ & $0.58-4.1$ (nonlinear) $^{c}$ & $\begin{array}{c}0.32 \\
\text { (1.64 at infinite dilution) }\end{array}$ \\
\hline $\begin{array}{l}\text { Bullfrog matrix } K_{d} \text { in Pathway } 2 \text { assuming Central Bullfrog } \\
\text { Tuff }{ }^{b}\end{array}$ & 0.74 & $\begin{array}{c}0.19 \\
\text { (0.44 at infinite dilution) }\end{array}$ \\
\hline $\begin{array}{l}\text { Bullfrog matrix } K_{d} \text { in Pathway } 2 \text { assuming Lower Bullfrog } \\
\text { Tuff }{ }^{b}\end{array}$ & 3.04 & $\begin{array}{c}0.32 \\
\text { (1.64 at infinite dilution) }\end{array}$ \\
\hline
\end{tabular}

Output DTN: LA0303PR831231.005.

NOTE: These lithium partition coefficients $\left(K_{d}\right.$ values) were derived from field tracer tests assuming transport in different lithologies within the test intervals.

a Values at "infinite dilution" obtained from Langmuir isotherm fits to the data (asymptotic slope at very low concentrations (i.e., $K_{\mathrm{L}} S_{\max }-$ see Section C.1.2 for definitions). Other values obtained from a simple linear fit to the entire range of data.

b "Pathway 1" refers to pathways that resulted in the first tracer peak in the Bullfrog reactive tracer test, and "Pathway 2" refers to pathways that resulted in the second peak in this test. $K_{d}$ values were calculated from the smallest matrix retardation factors obtained from alternative interpretations of the test.

${ }^{c}$ The first number corresponds to a $K_{d}$ value calculated at approximately $600 \mathrm{mg} / \mathrm{L} \mathrm{Li}^{+}$using the three-component cation exchange model parameters yielding the best fit to the first lithium peak (see Section C.3.1.3 for description of three-component model); the second number corresponds to a $K_{d}$ value calculated at $0.5 \mathrm{mg} / \mathrm{L} \mathrm{Li}$ concentration using the same model parameters. In obtaining the field parameters, a matrix porosity of 0.10 was assumed in the MULTRAN V 1.0 (STN: 10666-1.0-00 [DIRS 159068]) simulations (approximately equal to that of the Central Bullfrog Tuff). The $K_{d}$ values for pathway 1 would increase if a greater matrix porosity was assumed, and they would decrease if a smaller matrix porosity was assumed.

\section{D4.8.5 Effective Flow Porosity}

Contaminant transport predictions are generally very sensitive to assumed flow porosities because transport rates are directly proportional to the specific discharge divided by flow porosity. The effective flow porosity in a cross-hole tracer test without recirculation can be estimated from the following equation, which assumes a steady-state, two-dimensional (confined with fully penetrating well), homogeneous and isotropic flow system (Guimera and Carrera 2000 [DIRS 156830], Equation 6):

$$
\eta=\frac{Q \tau}{\pi r_{\mathrm{L}}^{2} T}
$$

where

$\eta=$ effective flow porosity

$Q=$ production flow rate, $\mathrm{m}^{3} / \mathrm{hr}$

$\tau=$ mean residence or transport time, $\mathrm{hr}$

$r_{\mathrm{L}}=$ distance between wells, $\mathrm{m}$

$T=$ formation thickness (assumed to be interval length). 
With recirculation, the situation is complicated by the fact that there is a hypothetical stagnation point; hence, the mean tracer residence time theoretically approaches infinity. However, the interpretive method described in this report allows for incomplete tracer mass recoveries that could result from stagnation, so a finite estimate of the mean tracer residence time can always be obtained. Guimera and Carrera (2000 [DIRS 156830]) discuss an alternative method of estimating effective flow porosity from peak, rather than mean, tracer arrival times in tests with partial recirculation. However, their method was derived for system Peclet numbers $\left(r_{\mathrm{L}} / \alpha\right)$ ranging from 10 to 100 , which are considerably larger than the Peclet numbers obtained in the C-wells multiple-tracer tests (1.3 to 9.3); therefore, their method was not applied here.

For the mean tracer arrival times and flow conditions in the C-wells tracer tests, Table D-10 gives the effective flow porosities calculated using Equation 10 for the Bullfrog and Prow Pass tests. The upper and lower bounds given in Table D-10 were calculated using the mean tracer residence times calculated assuming linear and radial flow, respectively (values in Tables D-6 and D-7). Also, in the Bullfrog test, it was assumed that 75 percent of the total production flow rate was associated with the first tracer peak and 25 percent was associated with the second tracer peak (based on flow survey information suggesting that a large amount of flow occurred in the upper part of the injection interval in c\#2 (DTN: GS030508312314.003 [DIRS 164425], p. 6, Table 1; Figure 6.1-2).

The relatively large effective porosity estimates obtained from Equation 10 could be due to heterogeneities in the flow field. Flow is undoubtedly not radial, as assumed in the above equations, but rather it very likely follows tortuous pathways between the injection and production wells. Furthermore, it is conceivable that a single high-conductivity feature, such as a large, open fracture or fault, could transmit the vast majority of the flow to the production well. If this feature does not pass near the injection well, the effective flow rate drawing tracers to the production well will be greatly reduced relative to what would occur in a radial flow field.

\section{D4.8.6 Longitudinal Dispersivity}

Longitudinal dispersivity estimates from cross-hole tracer tests generally have considerable uncertainty due to (1) uncertainty in the actual tracer transport distance (the actual flow pathways followed by tracers are unknown); (2) whether the flow field is radial, linear, or some combination; (3) the amount of apparent dispersion caused by nonidealities such as a poorly mixed injection wellbore or density/buoyancy effects; and (4) the amount of apparent dispersion caused by recirculation or the ambient flow field. It is beyond the scope of this report to address in detail the possible effects of each of these uncertainties on the longitudinal dispersivity estimates provided in Table D-10. These estimates can be considered "upper and lower bounds" that were obtained as follows.

1. The maximum transport distance, $r_{\mathrm{L}}$, was assumed to be the distance from the top of one packed-off interval in the production well to the bottom of the packed-off interval in the injection well $(80$ to $100 \mathrm{~m})$ while the minimum transport distance was assumed to be the linear distance between the wells (approximately $30 \mathrm{~m}$ ). 
2. The radial and linear Peclet numbers were used to obtain estimates of the dispersivity for the two cases above $\left(\alpha=r_{\mathrm{L}} / \mathrm{Pe}\right)$, and the most extreme values were used for the upper and lower bounds.

3. The RELAP V 2.0 code (STN: 10551-2.0-00 [DIRS 159065]) simulated a gradual release of tracer from the borehole to the formation by assuming a well-mixed interval, resulting in an exponential decay in tracer concentration in the wellbore. The decay time constant was determined from the volume of the packed-off interval divided by the injection/recirculation rate. Thus, the slow release of tracers from the injection well did not bias the dispersivity (or mean residence time) estimates.

4. An attempt to "subtract out" the apparent dispersion caused by recirculation in the Prow Pass test was made by the following (Reimus 2003 [DIRS 165129], pp. 123 to 129).

a. Obtaining a simulated tracer response for a cross-hole test with the appropriate amount of recirculation in a homogeneous, isotropic medium using the 2WELLS_2D V 1.0 computer code (STN: 10665-1.0-00 [DIRS 159067])

b. Calculating the variance of the particle residence times in (a)

c. Calculating the variance of tracer response in the actual field test from $\sigma^{2}=2 \frac{\tau^{2}}{P e}$ where $\sigma^{2}$ is the variance

d. Subtracting the variance in (b) from the variance in (c) to obtain the variance due to "true hydrodynamic dispersion", $\sigma_{T}$, in the flow system (this assumes that the variance due to recirculation and the variance due to true dispersion are additive, which assumes that the two processes giving rise to the total variance are independent)

e. Rearranging the above expression to obtain the Peclet number and, hence, dispersivity, that represents true hydrodynamic dispersion; i.e., $P e=2 \frac{\tau^{2}}{\sigma_{T}^{2}}$.

Corrections for dispersion caused by recirculation in the Bullfrog test were assumed to be negligible because 2WELLS_2D V 1.0 (STN: 10665-1.0-00 [DIRS 159067]) simulations indicated that the variance in tracer transport times for 3.5 percent recirculation was very small (Reimus 2003 [DIRS 165129], Attachment A).

\section{D4.8.7 Colloid Transport}

The microsphere filtration and detachment rate constants deduced from the Bullfrog and Prow Pass tracer tests can potentially be used as estimates of filtration and detachment rate constants for natural colloids that could facilitate the transport of radionuclides strongly adsorbed to colloids. However, it must be kept in mind that the CML microspheres do not have the same physical and chemical properties as natural inorganic colloids [see the SZ colloid transport report 
(BSC 2004 [DIRS 170006], Section 6.8)]. The SZ colloid transport report summarizes laboratory experiments (BSC 2004 [DIRS 170006], Section 6.8), in which it was shown that 330-nm-diameter CML microspheres transported with the same attenuation or less attenuation through saturated fractures than 100-nm-diameter silica spheres, suggesting that microsphere filtration and detachment rate constants may be conservative if used to predict silica colloid transport in fractured media.

Perhaps of greater importance than the microsphere filtration and detachment rate constants derived from the field tests is the fact that the microsphere responses qualitatively indicate that (1) colloid detachment from fracture surfaces is a process that clearly occurs in fractured tuffs, and (2) colloid detachment is apparently enhanced by flow transients. These qualitative results suggest that it is not sufficient to consider only colloid filtration when assessing colloid-facilitated radionuclide transport, but that colloid detachment and its dependence on other variables must also be considered and could possibly dominate the transport behavior of colloids. It is beyond the scope of this report to discuss how the dependence of colloid detachment on other variables should be incorporated into transport models. However, colloid detachment, in general, can be accounted for in models with simple first-order kinetics expressions.

\section{D5. LIMITATIONS AND UNCERTAINTIES ASSOCIATED WITH TRANSPORT PARAMETER ESTIMATES}

\section{D5.1 LIMITATIONS AND UNCERTAINTIES INHERENT IN TRACER TESTING}

Several factors contributed to the uncertainty in transport parameters derived from tracer test interpretations. First, there are data uncertainties which are related to the accuracy and precision of the tracer chemical analyses, including both random and systematic errors. Random errors were estimated to be small because the breakthrough-curve data are not widely scattered and show well-defined trends. The most significant sources of systematic errors would have been day-to-day differences in analytical instrument operation and in analytical standard preparation over extended periods of time. However, repeat measurements on separate days indicate that these errors were also minimal.

During the iodide tracer test in the Bullfrog-Tram interval (February to April 1996), the pump gradually failed, resulting in a decreasing flow rate during the entire test, which changed from $526 \mathrm{~L} / \mathrm{min}(139 \mathrm{gpm})$ at the beginning to $371 \mathrm{~L} / \mathrm{min}(98 \mathrm{gpm})$ at the end (Umari 2002 [DIRS 162858], Binder 5, Section G-10, pp. 65 to 77). This violated the assumption of a steady-state flow field in the Moench (1989 [DIRS 101146]) semi-analytic method employed to analyze the tracer test results. This source of uncertainty was eliminated for subsequent tests by replacing the pump.

There was uncertainty regarding the extent to which the tracers were evacuated from the injection intervals to the aquifer in each test. The very long injection intervals (ranging from $75 \mathrm{~m}$ to almost $200 \mathrm{~m}$ ) and the lack of down-hole mixing contributed to this uncertainty. Slow release of tracers from the injection intervals could have contributed to tailing in the solute tracer responses that would have been interpreted as dispersion or matrix diffusion when only one nonsorbing tracer was used. Attempts to reduce this uncertainty in the Prow Pass tests were made by deploying a down-hole system capable of mixing the tracer solution after its injection 
into the borehole. Although the down-hole mixing system worked only marginally, it is believed that lingering of tracer in the injection borehole was minimized because recirculation of 30 percent of the water produced from $\mathrm{c} \# 2$ during the Prow Pass test should have served to "flush" tracers out of the injection interval.

The influence of the natural gradient that exists at the C-wells on tracer recovery at the pumped well is a source of uncertainty. Determinations of the capture zone of the pumped well, and how it is altered by the existence of a natural gradient depend on the assumptions made regarding flow heterogeneity and anisotropy. Mass not recovered by the pumped well is potentially the result of pathways other than the postulated radially convergent or partially recirculating streamlines toward the pumped well. However, it could also be a result of some of the tracer mass moving through the matrix rather than fractures; transport through the matrix would be so slow that the mass would not be expected to appear in the production well during the time of the tracer tests.

A limitation of all tracer tests conducted at the C-wells is that they produce estimates only of longitudinal dispersivity, not transverse dispersivity (because sampling occurs only at the production well and is not spatially distributed). In addition, the estimate of flow porosity has the uncertainty of an unknown travel distance between the tracer injection and production points in the boreholes (i.e., the source and the sink locations). This travel distance was bounded by assuming a minimum of the straight-line distance between the injection and production wells and a maximum of the formation thickness, defined by the distance between packers in the injection and the pumped intervals.

\section{D5.2 UNCERTAINTIES ASSOCIATED WITH TEST INTERPRETATION METHODS}

When estimating transport parameters using a semi-analytical solution to the advection-dispersion equation, such as the Moench (1989 [DIRS 101146]) solution or the RELAP V 2.0 computer code (STN: 10551-2.0-00 [DIRS 159065]) employed in this study, several assumptions are made. The medium is assumed to be homogeneous and isotropic, and the flow regime is assumed to be either radial or linear (i.e., having a velocity that varies as $1 / \mathrm{r}$ or having a constant velocity between injection and production well). Also, the aquifer is assumed to be two-dimensional (flow only in the two horizontal dimensions without a vertical component); to the extent that these assumptions do not reflect the true nature of the media, the transport parameter estimates will be erroneous. However, the information necessary to implement more sophisticated models that explicitly account for flow and transport heterogeneity does not exist. Even data to support stochastically generated hydraulic conductivity distributions in numerical models are scarce to nonexistent. Thus, the interpretive approaches used in this report reflect the level of knowledge of flow and transport heterogeneity at the scale of the tracer tests. Uncertainty associated with assuming either radial or linear flow (when the actual nature of the flow field could be somewhere in between) is addressed in the multiple tracer-test interpretations by reporting mean residence times and Peclet numbers for both radial and linear flow assumptions.

The Moench (1989 [DIRS 101146]; 1995 [DIRS 148784]) and RELAP V 2.0 (STN: 10551-2.0-00 [DIRS 159065]) semi-analytical solutions are mathematically very similar. However, differences in the methodologies and assumptions used in the implementation of the 
models to interpret tracer responses result in differences in the resulting transport parameter estimates. Highlights of the differences in the two approaches are the following.

(1) The first approach (Moench, Section D1) involves normalizing tracer concentrations to the maximum (peak) tracer concentration, whereas the second approach (RELAP, Section D4.6) involves normalizing tracer concentrations to the injection mass. The first method results in matching the shapes of breakthrough curves (or differences in shapes when there are multiple tracers), while the second is aimed at matching not only shapes, but also peak normalized concentrations and total recoveries. Thus, the second method has some additional fitting constraints that result in different transport parameter estimates compared to the first method.

(2) Both methods use essentially the same mathematical model to account for the tracer residence time in the injection borehole (i.e., a well-mixed interval with an exponential decay in tracer concentration). However, the mean residence time in the borehole was allowed to be much larger when running simulations using the first method (Section D1) compared to the second method (Section D4.6). A larger residence time in the injection borehole effectively adds dispersion to the simulated response curves, which results in a smaller flow-system dispersivity when the tracer data are fitted. Thus, the longitudinal dispersivity estimates from the first method tend to be lower than from the second method.

To assess the different results obtained from the two approaches qualitatively, the RELAP V 2.0 (STN: 10551-2.0-00 [DIRS 159065]) computer code was used to interpret the iodide and 2,4,5-TFBA tracer test in the Prow Pass Tuff. The Moench solution (Moench 1995 [DIRS 148784]) interpretation of this test is presented in Section D1.2.1. First, the parameters obtained from the Moench model analysis were used in RELAP to see how well the two solutions agree when using the same inputs. It can be shown through algebraic manipulations that the mass transfer coefficient $\frac{\phi}{\mathrm{b}} \sqrt{D_{\mathrm{m}}}$ in RELAP is equivalent to $6 \mathrm{~b}^{\prime} \sqrt{\frac{\sigma^{\prime} \gamma^{\prime}}{\tau}}$ in the Moench solution (Moench 1995 [DIRS 148784]), where $b^{\prime}=$ radius of spheres that represent matrix blocks (into which diffusion occurs), $\sigma^{\prime}=$ dimensionless storage parameter $=\frac{\phi}{\phi_{f}}$, and $\gamma^{\prime}=$ $\frac{D_{\mathrm{m}} \tau}{\phi_{f}\left(\mathrm{~b}^{\prime}\right)^{2}} . \phi_{f}$ is the fracture porosity in this case, and $\tau$ is defined as $\frac{\pi \mathrm{h} \phi_{\mathrm{f}}\left(\mathrm{r}_{\mathrm{L}}^{2}-\mathrm{r}_{\mathrm{w}}^{2}\right)}{\mathrm{Q}}$, where $\mathrm{h}$ is the aquifer thickness, $r_{L}$ is the distance between the injection and production wells, $r_{w}$ is the radius of the production well, and Q is the volumetric flow rate from the production well. Additionally, an injection borehole "mixing length" of $30.5 \mathrm{~m}$ was used in the Moench solution analysis of Section D1.2.1. This mixing length can be shown to translate to an injection borehole time constant of approximately $0.0023 \mathrm{hr}^{-1}$ in the RELAP solution (time constant $=\frac{4 Q r_{i}}{2 \pi r_{L}}\left(\frac{1}{\pi r_{i}^{2} h_{i}}\right)$, where $r_{i}=$ injection well radius and $h_{i}=$ mixing length (Moench 1989 [DIRS 101146]). Using these input parameters, along with a Peclet number of 100 (i.e., a longitudinal dispersivity of $0.29 \mathrm{~m}$ ), the RELAP code yields the fits shown in Figure D-31 (the 
mean residence time and mass fraction were adjusted to obtain these fits). The longitudinal dispersivity reported in Section D1.2.1 was $0.27 \mathrm{~m}$. The tracer responses and fits in Figure D-31 are adjusted so that they all have the same maximum concentration, which is consistent with the analysis used in Section D1.2.1. A comparison of Figure D-31 and Figure D-16 shows that the two methods yield almost indistinguishable results when the same input parameters are used.

The injection borehole time constant of $0.0023 \mathrm{hr}^{-1}$ used in the above analysis translates to a mean tracer residence time in the borehole of $1 / 0.0023$, or approximately $435 \mathrm{hr}$. This residence time is at odds with the tracer concentration measurements in the injection borehole described in Section D1.2.1.1, where it is stated that the borehole was effectively flushed of tracer in approximately $8.5 \mathrm{hr}$. The fact that the tracer was flushed from the borehole in such a short time is not surprising given that there was a continuous injection of approximately $1.5 \mathrm{gpm}$ (approximately $5.7 \mathrm{~L} / \mathrm{min}$ ) of groundwater into the injection zone following the injection of tracers. A mean residence time of approximately $9 \mathrm{hrs}$ is calculated by dividing the volume of the injection interval (approximately 3,000 L) by the $5.7 \mathrm{~L} / \mathrm{min}$ flow rate. For these reasons, a second RELAP simulation was conducted in which it was assumed that the injection borehole

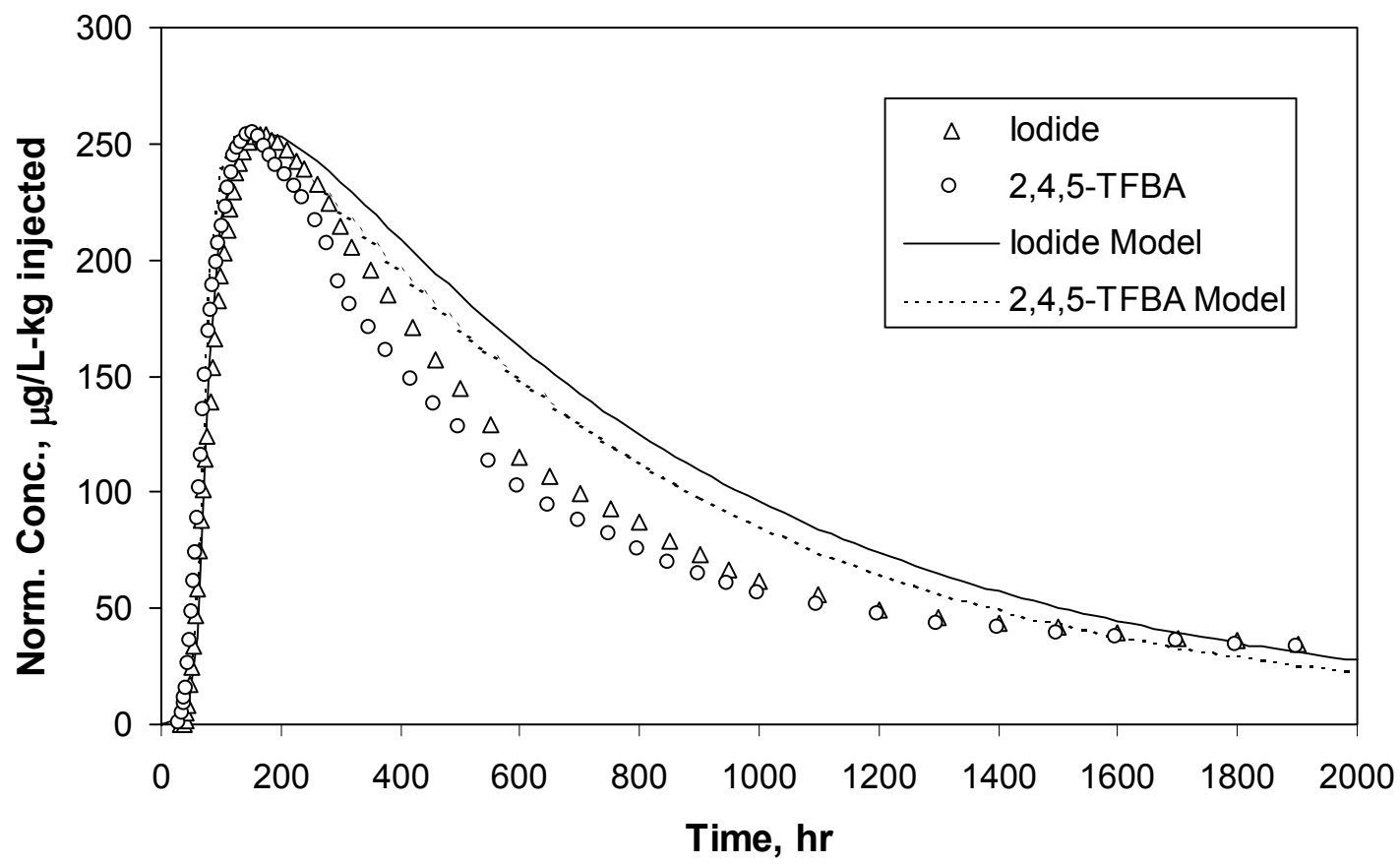

Output DTN: LA0304PR831231.001.

NOTE: Data points represent a subset of the actual data. Data and curves are adjusted so that they all have the same maximum normalized concentration (see Figure D-16 for comparison). The same parameters obtained from the Moench solution in Section D1.2.1 were used. "Model" refers to a fit generated by the RELAP code.

Figure D-31. RELAP Fits to the lodide and 2,4,5-TFBA Responses in the Prow Pass Tuff Tracer Test Assuming an Injection Zone Time Constant of $0.0023 \mathrm{hr}^{-1}$ 
time constant was $0.11 \mathrm{hr}^{-1}((5.7)(60) / 3,000)$. This is the same time constant value that was used in the analysis of the PFBA and bromide tracer test conducted in the Prow Pass Tuff described in Section D4.7.1. The resulting RELAP fits to the tracer data are shown in Figure D-32, where in this case the tracer concentrations are normalized to tracer injection mass, as in Section D4. The RELAP transport parameters for the simulations of Figures D-31 and D-32 are listed in Table D-12. Also listed in this table are the parameters obtained from RELAP fits to the PFBA and bromide data in the Prow Pass Tuff, discussed in Section D4.7. This test was conducted in the same configuration and with the same flow rates as the iodide and 2,4,5-TFBA test, although the volume of the tracer solution injected was considerably larger. Clearly, there is a very large difference in the mean residence times and Peclet numbers of the simulations with significantly different borehole time constants, although the iodide mass transfer coefficients, $\frac{\phi}{b} \sqrt{D_{m}}$, are in reasonably good agreement in all simulations.

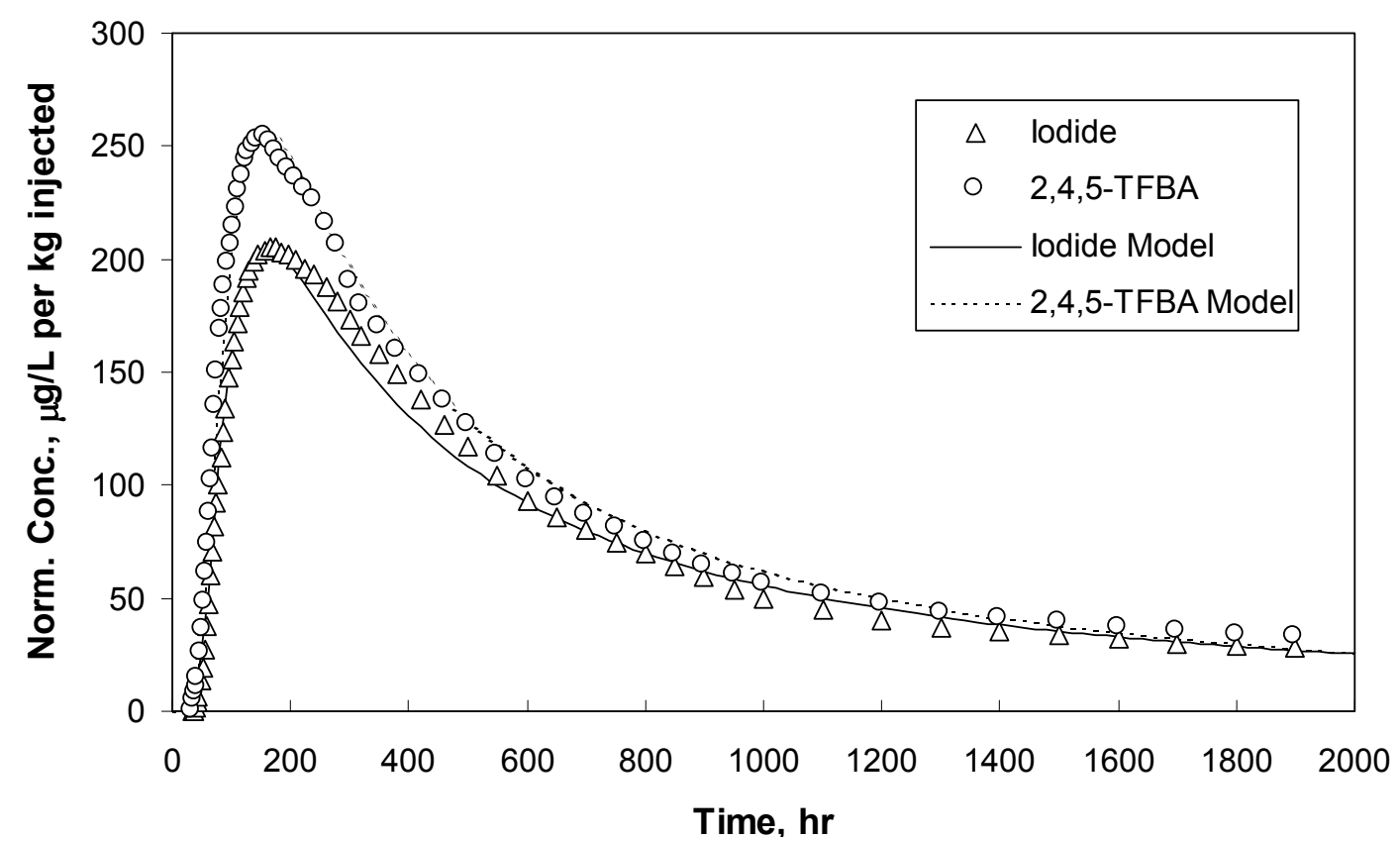

Output DTN: LA0304PR831231.001.

NOTE: Data points represent a subset of the actual data. "Model" refers to a fit generated by the RELAP code.

Figure D-32. RELAP Fits to the lodide and 2,4,5-TFBA Responses in the Prow Pass Tuff Tracer Test Assuming an Injection Borehole Time Constant of $0.11 \mathrm{hr}^{-1}$

The reason for the large differences in mean residence times and Peclet numbers in Table D-12, particularly between the two interpretations of the iodide and 2,4,5-TFBA test, becomes clear when one considers the implications of the different borehole mixing assumptions. Figure D-33 shows tracer responses calculated by RELAP V 2.0 (STN: 10551-2.0-00 [DIRS 159065]) in a hypothetical system with a mean residence time in the aquifer (not the injection borehole) of $1 \mathrm{hr}$, a Peclet number of 100 , and no matrix diffusion. With this choice of parameters, the responses are due almost entirely to tracer residence time in the injection borehole. The tails of the responses are linear on a semi-log plot because tracer concentrations in a well-mixed region decay exponentially. The curve with the largest time constant corresponds to the tracer residence time distribution in the borehole for the RELAP fits of Figure D-32, and the curve with the 
smallest time constant shows the residence time distribution associated with the fits of Figure D-31. The iodide response in the Prow Pass tracer test is also shown in Figure D-33. It is apparent that the curve with the smallest time constant has a tail that matches the tracer data quite well. Thus, to match the entire breakthrough curve, it is only necessary to impose a lag on the borehole response (accounted for by a finite residence time in the flow system), with only a very small amount of additional dispersion or matrix diffusion in the flow system necessary to optimize the fit. However, as the borehole time constants get larger, it becomes necessary to impose a greater lag and account for more dispersion or matrix diffusion in the flow system to achieve a match to the data.

Table D-12. Transport Parameters Estimates from RELAP Fits of Figures D-31, D-32, and from the Fits to the PFBA and Bromide Responses in the Prow Pass Tuff

\begin{tabular}{|l|c|c|c|}
\hline \multicolumn{1}{|c|}{ Parameter } & $\begin{array}{c}\text { I, TFBA } \\
\text { Figure D-31 }\end{array}$ & $\begin{array}{c}\text { I, TFBA } \\
\text { Figure D-32 }\end{array}$ & Br, PFBA Test \\
\hline Borehole Time Constant, $\alpha, \mathrm{hr}^{-1}$ & 0.0023 & 0.11 & 0.11 \\
\hline Mean Res. Time, $\tau$, hr (linear flow) & 55 & 520 & 1210 \\
\hline Peclet number, Pe (linear flow) & 100 & 1.6 & 0.9 \\
\hline MTC, $\frac{\phi}{\mathrm{b}} \sqrt{\mathrm{D}_{\mathrm{m}}}, \mathrm{sec}^{-1 / 2}$ & 0.00161 & 0.001 & 0.000949 \\
\hline
\end{tabular}

Output DTN: LA0304PR831231.001.

MTC=mass transfer coefficient; PFBA= pentafluorobenzoic acid or pentafluorobenzoate; TFBA= trifluorobenzoic acid

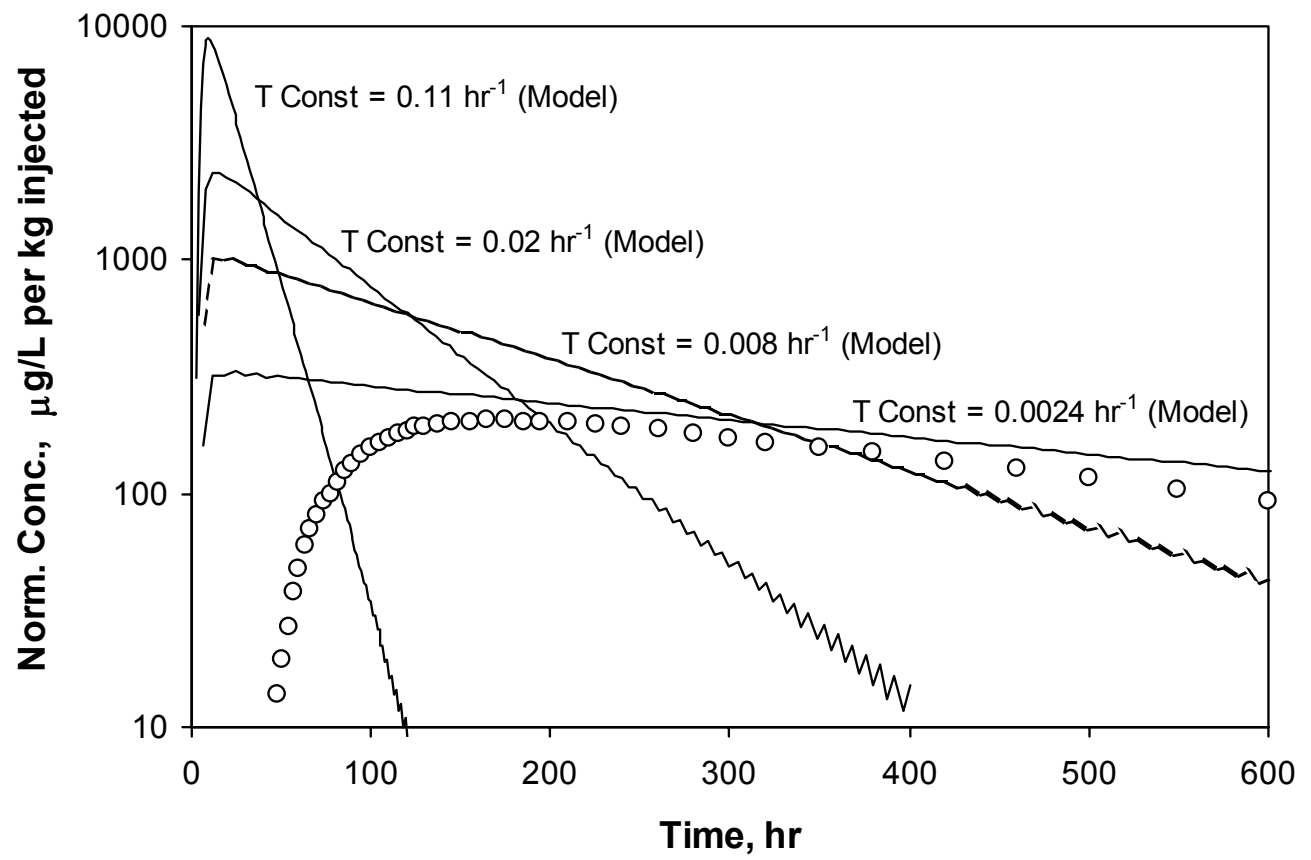

Output DTN: LA0304PR831231.001.

NOTE: Data points represent a subset of the actual data. lodide data from the Prow Pass Tuff tracer test (Figures D-31 and D-32) are shown for comparison. See Section D4.7 for discussion. "Model" refers to a fit generated by the RELAP code. 
Figure D-33. Tracer Responses as a Function of Injection Borehole Time Constant in a Hypothetical Flow System with a Mean Residence Time of $1 \mathrm{hr}$ in the Aquifer, a Peclet Number of 100, and No Matrix Diffusion

Figure D-34 shows the mean residence times (in the aquifer), Peclet numbers, and mass transfer coefficients, $\frac{\phi}{\mathrm{b}} \sqrt{D_{\mathrm{m}}}$ or mass transfer coefficient (MTC), that provided best fits to the combined iodide and 2,4,5-TFBA tracer data sets as a function of borehole time constant. The fits were equally good until the time constant became less than about $0.0025 \mathrm{hr}^{-1}$, which roughly corresponds to the time constant used in Figure D-31. Note that there is a sharp transition at a time constant of approximately $0.007 \mathrm{hr}^{-1}$, where residence times increase and Peclet numbers decrease dramatically. This transition corresponds to the point where the tracer residence time in the borehole can no longer account for the majority of the dispersion in the tracer curves. Figure D-34 shows that the MTC does not vary nearly as much as the mean residence time and Peclet number, although it goes through a maximum at the transition point because of an attempt to account for tracer dispersion with increased matrix diffusion. This result is important because it indicates that despite the dramatic differences in mean residence time and Peclet number as a function of borehole time constant, matrix diffusion is always necessary to explain the tracer responses (at least until borehole residence times become so low that all fits are poor). Furthermore, the estimates of matrix diffusion parameters do not vary all that much. Thus, the various interpretations, while significantly different in mean residence time and Peclet number, are all consistent with a dual-porosity conceptualization of the fractured volcanics.

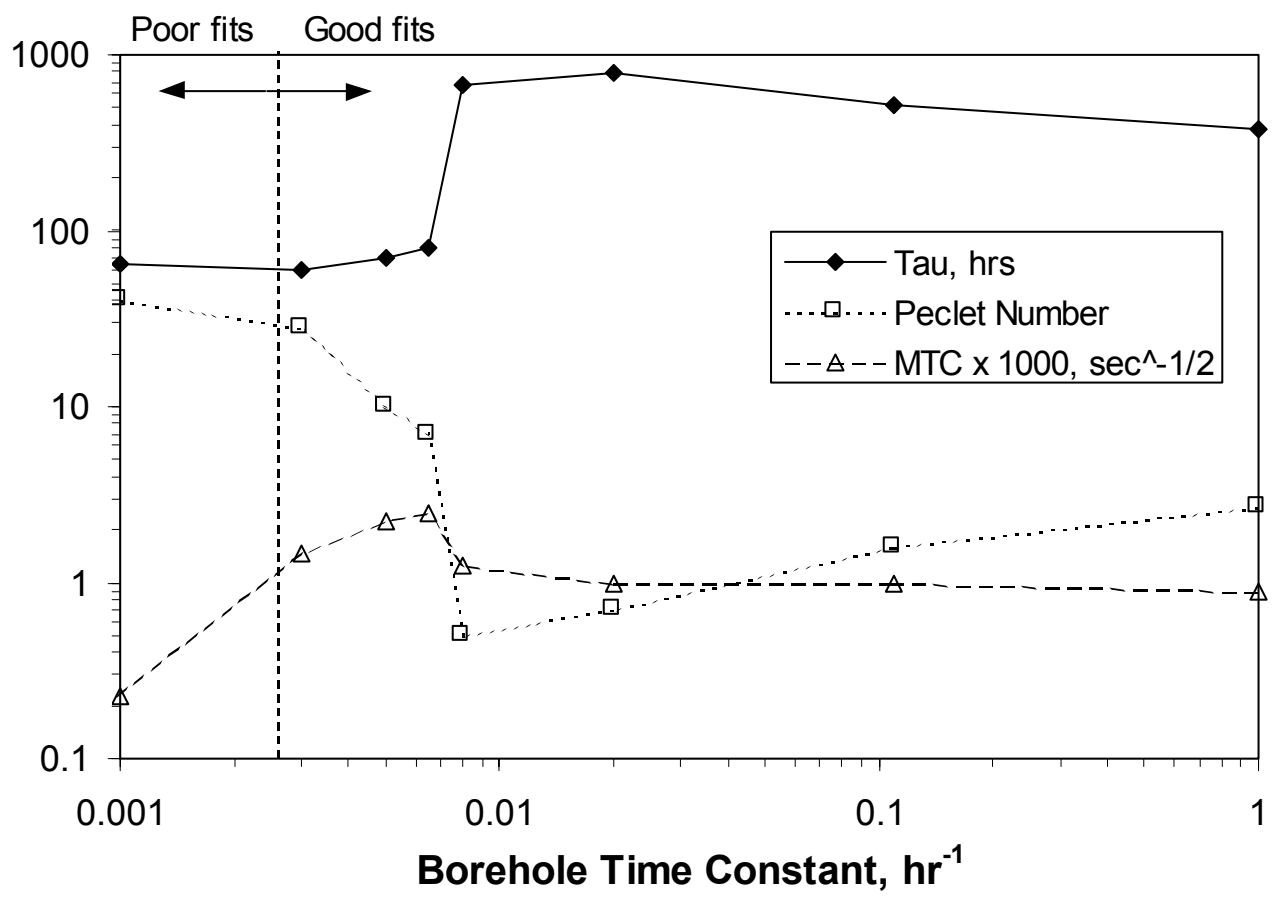

Output DTN: LA0304PR831231.001.

NOTE: Units on y axis depend on the curve.

Figure D-34. Mean Residence Time $(\tau)$, Peclet Number, and MTC (x 1000) as a Function of Borehole Time Constant from RELAP Fits to the lodide and 2,4,5-TFBA Data of Figure D-32 


\section{D5.3 UNCERTAINTIES ASSOCIATED WITH NONUNIQUENESS OF TEST INTERPRETATIONS}

Nonuniqueness of tracer test interpretations must be considered before uncertainties in transport parameters derived from tracer tests can be fully addressed. A prime example of nonuniqueness is that long tails in tracer responses can be interpreted as either being the result of a large amount dispersion (assumed to be longitudinal but transverse dispersion may also play a role) or significant matrix diffusion. In the nonsorbing tracer tests, nonuniqueness was addressed by using PEST V 5.5 (STN: 10289-5.5-00 [DIRS 161564]) to obtain optimal transport parameter estimates and to estimate confidence intervals associated with the parameters. In the multiple tracer tests, nonuniqueness of interpretations was minimized by simultaneously fitting the tracer responses using known ratios of diffusion coefficients as constraints on the relative matrix diffusion of different tracers. However, even after taking these measures, there is considerable nonuniqueness associated with tracer test interpretations.

First, nonuniqueness associated with the interpretation of responses of single tracers is addressed. Figure D-35 shows three RELAP V 2.0 (STN: 10551-2.0-00 [DIRS 159065]) fits to the iodide response in the Prow Pass tracer test shown in Figure D-32. These fits, which were obtained by arbitrarily fixing the Peclet number and then allowing the mean residence time, mass fraction, and MTC to be adjusted to achieve a fit, are arguably equally good. However, the best-fitting parameters, listed in Table D-13, vary by 2 to 4 orders of magnitude, and it is not even possible to distinguish between a single-porosity and a dual-porosity system (MTC can be zero). Clearly, nonuniqueness associated with interpreting single tracer responses is excessive and probably unacceptable for the purpose of transport parameter estimation.

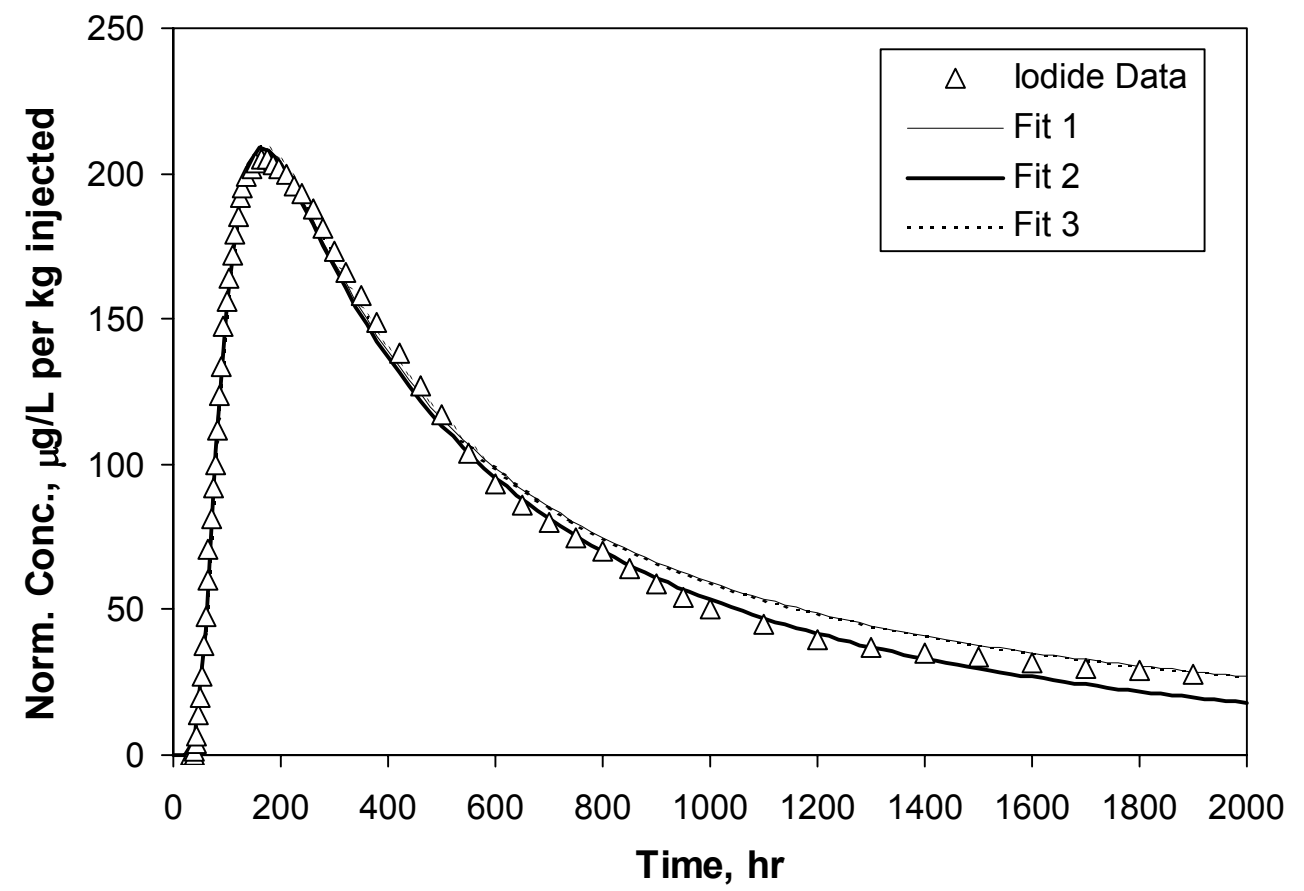

Output DTN: LA0304PR831231.001.

NOTE: Data points represent a subset of the actual data. Parameters associated with the fits are listed in Table D13. Note that Fits 1 and 3 essentially fall on top of each other.

Figure D-35. RELAP Fits to lodide Data from Prow Pass Tracer Test 
Table D-13. Transport Parameters Obtained from RELAP Fits to lodide Data Shown in Figure D-35

\begin{tabular}{|l|c|c|c|}
\hline \multicolumn{1}{|c|}{ Parameter } & Fit 1 & Fit 2 & Fit 3 \\
\hline Mass Fraction & 0.23 & 0.11 & 0.24 \\
\hline Borehole Time Constant, hr ${ }^{-1}$ & 0.11 & 0.11 & 0.11 \\
\hline Mean Res. Time, $\tau$, hr (linear flow) & 50 & 700 & 9000 \\
\hline Peclet number, Pe (linear flow) & 17 & 1.3 & 0.1 \\
\hline lodide MTC, $\frac{\phi}{\mathrm{b}} \sqrt{\mathrm{D}_{\mathrm{m}}}, \mathrm{sec}^{-1 / 2}$ & 0.01 & 0.0 & 0.0001 \\
\hline
\end{tabular}

Output DTN: LA0304PR831231.001.

A similar exercise in determining nonuniqueness of test interpretations was conducted for each of the multiple tracer responses (i.e., two in the Prow Pass Tuff and two in the Bullfrog Tuff (two peaks in this case)). Although the absolute best-fitting parameters in each case, as determined by minimizing the sum of squares of differences between the semi-analytical solution and data, are reported in Sections D1 and D4, there is still considerable nonuniqueness of the fits. If we arbitrarily establish a criterion that any sum of squares of differences less than 1.5 times the minimum is an equally good fit to the data, then the ranges of parameter values that provide equally good fits to the data sets are listed in Table D-14. Fits having sum-of-squares differences of less than a factor of 1.5 times the minimum are essentially equally good in appearance; and when one considers that the best fits are dependent on data scatter and on variability in data point density in the breakthrough curves (e.g., more data in tails as opposed to peaks), then a good case can be made that the fits are equally plausible. The parameter ranges were determined by varying each parameter in Table D-14 manually over a wide range of values while letting all other parameters in Table D-14 be adjusted to achieve fits to the data sets. Figure D-36 shows the fits to the iodide and 2,4,5-TFBA data from the Prow Pass tracer test (Figure D-32) that had the lowest and highest optimized sum-of-squares differences (with the highest still being within a factor of 1.5 of the lowest). Another "parameter" that was varied in the exercise was the ratio of the diffusion coefficients of halides (bromide and iodide) and fluorobenzoates (PFBA and TFBA) in the multiple tracer tests. This ratio is somewhat uncertain, especially in rock matrices, because most literature values are based on free water measurements. However, the values of the other transport parameters were found to be quite insensitive to this ratio when it was varied over a reasonable range.

Table D-14. Transport Parameter Ranges from Multiple-Tracer Tests at the C-wells

\begin{tabular}{|l|c|c|c|c|}
\hline \multicolumn{1}{|c|}{ Parameter } & BF, Peak 1 & BF, Peak 2 & PP, I-TFBA & PP, Br-PFBA \\
\hline Mass Fraction & $0.11-0.13$ & $0.56-0.7$ & $0.17-0.3$ & $0.56-0.82$ \\
\hline $\begin{array}{l}\text { Mean Res. Time, } \tau \text {, hr (linear } \\
\text { flow) }\end{array}$ & $320-420$ & $700-1,800$ & $340-1,340$ & $600-1,900$ \\
\hline Peclet number, Pe (linear flow) & $5-8$ & $0.9-2.4$ & $0.6-2.6$ & $0.6-1.9$ \\
\hline Halide MTC, $\frac{}{b} \sqrt{\mathrm{D}_{\mathrm{m}}}, \mathrm{sec}^{-1 / 2}$ & $0.000837-$ & $0.000245-$ & $0.000775-$ & $0.000632-$ \\
& 0.00224 & 0.000775 & 0.00122 & 0.00122 \\
\hline
\end{tabular}

Output DTN: LA0304PR831231.001.

$\mathrm{BF}=$ Bullfrog; $\mathrm{PFBA}=$ pentafluorobenzoic acid or pentafluorobenzoate; $\mathrm{PP}=$ Prow Pass; TFBA= trifluorobenzoic acid 
It is important to note that the ranges of parameter values in Table D-14 are not completely independent of each other. That is, when one parameter value is taken from the high end of its range, another may have to be taken from near the low end of its range to achieve a good fit. This is especially true of the mean residence time and Peclet number, which have a very strong inverse correlation. Figure D-37 shows the relationship between best-fitting values of Peclet number and mean residence time for the four multiple-tracer tests at the $\mathrm{C}$-wells. All of the points plotted in this figure are associated with equally good fits to the data according to the criterion stated in the previous paragraph. Note that the range of mean residence times is significantly lower for the data set with the largest Peclet numbers compared to the three data sets with smaller Peclet numbers. This result was found to be true in general; i.e., the range of mean residence times was smaller for hypothetical tracer responses with less longitudinal dispersion.

Figure D-38 shows that the best-fitting mass fractions are positively correlated with the best-fitting mean residence times for the iodide and 2,4,5-TFBA responses in the Prow Pass Tuff. This result and Figure D-37 imply a negative correlation of mass fraction with Peclet number. These same trends were obtained for all other multiple-tracer tests. Interestingly, the MTC, $\frac{\phi}{\mathrm{b}} \sqrt{D_{\mathrm{m}}}$, was poorly correlated with any of the other transport parameters. In fact, the extremes of MTC values were generally associated with values of other parameters not near the ends of their respective ranges. Also, the range of MTC values never included zero, which indicates that a dual-porosity system is always implied from the fits.

The parameter ranges in Table D-14 reflect considerable uncertainty associated with the nonuniqueness of interpretive fits for multiple tracer tests. These ranges, in general, are comparable in magnitude to the ranges of derived parameter values provided in Table D-10, which were based on uncertainties in tracer travel distances and radionuclide diffusion coefficients, as well as the range of parameter values obtained from different tests in the same interval. The ranges in Table D-10 would have to be expanded somewhat to account for the additional uncertainty associated with the nonuniqueness of fits. Expanding these ranges by multiplying the lower value of any parameter in Table D-10 by 0.5 and the upper value by 2 would effectively capture this additional uncertainty. 


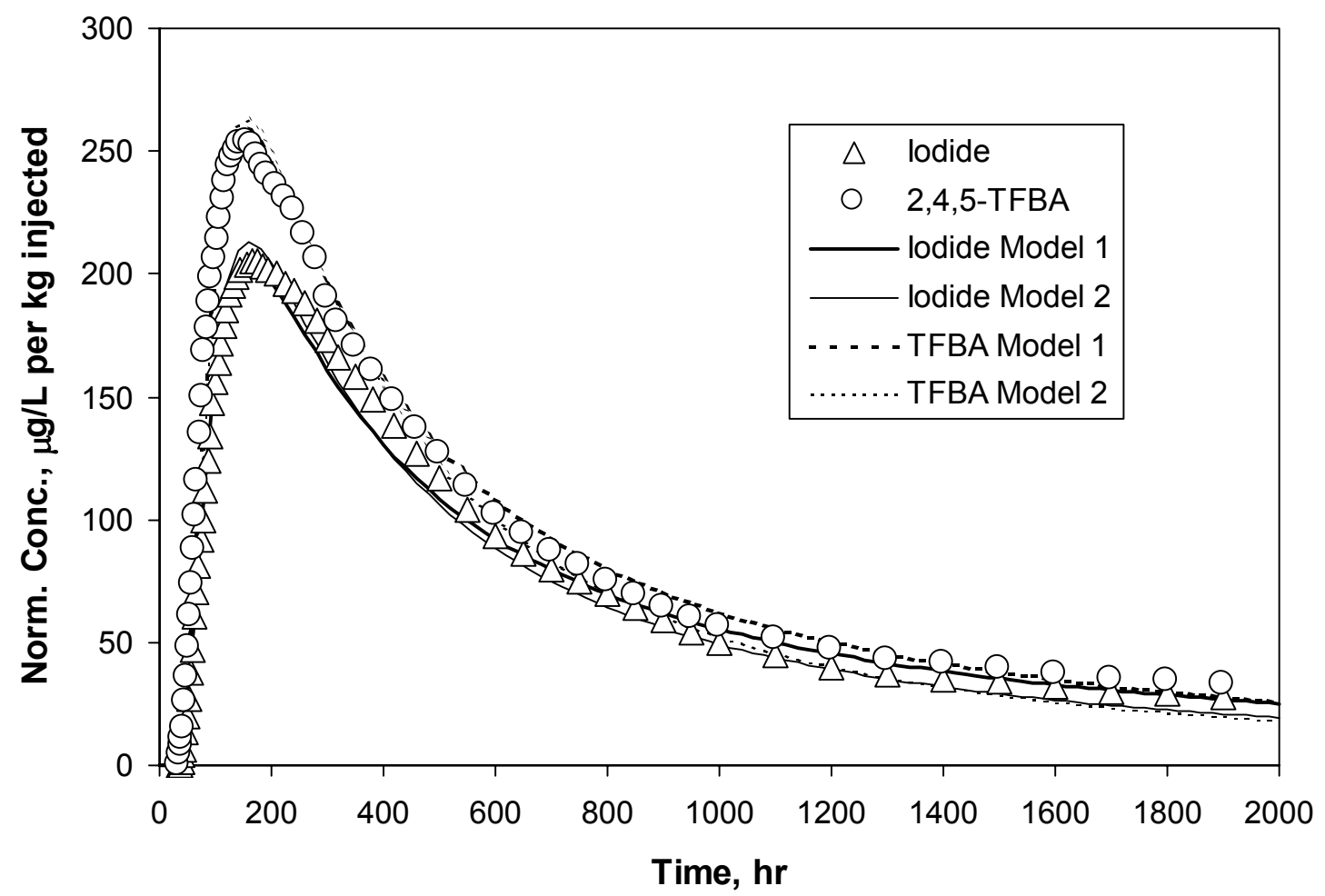

Output DTN: LA0304PR831231.001.

NOTE: Data points represent a subset of the actual data. Bold curves represent the best fits to data. The sum of squares differences between data and curves are within a factor of 1.5 of each other. "Model" refers to a fit generated by the RELAP code.

Figure D-36. RELAP Fits to the lodide and 2,4,5-TFBA Data from the Prow Pass Tracer Test

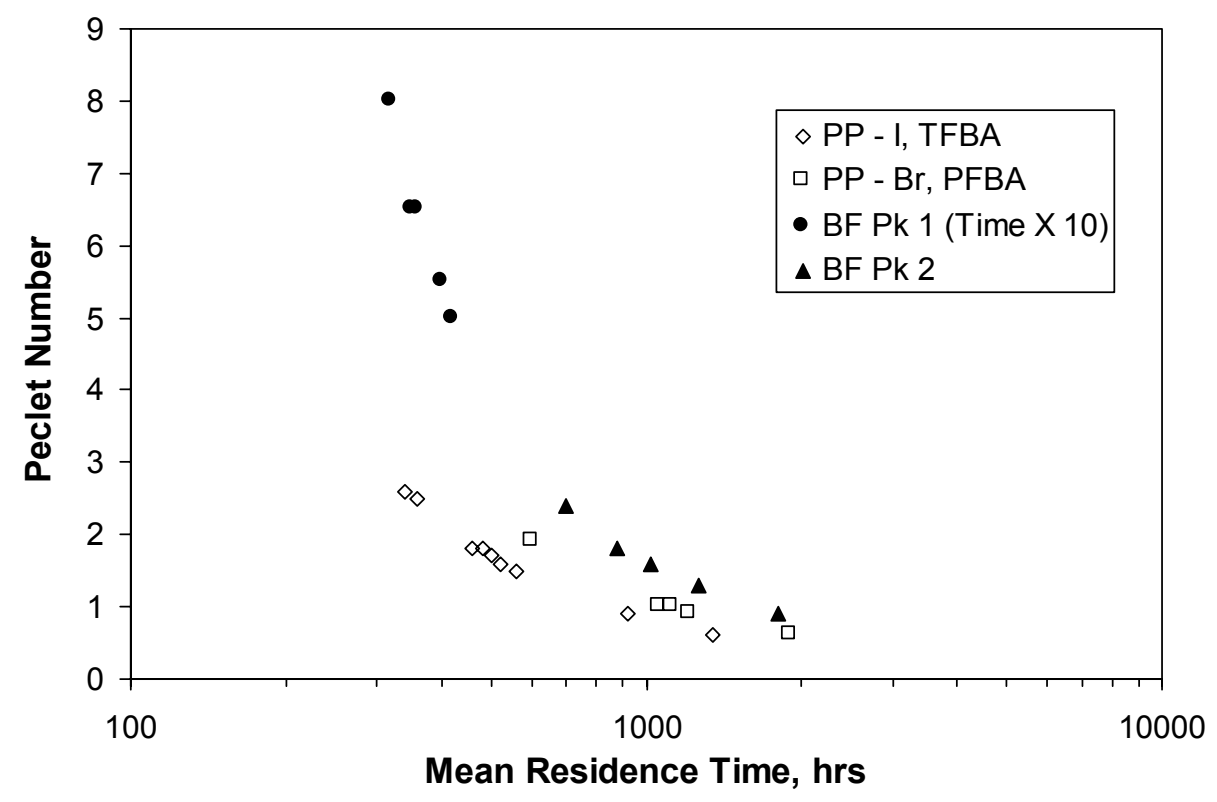

Output DTN: LA0304PR831231.001.

NOTE: PP refers to Prow Pass; BF refers to Bullfrog. Note that the residence times (but not Peclet numbers) are multiplied by 10 for peak 1 of the Bullfrog Tuff tracer test. 
Figure D-37. Correlation Between Best-Fitting Peclet Numbers and Mean Residence Times for the Multiple-Tracer Tests at the C-wells

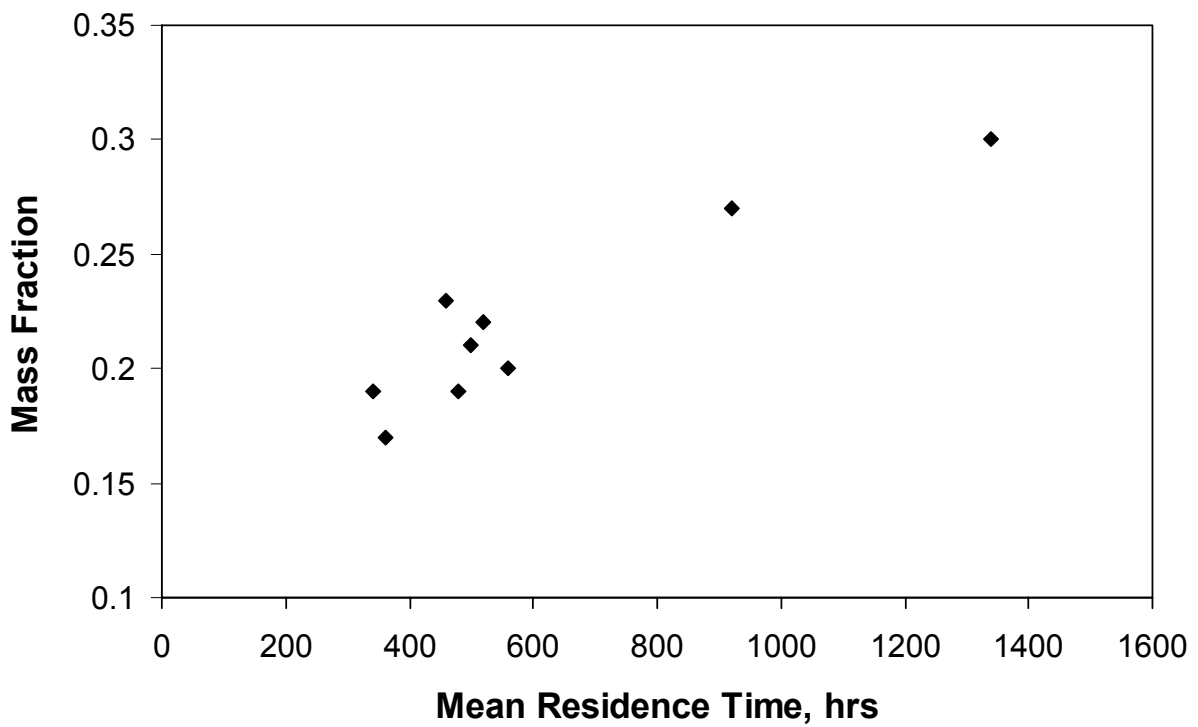

Output DTN: LA0304PR831231.001.

Figure D-38. Correlation Between Best-Fitting Mass Fractions and Mean Residence Times for the Multiple-Tracer Tests at the C-wells

A few points are worthy of mention regarding uncertainty associated with nonuniqueness of the semi-analytical solution fits to obtain transport parameter estimates:

1. Although there is considerable uncertainty associated with model fits to multiple-tracer data sets, the uncertainty is far less than the uncertainty associated with fits to single-tracer data sets (compare Tables D-13 and D-14). Also, all the fits to multiple-tracer data sets indicated a dual-porosity system (in which flow occurs primarily through fractures but with a significant volume of stagnant or near-stagnant water in the matrix that is in diffusive communication with the flowing water), while fits to single-tracer data sets cannot effectively distinguish between a single- and dualporosity transport system.

2. This uncertainty analysis and discussion is by no means complete. Other factors must be considered when doing a rigorous uncertainty analysis. A couple of additional considerations that go beyond the scope of this report are:

- When fitting multiple data sets, one must be careful to not inadvertently give one set more weight than the others in the fitting procedure. Inappropriate weighting can occur, for instance, when one data set has significantly more data points than the other(s) or when one set has much larger numerical values than the other(s). Approaches to dealing with this problem include (1) various weighting schemes, (2) making the number of data points the same for all data sets (by dropping some data from the larger data sets), or (3) normalizing the sum-of-squares errors for each data set by dividing by the number of points fitted for each set. Each of these 
approaches introduces some arbitrary bias into the fitting procedure, which introduces bias into the errors associated with the parameter estimates. In this report, we use approach (3).

- The fitting criteria (or objective function) are very important and can have a significant influence on both parameter estimates and error estimates. For instance, one will obtain different answers if the sum-of-squares differences between semianalytical solution and data are minimized vs. minimizing the sum-of-squares differences between the log of the data and the solution. In this report, it was chosen to minimize the straight sums-of-squares differences rather than the differences in any transformations of the data and solution values.

Although the transport parameter uncertainty analysis is not necessarily complete or entirely quantitative, it is important to point out that the uncertainties in the parameter estimates obtained from tracer testing are considered to be very effectively, and even conservatively, captured in Saturated Zone Flow and Transport Model Abstraction (BSC 2004 [DIRS 170042]). Thus, conservatism is ultimately built into the downstream propagation of transport parameter uncertainties in the TSPA.

\section{D6. CONCLUDING REMARKS ABOUT FIELD TRACER TESTS}

It is recognized that the tracer-test interpretations using primarily semi-analytical solution methods that assume an idealized geometry and steady flow rates are a considerable simplification of reality. Numerical models could certainly be used to account for greater system heterogeneity. Also, more sophisticated semi-analytical representations of dual-porosity systems, such as the multirate-diffusion solution of Haggerty and Gorelick (1995 [DIRS 156831], pp. 2,383 to 2,400), could be applied. However, the information available to support these more sophisticated representations of the flow and transport system is sparse to nonexistent. Furthermore, the agreement between the relatively simple semi-analytical solutions (either the Moench 1989 [DIRS 101146]; 1995 [DIRS 148784]) solution or RELAP (LANL 2002 [DIRS 159065]) and the tracer responses are considered to be very good. The only additional interpretive complexity needed to explain any portion of the tracer-test data sets was the multicomponent transport and ion exchange capabilities of the MULTRAN V 1.0 (STN: 1066-1.0-00 [DIRS 159068]) code needed to match the lithium response in the first peak of the Bullfrog tracer test. Although the introduction of additional interpretive complexity could improve the agreement between solution and data, it appears that all of the critical features of the tracer responses are effectively captured, and the introduction of additional complexity, especially in light of the minimal information to support it, is not justified.

One must also keep in mind that the tracer-test results are intended to support predictive calculations that span much larger time and distance scales than represented by the test. With this in mind, it is desirable to capture the important transport processes with as concise an interpretation as possible so that others can incorporate a relatively simple conceptual model on a local scale into a more sophisticated flow model that captures the important hydraulic features of the larger-scale flow system. It is believed that the $\mathrm{C}$-wells tracer tests and their interpretations presented in this report accomplish this objective. 


\section{INTENTIONALLY LEFT BLANK}


APPENDIX E

LABORATORY TESTING CONDUCTED TO SUPPORT INTERPRETATIONS OF TRACER TESTS AT THE C-WELLS COMPLEX 


\section{E1. BATCH TESTING OF LITHIUM SORPTION TO C-WELLS TUFFS}

\section{E1.1 MATERIALS AND METHODS}

The batch lithium sorption experiments were conducted as follows (full details of the sorption measurements are provided by Reimus in YMP C-Wells Sorption (2000 [DIRS 164625]):

- C-wells core from a stratigraphic unit of interest was crushed, pulverized, and passed through a $500-\mu \mathrm{m}$ sieve but retained on a $75-\mu \mathrm{m}$ sieve.

- A specified amount of crushed tuff was added to polycarbonate (polyallomer) Oak Ridge centrifuge tubes. In some experiments, the tuff and centrifuge tubes were autoclaved prior to contacting the tuff with the lithium solution.

- The tuff was preconditioned with filter-sterilized $(0.2-\mu \mathrm{m}$ filter $) \mathrm{J}-13$ well water.

- A specified amount of lithium-bearing water (either from well J-13 or well c\#3) was added to the preconditioned tuff, and the mixture was continuously shaken for 24 to $72 \mathrm{hr}$ at either $25^{\circ} \mathrm{C}$ or $38^{\circ} \mathrm{C}$. Previous studies had indicated that lithium sorption equilibrium onto $\mathrm{C}$-wells tuffs was reached in approximately 1 hour (Newman et al. 1991 [DIRS 156849]), so 24 hours should have been sufficient to achieve equilibration between solid and solution.

- After equilibration, the tubes were centrifuged and a portion of the supernate was filtered (0.2- or $0.4-\mu \mathrm{m}$ filter) for tracer analysis to determine the tracer concentration remaining in solution. Lithium was analyzed by inductively coupled plasma-atomic emission spectrometry (ICP-AES).

- The mass of tracer sorbed to the tuff was determined by mass balance, with corrections if necessary, to account for sorption to the container walls, which was measured in control experiments in which tuff was omitted.

- All measurements were made in duplicate or triplicate.

Sorption isotherms were determined under several different experimental conditions:

- 1:1 solution:solid ratio in $\mathrm{J}-13$ water at $25^{\circ} \mathrm{C}$

- 1:1 solution:solid ratio in $\mathrm{J}-13$ water at $38^{\circ} \mathrm{C}$

- 2:1 solution:solid ratio in $\mathrm{J}-13$ water at $25^{\circ} \mathrm{C}$

- 4:1 solution:solid ratio in $\mathrm{C}-3$ water at $38^{\circ} \mathrm{C}$

- 4:1 solution:solid ratio in $\mathrm{J}-13$ water at $25^{\circ} \mathrm{C}$

- $4: 1$ solution:solid ratio in $\mathrm{J}-13$ water at $38^{\circ} \mathrm{C}$.

The two temperatures were intended to approximate the range of conditions under which sorption would occur in either the laboratory or the field [the groundwater temperature in the Bullfrog Tuff at the C-wells ranges from about $38^{\circ} \mathrm{C}$ to $45^{\circ} \mathrm{C}$ (Geldon 1993 [DIRS 101045], pp. 68 to 70 , Figures 31 to 33)]. 
At the time of these studies, groundwater from the $\mathrm{C}$-wells complex was not consistently available, so groundwater from well $\mathrm{J}-13$, located $4 \mathrm{~km}$ southeast of the $\mathrm{C}$-wells complex, was used as a surrogate in most tests. J-13 well water is well-characterized and has become a de facto standard groundwater for use in Yucca Mountain sorption studies (Harrar et al. 1990 [DIRS 100814], pp. 6.6 to 6.7; Triay et al. 1997 [DIRS 100422], pp. 11, 16, 45). A comparison of J-13 and C-wells groundwater chemistry shows that the two waters are both sodium bicarbonate dominated and, in all regards, quite similar (Table E-1). Lithium solutions for sorption tests were prepared by dissolving reagent-grade lithium bromide in either $\mathrm{c} \# 3$ or $\mathrm{J}-13$ well water. All solutions were filter-sterilized before use.

Table E-1. Comparison of Major lon Chemistry of $\mathrm{J}-13$ and c\#3

\begin{tabular}{|l|c|c|}
\hline \multirow{2}{*}{ Species } & \multicolumn{2}{|c|}{ Concentration $(\mu \mathrm{g} / \mathrm{mL})$} \\
\cline { 2 - 3 } & $\mathrm{J}-13$ & C-wells \\
\hline $\mathrm{Ca}$ & 12 & 11 \\
\hline $\mathrm{Cl}$ & 7.1 & 7.2 \\
\hline $\mathrm{K}$ & 5 & 1.9 \\
\hline $\mathrm{Mg}$ & 2.1 & 0.4 \\
\hline $\mathrm{Na}$ & 42 & 55 \\
\hline $\mathrm{SiO}_{2}$ & 47 & 53 \\
\hline $\mathrm{SO}_{4}$ & 17 & 22 \\
\hline $\mathrm{HCO}_{3}$ & 124 & 137 \\
\hline $\mathrm{pH}^{2}$ & 7.2 & 7.7 \\
\hline
\end{tabular}

Source: DTNs: MO0007MAJIONPH.013 [DIRS 151530] (J-13); MO0007MAJIONPH.011 [DIRS 151524] (c\#3).

A few tests were conducted in a sodium bicarbonate solution having the same ionic strength as J13 well water but without the calcium and other cations present in J-13 well water. Lithium sorption in this solution was noticeably greater than in J-13 well water, presumably because of the absence of cations that compete with lithium for sorption sites (primarily calcium). The results of these experiments are not reported here (Callahan 2001 [DIRS 165123]).

Ion-exchange theory suggests that the actual ion-exchange process is rapid and will reach equilibrium quickly; in natural systems, apparent equilibration rates are limited by diffusion of ions through the solution to the mineral surface (Bolt et al. 1978 [DIRS 113856], pp. 54 to 90). In a well-mixed system, such as a shaken centrifuge tube, diffusion is not limiting, and equilibration should be achieved quickly. A previous study of lithium sorption to the Prow Pass member of the Crater Flat Tuff found that sorption equilibrium was reached within $1 \mathrm{hr}$, confirming this hypothesis (Newman et al. 1991 [DIRS 156849]). For consistency with other sorption studies and for scheduling convenience, a minimum equilibration period of $24 \mathrm{hr}$ was adopted for these studies.

Tuffs from seven different lithologies were tested, including two samples of the same unit (the central Bullfrog Tuff) from two different holes (c\#1 and c\#2), to allow an assessment of spatial heterogeneity in lithium-sorption parameters. The experimental matrix of tuffs, groundwaters, temperatures, and solid-solution ratios is summarized in Table E-2. Figure E-1 shows the sampling locations of the $\mathrm{C}$-wells core used in the experiments. This figure is essentially 
identical to Figure 6.1-2 except that the triangles indicating flow zones in the wells have been replaced with triangles identifying locations of core samples used in the batch experiments.

Batch-sorption experiments were also conducted on each of the tuffs to determine whether pentafluorobenzoate (PFBA) and bromide sorbed to them. The bromide experiments were actually conducted simultaneously with the lithium experiments, as lithium was added to the solutions as lithium bromide. The starting bromide concentrations ranged from approximately 10 parts per million (ppm) to approximately $1000 \mathrm{ppm}$. The PFBA experiments were conducted at a single concentration (1 ppm). These experiments were conducted on each rock type at $25^{\circ} \mathrm{C}$. There was no measurable sorption of PFBA or bromide on any of the tuffs (DTN: LA0302PR831231.001 [DIRS 162605]).

Table E-2. Summary of C-Wells Experimental Batch Lithium Sorption Test Matrix

\begin{tabular}{|c|c|c|c|}
\hline Tuff (Lithology, Borehole, Depth (m)) & Water (Well ID) & Solution: Solid (mL:g) & Temperature $\left({ }^{\circ} \mathrm{C}\right)$ \\
\hline \multirow{2}{*}{ Central Bullfrog, c\#1, 715 m (1) } & $\mathrm{J}-13$ & $2: 1$ & 25 \\
\hline & $\mathrm{J}-13$ & $2: 1$ & 38 \\
\hline \multirow[t]{3}{*}{ Central Bullfrog, c\#2, 734 m (2) } & $\mathrm{J}-13$ & $1: 1$ & 25 \\
\hline & $\mathrm{J}-13$ & $1: 1$ & 38 \\
\hline & $\mathrm{c \# 3}$ & $4: 1$ & 38 \\
\hline \multirow[t]{3}{*}{ Lower Bullfrog, c\#1, 795 m (3) } & $\mathrm{J}-13$ & $4: 1$ & 25 \\
\hline & $\mathrm{J}-13$ & $4: 1$ & 38 \\
\hline & $\mathrm{J}-13$ & $2: 1$ & 25 \\
\hline \multirow[t]{3}{*}{ Upper Prow Pass, c\#2, 533 m (4) } & $\mathrm{J}-13$ & $4: 1$ & 25 \\
\hline & $\mathrm{J}-13$ & $4: 1$ & 38 \\
\hline & $\mathrm{J}-13$ & $2: 1$ & 25 \\
\hline \multirow[t]{3}{*}{ Central Prow Pass, c\#2, 553 m (5) } & $\mathrm{J}-13$ & $4: 1$ & 25 \\
\hline & $\mathrm{J}-13$ & $4: 1$ & 38 \\
\hline & $\mathrm{J}-13$ & $2: 1$ & 25 \\
\hline \multirow[t]{3}{*}{ Lower Prow Pass, c\#1, 573 m (6) } & $\mathrm{J}-13$ & $4: 1$ & 25 \\
\hline & $\mathrm{J}-13$ & $4: 1$ & 38 \\
\hline & $\mathrm{J}-13$ & $2: 1$ & 25 \\
\hline \multirow[t]{3}{*}{ Bedded Prow Pass, c\#2, 643 m (7) } & $\mathrm{J}-13$ & $4: 1$ & 25 \\
\hline & $\mathrm{J}-13$ & $4: 1$ & 38 \\
\hline & $\mathrm{J}-13$ & $2: 1$ & 25 \\
\hline \multirow[t]{3}{*}{ Upper Tram, c\#2, 839 m (8) } & $\mathrm{J}-13$ & $4: 1$ & 25 \\
\hline & $\mathrm{J}-13$ & $4: 1$ & 38 \\
\hline & $\mathrm{J}-13$ & $2: 1$ & 25 \\
\hline
\end{tabular}

Source: DTN: MO0012SORBCHOL.000 [DIRS 153375].

NOTE: The numbers in parentheses correspond to the numbers in Figure E-1 (the locations where core was collected from the C-wells). 


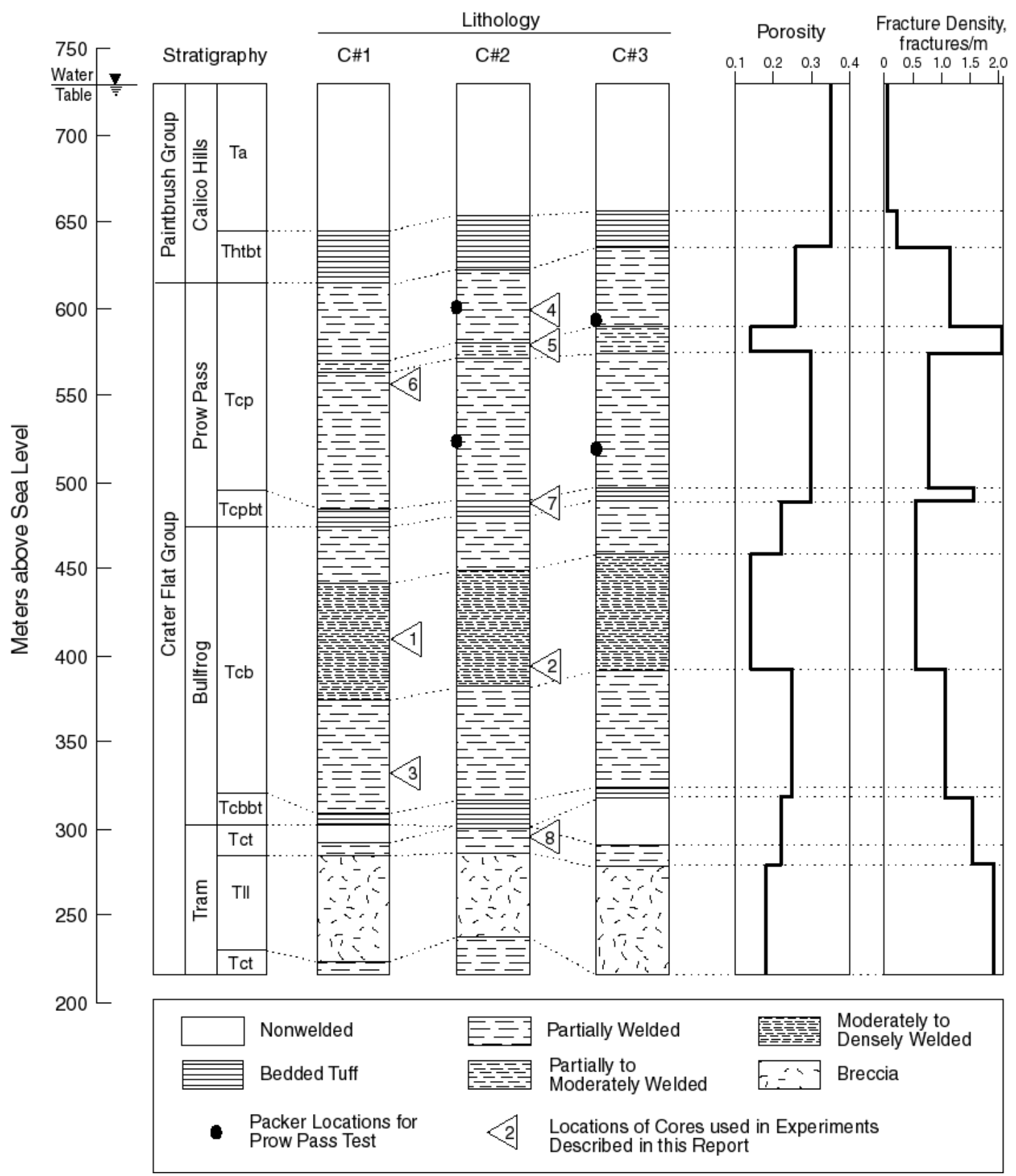

Source: Geldon (1993 [DIRS 101045], pp. 35 to 37, 43 to 51, 58 to 64) for lithology, stratigraphy, porosity, and fracture density information. Umari (2002 [DIRS 162858], Binder 10, Section L-11, pp. 70 to 71 ,

Section L-9, pp. 57 to 58) for packer locations. Reimus (2000 [DIRS 165124], pp. E1 to E10, M1 to M14, Q1 to Q20, W1 to W15, X1 to X14, AB1 to AB11, AC1 to AC17) for locations of core samples.

NOTE: The numbers in the figure correspond to the numbers in Table E-2. Also shown are approximate locations of packers for the tracer tests in the Prow Pass Tuff.

Figure E-1. C-Wells Hydrogeology Showing Sampling Locations of All Core Used in the Laboratory Experiments Described in Sections E1, E2, and E3 
The mineralogy of the tuffs used in the batch-sorption experiments is listed in Table E-3. The mineralogy was determined from quantitative X-ray diffraction analyses. The tuffs differ primarily in their smectite and zeolite (clinoptilolite and mordenite) content, both of which have high cation-exchange capacities and would be expected to sorb lithium quite strongly compared to other minerals present in the rocks (Anghel et al. 2002 [DIRS 164635], Section 3.2 pp. 822 to 824$)$.

Table E-3. X-Ray Diffraction Results for Tuffs from Prow Pass, Bullfrog, and Tram Units

\begin{tabular}{|l|c|c|c|c|c|c|}
\hline \multirow{2}{*}{\multicolumn{1}{c|}{ Tuff }} & \multirow{2}{*}{$\begin{array}{c}\text { Depth } \\
(\mathbf{m})\end{array}$} & \multicolumn{5}{c|}{ Concentration (wt \%) } \\
\cline { 3 - 7 } & Smectite & Clinoptilolite & Mordenite & Analcime & Calcite \\
\hline Central Bullfrog, c\#1 & 715 & $2 \pm 1$ & - & - & - & $2 \pm 1$ \\
\hline Central Bullfrog, c\#2 & 734 & $5 \pm 2$ & - & - & - & - \\
\hline Lower Bullfrog, c\#1 & 795 & $9 \pm 3$ & $4 \pm 1$ & $3 \pm 1$ & $12 \pm 1$ & $4 \pm 1$ \\
\hline Upper Prow Pass, c\#2 & 533 & - & - & - & - & Trace \\
\hline Central Prow Pass, c\#2 & 553 & $2 \pm 1$ & - & - & - & $2 \pm 1$ \\
\hline Lower Prow Pass, c\#1 & 573 & $2 \pm 1$ & - & - & - & - \\
\hline Bedded Prow Pass, c\#2 & 643 & - & - & $20 \pm 4$ & $39 \pm 2$ & - \\
\hline Upper Tram, c\#2 & 839 & $1 \pm 1$ & - & - & - & - \\
\hline
\end{tabular}

Source: DTNs: MO0012MINLCHOL.000 [DIRS 153370]; LA9909PR831231.004 ([DIRS 129623] for Central Bullfrog $\mathrm{C \# 2}$ only (qualified for use in this report in Appendix J).

NOTE: $\quad$ C\#1, c\#2, and c\#3 are abbreviations for Boreholes UE-25 c\#1, UE-25 c\#2, and UE-25 c\#3, respectively. Trace: trace abundance of less than $0.5 \mathrm{wt}$ percent. Only the main sorptive mineral fractions are listed; the balance of the tuffs was mostly quartz and feldspar with small amounts of hematite, mica/illite, and/or kaolinite. Dashes indicate "not measured."

A Li-specific cation-exchange-capacity (CEC) method was developed to quantify the Li affinity for the selected tuffs. The method involved two steps: saturation of the exchange sites with $\mathrm{Li}$, followed by displacement of the $\mathrm{Li}$ and other cations with Cs. The mineralogical composition of the samples was preserved as close as possible to the field conditions; therefore, no pretreatment was applied to remove carbonate or organic matter. The method involved the following steps (Anghel et al. 2002 [DIRS 164635], Section 3.2, pp. 822 to 824).

- The tuff samples were crushed and wet-sieved with J-13 well water to a particle-size range between 75 to $500 \mu \mathrm{m}$. Then approximately $5 \mathrm{~g}$ of each tuff was weighed into a 50-mL centrifuge Teflon tube. Each tuff sample was tested in triplicate.

- The samples were saturated three times with $30 \mathrm{~mL}$ of $0.8 \mathrm{~N} \mathrm{LiBr}-0.2 \mathrm{~N}$ LiOAc solution to ensure replacement of cations present on mineral surface sites with Li. The $\mathrm{pH}$ of the solution was maintained at approximately 8.2 to prevent dissolution of calcite. After each $\mathrm{LiBr}$ addition, the tubes were sonicated to disperse the centrifuged sediment, and then the samples were shaken for $30 \mathrm{~min}$.

- The samples were centrifuged at $10,000 \mathrm{rpm}$ for 15 minutes to achieve a good separation of solids and solution. The supernatant from each Li-sorption step was combined and analyzed for $\mathrm{Na}, \mathrm{K}, \mathrm{Ca}$, and $\mathrm{Mg}$. 
- After the Li-sorption steps, the tuff present in each centrifuge tube was washed three times with $30 \mathrm{~mL}$ of $1 \mathrm{~N} \mathrm{CsCl}$ to remove the sorbed $\mathrm{Li}$. The combined supernate from centrifuging was analyzed for $\mathrm{Li}, \mathrm{Na}, \mathrm{Ca}, \mathrm{K}$, and $\mathrm{Mg}$. Residual Li saturating solution remaining in the centrifuge tubes was accounted for by analyzing for $\mathrm{Br}$ and making the appropriate correction. Cs has more affinity for zeolites, and it should, therefore, displace more cations than Li. In many cases, Cs sorption gives a measure of the total CEC ( $\mathrm{Li}$ measurements of the aliquots give the CEC for Li-Cs exchange).

The method described yields two different CEC results: (1) CEC-LiT, the total CEC available to $\mathrm{Li}$, estimated from the total cations displaced by Li in the saturation step; and (2) CEC-CsT, the total $\mathrm{CEC}$ available to $\mathrm{Cs}$, estimated from the total cations displaced by $\mathrm{Cs}$ in the displacement step. CEC-CsT can be further subdivided into CEC-CsLi based on the Li displaced by Cs, and CEC-CsNat, based on the native cations ( $\mathrm{Na}, \mathrm{K}, \mathrm{Ca}, \mathrm{Mg}$ ) displaced by Cs. Each of these results is expressed in milliequivalents per $100 \mathrm{~g}$ of dry tuff.

\section{E1.2 RESULTS AND DISCUSSION}

During the course of the experiments, it became apparent that lithium sorption was essentially independent of solution:solid ratio, temperature, and water composition (J-13 or c\#3) over the range of conditions studied. Therefore, the data sets for a given tuff lithology were combined to estimate sorption parameters. Three common isotherm models, defined as follows, were fitted to the data for each tuff.

(1) Linear Isotherm:

$$
S=K_{\mathrm{d}} C
$$

where

$S=$ equilibrium sorbed concentration $(\mu \mathrm{g} / \mathrm{g})$

$C=$ equilibrium solution concentration $(\mu \mathrm{g} / \mathrm{mL})$

$K_{\mathrm{d}}=$ linear distribution coefficient $(\mathrm{mL} / \mathrm{g})$.

(2) Freundlich Isotherm:

$$
S=K_{\mathrm{F}} C^{n}
$$

where

$K_{\mathrm{F}}=$ Freundlich coefficient $(\mathrm{mL} / \mu \mathrm{g})^{n}(\mu \mathrm{g} / \mathrm{g})$

$n=$ Freundlich exponent (dimensionless).

(3) Langmuir Isotherm:

$$
S=\frac{K_{\mathrm{L}} S_{\max } C}{1+K_{\mathrm{L}} C}
$$


where

$K_{\mathrm{L}}=$ Langmuir coefficient $(\mathrm{mL} / \mu \mathrm{g})$

$S_{\max }=$ maximum attainable solid sorption capacity $(\mu \mathrm{g} / \mathrm{g})$.

Figures E-2 to E-8 show the experimental data for each tuff plotted as log-equilibrium-sorbed concentration, $\mathrm{S}(\mu \mathrm{g} / \mathrm{g})$, versus log-solution concentration, $\mathrm{C}(\mu \mathrm{g} / \mathrm{mL})$. A Langmuir isotherm consistently yielded better visual fits to the data than the other isotherms, so a fitted Langmuir isotherm is also shown in each figure. The Langmuir isotherm is the only one that captures the curvature of the data when graphed on log-log axes. Furthermore, only the Langmuir isotherm recognizes the finite sorptive capacity of the solid matrix; the other models imply potential infinite sorption. A previous study of lithium sorption to the Prow Pass member of the Crater Flat Tuff also revealed Langmuir behavior (Newman et al. 1991 [DIRS 156849]). The Langmuir, Freundlich, and linear isotherm parameters associated with the data in Figures E-2 to E-8 are given in Table E-4. It is concluded that a Langmuir isotherm provides the best representation of lithium sorption onto C-wells tuffs. However, a detailed statistical analysis to quantify how much better this representation is relative to the other isotherms (or whether it is statistically better) was not conducted. Statistical analyses were not conducted to determine whether there were significant isotherm differences as a function of temperature, solid-solution ratio, or core taken from different locations in the same lithological unit (i.e., the Central Bullfrog Tuff from c\#1 or c\#2). However, it appears from Figures E-2 to E-8 that any of these differences should have been minimal.

The error bounds shown in Figures E-2 to E-8 reflect the propagation of analytical errors associated with lithium concentration measurements in the solutions before and after contact with the sorbing tuffs (Reimus 2003 [DIRS 165129], p. 126). These bounds are shown relative to the fitted Langmuir isotherms, not relative to individual data points. The bounds were calculated assuming a 10 percent relative standard deviation in the lithium concentration measurements, which is high for ICP-AES measurements but it also serves to account for other experimental errors, such as imperfect separations of solid and solution phases during centrifugation. Errors increase as concentrations increase because there is a lower percentage of lithium sorbing at higher concentrations and, hence, a smaller relative difference between measured initial and final solution concentrations. It is apparent that the scatter in the data sets often exceeds the analytical error bounds, suggesting greater than 10 percent error in some of the measurements.

In Figures E-2 to E-6, the lithium isotherm associated with the ion-exchange parameters used in MULTRAN V 1.0 (STN: 1066-1.0-00 [DIRS 159068]) to obtain a good match to either the first lithium peak in the Bullfrog Tuff tracer test (Figure D-26) or the lithium response in the Prow Pass Tuff tracer test (Figure D-27) are plotted along with the laboratory data and the Langmuir isotherm fits to the laboratory data. In all cases, the isotherms derived from the simulations of the field data indicate greater lithium sorption in the field than the best-fitting Langmuir isotherms derived from the laboratory experiments. A likely explanation for this result is that the lithium in the field tests came into contact mineral surfaces that were not present or were underrepresented in the small-scale laboratory tests. "Field" isotherms are not shown in Figures E-7 and E-8 because the Bedded Prow Pass and Upper Tram Tuff lithologies were not part of the packed-off intervals in the reactive tracer tests. 
The fitted Langmuir isotherms corresponding to all seven C-wells tuff lithologies are plotted together in Figure E-9. By comparing Figure E-9 to the X-ray diffraction results of Table E-3, it is apparent that the two tuffs demonstrating the greatest affinity for lithium (Bedded Prow Pass and Lower Bullfrog) are also the tuffs that have the greatest smectite and/or zeolite contents. A quantitative relationship between lithium sorption and tuff mineralogy is discussed further below.

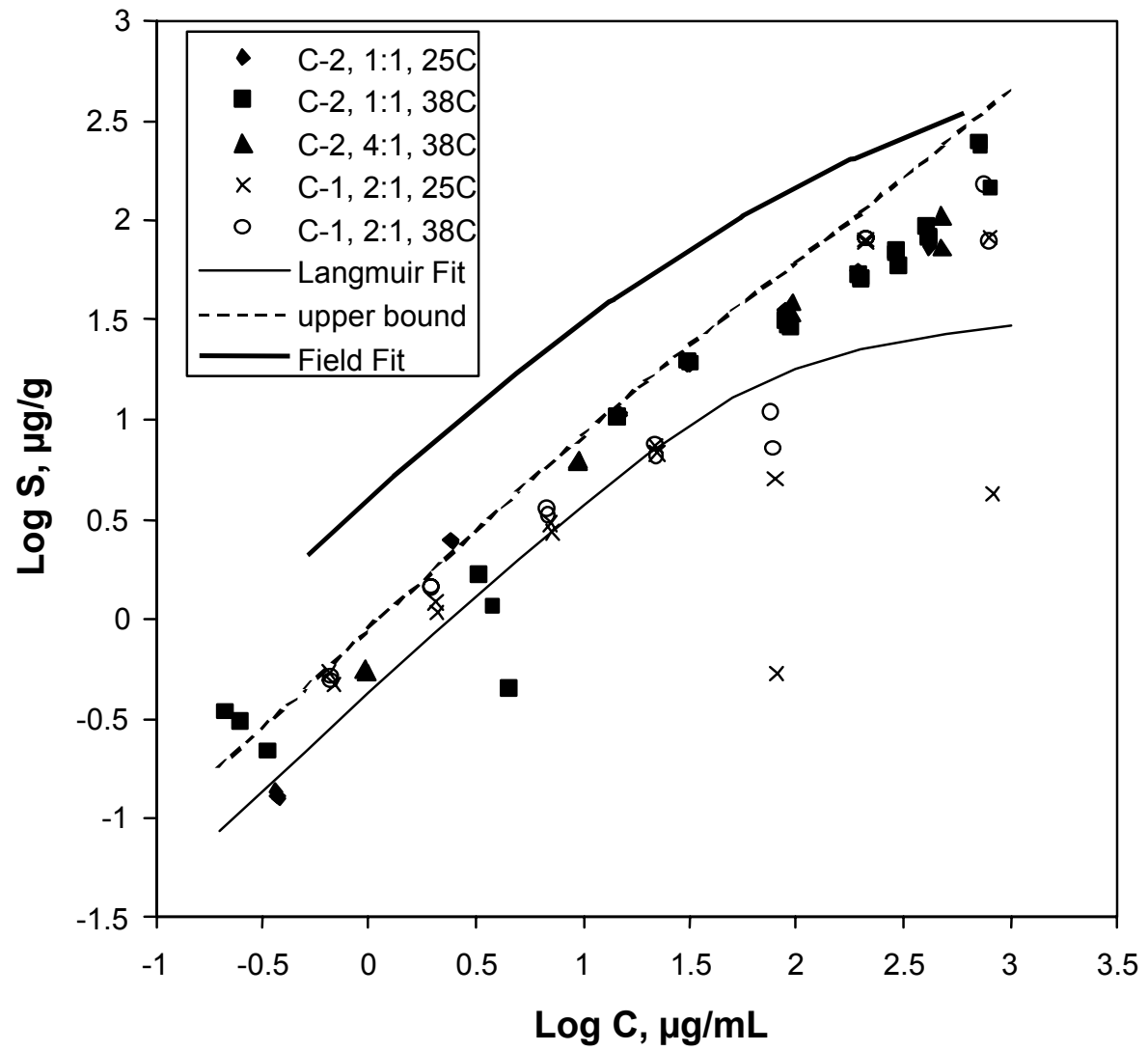

Source: DTN: MO0012SORBCHOL.000 [DIRS 153375] (data).

Output DTN: LA0303PR831341.003 (isotherm fits).

NOTE: C-1 and C-2 refer to UE-25 c\#1 and c\#2, respectively. The legend indicates the borehole (c\#1 or $\mathrm{C \# 2)}$ from which the tuff came, the solution:solid ratio $(\mathrm{mL}: \mathrm{g})$, and the temperature of the experiments. The dashed line is an upper error bar associated with a 10 percent experimental error (this error bar is plotted relative to the Langmuir isotherm line - lower error bound is off-scale over the entire range of data). The method for calculating the error bars is described by Reimus (2003 [DIRS 165129], p. 126). J-13 well water was used in all experiments except for "C-2, 4:1, 38C." Water from c\#3 was used for "C-2, 4:1, 38C." The lithium concentration range in the Bullfrog Tuff field test spanned from less than $0.1 \mu \mathrm{g} / \mathrm{mL}$ up to $1,200 \mu \mathrm{g} / \mathrm{mL}$. The line labeled "Field Fit" is the isotherm corresponding to the MULTRAN V 1.0 (STN: 1066-1.0-00 [DIRS 159068]) "fit" to the first lithium peak in the Bullfrog Tuff field tracer test (Figure D-26).

Figure E-2. Lithium Sorption Data and Fitted Langmuir Isotherm for the Central Bullfrog Tuff 


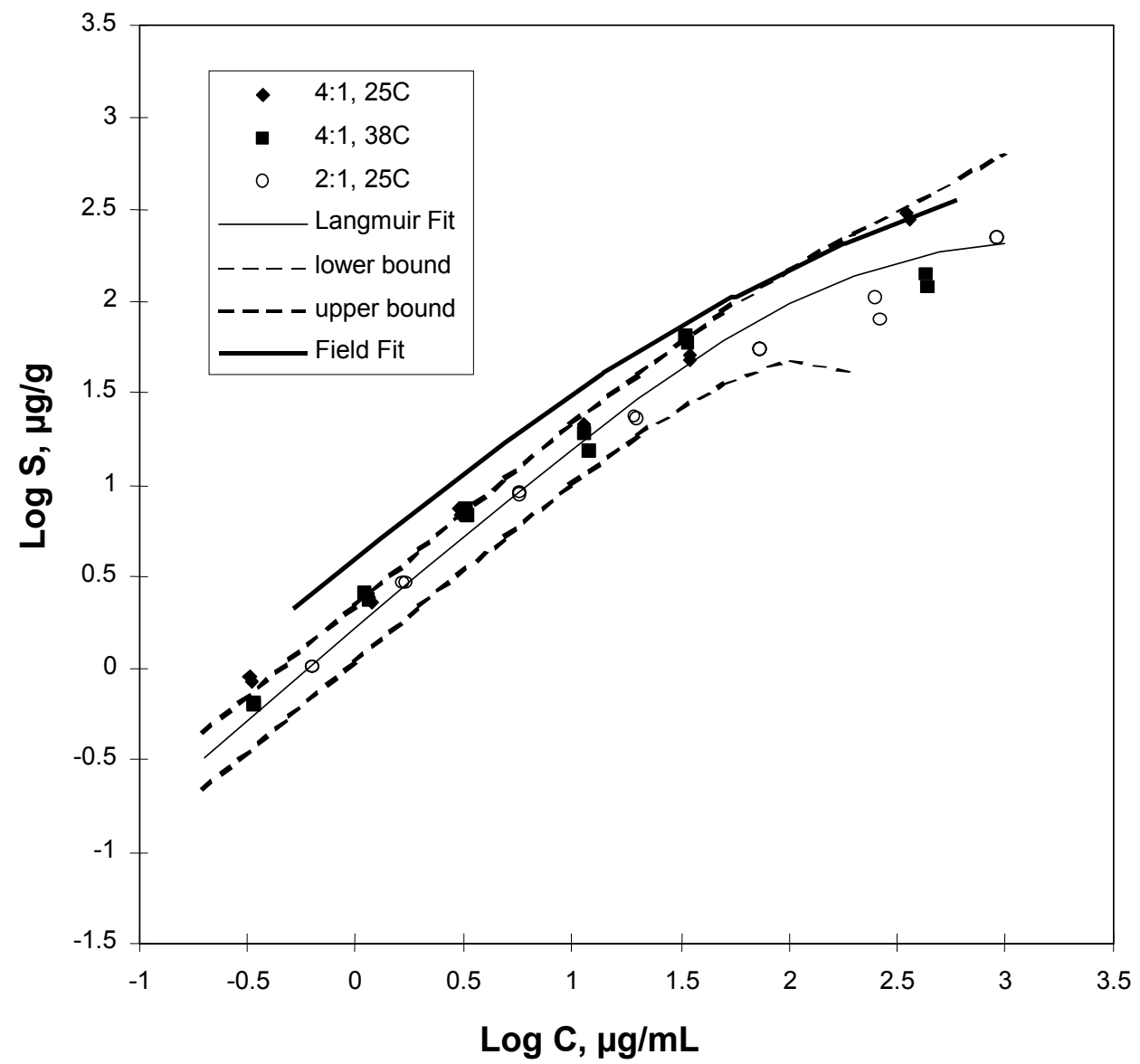

Source: DTN: MO0012SORBCHOL.000 [DIRS 153375] (data).

Output DTN: LA0303PR831341.003 (isotherm fits).

NOTE: The legend indicates the solution:solid ratio $(\mathrm{mL}: \mathrm{g})$ and the temperature of the experiments. The dashed lines are error bars associated with a 10 percent experimental error (these error bars are plotted relative to the Langmuir isotherm line). The method for calculating the error bars is by Reimus (2003 [DIRS 165129], p. 126). The lower bound at the highest concentrations is off scale. J-13 well water was used in all experiments. The lithium concentration range in the Bullfrog Tuff field test spanned from less than $0.1 \mu \mathrm{g} / \mathrm{mL}$ up to $1,200 \mu \mathrm{g} / \mathrm{mL}$. The line labeled "Field Fit" is the isotherm corresponding to the MULTRAN V 1.0 (STN: 1066-1.0-00 [DIRS 159068]) "fit" to the first lithium peak in the Bullfrog Tuff field tracer test (Figure D-26).

Figure E-3. Lithium Sorption Data and Fitted Langmuir Isotherm for the Lower Bullfrog Tuff (c\#1, $795 \mathrm{~m}$ Below Land Surface). 


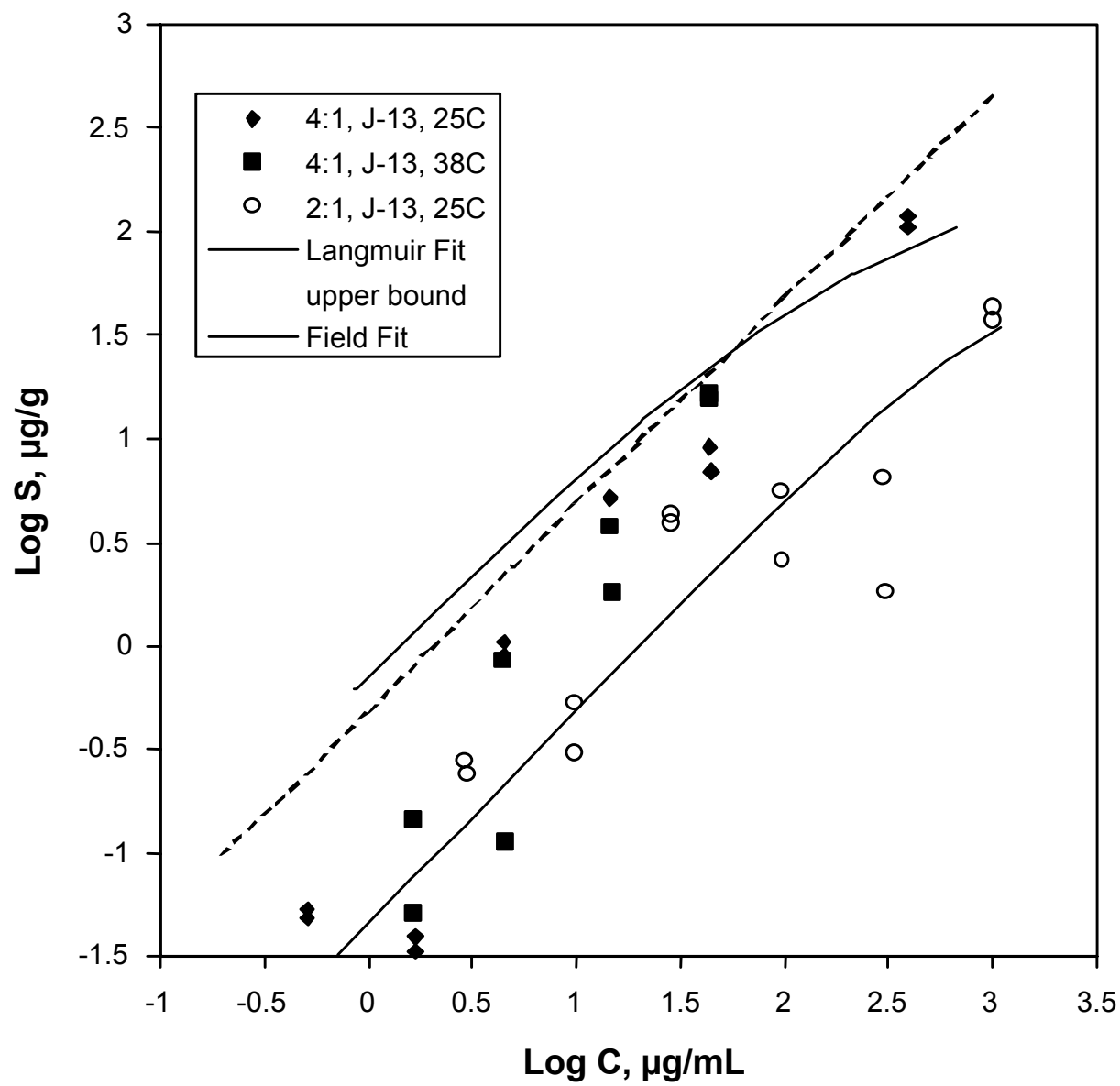

Source: DTN: MO0012SORBCHOL.000 [DIRS 153375] (data).

Output DTN: LA0303PR831341.003 (isotherm fits).

NOTE: The legend indicates the solution:solid ratio $(\mathrm{mL}: \mathrm{g})$ and the temperature of the experiments. The dashed line is an upper error bar associated with a 10 percent experimental error (this error bar is plotted relative to the Langmuir isotherm line - lower error bound is off-scale over entire range of data). The method for calculating the error bars is by Reimus (2003 [DIRS 165129], p. 126). J-13 well water was used in all experiments. The lithium concentration in the Prow Pass Tuff field test ranged from less than $0.1 \mu \mathrm{g} / \mathrm{mL}$ up to $2,700 \mu \mathrm{g} / \mathrm{mL}$.

The line labeled "Field Fit" is the isotherm corresponding to the MULTRAN V 1.0 (STN: 1066-1.0-00 [DIRS 159068]) "fit" to the lithium data in the Prow Pass Tuff field tracer test (Figure D-27).

Figure E-4. Lithium Sorption Data and Fitted Langmuir Isotherm for the Upper Prow Pass Tuff (c\#2, 533 m Below Land Surface) 


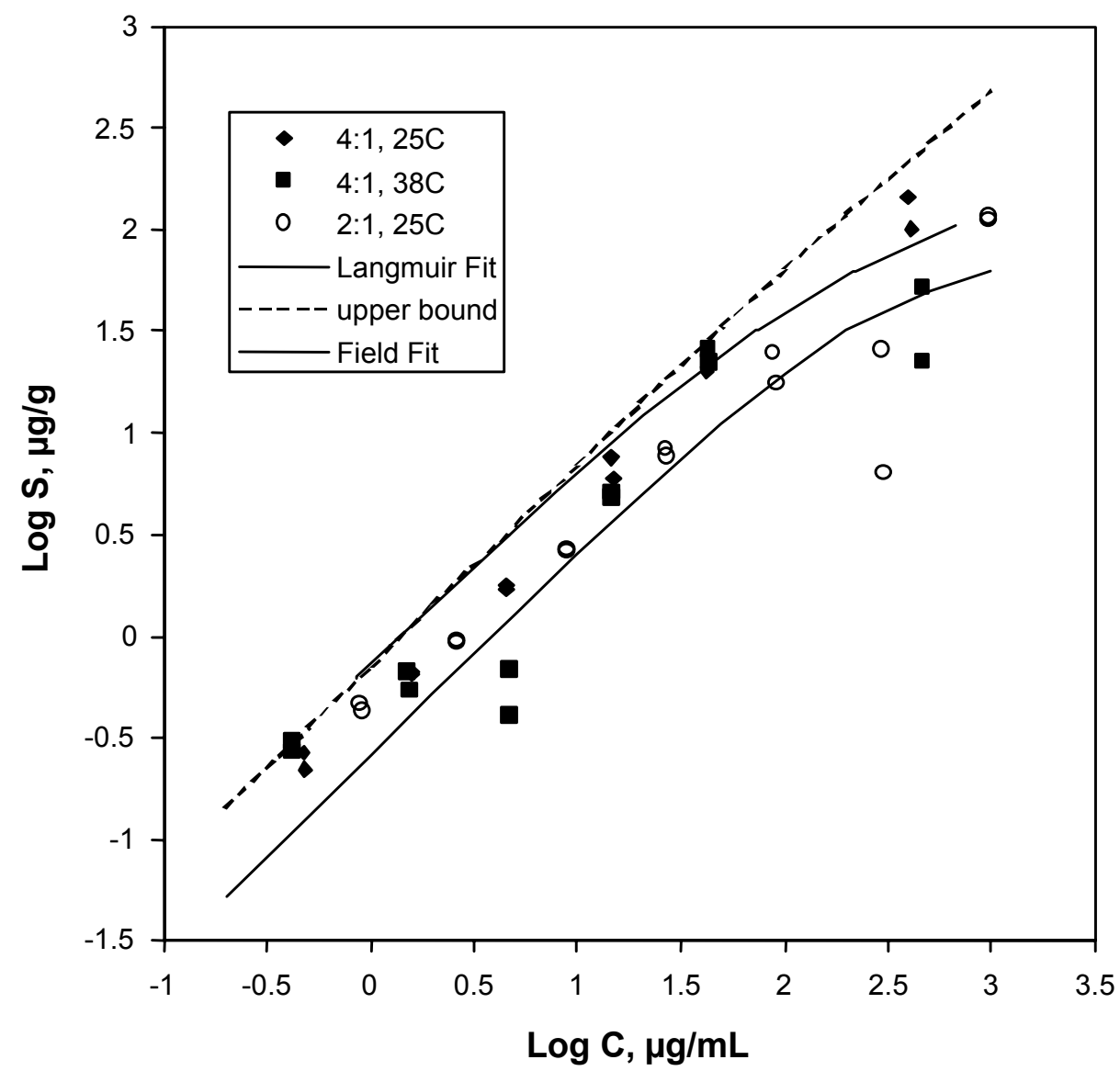

Source: DTN: MO0012SORBCHOL.000 [DIRS 153375] (data).

Output DTN: LA0303PR831341.003 (isotherm fits).

NOTE: The legend indicates the solution:solid ratio $(\mathrm{mL}: \mathrm{g})$ and the temperature of the experiments. The dashed line is an upper error bar associated with a 10 percent experimental error (this error bar is plotted relative to the Langmuir isotherm line - lower error bound is off-scale over entire range of data). The method for calculating the error bars is by Reimus (2003 [DIRS 165129], p. 126). J-13 well water was used in all experiments. The lithium concentration in the Prow Pass Tuff field test ranged from less than $0.1 \mu \mathrm{g} / \mathrm{mL}$ up to $2,700 \mu \mathrm{g} / \mathrm{mL}$. The line labeled "Field Fit" is the isotherm corresponding to the MULTRAN V 1.0 (STN: 1066-1.0-00 [DIRS 159068]) "fit" to the lithium data in the Prow Pass Tuff field tracer test (see Figure D-27).

Figure E-5. Lithium Sorption Data and Fitted Langmuir Isotherm for the Central Prow Pass Tuff (c\#2, 553 m Below Land Surface) 


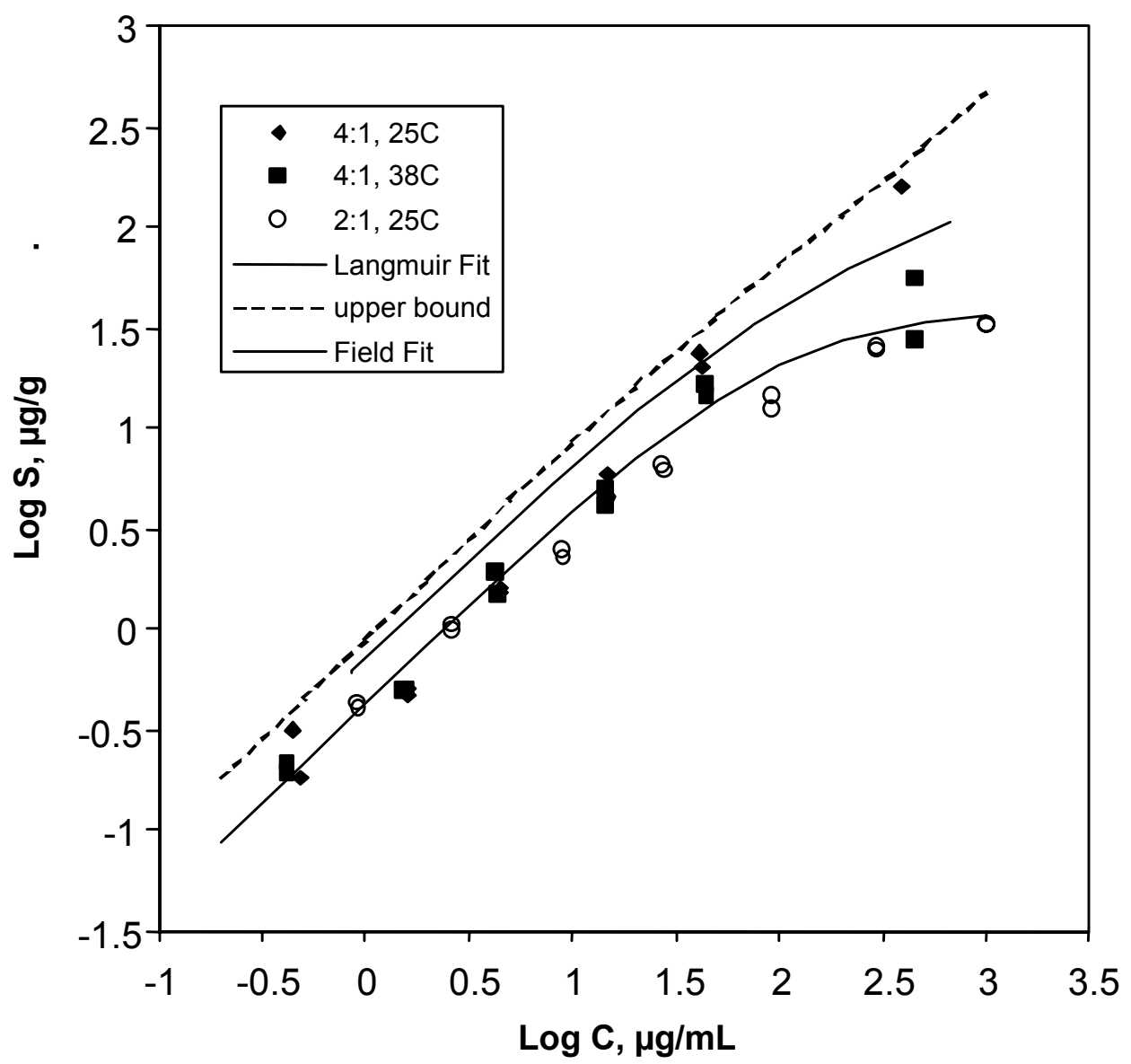

Source: DTN: MO0012SORBCHOL.000 [DIRS 153375] (data).

Output DTN: LA0303PR831341.003 (isotherm fits).

NOTE: The legend indicates the solution:solid ratio $(\mathrm{mL}: \mathrm{g})$ and the temperature of the experiments. The dashed line is an upper error bars associated with a 10 percent experimental error (this error bar is plotted relative to the Langmuir isotherm line - lower error bound is off-scale over entire range of data). The method for calculating the error bars is by Reimus (2003 [DIRS 165129], p. 126). J-13 well water was used in all experiments. The lithium concentration in the Prow Pass Tuff field test ranged from less than $0.1 \mu \mathrm{g} / \mathrm{mL}$ up to $2,700 \mu \mathrm{g} / \mathrm{mL}$.

The line labeled "Field Fit" is the isotherm corresponding to the MULTRAN V 1.0 (STN: 1066-1.0-00

[DIRS 159068]) "fit" to the lithium data in the Prow Pass Tuff field tracer test (Figure D-27).

Figure E-6. Lithium Sorption Data and Fitted Langmuir Isotherm for the Lower Prow Pass Tuff (c\#1, $573 \mathrm{~m}$ Below Land Surface) 


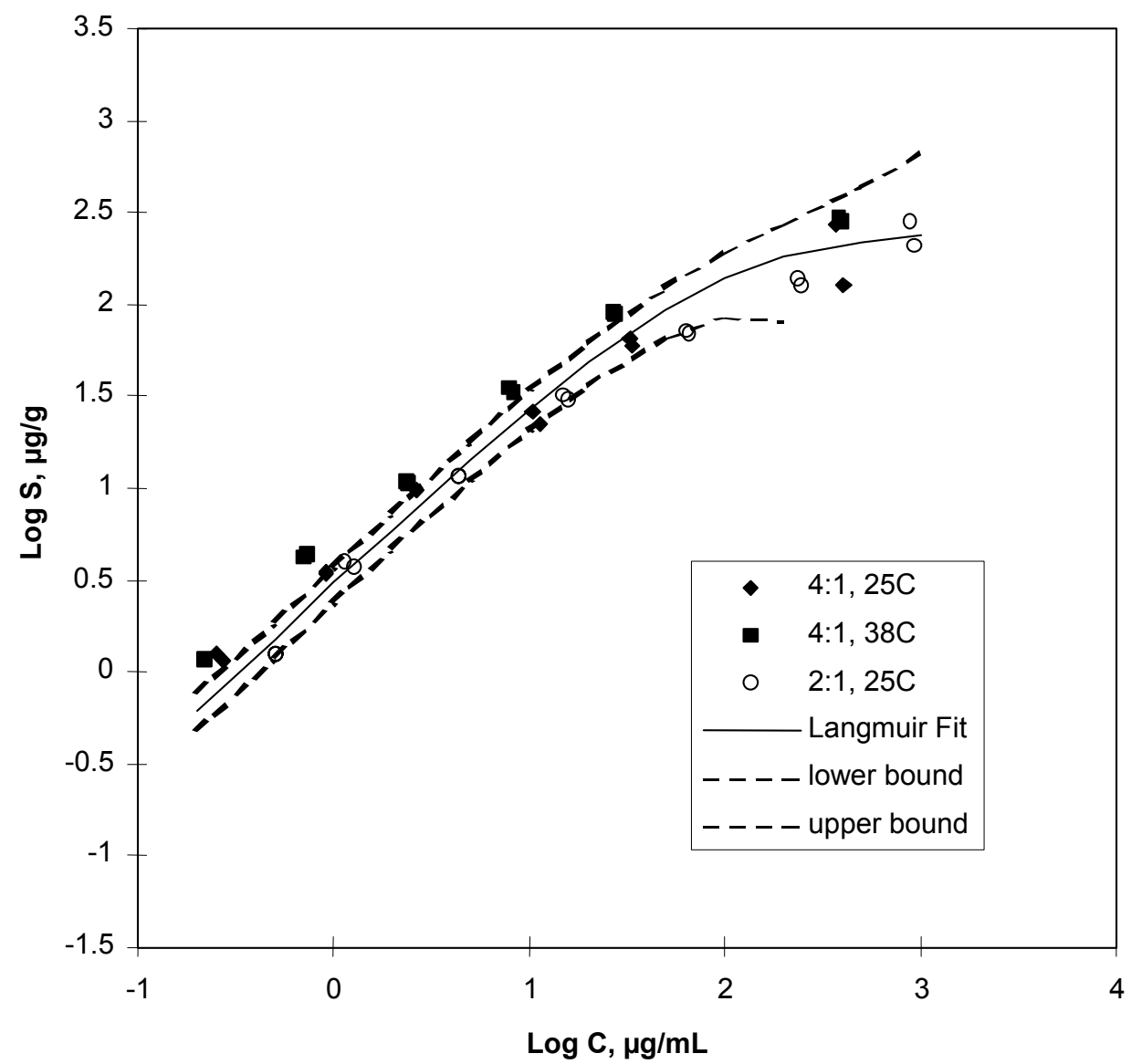

Source: DTN: MO00012SORBCHOL.000 [DIRS 153375] (data).

Output DTN: LA0303PR831341.003 (isotherm fits).

NOTE: The legend indicates the solution:solid ratio $(\mathrm{mL}: \mathrm{g})$ and the temperature of the experiments. The dashed lines are error bars associated with a 10 percent experimental error (these error bars are plotted relative to the Langmuir isotherm line). The method for calculating the error bars is by Reimus (2003 [DIRS 165129], p. 126). The lower bound at the highest concentrations is off scale. J-13 well water was used in all experiments.

Figure E-7. Lithium Sorption Data and Fitted Langmuir Isotherm for the Bedded Prow Pass Tuff (c\#1, $643 \mathrm{~m}$ Below Land Surface) 


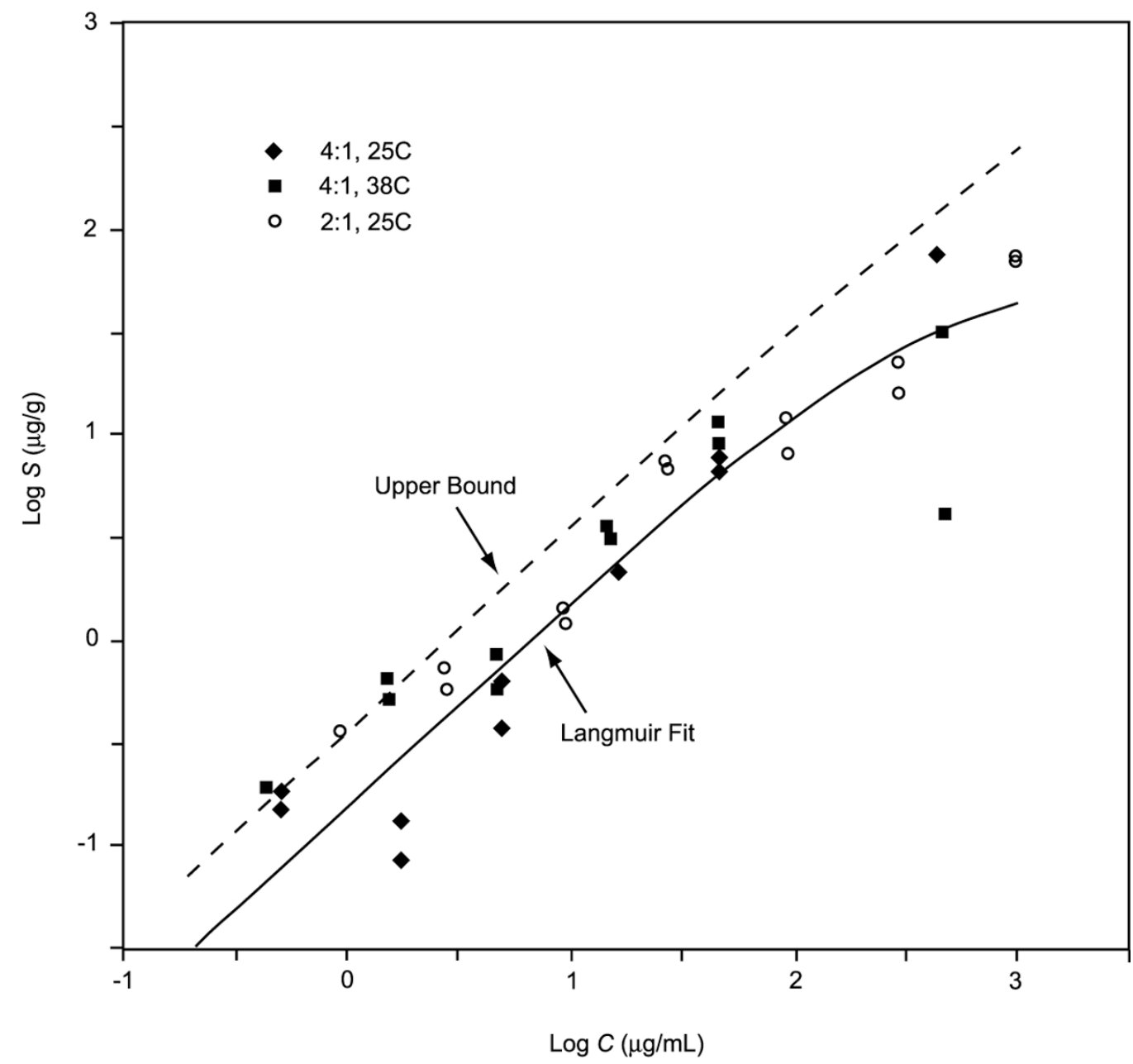

Source: DTN: MO0012SORBCHOL.000 [DIRS 153375] (data).

Output DTN: LA0303PR831341.003 (isotherm fits).

NOTE: The legend indicates the solution:solid ratio $(\mathrm{mL}: \mathrm{g})$ and the temperature of the experiments. The dashed line is an upper error bar associated with a 10 percent experimental error (these error bars are plotted relative to the Langmuir isotherm line - lower error bound is off-scale over entire range of data). The method for calculating the error bars is described by Reimus (2003 [DIRS 165129], p. 126). J-13 well water was used in all experiments.

Figure E-8. Lithium Sorption Data and Fitted Langmuir Isotherm for the Upper Tram Tuff (c\#2, $839 \mathrm{~m}$ Below Land Surface) 


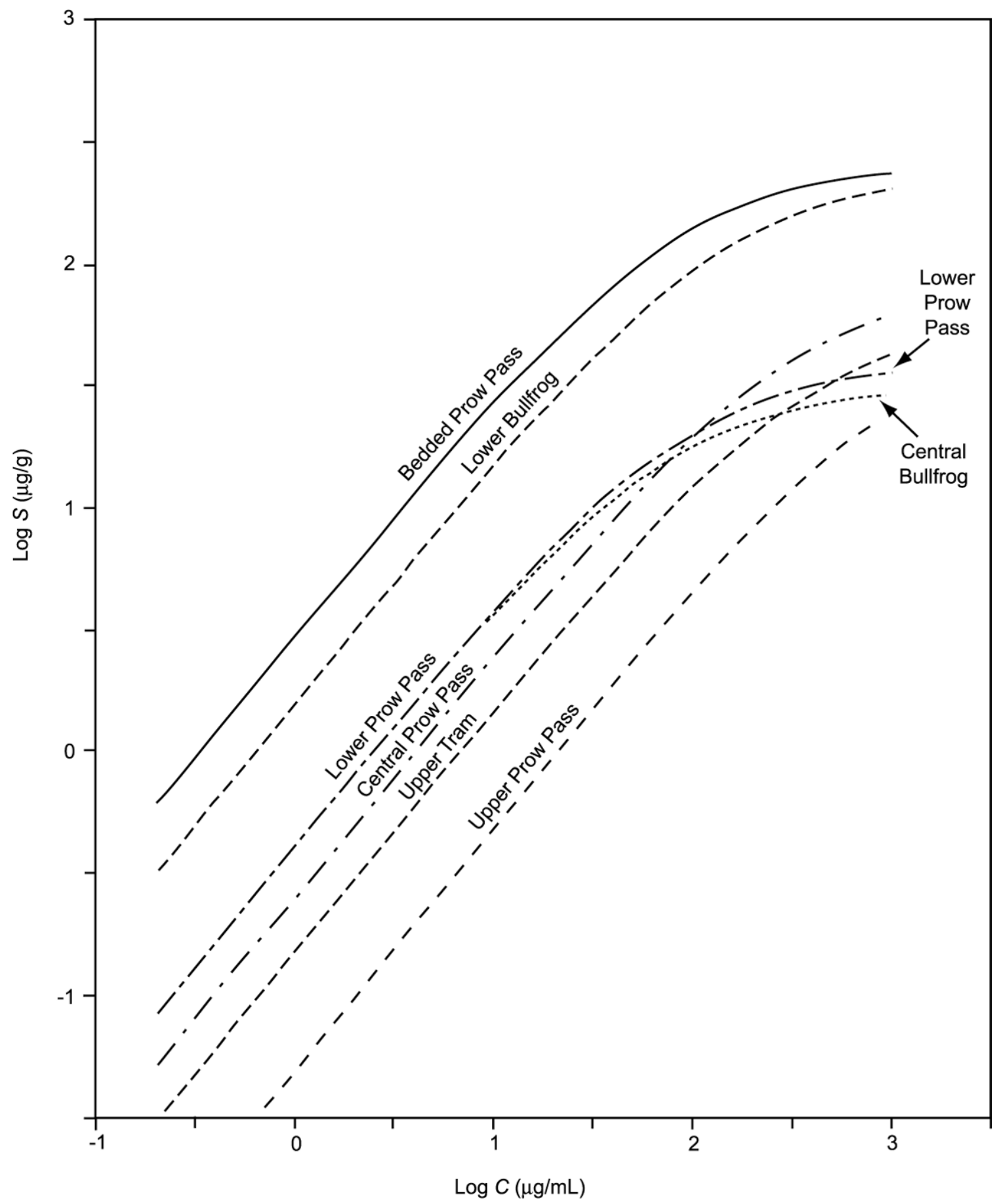

Output DTN: LA0303PR831341.003.

NOTE: The lithium concentration range in the field test in the central and lower Bullfrog Tuff spanned from less than $0.1 \mu \mathrm{g} / \mathrm{mL}$ up to $1200 \mu \mathrm{g} / \mathrm{mL}$. The concentration range in the Prow Pass Tuff field test ranged from less than $0.1 \mu \mathrm{g} / \mathrm{mL}$ up to $2700 \mu \mathrm{g} / \mathrm{mL}$.

Figure E-9. Fitted Langmuir Isotherms for the Seven C-Wells Tuffs 
Table E-4. Lithium Sorption Isotherm Parameters Associated with the Different C-wells Tuffs

\begin{tabular}{|c|c|c|c|c|c|}
\hline \multirow[b]{2}{*}{ Unit } & \multicolumn{2}{|c|}{ Langmuir } & \multicolumn{2}{|c|}{ Freundlich } & \multirow{2}{*}{$\begin{array}{c}\text { Linear } \\
K_{\mathrm{d}}(\mathrm{mL} / \mathrm{g})\end{array}$} \\
\hline & $K_{\mathrm{L}}(\mathrm{L} / \mathrm{mg})$ & $S_{\max }(\mu g / g)$ & $\begin{array}{c}K_{\mathrm{F}} \\
(\mathrm{mL} / \mu \mathrm{g})^{n}(\mu \mathrm{g} / \mathrm{g})\end{array}$ & $n$ & \\
\hline Central Bullfrog, $c \# 1+c \# 2^{a}$ & 0.014 & 31.4 & 0.70 & 0.79 & 0.186 \\
\hline Lower Bullfrog, c\#1 & 0.0070 & 233.9 & 2.26 & 0.75 & 0.321 \\
\hline Upper Prow Pass, c\#2 & 0.00094 & 53.1 & 0.075 & 1.03 & 0.068 \\
\hline Central Prow Pass, c\#2 & 0.0031 & 83.3 & 0.48 & 0.80 & 0.131 \\
\hline Lower Prow Pass, c\#1 & 0.011 & 39.8 & 0.48 & 0.78 & 0.084 \\
\hline Bedded Prow Pass, c\#2 & 0.012 & 254.9 & 4.17 & 0.69 & 0.383 \\
\hline Upper Tram. c\#2 & 0.0026 & 59.8 & 0.27 & 0.78 & 0.072 \\
\hline
\end{tabular}

Output DTN: LA0303PR831341.003 (also from Anghel et al. 2002 [DIRS 164635], Section 3.2, pp. 822 to 824).

NOTE: c\#1 and c\#2 are abbreviations for Boreholes UE-25 c\#1 and UE-25 c\#2, respectively.

a Sorption data from $\mathrm{C \# 1}$ and $\mathrm{C \# 2}$ tuffs are lumped together to obtain parameter estimates. $K_{\mathrm{L}}$ and $S_{\max }$ were $0.0053 \mathrm{~L} / \mathrm{mg}$ and $110 \mu \mathrm{g} / \mathrm{g}$, respectively, for the Central Bullfrog Tuff from c\#2 alone (used in crushed tuff column experiments of Section E3).

Results of the CEC measurements on the seven-tuff samples are presented in Figure E-10 and Table E-5. In all cases, the total CEC available to Cs (CEC-CsT) exceeds that available to Li (CEC-LiT). This result is not surprising; the hydrated ionic radius of Cs $(0.33 \mathrm{~nm})$ is smaller than that of $\mathrm{Li}(0.38 \mathrm{~nm})$ (Israelachvili 2000 [DIRS 156835], p. 55), which permits Cs access to internal exchange sites in zeolites that are not available to Li. More surprising is the consistent observation that $\mathrm{Cs}$ displaces more Li during the displacement step than Li displaced other cations during initial saturation (i.e., CEC-CsLi greater than CEC-LiT). This phenomenon, a "lithium excess" during the displacement step, was also reported by Eckstein et al. (1970 [DIRS 156653], pp. 341 to 342). They attributed this Li excess to a separate process that occurs in addition to normal cation exchange: selective and specific adsorption of Li, particularly to amorphous silicates and to edges and broken bonds of nonexpanding clay minerals. They state that "it [is] difficult or even doubtful that a 'true' value for the exchange capacity can be given for any specific clay." They further conclude that "the sum of cations replaced by Li will usually give a better value for the exchange capacity than the amount of $\mathrm{Li}$ retained and replaced by $\mathrm{Ca}(\mathrm{OAc}) 2 . "$

Inspection of the mineralogy of the samples, presented in Table E-3, indicates that the primary minerals likely to participate in cation exchange include smectite and the zeolite minerals clinoptilolite and mordenite. Although analcime has a high theoretical CEC (Ming and Mumpton 1995 [DIRS 156843], pp. 873 to 911), kinetic factors prevent significant cation exchange at normal environmental temperatures (Vaughan 1978 [DIRS 156867], pp. 353 to 371). To test whether a simple two-mineral model could explain the observed measurements, a multivariable linear regression was conducted on the CEC results, using measured smectite and (clinoptilolite + mordenite) fractions (fsmec, fclin/mord) as independent variables, and three CEC estimates as the dependent variables. In all cases, the model yielded the following results:

$C E C-L i_{\mathrm{T}}=106 \pm 8 \mathrm{meq} / 100 \mathrm{~g} \bullet f_{\mathrm{smec}}+99 \pm 3 \mathrm{meq} / 100 \mathrm{~g} \bullet f_{\text {clin } / \text { mord }}+1.5 \pm 0.3 \mathrm{meq} / 100 \mathrm{~g}, R^{2}=0.997$.

$C E C-C s_{\mathrm{Li}}=103 \pm 13 \mathrm{meq} / 100 \mathrm{~g} \bullet f_{\text {smec }}+95 \pm 5 \mathrm{meq} / 100 \mathrm{~g} \bullet f_{\text {clin } / \text { mord }}+6.1 \pm 0.5 \mathrm{meq} / 100 \mathrm{~g}, R^{2}=0.990$. 
$C E C-C s_{\mathrm{T}}=90 \pm 13 \mathrm{meq} / 100 \mathrm{~g} \bullet f_{\text {smec }}+199 \pm 5 \mathrm{meq} / 100 \mathrm{~g} \bullet f_{\mathrm{clin} / \mathrm{mord}}+7.7 \pm 0.5 \mathrm{meq} / 100 \mathrm{~g}, R^{2}=0.997$ where $R^{2}=$ coefficient of regression (sum of squares regression divided by sum of squares total).

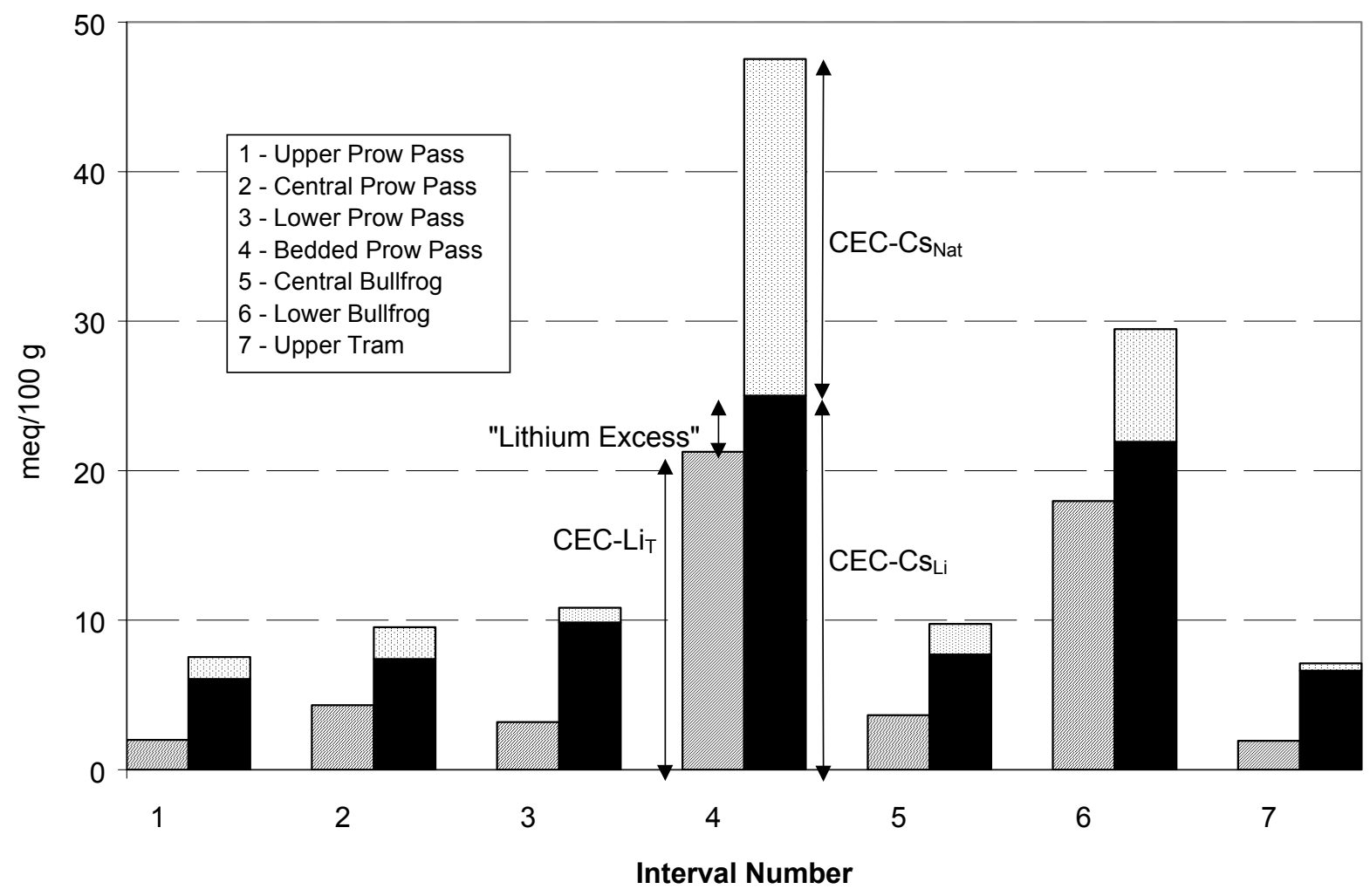

Source: DTNs: MO0012CATECHOL.000 [DIRS 153371] (CEC-Li data); LA0302PR831341.001 [DIRS 162604] (CEC-Cs data).

Output DTN: LA0303PR831341.001.

NOTE: Interval numbers in legend do not correspond to numbers in Table E-2 or Figure E-1. Explanation of bar patterns provided for interval 4 applies to all intervals.

Figure E-10. Cation-exchange Capacity Results for the Seven Different C-Wells Tuff Intervals 
Table E-5. Cation-exchange Capacity Measurements for C-wells Tuffs

\begin{tabular}{|l|c|c|c|c|c|}
\hline \multirow{2}{*}{\multicolumn{1}{c|}{ Sample }} & \multicolumn{5}{c|}{ Cation-exchange Capacity (meq/100g) } \\
\cline { 2 - 6 } & CEC-LiT & CEC-CsNat & CEC-CsLi & CEC-CsT & Li Excess \\
\hline Upper Prow Pass (1) & $2.0 \pm 0.5$ & $1.5 \pm 0.1$ & $6.1 \pm 0.8$ & 7.5 & 4.1 \\
\hline Central Prow Pass (2) & $4.3 \pm 0.1$ & $2.1 \pm 0.0$ & $7.4 \pm 0.4$ & 9.5 & 3.1 \\
\hline Lower Prow Pass (3) & $3.2 \pm 0.4$ & $1.0 \pm 0.9$ & $9.8 \pm 1.9$ & 10.8 & 6.6 \\
\hline Bedded Prow Pass (4) & $21.3 \pm 0.1$ & $22.5 \pm 0.4$ & $25.0 \pm 1.4$ & 47.5 & 3.8 \\
\hline Central Bullfrog (5) & $3.7 \pm 0.1$ & $2.0 \pm 0.5$ & $7.7 \pm 0.6$ & 9.7 & 4.1 \\
\hline Lower Bullfrog (6) & $18.0 \pm 0.2$ & $7.5 \pm 0.4$ & $21.9 \pm 0.2$ & 29.5 & 4.0 \\
\hline Upper Tram (7) & $1.9 \pm 0.1$ & $0.5 \pm 0.2$ & $6.6 \pm 0.5$ & 7.1 & 4.7 \\
\hline
\end{tabular}

Source: DTNs: MO0012CATECHOL.000 [DIRS 153371] (CEC-Li data); LA0302PR831341.001 [DIRS 162604] (CEC-Cs data).

Output DTN: LA0303PR831341.001.

NOTE: Range shown is \pm one standard deviation. Refer to text for definitions.

${ }^{\text {a }}$ Numbers correspond to numbers in Figure E-10.

${ }^{\mathrm{b}}$ Only the Central Bullfrog Tuff from c\#1 was analyzed for CEC.

The exchange factors for the individual minerals can be compared to literature values of $110 \pm 23 \mathrm{meq} / 100 \mathrm{~g}$ for smectite (Borchardt 1995 [DIRS 156639], Chapter 14) and $220 \mathrm{meq} / 100 \mathrm{~g}$ for clinoptilolite and mordenite (Ming and Mumpton 1995 [DIRS 156843]). Starting with the model for $C E C-L i_{\mathrm{T}}$, the specific exchange capacity for smectite matches the reported value from Borchardt (1995 [DIRS 156639], Chapter 14), whereas the modeled capacity for the zeolite minerals is less than half that reported by Ming and Mumpton (1995 [DIRS 156843]). This discrepancy is consistent with the inaccessibility of some of the internal zeolite exchange sites to the relatively large $\mathrm{Li}$ ion. The $C E C-L i_{\mathrm{T}}$ model includes a relatively small constant term, indicating that almost all of the observed behavior can be explained by smectite and clinoptilolite/mordenite cation exchange. Comparing this model to the $C E C-C s_{\mathrm{Li}}$ model, we see that the major difference lies in the constant term; the larger constant term in the second model reflects the observed $\mathrm{Li}$ excess. The similarity of the other two terms demonstrates that the Li-excess effect is not a result of exchange onto either smectite or clinoptilolite/mordenite; additional correlation analysis shows that the $\mathrm{Li}$ excess is not proportional to any of the mineral phases identified by quantitative x-ray diffraction. These observations, combined with the overall uniformity of the Li excess among these widely varying tuff samples, lead one to agree with Eckstein et al. (1970 [DIRS 156653], pp. 341 and 342) and attribute the $\mathrm{Li}$ excess to a noncation-exchange sorption process.

The final model for $C E C-C_{S_{\mathrm{T}}}$ reveals a similar specific CEC for smectite as found in the literature and the previous models but shows a much higher specific CEC for the zeolite minerals, which is more in line with published values (Ming and Mumpton 1995 [DIRS 156843]). This demonstrates the accessibility to the smaller Cs ion of internal exchange sites that were apparently unavailable to Li. The constant term in this model is the sum of the constant terms in the $C E C-L i_{\mathrm{T}}$ and $C E C-C s_{\mathrm{Li}}$ models.

To a first approximation, it can be seen that the two samples that sorb Li most strongly have the highest isotherms in Figure E-9 and the largest $K_{d}$ and $\mathrm{K}_{\mathrm{F}}$ values in Table E-4. These two rocks also showed the highest $\mathrm{CEC}$ values. To quantify the sorption relationships more rigorously, the linearization of the nonlinear Freundlich isotherm was undertaken, and $K_{\text {lin }}$ was calculated. $K_{\text {lin }}$ 
is an effective distribution coefficient with uniform units, identical to those of $K_{d}$. For this purpose, the equal-area linearization of van Genuchten et al. (1977 [DIRS 156868], pp. 278 to 285 ) was used:

$$
K_{\operatorname{lin}}=\frac{2 K_{\mathrm{F}} C_{\max }^{n-1}}{n+1}
$$

where $C_{\max }$ is the maximum solution concentration of interest; in this case, $1000 \mathrm{mg} / \mathrm{L}$, and $K_{\mathrm{F}}$ and $n$ are taken from Table E-4. Using the same multivariate linear regression methods described above, $K_{\text {lin }}$ can be modeled as a function of smectite and clinoptilolite/mordenite content:

$$
K_{\text {lin }}=2.28 \pm 0.45 \mathrm{~L} / \mathrm{kg} \bullet f_{\text {smec }}+2.46 \pm 0.18 \mathrm{~L} / \mathrm{kg} \bullet f_{\text {clin } / \text { mord }}+0.09 \pm 0.02 \mathrm{~L} / \mathrm{kg}, r^{2}=0.981 \text {. }
$$

This model does not fit the data quite as well as the CEC models described above but, nevertheless, demonstrates that Li sorption can be estimated fairly accurately for these tuffs, given smectite, clinoptilolite, and mordenite concentrations. The small constant term in the model indicates that the contribution of other minerals to Li sorption is quite low.

\section{E1.3 CONCLUSIONS FROM BATCH LITHIUM SORPTION STUDIES}

Lithium ion sorption onto devitrified tuffs from the saturated zone near Yucca Mountain follows nonlinear isotherm behavior. Both the lithium sorption parameters and the lithium-specific cation-exchange capacities of the tuffs are highly correlated with the clay (smectite) content and the zeolite (clinoptilolite + mordenite) content of the tuffs. Multiple linear regression analyses shows that these two classes of minerals account for the majority of the observed lithium exchange. Regression of cesium cation-exchange data yields results that are consistent with the accessibility of the smaller cesium ion to internal zeolite exchange sites that lithium cannot access. The cesium CEC data also suggest that some of the lithium sorption to the tuffs can be attributed to a noncation-exchange process. The results of this study support the development and use of mineralogy-based models for predicting cation sorption in the saturated zone near Yucca Mountain.

\section{E2. DIFFUSION CELL EXPERIMENTS}

\section{E2.1 MATERIALS AND METHODS}

Six diffusion cell experiments were conducted to determine diffusion coefficients of PFBA and bromide ion in five different C-wells tuff matrices [details are in YMP C-Wells Diffusion Cells (Reimus 2000 [DIRS 165121])]. Estimates of matrix diffusion coefficients are important because they can greatly reduce uncertainty in interpreting and predicting both field-scale and laboratory-scale tracer experiments. One of the tests was a repeat experiment using a different core from the same interval as another test (the lower Prow Pass Tuff). This test was conducted to determine the reproducibility and variability of the experiments. The five different intervals tested in the diffusion cell experiments represented all of the major lithologies in either the Bullfrog field tracer test or the Prow Pass field tracer test (see Table E-6 for specific intervals tested). 
A schematic drawing of the experimental diffusion cell apparatus is illustrated in Figure E-11. The apparatus consists of two Plexiglas reservoirs, one large and one small, separated by a "pellet" of tuff, which is cut/cored from C-wells core and incorporated into either a flat epoxy cast or a room-temperature vulcanizing silicone cast of the same thickness as the pellet. After saturating the tuff, experiments were initiated by carefully pouring a solution containing PFBA and $\mathrm{LiBr}$ into the large reservoir and tracer-free solution into the small reservoir. The pressures in the two reservoirs were kept approximately equal to minimize advective flow through the tuff, thus ensuring that tracer movement through the tuff was by diffusion only. The small reservoir was kept well mixed with a magnetic stir bar and flushed continuously at a relatively low flow rate. The flush water was collected in an automatic fraction collector, and fractions were analyzed for tracers to establish breakthrough curves through the tuff from which diffusion coefficients could be estimated. As in the other laboratory experiments, PFBA and bromide were analyzed by liquid chromatography, and lithium was analyzed by ICP-AES. Filtered J-13 well water or synthetic J-13 well water (a sodium/calcium bicarbonate solution having the same ionic strength as J-13 well water - refer to Reimus 2000 [DIRS 165121] for details) were used in all experiments.

The porosities of the tuffs were measured by subtracting dry weights from saturated weights of intact tuff samples and dividing by the volumes of the samples (measured by water displacement). Porosity measurements were used to obtain unambiguous estimates of diffusion coefficients in the tuff matrices (see equations below). Hydraulic conductivities/permeabilities of the tuffs were also measured by imposing a known head difference across the tuff pellets, either before or after a diffusion experiment was conducted. The flow through the pellets at the imposed head difference was measured by weighing the water that flowed through the pellet over a specified amount of time.

Hydraulic conductivities were then calculated from the following equation (Freeze and Cherry 1979 [DIRS 101173], p. 335, Eq. 8.24):

$$
K=-\frac{Q L}{A \Delta H}
$$

where

$K=$ hydraulic conductivity, $\mathrm{cm} / \mathrm{sec}$

$\Delta H=$ water height (head) difference across pellet, $\mathrm{cm}$

$A=$ surface area of pellet, $\mathrm{cm}^{2}$

$Q=$ volumetric flow rate through pellet, $\mathrm{mL} / \mathrm{sec}$

$L=$ thickness of pellet, $\mathrm{cm}$.

Permeabilities were calculated from hydraulic conductivities using the following well-known formula (Freeze and Cherry 1979 [DIRS 101173], pp. 26 to 30):

$$
k=\left(1.013 \times 10^{11}\right) \frac{K \mu}{\rho g}
$$


where

$k=$ permeability, millidarcys $(\mathrm{mD})$

$\mu=$ water viscosity, $\mathrm{g} / \mathrm{cm}$-sec $\left(1.00\right.$ centipoise or $0.01 \mathrm{~g} / \mathrm{cm}$-sec at $20^{\circ} \mathrm{C}$ (Weast and Astle 1981 [DIRS 100833], p. F-42))

$\rho=$ water density, $\mathrm{g} / \mathrm{cm}^{3}\left(0.998 \mathrm{~g} / \mathrm{cm}^{3}\right.$ at $20^{\circ} \mathrm{C}$ (Weast and Astle 1981 [DIRS 100833], p. F-11))

$g=$ acceleration due to gravity, $\mathrm{cm} / \mathrm{sec}^{2}\left(980 \mathrm{~cm} / \mathrm{sec}^{2}\right.$ on Earth (Weast and Astle 1981 [DIRS 100833], p. F-144))

and the constant $1.013 \times 10^{11}$ has units of $\mathrm{mD} / \mathrm{cm}^{2}$.

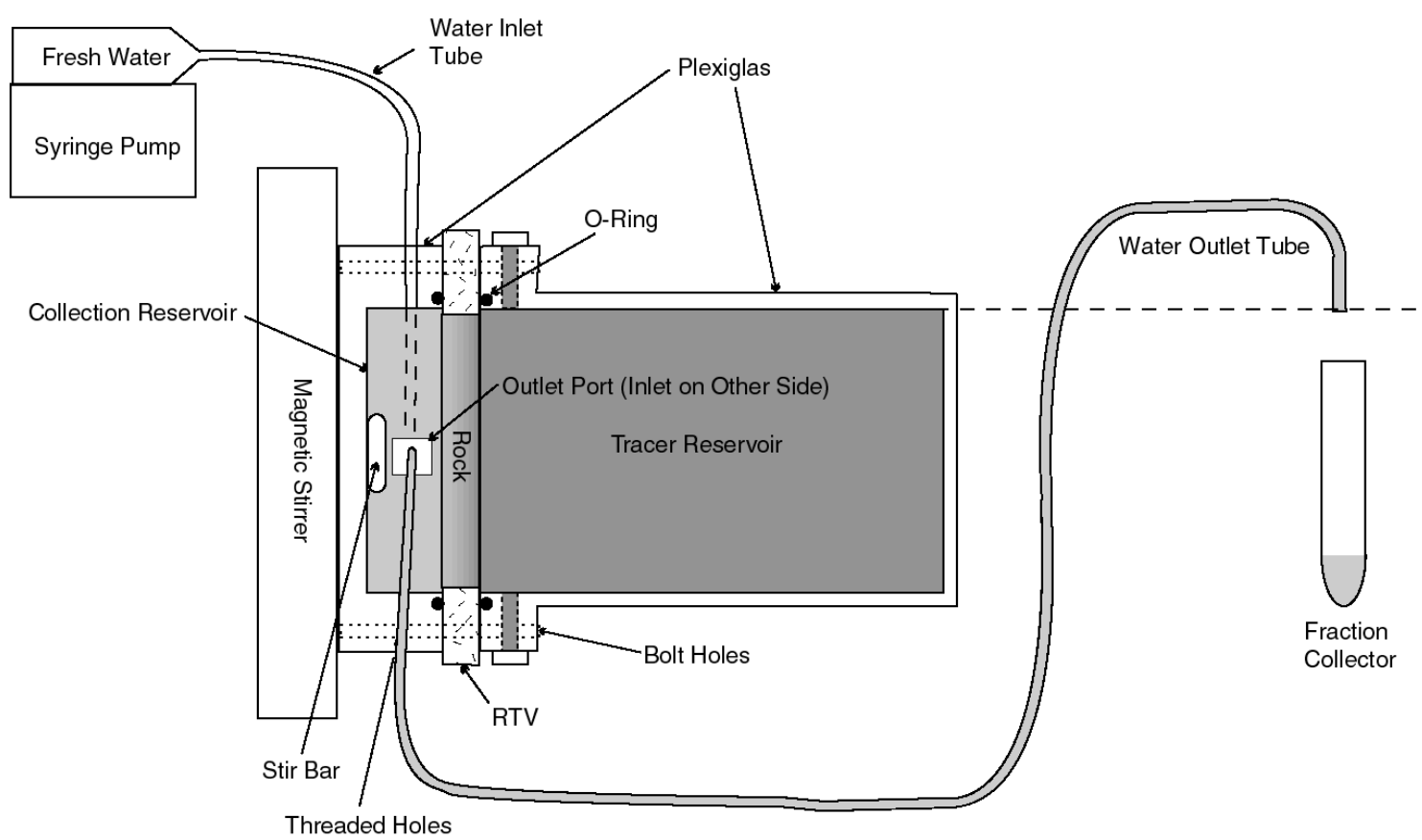

NOTE: For illustration purposes only.

Figure E-11. Diffusion Cell Experimental Apparatus

To estimate diffusion coefficients, it was assumed that the tracers moved according to onedimensional diffusive transport through the tuff pellets. The one-dimensional diffusion equation is:

$$
\frac{\partial c}{\partial t}=\frac{D}{R} \frac{\partial^{2} c}{\partial x^{2}}
$$


where

$c=$ tracer concentration in tuff pellet, $\mu \mathrm{g} / \mathrm{mL}$

$D=$ diffusion coefficient, $\mathrm{cm}^{2} / \mathrm{sec}$

$R=$ retardation factor (1 for nonsorbing solutes),

$x=$ position within tuff pellet $(\mathrm{x}=0$ at inlet reservoir $), \mathrm{cm}$

$t=$ time, sec.

Although analytical solutions to this simple partial differential equation exist for simple boundary conditions (Jenson and Jeffreys 1977 [DIRS 156836], pp. 291 to 295), the timedependent concentration boundary conditions at the inlet and outlet reservoirs in the diffusion cell experiments demand a numerical solution. Thus, Equation 17 was solved using an implicit finite-difference technique. The equations describing the tracer concentrations in the inlet and the outlet reservoirs (the first and last finite difference nodes), respectively, were:

$$
\begin{gathered}
\frac{\partial c_{\mathrm{i}}}{\partial t}=\left.\frac{\phi \pi r^{2} D}{V_{\mathrm{i}}} \frac{\partial c}{\partial x}\right|_{x=0} \\
\frac{\partial c_{\mathrm{o}}}{\partial t}=-\left.\frac{\phi \pi r^{2} D}{V_{\mathrm{o}}} \frac{\partial c}{\partial x}\right|_{x=L}-\frac{q}{V_{\mathrm{o}}} c_{\mathrm{o}}
\end{gathered}
$$

where

$$
\begin{aligned}
& c_{\mathrm{i}}=\text { tracer concentration in inlet reservoir, } \mu \mathrm{g} / \mathrm{mL} \\
& c_{\mathrm{o}}=\text { tracer concentration in outlet reservoir, } \mu \mathrm{g} / \mathrm{mL} \\
& V_{\mathrm{i}}=\text { volume of inlet reservoir, } \mathrm{mL} \\
& V_{\mathrm{o}}=\text { volume of outlet reservoir, } \mathrm{mL} \\
& q=\text { flush rate of outlet reservoir, } \mathrm{mL} / \mathrm{sec} \\
& \phi=\text { porosity of tuff } \\
& r=\text { radius of tuff "pellet", } \mathrm{cm} \\
& L=\text { thickness of tuff "pellet", } \mathrm{cm} .
\end{aligned}
$$

The numerical solution of Equations 17, 18, and 19 was obtained using computer code DIFFCELL 2.0 (STN: 10557-2.0-00 [DIRS 159063]). This code allows the user to specify changes in the flush rate, $q$, with time, which was necessary to simulate the manner in which the experiments were conducted.

\section{E2.2 RESULTS AND DISCUSSION}

Figures E-12 through E-17 show the breakthrough curves of the bromide and PFBA in each of the six diffusion cells along with "fits" to the data obtained using DIFFCELL 2.0 (STN: 10557-2.0-00 [DIRS 159063]). The "fits" are not actual least-squares fits; rather, they were obtained by manual adjustment of the diffusion coefficients until a reasonable match to the data was obtained. The apparent discontinuities in some of the data sets and the corresponding model predictions are a consequence of changes in the flush rate through the outlet reservoirs. A decrease in concentration occurs when the flush rate is increased and vice-versa. 
The resulting estimates of tracer diffusion coefficients in each diffusion cell are given in Table E-6 (measured tuff porosities, pellet thicknesses, and tuff permeabilities are also listed in this table). It is apparent that there is about an order of magnitude range of diffusion coefficients in the various tuff lithologies. Figures E-18 and E-19 show the bromide diffusion coefficients in the tuff matrices as a function of porosity and permeability, respectively, for the five different $\mathrm{C}$-wells tuffs. Although the diffusion coefficients are not well correlated with porosity, they are quite well correlated with permeability (on a log-log scale). This result suggests that permeability may be a good predictor of matrix diffusion coefficients. Such correlations could prove useful for estimating matrix diffusion coefficients, as diffusion coefficients are typically more difficult to measure than matrix properties such as permeabilities.

Table E-6 shows that excellent agreement was obtained between the two diffusion cell experiments conducted for the same lithology (the lower Prow Pass Tuff). This result suggests that the experiments have reasonably good reproducibility, although certainly more experiments should be conducted in the same lithologies before measurement uncertainty and tuff variability can be properly assessed.

It is interesting to note that although the PFBA and bromide diffusion coefficients are significantly different in the different tuffs, the ratios of the diffusion coefficients are approximately the same in each tuff. This result suggests that advection through the tuff pellets was successfully eliminated, as any advection would result in different ratios in different tests. The factor of approximately 3 difference in the diffusion coefficients of the PFBA and bromide is the basis for assuming a factor of 3 difference in all of the field and laboratory tracer-test interpretations in this report.

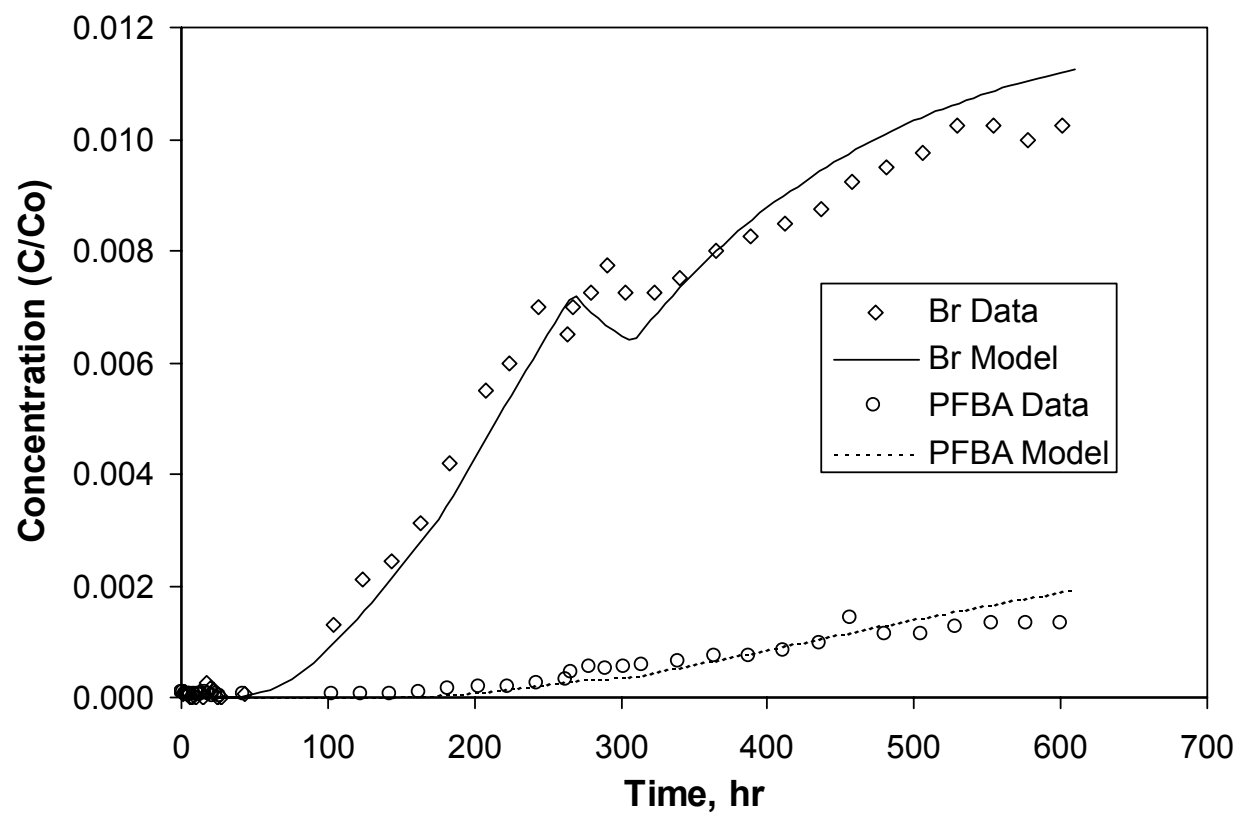

Source: DTN: MO0012DIFFCHOL.000 [DIRS 159243] (data).

Output DTN: LA0303PR831362.001 (DIFFCELL fits).

NOTE: Diffusion coefficients are given in Table E-6.

Figure E-12. Diffusion Cell Data (Tracer Concentrations in Outlet Reservoir Normalized to Starting Concentrations in Inlet Reservoir, Co) and DIFFCELL Fits for Bromide and PFBA in the Central Bullfrog Tuff 


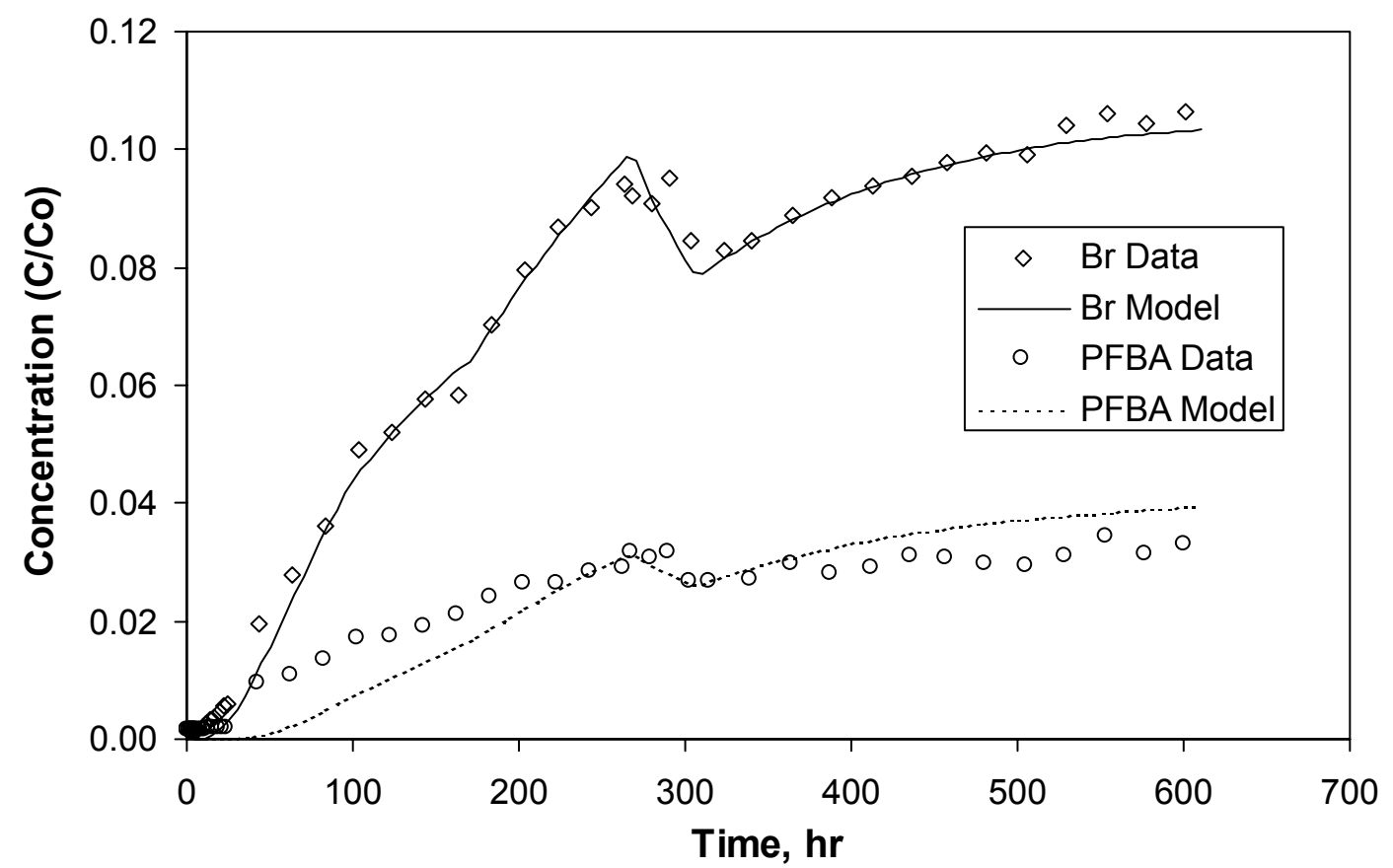

Source: DTN: MO0012DIFFCHOL.000 [DIRS 159243] (data).

Output DTN: LA0303PR831362.001 (DIFFCELL fits).

NOTE: Diffusion coefficients are given in Table E-6.

Figure E-13. Diffusion Cell Data (Tracer Concentrations in Outlet Reservoir Normalized to Starting Concentrations in Inlet Reservoir, Co) and DIFFCELL Fits for Bromide and PFBA in the Lower Bullfrog Tuff 


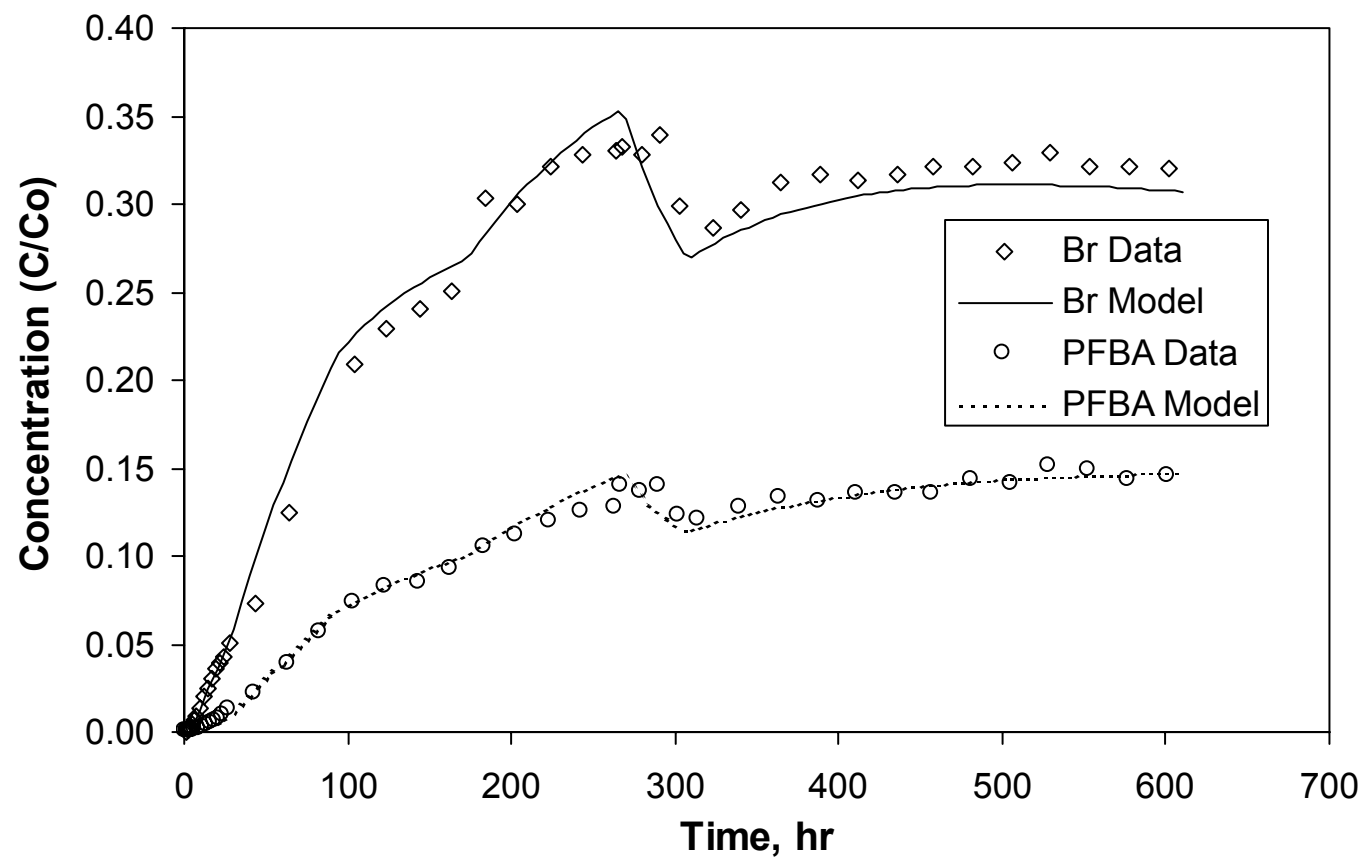

Source: DTN: MO0012DIFFCHOL.000 [DIRS 159243] (data).

Output DTN: LA0303PR831362.001 (DIFFCELL fits).

NOTE: Diffusion coefficients are given in Table E-6.

Figure E-14. Diffusion Cell Data (Tracer Concentrations in Outlet Reservoir Normalized to Starting Concentrations in Inlet Reservoir, Co) and DIFFCELL Fits for Bromide and PFBA in the Upper Prow Pass Tuff 


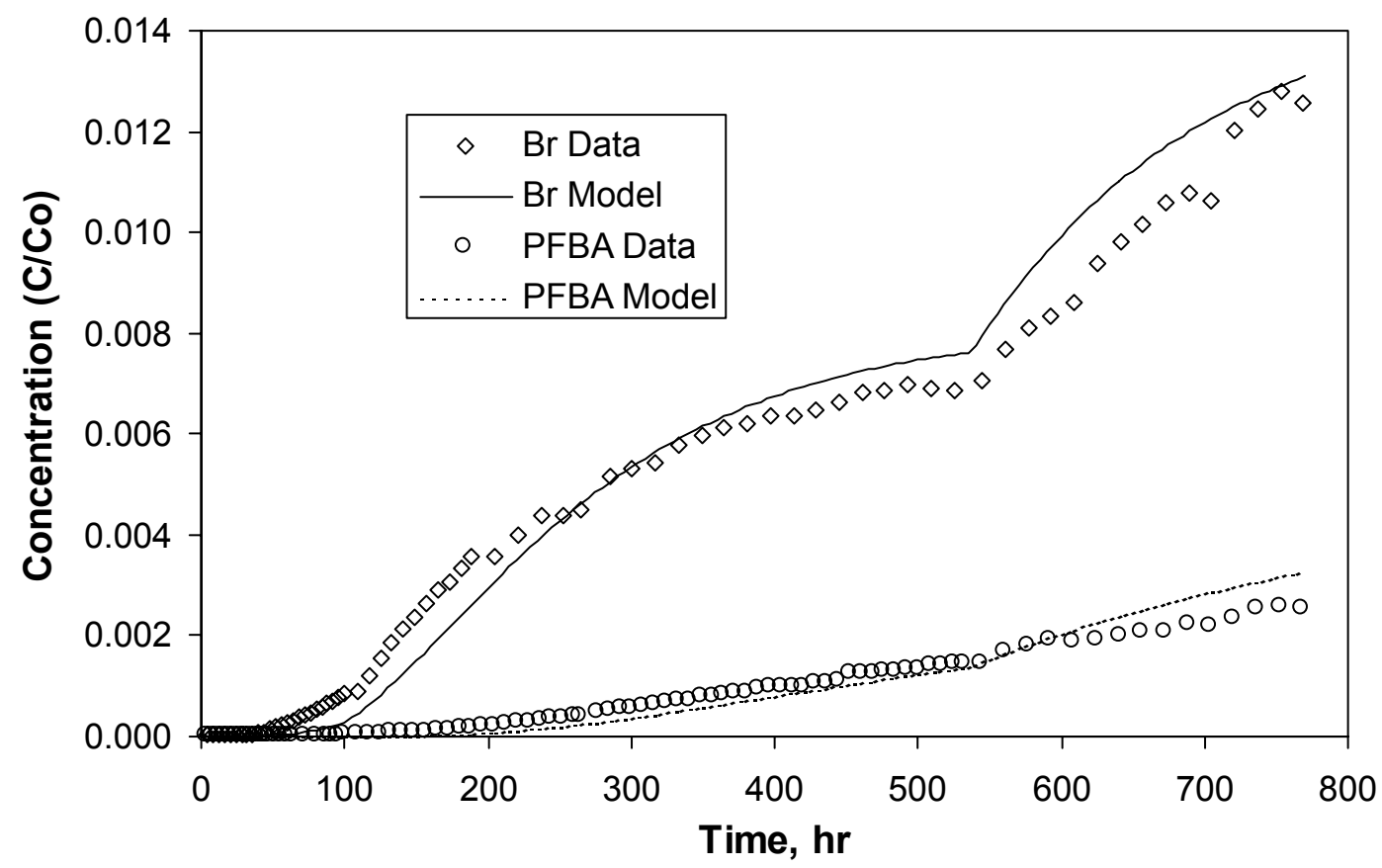

Source: DTN: MO0012DIFFCHOL.000 [DIRS 159243] (data).

Output DTN: LA0303PR831362.001 (DIFFCELL fits).

NOTE: Diffusion coefficients are given in Table E-6.

Figure E-15. Diffusion Cell Data (Tracer Concentrations in Outlet Reservoir Normalized to Starting Concentrations in Inlet Reservoir, Co) and DIFFCELL Fits for Bromide and PFBA in the Central Prow Pass Tuff 


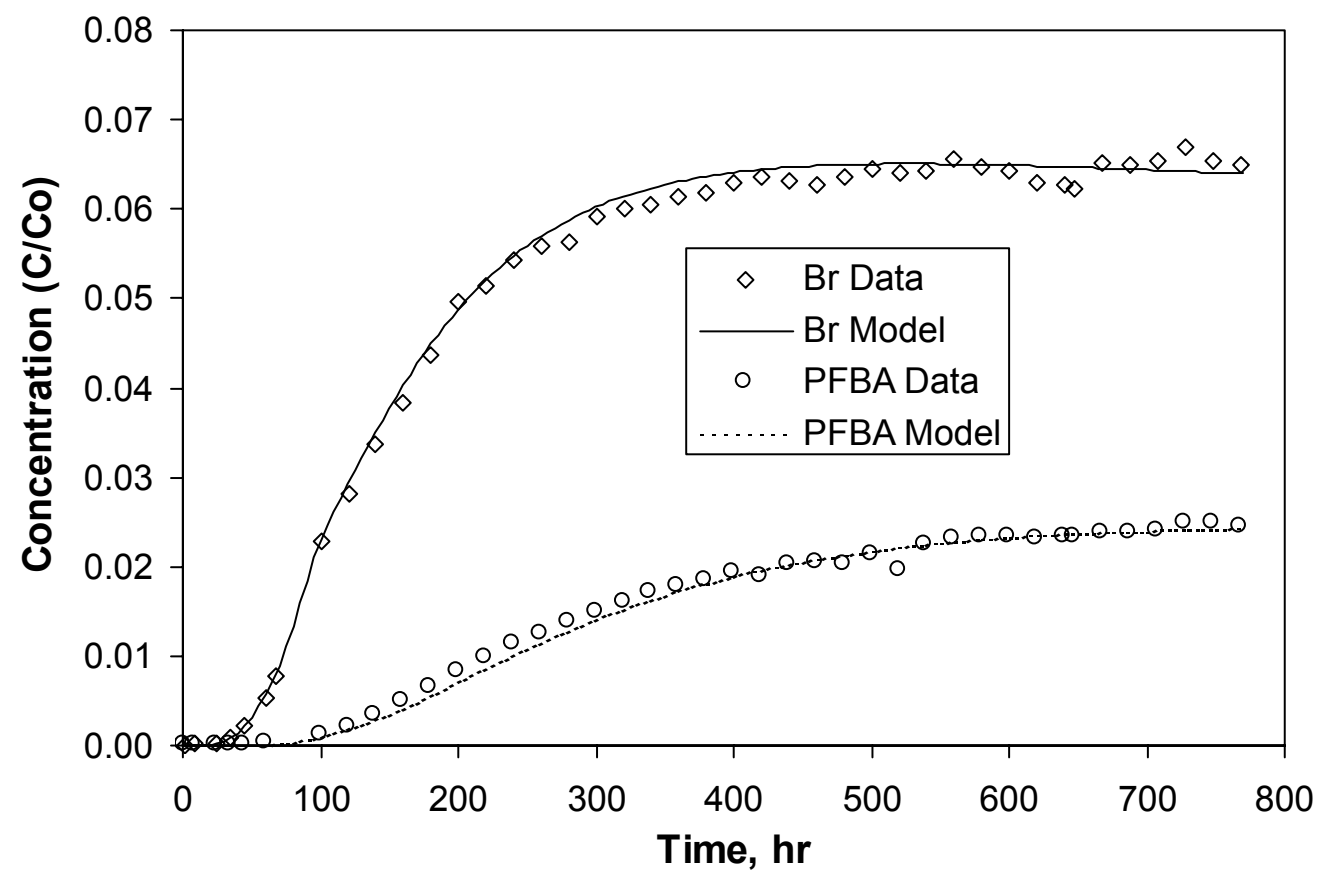

Source: DTN: MO0012DIFFCHOL.000 [DIRS 159243] (data).

Output DTN: LA0303PR831362.001 (DIFFCELL fits).

NOTE: Diffusion coefficients are given in Table E-6.

Figure E-16. First Diffusion Cell Data (Tracer Concentrations in Outlet Reservoir Normalized to Starting Concentrations in Inlet Reservoir, Co) and DIFFCELL Fits for Bromide and PFBA in the Lower Prow Pass Tuff 


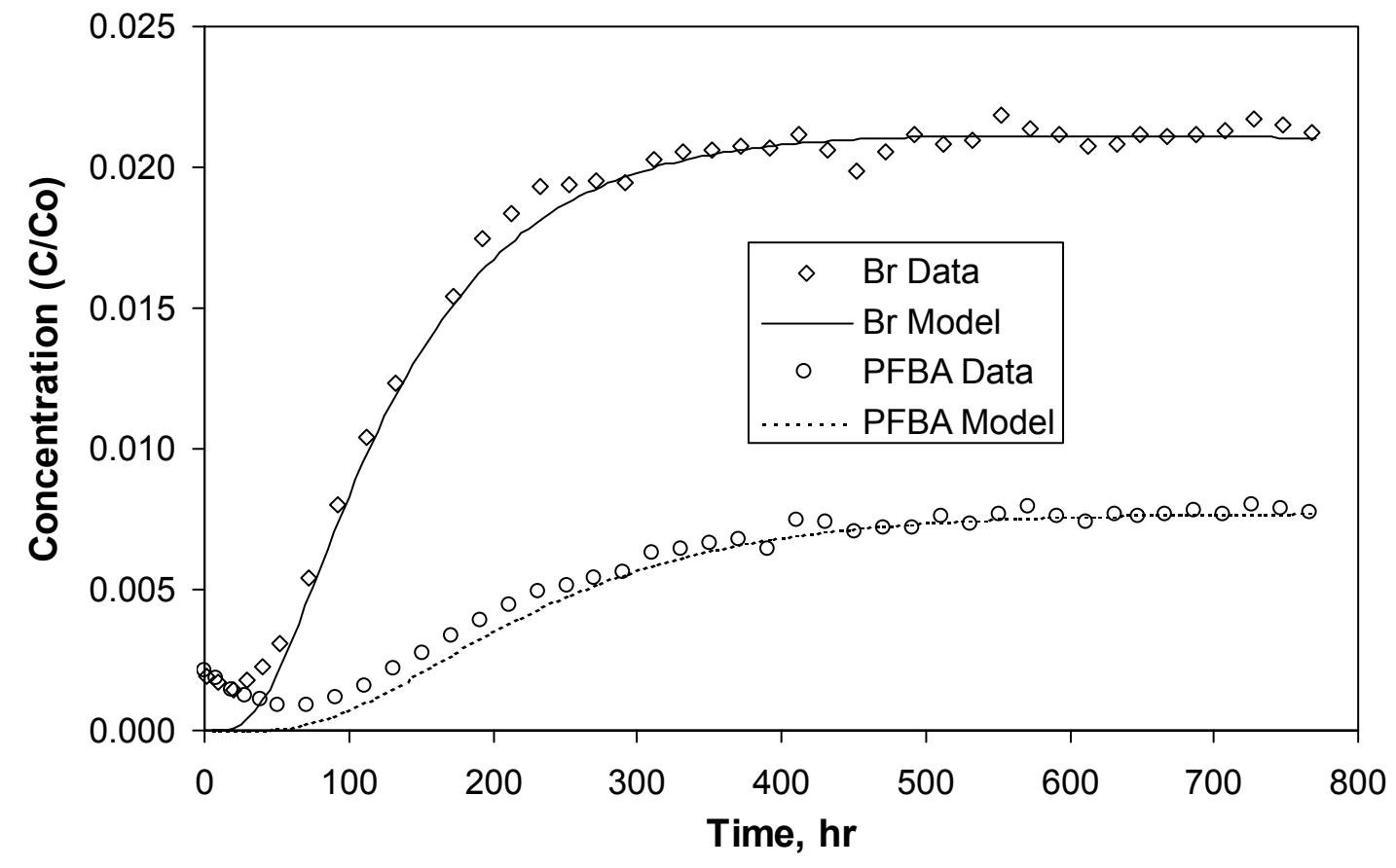

Source: DTN: MO0012DIFFCHOL.000 [DIRS 159243] (data).

Output DTN: LA0303PR831362.001 (DIFFCELL fits).

NOTE: Diffusion coefficients are given in Table E-6.

Figure E-17. Second Diffusion Cell Data (Tracer Concentrations in Outlet Reservoir Normalized to Starting Concentrations in Inlet Reservoir, Co) and DIFFCELL Fits for Bromide and PFBA in the Lower Prow Pass Tuff 
Table E-6. Measured Porosities, Permeabilities, and Matrix Diffusion Coefficients of Bromide and PFBA in C-wells Tuffs

\begin{tabular}{|c|c|c|c|c|c|c|}
\hline \multirow[b]{2}{*}{ Tuff $^{a}$} & \multirow[b]{2}{*}{ Porosity } & \multirow{2}{*}{$\begin{array}{c}\text { Permeability } \\
\text { (mDarcy) }\end{array}$} & \multirow{2}{*}{$\begin{array}{c}\text { Thickness }^{\mathrm{b}} \\
(\mathrm{cm})\end{array}$} & \multicolumn{2}{|c|}{$\begin{array}{l}\text { Diffusion Coefficient } \\
\left(\mathrm{cm}^{2} / \mathrm{s} \times 10^{6}\right)^{\mathrm{c}}\end{array}$} & \multirow{2}{*}{$\begin{array}{c}\text { Br/PFBA } \\
\text { (Ratio) }\end{array}$} \\
\hline & & & & $\mathrm{Br}$ & PFBA & \\
\hline Central Bullfrog (1) & 0.094 & 0.00107 & 1.12 & 0.42 & 0.12 & 3.5 \\
\hline Lower Bullfrog (3) & 0.298 & 0.0949 & 0.79 & 1.0 & 0.35 & 2.86 \\
\hline Upper Prow Pass (4) & 0.272 & 4.72 & 0.98 & 6.2 & 2.0 & 3.1 \\
\hline Central Prow Pass (5) & 0.138 & 0.000786 & 1.23 & 0.38 & 0.13 & 2.92 \\
\hline Lower Prow-1 (6) ${ }^{d}$ & 0.288 & 0.455 & 2.27 & 3.0 & 1.1 & 2.73 \\
\hline Lower Prow-2 (6) ${ }^{d}$ & 0.288 & 0.455 & 1.82 & 2.8 & 1.0 & 2.8 \\
\hline
\end{tabular}

Source: DTNs: MO0012POROCHOL.000 [DIRS 153376] (porosity); MO0012PERMCHOL.000 [DIRS 153368] (permeability); MO0012DIFFCHOL.000 [DIRS 159243] (diffusion cells).

Output DTN: LA0303PR831362.001 (DIFFCELL results - diffusion coefficients).

NOTE: Synthetic J-13 well water was used for the experiments involving the first three tuffs. Filtered J-13 well water was used in the other three experiments.

${ }^{\text {a }}$ Numbers in parentheses correspond to numbers in Figure E-1 (locations where core was collected from the C-wells) and in Table E-2 (where actual depths associated with the cores are listed).

b Thickness, $L$, of tuff pellet.

${ }^{d}$ Measured matrix diffusion coefficients are equal to values in these columns multiplied by $10^{-6}$.

${ }^{d}$ Experiments were conducted using two separate tuff pellets from the Lower Prow Pass Tuff.

PFBA=pentafluorobenzoic acid or pentafluorobenzoate 


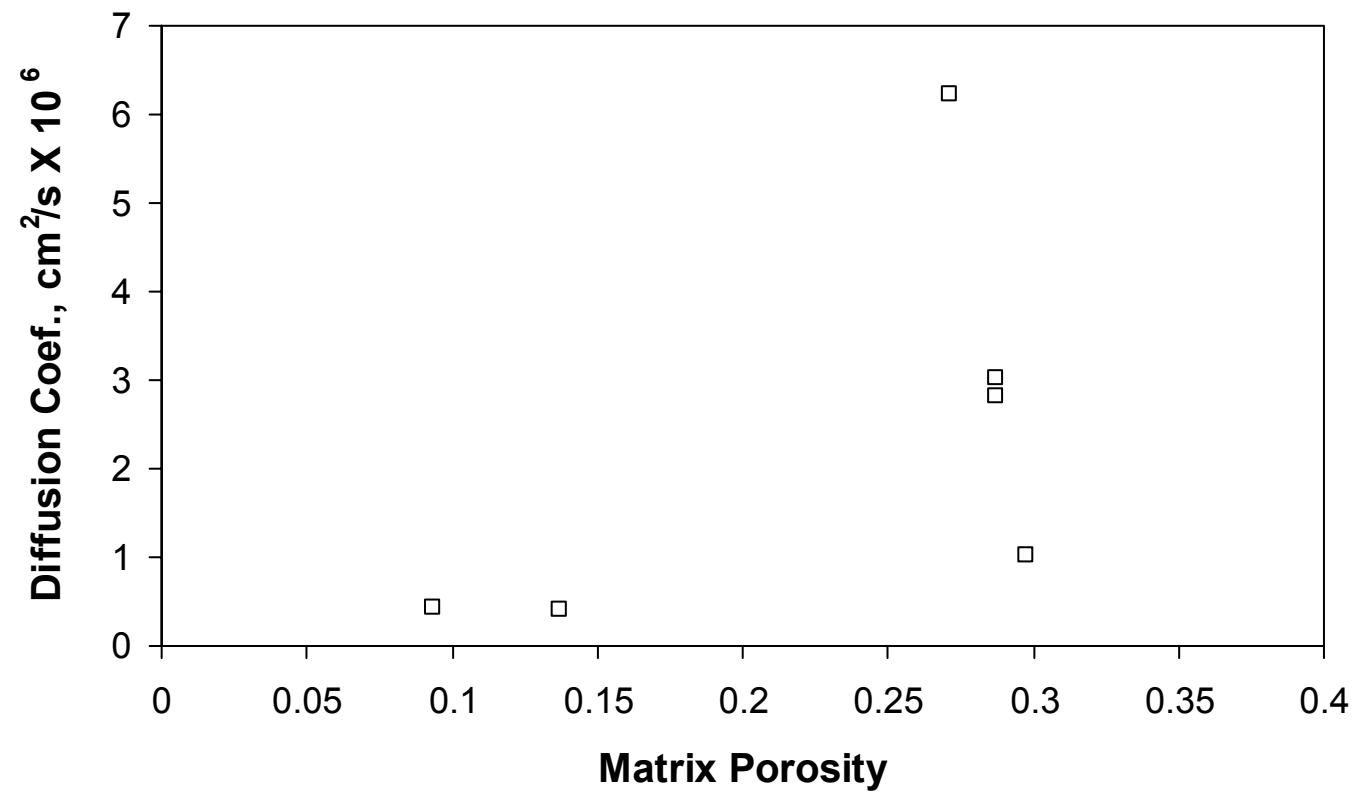

Source: DTN: MO0012POROCHOL.000 [DIRS 153376] (porosity data).

Output DTN: LA0303PR831362.001 (diffusion coefficients).

NOTE: Porosity and diffusion coefficient for bromide are listed in Table E-6.

Figure E-18. Bromide Diffusion Coefficients Versus Tuff Porosity for All C-Wells Diffusion Cell Experiments

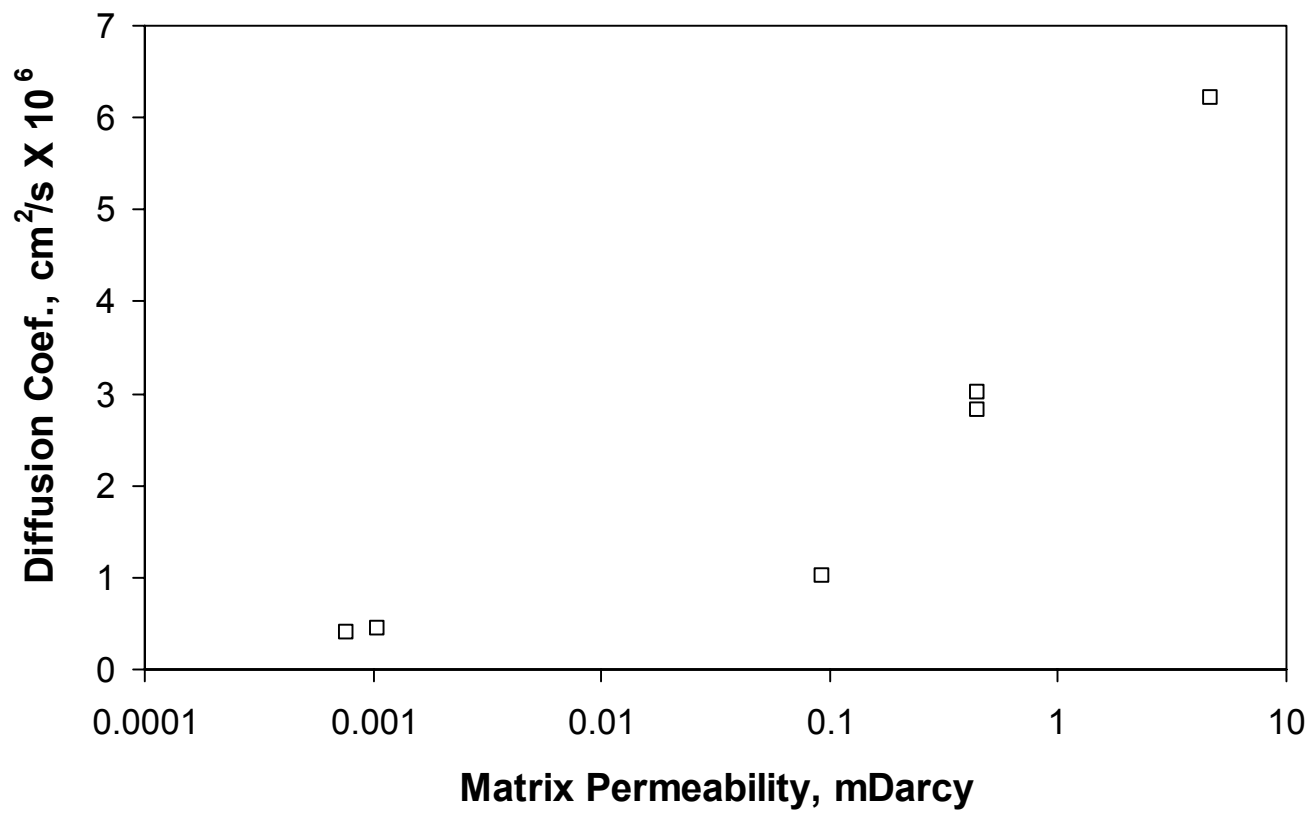

Source: DTN: MO0012PERMCHOL.000 [DIRS 153368] (permeability data).

Output DTN: LA0303PR831362.001 (diffusion coefficients).

NOTE: Permeability and diffusion coefficient are listed in Table E-6.

Figure E-19. Bromide Diffusion Coefficients Versus Tuff Permeability for All C-Wells Diffusion Cell Experiments 


\section{E3. LABORATORY STUDIES OF LITHIUM TRANSPORT IN CRUSHED TUFF COLUMNS AND FRACTURED CORES}

Several laboratory transport experiments were conducted to study lithium transport under flowing conditions in both columns packed with crushed $\mathrm{C}$-wells tuff and fractured C-wells cores (Reimus 2003 [DIRS 163760], Attachments A, B1, and B2). The crushed-tuff column experiments were conducted to compare lithium sorption parameters under flowing conditions to batch-sorption measurements. The fractured-core experiments were conducted to study lithium transport under more realistic fracture flow conditions where matrix diffusion and sorption in the matrix should also influence transport. The crushed-tuff experiments are described in Section E3.1, and the fractured-core experiments are described in Section E3.2.

\section{E3.1 CRUSHED-TUFF COLUMN EXPERIMENTS}

\section{E3.1.1 Experimental Methods}

A series of transport experiments was conducted in plexiglass columns $91.44 \mathrm{~cm}$ in length and $0.62 \mathrm{~cm}$ in diameter (Reimus 2003 [DIRS 163760], Attachment A). The columns were packed with crushed central Bullfrog Tuff (from location number 2 in Figure E-1) that had been wet-sieved to a size range between 75 and $500 \mu \mathrm{m}$. A wet slurry technique was used to pack the columns. Column porosity was measured at approximately 57 percent (average of two columns), and dry bulk density was calculated at $1.14 \mathrm{~g} / \mathrm{mL}$ by assuming a mineral density of $2.65 \mathrm{~g} / \mathrm{mL}$, which are typical values for columns prepared in this fashion (Treher and Raybold 1982 [DIRS 125967], pp. 8 to 9; Thompson 1989 [DIRS 100830], pp. 353 to 364). Two columns were prepared identically. The column apparatus included a constant-rate pump, a valve to switch between a reservoir containing J-13 "background" water and a solution of lithium bromide in J13 well water, and an automatic fraction collector at the downstream end of the column. Each experiment began by pumping approximately $180 \mathrm{~mL}$ (roughly 12 pore volumes) of J-13 well water through the column at a specified flow rate to equilibrate the tuff with the groundwater. The input was then switched to a lithium bromide solution, which was maintained for approximately three pore volumes before being switched back to tracer-free groundwater. Effluent samples were analyzed for lithium and bromide using liquid chromatography (detection limits were $0.10 \quad \mathrm{mg} \quad \mathrm{L}^{-1}$ for $\mathrm{Li}^{+}$ and $0.005 \mathrm{mg} \mathrm{L}^{-1}$ for $\mathrm{Br}^{-}$). Bromide was used as a nonsorbing tracer to determine mean residence times and dispersivities in the columns as well as to serve as a nonsorbing tracer against which lithium retardation could be gauged.

A total of five experiments were conducted in the two columns, with the tracer concentrations and flow rate both being varied. In three of the five column experiments, the responses of $\mathrm{Li}^{+}$ and $\mathrm{Br}^{-}$were monitored until concentrations returned to background levels; in the other two experiments, concentrations were monitored only until they leveled off at the inlet concentrations. The experimental conditions are summarized in Table E-7. The different tracer concentrations were intended to investigate potential effects of lithium sorption nonlinearity, and the different flow rates were intended to reveal rate-limited effects, such as sorption nonequilibrium or diffusion-controlled sorption rates. All tests were conducted at $25^{\circ} \mathrm{C}$. 
Table E-7. Results of RELAP Fits to Rising Limbs of Lithium and Bromide Breakthrough Curves in Crushed Tuff Columns

\begin{tabular}{|l|c|c|c|c|c|c|c|c|}
\hline Column & Figure & $\begin{array}{c}\text { Flow Rate } \\
(\mathbf{m L} / \mathbf{h r})\end{array}$ & $\begin{array}{c}\text { Li Conc. } \\
(\mathbf{m g} / \mathbf{L})\end{array}$ & $\begin{array}{c}\boldsymbol{\tau} \\
\mathbf{( h r})\end{array}$ & $\mathbf{P e}$ & $\mathbf{R}_{\mathbf{F}}$ & $\begin{array}{c}\mathbf{k}_{\mathbf{f}} \\
(\mathbf{1} / \mathbf{h r})\end{array}$ & $\mathbf{D a}$ \\
\hline $1^{\mathrm{a}}$ & $\mathrm{E}-20$ & 2.2 & 23.5 & 7.6 & 250 & $2.0(2.0)$ & 3.1 & 24 \\
\hline 1 & $\mathrm{E}-21$ & 1.6 & 23.5 & 10.3 & 260 & $2.0(2.0)$ & 3.7 & 38 \\
\hline $1^{\mathrm{a}}$ & $\mathrm{E}-22$ & 9.7 & 20.1 & 1.8 & 580 & $1.8(1.7)$ & 8.8 & 16 \\
\hline $2^{\mathrm{a}}$ & $\mathrm{E}-23$ & 2.2 & 5.9 & 7.7 & 870 & $2.3(2.3)$ & 22 & 169 \\
\hline 2 & $\mathrm{E}-24$ & 1.6 & 5.9 & 10.4 & 750 & $2.3(2.25)$ & 4.6 & 48 \\
\hline
\end{tabular}

Source: DTN: LA0301PR831231.001 [DIRS 162603] (for flow rates and concentrations).

Output DTN: LA0303PR831361.003 (RELAP results).

NOTE: Denotes experiments in which tracer concentrations were monitored until background levels were reached. In this table, $\tau$ is residence time; $P e$ is the Peclet number; $R_{\mathrm{f}}$ is the retardation factor; $k_{\mathrm{f}}$ is the rate constant for sorption onto the column material; and $D a$ is the Damkohler number $\left(=k_{\mathrm{f}} \tau\right)$, which represents the ratio of reaction rate to advection rate in the columns. $R_{\mathrm{f}}$ values in parentheses indicate the best-fitting retardation factors when equilibrium sorption was assumed (i.e., very fast sorption kinetics).

\section{E3.1.2 Interpretive Methods}

The bromide responses in the experiments were interpreted using the RELAP V 2.0 computer code (STN: 10551-2.0-00 [DIRS 159065]) to obtain estimates of mean residence times and dispersivities/Peclet numbers in the columns. RELAP was also used to fit the rising limbs of the lithium responses in each experiment to obtain an estimate of the lithium retardation factor in the columns. The rate-limited sorption features of RELAP were also used to obtain an estimate of the rate constant $\left(k_{\mathrm{f}}\right)$ describing lithium sorption onto the column packing material. The rate constants were obtained by relaxing the equilibrium sorption assumption and adjusting the rate constants for each data set until the RELAP fits were optimized. Damkohler numbers $\left(k_{\mathrm{f}} \tau\right)$, which represent the ratio of reaction rate to advection rate in the columns, were calculated for each experiment. Damkohler numbers significantly greater than one indicate a system that can be treated as being at equilibrium locally (Valocchi 1985 [DIRS 144579], pp. 808 to 820).

It was apparent that while RELAP V 2.0 (STN: 10551-2.0-00 [DIRS 159065]) could fit the arrival of lithium, it could not fit the tails of the lithium responses when concentrations were monitored until they returned to background levels. The tails exhibited a behavior suggesting that a portion of the lithium eluted with the bromide as if it were a nonsorbing tracer. This behavior can occur when an ion-exchanging cation such as lithium comprises the majority of the cation equivalents in the tracer solution, which was certainly the case in the higher-concentration $\mathrm{LiBr}$ experiments. Essentially, if the CEC of the tuff and the exchange equilibria are not sufficient to exchange all of the lithium injected into a column, then some of the lithium must elute with the bromide to maintain charge balance in the solution exiting the column. Thus, for the tests in which the lithium was fully eluted from the columns, the MULTRAN V 1.0 computer code ([STN: 10666-1.0-00 [DIRS 159068]), which is capable of explicitly modeling cation exchange and maintaining solution charge balance, was used to interpret the lithium responses (see Section E3.2.2 for description of the code). 


\section{E3.1.3 Results and Interpretations}

The rising limbs of the breakthrough curves for the five experiments along with the RELAP V 2.0 (STN: 10551-2.0-00 [DIRS 159065]) fits to the data are shown in Figures E-20 through E-24. The best-fitting parameters are listed in Table E-7. Although significant improvements to the RELAP fits of the lithium breakthrough curves were obtained by assuming finite sorption rates, the relatively large Damkohler numbers listed in Table E-7 suggest that the local equilibrium assumption is reasonably valid in the columns. Furthermore, this assumption should be even more valid in field experiments where tracer residence times are much longer than in the columns. Figure E-20 shows the results of fitting the lithium response curve from one of the experiments assuming a nonlinear (Langmuir) sorption isotherm with parameters obtained from batch sorption testing $\left(\mathrm{K}_{\mathrm{L}}=0.0058 \mathrm{~mL} / \mu \mathrm{g}\right.$ and $\mathrm{S}_{\max }=106 \mu \mathrm{g} / \mathrm{g}$ for the Bullfrog Tuff from c\#2 used in these columns). It is apparent that the RELAP fits are not improved by assuming a nonlinear isotherm. The RETRAN V 2.0 computer code (STN: 10552-2.0-00 [DIRS 159066]) was used for the nonlinear simulations.

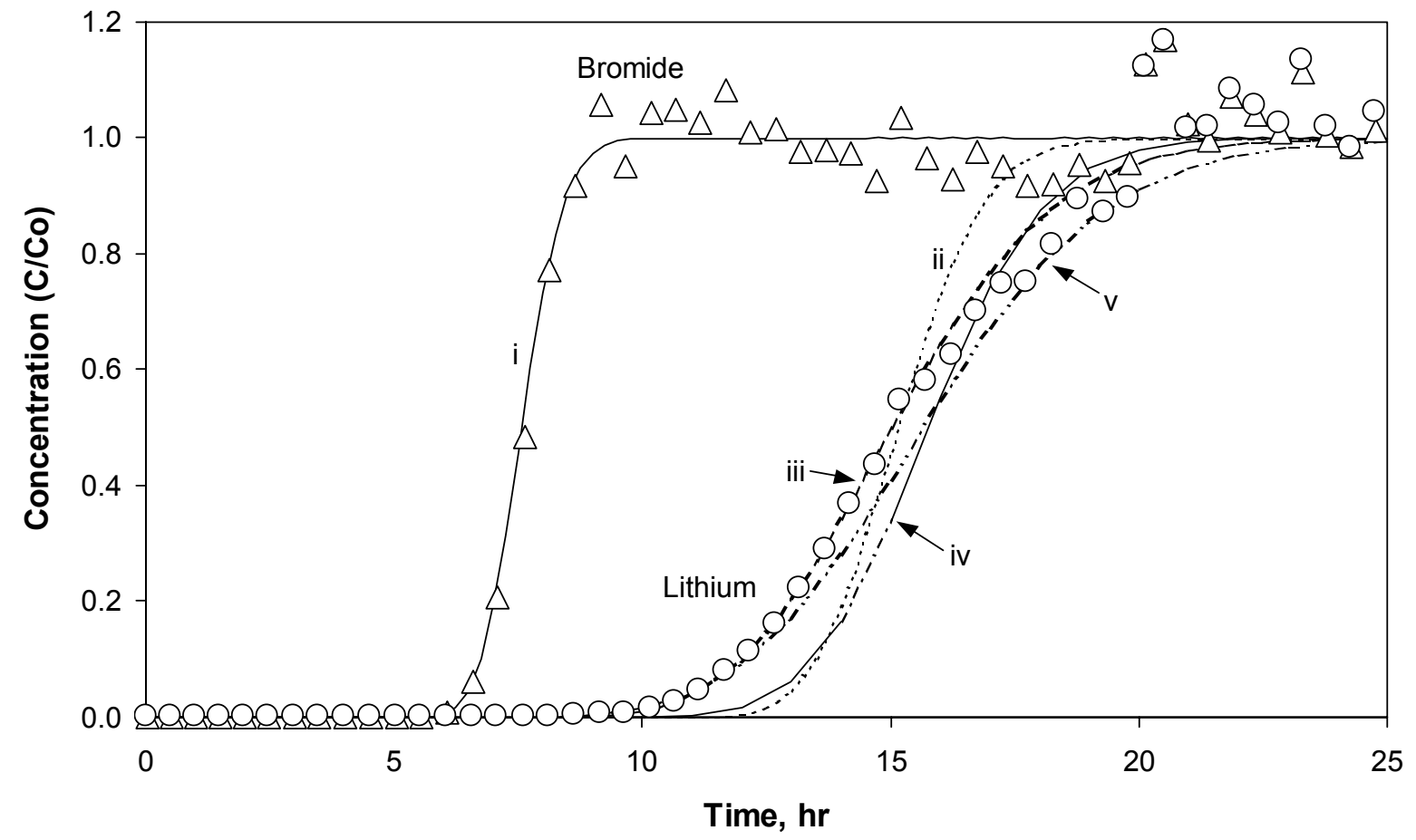

Source: DTN: LA0301PR831231.001 [DIRS 162603] (data).

Output DTN: LA0303PR831361.003 (fits).

NOTE: The curves above are numbered as follows:

(i) fit to bromide data with a Peclet number of 250

(ii) fit to lithium data assuming linear isotherm $\left(R_{\mathrm{F}}=2.0\right)$ with equilibrium sorption

(iii) fit to lithium data assuming linear isotherm with a forward rate constant of $3.11 / \mathrm{hr}\left(\right.$ and $R_{\mathrm{F}}=2.0$ )

(iv) fit to lithium data assuming a Langmuir isotherm with equilibrium sorption

(v) fit to lithium data assuming a Langmuir isotherm with a forward rate constant of $3.21 / \mathrm{hr}$.

Langmuir isotherm parameters: $K_{\mathrm{L}}=0.0058 \mathrm{~mL} / \mu \mathrm{g}$ and $S_{\max }=105.8 \mu \mathrm{g} / \mathrm{g}$ (batch isotherm values obtained for lithium on central Bullfrog Tuff from UE-25 c\#2).

Figure E-20. Bromide and Lithium Breakthrough Curves in Column 1 at a Flow Rate of $2.2 \mathrm{~mL} / \mathrm{hr}$ and Corresponding RELAP and RETRAN Fits to Data 


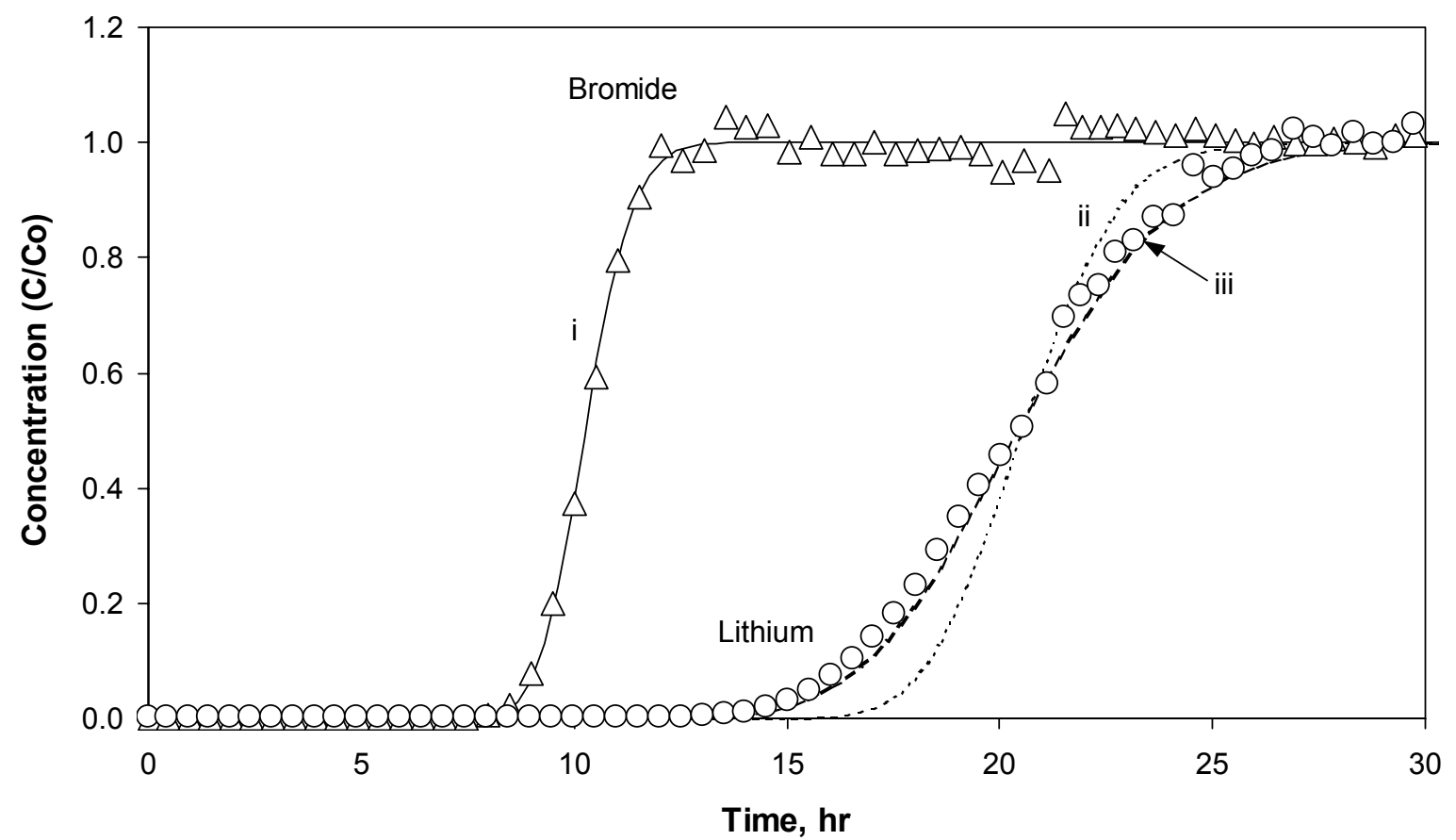

Source: DTN: LA0301PR831231.001 [DIRS 162603] (data).

Output DTN: LA0303PR831361.003 (fits).

NOTE: The curves above are numbered as follows:

(i) fit to bromide data with a Peclet number of 260

(ii) fit to lithium data assuming linear isotherm $\left(R_{\mathrm{F}}=2.0\right)$ with equilibrium sorption

(iii) fit to lithium data assuming linear isotherm with a forward rate constant of $3.71 / \mathrm{hr}$ (and $R_{\mathrm{F}}=2.0$ ).

Figure E-21. Bromide and Lithium Breakthrough Curves in Column 1 at a Flow Rate of $1.6 \mathrm{~mL} / \mathrm{hr}$ and Corresponding RELAP Fits to Data 


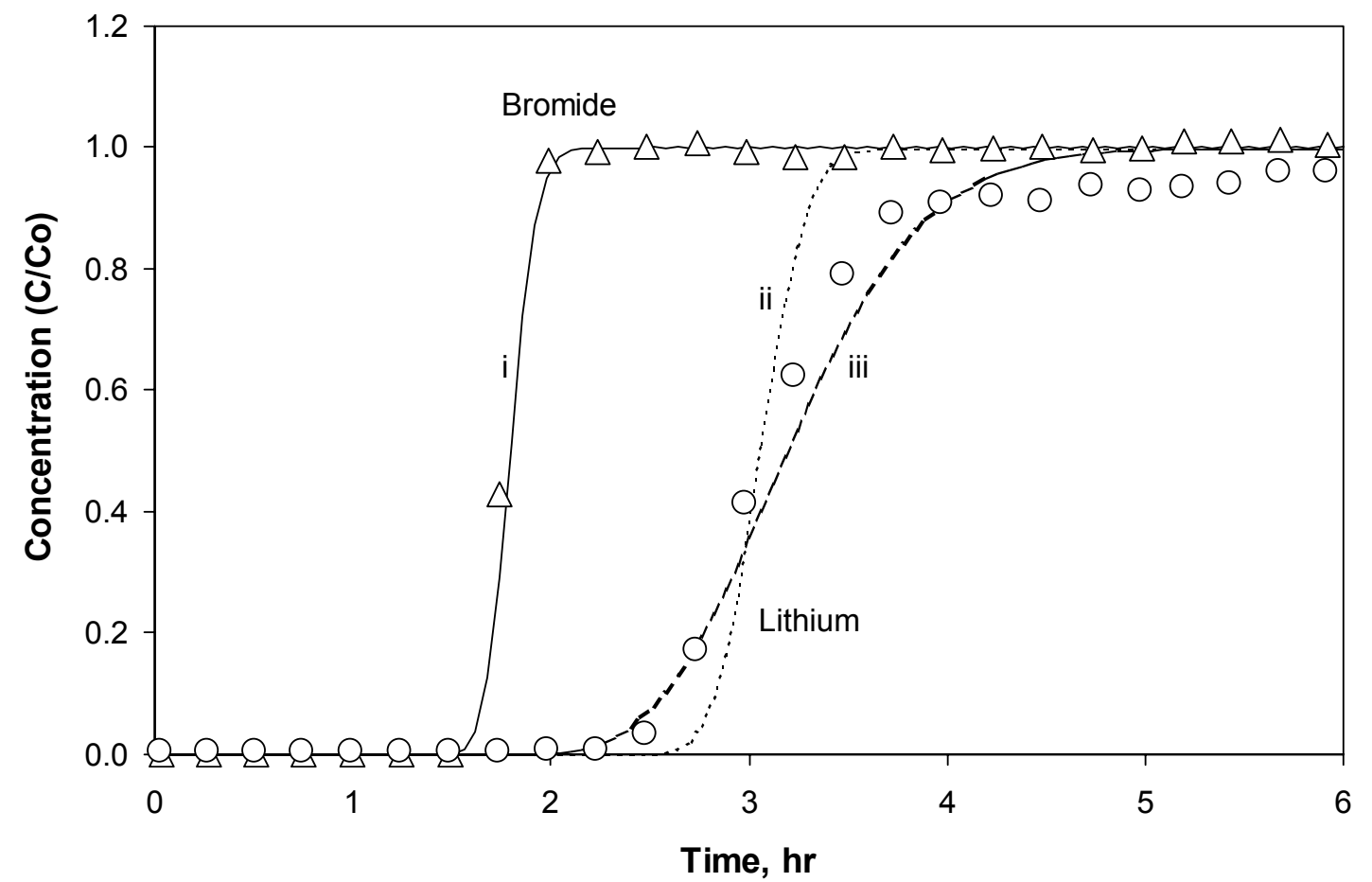

Source: DTN: LA0301PR831231.001 [DIRS 162603] (data).

Output DTN: LA0303PR831361.003 (fits).

NOTE: The curves above are numbered as follows:

(i) fit to bromide data with a Peclet number of 580

(ii) fit to lithium data assuming linear isotherm $\left(R_{\mathrm{F}}=1.7\right)$ with equilibrium sorption

(iii) fit to lithium data assuming linear isotherm with a forward rate constant of $8.81 / \mathrm{hr}$ (and $R_{\mathrm{F}}=1.8$ ).

Figure E-22. Bromide and Lithium Breakthrough Curves in Column 1 at a Flow Rate of $9.7 \mathrm{~mL} / \mathrm{hr}$ and Corresponding RELAP Fits to Data 


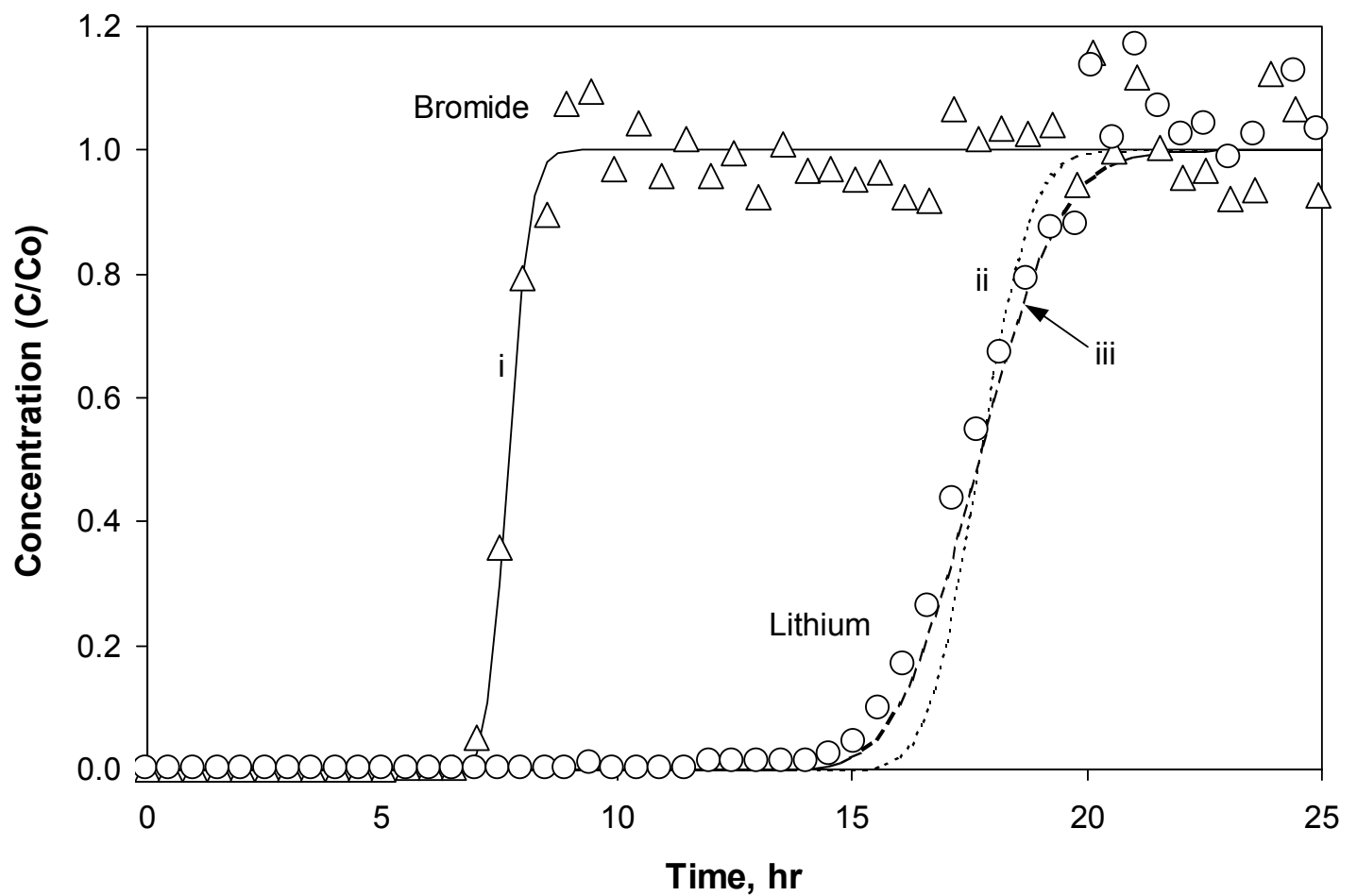

Source: DTN: LA0301PR831231.001 [DIRS 162603] (data).

Output DTN: LA0303PR831361.003 (fits).

NOTE: The curves above are numbered as follows:

(i) fit to bromide data with a Peclet number of 870

(ii) fit to lithium data assuming linear isotherm $\left(R_{\mathrm{F}}=2.3\right)$ with equilibrium sorption

(iii) fit to lithium data assuming linear isotherm with a forward rate constant of $221 / \mathrm{hr}$ (and $R_{\mathrm{F}}=2.3$ ).

Figure E-23. Bromide and Lithium Breakthrough Curves in Column 2 at a Flow Rate of $2.2 \mathrm{~mL} / \mathrm{hr}$ and Corresponding RELAP Fits to Data 


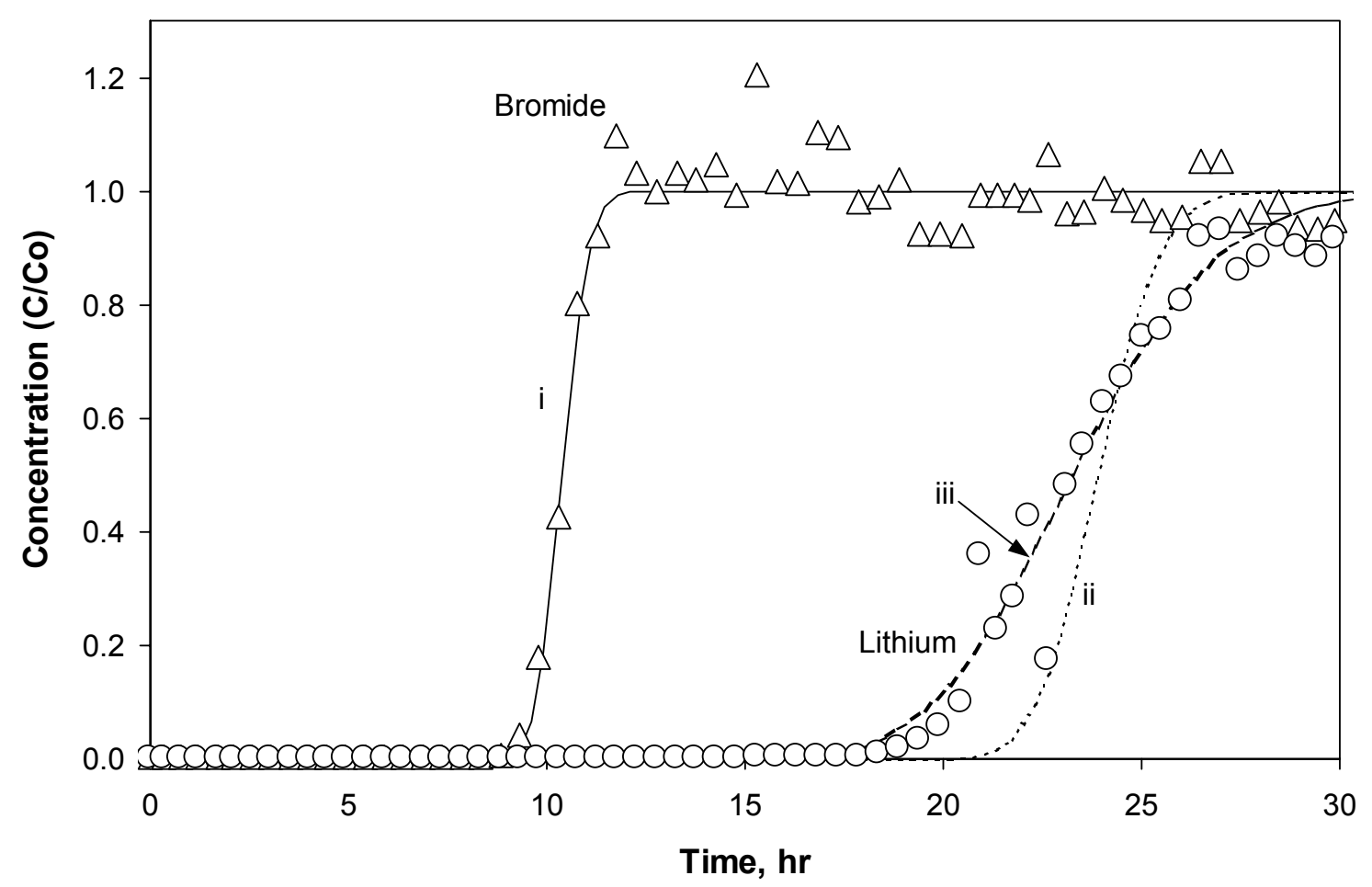

Source: DTN: LA0301PR831231.001 [DIRS 162603] (data).

Output DTN: LA0303PR831361.003 (fits).

NOTE: The curves above are numbered as follows:

(i) fit to bromide data with a Peclet number of 750

(ii) fit to lithium data assuming linear isotherm $\left(R_{\mathrm{F}}=2.3\right)$ with equilibrium sorption

(iii) fit to lithium data assuming linear isotherm with a forward rate constant of $4.61 / \mathrm{hr}\left(\right.$ and $\left.R_{\mathrm{F}}=2.25\right)$.

Figure E-24. Bromide and Lithium Breakthrough Curves in Column 2 at a Flow Rate of $1.6 \mathrm{~mL} / \mathrm{hr}$ and Corresponding RELAP Fits to Data

Table E-7 shows that lithium retardation factors $\left(R_{\mathrm{F}} \mathrm{s}\right)$ for the tests with lower tracer concentrations ranged from 2.2 to 2.3 , with a mean of 2.25; whereas $R_{\mathrm{F}} \mathrm{S}$ for the higher concentration tests ranged from 1.7 to 2.0 , with a mean of 1.87 . The observed decreased $R_{\mathrm{F}}$ at higher concentrations is consistent with a nonlinear sorption isotherm. For the Langmuir isotherm, the $R_{\mathrm{F}}$ can be shown to be (Fetter 1993 [DIRS 102009], pp. 122 to 123):

$$
R_{\mathrm{F}}=1+\frac{\rho_{\mathrm{B}}}{\theta}\left(\frac{K_{\mathrm{L}} S_{\max }}{\left(1+K_{\mathrm{L}} C\right)^{2}}\right)
$$

where

$\rho_{\mathrm{B}}$ is the dry bulk density of the medium $(\mathrm{g} / \mathrm{mL})$

$\theta$ is the volumetric moisture content, or porosity for a saturated medium. 
By solving Equation 20 with the batch Langmuir parameters obtained for the Central Bullfrog Tuff used in the column experiments $\left(K_{\mathrm{L}}=0.0053 \mathrm{~mL} / \mu \mathrm{g}\right.$ and $S_{\max }=110 \mu \mathrm{g} / \mathrm{g}-$ see Table E-4 footnote) and column values for $\rho_{\mathrm{B}}$ and $\theta$, retardation factor predictions of 2.11 are obtained for the lower concentration tests and 1.95 for the higher concentration tests. Overall these predictions match the $R_{\mathrm{F}}$ values of Table E-7 very well, differing by 7 percent or less for both concentration levels. The MULTRAN V 1.0 (STN: 10666-1.0-00 [DIRS 159068]) fits to the full data sets for the three experiments in which tracer concentrations were monitored until they returned to background levels are shown in Figures E-25 to E-27. The $Q_{1}$ and $Q_{2}$ values listed in these figures correspond to the "selectivity coefficients" for the following cation-exchange reactions (Reimus 2002 [DIRS 171587], MOL.20021021.0385, Section 2):

$$
\begin{gathered}
\mathrm{Li}^{+}+\mathrm{Na} X \leftrightarrow \mathrm{Li} X+\mathrm{Na}^{+} Q_{1}=\frac{[\mathrm{Li} X]\left[\mathrm{Na}^{+}\right]}{[\mathrm{Na} X]\left[\mathrm{Li}^{+}\right]} \\
2 \mathrm{Li}^{+}+\mathrm{Ca} X_{2} \leftrightarrow 2 \mathrm{Li} X+\mathrm{Ca}^{2+} Q_{2}=\frac{[\mathrm{Li} X]^{2}\left[\mathrm{Ca}^{2+}\right]}{\left[\mathrm{Ca} X X_{2}\right]\left[\mathrm{Li}^{+}\right]^{2}}
\end{gathered}
$$

where $X=$ a negatively charged surface site.

In addition to these reactions, MULTRAN V 1.0 (STN: 10666-1.0-00 [DIRS 159068]) also accounts for the exchange between sodium and calcium ions, and it solves the surface cation-exchange balance equation for a three-component system (Reimus 2002 [DIRS 171587], MOL.20021021.0385, Section 2):

$$
\begin{gathered}
2 \mathrm{Na}^{+}+\mathrm{Ca} X_{2} \leftrightarrow 2 \mathrm{Na} X+\mathrm{Ca}^{2+} \frac{Q_{2}}{Q_{1}^{2}}=\frac{[\mathrm{Na} X]^{2}\left[\mathrm{Ca}^{2+}\right]}{\left[\mathrm{Ca}_{2}\right]\left[\mathrm{Na}^{+}\right]^{2}}, \\
C E C=\frac{\rho_{B}}{\phi}\left([\mathrm{Li} X]+[\mathrm{Na} X]+2\left[\mathrm{Ca} X_{2}\right]\right)
\end{gathered}
$$

The measured CEC for the Bullfrog Tuff (Section E1.2) was used as the CEC value in the simulations, and the selectivity coefficients $Q_{1}$ and $Q_{2}$ were adjusted to fit the lithium data. However, without sodium and calcium concentration data, it was not possible to obtain a unique fit to the lithium responses. In fact, the lithium responses could be fit equally well assuming lithium exchange with only sodium or only calcium. Thus, the $Q_{1}$ and $Q_{2}$ values presented in Figures E-25 through E-27 should be considered as only one of many possible combinations that could fit the lithium data equally well. However, it is not the values of these parameters that are important but rather the recognition that cation-exchange equilibria must be explicitly accounted for to explain the observed transport behavior of the lithium. For comparison, a RELAP V 2.0 (STN: 10551-2.0-00 [DIRS 159065]) "fit" to the data from Figure E-25 is shown in Figure E-28. It is clear that the single-component equilibrium $K_{\mathrm{d}}$-model fit cannot capture the tailing behavior of the lithium. These results could have important implications for field tracer tests conducted in porous media that have a small sorption capacity for cation-exchanging tracers. 


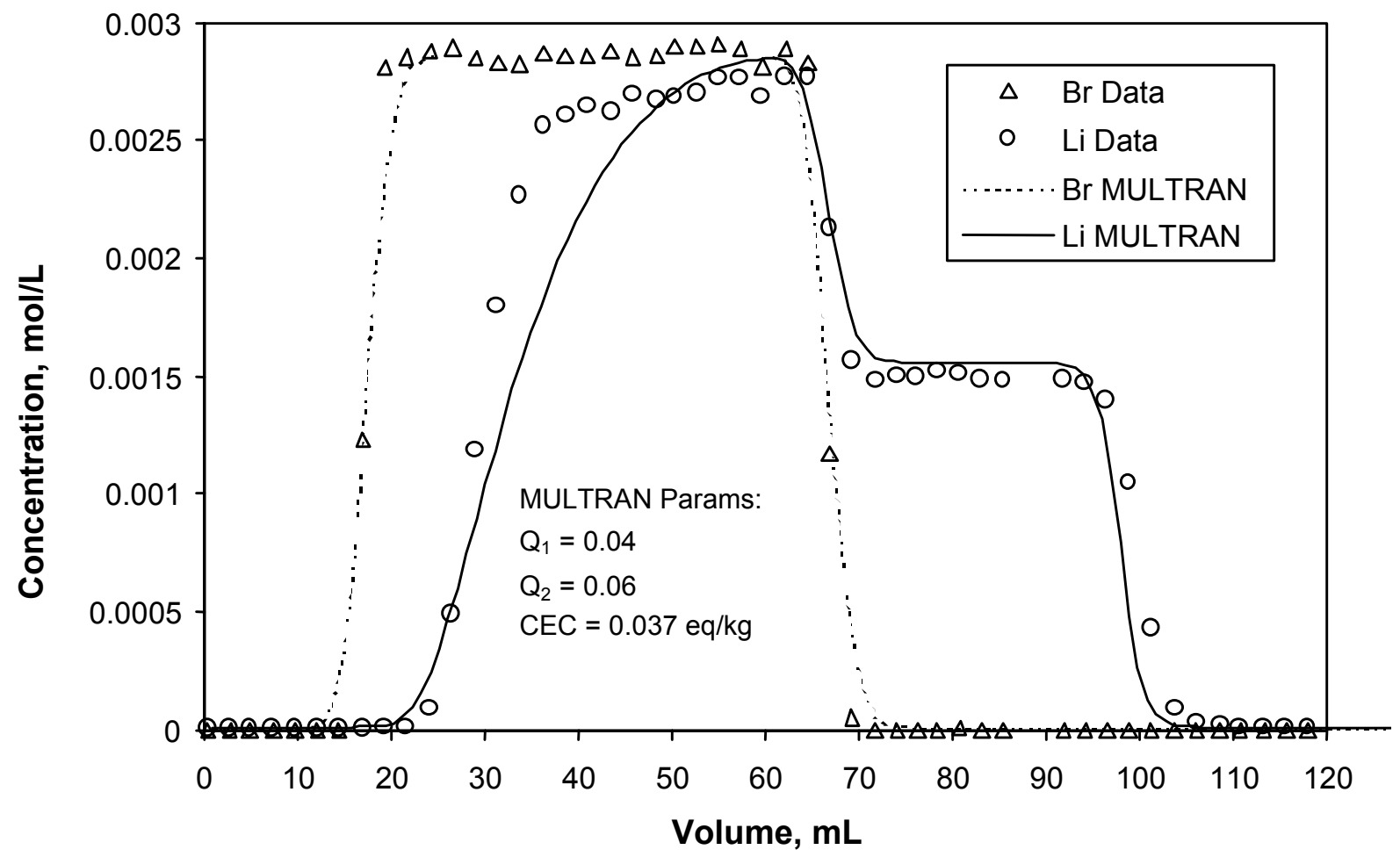

Source: DTN: LA0301PR831231.001 [DIRS 162603] (data).

Output DTN: LA0303PR831361.003 (fits).

NOTE: "MULTRAN Params" refers to the parameter values used in MULTRAN V 1.0 (STN: 10666-1.0-00 [DIRS 159068]) to obtain the simulated curves.

Figure E-25. MULTRAN Fits to Complete Bromide and Lithium Breakthrough Curves from High-Concentration Experiment Conducted at $9.7 \mathrm{~mL} / \mathrm{hr}$ in Column 1 (Figure E-22) 


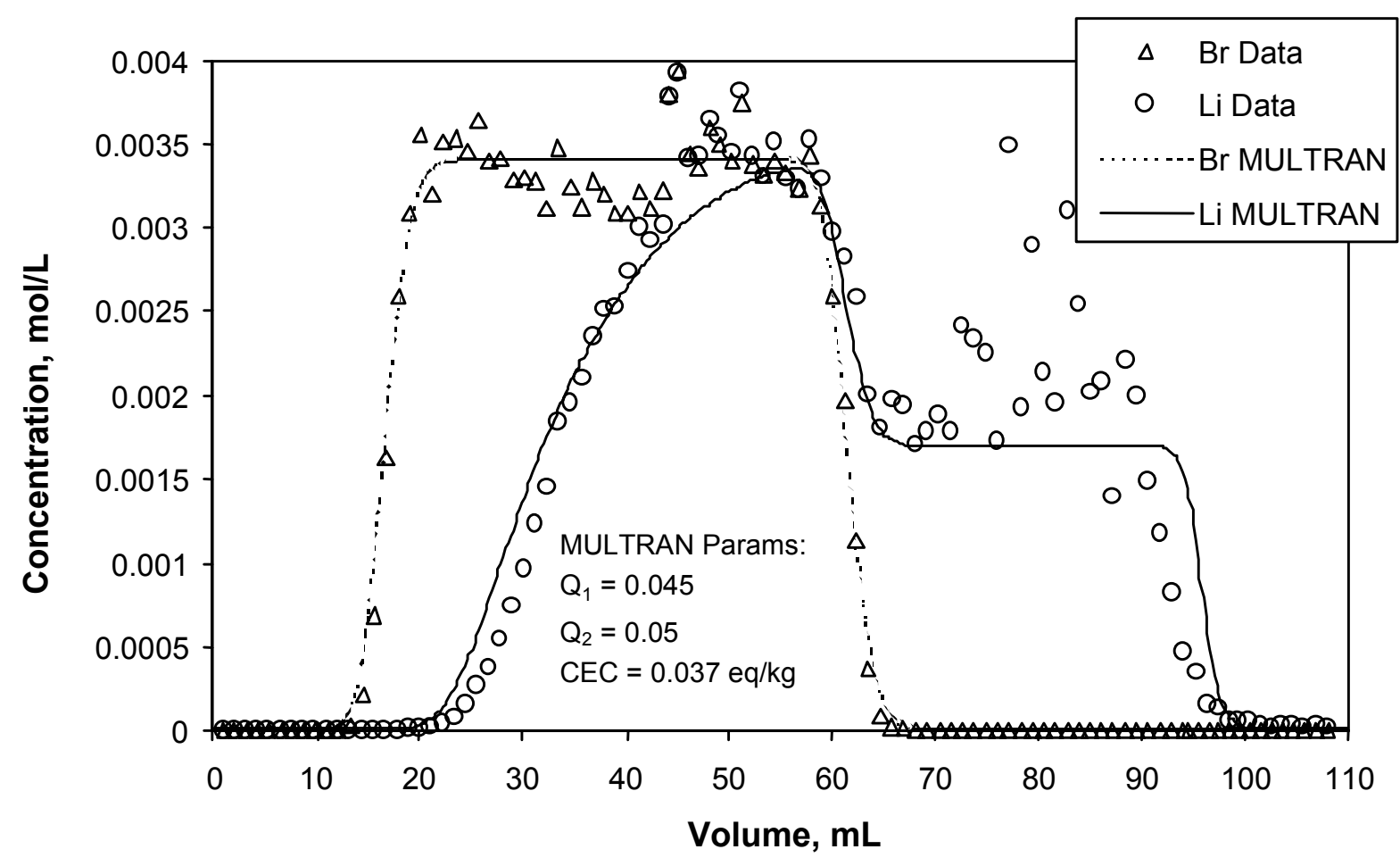

Source: DTN: LA0301PR831231.001 [DIRS 162603] (data).

Output DTN: LA0303PR831361.003 (fits).

NOTE: "MULTRAN Params" refers to the parameter values used in MULTRAN V 1.0 (STN: 10666-1.0-00 [DIRS 159068]) to obtain the simulated curves.

Figure E-26. MULTRAN Fits to Complete Bromide and Lithium Breakthrough Curves from High-Concentration Experiment Conducted at $2.2 \mathrm{~mL} / \mathrm{hr}$ in Column 1 (Figure E-20) 


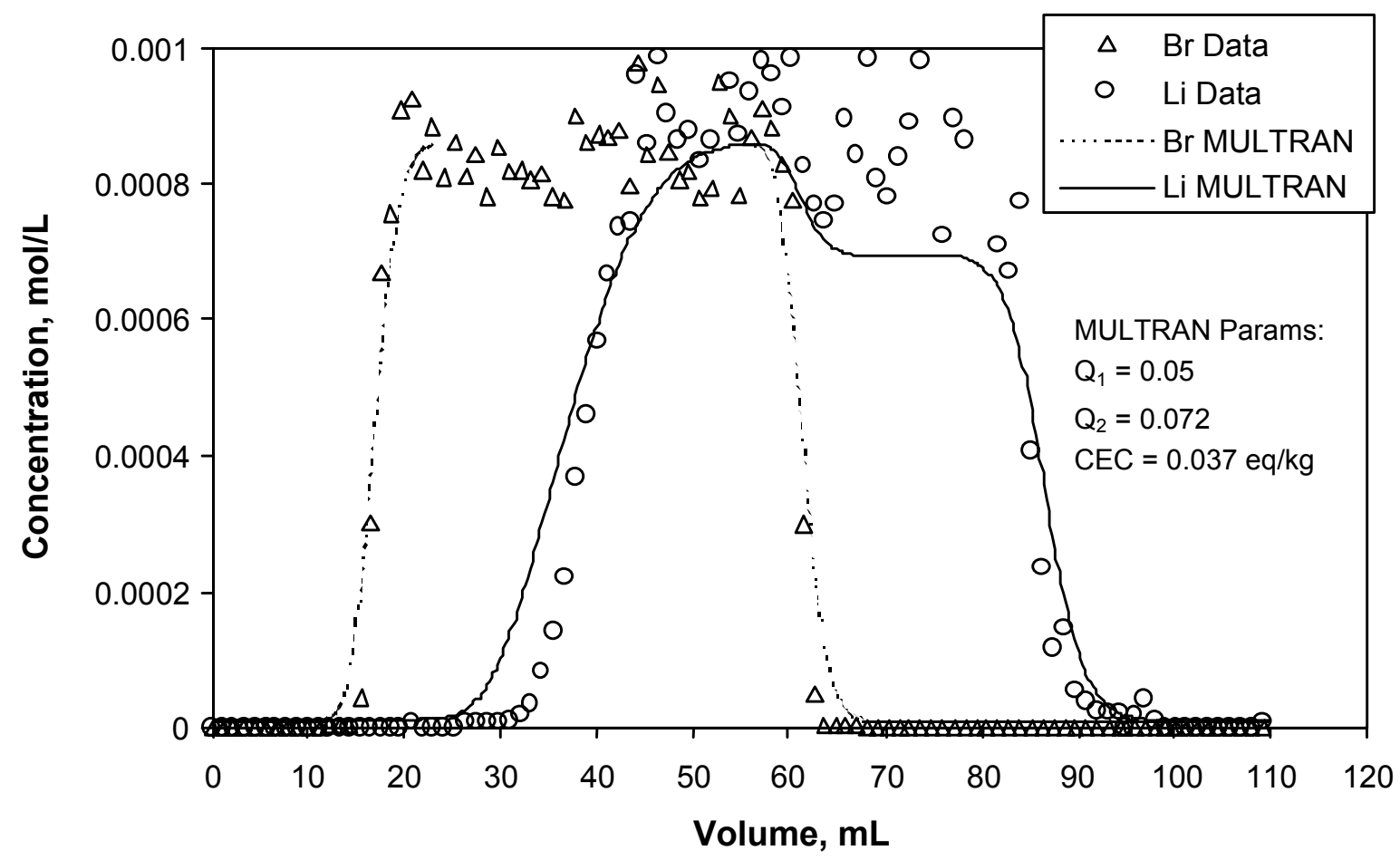

Source: DTN: LA0301PR831231.001 [DIRS 162603] (data).

Output DTN: LA0303PR831361.003 (fits).

NOTE: "MULTRAN Params" refers to the parameter values used in MULTRAN V 1.0 (STN: 10666-1.0-00 [DIRS 159068]) to obtain the simulated curves.

Figure E-27. MULTRAN Fits to Complete Bromide and Lithium Breakthrough Curves from Low-Concentration Experiment Conducted at $2.2 \mathrm{~mL} / \mathrm{hr}$ in Column 2 (Figure E-23) 


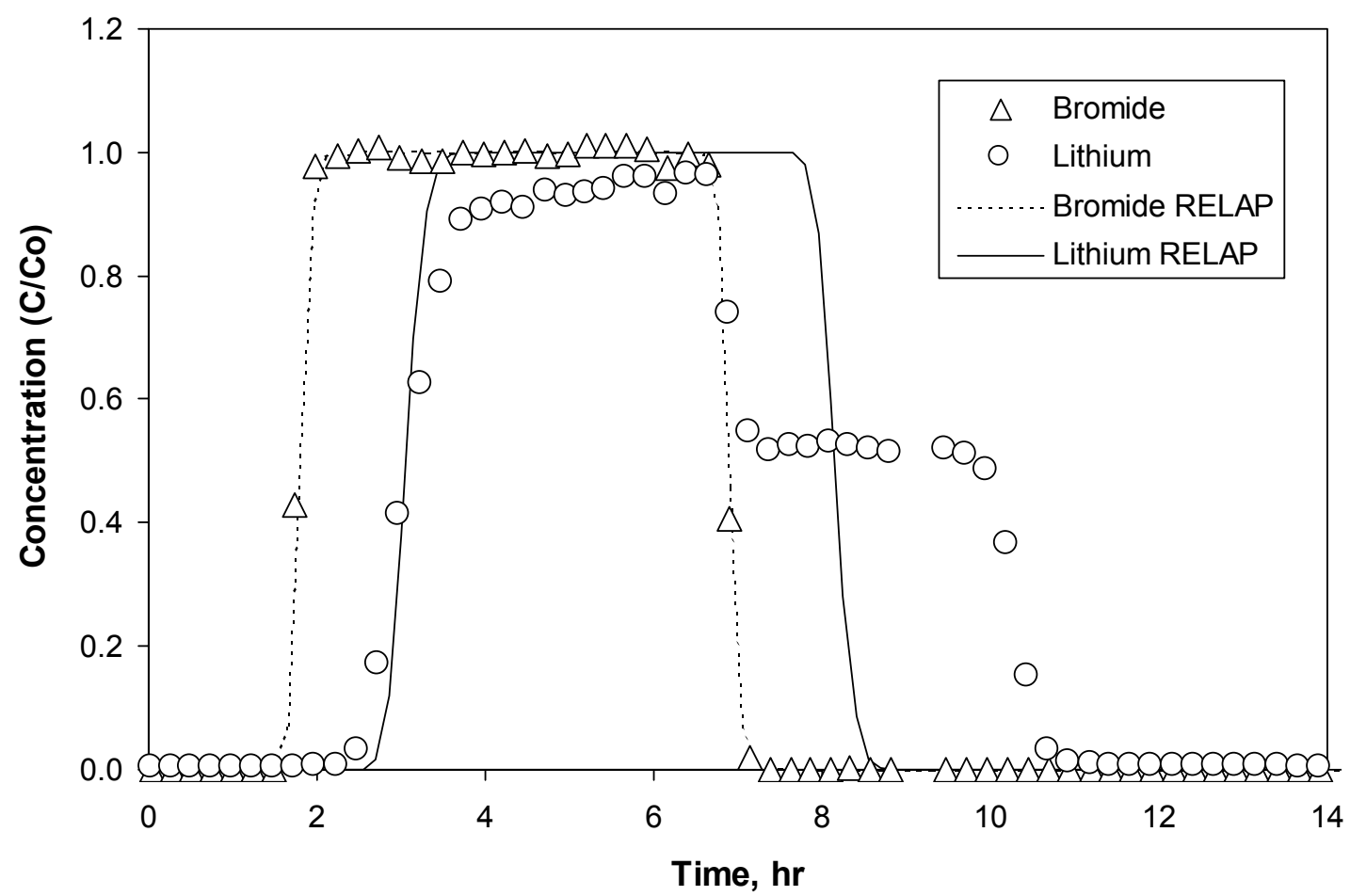

Source: DTN: LA0301PR831231.001 [DIRS 162603] (data).

Output DTN: LA0303PR831361.003 (fits).

Figure E-28. RELAP Fits to Complete Bromide and Lithium Breakthrough Curves from Experiment Conducted at $9.7 \mathrm{~mL} / \mathrm{hr}$ in Column 1 (Figure E-25 Shows the MULTRAN Fits)

\section{E3.2 FRACTURED-CORE EXPERIMENTS}

\section{E3.2.1 Experimental Methods}

Fractured-core transport experiments were conducted on four separate cores obtained from the C-wells following the procedure byCallahan et al. (2000 [DIRS 156648], pp. 3547 to 3558). The experiments are documented in detail by Reimus (2003 [DIRS 163760], Attachments B1 and B2). The cores were obtained from locations 3, 4, 5, and 6 in Figure E-1. In the following discussion, the cores from the upper, central, and lower flow zones of the Prow Pass Tuff (locations 4, 5, and 6, respectively) will be referred to as cores 1, 2, and 3, respectively. The core from the lower flow zone of the Bullfrog Tuff will be referred to as core 4. The mineralogy of the cores is given in Table E-3. Core 4 (lower flow zone of the Bullfrog Tuff) contained the highest percentage of clay and zeolite minerals, $9 \pm 3 \mathrm{wt} \%$ smectite, $4 \pm 1 \mathrm{wt} \%$ clinoptilolite, and $13 \pm 1 \mathrm{wt} \%$ analcime. A single fracture was mechanically induced in each of the four cores. The cores were laid on a cement floor and a four-pound hammer and chisel were used to induce an axial fracture running the length of the core. The cores were then encased in an epoxy and Plexiglas column apparatus following the procedure by Callahan et al. (2000 [DIRS 156648]). Figure E-29 shows a schematic illustration of a column experimental system. 


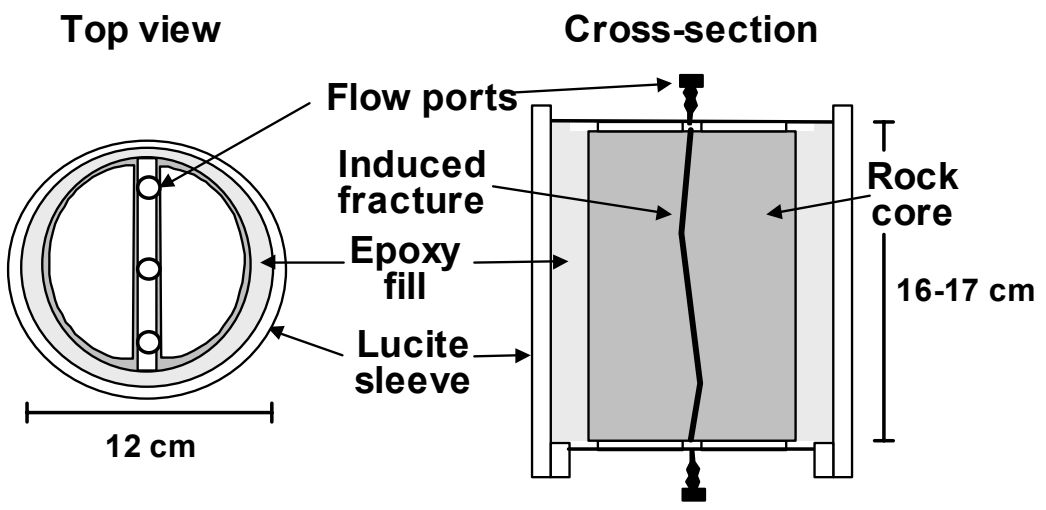

NOTE: For illustration purposes only. Three flow ports on each end of the core allowed access to the inlet and outlet regions; the central flow ports were used to connect the cores to a syringe pump and fraction collector via a $0.8-\mathrm{mm}$ diameter tubing. The lengths of the cores varied, but the diameters of all cores were $9.5 \mathrm{~cm}$.

Figure E-29. Schematic Illustration of a Fractured Rock Core Experimental System

The tracer experiments conducted in each core are summarized in Tables E-8 through E-13. As described by Callahan et al. (2000 [DIRS 156648]), cores 1 and 2 each featured three experiments in which iodide was used as a nonsorbing tracer at three different flow rates. The objective of these experiments was to obtain estimates of matrix-diffusion, mass-transfer parameters in the cores by using RELAP to fit simultaneously the iodide responses at each flow rate. All four cores also featured at least two multiple-tracer experiments that were conducted and interpreted very similarly to the $\mathrm{C}$-wells field tracer tests. Each experiment involved the injection of a pulse containing PFBA, lithium bromide ( $\mathrm{LiBr}$ ), and, in some cases, sodium iodide (NaI). Five multiple-tracer experiments were conducted in core 1. Two of these experiments were intended to be replicates, and they yielded very similar results, indicating good experimental reproducibility. Only two multiple-tracer tests were conducted in each of the other three cores. The flow rate in at least one of the multiple-tracer experiment in each core was approximately an order of magnitude lower than the flow rate(s) in the other multiple-tracer experiment(s). Flow rates were varied over this large range so that the effect of experiment time scale on matrix diffusion processes could be assessed in fracture systems of constant geometry. The fractures were thoroughly flushed after each experiment so that residual tracer concentrations were minimized in subsequent experiments.

A steady-state flow field was established in each core by continuously injecting degassed, filtered groundwater obtained from well J-13. A pulse of tracer solution (tracers dissolved in J13 well water) was then injected. After injection of the tracer pulse, continuous injection of tracer-free J-13 well water was resumed. The effluent was monitored for the tracer ions as well as for $\mathrm{Na}^{+}$and $\mathrm{Ca}^{2+}$ using ion chromatography for Brand PFBA and ICP-AES for analysis of $\mathrm{Li}^{+}, \mathrm{Na}^{+}$, and $\mathrm{Ca}^{2+}$. Iodide was analyzed either using an ion-selective electrode or ion chromatography. The quantitative detection limits were $0.05 \mathrm{mg} / \mathrm{L}$ for $\mathrm{Li}^{+}, \mathrm{Na}^{+}$, and $\mathrm{Ca}^{2+}$; $0.04 \mathrm{mg} / \mathrm{L}$ for Br$; 0.02 \mathrm{mg} / \mathrm{L}$ for I- ; and $0.02 \mathrm{mg} \mathrm{L}^{-1}$ for PFBA. $\mathrm{Na}^{+}$and $\mathrm{Ca}^{2+}$ were analyzed so that cation-exchange equilibria could be more rigorously quantified than in the crushed-tuff column experiments described in Section E3.1. Copper complexed with ethylenediamine tetraacetic acid was used as a tracer in some of the experiments to determine its potential to serve as a weakly sorbing tracer in field tests. In some of the tests (Tables E-9 through E-13), flow 
was interrupted for a time after the tracer concentrations had been tailing to verify diffusive mass transfer in the cores (Brusseau et al. 1997 [DIRS 156647], pp. 205 to 219; Callahan et al. 2000 [DIRS 156648]). This strategy was similar to that used in the Prow Pass multiple-tracer field test (Section D4.4).

Table E-8. Experimental Conditions for the lodide Fracture Transport Tests, Upper Prow Pass Tuff Core (Core 1)

\begin{tabular}{|c|c|c|c|}
\hline Experimental Parameters & & & \\
\hline Core length, $L(\mathrm{~m})$ & \multicolumn{3}{|c|}{0.161} \\
\hline Core width, $w(\mathrm{~m})$ & \multicolumn{3}{|c|}{0.095} \\
\hline Matrix porosity, $n_{m}$ & \multicolumn{3}{|c|}{0.272} \\
\hline Hydraulic aperture, $B_{h}(\mathrm{~m})^{a}$ & \multicolumn{3}{|c|}{$0.14 \times 10^{-3}$} \\
\hline lodide tests: & Test 1 & Test 2 & Test 3 \\
\hline Volumetric flow rate, $Q(\mathrm{~mL} / \mathrm{hr})$ & 2.2 & 19.6 & 8.7 \\
\hline Injection duration, $t_{p}(\mathrm{hr})$ & 28.02 & 3.08 & 7.23 \\
\hline Injection concentration, $C_{o}(\mathrm{mg} / \mathrm{L})$ & 1000 & 1000 & 1000 \\
\hline Flow interruption period, time since start of injection (hr) & $N / A^{b}$ & $N / A^{b}$ & $N / A^{b}$ \\
\hline Flow rate after restart, $Q(\mathrm{~mL} / \mathrm{hr})$ & $N / A^{b}$ & $N / A^{b}$ & $N / A^{b}$ \\
\hline Mass recovery (\%) & 86 & 96 & 94 \\
\hline
\end{tabular}

Source: Reimus 2003 [DIRS 163760], Attachment B1.

${ }^{a}$ Determined from a constant head permeameter method.

${ }^{\mathrm{b}} \mathrm{N} / \mathrm{A}$ : Not applicable; flow was not interrupted during these tests. 
Table E-9. Experimental Conditions for the Multiple-Tracer Fracture Transport Tests, Upper Prow Pass Tuff Core (Core 1)

\begin{tabular}{|c|c|c|c|}
\hline Experimental Parameters & \multicolumn{2}{|c|}{ Test 1} & Test 2 \\
\hline Volumetric flow rate, $Q(\mathrm{~mL} / \mathrm{hr})$ & \multicolumn{2}{|l|}{3.8} & 3.9 \\
\hline Injection duration, $t_{p}(\mathrm{hr})$ & \multicolumn{2}{|l|}{14.97} & 15.22 \\
\hline Injection concentration, $C_{o}(\mathrm{mg} / \mathrm{L})$ & \multicolumn{2}{|l|}{$\begin{array}{l}192\left(\mathrm{Li}^{+}\right) \\
0\left(\mathrm{Na}^{+}\right) \\
0\left(\mathrm{Ca}^{2+}\right) \\
1,728\left(\mathrm{Br}^{-}\right) \\
300\left(\mathrm{I}^{-}\right) \\
635(\mathrm{PFBA})\end{array}$} & $\begin{array}{l}192\left(\mathrm{Li}^{+}\right) \\
0\left(\mathrm{Na}^{+}\right) \\
0\left(\mathrm{Ca}^{2+}\right) \\
1,728\left(\mathrm{Br}^{-}\right) \\
300\left(\mathrm{I}^{-}\right) \\
635(\mathrm{PFBA})\end{array}$ \\
\hline Background groundwater concentration, $C_{i}(\mathrm{mg} / \mathrm{L})$ & \multicolumn{2}{|l|}{$\begin{array}{l}0.64\left(\mathrm{Li}^{+}\right) \\
46.7\left(\mathrm{Na}^{+}\right) \\
12.8\left(\mathrm{Ca}^{2+}\right) \\
3.63\left(\mathrm{Br}^{-}\right) \\
1.8\left(\mathrm{I}^{-}\right) \\
1.11(\mathrm{PFBA}) \\
\end{array}$} & $\begin{array}{l}1.79\left(\mathrm{Li}^{+}\right) \\
45.4\left(\mathrm{Na}^{+}\right) \\
12.8\left(\mathrm{Ca}^{2+}\right) \\
10.7\left(\mathrm{Br}^{-}\right) \\
0.55\left(\mathrm{I}^{-}\right) \\
3.86(\mathrm{PFBA}) \\
\end{array}$ \\
\hline $\begin{array}{l}\text { Flow interruption period, } \\
\text { time since start of injection (hr) }\end{array}$ & \multicolumn{2}{|l|}{$87.3-137.3$} & $87.1-137.2$ \\
\hline Flow rate after restart, $Q(\mathrm{~mL} / \mathrm{hr})$ & \multicolumn{2}{|l|}{3.96} & 3.99 \\
\hline Mass recovery $(\%)$ & \multicolumn{2}{|l|}{$\begin{array}{l}89\left(\mathrm{Li}^{+}\right) \\
89\left(\mathrm{Br}^{-}\right) \\
92\left(\mathrm{I}^{-}\right) \\
95(\mathrm{PFBA})\end{array}$} & $\begin{array}{l}89\left(\mathrm{Li}^{+}\right) \\
89\left(\mathrm{Br}^{-}\right) \\
86\left(\mathrm{I}^{-}\right) \\
95(\text { PFBA })\end{array}$ \\
\hline Experimental Parameters & Test 3 & Test 4 & Test 5 \\
\hline Volumetric flow rate, $Q\left(\mathrm{~mL} \mathrm{hr}^{-1}\right)$ & 0.51 & 7.9 & 6.3 \\
\hline Injection duration, $t_{p}(\mathrm{hr})$ & 156.85 & 19.0 & 10.5 \\
\hline Injection concentration, $C_{o}(\mathrm{mg} / \mathrm{L})$ & $\begin{array}{l}159\left(\mathrm{Li}^{+}\right) \\
394\left(\mathrm{Na}^{+}\right) \\
0\left(\mathrm{Ca}^{2+}\right) \\
1,870\left(\mathrm{Br}^{-}\right) \\
296\left(\mathrm{I}^{-}\right) \\
641(\mathrm{PFBA}) \\
145\left(\mathrm{Cu}^{2+}\right) \\
699(\mathrm{EDTA})\end{array}$ & $\begin{array}{l}1,010\left(\mathrm{Li}^{+}\right) \\
59.1\left(\mathrm{Na}^{+}\right) \\
0\left(\mathrm{Ca}^{2+}\right) \\
11,400\left(\mathrm{Br}^{-}\right) \\
\mathrm{N} / \mathrm{A}^{\mathrm{a}}\left(\mathrm{I}^{-}\right) \\
766(\mathrm{PFBA})\end{array}$ & $\begin{array}{l}216\left(\mathrm{Li}^{+}\right) \\
250\left(\mathrm{Na}^{+}\right) \\
0\left(\mathrm{Ca}^{2+}\right) \\
2,528\left(\mathrm{Br}^{-}\right) \\
\mathrm{N} / \mathrm{A}^{\mathrm{a}}\left(\mathrm{I}^{-}\right) \\
766(\mathrm{PFBA}) \\
192\left(\mathrm{Cu}^{2+}\right) \\
1,131(\mathrm{EDTA})\end{array}$ \\
\hline Background groundwater concentration, $C_{i}(\mathrm{mg} / \mathrm{L})$ & $\begin{array}{l}0.08\left(\mathrm{Li}^{+}\right) \\
51.8\left(\mathrm{Na}^{+}\right) \\
13.2\left(\mathrm{Ca}^{2+}\right) \\
10.87\left(\mathrm{Br}^{-}\right) \\
<0.4\left(\mathrm{I}^{-}\right) \\
2.07(\mathrm{PFBA})\end{array}$ & $\begin{array}{l}0.08\left(\mathrm{Li}^{+}\right) \\
45\left(\mathrm{Na}^{+}\right) \\
13.3\left(\mathrm{Ca}^{2+}\right) \\
<0.02\left(\mathrm{Br}^{-}\right) \\
<0.4\left(\mathrm{I}^{-}\right) \\
<0.005(\mathrm{PFBA})\end{array}$ & $\begin{array}{l}0.53\left(\mathrm{Li}^{+}\right) \\
45\left(\mathrm{Na}^{+}\right) \\
13.3\left(\mathrm{Ca}^{2+}\right) \\
0.98\left(\mathrm{Br}^{-}\right) \\
<0.4\left(\mathrm{I}^{-}\right) \\
<0.005(\mathrm{PFBA})\end{array}$ \\
\hline $\begin{array}{l}\text { Flow interruption period, } \\
\text { time since start of injection (hr) }\end{array}$ & $689-904$ & $\begin{array}{l}19.8-21.2 \\
49.9-64.2\end{array}$ & $44.0-64.0$ \\
\hline Flow rate after restart, $Q(\mathrm{~mL} / \mathrm{hr})$ & 0.51 & $\begin{array}{l}8.05 \\
8.04\end{array}$ & 6.46 \\
\hline Mass recovery $(\%)$ & $\begin{array}{l}83\left(\mathrm{Li}^{+}\right) \\
94\left(\mathrm{Br}^{-}\right) \\
82\left(\mathrm{I}^{-}\right) \\
94(\mathrm{PFBA})\end{array}$ & $\begin{array}{l}89\left(\mathrm{Li}^{+}\right) \\
89\left(\mathrm{Br}^{-}\right) \\
\mathrm{N} / \mathrm{A}^{\mathrm{a}}\left(\mathrm{I}^{-}\right) \\
95(\mathrm{PFBA})\end{array}$ & $\begin{array}{l}89\left(\mathrm{Li}^{+}\right) \\
89\left(\mathrm{Br}^{-}\right) \\
\mathrm{N} / \mathrm{A}^{\mathrm{a}}\left(\mathrm{I}^{-}\right) \\
95(\mathrm{PFBA})\end{array}$ \\
\hline
\end{tabular}

Source: Reimus 2003 [DIRS 163760], Attachment B1.

${ }^{a} \mathrm{~N} / \mathrm{A}$ : not applicable; iodide was not injected in these tests.

EDTA=ethylenediamine tetraacetic acid; PFBA=pentafluorobenzoic acid or pentafluorobenzoate. 
Table E-10. Experimental Conditions for the lodide Fracture Transport Tests, Central Prow Pass Tuff Core (Core 2)

\begin{tabular}{|l|c|c|c|}
\hline \multicolumn{1}{|c|}{ Experimental Parameters } & \multicolumn{3}{|c|}{0.173} \\
\hline Core length, $L(\mathrm{~m})$ & \multicolumn{3}{|c|}{0.095} \\
\hline Core width, $w(\mathrm{~m})$ & \multicolumn{3}{|c|}{0.138} \\
\hline Matrix porosity, $n_{m}$ & \multicolumn{3}{|c|}{ Test 2 } \\
\hline Hydraulic aperture, $B_{h}(\mathrm{~m})^{\mathrm{a}}$ & \multicolumn{3}{|c|}{ Test 3 $^{-3}$} \\
\hline & 19.7 & 49.3 & 11.3 \\
\hline Volumetric flow rate, $Q(\mathrm{~mL} / \mathrm{hr})$ & 4.0 & 1.47 & 6.05 \\
\hline Injection duration, $t_{p}(\mathrm{hr})$ & 1000 & 1000 & 1000 \\
\hline Injection concentration, $C_{o}(\mathrm{mg} / \mathrm{L})$ & $\mathrm{N} / \mathrm{A}^{\mathrm{b}}$ & $\mathrm{N} / \mathrm{A}^{\mathrm{b}}$ & $\mathrm{N} / \mathrm{A}^{\mathrm{b}}$ \\
\hline $\begin{array}{l}\text { Flow interruption period, } \\
\text { time since start of injection }(\mathrm{hr})\end{array}$ & $\mathrm{N} / \mathrm{A}^{\mathrm{b}}$ & $\mathrm{N} / \mathrm{A}^{\mathrm{b}}$ & $\mathrm{N} / \mathrm{A}^{\mathrm{b}}$ \\
\hline Flow rate after restart, $Q(\mathrm{~mL} / \mathrm{hr})$ & 89 & 98 & 84 \\
\hline Mass recovery $(\%)$ & & & \\
\hline
\end{tabular}

Source: Reimus 2003 [DIRS 163760], Attachment B2.

${ }^{a}$ Determined from a constant head permeameter method.

${ }^{b} \mathrm{~N} / \mathrm{A}$ : not applicable; flow was not interrupted during these tests.

Table E-11. Experimental Conditions for the Multiple-Tracer Fracture Transport Tests, Central Prow Pass Tuff Core (Core 2)

\begin{tabular}{|c|c|c|}
\hline Experimental Parameters & Test 1 & Test 2 \\
\hline Volumetric flow rate, $Q(\mathrm{~mL} / \mathrm{hr})$ & 5.9 & 0.44 \\
\hline Injection duration, $t_{p}(\mathrm{hr})$ & 12.3 & 170 \\
\hline Injection concentration, $C_{o}(\mathrm{mg} / \mathrm{L})$ & $\begin{array}{l}216\left(\mathrm{Li}^{+}\right) \\
205\left(\mathrm{Na}^{+}\right) \\
0\left(\mathrm{Ca}^{2+}\right) \\
2,528\left(\mathrm{Br}^{-}\right) \\
\mathrm{N} / \mathrm{A}^{\mathrm{a}}\left(\mathrm{I}^{-}\right) \\
766(\mathrm{PFBA}) \\
192\left(\mathrm{Cu}^{2+}\right) \\
1131(\mathrm{EDTA})\end{array}$ & $\begin{array}{l}159\left(\mathrm{Li}^{+}\right) \\
301\left(\mathrm{Na}^{+}\right) \\
0\left(\mathrm{Ca}^{2+}\right) \\
1,870\left(\mathrm{Br}^{-}\right) \\
296\left(\mathrm{I}^{-}\right) \\
641(\mathrm{PFBA}) \\
145\left(\mathrm{Cu}^{2+}\right) \\
699(\mathrm{EDTA})\end{array}$ \\
\hline Background groundwater concentration, $C_{i}(\mathrm{mg} / \mathrm{L})$ & $\begin{array}{l}0.08\left(\mathrm{Li}^{+}\right) \\
45\left(\mathrm{Na}^{+}\right) \\
13.3\left(\mathrm{Ca}^{2+}\right) \\
<0.02\left(\mathrm{Br}^{-}\right) \\
<0.4\left(\mathrm{I}^{-}\right) \\
<0.005(\mathrm{PFBA})\end{array}$ & $\begin{array}{l}0.55\left(\mathrm{Li}^{+}\right) \\
75.1\left(\mathrm{Na}^{+}\right) \\
10.0\left(\mathrm{Ca}^{2+}\right) \\
1.97\left(\mathrm{Br}^{-}\right) \\
0.9\left(\mathrm{I}^{-}\right) \\
0.98(\mathrm{PFBA})\end{array}$ \\
\hline Flow interruption period, time since start of injection (hr) & $42.9-62.9$ & 799-999 \\
\hline Flow rate after restart, $Q(\mathrm{~mL} / \mathrm{hr})$ & 5.95 & 0.44 \\
\hline Mass recovery $(\%)$ & $\begin{array}{l}84\left(\mathrm{Li}^{+}\right) \\
90\left(\mathrm{Br}^{-}\right) \\
\text {N/A (a) }\left(\mathrm{I}^{-}\right) \\
95(\mathrm{PFBA})\end{array}$ & $\begin{array}{l}68\left(\mathrm{Li}^{+}\right) \\
97\left(\mathrm{Br}^{-}\right) \\
97\left(\mathrm{I}^{-}\right) \\
102(\mathrm{PFBA})\end{array}$ \\
\hline
\end{tabular}

Source: Reimus 2003 [DIRS 163760], Attachment B2.

${ }^{a} \mathrm{~N} / \mathrm{A}$ : not applicable; iodide was not injected in these tests.

EDTA=ethylenediamine tetraacetic acid; PFBA=pentafluorobenzoic acid. 
Table E-12. Experimental Conditions for the Multiple-Tracer Fracture Transport Tests, Lower Prow Pass Tuff Core (Core 3)

\begin{tabular}{|c|c|c|}
\hline Experimental Parameters & & \\
\hline Core length, $L(\mathrm{~m})$ & \multicolumn{2}{|l|}{0.116} \\
\hline Core width, $w(m)$ & \multicolumn{2}{|l|}{0.095} \\
\hline Matrix porosity, $n_{m}$ & \multicolumn{2}{|l|}{0.288} \\
\hline \multirow[t]{2}{*}{ Hydraulic aperture, $B_{h}(m)^{a}$} & \multicolumn{2}{|l|}{$0.16 \times 10^{-3}$} \\
\hline & Test 1 & Test 2 \\
\hline Volumetric flow rate, $Q(\mathrm{~mL} / \mathrm{hr})$ & 11.4 & 0.46 \\
\hline Injection duration, $t_{p}(\mathrm{hr})$ & 14.5 & 340 \\
\hline Injection concentration, $C_{o}(\mathrm{mg} / \mathrm{L})$ & $\begin{array}{l}159\left(\mathrm{Li}^{+}\right) \\
331\left(\mathrm{Na}^{+}\right) \\
1.2\left(\mathrm{Ca}^{2+}\right) \\
1870\left(\mathrm{Br}^{-}\right) \\
296\left(\mathrm{I}^{-}\right) \\
641(\mathrm{PFBA}) \\
145\left(\mathrm{Cu}^{2+}\right) \\
699(\mathrm{EDTA})\end{array}$ & $\begin{array}{l}165\left(\mathrm{Li}^{+}\right) \\
310\left(\mathrm{Na}^{+}\right) \\
0\left(\mathrm{Ca}^{2+}\right) \\
1930\left(\mathrm{Br}^{-}\right) \\
299\left(\mathrm{I}^{-}\right) \\
681(\mathrm{PFBA}) \\
150\left(\mathrm{Cu}^{2+}\right) \\
699(\mathrm{EDTA})\end{array}$ \\
\hline Background groundwater concentration, $C_{i}(\mathrm{mg} / \mathrm{L})$ & $\begin{array}{l}0.08\left(\mathrm{Li}^{+}\right) \\
44.6\left(\mathrm{Na}^{+}\right) \\
13.3\left(\mathrm{Ca}^{2+}\right) \\
<0.02\left(\mathrm{Br}^{-}\right) \\
<0.35\left(\mathrm{I}^{-}\right) \\
<0.005(\mathrm{PFBA})\end{array}$ & $\begin{array}{l}4.41\left(\mathrm{Li}^{+}\right) \\
67.2\left(\mathrm{Na}^{+}\right) \\
16.4\left(\mathrm{Ca}^{2+}\right) \\
60.1\left(\mathrm{Br}^{-}\right) \\
9.49\left(\mathrm{I}^{-}\right) \\
16.2(\mathrm{PFBA})\end{array}$ \\
\hline Flow interruption period, time since start of injection (hr) & $43.6-68.6$ & 792-992 \\
\hline Flow rate after restart, $Q(\mathrm{~mL} / \mathrm{hr})$ & 11.4 & 0.47 \\
\hline Mass recovery (\%) & $\begin{array}{l}97.2\left(\mathrm{Li}^{+}\right) \\
95.7\left(\mathrm{Br}^{-}\right) \\
98.4\left(\mathrm{I}^{-}\right) \\
99.3(\mathrm{PFBA})\end{array}$ & $\begin{array}{l}72.4\left(\mathrm{Li}^{+}\right) \\
87.3\left(\mathrm{Br}^{-}\right) \\
84.2\left(\mathrm{I}^{-}\right) \\
80.1(\mathrm{PFBA})\end{array}$ \\
\hline
\end{tabular}

Source: Reimus 2003 [DIRS 163760], Attachment B1.

${ }^{a}$ Determined from a constant head permeameter method.

EDTA=ethylenediamine tetraacetic acid; PFBA=pentafluorobenzoic acid. 
Table E-13. Experimental Conditions for the Multiple-Tracer Fracture Transport Tests, Lower Bullfrog Tuff Core (Core 4)

\begin{tabular}{|c|c|c|}
\hline Experimental Parameters & Test 1 & Test 2 \\
\hline Volumetric flow rate, $Q(\mathrm{~mL} / \mathrm{hr})$ & 5.0 & 0.47 \\
\hline Injection duration, $t_{p}(\mathrm{hr})$ & 34.0 & 335.0 \\
\hline Injection concentration, $C_{o}(\mathrm{mg} / \mathrm{L})$ & $\begin{array}{l}165\left(\mathrm{Li}^{+}\right) \\
342\left(\mathrm{Na}^{+}\right) \\
0\left(\mathrm{Ca}^{2+}\right) \\
1930\left(\mathrm{Br}^{-}\right) \\
299\left(\mathrm{I}^{-}\right) \\
681(\mathrm{PFBA}) \\
150\left(\mathrm{Cu}^{2+}\right) \\
699(\mathrm{EDTA})\end{array}$ & $\begin{array}{l}192\left(\mathrm{Li}^{+}\right) \\
0\left(\mathrm{Na}^{+}\right) \\
0\left(\mathrm{Ca}^{2+}\right) \\
1728\left(\mathrm{Br}^{-}\right) \\
300\left(\mathrm{I}^{-}\right) \\
635(\mathrm{PFBA})\end{array}$ \\
\hline $\begin{array}{l}\text { Background groundwater concentration, } \\
C_{i}(\mathrm{mg} / \mathrm{L})\end{array}$ & $\begin{array}{l}0.04\left(\mathrm{Li}^{+}\right) \\
51.1\left(\mathrm{Na}^{+}\right) \\
11.0\left(\mathrm{Ca}^{2+}\right) \\
0.14\left(\mathrm{Br}^{-}\right) \\
0.07\left(\mathrm{I}^{-}\right) \\
0.14(\mathrm{PFBA})\end{array}$ & $\begin{array}{l}4.41\left(\mathrm{Li}^{+}\right) \\
67.2\left(\mathrm{Na}^{+}\right) \\
16.4\left(\mathrm{Ca}^{2+}\right) \\
60.1\left(\mathrm{Br}^{-}\right) \\
9.49\left(\mathrm{I}^{-}\right) \\
16.2(\mathrm{PFBA})\end{array}$ \\
\hline $\begin{array}{l}\text { Flow interruption period, } \\
\text { time since start of injection (hr) }\end{array}$ & $67.2-87.2$ & 79-992 \\
\hline Flow rate after restart, $Q(\mathrm{~mL} / \mathrm{hr})$ & 5.05 & 0.47 \\
\hline Mass recovery $(\%)$ & $\begin{array}{l}57\left(\mathrm{Li}^{+}\right) \\
96\left(\mathrm{Br}^{-}\right) \\
86\left(\mathrm{I}^{-}\right) \\
99(\mathrm{PFBA})\end{array}$ & $\begin{array}{l}85\left(\mathrm{Li}^{+}\right) \\
103\left(\mathrm{Br}^{-}\right) \\
86\left(\mathrm{I}^{-}\right) \\
91(\mathrm{PFBA})\end{array}$ \\
\hline
\end{tabular}

Source: Reimus (2003 [DIRS 163760], Attachment B2).

EDTA=ethylenediamine tetraacetic acid; PFBA=pentafluorobenzoic acid

\section{E3.2.2 Interpretive Methods}

The RELAP V 2.0 (STN: 10551-2.0-00 [DIRS 159065]) code was used to interpret the nonsorbing iodide, bromide, and PFBA tracer responses. For the iodide-only experiments conducted in cores 1 and 2, the responses at the three different flow rates were simultaneously fitted, assuming the same Peclet number and matrix diffusion mass transfer coefficient (mass transfer coefficient $\left.[\mathrm{MTC}]=\phi \mathrm{D}_{\mathrm{m}}{ }^{1 / 2} / \mathrm{b}\right)$ in each test, and a mean residence time $(\tau)$ that was inversely proportional to flow rate. This procedure assumes that the $M T C$ and Peclet number have no flow rate or time scale dependence.

For the multiple-tracer tests, the bromide and PFBA responses were simultaneously fitted, assuming that bromide had a matrix diffusion coefficient a factor of three greater than PFBA (this same assumption was used in the field tracer-test interpretations). However, because of the difficulties encountered in fitting the lithium responses in the crushed-tuff column experiments, and the fact that $\mathrm{Na}^{+}$and $\mathrm{Ca}^{2+}$ were analyzed in addition to $\mathrm{Li}^{+}$in the fractured-core experiments, it was decided to use the MULTRAN V 1.0 (STN: 10666-1.0-00 [DIRS 159068]) code 
(described below) rather than RELAP V 2.0 (STN: 10551-2.0-00 [DIRS 159065]) to interpret the lithium responses. The values of $\tau, P e$, and MTC that provided the best RELAP fits to the bromide and PFBA responses were used as inputs to MULTRAN (note that for tests conducted at different flow rates in the same core, $\tau$ was adjusted such that it was inversely proportional to flow rate and $P e$ was held constant for all tests). The parameters $Q_{1}$ and $Q_{2}$ were then adjusted to fit the $\mathrm{Li}^{+}, \mathrm{Na}^{+}$, and $\mathrm{Ca}^{2+}$ data while holding the CEC values equal to the measured $\mathrm{CEC}$ values.

MULTRAN V 1.0 (STN: 10666-1.0-00 [DIRS 159068]) employs an implicit-in-time, alternating-direction, finite-difference method to solve the two-dimensional numerical equations describing multicomponent transport of sorbing and nonsorbing solutes in a single- or dualporosity medium. Figure E-30 illustrates the assumed simulation domain and shows an example spatial discretization. Advective transport, simulated by solving the advection-dispersion equation, is assumed to occur only in the x-direction in Region I. The first and last nodes in the $x$-direction in this region are simulated as well-mixed regions that correspond to either boreholes in field experiments or flow manifolds in laboratory experiments. Reinjection of part or all of the solution entering the last node back into the first node can be specified to simulate recirculating conditions in tracer experiments. Only diffusive transport is assumed to occur in the $y$-direction in both regions I and II, with the code having the capability to simulate different diffusion coefficients in the different regions. Finally, within each region, additional diffusive transport can be simulated into "grains," which are assumed to be spherical. These grains can be assigned a lognormal distribution of diameters with specified mean and variance. The user can control the spatial discretization within each region and within the grains.

The user also can eliminate certain portions of the domain shown in Figure E-30 simply by specifying that they have zero porosity. For instance, if one wishes to simulate a single-porosity medium, it is only necessary to specify a zero porosity for region II and zero porosity for the grains in region I. This approach was taken to simulate the crushed-tuff column transport experiments described in Section E3.1 because the columns were packed with a relatively uniform material that had no apparent secondary porosity. Reducing the simulation effectively to a one-dimensional system (region I) greatly simplifies numerical computations. 


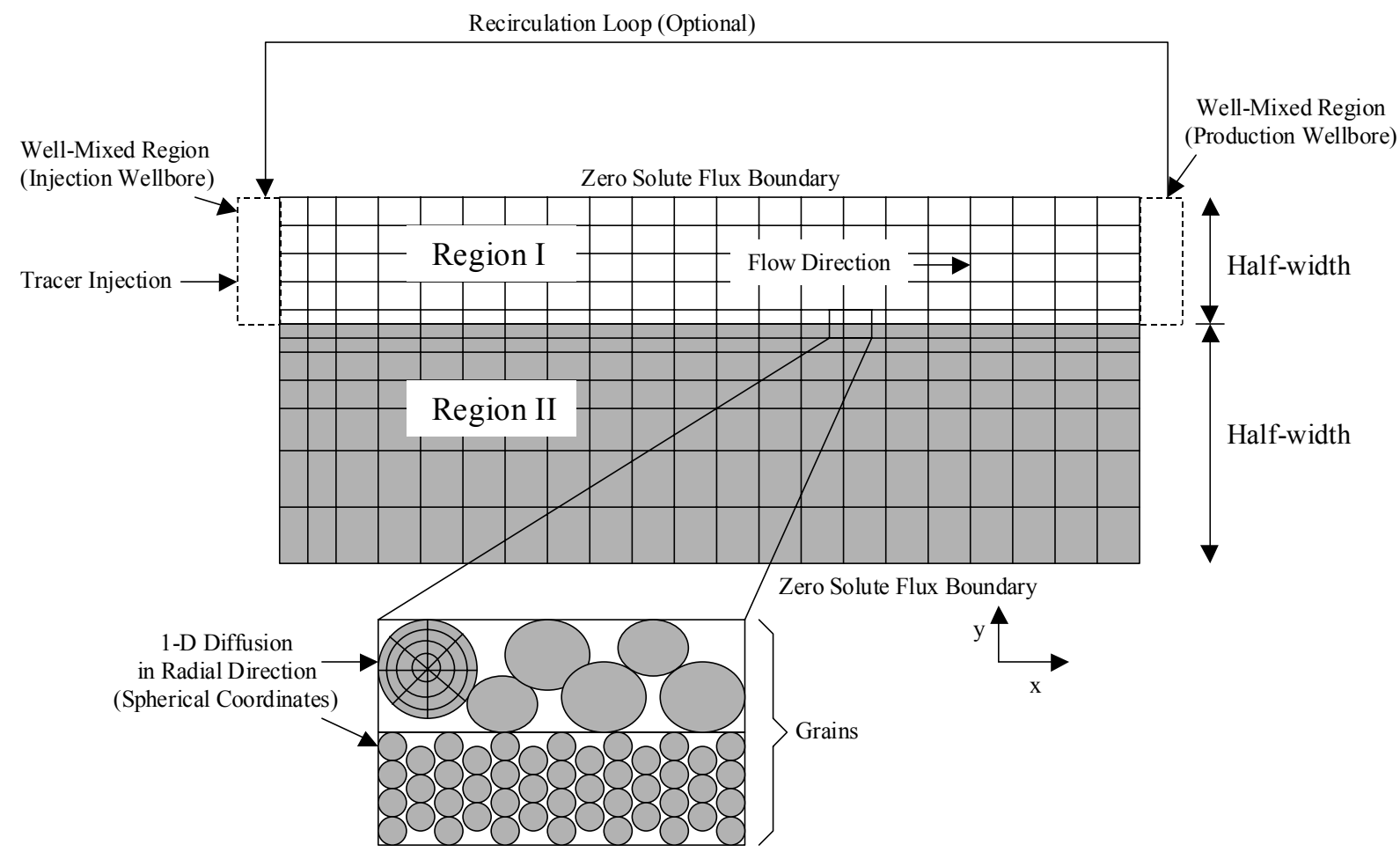

NOTE: For illustration purposes only. Blocks are finite-difference cells that are solved at their midpoints. Region I is the high-permeability layer (advective transport in $x$-direction, diffusive in $y$-direction); region II is the low-permeability layer (diffusive transport in $y$-direction only).

Figure E-30. Schematic Illustration of MULTRAN Simulation Domain

Each time-step of a MULTRAN V 1.0 (STN: 10666-1.0-00 [DIRS 159068]) simulation is broken into four computational segments conducted sequentially, as follows (Reimus 2002 [DIRS 171587], MOL.20021021.0385, Section 2):

(1) Solution of the advection-dispersion equation in the $x$-direction in region I:

$$
\frac{\partial c}{\partial t}=-v_{\mathrm{x}} \frac{\partial c}{\partial x}+D \frac{\partial^{2} c}{\partial x^{2}}
$$

where

$c=$ molar concentration, moles $/ \mathrm{L}$

$v_{\mathrm{x}}=$ velocity in $x$ direction, $\mathrm{cm} / \mathrm{sec}$

$D=$ dispersion coefficient, $\mathrm{cm}^{2} / \mathrm{sec}\left(D=\alpha v_{\mathrm{x}}, \alpha=\right.$ dispersivity, $\left.\mathrm{cm}\right)$.

(2) Solution of the multicomponent diffusion equation(s) and the local electroneutrality equation in the $y$-direction in regions I and II (coupled):

a. Multicomponent diffusion equation for all species except species $n$ (Newman 1973 [DIRS 148719], p. 228): 


$$
\frac{\partial c_{i}}{\partial t}=D_{i} \nabla^{2} c_{i}-\sum_{j} \frac{z_{j}}{z_{i}}\left(D_{j}-D_{n}\right) \nabla \cdot\left(t_{i} \nabla c_{i}\right)
$$

where

$$
\begin{aligned}
& c_{i}=\text { molar concentration of species } i, \mathrm{moles} / \mathrm{L} \\
& D_{i}=\text { diffusion coefficient of species } i, \mathrm{~cm}^{2} / \mathrm{sec} \\
& \nabla=\text { del operator } \\
& \nabla^{2}=\text { Laplacian operator } \\
& t_{i}=\frac{z_{i}^{2} u_{i} c_{i}}{\sum_{j} z_{j}^{2} u_{j} c_{j}}=\text { transference number of species } i \\
& z_{i}=\text { charge of species } i \\
& u_{i}=\frac{D_{i}}{R T}=\text { mobility of species } i, \text { where } R=\text { gas constant and } T=\text { temperature }(\mathrm{K}) \\
& n=\text { species being determined using electroneutrality equation. }
\end{aligned}
$$

\section{b. Electroneutrality equation for species $n$ :}

$$
z_{n} c_{n}=-\sum_{j \neq n} z_{j} c_{j}
$$

(3) Solution of the multicomponent diffusion equation(s) and the local electroneutrality equation in the radial direction in the grains of both regions I and II (same as step 2, but using spherical coordinates).

(4) Chemical re-equilibration of the entire system with respect to cation exchange. This step is accomplished by solving Equations 21 through 24 at each node in the simulation domain to ensure that the equilibrium expressions and the surface cation balance are locally satisfied. The system is assumed to always be at chemical equilibrium (i.e., reaction kinetics assumed to be fast relative to transport rates).

\section{E3.2.3 Results and Interpretations}

The experimental data and interpretive fits for the iodide-only tests conducted in cores 1 and 2 (three in each core) are shown in Figures E-31 and E-32, respectively. Tables E-14 and E-15 list the transport parameters associated with the fits shown in these figures. It is apparent that RELAP offered good simultaneous fits to the three data sets.

The experimental data and associated MULTRAN V 1.0 (STN: 10666-1.0-00 [DIRS 159068]) fits for Tests 1 and 3 in the Upper Prow Pass Tuff core (Core 1) are shown in Figure E-33. MULTRAN fits to the multiple-tracer tests in Cores 2, 3, and 4 (two tests in each core) are shown in Figures E-34, E-35, and, E-36, respectively. Table E-16 lists the transport parameters associated with the fits to the tracer responses in Cores 1 and 2, and Table E-17 lists the parameters associated with the fits to the responses in Cores 3 and 4. The $\mathrm{Br}^{-}$and PFBA responses in the two tests in each core were first fitted simultaneously using RELAP V 2.0 
(STN: 10551-2.0-00 [DIRS 159065]) (i.e., a total of four responses were fitted simultaneously, two from each test). The RELAP fits were executed only up to the time of a flow interruption (which was introduced in several of the tests). For these fits, the Peclet numbers and tracer matrix-diffusion parameters were constrained to be the same for both tests, and the mean residence times were constrained to be inversely proportional to the flow rates in the tests. The fracture spacing was also manually varied to improve the simultaneous fits to the tracer responses; this was justified because the residence times in the low-flow-rate tests were long enough for tracers to potentially diffuse to the epoxy sealing the periphery of the fractured cores, which should serve as a diffusion boundary. The parameters resulting from the RELAP fits were then used in MULTRAN with only the ion-exchange parameters, $Q_{1}$ and $Q_{2}$, being varied to achieve a match to the $\mathrm{Li}^{+}, \mathrm{Na}^{+}$, and $\mathrm{Ca}^{2+}$ responses.

Figures E-33 through E-36 indicate that MULTRAN V 1.0 (STN: 10666-1.0-00 [DIRS 159068]) was able to simulate very effectively the responses of all tracers in each multiple-tracer test in each core. The finite fracture spacing used in both the RELAP V 2.0 (STN: 10551-2.0-00 [DIRS 159065]) and MULTRAN simulations was found to be essential for obtaining a reasonable simultaneous fit to the tracer responses at the two significantly different flow rates in each core, suggesting that diffusion boundaries played an important role at the lower flow rates.

The matrix-diffusion, MTCs for $\mathrm{Br}^{-}$in the first two cores were surprisingly much smaller than the MTCs obtained for iodide in these two cores. In theory, these two halides should have very similar diffusion properties. However, the apparent dispersivities and deduced fracture apertures in the two cores were both larger in the multiple-tracer tests than in the iodide-only tests. Larger apertures directly decrease MTCs, and larger dispersivities indirectly decrease MTCs because greater dispersion results in longer-tailed and lower-peaked tracer responses, both of which matrix diffusion also produces. The greater apparent dispersion and lower apparent matrix diffusion in the multiple-tracer tests relative to the iodide-only tests cannot be explained. However, it is possible that microbial growth or small geometry changes in the flow systems could have played a role because the iodide-only tests were conducted well before the multiple-tracer tests in both cores. An inherent fundamental difference in the transport behavior of $\mathrm{Br}^{-}$and iodide can be ruled out because these two tracers behaved almost identically in the multiple- tracer tests in which both were injected simultaneously ( 8 of the 11 multiple tracer tests -Tables E-9 and E-11 to E-13). Another more subtle explanation could be that the iodide tests were conducted only at what would be considered the higher flow rates in the multiple-tracer tests, raising the possibility that tests conducted at higher flow rates could be biased toward greater apparent matrix diffusion because of a greater influence of diffusion into stagnant free water in the fractures or other time-scale effects (Section E4). 

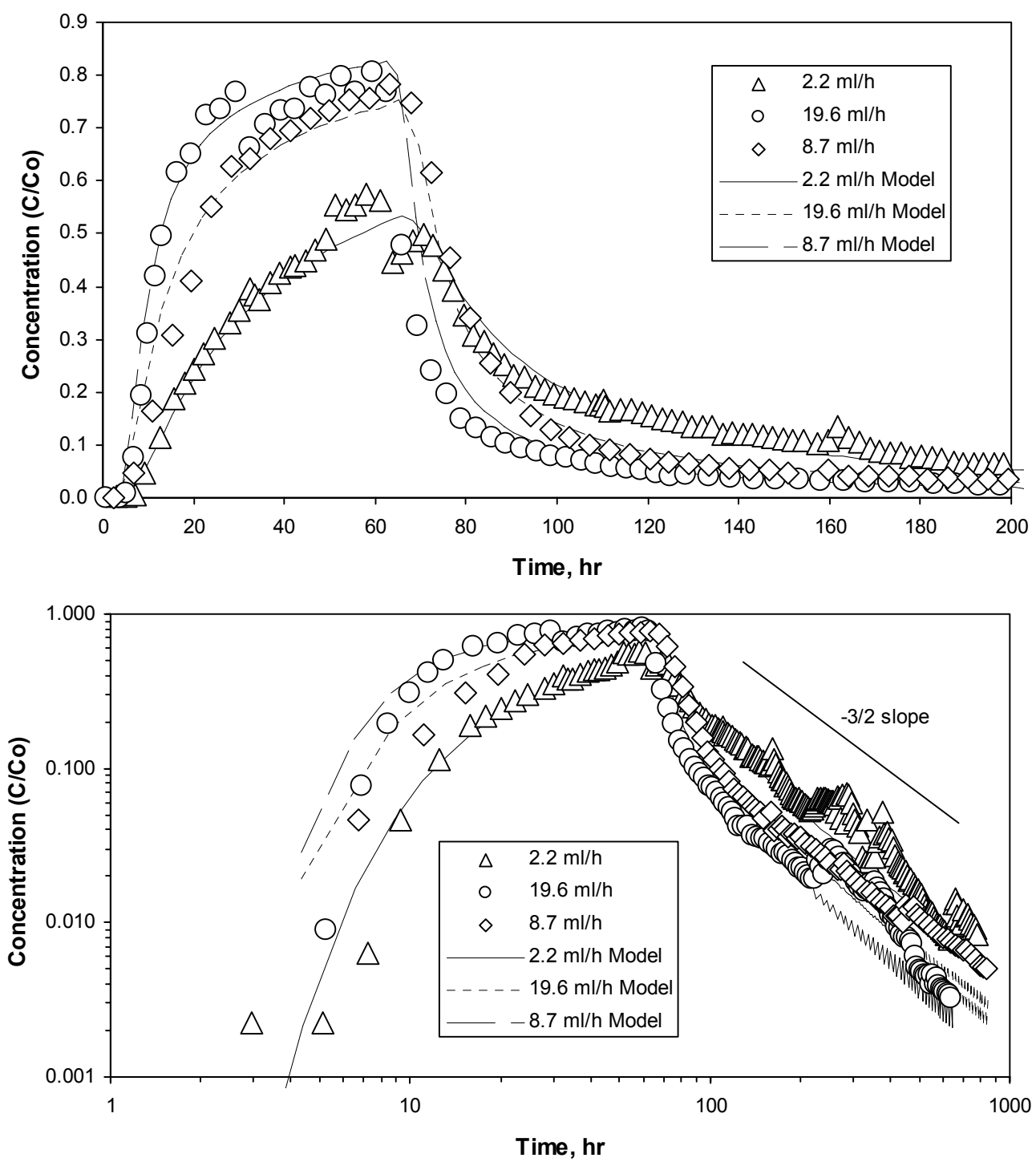

Source: DTN: LA0212PR831231.001 [DIRS 162607] (data).

Output DTN: LA0303PR831361.004 (fits).

NOTE: All three data sets were used to simultaneously fit $\tau, P e$, and $M T C$. Concentrations are normalized to injection concentration. Lower plot is same as upper plot except with log scales for the $\mathrm{x}$ - and $\mathrm{y}$-axes. The $-3 / 2$ slope on the log-log plot is the expected slope for a system experiencing single-rate matrix diffusion. "Model" refers to theRELAP simulation/fits.

Figure E-31. Experimental and Simulation Results from the Three lodide-Only Transport Tests in Core 1 

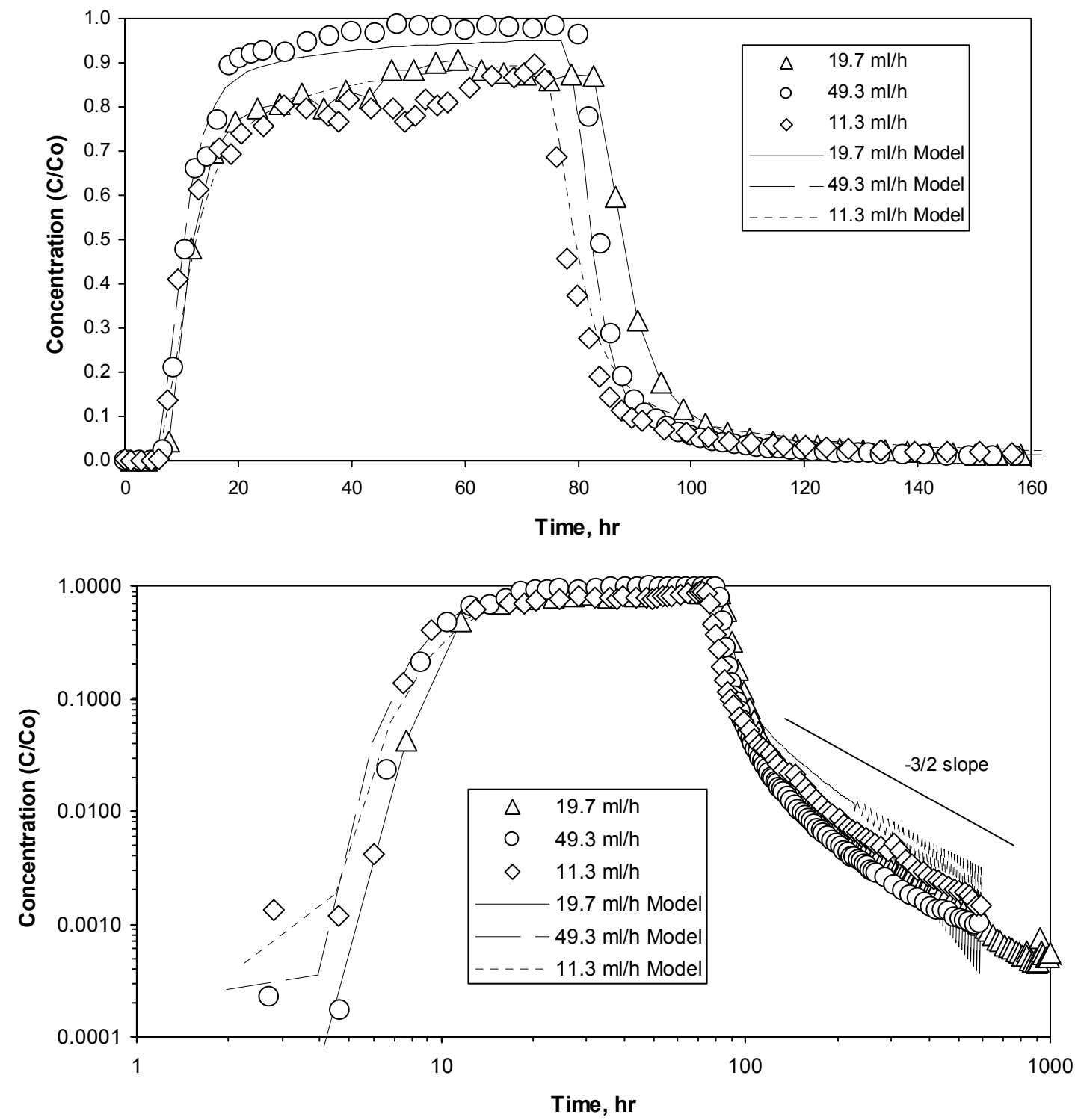

Source: DTN: LA0212PR831231.001 [DIRS 162607] (data).

Output DTN: LA0303PR831361.004 (fits).

NOTE: All three data sets were used to simultaneously fit $\tau$, Pe, and MTC. Concentrations are normalized to injection concentration. Lower plot is same as upper plot except with log scales for the $x$ - and $y$-axes.

The $-3 / 2$ slope on the log-log plot is the expected slope for a system experiencing single-rate matrix diffusion. "Model" refers to theRELAP simulation/fits.

Figure E-32. Experimental and Simulation Results from the Three lodide-Only Transport Tests in Core 2 
Table E-14. Simulation Results for the Three lodide Tracer Tests in Upper Prow Pass Tuff Core (Core 1)

\begin{tabular}{|c|c|c|c|}
\hline Fitted Transport Parameters ${ }^{(a)}$ & Test 1 & Test 2 & Test 3 \\
\hline Solute mean residence time, $\tau(\mathrm{hr})$ & 3.0 & 0.34 & 0.76 \\
\hline Peclet number, $P e$ & \multicolumn{3}{|c|}{18} \\
\hline Mass transfer coefficient, $M T C=\frac{\phi}{b} \sqrt{D_{m}}\left(\mathrm{hr}^{-0.5}\right)$ & \multicolumn{3}{|c|}{$1.56\left(I^{-}\right)$} \\
\hline Fracture aperture, $2 b(\mathrm{~cm})^{(\mathrm{b})}$ & \multicolumn{3}{|c|}{0.043} \\
\hline Dispersivity in fracture, $\alpha=\frac{L}{P e}(\mathrm{~cm})$ & \multicolumn{3}{|c|}{0.89} \\
\hline Matrix diffusion coefficient, $D_{m}\left(\times 10^{-10} \mathrm{~m}^{2} / \mathrm{s}\right)^{(\mathrm{c})}$ & \multicolumn{3}{|c|}{$4.3\left(\mathrm{I}^{-}\right)$} \\
\hline
\end{tabular}

Output DTNs: LA0303PR831361.004; LA0303PR831231.005.

${ }^{a}$ The three $\mathrm{I}^{-}$data sets were fit simultaneously assuming $P e$ was the same for the three tests and $\tau$ was inversely proportional to the volumetric flow rate.

${ }^{\mathrm{b}}$ Based on the relationship $b=\frac{Q \tau}{L w}$, where $\tau$ is the solute mean residence time.

${ }^{c}$ Determined from the MTC using the measured $\phi$ and the calculated $b$.

MTC=mass transfer coefficient

Table E-15. Simulation Results for the Three lodide Tracer Tests in Central Prow Pass Tuff Core (Core 2)

\begin{tabular}{|c|c|c|c|}
\hline Fitted Transport Parameters ${ }^{(a)}$ & Test 1 & Test 2 & Test 3 \\
\hline Solute mean residence time, $\tau(\mathrm{hr})$ & 0.48 & 0.19 & 0.84 \\
\hline Peclet number, $\mathrm{Pe}$ & \multicolumn{3}{|c|}{24} \\
\hline Mass transfer coefficient, $M T C=\frac{\phi}{b} \sqrt{D_{m}}\left(\mathrm{hr}^{-0.5}\right)$ & \multicolumn{3}{|c|}{$0.518\left(I^{-}\right)$} \\
\hline Fracture aperture, $2 b(\mathrm{~cm})^{(\mathrm{b})}$ & \multicolumn{3}{|c|}{0.058} \\
\hline Dispersivity in fracture, $\alpha=\frac{L}{P e}(\mathrm{~cm})$ & \multicolumn{3}{|c|}{0.72} \\
\hline Matrix diffusion coefficient, $D_{m}\left(\times 10^{-10} \mathrm{~m}^{2} / \mathrm{s}\right)^{(\mathrm{c})}$ & \multicolumn{3}{|c|}{$3.2\left(I^{-}\right)$} \\
\hline
\end{tabular}

Output DTNs: LA0303PR831361.004; LA0303PR831231.005.

${ }^{a}$ The three $\mathrm{I}^{-}$data sets were fit simultaneously assuming $P e$ was the same for the three tests and $\tau$ was inversely proportional to the volumetric flow rate.

${ }^{\mathrm{b}}$ Based on the relationship $b=\frac{Q \tau}{L w}$, where $\tau$ is the solute mean residence time.

${ }^{c}$ Determined from the MTC using the measured $\phi$ and the calculated $b$.

MTC=mass transfer coefficient. 

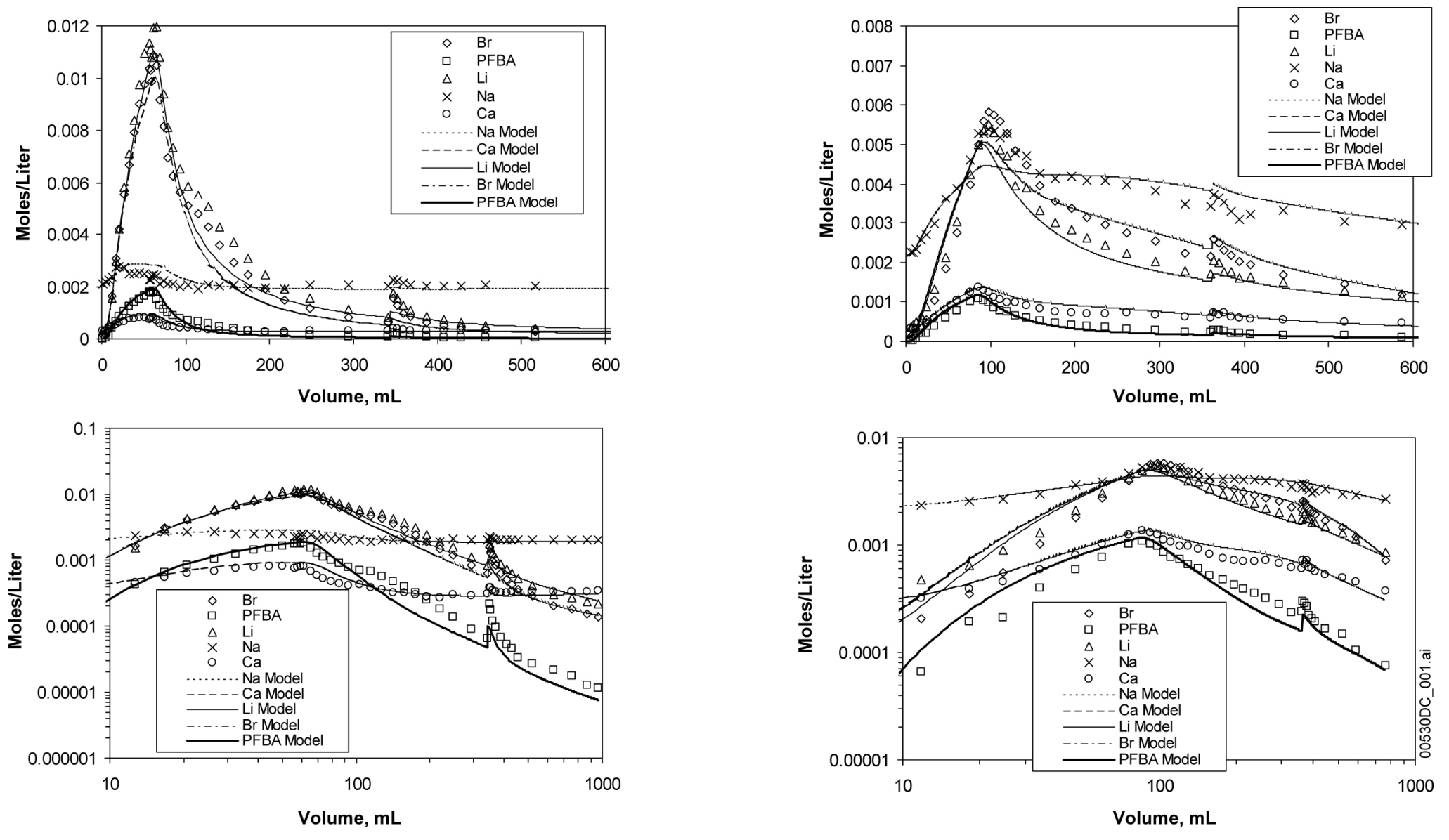

Test 1

Test 3

Source: DTNs: LA0212PR831231.003 [DIRS 162609] (Li, Br, PFBA data); LA0212PR831231.005 [DIRS 166215] (Na, Ca data).

Output DTN: LA0303PR831361.004 (simulations).

NOTE: The jumps in the concentrations and in the model curves correspond to flow interruptions in the tests. The flow rate in Test 1 (left) was $3.9 \mathrm{~mL} / \mathrm{h}$, and the flow rate in Test 3 (right) was $0.51 \mathrm{~mL} / \mathrm{h}$. The $B r$ and PFBA data were fit simultaneously by constraining the $\mathrm{D}_{\mathrm{m}}$ ratio for Br:PFBA to 3:1. "Model" refers to MULTRAN simulations.

Figure E-33. Experimental Data and MULTRAN Simulation Results for Multiple Tracer Tests 1 and 3 in the Upper Prow Pass Tuff Core (Core 1) 

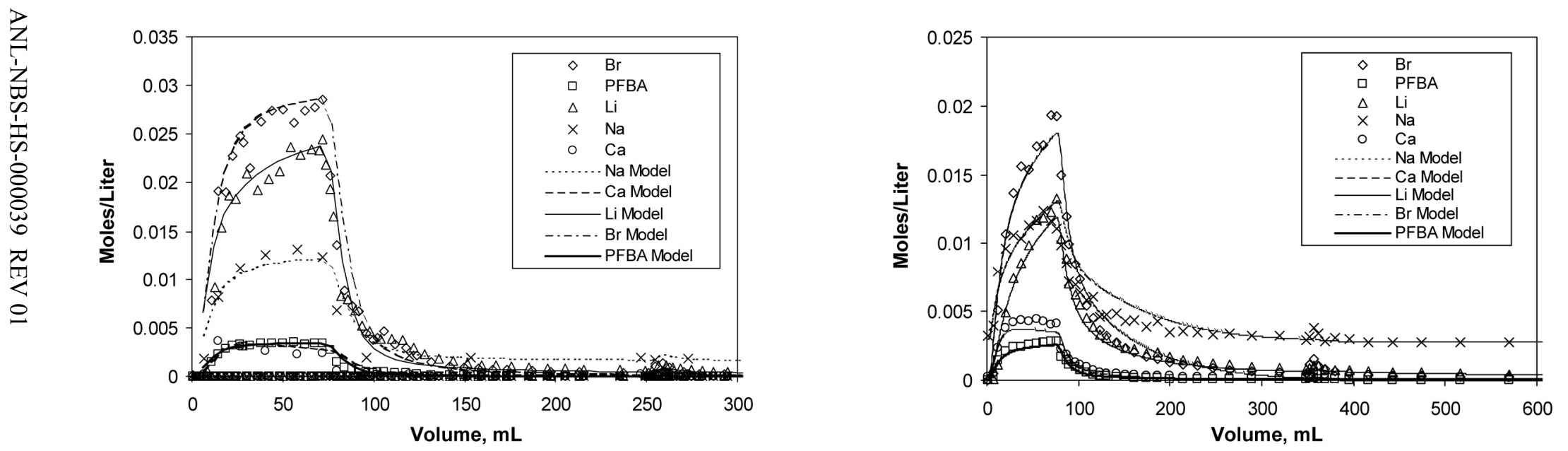

\footnotetext{
Source: DTNs: LA0212PR831231.002 [DIRS 162608] (Na, Ca data); LA0212PR831231.005 [DIRS 166215] (Li, Br, PFBA data).

Output DTN: LA0303PR831361.004 (simulations).

NOTE: The jumps in the concentrations and in the model curves correspond to flow interruptions in the tests. The flow rate in Test 1 (left) was $5.9 \mathrm{~mL} / \mathrm{h}$, and the flow rate in Test 2 (right) was $0.44 \mathrm{~mL} / \mathrm{h}$. The $\mathrm{Br}^{-}$and PFBA data were fit simultaneously by constraining the $\mathrm{D}_{\mathrm{m}}$ ratio for Br:PFBA to 3:1. "Model" refers to MULTRAN simulations.

Figure E-34. Experimental Data and MULTRAN Simulation Results for Multiple Tracer Tests 1 and 2 in the Central Prow Pass Tuff Core (Core 2)
} 

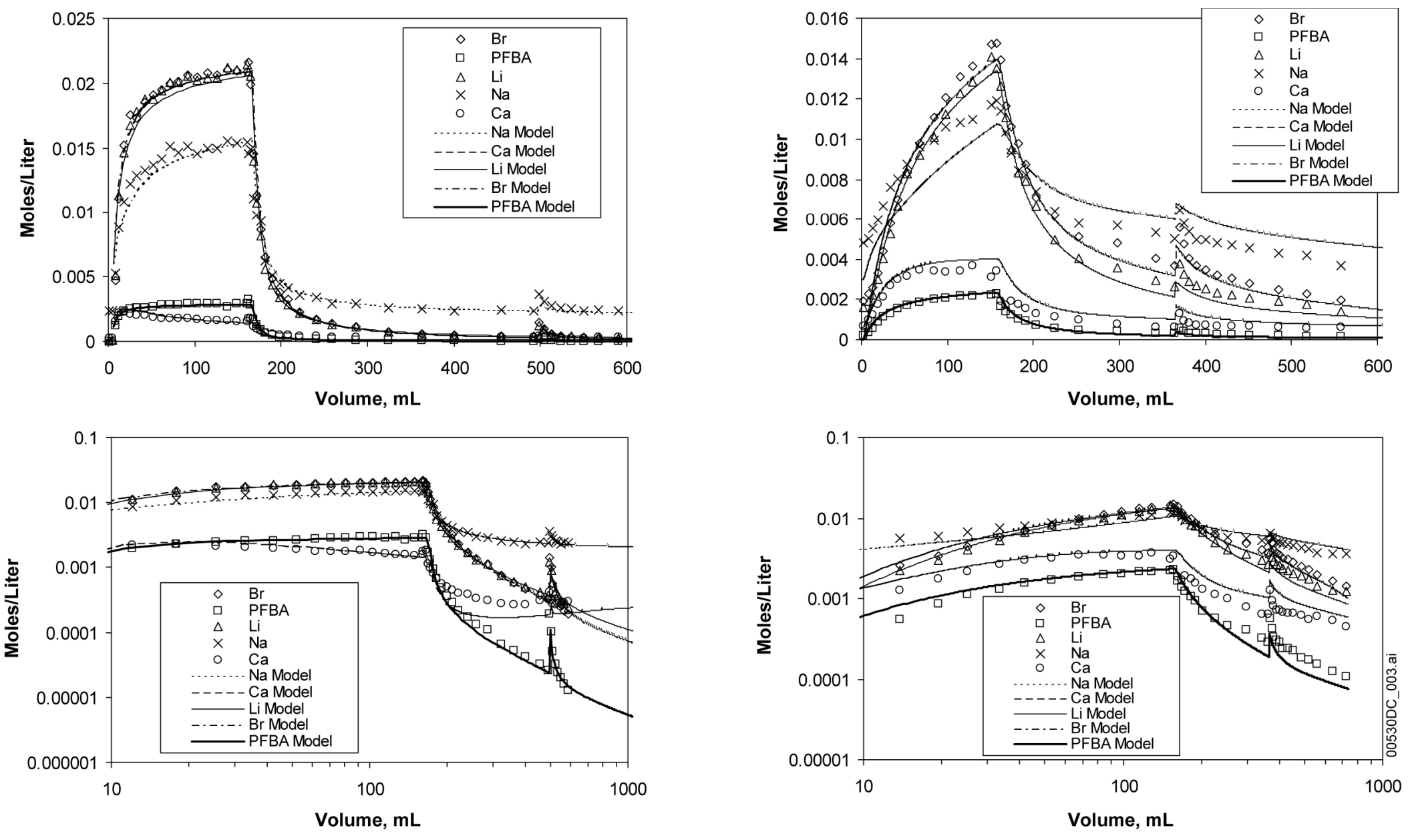

Test 1

Test 2

Source: DTNs: LA0212PR831231.002 [DIRS 162608] (Na, Ca data); LA0212PR831231.003 [DIRS 162609] (Li, Br, PFBA data).

Output DTN: LA0303PR831361.004 (simulations).

NOTE: The jumps in the concentrations and in the model curves correspond to flow interruptions in the tests. The flow rate in Test 1 (left) was $11.4 \mathrm{~mL} / \mathrm{h}$, and the flow rate in Test 2 (right) was $0.46 \mathrm{~mL} / \mathrm{h}$. The Br and PFBA data were fit simultaneously by constraining the $D_{m}$ ratio for Br:PFBA to 3:1. "Model" refers to MULTRAN simulations.

Figure E-35. Experimental Data and MULTRAN Simulation Results for Multiple Tracer Tests 1 and 2 in the Lower Prow Pass Tuff Core (Core 3 ) 
Table E-16. Best-Fit Model Parameters for the Multiple-Tracer Tests Conducted in Cores 1 and 2

\begin{tabular}{|c|c|c|c|c|}
\hline Modeling Parameters & $\begin{array}{l}\text { Core } 1 \text {, } \\
\text { Test } 1\end{array}$ & $\begin{array}{l}\text { Core 1, } \\
\text { Test } 3\end{array}$ & $\begin{array}{l}\text { Core } 2 \text {, } \\
\text { Test } 1\end{array}$ & $\begin{array}{l}\text { Core 2, } \\
\text { Test } 1\end{array}$ \\
\hline Porosity of matrix & 0.27 & 0.27 & 0.14 & 0.14 \\
\hline Solute mean residence time, $\tau(\mathrm{hr})^{a}$ & 5.4 & 40.2 & 1.95 & 26.1 \\
\hline Peclet number, $P e^{a}$ & 4.0 & 4.0 & 3.5 & 3.5 \\
\hline Dispersivity in fracture, $\alpha=\frac{L}{P e}(\mathrm{~cm})$ & 4.0 & 4.0 & 5.0 & 5.0 \\
\hline $\mathrm{Li}^{+}$Retardation factor, $R^{\mathrm{a}}$ & 2.25 & 1.1 & 4.2 & 5.9 \\
\hline $\mathrm{Li}^{+}$Partition coefficient, $K_{\mathrm{d}}(\mathrm{L} / \mathrm{kg})$ & 0.17 & 0.014 & 0.19 & 0.30 \\
\hline $\begin{array}{l}\text { Mass transfer coefficient }{ }^{\mathrm{a}} \\
M T C=\frac{\phi}{b} \sqrt{D_{m}}\left(\mathrm{hr}^{-0.5}\right)\end{array}$ & $\begin{array}{l}0.80\left(\mathrm{Br}^{-}\right) \\
0.46(\mathrm{PFBA})\end{array}$ & $\begin{array}{l}0.80\left(\mathrm{Br}^{-}\right) \\
0.46(\mathrm{PFBA})\end{array}$ & $\begin{array}{l}0.21\left(\mathrm{Br}^{-}\right) \\
0.12(\mathrm{PFBA})\end{array}$ & $\begin{array}{l}0.21\left(\mathrm{Br}^{-}\right) \\
0.12(\mathrm{PFBA})\end{array}$ \\
\hline Fracture aperture, $2 b(\mathrm{~cm})^{\mathrm{b}}$ & 0.134 & 0.134 & 0.07 & 0.07 \\
\hline $\begin{array}{l}\text { Distance to diffusion boundary (fracture half } \\
\text { spacing), }(\mathrm{cm})\end{array}$ & 1.9 & 1.9 & 0.9 & 0.9 \\
\hline $\begin{array}{l}\text { Matrix diffusion coefficient }{ }^{\mathrm{c}}, D_{m}\left(\times 10^{-10}\right. \\
\left.\mathrm{m}^{2} / \mathrm{s}\right)\end{array}$ & $\begin{array}{l}11.0\left(\mathrm{Br}^{-}\right) \\
3.7(\mathrm{PFBA})\end{array}$ & $\begin{array}{l}11.0\left(\mathrm{Br}^{-}\right) \\
3.7(\mathrm{PFBA})\end{array}$ & $\begin{array}{l}0.8\left(\mathrm{Br}^{-}\right) \\
0.27(\mathrm{PFBA})\end{array}$ & $\begin{array}{l}0.8\left(\mathrm{Br}^{-}\right) \\
0.27(\text { PFBA })\end{array}$ \\
\hline CEC (meq/kg), Measured & 19.9 & 19.9 & 43.2 & 43.2 \\
\hline$Q_{1}{ }^{d}$ & 0.05 & 0.025 & 10.2 & 6.0 \\
\hline$Q_{2}{ }^{d}$ & 0.079 & 0.04 & 3.0 & 0.45 \\
\hline
\end{tabular}

Source: DTN: MO00012POROCHOL.000 [DIRS 153376] (for porosity).

Output DTNs: LA0303PR831361.004 (model results); LA0303PR831231.005.

NOTE: Cores 1 and 2 are shown in Figures E-31 through E-34.

${ }^{a}$ Parameters obtained using RELAP to fit simultaneously the $\mathrm{Br}^{-}$and PFBA data from the two tests for a given core with the constraint that the $D_{m}$ ratio for Br:PFBA was 3:1. The matrix diffusion coefficient for $\mathrm{Li}^{+}$was assumed to be two-thirds the value for $\mathrm{Br}^{-}$.

${ }^{\mathrm{b}}$ Based on the relationship $b=\frac{Q \tau}{L w}$, where $\tau$ is the solute mean residence time.

${ }^{c}$ Determined from the MTC using the measured $\phi$ and the calculated $b$.

"Equilibrium ion-exchange coefficients, obtained using MULTRAN to manually "fit" the $\mathrm{Li}^{+}, \mathrm{Na}^{+}$, and $\mathrm{Ca}^{2+}$ data for each test.

MTC=mass transfer coefficient; PFBA= pentafluorobenzoic acid or pentafluorobenzoate . 

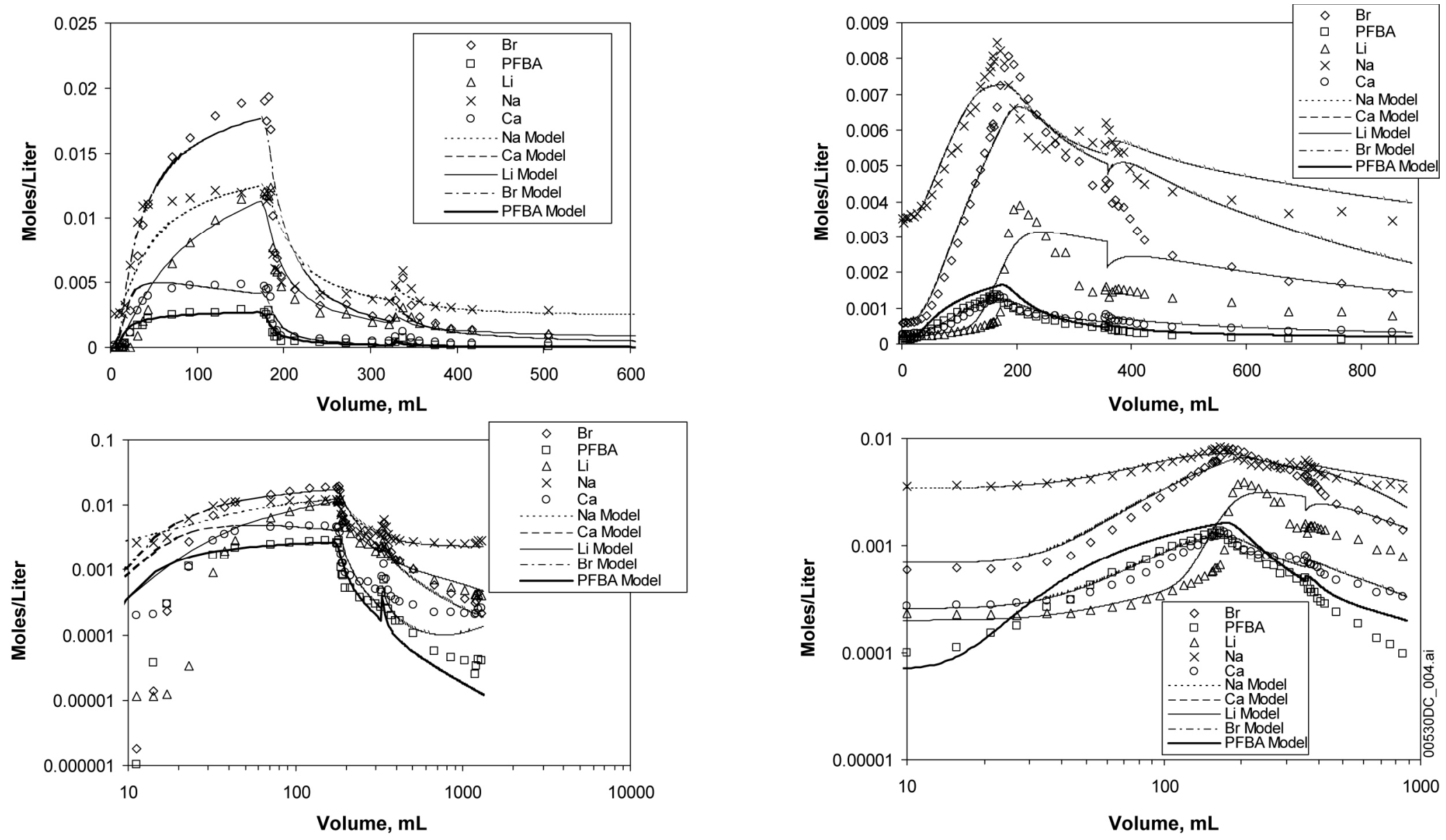

Test 1

Test 2

Source: DTNs: $\quad$ LA0212PR831231.002 [DIRS 162608] (Na, Ca data - Test 1); LA0212PR831231.005 [DIRS 166215] (Na, Ca data - Test 2); LA0212PR831231.003 [DIRS 162609] (Li, Br, PFBA data).

NOTE: The jumps in the concentrations and in the model curves correspond to flow interruptions in the tests. The flow rate in Test 1 (left) was $4.85 \mathrm{~mL} / \mathrm{h}$, and the flow rate in Test 2 (right) was $0.47 \mathrm{~mL} / \mathrm{h}$. The Br and PFBA data were fit simultaneously by constraining the $D_{m}$ ratio for Br:PFBA to 3:1. "Model" refers to MULTRAN simulations.

Figure E-36. Experimental Data and MULTRAN Simulations Results for Multiple Tracer Tests 1 and 2 in the Lower Bullfrog Tuff Core (Core 4). 
The ion exchange parameters, $Q_{1}$ and $Q_{2}$, exhibited a curious decreasing trend from the first to the second multiple-tracer test in each core, suggesting that some $\mathrm{Li}^{+}$may have become irreversibly sorbed in the first test and reduced the sorption capacity for $\mathrm{Li}^{+}$in subsequent tests. This speculation is consistent with the incomplete recovery of $\mathrm{Li}^{+}$in each test. In any case, the $\mathrm{Li}^{+}$sorption isotherms calculated from the ion-exchange parameters deduced from MULTRAN V 1.0 (STN: 10666-1.0-00 [DIRS 159068]) fits were generally higher than or comparable to the sorption isotherms derived from batch $\mathrm{Li}^{+}$sorption experiments (Figure E-37).

It is important to point out that the best-fitting values of the ion-exchange parameters $Q_{1}$ and $Q_{2}$ in the MULTRAN V 1.0 (STN: 10666-1.0-00 [DIRS 159068]) simulations were somewhat sensitive to the background concentrations specified for all three cations in the system. These background concentrations were chosen to match the concentrations measured in the first one or two samples collected in each experiment (prior to the arrival of the tracers), which generally differed slightly from one experiment to the next in a given core. There were also significant differences in the relative amounts of cations and the overall ionic strengths of the tracer solutions used in different experiments, which could have affected the experimental and simulation results. One notable difference in the cation mix occurred as a result of using either $\mathrm{NaOH}$ or $\mathrm{LiOH}$ to neutralize the PFBA in the tracer solutions (if a stoichiometric amount of $\mathrm{OH}^{-}$ was not added, the $\mathrm{pH}$ of the tracer solutions was $<2$ ). These differences in cation mix and ionic strength were accounted for in the MULTRAN inputs, but any "memory" effects resulting from the use of significantly different tracer solutions in consecutive experiments, which could affect the pre-experiment mix of cations sorbed to mineral surfaces, were not accounted for. It is possible that if these factors had been accounted for, the $Q_{1}$ and $Q_{2}$ values from consecutive experiments may have been in better agreement.

It was also found that reasonable matches to the cation responses in the cores could be obtained using almost any value of the CEC greater than some threshold, provided that $Q_{1}$ and $Q_{2}$ were both adjustable. This nonuniqueness problem was avoided by setting the CEC values in all MULTRAN V 1.0 (STN: 10666-1.0-00 [DIRS 159068]) simulations equal to the laboratory measurements for each tuff. However, if the effective CEC value had been reduced for each subsequent experiment in each core (because of some irreversible sorption of $\mathrm{Li}^{+}$), then the $Q_{1}$ and $Q_{2}$ values would have been higher in the later experiments, which would have brought them into better agreement with the values in earlier experiments.

Although not all of the experimental and simulation results can be completely explained, Figure E-38 shows that the use of the multicomponent ion-exchange MULTRAN V 1.0 (STN: 10666-1.0-00 [DIRS 159068]) code offers a significant improvement over the single-component RELAP V 2.0 (STN: 10551-1.0-00 [DIRS 159065]) code in simulating the responses of ion-exchanging tracers in dual-porosity systems. This improvement is especially pronounced when there is a large amount of sorption in the matrix, as there is for the Lower Bullfrog Tuff core (Figure E-38). 

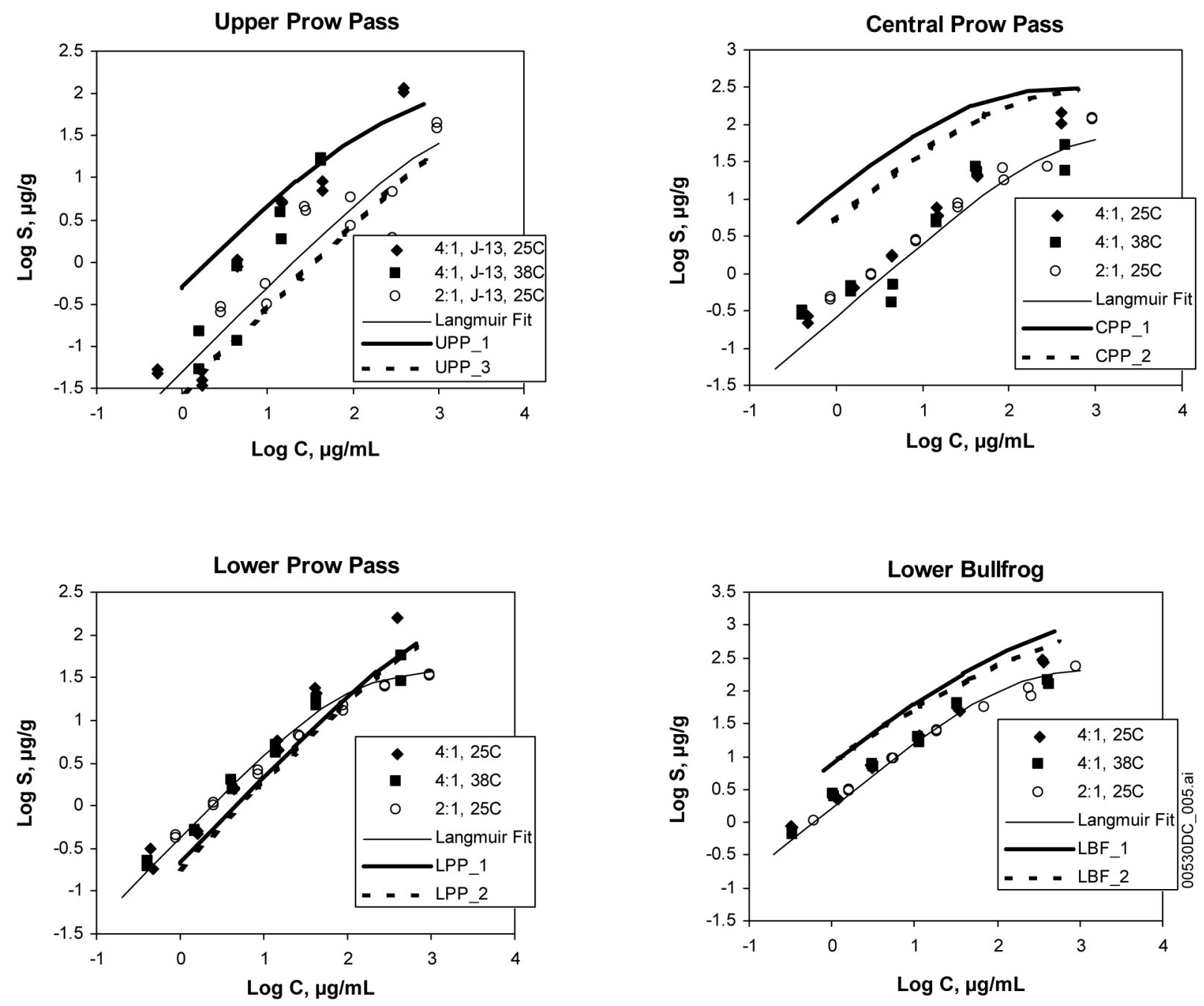

Source: DTN: MO0012SORBCHOL.000 [DIRS 153375] (data).

Output DTN: LA0303PR831341.003 (isotherms).

Figure E-37. Comparison of $\mathrm{Li}+$ Isotherms Calculated from Best-Fitting MULTRAN Parameters (Designated by XXX_Y, where $Y$ is the Fractured Core Test Number) and Obtained in Batch Sorption Experiments for the Four Different C-wells Tuffs Used in the Fracture Experiments 
Table E-17. Best-Fit Transport Parameters for the Multiple-Tracer Tests Conducted in Cores 3 and 4

\begin{tabular}{|c|c|c|c|c|}
\hline Transport Parameters & $\begin{array}{l}\text { Core } 3 \text {, } \\
\text { Test } 1\end{array}$ & $\begin{array}{l}\text { Core } 3 \text {, } \\
\text { Test } 2\end{array}$ & $\begin{array}{l}\text { Core 4, } \\
\text { Test } 1\end{array}$ & $\begin{array}{l}\text { Core 4, } \\
\text { Test } 2\end{array}$ \\
\hline Porosity of matrix & 0.29 & 0.29 & 0.30 & 0.30 \\
\hline Solute mean residence time, $\tau(\mathrm{hr})^{\mathrm{a}}$ & 0.55 & 13.6 & 2.0 & 21.3 \\
\hline Peclet number, $P e^{a}$ & 4.5 & 4.5 & 130 & 130 \\
\hline Dispersivity in fracture, $\alpha=\frac{L}{P e}(\mathrm{~cm})$ & 2.6 & 2.6 & 0.09 & 0.09 \\
\hline $\mathrm{Li}^{+}$Retardation factor, $R^{\mathrm{a}}$ & 1.3 & 1.6 & 9.2 & 8.2 \\
\hline $\mathrm{Li}^{+}$Partition coefficient, $K_{d}(\mathrm{~L} / \mathrm{kg})$ & 0.046 & 0.092 & 1.33 & 1.16 \\
\hline $\begin{array}{l}\text { Mass transfer coefficient }{ }^{\mathrm{a}} \text {, } \\
M T C=\frac{\phi}{b} \sqrt{D_{m}}\left(\mathrm{hr}^{-0.5}\right)\end{array}$ & $\begin{array}{l}1.32\left(\mathrm{Br}^{-}\right) \\
0.76(\mathrm{PFBA})\end{array}$ & $\begin{array}{l}1.32\left(\mathrm{Br}^{-}\right) \\
0.76(\mathrm{PFBA})\end{array}$ & $\begin{array}{l}1.45\left(\mathrm{Br}^{-}\right) \\
0.84(\mathrm{PFBA})\end{array}$ & $\begin{array}{l}1.45\left(\mathrm{Br}^{-}\right) \\
0.84(\mathrm{PFBA})\end{array}$ \\
\hline Fracture aperture, $2 b(\mathrm{~cm})^{\mathrm{b}}$ & 0.057 & 0.057 & 0.049 & 0.049 \\
\hline $\begin{array}{l}\text { Distance to diffusion boundary (fracture half } \\
\text { spacing), }(\mathrm{cm})\end{array}$ & 4.4 & 4.4 & 4.6 & 4.6 \\
\hline $\begin{array}{l}\text { Matrix diffusion coefficient }{ }^{\mathrm{c}}, D_{m}\left(\times 10^{-10}\right. \\
\left.\mathrm{m}^{2} / \mathrm{s}\right)\end{array}$ & $\begin{array}{l}4.6\left(\mathrm{Br}^{-}\right) \\
1.5(\mathrm{PFBA})\end{array}$ & $\begin{array}{l}4.6\left(\mathrm{Br}^{-}\right) \\
1.5(\mathrm{PFBA})\end{array}$ & $\begin{array}{l}3.8\left(\mathrm{Br}^{-}\right) \\
1.3(\mathrm{PFBA})\end{array}$ & $\begin{array}{l}3.8\left(\mathrm{Br}^{-}\right) \\
1.3\left(\mathrm{PFBA}^{-}\right)\end{array}$ \\
\hline CEC (meq/kg), Measured & 31.9 & 31.9 & 179.7 & 179.7 \\
\hline$Q_{1}^{d}$ & 0.1 & 0.085 & 6.0 & $0.2^{d}$ \\
\hline$Q_{2}{ }^{d}$ & 0.08 & 0.035 & 0.3 & $0.12^{d}$ \\
\hline
\end{tabular}

Source: DTN: MO00012POROCHOL.000 [DIRS 153376] (for porosity).

Output DTNs: LA0303PR831361.004 (simulation results), LA0303PR831231.005.

NOTE: $\quad$ Cores 3 and 4 are shown in Figures E-35 and E-36.

a Parameters obtained using RELAP V 2.0 (STN: 10551-2.0-00 [DIRS 159065]) to simultaneously fit the $\mathrm{Br}^{-}$and PFBA data from the two tests for a given core with the constraint that the $D_{m}$ ratio for Br:PFBA was 3:1. The matrix diffusion coefficient for $\mathrm{Li}^{+}$was assumed to be $2 / 3$ the value for $\mathrm{Br}^{-}$.

${ }^{\mathrm{b}}$ Based on the relationship $b=\frac{Q \tau}{L w}$, where $\tau$ is the solute mean residence time.

${ }^{c}$ Determined from the MTC using the measured $\phi$ and the calculated $b$.

${ }^{d}$ Equilibrium ion exchange coefficients, obtained using MULTRAN V 1.0 (STN: 10666-1.0-00 [DIRS 159068]) to manually "fit" the $\mathrm{Li}^{+}, \mathrm{Na}^{+}$, and $\mathrm{Ca}^{2+}$ data for each test.

e The MULTRAN V 1.0 (STN: 10666-1.0-00 [DIRS 159068]) "fit" shown for Core 4, Test 2 in Figure E-36 was actually obtained assuming sorption in both the fracture and the matrix. The fracture was assumed to have a porosity of 0.9 , a CEC of $200 \mathrm{meq} / \mathrm{kg}, K_{1}=5.0$, and $K_{2}=50.0$. The matrix had a CEC of $179.7 \mathrm{meq} / \mathrm{kg}$, and $K_{1}$ $=K_{2}=0.0223$. The resulting fit was somewhat better than the fit assuming sorption only in the matrix.

MTC=mass transfer coefficient;PFBA=pentafluorobenzoic acid or pentafluorobenzoate. 


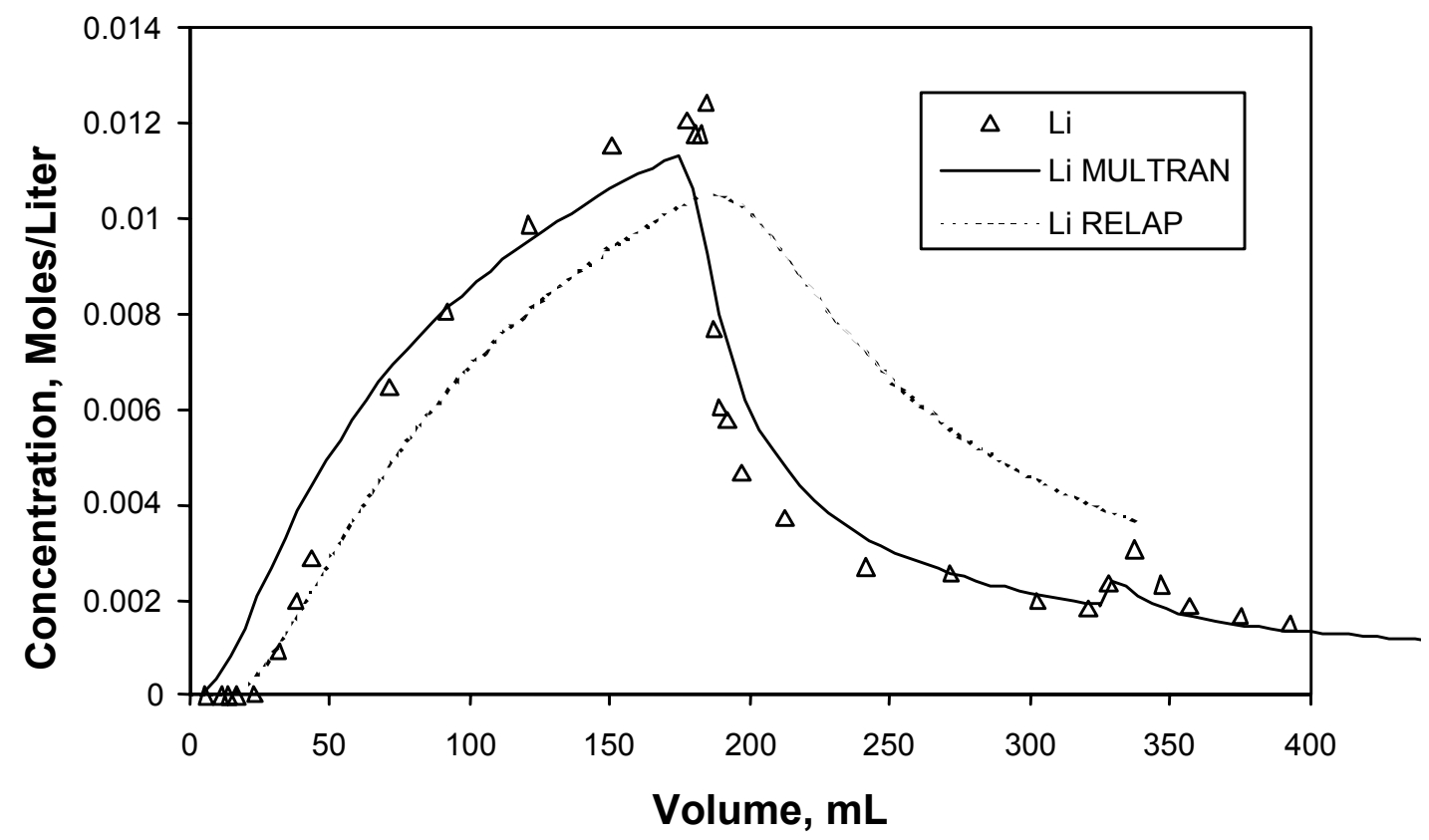

Source: DTN: LA0212PR831231.003 [DIRS 162609] (Li data).

Output DTN: LA0303PR831361.003 (simulations).

Figure E-38. Comparison of the Fits of the MULTRAN Multicomponent Ion-Exchange Model and the Single-Component RELAP Code to the Lithium Transport Data in the First Multiple-Tracer Test in Core 4

\section{E3.3 CONCLUSIONS REGARDING LITHIUM TRANSPORT EXPERIMENTS}

The lithium transport experiments in both crushed tuff columns and fractured tuff cores demonstrate the importance of accounting for multicomponent transport effects, particularly charge balance, when simulating and interpreting the transport behavior of an ion-exchanging cation tracer, especially when the tracer is the most abundant cation in solution. These experiments also indicate that sorption parameters derived from dynamic transport experiments tend to either agree quite well with those measured in batch sorption experiments or are somewhat greater than those measured in batch experiments (i.e., the batch experiments underpredict the amount of sorption observed in the dynamic transport experiments). This result is consistent with the comparison between field-derived sorption parameters and laboratory-derived batch sorption parameters (Section D4.8.4), and it lends additional credibility to the practice of using of laboratory-derived $K_{\mathrm{d}}$ values to predict radionuclide transport in saturated fractured tuffs near Yucca Mountain (suggesting that such predictions should, if anything, overestimate the transport rates of radionuclides). 


\section{E4. SCALE-DEPENDENCE OF TRANSPORT PARAMETERS IN FRACTURED TUFFS}

\section{E4.1 SCALE-DEPENDENCE OF LONGITUDINAL DISPERSIVITY}

A plot of the longitudinal dispersivity values as a function of test scale for several Nevada Test Site fractured-rock, tracer-test programs is shown in Figure E-39. The plot indicates that the longitudinal dispersivity increases with test scale that ranges from less than one meter to over 100 meters. Figure E-40 shows the range of longitudinal dispersivities as a function of scale derived from the $\mathrm{C}$-wells multiple-tracer tests (darkened area) superimposed on a plot of dispersivity versus scale prepared by Neuman (1990 [DIRS 101464], Figure 1). Note that the lower end of the range of length scales associated with the darkened area corresponds to the interwell separation in the tracer tests, and the upper end corresponds to the test interval thickness (used as an upper bound for the transport distance).

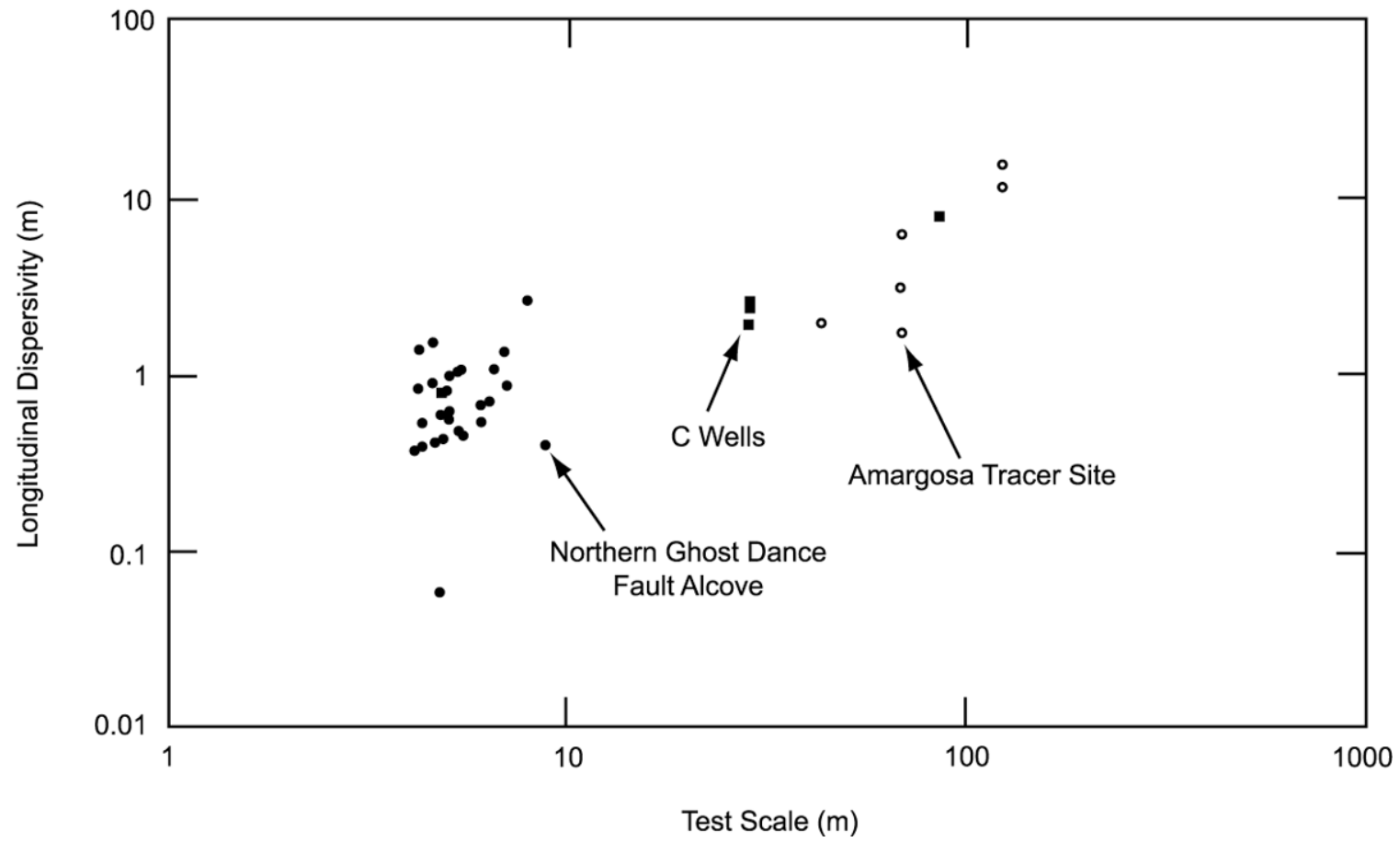

Source: LeCain et al. 2000 [DIRS 144612], Figure 19.

Figure E-39. Longitudinal Dispersivity as a Function of Test Scale in Several Tracer Tests Conducted in the Vicinity of Yucca Mountain 


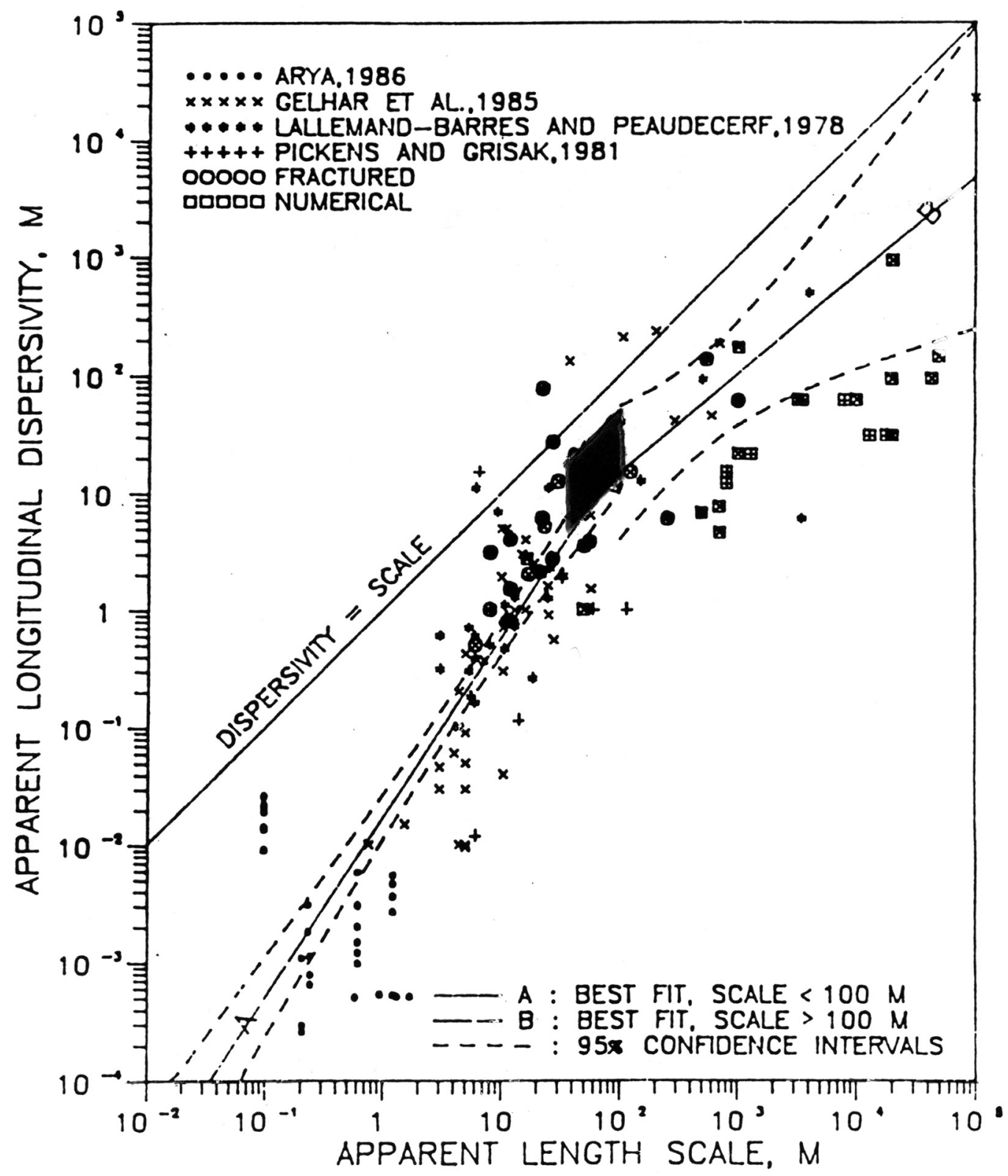

Source: Plot taken from Neuman 1990 [DIRS 101464], Figure 1.

Output DTN: LA0303PR831231.003 (dispersivities from C-wells).

NOTE: The darkened box shows the range of values derived from the multiple-tracer field tests at the $\mathrm{C}$-wells in which lithium ion was used as a sorbing tracer. The right edge of the box corresponds to the interwell separation distance, and the left edge of the box corresponds to the test interval thickness (taken to be the upper limit of transport distance).

Figure E-40. Plot of Longitudinal Dispersivity Versus Length Scale Showing the Range of C-Wells Values Derived from Interpretations of the Prow Pass and Bullfrog Multiple Tracer Tests in Which Lithium Ion Was Used as a Sorbing Tracer 


\section{E4.2 SCALE-DEPENDENCE OF MATRIX DIFFUSION}

There is some question about whether matrix diffusion parameters measured in laboratory-scale experiments can be used reliably in field-scale transport predictions. To address this issue, it is first of interest to compare the matrix diffusion coefficients measured in the diffusion cell tests of Section E2 with the diffusion coefficients calculated from the fractured-core tests of Section E3.2. Table E-18 shows that the Brmatrix diffusion coefficients deduced from the fractured-core experiments (from simultaneous RELAP V 2.0 (STN: 10551-2.0-00 [DIRS 159065]) fits to the $\mathrm{Br}^{-}$and PFBA responses at two different flow rates in each fracture) were consistently greater than the $\mathrm{Br}^{-}$diffusion coefficients obtained from the diffusion cell experiments. This result could be explained by the fact that matrix diffusion in the fractured cores was really a combination of diffusion into stagnant free water in the fractures (e.g., into voids along the rough walls of the fracture surfaces or into stagnant regions between flowing channels) and true diffusion into the matrix, whereas diffusion in the diffusion cell experiments, by design, occurred only in the matrix. The RELAP computer code interprets both free-water and matrix diffusion as matrix diffusion, so any free-water diffusion will tend to increase estimates of matrix diffusion coefficients (Callahan 2001 [DIRS 156649], Chapter 5). The time scales of the diffusion cell measurements also tended to be longer than in the fractured cores, which would have resulted in greater tracer penetration of the matrices and, hence, a more representative measurement of true matrix diffusion.

It is also of interest to compare matrix-diffusion MTCs derived from the fractured-core experiments (Section E3.2) with MTCs derived from the C-wells field tracer tests (Section D4.7). Such a comparison is provided in Figure E-41, which shows the laboratory and field MTCs plotted as a function of time scale in the tests. The MTCs derived from the laboratory experiments are plotted as lines that span the range of tracer residence times in the cores. It is apparent that the residence times in the iodide-only core experiments were shorter than in the multiple-tracer experiments, and there is a corresponding increase in the deduced MTC values in the iodide experiments. The MTCs from the field experiments are also plotted as lines that span the range of tracer residence times obtained assuming either linear or radial flow fields. Separate lines are plotted for the two pathways that resulted in the two tracer peaks in the Bullfrog Tuff field test.

It is clear that the MTCs collectively exhibit a decreasing trend with tracer residence times in Figure E-41. This trend is consistent with the notion that as time scales increase, more of the apparent diffusion will be true matrix diffusion and less will be diffusion into stagnant free water. However, it is also likely that effective fracture apertures over the 30-meter scales of the field tests were much larger than in the approximately 0.2 -meter-scale laboratory tests. Intuitively, one would expect that, as distance scales increase, there will be a higher probability of encountering larger-aperture fractures in which flow can occur. Larger apertures would have contributed to the decreasing trend of Figure E-41 because fracture apertures appear in the denominator of the MTC. Alternatively, matrix diffusion coefficients, which appear as a square-root term in the numerator of the MTC, would have to be nearly two orders of magnitude smaller in the field than in the lab to explain the trend of Figure E-41 if fracture apertures were held constant, which seems implausible. Similarly, matrix porosities, which appear in the numerator of the MTC, would have to be smaller by about a factor of 10 in the field to explain 
the observed trend if fracture apertures were held constant and matrix diffusion coefficients were assumed to be the same as in the lab experiments - also seemingly implausible.

One would expect an asymptotic lower limit to be reached eventually for the MTC in saturated fractured systems, given a long enough transport time or distance. However, for the $\mathrm{C}$-wells field system, the transport data suggest that this asymptotic value, if it exists, was not reached for characteristic transport times of up to approximately 1,200 hrs or travel distances of approximately $30 \mathrm{~m}$ (Figure E-41).

All of the test results discussed here are consistent with diffusive mass transfer having a strong influence on the migration of solutes in fractured volcanic tuffs. However, at short time and distance scales, there may be a significant influence of diffusion into stagnant free water within fractures in addition to "true" matrix diffusion. Thus, matrix diffusion parameters obtained from laboratory tracer experiments should be used cautiously when predicting contaminant migration at larger scales in fractured media.

Table E-18. Comparison of Matrix Diffusion Coefficients Calculated from Fractured-Core Tracer Tests and from Diffusion-Cell Experiments

\begin{tabular}{|c|c|c|}
\hline Core & $\begin{array}{l}\text { Fractured Core } \\
D_{\mathrm{m}}\left(\mathrm{Br}^{-}\right)\left(\mathrm{m}^{2} / \mathrm{s}\right)^{(\mathrm{a})}\end{array}$ & $\begin{array}{l}\text { Diffusion Cell } \\
D_{\mathrm{m}}{ }^{*}\left(\mathrm{Br}^{-}\right)\left(\mathrm{m}^{2} / \mathrm{s}\right)\end{array}$ \\
\hline Upper Prow Pass (1) & $11.0 \times 10^{-10}$ & $6.2 \times 10^{-10}$ \\
\hline Central Prow Pass (2) & $0.8 \times 10^{-10}$ & $0.38 \times 10^{-10}$ \\
\hline Lower Prow Pass (3) & $4.6 \times 10^{-10}$ & $2.9 \times 10^{-10(b)}$ \\
\hline Lower Bullfrog (4) & $3.8 \times 10^{-10}$ & $1.0 \times 10^{-10}$ \\
\hline \multicolumn{3}{|c|}{$\begin{array}{ll}\text { Output DTNs: } & \text { LA0303PR831362.001 (diffusion cells); } \\
& \text { LA0303PR831361.004 (fractured cores). }\end{array}$} \\
\hline \multicolumn{3}{|c|}{$\begin{array}{l}\text { a Determined from MTC using the measured matrix porosity and } \\
b \text { determined from } b=Q \tau \text { (see Tables E-16 and E-17). } \\
\text { b Average of two measurements. }\end{array}$} \\
\hline \multicolumn{3}{|c|}{ MTC=mass transfer coefficient. } \\
\hline
\end{tabular}




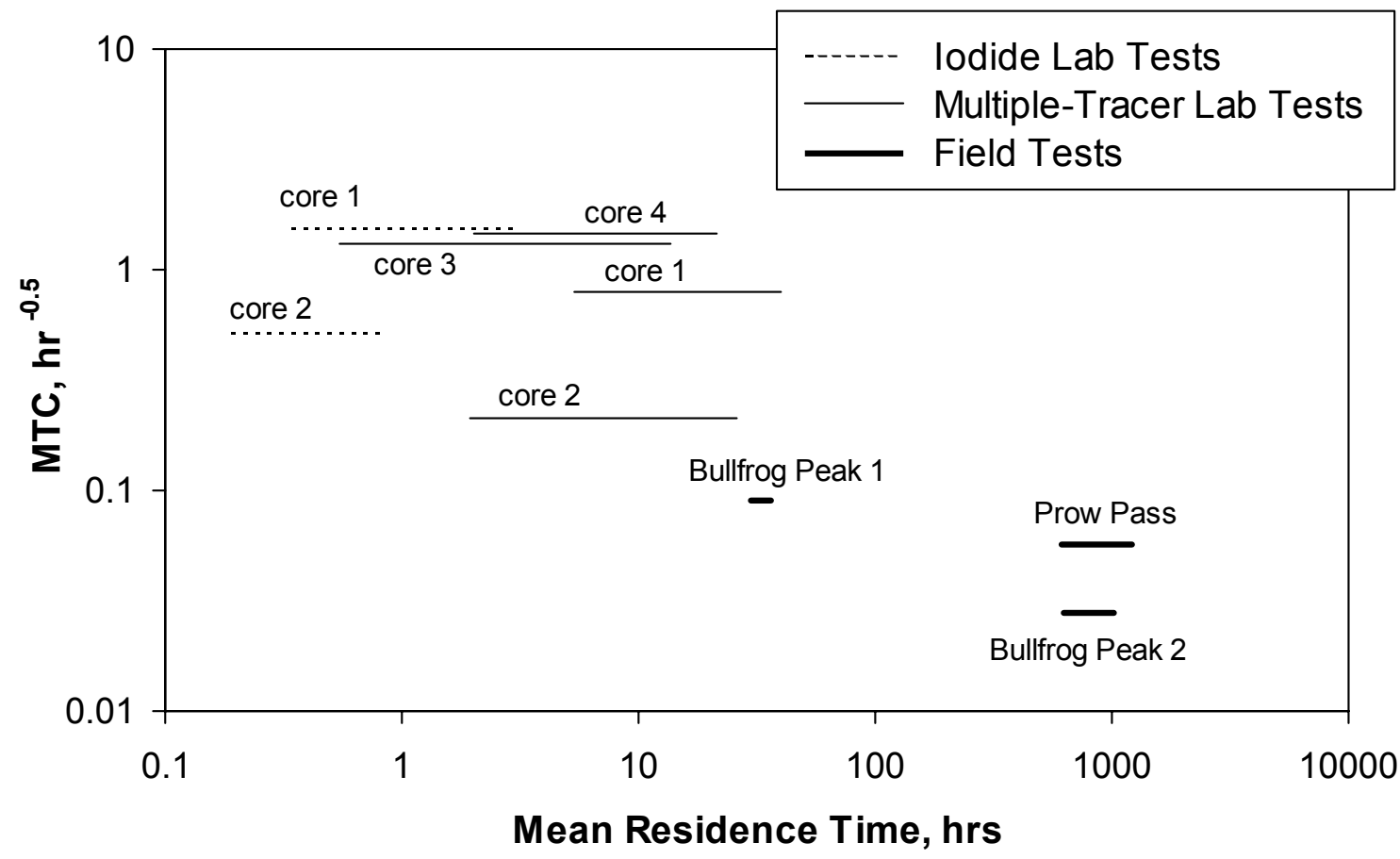

Output DTNs: LA0303PR831231.003 (field data); LA0303PR831361.004 (lab data); LA0303PR831231.005.

NOTE: The lines represent the field tests; endpoints of the lines reflect the uncertainty in the mean residence time depending on whether radial or linear flow is assumed.

The matrix diffusion mass transfer coefficient, MTC, is defined as $\frac{\phi}{b} \sqrt{D_{\mathrm{m}}}$.

The experimental time scale here is the mean residence time.

Figure E-41. Matrix Diffusion Mass Transfer Coefficient as a Function of Experimental Time Scale in All of the C-wells Laboratory and Field Multiple Tracer Test 


\section{INTENTIONALLY LEFT BLANK}


Hydrologic properties of the alluvium have been determined from both single-well and crosshole aquifer tests at the Alluvial Testing Complex (ATC), which is centered around well NC-EWDP-19D, located just outside the southwest corner of the Nevada Test Site (see Fig. 6.1-6). The tests, which are described in detail in this section, were interpreted using analytical methods similar to those used for interpretation of the hydraulic tests in fractured tuffs at the C-wells (Section 6.2 and Appendix C). Specifically, the unconfined aquifer solution of Neuman (1975 [DIRS 150321]) and the confined aquifer solution of Theis (1935 [DIRS 150327]) were used to interpret the single-well and cross-hole hydraulic responses, respectively. Although other analytical solutions were considered, the test responses appeared to conform most closely to these two solutions, so they were used for the analyses.

The analytic solutions provide first-order estimates of hydrologic parameters consistent with both the limited knowledge of the nature and extent of subsurface heterogeneities in the alluvium at the scale of the ATC and the manner in which hydrologic parameter estimates are used in the site-scale saturated zone (SZ) flow model. The analytical methods assume that the test interval has one average transmissivity and storativity value. Similarly, the SZ flow model assumes that single average intrinsic hydrologic property (i.e., permeability, porosity) values apply to the alluvium over large spatial areas in the SZ flow system. Furthermore, the hydrologic parameters derived from ATC testing are not used as direct inputs in the site-scale SZ flow model, but rather they are used primarily for qualitative/corroborative consistency checks with the hydrologic parameters derived from calibrations of the SZ flow model. Because of this qualitative end use of the parameter estimates, detailed analyses of the uncertainty and nonuniqueness of the estimates were not conducted.

\section{F1. ATC SINGLE-WELL HYDRAULIC TESTS}

Single-well hydraulic testing of the saturated alluvium in well NC-EWDP-19D was conducted between July 2000 and November 2000. This section presents the results and interpretations of those tests. Detailed documentation of the tests is reported by Umari et al. (2003 [DIRS 164573]). The single-well test results are presented here primarily to provide some indication of the variability in hydraulic conductivity that occurs with depth at the ATC location and also to provide information on the alluvium aquifer characteristics (e.g., confined, unconfined). Analyses of single-well step-drawdown tests (Section F1.4), calculations of leakage between screens 4 and 5 in NC-EWDP-19D (Section F1.5), and interpretations of subsequent cross-hole hydraulic tests (Section F2) all indicate that hydraulic conductivity estimates derived from single-well testing in NC-EWDP-19D are biased low because of significant near-wellbore head losses and/or artificial near-wellbore leakage between adjacent intervals. However, it is assumed that the relative values of hydraulic conductivities obtained from different intervals in the single-well tests are valid for comparison purposes, which implicitly assumes that the near-wellbore head losses in each interval (as a fraction of total drawdown) are comparable.

\section{F1.1 HYDRAULIC TEST OF THE FOUR COMBINED ALLUVIUM INTERVALS IN NC-EWDP-19D}

On July 7, 2000, a single-well hydraulic test of the alluvium aquifer to a depth of $247.5 \mathrm{~m}$ $(812 \mathrm{ft}$ ) below land surface was initiated in NC-EWDP-19D (referred to as 19D in the remainder 
of this document) to determine the transmissivity and hydraulic conductivity of the entire alluvium system at the 19D location. The construction of this well, including the location of all the screens discussed in this section, is summarized in Figure 6.1-8. The well was pumped for seven days, with production coming from the upper four screened intervals in 19D, for all of the intervals completed in the alluvium (a packer was inflated below the fourth screen to isolate the alluvium from the underlying tuffs). Prior to the completion of 19D, Nye County and U.S. Geological Survey/Los Alamos National Laboratory representatives agreed to install screens 5, 6 , and 7 in the tuffaceous units encountered by the well bore to allow for possible testing of these intervals in the future. Depth to water just before the test was approximately $106 \mathrm{~m}$ (approximately $349 \mathrm{ft}$ ) below land surface, and the effective alluvium thickness tested was approximately $136 \mathrm{~m}(446 \mathrm{ft})$, which is the distance from the water table to the bottom of the

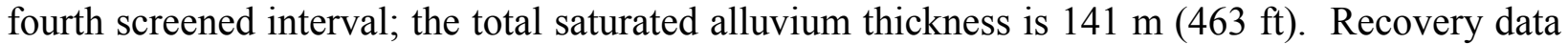
were collected for 14 days after pumping stopped. The test was used, along with the isolated-interval tests that followed, to obtain preliminary estimates of transmissivity and horizontal hydraulic conductivity that were then improved with cross-hole testing. Also, during this test, distant wells (NC-EWDP-15P, NC-EWDP-4PA, NC-EWDP-4PB, and Washburn-1x) were monitored. The nearby piezometer NC-EWDP-19P was also monitored. No responses were detected at these wells. (Note that the wells discussed in this report will be referred to by their abbreviated forms).

During the combined-interval test, 19D was pumped at the rate of approximately $564 \mathrm{~L} / \mathrm{min}(149$ gallons per minute [gpm]); after seven days of pumping, the drawdown was approximately 33.5 $\mathrm{m}$ (110 ft). Comparable pumping rates in the Nye County 48-hour (hr) well-development aquifer test in which all seven screened intervals in 19D were allowed to produce water caused an order of magnitude less drawdown. This result indicates that the Tertiary volcanics and tuff below the alluvium had contributed significantly to that test.

Figure F-1 presents the drawdown data for the entire combined-interval test, including both the pumping and recovery periods. Pumping was started at 12:00 P.M. on July 7, 2000, and ended at 12:00 P.M. on July 14, 2000. The open alluvium interval was allowed to recover until 1:00 P.M. on July 28,2000 . The average pumping rate during the test was $564 \mathrm{~L} / \mathrm{min}(149.11 \mathrm{gpm})$. The day markers in Figure F-1 are at 12:00 P.M., so the day-1 marker indicates 12:00 P.M. on July 8, 2000; the day-2 marker indicates 12:00 P.M. on July 9, 2000; and so forth. There were no changes in the pumping rate or any other configuration changes to cause the jump in drawdown seen at the 6-day marker. All drawdown values were calculated relative to the starting pressure head at 12:00 P.M. on July 7, 2000, registered by one of the two pressure transducers placed above the packer isolating the alluvium from the underlying tuffs (there were two transducers for redundancy; only one was used for drawdown measurements). Negative drawdown values during recovery indicate pressure heads higher than the starting pressure head. These negative drawdowns indicate that when the test was started on July 7, 2000, there was some residual drawdown relative to background water levels due to pumping associated with preparations for the test, including a step-drawdown test on July 6, 2000. 


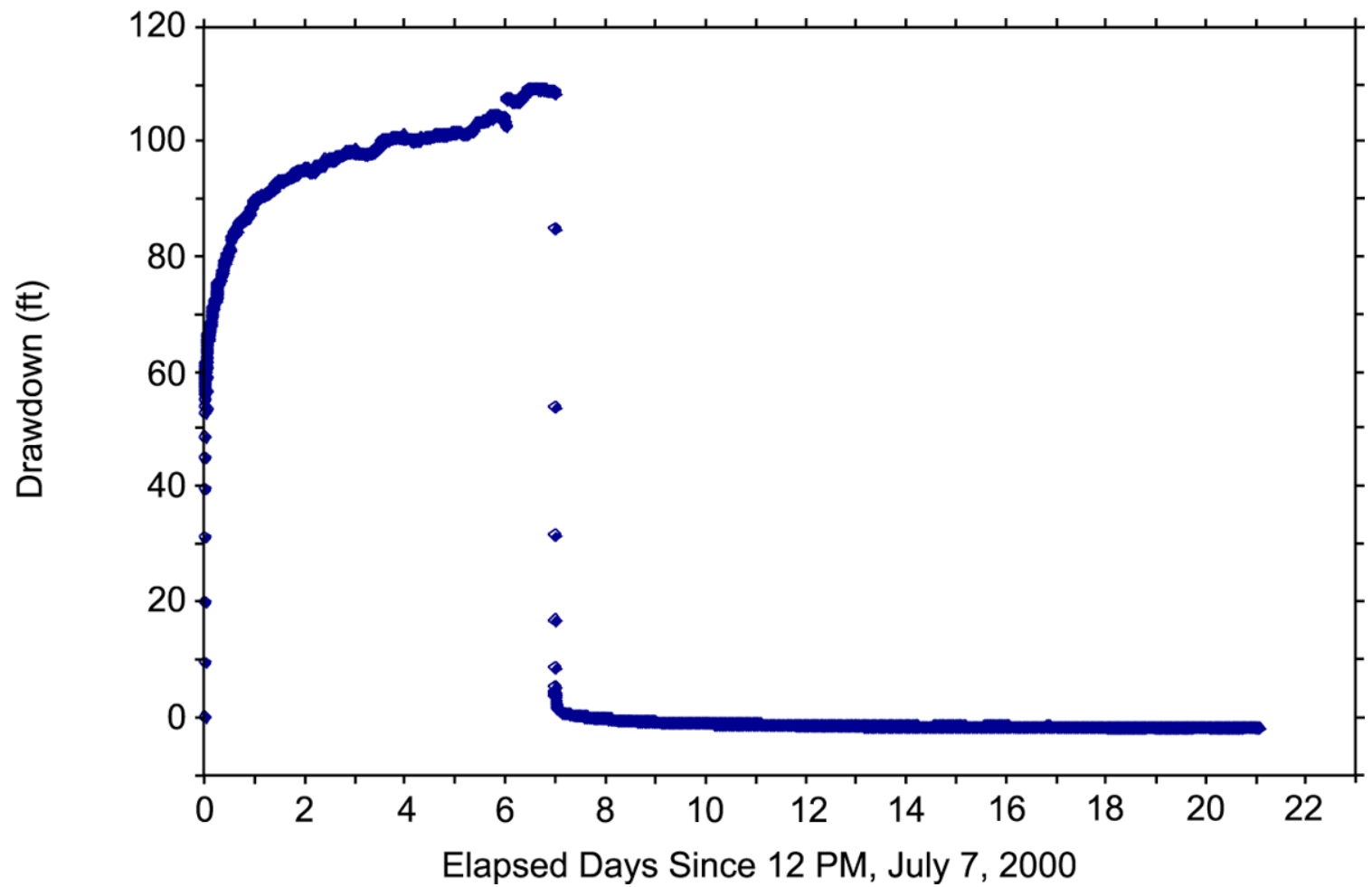

Source: DTN: GS020708312316.001 [DIRS 162678] (data).

NOTE: English units are shown in the figure because the analysis was conducted in English units. However, parameter estimates are reported in metric units to downstream users.

Figure F-1. Drawdown and Recovery Data Associated with the Pump Test of the Four Combined Alluvium Intervals in NC-EWDP-19D, July 2000

Figure F-2 presents a fit of the Neuman (1975 [DIRS 150321]) (Neuman.vi V 1.0, STN: 10972-1.0-00 [DIRS 162754]) fully penetrating unconfined aquifer analytic solution to the combined-interval test data. The Neuman solution gives a transmissivity value of $20.7 \mathrm{~m}^{2} /$ day $\left(223 \mathrm{ft}^{2} /\right.$ day). If the thickness of the saturated alluvium from the water table to the bottom of the fourth screened interval $136 \mathrm{~m}(446 \mathrm{ft})$ is used, a hydraulic conductivity of approximately $0.5 \mathrm{ft} /$ day is calculated. The type-curve matching procedure for the Neuman unconfined aquifer solution involves matching both the early and late portions of the drawdown data. In Figure F-2, these two portions of the matching type curve are graphically spliced together (the late portion of the type curve match is horizontally shifted to the left) to give the appearance of a single type curve. The latter portion of the early curve match and the early portion of the late curve match are not shown in Figure F-2. Both portions of this match are consistent with the transmissivity and hydraulic conductivity reported above. The slope of 1 for the early time data (less than 2 minutes) in Figure F-2 (log-log scale) is indicative of borehole storage (Papadopulos and Cooper 1967 [DIRS 150323]), so these very early time data were not considered in the curve-matching procedure. 


\section{F1.2 HYDRAULIC TESTS OF ISOLATED ALLUVIUM INTERVALS IN NC-EWDP-19D}

After the combined interval test, each of the four intervals in the alluvium in NC-EWDP-19D were isolated and hydraulically tested to obtain transmissivity and associated hydraulic conductivity. This interval testing program was initiated in an effort to evaluate heterogeneity in hydrologic properties over the thickness of the alluvium at the NC-EWDP-19D location to help determine the conceptual model of flow in the saturated alluvium south of Yucca Mountain.

The following description of the isolated-interval hydraulic tests is presented in order of screen depth, starting with screen \#1, the top screen, and ending with screen \#4, the bottom screen. The chronological order in which the tests were conducted was screens \#4, \#3, \#1, and \#2.

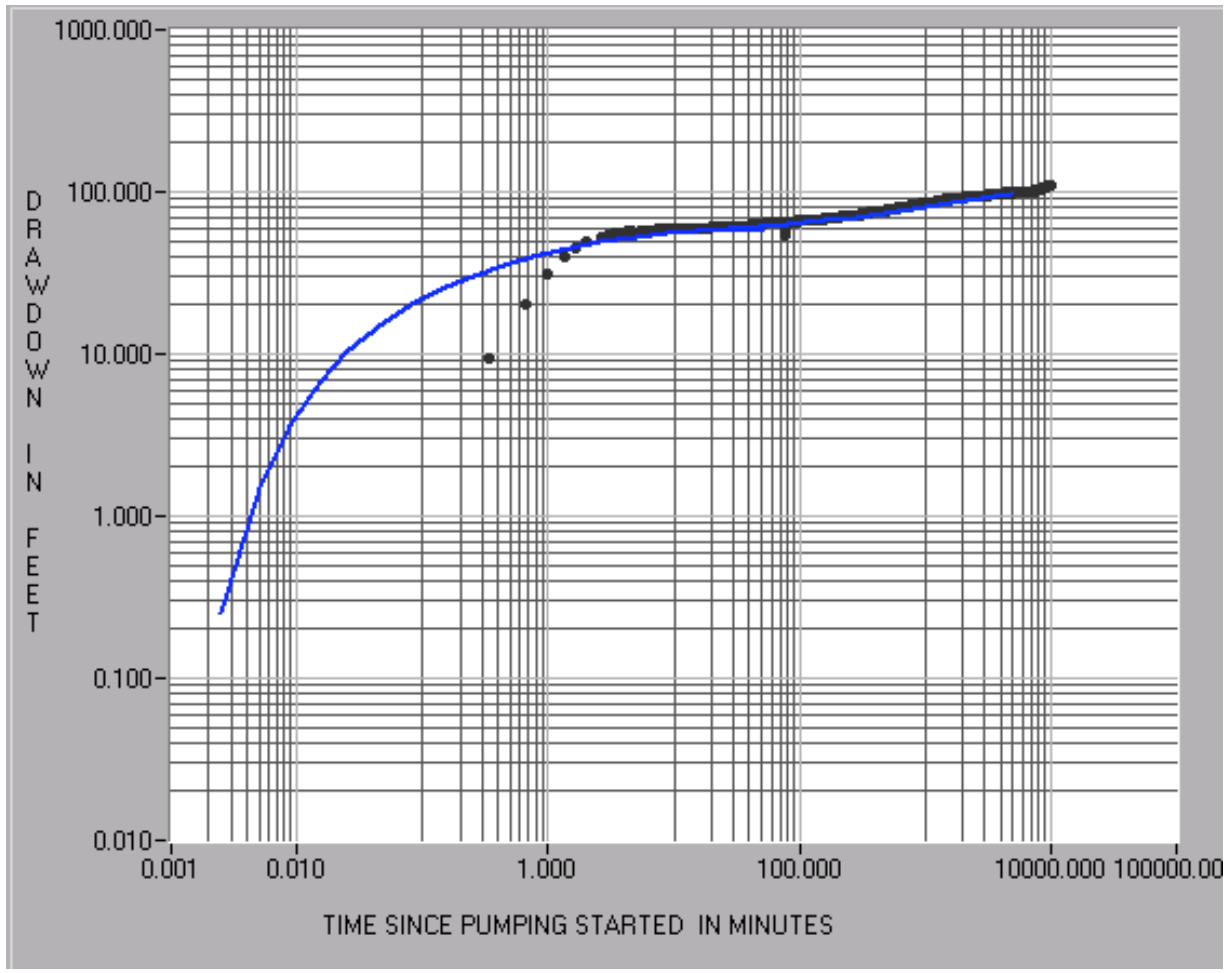

Source: DTN: GS020708312316.001 [DIRS 162678] (data).

Output DTN: GS031008312316.002 (analysis).

NOTE: The blue line is a composite curve showing both early- and late-time fits of July 7,2000 , open-hole drawdown data to Neuman's (1975 [DIRS 150321]) beta $=0.001$ type curve (latter portion of early time type curve and beginning portion of late-time type curve are truncated so that the two curves are joined into one continuous type curve). A value of beta $=0.001$ in the Neuman (1975 [DIRS 150321]) solution translates to a transmissivity of $20.7 \mathrm{~m}^{2} /$ day $\left(223 \mathrm{ft}^{2} /\right.$ day). The early time data (less than 2 minutes) were not considered in the type-curve analysis because this early time response was attributed to borehole storage, not aquifer response. English units are shown in the figure because the analysis was conducted in English units. However, parameter estimates are reported in metric units to downstream users.

Figure F-2. Drawdown as a Function of Elapsed Time for the Combined Interval Hydraulic Test in NC-EWDP-19D Overlaid with the Neuman Unconfined Aquifer Type Curve Solution 
On October 24, 2000, a hydraulic test in the top interval in the alluvium, screen \#1, was started in 19D. Pumping continued at a nominal rate of $61 \mathrm{~L} / \mathrm{min}(16 \mathrm{gpm})$, with an average of $61.7 \mathrm{~L} / \mathrm{min}$ (16.3 gpm), until October 27, 2000. Recovery was monitored until October 30, 2000. Figure F-3 presents the drawdown data from the test. Figure F-4 presents a fit of the Neuman (1975 [DIRS 150321]) (Neuman.vi V 1.0, STN: 10972-1.0-00 [DIRS 162754]) fully penetrating unconfined aquifer analytic solution to the data, which was obtained following the same procedure of matching the early- and late-time drawdown responses as in the combined-interval test, but with no horizontal shift required. The fully penetrating Neuman solution gives a transmissivity value of $6.1 \mathrm{~m}^{2} /$ day $\left(66 \mathrm{ft}^{2} /\right.$ day) (see Section F1.3 for correction needed because screen \#1 only partially penetrates the total saturated alluvium section).

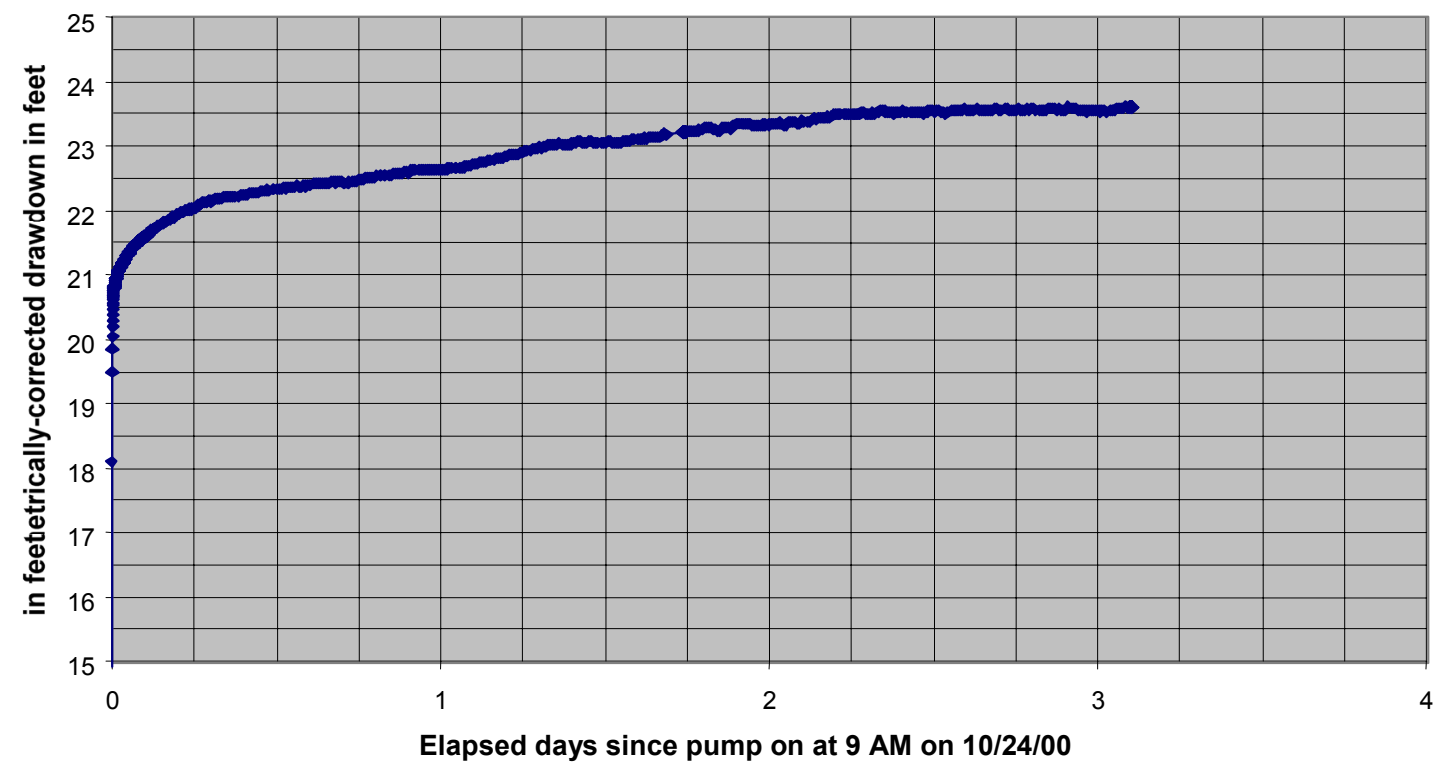

Source: DTN: GS020708312316.001 [DIRS 162678].(data).

NOTE: English units are shown in the figure because the analysis was conducted in English units. However, parameter estimates are reported in metric units to downstream users.

Figure F-3. Drawdown as a Function of Time for the Hydraulic Test in Screen \#1 of NC-EWDP-19D, October 24 to October 27, 2000 


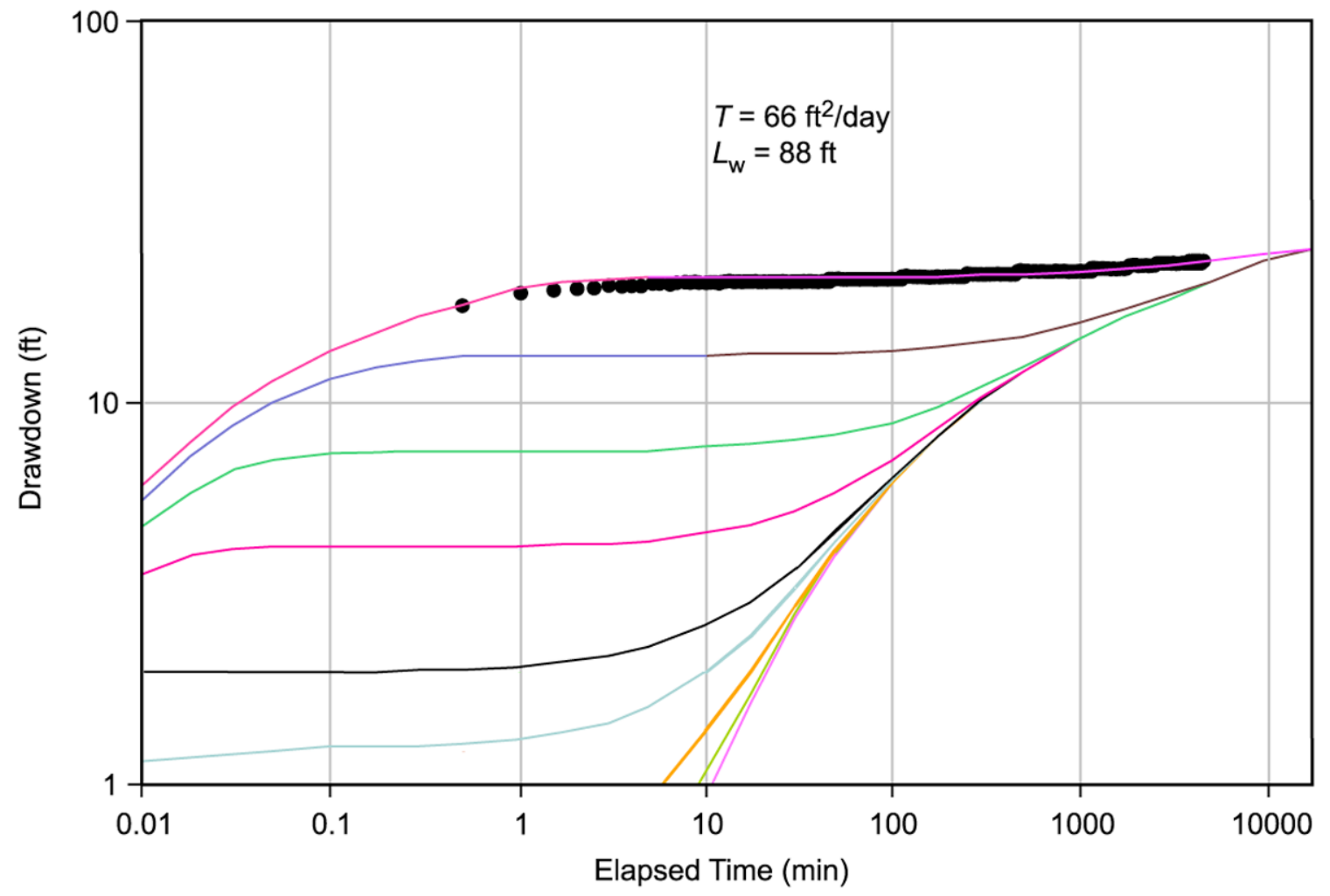

Source: DTN: GS020708312316.001 [DIRS 162678] (data).

Output DTN: GS031008312316.002 (analysis).

NOTE: The chosen type curve fits early- and late-time data simultaneously. Lw is defined in Section F1.3. English units are shown in the figure because the analysis was conducted in English units. However, parameter estimates are reported in metric units to downstream users.

Figure F-4. Drawdown Versus Elapsed Time for the Hydraulic Test in Screen \#1 of NC-EWDP-19D Overlaid with the Neuman Unconfined Aquifer Type Curves

On October 31, 2000, a hydraulic test in the second interval from the top in the alluvium, screen \#2, was started in 19D. Pumping continued at a nominal rate of $17 \mathrm{~L} / \mathrm{min}$ (19 gpm) until November 6, 2000. Recovery was monitored until November 9, 2000. Figure F-5 presents the drawdown data from the test. It is apparent that, unlike the other isolated interval hydraulic tests in 19D, the drawdown in screen \#2 increased at a relatively constant rate. This interval was completed just below a clay-rich layer in the alluvium, and there is a possibility (unconfirmed) that the screen and gravel pack may have been gradually clogging with fines during the test. Figure F-6 presents a fit of the Neuman (1975 [DIRS 150321]) (Neuman.vi V 1.0, STN: 10972-1.0-00 [DIRS 162754]) fully penetrating unconfined aquifer analytic solution to the drawdown data from screen $\# 2$, which was obtained following the same procedure of matching the early- and late-time drawdown responses as in the combined-interval test, but with no horizontal shift required. The fully penetrating Neuman solution gives a transmissivity value of $0.70 \mathrm{~m}^{2} /$ day $\left(7.5 \mathrm{ft}^{2} /\right.$ day) (Output DTN: GS031008312316.002) (see Section F1.3 for correction needed because screen $\# 2$ only partially penetrates the total saturated alluvium section). 


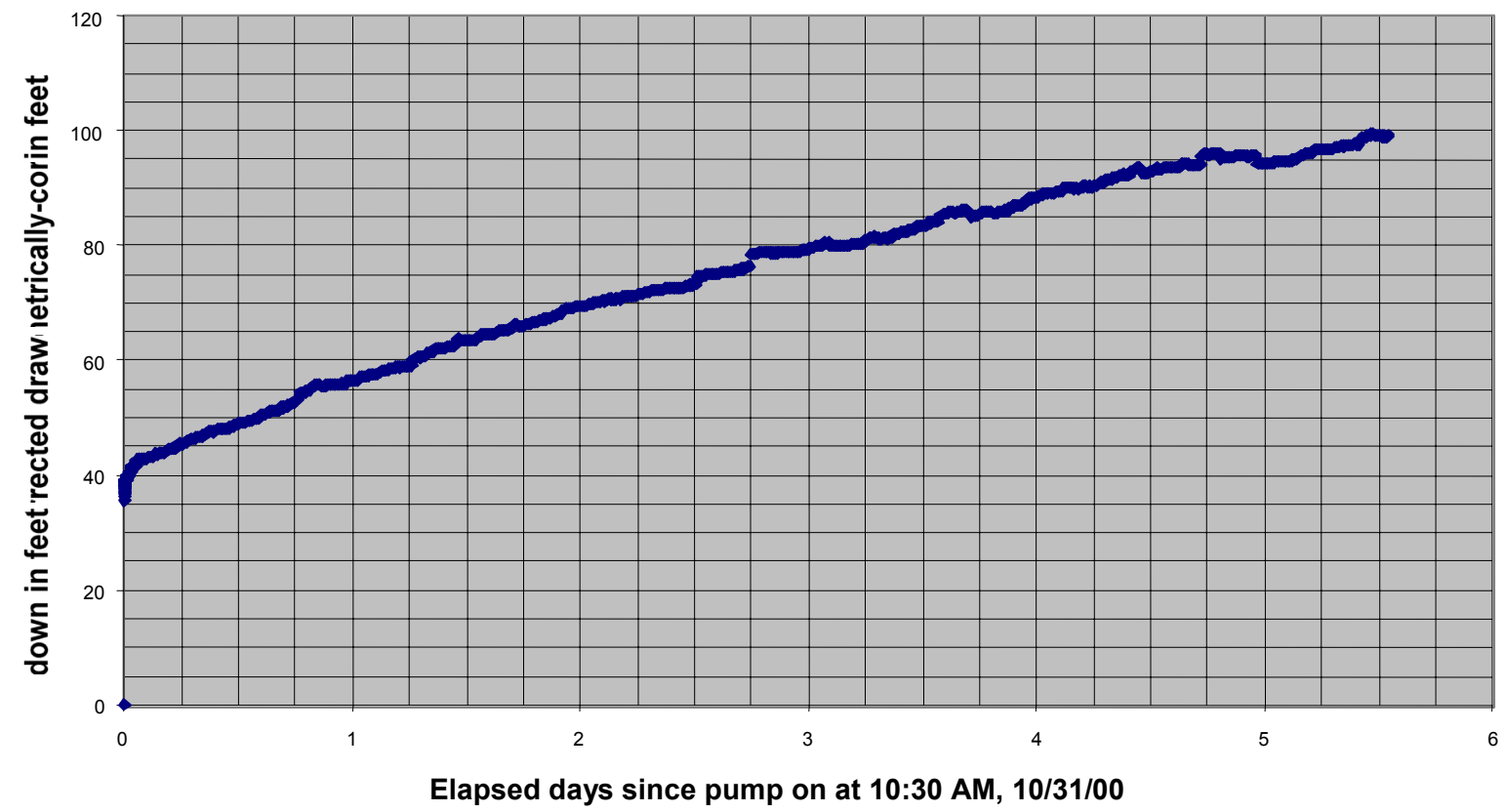

Source: DTN: GS020708312316.001 [DIRS 162678] (data).

Output DTN: GS031008312316.002 (analysis).

NOTE: English units are shown in the figure because the analysis was conducted in English units. However, parameter estimates are reported in metric units to downstream users.

Figure F-5. Drawdown as a Function of Time for the Hydraulic Test in Screen \#2, NC-EWDP-19D, October 31 to November 6, 2000 


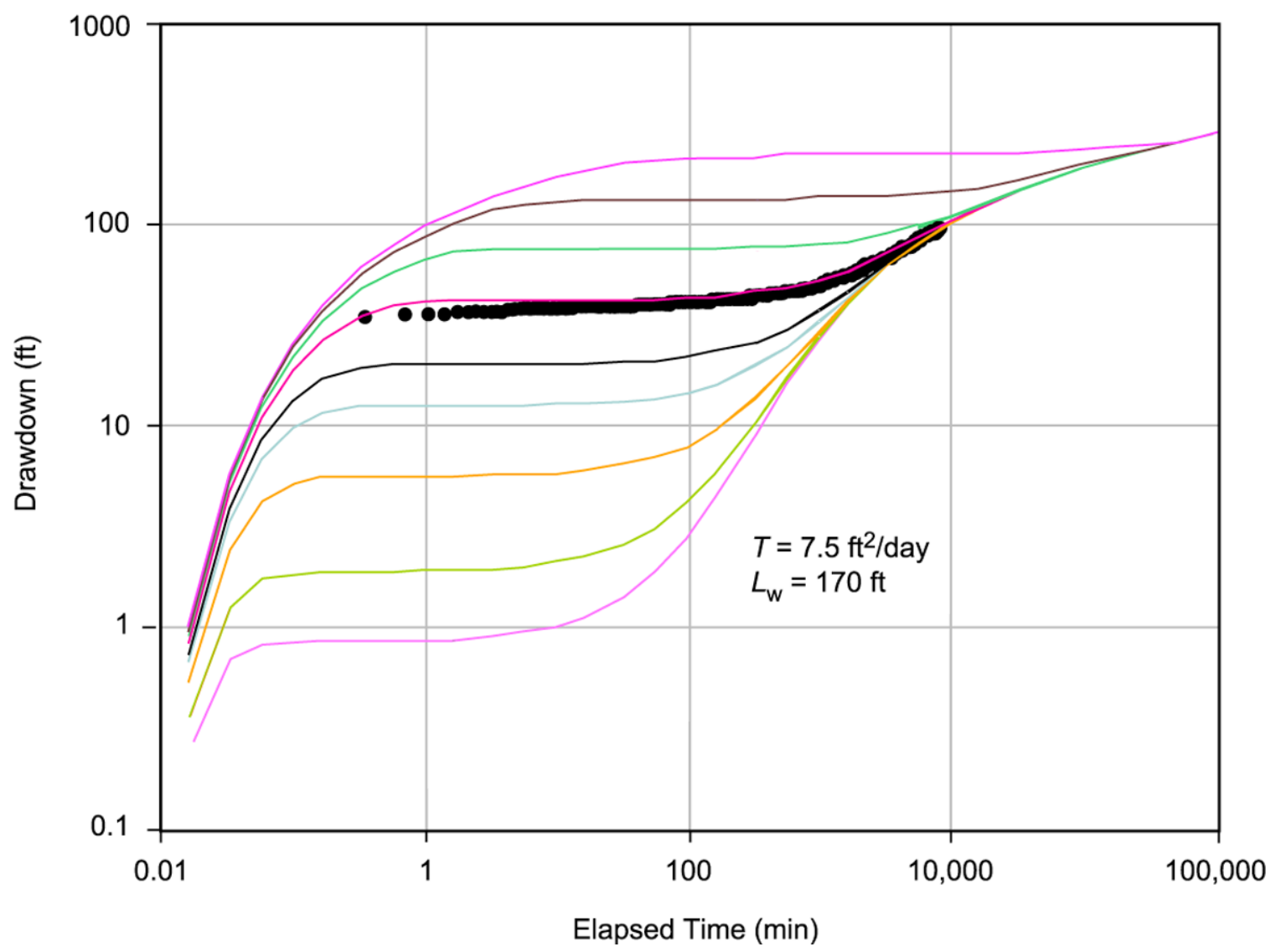

Source: DTN: GS020708312316.001 [DIRS 162678] (data).

Output DTN: GS031008312316.002 (analysis).

NOTE: The chosen type curve fits early- and late-time data simultaneously. Lw is defined in Section F1.3. English units are shown in the figure because the analysis was conducted in English units. However, parameter estimates are reported in metric units to downstream users.

Figure F-6. Drawdown as a Function of Time During the Hydraulic Test in Screen \#2, NC-EWDP-19D, Overlaid with the Neuman Unconfined Aquifer Type Curves

On September 9, 2000, a hydraulic test in the second interval from the bottom in the alluvium, screen \#3, was started in 19D. Pumping continued at a nominal rate of $314 \mathrm{~L} / \mathrm{min}(83 \mathrm{gpm})$, with an average of $309.3 \mathrm{~L} / \mathrm{min}$ (81.7 gpm), until September 16, 2000. Recovery was monitored until September 21, 2000. Figure F-7 presents the drawdown data from this test. The stair-step shape of the drawdown versus time curve suggests that the gravel pack was compacting at discrete times during this test, thus causing nearly instantaneous jumps in the drawdown. Figure F-8 presents a fit of the Neuman (1975 [DIRS 150321]) (Neuman.vi V 1.0, STN: 10972-1.0-00 [DIRS 162754]) fully penetrating unconfined aquifer analytic solution to the drawdown data from screen \#3, which was obtained following the same procedure of matching the early- and late-time drawdown responses as in the combined-interval test, but with no horizontal shift required. The fully penetrating Neuman (1975 [DIRS 150321]) solution gives a transmissivity value of $20.7 \mathrm{~m}^{2} /$ day $\left(223 \mathrm{ft}^{2} /\right.$ day) (see Section F1.3 for correction needed because screen \#3 only partially penetrates the total saturated alluvium section). 


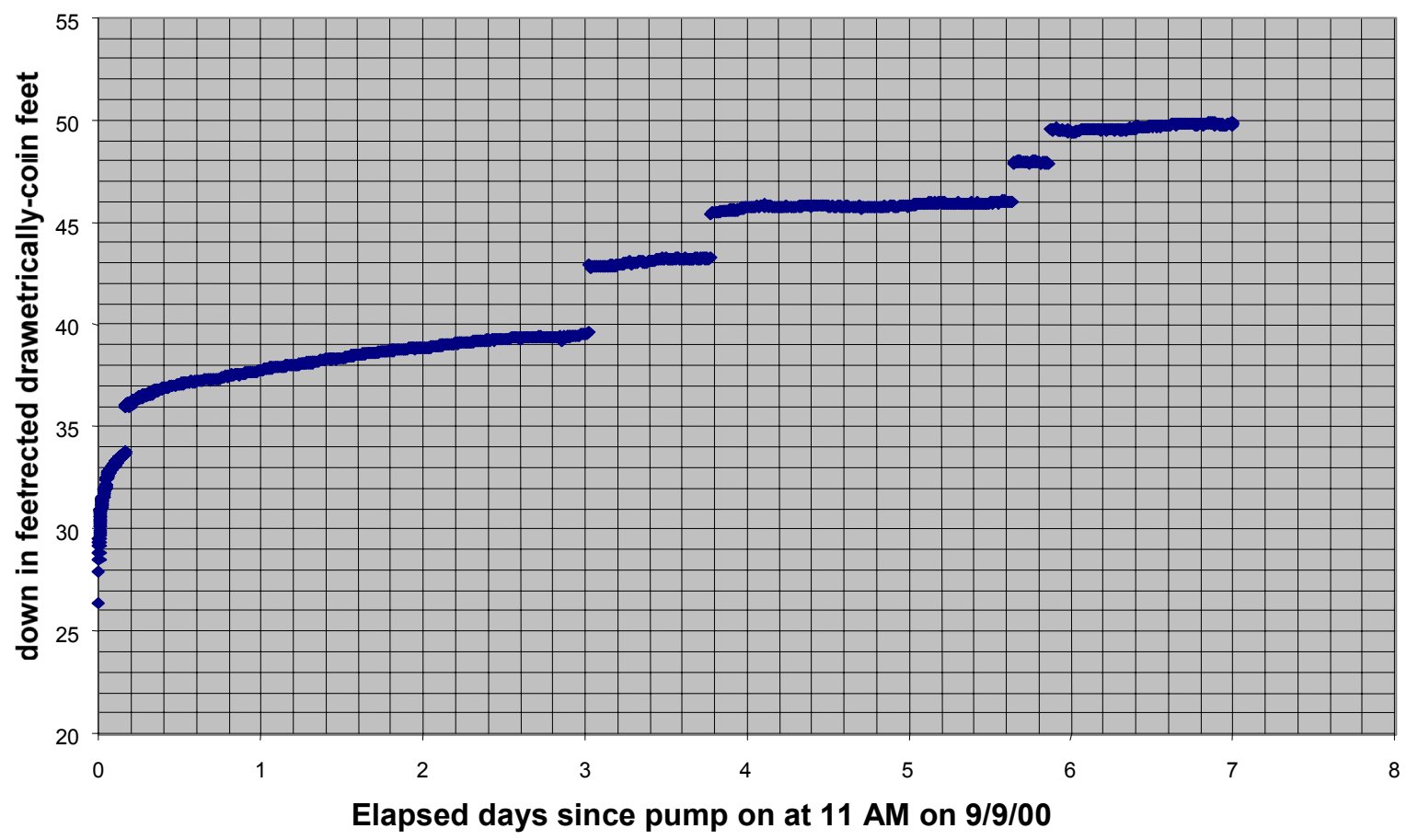

Source: DTN: GS020708312316.001 [DIRS 162678] (data).

Output DTN: GS031008312316.002 (analysis).

NOTE: English units are shown in the figure because the analysis was conducted in English units. However, parameter estimates are reported in metric units to downstream users.

Figure F-7. Drawdown as a Function of Elapsed Time for the Hydraulic Test in Screen \#3 of NC-EWDP-19D, September 9 to September 16, 2000 


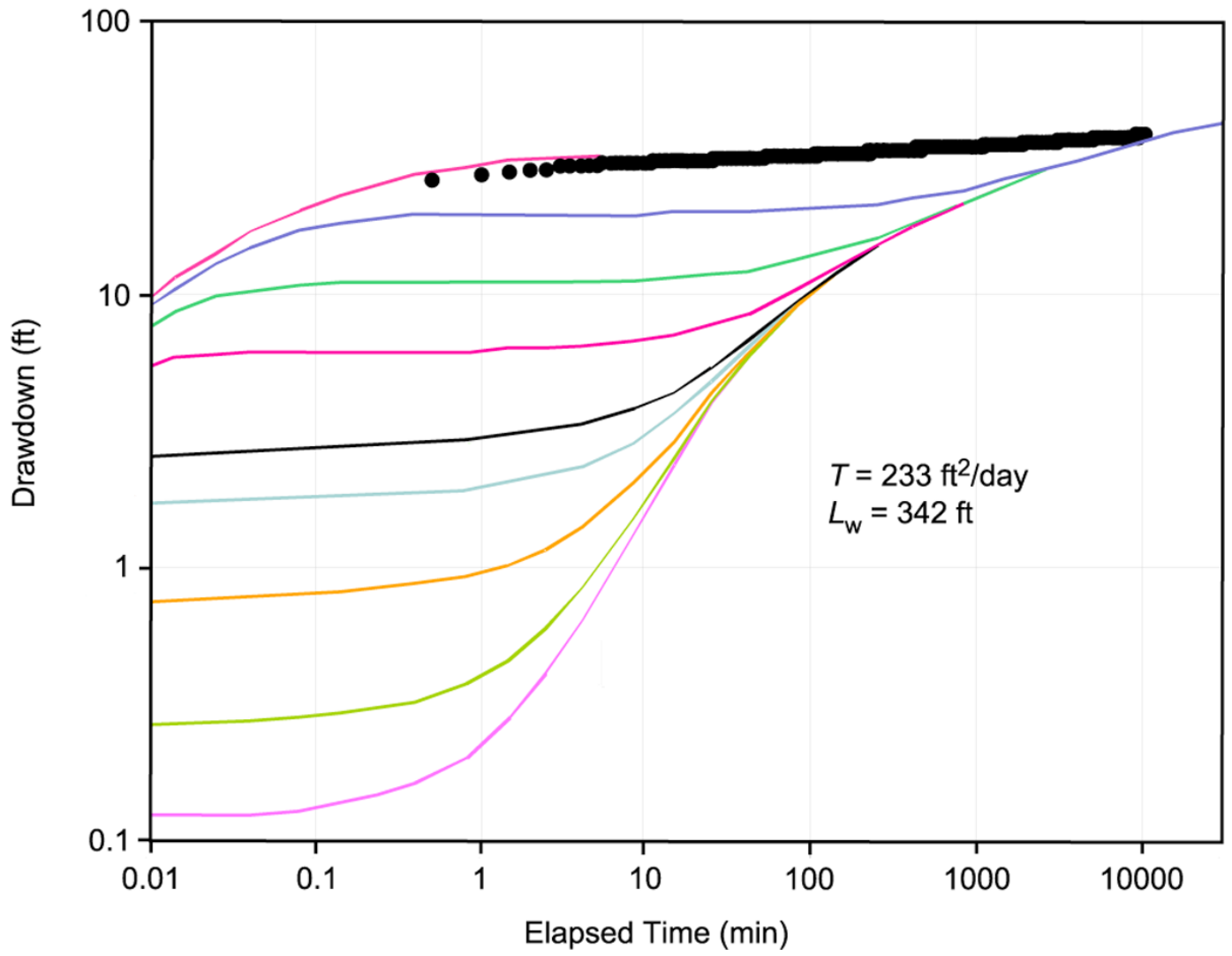

Source: DTN: GS020708312316.001 [DIRS 162678] (data).

Output DTN: GS031008312316.002 (analysis).

NOTE: The chosen type curve fits early- and late-time data simultaneously. $L_{w}$ is defined in Section F1.3. English units are shown in the figure because the analysis was conducted in English units. However, parameter estimates are reported in metric units to downstream users.

Figure F-8. Drawdown as a Function of Time During the Hydraulic Test in Screen \#3, NC-EWDP-19D, Overlaid with the Neuman Unconfined Aquifer Type Curves

On August 24, 2000, a hydraulic test in the lower-most screen in the alluvium section of 19D, screen \#4, was started. Pumping continued at the nominal rate of $299 \mathrm{~L} / \mathrm{min}$ (79 gpm) until August 31, 2000, with an average of $299.8 \mathrm{~L} / \mathrm{min}$ (79.2 gpm). Recovery was monitored from August 31, 2000, to September 7, 2000. Figure F-9 presents the drawdown data from this test, including both the pumping and recovery periods. Figure F-10 presents a fit of the Neuman (1975 [DIRS 150321]) (Neuman.vi V 1.0, STN: 10972-1.0-00 [DIRS 162754]) fully penetrating unconfined aquifer analytic solution to the drawdown data from screen \#4, which was obtained following the same procedure of matching the early- and late-time drawdown responses as in the combined-interval test. The fully penetrating Neuman solution gives a transmissivity value of $28 \mathrm{~m}^{2} /$ day (300 $\mathrm{ft}^{2} /$ day) (Output DTN: GS031008312316.002) (see Section F1.3 for correction needed because screen \#4 only partially penetrates the total saturated alluvium section).

The drawdown in the combined screens \#5, \#6, and \#7 interval as a function of elapsed time during the above test in screen \#4 beginning on August 24, 2000, is presented in Figure F-19 in Section F1.5, where it is used to calculate the rate of leakage from below the alluvium into the screen \#4 interval. 


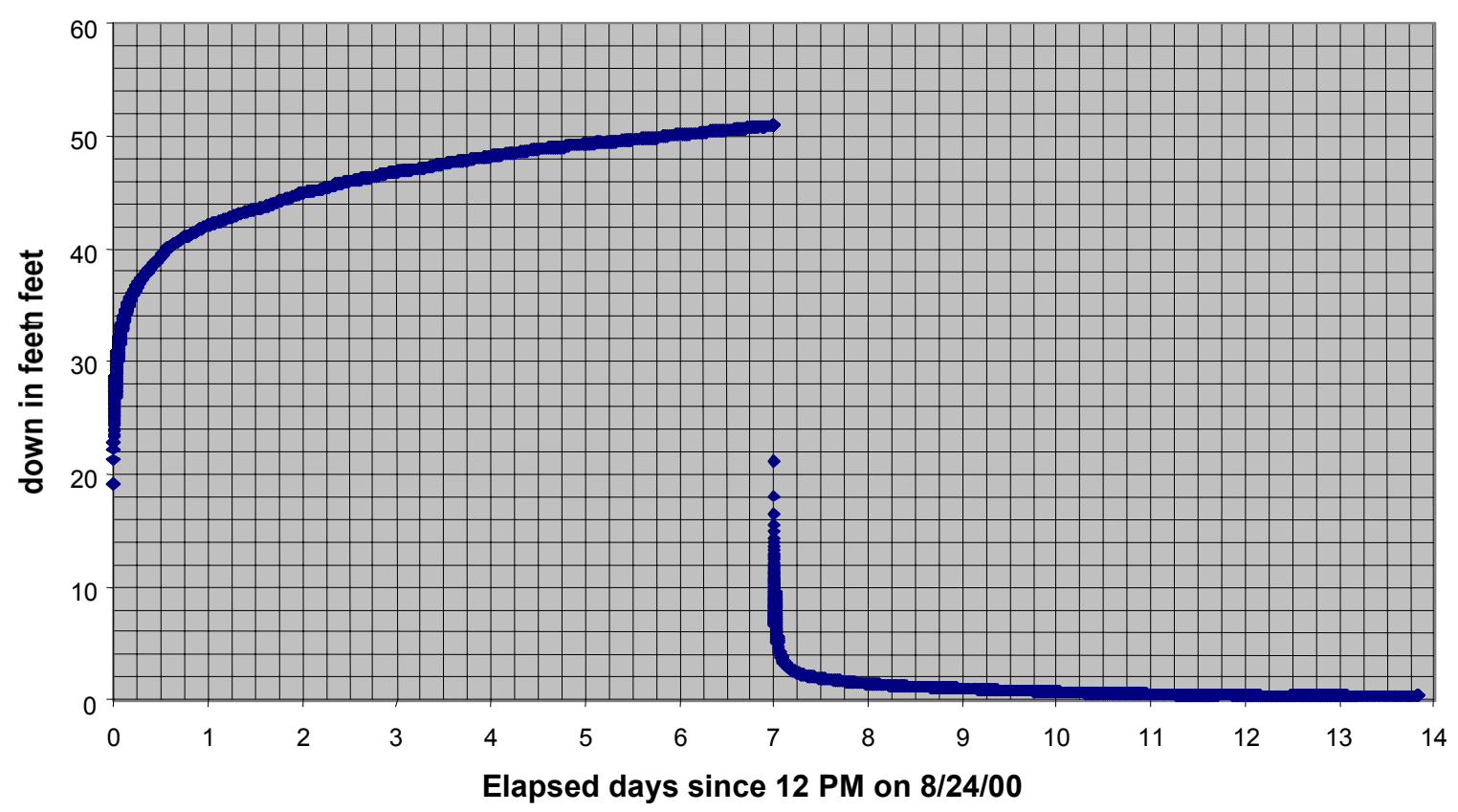

Source: DTN: GS020708312316.001 [DIRS 162678] (data).

NOTE: English units are shown in the figure because the analysis was conducted in English units. However, parameter estimates are reported in metric units to downstream users.

Figure F-9. Drawdown as a Function of Time for the Hydraulic Test in NC-EWDP-19D, Screen \#4, August 24 to August 31, 2000 


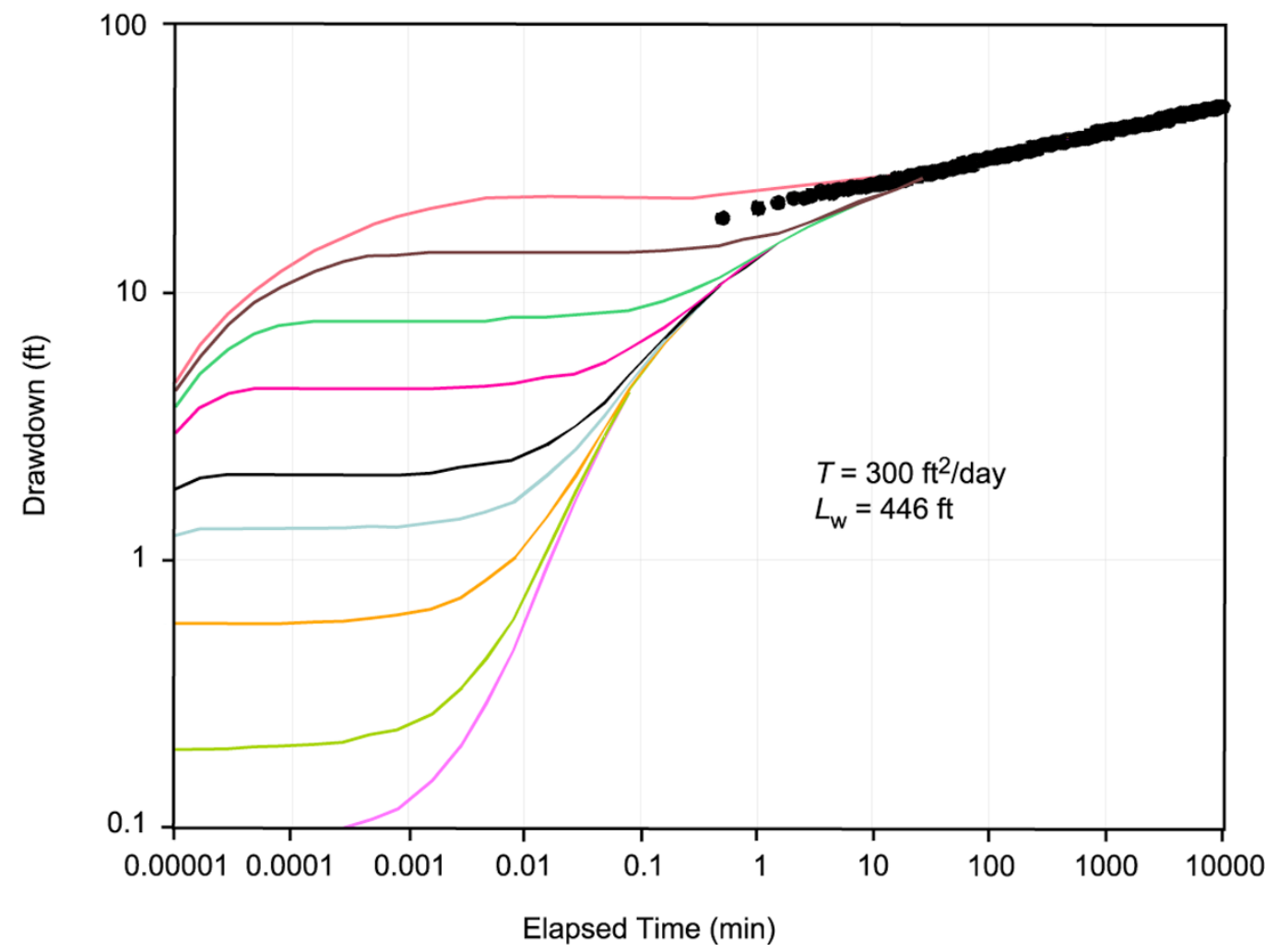

Source: DTN: GS020708312316.001 [DIRS 162678] (data).

Output DTN: GS031008312316.002 (analysis).

NOTE: The matching type curve has been shifted horizontally to emphasize the match to the late-time data. The early time data were also matched by this type curve, although, unlike in Figure F-2, the early-time and latetime type curve (Neuman 1975 [DIRS 150321]) matches are not "spliced " together to show a single composite fit. Lw is defined in Section F1.3. English units are shown in the figure because the analysis was conducted in English units. However, parameter estimates are reported in metric units to downstream users.

Figure F-10. Drawdown as a Function of Time During the Hydraulic Test in Screen \#4, NC-EWDP-19D, Overlaid with the Neuman Unconfined Aquifer Type Curves

\section{F1.3 SUMMARY OF SINGLE-WELL HYDRAULIC TESTS IN ALLUVIUM IN NC- EWDP-19D}

The hydraulic tests in 19D, screens 1 through 4, were analyzed using the fully penetrating Neuman (1975 [DIRS 150321]) (Neuman.vi V 1.0, STN: 10972-1.0-00 [DIRS 162754]) unconfined aquifer solution because all four individual screens, as well as the combined intervals, exhibited characteristic unconfined aquifer responses. Because each of the screens did not fully penetrate the unconfined alluvial aquifer, they should be analyzed by the partially penetrating Neuman solution. However, there is no Yucca Mountain Project-qualified software to perform this analysis, so the transmissivity, $T$, values resulting from the Neuman fully penetrating solution should be corrected to account for the length of the screen, $\mathrm{L}_{\mathrm{e}}$, and the depth from the water table to the bottom of the screen being tested, $\mathrm{L}_{\mathrm{w}}$ (see, for example, Bouwer 1978 [DIRS 162675], pp. 79 to 82, 114 to 117). An empirical relationship was sought between temperature and each of $\mathrm{L}_{\mathrm{e}}$ and $\mathrm{L}_{\mathrm{w}}$ by plotting temperature versus $\mathrm{L}_{\mathrm{e}}$ (Figure $\mathrm{F}-11$ ) and temperature versus $L_{w} / b$ in Figure F-12, where $b$ is the total unconfined alluvial aquifer thickness 
(136 $\mathrm{m}$ or $446 \mathrm{ft}$ ). The results from screen \#2 are not included in Figures F-11 and F-12 because they don't follow the trend of the results from the other screens, probably because the screen $\# 2$ interval is highly affected by a clay layer at the same horizon. Figure F-13 is a plot of temperature versus $\mathrm{L}_{\mathrm{w}} / \mathrm{b}$ showing results from all four screens.

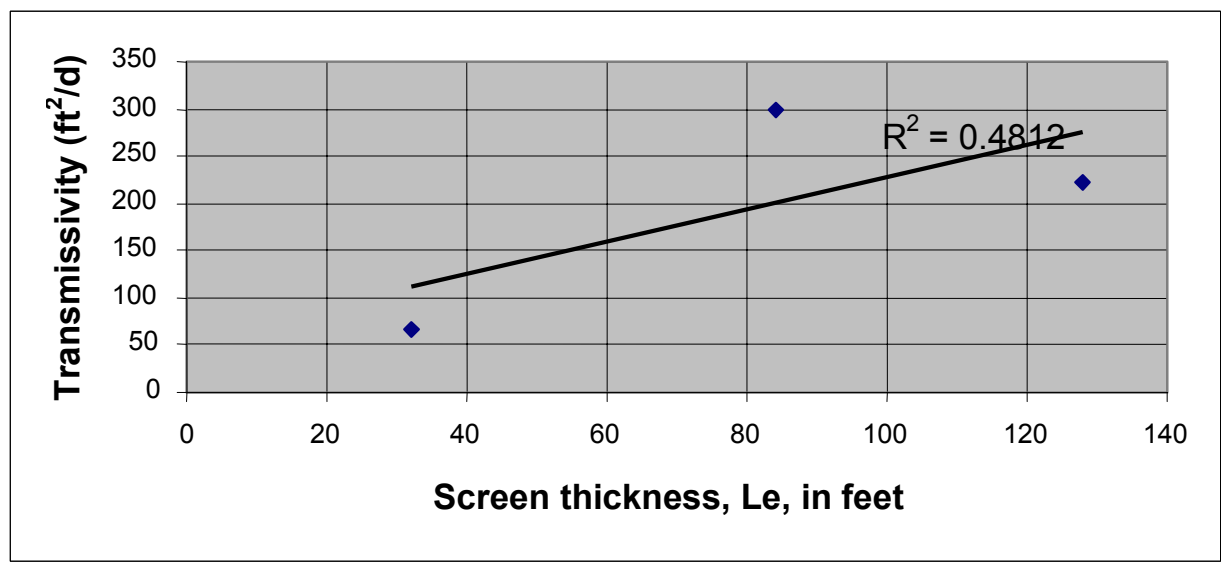

Source: DTN: GS020708312316.001 [DIRS 162678] (data).

Output DTN: GS031008312316.002 (analysis).

NOTE: English units are shown in the figure because the analysis was conducted in English units. However, parameter estimates are reported in metric units to downstream users.

Figure F-11. Transmissivity of Screens \#1, \#3, and \#4 of NC-EWDP-19D as a Function of Screen Thickness

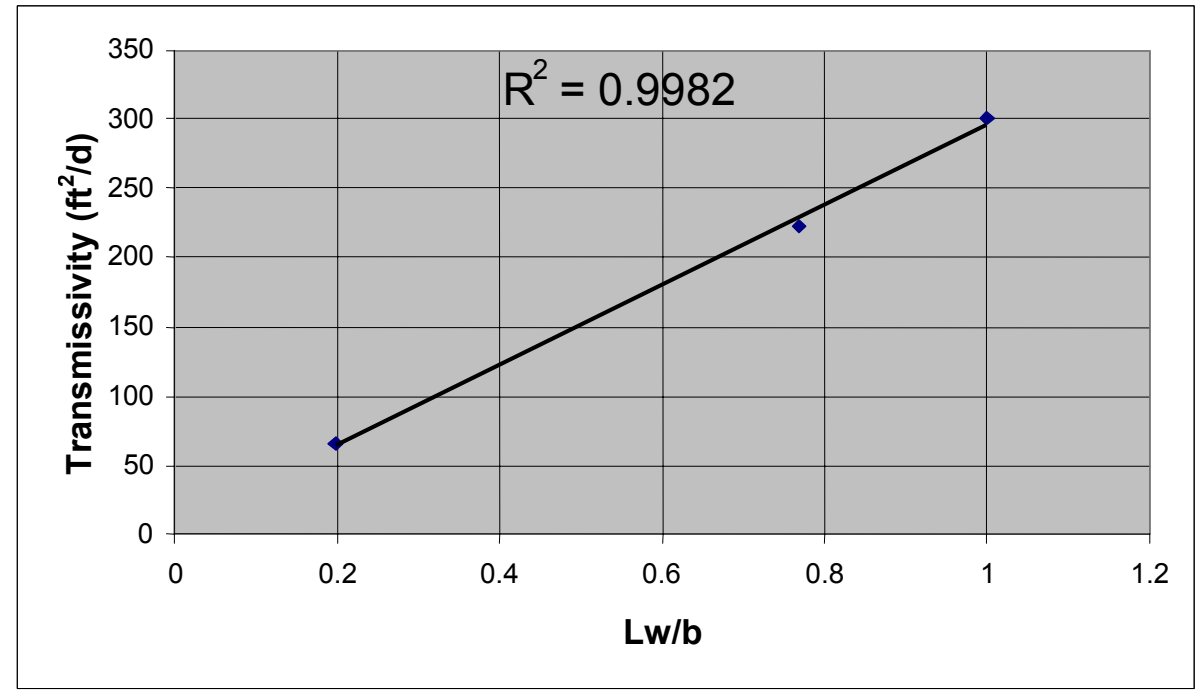

Source: DTN: GS020708312316.001 [DIRS 162678] (data).

Output DTN: GS031008312316.002 (analysis).

NOTE: English units are shown in the figure because the analysis was conducted in English units. However, parameter estimates are reported in metric units to downstream users.

Figure F-12. Transmissivity of Screens \#1, \#3, and \#4 of NC-EWDP-19D as a Function of Distance from Water Table to Bottom of Screen Divided by Distance from Water Table to Bottom of Screen \#4 


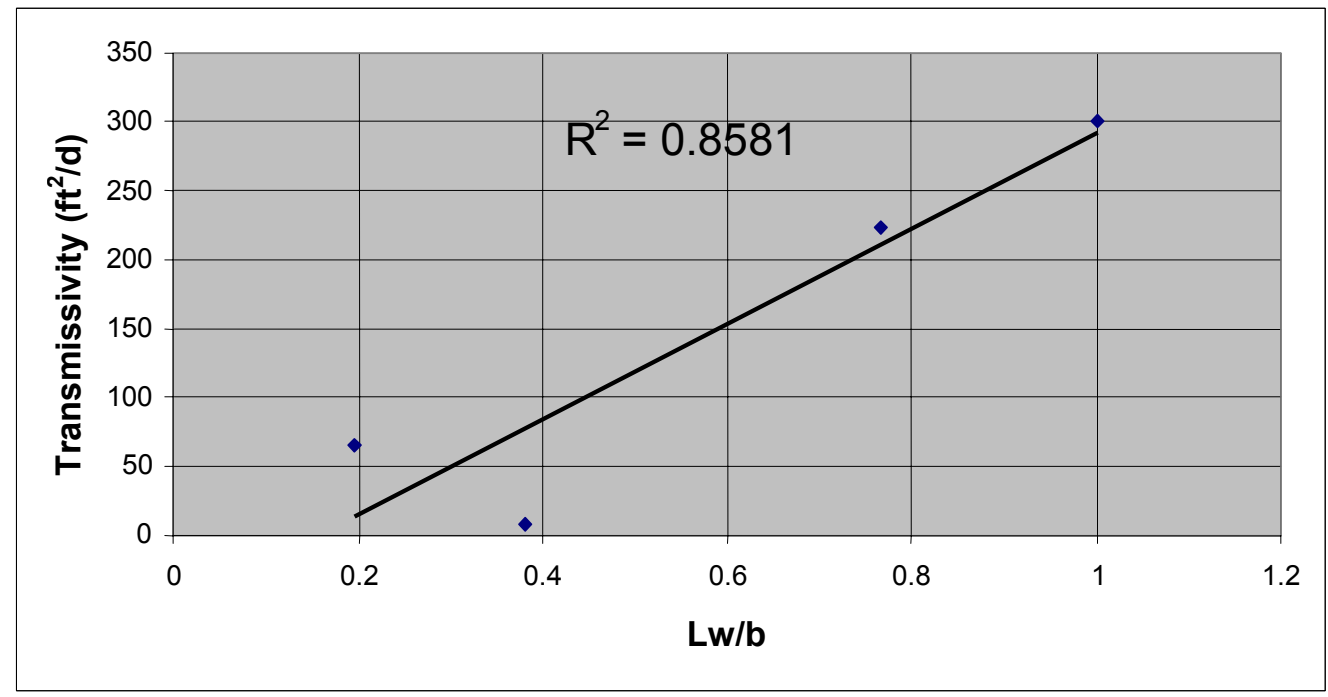

Source: DTN: GS020708312316.001 [DIRS 162678] (data).

Output DTN: GS031008312316.002 (analysis).

NOTE: English units are shown in the figure because the analysis was conducted in English units. However, parameter estimates are reported in metric units to downstream users.

Figure F-13. Transmissivity of Screens \#1, \#2, \#3, and \#4 of NC-EWDP-19D as a Function of Distance from Water Table to Bottom of Screen Divided by Distance from Water Table to Bottom of Screen \#4

It can be seen from Figures F-11 and F-12 that the hydraulic test results from screens \#1, \#3, and \#4 indicate that temperature calculated with the fully penetrating solution is a very weak function of $\mathrm{L}_{\mathrm{e}}\left(\mathrm{R}^{2}=0.4812\right)$ but is very strongly correlated $\left(\mathrm{R}^{2}=0.9982\right)$ with $\mathrm{L}_{\mathrm{w}} / \mathrm{b}$, and, therefore, with $\mathrm{L}_{\mathrm{w}}$. In fact, Figure F-12, and even Figure F-13, can be viewed as an empirical relationship derived from ATC single-well hydraulic testing for correction of the partially penetrating temperature values that give a value for temperature of $28 \mathrm{~m}^{2} /$ day $\left(300 \mathrm{ft}^{2} /\right.$ day $)$ as their upper limit when the aquifer is fully penetrated, i.e. at $\mathrm{L}_{\mathrm{w}} / \mathrm{b}=1$. Thus, the transmissivity values obtained in the hydraulic tests of screens \#1, \#3, and \#4 are all consistent with an overall transmissivity of $28 \mathrm{~m}^{2} /$ day $\left(300 \mathrm{ft}^{2} /\right.$ day $)$ for the saturated alluvium at 19D (Output DTN: GS031008312316.002). The temperature value of $28 \mathrm{~m}^{2} /$ day $\left(300 \mathrm{ft}^{2} /\right.$ day) from the $8 / 24 / 00$ screen \#4 test is essentially the same as the transmissivity from the fully penetrating open-hole test started on July 7, $2000\left(20.7 \mathrm{~m}^{2} /\right.$ day or $223 \mathrm{ft}^{2} /$ day $)$, considering that the borehole was slugged to increase its capacity between the two tests. Using an aquifer thickness equal to the distance from the water table to the bottom of screen \#4 (136 m or $446 \mathrm{ft})$, an overall transmissivity value of $28 \mathrm{~m}^{2} /$ day $\left(300 \mathrm{ft}^{2} /\right.$ day $)$ represents a hydraulic conductivity of $0.20 \mathrm{~m} /$ day (0.67 ft/day) (Output DTN: GS031008312316.002).

Because of the large head losses discussed in the next section, the results from single-well hydraulic testing at 19D are considered to have a high degree of uncertainty in their absolute values. It is recommended instead that values of transmissivity, and associated hydraulic conductivity, obtained from cross-hole testing at the ATC, which is discussed in Section F2, be used for the saturated alluvium. 


\section{F1.4 STEP-DRAWDOWN TESTS TO DETERMINE HEAD LOSSES}

A step-drawdown test was conducted prior to the hydraulic test in each interval. On July 6, 2000, prior to the open-alluvium hydraulic test starting on July 7, a step-drawdown test was conducted in the open-alluvium in well 19D. Two methods were attempted to analyze the data as presented below.

The drawdown in the well itself (as opposed to the drawdown in the aquifer at the well wall) is given by the following equation (modified from Bouwer 1978 [DIRS 162675], p. 83, Equation 4.38):

$$
s=B \cdot Q+C \cdot Q^{n}
$$

where

$$
\begin{aligned}
& S=\text { the drawdown } \\
& Q=\text { the pumping rate } \\
& B, C \text {, and } n \text { are coefficients. }
\end{aligned}
$$

$B \cdot Q$ represents the laminar flow that describes groundwater flow movement occurring in the aquifer and $C \cdot Q^{n}$ represents the turbulent flow and associated head losses caused by water entering the borehole on its way from the aquifer to the pump intake. Jacob assumed $n=2$ (Bouwer 1978 [DIRS 162675], p. 83, Equation 4.39) to obtain:

$$
s=B \cdot Q+C \cdot Q^{2} .
$$

The idea is to calculate $B$ and $C$ and then to calculate the fractional efficiency as the laminar drawdown divided by total (laminar plus turbulent) drawdown. Efficiency would, thus, be $B \cdot Q /\left(B \cdot Q+C \cdot Q^{n}\right)$, if Equation 28 is used, and $B \cdot Q /\left(B \cdot Q+C \cdot Q^{2}\right)$, if Equation 29 is used.

Calculations based on both equations were carried out on the data from the July 6, 2000, step-drawdown test in the open alluvium that indicate a negative value of $B$ (a similar result is obtained when analyzing a step-drawdown test conducted in screen \#4 on January 7, 2002). This result, of course, is incorrect because a negative $B$ leads to an indeterminate efficiency calculation. Calculation of $B$ is demonstrated below for the July 6, 2000, step-drawdown test.

Dividing Equation 29 by $Q$ to obtain

$$
\frac{s}{Q}=B+C \cdot Q
$$

indicates that a plot of $s / Q$ versus $Q$ yields a linear relationship with an intercept of $B$ and a slope of $C$. Figure F-14 is such a plot for the above step-drawdown test. It can be seen from the figure that the intercept $B$ is -0.1027 and the slope $C$ is 0.004 . Since the laminar flow component, $B \cdot Q$, cannot be negative, the negative value for $B$ is taken to indicate that $B \cdot Q$ is approximately zero. 


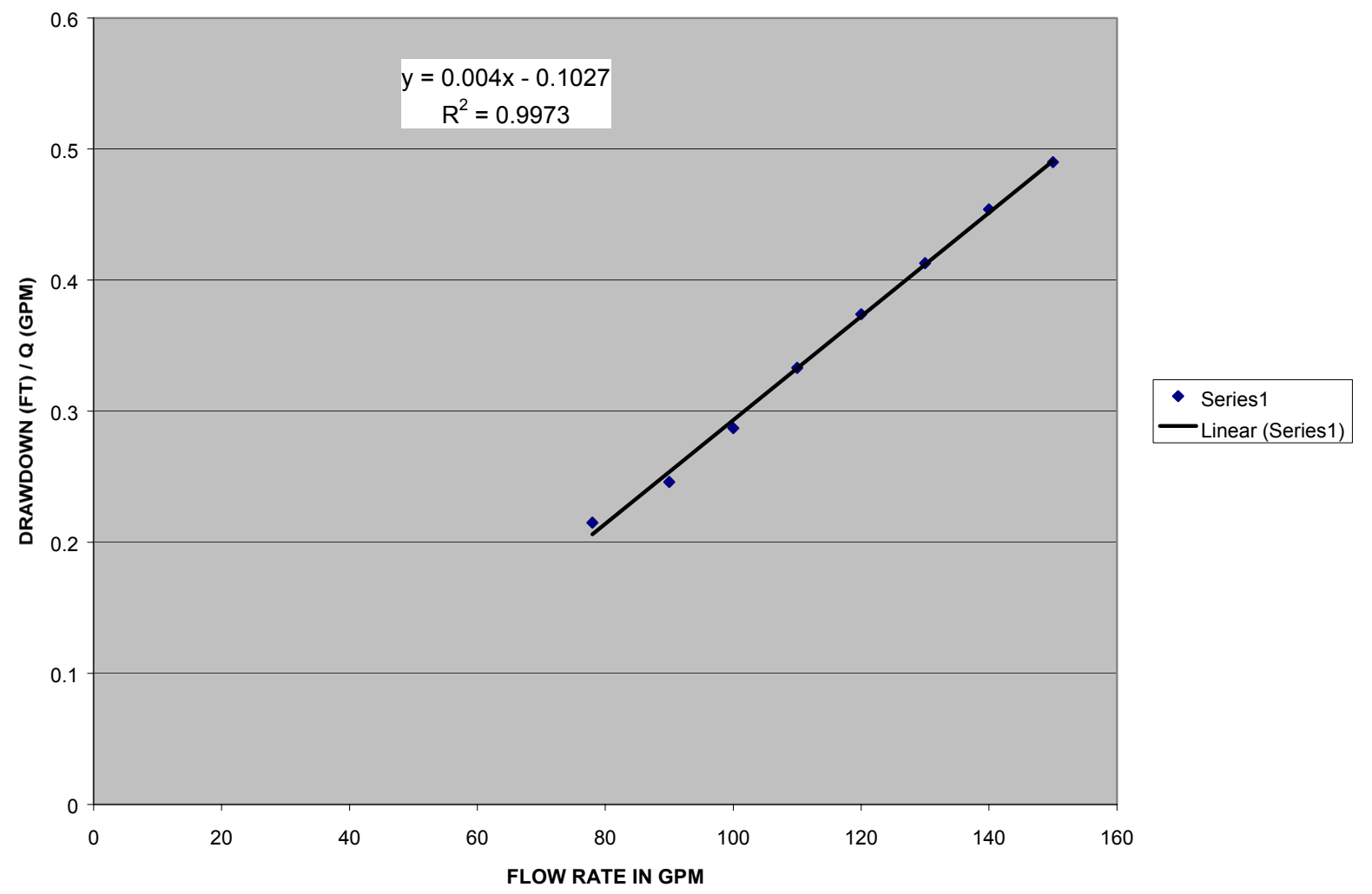

Source: DTN: GS020708312316.001 [DIRS 162678] (data).

NOTE: Each data point represents an average of several drawdown and flow rate measurements at each nominal pump rate. English units are shown in the figure because the analysis was conducted in English units. However, parameter estimates are reported in metric units to downstream users.

Figure F-14. Step-Drawdown Test in the Open Alluvium of NC-EWDP-19D, July 6, 2000

The cause of this problem is believed to be that the step-drawdown test was carried out at a flow-rate range too high to permit calculation of the laminar groundwater flow component, $B \cdot Q$. In the flow-rate range for the test, 295 to $568 \mathrm{~L} / \mathrm{min}$ (78 to $150 \mathrm{gpm}$ ), the turbulent head losses, $C \cdot Q^{2}$, were so large that they dominated the much smaller laminar-flow-caused drawdown, $B \cdot Q$, which, at the accuracy of the test results, is approximately zero. To have been able to calculate the laminar component and, therefore, quantify well efficiency, the step-drawdown test would have had to be run at a much lower range of flow rates than the range used, namely 295 to $568 \mathrm{~L} / \mathrm{min}$ ( 78 to $150 \mathrm{gpm}$ ). However, the pump used, which was required for pumping up to $606 \mathrm{~L} / \mathrm{min}(160 \mathrm{gpm})$ in the open-alluvium test and which was used in the screens \#4 and \#3 isolated interval tests, had a minimum operational rate of approximately $291 \mathrm{~L} / \mathrm{min}$ (77 gpm).

Because the 19D well efficiency could not be calculated from the step-drawdown tests conducted in it, the efficiency was estimated by comparing results from single-well hydraulic tests in that well with those of cross-hole tests. Single-well tests indicated a transmissivity of $28 \mathrm{~m}^{2} /$ day $\left(300 \mathrm{ft}^{2} /\right.$ day) for the saturated alluvium at 19D (Output DTN: GS031008312316.002) (Section F1.3), whereas cross-hole testing indicated a transmissivity of $306 \mathrm{~m}^{2} /$ day 
$\left(3,300 \mathrm{ft}^{2} /\right.$ day) (Output DTN: GS031008312316.002) by analyzing the response in observation well 19IM2 (Section F2).

Drawdown is related to $Q$ and transmissivity, $T$, by the relationship:

$$
s=\frac{Q}{4 \pi T} W(u)
$$

where

$$
\begin{aligned}
u= & r^{2} S / 4 T \mathrm{t}, \text { in which: } \\
& r[\mathrm{~L}]=\text { radial distance from the pumping well } \\
& \mathrm{S}\left[\mathrm{L}^{0}\right]=\text { storativity } \\
& \mathrm{t}[\mathrm{T}]=\text { elapsed time from the beginning of pumping }
\end{aligned}
$$

and

$$
\begin{aligned}
& W(u)=\int_{0}^{\infty}\left(\mathrm{e}^{-\mathrm{u}} / \mathrm{u}\right) \mathrm{du} ; W(u) \text { is the well function for a confined aquifer, or, in modified form, } \\
& \quad \text { for an unconfined or leaky aquifer. }
\end{aligned}
$$

Equation 31 is the same relationship as in Theis (1935 [DIRS 150327], p. 520, Equation 4) except that $s$ is used for drawdown instead of $v$, and $Q$ is used for the discharge rate instead of $F$.

Assuming that head losses in observation well 19IM2 in the cross-hole test when well 19D was being pumped (Section F2) to be negligible relative to those in the pumped well, the value of 306 $\mathrm{m}^{2} /$ day $\left(3,300 \mathrm{ft}^{2} /\right.$ day $)$ is considered to be the true transmissivity value of the alluvium aquifer at the ATC (Output DTN: GS031008312316.002). Therefore, in the single-well tests at well 19D, by substituting $306 \mathrm{~m}^{2} /$ day $\left(3,300 \mathrm{ft}^{2} /\right.$ day $)$ into Equation 31, the drawdown in the aquifer itself due to laminar flow is:

$$
S_{\text {laminar }}=\frac{Q}{4 \pi(306)} W(u)
$$

The actual drawdown in well 19D is the total drawdown (laminar plus turbulent) that was used to calculate a $T$ of $28 \mathrm{~m}^{2} /$ day ( $300 \mathrm{ft}^{2} /$ day), which when substituted into Equation 31 yields:

$$
s_{\text {laminar }}+s_{\text {turbulent }}=\frac{Q}{4 \pi(28)} W(u)
$$

The well function, $W(u)$, in both Equations 32 and 33 is the same because it pertains to the same well and time history. $Q$ is also the same; it is the actual pumping rate for the single-well testing.

The well efficiency for 19D (Output DTN: GS031008312316.002) is now calculated by dividing Equation 32 by Equation 33:

$$
\text { Efficiency }=\frac{s_{\text {laminar }}}{S_{\text {laminar }}+s_{\text {turbulent }}}=\frac{28}{306}=0.091=9.1 \%
$$




\section{F1.5 DETERMINATION OF LEAKAGE FROM SCREENS \#5, \#6, AND \#7 TO SCREEN \#4}

After single-well hydraulic and tracer tests in well 19D, screen \#4 had been selected to conduct cross-hole tracer testing by pumping 19D and injecting tracers into 19IM1 and 19IM2. For that reason, it was desirable to determine the upward contribution of the intervals below the alluvium (screens \#5, \#6, and \#7 in 19D) to the water withdrawn from screen \#4 in 19D during such a cross-hole tracer test (see Figure 6.1-8 for location of screens and other lithologic information). Such contribution from the intervals below the alluvium would be promoted by the natural upward gradient at the site and the creation of a substantial additional vertical gradient by pumping screen \#4 in 19D and lowering its hydraulic head. Knowledge of this contribution is necessary for the correct analysis of the results from cross-hole tracer testing in screen \#4, especially for effective porosity. The flow rate that should be used in calculating the effective porosity when analyzing the results of cross-hole tracer testing should be the portion of the pumped rate that is actually provided by screen $\# 4$ of the alluvium, that is, excluding the portion contributed by the intervals below the alluvium.

To determine the component of flow from below screen \#4, three "confirmatory" hydraulic tests were conducted in 19D. The results from these three tests will first be presented below, followed by an analysis to determine the leakage rate from below the screen $\# 4$ interval.

In the first confirmatory test from December 18 to 20, 2001, the combined interval below the alluvium containing screens \#5, \#6, and \#7 was pumped at the nominal rate of $356 \mathrm{~L} / \mathrm{min}$ (94 gpm) for $48 \mathrm{hr}$. During the test, the screen \#4 interval and the combined interval containing screens \#1, \#2, and \#3 were monitored. The drawdown in the combined screens \#5, \#6, and \#7 interval as a function of elapsed time is shown in Figure F-15.

In the second confirmatory test from January 4 to 6,2002 , the screen \#5 interval also (like the screens $\# 5$, \#6, and \#7 interval test) was pumped at the nominal rate of $356 \mathrm{~L} / \mathrm{min}$ (94 gpm) for $48 \mathrm{hr}$. During the test, the combined screens \#6 and \#7 interval, the screen \#4 interval, and the combined screens \#1, \#2, and \#3 interval were monitored. The drawdown in the screen \#5 interval as a function of elapsed time is shown in Figure F-16.

In the third confirmatory test from January 8 to 10,2002 , the screen $\# 4$ interval was pumped at the nominal rate of $254 \mathrm{~L} / \mathrm{min}(67 \mathrm{gpm})$ for $48 \mathrm{hr}$. During the test, the combined screens \#5, \#6, and \#7 interval, the screen \#3 interval, and the combined screens \#1 and \#2 interval were monitored. The drawdown in the screen \#4 interval as a function of elapsed time is shown in Figure F-17.

Also for this confirmatory test in screen \#4, the recovery for the screens \#5, \#6, and \#7 interval is shown in Figure F-18 because it is needed in the following analysis of leakage.

To determine the component of flow from below screen \#4 to withdrawal from screen \#4, a comparison was made of the drawdown in screens \#5, \#6, and \#7 when they were pumped at $356 \mathrm{~L} / \mathrm{min}$ (94 gpm) in the December 18, 2001, test (Figure F-15) with the drawdown in screens $\# 5$, \#6, and \#7 in response to pumping screen \#4 in the August 24, 2000, "screen \#4" test (Figure F-19). 
Figure F-20 presents the comparison. The responses are very similar with a ratio of 153 in the drawdown values. These are both drawdowns in the same intervals (i.e., screens \#5, \#6, and \#7): one in response to direct pumping at $356 \mathrm{~L} / \mathrm{min}(94 \mathrm{gpm})$ and the other in response to an unknown leakage rate from screens $\# 5$, \#6, and \#7 to screen $\# 4$. Thus,

$$
\frac{S_{5,6,7(12 / 18 / 01)}}{S_{5,6,7(8 / 24 / 00)}}=153
$$

where $s_{5,6,7(12 / 18 / 01)}$ is the drawdown for the combined screens \#5, \#6, and \#7 interval on December 18, 2001, and so forth.

48 HOUR PUMPING TEST IN INTERVALS 5,6,7 (TUFF \& TERTIARY SEDIMENTS) IN 19D1 STARTING AT 2PM ON 12/18/01

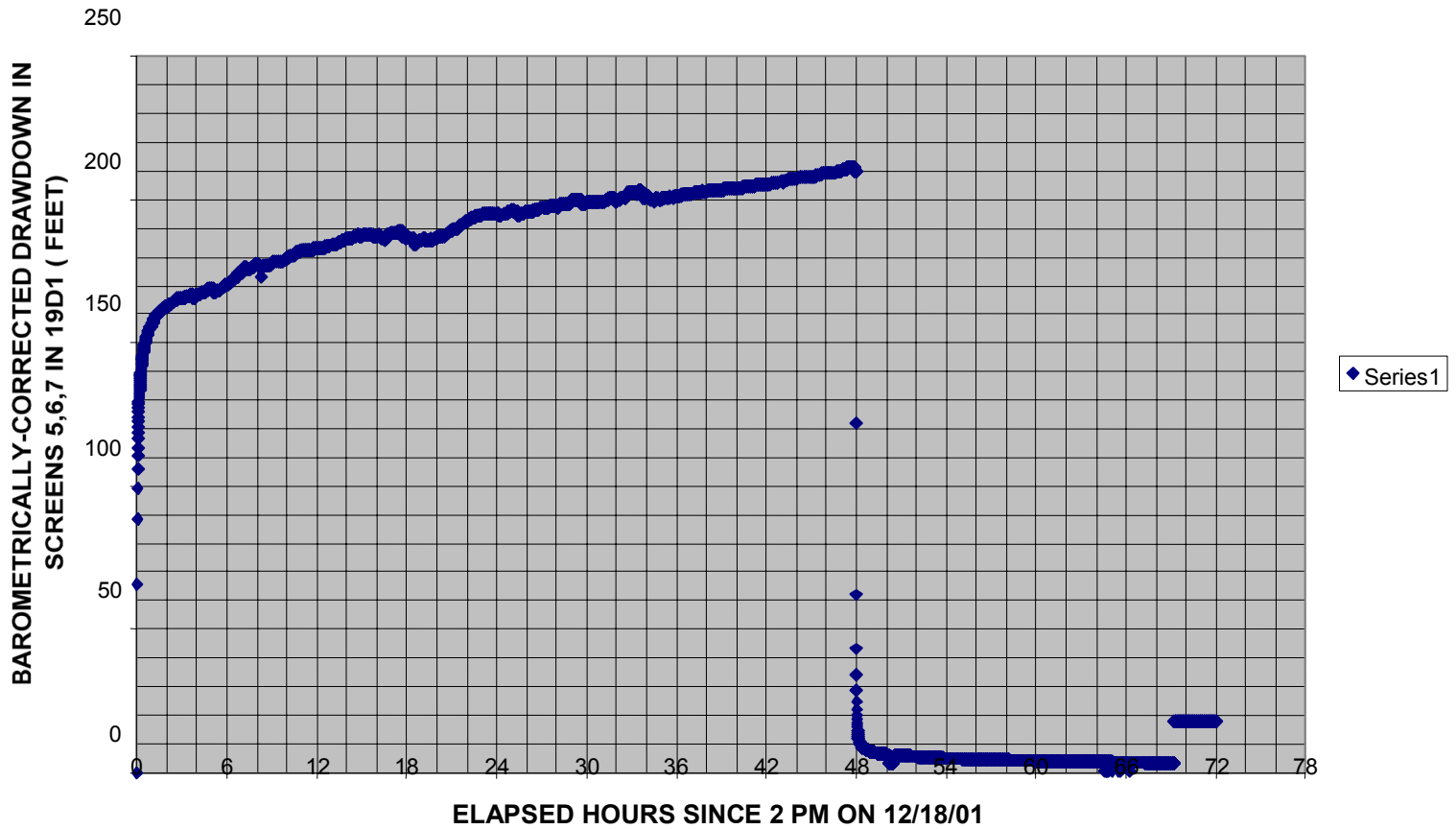

Source: DTN: GS020908312316.002 [DIRS 162679] (data).

NOTE: English units are shown in the figure because the analysis was conducted in English units. However, parameter estimates are reported in metric units to downstream users.

Figure F-15. Drawdown Versus Elapsed Time Since Pumping Started for the Confirmatory Hydraulic Test in Which the Combined Screens \#5, \#6, and \#7 Interval in NC-EWDP-19D Was Pumped 
48 HOUR TEST IN SCREEN \#5 OF NC-EWDP-19D1 STARTING AT 10:30 AM ON 1/4/02

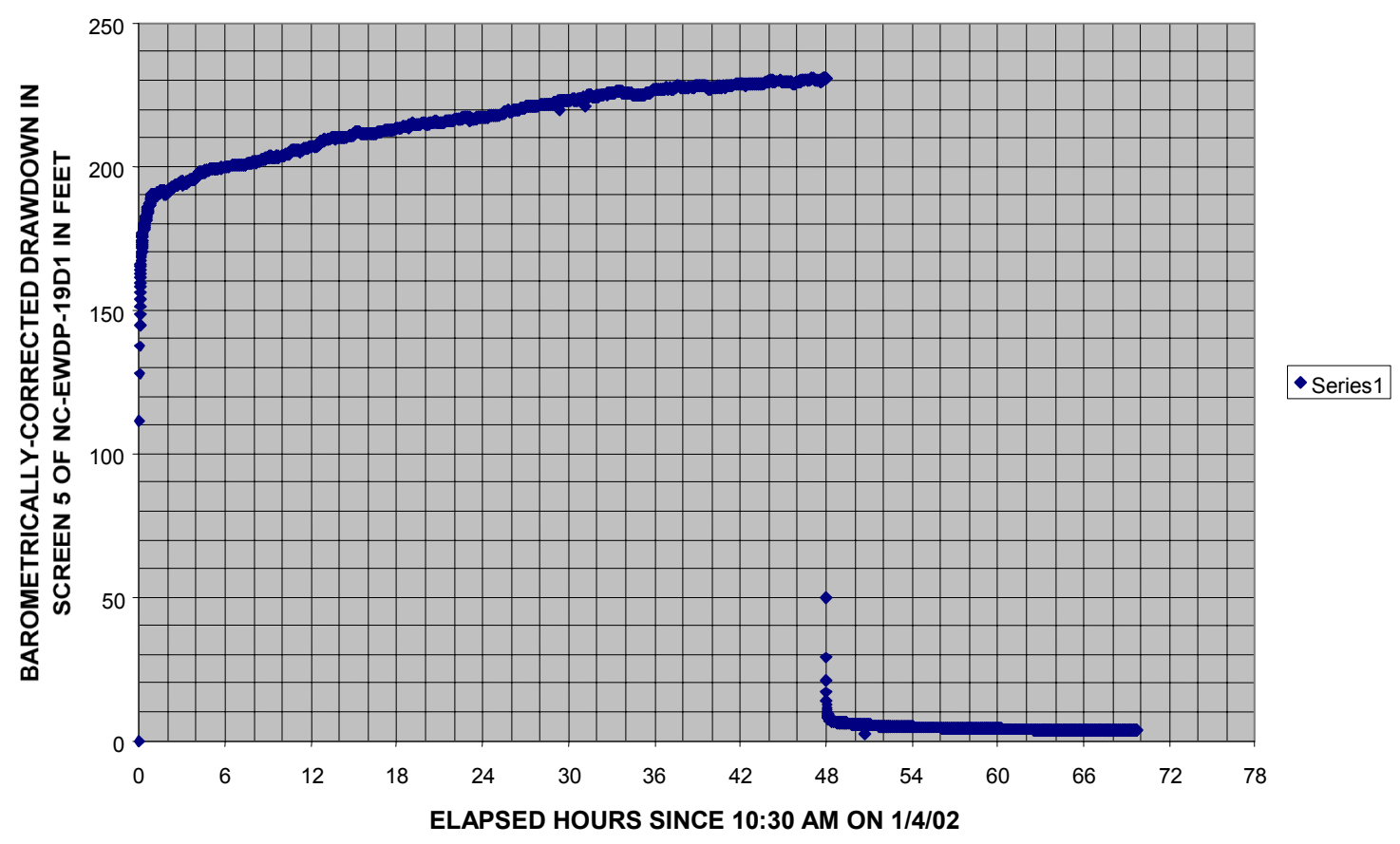

Source: DTN: GS020908312316.002 [DIRS 162679] (data).

NOTE: English units are shown in the figure because the analysis was conducted in English units. However, parameter estimates are reported in metric units to downstream users.

Figure F-16. Drawdown as a Function of Elapsed Time for the Confirmatory Hydraulic Test in Which the Screen \#5 Interval in NC-EWDP-19D Was Pumped 


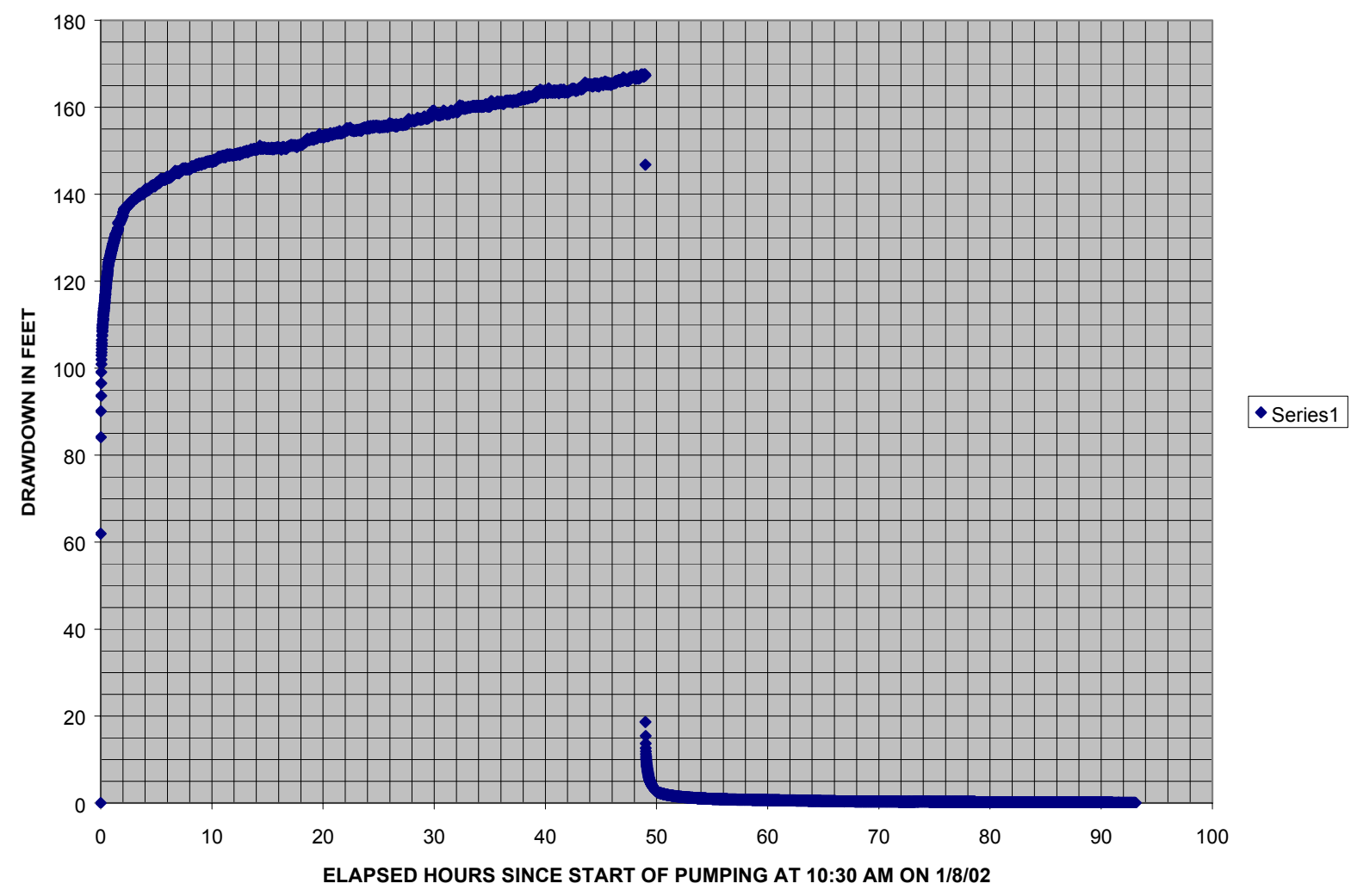

Source: DTN: GS020908312316.002 [DIRS 162679] (data).

NOTE: English units are shown in the figure because the analysis was conducted in English units. However, parameter estimates are reported in metric units to downstream users.

Figure F-17. Drawdown as a Function of Elapsed Time in Screen \#4 During Pumping and Recovery in the Confirmatory Hydraulic Test in that Screen, January 8 to 10, 2002 


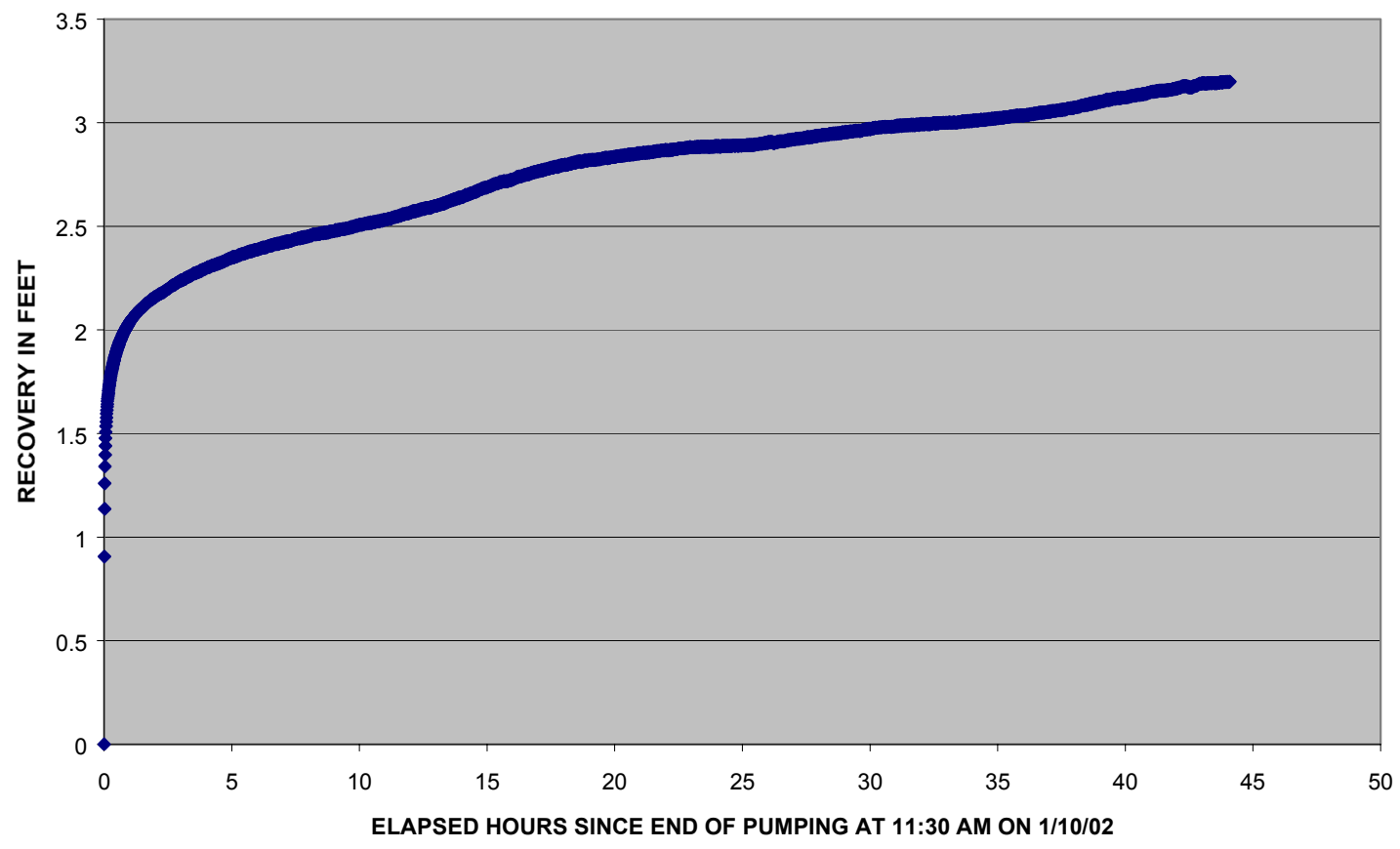

Source: DTN: GS020908312316.002 [DIRS 162679] (data).

NOTE: English units are shown in the figure because the analysis was conducted in English units. However, parameter estimates are reported in metric units to downstream users.

Figure F-18. Recovery Versus Elapsed Time for the Screens \#5, \#6, and \#7 Interval During the Confirmatory Hydraulic Test in Screen \#4 of NC-EWDP-19D, January 8 to 10, 2002 
DRAWDOWN IN SCREENS \#5,6,7 DURING THE 8/24/00 PUMPING TEST IN SCREEN \#4

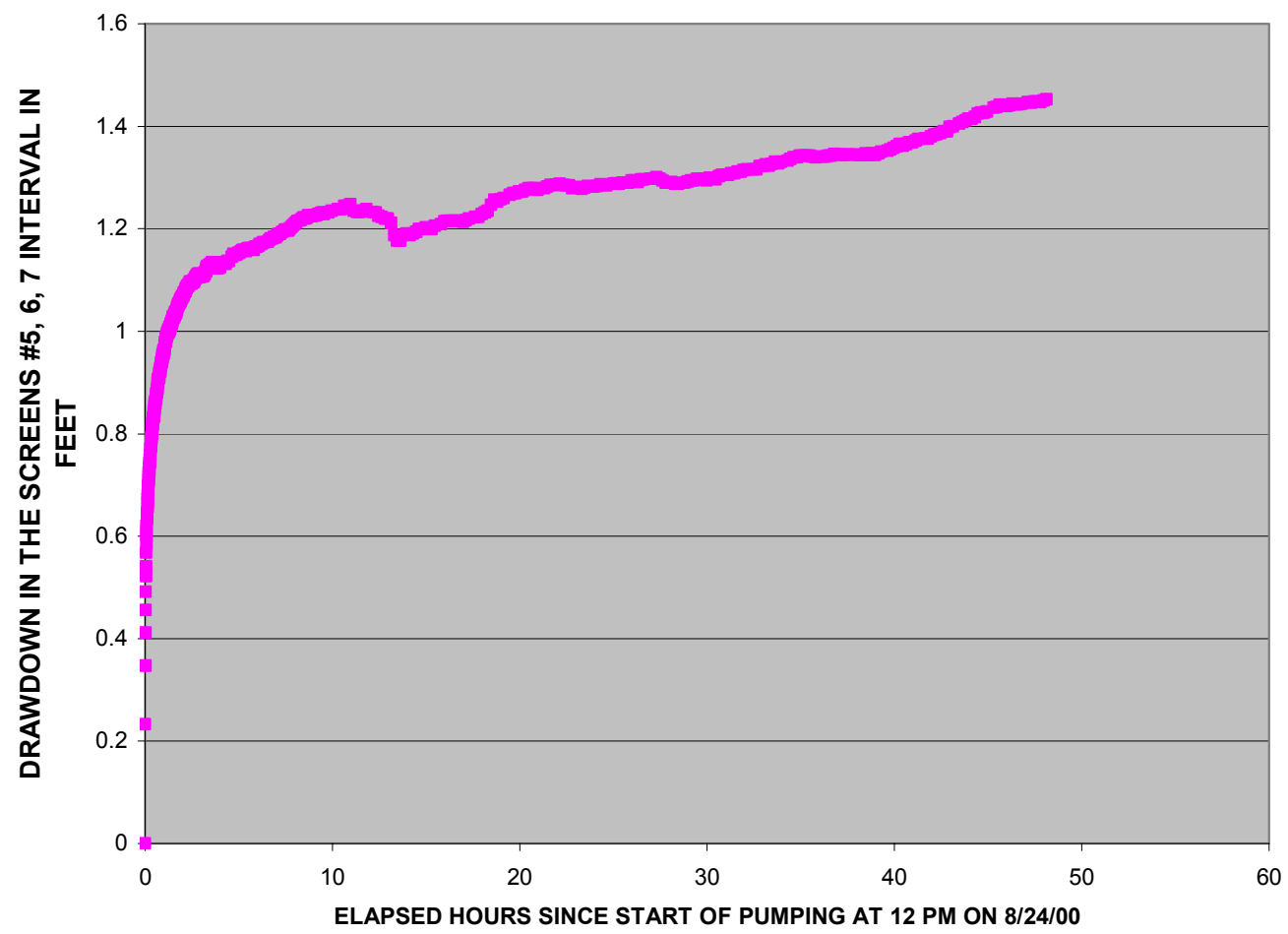

Source: DTN: GS020708312316.001 [DIRS 162678] (data).

NOTE: English units are shown in the figure because the analysis was conducted in English units. However, parameter estimates are reported in metric units to downstream users.

Figure F-19. Drawdown in the Screens \#5, \#6, and \#7 Interval During the August 24 to 31, 2000, Pumping Test in Screen \#4 
12/18/01 TEST IN SCREENS \#5,6,7 COMPARED WITH 8/24/00 RESPONSE ALSO IN \#5,6,7

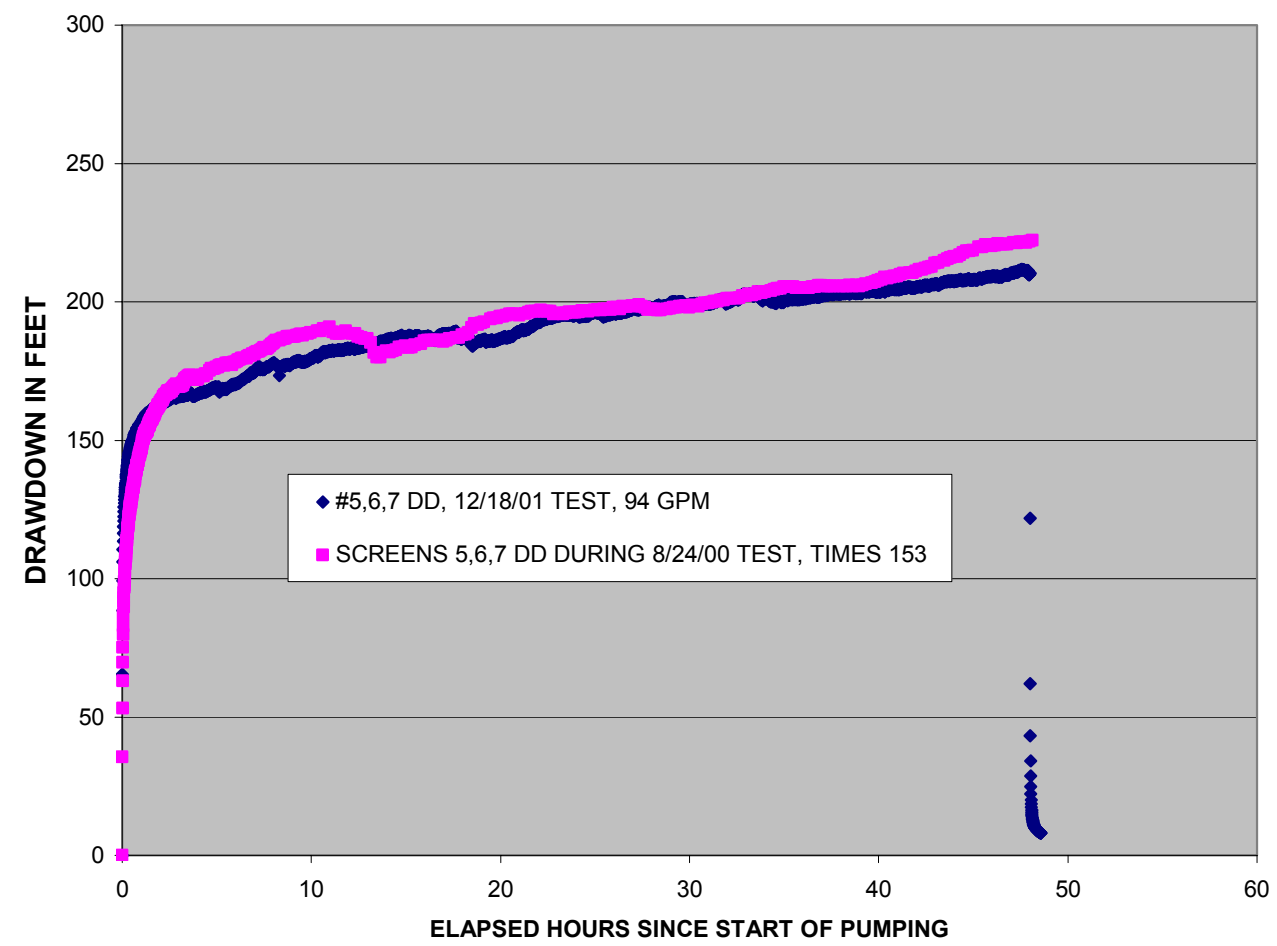

Source: DTNs: GS020708312316.001 [DIRS 162678] and GS020908312316.002 [DIRS 162679] (data).

NOTE: English units are shown in the figure because the analysis was conducted in English units. However, parameter estimates are reported in metric units to downstream users.

Figure F-20. Comparing Drawdown in the Screens \#5, \#6, and \#7 Interval While It Was Pumped During the December 18, 2001, Test with the Drawdown in the Same Interval During the August 24 to 31, 2000, Pumping Test in Screen \#4

A correction should be made, however, to the drawdown in the screens \#5, \#6, and \#7 interval during the December 18, 2001, test, based on the approximately 9 percent well efficiency of 19D, as determined by Equation 34. This efficiency indicates that the laminar component of the drawdown occurring in the aquifer is only 9 percent of the total drawdown recorded in the screens \#5, \#6, and \#7 interval of 19D when that interval was directly pumped during the December 18,2001 , test. In other words, using a prime to indicate laminar drawdown in the aquifer and multiplying the drawdown by the well efficiency (decimal equivalence 0.09) in order to calculate 9 percent of drawdown is mathematically expressed as,

$$
S_{5,6,7(12 / 18 / 01)}^{\prime}=(0.09) S_{5,6,7(12 / 18 / 01)}
$$


On the other hand, negligible head losses are assumed in the screens \#5, \#6, and \#7 interval when it was not pumped directly but leaked to the screen \#4 interval when the latter was pumped in the August 24, 2000, test - that is, if we do not subtract any drawdown for well inefficiency, then $s$ prime equals $s$, which is mathematically expressed as

$$
S_{5,6,7(8 / 24 / 00)}^{\prime}=S_{5,6,7(8 / 24 / 00)} \text {. }
$$

Therefore, the ratio of drawdowns occurring in the aquifer itself for the above two contrasted tests is

$$
\frac{s_{5,6,7(12 / 18 / 01)}^{\prime}}{s_{5,6,7(8 / 24 / 00)}^{\prime}}=(0.09) \frac{s_{5,6,7(12 / 18 / 01)}}{S_{5,6,7(8 / 24 / 00)}}=(0.09)(153)=13.77
$$

Assuming that the transmissivity of the screens $\# 5, \# 6$, and \#7 interval is the same during the August 24, 2000, and December 18, 2001, tests, the ratio of the two drawdown responses, which is 13.77, should be the same as the ratio of the flow rates that produced them - that is, from Equation 31 (Theis 1935 [DIRS 150327]),

$$
s_{5,6,7(12 / 18 / 01)}^{\prime}=\frac{356}{4 \pi T} W(u)
$$

and

$$
s_{5.6 .7(8 / 24 / 00)}^{\prime}=\frac{Q_{5,6,7(8 / 24 / 00)}}{4 \pi T} W(u)
$$

where $Q_{5,6,7(8 / 24 / 00)}$ is the "withdrawal" rate from the screens \#5, \#6, and \#7 interval that occurred while pumping screen \#4; that is, the leakage from screens \#5, \#6, and \#7 to screen \#4 during the August 24 to 31, 2000 test. Dividing Equation 39 by Equation 40 gives

$$
\frac{s_{5,6,7(12 / 18 / 01)}^{\prime}}{S_{5,6,7(8 / 24 / 00)}^{\prime}}=\frac{356}{Q_{5,6,7(8 / 24 / 00)}}
$$

or, using the value for the ratio of 13.77 from Equation 38 , we find that

$$
Q_{5,6,7(8 / 24 / 00)}=\frac{356}{13.77}=25.8 \mathrm{~L} / \mathrm{min} \text { or }(6.83 \mathrm{gpm})
$$

In other words, when screen \#4 was pumped at the rate of $299 \mathrm{~L} / \mathrm{min}$ (79 gpm) during the August 24, 2000, test, $25.8 \mathrm{~L} / \mathrm{min}(6.83 \mathrm{gpm})$ of the $299 \mathrm{~L} / \mathrm{min}$ (79 gpm) withdrawn (or 8.65 percent) actually came from the screens \#5, \#6, and \#7 interval.

The same analysis can be done by comparing the drawdown in the screens \#5, \#6, and \#7 interval when it was pumped in the December 18, 2001 test (Figure F-15) with the recovery in the same interval in response to pumping the screen \#4 interval in the January 8, 2002, test (Figure F-18). 
Figure F-21 presents the comparison. The responses are very similar with a ratio of 69 in the drawdown values - that is,

$$
\frac{S_{5,6,7(12 / 18 / 01)}}{S_{5,6,7(1 / 8 / 02)}}=69 .
$$

These are both drawdowns in the same intervals (i.e., the combined screens \#5, \#6, and \#7) - one in response to direct pumping at $356 \mathrm{~L} / \mathrm{min}(94 \mathrm{gpm})$ and the other in response to an unknown leakage rate from screens $\# 5$, \#6, and \#7 to screen \#4.

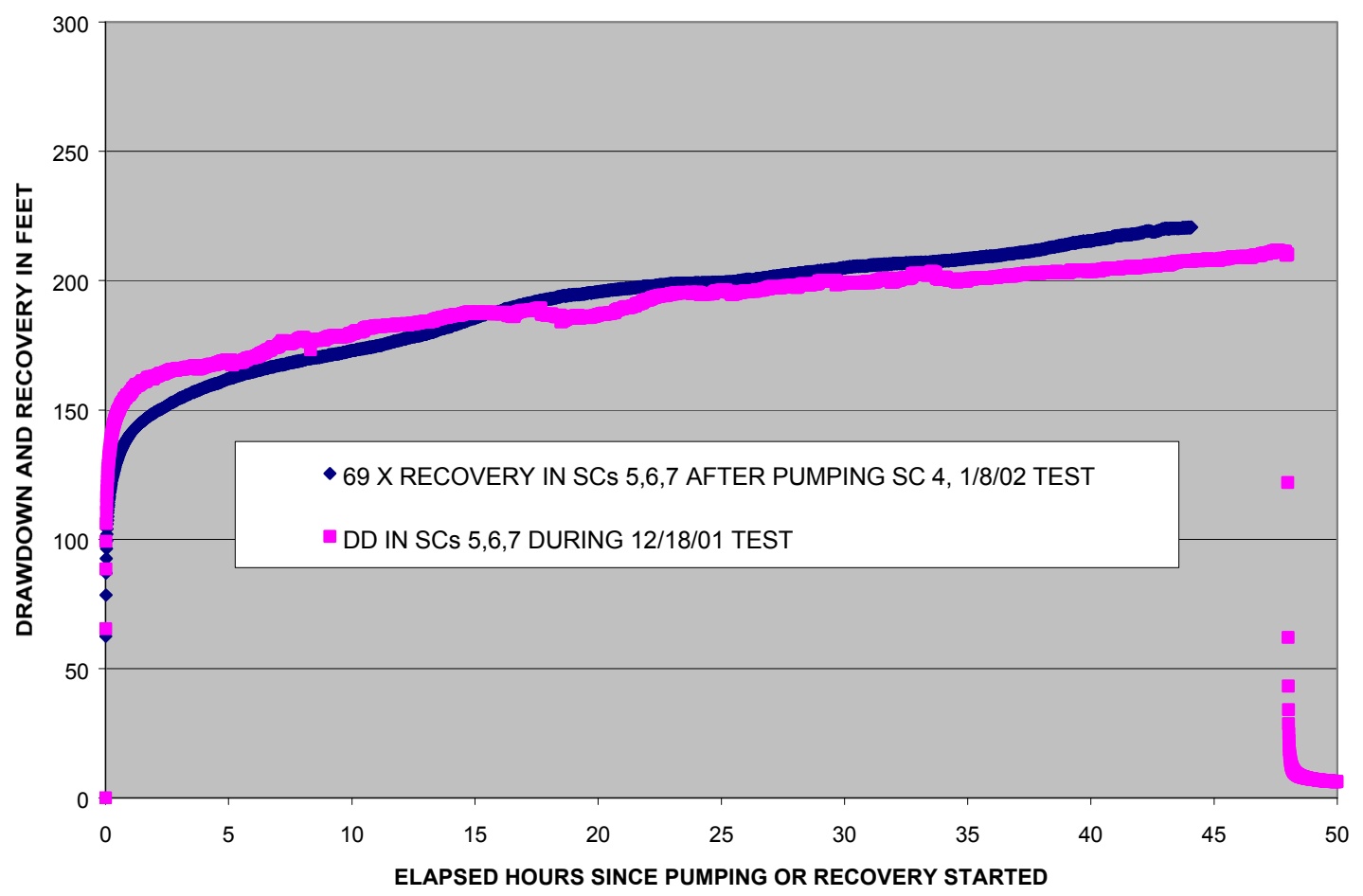

Source: DTN: GS020908312316.002 [DIRS 162679] (data).

NOTE: English units are shown in the figure because the analysis was conducted in English units. However, parameter estimates are reported in metric units to downstream users.

Figure F-21. Comparing Drawdown in the Screens \#5, \#6, and \#7 Interval While It Was Pumped During the December 18, 2001, Test with the Recovery in the Same Interval after Cessation of Pumping in Screen \#4 During the January 8, 2002, Test 
Negligible head losses are assumed in the screens \#5, \#6, and \#7 interval when it was not pumped directly but leaked to the screen \#4 interval when the latter was pumped in the January 8,2002 , test- that is,

$$
S_{5,6,7(1 / 8 / 02)}^{\prime}=S_{5,6,7(1 / 8 / 02)} .
$$

Assuming that the transmissivity of screens \#5, \#6, and \#7 is the same during the December 18, 2001 , and January 8, 2002, tests, the ratio of the two drawdown responses, which is 38.8 , should be the same as the ratio of the flow rates that produced them-that is, from Equation 31 (Theis 1935 [DIRS 150327], p. 520, Equation 4),

$$
s_{5,6,7(12 / 18 / 01)}^{\prime}=\frac{356}{4 \pi T} W(u),
$$

which is the same as Equation 39 (Theis 1935 [DIRS 150327], p. 520, Equation 4), and

$$
s_{5,6,7(1 / 8 / 02)}^{\prime}=\frac{Q_{5,6,7(1 / 8 / 02)}}{4 \pi T} W(u)
$$

where $Q_{5,6,7(1 / 8 / 02)}$ is the "withdrawal" rate from the screens \#5, \#6, and \#7 interval occurring during the pumping of screen \#4 (that is, the leakage from screens \#5, \#6, and \#7 to screen \#4) during the January 8, 2002, test. Dividing Equation 45 by Equation 46 (Theis 1935 [DIRS 150327], p. 520, Equation 4) gives

$$
\frac{s_{5,6,7(12 / 18 / 01)}^{\prime}}{s_{5,6,7(1 / 8 / 02)}^{\prime}}=\frac{356}{Q_{5,6,7(1 / 8 / 02)}} .
$$

Substituting $0.09 \mathrm{~s}_{5,6,7(12 / 18 / 01)}$ for $\mathrm{s}_{5,6,7,(12 / 18 / 01)}$ from Equation 36, and $\mathrm{s}_{5,6,7(1 / 8 / 02)}$ for $\mathrm{s}_{5,6,7(1 / 8 / 02)}$ from Equation 44, into Equation 47, and then further substituting 69 from Equation 43 for the

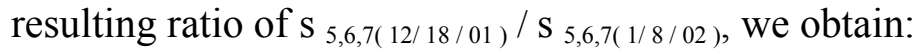

$$
\mathrm{Q}_{5,6,7(1 / 8 / 02)}=356 /(0.09 \times 69)=57.3 \mathrm{~L} / \mathrm{min}(15.14 \mathrm{gpm})
$$

In other words, when screen \#4 was pumped at the rate of $254 \mathrm{~L} / \mathrm{min}$ (67 gpm) during the January 8, 2002 test, $57.3 \mathrm{~L} / \mathrm{min}(15.14 \mathrm{gpm})$ of the $254 \mathrm{~L} / \mathrm{min}(67 \mathrm{gpm})$ withdrawn (or 22.6 percent) actually came from the screens $\# 5, \# 6$, and \#7 interval.

The increase in calculated leakage from screens \#5, \#6, and \#7 to screen \#4 in the January 8, 2002, test, 22.6 percent, compared to the calculated leakage in the August 24, 2000, test, 8.65 percent, is a result of the drop of efficiency of Borehole 19D (at least in screen \#4) in the time period between the two tests. When the screen \#4 drawdown of the January 8, 2002, test is analyzed by the Neuman (1975 [DIRS 150321] (Neuman.vi V 1.0, STN: 10972-1.0-00 [DIRS 162754]) solution, a transmissivity of $4.4 \mathrm{~m}^{2} /$ day $\left(48 \mathrm{ft}^{2} /\right.$ day) is obtained compared with the $28 \mathrm{~m}^{2}$ /day (300 $\mathrm{ft}^{2} /$ day) obtained by analyzing the August 24, 2000, screen \#4 interval test. Both of these transmissivities were estimated without accounting for leakage from screens \#5 to \#7 to screen \#4; if leakage were accounted for, the transmissivities would be somewhat smaller. 
This result indicates that the 19D (screen \#4) well efficiency during the January 8, 2002, test could have been as low as 16 percent (4.4/28) of the well efficiency during the August 24, 2000, test. Loss of well efficiency causes increased drawdown in the pumped interval, screen \#4, which causes an increase in the upward gradient, and resultant leakage, from screens \#5, \#6, and \#7 to screen \#4.

Based on the two analyses above that compare the drawdown in the screens \#5, \#6, and \#7 interval when it was directly pumped during the December 18, 2001, test with the drawdown in the screens \#5, \#6, and \#7 interval in response to pumping screen \#4 in both the August 24, 2000, and January 8, 2002, tests, it is concluded that up to 23 percent (upper envelope of 8.65 percent and 22.6 percent) of the flow rate may have been a contribution from the screens \#5, \#6, and \#7 interval when pumping screen \#4 in 19D (DTN: GS020708312316.001 [DIRS 162678]; DTN: GS020908312316.002 [DIRS 162679]; Output DTN: GS031008312316.002).

\section{F2. ATC CROSS-HOLE HYDRAULIC TESTING}

Two cross-hole hydraulic tests were conducted at the ATC in January 2002. In both tests, borehole 19D was pumped in the open-alluvium section while 19IM1 and 19IM2 were used as monitoring wells. The surface configuration of the three wells is shown in Figure 6.1-7, and Figure 6.1-8 shows the construction/completion of the wells. Cross-hole hydraulic responses in 19IM1 were not analyzed quantitatively for this scientific analysis report because data collection in this well was not conducted in strict accordance with Yucca Mountain Project Quality Assurance procedures.

In the first cross-hole hydraulic test, conducted from January 26 to 28, 2002, in 19D, both 19IM1 and 19IM2 were packed off, each isolating four intervals in the alluvium section. In the January 29 to February 4, 2002, test, 19IM1 was packed off while 19IM2 had only one packer inflated isolating the alluvium section from the intervals below it. Only results from the January 29 to February 4, 2002, test are presented in this report because the total transmissivity of the alluvium is less ambiguously obtained in this test than in the earlier test with isolated intervals in the observation wells.

The drawdown in the alluvium section of 19IM2 resulting from pumping the same section in well 19D at 109 gpm from January 29 to February 4, 2002, is presented in Figure F-22. This drawdown exhibits the characteristics of a confined aquifer, and the fit to the type curve of Theis (1935 [DIRS 150327]) (Neuman.vi V 1.0, STN: 10972-1.0-00 [DIRS 162754]) is presented in Figure F-23. The fact that the response at 19IM2 is that of a confined aquifer, whereas the response of single-well testing in 19D conformed to the Neuman (1975 [DIRS 150321]) unconfined response, indicates that there may be a unit causing confinement at 19IM2 that pinches out at 19D. The possibility was considered that the drawdown in 19IM2 was so small relative to the saturated thickness at this observation well (approximately 2 percent) that the response followed that of a confined aquifer even though the aquifer was unconfined. However, attempts to fit the Neuman (1975 [DIRS 150321]) (Neuman.vi V 1.0, STN: 10972-1.0-00 [DIRS 162754]) unconfined aquifer solution to the drawdown response indicated that the test had been conducted long enough to exhibit the flattening in drawdown at late times that would be expected if the aquifer were unconfined. Because this flattening did not occur, it appears likely that a confining layer influenced the response near 19IM2. 
The fit to the Theis (1935 [DIRS 150327]) curve presented in Figure F-23 results in an estimated transmissivity value of $306 \mathrm{~m}^{2} /$ day $\left(3,300 \mathrm{ft}^{2} /\right.$ day) (Output DTN: GS031008312316.002) and a storativity of 0.00045 (Output DTN: GS031008312316.002). The transmissivity estimate is approximately an order-of-magnitude higher than the $28 \mathrm{~m}^{2} /$ day $\left(300 \mathrm{ft}^{2} /\right.$ day $)$ value obtained from single-well testing in 19D (Section F1.2). This difference is the result of large head losses in the single-well testing, and the ratio of the single-well to the cross-hole transmissivities is shown in the discussion leading to Equation 34 to be the efficiency of well 19D. The tested interval in 19IM2 from the water table to the bottom of screen \#4 is approximately $133 \mathrm{~m}$ (437 $\mathrm{ft})$. Therefore, the hydraulic conductivity is $306 \mathrm{~m} /$ day/133 m (3,300 ft²/day/437 ft), which is approximately $2.3 \mathrm{~m} /$ day (7.5 ft/day) (Output DTN: GS031008312316.002).

The storativity estimate above allows calculation of the specific storage needed for calculation of total porosity in Section F3. The above storativity estimate of 0.00045 is for the entire open-alluvium thickness at 19IM2, which is $133.1 \mathrm{~m}$ (436.6 ft) (depth to bottom of sand at the bottom of screen \#4, $242.5 \mathrm{~m}$ [795.6 ft], minus depth to water, $109 \mathrm{~m}[359 \mathrm{ft}])$. These numbers give a value for the specific storage, $S_{\mathrm{s}}$, of $0.00045 / 133.1 \mathrm{~m}=0.00000338 \mathrm{~m}^{-1}(0.00045 / 436.6 \mathrm{ft}$ $\left.=0.000001031 \mathrm{ft}^{-1}\right)$ (Output DTN: GS031008312316.002).

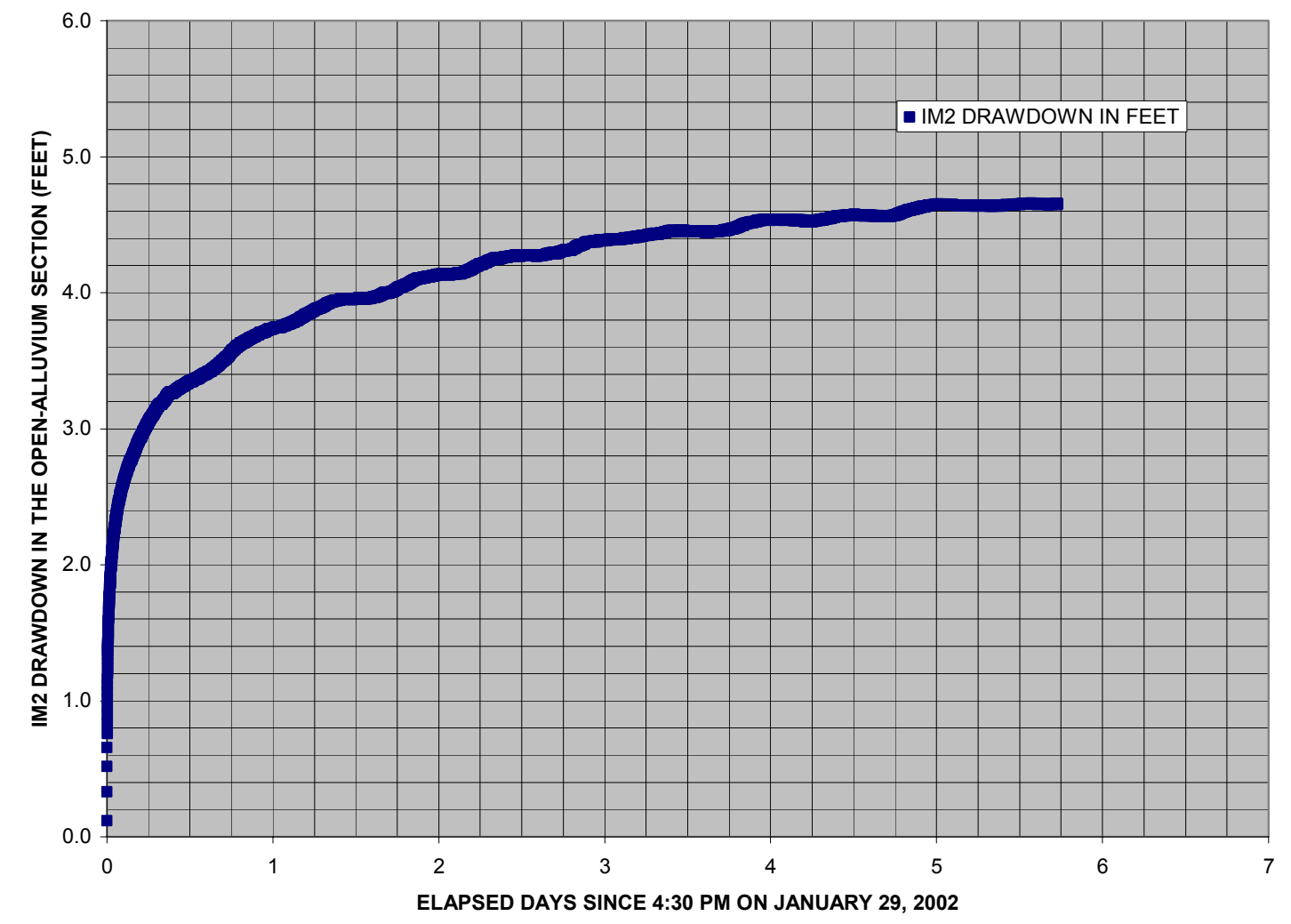

Source: DTN: GS020908312316.002 [DIRS 162679] (data).

NOTE: English units are shown in the figure because the analysis was conducted in English units. However, parameter estimates are reported in metric units to downstream users.

Figure F-22. Drawdown in the Open-Alluvium Section of Observation Well NC-EWDP-19IM2 While Pumping NC-EWDP-19D at the Nominal Rate of $109 \mathrm{gpm}$ 


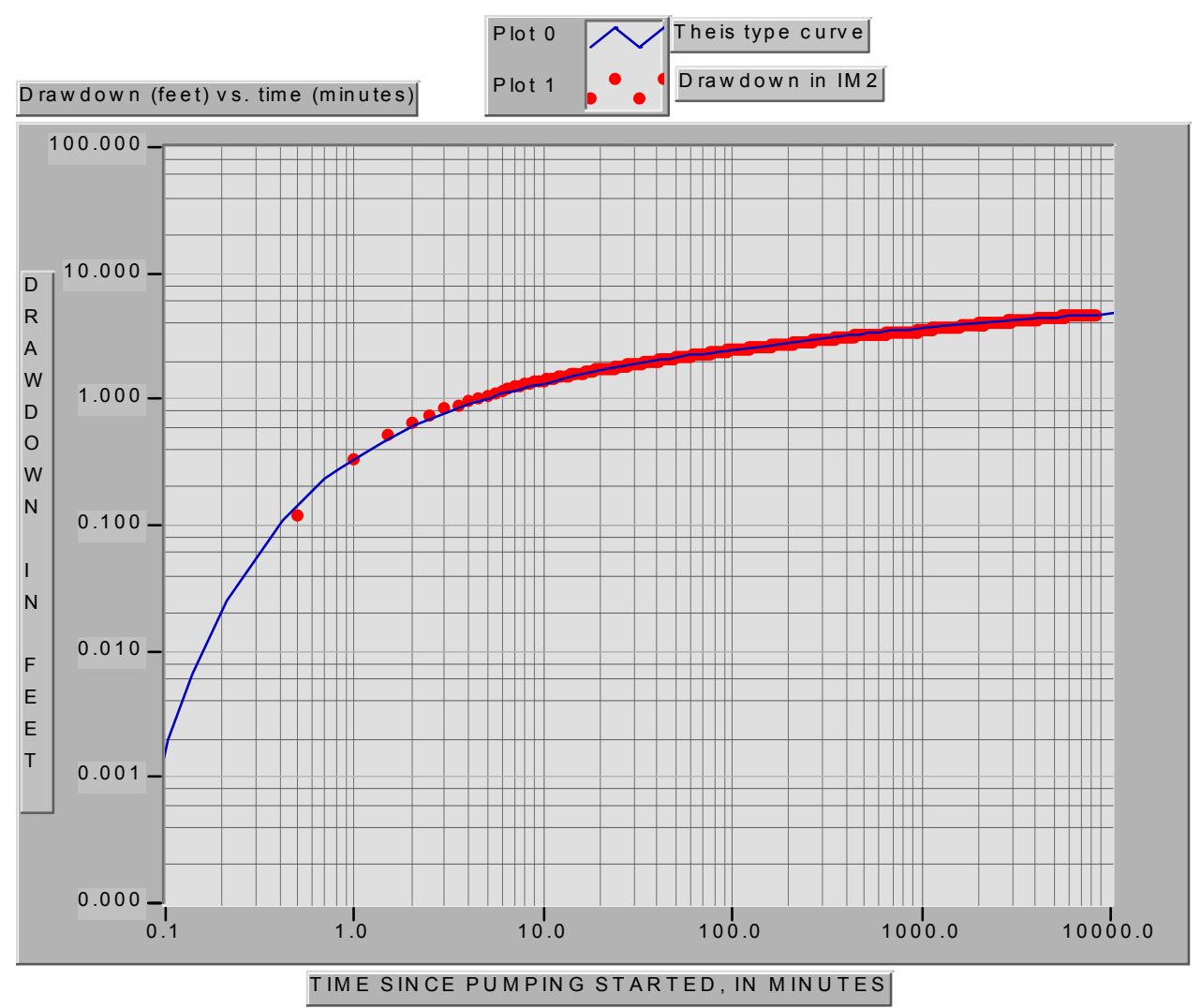

Source: DTN: GS020908312316.002 [DIRS 162679] (data).

Output DTN: GS031008312316.002 (analysis).

NOTE: English units are shown in the figure because the analysis was conducted in English units. However, parameter estimates are reported in metric units to downstream users.

Figure F-23. Fit to the Theis (1935) Confined-Aquifer Solution of the Drawdown in NC-EWDP-19IM2 Resulting from Pumping NC-EWDP-19D at $109 \mathrm{gpm}$

\section{F2.1 QUALITATIVE DISCUSSION OF HORIZONTAL ANISOTROPY OF THE HYDRAULIC CONDUCTIVITY}

The drawdown pattern at 19IM1 and 19IM2 in response to pumping 19D in both of the above cross-hole tests clearly indicated anisotropy in the horizontal hydraulic conductivity. It showed that the direction of the major principal hydraulic conductivity tensor is oriented in the northeast to southwest direction (Output DTN: GS031008312316.002). With only two observation wells, however, the degree of horizontal anisotropy and its precise orientation cannot be quantified. It should be noted that because the apparent transmissivity between 19D and IM2 was greater than the transmissivity between -19D and 19IM1, the estimate of well efficiency in Section F1.5 would have been greater if the transmissivity between 19D and 19IM1 had been used instead of the transmissivity between 19D and 19IM2. 


\section{F3. TOTAL POROSITY ESTIMATED FROM SPECIFIC STORAGE AND BAROMETRIC EFFICIENCY}

An estimate of total porosity was obtained by combining the specific storage value from cross-hole testing, namely $S_{\mathrm{s}}=0.00000338 \mathrm{~m}^{-1}\left(0.000001031 \mathrm{ft}^{-1}\right)$ (Section F2), with a value of barometric efficiency, $B E$, obtained from analyzing background water-level monitoring. Calculation of total porosity is done through use of a relationship derived for a confined aquifer in De Wiest (1965 [DIRS 162674], p. 191, Equation 4.77). This equation is also presented in Geldon et al. (1997 [DIRS 156827], p. 15, Equation 14) and attributed to Jacob. Using the notation of Geldon et al. (1997 [DIRS 156827]) and rearranging terms of his equation, an expression for total porosity, $\theta$, can be written as:

$$
\theta=\frac{S_{\mathrm{s}}(B E)}{\gamma \beta}
$$

where

$\gamma=$ the unit weight of water $=1000 \mathrm{~kg} / \mathrm{m}^{3}\left(0.434 \mathrm{lb} / \mathrm{in}^{2} / \mathrm{ft}\left[62.496 \mathrm{lb} / \mathrm{ft}^{3}\right]\right)(\mathrm{Lohman} 1972$

[DIRS 150250], Constants in Equations 20 and 21).

$\beta=$ the compressibility of water $=4.69 \times 10^{-9} \mathrm{~m}^{2} / \mathrm{kg}\left(3.3 \times 10^{-6} \mathrm{in}^{2} / \mathrm{lb}\left[2.29167 \times 10^{-8} \mathrm{ft}^{2} / \mathrm{lb}\right]\right)$

(Lohman 1972 [DIRS 150250], Constants in Equations 20 and 21).

The barometric efficiency, $B E$, was obtained by analyzing background water-level monitoring conducted between May 1 and July 3, 2002 (DTN: GS020908312316.003 [DIRS 162680]).

The atmospheric pressure is first subtracted from the absolute-pressure transducer values to obtain the hydraulic pressure (represented in equivalent feet of water.) The hydraulic pressure and atmospheric pressure (also represented as equivalent feet of water) records for the period of monitoring (DTN: GS020908312316.003 [DIRS 162680]) are then filtered (Output DTN: GS031008312316.002; Software: Filter.vi V 1.0, STN: 10970-1.0-00 [DIRS 162668]) to remove all oscillations with frequencies higher than 0.8 cycles/day. This step removes the effects of all semidiurnal atmospheric pressure changes and all earth tides on the hydraulicpressure record. It also removes the semidiurnal atmospheric pressure fluctuations from the atmospheric-pressure record. What remains are the low-frequency atmospheric pressure fluctuations associated with weather systems and the oscillations they cause in the hydraulic pressure record. The changes in the low-frequency hydraulic pressure record is then plotted against the changes in the low-frequency atmospheric pressure record, as shown in Figure F-24.

The slope of the best-fit line through the data in Figure F-24 is -56.54 percent, indicating that for any incremental change in the atmospheric pressure at the 19D location, a corresponding change in the hydraulic pressure occurs, which is opposite in sign to the atmospheric pressure change and equal to 56.54 percent of its magnitude. In other words, the barometric efficiency, $B E$, of the aquifer at the 19D location is 56.54 percent, or 0.5654 (Output DTN: GS031008312316.002). 
Substituting $B E=0.5654$ from above and $S_{\mathrm{s}}=0.00000338 \mathrm{~m}^{-1}\left(0.000001031 \mathrm{ft}^{-1}\right)$ (from Section F2) into Equation 49 (along with the values for $\gamma$ and $\beta$ listed under that equation) gives (Output DTN: GS031008312316.002):

$$
\theta=\frac{\left(0.00000338 \mathrm{~m}^{-1}\right)(0.5654)}{\left(1000 \mathrm{~kg} / \mathrm{m}^{3}\right)\left(4.69 \times 10^{-9} \mathrm{~m}^{2} / \mathrm{kg}\right)}=0.407=40.7 \% \text {. }
$$

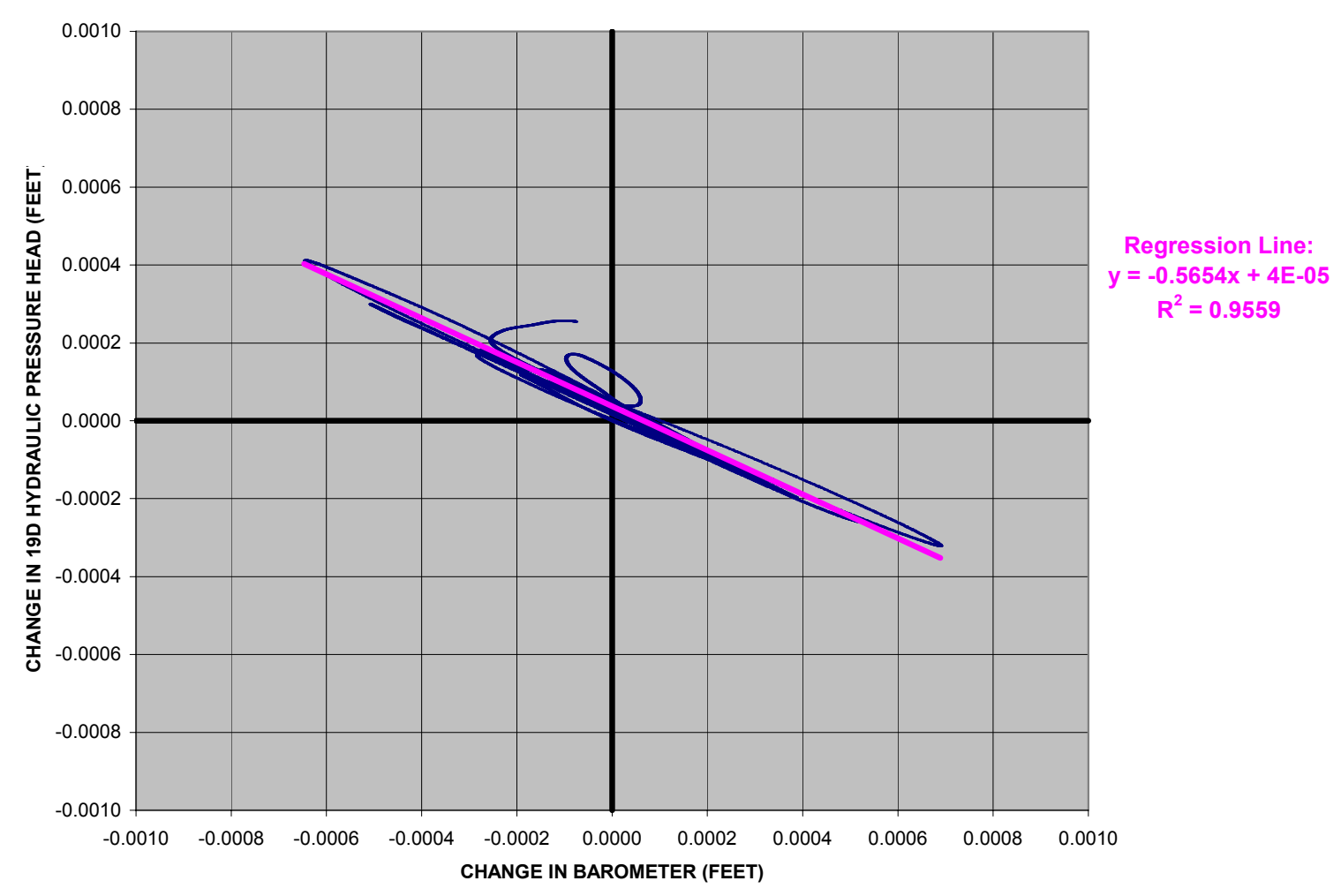

Source: DTN: GS020908312316.003 [DIRS 162680] (data).

Output DTN: GS031008312316.002 (analysis).

NOTE: English units are shown in the figure because the analysis was conducted in English units. However, parameter estimates are reported in metric units to downstream users.

Figure F-24. Relation of Low-Frequency Hydraulic-Pressure Change in NC-EWDP-19D to LowFrequency Atmospheric-Pressure Change at the NC-EWDP-19D Location: Data and Regression Line

The largest total porosity value obtained from grain-size distributions in well 19D is 0.33, occurring at the 152- to 154-m (500- to 505-ft) depth interval (DTN: LA0201JS831421.001 [DIRS 162613], Output DTN: GS031008312316.002). The largest total porosity value obtained from the Borehole Gravity Meter survey done in NC-EWDP-19D, presented in Section F4, is 0.29 , occurring at approximately $198 \mathrm{~m}(650 \mathrm{ft})$ of depth. The above values would indicate that the upper limit for total porosity in the alluvium at the 19D location ranges from 29 percent to approximately 40 percent. (The total porosity from grain-size distribution is obtained through the relation, Porosity $=0.255\left(1+0.83^{\mathrm{C}}\right)$, where $\mathrm{C}$, the coefficient of uniformity, is the ratio of the 60th grain-size percentile to the 10th percentile.) (Kasenow 2002 [DIRS 164666], p. 72). 
There are many assumptions involved in the derivation of Equation 49 (De Wiest 1965 [DIRS 162674], pp. 189 to 191). Uncertainties in the estimate of total porosity using this equation depend primarily on the extent to which these assumptions hold true in the saturated alluvium. Unfortunately, the data and information necessary to evaluate the validity of these assumptions were not available. Barometric efficiency was believed to be determined quite accurately from the large number of barometer and water-level measurements, and the storativity estimate obtained from cross-hole hydraulic testing at the ATC is considered less uncertain than the assumptions inherent in Equation 49. A formal analysis of uncertainty in the porosity estimate was not conducted.

\section{F4. TOTAL POROSITY ESTIMATED FROM BOREHOLE GRAVIMETRY AT NC-EWDP-19D}

Standard suites of geophysical logs were conducted during and after completion of all wells at the ATC. In addition, borehole gravimetry (BHGM) logging of 19D was conducted by EDCON, Inc. in September 2000 (DTN: MO0105GPLOG19D.000 [DIRS 163480]). BHGM logs provide bulk density as a function of depth, from which total porosity as a function of depth can be estimated if grain density is known or assumed. The total porosities deduced from BHGM logging are reported here because they serve as useful upper bounds for effective flow porosity in the alluvium. These estimates can be compared with the estimates of flow porosity obtained from analysis of single-well tracer tests in the alluvium, which are presented in Section G4. Other estimates of total porosity in the alluvium, obtained from specific storage and barometric efficiency and from grain size distributions, are discussed in Section F3.

For a water-saturated sample of alluvium, the mass of solids plus the mass of water is equal to the total mass of the sample, i.e.:

$$
\mathrm{V}_{\mathrm{s}} \rho_{\mathrm{s}}+\mathrm{V}_{\mathrm{v}} \rho_{\mathrm{w}}=\rho_{\mathrm{b}} \mathrm{V}_{\mathrm{T}}
$$

where

$\mathrm{V}_{\mathrm{s}}$ is the volume of solids

$\rho_{\mathrm{s}}$ is the density of solids (grain density)

$\mathrm{V}_{\mathrm{v}}$ is the volume of voids (filled with water for a saturated medium)

$\rho_{\mathrm{w}}$ is the density of water, $\rho_{\mathrm{b}}$ is the saturated (wet) bulk density of the sample

$\mathrm{V}_{\mathrm{T}}$ is the total volume of the sample.

By algebraic manipulation, the porosity, $\phi$, which is defined as $\mathrm{V}_{\mathrm{v}} / \mathrm{V}_{\mathrm{T}}$, can be obtained from Equation 51 as:

$$
\phi=\mathrm{V}_{\mathrm{v}} / \mathrm{V}_{\mathrm{T}}=\left(\rho_{\mathrm{s}}-\rho_{\mathrm{b}}\right) /\left(\rho_{\mathrm{s}}-\rho_{\mathrm{w}}\right)
$$

Using Equation 52 with $\rho_{\mathrm{s}}=2.52 \mathrm{~g} / \mathrm{cm}^{3}$ (USGS n.d. [DIRS 154495]) and $\rho_{\mathrm{w}} \cong 1.0 \mathrm{~g} / \mathrm{cm}^{3}$ (ranges from $0.9986 \mathrm{~g} / \mathrm{cm}^{3}$ at $18^{\circ} \mathrm{C}$ to $0.9959 \mathrm{~g} / \mathrm{cm}^{3}$ at $29^{\circ} \mathrm{C}$; (Dean 1992 [DIRS 100722], p. 5.87)), one can calculate $\phi$ from various values of $\rho_{\mathrm{b}}$. For the minimum $\rho_{\mathrm{b}}$ of $2.082 \mathrm{~g} / \mathrm{cm}^{3}$ and the maximum $\rho_{b}$ of $2.244 \mathrm{~g} / \mathrm{cm}^{3}$ in the alluvium section at 19D (DTN: MO0105GPLOG19D.000 
[DIRS 163480]), a maximum porosity of 0.29 and a minimum porosity of 0.18 (Output DTN: GS031008312316.003) are obtained from Equation 52.

Using the entire set of bulk densities for the entire section of 19D logged by the BHGM (DTN: MO0105GPLOG19D.000 [DIRS 163480]) for $\rho_{\mathrm{b}}$ in Equation 52 and the values of $\rho_{\mathrm{s}}$ and $\rho_{\mathrm{w}}$, given above, total porosities as a function of depth are obtained as shown in Figure F-25.

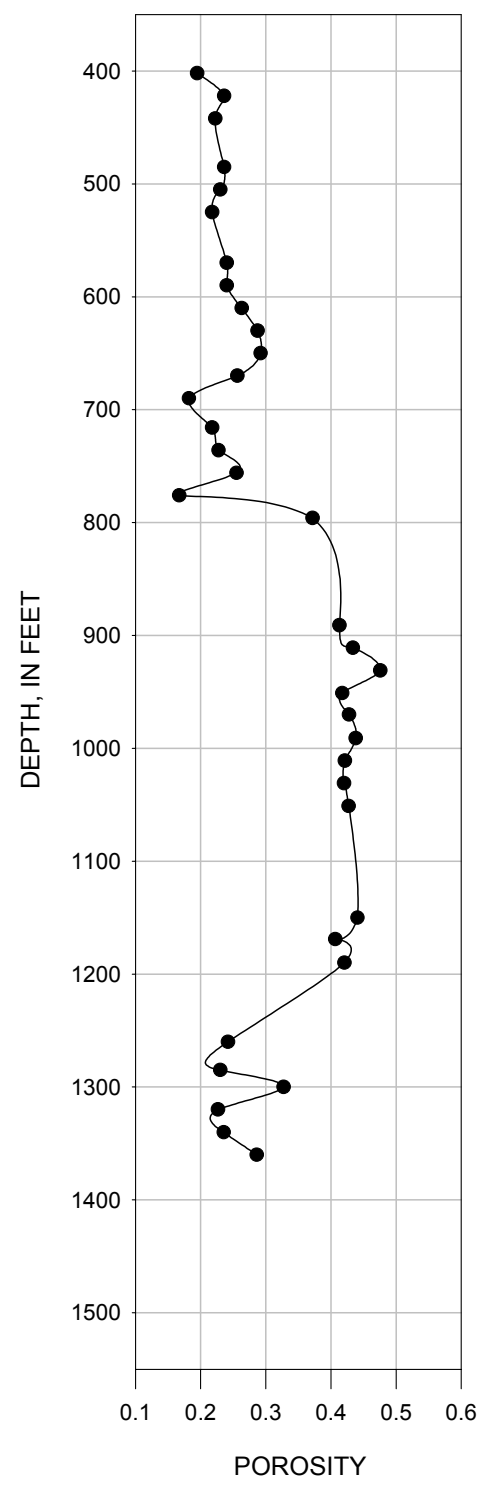

Source: DTN: MO0105GPLOG19D.000 [DIRS 163480].

Output DTN: GS031008312316.003.

NOTE: The figure is plotted in English units because the data were obtained in those units. However, parameter estimates are reported in metric units to downstream users.

Figure F-25. Total Porosities as a Function of Depth Below Land Surface at NC-EWDP-19D, Obtained from the Borehole Gravity Meter (BHGM) Survey Conducted in September 2000 


\section{F5. SUMMARY OF HYDROLOGIC PARAMETERS IN ALLUVIUM}

The single-hole testing indicated an overall transmissivity for the alluvium of $28 \mathrm{~m}^{2} /$ day $\left(300 \mathrm{ft}^{2} /\right.$ day) with an associated hydraulic conductivity of $0.20 \mathrm{~m} /$ day $(0.67 \mathrm{ft} /$ day) (Output DTN: GS031008312316.002). This is a horizontal hydraulic conductivity value with no directional dependence. The transmissivity and hydraulic conductivity estimates were also estimated without assuming any near-wellbore head losses, which apparently were very significant, possibly because of the narrow slots in the well screens and the relatively small particle size of the sand packs in 19D, among other reasons (well efficiency is determined to be 9.1 percent [Output DTN: GS031008312316.002]; see Section F1.4, Equation 34). Thus, the true transmissivity and hydraulic conductivity are believed to be approximately an order-of-magnitude higher than the single-hole apparent values.

Vertical hydraulic conductivities could not be estimated from the single-well testing, although they were presumably small, because none of the intervals above or below the isolated intervals in the hydraulic tests showed any pressure response during pumping (with the exception of interval \#5 in the tuffs, which responded slightly to pumping interval \#4). Also, there was minimal response in 19P when pumping any of the intervals in 19D except for screen \#1 and the combined-interval test.

Estimates of transmissivity and horizontal hydraulic conductivity were greatly improved after cross-hole hydraulic testing was conducted at the 19D location (Section F2). The cross-hole tests indicated a transmissivity of $306 \mathrm{~m}^{2} /$ day $\left(3,300 \mathrm{ft}^{2} /\right.$ day) (hydraulic conductivity of $2.0 \mathrm{~m} / \mathrm{day}[6.7 \mathrm{ft} / \mathrm{day}])$, which is about an order of magnitude higher than the transmissivity and hydraulic conductivity values obtained from single-well hydraulic tests. Because of well losses in 19D (well efficiency of 9.1 percent), the cross-hole transmissivity value of $306 \mathrm{~m}^{2} /$ day $\left(3,300 \mathrm{ft}^{2} /\right.$ day $)$ is considered to be much more representative of the saturated alluvium in the vicinity of $19 \mathrm{D}$ than the single-well transmissivity values of approximately $28 \mathrm{~m}^{2} /$ day (approximately $300 \mathrm{ft}^{2} /$ day). The cross-hole tests also provided storativity estimates as well as qualitative information on horizontal anisotropy of hydraulic conductivity in the saturated alluvium. 
APPENDIX G

DETAILS OF TRACER TESTING AND TRACER TEST INTERPRETATIONS AT THE ALLUVIAL TESTING COMPLEX (ATC) 


\section{G1. INTRODUCTION AND ALTERNATIVE CONCEPTUAL TRANSPORT MODELS}

Three single-well injection-withdrawal tracer tests were conducted in screen \#1 (the uppermost screened interval) of NC-EWDP-19D between December 2000 and April 2001 (see Figure 6.1-8 for a diagram showing well completion and lithology; note that well NC-EWDP-19D will be referred to by its abbreviated form [19D] in the remainder of this document; see Table B-1). The primary objective of these tests was to distinguish between alternative conceptual transport models for the saturated alluvium south of Yucca Mountain. A secondary objective was to obtain estimates of key transport parameters associated with the appropriate conceptual model. A fourth single-well injection-withdrawal tracer test was conducted in screen \#4 of 19D in February and March of 2002. This test is only briefly discussed in this report (Section D.4.5) because it was conducted for the purposes of comparing and contrasting parameter estimates obtained from single-well and cross-hole tests, but the cross-hole tests were not conducted. Detailed documentation of the tracer tests is reported by Umari et al. (2003 [DIRS 164573]) and Reimus (2003 [DIRS 165128]).

The three conceptual transport models considered for the saturated valley-fill deposits located south of Yucca Mountain prior to single-well tracer testing at 19D/D1 are depicted in Figure G-1 (with some additional variations/combinations). The first model assumes purely advective transport through a porous medium with no diffusive mass transfer into either the grains of the medium or between advective and nonadvective regions of the aquifer. This model does not necessarily imply a homogeneous flow field, but it does preclude a system with alternating layers of relatively narrow thickness and significant permeability contrasts. Such a conceptual model might be valid in a sandy aquifer with grains of relatively low porosity. The second model is similar to the first except that it assumes diffusive mass transfer into the grains of the porous medium. These grains have significant internal porosity, but the porosity is not well-connected over the scale of the grains; therefore, the grains transmit negligible flow. The third model assumes diffusive mass transfer between advective and nonadvective layers in the aquifer. In this model, the flow system is assumed to alternate between high and low conductivity layers, a simplified representation consistent with some depositional scenarios. Diffusive mass transfer in this case is only between the two layers, not into grains within the layers. However, one variation of this model is to assume that diffusion also occurs into grains in both the advective and nonadvective layers. This variation is, essentially, a combination of the second and third conceptual models, with an additional level of complexity allowing for diffusion in the nonadvective layer into both the inter- and intragranular pore spaces.

Pre-test predictions of the single-well injection-withdrawal tracer tests conducted at 19D are presented in Section G2. Pre-test predictions of cross-hole tracer test responses in the alluvium are provided in Section G3. The results and preliminary interpretations of the three single-well injection-withdrawal tests conducted in FY 2001 are presented in Section G4. 
(a) Advection only

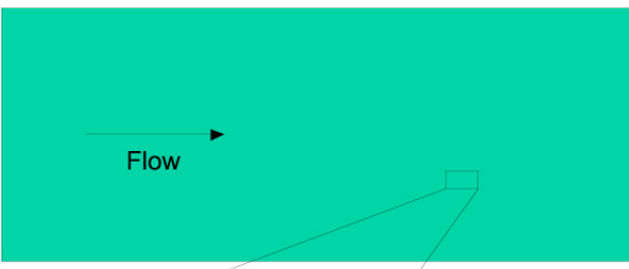

(b) Advection with diffusion in grains

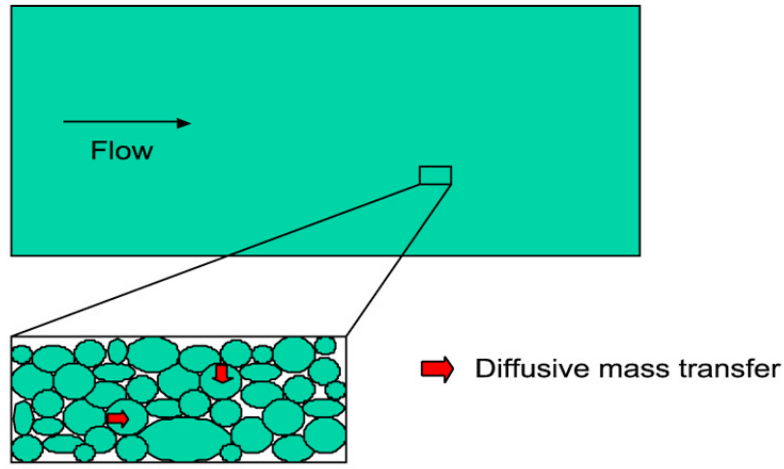

(c) Advection in high permeability layers with diffusion into low permeability layers (and diffusion into grains in both layers)

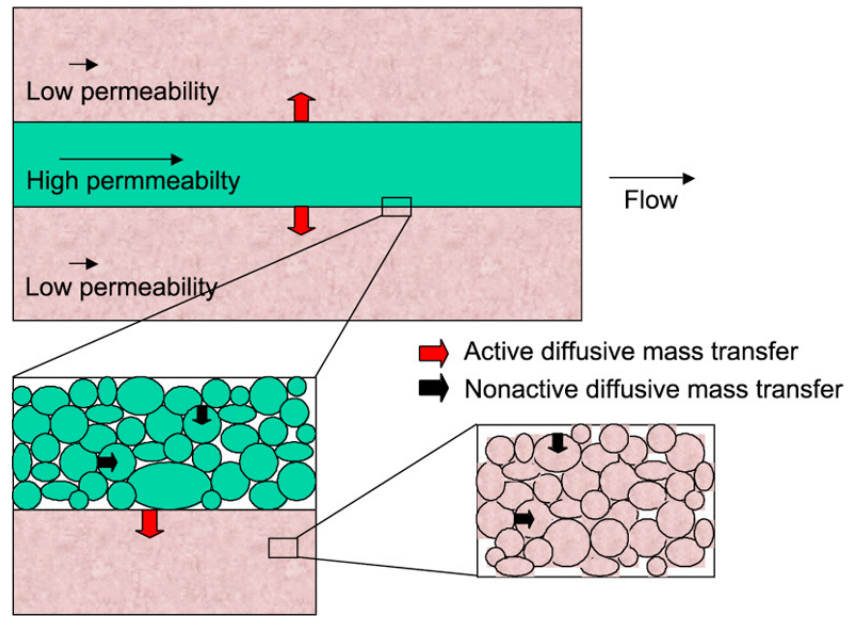

NOTE: For illustration purposes only. Red arrows in (c) indicate diffusive mass transfer options that were exercised in this scientific analysis, and black arrows indicate options that were not exercised.

Figure G-1. Schematic Illustration of Alternative Conceptual Transport Models for the Valley-Fill Deposits South of Yucca Mountain 


\section{G2. PRE-TEST PREDICTIONS OF SINGLE-WELL TRACER RESPONSES FOR EACH CONCEPTUAL MODEL}

Prior to conducting the single-well tracer tests in 19D, the MULTRAN model (Section E3.2.2) was used to simulate tracer responses, assuming each of the three alternative conceptual models of Figure G-1. Simulations were conducted for each of three planned single-well tests: a zero rest-period test, a 2-day rest-period test, and a 30-day rest-period test (where "rest period" refers to the time period after injection that is allowed to elapse before starting to pump the well). In each of these tests, it was anticipated that approximately $11,000 \mathrm{~L}$ (3,000 gallons) of tracer solution would be injected into the test interval followed by approximately 95,000 L (25,000 gallons) of tracer-free "chase" water to push the tracer solution out of the wellbore and gravel pack into the formation. The well would then be pumped for several days to several weeks after the prescribed rest period. Each of the three tracer tests was to include both a halide (bromide, chloride, or iodide) and a fluorinated benzoate so that any diffusion from flowing water into stagnant water could be identified from differences in the tracer responses.

In single-well simulations using MULTRAN V 1.0 (STN: 10666-1.0-00 [DIRS 159068]), only one end of the domain is modeled as a well-mixed borehole; the other end becomes a zero-concentration-gradient boundary. However, to minimize boundary effects, an initial calculation establishes a node spacing in the radial $(r)$ direction that results in a tracer "plume" that never reaches the edge of the domain. Furthermore, the numerical calculations are carried out assuming cylindrical coordinates with flow only in the radial direction (with a flow velocity that varies as $1 / r$ ), instead of Cartesian coordinates. Ambient flow during single-well tests, which is superimposed on the radial flow induced by injection into and pumping of the well, is not accounted for in the current version of MULTRAN because the code is deisgned primarily to predict and analyze differences in tracer responses resulting from differences in tracer diffusion coefficients and sorption properties, not to analyze the effects of ambient flow on tracer responses. Thus, the advection-dispersion equation in the flow direction solved by MULTRAN for single-well tests is (Bear 1979 [DIRS 105038], p. 247):

$$
\frac{\partial c}{\partial t}=-V(r) \frac{\partial c}{\partial r}+\frac{1}{r} \frac{\partial}{\partial r}\left(r D \frac{\partial c}{\partial r}\right)
$$

where

$$
\begin{aligned}
& c=\text { tracer concentration }(\mathrm{mol} / \mathrm{L}) \\
& r=\text { radial coordinate, } \mathrm{cm} \\
& V(r)=\text { flow velocity as a function of } \mathrm{r}(\mathrm{cm} / \mathrm{hr}) \\
& D=\text { dispersion coefficient }\left(\mathrm{cm}^{2} / \mathrm{hr}\right) .
\end{aligned}
$$

Single-well tracer test responses for all three single-well tests were simulated for both a generic halide (bromide or iodide) and a generic fluorinated benzoate, with the assumption that the halide has a factor-of-three larger diffusion coefficient than the benzoate. The response of a counter cation (potassium was assumed in all cases) was also simulated, as well as the responses of the cations with which it exchanges (see Sections E3.1.3 and E3.2.2). Also, a flow interruption of several hours was simulated for the test with zero rest period to illustrate the 
additional information that can be obtained by doing a planned flow interruption during the latter portion of the test.

The MULTRAN V 1.0 (STN: 10666-1.0-00 [DIRS 159068]) simulations associated with the different conceptual transport models illustrate how the appropriate conceptual transport model can be best determined by comparing the responses of the nonsorbing tracers with different diffusion coefficients for each of the different rest periods. The differences in the responses of the tracers with different diffusion coefficients as a function of rest period can provide information on the relative volumes of flowing and stagnant water in the system, which is very important for determining the ability of the alluvium to attenuate the transport of nonsorbing radionuclides. The MULTRAN simulations also illustrate how cation responses (both injected and exchanged cations) could potentially provide useful information on cation-exchange-capacity and, hence, cation sorption in the system. The flow system parameters that were assumed for the three different conceptual models are listed in Table G-1. Other input parameters that do not pertain to the flow system are listed in Table G-2.

Figure G-2 illustrates the tracer responses that can be expected in each of the three tracer tests if a homogeneous, single-porosity medium is assumed (conceptual model of Figure G-1a). Only one response is shown because there is no difference between the predicted responses of the nonsorbing tracers of different diffusion coefficients or the predicted responses after the different rest periods. Although not shown in Figure G-2, there is also no change in predicted tracer concentrations immediately after a flow interruption. The lack of a difference between tracers, and between tracer responses for different rest periods, as well as the lack of a response after a flow interruption are all indications of very little or no diffusive mass transfer in the flow system.

Table G-1. Flow System Parameters Used in the Single-Well Simulations

\begin{tabular}{|c|c|c|c|}
\hline Parameter & $\begin{array}{c}\text { Figure G-1a } \\
\text { Model }\end{array}$ & $\begin{array}{c}\text { Figure G-1b } \\
\text { Model }\end{array}$ & $\begin{array}{c}\text { Figure G-1c } \\
\text { Model }\end{array}$ \\
\hline Porosity in advective layers & 0.25 & 0.25 & 0.25 \\
\hline Porosity in nonadvective layers & $\mathrm{N} / \mathrm{A}$ & $\mathrm{N} / \mathrm{A}$ & 0.25 \\
\hline Porosity of grains & $\mathrm{N} / \mathrm{A}$ & 0.15 & $\mathrm{~N} / \mathrm{A}$ \\
\hline Width of advective layers $(\mathrm{cm})$ & $\mathrm{N} / \mathrm{A}$ & $\mathrm{N} / \mathrm{A}$ & 10.0 \\
\hline Width of nonadvective layers $(\mathrm{cm})$ & $\mathrm{N} / \mathrm{A}$ & N/A & 24.0 \\
\hline Grain diameter in advective layers (mm) & $\mathrm{N} / \mathrm{A}$ & $3.0(2.2)^{b}$ & $\mathrm{~N} / \mathrm{A}$ \\
\hline Grain diameter in nonadvective layers $(\mathrm{mm})$ & $\mathrm{N} / \mathrm{A}$ & $\mathrm{N} / \mathrm{A}$ & $\mathrm{N} / \mathrm{A}$ \\
\hline Halide diffusion coefficient in advective layers $\left(\mathrm{cm}^{2} / \mathrm{sec}\right)^{a}$ & $\mathrm{~N} / \mathrm{A}$ & $3 \times 10^{-6}$ & $3 \times 10^{-6}$ \\
\hline Halide diffusion coefficient in nonadvective layers $\left(\mathrm{cm}^{2} / \mathrm{sec}\right)^{a}$ & $\mathrm{~N} / \mathrm{A}$ & N/A & $1 \times 10^{-6}$ \\
\hline Halide diffusion coefficient in grains $\left(\mathrm{cm}^{2} / \mathrm{sec}\right)^{a}$ & $\mathrm{~N} / \mathrm{A}$ & $1 \times 10^{-6}$ & $N / A$ \\
\hline Drift velocity $(\mathrm{cm} / \mathrm{sec})$ & $0^{c}$ & $0^{\mathrm{c}}$ & $0^{c}$ \\
\hline
\end{tabular}

Output DTN: LA0303PR831231.001.

a The fluorinated benzoate diffusion coefficient is always assumed to be one-third of the halide diffusion coefficient (Section E.2).

$\mathrm{b}$ The number in parentheses is the standard deviation of In (diameter) used for a lognormal distribution of grain sizes in one set of simulations (see text).

${ }^{c}$ Drift velocity is assumed to be zero because of the small apparent hydraulic gradient in the vicinity of NC-EWDP-19D. 
Table G-2. Nonflow-System Input Parameters for the Single-Well Simulations

\begin{tabular}{|l|c|}
\multicolumn{1}{|c|}{ Parameter } & Value \\
\hline Volume of injection interval (including gravel pack) (L) & 500 \\
\hline Radius of gravel pack (cm) & 18 \\
\hline Duration of injection pulse (hr) & 3 \\
\hline Duration of chase (hr) & 28 \\
\hline Flow interruption duration (zero-rest-period test only) (hr) & 24 \\
\hline Flow rate during injection and pumping (L/min [gpm]) & $\begin{array}{l}\text { approximately 57 } \\
\text { [approximately 15] }\end{array}$ \\
\hline
\end{tabular}

Output DTN: LA0303PR831231.001.

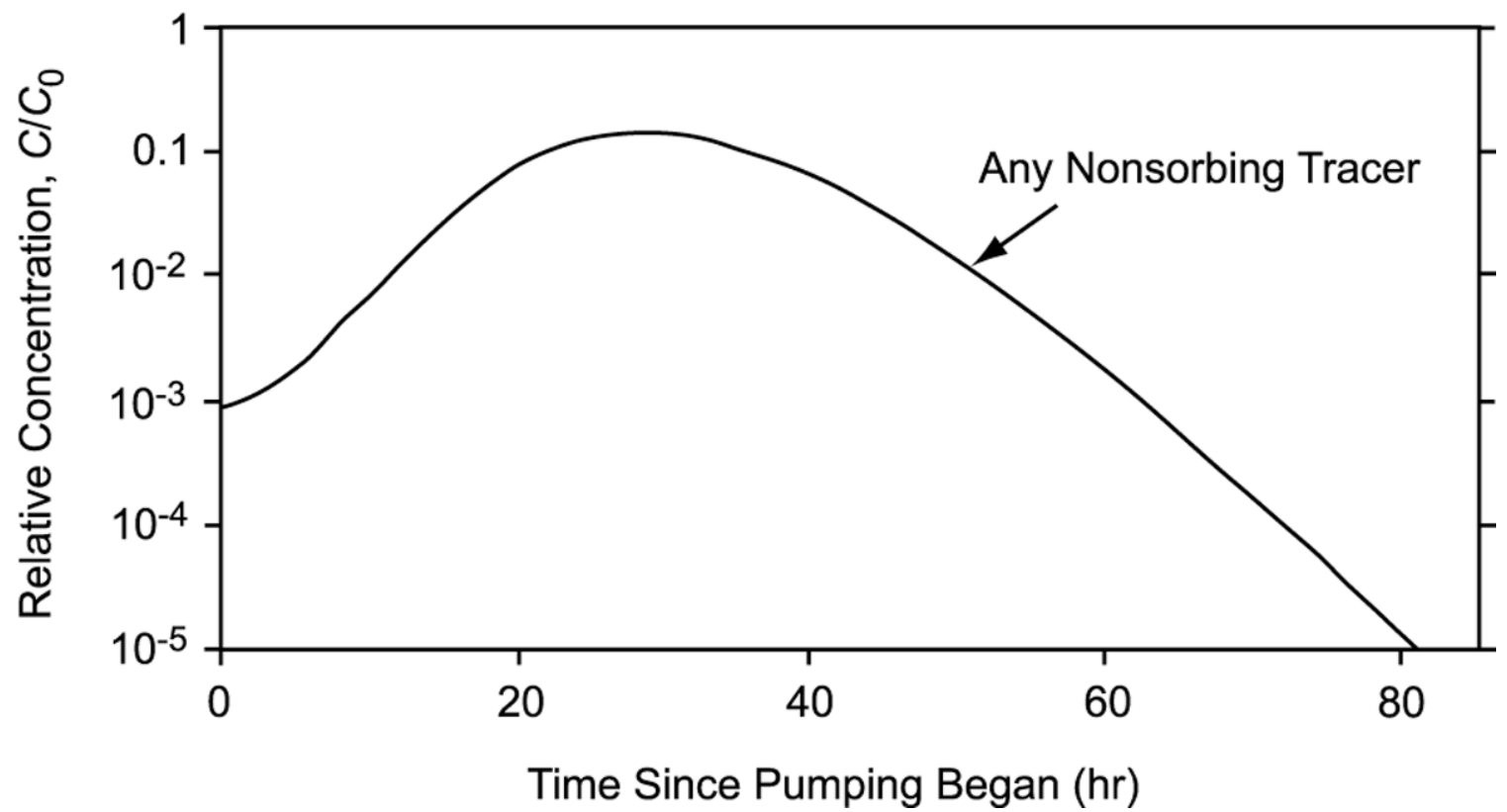

Output DTN: LA0303PR831231.001.

Figure G-2. Normalized Concentration Response of Any Nonsorbing Tracer in a Single-Well Test in a Porous Medium with No Diffusive Mass Transfer and/or No Stagnant Water (the Conceptual Model of Figure G-1a) 
Figure G-3 shows the tracer responses (normalized to injection concentrations) that can be expected in each of the three single-well tracer tests if a homogeneous system with porous grains is assumed (conceptual model of Figure G-1b). In this case, a uniform grain diameter of $3 \mathrm{~mm}$ was assumed, which corresponds to the mass-weighted mean diameter of the material collected from four different intervals in 19P. A mass-weighted mean diameter was used because tracer storage capacity in grains is proportional to mass, not number of grains. Cuttings collected from 19D (D1) were not used for grain-size analysis because the mud-rotary-drilling method used in this hole tended to truncate the upper and lower ends of the size range. Figure G-3 shows that there is a slight difference in the responses of the halide and FBA in each test, with the halide having a slightly higher peak concentration and a shorter tail than the FBA. These differences qualitatively indicate that there is some diffusion into stagnant water in the system. However, the fact that the halide has a higher peak concentration and a shorter tail than the FBA indicates that the characteristic diffusion lengths must be relatively short. Both tracers effectively diffused throughout the grains during the time that they were injected and chased into the system, so the responses primarily reflect the diffusion rates of the tracers back out of the grains, which is faster for the halide. The tracer mass recoveries (not presented) were very high (over 95 percent) in all of these simulations, with the recoveries of the two tracers being essentially the same at the end of the simulations. The halide initially had a higher recovery than the FBA (during the peak) because it diffused more rapidly out of the grains, but the FBA recovery approached that of the halide as pumping continued into the tails of the responses. Given a long enough pumping period, the recoveries of both tracers would have approached 100 percent.

Another indication of the short diffusion lengths is the lack of an increase in tracer concentrations after the flow interruption in the test with no rest period. If a significant amount of tracer remained in the grains at the time of the flow interruption, an increase in concentration would be expected upon resumption of flow due to the tracer diffusing out of the grains during the rest period. An additional indication of the relatively short diffusion distances in the system is the fact that both the halide and the FBA have essentially the same response in the 2-day rest period test as the 30-day rest period test. This result suggests that the tracers were able to effectively diffuse throughout the grains during the 2-day rest period so that very little additional diffusion occurred during the 30-day rest period. 

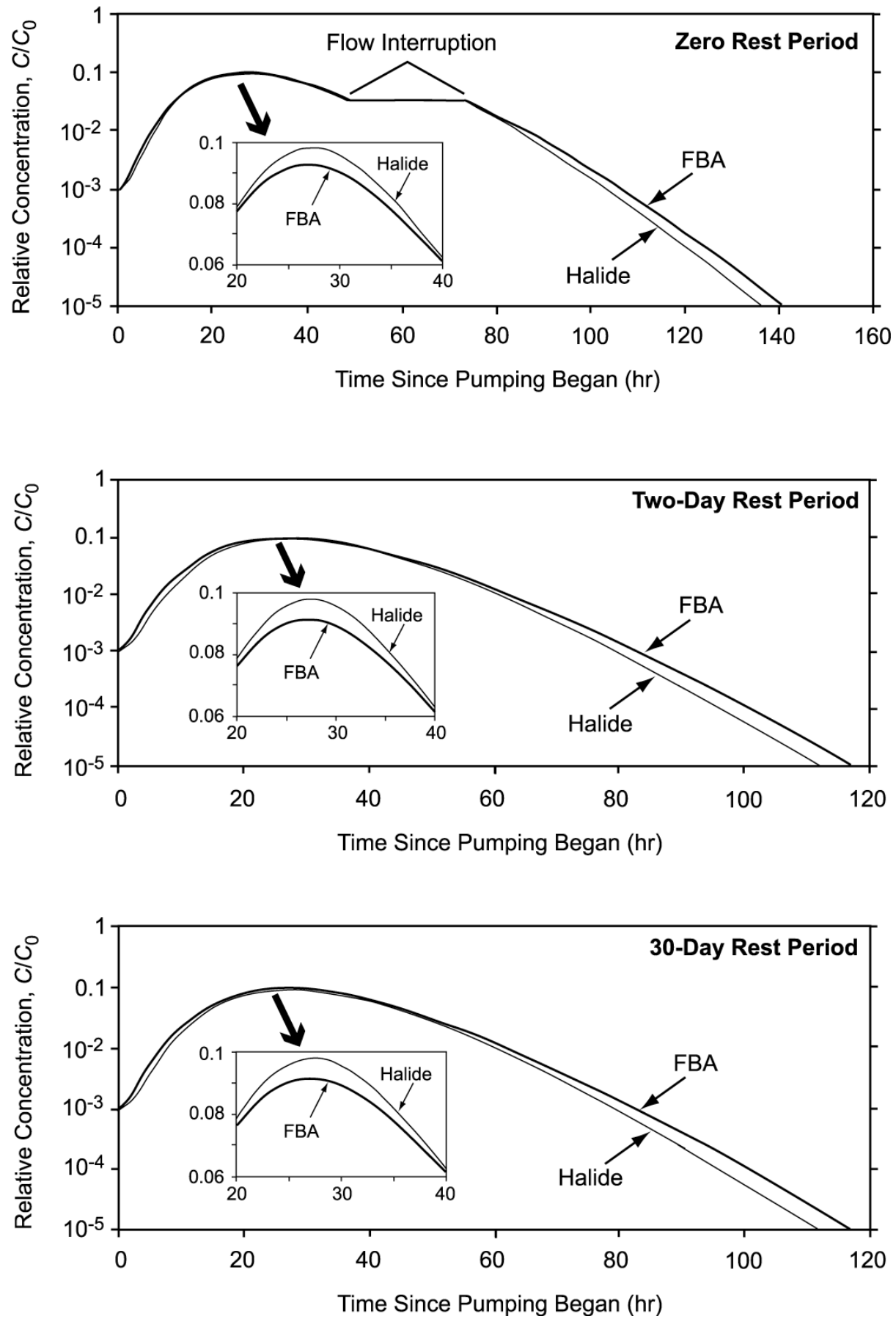

Output DTN: LA0303PR831231.001.

NOTE: The rest periods are zero (top), 2 days (middle), and 30 days (bottom); a 3-mm fixed grain diameter was used. $X$ axis extends to $160 \mathrm{hr}$ for zero-rest-period test because of 24 hours flow interruption.

Figure G-3. Normalized Concentration Responses of a Halide and a FBA in Single-Well Tests for the Conceptual Transport Model of Figure G-1b Using a Fixed Grain Diameter 
Figure G-4 shows the measured grain-size distribution of the material collected from 19P. A qualitative fit of a lognormal distribution to the data is also shown. Clearly, there is a relatively wide distribution of grain sizes not accounted for when a single mean grain size is assumed, as in the simulations that generated the tracer responses shown in Figure G-3. Figure G-5 shows the results of incorporating the lognormal distribution of grain sizes shown in Figure G-4 into the MULTRAN V 1.0 (STN: 10666-1.0-00 [DIRS 159068]) simulations. The only difference between Figures G-3 and G-5 is that the grain size in the former is uniform (equal to the mean), whereas in the latter, it is varied over the lognormal distribution of Figure G-5. It is apparent that the inclusion of larger grain sizes in the simulations greatly increases the length of the tails of both tracers. Additional simulations confirmed that the elimination of the smaller grain sizes in the lognormal distribution had very little effect on the tracer responses. The increase in the lengths of the tails is a result of the greater diffusion distances associated with the larger grains. Because of the greater distances, it takes longer for the tracer mass to diffuse back out into the advective pathways, resulting in the extended tailing. The longer diffusion distances are also indicated by the noticeable increase in tracer concentrations after the flow interruption in the test with no rest period. Note that in all cases the FBA still has a longer/higher tail than the halide, indicating that the responses are still dominated by diffusion back out of the grains. The mass recoveries of both tracers were slightly lower than in the simulations of Figure G-3 (for the same pumping time). However, by the end of the simulations, both tracer recoveries were well over 95 percent.

Figure G-6 shows the tracer responses that can be expected in each of the three single-well tracer tests if a layered dual-porosity system is assumed (Figure G-1c). Grains in both the advective and nonadvective regions were assumed to be nonporous for these simulations. The differences in the responses of the halide and the FBA in the tests, and the fact that the peak concentrations decrease while the lengths of the tails increase as the rest period increases all indicate relatively long diffusion lengths. However, in contrast to the results shown in Figures G-3 and G-5, the FBA has a higher peak concentration and a shorter/lower tail than the halide during the pumpback phase. This result is primarily due to the relatively wide advective flow pathways $(10 \mathrm{~cm})$, which tracers can only slowly diffuse out of because of the long distance to the nonadvective region. It is the slower diffusion of the FBA out of these advective pathways that is primarily responsible for the higher peak concentrations and lower tails of the FBA relative to the halide. 


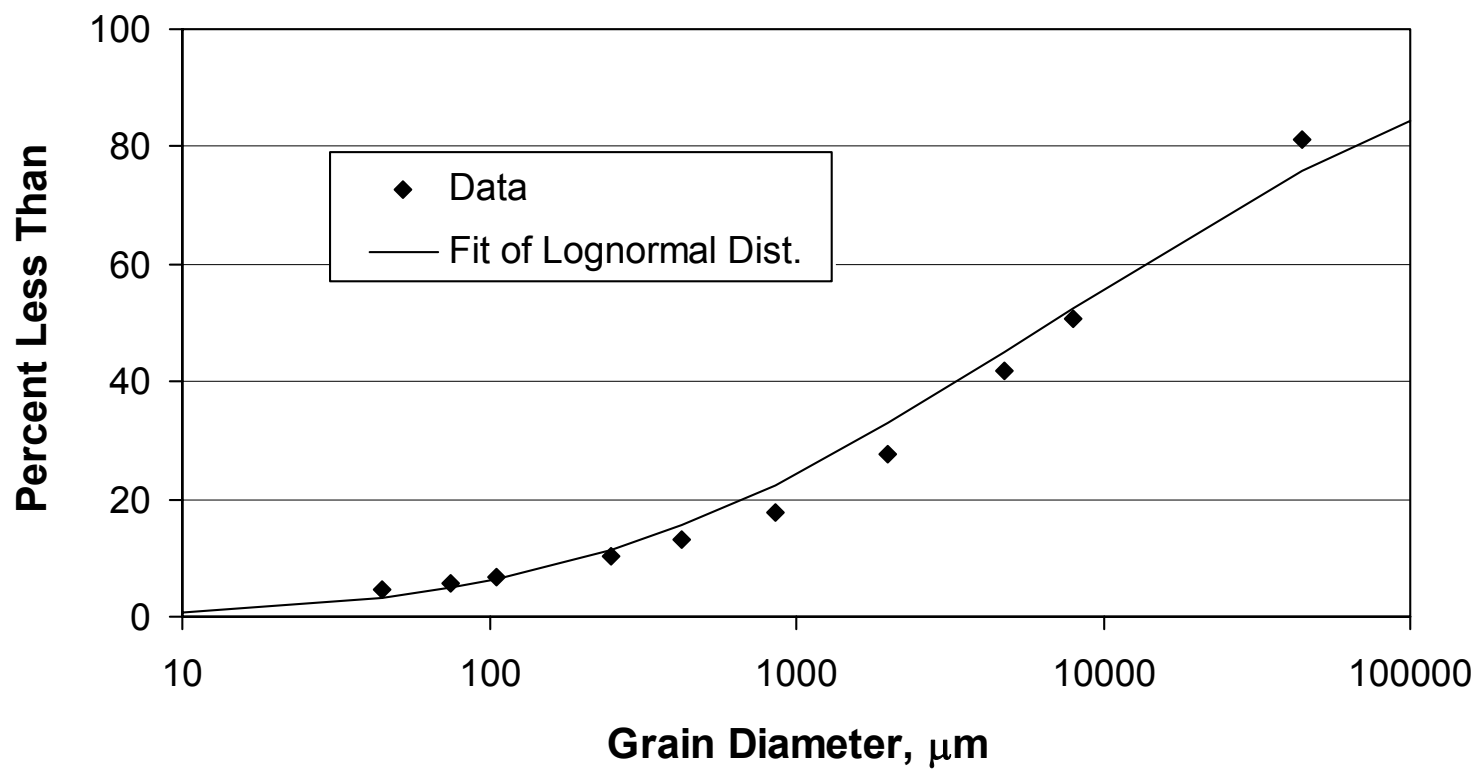

Source: DTN: LA0201JS831421.001 [DIRS 162613].

NOTE: The above data are a composite of four depth intervals.

Figure G-4. Measured and Fitted Grain Size Distributions from NC-EWDP-19P 

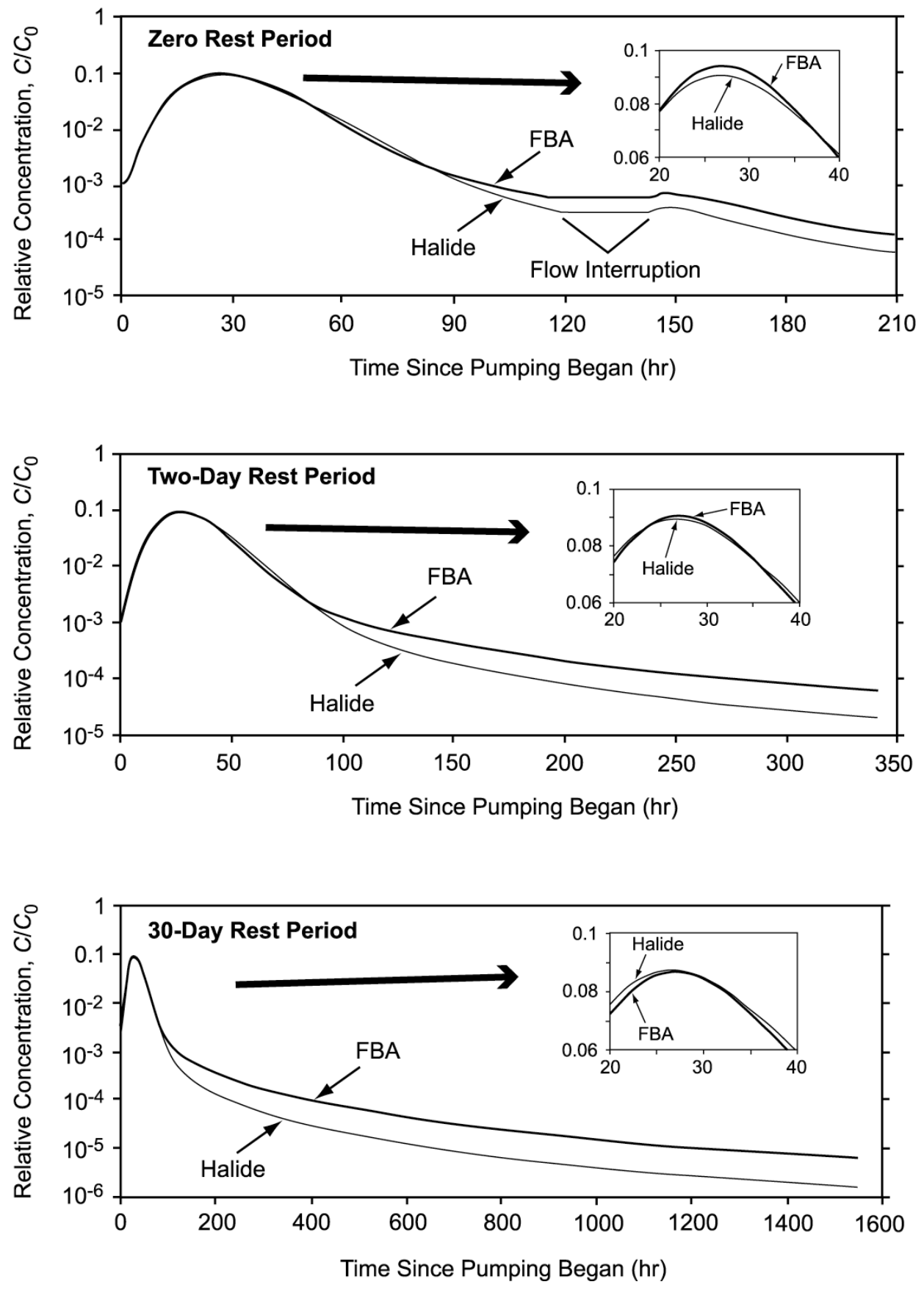

Output DTN: LA0303PR831231.001.

NOTE: The rest periods are zero (top) days, 2 days (middle), and 30 days (bottom); a mean grain diameter of $3 \mathrm{~mm}$ was used with a standard deviation for In (diameter) of 2.2. X axes have different scales to reflect the different pumping durations planned for the three tests.

Figure G-5. Normalized Concentration Responses of a Halide and an FBA in Single-Well Tests for the Conceptual Transport Model of Figure G-1b Using a Grain Size Distribution 

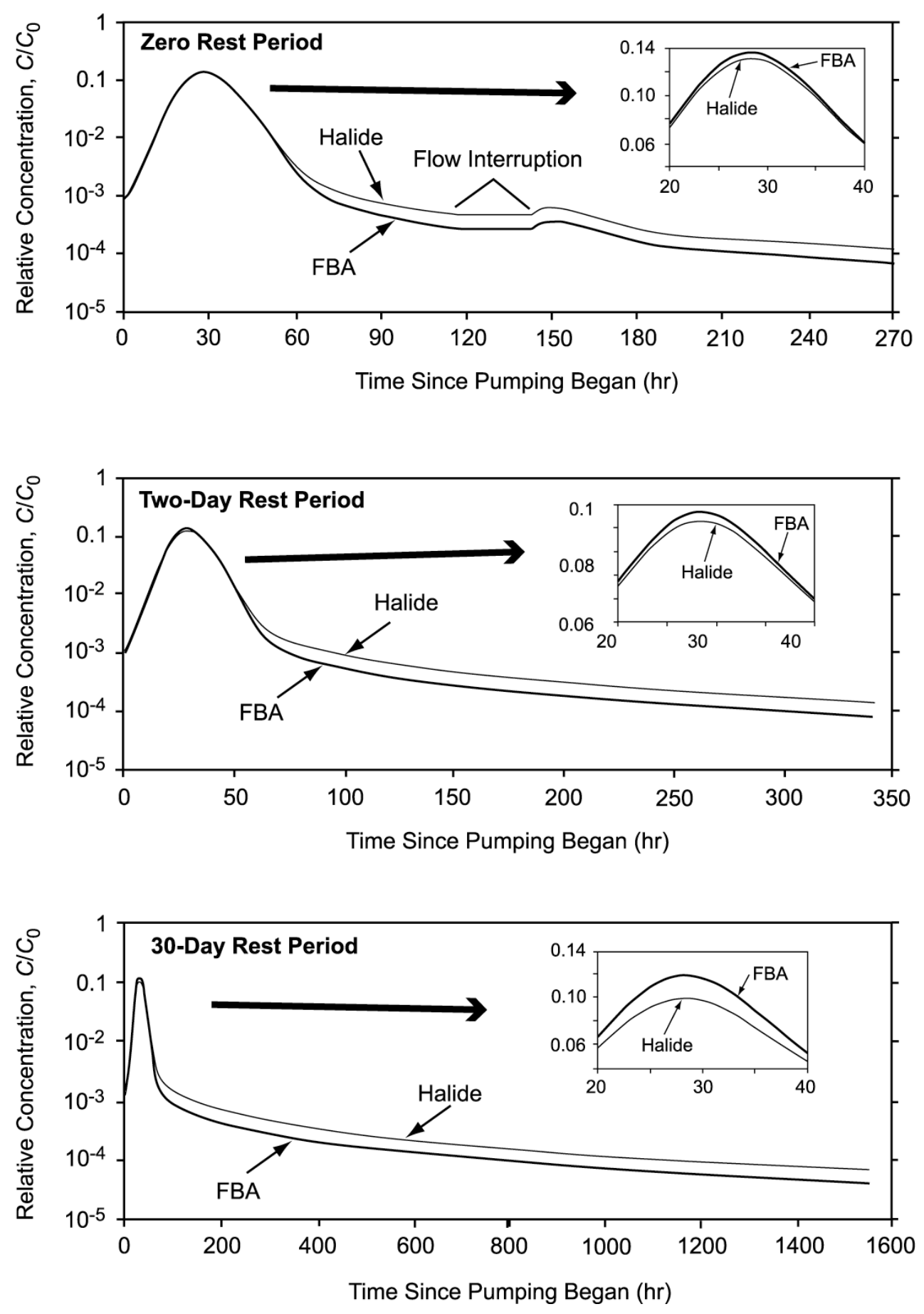

Output DTN: LA0303PR831231.001.

NOTE: The rest periods are zero (top) days, 2 days (middle), and 30 days (bottom). $X$ axes have different scales to reflect the different pumping durations planned for the three tests.

Figure G-6. Normalized Concentration Responses of a Halide and an FBA in Single-Well Tests for the Conceptual Transport Model of Figure G-1c 
The value of comparing the responses of the FBA and halide to help distinguish between alternative conceptual models is made apparent in Figure G-7, which shows the simulated responses of the FBA in the 2-day-rest period tests with the diffusion-into-grains model (Figure G-5) and the diffusion-into-layers model (Figure G-6). Other than a slightly broader peak in the diffusion-into-grains response (which could be attributed to hydrodynamic dispersion or tracer drift with the natural gradient), the two responses are very similar, and it would be difficult to distinguish between the two models on the basis of either one of these responses alone. However, by knowing whether the halide has a higher or lower tail, it will be possible to make a distinction between the models. The additional information obtained from the test with a longer rest period will also help in making this distinction. Also, quantitative estimates of diffusive mass-transfer rates and diffusion distances can be best made using the MULTRAN V 1.0 (STN: 10666-1.0-00 [DIRS 159068]) model to fit simultaneously the tracer responses from each test with the constraint that the halide has a factor-of-three larger diffusion coefficient than the FBA.

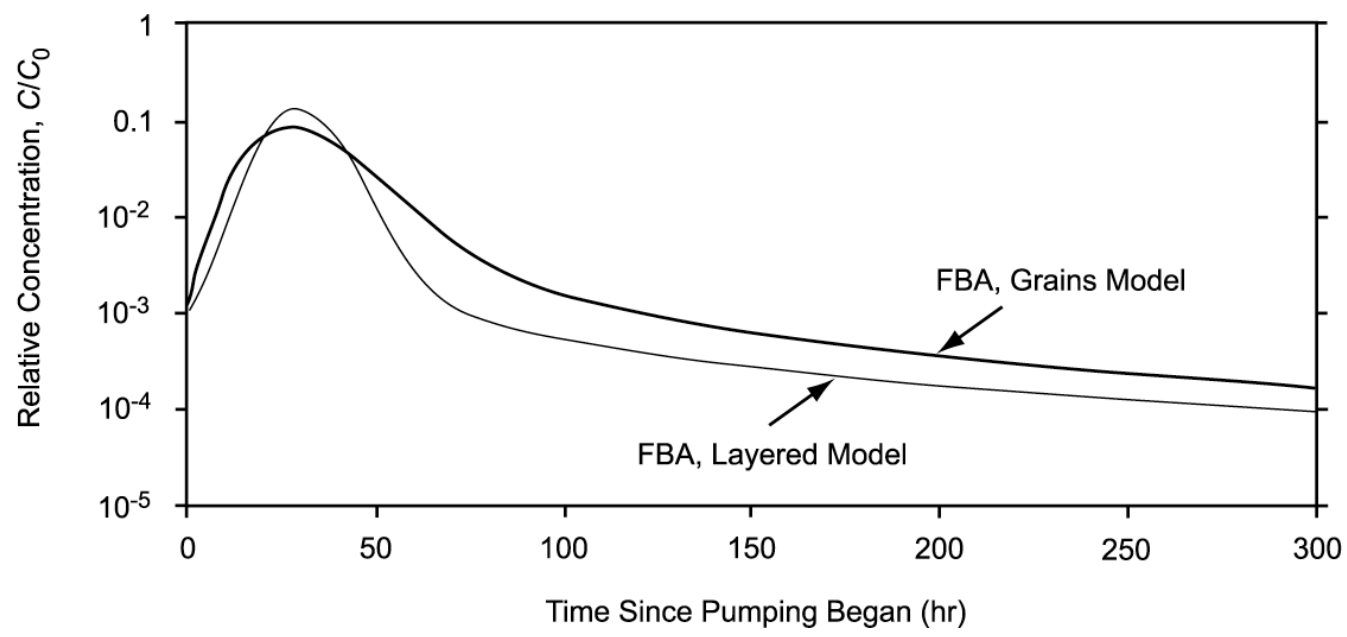

Output DTN: LA0303PR831231.001.

NOTE: The rest period was 2 days.

Figure G-7. Comparison of FBA Responses for the Layered Conceptual Model (Figure G-1c) and the Grain-Diffusion Model (Figure G-1b) with a Lognormal Distribution of Grain Sizes

Table G-3 summarizes the tracer-response characteristics from single-well tracer tests that are consistent with the different conceptual transport models of Figure G-1, including a diffusion-into-grains model (Figure G-1b) with a relatively wide distribution of grain sizes (see Figure G-4 and G-5). This table serves as a guide for how the appropriate conceptual transport model can be identified from the qualitative nature of the tracer responses in the three planned single-well tracer tests. 
Table G-3. Single-Well Tracer Test Response Characteristics Consistent with the Conceptual Models of Figure G-1

\begin{tabular}{|c|c|}
\hline Conceptual Model & Single-Well Tracer Test Response Characteristics \\
\hline $\begin{array}{l}\text { Single-Porosity } \\
\text { (Figure G-1a) }\end{array}$ & $\begin{array}{l}\text { - All nonsorbing tracers have the same normalized concentration } \\
\text { responses. } \\
\text { Response curves are independent of rest period (unless there is } \\
\text { significant tracer drift during the rest period, but even then, there } \\
\text { will be little or no difference in the response curves of different } \\
\text { nonsorbing tracers). } \\
\text { - No increase in tracer concentrations after a flow interruption in the } \\
\text { tail of the response curves. }\end{array}$ \\
\hline $\begin{array}{l}\text { Diffusion into Small Grains } \\
\text {-Short Diffusion Distances } \\
\text { (Figure G-1b) }\end{array}$ & $\begin{array}{l}\text { - Tracer with larger diffusion coefficient will tend to have higher peak } \\
\text { concentration and lower tail concentration than tracer with smaller } \\
\text { diffusion coefficient. } \\
\text { - Relatively minor differences in response curves of each individual } \\
\text { tracer as a function of rest period (unless there is significant tracer } \\
\text { drift during the rest period). } \\
\text { - Relatively minor increase in tracer concentrations after a flow } \\
\text { interruption in the tail of the response curves. }\end{array}$ \\
\hline $\begin{array}{l}\text { Diffusion into Variable-Sized } \\
\text { Grains-Combination of Short and } \\
\text { Long Diffusion Distances, but } \\
\text { Relatively Narrow Advective Flow } \\
\text { Pathways } \\
\text { (Figure G-1b, with grain size } \\
\text { distribution of Figure G-4) }\end{array}$ & $\begin{array}{l}\text { Either tracer (large or small diffusion coefficient) could have the } \\
\text { higher peak concentration, with the larger diffusion coefficient } \\
\text { tracer tending to have the higher peak concentration as grain sizes } \\
\text { decrease or rest periods increase. Tracer with smaller diffusion } \\
\text { coefficient will tend to have the higher concentration in the tails of } \\
\text { the responses. } \\
\text { - Tracer with smaller diffusion coefficient will tend to have the higher } \\
\text { concentration in the tails of the responses. } \\
\text { - Noticeable differences in response curves of each individual tracer } \\
\text { as a function of rest period, with longer, higher tails as rest period } \\
\text { increases. } \\
\text { - Significant increase in tracer concentrations after a flow interruption } \\
\text { in the tail of the response curves. }\end{array}$ \\
\hline $\begin{array}{l}\text { Diffusion into Layers- } \\
\text { Long Diffusion Distances and } \\
\text { Relatively Wide Advective Flow } \\
\text { Pathways } \\
\text { (Figure G-1c) }\end{array}$ & $\begin{array}{l}\text { - Tracer with smaller diffusion coefficient will tend to have higher } \\
\text { peak concentration and lower tail concentration than tracer with } \\
\text { larger diffusion coefficient. } \\
\text { - Significant differences in response curves as a function of rest } \\
\text { period, with longer, higher tails as rest period increases. } \\
\text { - Significant increase in tracer concentrations after a flow interruption } \\
\text { in the tail of the response curves. }\end{array}$ \\
\hline
\end{tabular}

Output DTN: LA0303PR831231.001.

NOTE: The characteristics in this table apply when tracer concentrations are normalized to injection concentrations.

Although sorption parameters for sorbing tracers are much more easily obtained from cross-hole tracer tests, Figure G-8 shows how information on cation sorption can also be obtained from a single-well tracer test. In this case, the counter-cation (assumed to be potassium ion) injected with the nonsorbing anion tracers exchanges with sodium and calcium, the two predominant cations in the system. The potassium ion initially responds more quickly than the nonsorbing anions because it traveled a shorter distance into the system during injection (due to ion exchange). This behavior results in an initial depression of the sodium and calcium concentrations because they displace potassium as the system is pumped back and also because 
charge balance must be maintained. As the anions respond, the concentrations of sodium and calcium increase and peak at the same time as the anions. In principle, the magnitude of the fluctuations of the sodium and calcium concentrations, as well as the response of the counter-cation, can provide qualitative estimates of ion-exchange parameters for the counter-cation in the system.

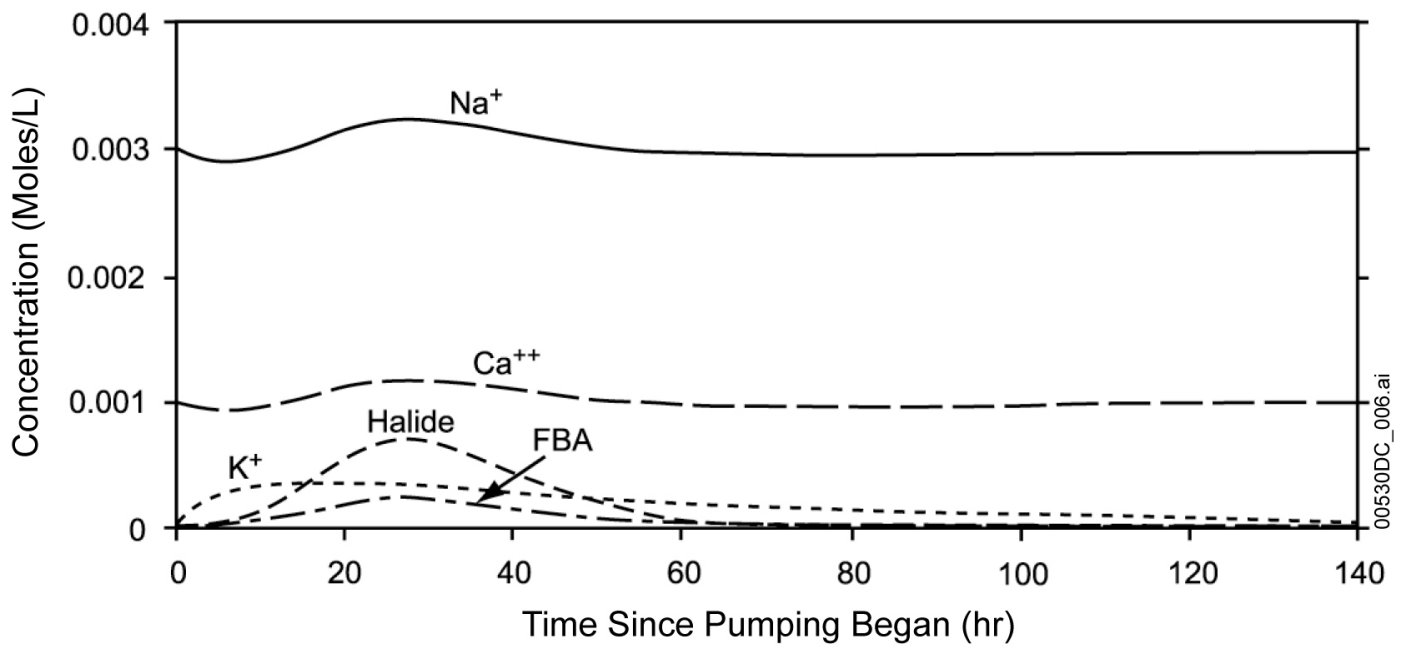

Output DTN: LA0303PR831231.001.

NOTE: The $\mathrm{Na}^{+}$and $\mathrm{Ca}^{++}$responses are the result of cation exchange with $\mathrm{K}^{+}$.

Figure G-8. Molar Responses of Injected Tracers ( $\mathrm{K}^{+}$, Halide, FBA) and Naturally Occurring Cations $\left(\mathrm{Na}^{+}\right.$and $\left.\mathrm{Ca}^{++}\right)$in the 2-Day-Rest-Period Test Assuming the Model of Figure G-1b

\section{G3. PRE-TEST PREDICTIONS OF CROSS-HOLE TRACER TEST RESPONSES}

After the single-well tracer tests were completed, Nye County drilled two additional wells (NC-EWDP-19IM1 and NC-EWDP-19IM2, known as 19IM1 and 19IM2) in the immediate vicinity of 19D to allow for cross-hole hydraulic and tracer testing. These wells were completed similarly to 19D so that they could be used interchangeably as production, injection, or observation wells. Cross-hole tracer tests were to be conducted immediately after cross-hole hydraulic testing was completed (Section D.2). However, water discharge and tracer injection permits issued by the State of Nevada were rescinded before tracer testing could be initiated.

In lieu of presenting results from the planned cross-hole tracer tests, this section provides a summary of the plans for testing as well as pre-test predictions of tracer responses in the cross-hole tests, with emphasis on (1) expected tracer arrival times under various assumptions, and (2) predicted lithium transport behavior given results of lithium sorption testing onto alluvium in the laboratory. The pre-test predictions served to satisfy environmental permitting requirements and address a Key Technical Issue raised by the U.S. Nuclear Regulatory Commission (KTI RT 2.04).

The cross-hole tracer tests were expected to provide additional information on diffusive mass-transfer properties and the appropriate conceptual transport model for the saturated valley-fill system. They were also expected to provide field estimates of several transport 
parameters for performance-assessment calculations that cannot be obtained from single-well tracer testing, including effective flow porosity, longitudinal dispersivity, sorption parameters, and colloid transport parameters. Because sorbing radionuclides of interest to Yucca Mountain performance assessments cannot be used in field tests, sorption parameters were to be obtained for a weakly sorbing cation tracer, lithium ion. Although lithium transport is not of immediate interest to the project, its field-sorption behavior was to be compared to its laboratory-sorption behavior to determine whether laboratory-derived parameters provide reasonable estimates of field-scale retardation. If that proved to be the case, or if the laboratory parameters resulted in underestimation of field-scale sorption, the Project would gain credibility in its approach of using laboratory-derived radionuclide sorption parameters in performance-assessment calculations. On the other hand, if the field transport behavior of lithium indicated that lithium was sorbing less than predicted from laboratory experiments, then conceptual models and parameterizations of radionuclide sorption might have to be revisited to account for differences between lab and field observations.

Cross-hole testing would have involved the simultaneous injection of several tracers into a screened interval of one well while a nearby well was continuously pumped. The plan was to establish a partial-recirculation flow pattern between the injection well and the production well prior to tracer injection and then maintain that recirculation pattern for at least one month after the injection. Partial recirculation means that a portion of the produced water would be recirculated into the injection well. This type of flow pattern ensures that the injected tracers are pushed out into the formation and do not linger in the injection well, which would result in biased estimates of transport parameters.

The tracer mixture would have included two nonsorbing solute tracers (probably bromide ion and an FBA), a weakly sorbing tracer (lithium ion), and at least one type of polystyrene microsphere as a colloid tracer. The sorption parameters for lithium and filtration parameters for the microspheres were to be determined by comparing the cross-hole responses of these tracers to that of the two nonsorbing solutes.

Cross-hole tracer-test predictions were conducted primarily to estimate how long a cross-hole test may take to conduct for scheduling and budgeting reasons. However, pre-test predictions were also a requirement imposed by the State of Nevada to obtain an environmental permit for tracer injections. Emphasis was placed on the sensitivity of the predictions to variables such as interwell separation, interval thickness, flow porosity, production rate, longitudinal dispersivity, two-dimensional vs. three-dimensional flow conditions, and most importantly, lithium sorption parameters. Two-dimensional flow conditions refers to a situation where a well fully penetrates a confined aquifer and, therefore, there is no flow in the vertical direction, whereas three-dimensional flow conditions refer to a situation in which a well is open to only a small fraction of the thickness of an aquifer so that flow occurs in all three dimensions without being influenced by upper and lower boundaries (e.g., confining layers). These represent two extremes of flow conditions (in a homogeneous, isotropic medium) with respect to cross-hole tracer transport times. 
Many of these sensitivities can be effectively captured using a simple analytical expression for nonsorbing tracer transport times in radial convergent flow to a pumping well in a two-dimensional homogeneous, isotropic medium (i.e., a rearrangement of Equation 10 from Section D4.8.5) (Guimera and Carrera 2000 [DIRS 156830], Equation 6):

$$
\tau=\frac{\eta \pi r_{\mathrm{L}}^{2} T}{Q}
$$

where

$\tau=$ mean transport time, $\mathrm{hr}$

$\eta=$ effective flow porosity

$r_{\mathrm{L}}=$ distance between injection and production wells, $\mathrm{m}$

$T=$ formation thickness, $\mathrm{m}$

$Q=$ production flow rate, $\mathrm{m}^{3} / \mathrm{hr}$.

Of course, any real flow system will never be completely homogeneous or isotropic, but this equation serves as a useful starting point for estimating transport times. It is clear that, all other things being equal, mean transport times will vary linearly with effective flow porosity and formation thickness, with the square of the distance between wells, and, inversely, with the production flow rate. Equation 54 does not account for any delays associated with diffusion into stagnant water in the system, although these delays are not expected to affect first arrival times and peak arrival times of tracers significantly in the valley-fill deposits, which are of greater practical interest than the mean arrival time.

The first arrival times and peak arrival times of tracers were estimated as a function of mean transport time and dispersivity using the RELAP V 2.0 computer code (STN: 10551-2.0-00 [DIRS 159065]). A set of response curves showing the effect of dispersivity (or, more specifically, Peclet number, which is equal to the travel distance/dispersivity) on the first and peak arrival times for a given mean tracer residence time is shown in Figure G-9. The ratio of first arrival time to mean arrival time, and the ratio of peak arrival time to mean arrival time were both found to have a relatively smooth dependence on the Peclet number of the system. By obtaining a polynomial fit to these ratios as a function of Peclet number, the first and peak arrival times could be estimated from the mean arrival time obtained from Equation 54 for any assumed value of dispersivity. Plots of these ratios and the polynomial fits as a function of Peclet number are shown in Figure G-10. 


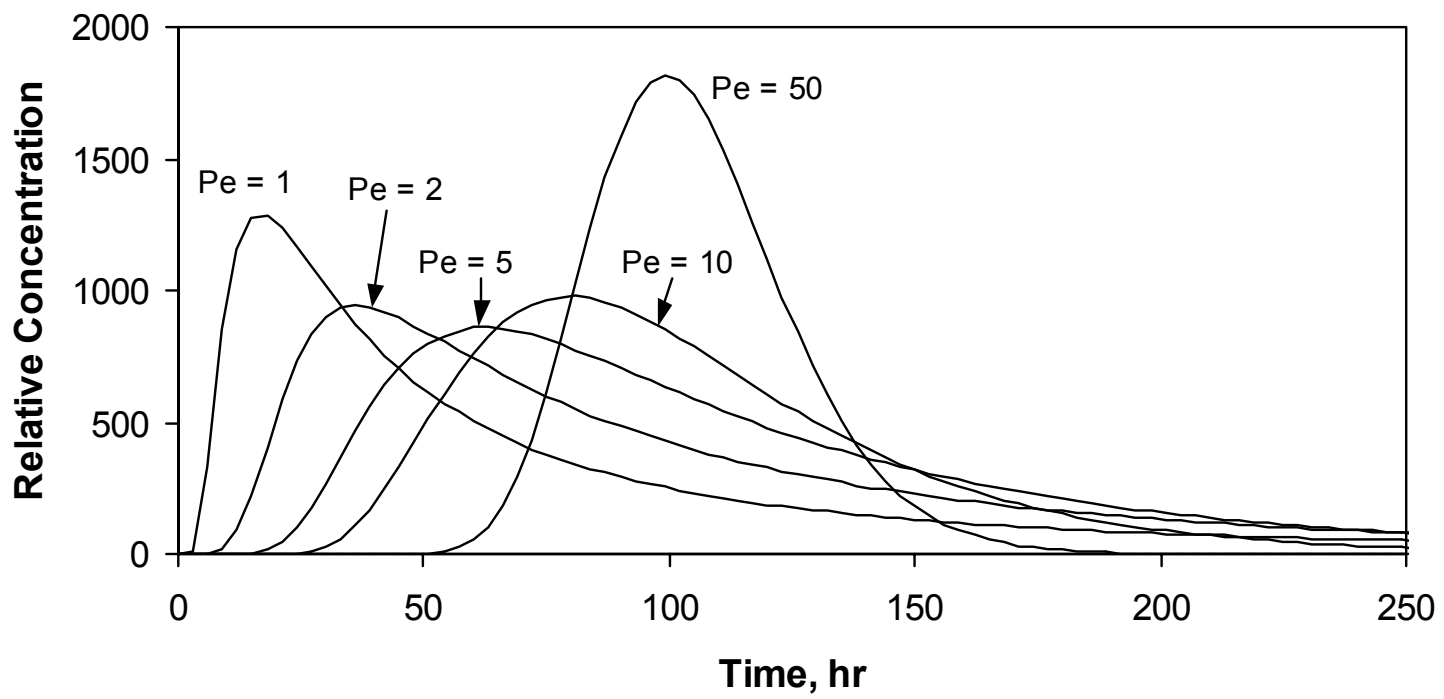

Output DTN: LA0403PR831231.001.

NOTE: Peclet number is travel distance/dispersivity; mean arrival time is $100 \mathrm{hr}$; and flow is assumed to be linear, not radial.

Figure G-9. Relative Responses in a Single-Porosity Medium to a Pulse Function Input for Different Peclet Numbers

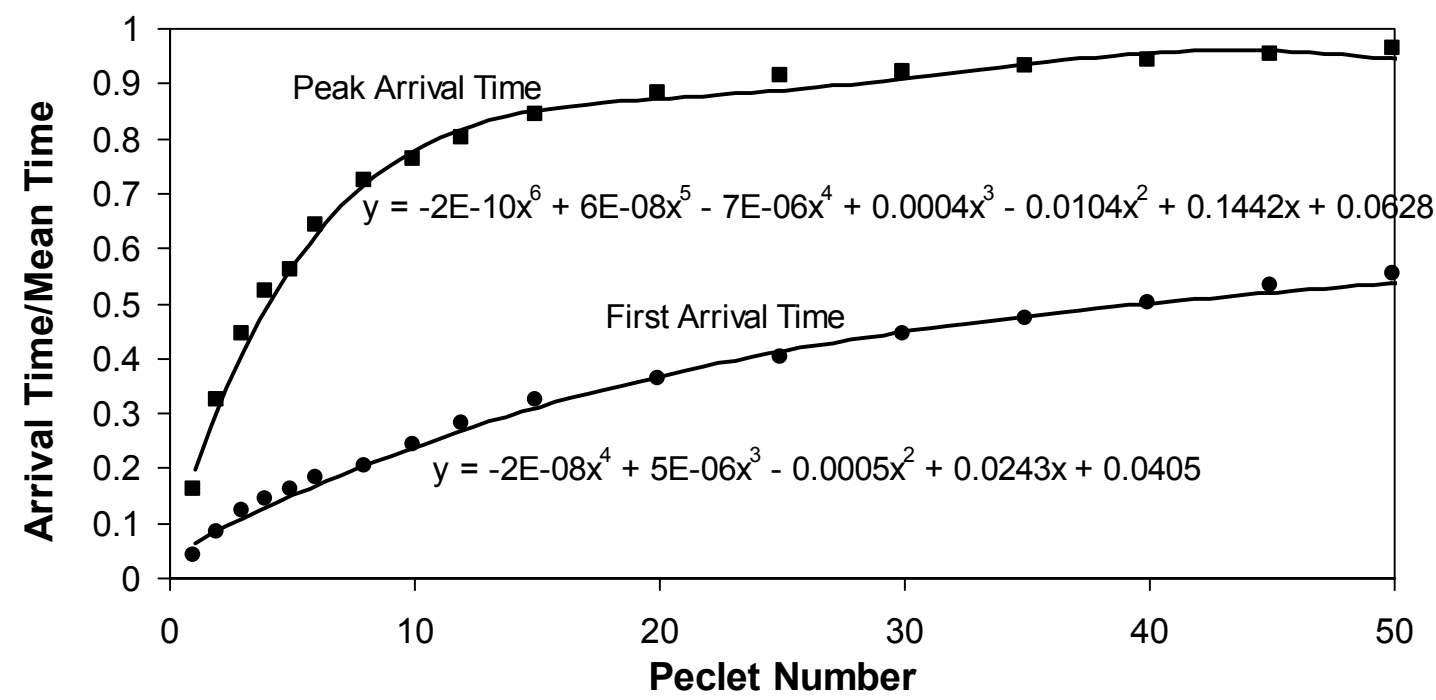

Output DTN: LA0403PR831231.001.

NOTE: Equations are polynomial fits to the "data." First arrival time is defined as the arrival time corresponding to 1 percent of the peak concentration.

Figure G-10. Ratios of First Arrival Time to Mean Arrival Time and Peak Arrival Time to Mean Arrival Time for Different Peclet Numbers 
To obtain estimates of the mean, first, and peak arrival times for a sorbing tracer, the corresponding arrival times for a nonsorbing tracer can be multiplied by the retardation factor, $R$, given by (Freeze and Cherry 1979 [DIRS 101173], p. 404, Equation 9.14):

$$
R=1+\frac{\rho_{\mathrm{B}}}{\phi} K_{\mathrm{d}}
$$

where

$$
\begin{aligned}
& K_{\mathrm{d}}=\text { linear partition coefficient, } \mathrm{mL} / \mathrm{g} \\
& \rho_{\mathrm{B}}=\text { bulk density of medium, } \mathrm{g} / \mathrm{cm}^{3} \\
& \phi=\text { porosity of medium. }
\end{aligned}
$$

To obtain an estimate of transport times in an unbounded three-dimensional flow system, the 2WELLS_3D V 1.0 computer code was used (STN: 10667-1.0-00 [DIRS 159036]). 2WELLS_3D is a particle-tracking code that simulates tracer transport between two wells in a homogeneous, isotropic medium. It assumes that flow streamlines between the injection and production well follow trajectories given by the prolate spheroidal coordinate system, shown in Figure G-11. This coordinate system reduces to spherical coordinates in the limit of $a=0$ (i.e., a point source instead of a line source). A number of 2WELLS_3D simulations with zero dispersion were conducted to determine mean nonsorbing tracer residence times as a function of the ratio of well separation to interval length (i.e., length of screen or gravel pack). Because 2WELLS_3D superimposes tracer movement (as particles) onto an analytical solution of the three-dimensional flow field, there is, effectively, no numerical dispersion in the simulated tracer responses. In the limit of a very large interval length relative to well separation, the arrival times approached those given by Equation 55 for radial flow in cylindrical coordinates; and in the limit of a very small interval length relative to well separation, the arrival times approached what would be expected for spherical flow [derivation found in Modeling and Interpretation of Transport Tests Scientific Notebook (Reimus 2003 [DIRS 165129], pp. 116 to 122)]:

$$
\tau=\frac{4 \eta \pi r_{\mathrm{L}}^{3}}{3 Q}
$$

where the symbols are defined the same as in Equation 54. 


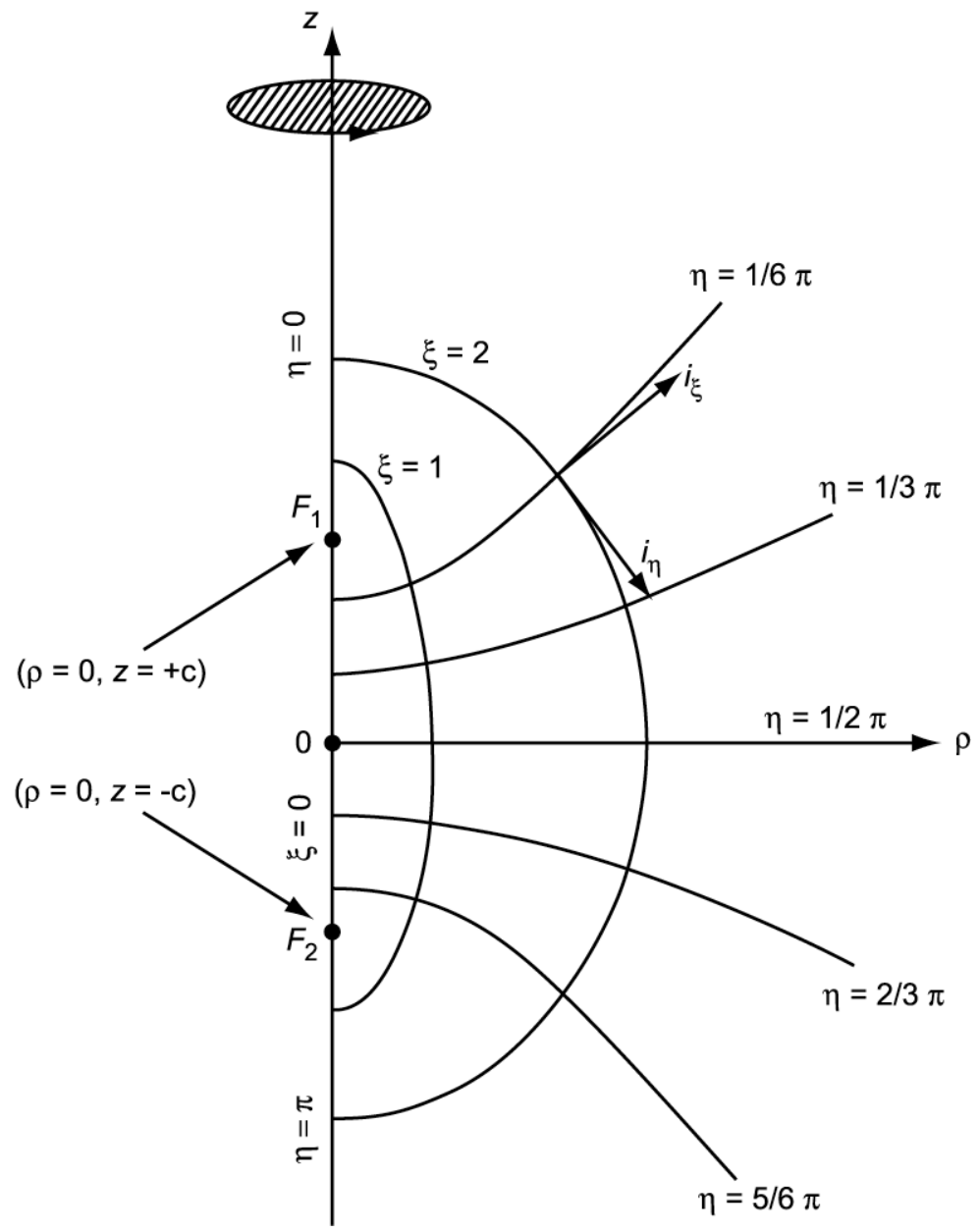

Source: Happel and Brenner (1965 [DIRS 156833], Appendix A, Figure A-17.1(a)).

NOTE: $\quad \eta$ and $\xi$ are coordinate designations by Happel and Brenner; they have no relation to $\eta$ and $\xi$ elsewhere in this report.

Figure G-11. Prolate Spheroidal Coordinate System Used for Unbounded Three-Dimensional Flow and Transport Calculations Using the 2WELLS_3D Code

The ratio of mean arrival time in unbounded three-dimensional flow to mean arrival time in two-dimensional flow was found to have a relatively smooth dependence on the ratio of well separation to interval length. This dependence and a piecewise fit to the simulated data are shown in Figure G-12. Using the piecewise fit, it was possible to "correct" the mean arrival times resulting from Equation 54 to obtain corresponding arrival times for unbounded three-dimensional flow. The relationship shown in Figure G-12 was obtained from 2WELLS_2D V 1.0 (STN: 10665-1.0-00 [DIRS 159067]) and 2WELLS_3D V 1.0 (STN: 10667-1.0-00 [DIRS 159036]) simulations, assuming zero longitudinal and transverse dispersivity. However, the same correction factors were assumed to apply to the first and peak arrival times in cases where the dispersivity was not zero.

A final "correction" applied to the calculations described above was to account for shifts in first and peak tracer arrival times due to recirculation of produced water. Recirculation establishes a 
dipole flow pattern (Figure G-13) that causes some of the tracer mass to arrive earlier and some later than in the case of no recirculation. A correction factor for various recirculation ratios (ratios of recirculation flow rate to production flow rate) was obtained by simulating a series of tracer responses with different recirculation ratios using the 2WELLS_2D V 1.0 code (STN: 10665-1.0-00 [DIRS 159067]). This code is very similar to the 2WELLS_3D V 1.0 code (STN: 10667-1.0-00 [DIRS 159036]) except that it simulates cross-hole responses in two-dimensional flow using a cylindrical coordinate system instead of three-dimensional flow. These simulations assumed no longitudinal or transverse dispersion, so the travel-time shifts reflected only the changing flow patterns. As in the case of 2WELLS_3D, 2WELLS_2D superimposes tracer movement (as particles) onto an analytical solution of the two-dimensional flow field, so there is effectively no numerical dispersion in the simulated tracer responses. A subset of the resulting response curves is shown in Figure G-14. In reality, the response curves for the larger amounts of recirculation (greater than about 20 percent) should all have multiple tracer peaks that are equally spaced in time due to tracer recirculation. However, all but the first peak for each response curve was suppressed from the 2WELLS_2D output to clarify Figure G-14. With typical amounts of dispersion, these secondary peaks would be highly damped relative to the first peak anyway. Note that because there was no dispersion assumed for the simulations associated with Figure G-14, the first and peak arrival times nearly coincide. The correction factor for both first arrival times and peak arrival times was taken to be the ratio of peak recirculation arrival time to the peak arrival time without recirculation. These correction factors as a function of recirculation ratio, as well as a polynomial fit to the simulated data, are plotted in Figure G-15.

The methods described above for estimating first and peak arrival times while accounting for dispersion, sorption, unbounded three-dimensional flow, and recirculation ratio in cross-hole tracer tests are amenable to simple spreadsheet calculations once adequate expressions/fits are obtained for the dependence of the correction factors on the appropriate input parameters. A Microsoft Excel spreadsheet was set up for this purpose (Output DTN: LA0303PR831231.001). It should be noted that the spreadsheet calculations assume that the correction factors are linearly independent and commutative. That is, corrections are made by multiplying the mean arrival time (given by Equation 54) by each of the appropriate correction factors for a given set of test conditions. 


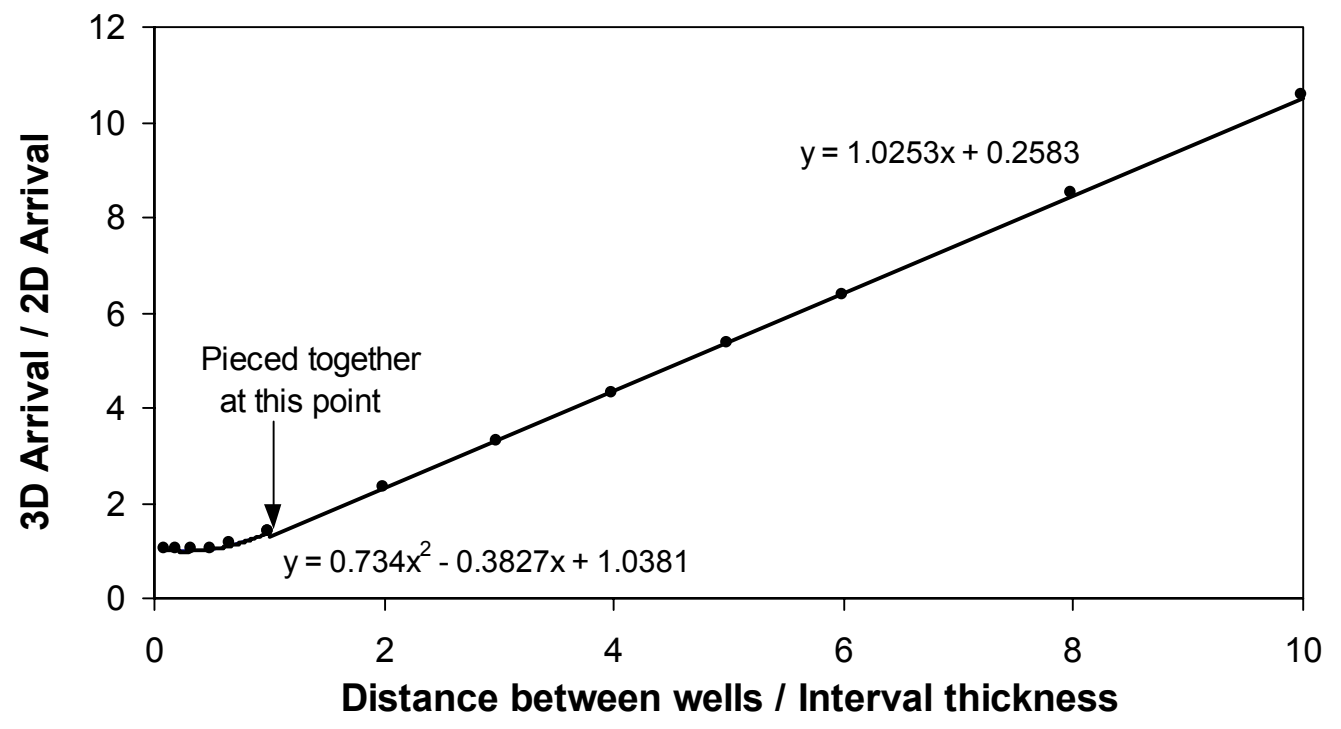

Output DTN: LA0403PR831231.001.

NOTE: A piecewise polynomial fit to the "data" is shown.

Figure G-12. Ratio of Mean Arrival Time in Unbounded Three-Dimensional Flow to Mean Arrival Time in Two-Dimensional Flow as a Function of Distance between Wells Divided by Interval Thickness

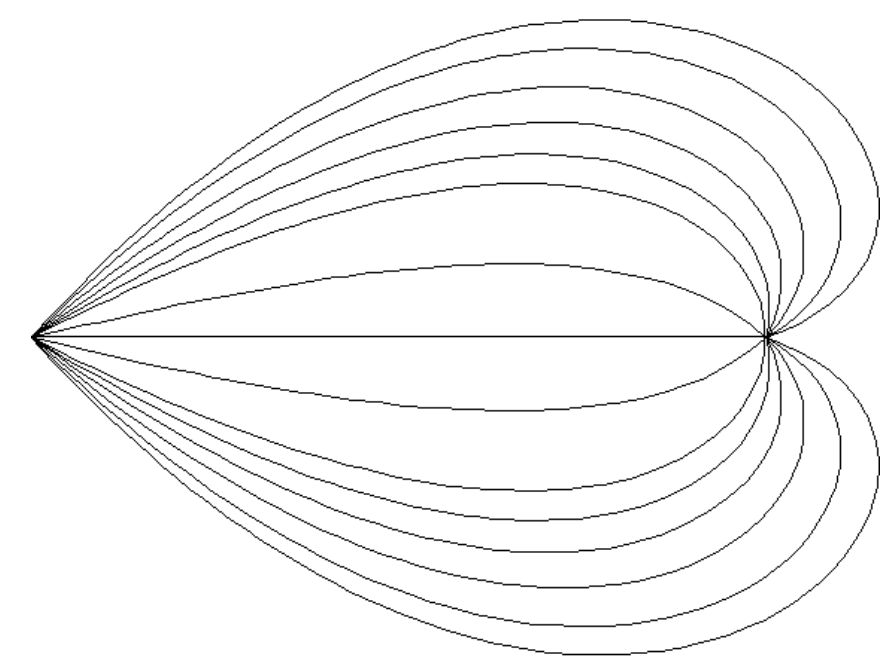

NOTE: For illustration purposes only. In the above pattern, the injection well is on the right, the production well is on the left, and the injection flow rate is 30 percent of the production flow rate. A homogeneous isotropic medium is assumed.

Figure G-13. Tracer Streamlines in a Weak Dipole Flow Pattern 


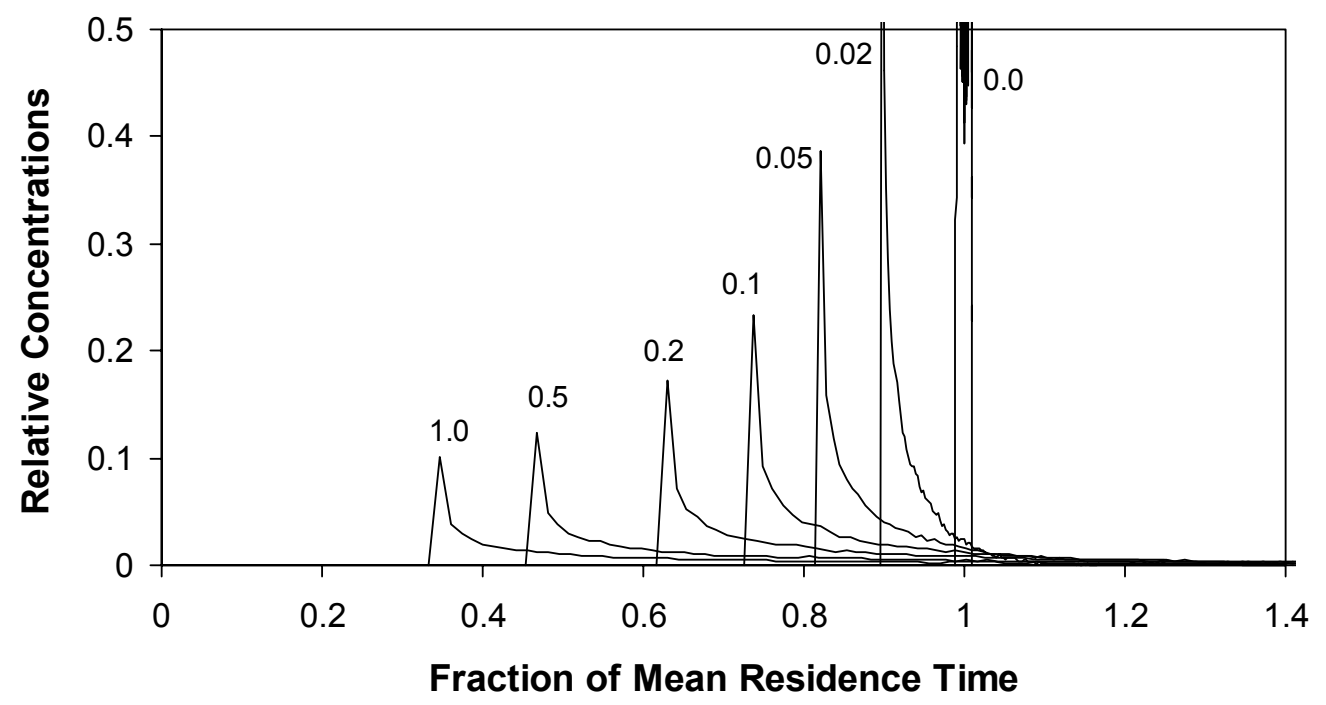

Output DTN: LA0403PR831231.001.

NOTE: The numbers next to the curves above are the recirculation fractions; local dispersivity was set equal to zero; and secondary tracer peaks associated with tracer recirculation are not shown. The sharp early arrivals occur because of the zero longitudinal and transverse dispersion assumed in the simulations. The long tails are the result of a small number of flow streamlines having very long residence times.

Figure G-14. Predicted Nonsorbing Tracer Responses in a Two-Dimensional Homogeneous Isotropic Medium as a Function of the Recirculated Fraction of Produced Water

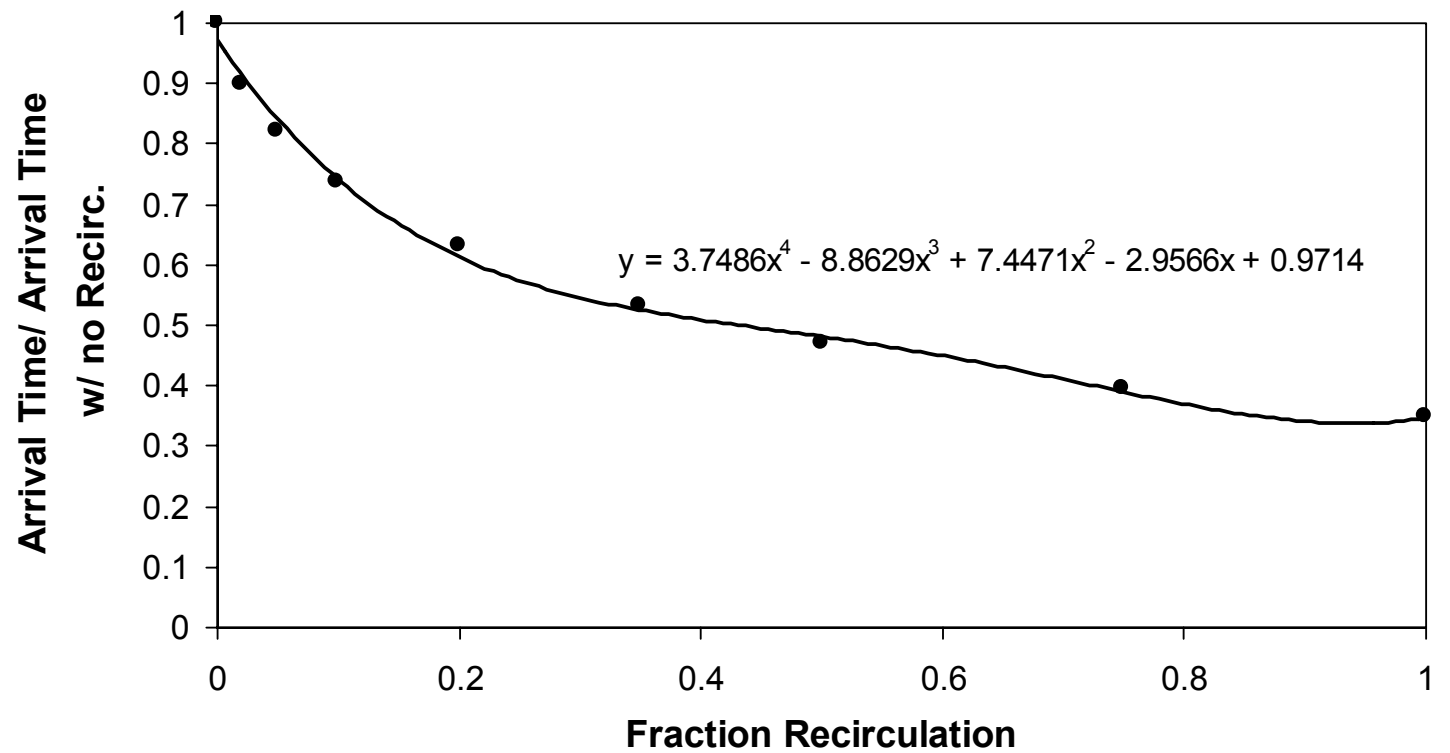

Output DTN: LA0403PR831231.001.

Figure G-15. Tracer Arrival Times as a Function of Fraction Recirculation in a Two-Dimensional Homogeneous Isotropic Medium 
A final feature added to the Excel spreadsheet was the propagation of uncertainties of two key input parameters: flow porosity and well separation. Flow porosity is an uncertain parameter because it is an unknown property of the flow system, and well separation is uncertain because of vertical deviations that can occur during well drilling, which can result in significantly different separations at depth than planned. The propagation of these uncertainties was accounted for using standard error propagation methods and assuming that the uncertainties were not correlated (i.e., linearly independent). Without derivation, when these methods are applied to Equation 54, they yield the following result for the relative standard deviation of the transport time of a nonsorbing tracer as a function of standard deviation of the flow porosity and well separation [flow derivation found in Modeling and Interpretation of Transport Tests Scientific Notebook (Reimus 2003 [DIRS 165129])]:

$$
\frac{\sigma_{\tau}}{\tau}=\sqrt{\frac{\sigma_{\eta}^{2}}{\eta^{2}}+4 \frac{\sigma_{r_{L}}^{2}}{r_{\mathrm{L}}^{2}}}
$$

where

$$
\begin{aligned}
& \sigma_{i}=\text { standard deviation of variable } i \\
& \tau=\text { mean residence time, } \mathrm{hr} \\
& \eta=\text { flow porosity } \\
& r_{\mathrm{L}}=\text { well separation, } \mathrm{m} .
\end{aligned}
$$

To provide a measure of transport time uncertainties, the Excel spreadsheet calculates mean, first, and peak tracer transport times associated with $\pm \sigma_{\tau} \tau$ (i.e., transport times that are plus and minus one standard deviation from the best estimate).

An additional parameter of considerable uncertainty is the $K_{\mathrm{d}}$ sorption parameter for sorbing tracers. However, a formal propagation of uncertainty calculation for this parameter was not included in the spreadsheet. Rather, it is left to the analyst to evaluate this uncertainty by manually entering different $K_{\mathrm{d}}$ values and determining what effect these have on predicted transport times.

As mentioned at the beginning of this section, all simulations using the RELAP V 2.0 (STN: 10551-2.0-00 [DIRS 159065]), 2WELLS_2D V 1.0 (STN: 10665-1.0-00 [DIRS 159067]), and 2WELLS_3D V 1.0 (STN: 10667-1.0-00 [DIRS 159036]) codes assumed a single-porosity system with no diffusive mass transfer into nonadvective water. Two sets of paired MULTRAN V 1.0 (STN: 10666-1.0-00 [DIRS 159068]) simulations were conducted to illustrate the impact of relaxing this assumption on predicted cross-hole responses. One set used sorption parameters corresponding to the strongest lithium sorption that has been observed in laboratory batch sorption tests with 19P or 19D material, and the other set used parameters corresponding to the weakest lithium sorption observed. Of the two simulations in each pair, one used parameters corresponding to the single-porosity system for the single-well tracer test simulations (conceptual model of Figure G-1a) and the other used parameters corresponding to the layered flow system for the single-well simulations (Figure G-1c). The latter system had the greatest predicted mass loss from advective flow pathways of the three conceptual models shown in Figure G-1 in the single-well simulations. The predicted cross-hole responses of a halide, an 
FBA, and lithium ion for each type of flow system are shown in Figures G-16 and G-17 for the cases of weak and strong lithium sorption, respectively. A mean tracer residence time of $150 \mathrm{hr}$ (for nonsorbing tracers) and a Peclet number of 10 were arbitrarily chosen for the simulations. There was no recirculation in the simulations. The $150 \mathrm{-hr}$ mean residence time corresponds to a relatively low effective flow porosity or a relatively high production flow rate in the valley-fill deposits if a well separation of 20 to $25 \mathrm{~m}$ is assumed and if the flow intervals are assumed to be 8 to $40 \mathrm{~m}$ thick, which is approximately the range of gravel-pack thicknesses in the valley-fill deposits in 19D. Table G-4 provides combinations of flow system parameters and production flow rates that result in mean nonsorbing tracer residence times of $150 \mathrm{hr}$ based on Equation 54.

It is apparent in Figures G-16 and G-17 that the differences in first and peak arrival times of any given tracer as a function of the system conceptualization (single porosity vs. layered system) are trivial. However, the first and peak arrival times for lithium are quite different in the two figures depending on whether weak (Figure G-16) or strong (Figure G-17) sorption is assumed. Also, the tails of the tracer responses are significantly different for the different system conceptualizations because the layered system has a secondary porosity that tracers diffuse into and out of, which results in the long tailing behavior typical of a dual-porosity system. The parameters assumed for the layered system are the same as those listed in Table G-1. The single-porosity system was assumed to have the same geometry and parameters as the layered system except that the nonadvective region was assigned a porosity of zero so that it played no part in tracer transport. The parameters used to describe cation exchange between lithium, sodium, and calcium are listed in the figure captions (see Equations 21 and 22 in Section E3.1.3). These parameters are representative of the smallest (Figure G-16) and largest (Figure G-17) amounts of lithium exchange observed in laboratory batch-sorption experiments conducted to date (see Section G6).

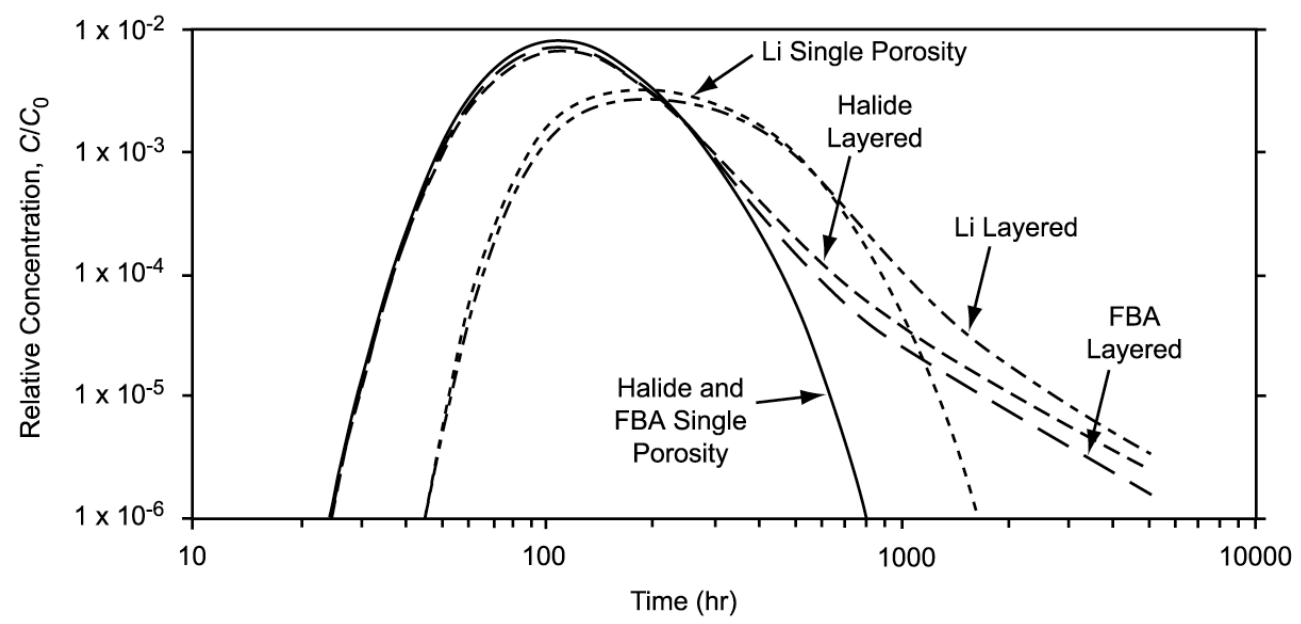

\section{Output DTN: LA0303PR831231.001.}

NOTE: Lithium sorption parameters are $Q_{1}=0.17, Q_{2}=0.019 \mathrm{~L} / \mathrm{kg}$, cation-exchange-capacity $(C E C)=0.024 \mathrm{eq} / \mathrm{kg}$ (see Equations 21, 22, and 24); the two systems have the same mean tracer residence time of $150 \mathrm{hr}$; and the peak lithium concentration occurs at about $190 \mathrm{hr}$, whereas the peak FBA and halide concentrations occur at about $110 \mathrm{hr}$.

Figure G-16. Predicted Cross-Hole Responses for a Halide, FBA, and Lithium Ion in a Single-Porosity System and a Layered System with Weak Lithium Sorption 


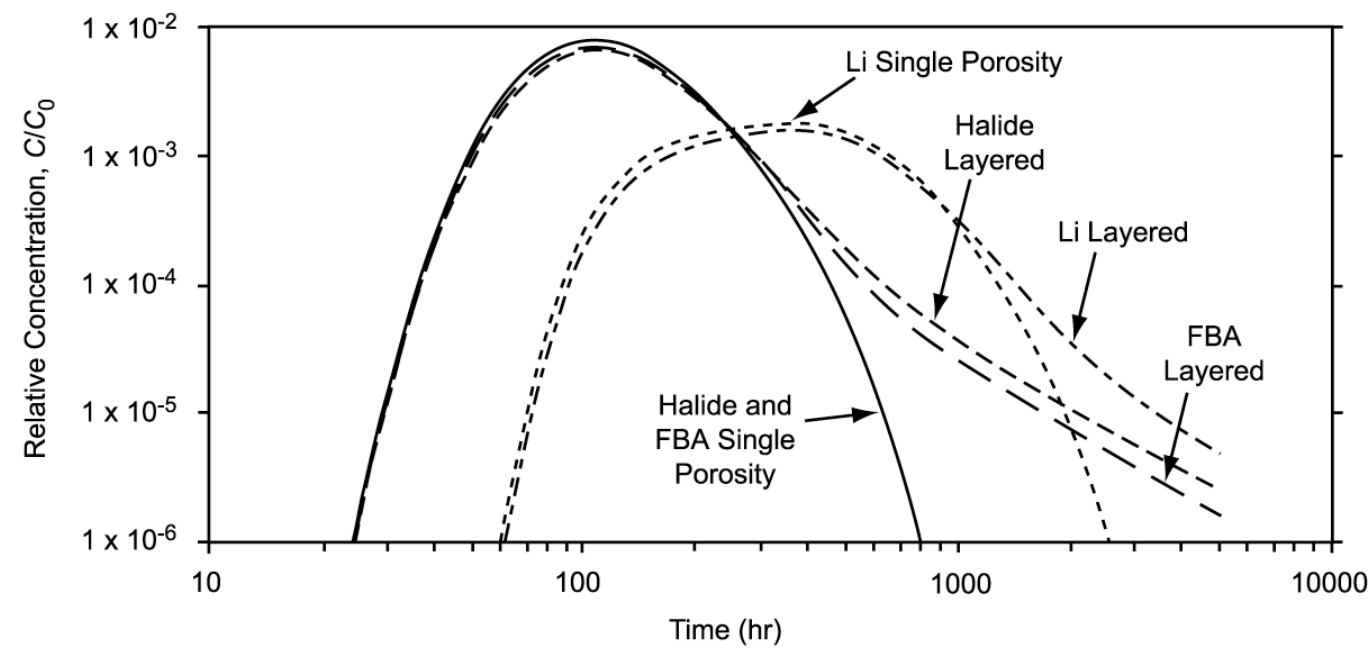

Output DTN: LA0303PR831231.001.

NOTE: Lithium sorption parameters are $Q_{1}=0.35, Q_{2}=0.005 \mathrm{~L} / \mathrm{kg}, C E C=0.345 \mathrm{eq} / \mathrm{kg}$ (see Equations 21,22 , and 24); the two systems have the same mean tracer residence time of $150 \mathrm{hr}$; the peak lithium concentration occurs at about $390 \mathrm{hr}$, whereas the peak FBA and halide concentrations occur at about $110 \mathrm{hr}$; and the peak lithium concentration is approximately 1.75 times lower than in Figure G-16.

Figure G-17. Predicted Cross-Hole Responses for a Halide, FBA, and Lithium Ion in a Single-Porosity System and a Layered System with Strong Lithium Sorption

Table G-4. Combinations of Flow-System Parameters and Production Flow Rate that Result in a Mean Nonsorbing Tracer Residence Time of 150 Hours in a Cross-Hole Tracer Test

\begin{tabular}{|c|c|c|c|}
\hline Well Separation $(\mathbf{m})$ & Interval Thickness $(\mathbf{m})$ & Flow Porosity & $\begin{array}{c}\text { Production Flow Rate } \\
\text { (L/min [gpm]) }\end{array}$ \\
\hline 25 & 40 & 0.1 & 874 [231] \\
\hline 25 & 40 & 0.3 & $2,619[692]$ \\
\hline 20 & 40 & 0.1 & $560[148]$ \\
\hline 20 & 40 & 0.3 & $1,677[443]$ \\
\hline 25 & 8 & 0.1 & $174[46]$ \\
\hline 25 & 8 & 0.3 & $522[138]$ \\
\hline 20 & 8 & 0.1 & $114[30]$ \\
\hline 20 & 8 & 0.3 & $337[89]$ \\
\hline
\end{tabular}

Output DTNs: LA0403PR831231.001; LA0303PR831231.d005.

\section{G4. RESULTS AND INTERPRETATION OF SINGLE-WELL TRACER TESTS IN ALLUVIUM}

Three single-well injection-withdrawal tracer tests were conducted in the saturated alluvium at NC-EWDP-19D between December 2000 and April 2001. Detailed documentation of these tracer tests is reported by Umari et al. (2003 [DIRS 164573]) and Reimus (2003 [DIRS 165128]). In each of the three tracer tests, two nonsorbing solute tracers with different diffusion coefficients were simultaneously injected (a halide and an FBA dissolved in the same solution). The three tests were conducted in essentially the same manner except for the time that was allowed to elapse between the cessation of tracer and chase water injection and the initiation 
of pumping - that is, the so-called "rest" or "shut-in" period. The rest period was systematically varied from approximately $0.5 \mathrm{hr}$, to approximately 2 days, to approximately 30 days in the tests to vary the time allowed for tracers to diffuse into stagnant water in the flow system and for the tracers to migrate with the natural groundwater flow. Test interpretations were based on comparing the responses of the different tracers in the same test and in different tests ("responses" refers to tracer concentrations normalized to injection mass as a function of time or volume pumped). As demonstrated in Section G2, the differences between the responses of two tracers with different diffusion coefficients in the same test and in tests with different rest periods can yield valuable information on diffusive mass transfer between flowing and stagnant water in the flow system and on the relative volumes of flowing and stagnant water in the system. In this section, it will be shown that differences in the responses of tracers with the same (or similar) diffusion coefficients in tests with different rest periods can provide information on ambient groundwater flow velocities in the flow system.

All three tests were conducted in the uppermost screened interval of 19D, which ranges from approximately 15 to $21 \mathrm{~m}$ (50 to $70 \mathrm{ft}$ ) below the water table (gravel pack from approximately 14 to $23 \mathrm{~m}$ ( 45 to $75 \mathrm{ft}$ ) below the water table). The static water table is approximately $107 \mathrm{~m}$ $(350 \mathrm{ft})$ below land surface at this location. The tracer solution volume injected in each test was approximately 11,000 L (2,900 gallons), and the volume of chase water (untraced water injected immediately after the tracer solution) was approximately 83,000 L (22,000 gallons). The chase water was intended to push the tracers into the formation so as to minimize the influence of the wellbore and gravel pack on the test results. Actual distances penetrated by the tracer solution into the formation ultimately depend on the effective porosity of the formation and its spatial variability in hydraulic conductivity, which are uncertain quantities at this time.

The tracers used in each test and their injection concentrations and recoveries, the injection and withdrawal flow rates (averages), and the volumes pumped during each test are listed in Table G-5. Tracer solutions were prepared by adding tracers to groundwater that had been withdrawn from 19D prior to any of the tests. Tracer concentrations were kept low and the solutions were heated to roughly match the ambient groundwater temperature to minimize density contrasts between the injection and chase solutions and the groundwater.

Table G-5. Summary of Tracers and Test Conditions in the Three Single-Well Tracer Tests in NC-EWDP-19D

\begin{tabular}{|l|c|c|c|}
\hline \multicolumn{1}{|c|}{ Rest Period (Test) } & \multicolumn{1}{c|}{$\mathbf{0 . 5} \mathbf{~ h r}$} & \multicolumn{1}{c|}{$\mathbf{2 ~ d a y s}$} & $\mathbf{3 0}$ days \\
\hline Dates & \multicolumn{1}{|c|}{$1 / 5 / 01-1 / 12 / 01$} & $12 / 1 / 00-12 / 18 / 00$ & $1 / 27 / 01-4 / 25 / 01$ \\
\hline Tracers (injection concentration)* & $\begin{array}{l}2,4-\mathrm{DFBA}(0.46 \mathrm{~g} / \mathrm{L}) \\
\mathrm{Cl}^{-}(0.62 \mathrm{~g} / \mathrm{L} \mathrm{NaCl}) \\
640-\mathrm{mm} \text { microspheres }\end{array}$ & $\begin{array}{l}2,6-\mathrm{DFBA}(0.46 \mathrm{~g} / \mathrm{L}) \\
\mathrm{I}^{-}(0.64 \mathrm{~g} / \mathrm{L} \mathrm{KI})\end{array}$ & $\begin{array}{l}\mathrm{PFBA}(0.46 \mathrm{~g} / \mathrm{L}) \\
\mathrm{Br}^{-}(0.64 \mathrm{~g} / \mathrm{L} \mathrm{NaBr})\end{array}$ \\
\hline Injection rate (L/min [gpm]) & $56.8[15.0]$ & $56.8[15.0]$ & $56.8[15.0]$ \\
\hline $\begin{array}{l}\text { Average pumping rate (L/min } \\
\text { [gpm]) }\end{array}$ & $50.3[13.3]$ & $41.3[10.9]$ & $51.67[13.65]$ \\
\hline Pumping duration (days) & 7 & 14 & 54 \\
\hline Total liters [gallons] pumped & $510,600[134,900]$ & $833,000[220,000]$ & $4,024,000[1,063,000]$ \\
\hline Tracer recovery (FBA) & 0.864 & 0.928 & 0.913 \\
\hline
\end{tabular}

DTNs: $\quad$ GS020708312316.001 [DIRS 162678] (data); UN0109SPA008IF.006 [DIRS 162442] (data); UN0109SPA008KS.007 [DIRS 162615] (data); UN0109SPA008KS.008 [DIRS 162616] (data).

DFBA =difluorobenzoate; FBA=fluorobenzoate; $P F B A=$ pentafluorobenzoate 


\section{G4.1 SINGLE-WELL TRACER TEST RESULTS}

Figures G-18, G-19, and G-20 show the normalized tracer responses in the each of the three tracer tests. The two solute tracers had essentially identical responses (within experimental error) in each test. This result is consistent with very little diffusive mass transfer between flowing and stagnant water in the aquifer over the time scales of the tests. It is, therefore, consistent with a single-porosity conceptualization of the saturated alluvium. The flow interruptions during the tailing portions of the two longer tests provided additional evidence for very little diffusive mass transfer in the aquifer. If diffusive mass transfer were an important process, the tracer concentrations would have increased significantly immediately after the flow interruptions due to tracers diffusing out of stagnant water and into flowing water during the interruptions. The microspheres used in the shortest rest period test (Figure G-18) provided information on colloid filtration and detachment rates in the flow system (see Section G4.6).

Figure G-21 shows how the responses of the FBAs differed as a function of volume pumped in each of the three tracer tests. Because diffusion can be ruled out as having caused these differences, the most plausible explanation is that the differences are due to drift during the different rest periods. These different responses and the assumption that they are due to drift form the basis of three separate methods of estimating drift or seepage velocities in the aquifer.

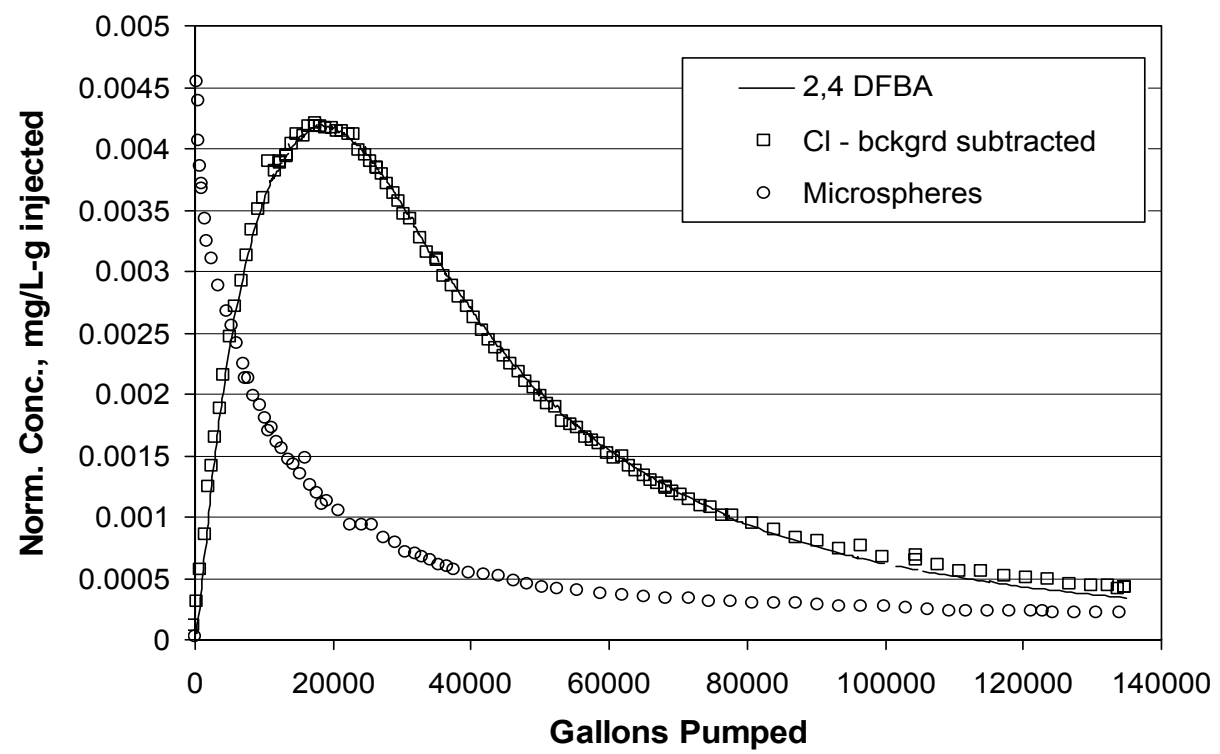

DTNs: UN0109SPA008IF.006 [DIRS 162442] (2,4-DFBA and CI), LA0207PR831352.001 [DIRS 162431] (microspheres).

NOTE: Microspheres were 640-nm diameter carboxylate-modified latex (CML) polystyrene spheres tagged with a UV-excited fluorescent dye for detection. The figure is plotted in English units because the data were obtained in those units. However, parameter estimates are reported in metric units to downstream users.

Figure G-18. Normalized Concentrations of Tracers in Production Water from NC-EWDP-19D as a Function of Gallons Pumped after a Rest Period of Approximately 0.5 Hours 


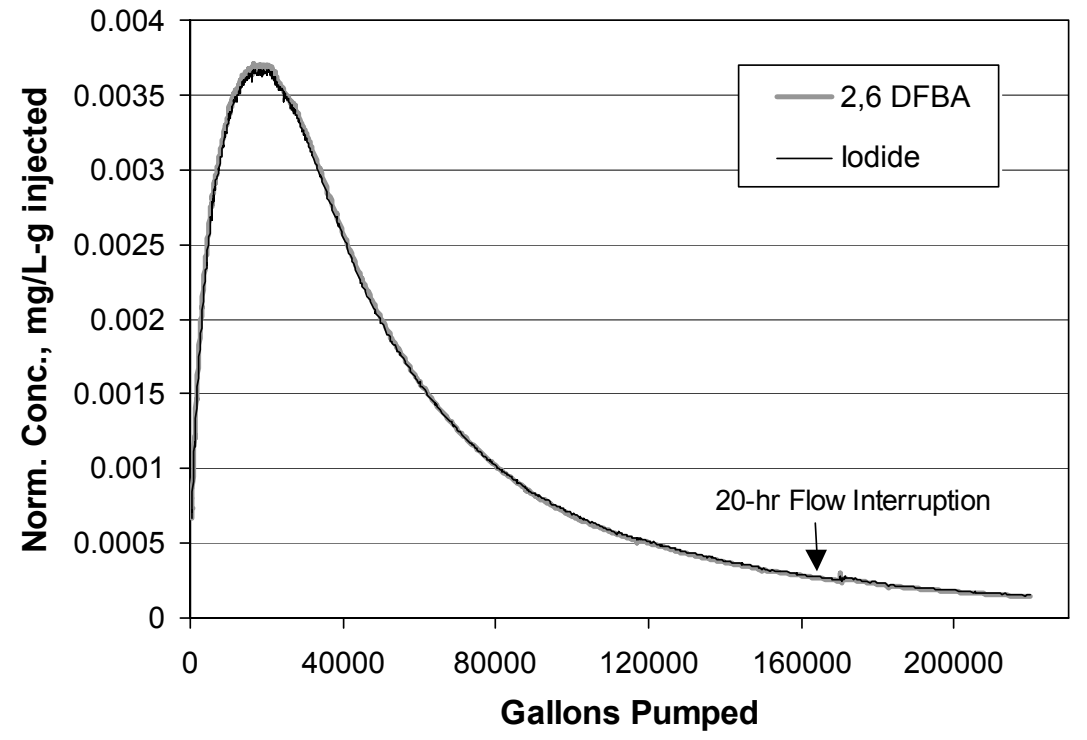

DTN: UN0102SPA008KS.003 [DIRS 162614].

Output DTN: LA0303PR831231.002 (volumes).

NOTE: The tracer responses are almost identical, so it is difficult to distinguish between the two responses. The figure is plotted in English units because the data were obtained in those units. However, parameter estimates are reported in metric units to downstream users.

Figure G-19. Normalized Concentrations of Tracers in Production Water from NC-EWDP-19D as a Function of Gallons Pumped after a Rest Period of Approximately 2 Days

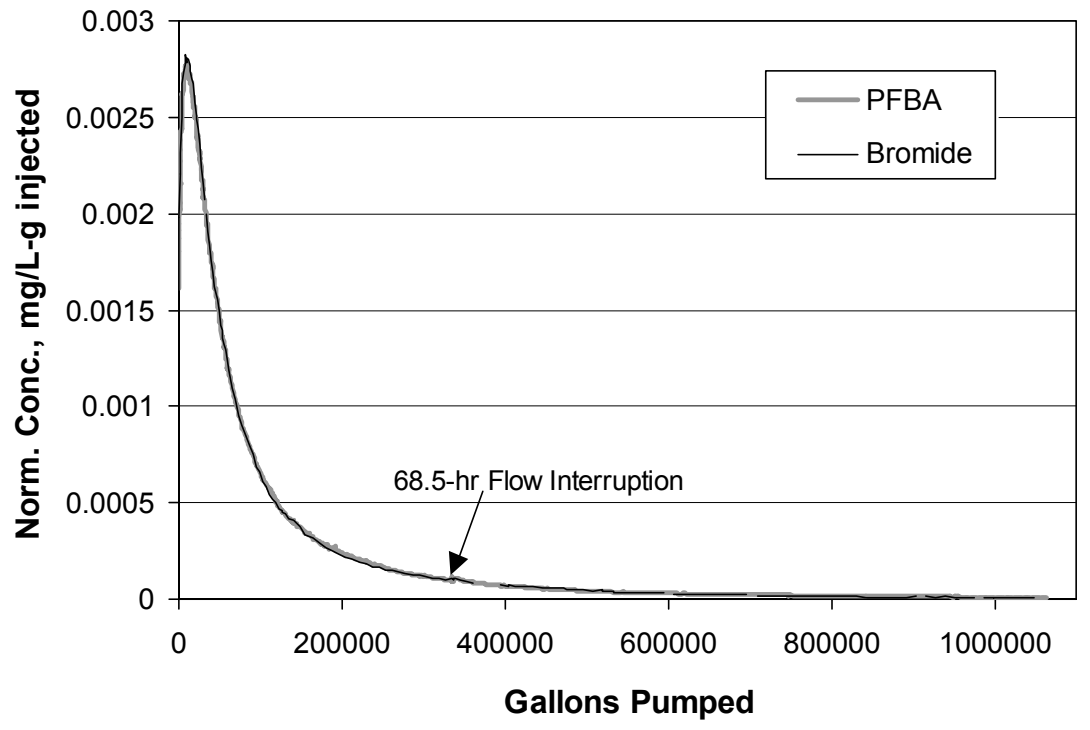

DTNs: UN0109SPA008KS.007 [DIRS 162615] (PFBA), UN0109SPA008KS.008 [DIRS 162616] (Br).

Output DTN: LA0303PR831231.002. (volumes).

NOTE: The tracer responses are almost identical, so it is difficult to distinguish between the two responses. The figure is plotted in English units because the data were obtained in those units. However, parameter estimates are reported in metric units to downstream users.

Figure G-20. Normalized Concentrations of Tracers in Production Water from NC-EWDP-19D as a Function of Gallons Pumped after a Rest Period of Approximately 30 Days 

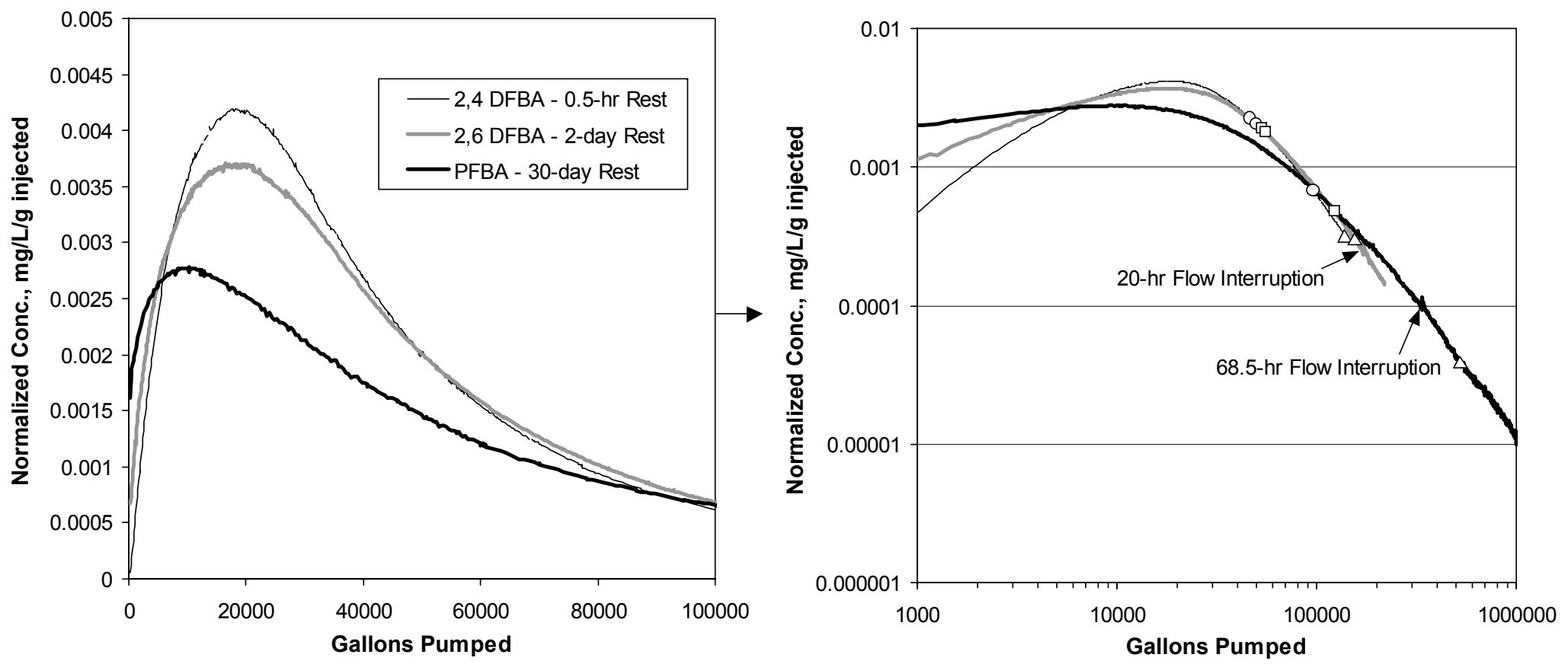

DTNs: UN0109SPA008IF.006 [DIRS 162442] (2,4-DFBA), UN0102SPA008KS.003 [DIRS 162614] (2,6-DFBA), UN0109SPA008KS.007 [DIRS 162615] (PFBA). Output DTN: LA0303PR831231.002. (volumes).

NOTE: On the right-hand plot, circles indicate volumes associated with mean arrival times (for each tracer response), squares indicate volumes associated with alternate mean arrival times, and triangles indicate volumes associated with "late" arrival times. The left-most symbol is always associated with the 0.5-hr rest-period test, and the right-most symbol is associated with the 30-day rest-period test. The bases for these different arrival times/volumes are discussed in detail in Section G4.2. The figure is plotted in English units because the data were obtained in those units. However, parameter estimates are reported in metric units to downstream users.

Figure G-21. Normalized Concentrations of Fluorinated Benzoates as a Function of Gallons Pumped in Each of the Three Single-Well Tracer Tests in NC-EWDP-19D 


\section{G4.2 ESTIMATION OF GROUNDWATER VELOCITY}

Four methods were used to obtain groundwater velocity estimates from the single-well tracer tests. The first three methods involve relatively simple spreadsheet calculations that, given various simplifying assumptions, solve for groundwater velocities that are consistent with the observed differences in the following:

(1) Peak tracer concentration arrival times.

(2) "Late" arrival times, defined as the times in each test when the fractional tracer mass recovery was equal to the final recovery in the test having the lowest overall mass recovery. Given that the total mass recoveries in the three tests were $0.864,0.928$, and 0.913 (Table G-5), then the late arrival time in each test was the time at which the mass recovery was 0.864 .

(3) "Mean" arrival times of tracer mass recovered at the same arbitrarily selected high fractional recovery in each test. Two different fractional recoveries were selected to calculate mean arrival times: 0.864 , the lowest fractional recovery in any of the tests, and 0.913 , the fractional recovery in the 30-day-rest-period test. In the latter case, the tracer responses in the test with a mass recovery of 0.864 were extrapolated to 0.913 (see Section G4.2.3 for details) to allow a calculation of the mean arrival time. This alternative method of calculating the mean arrival time was employed because the 30-day test had the largest calculated mean arrival time, and it was, therefore, considered to have the greatest amount of information pertinent to groundwater velocity estimates.

Note that these three times also correspond to volumes pumped, and because the pumping rates varied in the different tests, the relationship between times and volumes is different for each test. The peak, late, and mean arrival times (and corresponding volumes) for each test are listed in Table G-6. The points on the tracer breakthrough curves corresponding to the mean and late arrival times in each test are identified in the right-hand plot of Figure G-21. The fourth method involved detailed analytical calculations of tracer migration during the tests by linking together solute transport solutions that assume a two-dimensional homogeneous and isotropic aquifer.

Because the peak tracer concentration occurred earliest in the test with the longest rest period, the tracer mass corresponding to the peak probably moved upgradient during injection and then drifted back toward the well during the rest period. In contrast, the tracer mass corresponding to times at which fractional recoveries were high (i.e., mass recovered far out in the tails of the responses) probably moved downgradient during injection and arrived late because of the competing effects of drift that moved the tracer further from the well and pumping the tracers toward the well. The mean tracer arrival time represents a compromise between these two cases, as the mean is influenced by both early and late-arriving tracer mass. However, for asymmetric long-tailed distributions, the mean is more strongly influenced by late-arriving mass than early arriving mass, so it was assumed that the differences in mean arrival times were due mainly to tracer mass that had moved downgradient during injection. 
Table G-6. Times and Pumped Volumes Associated with Each of the Arrival Times Used in the Different Methods of Estimating Groundwater Velocities

\begin{tabular}{|c|c|c|c|}
\hline \multirow{2}{*}{ Rest Period (Test): } & \multicolumn{3}{|c|}{ Arrival Time (hr)/Volume (L [gal]) } \\
\hline & $0.5 \mathrm{hr}$ & 2 days & 30 days \\
\hline Peak arrival & $24 / 76,000[20,000]$ & $30.5 / 76,000[20,000]$ & $12.2 / 38,600[10,200]$ \\
\hline Late arrival $^{a}$ & $168 / 511,000[135,000]$ & $225 / 556,000[147,000]$ & $\begin{array}{l}639 / 1,780,000 \\
{[471,000]}\end{array}$ \\
\hline Mean arrival ${ }^{\mathrm{b}}$ & $52 / 161,000[42,500]$ & $71 / 178,000[46,500]$ & $109 / 344,000[91,000]$ \\
\hline Alternate mean arrival ${ }^{\mathrm{c}}$ & $61.5 / 189,000[50,000]$ & $81 / 201,000[53,000]$ & $149 / 469,000[124,000]$ \\
\hline \multicolumn{4}{|c|}{$\begin{array}{ll}\text { DTNs: } & \text { UN0109SPA008IF.006 [DIRS 162442] (0.5 hr); UN0102SPA008KS.003 [DIRS 162614] (2 days); } \\
& \text { UN0109SPA008KS.007 [DIRS 162615] (30 days). }\end{array}$} \\
\hline \multicolumn{4}{|c|}{ Output DTN: LA0303PR831231.002 (volumes). } \\
\hline \multicolumn{4}{|c|}{$\begin{array}{l}\text { Time/volume associated with approximately } 86.4 \text { percent mass recovery in each test (the final recovery in the } \\
0.5 \text {-hr rest period test, which had the lowest final recovery of any test). } \\
\text { b Mean arrival time calculated by truncating all tracer response curves at approximately } 86.4 \text { percent recovery in } \\
\text { each test. } \\
\text { c Alternate mean arrival time calculated by extrapolating the tracer response curves in the } 0.5 \text {-hr rest period test to } \\
91.3 \text { percent and truncating the response curves in the } 2 \text {-day rest period test to } 91.3 \text { percent recovery (the final } \\
\text { recovery in the } 30 \text {-day rest period test). }\end{array}$} \\
\hline
\end{tabular}

In all four estimation methods, it is assumed that injection into and pumping from the well results in a two-dimensional radial flow field in which the flow velocity varies as $1 / \mathrm{r}$ :

$$
\mathrm{v}(\mathrm{r})=\frac{\mathrm{Q}}{2 \mathrm{~h} \eta \pi \mathrm{r}}
$$

where

$\mathrm{v}(\mathrm{r})=$ linear velocity as a function of radial position, $\mathrm{m} / \mathrm{hr}$

$\mathrm{Q}=$ injection or production flow rate, $\mathrm{m}^{3} / \mathrm{hr}$ (negative number for production)

$\mathrm{h}=$ interval thickness, $\mathrm{m}$

$\eta=$ flow porosity

$\mathrm{r}=$ radial distance from the well, $\mathrm{m}$.

For the first three methods, the ambient groundwater flow is superimposed on the radial flow induced by injection or pumping, and it is present during the rest period when there is no radial flow component. The ambient flow is assumed to be unidirectional.

Flow fields resulting from injection and pumping will not be ideally radial unless the aquifer is perfectly homogeneous, isotropic, and two-dimensional. Figure G-22 shows a hypothetical representation of how injected tracer solution and chase water might be distributed in the aquifer immediately after injection. Figure G-22 represents only one of many possibilities for how heterogeneity might affect tracer distribution in the system, and all of these possibilities must be considered equally likely given the present knowledge of the flow system. Although it may not be strictly correct, the radial flow assumption is qualitatively consistent with the picture of heterogeneity shown in Figure G-22 because the flow velocity will maintain an approximately $1 / \mathrm{r}$ dependence as long as the flow cross-sectional area "fans out" such that it increases approximately linearly with $r$. Only highly channelized flow that does not increase significantly 
in cross-sectional area with $r$ will have a velocity that does not decrease as approximately $1 / r$. In pipeline flow, the extreme case of channelized flow, there is no dependence of velocity on $\mathrm{r}$.

Alternatively, if the system is not two-dimensional, the flow cross-sectional area could increase with more than a linear dependence on $r$, with the extreme case being spherical flow where the velocity decreases as $1 / \mathrm{r}^{2}$ (at sufficiently large distances from the well). However, this latter possibility was ignored because (1) there is qualitative evidence (both lithologic and from hydraulic testing) of layering in the aquifer that could cause considerable vertical confinement, and (2) the injection volumes were small enough relative to the interval thickness and potential flow porosities that the tracer injection distances into the formation should have been relatively short compared to what it would take to approximate a spherical flow condition.
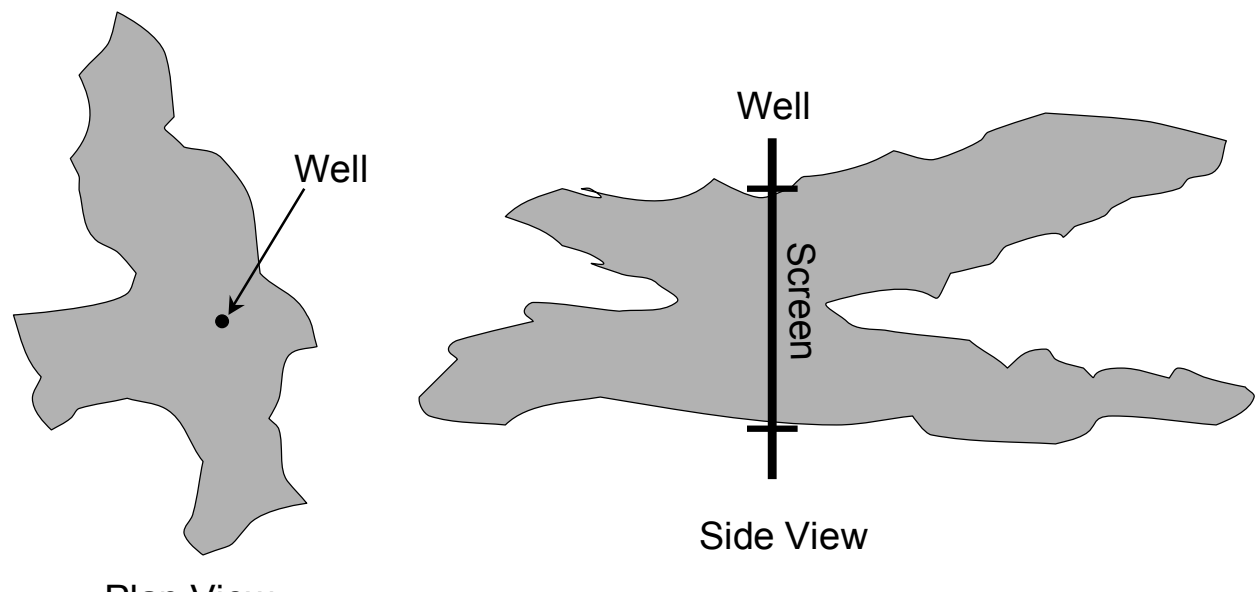

Side View

Plan View

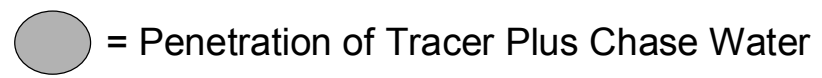

NOTE: For illustration purposes only.

Figure G-22. Depiction of How Tracer and Chase Water Might Be Distributed after Injection into a Heterogeneous Porous Medium

\section{G4.2.1 Peak-Arrival-Time Analysis}

For the analysis comparing the peak tracer arrival times, the mass contributing to the peak was assumed to move directly upgradient during injection. That is, the radial flow pushing the mass was assumed to be in the exact opposite direction as the ambient groundwater flow (Figure G23). Any estimate of groundwater drift velocity using this assumption should be considered a lower bound because the peak mass will have the greatest decrease in arrival time as the rest period is increased when the mass is injected directly upgradient. Trigonometric calculations show that if the tracer mass corresponding to the peak concentration were injected at some angle relative to the ambient gradient direction, the groundwater velocity would have to be greater to result in the same decrease in arrival time (assuming a reasonably homogeneous system). 


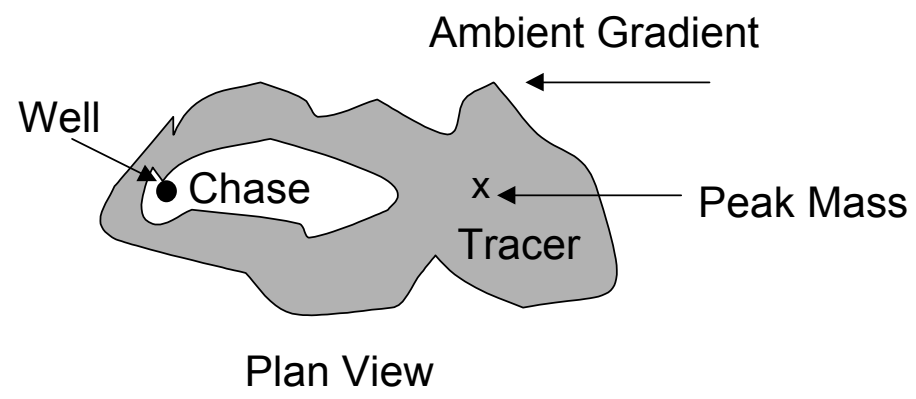

NOTE: For illustration purposes only. The shape of the distribution is not important; the key assumption is that the tracer mass associated with the peak concentration is located directly up-gradient.

Figure G-23. Depiction of Assumed Tracer Mass Distribution Immediately after Injection

Given the assumption of the peak tracer mass moving strictly upgradient, the distance that the tracer mass moved into the formation during the injection and chase phase is given by [derivations of Equations 59 to 68 are documented in Modeling and Interpretation of Transport Tests Scientific Notebook (Reimus 2003 [DIRS 165129])]:

$$
\mathrm{r}_{\text {inj }}=\sqrt{\frac{\left(0.5 \mathrm{~V}_{\text {tracer }}+\mathrm{V}_{\text {chase }}\right)}{\pi \eta \mathrm{h}}}-\mathrm{v}_{\mathrm{GW}} \frac{\left(0.5 \mathrm{~V}_{\text {tracer }}+\mathrm{V}_{\text {chase }}\right)}{\mathrm{Q}_{\text {inj }}}
$$

where

$$
\begin{aligned}
& \mathrm{r}_{\text {inj }}=\text { upgradient injection distance, } \mathrm{m} \\
& \mathrm{V}_{\text {tracer }}=\text { volume of tracer solution injected, } \mathrm{m}^{3} \\
& \mathrm{~V}_{\text {chase }}=\text { volume of chase water injected, } \mathrm{m}^{3} \\
& \mathrm{~V}_{\mathrm{GW}}=\text { groundwater velocity (seepage velocity), } \mathrm{m} / \mathrm{hr} \\
& \mathrm{Q}_{\text {inj }}=\text { injection flow rate, } \mathrm{m}^{3} / \mathrm{hr} \\
& \mathrm{h}=\text { interval thickness, } \mathrm{m} \\
& \eta=\text { flow porosity. }
\end{aligned}
$$

The first term in Equation 59 accounts for the distance injected under pure radial flow conditions, and the second term accounts for the drift back toward the well during injection. Only half of the tracer solution volume is used in Equation 59 because it is assumed that the tracer mass resulting in the peak should have corresponded to approximately the midpoint of the injection volume. However, the calculations are not sensitive to this assumption because the tracer solution volume in all tests was small relative to the chase volume. Because the tracer and chase volumes and the injection rates were essentially the same in the three tests, the injection distance given by Equation 59 is the same for all three tests.

The radial distance, $r_{\text {rest }}$, between the peak tracer mass and the well at the end of the rest period is given by:

$$
r_{\text {rest }}=r_{\text {inj }}-v_{\text {GW }} t_{\text {rest }}
$$


where $t_{\text {rest }}=$ duration of the rest period, hr.

The time required to pump the peak tracer mass back to the well after the rest period, $\mathrm{t}_{\text {pump }}$, is calculated from the following integral:

$$
\mathrm{t}_{\text {pump }}=\int_{\mathrm{r}_{\text {rest }}}^{0} \frac{\mathrm{dr}}{\mathrm{V}(\mathrm{r})}
$$

where

$$
\begin{aligned}
& \mathrm{v}(\mathrm{r})=-\frac{\left|\mathrm{Q}_{\text {pump }}\right|}{2 \mathrm{~h} \eta \pi \mathrm{r}}-\mathrm{v}_{\mathrm{GW}} \\
& \mathrm{Q}_{\text {pump }}=\text { production flow rate, } \mathrm{m}^{3} / \mathrm{hr} .
\end{aligned}
$$

The solution to this integral (with $\mathrm{v}(\mathrm{r})$ from Equation 58 inserted and using the appropriate upper and lower limits) is (Weast and Astle 1981 [DIRS 100833], p. A-36, Equations 84 and 85):

$$
\mathrm{t}_{\text {pump }}=\left[-\frac{\mathrm{r}}{\mathrm{v}_{\mathrm{GW}}}+\frac{\left|\mathrm{Q}_{\text {pump }}\right|}{2 \pi \eta \mathrm{h}_{\mathrm{GW}}{ }^{2}} \ln \left(\frac{\left|\mathrm{Q}_{\text {pump }}\right|}{2 \pi \eta \mathrm{h}}+\mathrm{v}_{\mathrm{GW}} \mathrm{r}\right)\right]_{\mathrm{r}=\mathrm{r}_{\text {rest }}}^{\mathrm{r}=0}
$$

$t_{\text {pump }}$ can be converted to a volume corresponding to the arrival time of the peak concentration using:

$$
\mathrm{V}_{\text {pump }}=\mathrm{t}_{\text {pump }}\left|\mathrm{Q}_{\text {pump }}\right| \text {. }
$$

The pertinent equations above were encoded into an Excel spreadsheet for the analysis (Output DTN: LA0303PR831231.002). The only unknown variables for each of the three tests were the groundwater velocity, $\mathrm{v}_{\mathrm{GW}}$, and the flow porosity, $\eta$, both of which were assumed to be the same in all three tests. The procedure for obtaining an estimate of $\mathrm{v}_{\mathrm{GW}}$ involved selecting $\eta$ and then varying $\mathrm{v}_{\mathrm{GW}}$ by trial-and-error until the calculated peak arrival volumes in the three tests had approximately the same ratios as in the actual field tests. It was considered more important to match the ratios of times rather than to match the actual times, although the calculated times were generally in reasonable agreement with the actual times, once the ratios were matched. Also, greater emphasis was placed on matching the volume ratio between the 30-day-rest-period test and the approximately 0.5 -hr-rest-period test than on matching the volume ratios in any other pair of tests, particularly the two shorter tests. The uncertainty associated with a groundwater velocity estimate obtained from the two shorter duration tests was considered to be far greater than estimates obtained using the 30-day test results because of the much greater time allowed for drift to take place in the 30-day test.

The process of estimating $\mathrm{v}_{\mathrm{GW}}$ was repeated for three different values of $\eta-0.05,0.18$, and 0.3 . These values are approximately the lowest, expected (mean), and highest values, respectively, used for alluvium flow porosity in Yucca Mountain performance assessment simulations 
(BSC 2004 [DIRS 170042]). The value of $\mathrm{v}_{\mathrm{GW}}$ was different in each case because of the dependence of Equations 59 and 62 on $\eta$. For each case, a specific discharge, $\mathrm{v}_{\mathrm{S}}$, was calculated from $\mathrm{v}_{\mathrm{GW}}$ using $\mathrm{V}_{\mathrm{S}}=\eta \mathrm{v}_{\mathrm{GW}}$.

\section{G4.2.2 Analysis of Late Arrival Times (Associated with High Fractional Tracer Recoveries)}

The analysis of late arrival times (arrival times associated with high fractional tracer recoveries) was similar to the analysis of peak arrival times except that the tracer mass associated with the late arrival time was assumed to have been injected downgradient rather than upgradient. This assumption seems reasonable, given that any mass injected upgradient should arrive earlier than the mean tracer arrival time, not later. Analogous to the peak arrival-time analysis, it was assumed that the mass was injected directly downgradient (in the same direction as the ambient groundwater flow). Any estimate of groundwater velocity using this assumption should be considered an upper bound because the late-arriving mass will have the greatest increase in arrival time as the rest period is increased when the mass is injected directly downgradient.

The times/volumes associated with the final recovery in the approximately 0.5 -hr-rest-period test (0.864), which had the lowest recovery of the three tests, were used as the basis of comparison of the late arrival times for the three tests. Although this is a somewhat arbitrary definition of the late arrival time because it depends on when pumping was stopped in the approximately 0.5-hr-rest-period test, it was considered to be the most objective measure because times associated with recoveries greater than 0.864 would require an extrapolation of the tracer responses in the $0.5-\mathrm{hr}$ test. Clearly, if the $0.5-\mathrm{hr}$ test had been pumped longer, the late arrival times in the tests would have all been greater, and the estimates of groundwater velocities would be slightly different. However, the pumped volumes associated with the arrival times would also have been greater, which would tend to have a moderating effect on the changes in velocity estimates.

The analysis requires that Equations 59, 60, and 61 be modified as shown in Equations 64, 65, and 66, respectively.

$$
\begin{gathered}
\mathrm{r}_{\text {inj }}=\sqrt{\frac{\left(\mathrm{V}_{\text {tracer }}+\mathrm{V}_{\text {chase }}\right)}{\pi \eta \mathrm{h}}}+\mathrm{v}_{\mathrm{GW}} \frac{\left(\mathrm{V}_{\text {tracer }}+\mathrm{V}_{\text {chase }}\right)}{\mathrm{Q}_{\text {inj }}} \\
\mathrm{r}_{\text {rest }}=\mathrm{r}_{\text {inj }}+\mathrm{v}_{\mathrm{GW}} \mathrm{t}_{\text {rest }} \\
\mathrm{t}_{\text {pump }}=\left[\frac{\mathrm{r}}{\mathrm{v}_{\mathrm{GW}}}+\frac{\left|\mathrm{Q}_{\text {pump }}\right|}{2 \pi \eta \mathrm{h} \mathrm{v}_{\mathrm{GW}}^{2}} \ln \left(\frac{\left|\mathrm{Q}_{\text {pump }}\right|}{2 \pi \eta \mathrm{h}}-\mathrm{v}_{\mathrm{GW}} \mathrm{r}\right)\right]_{\mathrm{r}=\mathrm{r}_{\text {rest }}}^{\mathrm{r}=0}
\end{gathered}
$$

The modifications are primarily changes in sign associated with the $\mathrm{v}_{\mathrm{GW}}$ terms because the groundwater drift velocity is now assumed to push the tracer mass further from the well during injection and slow down the movement of the mass toward the well during pumping. Also, the mass associated with the high fractional recovery is assumed to be on the leading edge of the 
tracer injection volume rather than at the midpoint of the volume (Equation 64). One additional difference between the peak- and late-arrival analyses that does not involve equation modifications is that the flow interruption times were added to $t_{\text {rest }}$ for the late-arrival analyses because the tracer mass associated with the latter analyses arrived after the flow interruptions.

As with the peak arrival time analyses, $\mathrm{v}_{\mathrm{GW}}$ was varied to achieve matches to the ratios of the arrival volumes, rather than the actual volumes. However, unlike the peak analyses, the calculated volumes were typically much smaller than the actual volumes associated with the late recoveries. The most likely reason for this discrepancy is that this simple analysis does not account for any hydrodynamic dispersion during any of the three test phases (injection, rest period, withdrawal). Dispersion during each of these three phases could have significantly increased late-recovery arrival times relative to those calculated without dispersion because a fraction of the tracer mass should always disperse further away from the well at any given time. However, if it is assumed that dispersion during each test had approximately the same effect on the tracer plume (disregarding the expected slight increase in dispersion for the longest test), then a comparison of the ratios of the late arrival times should still yield a reasonable estimate of groundwater velocity.

\section{G4.2.3 Mean-Arrival-Time Analysis}

The mean tracer arrival-time analysis was essentially identical to the analysis of the late-recovery arrival time, with the only exception being that the mass associated with the mean tracer mass was assumed to be at the midpoint of the tracer injection volume rather than at the leading edge. Thus, Equation 64 was modified to

$$
\mathrm{r}_{\text {inj }}=\sqrt{\frac{\left(0.5 \mathrm{~V}_{\text {tracer }}+\mathrm{V}_{\text {chase }}\right)}{\pi \eta \mathrm{h}}}+\mathrm{v}_{\mathrm{GW}} \frac{\left(0.5 \mathrm{~V}_{\text {tracer }}+\mathrm{V}_{\text {chase }}\right)}{\mathrm{Q}_{\text {inj }}}
$$

The primary difference between the mean and late arrival time analyses was in how the times/volumes used for comparison with the calculations were obtained from the actual field tracer data. For the late-recovery time analysis, it was a simple matter to extract the times/volumes associated with a specific (though arbitrary) tracer recovery. However, for the mean analysis, it was necessary to calculate a meaningful estimate of the mean arrival time/volume from the data. Without 100 percent tracer recovery, it is impossible to calculate a true mean, so a mean for comparison purposes was calculated by truncating the tracer responses in the two longer-rest-period tests at the final recovery of the approximately 0.5 -hr-rest-period test (0.864). The mean volume was calculated by:

$$
\mu=\frac{\sum_{i}\left(f_{i}-f_{i-1}\right) V_{\text {pump } i}}{\sum_{i}\left(f_{i}-f_{i-1}\right)}
$$

where

$$
\mu=\text { mean volume, } \mathrm{m}^{3}
$$


$\mathrm{f}_{\mathrm{i}}=$ mass fraction recovered at volume $\mathrm{V}_{\text {pump }} \mathrm{i}$

$\mathrm{f}_{\mathrm{i}-1}=$ mass fraction recovered at volume $\mathrm{V}_{\text {pump } \mathrm{i}-1}$.

However, because the mean times/volumes are sensitive to the tails of the tracer response curves, an alternative method of calculating the mean arrival time was devised to include all the data from the 30-day-rest-period test, which had the largest mean of the three tests and, therefore, was considered to contain the greatest amount of information pertinent to ambient groundwater velocities. Although this method required that the data from the approximately $0.5-\mathrm{hr}$ rest-period-test be extrapolated until the fractional recovery in that test matched the final recovery in the 30-day test (0.913), the extrapolation was considered justified in light of the additional information contained in the tracer responses from the 30-day test. Also, it was desirable to determine the sensitivity of the ambient groundwater velocity estimates to different methods of calculating the mean arrival time.

The extrapolation of the approximately $0.5-\mathrm{hr}$ test data was accomplished by doing the mathematical equivalent of linearly extending the tail of the tracer response curve on a log-log plot. The means were then recalculated using Equation 68. The recalculated means for all three tests increased significantly relative to the means calculated from the breakthrough curves that were truncated at a fractional tracer recovery of 0.864 . However, the mean for the 30-day test increased by the greatest percentage (about 36 percent compared to 18 percent and 15 percent for the approximately 0.5 -hr and 2-day tests, respectively). The (re)calculated mean for the approximately 0.5 -hr test was found to be relatively insensitive to the slope of the line used to extrapolate the tracer data. This insensitivity was probably due to the relatively steep slope of the tail of the response curve in this test.

\section{G4.2.4 Linked Analytical Solutions}

Three different analytical solutions of the advection-dispersion equation, with appropriate boundary conditions representing the three distinct single-well tracer test phases (injection/chase, drift, and pump back) were combined into one Personal Computer-based Windows program with a user interface called Injection-Pumpback.vi V 1.0 (STN: 10675-1-00 [DIRS 162749]). Injection-Pumpback.vi is a "LabView" program where LabView is the graphical-programming language "G" as implemented by National Instruments, Inc. The linked analytical solutions were intended to provide an alternative, more rigorous method of estimating groundwater drift velocities in the alluvium from single-well tracer tests than the analytical approaches described in Sections G4.2.1 through G4.2.3. This method was also intended to provide estimates of other transport parameters derived from single-well tracer testing in the alluvium (flow porosity, dispersivity) given an assumption of a homogeneous and isotropic flow system. The method was chosen instead of numerical modeling approaches because of the relative simplicity of the analysis and the desire to avoid numerical dispersion that occurs in numerical models. A description of the three analytical solutions that constitute the program Injection-Pumpback.vi and the application of the program to analyze the three injection-pumpback tracer tests conducted in Borehole 19D follows.

The tracer injection and chase phase was analyzed using simple flow displacement calculations combined with a one-dimensional uniform-flow solution of the advection-dispersion equation by Crank (Bear 1979 [DIRS 105038], p. 266, Equation 7-123) to determine the location and width 
of the "tracer ring" resulting from the outward radial flow. The inner radius of the ring was calculated directly from the volume of chase water injected, and the one-dimensional solution was then used to determine the width and, hence, outer radius, of the ring. This approach is only approximate because the one-dimensional column solution assumes a constant velocity flow field, whereas a divergent radial flow field has a decreasing velocity with increasing distance from the injection well. In the one-dimensional column solution, dispersion of the "plume" results in the leading and trailing edges of the plume being essentially equidistant from the plume center of mass. However, in an outward radial flow field, the leading edge will tend to be closer to the center of mass than the trailing edge because of the velocity decrease in the radial direction. Given this approximation, the analysis of the tracer injection and chase phase is conducted as follows.

The column solution by Crank (Bear 1979 [DIRS 105038]) is given by:

$$
\mathrm{C}_{\mathrm{CR}}(\mathrm{x}, \mathrm{t})=\frac{\mathrm{M} / \eta}{\left(4 \pi \mathrm{D}_{\mathrm{h}} \mathrm{t}\right)^{1 / 2}} \exp \left\{-\frac{\mathrm{x}^{\prime 2}}{4 \mathrm{D}_{\mathrm{h}} \mathrm{t}}\right\}
$$

where

$\mathrm{C}_{\mathrm{CR}}(\mathrm{x}, \mathrm{t})=$ concentration of solute at a point $\mathrm{x}$ meters from the point of tracer injection (top of the column) at $\mathrm{t}$ minutes after injection $\left(\mathrm{kg} / \mathrm{m}^{3}\right)$

$\mathrm{M}=$ mass of tracer injected per unit cross-sectional area in kilograms $\left(\mathrm{kg} / \mathrm{m}^{2}\right)$

$\eta=$ flow porosity

$\mathrm{D}_{\mathrm{h}}=$ coefficient of hydrodynamic dispersion (longitudinal) as given by Equation 70 $\left(\mathrm{m}^{2} / \mathrm{sec}\right)$

$\mathrm{x}^{\prime}=$ distance in meters from the top of the column (where the tracer slug is introduced at time $\mathrm{t}=0$ ) to the centroid of the slug at time $\mathrm{t}$ as given by Equation $71(\mathrm{~m})$

$\mathrm{t}=27.6$ hours (for this application), the time it took to inject the tracer volume, $10,600 \mathrm{~L}$ (2,800 gallons), followed by the chase volume, 83,000 L (22,000 gallons), at an injection rate of $56.8 \mathrm{~L} / \mathrm{min}(15 \mathrm{gpm})$.

If molecular diffusion is ignored, $\mathrm{D}_{\mathrm{h}}\left(\mathrm{m}^{2} / \mathrm{min}\right)$ is given by (Bear 1979 [DIRS 105038], p. 264):

$$
\mathrm{D}_{\mathrm{h}}=\alpha_{\mathrm{L}}|\mathrm{q}| / \eta
$$

where

$$
\begin{aligned}
& \alpha_{\mathrm{L}}=\text { longitudinal dispersivity }(\mathrm{m}) \\
& \mathrm{q}=\text { specific discharge in cubic meters per minute for a unit area of one meter squared } \\
& (\mathrm{m} / \mathrm{sec}) .
\end{aligned}
$$

For one-dimensional flow in a column, $x^{\prime}$ is given by Bear (1979 [DIRS 105038], p. 266, Equation 7-120):

$$
\mathrm{x}^{\prime}=\mathrm{x}-(\mathrm{q} / \eta) \mathrm{t}
$$


where

$$
\mathrm{x}=\text { distance from top of column }(\mathrm{m}) \text {. }
$$

Equations (69 to 71), representing movement of a tracer slug in a one-dimensional column experiment, were modified to represent outwardly divergent flow from an injection well as follows. The radial distance from the center of the well, $r$, was converted to an equivalent linear column length $\mathrm{x}$ by calculating the length of a column whose volume is equivalent to that of a cylinder centered at the well with height equal to the test-interval thickness, $h$, and with radius $r$. This cylinder has radial cross-sectional areas increasing from a minimum of $2 \pi \mathrm{r}_{\mathrm{w}} \mathrm{h}$ at the well, (where $r=r_{w}$ (the well radius, $m$ )), to $2 \pi r h$ at a radius of $r$ from the center of the well. The equivalent column is defined as having a constant cross-sectional area of $2 \pi r_{w} h$ (representing the cross-sectional area of the aquifer in contact with the well) and a volume equal to that of the cylinder. For the same porosity, this equivalent column would contain the same volume of water as the cylinder.

The volume of the above cylinder, $\mathrm{V}_{\mathrm{CYL}}$, is given by:

$$
\mathrm{V}_{\mathrm{CYL}}=\pi \mathrm{r}^{2} \mathrm{~h}
$$

where

$$
\mathrm{h}=\text { interval thickness }(\mathrm{m}) \text {. }
$$

The volume of the equivalent linear column, $\mathrm{V}_{\mathrm{COL}}$, is:

$$
\mathrm{V}_{\mathrm{COL}}=\mathrm{A}_{\mathrm{COL}} \mathrm{x}
$$

where

$$
A_{C O L}=\text { cross-sectional area of the column }\left(\mathrm{m}^{2}\right) \text {, which is } 2 \pi r_{w} h \text {, by definition. }
$$

Setting $\mathrm{V}_{\mathrm{CYL}}$ equal to $\mathrm{V}_{\mathrm{COL}}$ and $\mathrm{A}_{\mathrm{COL}}$ equal to $2 \pi \mathrm{r}_{\mathrm{w}} \mathrm{h}$ in Equations 72 and 73 , and solving for $\mathrm{x}$, results in Equation 74:

$$
\mathrm{x}=\pi \mathrm{r}^{2} \mathrm{~h} / 2 \pi \mathrm{r}_{\mathrm{w}} \mathrm{h}=\mathrm{r}^{2} /\left(2 \mathrm{r}_{\mathrm{w}}\right)
$$

where

$$
\mathrm{r}_{\mathrm{w}}=\text { injection well radius }(\mathrm{m}) \text {. }
$$

So, for a particular radius r, Equation 74 is used to calculate the equivalent linear column distance, $x$. This value of $x$ is used to calculate $x^{\prime}$ in Equation 71, and then Equation 69 is used to calculate the concentration $\mathrm{C}_{\mathrm{CR}}(\mathrm{x}, \mathrm{t})\left(\mathrm{kg} / \mathrm{m}^{3}\right)$, according to Crank (Bear 1979 [DIRS 105038], p. 266, Equations 7-120 and 7-123). $\mathrm{C}_{\mathrm{CR}}(\mathrm{x}, \mathrm{t})=\mathrm{C}_{\mathrm{CR}}(\mathrm{r}, \mathrm{t})$, obtained in this manner, describes the change of concentration as a function of radial distance from the injection well. 
The specific discharge, $\mathrm{q}(\mathrm{m} / \mathrm{sec})$, used in Equations 70 and 71 , is obtained by dividing the injection rate, $\mathrm{Q}_{\mathrm{INJ}}=56.8 \mathrm{~L} / \mathrm{min}(15 \mathrm{gpm})$, by the cross-sectional area of the aquifer in contact with the well, $2 \pi \mathrm{r}_{\mathrm{w}} \mathrm{h}$ :

$$
\mathrm{q}=\mathrm{Q}_{\mathrm{INJ}} /\left(2 \pi \mathrm{r}_{\mathrm{w}} \mathrm{h}\right) .
$$

By defining a threshold concentration at which a sharp edge of the tracer ring starts at its inner circumference and ends at its outer circumference $\left(5 \mathrm{mg} / \mathrm{L}\right.$ or $5 \times 10^{-9} \mathrm{~kg} / \mathrm{m}^{3}$ for this analysis), a width can be determined for the tracer ring from the modified Equation 69. In summary, the modified solution has been used to define the width of the tracer ring (formed by the chase fluid pushing the tracer outward from the well) as a function of the assumed effective porosity and longitudinal dispersivity. The tracer ring is then positioned with its inner radius at a distance $\mathrm{r}_{\mathrm{C}}$ (radius of chase zone) calculated from the assumed effective porosity and known volume of chase water, $\mathrm{Vc}\left(\mathrm{r}_{\mathrm{C}}\right.$ from $\mathrm{Vc}=83,000 \mathrm{~L}[22,000$ gallons $]=\pi \mathrm{r}_{\mathrm{C}}^{2} \mathrm{~h} \eta$ ), and with its width as determined from the analytical solution by Crank (Bear 1979 [DIRS 105038], p. 266, Equation 7-123). The superposition of the ambient groundwater flow on the outward-radial flow caused by tracer injection and chase was ignored (i.e., it was assumed that the injection and chase dominated the flow field). Given that the tracer injection and chase phase in all the single-well tests was relatively short compared to the drift plus pumpback phase, this approximation should not preclude obtaining reasonable estimates of groundwater velocity for the purposes of comparing with the analytical methods of Sections G4.2.1 through G4.2.3. Figure G-24 shows a LabView depiction of the tracer "plume" after injection and chase.

A two-dimensional analytical solution of the advection-dispersion equation for a tracer slug injected in a uniform flow field (Bear 1979 [DIRS 105038], as given in Bachmat et al. (1988 [DIRS 162534], p. 149, Equation 11) was used to calculate tracer movement during the "drift" phase of each single-well test:

$$
\mathrm{C}_{\mathrm{i}}\left(\mathrm{x}_{1}, \mathrm{y}_{1}, \mathrm{t}_{1}\right)=\frac{\mathrm{M}_{1} / \mathrm{h} \eta}{4 \pi\left(\alpha_{\mathrm{L}} \alpha_{\mathrm{T}}\right)^{1 / 2} \mathrm{~V}_{\mathrm{o}} \mathrm{t}_{1}} \exp \left\{-\frac{1}{4 \mathrm{~V}_{\mathrm{o}} \mathrm{t}_{1}}\left[\frac{\left(\mathrm{x}_{1}-\mathrm{V}_{\mathrm{o}} \mathrm{t}_{1}\right)^{2}}{\alpha_{\mathrm{L}}}+\frac{\mathrm{y}_{1}^{2}}{\alpha_{\mathrm{T}}}\right]\right\}
$$

where

$\mathrm{C}_{\mathrm{i}}\left(\mathrm{x}_{1}, \mathrm{y}_{1}, \mathrm{t}_{1}\right)=$ concentration at one of the grid blocks (with transformed coordinates $\left(x_{1}, y_{1}\right)$ see below) in Figure G-25 resulting from drift of a mass $\mathrm{M}_{1} \mathrm{~kg}$ initially positioned at the centroid of the particular wedge, wedge $\mathrm{i}(\mathrm{i}=1$ through 18) of Figure G-24. Wedge numbering is not unique and the index "i" is only used here to indicate enumeration of wedges.

$x_{1}$ and $y_{1}$ are the coordinates of this grid block relative to an orthogonal system centered at the centroid of wedge i. For this orthogonal coordinate system, the positive $x_{1}$ axis is oriented parallel to streamlines of the ambient flow field and in the direction of flow.

$\alpha_{\mathrm{L}}=$ longitudinal dispersivity $(\mathrm{m})$

$\alpha_{\mathrm{T}}=$ transverse dispersivity (m)

$\mathrm{V}_{\mathrm{o}}=$ interstitial velocity caused by the ambient gradient $(\mathrm{m} / \mathrm{sec})$

$\mathrm{t}_{1}=$ duration of drift allowed before pumpback (hr). 


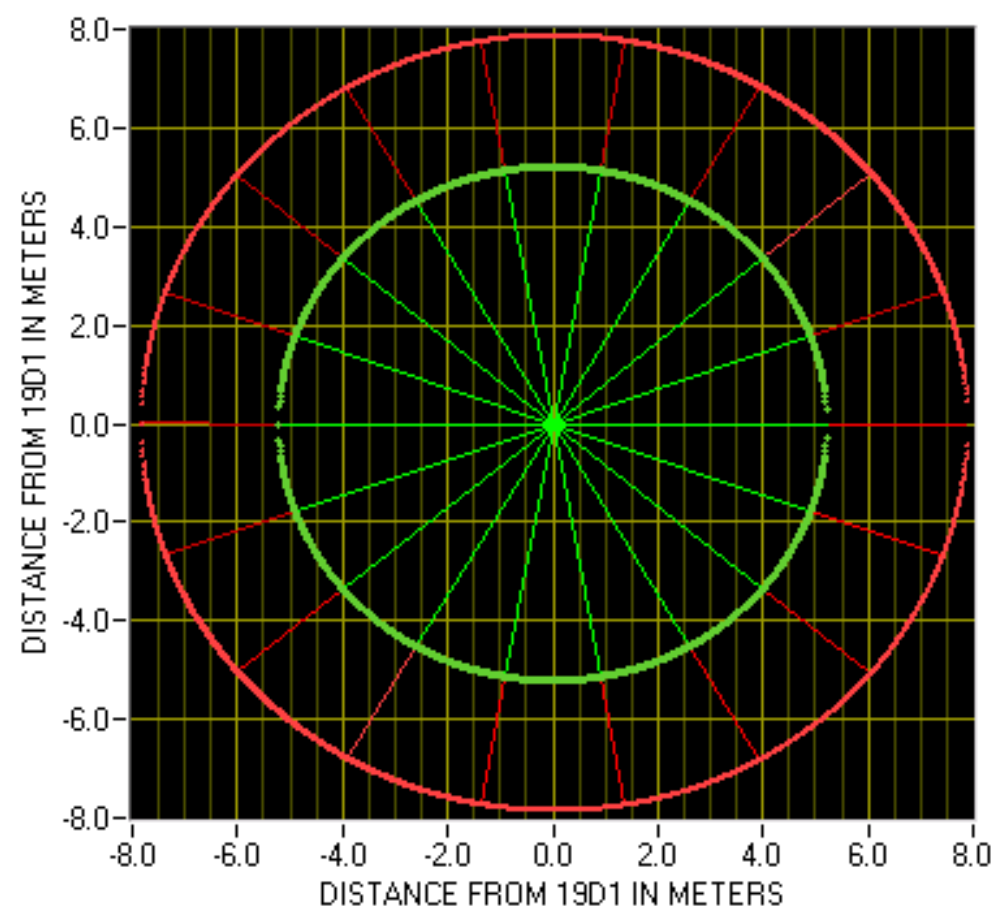

Source: DTNs: GS020708312316.001 [DIRS 162678] (data); GS020908312316.002 [DIRS 162679] (data).

Output DTN: GS031008312316.003 (analysis).

Figure G-24. Tracer Ring (Red-Hatched Area) and Chase Ring (Green-Hatched Area) around the Injection Well NC-EWDP-19D

In essence, Equation 76 is solved in the transformed coordinate system to obtain the distribution of tracer mass resulting from the drift of tracer initially located in each of the wedge-shaped volume elements of Figure G-24. Then, the solutions for all 18 wedge-shaped volume elements are superimposed to obtain the overall distribution of tracer mass after the drift phase. The relatively coarse discretization of the tracer mass at the centroid of the 18 wedges of Figure G-24 at the beginning of the drift phase is an inherent approximation in the method. The resultant concentration field representing the drifted plume is shown in Figure G-25. 


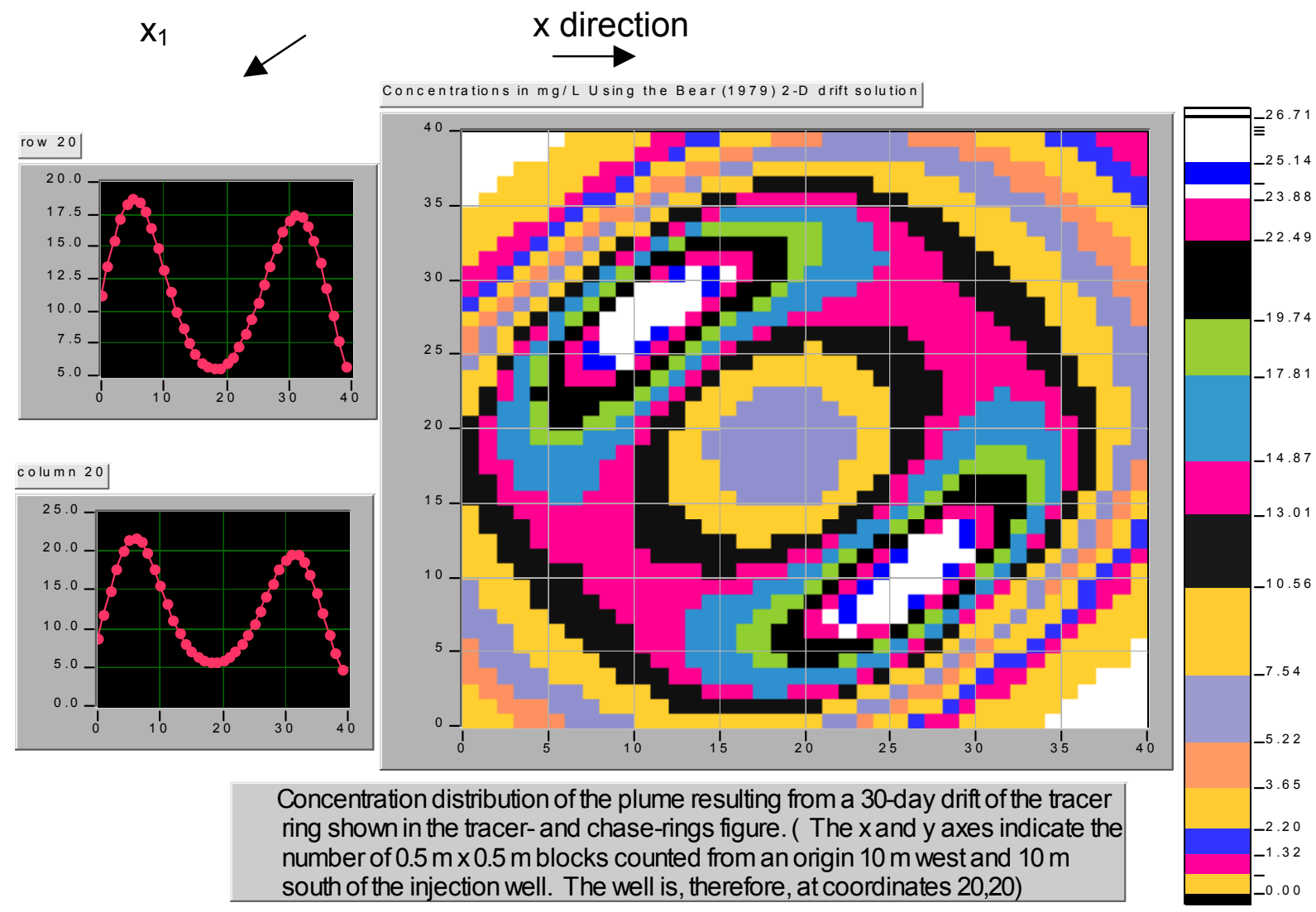

Source: DTNs: GS020708312316.001 [DIRS 162678] (data); GS020908312316.002 [DIRS 162679] (data); UN0109SPA008IF.006 [DIRS 162442] (conc.); UN0109SPA008KS.007 [DIRS 162615] (conc.); UN0109SPA008KS.008 [DIRS 162616] (conc.).

Output DTN: GS031008312316.003 (analysis).

NOTE: The $x$ and $y$ axes indicate the number of blocks counted from an origin $10 \mathrm{~m}$ west and $10 \mathrm{~m}$ south of the injection well; the blocks are $0.5 \mathrm{~m}$ on a side; and the well is, therefore, at coordinate $(20,20)$. Concentrations are calculated using the Bear (1979 [DIRS 105038]) two-dimensional drift solution. The $x-y$ plots to the left of the main two-dimensional plot show the tracer concentration distribution along linear profiles in the east-west (top) and north-south (bottom) directions through the grid point corresponding to the location of the well $(20,20)$. The $x_{1}$ direction is the direction of ambient flow.

Figure G-25. Concentration Distribution of Tracer Plume Resulting from a 30-Day Drift of the Tracer Ring Shown in Figure G-24

For each block, the total concentration, $\mathrm{C}_{1}+\mathrm{C}_{2}+\mathrm{C}_{3}+\ldots+\mathrm{C}_{18}$, is multiplied by the volume of the block, $0.5 \mathrm{~m} \times 0.5 \mathrm{~m} \times \mathrm{h}$, times the porosity, $\eta$, to obtain the mass of the tracer slug, $\mathrm{M}_{\text {slug }}$, used at that block for the pumpback phase. A radial solution of the advection-dispersion equation for a cross-hole convergent tracer test with slug injection (Moench 1989 [DIRS 101146], pp. 440 to 443; 1995 [DIRS 148784], pp. 1824 to 1827) was then used to calculate tracer movement during the pumpback phase of each test.

The mass in each of the $0.5 \mathrm{~m} \times 0.5 \mathrm{~m}$ blocks of the calculation grid of Figure G-25 was considered a slug injection in a convergent flow field towards the pumped well located at coordinates 20,20 of the figure. 
Moench (1989 [DIRS 101146], pp. 440 to 443; 1995 [DIRS 148784], pp 1824 to 1827) used the Laplace transform method to solve the following dimensionless governing advection-dispersion equation for horizontal, radial flow in a homogeneous, double-porosity aquifer:

$$
\frac{1}{{\operatorname{Pe~} r_{D}}_{D}} \frac{\partial^{2} C_{D}}{\partial r_{D}^{2}}+\frac{1}{r_{D}} \frac{\partial C_{D}}{\partial r_{D}}-\frac{2 R}{\left(1-r_{w D}^{2}\right)} q_{D}^{\prime}=\frac{2 R}{\left(1-r_{w D}^{2}\right)} \frac{\partial C_{D}}{\partial t_{D}}
$$

where

$\mathrm{Pe}=\mathrm{r}_{\mathrm{L}} / \alpha_{\mathrm{L}}$, the Peclet number, and $\mathrm{r}_{\mathrm{L}}=$ distance from the tracer injection point (normally a well) to the pumped well

$r_{D}=r / r_{L}$ is the dimensionless radial distance from the pumping well, where $r$ is the dimensional distance from the pumping well

$\mathrm{C}_{\mathrm{D}}=$ dimensionless concentration, which for a slug injection is given by $\mathrm{C}_{\mathrm{D}}=\mathrm{C} / \mathrm{C}_{\mathrm{i}}$, where $\mathrm{C}=$ concentration at $\mathrm{r}$, and $\mathrm{C}_{\mathrm{i}}=$ reference concentration given by $\mathrm{C}_{\mathrm{i}}=\mathrm{M}_{\text {slug }} /[\pi \mathrm{h} \eta$ $\left(\mathrm{r}_{\mathrm{L}}{ }^{2}-\mathrm{r}_{\mathrm{w}}{ }^{2}\right)$ ] in which $\mathrm{r}_{\mathrm{w}}=$ radius of the pumping well

$\mathrm{r}_{\mathrm{wD}}=\mathrm{r}_{\mathrm{w}} / \mathrm{r}_{\mathrm{L}}$, the dimensionless well radius

$t_{D}=$ dimensionless time, $t / t_{a}$, where $t_{a}$ is the advection transport time given by $t_{a}=$ $\left(\pi \mathrm{r}_{\mathrm{L}}{ }^{2} \mathrm{~h} \eta\right) / \mathrm{Q}$ in which $\mathrm{Q}=$ pumping rate

$\mathrm{R}=$ retardation factor

$\mathrm{q}_{\mathrm{D}}^{\prime}=$ dimensionless distributed sources or sinks of tracer due to diffusion of the tracer into stagnant porosity.

Moench (1989 [DIRS 101146], pp. 440 to 443; 1995 [DIRS 148784], 1824 to 1827) provided a FORTRAN program, rcv2amos.exe V 1.0 (STN: 10583-1.0-00 [DIRS 162750]), that computes the Laplace transform of Equation 77 and then the inverse Laplace transform to finally give dimensionless concentration, $\mathrm{C}_{\mathrm{D}}$, versus dimensionless time, $\mathrm{t}_{\mathrm{D}}$, at the pumped well in the form of two numerical arrays. The $\mathrm{C}_{\mathrm{D}}$ versus $\mathrm{t}_{\mathrm{D}}$ dimensionless theoretical breakthrough curve is then converted to a dimensional curve of $\mathrm{C}$ versus $\mathrm{t}$ using the above relation. Injection-Pumpback.vi V 1.0 (STN: 10675-1-00 [DIRS 162749]) uses rcv2amos.exe to obtain the effect at the pumping well of a slug of mass $\mathrm{M}_{\text {slug }}$ placed at each block of the calculation grid of Figure G-25. It then superposes all of these solutions to obtain the final effect at the pumping well of a slug of mass $M_{\text {slug }}$ placed at each block of the calculation grid of Figure G-25, and then superposes all of these solutions to obtain the final calculated breakthrough. The superposition of the ambient groundwater flow on the radial flow caused by the pumping well was ignored (i.e., it was assumed that the pumping dominated the flow field). This approximation clearly introduces some error to the analysis. However, given that the curve-matching procedure discussed below is heavily influenced by tracer data obtained early in the pumpback phase of each test (the tracer peaks occur within a day), the error should not preclude reasonable estimates of groundwater velocity for the purposes of comparing with the analytical methods of Sections G4.2.1 through G4.2.3.

The complete analysis involves adjusting the flow porosity, longitudinal dispersivity, transverse dispersivity, and specific discharge in all three computational stages (keeping them the same in 
each stage) until simulated tracer responses offer a reasonable match to the observed tracer responses in each single-well test. The results of such a match to the three injection-pumpback tracer responses in well 19D are shown in Figure G-26. The analysis indicates a flow porosity value of 0.10 , a longitudinal dispersivity of $5 \mathrm{~m}$, and a specific discharge of $1.5 \mathrm{~m} /$ year (Output DTN: GS031008312316.003). Although a rigorous sensitivity analysis to evaluate the uniqueness of the solution was not conducted, many combinations of parameter values were considered, and there appeared to be qualitative convergence to these values. The top three plots in Figure G-26 present dimensional (actual) concentrations, whereas the bottom three plots present concentrations normalized relative to maximum concentrations. The assumed input parameter combination yields a reasonable fit to all three single-well tracer data sets.

The flow porosity value of 0.10 should be less than the total porosity and is, therefore, consistent with three estimates of total porosity presented in different sections of this report: (1) a value of 0.29 obtained from the Borehole Gravity Meter survey in 19D, presented in Section D.4; (2) a value of 0.41 obtained from estimates of barometric efficiency and specific storage, presented in Section D.3; and (3) a value of 0.33 obtained from grain-size-distribution analysis, presented in Section D.3.

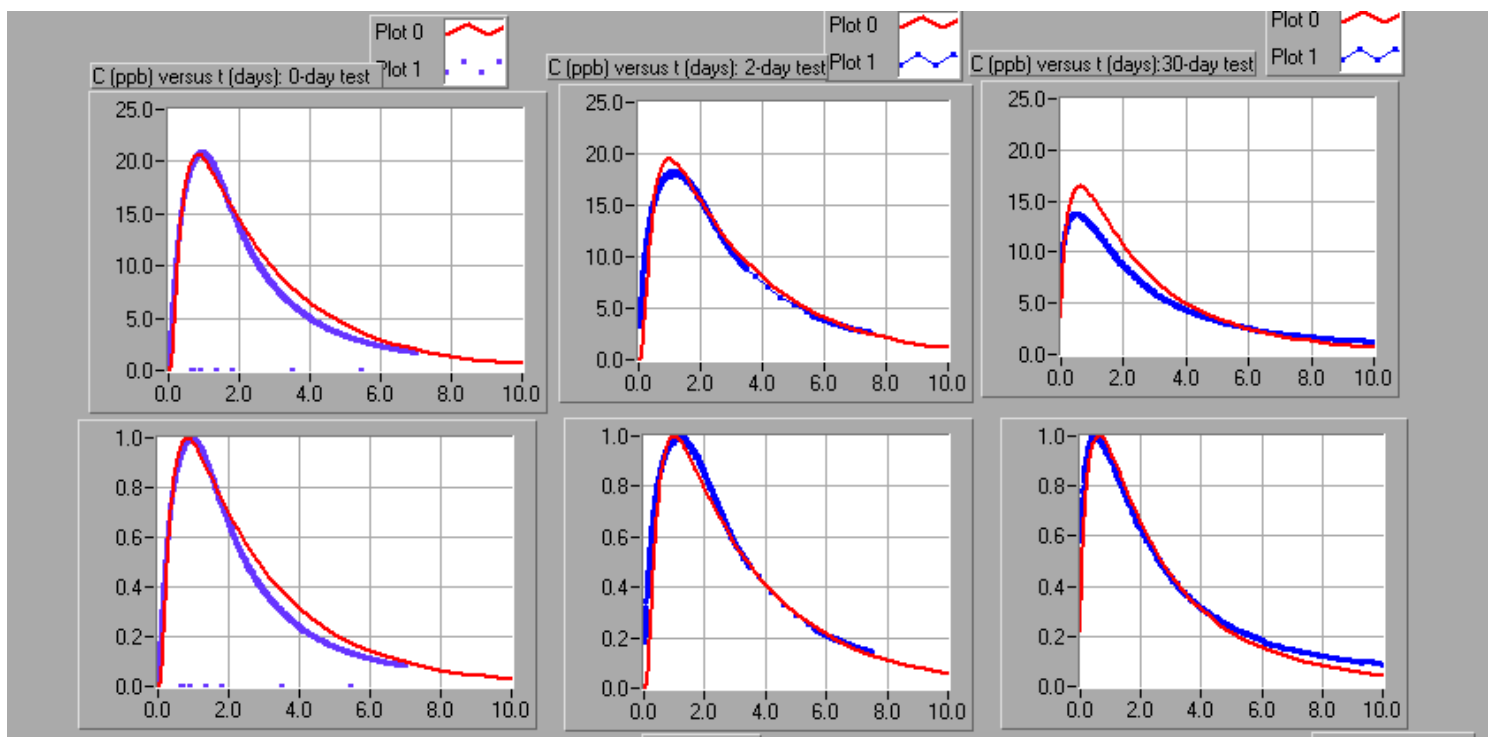

DTN: UN0109SPA008IF.006 [DIRS 162442] (0-day test), UN0102SPA008KS.003 [DIRS 162614] (2-day test), UN0109SPA008KS.007 [DIRS 162615] (30-day test).

Output DTN: GS031008312316.003 (analysis).

NOTE: The plots are fits of three injection-pumpback tracer tests with theoretical curves that result from three solutions to the advection-dispersion equation for the three phases of injection, drift, and pumpback. The red curves are the model fits and the blue curves are the data curves. The three top graphs are actual concentrations versus elapsed days, and the bottom three graphs are normalized concentrations versus elapsed days. The parameters used in the calculations are: flow porosity $=0.1$; matrix porosity $=0.0$; longitudinal dispersivity $=5.05 \mathrm{~m}$; transverse dispersivity $=1.00 \mathrm{~m}$; test interval thickness $=9.75 \mathrm{~m}(32.0 \mathrm{ft})$; tracer volume injected $=10,600 \mathrm{~L}(2,800 \mathrm{gal})$; chase volume injected $=83,000 \mathrm{~L}(22,000$ gal $)$; injection rate $56.8 \mathrm{~L} / \mathrm{min}=(15.0 \mathrm{gpm}) ;$ mass injected $=5.0 \mathrm{~kg} ;$ natural gradient $=0.002 \mathrm{~m} / \mathrm{m} ; T$ for gradient $=20.0 \mathrm{~m}^{2} / \mathrm{d}$; and specific discharge $=1.5 \mathrm{~m} /$ year; the $Q$ values for the $0-, 2-$, and 30 -day tests are $13.41,11.00$, and 13.50 , respectively.

Figure G-26. Fitting the Injection-Pumpback Tracer Tests in Screen \#1 of NC-EWDP-19D Using the Linked-Analytical Solutions Method 


\section{G4.3 GROUNDWATER VELOCITY ANALYSIS RESULTS}

Table G-7 lists the results obtained for both $\mathrm{v}_{\mathrm{GW}}$ and the specific discharge, $\mathrm{v}_{\mathrm{S}}\left(=\eta \mathrm{v}_{\mathrm{GW}}\right)$, as a function of assumed flow porosity $(\eta)$ by all four methods of estimation. As expected, of the first three methods, the peak analysis method offers the smallest estimates, and the analysis of late-arriving mass (high recovery) offers the largest. The range of the estimates from the four methods spans about a factor of three for a given assumed value of flow porosity. The velocity estimate from the linked analytical solutions is in very good agreement with the peak analysis method. The peak-analysis method yields a velocity estimate of $17.5 \mathrm{~m} /$ year (specific discharge of $1.75 \mathrm{~m} /$ year), as compared to $15 \mathrm{~m} /$ year $(1.5 \mathrm{~m} /$ year specific discharge) from the linked analytical solutions, when a flow porosity of 0.10 is assumed (the flow porosity obtained from the linked analytical solutions).

The specific discharge estimates of Table G-7 are in good agreement with the range of 1.9 to 3.2 $\mathrm{m} /$ year derived from SZ flow-model calibrations (to head and hydraulic conductivity data), which assume a wide range of potential anisotropy in horizontal hydraulic conductivity (BSC 2004 [DIRS 170042], Table 6-6). The range of values in Table G-7 has been factored into the probability distribution used for specific discharge in the alluvium in Yucca Mountain performance assessment simulations (BSC 2004 [DIRS 170042], Figure 6-7).

Table G-7. Specific Discharges and Seepage Velocities Estimated from the Different Drift Analysis Methods as a Function of Assumed Flow Porosity

\begin{tabular}{|l|c|c|c|}
\hline & \multicolumn{3}{|c|}{ Specific Discharge (m/yr) / Seepage Velocity (m/yr) } \\
\hline \multicolumn{1}{|c|}{ Assumed Flow Porosity } & $\mathbf{0}$ & $\mathbf{0 . 1 8}$ & $\mathbf{0 . 3}$ \\
\hline Peak Arrival Analysis & $1.2 / 24.5$ & $2.4 / 13.1$ & $3.0 / 9.9$ \\
\hline Late Arrival Analysis $^{\mathrm{b}}$ & $3.9 / 77.1$ & $7.3 / 40.4$ & $9.4 / 31.3$ \\
\hline Mean Arrival Analysis $^{\mathrm{c}}$ & $2.0 / 40.3$ & $3.8 / 20.9$ & $4.9 / 16.4$ \\
\hline Mean Arrival Analysis $^{\mathrm{d}}$ & $2.5 / 49.1$ & $4.6 / 25.8$ & $6.0 / 20.2$ \\
\hline Linked Analytical Solutions $^{2}$ & $1.5 / 15$ with a flow porosity of 0.10 and a longitudinal dispersivity of $5 \mathrm{~m}$. \\
\hline
\end{tabular}

Output DTN: LA0303PR831231.002.

a The three values are approximately the lowest, expected, and highest values of the alluvium flow porosity used in Yucca Mountain performance assessments (BSC 2004 [DIRS 170042]).

b Time/Volume associated with approximately 86.4 percent recovery in each test (the final recovery in the 0.5 -hr rest period test, which had the lowest final recovery of any test).

${ }^{c}$ Mean arrival time calculated by truncating all tracer response curves at approximately 86.4 percent recovery in each test.

d Alternative mean arrival time calculated by extrapolating the tracer response curves in the 0.5-hr rest period test to 91.3 percent and truncating the response curves in the 2-day rest period test to 91.3 percent recovery (the final recovery in the 30-day rest period test).

\section{G4.4 DISCUSSION OF GROUNDWATER-VELOCITY ANALYSES}

Some significant uncertainties are associated with each of the estimation methods for $\mathrm{v}_{\mathrm{GW}}$ and $\mathrm{v}_{\mathrm{S}}$ described in this report. Although it would be of interest to determine which of the methods provides the best estimate, a detailed analysis of uncertainties was not conducted. In the discussion that follows, qualitative comments are provided on several uncertainties, and some advantages and potential pitfalls of the different methods are discussed. 
The linked-analytical-solution method offers the advantage of providing estimates of flow porosity and longitudinal dispersivity, which are very important parameters for repository performance assessment, in addition to providing flow velocity estimates. Although the parameter estimates in Table G-7 for this method were obtained after many trials using various values of flow porosity, dispersivity, and groundwater flow velocity to fit the three tracer responses simultaneously, an exhaustive sensitivity analysis to evaluate the uniqueness of the matches was not conducted. With such an analysis, it is possible that other combinations of flow porosity, dispersivity, and groundwater-flow velocity could yield essentially equally good matches to the tracer responses.

The value of longitudinal dispersivity obtained from the linked analytical solutions $(5 \mathrm{~m})$ intuitively seems large given that calculated injection distances from the well should have been only about 5 to $6 \mathrm{~m}$ with a flow porosity of 0.1 . This large dispersivity probably reflects that the aquifer was not truly homogeneous and isotropic as assumed, and a large dispersivity was the only way the analytical solutions could account for tracer plume spreading that occurred due to flow heterogeneity.

The impact of ignoring tracer drift during the injection and pumpback phases of testing for the linked-analytical-solution method is not clear. The error introduced by this assumption may be important for the two tests with the shortest rest periods, as the injection and pumpback phases were collectively longer than the rest period in both tests. The remaining discussion is focused on the other three estimation methods, although some aspects of it also apply to the linked-analytical-solution method.

The peak-analysis method would intuitively seem to have considerable uncertainty associated with it because of the inability to determine whether the tracer mass associated with the peak remained upgradient of the well during the rest period or if it drifted back downgradient of the well during the rest phase. The former case was assumed here, as it provides the lowest estimate of groundwater velocity and specific discharge. If the latter case were assumed, the estimated velocity would have been about twice the estimates obtained by the other methods instead of about half the other estimates. Another uncertainty associated with the peak-analysis method is that at least part of the shift in the peak-arrival time/volume may have been due to hydrodynamic dispersion in the system rather than pure advection (as was assumed). A considerable amount of dispersion during the rest phase could have shifted the peak-arrival time without significant translation of the tracer plume's "center of mass" due to advection. However, some advection is necessary for dispersion to occur.

Both the analyses of late-arrival times and mean-arrival times are potentially highly sensitive to diffusion into stagnant water and to density-driven flow resulting from density contrasts between the injection solution and the ambient groundwater. Both of these phenomena can dramatically increase tailing in the tracer response curves and, hence, increase the late-arrival or mean-arrival times/volumes. Although the nearly identical responses of the tracers with different diffusion coefficients in all three tests provide strong evidence that diffusion did not play an important role in the observed tailing behavior in the tests, density contrasts cannot be ruled out. If the tracer solution was more or less dense than the ambient groundwater during injection (due to either concentration or temperature differences), a portion of the tracer mass could have moved upward or downward into nearly stagnant regions of the aquifer by density-driven flow. Under these 
conditions, a portion of the tracer mass could remain in the aquifer for an extended period of time because pumping will not rapidly "draw" the tracer out of the nearly stagnant regions. Despite the disadvantages mentioned above, the peak-analysis method offers an advantage in this situation because the peak-arrival time should be relatively unaffected by such "artificial" tailing behavior.

Assuming that diffusion can either be neglected or corrected for, and that the effects of density contrasts are negligible, the mean-arrival-time analysis would intuitively seem to be the method least affected by hydrodynamic dispersion in the system. In theory, dispersion should not affect the mean-arrival time, whereas it will affect the other arrival times. However, the mean-arrivalanalysis method has the disadvantage that complete recoveries are seldom achieved in field tracer tests, so the mean must generally be estimated somewhat arbitrarily from either a truncated or an extrapolated distribution, as in the analyses described in this report.

Finally, some practical considerations associated with hypothetically possible test results are worth discussing. Consider a case in which the heterogeneity in aquifer hydraulic conductivity in the vicinity of the well is such that the entire tracer mass moves upgradient of the well during injection. In this situation, it is possible that both the mean and late arrival volumes could be less than the sum of the injection and chase volumes. Under these circumstances, the test analyst will have to recognize that the equations used in both the late- and mean-arrival analyses should be modified to account for groundwater flow moving the tracer mass back toward the well. The late-arrival-analysis method will also be sensitive to dispersion in this case.

If the tracer mass moves primarily perpendicular to the direction of ambient groundwater flow during injection but slightly upgradient, the peak-, late-, and mean-arrival methods all have the potential to underestimate groundwater velocities because drift may only slightly alter the separation distance between the tracer mass and the well before pumping starts (Figure G-27). Each of the first three methods will work best if the "center of mass" of the tracer plume is injected either directly upgradient or downgradient. Intuitively, it also seems likely that the uncertainty associated with all the methods should decrease as the difference between the rest periods of the tests, and, hence, the difference in the amount of drift in the tests, increases. An increase in the difference in drift should result in a greater difference in each of the arrival times, which should make the analyses less sensitive to subtle differences in the injection/withdrawal procedures or other nonidealities in the tests.

Additional insights into uncertainties associated with the estimation methods could probably be obtained by (1) generating random-stochastic-hydraulic-conductivity fields having statistics consistent with the current knowledge of the alluvium, and then (2) numerically simulating injection-withdrawal tests in these fields (for various assumed drift velocities). These methods could ultimately yield more refined estimates of groundwater velocities in the alluvium. 


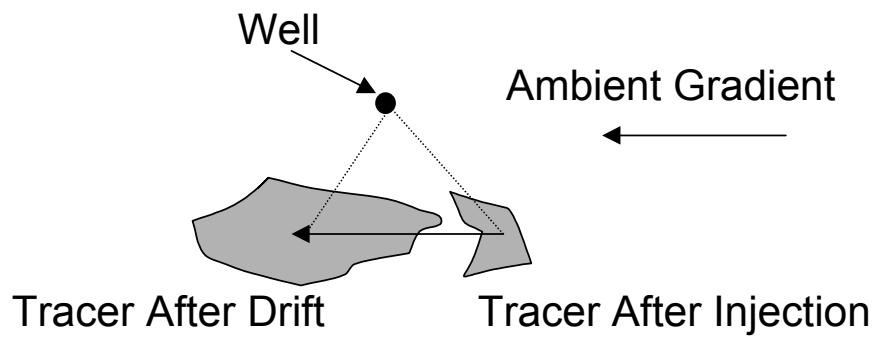

NOTE: For illustration purposes only. The dashed lines connect the well with the center of mass of the tracer "plume" before and after the rest period.

Figure G-27. Depiction of a Tracer Injection Scenario That Could Result in Underestimation of Groundwater Velocity

\section{G4.5 CONCLUSIONS FROM GROUNDWATER-VELOCITY ANALYSES}

Four methods of estimating groundwater velocities from multiple single-well injection-withdrawal tracer tests conducted with varying rest periods in the saturated alluvium south of Yucca Mountain, Nye County, Nevada are presented in this report. The resulting estimates of groundwater velocity and specific discharge vary over a range of about a factor of 3 for a given assumed flow porosity, and by about a factor of 8 for a reasonable range of flow porosities. The estimates of specific discharge range from 1.3 to $9.4 \mathrm{~m}$ per year, which falls within the range of specific discharges being used in Yucca Mountain performance assessments (obtained using potentiometric head and hydraulic conductivity data). Flow porosity and longitudinal dispersivity estimates of 0.10 and $5 \mathrm{~m}$, respectively (Output DTN: GS031008312316.003), were obtained using a linked-analytical-solution method.

The same aquifer parameter values obtained from analyzing the three injection-pumpback tracer tests in screen $\# 1$ above were used to fit the theoretical breakthrough curve of the above linked-analytical-solutions method to the actual breakthrough curve from the screen \#4 injection-pumpback tracer test (detailed documentation reported by Umari et al. (2003 [DIRS 164573]). The results are shown in Figure G-28. The close fit indicates that the same aquifer parameters that were suitable for screen \#1 in well 19D are also suitable for screen \#4 in the same well. 


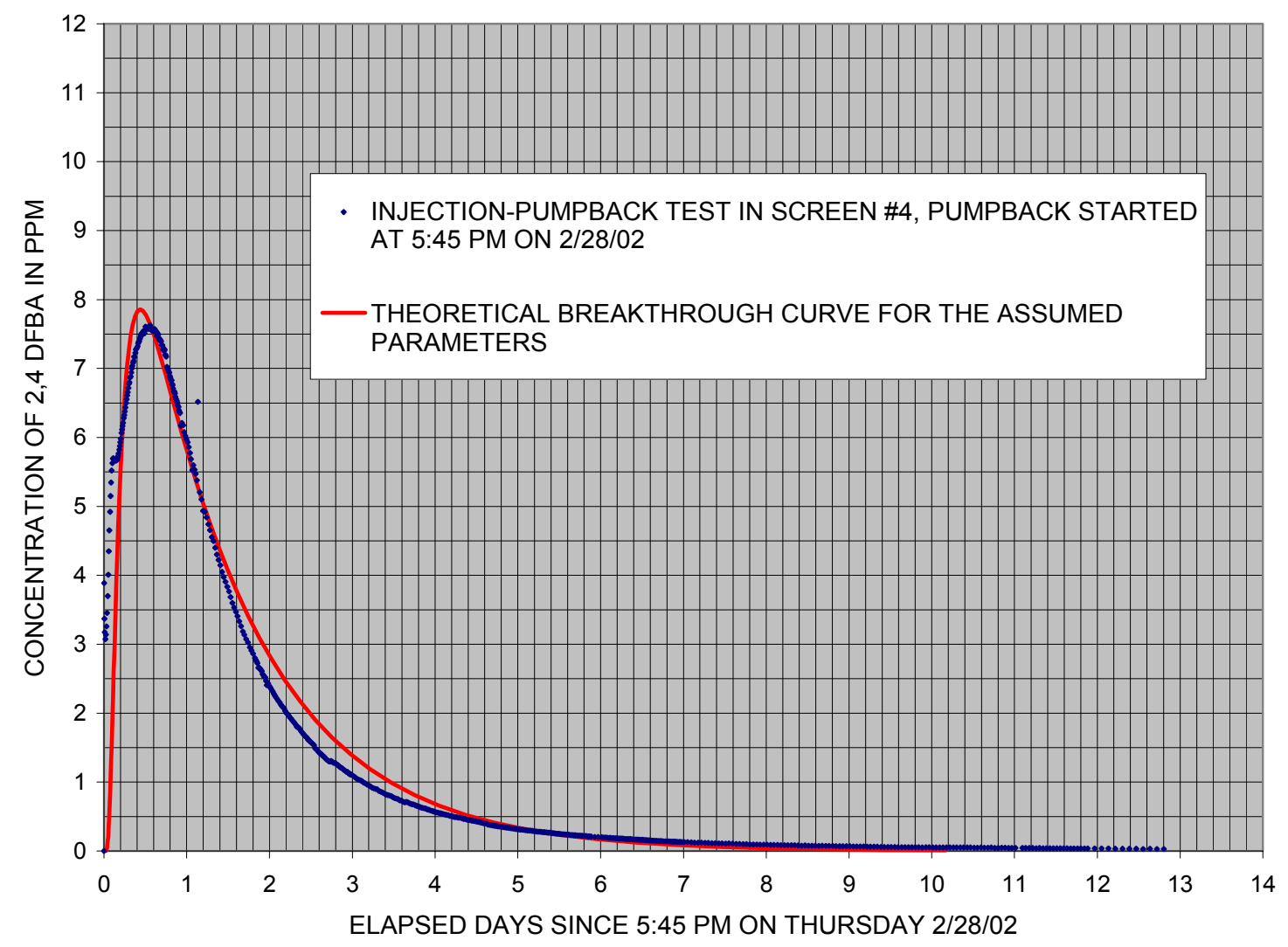

DTNs: MO0205UCC008IF.001 [DIRS 162617] (data).

Output DTN: GS031008312316.003 (analysis).

Figure G-28. Fitting the Theoretical Breakthrough Curve from the Linked-Analytical-Solutions Method to the Actual Breakthrough Curve from the Injection-Pumpback Tracer Test in Screen \#4 of NC-EWDP-19D

\section{G4.6 ESTIMATE OF COLLOID DETACHMENT RATE CONSTANT FROM MICROSPHERE RESPONSE IN SINGLE-WELL TEST}

A rough estimate of the effective detachment rate constant for the 640-nm-diameter polystyrene microspheres that were injected in the zero-rest-period single-well tracer test at 19D (Figure G-18) was made as follows. First, the assumption was made that after $90 \mathrm{hr}$ of pumping, the microsphere response is entirely the result of detachment from the alluvium. At this time, about 72 percent of the solutes had been recovered but only 26 percent of the microspheres (the final recoveries were 87 percent and 32 percent, respectively). In fact, there may have been some spheres recovered after $90 \mathrm{hr}$ that were not truly detaching (they were just making their way out of the system without ever having become attached), so counting these as being detached spheres increases the estimate of the detachment rate constant.

The following simple mass action equation was assumed to apply:

$$
Q C=k_{\mathrm{r}} M\left[\left(1-f_{\text {sphere }}\right)-\left(1-f_{\text {solute }}\right)\right]
$$


where

$C=$ concentration of spheres in water produced from well, number/L

$Q=$ production rate from well $=3066 \mathrm{~L} / \mathrm{hr}$

$k_{\mathrm{r}}=$ detachment rate constant, $1 / \mathrm{hr}$

$M=$ total number of spheres injected (a known value)

$f_{\text {sphere }}=$ fraction of spheres recovered (so $\left(1-f_{\text {sphere }}\right)$ is the fraction not recovered)

$f_{\text {solute }}=$ fraction of solutes recovered.

Equation 78 assumes that the spheres remaining on the alluvium surfaces are equal to the total number of spheres injected times the fraction of spheres not recovered $\left(1-f_{\text {sphere }}\right)$ minus the fraction of solutes not recovered $\left(1-f_{\text {solute }}\right)$. Subtracting $\left(1-f_{\text {solute }}\right)$ from $\left(1-f_{\text {sphere }}\right)$ is a correction that accounts for the fraction of spheres that would not have been recovered at a given time, even if they did not interact with alluvium surfaces. The quantity $\left[\left(1-f_{\text {sphere }}\right)-\left(1-f_{\text {solute }}\right)\right]$ averages about 0.5 over the last $77 \mathrm{hr}$ of the test $(0.46$ at $90 \mathrm{hr}$ and 0.545 at $167 \mathrm{hr}$ ).

Rearranging Equation 78 to solve for $k_{\mathrm{r}}$ yields the following:

$$
k_{\mathrm{r}}=\left(\frac{Q}{\left[\left(1-f_{\text {sphere }}\right)-\left(1-f_{\text {solute }}\right)\right]}\right)\left(\frac{C}{M}\right) .
$$

The quantity $C / M$ is the normalized concentration plotted in Figure G-18. It has a value of approximately $0.0000002 / \mathrm{L}$ during the latter portion of the test. Using the average pumping rate during the test of $3066 \mathrm{~L} / \mathrm{hr}$, Equation 79 yields a value of $0.0012 / \mathrm{hr}$ for $k_{\mathrm{r}}$ (Output DTN: LA0303PR831352.001). This estimate of the detachment-rate constant can be considered high (upper bound) because $\mathrm{d} C / \mathrm{d} t$ slowly decreased as the test proceeded and the fractional recovery of solutes increased faster than the microsphere recovery (which means that the estimate of the number of spheres remaining on the surfaces according to Equations 78 and 79 actually increased with time - a physical impossibility). The latter contradiction could be remedied by simply setting $\left(1-f_{\text {solute }}\right)$ equal to zero, which would lower the detachment-rate constant estimate by about 30 percent.

\section{G4.7 CONCLUSIONS FROM SINGLE-WELL TRACER TESTING IN ALLUVIUM}

The fact that there was virtually no difference in the normalized responses of the halide and FBA tracers in the three single-well tracer tests conducted in 19D strongly suggests that a single-porosity conceptual model is appropriate for modeling radionuclide transport in the saturated alluvium south of Yucca Mountain. Differences in the tracer responses for the different rest periods in the three tests were apparently the result of groundwater drift during the rest periods, not the result of diffusion between flowing and stagnant water. Further evidence for a single-porosity flow/transport system was provided by the lack of an increase in tracer concentrations after flow interruptions during the tailing portions of the tracer responses in the two tests featuring flow interruptions. This lack of increase in tracer concentrations indicates a lack of diffusive mass transfer between flowing and stagnant water in the flow system. 
Four methods were used to estimate groundwater drift velocities from the three single-well tracer tests. The resulting estimates of groundwater velocity and specific discharge vary over a range of about a factor of three. The estimates are in reasonably good agreement with estimates obtained using potentiometric head and hydraulic conductivity data. It is doubtful that these estimates would be improved significantly by more sophisticated modeling without more detailed information on the distribution of tracer mass after the injection and rest phases of the single-well tests. However, the generation of random-stochastic-hydraulic-conductivity fields having statistics consistent with the current knowledge of the alluvium, followed by the numerical simulation of injection-withdrawal tests within these fields (for various assumed drift velocities), would probably yield considerable additional information on the uncertainties associated with the estimation methods. 


\section{INTENTIONALLY LEFT BLANK}




\section{APPENDIX H}

\section{LABORATORY TESTING CONDUCTED TO SUPPORT PLANNED TRACER TESTING AT THE ALLUVIAL TESTING COMPLEX (ATC)}




\section{H1. ALLUVIUM CATION-EXCHANGE-CAPACITY MEASUREMENTS AND LITHIUM BATCH-SORPTION EXPERIMENTS}

Laboratory measurements of lithium-ion sorption onto alluvium material and tracer transport tests in alluvium-packed columns were carried out in parallel with field tracer testing at the Alluvial Testing Complex (ATC). The objectives of the laboratory tests are the same as for the laboratory testing conducted to support C-wells tracer testing in fractured tuffs: (1) to obtain transport parameter estimates that can help constrain interpretations of the field tracer tests, and (2) to obtain laboratory estimates of lithium sorption parameters that can be compared to field-derived sorption parameter estimates. The latter will allow an assessment of the ability to predict field-scale sorption in the alluvium using laboratory-derived sorption parameters, which is important because laboratory-scale sorption parameters must be used for field-scale predictions of radionuclide transport. Detailed documentation of both the batch and column laboratory tests (the remainder of this attachment) is reported by Sullivan (2002 [DIRS 164623]).

\section{H1.1 ALLUVIUM SAMPLES AND THEIR CHARACTERISTICS}

Cation-exchange capacity (CEC) and lithium batch-sorption measurements were conducted on alluvium samples collected from several different depth intervals in wells 19D and 19P. The intervals from which material was collected were (in meters (feet) below land surface) 123 to $125 \mathrm{~m}$ (405 to $410 \mathrm{ft}$ ), 128 to $130 \mathrm{~m}$ (420 to $425 \mathrm{ft}$ ), 152 to $154 \mathrm{~m} \mathrm{(500} \mathrm{to} 505 \mathrm{ft}$ ), 177 to $178 \mathrm{~m}$ (580 to $585 \mathrm{ft}$ ), 201 to $203 \mathrm{~m}$ (660 to $665 \mathrm{ft}$ ), 207 to $209 \mathrm{~m} \mathrm{(680} \mathrm{to} 685 \mathrm{ft}$ ), 219 to $221 \mathrm{~m}$ (720 to $725 \mathrm{ft}$ ), and 238 to $239 \mathrm{~m}$ ( 780 to $785 \mathrm{ft}$ ) in 19D, and 125 to $126 \mathrm{~m} \mathrm{(410} \mathrm{to} 415 \mathrm{ft}$ ) and 128 to $130 \mathrm{~m}$ (420 to $425 \mathrm{ft}$ ) in 19P. Particle-size distributions of samples collected from 123 to $125 \mathrm{~m}$ and 128 to $130 \mathrm{~m}$ in 19D, and from 125 to $126 \mathrm{~m}$ and 128 to $130 \mathrm{~m}$ in $19 \mathrm{P}$ were determined by a wet-sieve method. Particle-size distributions in all other intervals (all of which were in 19D) were determined by dry sieving. Well 19P was drilled by a reverse-circulation air hammer method, so the high and low ends of the particle size distribution were considered more representative than in the samples from 19D, which was drilled using a rotary bit with water as the lubricant. The rotary bit probably broke up the larger particles, and the water washed out most of the smaller particles from the 19D samples. Figure H-1 shows a size distribution comparison for material from approximately the same depth intervals in wells 19D and 19P.

For the CEC and lithium batch-sorption experiments, measurements were made on material that had been wet- or dry-sieved to a size range between 75 and $2000 \mu \mathrm{m}$, and also on material that was wet or dry-sieved to less than $75 \mu \mathrm{m}$ in size. Although the size distribution for the 19P material in Figure H-1 indicates that alluvium particles with sizes larger than $2000 \mu \mathrm{m}$ comprise a significant fraction of the alluvium mass, the surface area available for sorption is expected to be dominated by smaller particles, so the CEC and sorption experiments focused on material smaller than $2000 \mu \mathrm{m}$. Excluding the larger material could result in overestimation of sorption partition coefficients ( $\mathrm{K}_{\mathrm{d}}$ values) based on alluvium mass; this potential overestimation was to be evaluated by comparing the laboratory $K_{d}$ values with field $K_{d}$ values obtained from cross-hole tracer testing, which unfortunately never occurred (See Appendix G).

The materials from 19P and from the two uppermost intervals in 19D (123 to $125 \mathrm{~m}$ and 128 to $130 \mathrm{~m}$ ) were wet-sieved, and all of the remaining material was dry-sieved. Quantitative minerals abundance analysis using x-ray diffraction (Chipera and Bish 1995 [DIRS 105075]) was 
conducted on each fraction used for testing (Table H-1). Not surprisingly, the samples sieved to the smaller size range tended to be richer in smectite clays and zeolites, which have higher CECs than the other minerals listed in Table H-1. Specific surface areas of the samples were measured by a single-point Brunauer-Emmet-Teller (BET) nitrogen adsorption/desorption method (Brunauer et al. 1938 [DIRS 156646], pp. 309 to 319). The BET surface areas are listed in Table H-2 for each sample. Table H-2 also lists the lithium and cesium CECs of the samples, which are discussed in Section H1.5.
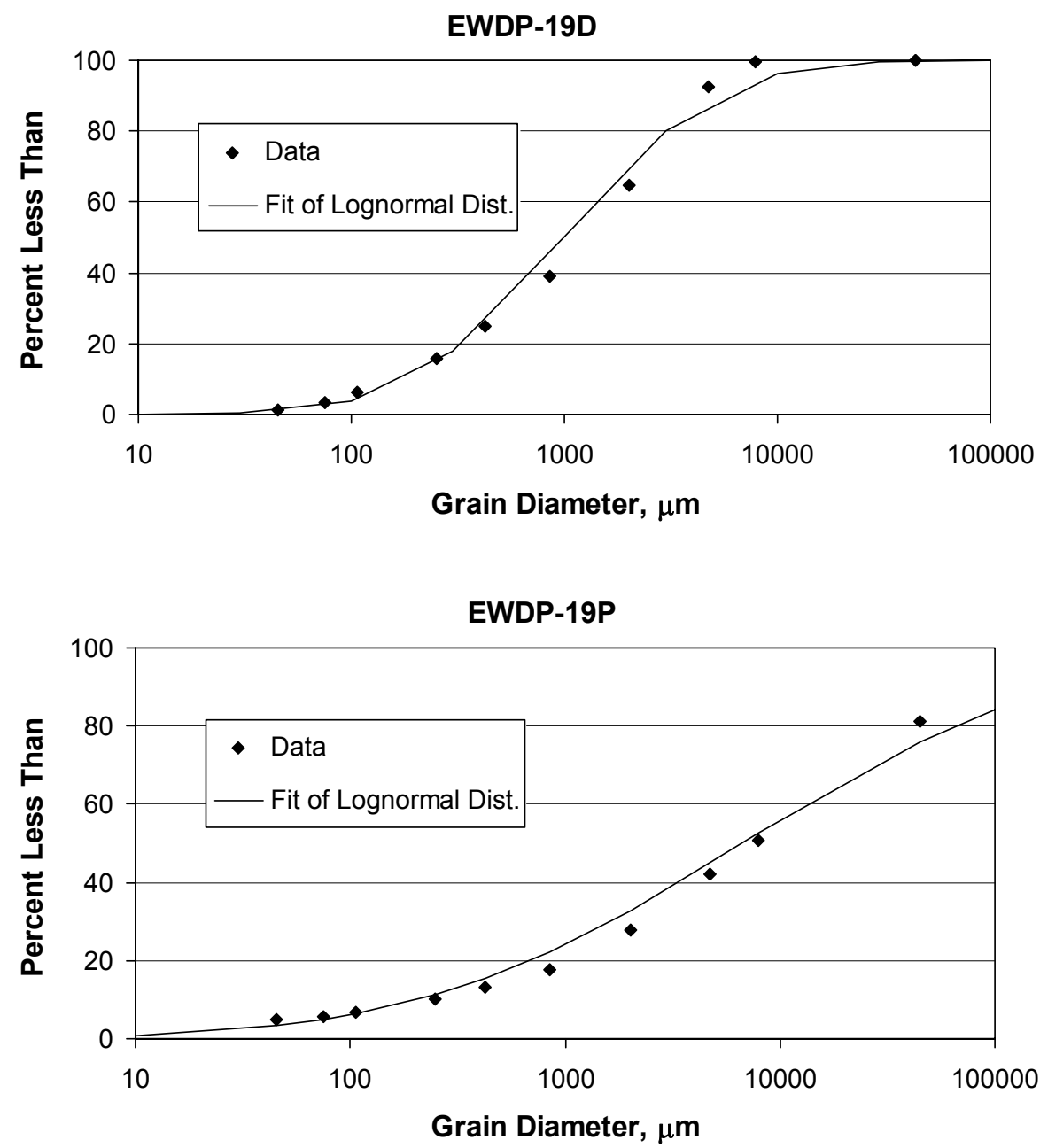

Source: DTN: LA0201JS831421.001 [DIRS 162613].

NOTE: The mass-weighted particle size distributions above for the two wells are from the same depth interval of 123 to $130 \mathrm{~m}$ (405 to $425 \mathrm{ft}$ ) below land surface; and the size distributions were determined by dry-sieve analyses.

Figure H-1. Particle Size Distributions of Material in NC-EWDP-19D and NC-EWDP-19P 
Table H-1. Mineralogy of Alluvium Samples Used in the Cation-Exchange-Capacity and Lithium Batch-Sorption Experiments Determined by Quantitative X-ray Diffraction

\begin{tabular}{|c|c|c|c|c|c|c|c|c|c|c|c|c|}
\hline Sample Label* & $\begin{array}{c}\text { Smec- } \\
\text { tite }\end{array}$ & $\begin{array}{l}\text { Clino- } \\
\text { ptilolite }\end{array}$ & $\begin{array}{c}\text { Kaoli- } \\
\text { nite }\end{array}$ & Mica & $\begin{array}{c}\text { Tridy- } \\
\text { mite }\end{array}$ & $\begin{array}{c}\text { Cristob- } \\
\text { alite }\end{array}$ & Quartz & $\begin{array}{l}\text { Feld- } \\
\text { spar }\end{array}$ & Calcite & $\begin{array}{c}\text { Hem- } \\
\text { atite }\end{array}$ & $\begin{array}{l}\text { Horn- } \\
\text { blende }\end{array}$ & Total \\
\hline 19D 405-410 <75 $\mu \mathrm{m}$ & $20 \pm 6$ & $10 \pm 1$ & $1 \pm 1$ & Trace & $3 \pm 1$ & $7 \pm 2$ & $14 \pm 1$ & $39 \pm 6$ & $1 \pm 1$ & $1 \pm 1$ & - & $96 \pm 9$ \\
\hline 19D 405-410 >75 $\mu \mathrm{m}$ & $4 \pm 1$ & $7 \pm 1$ & $1 \pm 1$ & $1 \pm 1$ & $5 \pm 1$ & $13 \pm 1$ & $17 \pm 1$ & $53 \pm 8$ & - & $1 \pm 1$ & - & $102 \pm 8$ \\
\hline $19 \mathrm{P} 410-415<75 \mu \mathrm{m}$ & $34 \pm 10$ & $26 \pm 2$ & $1 \pm 1$ & Trace & $3 \pm 1$ & $5 \pm 1$ & $8 \pm 1$ & $28 \pm 5$ & $1 \pm 1$ & - & Trace & $106 \pm 12$ \\
\hline $19 \mathrm{P} 410-415>75 \mu \mathrm{m}$ & $5 \pm 2$ & $7 \pm 1$ & $1 \pm 1$ & $1 \pm 1$ & $4 \pm 1$ & $15 \pm 1$ & $18 \pm 1$ & $49 \pm 7$ & - & Trace & - & $100 \pm 8$ \\
\hline 19D $420-425<75 \mu \mathrm{m}$ & $16 \pm 5$ & $8 \pm 1$ & $1 \pm 1$ & Trace & $5 \pm 1$ & $8 \pm 2$ & $13 \pm 1$ & $42 \pm 6$ & $2 \pm 1$ & $1 \pm 1$ & Trace & $96 \pm 8$ \\
\hline 19D $420-425>75 \mu \mathrm{m}$ & $6 \pm 2$ & $6 \pm 1$ & $1 \pm 1$ & Trace & $6 \pm 1$ & $16 \pm 1$ & $20 \pm 2$ & $44 \pm 6$ & $1 \pm 1$ & Trace & - & $100 \pm 7$ \\
\hline $19 \mathrm{P} 420-425<75 \mu \mathrm{m}$ & $40 \pm 12$ & $24 \pm 2$ & $1 \pm 1$ & Trace & $2 \pm 1$ & $4 \pm 1$ & $8 \pm 1$ & $24 \pm 4$ & - & Trace & - & $103 \pm 13$ \\
\hline $19 \mathrm{P} 420-425>75 \mu \mathrm{m}$ & $11 \pm 3$ & $6 \pm 1$ & $1 \pm 1$ & Trace & $4 \pm 1$ & $11 \pm 1$ & $22 \pm 2$ & $45 \pm 7$ & - & $1 \pm 1$ & $1 \pm 1$ & $102 \pm 8$ \\
\hline 19D 500-505 <75 $\mu \mathrm{m}$ & $10 \pm 3$ & $10 \pm 1$ & $1 \pm 1$ & Trace & $5 \pm 1$ & $9 \pm 3$ & $16 \pm 1$ & $43 \pm 6$ & $1 \pm 1$ & $1 \pm 1$ & - & $96 \pm 8$ \\
\hline 19D 500-505 >75 $\mu \mathrm{m}$ & $5 \pm 2$ & $6 \pm 1$ & $1 \pm 1$ & Trace & $5 \pm 1$ & $15 \pm 1$ & $20 \pm 2$ & $43 \pm 6$ & - & Trace & - & $95 \pm 7$ \\
\hline 19D 580-585 $<75 \mu \mathrm{m}$ & $7 \pm 2$ & $24 \pm 2$ & $1 \pm 1$ & Trace & $3 \pm 1$ & $7 \pm 2$ & $16 \pm 1$ & $44 \pm 7$ & $1 \pm 1$ & $1 \pm 1$ & Trace & $104 \pm 8$ \\
\hline 19D 580-585 >75 $\mu \mathrm{m}$ & $5 \pm 2$ & $10 \pm 1$ & $1 \pm 1$ & Trace & $4 \pm 1$ & $14 \pm 1$ & $18 \pm 1$ & $45 \pm 7$ & - & Trace & - & $97 \pm 8$ \\
\hline 19D 660-665 <75 $\mu \mathrm{m}$ & $21 \pm 6$ & $24 \pm 2$ & $1 \pm 1$ & $1 \pm 1$ & $2 \pm 1$ & $5 \pm 1$ & $10 \pm 1$ & $36 \pm 6$ & - & Trace & $1 \pm 1$ & $101 \pm 9$ \\
\hline 19D 660-665 >75 $\mu \mathrm{m}$ & $3 \pm 1$ & $10 \pm 1$ & $1 \pm 1$ & $1 \pm 1$ & $4 \pm 1$ & $12 \pm 1$ & $18 \pm 1$ & $49 \pm 7$ & - & Trace & Trace & $98 \pm 7$ \\
\hline 19D 680-685 <75 $\mu \mathrm{m}$ & $12 \pm 4$ & $41 \pm 2$ & Trace & Trace & $3 \pm 1$ & $6 \pm 1$ & $8 \pm 1$ & $29 \pm 5$ & - & - & $1 \pm 1$ & $100 \pm 7$ \\
\hline 19D 680-685 >75 $\mu \mathrm{m}$ & $4 \pm 1$ & $14 \pm 1$ & $1 \pm 1$ & $1 \pm 1$ & $3 \pm 1$ & $14 \pm 1$ & $19 \pm 1$ & $48 \pm 7$ & - & Trace & - & $104 \pm 7$ \\
\hline $19 \mathrm{D} 725-730<75 \mu \mathrm{m}$ & $17 \pm 5$ & $42 \pm 3$ & $1 \pm 1$ & Trace & $2 \pm 1$ & $5 \pm 1$ & $11 \pm 1$ & $21 \pm 4$ & Trace & - & Trace & $99 \pm 7$ \\
\hline 19D $725-730>75 \mu \mathrm{m}$ & $5 \pm 2$ & $15 \pm 1$ & $1 \pm 1$ & Trace & $3 \pm 1$ & $14 \pm 1$ & $24 \pm 2$ & $41 \pm 6$ & - & Trace & - & $103 \pm 7$ \\
\hline 19D $780-785<75 \mu \mathrm{m}$ & $16 \pm 5$ & $31 \pm 2$ & Trace & Trace & $2 \pm 1$ & $8 \pm 2$ & $12 \pm 1$ & $34 \pm 6$ & $1 \pm 1$ & - & Trace & $104 \pm 8$ \\
\hline 19D $780-785>75 \mu \mathrm{m}$ & $6 \pm 2$ & $11 \pm 1$ & Trace & - & $3 \pm 1$ & $14 \pm 1$ & $21 \pm 2$ & $47 \pm 7$ & - & Trace & Trace & $102 \pm 8$ \\
\hline
\end{tabular}

Source: DTN: LA0201JS831321.001 [DIRS 162623]

NOTE: Bold entries denote material used in column experiments. Mineral abundances are in weight percent. Errors are 2-sigma values. $-=$ not detected; Trace $=$ trace amount at less than $0.5 \mathrm{wt}$ percent. Materials from NC-EWDP-19P and the two uppermost intervals in NC-EWDP-19D (123 to $125 \mathrm{~m}$ [405 to $410 \mathrm{ft}$ ] and 128 to $130 \mathrm{~m} \mathrm{[420} \mathrm{to} 425 \mathrm{ft}]$ ) were wet-sieved; all other materials were dry-sieved. Sample Labels include the interval in feet because the data were collected using English units.

Table H-2. Surface Areas and Lithium and Cesium Cation-Exchange-Capacities (CEC) of Alluvium Samples Used in the Lithium Batch-Sorption Experiments

\begin{tabular}{|c|c|c|c|}
\hline $\begin{array}{c}\text { Interval }^{\ddagger} \\
\text { (Well, } \mathrm{ft} \text { below land surface, size) }\end{array}$ & $\begin{array}{l}\text { BET Surface Area* } \\
\left(\mathrm{m}^{2} / \mathrm{g}\right)\end{array}$ & $\begin{array}{l}\text { Li CEC } \\
(\mathrm{meq} / \mathrm{kg})\end{array}$ & $\begin{array}{c}\text { Cs CEC } \\
(\mathrm{meq} / \mathrm{kg})\end{array}$ \\
\hline $19 \mathrm{D}, 405-410,<75 \mu \mathrm{m}$ & 15.96 & 183 & 258 \\
\hline 19D, 405-410, > $75 \mu \mathrm{m}$ & 5.34 & 70 & 99 \\
\hline $19 \mathrm{P}, 410-415,<75 \mu \mathrm{m}$ & NM & 360 & 559 \\
\hline $19 \mathrm{P}, 410-415,>75 \mu \mathrm{m}$ & NM & 126 & 141 \\
\hline 19D, 420-425, <75 $\mu \mathrm{m}$ & 9.80 & 175 & 231 \\
\hline 19D, 420-425, > $75 \mu \mathrm{m}$ & 5.64 & 89 & 119 \\
\hline $19 \mathrm{P}, 420-425,<75 \mu \mathrm{m}$ & NM & 395 & 667 \\
\hline
\end{tabular}


Table H-2. Surface Areas and Lithium and Cesium Cation-Exchange-Capacities (CEC) of Alluvium Samples Used in the Lithium Batch-Sorption Experiments (Continued)

\begin{tabular}{|c|c|c|c|}
\hline $\begin{array}{c}\text { Interval }^{\ddagger} \\
\text { (Well, } \mathrm{ft} \text { below land surface, size) }^{\text {(W) }}\end{array}$ & $\begin{array}{l}\text { BET Surface Area* } \\
\left(\mathrm{m}^{2} / \mathrm{g}\right)\end{array}$ & $\begin{array}{l}\text { Li CEC } \\
(\mathrm{meq} / \mathrm{kg})\end{array}$ & $\begin{array}{l}\text { Cs CEC } \\
\text { (meq/kg) }\end{array}$ \\
\hline $19 \mathrm{P}, 420-425,>75 \mu \mathrm{m}$ & 8.67 & 171 & 186 \\
\hline $19 \mathrm{D}, 500-505,<75 \mu \mathrm{m}$ & 10.15 & 125 & 171 \\
\hline 19D, $500-505,>75 \mu \mathrm{m}$ & 6.17 & 137 & 229 \\
\hline $19 \mathrm{D}, 580-585,<75 \mu \mathrm{m}$ & NM & 204 & 285 \\
\hline 19D, 580-585, > $75 \mu \mathrm{m}$ & 5.17 & 132 & 279 \\
\hline 19D, $660-665,<75 \mu \mathrm{m}$ & NM & 303 & $130^{\dagger}$ \\
\hline 19D, $660-665,>75 \mu \mathrm{m}$ & 5.16 & 119 & 368 \\
\hline 19D, $680-685,<75 \mu \mathrm{m}$ & 11.16 & 257 & 663 \\
\hline 19D, $680-685,>75 \mu \mathrm{m}$ & 3.99 & 118 & 439 \\
\hline 19D, $720-725,<75 \mu \mathrm{m}$ & NM & 424 & 620 \\
\hline 19D, $720-725,>75 \mu \mathrm{m}$ & 5.66 & 114 & 433 \\
\hline 19D, $780-785,<75 \mu \mathrm{m}$ & NM & 237 & $131^{\dagger}$ \\
\hline 19D, $780-785,>75 \mu \mathrm{m}$ & 4.43 & 78 & 366 \\
\hline
\end{tabular}

DTNs: LA0201JS831421.002 [DIRS 162625] (BET data); LA0201JS831341.001 [DIRS 162627] (CEC data).

NOTE: Bold denotes material used in column experiments. NM: not measured, generally because of insufficient material quantity. Materials from NC-EWDP-19P and the two uppermost intervals in NCEWDP-19D (123 to $125 \mathrm{~m}$ [405 to $410 \mathrm{ft}$ ] and 128 to $130 \mathrm{~m}$ [420 to $425 \mathrm{ft}$ ) were wet-sieved; all other materials were dry-sieved.

* Surface areas were determined using the nitrogen BET technique.

$\dagger$ Suspected erroneous measurements - Cs CEC should be greater than Li CEC.

$\ddagger$ The interval is listed in feet because the data were collected using English units.

$\mathrm{BET}=$ Brunauer-Emmett-Teller (surface area measurement); CEC=cation-exchange-capacity

\section{H1.2 CATION-EXCHANGE-CAPACITY MEASUREMENTS}

CECs of the alluvium from the different depth intervals in well 19D were measured using a three-step process of saturating the alluvium surface sites with lithium ion, modified from that of Ming and Dixon (1987 [DIRS 156842]). Half-gram samples of alluvium were placed in contact with approximately $30 \mathrm{~mL}$ of $1 \underline{\mathrm{M}} \mathrm{LiBr}$ solution prepared in deionized water. The alluvium-solution mixture was shaken for at least $1 \mathrm{hr}$, centrifuged, and the supernatant was decanted off into a collection container. This treatment was repeated two more times, with the supernatant from each step being combined with that from the previous steps. The final solution (approximately $90 \mathrm{~mL}$ ) was analyzed for $\mathrm{Na}^{+}, \mathrm{Ca}^{++}, \mathrm{K}^{+}$, and $\mathrm{Mg}^{++}$using inductively coupled plasma-atomic emission spectrometry (ICP-AES) to determine the total number of equivalents of cations that lithium had displaced from the alluvium surfaces. This total number of equivalents divided by the mass of the alluvium sample is the CEC of the alluvium, expressed as meq $/ \mathrm{kg}$.

It is well known that CECs of materials are dependent on the cation used to saturate the material surfaces (Anghel et al. 2002 [DIRS 164635], Section 3.1, pp. 821 to 822). The $\mathrm{Cs}^{+}$ion is often used to obtain a measure of the "total" CEC of a material because $\mathrm{Cs}^{+}$sorbs very strongly to mineral surfaces and will displace most exchangeable cations encountered in nature. To obtain an estimate of the $\mathrm{Cs}^{+}$-exchangeable $\mathrm{CEC}$, the above procedure was repeated on each of the half-gram alluvium samples that had been subjected to $\mathrm{LiBr}$ solution treatments using $1 \underline{\mathrm{M}} \mathrm{CsCl}$ 
as the saturating solution. However, the CEC determined from the lithium saturation steps was the value used in subsequent modeling of the batch-sorption and column experiments (Section $\mathrm{H} 2$ ) because only cations displaced by lithium are of practical interest when lithium is the sorbing species.

\section{H1.3 BATCH-SORPTION EXPERIMENTS}

Lithium batch-sorption experiments were conducted on each of the sieved alluvium samples. Duplicate measurements were conducted at starting lithium concentrations of approximately 1, 3, $10,30,100$, and $300 \mathrm{mg} / \mathrm{L} \mathrm{Li}^{+}$for each material to obtain a sorption isotherm over a 2.5 -orderof-magnitude range of concentrations. Starting solutions were prepared by dissolving a known mass of $\mathrm{LiBr}$ in a known volume of 19D well water and then diluting by weight with well water to the desired starting concentrations. In all of the batch tests, $20 \mathrm{~mL}$ of lithium solution was placed in contact with approximately $5 \mathrm{~g}$ of alluvium material in $50-\mathrm{mL}$ polycarbonate Oak Ridge centrifuge tubes that were shaken for $48 \mathrm{hr}$ on an orbital shaker. Separate control samples (lithium-spiked solutions in centrifuge tubes without any alluvium material) and blanks (nonspiked well water in contact with alluvium) were processed in parallel with the tubes containing both lithium and alluvium. The controls were used to verify that lithium sorption to tube walls was insignificant, and the blanks were used to measure any lithium background that might be leached out of the alluvium samples. After shaking, the tubes were centrifuged at $30,000 \mathrm{xg}$ for $1 \mathrm{hr}$, and then an aliquot of supernatant was pipetted off for cation and bromide analyses. Cations ( $\mathrm{Li}, \mathrm{Na}, \mathrm{K}, \mathrm{Ca}$, and $\mathrm{Mg}$ ) were analyzed by inductively coupled ICP-AES, and bromide (nonsorbing tracer) was analyzed by liquid chromatography with a conductivity detector.

The starting lithium concentration for each measurement was determined from both the corresponding bromide and lithium concentrations in the control samples. In general, lithium concentrations measured in the control samples were in good agreement with those determined from the bromide measurements, indicating that lithium sorption to centrifuge tube walls was negligible. The mass of lithium sorbed per unit mass of alluvium material was determined from

$$
S=\frac{V\left(C_{0}-C\right)}{M}
$$

where

$S=$ lithium mass sorbed per unit mass of alluvium, $\mathrm{mg} / \mathrm{g}$

$V=$ volume of solution in contact with alluvium, $\mathrm{L}$

$M=$ mass of alluvium in contact with solution, $\mathrm{g}$

$C_{0}=$ initial concentration of lithium in solution prior to sorption, $\mathrm{mg} / \mathrm{L}$

$C=$ final concentration of lithium in solution after sorption, $\mathrm{mg} / \mathrm{L}$.

\section{H1.4 INTERPRETATION OF BATCH-SORPTION EXPERIMENTS}

It became apparent very early in the batch-sorption experiments that only two cations, $\mathrm{Na}^{+}$and $\mathrm{Ca}^{++}$, exchanged significantly with $\mathrm{Li}^{+} . \mathrm{K}^{+}$was exchanged to a minor degree, but the amount was so small relative to $\mathrm{Na}^{+}$and $\mathrm{Ca}^{++}$that it was considered reasonable to lump the $\mathrm{K}^{+}$with the 
$\mathrm{Na}^{+}$as a generic "monovalent cation." Thus, a simplified three-component cation-exchange model analogous to the three-component exchange model used in the MULTRAN V 1.0 code (STN: 10666-1.0-00 [DIRS 159068]) (Equations 21 through 24 in Section E3.1.3) was used to interpret the batch experiments.

A simple FORTRAN program called EQUIL_FIT V 1.0 (STN: 10668-1.0-00 [DIRS 159064]) was developed to obtain the best simultaneous fit to the $\mathrm{Li}^{+}, \mathrm{Na}^{+}$, and $\mathrm{Ca}^{++}$data obtained in the batch-sorption experiments using $Q_{1}$ and $Q_{2}$ from Equations 21 and 22 as adjustable parameters. The CEC was set equal to the measured lithium CEC of the alluvium samples. The fits were optimized by minimizing the sum of squares of the differences between the logarithms of the model-predicted concentrations and the experimental concentrations. Logarithms were used in the optimization algorithm so that the fits would not be biased toward the data obtained at the highest lithium concentrations.

\section{H1.5 RESULTS OF CATION-EXCHANGE-CAPACITY MEASUREMENTS}

The lithium and cesium CECs of the materials from the sampled alluvium intervals in wells 19D and 19P are listed in Table H-2. Only the lithium CEC results were used to interpret the lithium batch-sorption and column transport tests (Section $\mathrm{H} 2$ ) because only cations displaced by lithium are of practical interest in these experiments. It is apparent that the smaller-size fraction material generally had a larger CEC value than the larger-size fraction material from each interval that was tested. Also, the wet-sieved 75- to 2000- $\mu \mathrm{m}$ material from the two uppermost intervals in 19D had relatively low CECs compared to the other samples, presumably because the wet-sieving procedure removed many of the clays and zeolite minerals that have high CEC values.

\section{H1.6 RESULTS OF BATCH-SORPTION EXPERIMENTS}

The $Q_{1}$ and $Q_{2}$ values yielding the best simultaneous fits to the $\mathrm{Li}^{+},\left(\mathrm{Na}^{+}+\mathrm{K}^{+}\right)$, and $\mathrm{Ca}^{++}$data obtained in the lithium batch-sorption experiments are listed in Table H-3 along with the lithium CEC values for each alluvium material tested. Two sets of $Q_{1}$ and $Q_{2}$ values are listed for each material: (1) one obtained using a direct measurement of the starting lithium concentration as the initial lithium concentration in each experiment and (2) one obtained by using a bromide concentration measurement to determine the starting lithium concentration (the lithium was introduced as $\mathrm{LiBr}$ ). The differences between these two sets of values are sometimes quite large for a given alluvium interval. These differences reflect the uncertainty in the $Q_{1}$ and $Q_{2}$ values due to analytical errors in tracer concentration measurements, and they also reflect the relative insensitivity of the fits to the $Q$ values. Table H-3 also lists the Freundlich isotherm parameters (Equation 12, Section E1.2) that yielded the best fits to the lithium sorption data. Larger values of the $K_{\mathrm{F}}$ parameter tend to reflect greater lithium sorption. 
Table H-3. Cation Exchange Coefficients (CEC) and Freundlich Isotherm Parameters Resulting in Best Fits to the $\mathrm{Li}^{+}, \mathrm{Na}^{+}$, and $\mathrm{Ca}^{++}$Data from the Lithium Batch-Sorption Experiments for Alluvium Material

\begin{tabular}{|c|c|c|c|c|c|c|c|c|c|}
\hline \multirow[b]{2}{*}{$\begin{array}{c}\text { Interval }^{\dagger} \\
\text { (well, ft below land } \\
\text { surface, size) }\end{array}$} & \multirow{2}{*}{$\begin{array}{c}\text { Li } \\
\text { CEC } \\
\text { (meq } \\
\text { lkg) }\end{array}$} & \multicolumn{2}{|c|}{$\begin{array}{c}\text { Li as Starting } \\
\text { Conc. }\end{array}$} & \multicolumn{2}{|c|}{$\begin{array}{c}\mathrm{Br} \text { as Starting } \\
\text { Conc. }\end{array}$} & \multicolumn{2}{|c|}{$\begin{array}{c}\text { Li as Starting } \\
\text { Conc. }\end{array}$} & \multicolumn{2}{|c|}{$\begin{array}{c}\mathrm{Br} \text { as Starting } \\
\text { Conc. }\end{array}$} \\
\hline & & $Q_{1}$ & $\begin{array}{c}Q_{2} \\
\left(L^{2} / k^{2}\right)\end{array}$ & $Q_{1}$ & $\begin{array}{c}Q_{2} \\
\left(L^{2} / \mathbf{k g}^{2}\right)\end{array}$ & $\begin{array}{c}K_{F} \\
(m L / \mu g) \\
n(\mu g / g) \\
\end{array}$ & $n$ & $\begin{array}{c}K_{F} \\
(m L / \mu g) \\
n(\mu g / g) \\
\end{array}$ & $n$ \\
\hline $19 \mathrm{D}, 405-410,<75 \mu \mathrm{m}$ & 183 & 0.06 & 0.22 & 0.06 & 0.22 & 0.58 & 0.82 & 0.41 & $0.7 \varepsilon$ \\
\hline $19 \mathrm{D}, 405-410,>75 \mu \mathrm{m}$ & 70 & 0.07 & 0.03 & 0.06 & 0.02 & 0.35 & 0.85 & 0.26 & 0.82 \\
\hline $19 \mathrm{P}, 410-415,<75 \mu \mathrm{m}$ & 360 & 0.13 & 0.004 & 0.22 & 0.003 & 1.48 & 0.86 & 0.82 & 0.81 \\
\hline $19 \mathrm{P}, 410-415,>75 \mu \mathrm{m}$ & 126 & 0.11 & 0.003 & 0.17 & 0.003 & 0.47 & 0.84 & 0.26 & 0.77 \\
\hline 19D, 420-425, < $75 \mu \mathrm{m}$ & 175 & 0.05 & 0.15 & 0.04 & 0.09 & 0.75 & 0.89 & 0.31 & $0.7 \varepsilon$ \\
\hline $19 \mathrm{D}, 420-425,>75 \mu \mathrm{m}$ & 89 & 0.05 & 0.07 & 0.04 & 0.04 & 0.58 & 0.94 & 0.23 & 0.84 \\
\hline $19 \mathrm{P}, 420-425,<75 \mu \mathrm{m}$ & 395 & 0.04 & 0.5 & 0.04 & 0.5 & 1.25 & 0.84 & 1.08 & 0.82 \\
\hline $19 \mathrm{P}, 420-425,>75 \mu \mathrm{m}$ & 171 & 0.05 & 0.01 & 0.07 & 0.002 & 0.77 & 0.90 & 0.38 & 0.82 \\
\hline $19 \mathrm{D}, 500-505,<75 \mu \mathrm{m}$ & 125 & 0.07 & 0.03 & 0.06 & 0.02 & 0.44 & 0.79 & 0.55 & 0.85 \\
\hline $19 \mathrm{D}, 500-505,>75 \mu \mathrm{m}$ & 137 & 0.05 & 0.03 & 0.04 & 0.012 & 0.43 & 0.83 & 0.20 & $0.7 \varepsilon$ \\
\hline $19 \mathrm{D}, 580-585,<75 \mu \mathrm{m}$ & 204 & 0.07 & 0.63 & 0.06 & 0.49 & 0.32 & 0.71 & 0.56 & $0.7 \varepsilon$ \\
\hline $19 \mathrm{D}, 580-585,>75 \mu \mathrm{m}$ & 132 & 0.07 & 0.09 & 0.06 & 0.06 & 0.05 & 0.55 & 0.13 & 0.66 \\
\hline 19D, 660-665, <75 $\mu \mathrm{m}$ & 303 & 0.28 & 0.002 & 0.24 & 0.002 & 0.47 & 0.74 & 0.74 & 0.80 \\
\hline $19 \mathrm{D}, 660-665,>75 \mu \mathrm{m}^{*}$ & 119 & 0.13 & 0.09 & 0.13 & 0.05 & 3.67 & 1.03 & 2.99 & 1.01 \\
\hline 19D, 680-685, < $75 \mu \mathrm{m}$ & 257 & 0.16 & 0.1 & 0.14 & 0.04 & 1.31 & 0.80 & 1.10 & 0.77 \\
\hline $19 \mathrm{D}, 680-685,>75 \mu \mathrm{m}$ & 118 & 0.17 & 0.05 & 0.16 & 0.03 & 0.64 & 0.78 & 0.46 & 0.74 \\
\hline $19 \mathrm{D}, 720-725,<75 \mu \mathrm{m}$ & 424 & 0.13 & 0.011 & 0.14 & 0.009 & 1.25 & 0.78 & 1.10 & 0.77 \\
\hline 19D, $720-725,>75 \mu \mathrm{m}$ & 114 & 0.21 & 0.017 & 0.23 & 0.01 & 0.67 & 0.78 & 0.48 & 0.73 \\
\hline 19D, $780-785,<75 \mu \mathrm{m}$ & 237 & 0.09 & 0.27 & 0.09 & 0.27 & 0.71 & 0.77 & 0.50 & 0.73 \\
\hline 19D, 780-785, > $75 \mu \mathrm{m}$ & 78 & 0.26 & 0.03 & 0.26 & 0.013 & 0.52 & 0.75 & 0.38 & 0.74 \\
\hline
\end{tabular}

Source: DTN: LA0201JS831341.001 [DIRS 162627] (CEC values).

Output DTN: LA0303PR831341.002 (sorption parameters).

NOTE: Bold denotes material used in column experiments. Materials from NC-EWDP-19P and the two uppermost intervals in NC-EWDP-19D (123 to $125 \mathrm{~m}$ [405 to $410 \mathrm{ft}$ ] and 128 to $130 \mathrm{~m}$ [420 to $425 \mathrm{ft}$ ) were wet-sieved; all other materials were dry-sieved. Estimates of the uncertainties in the parameter values listed in this table were not rigorously obtained because these uncertainties are not critical for Performance Assessment calculations. Values represent best estimates only. $Q_{1}$ is dimensionless.

* The sorption parameters derived for this alluvium material are suspect because there were very few data points to analyze.

$\dagger$ The interval is given in feet because the data were collected using English units.

CEC=cation-exchange-capacity

Figures $\mathrm{H}-2$ and $\mathrm{H}-3$ show the best fits to the $\mathrm{Li}^{+},\left(\mathrm{Na}^{+}+\mathrm{K}^{+}\right)$, and $\mathrm{Ca}^{++}$data obtained for the wet-sieved 75- to 2000- $\mu \mathrm{m}$ material from the two uppermost intervals in NC-EWDP-19D (123 to $125-\mathrm{m}$ [ 405 to $410 \mathrm{ft}$ ] and 128 to $130 \mathrm{~m}$ [420 to $425 \mathrm{ft}$ ], respectively). These two materials were combined in a 50:50 mass ratio and used to pack the columns described in Section H2. The data and fits to the data for both the lithium-based starting concentrations and the bromide-based starting concentrations are shown in these figures. 

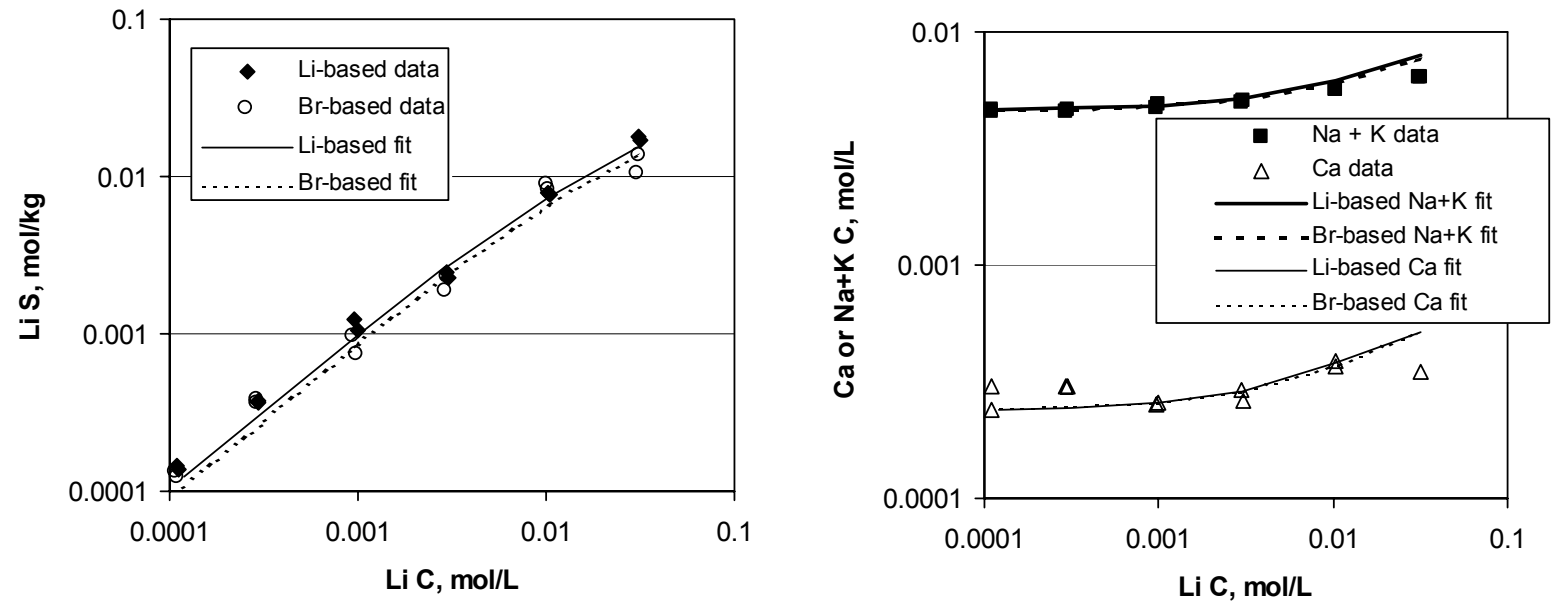

Source: DTN: LA0302JS831341.001 [DIRS 162628]. (data).

Output DTN: LA0303PR831361.002 (model results).

NOTE: The alluvium material is from a depth below the land surface of 123 to $125 \mathrm{~m}$ ( 405 to $410 \mathrm{ft}$ ) with a size distribution of 75 to $2000 \mu \mathrm{m}$; parameters yielding the fits are listed in Table $\mathrm{H}-3$.

Figure H-2. Best Fits of the Three-Component Cation-Exchange Model to the Lithium Sorption Isotherm (left) and the $\left(\mathrm{Na}^{+}+\mathrm{K}^{+}\right)$and $\mathrm{Ca}^{++}$Concentration Data (right) for Alluvium Material from NC-EWDP-19D at 123 to $125 \mathrm{~m}$ (405 to $410 \mathrm{ft}$ )
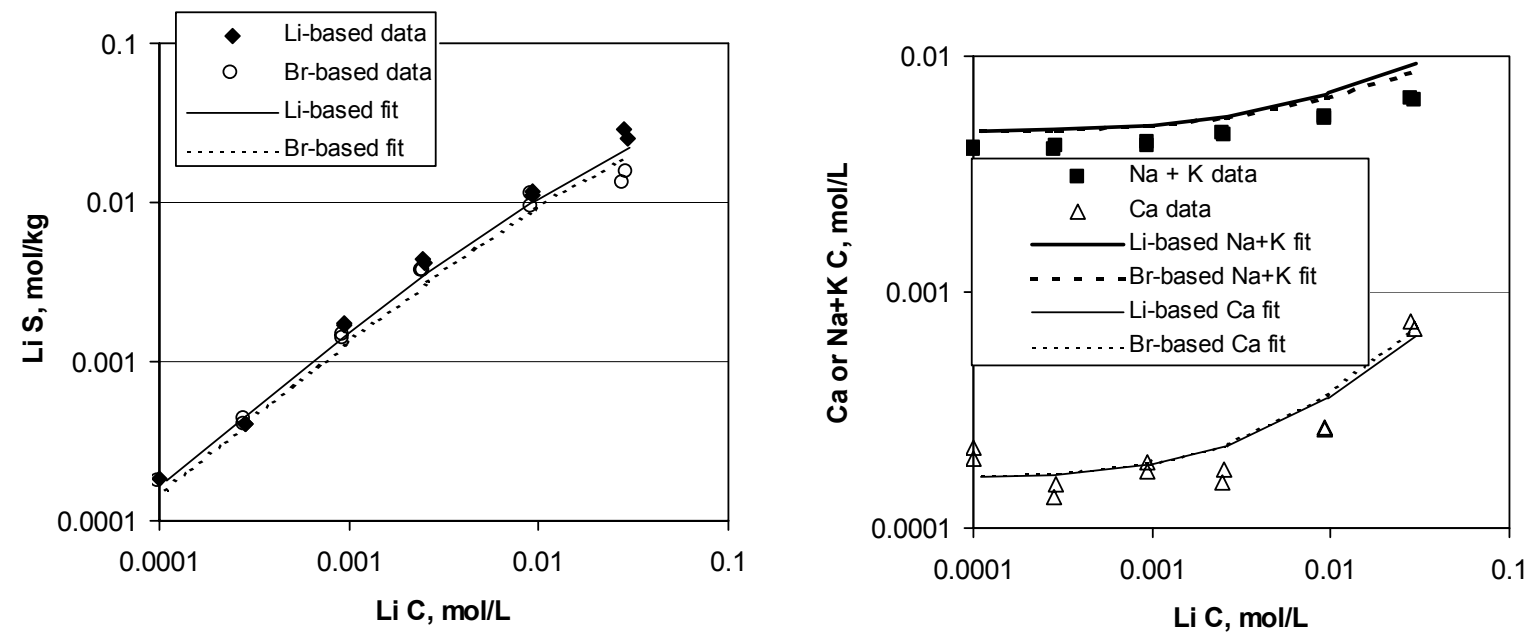

Source: DTN: LA0302JS831341.001 [DIRS 162628] (data).

Output DTN: LA0303PR831341.002 (model results).

NOTE: The alluvium material is from a depth below the land surface of 128 to $130 \mathrm{~m} \mathrm{(420} \mathrm{to} 425 \mathrm{ft}$ ) with a size distribution of 75 to $2000 \mu \mathrm{m}$; and parameters yielding the fits are listed in Table H-3.

Figure H-3. Best Fits of the Three-Component Cation-Exchange Model to the Lithium Sorption Isotherm (Left) and the $\left(\mathrm{Na}^{+}+\mathrm{K}^{+}\right)$and $\mathrm{Ca}^{++}$Concentration Data (Right) for Alluvium Material from NC-EWDP-19D at 128 to $130 \mathrm{~m}$ (420 to $425 \mathrm{ft}$ ) 


\section{H2. TRANSPORT TESTS IN ALLUVIUM-PACKED COLUMNS}

This section presents the results and interpretations of several column transport experiments using groundwater and alluvium obtained from the site of the ATC well 19D (Figures 6.1-6). These experiments involved injecting lithium bromide as pulses at three different concentrations spanning the range of concentrations expected in the field. The multicomponent numerical transport model, MULTRAN V 1.0 (STN: 10666-1.0-00 [DIRS 159068]) (see Section E3.2.2), was used to describe lithium transport through the columns. Companion batch lithium sorption and CEC measurements are discussed in Section H1.

\section{H2.1 MATERIALS AND METHODS}

All experiments were conducted using groundwater batches collected from well 19D in June 2000 or November 2000. The batches had slightly different chemistries because they were collected from different depth intervals (Table H-4). Batch 1 was used for all experiments except the column experiments with the intermediate $\mathrm{LiBr}$ injection concentration. Both waters are essentially sodium-bicarbonate waters that are nearly saturated with respect to silica and with a $\mathrm{pH}$ greater than 8 . The higher $\mathrm{pH}$ of the Batch 1 water relative to the Batch 2 water reflects the higher pHs encountered in the deeper zones in well 19D (Batch 2 water was obtained from only the two shallowest zones in 19D). The groundwater was filter-sterilized using a $0.2-\mu \mathrm{m}$ filter before use.

The alluvium used in the experiments was obtained from well 19D at the depth intervals of 123 to $125 \mathrm{~m}$ (405 to $410 \mathrm{ft}$ ) and 128 to $130 \mathrm{~m}$ (420 to $425 \mathrm{ft}$ ) below ground surface, approximately 15 to $23 \mathrm{~m}$ (50 to $75 \mathrm{ft}$ ) below the water table. Cuttings samples were wet-sieved (using 19D well water) in the laboratory, and the size range between $75 \mu \mathrm{m}$ and $2000 \mu \mathrm{m}$ was retained for testing. Material from the two intervals was combined in a 50:50 mass ratio for the column experiments because there was not enough material from the individual intervals to pack the columns. Table $\mathrm{H}-1$ gives the bulk mineralogy of the alluvium from the two intervals (in bold) as determined by quantitative minerals abundance analysis using x-ray diffraction (Chipera and Bish 1995 [DIRS 105075]). Table H-2 lists the surface area of the samples (again, in bold) determined by a single-point BET nitrogen adsorption/desorption method (Brunauer et al. 1938 [DIRS 156646]).

Table H-4. Major Ion Chemistry of NC-EWDP-19D Water Used in the Experiments

\begin{tabular}{|l|c|c|}
\hline \multicolumn{1}{|c|}{ Species } & Batch 1 $^{\text {a }}$ (mg/L) & Batch 2 ${ }^{\mathbf{b}}$ (mg/L) \\
\hline $\mathrm{Ca}^{++}$ & 2.2 & 7.5 \\
\hline $\mathrm{Na}^{+}$ & 118 & 75.5 \\
\hline $\mathrm{K}^{+}$ & 5.2 & 4.1 \\
\hline $\mathrm{Mg}^{++}$ & 1.13 & 0.65 \\
\hline $\mathrm{Li}^{+}$ & 0.15 & 0.09 \\
\hline $\mathrm{Si}$ & 52.5 & 27.1 \\
\hline $\mathrm{HCO}_{3}{ }^{-}$ & 193 & 168 \\
\hline $\mathrm{CO}_{3}{ }^{2-}$ & 43.8 & 0 \\
\hline $\mathrm{SO}_{4}{ }^{2-}$ & 25.9 & 23.0 \\
\hline
\end{tabular}


Table H-4. Major lon Chemistry of NC-EWDP-19D Water Used in the Experiments (Continued)

\begin{tabular}{|c|c|c|}
\hline Species & Batch $1^{a}$ (mg/L) & Batch $2^{b}(\mathrm{mg} / \mathrm{L})$ \\
\hline $\mathrm{Cl}^{-}$ & 5.7 & 5.6 \\
\hline $\mathrm{F}^{-}$ & 2.1 & 1.8 \\
\hline $\mathrm{pH}$ & 9.2 & 8.1 \\
\hline
\end{tabular}

Source: DTN: LA0303PR831232.001 [DIRS 162781].

${ }^{\text {a }}$ Batch 1 was collected in June 2000 from an open borehole.

${ }^{\mathrm{b}}$ Batch 2 was collected from two isolated screened intervals in the upper

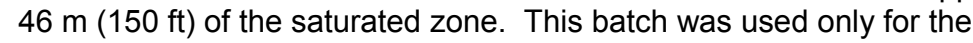
$0.006 \underline{\mathrm{M}} \mathrm{LiBr}$ column experiments.

Column experiments were conducted in duplicate using separate $30-\mathrm{cm}$ long by $2.5-\mathrm{cm}$ diameter glass columns equipped with polytetrafluoroethylene end fittings, including a $20-\mu \mathrm{m}$ end frit and PTFE tubing. Each column was presoaked in deionized water to remove any residual ions. The columns were packed dry with a 50:50 mass ratio of the wet-sieved alluvium from the two intervals used in batch-sorption and CEC testing. The columns then were saturated by flushing with deaerated groundwater until air bubbles were no longer visible. They also were packed in ice for $8 \mathrm{hr}$ to promote oxygen and nitrogen dissolution in the water. The saturated versus dry weights of the columns indicated a final porosity of about 40 percent with a pore volume of about $60 \mathrm{~mL}$ in each column.

Three transport experiments were conducted in each column at a flow rate of approximately $10 \mathrm{~mL} / \mathrm{hr}$ with the two columns run in parallel. Each experiment involved the injection of approximately one pore volume of a tracer solution containing $\mathrm{LiBr}$ and $2 \mathrm{mg} / \mathrm{L}$ of an fluorobenzoate (FBA)(either pentafluorobenzoate or 2,4-difluorobenzoate) dissolved in 19D groundwater. The experiments differed in the concentrations of $\mathrm{LiBr}$ in the injection pulses. The first duplicate set of experiments was conducted using an injection concentration of 0.0275 $\underline{\mathrm{M}} \mathrm{LiBr}\left(190 \mathrm{mg} / \mathrm{L} \mathrm{Li}^{+}\right)$, the second set had a concentration of $0.006 \underline{\mathrm{M} \mathrm{LiBr}}\left(42 \mathrm{mg} / \mathrm{L} \mathrm{Li}^{+}\right)$, and the third set had a concentration of $0.0013 \underline{\mathrm{M}} \mathrm{LiBr}\left(9 \mathrm{mg} / \mathrm{L} \mathrm{Li}^{+}\right)$. These concentrations were selected so that $\mathrm{Li}^{+}$dominated the cation equivalents in solution in the first case (91 percent of total cation equivalents), accounted for about half of the cation equivalents in the second case (61 percent), and were a relatively minor fraction of the total cation equivalents in the third case (24 percent). These three situations represent a range of conditions that will likely occur during field testing, with relatively high concentrations present near the injection well immediately after injection, and concentrations decreasing as the tracer pulse advects and disperses through the flow system.

The tracer solutions were injected simultaneously into the two columns using a syringe pump (Harvard Systems). After one pore volume of tracer was injected, tracer-free groundwater was injected at $10 \mathrm{~mL} / \mathrm{hr}$ using a piston pump (SciLog). Column effluent samples were collected using an automatic fraction collector (Gilson) set up to collect samples simultaneously from both columns in pre-weighed test tubes at pre-set time intervals. The samples were analyzed for the same cations ( $\mathrm{Li}, \mathrm{Na}, \mathrm{K}, \mathrm{Ca}$, and $\mathrm{Mg}$ ) that were analyzed in the batch-sorption experiments using ICP-AES. Bromide and the FBAs were analyzed by liquid chromatography, with the latter being quantified by UV absorption. Samples were diluted as necessary for the tracer analyses. 


\section{H2.2 Interpretive Modeling Approach}

The column transport experiments were simulated using the MULTRAN V 1.0 (STN: 106661.0-00 [DIRS 159068]) multicomponent ion-exchange transport model (Section E3.2.2). The columns were modeled as single-porosity systems because the FBAs and bromide had essentially identical normalized concentration responses in all experiments, indicative of a system that lacks secondary (stagnant) storage porosity (see Section G2). The mean residence time and Peclet number (dispersivity) were adjusted to achieve a qualitative fit to the bromide responses in each experiment. The lithium responses were then fitted by adjusting the CECs, $Q_{1}$ and $Q_{2}$ (see Section H1.3) while setting the CEC of the alluvium equal to the average CEC of the two materials used to pack the columns ( $80 \mathrm{meq} / \mathrm{kg}$; see Table H-2).

\section{H2.3 EXPERIMENTAL RESULTS AND ANALYSES}

The breakthrough curves of $\mathrm{Br}^{-}, \mathrm{Li}^{+}, \mathrm{Na}^{+}$, and $\mathrm{Ca}^{++}$, expressed as meq/L versus volume eluted through the columns, are shown in Figures H-4, H-5, and H-6, for the experiments conducted at each of the three $\mathrm{LiBr}$ injection concentrations, respectively. These figures also show the MULTRAN V 1.0 (STN: 10666-1.0-00 [DIRS 159068]) fits to each data set. The FBA data are not shown in these figures because these data were essentially identical to the bromide data when normalized to the injection concentration. However, the FBA concentrations were accounted for in the MULTRAN modeling. A negligible concentration shift of the tracers after a flow interruption in test 2 (Figure H-5, at approximately $500 \mathrm{~mL}$ eluted) verified the lack of diffusive mass transfer into secondary storage porosity in the system that was suggested by the identical normalized concentration responses of the bromide and FBA. The apparent slight perturbation in $\mathrm{Na}^{+}$concentrations after the flow interruption, with column A showing a minor decrease and column B showing a minor increase, is unexplained. Analyses of additional cations and anions would have been necessary to better understand this phenomenon, although it ultimately has negligible impact on the test interpretations. 

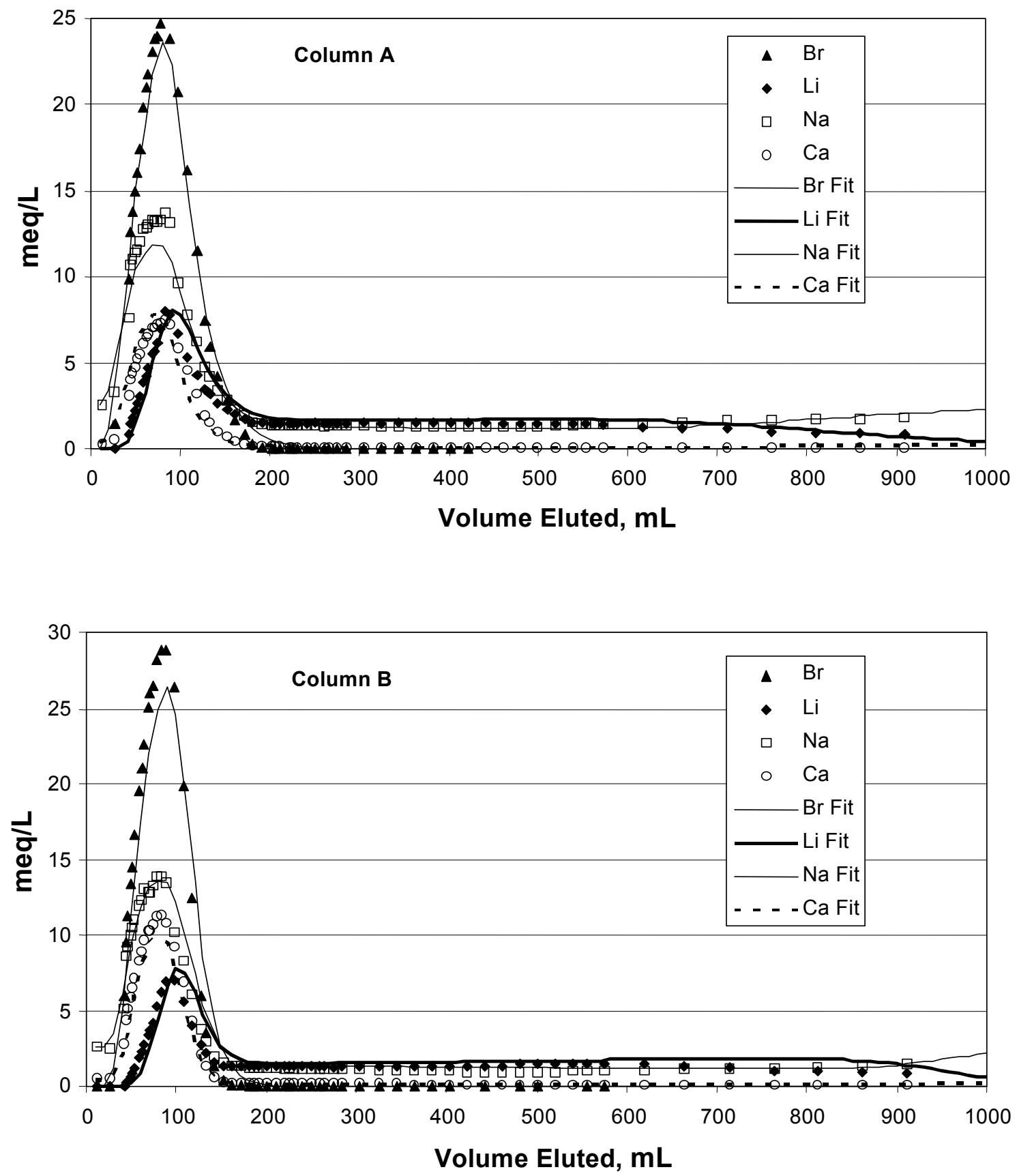

Source: DTN: LA0201JS831361.001 [DIRS 162629] (data).

Output DTN: LA0303PR831361.002 (model results).

Figure H-4. Column Data and MULTRAN Fits for Experiments with a $\mathrm{LiBr}$ Injection Concentration of $0.0275 \underline{M}$ 

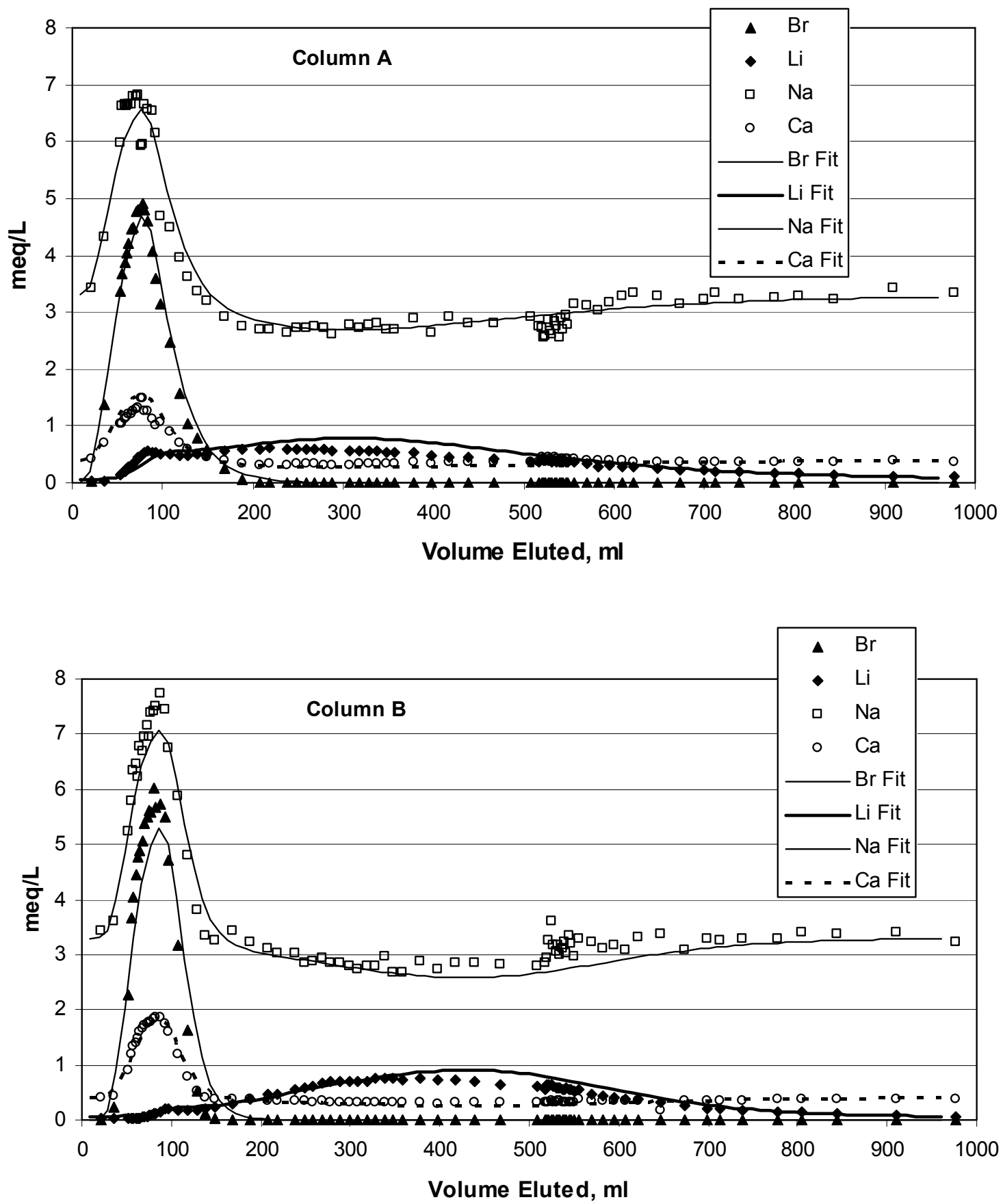

Source: DTN: LA0201JS831361.007 [DIRS 162630] (data).

Output DTN: LA0303PR831361.002 (model results).

Figure H-5. Column Data and MULTRAN Fits for Experiments with a $\mathrm{LiBr}$ Injection Concentration of $0.006 \underline{M}$ 

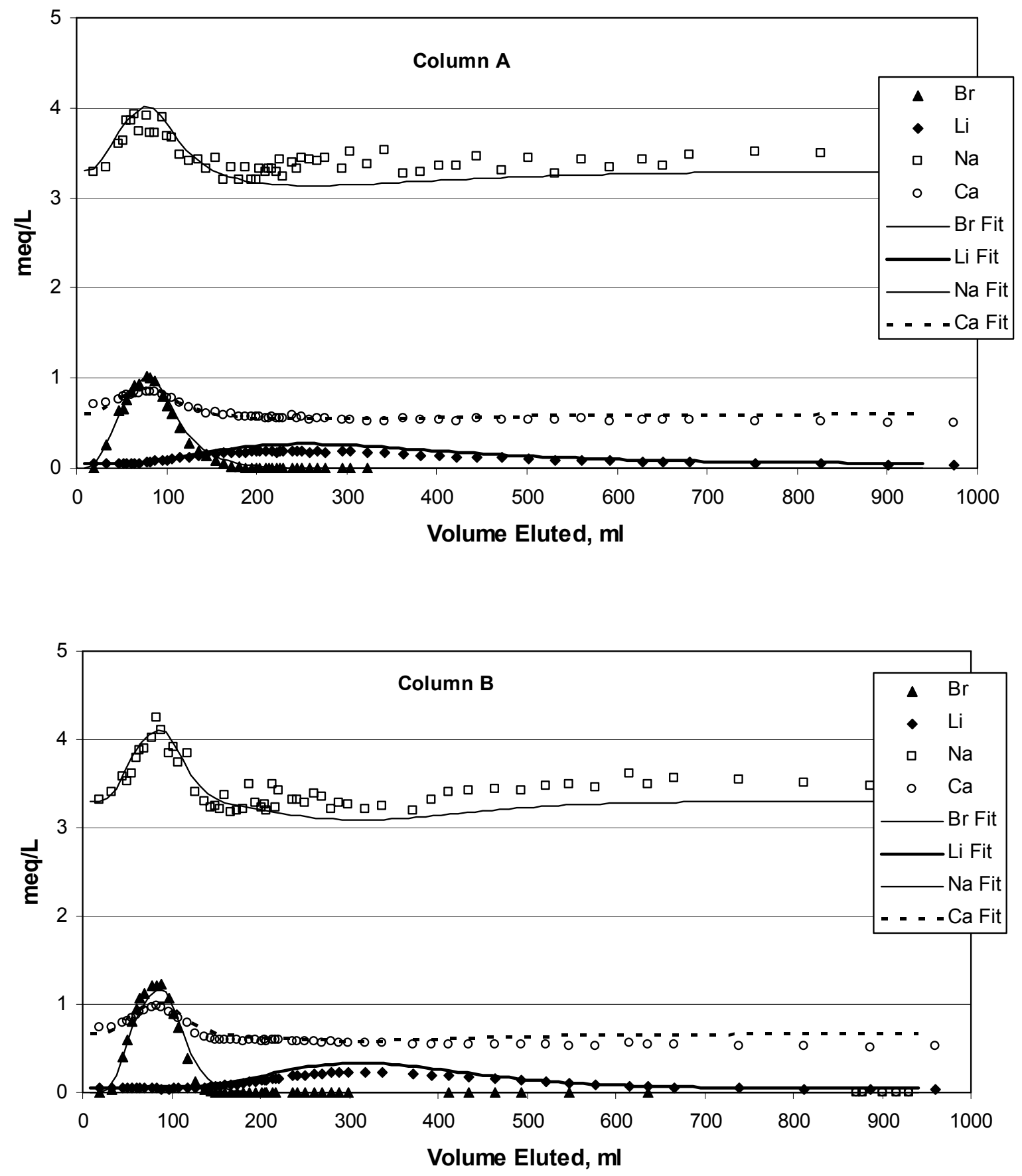

Source: DTN: LA0201JS831361.005 [DIRS 166205] (data).

Output DTN: LA0303PR831361.002 (model results).

Figure H-6. Column Data and MULTRAN Fits for Experiments with a $\mathrm{LiBr}$ Injection Concentration of $0.0013 \underline{\mathrm{M}}$ 
The MULTRAN V 1.0 (STN: 10666-1.0-00 [DIRS 159068]) model parameters resulting in the best fits shown in Figures H-4, H-5, and H-6 are listed in Table H-5. As with the interpretation of the batch-sorption experiments, the lithium CEC was fixed to $0.08 \mathrm{eq} / \mathrm{kg}$ for all of the experiments, and $Q_{1}$ and $Q_{2}$ were adjusted to fit the data. The dispersivity in the column was also adjusted to obtain a reasonable fit to the bromide response curve. The fits were found to be quite sensitive to the background concentrations assumed in the simulations, which were variable in the experiments because the columns were re-used to conduct subsequent experiments, and residual concentrations of the cations varied somewhat. As Tables $\mathrm{H}-3$ and $\mathrm{H}-5$ indicate, the best-fitting ion-exchange constants for lithium exchange with both sodium/potassium $\left(Q_{1}\right)$ and calcium $\left(Q_{2}\right)$ were generally higher in the column experiments than in the batch experiments. The use in MULTRAN of the $Q_{1}$ and $Q_{2}$ values obtained from the batch experiments consistently overpredicted lithium responses and underpredicted sodium and calcium responses than were observed.

Table H-5. MULTRAN Model Parameters Associated with the Fits to the Column Transport Data

\begin{tabular}{|l|c|c|c|}
\hline \multicolumn{1}{|c|}{ Experiment } & Dispersivity $\mathbf{( c m )}$ & $\mathbf{Q}_{\mathbf{1}}$ & $\left.\mathbf{Q}_{\mathbf{2}} \mathbf{( L}^{\mathbf{2}} \mathbf{k} \mathbf{k g}^{\mathbf{2}}\right)$ \\
\hline $0.0275 \underline{\mathrm{M}} \mathrm{LiBr}$, Column A (Figure H-4) & 5.4 & 0.06 & 0.12 \\
\hline $0.0275 \underline{\mathrm{M}} \mathrm{LiBr}$, Column B (Figure H-4) & 1.8 & 0.045 & 0.22 \\
\hline $0.006 \underline{\mathrm{M}} \mathrm{LiBr}$, Column A (Figure H-5) & 5.4 & 0.104 & 0.083 \\
\hline $0.006 \underline{\mathrm{M}} \mathrm{LiBr}$, Column B (Figure H-5) & 1.8 & 0.104 & 0.083 \\
\hline $0.0013 \underline{\mathrm{M}} \mathrm{LiBr}$, Column A (Figure H-6) & 5.4 & 0.104 & 0.083 \\
\hline $0.0013 \underline{\mathrm{M}} \mathrm{LiBr}$, Column B (Figure H-6) & 1.8 & 0.104 & 0.083 \\
\hline
\end{tabular}

Output DTNs: LA0303PR831361.002; LA0303PR831231.005.

NOTE: The model parameters above do not include mean residence times. The column transport data are shown in Figures $\mathrm{H}-4, \mathrm{H}-5$, and $\mathrm{H}-6$. The lithium cation-exchange-capacity value was assumed to be $0.08 \mathrm{eq} / \mathrm{kg}$ for all simulations. Estimates of the uncertainties in the parameter values listed in this table were not rigorously obtained because these uncertainties are not critical for Performance Assessment calculations. Values represent best estimates only. $Q_{1}$ is dimensionless.

The $Q_{1}$ and $Q_{2}$ values obtained for each experiment within a given column or for the different columns at a given $\mathrm{LiBr}$ injection concentration were in reasonably good agreement, especially after the first set of tests (Table H-5). In principle, these values should not change from column to column or from experiment to experiment because the columns contained exactly the same material. The MULTRAN V 1.0 (STN: 10666-1.0-00; [DIRS 159068]) fits were not obtained using a least-squares minimization or optimization algorithm, but rather they were obtained by manually adjusting parameters to obtain a good visual fit to the data.

\section{H2.4 DISCUSSION}

Examination of the MULTRAN V 1.0 (STN: 10666-1.0-00 [DIRS 159068]) model fits shown in Figures H-4, H-5, and H-6 indicates that the model describes well the transport behavior of the cations through the columns, even though the response curves varied significantly for the three different LiBr injection concentrations. Furthermore, the model parameters did not have to be changed significantly for the different injection concentrations to achieve good fits. This result suggests that the model accurately represented the transport processes occurring in the columns. 
The partial nonsorbing transport behavior of lithium ion at high injection concentrations (e.g., Figure H-4) is a consequence of both the limited lithium sorption capacity of the alluvium and the requirement that local charge balance must be maintained throughout the columns. When the concentration of lithium ion was a significant fraction of the total cation concentrations in the injection solution (in eq/L), some of the lithium was forced to move without sorbing through the columns with the nonsorbing anion tracers to maintain charge balance. This phenomenon occurred because the CEC and the cation exchange constants $\left(Q_{1}\right.$ and $\left.Q_{2}\right)$ of the alluvium were not so large that all of the injected lithium could be exchanged for sodium and calcium ions to balance the anion tracer charge. The fraction of early arriving lithium in the column tests decreased as the $\mathrm{LiBr}$ injection concentration decreased; and when the $\mathrm{Li}^{+}$concentration was only 24 percent of the total cation eq/L, the lithium was essentially completely retarded (Figure H-6). The lithium responses at the lowest $\mathrm{LiBr}$ injection concentration were the only responses that could be adequately modeled when a simple linear partition coefficient, $\left(K_{\mathrm{d}}=\right.$ mass sorbed per unit mass of solid/solution concentration) was assumed (fits not shown). Such a model assumes that lithium transport is independent of all other species in solution, which is clearly inaccurate at higher injection concentrations for which it becomes a significant fraction of the total cation equivalents in solution.

\section{H2.5 IMPLICATIONS OF COLUMN EXPERIMENT RESULTS FOR FIELD TESTING}

The lithium transport behavior observed in the column experiments and depicted in Figures H-4 through H-6 has important implications for potential cross-hole field tracer testing in the alluvium south of Yucca Mountain. It is common practice to inject large masses and, hence, high concentrations of sorbing tracers in field tests because the combination of sorption, dispersion, and dilution can result in very low concentrations at the production well. Large tracer injection masses and concentrations would, therefore, be used in cross-hole field tests to ensure adequate detection and quantification of lithium concentrations at the production well. This strategy means that lithium concentrations could tend to remain quite high for some time (and distance) near the injection well, which could result in some of the lithium moving without sorbing through the flow system until the tracer "slug" became dispersed and diluted.

There are two possible extremes of sorbing tracer transport in a cross-hole field tracer test that could result in the same observed concentrations at the production well. The first is that the injected tracer slug could disperse and dilute rapidly near the injection well, resulting in a low average concentration throughout the flow system. The second is that the tracer slug could remain relatively concentrated as it moves to the production well and then be diluted in the well bore as a result of mixing with tracer-free water that is also being drawn into the well. There is no way to distinguish between these two extremes, or any intermediate situation, when nonsorbing tracer responses are analyzed. However, the results and interpretations of the column experiments in this scientific analysis report suggest that the shape of a lithium breakthrough curve in a cross-hole field tracer test may provide a good indication of whether dilution is occurring early or late in the flow system. If dilution occurs early, a lithium response curve similar to those in Figure H-6 can be expected. However, if dilution occurs late, the lithium response curve may look more like those of Figures H-4 or H-5, where there is some asymmetry and nonsorbing transport, even though measured concentrations are quite low because of dilution in the production wellbore. Knowing whether dilution occurs early or late is important when 
making comparisons between laboratory and field transport behavior. If concentrations remain high in the field test (late dilution), then the lithium may appear to be transporting with less sorption than would be inferred from laboratory batch-sorption measurements, even though the field transport behavior is consistent with the laboratory data if the existence of high concentrations is recognized.

The ability to distinguish between early and late dilution could help refine or constrain estimates of effective flow porosities derived from cross-hole tracer tests. When nonsorbing tracer responses are analyzed, flow porosity estimates are typically based on first, mean, or peak arrival times of nonsorbing tracers. Under ideal radial flow conditions in a two-dimensional aquifer, Equation 10 (introduced in Section D4.8.5) can be used to estimate effective flow porosity. Equation 10 (which is a rearrangement of Equation 6 of Guimera and Carrera 2000 [DIRS 156830]) and the definitions of its variables are repeated here for convenience:

$$
\eta=\frac{\mathrm{Q} \tau}{\pi L^{2} T}
$$

where

$$
\begin{aligned}
& \eta=\text { flow porosity } \\
& \mathrm{Q}=\text { production flow rate, } \mathrm{m}^{3} / \mathrm{hr} \\
& \tau=\text { mean residence time of a nonsorbing tracer, } \mathrm{hr} \\
& L=\text { distance between wells, } \mathrm{m} \\
& T=\text { formation thickness (assumed to be well screen length), } \mathrm{m} .
\end{aligned}
$$

If flow heterogeneity exists, causing the flow field to not be radial, then estimates using Equation 10 will be erroneous. For instance, if most of the flow to the production well is channeled from a direction that does not intersect the tracer slug, then the interwell transport time for the slug can be very long, even if flow occurs in only a small fraction of the system volume. In this case, a considerable amount of dilution will occur late in the system (in the production well), and a misleadingly high flow porosity will be deduced from Equation 10 . If an asymmetric lithium response curve with some apparent nonsorbing transport is detected at the production well, the degree of asymmetry in the response can, in principle, be used to estimate the volume that the tracer pulse flowed through within the system. Such an estimate can be obtained by first using MULTRAN V 1.0 (STN: 10666-1.0-00 [DIRS 159068]) in inverse mode to match the shape of the response curve, given a known injection pulse concentration, injection duration, alluvium CEC (estimated from laboratory tests), and a longitudinal dispersivity (estimated from the nonsorbing tracer responses). Once a curve shape is matched given these constraints, the flow system volume can be estimated by multiplying the volume of the injection pulse in the field test by the ratio of flow system volume to injection pulse volume assumed in the MULTRAN simulations. An estimate of flow porosity can then be obtained from:

$$
\eta=\frac{V}{\pi L^{2} T}
$$


where $V=$ volume determined from MULTRAN matches to the lithium response.

The flow porosity estimate given by Equation 83 is independent of tracer transport times and, therefore, is not biased by flow channeling resulting from flow system heterogeneity. Of course, if the lithium response curve shows no asymmetry, then the method described above can only be used to establish a lower bound for the effective flow porosity. The method relies on the assumption of fast ion exchange kinetics relative to transport times in the flow system (i.e., the local equilibrium assumption), which should be satisfied unless transport times are less than a few hours. Six-hour residence times in the laboratory columns were apparently long enough that the local equilibrium assumption was satisfied. 


\section{APPENDIX I}

\section{TWO EXAMPLES OF STEPS INVOLVED IN PROCESSING INPUT DATA TO} ARRIVE AT OUTPUT DATA 


\section{I1. HYDRAULIC TEST INTERPRETATION EXAMPLE}

The following steps are involved in the hydraulic test interpretation depicted in Figure C-21:

Definitions of terms -

$\mathrm{P}_{\mathrm{h}}(\mathrm{ft})=$ Total pressure head in feet of water (hydraulic pressure head plus barometric pressure head) in a monitored interval

$\mathrm{P}_{\mathrm{h}}(\mathrm{psi})=$ Total pressure in $\mathrm{psi}=\mathrm{P}_{\mathrm{h}}(\mathrm{ft}) / 2.3078$, where 2.3078 is the $\mathrm{ft} / \mathrm{psi}$ conversion factor stored in the ParoScientific Inc. pressure transducers used at the $\mathrm{C}$-holes

$\mathrm{P}_{\mathrm{bar}}(\mathrm{psi})=$ barometric $($ atmospheric) pressure at land surface in psi

$\mathrm{P}_{\mathrm{bar}}(\mathrm{ft})=$ barometric pressure head in feet of water $=2.32 \times \mathrm{P}_{\text {bar }}(\mathrm{psi})$, where 2.32 is the $\mathrm{ft} / \mathrm{psi}$ conversion factor at temperature of monitored interval

$\mathrm{P}_{\mathrm{w}}(\mathrm{psi})=$ hydraulic pressure in monitored interval in $\mathrm{psi}=\mathrm{P}_{\mathrm{h}}(\mathrm{psi})-\mathrm{P}_{\mathrm{bar}}(\mathrm{psi})$

$\mathrm{P}_{\mathrm{w}}(\mathrm{ft})=$ hydraulic pressure head in monitored interval in $\mathrm{ft}$ of water $=2.32 \times \mathrm{P}_{\mathrm{w}}(\mathrm{psi})$, where 2.32 is the $\mathrm{ft} / \mathrm{psi}$ conversion factor at temperature of monitored interval

$\left.\right|_{\text {start }}$ : At the start time of the test

$\mid t:$ At time $t$ during the test

BE: Barometric Efficiency of interval

$\mathrm{dd}_{\text {corrected }}(\mathrm{ft})=$ Barometrically corrected drawdown in feet

$\mathrm{dd}_{\text {corrected }}(\mathrm{ft})=\left[\left.\mathrm{P}_{\mathrm{w}}(\mathrm{ft})\right|_{\text {start }}-\left.\mathrm{P}_{\mathrm{w}}(\mathrm{ft})\right|_{\mathrm{t}}\right]+\mathrm{BE}\left[\mathrm{P}_{\text {bar }}\left(\left.\mathrm{ft}\right|_{\text {start }}-\left.\mathrm{P}_{\text {bar }}(\mathrm{ft})\right|_{\mathrm{t}}\right]\right.$.

1. Go to DTN: GS990408312315.002 [DIRS 140115] in the ATDT, download the data file, and cut and paste all the data into an Excel spreadsheet using commas as delimiters. It may be necessary to use the "text to columns" feature of Excel after the cut-and-paste to get the head and temperature data in columns D and E to appear in separate columns (in this case, specify commas as delimiters).

2. In the resulting spreadsheet:

Column D is $\mathrm{P}_{\mathrm{h}}(\mathrm{ft})$ and Column $\mathrm{J}$ is $\mathrm{P}_{\mathrm{bar}}(\mathrm{psi})$

Start time is $16: 00: 02$ on $6 / 2 / 98$.

3. Perform above calculations to get a $\mathrm{dd}_{\text {corrected }}$ column. Use $\mathrm{BE}=0.96$ (see table C-3).

4. Create an "elapsed minutes" column by performing spreadsheet functions using the time column C.

5. Plot $\mathrm{dd}_{\text {corrected }}$ versus “elapsed minutes' to obtain Figure C-21. 


\section{I2. TRACER TEST INTERPRETATION EXAMPLE}

The following steps are involved in the tracer test interpretation depicted in Figure B-37, which are model fits to solute tracer breakthrough curves in the Prow Pass Tuff tracer test:

1. Sample collection during field tracer test is documented in C-Wells Prow Pass Field Scientific Notebook (Reimus 2000 [DIRS 162852]).

2. Analytical data for the tracers (raw concentration data) is reported in DTN: LAPR831231AQ99.001 [DIRS 140134].

3. The acquisition of the analytical data is documented in UZ Transport Test Notebook 2 (Bussod 2001 [DIRS 165281]), which has many attachments. Note that this notebook is a key roadmapping element for DTN: LAPR831231AQ99.001 [DIRS 140134], although the notebook does not appear explicitly in the report because the raw concentration data does not appear in the report (all concentrations in the report are normalized to injection mass).

4. The conversion of the raw pentafluorobenzoate, $\mathrm{Br}$, and Li concentration data $(\mathrm{mg} / \mathrm{L})$ to the normalized concentrations plotted in Figure D-27 is documented in Appendix A (specifically pp. A-87 to A-144) of Modeling and Interpretation of Transport Tests (Reimus 2003 [DIRS 165129]). The tracer masses (and where they came from) used in these normalization calculations are documented in the main body of this notebook.

5. The RELAP and MULTRAN fits to the breakthrough curves shown in Figure D-27 are documented in DTN: LA0303PR831231.003 (see Readme file in this data tracking number's zip file for more details). 
APPENDIX J

QUALIFICATION OF MINERALOGY DATA FOR SAMPLE FROM UE25C\#2, 2406 FT BELOW LAND SURFACE (DTN: LA9909PR831231.004 [DIRS 129623]) 
The qualification of the quantitative x-ray diffraction data for a crushed tuff sample from UE25c\#2, $2406 \mathrm{ft}$ below land surface (bls), contained in DTN: LA9909PR831231.004 [DIRS 129623], is documented here in accordance with AP-SIII.2Q, Qualification of Unqualified Data. This qualification provides the desired level of confidence that the data are suitable for their intended use, which is limited to the analysis and discussion in Section E1 of this analysis report. The qualification is based on corroboration of data, and it is carried out in accordance with data qualification plan, UE25c\#2 2406ft Quantitative X-Ray Diffraction Data.

The quantitative x-ray diffraction (XRD) data for the sample from UE25c\#2, $2406 \mathrm{ft}$ bls can be corroborated directly with the qualified XRD data for a sample from UE25c\#1, $2346 \mathrm{ft}$ bls (DTN: MO0012MINLCHOL.000 [DIRS 153370]). These two samples (called UE25c\#2-2406 and UE25c\#1-2346) were taken from the same lithologic interval, the central Bullfrog Tuff, which is a moderately to densely welded ash-flow tuff, at similar depths in wells that are less than $100 \mathrm{~m}$ apart (Figures 6.1-1 and 6.1-2). Although some minor variations in mineralogy can be expected over small scales within such intervals, the overall mineralogy should be very similar for samples that are less than $100 \mathrm{~m}$ apart. Therefore, the criterion for corroborating the UE25c\#2-2406 data with the UE25c\#1-2346 data is that the mineral weight percentages determined by XRD agree to within the combined reported errors of the two analyses. For example, if both analyses report a \pm 1 -wt $\%$ error for a given mineral, then the reported weight percentages for the two samples should agree to within $2 \mathrm{wt} \%$ for that mineral. This criterion is considered acceptable because both samples were analyzed by the same person (Steve Chipera of Los Alamos National Laboratory) using almost identical equipment and procedures, and the reporting of mineral weight percentages and errors was consistent.

Table J-1 provides the reported XRD analyses of the two samples, which were prepared by the same method (dry sieving, followed by wet sieving with J-13 well water, and retaining the 75 - to 500-mm particle size fraction for XRD analyses). Note that DTN: MO0012MINLCHOL.000 [DIRS 153370] also contains data for UE25c\#1-2346 for different sample preparation methods.

It is apparent from examining Table $\mathrm{J}-1$ that the criterion established above for qualification of the UE25c\#2-2406 data is met for all minerals. Thus, the XRD data for UE25c\#2-2406 are considered qualified for their intended use in the analysis presented in Section E1 of this analysis report. The source DTN: LA9909PR831231.004 [DIRS 129623] will remain unqualified for other uses. 
Table J-1. Mineral Weight Percentages and Reported Errors (in Weight Percent Units) from Quantitative XRD Analyses of UE25c\#2-2406 and UE25c\#1-2346

\begin{tabular}{|l|c|c|}
\hline \multicolumn{1}{|c|}{ Mineral } & UE25c\#2-2406 $^{\mathbf{a}}$ & UE25c\#1-2346 $^{\mathbf{b}}$ \\
\hline Smectite & $5 \pm 2$ & $2 \pm 1$ \\
\hline Mica & $1 \pm 1$ & $3 \pm 1$ \\
\hline Clinoptilolite & ND & ND \\
\hline Mordenite & ND & ND \\
\hline Analcime & ND & ND \\
\hline Quartz & $32 \pm 2$ & $34 \pm 2$ \\
\hline Feldspar & $62 \pm 7$ & $61 \pm 9$ \\
\hline Hematite & $1 \pm 1$ & Trace \\
\hline Calcite & ND & $1 \pm 1$ \\
\hline Kaolinite & ND & ND \\
\hline
\end{tabular}

NOTE: ND means Not Determined.

a Taken from DTN: LA9909PR831231.004 [DIRS 129623], SEP Table S99488_003 (unqualified).

b Taken from DTN: MO0012MINLCHOL.000 [DIRS 153370], SEP Table S00449_001 (qualified). 


\begin{tabular}{|c|c|l|}
\hline \multirow{2}{*}{ BSC } & DATA QUALIFICATION PLAN & QA: QA \\
\cline { 3 - 3 } & Page 1 of $\begin{array}{c}\text { Prz } 1 \\
\operatorname{mak} \% / \mathrm{m} / .4\end{array}$ \\
\hline
\end{tabular}

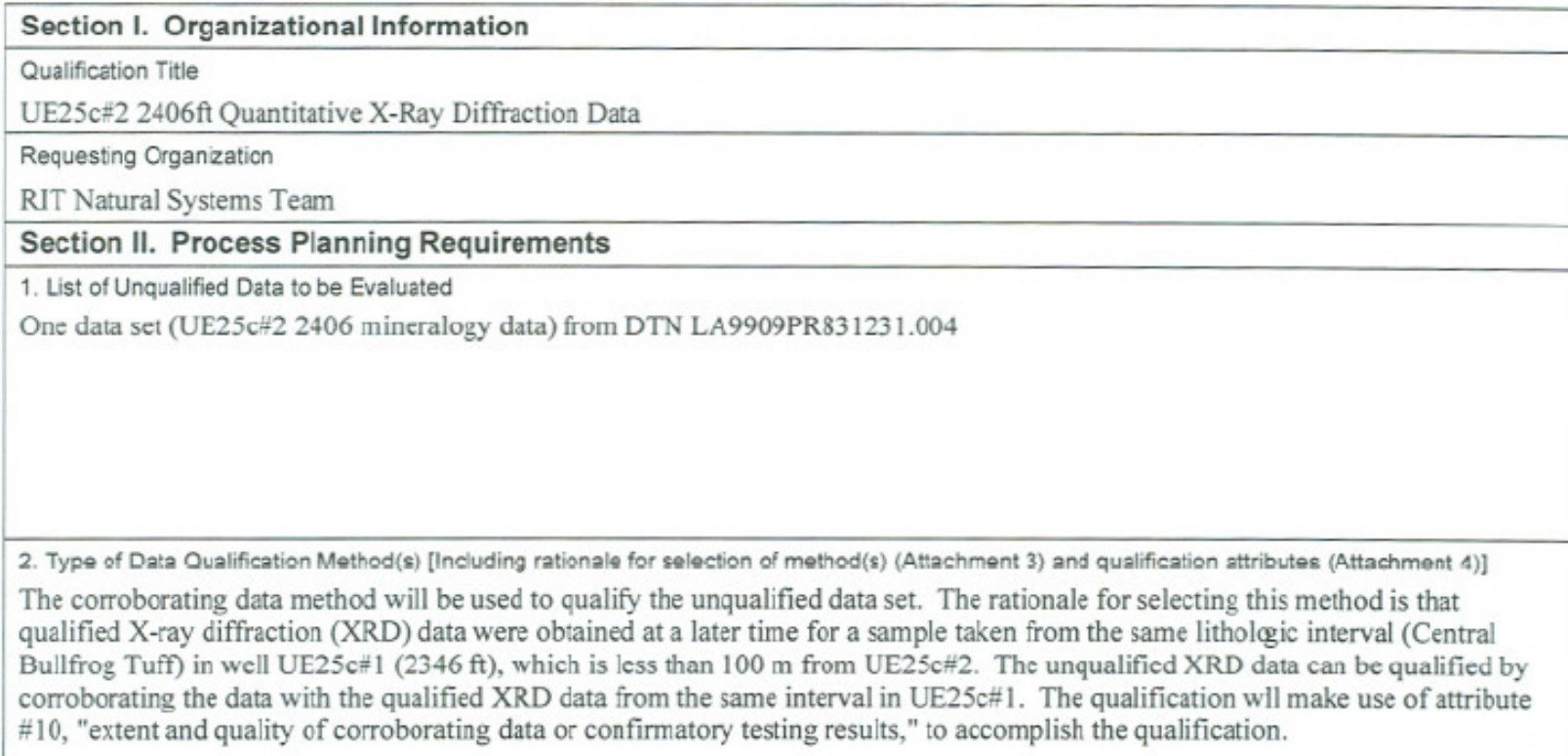

3. Data Qualification Team and Additional Support Staff Required

Paul Reimus

Marc Haga

4. Data Evaluation Criteria

The data will be evaluated by comparing the weight fractions of minerals determined by XRD in the two samples. The comparison will be made using the UE25c\# sample that received the same sieving treatment as the UE25c\#2 sample. If the weight percentages agree within the reported combined errors of the two analyses, then the data for the UE $25 \mathrm{c} \# 2$ sample will be considered qualified by corroboration. This criterion is based on the expectation that two samples from the same lihologic unit that are located in such close proximity should have very similar bulk mineralogies. A significantly different mineralogy would suggest a potential problem with the quality of the unqualified data, and conversely, good agreement between the two data sets would suggest acceptable quality of the unqualified data for the intended use in the SZ In-Situ Testing Analysis Report (ANL-NBS-HS-000039).

5 Identification of Procerdures I Ised

AP-SIII.9Q, Scientific Analysis - Qualification to be documented and reviewed in an appendix to a Scientific Analysis Report.

\begin{tabular}{|l|c|c|}
\hline Section III. Approval & Date \\
\hline $\begin{array}{l}\text { Qualification Chairperson Printed Name } \\
\text { Paul Reimus }\end{array}$ & Qualifigation Chairpersgn Signature & $9 / 104$ \\
\hline $\begin{array}{l}\text { Responsible Manager Printed Name } \\
\text { Ahmed Monib }\end{array}$ & Responsible Manager Signature & Date \\
\hline
\end{tabular}

AP-SIII.2Q

PA_ASIII2-1 (Rev. 01/29/2004) 


\section{INTENTIONALLY LEFT BLANK}


APPENDIX K

QUALIFICATION OF NC-EWDP-19IM2 WELL COMPLETION DATA (DTN: MO0306NYE05260.166 [DIRS 165877]) 
The qualification of the well completion data for NC-EWDP-19IM2 is documented here in accordance with AP-SIII.2Q, Qualification of Unqualified Data. This qualification provides the desired level of confidence that the data are suitable for their intended use, which is limited to the analysis and discussion in Section F2 of this analysis report. The qualification is based on technical assessment and corroborative information, and it is carried out in accordance with data qualification plan entitled Qualification of NC-EWDP-19IM2 Well Completion Data.

The well completion diagram for NC-EWDP-19IM2 (19IM2) is shown in Figure K-1. This diagram was used to determine the thickness of the saturated alluvium from the water table to the bottom of the screen 4 sand pack so that the cross-hole hydraulic test described in Section F2 of this report could be analyzed. A similar well completion diagram for NC-EWDP-19D (19D) is shown in Figure K-2. The latter diagram constitutes the qualified "data" contained in DTN: MO0112DQRWLNYE.018 [DIRS 157187] (the Technical Data Management System provides a link to this diagram when the DTN is accessed). The field geologist providing the information for both diagrams was the same person (Jamie Walker, Nye County consultant), so the accuracy of the information in both diagrams should be similar. The 19D well completion data were qualified in accordance with AP-SIII.2Q, Rev. 0, ICN 3 in December 2001. The qualification process for this well and for several other Nye County wells was accomplished through the preparation and approval of the following data qualification report:

Charles R. Wilson. December 2001. "Data Qualification Report: Water Level Data from Nye County Wells for Use on the Yucca Mountain Project", TDR-NBS-HS-000016 REV 00 [DIRS 172175] (Accession \#: MOL.20011218.0002).

This data qualification report provides an extensive evaluation of the well completion data, including wellhead elevations and locations for Nye County Early Warning Drilling Program wells that existed in December 2001 (19IM2 was completed in August/September 2002). In Section 3.3 (Borehole Completion Data) of the data qualification report, it was concluded that the screened interval depths for the Nye County wells were accurate to within the $\pm 1 \mathrm{~m}$ tolerance required for the Yucca Mountain Project's saturated zone (SZ) flow model at that time. In fact, the total depth measurements made by both Yucca Mountain Project and Nye County personnel for 10 different Early Warning Drilling Program wells never differed by more than 0.3 feet (Table 6 of TDR-NBS-HS-000016 REV 00 [DIRS 172175]). The general recommendation of the data qualification report was that the well completion and water level data for all the Nye County wells, with the exception of some of the water level data from multilevel piezometers (but not well completion data), should be qualified for use in developing technical products on the Yucca Mountain Project. This recommendation and the subsequent qualification of the data, combined with the fact that the well completion data in DTN: MO0306NYE05260.166 [DIRS 165877] were developed using the same methods and by the same person as the data qualified via TDR-NBS-HS-000016 REV 00 [DIRS 172175], provide a strong case for qualification of the 19IM2 well completion data for intended use in this analysis report.

Unfortunately, the data qualification report did not address the depths of the contacts between the sand packs and bentonite grout seals that define the actual hydraulic thicknesses of the screened intervals in the wells (hydraulic thickness is the thickness of aquifer that is hydraulically connected to the screen through the permeable sand packs). These contact depths are considered more uncertain than the screen locations of the borehole casing, which were the focus of the 
assessment of well completions in the data qualification report (the screen locations can be determined quite accurately from the length and number of joints in the casing). The sand-grout contact depths were determined by standard tagging procedures in the field using piping of known lengths that was inserted into the annulus between the borehole wall and the casing to "tag" the top of the sand or grout. Some confirmatory information on the location of the contacts was also obtained by geophysical logging techniques after well completion. In the borehole completion diagrams, the contact depths are reported in tenths of a foot, but they should probably be considered accurate to only within 1 to 2 feet.

However, even if the accuracy were considerably worse than 1 to 2 feet (like several feet), the resulting uncertainty in interval thickness would be acceptable for the cross-hole hydraulic test analysis discussed in Section F2. The test analyzed to obtain hydrologic parameter estimates for the alluvium was conducted by pumping 19D from the 4 shallowest screened intervals in 19D while monitoring the 4 shallowest intervals in 19IM2. The only inflated packers in the wells were between the fourth and fifth intervals (from the top) in each well, so the four shallowest intervals in each well were effectively combined to act as one large interval. The inflated packers kept the saturated alluvium isolated from the underlying bedrock (tuff). In this test configuration, the effective thickness of the hydraulic test interval was the entire thickness of the saturated alluvium from the water table to the bottom of the fourth screened interval $-\mathrm{a}$ thickness of approximately $133 \mathrm{~m}$ or $437 \mathrm{ft}$, as stated in Section F2. In this case, inaccuracies of as much as 4 feet in the overall thickness of the test interval would result in errors of less than a 1 percent in the interval thickness, which would translate to errors of less than 1 percent in the hydrologic parameter estimates from the test.

In Section 6.4.6 of this report, it is stated that hydrologic parameter estimates (storativity and transmissivity) derived from hydraulic testing in the alluvium are considered accurate to only within one significant figure (given all of the uncertainties associated with the testing). Thus, even inaccuracies of tens of feet in the test interval thickness would not have a significant impact on the parameter estimates, as reported in Section 6.4.6. Furthermore, it is also stated in Section 6.4.6 that "hydrologic parameters derived from ATC testing are not used as direct inputs in the Saturated Zone Site-Scale Flow Model (BSC 2004 [DIRS 170037]), but rather they are used primarily for qualitative/corroborative consistency checks with the hydrologic parameters that are derived from calibrations of the Saturated Zone Site-Scale Flow Model (BSC 2004 [DIRS 170037].”

Given the reported accuracy of the data (Section 6.4.6), the ultimate end use of the hydrologic parameters derived from the data, and the fact that several Nye County well completion diagrams prepared by the same methods and same personnel were previously qualified, the well completion diagram in DTN: MO0306NYE05260.166 [DIRS 165877] is considered qualified for its intended use in the analysis presented in Section F2 of this report. The source DTN: MO0306NYE05260.166 [DIRS 165877] will remain unqualified for other uses. 


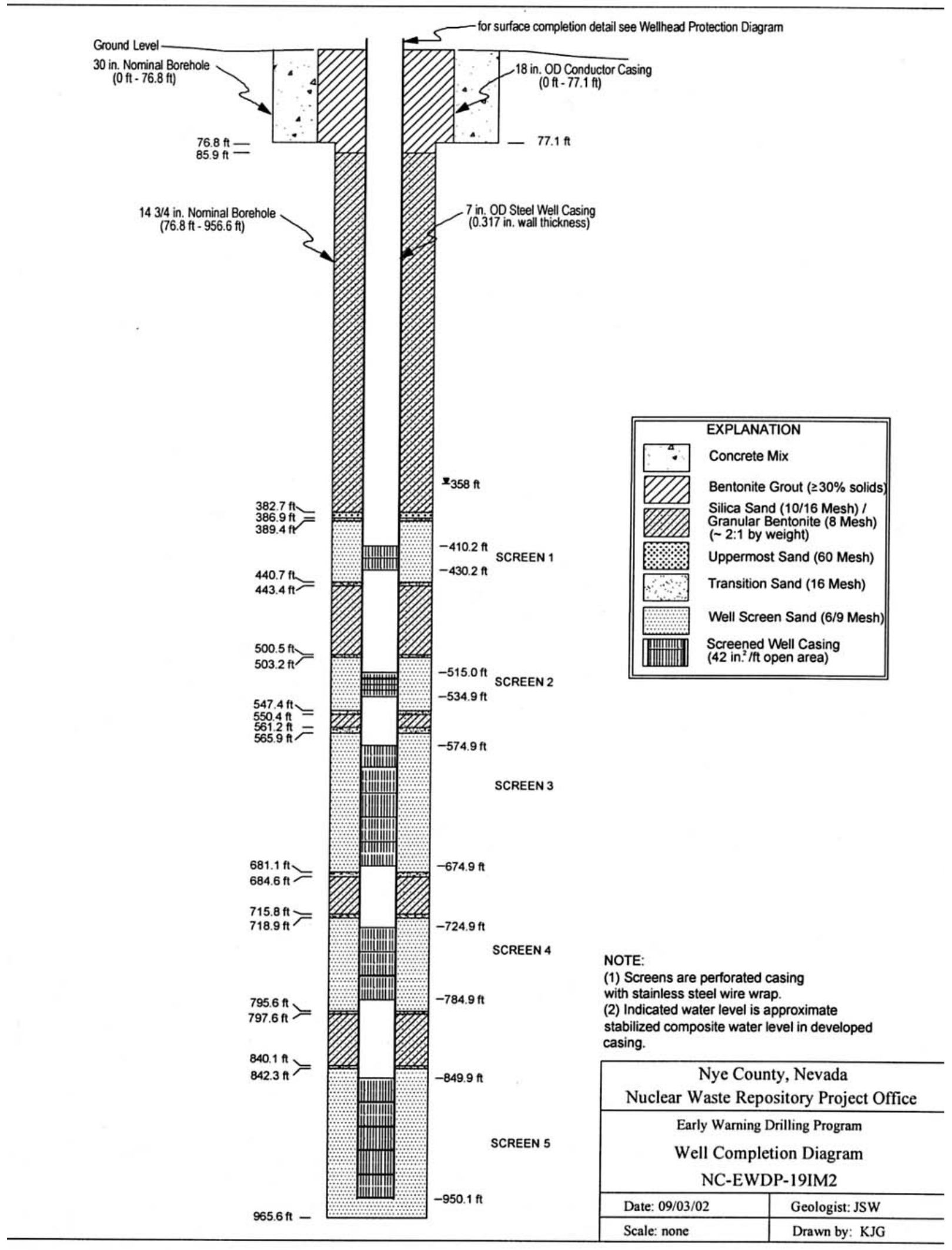

Figure K-1. NC-EWDP-19IM2 Well Completion Diagram (DTN: MO0306NYE05260.166 [DIRS 165877]) 


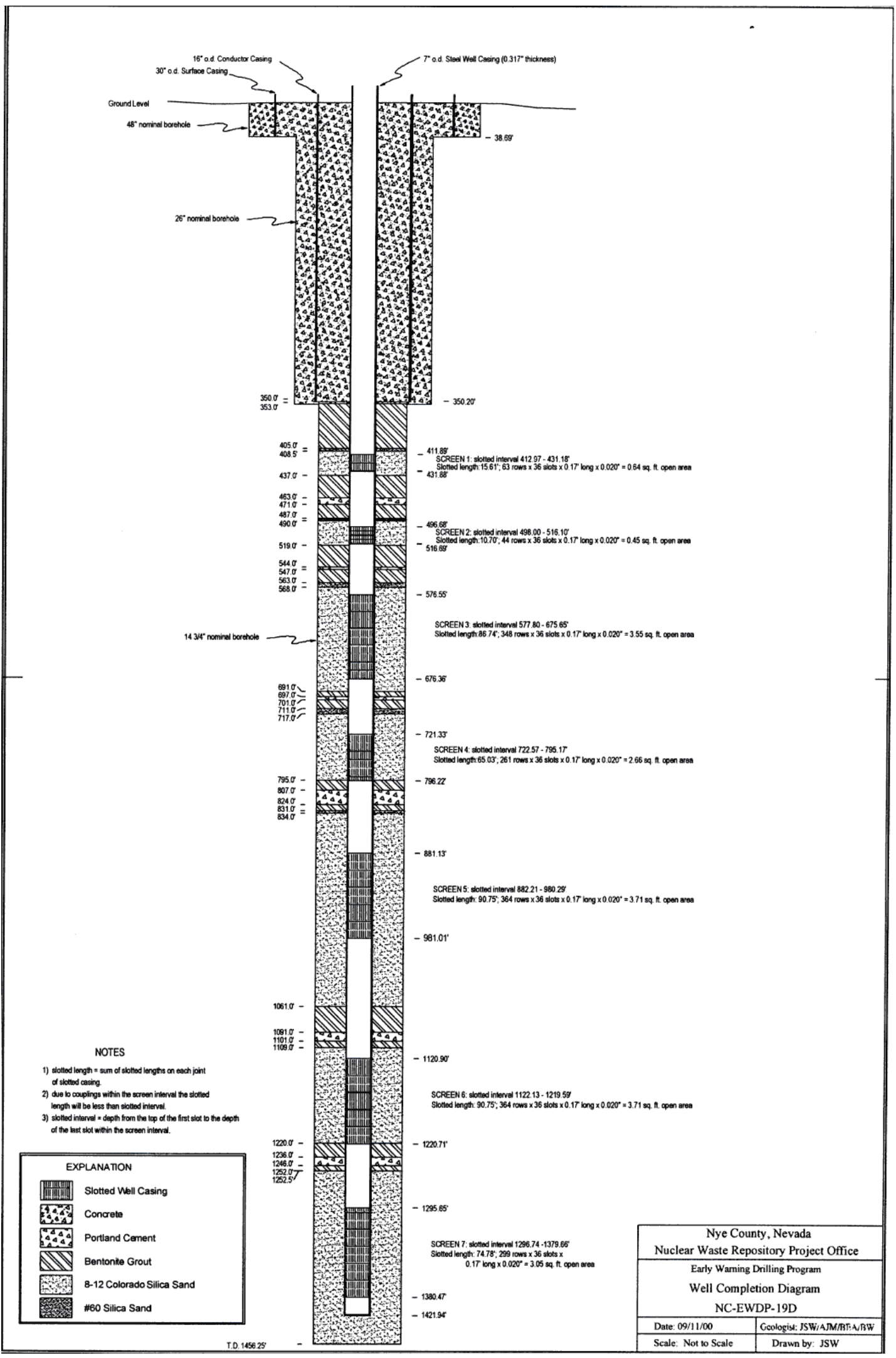

Figure K-2. NC-EWDP-19D Well Completion Diagram (DTN: MO0112DQRWLNYE.018 [DIRS 157187]) 


\begin{tabular}{|c|c|c|}
\hline \multirow{2}{*}{ BSC } & \multirow{2}{*}{ Data Qualification Plan } & $Q A: Q A$ \\
\hline & & $\begin{array}{l}\text { Page } 1 \text { of } \times 2 \\
\quad 1 / 4 \times 9 / 10 / 04\end{array}$ \\
\hline
\end{tabular}

\begin{tabular}{|l|}
\hline Section I. Organizational Information \\
\hline Qualification Title \\
Qualification of NC-EWDP-19IM2 well completion data. \\
\hline Requesting Organization \\
RIT Natural Systems Team \\
\hline Section II. Process Planning Requirements \\
\hline
\end{tabular}

1. List of Unqualified Data to be Evaluated

NC-EWDP-19IM2 well completion data contained in DTN MO0306NYE05260.166

2. Typo of Data Qualifieation Mothod(c) [Ineluding rationalo for solection of mothod(e) (Attachment 3) and qualification attributos (Attaohment 4)] The technical assessment and corroborative data methods will be used to qualify the data set. The rationale for selecting these methods is that very similar Nye County data were previously qualified in TDRNBS-HS-000016, "Data Qualification Report: Water Level Data from Nye County Wells for Use on the Yucca Mountain Project," prepared by Charles Wilson in December 2001. In this report, both water level data and well completion data from Nye County were carefully assessed, and the datawere recommended for qualification (and ultimately qualified). Nye County methods for documenting the NGEWDP-19IM2 well completion will be assessed and compared to the methods used to document the well completion for NGEWDP-19D, which was qualified in TDR-NBSHS-000016. If the methods are essentially the same, then the 19IM2 well completion data should receive the same qualification status as the earlier well completion data. The qualification process will rely primarily on attribute 7 from Attachment4.

3. Data Qualification Team and Additional Support Staff Required

Paul Reimus

Robert Roback

\section{Data Evaluation Criteria}

The NC-EWDP-19IM2 well completion data will be evaluated for consistency with the well completion datafor other Nye County wells that are discussed in TDR-NBS-HS-000016. If the 19IM2 well completion data and the data discussed in TDR-NBS-HS000016 are consistent and are determined to have been obtained/documented using the same or very similar methods, ben the $19 \mathrm{IM} 2$ well completion data will be considered qualified for intended use in the SZ In-Situ Testing Analysis Report (ANL-NBS-HS. 000039).

5. Identification of Procedures Used

AP-SIII.9Q, Scientific Analysis - Qualification to be documented and reviewed in an appendix to a Scientific Analysis Report. 


\begin{tabular}{|l|l|l|}
\hline \multirow{2}{*}{ BSC } & DATA QUALIFICATION PLAN & QA: QA \\
\cline { 3 - 3 } & $\begin{array}{c}\text { Page } 2 \text { of } \not 2 \\
\text { fuR } 5 / 10 / 04\end{array}$ \\
\hline
\end{tabular}

\begin{tabular}{|l|l|l|}
\hline Section III. Approval & Date \\
\hline Qualification Chairperson Printed Name & Qualification Chairperson Signature & $9 / 10 / 04$ \\
Paul Reimus & Responsible Manager Signature & Date \\
Responsible Manager Printed Name & Ahmed Monib & $9 / 14 / 04$ \\
\hline
\end{tabular}




\section{APPENDIX L}

\section{QUALIFICATION OF C-WELLS FLOW DISTRIBUTION DATA} (DTN: GS931008312313.016 [DIRS 148173]) 
The qualification of the flow distribution data for the C-wells is documented here in accordance with AP-SIII.2Q, Qualification of Unqualified Data. This qualification provides the desired level of confidence that the data are suitable for their intended use, which is limited to the analysis of effective flow porosity of the Bullfrog Tuff, as presented in Table D-10 (the actual flow distribution data is schematically represented in Figure 6.1-2). The qualification is based on corroborative information and is carried out in accordance with data qualification plan Qualification of NC-EWDP-19IM2 Well Completion Data.

The flow distribution data at the C-wells, as presented in Tables 10, 11, and 12 of USGS report (Geldon 1996 [DIRS 100396]) (DTN: GS931008312313.016 [DIRS 148173]), was developed primarily from tracejector (radioactive iodine) and temperature survey data collected under open-hole pumping conditions in the C-wells in the 1980s. The relative percentages of flow being produced from different depth intervals in the $\mathrm{C}$-wells was used to refine the effective flow porosity estimates in the lower Bullfrog Tuff presented in Table D-10 of this analysis report. The information on the depths of the flowing intervals was previously qualified for use on the Yucca Mountain Project as a result of the preparation and approval of Data Qualification Report: Flowing Interval Data for Use on the Yucca Mountain Project (CRWMS M\&O 2000 [DIRS 172177]).

This report provides an extensive evaluation of the flowing interval data obtained for a number of wells near Yucca Mountain in the 1980s, including the three C-wells. Although the qualified DTNs resulting from this qualification effort include only the depths of the flowing intervals (not the relative percentages of flow from each interval), there is considerable discussion in the report about the quality of the methods used, which were found to be acceptable to support the use of the data in technical products for the Yucca Mountain Project. With respect to the tracejector survey data the authors state "Unlike temperature logging, which can be more sensitive but does not provide a direct hydrologic measurement, a tracejector survey performed during pumping provides a quantitative measurement of the contribution of each interval to the total borehole flow."

The authors also cite a comparison of 1984 UE25c\#3 tracejector survey data with more recent spinner and oxygen-activation survey data taken under pumping conditions in the same well in 1995 (Thompson, 1997 - in qualified DTN: TMUE25C3000095.001 [DIRS 172179]). They conclude that the qualified data from 1995 corroborate the unqualified 1984 data. Thompson (1997 [DIRS 172179], p. 5) stated that "Close agreement between the Full-Bore Flowmeter (spinner) and Water Flow Log (oxygen activation) provide confidence in the accuracy of the calculation of water flow rates. The radioactive tracer (tracejector) survey, which was run 10 years earlier, also indicates close agreement with the Full-Bore Flowmeter and Water Flow Log, though the absolute flow rates are slightly greater." He summarizes by stating "Comparison of flow measurements taken 10 years earlier indicated flow from the same zones in the borehole, and resulted in comparable flow rates and percentage of contribution." (DTN: TMEU25C3000095.001 [DIRS 172179]). The reader can verify these conclusions by comparing the flow distribution data from UE25c\#3 depicted in Figures 6.1-2 [based on work by Geldon (1996 [DIRS 100396])] and C-4 (DTN: TMEU25C3000095.001 [DIRS 172179]) of this analysis report.

For the purposes of estimating effective flow porosity in the lower Bullfrog Tuff in this analysis report, it was assumed that the early arriving tracer peak in the multiple-tracer test discussed in 
Sections D4.5 and D4.6 occurred as a result of flow pathways that accounted for 75 percent of the total cross-flow between the injection and production wells (c\#2 and c\#3, respectively). This assumption is based on the underlying assumption that the early arriving tracer mass exited c\#2 from the upper half of the injection interval (because of arguments spelled out in Section D4.5). Figure 6.1-2 [based on information from (Geldon 1996 [DIRS 148173])] indicates that actually 79 percent of the flow into $\mathrm{c} \# 2$ occurred in the upper portion of the injection interval in the 1984 flow surveys (which translates into more than 80 percent of the flow when the interval is isolated), but because there appears to be a lower percentage of flow occurring in the upper portion of the production interval in $\mathrm{c} \# 3$ (in both the 1984 and the 1995 surveys), only 75 percent of the total cross-hole flow was assumed to be responsible for the first tracer peak. This assumption is clearly quite uncertain, especially since cross-hole flow pathways are being inferred from single-well flow data. However, this relatively large uncertainty means that the data upon which the assumption is based (i.e., the flow distribution data) should not require a high degree of accuracy or precision to be considered qualified for its intended use in this analysis report.

Given the previous qualification of the flowing interval depth data, the good agreement between the 1984 and 1995 quantitative flow survey information from UE25c\#3, and the ultimate use of the flow distribution information to obtain an estimate with a relatively high degree of uncertainty, the flow distribution data in the U.S. Geological Survey Report (Geldon 1996 [DIRS 148173]) that constitutes DTN: GS931008312313.016 [DIRS 148173] is considered qualified for its intended use in this analysis report. The source DTN: GS931008312313.016 [DIRS 148173] will remain unqualified for other uses. 


\begin{tabular}{|l|l|l|}
\hline \multirow{2}{*}{ BSC } & DATA QUALIFICATION PLAN & QA QA \\
\cline { 3 - 3 } & Page 1 of 1 \\
\hline
\end{tabular}

\begin{tabular}{|c|c|c|}
\hline \multicolumn{3}{|c|}{ Section I. Organizational Information } \\
\hline \multicolumn{3}{|c|}{$\begin{array}{l}\text { Qualification of C-wells flow distribution data from the USGS report "Results and Interpretation of Preliminary Aquifer Tests in } \\
\text { Boreholes UE-25c\#1, UE-25c } \# 2 \text {, and UE-25c\#3, Yucca Mountain, Nye County, Nevada," by Geldon (1996). }\end{array}$} \\
\hline \multicolumn{3}{|c|}{ Requesting Organization } \\
\hline \multicolumn{3}{|l|}{ RIT Natural Systems Team } \\
\hline \multicolumn{3}{|c|}{ Section II. Process Planning Requirements } \\
\hline \multicolumn{3}{|c|}{ 1. List of Unqualified Data to be Evaluated } \\
\hline \multicolumn{3}{|c|}{$\begin{array}{l}\text { Flow distribution data contained in the USGS report "Results and Interpretation of Preliminary Aquifer Tests in Boreholes UE-25c\#1, } \\
\text { UE-25c } \# 2 \text {, and UE-25c } \# 3 \text {, Yucca Mountain, Nye County, Nevada," by Geldon (1996). This report is associated with DTN } \\
\text { GS031008312313.016. }\end{array}$} \\
\hline \multirow{2}{*}{\multicolumn{3}{|c|}{$\begin{array}{l}\text { 2. Type of Data Qualification Method(s) [Including rationale for selection of method(s) (Attachment 3) and qualification attributes (Attachment 4)] } \\
\text { The corroborating data method will be used to qualify the data set. The flowing interval data from the Gwells were qualified for use } \\
\text { in the AMR, "Probability Distribution of Flowing Interval Spacing" (Kuzio, 1999) in TDR-NBS-GS-000017, "Data Qualification } \\
\text { Report: Flowing Interval Data for Use on the Yucca Mountain Project," prepared by Charles Wilson in July 2000. However, the } \\
\text { resulting qualified data sets only identified the depths of the flowing intervals, not the percentages of flow contributed by each } \\
\text { flowing interval (which is used in the SZ InSitu Testing Analysis Report). Recognizing that the data used in the two AMRs are the } \\
\text { same data, the qualification efforts documented in TDR-NBS-GS-000017 will be used to directly qualify the percentages of flow in } \\
\text { the flowing intervals at the C-wells. The qualification process will rely primarily on attribute } 7 \text { from Attachnent } 4 \text {. }\end{array}$}} \\
\hline & & \\
\hline \multicolumn{3}{|c|}{ 3. Data Qualification Team and Additional Support Staff Required } \\
\hline \multicolumn{3}{|c|}{$\begin{array}{l}\text { Paul Reimus } \\
\text { Mei Ding }\end{array}$} \\
\hline \multicolumn{3}{|l|}{$\begin{array}{l}\text { 4. Data Evaluation Criteria } \\
\text { The data will be evaluated by closely } \\
\text { same source as the data used in the SZ } \\
\text { Report are essentially the same as the } \\
\text { accurate and precise the data have to b } \\
\text { including the percentages of flow in ea } \\
\text { data. }\end{array}$} \\
\hline \multirow{2}{*}{\multicolumn{3}{|c|}{$\begin{array}{l}\text { 5. Identification of Procedures Used } \\
\text { AP-SIII.9Q, Scientific Analysis - Qualification to be documented and reviewed in at }\end{array}$}} \\
\hline & & \\
\hline \multicolumn{3}{|l|}{ Section III. Approval } \\
\hline $\begin{array}{l}\text { Qualification Chairperson Printed Name } \\
\text { Paul Reimus }\end{array}$ & Qualifigation Chairpersgn Signature & Date $9 / 10 / 04$ \\
\hline $\begin{array}{l}\text { Responsible Manager Printed Name } \\
\text { Ahmed Monib }\end{array}$ & Responsible Manager Signature & Date $9 / 14 / 04$ \\
\hline
\end{tabular}




\section{INTENTIONALLY LEFT BLANK}




\section{APPENDIX M}

QUALIFICATION OF UE25 ONC-1 DRAWDOWN DATA FROM APRIL 24, 1996 TO NOVEMBER 12, 1997 (DTN: MO0212SPANYESJ.149 [DIRS 161274]) AND CORRESPONDING QUALIFICATION OF PAGES 4 TO 51 OF "RESULTS OF HYDRAULIC TESTS IN MIOCENE TUFFACEOUS ROCKS AT THE C-HOLE COMPLEX, 1995 TO 1997, YUCCA MOUNTAIN, NEVADA" (DTN: GS030508312314.003 [DIRS 164425]) 


\section{M1. INTRODUCTION}

The qualification of the UE25 ONC-1 drawdown data from April 24, 1996, to November 12, 1997, is documented here in accordance with AP-SIII.2Q, Qualification of Unqualified Data. This qualification provides the desired level of confidence that the data are suitable for their intended use, which includes both the estimation of hydrologic parameters based on the ONC-1 drawdown data (discussed in Section C4.6) and the analysis of anisotropy in horizontal hydraulic conductivity in the volcanic tuffs (presented in Section 6.2.6, with additional details provided in Section C6). The ONC-1 drawdown data are presented in Figures C-32, C-37, and C-41. However, the ONC-1 data in these figures were plotted after filtering (and various other minor corrections or manipulations) of the raw pressure transducer data contained in DTN: MO0212SPANYESJ.149 [DIRS 161274], which is the subject of the qualification in this appendix. This qualification is based on both technical assessment and corroborating data, and it is carried out in accordance with data qualification plan entitled Qualification of UE25 ONC-1 Drawdown Data During the 1996-97 Hydraulic Test of the Bullfrog Tuff at the C-Wells. The qualification is limited to the data from pressure transducer 9 in ONC-1, which was the deepest transducer in this well; only one other transducer was placed below the water table in ONC-1.

By qualifying the ONC-1 drawdown data for intended use in this analysis report, pages 4 through 51 of the USGS Water Resources Investigation Report 02-4141, Results of Hydraulic Tests in Miocene Tuffaceous Rocks at the C-Hole Complex, 1995 to 1997, Yucca Mountain, Nevada" (DTN: GS030508312314.003 [DIRS 164425]) will also become qualified for intended use in this analysis report. This U.S. Geological Survey (USGS) report/data tracking number (DTN) documents the analyses of the C-wells hydraulic test data acquired between 1995 and 1997 to obtain hydrologic parameter estimates for the fractured volcanic tuffs. It is cited extensively as a source DTN throughout Section 6.2 and Appendix C. The only reason that DTN: GS030508312314.003 [DIRS 164425] is unqualified is because the ONC-1 data is an unqualified source DTN. All other source DTNs for DTN: GS030508312314.003 [DIRS 164425] are qualified.

\section{M2. BASES FOR ONC-1 DATA QUALIFICATION}

The qualification of the ONC-1 drawdown data is based on the following:

1. The ONC-1 hydraulic response is consistent with the hydraulic responses of other wells (for which the drawdown data are qualified) that responded to pumping of UE25c\#3 during the subject time period. The criteria for "consistency" are:

a. ONC-1 should respond (i.e., exhibit observable drawdown) faster than wells that are further away from UE25c\#3 and slower than wells that are closer to $\mathrm{c} \# 3$.

b. The overall drawdown curve for ONC-1 should exhibit similar characteristics to the drawdown curves of other wells that responded to the pumping of $\mathrm{c} \# 3$, especially when time since pumping began is divided by the square of the distance to the observation well.

2. The raw pressure data from transducer 9 in ONC-1 is in good agreement with the data from the other transducer placed below the water table in this well (transducer 8). Although the data from both transducers are unqualified, good agreement between the 
two transducers greatly increases the confidence in the quality of the data from either transducer. It is important to note that absolute pressure measurements are not critical for the drawdown analysis; only relative pressures (relative to the starting pressure) are important for the drawdown analysis.

3. The end use of the data is to serve as input for analyses conducted to estimate transmissivity and storativity in the fractured volcanic tuffs between ONC-1 and the $\mathrm{C}$-wells. These estimates were considered accurate to only one significant figure, and they differ significantly for different methods of analysis. The required confidence in the data quality should be commensurate with the level of uncertainty in the parameter estimates obtained from these analyses.

These items are discussed in turn in the following three sections.

\section{M3. CONSISTENCY OF ONC-1 DRAWDOWN DATA WITH QUALIFIED DATA FROM OTHER WELLS}

It is apparent from Figure $\mathrm{C}-41$ that $\mathrm{ONC}-1$ responded more quickly to pumping of UE25c\#3 than USW H-4, UE25 WT\#3, and UE24 WT\#14 (i.e., drawdown was observed earlier in ONC-1 than in these wells). The drawdown data for these other wells are qualified (DTN: GS970308312314.002 [DIRS 161273]). The more rapid response of ONC-1 compared to these wells is consistent with the fact that ONC-1 is located considerably closer to c\#3 than the other wells (approximately $850 \mathrm{~m}$, as opposed to over 2,200 m for the other wells). If the aquifer in the vicinity of the C-wells behaves as a homogeneous system (at least in the sense that pressure pulses propagate at similar rates in all directions), these relative responses are exactly what would be expected. The fact that ONC-1 responded more rapidly than $\mathrm{H}-4$ is probably the most convincing observation because these wells are located in the same general direction from the $\mathrm{C}$-wells (northwest). Thus, even if there were some large-scale heterogeneities or flow anisotropy affecting the relative responses of the distant wells, it is expected (at least as a first approximation) that $\mathrm{ONC}-1$ and $\mathrm{H}-4$ should be similarly affected because they have a very similar directional orientation to the $\mathrm{C}$-wells. The fact that the $\mathrm{ONC}-1$ response qualitatively conforms to the expectation of a more rapid drawdown than the more distant wells, especially $\mathrm{H}-4$, supports the qualification of the ONC-1 drawdown data.

The drawdown curves of Figure C-37 further support the qualification of the ONC-1 data. In this figure, the ONC-1 drawdown curve falls almost directly on top of the drawdown curves for c\#2 and WT-3 when the time since pumping began is divided by the square of the distance between the observation wells and the pumping well. This relationship is expected for observation wells in a homogeneous, isotropic system (Freeze and Cherry [DIRS 101173], p. 317); and although the volcanic tuff aquifer is neither homogeneous or isotropic, the fact that the relationship holds for wells that range from approximately $30 \mathrm{~m}$ to over $3000 \mathrm{~m}$ from the pumping well (including approximately $850 \mathrm{~m}$ for ONC-1) is a strong endorsement of the quality of the ONC-1 drawdown data. Figure C-37 actually represents a more quantitative assessment than the preceding paragraph of how closely the ONC-1 drawdown data conforms to expectations for a system with multiple observation wells. It shows that the ONC-1 response is not only more rapid than the response of a more distant well, but it is also slower than the response of a much closer well (c\#2). Furthermore, Figure C-37 shows that the shapes of the curves are in very good agreement, which agrees with expectations for a homogeneous, isotropic flow system. Again, even though it cannot be claimed that the volcanic 
tuffs are homogeneous or isotropic, the fact that the ONC-1 data agree so well with the c\#2 and the WT-3 data when time is normalized by dividing by the distance squared is a strong endorsement of the quality of the ONC-1 data.

\section{M4. AGREEMENT BETWEEN PRESSURE DATA FROM TWO TRANSDUCERS IN ONC-1}

Figure M-1 shows the raw pressure data from transducers 8 and 9 in $\mathrm{ONC}-1$ as a function of time just prior to and during the early part of the hydraulic test in c\#3 (from April 24 to May 29, 1996). In this figure, 10.5 psi was added to all readings from transducer 8 so that the data from the two transducers would plot very close to each other to facilitate a comparison. The sharp drop in pressure indicated by both transducers on May 8 corresponds to the start of the c\#3 aquifer test.

Figure M-2 shows the difference between the two transducer readings as a function of time over the same time period as shown in Figure M-1. The difference between the two transducers was very consistent except for a 2- to 3-day period around May 10, and even the difference during this time period amounts to only about $1 \mathrm{~cm}$ (head) less than the difference during the remainder of the overall period. Differences between the pressure readings of the two transducers at approximately the middle of the aquifer test (Feb. 3 to 27, 1997) and at the end of the test (Oct. 28 to Nov. 12, 1997) are shown in Figure M-3. Clearly, the differences drifted over time, but the absolute difference never drifted by more than approximately $3 \mathrm{~cm}$ during the entire test. Given that the drawdown for both transducers exceeded $14 \mathrm{~cm}$ after June 1, 1996, and that the drawdown data are transformed to log units prior to the type-curve analyses that yield hydrologic parameter estimates, the approximately $3 \mathrm{~cm}$ drift translates to less than a 7 percent difference in the $\log$ values used in the drawdown analyses. Furthermore, the pressure record before June 1, 1996, constitutes nearly two-thirds of the drawdown record in log time units (time is also transformed to $\log$ units for the type-curve analyses), so the effect of the $3 \mathrm{~cm}$ drift for times after June 1, 1996, has a very minor effect on the analysis.

The minor effect of the drift in the relative readings of the two transducers on the overall drawdown curve is illustrated in a log-log plot of drawdown vs. time in Figure M-4, which shows the unfiltered and uncorrected drawdown data from the two transducers for the time periods mentioned in the preceding paragraph as well as some additional time periods that are roughly evenly spaced in log time over the duration of the test. All data were obtained by subtracting the starting pressures from both transducers (for the day before starting the pump in c\#3) from the pressures measured after pumping began. The drawdown data from the two transducers are nearly indistinguishable after the first 10,000 minutes of the test. The data of Figure M-3 can be compared to Figure C-32 to see that the drawdown curves from both transducers correspond very closely to the filtered drawdown data analyzed to obtain hydrologic parameter estimates in this analysis report. It is apparent that even the differences in the transducer measurements at early times would have little impact on the overall type-curve analysis shown in Figure C-32. The good agreement between the drawdown curves for the two transducers greatly increases the confidence in the quality of the data obtained from either one of the transducers individually. 


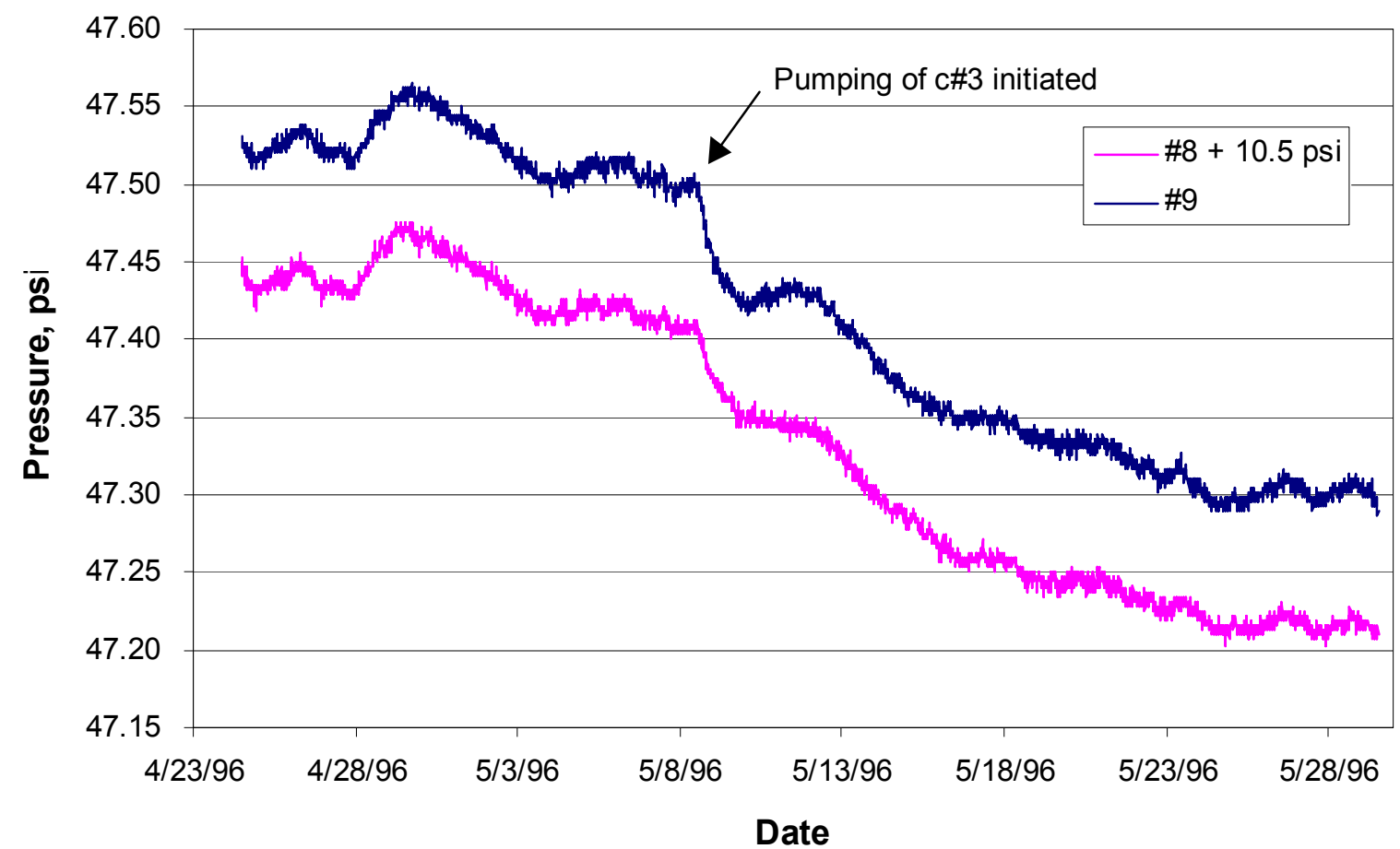

Figure M-1. Pressure Readings from Transducers 8 and 9 in ONC-1 from April 24, 1996, to May 29, 1996

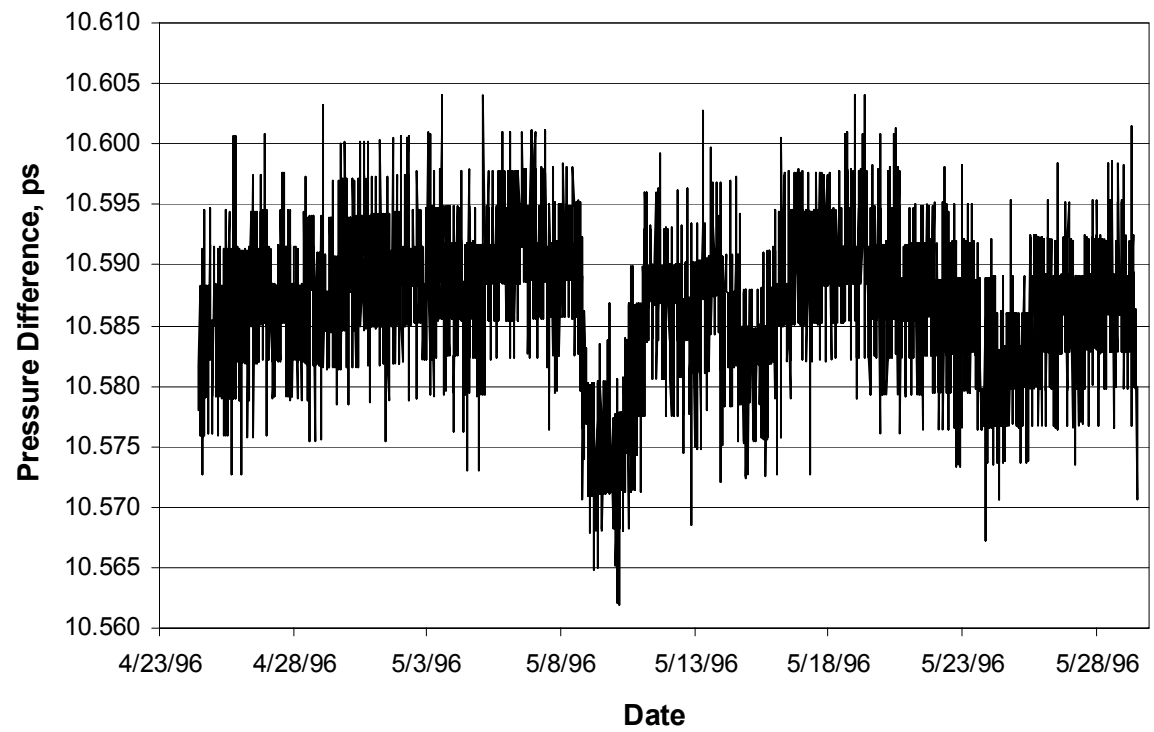

Figure M-2. Differences in Pressure Readings from Transducers 8 and 9 in ONC-1 from April 24, 1996, to May 29, 1996 

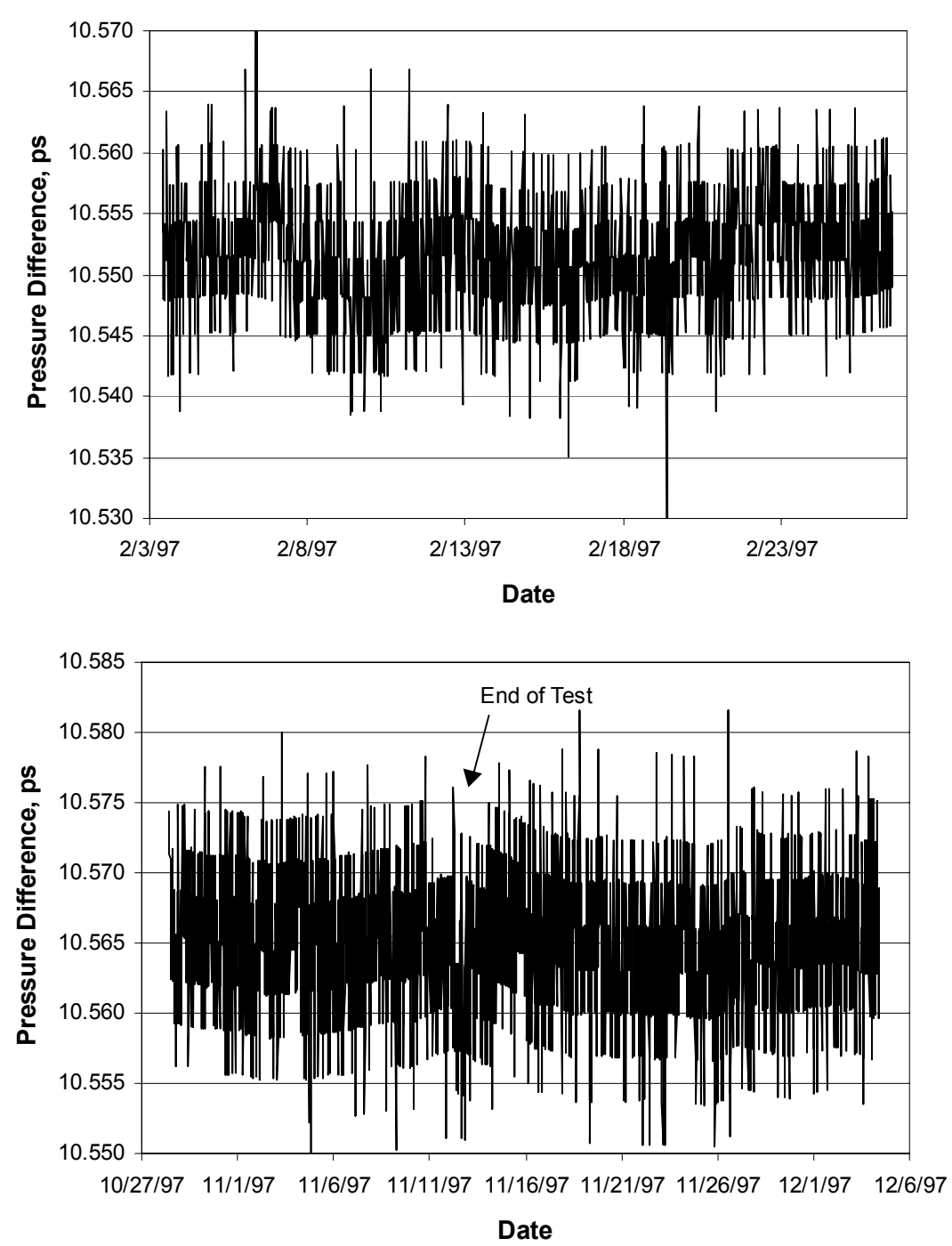

Figure M-3. Differences in Pressure Readings from Transducers 8 and 9 in ONC-1, Feb. 3-26, 1997, and Oct. 28 to Dec. 4, 1997

\section{M5. REQUIRED CONFIDENCE IN DATA QUALITY GIVEN UNCERTAINTY IN PARAMETERS DERIVED FROM DATA}

It is stated in Section 6.2.7 of this analysis report that the transmissivity and storativity estimates derived from the $\mathrm{C}$-wells hydraulic tests are accurate to only one significant figure. Table 6.2-3 provides a range of transmissivity estimates of 1,000 to $1,465 \mathrm{~m}^{2} /$ day for different methods of analyzing the ONC-1 drawdown data, with a corresponding range of 0.001 to 0.008 for storativity estimates (details in Section C6). Similar parameter ranges are reported in Table 6.2-3 from analyses of qualified drawdown data from three other wells. Ultimately, these large uncertainties in parameter estimates are reflected by a relatively broad distribution of horizontal anisotropy ratios derived from the drawdown data from all four wells (Section 6.2.6 of this report). Given the large uncertainties associated with both the hydrologic parameter estimates from any individual well and with the horizontal anisotropy ratio, the preceding discussion in this appendix establishes adequate confidence in the quality of the ONC-1 drawdown data for its intended use in this analysis report. 


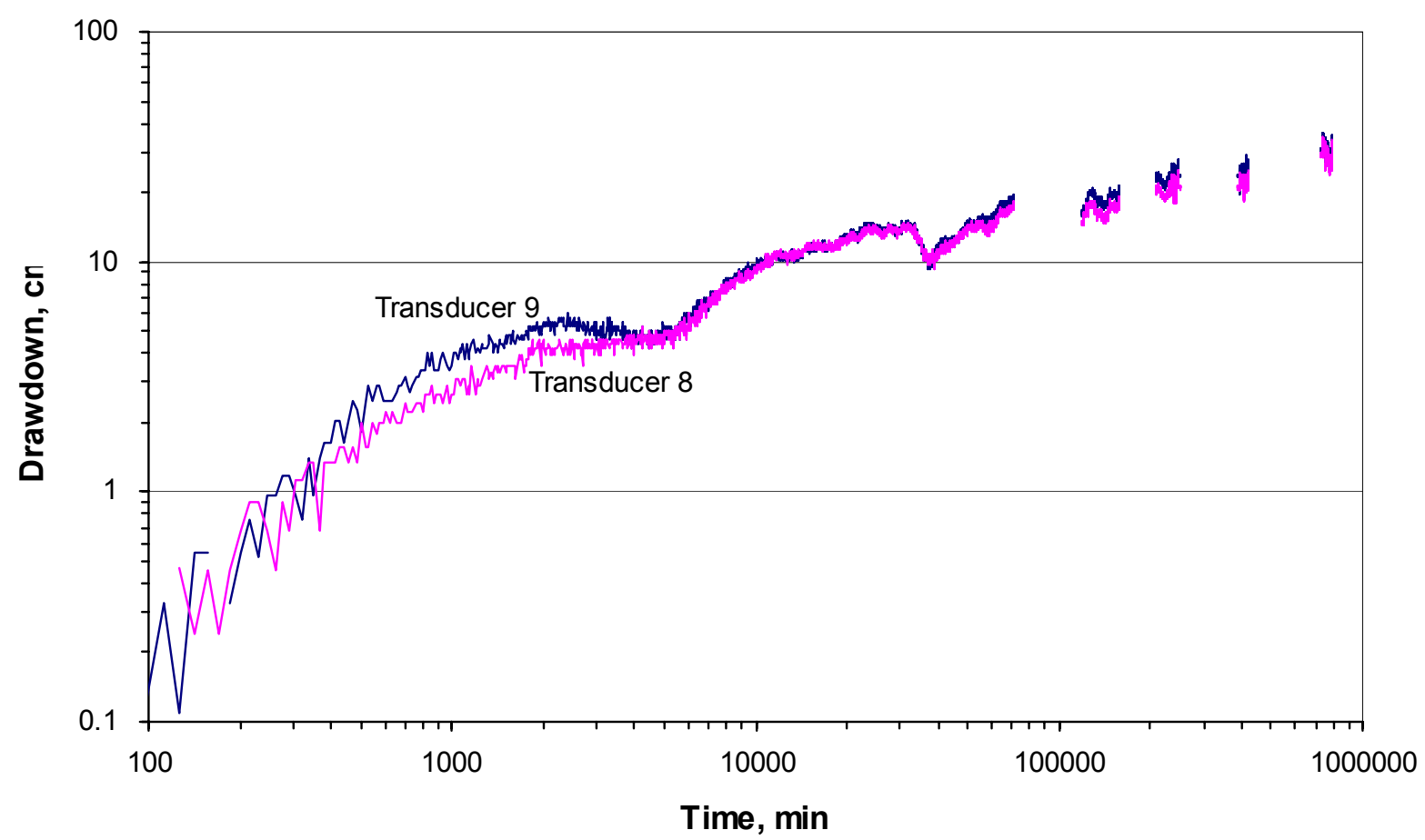

Figure M-4. Uncorrected/Unfiltered ONC-1 Drawdown Curves from Pumping of UE25c\#3 Between May 8, 1996, and Nov. 12, 1997, Based on Pressure Data from Transducers 8 and 9

\section{M6. SUMMARY}

In summary, the qualification of the ONC-1 drawdown data for its intended use in this analysis report is supported by:

- The fact that the ONC-1 drawdown data are consistent with qualified drawdown data from other wells that responded to pumping of c\#3 (response times are consistent with distances between observation and pumping wells, and ONC-1 has a nearly identical drawdown curve to two other wells when time is divided by distance squared)

- The good agreement between the uncorrected drawdown curves for the two ONC-1 transducers, as shown in Figure M-4

- The good agreement between the curves of Figure M-4 and the filtered data shown in Figure C-32

- The fact that the hydrologic parameter estimates derived from the ONC-1 drawdown data have a high degree of uncertainty that is commensurate with the uncertainties associated with parameter estimates derived from the qualified drawdown data from other wells.

It is concluded that the ONC-1 drawdown data in DTN: MO0212SPANYESJ.149 [DIRS 161274] should be considered qualified for its intended use in this analysis report. The source DTN: MO0212SPANYESJ.149 [DIRS 161274] will remain unqualified for other uses. 
By virtue of qualifying DTN: MO0212SPANYESJ.149 [DIRS 161274] for its intended use in this report, pages 4 to 51 of the USGS Water Resources Investigation Report 02-4141, Results of Hydraulic Tests in Miocene Tuffaceous Rocks at the C-Hole Complex, 1995 to 1997, Yucca Mountain, Nevada (DTN: GS030508312314.003 [DIRS 164425]) should also be qualified for intended use in this analysis report. DTN: MO0212SPANYESJ.149 [DIRS 161274] is the only unqualified source DTN for DTN: GS030508312314.003 [DIRS 164425], so its qualification should suffice to qualify DTN: GS030508312314.003 [DIRS 164425] for intended use. 


\begin{tabular}{|c|c|c|}
\hline \multirow{2}{*}{ BSC } & \multirow{2}{*}{ DATA QUALIFICATION PLAN } & QA: QA \\
\hline & & 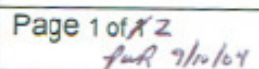 \\
\hline
\end{tabular}

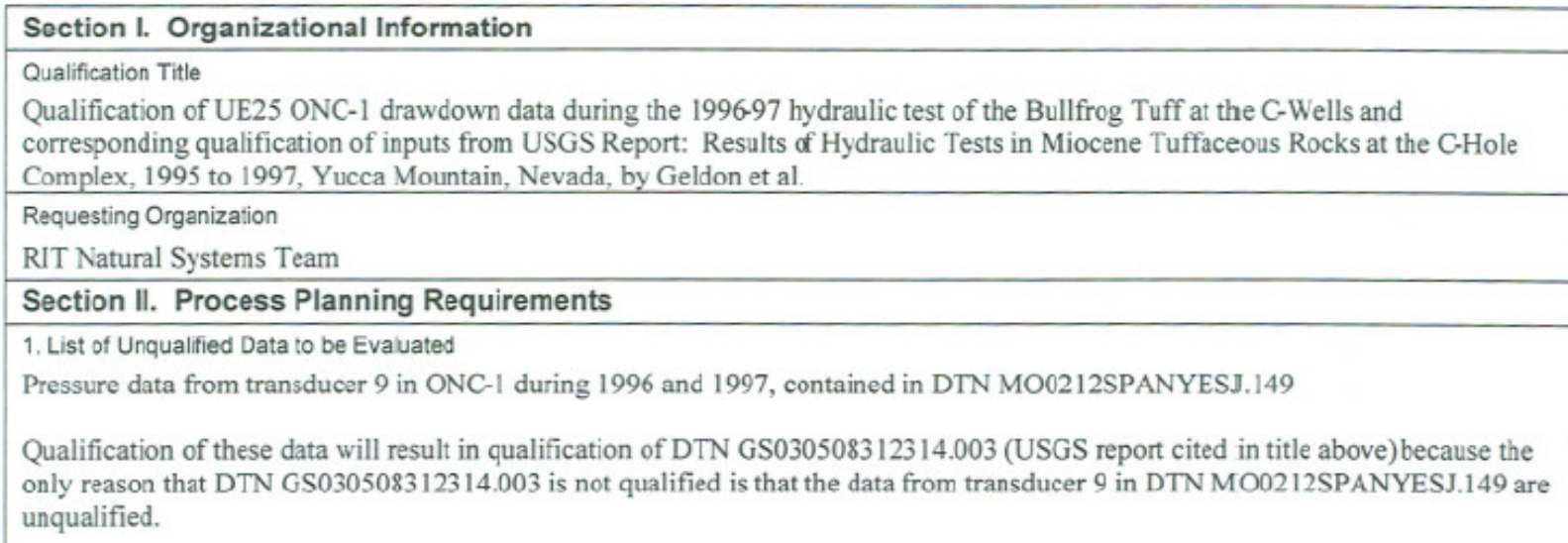

2. Type of Data Qualification Method(s) [Inclucing rationale for selection of method(s) (Attachment 3) and qualification attributes (Attachment 4)] A combination of the corroborating data method and the technical assessment method will be used to qualify the data set. The rationale for selecting a combination of these methods is as follows: Qualfied drawdown data were obtained from UE25c\#2, WT\#3, and USW H-4 during the 1996-97 hydraulic test. The ONC-1 drawdown data can be corroborated in a general sense with the drawdown responses in these wells by comparing the drawdown curves in the variouswells after dividing time by the distance to the pumping well squared, and also by recognizing that ONC-1 should respond a bit more quickly but with a similar overall characteristic response as $\mathrm{H}-4$ ( compare the pressure readings from two redundant pressure transducers in ONGI, thus providing additional confidence in the data quality. Attributes 3 and 10 from Attachment 4 will be used in thequalification process.

3. Data Qualification Team and Additional Support Staff Required

Paul Reimus

Marc Haga

4. Data Evaluation Criteria

The ONC-1 drawdown data will be evaluated against the qualified $\mathrm{H}-4$ drawdown data to determine if the ONC-1 data follow the expected behavior for a well that is located in the same general direction, but closer to the pumping well, as H4. Also, the ONC-1 data would be expected to follow a similar response curve as the other wells after dviding time by the distance to the pumping well squared. If these expectations are met in the ONC-1 data, then it will be a positive indicator of the quality of the data. Also, the ONC-1 data were obtained with redundant pressure transducers, and good agreement (within 5\%) of the relative readings of two transducers will provide additional confidence in the data quality. Because drawdown is measured relative to a starting pressure, accurate relative pressure readings are more important than accurate absolute pressure readings for drawdown analyses.

5. Identification of Procedures Used

AP-SIII.9Q, Scientific Analysis - Qualification to be documented and reviewed in an appendix to a Scientific Analysis Report. 


\begin{tabular}{|l|l|l|}
\hline \multirow{2}{*}{ BSC } & DATA QUALIFICATION PLAN & QA: QA \\
\cline { 3 - 3 } & $\begin{array}{l}\text { Page } 2 \text { of } \pi 2 \\
\text { pum } 9 / 10 / 04\end{array}$ \\
\hline
\end{tabular}

\begin{tabular}{|l|l|l|}
\hline \multicolumn{2}{|l|}{ Section III. Approval } & Date \\
\hline $\begin{array}{l}\text { Qualification Chairperson Printed Name } \\
\text { Paul Reimus }\end{array}$ & Qualification Chairperson Signature & $9 / 10 / 04$ \\
\hline $\begin{array}{l}\text { Responsible Manager Printed Name } \\
\text { Ahmed Monib }\end{array}$ & Responsible Manager Signature & Date \\
\hline
\end{tabular}




\section{INTENTIONALLY LEFT BLANK}

